Robin Kellermann

\title{
IM ZWISCHENRAUM \\ DER BESCHLEUNIGTEN \\ MODERNE
}

Eine Bau- und Kulturgeschichte des Wartens auf Eisenbahnen, $1830-1935$

[transcript] Edition Kulturwissenschaft 
Robin Kellermann

Im Zwischenraum der beschleunigten Moderne 
Zugl.: Berlin, Technische Universität, Diss., 2020 u. d. T. Im Rückraum der beschleunigten Moderne: Eine Bau- und Kulturgeschichte des Wartens auf Eisenbahnen (1830-1935)

Robin Kellermann (Dr. phil.), geb. 1983, ist wissenschaftlicher Mitarbeiter an der Technischen Universität Berlin und arbeitet im Bereich der historischen und sozialwissenschaftlichen Mobilitätsforschung. 
Robin Kellermann

\section{Im Zwischenraum der beschleunigten Moderne}

Eine Bau- und Kulturgeschichte des Wartens auf Eisenbahnen, 1830-1935 
Diese Publikation wurde aus dem Open-Access-Publikationsfonds der Technischen Universität Berlin unterstützt.

\section{Bibliografische Information der Deutschen Nationalbibliothek}

Die Deutsche Nationalbibliothek verzeichnet diese Publikation in der Deutschen Nationalbibliografie; detaillierte bibliografische Daten sind im Internet über http:// dnb.d-nb.de abrufbar.

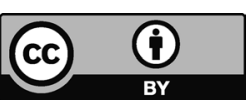

Dieses Werk ist lizenziert unter der Creative Commons Attribution 4.0 Lizenz (BY). Diese Lizenz erlaubt unter Voraussetzung der Namensnennung des Urhebers die Bearbeitung, Vervielfältigung und Verbreitung des Materials in jedem Format oder Medium für beliebige Zwecke, auch kommerziell. (Lizenztext: https://creativecommons.org/licenses/by/4.o/deed.de)

Die Bedingungen der Creative-Commons-Lizenz gelten nur für Originalmaterial. Die Wiederverwendung von Material aus anderen Quellen (gekennzeichnet mit Quellenangabe) wie z.B. Schaubilder, Abbildungen, Fotos und Textauszüge erfordert ggf. weitere Nutzungsgenehmigungen durch den jeweiligen Rechteinhaber.

\section{Erschienen $2021 \mathrm{im}$ transcript Verlag, Bielefeld (c) Robin Kellermann}

Umschlaggestaltung: Maria Arndt, Bielefeld

Umschlagcredit: Cover: Hans Baluschek: Wartesaal IV, 1923. Aquarell und Pastellkreide auf Papier. Inv.-Nr.: 80-016, Bröhan-Museum, Berlin. Foto: Martin Adam, Berlin

Druck: Majuskel Medienproduktion $\mathrm{GmbH}$, Wetzlar

Print-ISBN 978-3-8376-5589-6

PDF-ISBN 978-3-8394-5589-0

https://doi.org/10.14361/9783839455890

Gedruckt auf alterungsbeständigem Papier mit chlorfrei gebleichtem Zellstoff. Besuchen Sie uns im Internet: https://www.transcript-verlag.de Unsere aktuelle Vorschau finden Sie unter www.transcript-verlag.de/vorschau-download 


\section{Inhalt}

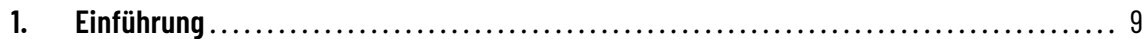

1.1 Zum Gegenstand des Wartens ........................................... 9

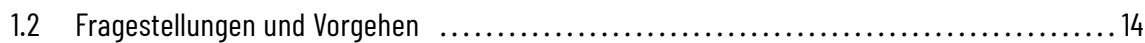

1.3 Expeditionen ins Warten (Forschungsstand) . .............................. 16

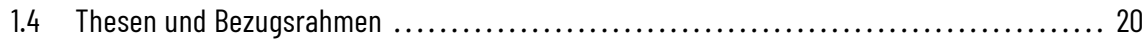

1.5 Methodische Eingrenzungen und Betrachtungszeitraum .......................... 26

1.6 Aufbau der Arbeit................................................. 29

2. 'Zeitreise: Theorien und Strukturen der Konstituierung von Zeiterfahrung ........... 31

2.1 Philosophische Zeittheorien ............................................. 33

2.1.1 Antike Zeittheorien .............................................. 34

2.1.2 Neuzeitliche und moderne Zeittheorien................................ 41

2.1.3 Aporien der Zeit: Resümee philosophischer Zeittheorien .................... 50

2.2 Sozialwissenschaftliche und kulturanthropologische Zeittheorien .................... 53

2.2.1 Grundlegungen zum Zeitbegriff im Rahmen klassisch-soziologischer Theoriebildung ................................ 54

2.2.2 Gesellschaftliche und soziale Funktionen der Zeit........................ 57

2.2.3 Dimensionen, Ebenen und Strukturen des subjektiven und sozialen Zeiterlebens ...60 60

2.2.4 Evolution und Charakteristik des modernen Zeitbewusstseins .................. 64

2.2.5 Kulturanthropologische Zeitstudien ................................ 76

2.3 Was ist die Zeit? Fünf Kernbefunde für einen Orientierungsrahmen .................... 81

2.4 Von der Zeit zur Wartezeit: Versuch einer Theoretisierung ......................... 89

2.4.1 Individuell-subjektive Grundbedingungen für die Erfahrung von Wartezeiten ...... 89

2.4.2 Ursprünge und Entstehungsbedingungen des Wartens ................. 92

3. Die Wartezeit als Konfliktfall der Moderne .................................. 97

3.1 Zeithistorische Verortung und Eingrenzung:

Warten als temporales Phänomen inı der Moderne ........................... 97

3.1.1 Auf der Suche nach den Wurzeln des modernen Wartens:

Wartezeiten als Komplementäreffekt von Beschleunigungsprozessen ............ 106

3.1.2 Die Problematisierung des Stillstands und deren Voraussetzungen ...............111 
3.2 Exkurs: Warten im Spiegel empirischer und theoretischer Forschung

- Panorama disziplinärer Perspektiven

3.2.1 Queuing Theory und Operations Management: Wartezeiten als stochastisches Problem und mathematische Beschreibung

3.2.2 Die Empfindung des Wartens: Psychologische Beschreibungsebenen ............ 126

3.2.3 Marketing und Management Studies: Attraktivierung eines ungeliebten Zustands ... 131

3.3 Synthese: Warten im Spiegel theoretischer und empirischer Zeitforschung ............. 146

3.4 Verkehrsinduziertes Warten ............................................... 149

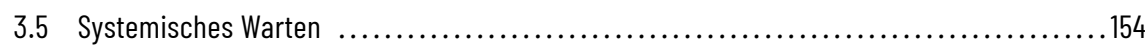

4. Die Eisenbahn als zentrales Verkehrsmittel der Moderne: Eine Kontextualisierung..... 161

4.1 Verkehrs- und technikgeschichtlicher Überblick:

Aufstieg, Blüte und beginnender Rollenverlust des Eisenbahnwesens ................. 161

4.1.1 Vorläufertechnologien auf dem Weg zur Eisenschiene ....................... 162

4.1.2 Anfänge des Personenverkehrs ....................................... 165

4.1.3 Statistische Befunde zur Verkehrsentwicklung .......................... 170

4.1.4 Wirtschaftsfaktor und Widerstandsobjekt ................................. 172

4.1.5 Nebeneinander der Verkehrsträger .................................... 177

4.1.6 Einsatzfelder und Heilsversprechen ................................. 178

4.1 .7 Treibende Akteure ............................................... 181

4.1.8 Verlauf der Technikentwicklung und Betriebsorganisation .................... 184

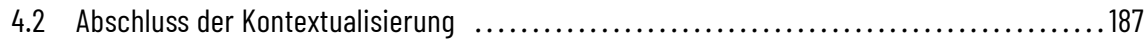

5. Warten auf Eisenbahnen: Räume und Rezeptionen (1830-1935) .................. 191

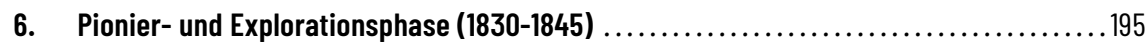

6.1 Der Bahnhofsbau zwischen Persistenz und neuheitlicher Bauaufgabe ................ 196

6.2 Die Orte des (frühen) Wartens: Bahnhöfe der ersten Generation .................... 206

6.2.1 Liverpool - Crown Street Station (1830) ............................... 206

6.2.2 Manchester - Liverpool Road Station (1830) ............................. 213

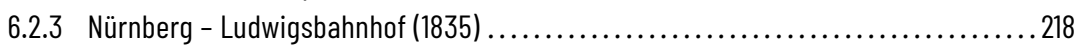

6.2.4 Berlin - Potsdamer Bahnhof (1838) ................................... 226

6.3 Zur baulichen, betrieblichen und kollektiven >Entdeckungs

des Wartens in der Pionierzeit der Eisenbahnen ............................. 236

6.3.1 Bauliche Entdeckung des Wartens: Räume und Orte ...................... 236

6.3.2 Betriebliche Entdeckung des Wartens: Herausbildung eines stationären Warteimperativs in Betriebsorganisation und Passagierabfertigung ........... 242

6.3.3 Kollektive Entdeckung des Wartens: Rezeptionen und Praktiken............... 244

7. Standardisierung und Konsolidierung (1845-1870)

Etablierung und erweiterte Rahmung des stationären Warteimperativs ............... 255

7.1 Bauliche und betriebliche Rahmenentwicklungen ........................... 257

7.1.1 Auf dem Weg zu einer >Normalform ‘:

Direktiven und Anforderungen des Bahnhofsbaus (1845-1870) ............... 258

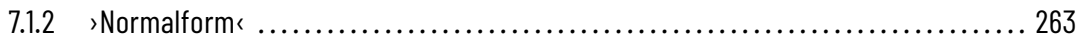


7.1.3 Verstetigung und Etablierung des stationären Warteimperativs 266

7.2 Räumliche und betriebliche Differenzierungen des verkehrlichen Wartens (1845-1870) . . . 267

7.2.1 Nationale und regionale Unterschiede ................................ 267

7.2.2 Erweiterte Rahmung und Kompensation des stationären Warteimperativs: Kulinarisierung, Mediatisierung und Kommerzialisierung des Wartens ........... 275

7.3 Exemplarische Bahnhofsbauten der Wachstums- und Standardisierungsphase ........... 291

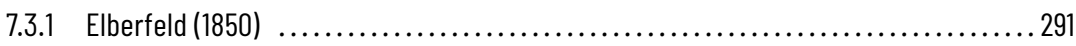

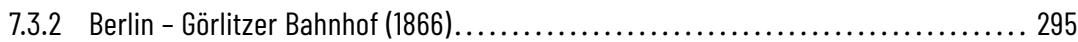

7.4 Rezeptionsgeschichte des verkehrlichen Wartens $(1845-1870)$..................... 301

7.4 .1 Lyrik ........................................................ 301

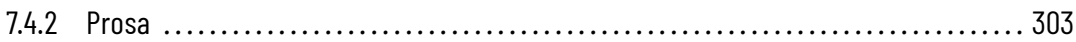

7.4 .3 Lieder .......................................................... 315

7.4 .4 Zeichnungen ...................................................... 316

7.5 Abschluss: Rahmung und Rezeption des Wartens in der Standardisierungs- und Konsolidierungsphase der Eisenbahnen (1845-1870) ............................. 319

8. Blütephase des Eisenbahnwesens

Warten im modernen Großstadtbahnhof zwischen Kultivierung und >Verflüssigung،

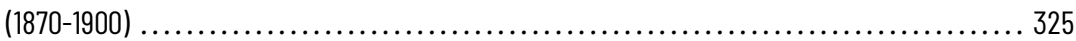

8.1 Bauliche und betriebliche Rahmenentwicklungen ............................. 327

8.1.1 Empfangsgebäude in Seitentieflage: Der >Typ Hannover ‘ ................... 327

8.1.2 Neue Zirkulations- und Wartezonen: Mittel-, Kopf- und Querbahnsteige und das Paradigma eines >reibungslosen Betriebs ...................... 332

8.1 .3 Bahnsteigsperre ............................................ 338

8.1.4 Vereinheitlichung des Zeitbezugssystems: Eisenbahnzeit ................... 340

8.2 Soziale Differenzierung der Warteraumstrukturen:

Von Damenzimmern, Auswanderer- und Saisonarbeitersälen ....................... 341

8.2.1 Damenzimmer ..................................................... 342

8.2 .2 Auswanderersäle ............................................. 348

8.2 .3 Saisonarbeitersäle................................................ 349

8.3 Bahnhofsarchitektur: Die Beruhigung der Massen ............................ 350

8.4 Exemplarische Bahnhofsbauten der Blütephase .............................. 355

8.4.1 Berlin - Potsdamer Bahnhof (1872) ..................................... 355

8.4.2 Frankfurt a.M. (1888) .......................................... 365

8.5 Rezeptionsgeschichte des verkehrlichen Wartens $(1870-1900)$....................... 372

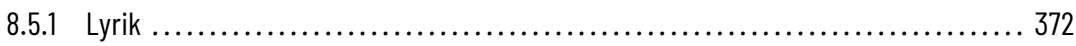

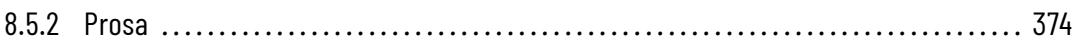

8.6 Abschluss: Rahmung und Verhandlung des Wartens

im modernen Großstadtbahnhof $(1870-1900)$.............................. 380

9. Marginalisierung des stationären Wartens im modernen Zweckbau (1900-1935) ...... 385

9.1 Bauliche und betriebliche Rahmenentwicklung: Zweifel an etablierten Formen und Triumph der modernen Zweckmäßigkeit.................................. 386

9.2 Exemplarische Bahnhofsbauten der Marginalisierung des stationären Wartens ......... 400

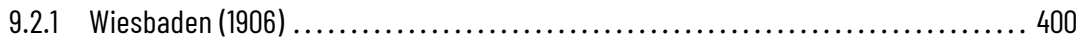


9.2 .2 Stuttgart (1922) ................................................ 404

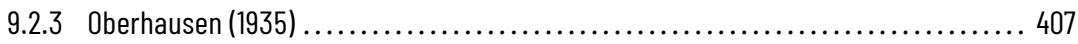

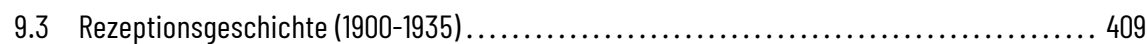

9.3 .1 Lyrik ................................................. 410

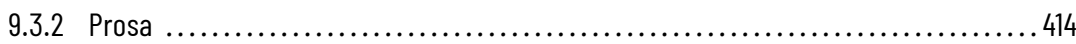

9.3.3 Lithografien und Zeichnungen ........................................... 419

9.4 Abschluss: Rahmung und Verhandlung des verkehrlichen Wartens am Ende der $>$ Ersten Moderner . .......................................... 424

10. Exploration: Bau- und Wahrnehmungskonjunkturen im weiteren Verlauf des 20. und

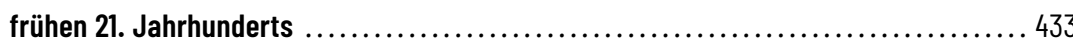

Fazit: Zur Bau- und Kulturgeschichte des (verkehrlichen) Wartens .................. 451

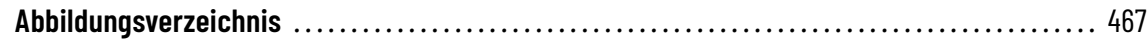

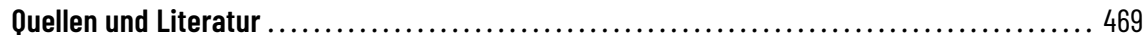

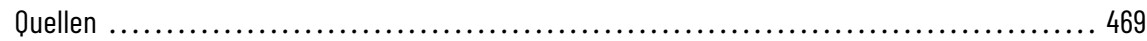

Literatur ......................................................... 476 


\section{Einführung}

»Waiting is a temporal region hardly mapped and badly documented. «'

\subsection{Zum Gegenstand des Wartens}

Der Mensch pflegt ein bisweilen rätselhaftes Verhältnis zur Zeit. Sie ist omnipräsent und zugleich unsichtbar, sie tickt permanent und doch können wir sie weder riechen noch schmecken. Gleichwohl sind wir alle, so Helga Nowotny, »Praktiker und Theoretiker der Zeit. « Selten meinen wir ausreichend von ihr zu haben (meist eher zu wenig) und manchmal vergeht sie scheinbar nie. Die vorliegende Arbeit nimmt sich zum Ziel, exakt jene Momente zu erkunden, in denen sie scheinbar nie vergeht: die Momente des Wartens.

Wartezeiten bilden ein unausweichliches wie alltägliches Temporalphänomen moderner Lebenswelten. Wir warten auf Personen, Güter oder Dienstleistungen, auf Antwort oder Abfahrt, auf Ernten und Erlösung oder warten einfach ab. Wir warten ungeduldig, routiniert oder mitunter unerträglich lang auf Anfänge, Veränderungen, Wiederkehr oder gar auf den Tod. Mit seinen schier endlosen Bezügen und Anlässen erscheint das Warten als anthropologische Grundverfassung des Menschen, die zu einer »vermeintlich vertrauten Gewissheit des alltäglichen Welterlebens « ${ }^{3}$ gehört, aber im Grunde den Status »unserer ersten großen Kulturleistung « ${ }^{4}$ beanspruchen kann, da die in Wartesituationen greifende Imagination des Kommenden auf die Urform des selbstreflexiven Modus der Welterfahrung ${ }^{5}$ verweist, eine Eigenschaft, die nach Ansicht des Sozialpsychologen Andrew J. Weigert den Menschen letztlich scharf vom Tierreich unterscheide:

$1 \quad$ Harold Schweizer, On Waiting (London; New York: Routledge, 2008), 1 [Herv. i. O.].

2 Helga Nowotny, Eigenzeit: Entstehung und Strukturierung eines Zeitgefühls (Frankfurt a.M.: Suhrkamp, 1989), 7.

Vgl. Nadine Benz, (Erzählte) Zeit des Wartens: Semantiken und Narrative eines temporalen Phänomens (Göttingen: V\&R Unipress, 2013), 14.

$4 \quad$ Andrea Köhler, Lange Weile: Über das Warten (Frankfurt a.M.: Insel Verlag, 2007), 10.

5 Vgl. Helmuth Plessner, Die Stufen des Organischen und der Mensch: Einleitung in die philosophische Anthropologie (Berlin; New York: Walter de Gruyter, 1975). 
»All humans wait, and in the fullest sense of the term, only humans wait. ${ }^{6}$

Der Soziologe Rainer Paris definiert den Zustand als »eine mehr oder minder andauernde ortsgebundene Tätigkeit, ein stationäres Verweilen [...], bei der eine oder mehrere Personen ihre Aufmerksamkeit auf ein künftiges Ereignis richten und sich mental darauf vorbereiten. " Giovanni Gasparini präzisiert diese eigentümliche Qualität des Wartens zudem in der Einschätzung, dass es uns wie kaum ein anderer temporaler Zustand mit dem Wesen und dem Wert der Zeit selbst und nicht zuletzt mit existentiellen Sinnfragen des eigenen Daseins konfrontiert:

»Aside from different ideological or religious beliefs, waiting, even when it is experienced at an everyday or micro level, relates to the value of time and therefore, from the actor's point of view, to the general meaning of life. ${ }^{8}$

Jene Momente des Aufschubs nehmen im nebulösen Spektrum menschlicher Zeitwahrnehmungen die vielleicht spannungsreichste Rolle aller temporalen $\mathrm{Zu}$ stände ein. Ob als kurzes, situatives und banales Erfordernis oder lang andauernde, krisenhafte Leerstelle, das Warten stellt eine Anomalie im normativ-linearen Zeitfluss dar und erzeugt die oft schmerzliche Zäsur des sonst sicher Erwartbaren. Es konfrontiert uns zum Teil mit fundamentalen Herausforderungen und erfordert das Erlernen kultureller und sozialer Umgangs- und Bewältigungspraktiken. Zugleich gehören jene zeitlichen Unterbrechungen und Störungsmomente, Fehlstellen und (Zwangs-)Pausen zur alltagspraktischen wie biografischen Realität und tragen in ihrer jeweils ganz unterschiedlichen temporalen Qualität in nicht geringem Maße erst zur Ausbildung einer "Signatur des Lebens « ${ }^{9}$ bei. Während etwa Walter Benjamin in jenen Brüchen eine Vermittlungsfunktion zu einer nächsten Entwicklungsstufe und damit eine wesentliche Ressource der Produktion von Erfahrungen sieht, ${ }^{10}$ gelten solche zeitlichen Diskontinuitäten für den Sozialpsychologen George Herbert Mead gar als lebensnotwendige Vorbedingung zur Erfahrung der Wirklichkeit: »Without this break within continuity, continuity would be inexperienceable. « ${ }^{11}$ Lebenszeit ist demnach nicht homogen in einer physikalisch gleichförmigen Abfolge bzw. einem einheitlichen

6 Andrew ]. Weigert, Sociology of everyday life (New York: Longman, 1981), 227. Diese Auffassung schließt an die bereits prominent durch Déscartes verbreitete These an, nach der Tiere über keine Empfindungsfähigkeit und kein eigenes Bewusstsein verfügen würden. Weigerts These einer exklusiv menschlichen Fähigkeit des bewussten Wartens dürfte aus Sicht der human-animal studies jedoch durchaus kontrovers diskutiert werden. Zur kritischen Reflektion des moralischen Status von Tieren und ihrer Rolle in der Cesellschaftsgeschichte: Dorothee Brantz, »Introduction«, in Beastly natures: Animals, humans, and the study of history, hg. von Dorothee Brantz (Charlottesville: University of Virginia Press, 2010), 1-13.

7 Rainer Paris, »Warten auf Amtsfluren«, KZfSS Kölner Zeitschrift für Soziologie und Sozialpsychologie 53, Nr. 4 (2001): 706 [Herv. i. O.].

8 Giovanni Gasparini, »On Waiting«, Time \& Society 4, Nr. 1 (1995): 43.

9 Heinz Schilling, »Zeitlose Ziele: Versuch über das lange Warten«, in Welche Farbe hat die Zeit, hg. von ders. (Frankfurt a.M.: Universität Frankfurt, Institut für Kulturanthropologie, 2002), 264.

10 Zit. in ebd., 248.

11 Ceorge Herbert Mead, »The nature of the past«, in Essays in Honour of John Dewey, hg. von John Cross (New York: Henry Hall, 1929), 239. 
Lebensablauf, sondern vielmehr in Rhythmen organisiert, die auch Punktierungen der gefühlten Bewegungslosigkeit einschließen. Entsprechend ist auch im Hinblick auf die sprachliche Reflexion des Zeiterlebens festzustellen, dass sie nicht exklusiv auf kinetische Zuschreibungen rekurriert, sondern gleichwohl auch auf Formen ihrer scheinbaren Unbeweglichkeit. Anders ausgedrückt: Nicht immer fließt oder rennt die Zeit, sondern manchmal bleibt sie auch einfach stehen.

Im gefühlten Stillstand des Wartens wird die sonst implizite Flüchtigkeit der Zeit unweigerlich zum expliziten Erlebnis. Es lässt den vielleicht einzigen Temporalzustand entstehen, der uns »das Nagen der Zeit fühlbar und ihre Versprechen erfahrbar macht. « ${ }^{12}$ Darin erwächst die Wahrnehmung eines intensiven zeitlichen Ausnahmezustands, der meist von Ungewissheit und erzwungener Passivität geprägt wird und in einem affektiven Reaktionsspektrum von Langeweile, Ruhelosigkeit und Stress bis hin zu Angst resultiert. ${ }^{13}$ Diese primär negative Charakteristik des Wartens verwundert kaum, denn die Zeit, so Norbert Elias, erfüllt im Allgemeinen die Funktion einer fortschreitenden symbolischen Syntheseleistung mit dem Ziel der gesellschaftlichen Gewährleistung von Orientierung, Synchronisation und Vergleichbarkeit. ${ }^{14} \mathrm{Im}$ Zustand des Wartens jedoch bewirken die sonst unbewussten Ordnungs- und Orientierungsfunktionen einen problematischen Sonderfall, weil die Zeitfunktionen plötzlich (zu) stark expliziert werden und unweigerlich den dominierenden Erfahrungs- und Wahrnehmungsmittelpunkt bilden. Mit anderen Worten: Während die Zeit im Zustand des Wartens unverändert weiterzulaufen scheint, droht das eigene Dasein in der Folge zunehmend vom objektiven Zeitfluss der anderen Gesellschaftsmitglieder abgekoppelt und desynchronisiert zu werden. ${ }^{15}$ Die erhöhte Zeitsensibilität im Warten generiert so ein Paradoxon: Es schärft das Bewusstsein darüber, der eigenen Kontrolle entzogen zu viel Zeit zu haben oder bildlich gesprochen, eine Währung zu besitzen, die an anderer Stelle wertvoll, im Warten aber nutzlos ist. Weil das Warten dabei nie Selbstzweck ist, erzeugt es somit einen Zustand, der stets nach seiner unmittelbaren Abschaffung strebt. $^{16}$

Den systemischen Grund für die Entstehung von Wartezeiten sieht der Soziologe Hartmut Rosa insbesondere im hochentwickelten Stadium moderner Gesellschaften. Stets müssten wir in solchen unser Handeln »an den komplementären Aktivitäten und Zeitmustern unserer Kooperationspartner orientieren und wenigstens temporäre Synchronisation sicherstellen - was in funktional ausdifferenzierten Gesellschaften unvermeidlich zu einer hohen Anzahl kleiner und größerer Wartezeiten [...] führt. «" Auch Walter Benjamin erkannte den engen Zusammenhang von Modernisierungsprozessen

12 Köhler, Lange Weile, 9.

13 Vgl. Edgar Elias Osuna, »The psychological cost of waiting«, Journal of Mathematical Psychology 29, Nr. 1 (1985): 82-105; Shirley Taylor, »Waiting for service: the relationship between delays and evaluations of service«, The Journal of Marketing 58, Nr. 2 (1994): 56-69; Mark Wardman, »Public Transport Values of Time«, Transport Policy 11, Nr. 4 (Oktober 2004): 363-77.

Vgl. Norbert Elias, Über die Zeit, hg. von Michael Schröter, Gesammelte Schriften 9 (Frankfurt a.M.: Suhrkamp, 2004), 10.

15 Vgl. Heinz Schilling, »Zeitlose Ziele«, 249.

16 Vgl. Timo Reuter, Warten: Eine verlernte Kunst (Frankfurt a.M.: Westend, 2020), 14.

17 Hartmut Rosa, Beschleunigung: die Veränderung der Zeitstrukturen in der Moderne (Suhrkamp Verlag, 2005), 34. 
und auftretender Verlangsamungen und prognostizierte bereits im frühen 20. Jahrhundert eine Zunahme von Wartezeiten als Folge der Bürokratisierung: »Je mehr das Leben administrativ genormt wird«, so Benjamin, »desto mehr müssen die Leute das Warten lernen. ${ }^{18}$ Angesichts der omnipräsenten Notwendigkeit temporärer Synchronisationen ließen sich über Benjamins Beispiel hinaus zweifellos unzählige weitere situative Felder und Orte beschreiben, in und an denen wir warten müssen. Im Zentrum der vorliegenden Arbeit steht im Folgenden jedoch ein ganz spezifisches Auftrittsfeld der modernen Alltagswelt.

\section{Warten auf öffentlichen Verkehr}

$\mathrm{Zu}$ den wohl prominentesten Schauplätzen alltäglich generierter Wartezeiten zählen die Mobilität im weiteren und der Verkehr im engeren Sinne. Wie kaum ein anderes Handlungsfeld generiert der öffentliche Personentransport - verstanden als physisch realisierte Mobilität ${ }^{19}$ - aufgrund seiner organisatorischen Notwendigkeit zur Synchronisation und Bündelung heterogener Fahrtwünsche selbst im Rahmen eines reibungslosen Ablaufs Raum- und Sachzwänge, die für Reisende in prozessimmanenten Wartesituationen resultieren. Sie entstehen, weil die Organisation als auch die Nutzung von öffentlichem Verkehr gegenüber dem Individualverkehr einen vergleichsweise höheren Regelungs- und Informationsaufwand vor der Abfahrt erfordert. Aus operationaler Sicht entstehen Wartezeiten dabei aufgrund der kontrollintensiven Transportorganisation, die innerhalb von Verkehrsbauten Prozesszonen der Retardierung erfordert, um Ströme und Zugangsberechtigungen zu kontrollieren bzw. Betriebsvorgänge im Hintergrund abwickeln zu können. Aus Sicht der Reisenden wiederum werden Wartezeiten - wenngleich weit weniger intendiert - im notwendigen Einräumen von Zeitkapazitäten zur Bewerkstelligung des Übergangs vom privaten oder öffentlichen Raum in den öffentlichen Verkehrsraum erforderlich. ${ }^{20}$ Weil dieser Übergang sich als äußerst zeitsensitiv darstellt, müssen Reisende am Abfahrtsort meist ein mehr oder weniger langes, stationäres Verweilen im Transitraum von Wartehallen und Bahnsteigen oder ein indirektes Warten in Restaurants und Geschäften absolvieren. Darüber hinaus ist wie allen Servicebereichen auch dem öffentlichen Verkehrswesen eine Anfälligkeit für unplanmäßige Verzögerungen oder Annullierungen inhärent, ${ }^{21}$ die sich regelmäßig in zusätzlichen Wartezeiten niederschlagen.

Das Warten kennzeichnet damit aus verkehrshistorischer Perspektive nicht nur einen immanenten und aus Passagierperspektive zutiefst wahrnehmungsrelevanten Parameter, es prägt aus mobilitätstheoretischer Perspektive ein geradezu paradigmatisches Komplementärphänomen der verkehrlichen Moderne im Rückraum des dominierenden Primats von Beschleunigung und Bewegung, das trotz aller Interventionsversuche und Auslöschungstendenzen untrennbarer Bestandteil des Verkehrswesens

18 Walter Benjamin, Das Passagen-Werk, hg. von Rolf Tiedemann (Frankfurt a.M.: Suhrkamp, 1982), D 10a, 2 (S. 178).

19 Zur Differenzierung der Begriffe Mobilität und Verkehr: Weert Canzler und Andreas Knie, Möglichkeitsräume: Crundrisse einer modernen Mobilitäts-und Verkehrspolitik (Wien: Böhlau, 1998).

20 Hierzu auch Kap. 3.4.

21 Vgl. V.A. Zeithaml, M. J. Bitner, und D. D Gremler, Services Marketing: Integrating Customer Focus across the Firm (New York; London: McCraw-Hill Higher Education, 2012). 
geblieben ist. Verkehrsinduzierte punktuelle Unterbrechungen, Zäsuren und Stillstände - sei es als Stau, Verspätung oder reguläre Wartezeit auf Beförderung - gehörten und gehören trotz bzw. gerade aufgrund der Diagnose anhaltender sozialer und technischer Beschleunigungsprozesse zu einem stillen, aber wirkmächtigen Begleiter des Mobilitätsalltags. ${ }^{22}$ Kurzum: Die tatsächlich erlebte Mobilitätspraxis bleibt im Schatten einer inflationären Aufmerksamkeit für Bewegungen und Ströme nur allzu oft durch die zur Bewegung korrelative Erfahrung des Wartens an Bahnhöfen, Flugsteigen oder auf Straßen gekennzeichnet.

Der mitunter immense zeitliche Umfang dieses situativen Aufenthalts vor Abfahrt wird regelmäßig durch Studien und Statistiken quantifiziert. So erhob bspw. die Deutsche Bundesbahn in einer Infas-Studie des Jahres 1979, dass $35 \%$ der Fernverkehrsreisenden vor Abfahrt eine Wartezeit von 6-15 Minuten, 32 \% eine Wartezeit von 15-30 Minuten, $14 \%$ 30-60 Minuten und $5 \%$ gar eine Wartezeit von mehr als 60 Minuten verbrachten. Nur $12 \%$ der Reisenden absolvierten demnach ein Kurzzeitwarten von 0-6 Minuten. ${ }^{23}$ Aber auch gegenwärtig bleibt die Erfahrung des Wartens ein persistenter Reisebegleiter. So fielen etwa im Betriebsjahr 2018 innerhalb des Fernverkehrsnetzes der Deutschen Bahn 3,7 Millionen Verspätungsminuten an. Knapp 75 \% der Fernverkehrszüge fuhren demnach nicht pünktlich. ${ }^{24} \mathrm{Ob}$ in der Vergangenheit oder der Gegenwart, der Eisenbahnverkehr ist damit aufs Engste an die Entstehung bzw. >Produktion v von Wartezeiten gebunden, deren wahrgenommener Zeitwert bzw. deren Kosten im spezifischen Kontext des Eisenbahnverkehrs gegenüber dem Modus der verbrachten Fahrtzeit im Zug um den Faktor 2.5 mal höher eingeschätzt werden. ${ }^{25}$

Angesichts der Persistenz und passagierseitigen Bedeutung verkehrsbezogener Wartesituationen bleibt dennoch zum Erstaunen festzustellen, dass das Phänomen bislang "eine in ihrer Bedeutung von der Historiografie bisher unterschätzte Mobilitätsform « ${ }^{26}$ geblieben ist. So prominent und umfassend Verkehr und Mobilität auch als Schlüsselthemen der Moderne identifiziert worden sind, eine (historische) Thematisierung des wartenden Passagiers im Verkehrskontext wird schlicht als Leerstelle befunden, so konstatiert David Bissell:

»If the experience of waiting is therefore such a common everyday prosaic experience, particularly with regard to the travel experience, it is surprising that it has not received any form of specific sustained attention. « $^{27}$

22 Vgl. Paul Virilio, Vitesse et politique: essai de dromologie, Bd. 6 (Paris: Editions Galilée, 1977).

23 Zitiert aus Karl Radlbeck, »Bahnhof und Empfangsgebäude: die Entwicklung vom Haus zum Verkehrswegekreuz« (Dissertation, TU München, 1981), 132.

24 Deutscher Bundestag, »Pünktlichkeit und Zugausfälle bei der Deutschen Bahn bis 2018«, 2019, https://dipbt.bundestag.de/doc/btd/19/084/1908483.pdf, zugegriffen am 25.01.2020. Wardman, »Public Transport Values of Time«, 375. Ueli Haefeli, »Beobachter einer mobilen Welt. Cedanken zum mobilitätshistorischen Wert belletristischer Quellen am Beispiel Friedrich Dürrenmatt«, Wege und Ceschichte, Nr. 1 (2017): 36 [Hervorhebung des Verfassers, R.K.]. Damit übereinstimmend wurde auch an anderer Stelle der fehlende Einbezug des Wartephänomens in verkehrs- und mobilitätshistorischen Arbeiten angemahnt: Andrey Vozyanov, »Approaches to Waiting in Mobility Studies: Utilization, Conceptualization, Historicizing «, Mobility in History 5, Nr. 1 (2014): 64-73. 


\subsection{Fragestellungen und Vorgehen}

Die vorliegende Arbeit nimmt diesen kritischen Befund als Anlass, eine Bau- und Kulturgeschichte des Wartens im Kontext des Eisenbahnwesens zu verfassen. Dabei wird der leitenden Fragestellung nachgegangen, wie sich das Warten auf Beförderung im Eisenbahnverkehr im Laufe der letzten zwei Jahrhunderte aus Sicht unterschiedlicher Akteursgruppen wandelte. Hierfür stehen zwei sich ergänzende Analysestränge im Zentrum der Untersuchung. Zum einen die Rekonstruktion der baugeschichtlichen Entwicklung von Warteräumen innerhalb der Bahnhofsgebäude. Zum anderen die systematische Erschließung und Interpretation der erfahrungs- und rezeptionsgeschichtlichen Reflektionen bezüglich verkehrsinduzierter Wartezeiten. Mithilfe dieser diachronen Untersuchung der baulich-operativen Arrangements auf Anbieterseite sowie der literarisch-künstlerischen Niederschläge von Wartezeiten seitens der Betroffenen werden die planerische Außenperspektive sowie die passagierbezogene Innenperspektive des Wartens in einem historiografischen Panorama verdichtet, auf dessen Grundlage synthetisierte Entwicklungslinien für eine >Geschichte des Wartens` gewonnen werden können.

Im Zentrum des baugeschichtlichen Analysestranges steht die Frage, wie Eisenbahngesellschaften, Architekten und Ingenieure ${ }^{28}$ das Warten auf Abfahrt im historischen Wandel organisiert und gestaltet haben bzw. welche betrieblichen und sozialen Funktionen das Warten am Bahnhof erfüllte. Konkretes Ziel ist die Rekonstruktion der Entwicklung des Bahnhofswartesaals in Form der Aufarbeitung von Raumprogrammen, Grundrissdispositionen und entsprechender Planungsdiskurse, die Aufschluss über Orte, Atmosphären und Ordnungen des Wartens im funktional-operativen Gefüge des Bahnbetriebs, über mögliche Problemlagen sowie regional und national variierende Betriebskonzepte geben können. Hierfür werden eine Vielzahl historischer Textquellen (Fachzeitschriften ${ }^{29}$, Handbücher, Tagungs- und Vereinsprotokolle), Bildquellen (Grundrisse, Baupläne und Ansichten) historischer Bahnhofsbauten sowie Statistiken ausgewertet, für die auf zahlreiche (digitalisierte) Bibliotheks- und Archivbestände zurückgegriffen werden konnte.

Im Zentrum des erfahrungs- und rezeptionsgeschichtlichen Analysestrangs steht demgegenüber die Frage, wie Passagiere jene verkehrsinduzierten Wartephänomene im historischen Wandel erfahren, reflektiert und verhandelt haben. Ziel dieser subjektzentrierten Perspektivierung ist die Betrachtung der am Bahnhof vollzogenen strukturund sinnbildenden Wartepraktiken bzw. der Rekonstruktion kollektiver Grunderfahrungen und Bewertungen des transitorischen Aufenthalts. Dazu werden eine Vielzahl literarischer Werke mit Eisenbahnbezug aus Prosa und Lyrik, aber auch Lieder, Lithografien und Zeichnungen ausgewertet, die als prädestinierte Reflexionsinstanzen des transitorischen Wartemodus aufgefasst werden und eine empirische Erfahrbarkeit des Aufenthalts am Bahnhof vermitteln. Für die Korpusbildung wurden hierfür in großem

28 Mit Nennung der männlichen Funktionsbezeichnung ist in diesem Buch, sofern nicht anders gekennzeichnet, stets immer auch die weibliche Form mitgemeint.

29 Hierzu zählen insbesondere folgende Zeitschriften: Allgemeine Bauzeitung (1836-1918), Zeitschrift für Bauwesen (1851-1914), Organ für die Fortschritte des Eisenbahnwesens (1845-1944), Deutsche Bauzeitung (1867-1920) sowie das Zentralblatt der Bauverwaltung (1881-1931). 
Umfang Präsenz-, Magazin- und Archivbestände - etwa der Staatlichen Museen zu Berlin (Kunstbibliothek, Lipperheidesche Kostümbibliothek), der Staatsbibliothek Berlin, der Universitätsbibliothek der Technischen Universität Berlin - sowie Anthologien und Textsammlungen konsultiert.

Der gewählte Zugriff über eine Außen- und Innenperspektive des Wartens bildet nicht nur die heuristischen Prämissen mit denen die Fülle von Quellenmaterial zum Thema >Zeit < eingegrenzt wird. Die analytische Zweiteilung erscheint vor allem notwendig, weil die Zeugnisse der subjektiven Erfahrungen von Wartezeiten für sich allein schwerlich ohne die kontextuellen Aussagen der jeweiligen räumlichen und verkehrsorganisatorischen Situation eingeordnet und interpretiert werden könnten. Zudem wird mit Einbezug der Betrachtung einer Materialität des Wartens (Räume, Ausstattungen etc.) der Gefahr begegnet, dass historische Arbeiten oftmals zu sehr an Diskursen verhaftet bleiben, ohne sie bezüglich ihrer Entstehung an materielle Strukturen zurückzukoppeln. ${ }^{30}$ Nicht allein sprachliche Niederschläge, sondern auch jene der materiellen Kultur ${ }^{31}$ sollen damit verstärkte Berücksichtigung finden.

Die Betrachtung der Außen- und Innenperspektive des Wartens wird zudem von der übergeordneten zeithistorischen Fragestellung begleitet, ob und inwiefern sich am Beispiel des Eisenbahnwesens ein wachsendes Spannungsverhältnis zwischen systembedingter Verlangsamung bzw. Stauung und der Optimierung von Raum und Zeit unter dem Dogma der Beschleunigung abzeichnete. Ausgehend vom Befund des Beschleunigungsprinzips als der »zentralen Fortschrittskomponente $«^{32}$ und »charakteristischen Grunderfahrung « ${ }^{33}$ der Moderne wird die bau- und rezeptionsgeschichtliche Analyse des Wartens somit von der Frage begleitet, wann innerhalb der historischen Längsschnittbetrachtung Unterbrechungen, Pausen und Retardierungsmomente als Gefährdung für den Erfolg der Modernisierungsprozesse wahrgenommenen wurden. Oder anders ausgedrückt: War der situative Aufenthalt im Transitraum des Bahnhofswartesaals vom Anbeginn des Eisenbahnwesens Gegenstand einer ungeliebten Kollektiverfahrung bzw. $\mathrm{zu}$ welchem Zeitpunkt erfuhr das Warten innerhalb moderner Gesellschaften seine bis zur Gegenwart hinein wirkmächtige Problematisierung als ein erfahrungsgesättigtes, negativ konnotiertes Alltagsphänomen?

Die beiden historiografischen Fragestellungen werden schließlich um den vorangestellten Analysestrang einer umfangreichen zeittheoretischen Einordnung ergänzt, mit dem erfragt wird, wie und unter welchen Bedingungen Zeit überhaupt zu einer Wartezeit reifen kann. Ziel ist es hierbei, ein zeittheoretisch informiertes Verständnis des

Vgl. Andreas Marklund und Mogens Rüdiger, Hg., Historicizing infrastructure (Aalborg: Aalborg University Press, 2017).

31 Harvey Green definiert den Einbezug der materiellen Kultur in historiografische Untersuchungen als »the study of the made and built world « und führt fort: »Material culture challenges the historian to discover the often unspoken mental and technical processes by which artefacts attained their appearance and form as well as the ways artefacts embody the beliefs and values of those who made and used them. « Harvey Green, »Cultural History and the Material(s) Turn«, Cultural History 1, Nr. 1 (2012): 61.

32 Peter Borscheid, Das Tempo-Virus: eine Kulturgeschichte der Beschleunigung (Frankfurt a.M.; New York: Campus, 2004), 10.

33 Rosa, Beschleunigung: die Veränderung der Zeitstrukturen in der Moderne, 40. 
Phänomens zu entwickeln, indem die Grundbedingungen, Besonderheiten und Strukturmerkmale der Wartezeit herausgearbeitet werden, die sie als spezifisch (kritisches) Phänomen innerhalb der menschlichen Zeitwahrnehmung begründen. Dazu wird auf Grundlage der eingehenden Untersuchung philosophischer und sozialwissenschaftlicher Theorieangebote die generelle Konstituierung lebensweltlicher Zeitwahrnehmung aufgearbeitet, aus der heraus wesentliche Erkenntnisse für die Konstituierung von Wartezeiten abgeleitet werden.

\subsection{Expeditionen ins Warten (Forschungsstand)}

Bis ins späte 20. Jahrhundert blieb das Warten aufgrund seiner abstrakten und schwer greifbaren Aura ein vorwiegend unbefragtes Alltagsphänomen. Weit bevor der Zustand und dessen vielfältige Formationen vermehrt das Forschungsinteresse der Sozial- und Kulturwissenschaften weckten, widmeten sich Literatur, Philosophie, Kunst und Mathematik dem Gegenstand. Angefangen von Victor Hugos literarisch-aufklärerischer Adressierung des Wartens im berühmten Diktum »Rêver, c'est le bonheur, attendre, c'est la vie ${ }^{34}$, verdeutlichen etwa die zeitphilosophischen Arbeiten von Bergson ${ }^{35}$ oder Husser $^{36}$, dass es insbesondere die »leere Zeit « des Wartens war, welche die Philosophie seit jeher ganz besonders herausgefordert hat, ein ontologisches Verständnis der Zeit und des Zeitempfindens zu entwickeln. ${ }^{37}$ Eine zentrale Erkenntnis dieser Beschäftigung uferte in der Auffassung, dass das Warten als gelebte Dauer ${ }^{38}$ bzw. "zögerndes Geöffnetsein « ${ }^{39}$ eine dezidiert eigenständige temporale Daseinsqualität gegenüber der physikalisch dominierten Auffassung eines linearen Zeitflusses besitzt. Eine weitere, dass der im temporären Aufschub unweigerliche Zwang zur Auseinandersetzung mit der Zeit uns an die unüberholbare Endlichkeit des Lebens, das »Sein zum Tod ${ }^{40}$ erinnert. ${ }^{41}$

In jener existentialistischen Interpretation des Wartens fand auch die Kunst einen inspirierenden Arbeitsgegenstand, der mit Samuel Beckett's Theaterstück Warten auf Godot (1949) seinen wohl bekanntesten Ausdruck erfuhr. Darin wird der Modus eines

34 Victor Hugo, »À mes amis L. B. et S.-B. - Les Feuilles d'automne«, in Fruvres complètes: Les feuilles d'automne; Les chants du crépuscule; Les voix intérieures; Les rayons et les ombres, Bd. 2 (Paris: Ollendorf, 1909), 78.

35 Henri Bergson, Schöpferische Entwicklung (Jena: E. Diederichs, 1921).

36 Edmund Husserl, Zur Phänomenologie des inneren Zeitbewusstseins (Hamburg: Felix Meiner, 2013).

37 Vgl. Rüdiger Safranski, Zeit: Was sie mit uns macht und was wir aus ihr machen (München: Carl Hanser, 2015), 12. Ferner sieht Safranski die Relevanz der Analyse von Stillstandsmomenten auch salopp darin begründet, »dass man besonders gut erkennen kann, was mit dem Menschen los ist, wenn sonst nichts los ist«, Safranski, ebd.

38 Vgl. Bergson, Schöpferische Entwicklung, 16.

39 Siegfried Kracauer, »Die Wartenden«, in Schriften Band 5.1: Aufsätze 1915-1926 (Frankfurt a.M.: Suhrkamp, 1990), 168 [Herv. i. O.].

40 Martin Heidegger, Sein und Zeit, 17. unveränderte Aufl. (Tübingen: Niemeyer, 1993), 234.

41 Eine vertiefende Betrachtung des antiken und neuzeitlichen philosophischen Denkens über Zeit (und Wartezeit) erfolgt in Kap. 2. 
absurden und vergeblich langen Wartens inszeniert, der das menschliche Dasein in seiner Geworfenheit und (hoffnungslosen) Suche nach Sinnstiftung in der Grenzsituation zwischen Leben und Tod enthüllt. Wenngleich weniger existentiell, nahmen sich auch der Film und die Fotografie dem Warten immer wieder hinsichtlich dessen transitorischer Qualität und Ästhetik sowie dessen Charakteristik eines zentralen Erfahrungsund Möglichkeitsraums an. ${ }^{42}$ Während die Fotografie etwa in den Motiven von Haltestellen und wartenden Menschen seit jeher unerschöpfliche Bearbeitungsgegenstände findet, ${ }^{43}$ bildet das Warten für den Film oftmals den entscheidenden funktionalen Hintergrund der Handlung. So etwa exemplarisch im britischen Filmklassiker BriefEncounter (1945), in dem sich die tragische Liebesbeziehung einer verheirateten Hausfrau mit einem ebenfalls verheirateten Arzt erst im Schutze des transitorischen Umfelds eines Bahnhofswartesaals zu entwickeln beginnt.

Jenseits solcher existentialistischen und ästhetischen Interpretationen erfuhr das Phänomen im Bereich der exakten Wissenschaften erstmals eine problemorientierte Bearbeitung im Kontext mathematischer Verteilungsprobleme in Telefonnetzen des frühen 20. Jahrhunderts. ${ }^{44}$ Die zentrale Formation der Warteschlange trat hierbei als ein dezidiert stochastisches Problem in Erscheinung, das im Sinne der Gewährleistung eines reibungslosen Kommunikationsflusses durch geeignete Abfertigungsprinzipien umgangen oder minimiert werden sollte. ${ }^{45}$

Die mit Abstand umfassendste Bearbeitung des Wartephänomens fand jedoch im Rahmen der angelsächsisch dominierten Marketing- und Managementforschung statt, die das Problem von Wartezeiten in den 1980er und 1990er Jahren ausgiebig im Kontext der Transformation von der Industrie- zur Dienstleistungsgesellschaft thematisierte. Fragen zu und Perspektiven auf Wartezeiten basierten hierbei ausschließlich auf einer produktivistischen Zeitauffassung, in der die Wahrnehmung unaufhebbarer Wartezeiten in Einzelhandel oder Freizeitindustrie - informiert durch psychologische Untersuchungen - mittels zahlreicher Service- und Gestaltungsinterventionen verkürzt oder gelindert werden sollte. ${ }^{46}$

Den Kern sozial- und kulturwissenschaftlicher Zugriffe auf Wartephänomene bildeten neben den bereits zitierten Arbeiten von Rainer Paris, Giovanni Gasparini oder

42 Zur Erkundung des Wartens als einem Motiv in der Kunst der Moderne sei verwiesen auf den jüngst erschienen Sammelband von Brigitte Kölle und Claudia Peppel, Die Kunst des Wartens (Berlin: Verlag Klaus Wagenbach, 2019).

43 Hierzu sei nur exemplarisch auf folgenden etwa jüngst erschienenen Fotoband verwiesen: Klaus Honnef und Dieter Leistner, Waiting: Menschen an Haltestellen (Stuttgart: avedition, 2019).

44 Agner Krarup Erlang, »The theory of probabilities and telephone conversations«, Nyt Tidsskrift for Matematik B 20, Nr. 6 (1909): 87-98.

45 Dem Themenkomplex der mathematischen Abwendung von Wartezeiten widmet sich im Detail Kap. 3.2.1.

46 Um näheren Einblick in die Fülle von Erkenntnissen zu erhalten, die im Rahmen dieser Hochphase der forschungsseitigen Beschäftigung mit Wartezeiten entstanden, wird Kap. 3.2.3 den Forschungsstand in einem gesonderten Exkurs ausführlicher zusammentragen. 
Hartmut Rosa eine Reihe (zeit-)soziologischer, ${ }^{47}$ sozialpsychologischer ${ }^{48}$ und kulturanthropologischer ${ }^{49}$ Arbeiten, die Wartephänomene entweder im Kontext sich darin abbildender Machtdispositionen zu systematisieren, Warteformationen als soziale Systeme zu erschließen oder sie in jeweiligen kulturellen Kontexten zu verorten und vergleichen versuchten. Dabei wurden unter anderem fünf zentrale Strukturmerkmale herausgearbeitet, die im Zustand des Wartens wirksam werden und die Besonderheit des Temporalphänomens begründen. Sie umfassen die allgemeine Zentralität des Zeitfaktors (1), die den Wartenden aufgrund der situativen Abhängigkeit und Kontingenz (2) eine starke Zielgerichtetheit und Ergebnisorientierung (3) auferlegt und in ihnen durch die von außen veranlasste, erzwungene Passivität (4) das Gefühl sozialer Isolation und Selbstbezogenheit (5) hervorrufen kann. ${ }^{50}$

Eine vierte Säule der sozial- und kulturwissenschaftlichen Auseinandersetzung bildeten zudem eine Reihe kulturkritischer Arbeiten, die auf eine Rehabilitierung des Wartens im Kontext einer als überhitzt erfahrenen, von Beschleunigung und Verwertungslogik geprägten Moderne abzielten. ${ }^{51}$ Die Kernkritik jener Arbeiten lautete, dass das Primat einer produktivistischen und effizienzzentrierten Zeitlogik das Warten kanonisch zur Verschwendung und zum Ärgernis, zu einer nutzlosen und unproduktiven bzw. toten Zeit degradierte, ohne jedoch dessen psychologischen und kreativen Eigenwert anzuerkennen.

Einer solchen Trivialisierung des Wartens stellten sich auch jüngst die Literaturwissenschaften entgegen, die sich mit Fragen der Narrative des Stillstands und der

47 Gasparini, »On Waiting«; Paris, »Warten auf Amtsfluren«; Rodion Ebbighausen, Das Warten: ein phänomenologisches Essay (Würzburg: Königshausen \& Neumann, 2010); Helga Zeiher, »Thema: Warten müssen Einführung in den Themenschwerpunkt«, Zeitpolitisches Magazin 9, Nr. 20 (Juli 2012): 1-3; Andreas Cöttlich, »Einleitung. Warten - Cesellschaftliche Dimensionen Und Kulturelle Formen«, Sociologia Internationalis 54, Nr. 1-2 (Januar 2016): 1-25; sowie die pionierhaften Studien zur sozialen Formation der Warteschlange durch Leon Mann, »Queue culture: The waiting line as a social system «, American Journal of Sociology 75, Nr. 3 (1969): 340-54.

48 Barry Schwartz, »Waiting, exchange, and power: The distribution of time in social systems «, American Journal of Sociology 79, Nr. 4 (1974): 841-70; Barry Schwartz, Queuing and Waiting: Studies in the Social Organization of Access and Delay (Chicago: University of Chicago Press, 1975); Osuna, »The psychological cost of waiting «; David H. Maister, »The Psychology of Waiting Lines «, in The Service Encounter: Managing Employee/Customer Interaction in Service Businesses, hg. von Michael R. Solomon, Carol F. Suprenant, und John A. Czepiel (Lexington: Lexington Books, 1985), 113-23; Margareta Friman, »Affective dimensions of the waiting experience «, Transportation research part F: traffic psychology and behaviour 13, Nr. 3 (2010): 197-205.

49 Edward Twitchell Hall, The Dance of Life: The Other Dimension of Time (New York, NY: Anchor Books, Doubleday, 1989); Robert Levine, Eine Landkarte der Zeit: wie Kulturen mit Zeit umgehen (München: Piper, 1998); Joe Moran, »November in Berlin: the End of the Everyday«, History Workshop Journal 57, Nr. 1 (2004): 216-34; Chassan Hage, Waiting, MUP Academic Monographs (Carlton: Melbourne University Publishing, 2009).

50 Paris, »Warten auf Amtsfluren«, 706ff.

51 Alfred Bellebaum, »Warten. Über Umgang mit Zeit«, in Unser Alltag ist voll von Cesellschaft: sozialwissenschaftliche Beiträge, hg. von Robert Hettlage und Alfred Bellebaum (Wiesbaden: Springer VS, 2014), 231-58; Billy Ehn und Orvar Löfgren, Nichtstun: eine Kulturanalyse des Ereignislosen und Flüchtigen (Hamburg: Hamburger Edition, 2012); Karlheinz Geißler, »Last und Lust des Wartens «, Zeitpolitisches Magazin 9, Nr. 20 (Juli 2012): 4-5; Reuter, Warten: Eine verlernte Kunst. 
erlebten Wartezeit literarischer Figuren befassten. Im Zuge der sprachlich-semantischen Erschließung des Phänomens wurde nicht nur herausgearbeitet, wie in der Literatur Zustände der Leere, des Verweilens und der Ereignislosigkeit sprachlich gefasst werden, sondern auch erschlossen, welche zentrale Bedeutung den Phasen des Aufschubs, der Pause und des Wartens innerhalb literarischer Handlungen zukommt. ${ }^{52}$ Zudem verwies die literaturwissenschaftliche Perspektivierung auf die Notwendigkeit einer begrifflichen Trennung der verwandten Ableger des Wartens, dem Erwarten und dem Abwarten. ${ }^{53}$

Eine sechste Säule der sozial- und kulturwissenschaftlichen Auseinandersetzung bilden seit jüngster Zeit die interdisziplinär arbeitenden Mobility Studies, die das Warten als empirisch wie theoretisch bedeutsames Phänomen der Mobilitätswelt herausstellen. Infolge des durch den mobility turn ausgerufenen Postulats einer ganzheitlicheren Betrachtung von Mobilitätsphänomenen ${ }^{54}$ widmete sich darin zuletzt eine wachsende Anzahl von Arbeiten mittels humangeografischer ${ }^{55}$ und ethnografischer ${ }^{56}$ Zugriffe den spezifischen Formen der Immobilität $\mathrm{t}^{57}$, des Stillstands sowie den relationalen $\mathrm{Zu}$ sammenhängen von Stillstand und Bewegung. ${ }^{58}$ Besonders diesen Arbeiten ist es $\mathrm{zu}$ verdanken, das Phänomen aus dem Schatten seiner vermeintlichen Trivialität gehoben und mobilitätsbezogene Wartesituationen in ihrer eigentlichen sozialen, materiellen und emotional-körperlichen Komplexität erschlossen zu haben.

52 Hier ist insbesondere folgender jüngst erschienener Sammelband hervorzuheben: Christoph Singer, Timescapes of waiting: spaces of stasis, delay and deferral (Leiden; Boston: Brill, 2019); Zudem auch Nadine Benz, (Erzählte) Zeit des Wartens.

53 So vermittelt etwa das nicht-transitive Verb >warten< bereits eine gewisse Leere und Passivität, während die transitiven Verben serwarten oder >abwarten eine vergleichsweise klarere Gewissheit des Eintreffens des erhofft Kommenden bekunden. Vgl. Lothar Pikulik, Warten, Erwartung: eine Lebensform in End-und Übergangszeiten: in Beispielen aus der Ceistesgeschichte, Literatur und Kunst (Göttingen: Vandenhoeck \& Ruprecht, 1997), 15.

54 Mimi Sheller und John Urry, »The new mobilities paradigm«, Environment and planning A 38, Nr. 2 (2006): 207-26.

55 Peter Adey, »If mobility is everything then it is nothing: towards a relational politics of (im) mobilities«, Mobilities 1, Nr. 1 (2006): 75-94; Bissell, »Animating Suspension«; Gillian Fuller, »The queue project«, The Semiotic Review of Books 16, Nr. 3 (2007): 1-5; David Bissell und Gillian Fuller, Hg., Stillness in a mobile world (London; New York: Routledge, 2011).

56 Phillip Vannini, »Mind the gap: The tempo rubato of dwelling in lineups«, Mobilities 6, Nr. 2 (2011): 273-99; Ders., „Slowness and Deceleration«, in The Routledge Handbook of Mobilities, hg. von Peter Adey u.a. (London; New York: Routledge, 2014), 116-24.

57 Hierunter entstanden vor allem Arbeiten zur erfahrenen (bzw. auferlegten) Langzeit-Immobilität im Kontext von Migration und Sklaverei: Diana Mata-Codesal, »Ways of Staying Put in Ecuador: Social and Embodied Experiences of Mobility-Immobility Interactions«, Journal of Ethnic and Migration Studies 41, Nr. 14 (2015): 2274-90; Laurent Vidal und Alain Musset, Hg., Waiting territories in the Americas: life in the intervals of migration and urban transit (Newcastle upon Tyne: Cambridge Scholars Publishing, 2016); Mimi Sheller, Mobility justice: the politics of movement in the age of extremes (London: Verso, 2018).

58 John Urry, Global Complexity (Malden, MA: Polity, 2003); Adey, »If mobility is everything then it is nothing: towards a relational politics of (im) mobilities«; Tim Cresswell, »Towards a Politics of Mobility«, Environment and Planning D: Society and Space 28, Nr. 1 (2010): 17-31; Tim Cresswell, »Friction«, in The Routledge Handbook of Mobilities, hg. von Peter Adey u.a. (London; New York: Routledge, 2014), 105-15. 
Die vorliegende Arbeit knüpft mit der Fokussierung auf Wartesituationen im Eisenbahnwesen unmittelbar an dieser Perspektivierung eines mobilitätsrelevanten Phänomens an und erfährt damit eine thematische Eingrenzung innerhalb der zahlreichen Auftrittsfelder des Phänomens. ${ }^{59}$

\subsection{Thesen und Bezugsrahmen}

Das 19. und 20. Jahrhundert gelten zwar weitgehend konsensual als die Jahrhunderte gewaltiger soziotechnischer Transformationen in der Ausprägung einer sozialen, kulturellen und technischen Beschleunigung ${ }^{60}$, doch, so die forschungsleitende Ausgangsthese dieser Arbeit, sie markieren gleichermaßen die Jahrhunderte der inflationären Generierung nicht-intendierter (und intendierter) Wartezeiten. Wenn, wie eingangs erwähnt, die zeitlichen Unterbrechungsmomente zur universellen »Signatur des Lebens« gehören, so sind sie aus kultur- und mobilitätsgeschichtlicher Perspektive als nicht weniger konstitutiv für eine "Signatur der Moderne« einzustufen, denn in keiner vorherigen Epoche wurden aufgrund der Zunahme von Raum-Zeit-Kompressionen ${ }^{61}$ und technisch-organisatorischen System- und Synchronisationszwängen anhaltend mehr kleinteilige Wartezeiten produziert als seit der Durchsetzung von Industrialisierung, Urbanisierung und entscheidend mit dem Aufkommen des modernen öffentlichen Verkehrswesens.

Die Arbeit basiert somit auf der Überzeugung, dass es erst die sich seit Mitte des 19. Jahrhunderts vermehrenden System- und Synchronisationszwänge waren, die eine Empfindung von situativen bzw. systemischen Wartezeiten überhaupt erzeugen konnten und damit einen neuartigen, von der Empfindung eines vormodernen Wartens unterschiedenen Modus begründeten. Zwar kann kein Zweifel darin bestehen, dass dem Menschen das Warten als Referenzsystem im Kanon der epochal veränderlichen Zeitwahrnehmungen seit jeher vertraut gewesen sein muss. Dennoch ist es insbesondere die Epoche der Moderne ${ }^{62}$, die mit ihrer als grundlegend konstatierten Beschleunigungserfahrung erst den zeittheoretischen Hintergrund für die quantitative Häufung bzw. eine Evolution der Wahrnehmung von Zeit im Allgemeinen und von Wartezeiten im Besonderen prägte. Anders formuliert: Wenn nach Ansicht von Wolfgang Schivelbusch die durch die Eisenbahn evozierte Erfahrung von Geschwindigkeit im frühen 19.

59 Für einen weiterführenden systematischen Forschungsüberblick sei an dieser Stelle auch auf die jüngste Publikation des Autors verwiesen: Robin Kellermann, »Waiting (for Departure)«, in Routledge Handbook for Urban Mobilities, hg. von Ole B. Jensen u.a. (London; New York: Routledge, 2020), 144-153; einen guten Überblick verschafft auch Timo Reuter, Warten: Eine verlernte Kunst. Zudem werden die Kap. 2 und 3.2 dieser Arbeit nochmals eine breite Beleuchtung interdisziplinärer Forschungsstände leisten.

60 Vgl. Rosa, Beschleunigung: die Veränderung der Zeitstrukturen in der Moderne; Borscheid, Das TempoVirus; Stephen Kern, The culture of time and space, 1880-1918 (Cambridge: Harvard University Press, 2003).

61 Vgl. David Harvey, »Time-space compression and the postmodern condition«, Modernity: Critical Concepts 4 (1999): 98-118.

62 Zur weiteren Klärung des hier vorliegenden Moderneverständnisses siehe Kap. 3.1. 
Jahrhundert das Erlernen eines neuen "panoramatischen Sehens « ${ }^{63}$, einer neuartigen psychologischen Disposition und Reisetechnik erforderte, so wird daran anschließend vermutet, dass die Erfahrung situativer Stillstandsmomente vor Abfahrt dieses neuen Verkehrsmittels einer ähnlichen Novität gleichkam, die in Form neuartiger Bau- und Kulturpraktiken erlernt, konditioniert, moderiert und vermittelt werden musste.

Die Arbeit wird daher zusammenfassend von der Überzeugung geleitet, dass sowohl die verkehrsbezogenen Modernisierungsprozesse als auch die Veränderung der Temporalstrukturen in der Moderne mit der dominierenden Erklärungsebene schnellerer Raumüberwindung und gesellschaftlicher Beschleunigungs- und Rationalisierungserfahrung nicht hinreichend erklärt worden sind. Vielmehr kann sich ein umfassendes Verständnis des sich verändernden Zeitbewusstseins der Moderne nur unter Einbezug der Komplementärerfahrung einer Vielzahl neu entstandener Wartezeiten vervollständigt werden, in denen sich die kontinuierlich gesteigerte Zeitsensibilität moderner Gesellschaften erst kristallisiert bzw. spiegelt. Jenseits der Emphase einer $>$ Wahlverwandtschaft von Moderne und Mobilität ${ }^{64}$ erscheinen somit die zahlreichen Retardierungsmomente und zeitlichen Zwischenräume als der unpopuläre und oftmals leichtfertig diskreditierte Komplementärbestandteil einschlägiger Theorien und Befunde allgegenwärtiger Beschleunigungsprozesse. ${ }^{65}$ Auf Basis dieses Verständnisses können die sozialwissenschaftliche als auch die historische Mobilitäts- und Verkehrsforschung frühere, gegenwärtige und zukünftige Mobilitätserfahrungen folglich keineswegs ganzheitlich erklären und angemessen beschreiben, ohne den spezifischen Modus des wartenden Passagiers zu berücksichtigen.

Ferner vermag die historische Rekonstruktion variierender Verhandlungen und Wahrnehmungen von Wartezeiten im Verkehrskontext einen der wenigen sensiblen Seismographen jeweils vorherrschender Zeit- und Gesellschaftsauffassungen zu eröffnen, denn, so argumentiert Hartmut Rosa insgesamt zum Potential sozialwissenschaftlicher Betrachtungen über Zeitphänomene:

»Wenn Zeitmuster und -perspektiven somit also den paradigmatischen Ort von Struktur und Kultur, von System- und Akteursperspektiven und damit auch von systemischen Notwendigkeiten und normativen Erwartungen darstellen, so bedeutet dies zugleich, dass sie einen privilegierten Zugang für die sozialwissenschaftliche Analyse der kulturellen und strukturellen Gesamtformation eines Zeitalters eröffnen. «66

63 So stellt Schivelbusch bezüglich des neuartigen Charakters der Wahrnehmungsanpassungen durch die Fahrt mit der Eisenbahn fest: »Das spanoramatische Sehen< ist eine derartige Innovation, ebenso wie das allgemeine neue Raum-Zeit-Bewußtsein aufgrund der Fahrpläne, sowie die neuartige Tätigkeit der Reiselektüre. «Wolfgang Schivelbusch, Ceschichte der Eisenbahnreise: zur Industrialisierung von Raum und Zeit im 19. Jahrhundert (Frankfurt a.M.: Fischer-Taschenbuch-Verlag, 2000), 143.

64 Stephan Rammler, »The Wahlverwandtschaft of modernity and mobility«, in Tracing Mobilities. Towards a Cosmopolitan Perspective, hg. von Weert Canzler, Vincent Kaufmann, und Sven Kesselring (London; New York: Routledge, 2008), 57-76.

65 David Bissell charakterisiert den unpopulären Status des Wartens in modernen Gesellschaften treffend als »Achilles heel of modernity«, Bissell, »Animating Suspension«, 277. 
Darüber hinaus wird mit den gewählten Fragestellungen die These vertreten, dass das verkehrsbedingte Warten historiografisch in weit mehr als nur in der Zuschreibung einer verlorenen Zeit in Erscheinung tritt, sondern als komplexer Temporalzustand bzw. als »meaningful experience ${ }^{67}$, die nicht per se negativ erfahren wurde, sondern historisch oszillierenden Bewertungen und alternierenden planerischen, räumlichen und rezeptionsgeschichtlichen Verhandlungen unterlag. Zwar wird hierbei die negative Konnotation des Wartens, das Walter Benjamin einmal als die »ausgefütterte Innenseite der Langenweile ${ }^{68}$ bezeichnete, nicht in Frage gestellt, dennoch wird vermutet, dass diese Zuschreibung erst im Laufe der Modernisierungsprozesse gewachsen ist und die gegenwärtige Negativwahrnehmung einer historisch informierten Relativierung bedarf. Aus dieser Überzeugung heraus ist die vorliegende Arbeit von der allgemeinen Neugier und Motivation getrieben, das weithin unhinterfragte Alltags- und Nischenphänomen des Wartens hinsichtlich seiner historischen Genese und Verhandlung aufzudecken und folgt damit einem an die Husserl'sche Phänomenologie angelehnten »naiven Hinterfragen ${ }^{69}$ des Wartens als einer scheinbaren Selbstverständlichkeit des Verkehrswesens.

\section{Geschichtswissenschaftlicher Bezugsrahmen}

Wie bereits aus dem oben skizzierten Spektrum bisheriger Zugriffe und Bearbeitungen hervorging, erschließen sich für die Analyse von Wartephänomenen zahlreiche Forschungsperspektiven. Angefangen von der Philosophie (Zeittheorie) über die Psychologie (Zeitwahrnehmung), Soziologie (Wer wartet wie?), Architektur- und Verkehrsgeschichte (Wer wartet wo?) bis hin zur Ökonomie (Kosten und Profiteure des Wartens) bietet der Gegenstand eine Vielzahl denkbarer Zugänge, die zur Beantwortung der gewählten Fragestellung gewinnbringend erscheinen. Um zwischen diesen disziplinären Perspektiven und ihren jeweiligen Erkenntnisschwerpunkten zu vermitteln, wird hier für die Beantwortung der Fragestellungen ein kulturgeschichtlicher Ansatz verfolgt, der sich dadurch auszeichnet, mittels interdisziplinärer Perspektiven und einer breiten Quellenvielfalt Wahrnehmungen, Symboliken und materielle Niederschläge gesellschaftlicher Phänomene zu beleuchten. ${ }^{70}$ Ferner erfordert die Spezifik des Gegenstands eines nur schwer greifbaren Zeitphänomens einen solchen offenen geschichtswissenschaftlichen Ansatz samt breiter Korpusbildung, da sich aussagekräftige Niederschläge des Phänomens in nicht nur einer Quellengattung finden lassen, sondern weit verstreut vorliegen. In Abgrenzung strukturgeschichtlicher oder quantifizierender Ansätze der Sozialgeschichte oder deskriptiven Zugängen der Verkehrs- und Technikgeschichte wird der kulturgeschichtliche Zugriff auf den Gegenstand somit in erster Linie durch die Perspektivierung auf »historische Sinn- und Bedeutungszusammenhänge $\ll^{71}$ konstituiert. Zwar definiert sich die Kulturgeschichte »nicht über das Objekt

67 Gasparini, »On Waiting«, 32.

68 Benjamin, Das Passagen-Werk, 2: D 9 a, 5 (S. 176).

69 Vgl. Edmund Husserl, Erfahrung und Urteil, Untersuchungen zur Genealogie der Logik (Hamburg: Claassen Verlag, 1954).

70 Vgl. Achim Landwehr, Kulturgeschichte (Stuttgart: Ulmer, 2009), 9f. sowie vgl. Ute Daniel, Kompendium Kulturgeschichte: Theorien, Praxis, Schlüsselwörter (Frankfurt a.M.: Suhrkamp, 2001), 13. 
ihrer Beschäftigung, sondern über die Perspektive, mit der sie sich dem jeweiligen Objekt nähert. « ${ }^{72}$ Dennoch steht im Falle der vorliegenden Arbeit - und damit wiederum in Abgrenzung zu klassischen kulturgeschichtlichen Ansätzen - ein feststehendes Untersuchungsobjekt im Fokus, das jedoch eine kulturgeschichtliche Betrachtung erfährt. Eine in diesem Verständnis betriebene Kulturgeschichte des Wartens zielt folglich auf die Rekonstruktion von materiellen, betrieblichen und symbolischen Ordnungen und Sinnhorizonten, in die sich wartende Passagiere einfügen mussten bzw. mit denen sie sich ausgestattet haben.

Diese Betrachtung verfolgt nicht das Ziel einer permanenten Messung von (statistischen) Unterschieden zwischen früheren und späteren Zeitpunkten als vielmehr eine qualitative Beleuchtung des Wandels der baulichen Rahmung und Rezeption verkehrsbezogener Wartesituationen. Weniger bilden somit die verkehrstechnischen Erfindungen den Erkenntnisschwerpunkt als vielmehr die betrieblichen, räumlichen und sozialpsychologischen Implikationen und Herausforderungen, kurzum, die >rückseitigen Effekte der beschleunigten Raumüberwindung mit der Eisenbahn. Dabei soll für die vorliegende Analyse zudem weniger eine historische Kontextualisierung politischer und gesellschaftlicher Verhältnisse als vielmehr eine verkehrshistorische und zeitkulturelle Kontextualisierung verfolgt werden.

\section{Theoretischer Bezugsrahmen}

Die historische Aufarbeitung von Wartephänomenen im Eisenbahnverkehr zeigt sich insbesondere durch zwei zentrale Theoriebezüge informiert. Erstens durch das zeitphilosophische bzw. -soziologisch gewachsene Verständnis einer sich spätestens seit dem 18. Jahrhundert fundamental gewandelten Temporalstruktur der Moderne, die im Schatten der Beschleunigungseffekte die dialektische Entstehung von Retardierungsprozessen begründeten. ${ }^{73}$ Mithilfe eines solchen Verständnisses der Wechselseitigkeit von Bewegung und Verlangsamung kann auch das verkehrsbezogene Warten als inhärentes (und zugleich komplementäres) Phänomen zur Beschleunigung von Modernisierungsprozessen aufgefasst werden, die Hartmut Rosa übergeordnet als dysfunktionale Nebenfolgen bezeichnet. Hinsichtlich dieses paradoxalen Zusammenhangs von Moderne und Verlangsamung vermerkt er:

»Verlangsamung und Hemmung treten in der modernen Cesellschaft in zunehmend gravierendem Maße und immer häufiger als unbeabsichtigte Nebenfolge von Akzelerationsprozessen auf. « $^{74}$

Neben den räumlichen Verdichtungen sind es daher vor allem auch Formen temporaler Verdichtungen oder »Punktualisierungen ${ }^{75}$, die den Modernisierungsprozessen

72 Ebd., 13.

73 Die bestehende Relationalität von Beschleunigung und Verharrung könnte aufgrund der anhaltenden Modernisierungsprozesse zudem aus Sicht von Paul Virilio schließlich derart prominent zu Tage treten, dass sie in einer pathologischen Bewegungslosigkeit bzw. in einem srasenden Stillstand < resultieren würde: Paul Virilio, Rasender Stillstand: Essay (München: Hanser, 1992). Rosa, Beschleunigung: die Veränderung der Zeitstrukturen in der Moderne, 144f. [Herv. i. O.].

75 Vgl. David Bissell und Gillian Fuller, »Stillness unbound «, in Stillness in a mobile world, hg. von David Bissell und Gillian Fuller (London; New York: Routledge, 2011), 3. 
inhärent sind und eine Dialektik von Bewegung und Stillstand begründen. Die Einbettung der historischen Analyse des verkehrlichen Wartens in das Theorieangebot der (modernen) Relationalität von Bewegung und Verlangsamung erscheint hier deshalb als zentral, weil es darüber Aufschluss gibt, dass situative Wartephänomene, wie sie nicht zuletzt im Verkehrswesen auftreten, keinesfalls kontextfreie Phänomene darstellen, sondern nur in Verbindung bzw. erst als Folgeerscheinungen von angestrebten oder realisierten Bewegungsprozessen zu verstehen sind.

Den zweiten zentralen Theoriebezugsrahmen bildet die innerhalb der sozialwissenschaftlichen Mobilitätsforschung gewachsene Sensibilität für die Komplexität von Mobilitätsprozessen hinsichtlich der Akteursgefüge, den zum Ausdruck kommenden Ungleichheiten sowie der vielgestaltigen Temporalität, der Imaginationen und Erfahrungen solcher Prozesse. ${ }^{76}$ So stehen innerhalb eines ganzheitlichen Mobilitätsverständnisses der Mobility Studies nicht mehr allein exklusiv Bewegungsprozesse im Erkenntnisinteresse, sondern vielmehr das kritische Hinterfragen des traditionellen geschwindigkeits- und bewegungsaffinen Ethos der an Verkehrsphänomenen interessierten Sozialwissenschaften. ${ }^{77}$ In diesem Zusammenhang vermerken etwa Bissell und Fuller kritisch zum bisherigen Umgang mit Stillstands- und Verlangsamungsphänomenen (zu denen auch das Warten auf Beförderung zählt):

»Yet, curiously, stillness is so often anticipated, more or less, as an aberration and thus a problem to be dealt with. A moment of emptiness or misused productivity, producing a hobbled subjectivity without active agency. In an epoch that privileges the mobilization of mobility, still has been stilled; turned into a stop that is just waiting to go again. Waiting to be re-moved. $\aleph^{78}$

Statt Phänomene des Stillstands und der Verlangsamung in einem »dominant narrative of active mobilities « ${ }^{79} \mathrm{zu}$ übersehen oder $\mathrm{zu}$ trivialisieren, vermögen die Mobility Studies nicht nur jene bislang randständigen Phänomene auf die Forschungsagenda zu setzen, sondern sie zudem einer potentiellen Reinterpretation zu unterziehen und darin Wartephänomene als eine eigenständige Erkenntnisgröße zu begründen. Damit erscheint der durch den cultural turn inspirierte mobility turn ${ }^{80}$ übergreifend als intellektuell fruchtbarer Rahmen für die Beschäftigung mit den scheinbaren Trivialitäten und vergessenen Nischenphänomenen der Mobilitätswelt. Von dieser ganzheitlichen Betrachtung von Mobilitätsphänomenen wird schließlich auch die historische Verkehrs-

Diese auch oftmals als >new mobility paradigm ^oder >new mobility turn < bezeichnete inhaltliche Erneuerung der sozialwissenschaftlichen Mobilitätsforschung umreisst Noel Salazar prägnant als »new ways of theorizing how people, objects, and ideas move around by looking at social phenomena through the lens of movement. « Noel B. Salazar, »Keywords of mobility«, in Keywords of mobility: Critical engagements, hg. von Noel B. Salazar und Kiran Jayaram, Bd. 1 (New York: Berghahn Books, 2016), 2. immobilities and moorings«, Mobilities 1, Nr. 1 (2006): 1-22.

78 Bissell und Fuller, »Stillness unbound «, 3.

79 Bissell, »Animating Suspension«, 294.

80 Sheller und Urry, »The new mobilities paradigm«. 
forschung dahingehend informiert (und reformiert), ${ }^{81}$ nunmehr bspw. die rückseitigen Effekte verkehrsinduzierter Wartephänomene als zentrale und wirkmächtige Komponenten der Reisezeiterfahrung anzuerkennen sowie damit den Passagier im Modus des Wartens erstmals stärker in das Blickfeld der historischen Forschung zu rücken.

Innerhalb der extrem heterogenen Theoriebildung der Mobility Studies ${ }^{82}$ erscheinen zudem für die Einbettung der historischen Analyse des Wartens insbesondere die Theoreme infrastruktureller moorings ${ }^{83}$ sowie das Konzept einer friction ${ }^{84}$ von Interesse. Sie verweisen zum einen darauf, dass globale Bewegungsströme nur mittels der Vorbedingung massiver immobiler Strukturen und Prozesse bewältigt werden können. ${ }^{85} \mathrm{Zum}$ anderen verdeutlichen sie, dass für jegliche Bewegungsprozesse die Gegengröße einer Reibung benötigt wird. ${ }^{86}$ Jene Theorieangebote rekurrieren abermals auf die Relationalität von Bewegung und Hemmung und schärfen dabei konkret das Verständnis der Rolle und Funktion immobiler Raumstrukturen von Bahnhofsgebäuden im Allgemeinen und der Wartesäle im Besonderen, die eine Bedingung zur Gewährleistung öffentlicher Verkehrsströme bilden.

Zusammengenommen ermöglichen die gewählten Theorieangebote, das Warten zeithistorisch als ein sich aus modernen Beschleunigungsdiskursen formierendes Temporalphänomen zu kontextualisieren und es daran anknüpfend im relationalen Selbstverständnis der Mobility Studies als ein wirkmächtiges Phänomen des Verkehrswesens zu begreifen, das - analog des traditionellen Fokus auf Bewegungsphänomene - eine eigenständige historiografisch-empirische Untersuchung legitimiert. Dem von Reinhart Kosellek postulierten Grundsatz einer theoriebedürftigen geschichtswissenschaftlichen Forschung folgend, ${ }^{87}$ prägen somit vor allem sozialwissenschaftliche Theorien der durch Modernisierungsprozesse veränderten Wahrnehmungsstrukturen von Raum

81 Vgl. Massimo Moraglio, »Seeking a (New) Ontology for Transport History«, The Journal of Transport History 38, Nr. 1 (Juni 2017): 3-10.

82 Vgl. Kaufmann Vincent, »Mobility as a Tool for Sociology«, Sociologica, Nr. 1 (2014): $5 \mathrm{ff}$.

83 Urry, Clobal Complexity.

84 Cresswell, »Friction«.

85 So wird bezeichnend für das Verhältnis verkehrlicher Infrastrukturen und der Cewährleistung einer im Bauman'schen Sinne >verflüssigten Moderneく der Crundsatz festgehalten: »There is no linear increase in fluidity without extensive systems of immobility. "Hannam, Sheller, und Urry, »Mobilities, immobilities and moorings«, 3.

86 Die Vorbedingung einer gewährleisteten Reibung ist zum einen physikalischer Natur, zum anderen sozialer Natur. So kann in physikalischer Hinsicht die Bewegung eines Reifens nur aufgrund der Bodenhaftung auf dem Asphalt entwickelt werden, eine (Verkehrs-) Bewegung im sozialen Kontext dagegen nur dann vollzogen werden, wenn sie innerhalb eines soziotechnischen Regimes stattfindet, das den Passagier an vielen Punkten intentional bremst (Check-in Schalter, Wartesäle etc.). Tim Cresswell vermerkt ferner zur Bedeutung des Konzepts der Reibung bzw. Haftung: »The significance of friction is in the way it draws our attention to the way in which people, things and ideas are slowed down or stopped.«Cresswell, » Friction«, 108.

87 Vgl. Reinhart Koselleck, Zeitschichten: Studien zur Historik (Frankfurt a.M.: Suhrkamp, 2013), 299316. Kosellek bemerkt zur Notwendigkeit theoriegeleitenden Ceschichtsforschung, dass »(...) erst ein theoretischer Vorgriff, der einen spezifischen Freiraum freilegt, (...) überhaupt die Möglichkeit [öffnet, R.K.], bestimmte Lesarten durchzuspielen (...)«, $303 \mathrm{f}$. 
und Zeit die gewählten geschichtswissenschaftlichen Fragestellungen, ${ }^{88}$ die heuristische Vorgehensweise und das Erkenntnisinteresse.

\subsection{Methodische Eingrenzungen und Betrachtungszeitraum}

Jede Analyse von Temporalphänomen steht vor einer Reihe methodischer Herausforderungen, die nicht zuletzt auch die Analyse von Wartephänomenen betreffen. Das Warten gilt aufgrund seiner diffusen Bedeutungsaura aus Sicht der Forschung bisweilen als affektive Erfahrungsebene »that cannot be brought into the systematisation, thematisation and conceptualisation that defines the work of social analysis. ${ }^{89}$ Trotz der sichtbaren Allgegenwart von Wartesituationen und -orten entzieht es sich angesichts seines situativen und individuell erlebten Charakters einem einfachen empirischen Zugriff und zeigt mitunter die Grenzen klassischer sozialwissenschaftlicher Forschung auf. ${ }^{90}$ Aber auch aus geisteswissenschaftlicher Perspektive scheint der Zugriff auf das Phänomen des Wartens mit methodischen Hindernissen versehen zu sein, so konstatiert etwa der Literaturwissenschaftler Harold Schweizer: »Waiting is as resistant to description and analysis as time or boredom. «"1 Andrey Vozyanov betrachtet diese Gemengelage aus anthropologischer Perspektive als nicht weniger problematisch und stellt fest: »The essence of waiting is elusive. It always serves as a container, a frame, a context in which other activities take place (or take time). ${ }^{92}$

Vor dem Hintergrund jener epistemologischen und methodischen Herausforderungen präsentiert der Kulturanthropologe Heinz Schilling einen Lösungsvorschlag, der für die vorliegende Untersuchung den zentralen methodischen Zugang zum Temporalphänomen des Wartens darstellt:

»Wir müssen uns methodisch ein Forschungsfeld vorstellen, auf dem wir statt zu beobachten vor allem das betrachten, was Interviewpartner, literarische und andere Quellen uns sagen. Die Auskünfte werden wir als Beobachtungsergebnisse behandeln. « $^{93}$

Den Schauplatz für solche Beobachtungsergebnisse bilden in dieser Arbeit insbesondere die statischen Verkehrslandschaften in Form der vielfältigen Wartestrukturen an Bahnhöfen sowie die literarisch-künstlerischen Niederschläge, die sich zu diesem Phänomen im Verkehrswesen äußerten. Der Problematik der Analyse von Zeitphänomenen wird dabei insofern begegnet, als dass der zu analysierende Verkehrsraum des Bahnhofs im Verständnis von Ernst Cassirer als »Kristallisation von Bedeutung « ${ }^{94}$ aufge-

88 Damit verortet sich die vorliegende Arbeit in der Traditionslinie kulturgeschichtlicher Theoriebezüge, die sich laut Ute Daniel meist aus wissenschaftstheoretischen, philosophischen oder sozialwissenschaftlichen Theorieangeboten speisen. Vgl. Daniel, Kompendium Kulturgeschichte, 8.

89 Paul Harrison, »)How shall I say it...? Relating the nonrelational«, Environment and Planning A 39 , Nr. 3 (2007): 591.

90 Vgl. Bissell, »Animating Suspension«, 292.

91 Schweizer, On Waiting, 1.

92 Andrey Vozyanov, »Approaches to waiting in mobility studies«, 68.

93 Schilling, »Zeitlose Ziele: Versuch über das lange Warten«, 247.

94 Oswald Schwemmer, Ernst Cassirer: Ein Philosoph dereuropäischen Moderne (Berlin: Akademie Verlag, 1997), 86. 
fasst wird. Erst jene kulturelle und materiell-räumliche Kristallisation ist es, die dem abstrakten Wesen des Passagiers im spezifischen Modus des Wartens überhaupt eine lesbare Struktur verleiht und es zu einem gewinnbringenden analytischen Zugriffsfeld formt, das die historische Transformation von zeitbezogenen Selbstverständnissen, Handlungslogiken und strukturbildenden Praktiken zulässt.

Die Ursache für diese lesbare Struktur des Wartens liegt darin begründet, dass das verkehrsinduzierte Warten zu seiner ohnehin zeitlichen Dimension durch die Einbettung in Wartearchitekturen eine zusätzlich räumlich-physische Dimension erhält. Das Warten im modernen Massenverkehr geschieht demnach im Vergleich zu anderen Wartesituationen keineswegs ortlos oder ungeordnet, sondern erfordert - wie zu zeigen sein wird - seit Anbeginn des Eisenbahnwesens die Notwendigkeit einer materiell-technischen Rahmung und einer betrieblichen Abfertigungslogik. Anders als etwa in den abstrakteren und weniger lokalisierbaren Modi des »langen Wartens « ${ }^{95}$, bspw. dem Warten auf das Ende einer Langzeitarbeitslosigkeit oder den Erhalt eines Spenderorgans, prallen im verkehrsinduzierten Mikro-Warten die Kategorien von Raum und Zeit bzw. Akteurs- und Systemperspektiven in den Transit-Zonen von Warteräumen und Bahnsteigen unmittelbar schärfer und nicht zuletzt lokalisierbar aufeinander. Somit erfährt das schwer zu greifende Phänomen des verkehrlichen Wartens neben seiner subjektiv-psychischen Dimension auch einen materiell-räumlichen Niederschlag, der - quasi im Sinne einer behavioristischen Forschungstradition - beobachtbare Indizien schafft, wie Passagiere an jenen Orten festgehalten, platziert und konditioniert wurden.

Um das diffuse Zeitphänomen des Wartens zudem noch weiter zu operationalisieren, stehen zuvorderst Wartesituationen vor Abfahrt eines Verkehrsmittels im Mittelpunkt der Untersuchung, die analytisch von Wartesituationen während der Fahrt (Aufenthalt im sich bewegenden Fahrzeug) oder nach der eigentlichen Transportleistung (bspw. Gepäckrückgabe oder Passkontrollen) zu unterscheiden sind. Auch wenn der Moment der Fortbewegung in einem Fahrzeug ebenfalls eine Form des Aufschubs, der Zielorientierung und Imagination des Kommenden darstellt, ${ }^{96}$ also typische Strukturmerkmale des Wartens zeigt, wurde in psychologischen und verkehrsplanerischen Arbeiten mehrfach nachgewiesen, dass insbesondere Wartezeiten vor der Abfahrt wesentlich stärkere affektive Reaktionen hervorrufen als die eigentliche Fahrt im Verkehrsmittel. ${ }^{97}$ Während das Warten im Verkehrskontext meist stationärer, ortsgebundener Natur ist, steht die Beförderung zum Zielort bereits wesentlich stärker im Zeichen des Erlebens räumlicher Kategorien wie Bewegung, Raumüberwindung und Geschwindigkeit. Die im Moment des stationären Wartens auf Beförderung antizipierte Bewegung

95 Vgl. Schilling, »Zeitlose Ziele: Versuch über das lange Warten«, 245-310.

96 Auch wenn die vor- und nachbereitende Wartezeit im Grunde in die Rechnung der Cesamtreisezeit eingerechnet werden muss, wird die eigentliche Reisezeit in der Regel mit der durch das Fahrzeug realisierten Raumüberwindung assoziiert.

97 Laurette Dube-Rioux, Bernd H. Schmitt, und France Leclerc, »Consumers< reactions to waiting: when delays affect the perception of service quality «, NA-Advances in Consumer Research 16 (1989): 59-63; Friman, »Affective dimensions of the waiting experience«; Wardman, »Public Transport Values of Time « sowie auch Mark Wardman, »Valuing Convenience in Public Transport: Roundtable Summary and Conclusions«, International Transport Forum Discussion Papers (Paris: OECD/ITF, 2014). 
wird im Modus des Transports letztlich physisch realisiert. Zweifelsohne wird auch während des Transports die Ankunft imaginiert, dennoch rückt das Ziel der Reise im Moment der Fahrt bereits ein Stück näher und evoziert eine anders geartete psychische Disposition. Kurzum: Der wartende Passagier wird mit Zustieg in das sich bewegende Verkehrsmittel zum Reisenden, das Warten wandelt sich mit Beginn der Fortbewegung quasi von einer stationären in eine ambulante Natur. Es steht daher zu vermuten, dass das moderne Spannungsverhältnis von Bewegung und Verlangsamung im stationären Warten vor Fahrtbeginn besonders spürbar wird. Wartesäle und Bahnsteige werden so zu jenen qualifizierten Orten, an denen der Frage nachgegangen werden soll, ob sich die These verschärfender sozialer Beschleunigung auch in der sich historisch wandelnden Wahrnehmung von Wartezeiten und deren baulich-materiellen Strukturen niederschlägt.

Der Betrachtungszeitraum der diachronen Analyse fällt im Kern auf die Periode zwischen dem Jahr 1830, das mit Eröffnung der Eisenbahnstrecke zwischen Liverpool und Manchester den Beginn der Aufnahme des ersten regelmäßigen Linienverkehrs im Eisenbahnpersonenverkehr markiert, und dem Jahr 1935, das im deutschen Kontext mit Eröffnung des neuen Hauptbahnhofes Oberhausen den vorläufigen Schlusspunkt einer langen Neubautätigkeit von Empfangsgebäuden bildet. Dieser Kernbetrachtungszeitraum wurde auf Grundlage der heuristischen Vorüberlegung getroffen, Wartephänomene im verkehrsgeschichtlichen Kontext des Aufstiegs, der Konsolidierung, der Blüte sowie des einsetzenden Bedeutungsverlustes des Eisenbahnwesens zu untersuchen. All diese Phasen vollzogen sich innerhalb des ersten, hochdynamischen Jahrhunderts des Eisenbahnwesens. Dessen vertiefende Betrachtung erscheint daher besonders aufschlussreich, um den Wandel des verkehrsinduzierten Wartens aufzudecken. Obwohl der Fokus also klar auf den Entwicklungen des ersten Eisenbahnjahrhunderts liegt, wird die Geschichte des Wartens im Eisenbahnkontext in einem abschließenden Explorationskapitel bis in die Gegenwart hinein nachverfolgt - wenngleich thesenhafter und in geringerer analytischer Tiefe.

Der geografische Fokus der Arbeit liegt auf dem deutschen Eisenbahnwesen, zeigt sich aber durch die vergleichende Betrachtung internationaler Entwicklungen - insbesondere jener in England, Frankreich und Österreich - sowie durch häufige komparative Momente und Querverweise informiert. Die Entscheidung hinsichtlich dieser geografischen Schwerpunktsetzung erfolgte zum einen aus forschungspragmatischen Gründen (Quellenlage samt ihrer Zugänglichkeit) sowie auf Basis des gewichtigen Ausgangsbefunds, dass deutsche Bahnhöfe im europäischen Vergleich mit Abstand die raumgreifendsten und opulentesten Formen des Bahnhofswartesaals hervorbrachten, das verkehrliche Warten hier also womöglich eine baulich wie kulturell rezipierte Sonderstellung erhalten haben könnte.

Ferner wird die vorliegende Analyse von Wartesituationen insbesondere in der Großstadt als dem paradigmatischen Ort der Moderne samt ihrer veränderten Zeitstrukturen schlechthin verortet. So ist sie Georg Simmel zufolge gegenüber dem ländlichen Raum nicht zuletzt durch ihre Schnelligkeit charakterisiert, die in einer »Steigerung des 
Nervenlebens ${ }^{98}$ resultiert. Auch wenn das verkehrsinduzierte Warten, wie zu zeigen sein wird, zweifelsohne im Zuge der kapillaren Vergrößerung des Eisenbahnverkehrssystems zunehmend im ländlichen oder stadtnahen Raum erfahren wurde, musste, so wird vermutet, das Warten bzw. das Spannungsverhältnis zwischen Bewegung und Verlangsamung im großstädtischen Kontext aufgrund einer herausgehobenen Temporalstruktur stärker hervortreten als anderswo.

\subsection{Aufbau der Arbeit}

Im Anschluss an das Einführungskapitel unterteilt sich die Arbeit in die zwei großen Komplexe eines eröffnenden zeittheoretischen Teils und eines empirisch-historiografischen Hauptteils. Der zeittheoretische Komplex gliedert sich zunächst in die vertiefende Rekonstruktion der Zeitvorstellungen von Antike bis Gegenwart mit dem Ziel der Entwicklung eines weitreichenden Zeitverständnisses aus dem heraus eine Verengung auf die Beantwortung der Frage erfolgen soll, wie Zeit zu einer Wartezeit wird (Kap. 2). Im Anschluss dieser theoretischen Grundlegungen erfolgt die kultur- und mobilitätsgeschichtliche Verortung des Wartens innerhalb der zeitstrukturellen Veränderungen der Moderne als Komplementärphänomen von Beschleunigungsprozessen. Verstanden als Epoche allgegenwärtiger Beschleunigung und Raumüberwindung wird die Moderne hinsichtlich der Zunahme temporärer Stillstände bzw. der Genese und Entdeckung einer neuartigen Temporalität beleuchtet, die schließlich im Theorie- und Begriffsangebot des systemischen Wartens verdichtet, charakterisiert und von anderen Wartephänomenen abgegrenzt wird (Kap. 3).

Der empirisch-historiografische Hauptteil (Kap. 5-9) rekonstruiert darauf aufbauend die Entwicklungen des systemischen Wartens auf Eisenbahnen entlang einer viergliedrigen Phasenunterteilung des Kernbetrachtungszeitraums, die sich an grundlegenden Entwicklungsphasen des Bahnhofsbaus orientiert. Sie umfassen die Phasen der pionierhaften Exploration (1830-1845), der Konsolidierung und Standardisierung des Bahnhofsbaus (1845-1870), den Aufstieg zur Blütephase (1870-1900) sowie den Bahnhofsbau in der Großstadt der Hochmoderne (1900-1935). Die monografisch angelegten Kapitel des Hauptteils werden dazu jeweils entsprechend der Kernfragestellungen in die Analysestränge einer Bau- bzw. Rezeptionsgeschichte des Wartens aufgetrennt. Darin erfolgen auf der einen Seite eine Rekonstruktion wartezeitrelevanter Bauentwicklungen (Direktiven, Raumprogramme, Grundrissdispositionen etc.) sowie die Beleuchtung exemplarischer Bahnhofsbeispiele der jeweiligen Entwicklungsphase. Auf der anderen Seite die Auswertung relevanter Quellen aus Literatur und Kunst des jeweiligen Zeitabschnitts hinsichtlich der Wahrnehmung, Praktik und Verhandlung von Wartesituationen. Im Hauptteil wechseln sich chronologische und systematisch-thematische Darstellungselemente ab, um Entwicklungstendenzen aufzuzeigen, zugleich aber mithilfe deskriptiv-analytischer Bearbeitungsweisen das Bedingungsgefüge des Geschehenen bzw. die Komplexität des Phänomens greifbar zu machen. Ferner wer- 
den die Hauptkapitel jeweils am Ende von einer Synthese abgeschlossen, welche die Entwicklungen gegenüber der vorangegangenen Phase beleuchtet.

Flankiert werden die beiden großen Komplexe von zwei kleineren Komplexen: einem Kontextualisierungskapitel zum Eisenbahnwesen (Kap. 4) sowie einem thesenhaften Explorationskapitel zu Bau- und Wahrnehmungskonjunkturen des verkehrlichen Wartens im weiteren Verlauf des 20. und frühen 21. Jahrhunderts (Kap. 10.). Während das Kontextualisierungskapitel eine bessere Einordnung der Befunde der Hauptkapitel gewährleistet, unternimmt das Explorationskapitel eine komprimierte Betrachtung der Bau- und Wahrnehmungsentwicklungen im Verlauf der `Zweiten Moderne und erkundet zudem die sich aus der diachronen Analyse aufdrängende Frage, ob das Warten im Verkehrskontext vor dem Hintergrund der Durchdringung von Informations- und Kommunikationstechnologien eine Neubewertung erfährt.

Abschließend wird ein Fazit die gesammelten Erkenntnisse zur Beantwortung der Forschungsfragen zusammenfassen, ihre wissenschaftliche Anschlussfähigkeit im disziplinären Spektrum von historischer Verkehrsforschung bis zur Mediengeschichte aufzeigen sowie einen Ausblick auf sich daraus ableitende, weiterführende Forschungsfragen offerieren. 


\title{
2. 'Zeitreiser: Theorien und Strukturen der Konstituierung von Zeiterfahrung
}

\author{
$»(.$.$) we should reinstate time at the centre of$ \\ studies of waiting. «"
}

\begin{abstract}
»Was ist die Zeit?«, fragte Augustinus bereits im 4. Jahrhundert nach Christus und fährt mit einer Erklärung fort, die gleichsam >zeitlos` wie paradigmatisch für die Schwierigkeit der Analyse von Temporalphänomenen steht: »Wenn mich jemand fragt, so weiß ich es; will ich es aber jemandem auf seine Frage hin erklären, so weiß ich es nicht. «² Die Zeit mutet uns zunächst als Selbstverständlichkeit, als unsichtbarer Hintergrund und als implizites Orientierungs- und Hilfsmittel an. Sie bezeichnet im philosophischen Verständnis grundsätzlich eine durch das Bewusstsein wahrgenommene Form von Abfolgen und Veränderungen sowie die referentielle Bestimmung von Stabilität. Zweifellos, wir >spüren die Zeit. Ihre wie auch immer auszumachende >Anwesenheit< mag unbestritten sein, dennoch ist sie im Kontext hochindustrialisierter Gesellschaften derart überpräsent bzw. verinnerlicht, dass ihre Problematisierung zunächst eine hohe Hürde der anscheinend unhinterfragbaren Selbstverständlichkeit überspringen muss. Barbara Adam bemerkt zu dieser Problematik des Impliziten besonders trefflich:
\end{abstract}

»It is everywhere yet it eludes us. It is so deeply implicated in our existence that it is almost invisible. This poses problems for understanding and analysis not only for the ordinary members of society but also for those members who see it as their professional task to provide theories about this reality. $\ll^{3}$

Überspringt man nun aber die Hürde jener Selbstverständlichkeit - was mit diesem eröffnenden zeittheoretischen Kapitel beabsichtigt wird - wirft die Beschäftigung mit dem Gegenstand `Zeit` bei näherer Betrachtung jedoch vielfältige Fragen auf. Zu den geschichtsträchtigsten Fragen überhaupt zählt dabei, wie bereits zu Eingang dieser Arbeit 
erwähnt, die Frage nach dem ontologischen Status der Zeit als Natur- und/oder Kulturobjekt. Eng mit dieser Positionsbestimmung verknüpft, bildet ein weiteres zentrales Erkenntnisinteresse die Frage danach, wie sich Zeiterfahrung und Zeitbewusstsein des Menschen im Verhältnis objektiver und subjektiver Zeitauffassungen konstituieren. Wie wird Zeit zu einer wahrnehmbaren Größe und welche kulturell divergierenden Zeitauffassungsmuster zeichnen sich dabei ab?

Auch eine Analyse historischer Wartezeiterfahrungen und -rahmungen kann nur schwerlich unabhängig von vorgängigen Überlegungen zur generellen Konstituierung von Zeit und lebensweltlicher Zeitwahrnehmung erfolgen. Daher sollen zunächst mittels eines wissenschaftshistorischen Überblicks grundlegende philosophische und sozialwissenschaftliche Theoreme zur Zeitkonstitution und -wahrnehmung sowie zu Zeitfunktionen und ihren kulturell divergierenden Auffassungen skizziert werden, um daraus anschließend ein zeittheoretisch informiertes Verständnis von Wartezeiten zu entwickeln. Zwar stehen im Mittelpunkt dieser Arbeit wohlgemerkt die historisch variierenden räumlich-materiellen und subjektiven Verhandlungen des Wartephänomens, dennoch erscheint dieser zeittheoretische Prolog notwendig, denn schließlich kann erst die Frage danach, ob und wie wir ein Zeitbewusstsein ausbilden, wie wir Zeit denken bzw. welche Bedeutungen, Funktionen und Probleme mit ihr verbunden sind, die Modalität einer Zeit des Wartens als spezifisch (kritisches) Phänomen innerhalb der Zeitwahrnehmung herausstellen. ${ }^{4}$ Entlang welcher Zeitbegriffe haben sich also die Zeitauffassungen und die Konstituierung der Zeitwahrnehmung im Laufe von mehr als zwei Jahrtausenden entwickelt? Die wandelnden Auffassungen werden dazu im Folgenden nach philosophischer sowie sozialwissenschaftlicher Theoriebildung gefächert und anschließend - wo dies möglich und besonders ertragreich erscheint - jeweils im Sinne eines systematischen Erkenntnisinteresses ${ }^{5}$ bezüglich ihres Erklärungsgehalts für die spezifische Charakteristik des Wartens untersucht und interpretiert.

Aus dem selektiven Querschnitt zeittheoretischer Debatten wird bereits schnell ersichtlich werden, welche außerordentliche Diskurskraft und welche historisch gewachsene Komplexität den Gegenstand `Zeitく auszeichnet. Wenn auch im Folgenden Wert auf die Erlangung eines geistesgeschichtlichen Grundverständnisses über den Zeitbegriff gelegt wird, soll an dieser Stelle relativierend vermerkt werden, dass mit den folgenden Abschnitten weniger eine vollumfassende >Geschichte der Zeit als vielmehr die Einordung des Wartephänomens in einen größeren zeittheoretischen und zeitphilosophischen Rahmen bzw. eine qualitative Positionsbestimmung des Wartephänomens in der Zeit angestrebt wird.

Zum einen soll dazu der chronologische Überblick klassisch-philosophischer sowie neuerer soziologisch-anthropologischer Zeittheorien die historische Entwicklung der Beantwortung der Fragestellungen nach ontologischem Status und kulturell variierender Konstituierung von Zeiterfahrung umreißen. Zum anderen sollen die Grundlage

Vgl. Benz, (Erzählte) Zeit des Wartens, 19.

5 Gemeint ist mit dieser >systematischen< Betrachtung der Versuch einer gegenüber der rein historisch-hermeneutischen Betrachtung von Texten dezidiert >produktiven< Nutzung von Texten im Hinblick auf die eigene (gegenwärtige) Problemstellung. Vgl. Helmut Seiffert, Einführung in die Wissenschaftstheorie 2: Phänomenologie-Hermeneutik und historische Methode-Dialektik (München: Beck'sche schwarze Reihe, 1996), 247ff. 
und das Erklärungspotential zur anschließenden Einordnung und Erkundung der besonderen Charakteristik der Wartezeit als einem von vielen Temporalphänomenen gebildet werden. Der Überblick stellt sonach im doppelten Sinne eine `Zeitreise dar, die vom Übergang eines anfänglich zyklischen zu einem immer stärker linear vermittelten Zeitverständnis geprägt ist und mit der Evolution von einem naturwissenschaftlichen hin zu einem subjektimmanenten Zeitparadigma konvergiert.

\subsection{Philosophische Zeittheorien}

Zwei Modelle konkurrierten in der kondensierten Zusammenschau der zeitphilosophischen Forschungstradition um die Erklärung der ursprünglichen, fundamentalen Zeitvorstellung: Ein mathematisch-quantitatives Modell und ein modal-qualitatives Modell. ${ }^{6}$ Aus Sicht des quantitativ-naturwissenschaftlichen Lagers, allen voran der Physik Newton'scher Prägung, wird Zeit als objektive und außerhalb des Subjekts wirksame Größe verstanden, die als Grundkonstante zur Bestimmung von Bewegungen und Veränderungen im Raum fungiert. Zeit ist hiernach real existent und wird in einer linearen und quantifizierbaren Flusslogik begriffen. Auf der modal-qualitativen Seite hingegen betonten zunächst neuzeitliche ${ }^{7}$ und später moderne philosophische Perspektiven ${ }^{8}$ die Unzulänglichkeit rein objektiver Zeitvorstellungen für das Verständnis und die Analyse menschlicher Zeiterfahrung. Vielmehr ließe sich Zeit aus jener Forschungstradition heraus ohne ein die Zeit erfahrendes Subjekt schlichtweg nicht verstehen. In den Mittelpunkt zeitphilosophischer Debatten rückte damit seit der Neuzeit die unabdingbare Subjektivität der Zeit, die, gipfelnd im Denken Heideggers, zur Fundamentalkategorie menschlichen >Daseins < erklärt wurde.

Sandbothe spricht in diesem Zusammenhang ferner von drei wesentlichen Positionsbestimmungen innerhalb der philosophiegeschichtlichen Beschäftigung mit Zeit. Zum einen steht der Zeitbegriff im Zeichen einer Aufspaltung in eine nicht miteinander vermittelbare Vielfalt heterogener Zeitkonzepte. Vertreter jener Pluralisierungstendenz wie etwa Paul Ricœur oder Henri Bergson - bezweifeln grundsätzlich die Repräsentationsfähigkeit der Zeit, sei es im astronomisch-physikalischen oder im subjektiven Sinne und verweisen auf die einzig mögliche Erschließung der Zeit in ihrer >Pluralitätく, etwa im Medium sprachlicher Erzählung oder dem unmittelbaren menschlichen Bewusstsein. Eine zweite Tendenz propagiert die Historisierung und Relativierung der Zeit. Grundgedanke dieser Relativierungstendenz bildet die Auffassung, dass das Zeitverständnis als kulturell wandelbar und nicht als starr begriffen wird und die Zeit in ihrer Rolle als praktische Weise des Weltumgangs jeweils epochal verschieden zu behandeln ist. Hierbei wird vom Grundgedanken ausgegangen, »dass die Rolle, welche die Zeit für das menschliche Selbst- und Weltverständnis spielt, Aspekt eines kulturell divergierenden und sich innerhalb einer Kultur unter kontingenten Bedingungen

\footnotetext{
6 Vgl. Karen Gloy, Philosophiegeschichte der Zeit (München: Wilhelm Fink, 2008), 11.

7 So vor allem der Zeitbegriff Kants.

8 Etwa die Zeitbegriffe von Husserl, Bergson, Whitehead oder Heidegger.
} 
historisch wandelnden Systems von praktischen und technischen Gewohnheiten ist. «" Drittens ist die jüngere zeitphilosophische Forschungstradition nach Sandbothe von einer Vereinheitlichungs- und Universalisierungstendenz geprägt. Zeitaspekte bilden darin die entscheidenden Dreh- und Angelpunkte, die gleichermaßen für unsere alltägliche Selbst- und Welterfahrung als auch für die wissenschaftliche Theoriebildung sinnstiftend wirken. Mit anderen Worten: Der Zeitaspekt wird hierbei als gleichermaßen naturwissenschaftlich wie lebensweltlich evidente Wahrheit bzw. als »einheitliche und universale Grundstruktur begriffen, die sich der historischen Kontingenz und dem kulturellen Wandel entzieht. « ${ }^{10}$ Im Zuge dieser vor allem naturwissenschaftlich motivierten Vereinheitlichungstendenz wird nicht zuletzt eine Überwindung der schier endlosen ontologischen Auseinandersetzungen über den Status der Zeit als Kultur- oder Naturobjekt angestrebt. ${ }^{11}$

Nichtsdestotrotz behält der Zeitbegriff eine bedeutende Restmenge des Rätselhaften. Der Streit um subjektive und objektive Auffassungen von Zeit gilt heute trotz der Bestrebungen einer Universalisierung, ähnlich wie zur Hochzeit der Auseinandersetzungen im frühen 20. Jahrhundert, keineswegs als entschieden, sondern ist unbestimmt wie einst. ${ }^{12}$ Zwar hat die wissenschaftliche Beschäftigung mit dem Gegenstand `Zeit< seit Mitte der 1980er Jahre eine wahre Hochkonjunktur erfahren und wurde Zeit vermehrt in den sozialwissenschaftlichen Disziplinen als analytischer Schlüssel zum Verständnis von Gesellschaften und deren Entfremdungsproblematiken diskutiert und theoretisiert. In der Folge dieser umfangreichen Beschäftigung entstand jedoch der gegenwärtige Befund einer >Pluralität heterogener Zeitkonzepte`, der es abermals problematisch erscheinen lässt, eine einheitliche Theoriebildung des Zeitbegriffes zu erzeugen. ${ }^{13}$ Wissen wir also bezüglich der >Zeitfrageく womöglich gegenwärtig doch nicht bedeutend mehr als etwa die griechischen Philosophen?

\subsubsection{Antike Zeittheorien}

\section{Platonische Zeittheorie: Zeit als Beschreibungsebene der 'Ewigkeit،}

Die erste und älteste zusammenhängende Zeittheorie der europäischen Geistesgeschichte geht auf Platon und seine im Spätdialog Timaios überlieferten Überlegungen zurück. Zeit definiert Platon darin »als ein nach der Zahl (in bestimmten Maßen) fortschreitendes Abbild der in Einheit beharrenden Ewigkeit. ${ }^{14}$ Im Rahmen der Platonischen Ideenlehre, die eine ewige Ideenwelt (jenseitige Wirklichkeiten bzw. das eigentlich

$9 \quad$ Mike Sandbothe, Die Verzeitlichung der Zeit: Crundtendenzen der modernen Zeitdebatte in Philosophie und Wissenschaft (Darmstadt: Wissenschaftliche Buchgesellschaft, 1998), 3.

10 Ebd.

11 Zu den Vertretern jener Überwindung zählen etwa der Philosoph Hermann Lübbe, der Naturwissenschaftler Ilya Prigogine oder auch die Soziologin Barbara Adam.

12 Vgl. Gloy, Philosophiegeschichte der Zeit, 10.

13 Vgl. Rosa, Beschleunigung: die Veränderung der Zeitstrukturen in der Moderne, 22f.; Antje Gimmler, Mike Sandbothe, und Walther Ch. Zimmerli, Die Wiederentdeckung der Zeit: Reflexionen - AnalysenKonzepte (Darmstadt: Wissenschaftliche Buchgesellschaft, 1997), 1.

14 Platon, Sämtliche Dialoge. Timaios und Kritias. Sophistes [u.a.] (Hamburg: Felix Meiner, 1998), 55 [Hervorhebung des Verfassers, R.K.]. 
Seiende) von einem irdischen Weltreich (Abbilder der Ideenwelt bzw. noch unvollkommenes Sein) unterscheidet, fungiert die göttliche Einführung der Zeit als ein bewegtes Abbild der ewigen Ideenwelt und somit als vermittelndes Bindeglied zwischen Urbild und der irdischen Welt. Zeit, so Platons Auffassung, wurde vom schaffenden Vater der Schöpfung (dem Demiurg) im Antrieb installiert, die irdische Welt dem Urbild noch ähnlicher zu machen. ${ }^{15}$ Die Einführung der Zeit fungiert somit als Medium für die Wahrnehmung der in der irdischen Welt idealisierten Ewigkeit bzw. der Nachahmung des Urbildes aus dem Ideenhimmel. Um dem Subjekt die perfekte Beharrlichkeit des Seins der idealisierten Ideenwelt wahrnehmbar zu machen, musste dazu die Zeit mittels eines der Beharrlichkeit oppositionären, nie endenden Flusses nachgebildet werden. Zeit und Ewigkeit werden somit nicht vollends voneinander getrennt, sondern werden in eine Ähnlichkeitsbeziehung zueinander gebracht, ${ }^{16}$ was schließlich in der Aufstellung zweier Zeitbegriffe ufert, einem ewigen, zeitenthobenen und einem rein zeitlichen. Entscheidend ist dabei, dass das zuvor vorherrschende Zeitverständnis einer (unbeweglichen) Ewigkeit mit diesem zweiten, rein zeitlichen Zeitbegriff nun erstmals in Zahlen und in der Bewegung beschreibbar wird.

Jene Bewegung ist für Platon dabei unstrittig an die kreisförmige und zunächst noch ungerichtete Bewegung von Himmelskörpern gekoppelt. Das Maß der Zeit wird dabei also allein durch die Bewegungen der Sternenwelt bestimmt. Wenngleich die unendliche, kreisförmige Bewegung der Himmelskörper noch keine Unterscheidung in Vergangenheit, Gegenwart und Zukunft enthält, transferiert diese skosmologische Fundierung ${ }^{17}$ der Zeit die Ewigkeit in ein quantitatives Feld. Mit anderen Worten: Zeit wird mit Platon angesichts des Abbilds der Bewegung von Himmelskörpern zu einem realen, objektiven Geschehen, das durch das Subjekt (erstmals) sinnlich wahrnehmbar wird. Die >kosmologische Fundierung der Zeit und deren Nachvollziehbarkeit bedingen somit eine enge Beziehung der Zeit zur Seele ${ }^{18}$, was schließlich als die philosophische Geburtsstunde der an Bewegungen gekoppelten Zeitwahrnehmung interpretiert werden könnte. Platon, wichtigster Schüler des Sokrates, bricht mit der vorsokratischen Auffassung einer rein zyklischen Zeitvorstellung (ständige Wiederkehr des Gleichen) insofern, als dass sich die zyklische Zeitauffassung nunmehr in die lineare Zeitvorstellung einschreibt. Die Zeit ist zwar analog der rein zyklischen Zeitauffassung der Vorsokratiker sewig‘, aber mit Platon wird diese erstmals als zählbar, wahrnehmbar und fortschreitend begriffen. Rhythmen und Umläufe der Himmelkörper, die eigentlich richtungslos sind, werden nunmehr seriell abzählbar, was philosophiegeschichtlich einen Übergang von der gestalttheoretischen zur reihentheoretischen Auffassung von Zeit markiert. ${ }^{19}$

15 Vgl. Platon, 55.

16 Vgl. Cloy, Philosophiegeschichte der Zeit, 7.

17 Vgl. ebd., 8.

18 Gemeint ist mit dem Begriff der Seele im Platonischen Verständnis jedoch nicht die individuelle menschliche Seele, sondern eine `Weltseeleく, die als eigenständiger Organismus sämtliche Elemente des Kosmos in sich vereinigt. Der Mensch bzw. die Einzelseele lebt nach diesem Verständnis in der Weltseele und partizipiert lediglich von ihr. Die Weltseele ist dadurch als belebendes Prinzip des menschlichen Körpers gegenüber der Einzelseele wesensgleich. Vgl. dazu Heinz Robert Schlette, Weltseele: Ceschichte und Hermeneutik (Frankfurt a.M.: J. Knecht, 1993). 
Mit Platon, so resümiert Gloy die Tragweite dieser frühesten aller Zeittheorien, »beginnt das Problem der Realität oder Idealität, der Objektivität oder Subjektivität der Zeit, d.h. die Frage nach ihrer Existenzweise außerhalb des Subjekts in der realen Welt oder innerhalb des Subjekts. $"{ }^{20}$ Jene drei Problemkomplexe des Platonischen Zeitbegriffs bilden seither den Ausgangspunkt nachfolgender Debatten, die jene Fragestellungen entweder unterstützend ausbauten oder polemisierten.

\section{Aristoteles: Zeit als Zahl der Bewegung}

Wenn der Platonische Zeitbegriff den Beginn der an Bewegungen im Raum geknüpften Vorstellungen von Zeit markierte, bildete die Aristotelische Zeittheorie deren konsequente Weiterentwicklung. Für Aristoteles ist der Begriff der Zeit fest an Veränderungen und Bewegungen gebunden. Veränderungen geschehen dabei nur in der Zeit, d.h. sie selbst ist bewegungslos. Schnellere oder langsamere Veränderungen können erst durch die Zeit bestimmt werden. Folglich bezweifelt Aristoteles eine objektive Realität der punktuellen Zeit, da sie stets nur aus dem Vergangenen oder dem Kommenden zu bestehen scheint. ${ }^{21}$ Stattdessen konstituiert sich für ihn die Zeit erst als das Abzählbare in Bezug auf ein Davor oder ein Danach und definiert sie folglich prominent als "Maß der Bewegung « ${ }^{22}$. Aristoteles betont damit deutlich ein relationales Verhältnis von Zeit und Bewegung, denn mithilfe der Zeit wird die Bewegung gemessen, aber zugleich mittels der Bewegung auch die Zeit. Mit anderen Worten: Zeit ist für Aristoteles ohne Veränderung und Bewegung nicht denkbar, weil das rein punktuelle >Jetzt $<$ keinen Seins-Status besitzt und daher nicht als Zeit denkbar ist.

Die zentrale Idee des Aristotelischen Zeitbegriffs bildet somit das Verständnis eines linearen Verlaufs von Zeit, die über Bewegungen und Veränderungen quantifizierbar und messbar wird. Das Zeitbewusstsein ist für den wichtigsten Schüler Platons nicht auf ein stets flüchtiges oder noch bevorstehendes punktuelles $>$ Jetzt $<$ bezogen. Stattdessen gruppiert Aristoteles vielmehr die Zeittermini um das `Jetzt $<$ herum. Mit der daraus resultierenden Grundlegung eines Raum-Zeit-Kontinuums gilt Aristoteles als Begründer des physikalischen Zeitbegriffs. Dennoch bleibt die Zeit im Aristotelischen Verständnis nicht vollends auf eine Maßeinheit reduziert. Vielmehr ist für ihn die Wahrnehmung von Zeit nicht untrennbar an eine äußere Bewegung gekoppelt. Auch im Dunkeln oder mit geschlossenen Augen, also ohne Wahrnehmung einer äußeren Bewegung, würde es möglich sein, eine innere Bewegung der Zeit wahrzunehmen. ${ }^{23}$ Mit diesem Beispiel verlagert Aristoteles den Zeitbegriff aus der objektiven Welt in das Subjekt. ${ }^{24}$ Nicht nur die Bewegung steht im relationalen Verhältnis zur Zeit, sondern schließlich auch ein jene Relation wahrnehmendes, zählendes Subjekt.

Ebd., 8.

Zur Problematik des Sein-Status des punktuellen `]etzt ‘ führt Aristoteles aus: »Was aber aus Nichtseiendem besteht, scheint keinerlei Sein besitzen zu können. Aristoteles, Physikvorlesung, hg. von Hellmut Flashar (Berlin: Akademie Verlag, 1995), 218a.

Ebd., 221b.

Vgl. ebd., 219a.

Vgl. Cloy, Philosophiegeschichte der Zeit, 8. 


\section{Augustinischer Zeitbegriff: Zeit als seelische Syntheseleistung}

Wesentlich nachdrücklicher als beginnend mit den indirekten subjektivistischen Andeutungen des Platon oder Aristoteles verlagerte im 4. Jahrhundert Augustinus von Hippo den Schauplatz der Zeitverhandlung in das Subjekt bzw. in die menschliche Seele. Nur in der menschlichen Seele seien die drei Zeitdimensionen von Vergangenheit, Gegenwart und Zukunft ${ }^{25}$ mittels der Akte von Erinnerung, Wahrnehmung bzw. Erwartung überhaupt realisierbar. Außerhalb der Seele würde die Zeit dagegen eindimensional bleiben.

Im Unterschied zu den Platonischen und Aristotelischen Zeitauffassungen existiert die Zeit für den aus Algerien stammenden Religionsphilosophen Augustinus außerhalb einer kosmologischen Fundierung. Sie ist folglich nicht mehr an die Rotationsbewegung von Himmelskörpern geknüpft. Die Wahrnehmung von Zeit könne vielmehr nur im Inneren der Subjekte ausgeprägt werden und sollte auch vorzugsweise dort erforscht werden. Diese subjektbasierte Zeitwahrnehmung reift für Augustinus deshalb zur primatischen Form des Zeitverständnisses, weil nach seiner Auffassung die Zeit im Grunde "zum Nichtsein hinstrebt ${ }^{26}$, d.h. sie eigentlich immer schon vorbei sei oder erst noch bevorstünde. Dadurch, dass Vergangenes und Zukünftiges nicht definitiv nachweisbar seien - weil sie schon waren oder noch nicht sind - ist die Zeit für ihn nicht als objektive Größe mess- oder quantifizierbar. Er begründet diese insbesondere gegenüber Aristoteles oppositionäre Haltung damit, dass eigentlich nur das Gegenwärtige (das Seiende) messbar sei, dieses aber wiederum keinerlei räumliche Ausdehnung besitzt, die in irgendeine Weise messbar wäre. ${ }^{27}$ Diese Feststellung führt daher zum paradoxalen Umstand, dass im Grunde nur etwas gemessen werden kann, was eigentlich nie ist. ${ }^{28}$ Dennoch gesteht Augustinus der menschlichen Zeitwahrnehmung eine qualitative Komponente der Zeitbestimmung bzw. der Bestimmung einer langen oder kurzen Zeitdauer zu. So ist auch für Augustinus nicht zu bestreiten, dass die Zeit in irgendeiner Weise existent ist. Messbar werde die Zeit, selbst wenn die Zeiten des Zukünftigen oder Vergangenem eigentlich nicht mehr oder noch nicht sind, nur, indem sie im immer schon verstreichenden Moment vorüber geht.

Um nun das Paradox einer Messbarkeit dessen, was eigentlich nie ist, zu lösen und $\mathrm{zu}$ verstehen warum dennoch zu Lebzeiten Augustinus' bereits stets von drei Zeitdimensionen Vergangenheit, Gegenwart und Zukunft gesprochen wurde, von denen zumindest die Vergangenheit und die Zukunft nie sind, führt Augustinus das Konzept der >dreifachen Gegenwart« bzw. der >distentio animi<, der Erstreckung und Ausdehnung des Geistes, ein.

Die Auffassung der Unterscheidung dreier Zeitdimensionen sowie der Grundlegung eines Zeitflusses verdeutlicht sich in folgender Aussage: »(...) alle Zeiten sind zukünftig und werden zu vergangenen, sobald sie gekommen sind. «Augustinus, Des heiligen Kirchenvaters Aurelius Augustinus Bekenntnisse, 281.

26 Ebd., 283.

27 Ebd., $284 \mathrm{f}$

28 Diese wie andere zeitphilosophische Paradoxien werden gemeinhin als >Aporien der Zeit< beschrieben. 
»Es gibt drei Zeiten, eine Gegenwart in bezug auf die Vergangenheit, eine Cegenwart in bezug auf die Gegenwart und eine Gegenwart in bezug auf die Zukunft. Denn in unserer Seele sind die Zeiten in dieser Dreizahl vorhanden, anderswo aber finde ich sie nicht. ${ }^{29}$

Gedächtnis, Wahrnehmung und Erwartung werden folglich $\mathrm{zu}$ den drei operativen Instrumenten, um eine Quantität von Zeit in Form der Vorstellung von Vergangenheit, Gegenwart und Zukunft zu ermöglichen. Erst durch jene »triadische Auffächerung der subjektiven Vorstellungskraft ${ }^{30}$ stellt sich die >Gegenwärtigkeitく der Zeit und dessen Quantifizierbarkeit ein. ${ }^{31}$ Die >Gegenwärtigkeit< gilt somit als eine entscheidende Grundbedingung zur Ausbildung der Zeitvorstellung. Eine zweite Bedingung bildet die Gegenwärtigung der drei Zeitmodi in einem Modus der >Extensionalität‘, der es ermöglicht, das zu denken und vorzustellen, was sich objektiv nicht eindeutig messen lässt. $^{32}$

Der 〉Ort an dem diese Zeitvorstellung realisiert werden kann, ist dabei für Augustin einzig und allein das Subjekt. Nur hier - und nicht in der außerseelischen Welt können durch die Akte von Erinnerung, Wahrnehmung und Erwartung auch so noch weit von der Gegenwart entfernt liegende Punkte überwunden und zu einer Zeitvorstellung synthetisiert werden. Geist und Seele werden zum Ort der Zeit. Mit anderen Worten: Der Zeitfluss wird erst durch geistige Arbeit >reak. Nicht die objektive Messung ermöglicht die Vorstellung von Vergangenem oder Zukünftigem, sondern die Fähigkeit der menschlichen Psyche, wie Augustinus mit einem Beispiel der Kindheitserinnerung aufzeigt, die faktisch zwar unwiederbringlich vergangen ist, aber in der memoria weiter fortbesteht.

»Wenn wir Vergangenes der Wahrheit gemäß erzählen, so werden aus dem Cedächtnisse nicht etwa die Cegenstände selber, die vergangen sind, hervorgeholt, sondern die in Worte gefaßten Bilder der Gegenstände, die diese, da sie an den Sinnen vorüberzogen, gleichsam als Spuren im Geiste zurückließen. $^{33}$

Augustinus' subjektbezogene Zeittheorie bricht demnach mit der klassisch hellenistischen Wissenschaftstradition einer kosmologischen Zeitfundierung. ${ }^{34}$ Die zuvor bei

29 Ebd., 288.

30 Gloy, Philosophiegeschichte der Zeit, 114.

31 Vgl. ebd., 112.

32 Vgl. Benz, (Erzählte) Zeit des Wartens, 29.

33 Augustinus, Des heiligen Kirchenvaters Aurelius Augustinus Bekenntnisse, 286.

34 Als Wegbereiter für den Übergang zu einem subjektivistischen Zeitbegriff sei an dieser Stelle der römische Neuplatoniker Plotin genannt, der in seiner Enneade III,7 bereits 150 Jahre vor Augustinus einen zeitphilosophischen Ansatz verfasste, der die Zeit als immanente Existenzweise der Psyche definiert. Das noch diffuse Verhältnis von Zeit und Seele bei Platon und Aristoteles wird mit Plotin zugunsten einer Psychologisierung der Zeit entschieden, in dem die Zeit bei Plotin die »an sich seiende Lebens- und Vollzugsform der Seele«darstellt. Cloy, Philosophiegeschichte der Zeit, 74 [Herv. i. O.]. Da Plotin jedoch noch an der kosmologischen Fundierung der Zeitwahrnehmung sowie an der Existenz einer Weltseele festhält, steht dessen Zeitbegriff noch nicht im Zeichen der weitaus stärkeren Augustinischen Subjektzentrierung. Vgl. ebd., $73 \mathrm{ff}$. 
Platon und Aristoteles postulierte Objektivität der Zeit wird mit Augustinus entscheidend in Richtung einer Zeitvorstellung transferiert, in dessen Folge sich schließlich wiederum in starker Abgrenzung einer intersubjektiven Weltseele - jeder Mensch seine eigene Zeit schaffen würde. Die Subjektivierung des Zeitverständnisses wird dabei jedoch nicht aus einem bestimmten Forschungsinteresse heraus motiviert, sondern aus der Überzeugung, die ungelösten Aporien des Platonischen und Aristotelischen Zeitbegriffs mit dem Schritt der Verlagerung in das Subjekt (endlich) lösen zu können.

Nur ein Akteur bleibt für Augustinus von der subjektiven Zeitvorstellung ausgeklammert: Gott. Da Raum und Zeit ohnehin erst dem Willen Gottes, also der göttlichen Schöpfung entspringen, würde Gott selbst (und dessen Wort) jeder Zeitlichkeit entbehren und stattdessen den Charakter des >Ewigen< tragen. »Gottes Ewigkeit ist der Begriff Zeit fremd $\aleph^{35}$, proklamiert Augustinus, was wiederum eine Analogie zum Ewigkeitsbegriff der Platonischen Ideenwelt aufzeigt bzw. an dessen Trennung eines zeitenthobenen und eines rein zeitlichen Begriffs von Zeit anknüpft.

\section{Synthese antiker Zeittheorien bezüglich der Ausbildung einer (Warte-)Zeiterfahrung}

Im Hinblick auf den Gegenstand des Temporalphänomens des >Wartens` muss konstatiert werden, dass es ein Warten im Platonischen Zeitverständnis noch nicht gegeben haben konnte. Zeit wurde hierin allein als geschlossene Kreislaufbewegung (der Planeten) verstanden, die keinerlei Entstehen und Vergehen, keine $\mathrm{Zu}$ - und Abnahme repräsentiert, sondern einzig die Ewigkeit der Ideenwelt. Augenblickliche Erlebnisse sind nach der Platonischen Zeitauffassung lediglich vergängliche Abbilder bzw. Nachahmungen der dahinter liegenden unveränderlichen Ewigkeit. Mit anderen Worten: Zeit wurde zwar als in Zahlen beschreibbare Bewegung verstanden, jedoch (noch) nicht in Vergangenheit, Gegenwart und Zukunft geschieden, weshalb ein Warten als eine Antizipation des Kommenden im Platonischen Verständnis noch keine theoretische Begründung erfährt. Auch wenn das Prinzip der an die Bewegung gebundenen Zeit im Zeitverständnis des Aristoteles deutlich ausgebaut wird, gilt die Abwesenheit einer Theoretisierung von Wartezeiten auch für den Platon-Schüler.

Dennoch kann aus der knappen Rückschau antiker Zeitlehren als eine zentrale Erkenntnis für diese Arbeit destilliert werden, dass die Ausbildung einer Zeiterfahrung offenbar in jedem Falle zunächst eines wahrnehmenden Subjekts benötigt. Wenn diese Bedingung als Grundvoraussetzung der Zeitwahrnehmung generell gilt, so muss sie ebenfalls für die Ausprägung und Wahrnehmung einer Wartezeit gelten. Zwar werden durch Platon und Aristoteles noch keine spezifischen Zeitmodi erschlossen, sondern vorerst nur die Möglichkeit einer an Bewegungen geknüpften schnellen und langsamen Zeit begründet (Aristoteles). Dennoch lässt sich aber zunächst für die Suchbewegung nach den Entstehungsbedingungen und Spezifika einer Wartezeit festhalten, dass - auch wenn es selbstverständlich anmuten mag - nur ein sich darüber bewusst seiendes Subjekt die Zeit überhaupt und schließlich auch den spezifischen Modus einer Wartezeit erfahren kann. 
Welche Schlüsse lassen sich nun zudem aus der für das antike Denken disruptiven ${ }^{36}$ Augustinischen Zeitauffassung hinsichtlich des im Mittelpunkt der Arbeit stehenden Temporalphänomens des Wartens ziehen? Mit Augustinus, so lässt sich argumentieren, erfolgt nicht nur die zeittheoretische Grundlegung der Subjektbezogenheit jeder Zeiterfahrung, sondern zudem auch die Grundlegung einer Vorbedingung des Wartemodus. ${ }^{37}$ Gemeint ist die in den Bekenntnissen beschriebene seelische Kompetenz einer Antizipation des Kommenden, noch Ausstehenden und noch nicht Seienden. Wie die Fähigkeit zur Erinnerung, die es ermöglicht, längst vergangene Zeitpunkte gegenwärtig erscheinen zu lassen, versucht Augustinus auch eine Konstruktion der Zukunftserwartung $\mathrm{zu}$ entwerfen, die eigentlich noch bevorstehende Momente gegenwärtig und damit vorstellbar erscheinen lässt. Diese Erwartung (expectatio) bezeichnet Augustin im Rahmen des konstitutiven Spektrums der Akte von Erinnerung und Wahrnehmung als "geheimnisvolles Vorgefühl ${ }^{38}$, das wiederum als Gegenwärtigung des Zukünftigen fungiert. Zur handlungstheoretischen Dimension der alltäglich praktizierten Zukunftsbezogenheit vermerkt Augustinus:

»Das aber weiß ich sicher, daß wir sehr oft über unsere zukünftigen Handlungen im voraus nachdenken und daß diese Überlegung gegenwärtig ist, die Handlung dagegen, über die wir nachdenken, noch nicht ist, da sie in der Zukunft liegt. Wenn wir uns aber an die Sache heranmachen und, was wir vorher überlegten, auszuführen beginnen, dann tritt die Handlung ins Sein, weil sie dann nicht mehr zukünftig, sondern gegenwärtig ist. $\ll^{39}$

Jene zukunftsbezogene Gegenwärtigung würde ferner im Spektrum dreier Akte vollzogen werden können: 1) mittels prophetischer Zukunftsvision, 2) mittels zukunftsorientierten Handelns (Pläne, Entwürfe, Projekte), und schließlich 3) in Form naturgesetzlicher Prognosen (gesicherte Ableitungen auf Basis formulierter Grundsätze). ${ }^{40}$ Alle drei Akte würden es ermöglichen, Zukünftiges als Gegenwärtiges zu denken, was am Rande bemerkt auch einer Grundlegung der historischen Zukunftsforschung entspricht, die das Entwerfen von Visionen, Utopien und Szenarien immer auch als reflexive Akte zur impliziten Veränderungen gegenwärtiger Zustände interpretiert. ${ }^{41}$

Zwar werden Fragen der Psychologisierung und Subjektivierung der Zeit bereits bei Platon und Aristoteles thematisiert, bspw. im Punkt, dass etwa die Zeitmessung eine zählende Seele voraussetzt (Aristoteles). Disruptiv dagegen erscheint die Augustinische Auffassung eines ausschließlich im Inneren der Seele erlebbaren Zeitflusses. Die innovatorische Leistung Augustins, so Karen Cloy, »besteht in der Entdeckung der subjektimmanenten Zeit, unangesehen dessen, was die Zeit darüber hinaus noch sein mag. Gegenüber dem kosmologisch- astronomischen Interesse der Griechen gilt sein [Augustinus, R.K.] Interesse dem epistemologischen und psychologischen Aspekt der Zeit. So tritt bei ihm an die Stelle der Weltzeit die Ichzeit. «Gloy, Philosophiegeschichte der Zeit, 98.

37 Dazu ausführlicher Kap. 2.4.

38 Augustinus, Des heiligen Kirchenvaters Aurelius Augustinus Bekenntnisse, 287.

39 Ebd., 286f.

40 Vgl. Gloy, Philosophiegeschichte der Zeit, 113.

41 Augustin erklärt den psychischen Mechanismus der Gegenwärtigung des Zukünftigen folgendermaßen: „Wenn man also von einem Schauen in die Zukunft redet, so meint man damit nicht ein Schauen dessen, was noch nicht ist, also ein Schauen der eigentlichen Zukunft, sondern nur ih- 
Die Fähigkeit zum Zukunftsdenken sowie die daran anschließende mögliche Diskrepanzerfahrung im Abgleich zwischen Zukunftsziel (anvisiertes Sein) und Gegenwart (noch nicht gegenwärtiges Sein) bilden somit zwei weitere wichtige Vorbedingungen der Ausbildung des Zeitmodus >Warten bzw. zum Verständnis, wie Zeit zu Wartezeit wird. Auch wenn die Wahrnehmung von Wartezeiten bei Augustinus nicht explizit thematisiert wird ${ }^{42}$ bilden dessen Bekenntnisse einen wichtigen Schritt zur geistesgeschichtlichen Verortung und damit zur Herleitung des Temporalphänomens. Augustinus gilt darüber hinaus retrospektiv als geistiger »Vater des psychologischen Zeitbegriffs $\aleph^{43}$, der schließlich richtungsweisenden Einfluss auf neuzeitliche (Kant) und moderne Zeitbegriffe (etwa von Bergson oder Heidegger) ausübte, die nun im Folgenden skizziert werden sollen.

\subsubsection{Neuzeitliche und moderne Zeittheorien}

Mehr als ein Jahrtausend nach Augustinus postulierte Immanuel Kant in seiner 1781 erschienenen Kritik der reinen Vernunft ein neuzeitliches Zeitverständnis, das Augustinus' psychologisches Zeitverständnis wohl am prominentesten erweitern und zugleich das in der Zwischenzeit durch Newton etablierte mathematisch-physikalische Zeitverständnis ${ }^{44}$ radikal infrage stellen sollte. Ausgehend von den Gegenständen der Erfahrung bzw. der objektiven Welt, liegt das Interesse der Kantischen Transzendentalphilosophie auf den Ermöglichungsgründen der Wahrnehmung dieser Welt. ${ }^{45}$ Für Kant

rer Ursachen und Anzeichen, die bereits sind; diese sind für den Seher nicht zukünftig, sondern gegenwärtig, aus ihnen ersieht er die Zukunft und sagt sie vorher.« Augustinus, Des heiligen Kirchenvaters Aurelius Augustinus Bekenntnisse, 287. Zum impliziten Cegenwartsbezug literarischer und politischer Zukunftsstudien, James W. Carey, Communication as culture: essays on media and society, Media and popular culture (Boston: Unwin Hyman, 1989), 174; Karlheinz Steinmüller, »Zukunftsforschung in Deutschland«, Zeitschrift für Zukunftsforschung 1, Nr. 1 (2012): 6-19; Massimo Moraglio, Hans-Liudger Dienel, und Robin Kellermann, »Didactical Functions of Dark and Bright Scenarios: Examples from the European Transport Industry«, in Envisioning Uncertain Futures, hg. von Roman Peperhove, Karlheinz Steinmüller, und Hans-Liudger Dienel (Wiesbaden: Springer, 2018), 83-103. Im konzeptionellen Sinne des Religionsphilosophen wäre die Vorstellung von Wartezeiten, analog zur Vorstellung von Vergangenem und Zukünftigem, wohl zweifelsohne ebenfalls an die Bedingung der `Gegenwärtigung`der Dinge geknüpft. Mehr noch könnten Wartezeiten als Prototyp der `Cegenwärtigung «der Zeiterfahrung erscheinen, da Warten immer nur im `Jetzt«spürbar wird. Warten, so ließe sich vielleicht im Augustinischen Sinne fortführen, erscheint damit als die Urform der vergegenwärtigten Zukunftsvorstellung.

43 Vgl. Ulrich Duchrow, »Der sogenannte psychologische Zeitbegriff Augustins im Verhältnis zur physikalischen und geschichtlichen Zeit«, Zeitschrift für Theologie und Kirche 63, Nr. 3 (1966): 267-88. Isaac Newton definierte die Zeit in seinem 1676 erschienen Hauptwerk Philosophiae naturalis principia mathematic als absolute, reale, unendliche und gleichförmig fließende Cröße, die Teil der Schöpfung ist. Die Zeit als auch der Raum seien leer und dienen als Medium der Aufnahme von materiellen und zeitrelativen (Stunden, Wochen, Tage) >Füllungen Newton eindeutig metrisier- und quantifizierbar, was sie schließlich in den Stand einer physikalischen und damit subjektunabhängigen Zeit hebt. Newton wurde damit zum vielleicht prominentesten Vertreter einer objektivistischen Zeitauffassung, die von Kant und später insbesondere von Einstein kritisiert wurde. Vgl. Elias, Über die Zeit, 12. 
existiert in diesem Rahmen die Zeit weder als eigenständige, objektive, messbare Größe noch als Gegenwärtigung im Augustinischen Sinn. Stattdessen ist die Zeit für Kant bereits a priori und somit der eigentlichen Erfahrung vorausgehend, in unser Bewusstsein eingebaut.

»Die Zeit ist eine nothwendige Vorstellung, die allen Anschauungen zum Grunde liegt. Man kann in Ansehung der Erscheinungen überhaupt die Zeit selbst nicht aufheben, ob man zwar ganz wohl die Erscheinungen aus der Zeit wegnehmen kann. Die Zeit ist also a priori gegeben. In ihr allein ist alle Wirklichkeit der Erscheinungen möglich. Diese können insgesammt wegfallen, aber sie selbst (als die allgemeine Bedingung ihrer Möglichkeit) kann nicht aufgehoben werden. ${ }^{46}$

Die Zeit ist nach Kant »reine Form der sinnlichen Anschauung « ${ }^{47}$, die der eigentlichen Erfahrung voraus geht und Zeit erst entstehen lässt. Zeit ist folglich von den Dingen losgelöst zu betrachten. Die Wirklichkeit samt der Dinge, die uns umgeben, lässt sich damit in Kants Verständnis eigentlich gar nicht ohne Weiteres erkennen. Wir kennen die Dinge nicht an sich, sondern kennen stattdessen nur wie sie uns erscheinen. Verkürzt ausgedrückt, >denkt` das Subjekt die Dinge mithilfe einer architektonischen Struktur (den Kategorien) erst in die Welt shinein<, wobei Raum und Zeit die allgemeinen Möglichkeiten der Erscheinungen bilden. Resultat dieses /Vollsubjektivismus ist, dass die Zeit als Form des inneren Sinnes einen Spiegel unseres Selbst und unseres inneren Zustandes darstellt. Kant verweist dabei zugleich auf die Gestaltlosigkeit jenes Zeitbewusstseins, weshalb wir uns stets der Analogie einer ins Unendliche fortgehenden Linie behelfen, die zwar eindimensional bleibt, aber eine Positionsbestimmung des Nacheinanders ermöglicht. ${ }^{48}$

Die Kantische Idee der Transzendenz gilt zwar als der bis heute wohl meistbesprochene und meistgedeutete philosophische Ansatz der neuzeitlichen Erkenntnistheorie, zugleich konnte er aber das allägliche Zeiterleben bislang nur schwer durchdringen. Kaum ist für ein alltägliches Zeiterleben zu begreifen, wie Zeit (und auch der Raum) uns als reine Verstandeskategorien und sinnliche Anschauungen und Erscheinungen, aber ohne jede außergeistige Realität gegenübertreten können. Auch sind die apriorischen Voraussetzungen jeder Erfahrungsbildung nicht ohne Weiteres nachvollziehbar. Die Bezüge auf Newton, der für Kant allein durch seine intensive geistige Beschäftigung mit physikalischen Fragestellungen die naturgesetzlichen Grundsätze zu entschlüsseln vermochte, dienen eher als abstrakte Beweisführungen der Existenz apriorischer Orientierungsmuster. Stattdessen sind für das alltägliche Zeiterleben nach wie vor enge Bezüge zum absoluten Newton'schen Zeitbegriff erkennbar, die sich, vermittelt und reproduziert im Sprachgebrauch, bis heute kaum zu verändern scheinen.

46 Immanuel Kant, Kritik der reinen Vernunft (Riga: Johann Friedrich Hartknoch, 1781), Abschnitt II, 31.

47 Ebd.

48 Kant vermerkt zur Behelfsgestalt des imaginierten Zeitpfeils: »Und, eben weil diese innre Anschauung keine Gestalt giebt, suchen wir auch diesen Mangel durch Analogien zu ersetzen, und stellen die Zeitfolge durch eine ins unendliche fortgehende Linie vor, in welcher das Mannigfaltige eine Reihe ausmacht, die nur von einer Dimension ist, und schliessen aus den Eigenschaften dieser Linie auf alle Eigenschaften der Zeit, ausser dem einigen, daß die Theile der erstern zugleich, die der letztern aber jederzeit nach einander sind.«Ebd., 33. 
Abschließend zur neuzeitlichen Zeitauffassung einer subjektiven Anschauungsweise sei im Hinblick auf die Verengung von Zeitbegriffen gefragt, ob das Wartephänomen im Kantischen Verständnis ebenfalls eine Art angeborener Erlebnisform darstellt. Ohne an dieser Stelle eine philosophische Auseinandersetzung anstreben zu können, würde Kant wahrscheinlich aber wohl auch den temporären Aufschub der Wartezeit als eine apriorische Welterfahrung deklarieren. Dennoch würde sich hier die Frage stellen, warum das Warten dann oftmals als Irritation bzw. als Anomalie aufgefasst wird. An dieser Stelle muss daher offenbleiben, ob das Warten im Kantischen Sinne gewissermaßen einen Systemfehler des apriorischen Denkens darstellt oder ob der Wartemodus ebenfalls eine Form der sinnlichen Anschauung bildet.

\section{Henri Bergsons Zeitkonzept der iduréer}

In noch stärkere Opposition zu Newton tritt in Bezug auf dessen Postulat der Quantifizier- und Messbarkeit von Zeit zu Ende des 19. Jahrhunderts der französische Philosoph Henri Bergson. Noch vor Husserls >Phänomenologie des inneren Zeitbewusstseins und somit als erster Vertreter der modernen subjektivistischen Zeitphilosophie, machte Bergson darauf aufmerksam, dass das Zeiterleben mit den etablierten Methoden der Zeitmessung nicht vollends erklärt werden könnte. ${ }^{49}$ Stattdessen würde das alltagspraktisch erlernte Modell einer objektiven Zeit in den Augen Bergsons dazu führen, den Blick auf das eigentlich nichtfunktionale, spontane und kontingente Wesen der Zeit zu verschleiern.

Entgegen der physikalischen (Uhr-)Zeit, die fragmentiert und in Abschnitte eingeteilt werde, sei die Zeit für lebendige Dinge eine grundverschiedene. Bergson führt dazu mit dem Begriff der >durée`, der reinen Dauer, ein Konzept ein, das auf eine innere Zeitlichkeit, kurzum auf ein rein qualitatives Zeitbewusstsein der >wahren<, >reinen und 'gelebten Dauer verweist. Für ihn ist das konventionelle Zeitmaß nur eine Anzahl von virtuellen zeitlichen Ruhepunkten zwischen denen sich Beliebiges abspielen kann. Die alltägliche Rede von einer Zeitdauer bezieht sich somit im Grunde stets nur auf die Messabstände einer Bewegung, nicht jedoch auf die qualitative Ausgestaltung szwischen jenen im Grunde unbeweglichen Messpunkten.

»Wenn wir in der Umgangssprache von Zeit reden, denken wir für gewöhnlich an das Maß der Dauer und nicht an die Dauer selbst. Aber man fühlt und erlebt diese Dauer, die die Wissenschaft eliminiert, die so schwierig zu erfassen und auszudrücken ist. Sollten wir nicht einmal untersuchen, wie sie wirklich ist? « ${ }^{50}$

Im Rahmen seiner Untersuchungen verliert die Zeit für Bergson »jeden bloß formalen Charakter und wird zu einem konstitutiven schöpferischen Prinzip der Wirklichkeit. ${ }^{51}$ Die innere Zeitlichkeit konstituiert sich dabei nach Bergsons Auffassung im Unterbewusstsein. Wahre Zeit ist somit nur erlebbar, aber nicht messbar, sie kann nicht analytisch oder sprachlich gefasst werden. Der einzige Zugang der Bewusstwerdung ist für ihn die Intuition, die Bergson der Intelligenz als konventionellem Mechanismus der 
Bewusstwerdung (von Zeit) gegenüberstellt. Während die Intuition eine Methode darstellt, die uns quasi mit unverstelltem Blick zu den Dingen selbst führen und damit den Geist befreien würde, ${ }^{52}$ versucht sich dagegen die Intelligenz stets einen festen Halt zu suchen, der ihr mittels der physikalischen Zeitauffassung und etablierter sprachlicher Begriffe bereitgestellt werde, die jedoch Zeit nur als nebeneinandergesetzte Momentaufnahmen bzw. künstliche Rekonstruktionen eines Zeitflusses erscheinen lasse. ${ }^{53}$ Bergsons Zeitbegriff der >durée< stellt sich damit weitaus komplexer als die Konzeption einer objektiv-mathematischen Zeit dar bzw. als dessen qualitative Ergänzung. Die (zeitliche) Wirklichkeit lasse sich mit der Bequemlichkeit absoluter Methoden demgegenüber letztlich nur partiell und unzureichend erfassen.

»Was also wirklich ist, das sind nicht die in Momentaufnahmen fixierten `Zuständeく, die wir im Verlauf der Veränderung aufnehmen, sondern das ist im Gegenteil der Fluß, das ist die Kontinuität des Übergangs, das ist die Veränderung selbst. ${ }^{44}$

Die knappe Beleuchtung des Bergson'schen Plädoyers einer intuitiven Philosophie wird hier nicht zuletzt deshalb vorgenommen, weil jener Ansatz einer der wenigen (im Grunde der einzige) unter den modernen philosophischen Ansätzen darstellt, der sich explizit dem Phänomen des Wartens widmet. Das Konzept der gelebten Dauer illustriert Bergson in einem Gedankenexperiment bei dem Zucker in einem Wasserglas geschmolzen wird. Das Schmelzen des Zuckers steht dabei exemplarisch für die Dauer, die sich der intellektuellen Steuerung entzieht und die im Subjekt eine eigene Zeitlichkeit ausbildet. Die Dauer des Schmelzens bewegt das Subjekt dazu, den Blick nicht mehr wie gemeinhin aktiv nach vorn zu richten, sondern erzeugt ein »abwartendes Wahrnehmen, das den Bezug von Vergangenheit zu Gegenwart und Zukunft herstellt, das Akzeptieren der wechselseitigen Bedingungen aller dreier Zeitsphären. ${ }^{55}$ Mithilfe dieses einfachen Experiments gelingt es Bergson, darauf aufmerksam zu machen, dass es eine Zeitlichkeit jenseits der mechanisierten Zeitmessung gibt: ein spannungsvolles Warten, eine Konzentration auf das Geschehen, das keineswegs als Passivität zu deuten ist, sondern ein aktives Moment in Form der Anpassung an den Rhythmus des Ereignisses beinhaltet.

»[...] die Zeit, die ich warten muss, ist nicht mehr jene mathematische, die sich mit der Ceschichte des Universums auch dann noch decken würde, wenn diese auf einen Schlag im Raum hingebreitet worden wäre. Sie fällt zusammen mit meiner Ungeduld, d.h. mit einem Teil meiner eignen Dauer, der weder willkürlich ausdehnbar noch ab-

52 Bergson beschreibt den Zustand des intuitiven Erkennens als Zustand der völligen Unvoreingenommenheit: »Nichts schiebt sich mehr dazwischen, keine Brechung der Strahlen durch das Prisma, dessen eine Fläche der Raum und dessen andere die Sprache ist. « Bergson, Denken und schöpferisches Werden, 44.

55 Ina Schmidt, Vom Leben zum Sein: der frühe Martin Heidegger und die Lebensphilosophie (Würzburg: Königshausen \& Neumann, 2005), 190. 
kürzbar ist. Nicht mehr Cedachtes ist hier, sondern Celebtes, nicht Relatives mehr, sondern Absolutes. $\aleph^{56}$

Der entscheidende Aspekt in der Auflösung des Zuckers liegt also darin, dass analog zum kontinuierlichen Diffusionsprozess einzelner Zuckerpartikel die Zeit nicht mehr als Aneinanderreihung von an relativen Bezugssystemen ausgerichteten Zeitpunkten gedacht und wahrgenommen wird, sondern als ganzheitliche Bewegung, als Veränderung oder, mit Deleuzes zu sprechen, als »qualitativer Übergang ${ }^{57}$ Jener kontinuierliche Übergang bildet das Zeitempfinden aus, das Bergson mit dem Konzept der >durée< aufzuzeigen beabsichtigt und das für den französischen Philosophen interessanterweise in einem Dauerzustand des spannungsvollen Wartens resultiert. Jenes Warten erwächst dabei für Bergson nicht nur zu einer subjektbezogenen Grundverfassung im vorgestellten Experiment, sondern schlechthin gar zu einer Grundverfassung des Universums.

»Außerhalb des Organischen erscheint uns die anorganische Materie zweifellos als zerlegbar in Systeme, über die die Zeit hinweggleitet, ohne in sie einzudringen, Systeme, die von der Wissenschaft abhängen und auf die sich der Verstand bezieht. Aber das materielle Universum als Ganzes nötigt unserem Bewußtsein die Spannung des Wartens auf. Es befindet sich selbst in dieser Spannung. ${ }^{58}$

Abermals mit Bezug auf sein Zuckerwürfel-Experiment betont Bergson an anderer Stelle, wie vielfältig das Zeitbewusstsein im Gegensatz zur abstrakten, an relative Bezugsgrößen gekoppelten Zeiterfahrung eigentlich zu begreifen ist.

»Diese Notwendigkeit, zu warten [auf die Auflösung des Zuckers, R.K.], ist die Tatsache, die von Bedeutung ist. Sie drückt aus, daß - wenn man aus dem Universum Systeme herausschneiden kann, für die die Zeit nur eine Abstraktion, eine Beziehung, eine Zahl ist - doch das Universum selbst etwas anderes ist. Wenn wir es in seiner Gesamtheit umfassen könnten, als unorganisch, aber durchwoben von organischen Wesen, so würden wir sehen, wie es unaufhörlich ebenso neue, ebenso originelle, ebenso unvorhersehbare Formen annähme wie unsere Bewußtseinszustände. $\aleph^{59}$

Bergsons Verständnis des Wartens als qualitativer Übergang und als aktives Erleben wird im Rahmen dieser Arbeit als bedeutende theoretische Denkfigur aufgefasst, die es erlaubt, das alltägliche Phänomen verkehrsinduzierten Wartens in einer anderen Daseinsqualität zu fassen. Auch wenn die menschliche Grundverfassung des spannungsvollen Wartens bei Bergson nicht per se als positive Erfahrung deklariert wird, kann das Bergson'sche Zeitkonzept der >duréer schließlich dabei helfen, eine Neukonzeption des (verkehrlichen) Wartens jenseits der antithetischen Wahrnehmung als toter oder verlorener Zeit zu entwerfen. 


\section{Zeittheorie bei Heidegger}

»Das ontologische Vordringen zum »Ursprung« kommt nicht zu ontischen Selbstverständlichkeiten für den »gemeinen Verstand «, sondern ihm öffnet sich gerade die Fragwürdigkeit alles Selbstverständlichen. ${ }^{60}$

Die im Rahmen der modernen Philosophie wohl bislang tiefgreifendste Analyse zum Zeitbegriff entstammt der fundamentalontologischen Forschung Martin Heideggers, genauer dessen 1927 erschienenen Hauptwerk Sein und Zeit. Ausgangspunkt der letztlich unvollendet gebliebenen Grundlegungen zur Bedeutung der Zeitlichkeit für die menschliche Existenz bildet - ähnlich wie für Bergson - der kritische Befund einer offensichtlichen Zeit- und Seinsvergessenheit der philosophischen Tradition seit der Antike. Die grundlegende Frage nach dem Sinn des Seins wurde für Heidegger über lange Zeit trivialisiert, sanktioniert oder schlichtweg als undefinierbar oder selbstverständlich abgetan. Zu lange hätte die Philosophiegeschichte das Seiende (die konkreten Erscheinungen) mit dem Sein (den Voraussetzungen der Erscheinungen) verwechselt. Vor diesem Hintergrund sieht er die Notwendigkeit, die Frage nach dem Sein unter dem folgenden Leitgedanken neu aufzurollen:

»Alle Ontologie, mag sie über ein noch so reiches und festverklammerstes Kategoriensystem verfügen, bleibt im Grunde blind und eine Verkehrung ihrer eigensten Absicht, wenn sie nicht zuvor den Sinn von Sein zureichend geklärt und die Klärung als ihre Fundamentalaufgabe begriffen hat. « $^{61}$

Die Tiefensuche bzw. philosophische Anthropologie nach dem Ursprung des Seins führt Heidegger zu einer fundamentalontologischen Konzeption von Zeit. Danach bildet zunächst das Dasein, die zwischen Geburt und Tod sich aufspannende und in die Welt geworfene Existenz, die grundlegende Seinsart jedes Menschen. Das Dasein ist jeglichem Sein und damit jeglicher Form des Umgangs mit Zeit vorgängig und gilt für Heidegger im Hinblick auf dessen Suche nach dem Sinn des Seins als primäres Befragungsfeld. ${ }^{62}$ Jenes Dasein selbst besitzt jedoch keine Zeitlichkeit im Verständnis des linearen Erlebens, sondern wir sind stattdessen stets schon »in der Zeit«. Diese übergeordnete Zeitlichkeit des Daseins ermöglicht überhaupt erst das Erleben einer zeitlichen Ordnung bzw. das Erleben von Zeitmodi und -derivaten. Mit anderen Worten: Die Zeit ist dem zeitlichen Erleben im zeittheoretischen Verständnis Heideggers stets vorgängig. Sie wird somit zur eigentlichen Bedingung der Möglichkeit des In-der-Welt-Seins und muss nach dessen Worten "als der Horizont alles Seinsverständnisses und jeder Seinsauslegung ans Licht gebracht und genuin begriffen werden. ${ }^{63}$ Der fundamentalontologische Zeitbegriff gestattet für Heidegger ferner erst den Zugang, um das Sein in all seiner Bestimmtheit - in Form der jeweiligen »Temporalität des Seins ${ }^{64}$ - erfassen

\footnotetext{
60 Martin Heidegger, Sein und Zeit, 334.

61 Ebd., 11 [Herv. i. O.].

62 Vgl. ebd., $13 f$.

63 Ebd., 17.

64 Ebd., 19.
} 
zu können. Als Methode seiner wie erwähnt unvollständig gebliebenen Daseinsanalyse, die die Vielzahl der im Dasein fundierten Strukturen (Existenzialien) freizulegen beabsichtigt, dient für Heidegger eine durch die Phänomenologie Husserls inspirierte Hermeneutik, also die Auslegung alles Vorfindbaren mittels einer Rekonstruktion des in einer Sache originär eingeschriebenen Sinns und dessen Reinterpretation. ${ }^{65}$ Nicht selten geht diese Reinterpretation dabei in eine Form der (gewaltsamen) Destruktion traditioneller Denkmuster und Wissensbestände über, bei der Tradition, Geschichte und wissenschaftliche Disziplinen grundlegend hinterfragt werden müssen.

Welche handlungsrelevante Dynamik lässt sich nun aber im Zusammenhang zwischen der fundamentalen Vorgängigkeit und Ursprünglichkeit der Zeit und der alltäglichen Lebenspraxis erkennen? Welchen Grundcharakter trägt nun das Dasein bzw. was hält es zusammen? Die Antwort liefert Heidegger in der Auffassung, dass die existenziale Gesamtstruktur des Daseins durch die Sorge charakterisiert sei, dem planerischen, steuernden und berechnenden, kurzum aktiven und umsichtigen Umgang mit der Zeit. Dasein geht demnach einher mit permanenter Sorge, wobei der Terminus auch deshalb gewählt wurde, um auf den praktischen Umgang des Menschen mit der Welt zu verweisen, der dem bloßen Anschauen und Erkennen der Welt entgegengesetzt wird. Die drei charakteristischen Merkmale dieser Sorge-Struktur liegen im Schon-in-der-WeltSein (der geworfenen Faktizität des Daseins in einen bereits bestehenden Zusammenhang), einem Sich-vorweg-Sein (der Existenzialität bzw. dem Bewusstsein der zukunftsorientierten Notwendigkeit zum Ergreifen von Handlungsoptionen) und einem Seinsbei (dem Verfallensein bzw. dem immer schon bei den besorgenden Dingen sein). Die Einheit dieser Strukturelemente bildet für Heidegger den eigentlichen Sinn des Daseins bzw. »die konkrete Verfassung der Existenz«. ${ }^{66}$ Jene Strukturmomente bestimmen schließlich auch die verschiedenen Zeitmodi des Daseins (Ekstasen), die wiederum gegen die philosophische Tradition als Zukunft, Gewesenheit und Gegenwart bezeichnet werden. ${ }^{67}$

Begründet und motiviert werden die drei Strukturelemente der Sorge dabei durch das Bewusstsein der unüberholbaren Endlichkeit des eigenen Lebens, der permanenten Aushandlung des Menschen mit dem Tod als ein permanentes Sein zum Tod. Die grundlegende Voraussetzung aber, um sich überhaupt erst auf den Tod ausrichten zu können, bildet dabei die Zeitlichkeit. ${ }^{68}$ Sie wird als ursprünglichstes Moment wiederum erst zur Voraussetzung für die Ausbildung einer Sorgestruktur - Heidegger sagt zum »Sinn der Sorge ${ }^{69}$ - und gilt somit als grundlegender Unterbau der Existenz des Daseins.

»Wenn die Zeitlichkeit den ursprünglichen Seinssinn des Daseins ausmacht [...], dann muß die Sorge »Zeit«brauchen und sonach mit »der Zeit« rechnen. Die Zeitlichkeit des Daseins bildet »Zeitrechnung« aus. Die in ihr erfahrene »Zeit« ist der nächste phäno-

\footnotetext{
65 Vgl. ebd., 37.

66 Ebd., 231.

67 Vgl. Gloy, Philosophiegeschichte der Zeit, 185.

68 Vgl. Heidegger, Sein und Zeit, 234f.

69 Ebd., 326.
} 
menale Aspekt der Zeitlichkeit. Aus ihr erwächst das alltäglich-vulgäre Zeitverständnis und dieses entfaltet sich zum traditionellen Zeitbegriff. $^{70}$

Aus dieser Aussage wird deutlich, dass Heidegger mit der ursprünglichen Zeit ${ }^{71}$ etwas anderes meint als unseren herkömmlichen Zeitbegriff. Vielmehr lässt sich letzterer erst aus dem ursprünglichen Zeitbegriff ableiten und verständlich machen. Trotz der für jegliche Sorgestruktur grundlegenden Vorbedingung einer ursprünglichen Zeitlichkeit, die für Heidegger als endlich und der Zukunft entspringend verstanden wird, ${ }^{72}$ gesteht er aber dennoch ein, unterschiedliche Dimensionen und Stufen der Zeitlichkeit ableiten zu müssen. Die fundamentalontologische Rekonstruktion des Ursprungs aller Zeitlichkeit bewegt ihn damit zur Argumentation eines Übergangs von einer Zeitlichkeit in die andere. Heidegger besetzt dazu auf der basalen Stufe das Dasein als ursprünglichster aller Zeitlichkeiten mit den Begriff der »Weltzeit« bzw. der »besorgten Zeit« und führt am oberen Ende der Stufen des zeitlichen Daseins die Begriffe der »Vulgärzeit « bzw. "Jetzt-Zeit« ein, die unserem alltagspraktischen Verständnis einer mechanisierten Uhrzeit entsprechen.

Während die »besorgte Zeit« für Heidegger noch keine lineare Zeitfolge, sondern ein aktives und sinnhaftes Moment der Datierung, Bedeutsamkeit, Gespanntheit und Öffentlichkeit beinhaltet, reduziert die »Vulgärzeit« - als Abstraktion von den Bedeutungszusammenhängen der »besorgten Zeit« - die Zeit vollends zu einer im Aristotelischen Verständnis zählbaren Zeitreihe. ${ }^{73}$ Zeitlichkeit wird dabei nur noch als Aneinanderreihung von Jetzt-Punkten und als endlose Abfolge verstanden, die die eigentlichen Charakteristika der »Weltzeit« verdecken und nivellieren würden. Der Grund für unsere alltagspraktische Romanze mit der nunmehr als endlos verrinnend wahrgenommenen »Vulgärzeit« sei der Umstand, dass wir unsere eigene Endlichkeit, den Tod, zu verdrängen suchen.

»In der besorgten Flucht liegt die Flucht vor dem Tode, das heißt ein Wegsehen von dem Ende des in-der-Welt-Seins. ॥ $^{74}$

Im Resultat seiner Ableitung der »Vulgärzeit« aus der ursprünglichen Zeitlichkeit erwächst letztlich eine deutlich erkennbare Enttäuschung und Kulturkritik Heideggers. Die »Vulgärzeit« hätte zwar ihr natürliches Recht, sie hätte uns jedoch gleichwohl dazu gebracht, die Eigentlichkeit der Zeit zu verdecken und zu nivellieren. Wir geben uns im Alltag selbstvergessen den Dingen hin, leben uneigentlich, erheben uns damit über die natürlichen Dinge und finden kein Ende mehr. Trotz seiner Polemik gegen den vulgären Zeitbegriff geht es hier Heidegger nach Auffassung von Gloy jedoch »nicht um eine Suspendierung der Uhrzeit, sondern um ihre angemessene Einstufung in die Hierarchie der Zeitvorstellungen. « ${ }^{75}$ 
Zwar bleibt im Anschluss an die Einstufungen von Welt- und Vulgärzeit die Herleitung eines allgemeinen Zeitbegriffs unvollendet, doch das Postulat einer Zentralität der Zeitlichkeit als vorgängige Verfassung der Daseinsganzheit markiert nichtsdestotrotz eine entscheidende Wegmarke der (Zeit-)Philosophie. Sie umfasst eine disruptive Zeitauffassung, die bis in die Gegenwart hinein wirkungsmächtig bleibt und mit der sich Heidegger schließlich klar gegen den konventionellen, erstmals mit Aristoteles aufkeimenden objekt- und raumbezogenen Zeitbegriff abzugrenzen versucht, die Zeiterfahrung vollends in den Bereich des Subjektes verlagert und schließlich die Zeitlichkeit als Grundverfassung, Bedingung und erklärender Struktur der Möglichkeiten des Daseins proklamiert. Somit wird der bereits zuvor mit der Phänomenologie Husserls eingeleitete Bruch zwischen Physik und Philosophie hinsichtlich des ontologischen Status der Zeit abermals verstärkt. Mit Heidegger wird dem antiken Geozentrismus wird nunmehr eine radikale Form des Egozentrismus gegenüberstellt.

Wiederum mit Bezug auf das Temporalphänomen des Wartens stellt sich nun die Frage, welche Einblicke sich mit der fundamentalontologischen Philosophie Heideggers für das Warten gewinnen ließen. Sein und Zeit widmet sich in seinem zweiten Abschnitt der Freilegung der existentialen Grundstruktur der Zeitlichkeit, allerdings bleibt hier angesichts des abstrakten, philosophietheoretischen Blickwinkels eine tiefere Betrachtung oder Einordnung alltäglicher Zeitmodi (etwa dem Warten) aus. Dennoch widmet sich Heidegger im Rahmen der Zeitlichkeit der Alltäglichkeit randständig dem Erwarten zukünftiger Ereignisse. Der Modus des Erwartens gilt ihm hier als Beweisführung dafür, dass sich auch das uneigentliche Dasein (einem Dasein, das sich nur den gegenwärtigen Dingen und Tätigkeiten widmet, sich aber nicht aus seiner Endlichkeit versteht) sich im Kern aber gleichwohl auf ein eigentliches Dasein stützt, das sich seiner Endlichkeit bewusst ist und daraufhin im Rahmen seiner Möglichkeiten handelt. Während das Gegenwärtigen als Verfolgung rein gegenwartsbezogener Alltagsgeschäfte ein uneigentliches Dasein verkörpert, würde dagegen das Vorlaufen ein eigentliches Dasein begründen, das sich aus seiner eigenen Endlichkeit begreift. Jedes Antizipieren von Zukunft - und so etwa auch der Modus des Wartens - würde zwar im alltäglichen Kontext gegenwartsbezogen wirken, das Antizipieren wäre aber erst dadurch möglich, dass die ursprüngliche Zeitlichkeit als vorgängige Ur-Bedingung aller Möglichkeiten des Daseins fungiere.

»Das Cewärtigen muß schon je den Horizont und Umkreis erschlossen haben, aus dem etwas erwartet werden kann. Das Erwarten ist ein im Cewärtigen fundierter Modus der Zukunft, die sich eigentlich zeitigt als Vorlaufen. Daher liegt im Vorlaufen ein ursprünglicheres Sein zum Tode als im besorgten Erwarten seiner. ${ }^{76}$

Daraus schlussfolgernd ließe sich also argumentieren, dass die alltäglichen Wartesituationen in der Perspektive Heideggers womöglich als wichtige funktionale Schlüsselstellen zur Selbstbestimmung des eigentlichen Daseins dienen könnten. Die erzwungene Zeitbezogenheit im Warten, insbesondere im Langzeitwarten, beinhaltet eine unterbewusste Erinnerung an die eigene Endlichkeit des Lebens, die in anderen Situationen 
meist durch Aktivitäten oder Auslagerungen auf das Man verdeckt werden würde. Dies würde aber für Heidegger nur dazu führen, das Dasein uneigentlich zu führen. Nur wenn die eigene Endlichkeit tatsächlich wahrgenommen und aktiv berücksichtigt wird, sei nach Heidegger ein wirkliches Dasein und eine Sorgestruktur möglich. Das eigentliche Existieren wird Heidegger zufolge zuallererst möglich durch eine dieser Verdeckung entgegenwirkende Besinnung des Daseins auf seinen eigenen Tod. ${ }^{77}$ Die modernen Erfahrungen der Zeitnot, des Lärms, des Gerennes und der übermäßigen Geschäftigkeit sieht Heidegger folglich dezidiert als Konsequenz der Fixierung auf die uneigentliche Zeit der Gegenwart.

»Keine Zeit haben heißt, die Zeit in die schlechte Gegenwart des Alltags werfen. ${ }^{78}$

So ließe sich argumentieren, dass es womöglich erst die im Warten wieder aktivierte Erinnerung an den Tod und die eigene Vergänglichkeit sind, die die Aufhebung des uneigentlichen Daseins und die Erinnerung an das eigentliche Sein gewährleisten und der Wartezeit im Heidegger'schen Zeitdenken eine funktionale Schlüsselstellung als existenziellem Modus zukommen lassen könnte.

\subsubsection{Aporien der Zeit: Resümee philosophischer Zeittheorien}

Aus der komprimierten Gesamtschau philosophischer Zeittheorien von der Antike über die Neuzeit bis zur Moderne wurden die polarisierenden Traditionslinien zwischen der Anschauung von Zeit als objektiver, universaler Größe einerseits und rein subjektiver bzw. relativer Vermitteltheit andererseits deutlich. Während die Auffassung von Zeit als subjektimmanenter Größe beginnend mit Augustinus über die apriorischen Überlegungen Kants und den bedeutenden Weiterentwicklungen von Husserl, Bergson oder Heidegger als noch vergleichsweise jung gilt, bildet die Auffassung von Zeit als einer linearen, objektiven und in Form von Bewegungen messbaren Größe die deutlich ältere Traditionslinie. Zeit wird im Resultat dieser älteren Traditionslinie in eine Vergangenheit, Gegenwart und Zukunft gegliedert. McTaggart bezeichnet jene kanonische Denkweise, die den erlebten Fluss der Zeit und die Flüchtigkeit des Gegenwartspunktes hervorhebt in seiner 1908 erschienenen Systematisierung der widerstreitenden Denkströmungen als Präsentismus. Ihm stellt er den Eternalismus gegenüber, der keinen Gegenwartspunkt kennt, sondern nur ein früher oder später. Zeit fließt darin nicht, sondern ist einzig und allein relationales Konstrukt. ${ }^{79}$

Der Präsentismus bildet innerhalb der westlichen Zeitkultur den zentralen Bezugsrahmen und die Idealvorstellung menschlicher Sinnsetzungen. Jene Zeitkultur ist zwar von Seiten der modernen Philosophie als auch von Seiten der Naturwissenschaften selbst unter Druck geraten, ${ }^{80}$ dennoch scheinen wir nach wie vor der Illusion einer

77 Vgl. Römer, Das Zeitdenken bei Husserl, Heidegger und Ricœur, 145.

78 Martin Heidegger, Der Begriff der Zeit (Frankfurt a.M.: Vittorio Klostermann, 2004), 118. Vgl. dazu auch Rosa, Beschleunigung: die Veränderung der Zeitstrukturen in der Moderne, $450 f$.

79 Vgl. John M.E. McTaggart, »The Unreality of Time«, Mind 17, Nr. 68 (1908): 457-74.

80 Hier ist etwa der Chemienobelpreisträger llya Prigogine zu nennen, der bereits in den frühen 1970er Jahren im Rahmen seiner Theorie irreversibler Prozesse vermerkte, dass es die Physik selbst sei, die beginne, die Trennung eines physikalischen und eines philosophischen Zeitbegriffs zu 
objektiven Zeit verhaftet zu sein. So prominent und leidenschaftlich Autoren wie Bergson oder Heidegger auch ihre alternativen Zeitauffassungen als gelebter Dauer oder untergründiger Primärstruktur präsentiert haben mögen, so sind doch die paradigmatischen Vorstellungen einer messbaren Uhrzeit oder eines Zeitflusses in den kollektiven Zeitauffassungen letztlich zu sehr verankert geblieben. Mehr noch, je größer die Kritik des naturwissenschaftlichen Begriffs der messbaren Zeit wurde, desto durchdringender wurde paradoxerweise die chronometrische Orientierung moderner Gesellschaften.

So bleibt auch heute noch die für den Gegenstand `Zeit< in philosophischer Betrachtung traditionelle Feststellung der Rätselhaftigkeit und Aporizität bestehen. Zeit bleibt etwa nicht nur für Paul Ricœur das Mysterium, das sich der Repräsentation verweigert, indem es unser Dasein auf eine für das Denken uneinholbare Weise umgreift. ${ }^{81}$ Auch Bergson verdeutlicht die allgemeine Ernüchterung über die in der Philosophie nur halbherzig und unpräzise durchlaufene "Suche nach der verlorenen Zeit « ${ }^{82}$ und weist darauf hin, dass die Literatur und die Poesie, wenn auch methodisch weniger versiert, hier vielleicht bereits viel weiter seien. ${ }^{83}$

Zusammenfassend erschließt die jahrhundertealte philosophische Beschäftigung mit der Zeit nach dem Phänomenologen Paul Ricœur drei unvermeidliche >Aporien der Zeit<. Die erste Aporie betrifft die schon angesprochene Heterogenität von subjektiver und objektiver Zeit. Danach sind ein im Aristotelischen oder Newton'schen Sinne kosmologischer, objektiver Zeitbegriff und einer im Heidegger'schen Sinne ursprünglicher, phänomenologischer Zeitbegriff nicht voneinander ableitbar, wenngleich sie eine wechselseitige Abhängigkeit aufweisen. ${ }^{84}$

Die zweite Aporie der Zeit besteht nach Ricœur darin, dass die Zeit durch die Philosophen, aber auch im Alltagsverständnis, stets leichtfertig, unhinterfragt und verkürzt als >Kollektivsingular verstanden wird, obwohl der Begriff im Grunde einen Plural erfordert. Die scheinbare Ganzheit der Zeit wird und wurde zu oft schlichtweg als einzigartig vorausgesetzt, obwohl sich diese Behauptung angesichts des Auseinanderbrechens der Zeit in eine Vielzahl von Zeitmodi und -vorstellungen kaum glaubhaft nachvollziehen lässt. ${ }^{85}$

Die dritte und schwierigste Aporie der Zeit aber betrifft ihre eigentliche Unerforschlichkeit, weil sie immer schon uneinholbar vorgängig ist. So könne Zeit nie vollständig zum Objekt unserer Reflexion werden und würde somit stets eine Restgröße der Unerforschlichkeit behalten. ${ }^{86}$ Diese Aporizität wird erstmals durch Augustinus erfasst und mithilfe der geistigen Syntheseleistung der bereits erwähnten `dreifachen Gegenwart

überwinden. Ilya Prigogine, »Time, Irreversibility and Structure«, in The Physicist's Conception of Nature, hg. von Jagdish Mehra (Dordrecht: Springer, 1973), 561-93. Zur im Vergleich zu den Sozialwissenschaften generell stärker hinterfragenden Selbstverständnis der Physik vgl. auch Adam, Time and Social Theory, $48 \mathrm{ff}$.

Vgl. Paul Ricœur, Die erzählte Zeit (München: Wilhelm Fink, 1991), 436.

Bergson, Denken und schöpferisches Werden, 38.

Vgl. ebd.

Vgl. Ricœur, Die erzählte Zeit, 16-36.

Vgl. ebd., 349ff.

Vgl. Römer, Das Zeitdenken bei Husserl, Heidegger und Ricœur, 284. 
zu lösen versucht. Zur Schwierigkeit der objektiven Reflexionsfähigkeit über die Zeit trägt zudem das Paradox bei, dass das die Zeit wahrnehmende Subjekt zugleich immer auch das Zeit generierende Subjekt ist. Ein Lösungsweg dieser Problematik wird dabei in der Refiguration der Zeiterfahrung in der Erzählung (Ricœur) oder aber einer Vermittlungsleistung mittels der Intuition (Bergson) gesehen.

Im Rückblick auf die lange philosophische Forschungstradition im Umgang mit `Zeit lässt sich also festhalten, dass weder ein rein phänomenologisch-subjektives noch ein rein objektives Verständnis von Zeit genügen, um ein ganzheitliches und operationalisierbares Verständnis von Zeit zu erlangen. Auch wenn im Laufe der Moderne die Tendenz zum Primat einer subjektivistischen Zeitauffassung vorherrschte, mochte sich bis dato keine der Positionen vollends durchsetzen. Die philosophische Dichotomie und die daran geknüpften endlosen Debatten der beiden Lager (Subjektivisten vs. Objektivisten) erscheinen nur wenig gewinnbringend.

Wissen wir nun also kaum substantiell mehr über die Zeit als die griechischen Philosophen? Die etwas überspitzte Eingangsfrage sollte mit einem >Nein<beantwortet werden. Das Wissen über die Zeit ist opulent geworden, wenngleich um den Preis ihrer Unentschiedenheit. Die Errungenschaften der modernen und jüngeren Philosophiegeschichte sind gerade im grundsätzlichen Hinterfragen der Zulässigkeit rein naturwissenschaftlich-absoluter Zeitauffassungen zu suchen. Fraglos hat sich dadurch die scheinbare Einfachheit und Eindeutigkeit eines Newton'schen Zeitbegriffes verkompliziert, mit Blick auf Einsteins Relativitätstheorie nicht zuletzt auch durch die Naturwissenschaften selbst. Wir wissen mehr und denken heute anders über die Zeit, obschon diese Vielfalt das Verständnis über sie keineswegs einfacher gemacht hat. Im Gegenteil, die Rätselhaftigkeit der Zeit von der schon Augustinus sprach, hat gerade erst durch die Erweiterung der Sichtweisen von Bergson oder Heidegger an Substanz gewonnen.

Im Alltagsverständnis von Zeit lässt sich die Rätselhaftigkeit der Zeit jedoch vergleichsweise weniger ablesen als in den skizzierten zeitphilosophischen Debatten. Hier erscheinen die Langzeiteffekte neuzeitlich-objektivistischer Zeitbetrachtung - etwa in sprachlichen Bezügen vom `Zeitraum` oder `Zeitfluss` - in bemerkenswerter Persistenz. Zu stark wirken bis heute die Grundzüge der Newton'schen oder Aristotelischen Zeitauffassung im Vergleich zum Zeitverständnis eines Heidegger oder Einsteins. Erstere versprechen vielmehr eine einfachere und vor allem operationalisierbare Zeitlogik, die für die permanenten Synchronisationsprozesse hochentwickelter Gesellschaften als etabliert gelten und deshalb konsensual reproduziert werden. Zeit tritt hiernach den Akteuren als solide Faktizität gegenüber. Zugleich sind aber auch deutliche Charakteristika des subjektivistischen Lagers zu finden. Zeit vergeht zugleich doch scheinbar schnell oder langsam, man empfindet das Bedürfnis seine seigene Zeit zu brauchen oder die Zeit anhalten zu müssen. Zeit wird demnach nicht nur als im Maß der Bewegung repräsentierte und nutzbare Größe verstanden, sondern natürlich ebenso auch serlebt $<$. Mit Blick auf die aus der philosophischen Forschungstradition identifizierten, schwerlich zu lösenden Aporien der Zeit lässt sich somit festhalten, dass die Auffassungen über Zeit nur äußerst langwellig wirksam werden. Die Verinnerlichung von Zeit, vor allem deren Transformation, braucht Zeit und ist zudem stark kulturabhängig.

Welche >Mitnahmen lassen sich nun aber trotz der idiosynkratischen und zum Teil stark widersprechenden Zeitbetrachtungen innerhalb der Philosophie bezüglich des 
tieferen Verständnisses einer Wartezeit ableiten? Dieser Beantwortung wird sich das Kapitel 2.3 widmen. Diesem Schritt vorgelagert sollen zunächst noch der philosophischen Betrachtung direkt angeschlossen die sozialwissenschaftlich-anthropologischen Zeittheorien gegenübergestellt werden. Schaffen jene Bearbeitungen des Zeitbegriffs ein gegenüber der philosophischen Betrachtung konsensfähigeres und operationalisierbares Theorieverständnis über die Zeit und welche Aussagen halten Sie für die Frage der Besonderheit des Temporalphänomens >Warten` bereit?

\subsection{Sozialwissenschaftliche und kulturanthropologische Zeittheorien}

Neben den philosophischen und naturwissenschaftlichen ${ }^{87}$ Zeitbegriffen etablierte sich im Laufe des 20. Jahrhunderts mit der Zeitsoziologie als auch der zeitsensitiven Kulturantrophologie eine dritte wichtige Säule der Erforschung von Temporalphänomenen. Die Betrachtung von Zeit aus Perspektive der Soziologie erkannte dabei - anders als die Philosophie oder Teile der Naturwissenschaften - in zunehmendem Maße die Wirkmächtigkeit und sozialprägende Realität der durch Uhren und Kalender vergegenständlichten »Vulgärzeit« als konstitutiv an. Jenseits des Widerstreits der ontologischen Bestimmungen der Zeit als Kultur- oder Naturobjekt wird in der soziologischen Betrachtung somit zunächst offenkundig angenommen, dass es eine strukturbildende Faktizität der Zeit im alltäglichen Erleben gibt. ${ }^{88}$

Der Fokus soziologischer Zeitanalysen fällt folglich auf die gesellschaftlichen Funktionen von Zeit und somit auf die grundlegenden Fragestellungen, welche konstitutive und regulative Rolle die Zeit in unserem alltäglichen Welt- und Selbstverständnis spielt und entlang welcher subjektiver und intersubjektiver Dimensionen, Strukturen und Institutionen die Zeitauffassung generiert und beeinflusst wird. Mit einem Wort: Die soziologische Perspektive versucht die Zeit als soziales Phänomen zu erfassen und die sich dynamisch verändernden Zeitverhältnisse, Zeitordnungen und -rhythmen, die unser Leben in unterschiedlichen Bereichen auf je unterschiedliche Weise bestimmen, $\mathrm{zu}$ analysieren. Entscheidend ist hierbei, dass diese sich daraus ergebende >zeitliche Ordnung der sozialen Organisation als von anderen zeitlichen Ordnungssystemen (etwa aus biologischen oder physikalischen) gänzlich verschieden betrachtet werden muss:

»This [social, R.K.] order is clearly distinct from other temporal orders. Whereas the physiotemporal and biotemporal orders, for example, are natural, and thus, inevitable, the sociotemporal order is essentially a socially constructed artifact which rests upon rather arbitrary social conventions. $" 89$

87 Hierzu zählen neben den bereits erwähnten physikalischen Ansätzen insbesondere auch die Ansätze aus der Biologie, die sich traditionell mit den zeitlichen Ordnungen und Rhythmen beschäftigten, welche die Bewegungen und das Leben von Organismen regulieren.

88 Diese vor allem oftmals in empirischen Studien vorausgesetzte und unhinterfragte Selbstevidenz der Zeit als quasi-objektive Größe bildet bis heute einen wesentlichen Kritikpunkt gegenüber zeitsoziologischen Studien. Vgl. hier zu etwa Rosa, Beschleunigung: die Veränderung der Zeitstrukturen in der Moderne, 23.

89 Eviatar Zerubavel, Hidden Rhythms: Schedules and Calendars in Social Life (Berkeley: Univ. of California Press, 1985), xii. 
Während die naturwissenschaftlichen Ansätze mehrheitlich die objektiven Qualitäten der Zeit zu beleuchten versuchen, sieht die soziologische bzw. sozialwissenschaftliche Erforschung der Zeit ihre Aufgabe in der Entdeckung der subjektiven Qualitäten, also der zeitbezogenen Sinnstiftungen und Bedeutungszuschreibungen. In ähnlichem Duktus fasst auch Werner Bergmann die allgemeine soziologische Beschäftigung mit dem Phänomen der Zeit zusammen:

"Sociology is not interested in the structure and the psychological functions of temporal perspectives as such, but in the relationship between temporal perspectives and social roles, social classes, certain other social groups, specific cultural and social types, social planning, and so on. ${ }^{90}$

Das Arbeitsprogramm, das aus diesem Diktum hervorgeht, ist beträchtlich, daher können und sollen im Folgenden vier spezifische Aspekte bzw. Fragestellungen zeitsoziologischer Forschung herausgegriffen werden. Diese umfassen die frühen theoretischen Grundlagenwerke, die gesellschaftliche Funktion der Zeit, die Dimensionen und Strukturelemente des Zeiterlebens sowie die Frage nach Evolution, Einflussfaktoren und Charakteristik der modernen Zeitvorstellung. Diese vier Leitperspektiven dienen als Achse entlang der im Folgenden die Erlangung eines Grundverständnisses der gesellschaftlichen Funktionen von Zeit erzeugt und zum anderen ein Verständnis der zeithistorischen Abhängigkeit von Zeiterfahrungen erreicht werden soll. Jene Leitperspektiven informieren zudem wiederum die anschließende Ableitung von Entstehungsbedingungen und qualitativ-inhaltlichen Ausformungen des Wartens als spezifisches Temporalphänomen in der Zeit.

\subsubsection{Grundlegungen zum Zeitbegriff im Rahmen klassisch-soziologischer Theoriebildung}

Eine der frühesten soziologischen Arbeiten zum Zeitbegriff geht auf Émile Durkheim und dessen 1912 erschienenes Werk Die elementaren Formen des religiösen Lebens zurück. Darin wurden drei für ein weiterführendes sozialwissenschaftliches Zeitverständnis wegweisende Aspekte herausgearbeitet: 1) Zeit wird dezidiert als Produkt kollektiven Denkens verstanden, 2) Zeit wird als soziale Tatsache verstanden, die auf individueller wie auf Gruppen- und Gesellschaftsebene wirksam wird, und 3) werden Zeitmesssysteme wie Kalender und Uhren nicht mehr alleinig als astronomisch-physikalische Messinstrumente aufgefasst, sondern als Repräsentation sozialer Aktivitäten und Rhythmen. ${ }^{91}$ Durkheim prägte mit seinen Arbeiten den Terminus der »sozialen Zeit«, welche außerhalb des individuellen Bewusstseins als intersubjektive und überindividuelle Ordnungsgröße konstitutiv für das gesellschaftliche Zusammenleben werde. Das Postulat

90 Werner Bergmann, »The problem of time in sociology: An overview of the literature on the state of theory and research on the >Sociology of Timeく, 1900-82 «, Time \& Society 1, Nr. 1 (1992): 85.

91 Vgl. Andrea Maurer, »Stand und Perspektiven der zeitsoziologischen Forschung «, in Soziologie in Deutschland und die Transformation großer gesellschaftlicher Systeme, hg. von Hansgünter Meyer (Berlin: Akademie Verlag, 1992), 591. 
der Existenz einer sozialen Zeit stellt sich somit gegen eine idealistische Zeitvorstellung Kantischer Prägung (Zeit als Kategorie der Gedankenwelt) als auch gegen eine empiristische Zeitvorstellung (Zeit als objektiv-messbare Größe). Anders als in einer astronomisch-physikalischen Zeitordnung werde die Orientierungsfunktion in der sozialen Zeitordnung vielmehr entlang kollektiver gesellschaftlicher Rhythmen (z.B. Feste und Rituale) ermöglicht. Individuen einer Gesellschaft agieren für Durkheim daher nie unabhängig von einer sie umgebenden >Weltzeit und einer >Sozialzeit‘. Das dialektische Verhältnis zwischen Zeit und sozialen Rhythmen verdeutlicht sich für Durkheim etwa exemplarisch an der Institution des Kalenders. Einerseits repräsentieren Kalender den Rhythmus sozialer und kollektiver Aktivitäten, andererseits sichern sie zugleich deren Regelmäßigkeit. Zusammenfassend wird Zeit mit Durkheim erstmals als sozial fundiertes und kollektiv wirksames Konstrukt theoretisiert, das den Weg für alle weiteren sozialwissenschaftlichen Zeitanalysen ebnete und bis heute einen ihrer zentralen Bezugspunkte bildet. ${ }^{92}$ Gleichwohl muss jedoch konstatiert werden, dass für Durkheim weder individuelle Zeiterfahrungen noch die persönlichen Konstruktionen von Zeit Problematisierungen des Theorems der sozialen Zeit bildeten. ${ }^{93}$

Durkheims pionierhafte Zeitanalyse übte in der Folge nicht nur starken Einfluss auf die französische Annales-Schule um Bloch, Febvre und Braudel aus, sondern wurde im US-amerikanischen Raum insbesondere durch die Soziologen Sorokin und Merton aufgegriffen. Sie stellten das Konzept der sozialen Zeit ebenfalls der astronomischmathematischen gegenüber, betonten aber noch stärker als Durkheim die qualitative Andersartigkeit der sozialen Zeit, die nicht kontinuierlich fließt oder beliebig teilbar sei, sondern stetig durch (kritische) Ereignisse beeinflusst und kollektiv neu ausgehandelt werden würde. In der Folge sei die soziale Zeit variabel und kontingent bzw. eher zyklisch als linear. Sie stellten fest, dass die Zeitbestimmung im alltäglichen Handeln wesentlich häufiger an sozialen Referenzpunkten und weniger an astronomischen festgemacht werde und somit eine kalendarisch-astronomische Referenz nur sinnhaft werden könne, wenn sie in eine soziale Zeit transformiert wird. ${ }^{94}$ Sorokin und Merton vertraten in diesem Zusammenhang die These, dass die Evolution der astronomischen Zeitmessung überhaupt gar erst aus dem Zweck jener sozialen Zeitbestimmung entspringt, welche die sozialen Prozesse zu synchronisieren versucht:

92 Wie tiefgreifend die Rezeption der Durkheim'schen Grundlegung des soziologischen Zeitbegriffs tatsächlich ist, zeigt sich etwa bspw. in Helga Nowotnys knapp 80 Jahre später entstandenem Essay »Eigenzeiten«, in dem die Zeit abermals in sichtlichem Duktus Durkheims als »Crundelement zur Strukturierung zwischenmenschlicher Beziehungen « beschrieben wird; Nowotny, Eigenzeit, 148.

93 Vgl. Simonetta Tabboni, »The Idea of Social Time in Norbert Elias«, Time \& Society 10, Nr. 1 (März 2001): 6 .

94 Vgl. Pitirim A. Sorokin und Robert K. Merton, „Social time: A methodological and functional analysis«, American Journal of Sociology 42, Nr. 5 (1937): 619. Darauf aufbauend wurden speziell in den 1980er Jahren mit den einflussreichen Arbeiten von Eviatar Zerubavel die soziale Konstruktion der Wochenzeit oder die Entstehung der standardisiert-kalendarischen Zeitbestimmung vertieft, vgl. Eviatar Zerubavel, The seven day circle: the history and meaning of the week (Chicago: University of Chicago Press, 1989); Eviatar Zerubavel, »The standardization of time: A sociohistorical perspective«, American Journal of Sociology 88, Nr. 1 (1982): 1-23. 
»Thus, the social function of time reckoning and designation as a necessary means of co-ordinating social activity was the very stimulus to astronomical time systems, the introduction of which was made imperative by the inadequacy of local systems with the spread of contact and organized interaction and the resulting lack of uniformity in the rhythms of social activities. $\ll^{95}$

Ausgehend von einem Grundverständnis von Zeit als einem »social fact «" ${ }^{96}$ sehen Sorokin und Merton schließlich in den zeitlichen Maßeinheiten von Wochen, Monaten und Jahren keine natürlichen Einheiten, sondern im tieferen Sinne soziale Konstrukte, deren symbolischer Wert stärker sei als deren empirischer. ${ }^{97}$ Ihre Studie eröffnete in Anschluss an Durkheim eine wichtige Perspektive zum Verständnis der zahlreichen Dimensionen sozialzeitlicher Ordnungen, die noch anderer Stelle dieses Kapitels Erwähnung finden werden.

Neben diesen genannten Klassikern der sozialwissenschaftlichen Zeitforschung entstand der wohl bislang größte Theoriekomplex im Rahmen Niklas Luhmanns moderner Systemtheorie. Die Zeit bildet darin nicht allein den eigentlichen Erkenntnisgegenstand (wie etwa in der Philosophie), sondern wird als qualitative Erklärungsgröße und Rahmen systemtheoretischer Fragestellungen eingesetzt. Sie wird in Luhmanns Schaffen zum fundamentalen Gegenstand sozialwissenschaftlicher Theoriebildung erklärt und als fortwährender Prozess der »Interpretation der Realität im Hinblick auf eine Differenz von Vergangenheit und Zukunft ${ }^{98}$ definiert, der das systematische Orientierungsparadigma moderner Gesellschaften begründet. Das von Luhmann postulierte Strukturprinzip der »funktionalen Differenzierung« führt unter temporalanalytischen Gesichtspunkten betrachtet unter anderem dazu, dass die aus der Differenzierung resultierenden gesellschaftlichen Teilsysteme zunehmend eigene Zeitstrukturen entwickeln würden. ${ }^{99}$ Mit dem Aufkommen der bürgerlichen Gesellschaft zwischen dem 17. und 19. Jahrhundert hätten sich die Zeitstrukturen dabei nicht nur vervielfältigt, sondern sich insgesamt »drastisch in Richtung auf höhere Komplexität verändert « ${ }^{100}$ und würden seitdem dauerhaft auf jede soziale Struktur und Begrifflichkeit einwirken. Luhmann beschreibt diesen Modernisierungsprozess der zunehmenden funktionalen Differenzierung als einen Prozess, der mit einer fortlaufenden Temporalisierung von Komplexität einhergeht. Die der steigenden Differenzierung inhärenten Komplexitätssteigerungen würden demnach nur kompensiert werden können, indem nicht alle Entscheidungen gleichzeitig getroffen, sondern Entscheidungen in unterschiedlichen gesellschaftlichen Teilbereichen (insbesondere in Organisationen) in sequentielle Folgen verlagert werden, um noch zielorientiert bearbeitet werden zu können. Zeitaspekte

95 Sorokin und Merton, »Social time: A methodological and functional analysis«, 628.

96 Ebd.

97 Vgl. ebd., 619, 624f.

98 Niklas Luhmann, »Die Zukunft kann nicht beginnen. Temporalstrukturen der modernen Gesellschaft«, in Vor der Jahrtausendwende: Bericht zur Lage der Zukunft, hg. von Peter Sloterdijk (Frankfurt a.M.: Suhrkamp, 1990), 124.

Niklas Luhmann, »Temporalisierung von Komplexität. Zur Semantik neuzeitlicher Zeitbegriffe«, in Gesellschaftsstruktur und Semantik. Studien zur Wissenssoziologie der modernen Gesellschaft, hg. von ders. (Frankfurt a.M.: Suhrkamp, 1980), 235-300. 
dienen für Luhmann damit als qualitative Erklärungsgröße als auch zum Indikator der wachsenden funktionalen Differenzierung hochentwickelter Gesellschaften.

Luhmanns systemtheoretische Zugriff auf den Begriff der Zeit lässt sich vor diesem Hintergrund zweifelsohne als eine der theoretischen Erklärungsmuster für die Produktion von Wartezeiten heranziehen. Da sich die systemtheoretische Betrachtung von Zeit als konstitutives Element der modernen Gesellschaft jedoch nur schwerlich auf die subjektive Erfahrungsebene von Zeit im Allgemeinen und der Erfahrung von Wartezeit im Besonderen heben lässt, kann Luhmanns Werk bezüglich der Frage nach der konkreten Ausprägung von Zeiterfahrung an dieser Stelle keine relevanten Erkenntnisse beitragen.

\subsubsection{Gesellschaftliche und soziale Funktionen der Zeit}

Die Frage nach den gesellschaftlichen und sozialen Funktionen der Zeit bildet zweifellos den elementaren Interessensschwerpunkt zeitsoziologischer Forschung, der auch für die hier im Mittelpunkt stehenden Wartephänomene zunächst der Klärung bedarf. Exemplarisch soll zur Beantwortung dieser Kernfrage Norbert Elias' 1984 erschienenes Werk »Über die Zeit« herausgehoben werden, das im Rahmen seiner allgemeinen Zivilisationstheorie entstand. Ernüchtert von den klassischen philosophischen Erklärungsangeboten zum Zeitphänomen, die aus Elias' Sicht entweder dem Objektivismus oder dem Subjektivismus zuzurechnen sind, ${ }^{101}$ zielt seine Analyse darauf ab, die Zeit zuvorderst in ihrer Funktion als soziales Symbolsystem ins Licht zu rücken, das jedoch zugleich Bezüge zum physikalisch-mathematischen Zeitbegriff aufweist. Die Zeit ist für ihn - in Analogie zu Durkheim - folglich weder apriorische Gegebenheit des menschlichen Geistes, noch eigenständige Naturgröße, denn, so Elias, »Wo immer man mit >Zeit operiert, sind in der Tat immer Menschen in ihrer `Umwelt‘, also soziale und physikalische Abläufe zugleich im Spiel. « ${ }^{102}$ Mittels der Zeit werden in erster Linie funktionale und soziale Bedürfnisse befriedigt, die historischen Wandlungsprozessen unterliegen und infolgedessen rekonstruiert bzw. - im Sinne der Überwindung einer irreführenden >Verrätselung der Zeit - dechiffriert werden sollten. Entgegen jener vorherrschenden >Verrätselungく legt Elias den Fokus seiner wissenssoziologischen Untersuchung daher auf die Orientierungs- und Regulierungsfunktionen der Zeit, kurz, ihren instrumentellen Charakter. Für ihn ist das menschliche Zeitverständnis Ausdruck einer menschlichen Syntheseleistung, die nur aus bestimmten sozialen Entwicklungen heraus zu verstehen ist. Diese Syntheseleistungen werden aus dem Motiv heraus durchgeführt, um durch Zeitbestimmungen Positionen und Abläufe vergleichbar zu machen, die ohne jene Bestimmung im unaufhörlichen Fluss der Geschehensabfolgen schlichtweg nicht vergleichbar wären oder sich nicht nebeneinanderstellen ließen. Der Mechanismus jeder Zeitbestimmung besteht demnach darin, dass dem unaufhörlich schwindenden Fluss der Ereignisse eine zweite Geschehensabfolge in Form eines standardisierten

101 Elias moniert: »Das Problem der Zeit erscheint häufig als ein Problem der Physiker und der Metaphysiker. Dadurch hat man beim Nachdenken über die Zeit den Grund unter den Füßen verloren.« Elias, Über die Zeit, 17. 
Bezugssystems mit wiederkehrenden Ablaufmustern (z.B. Bewegungen von Himmelskörpern durch einen bestimmten Punkt oder Zeigerbewegungen durch einen Punkt auf dem Ziffernblatt) gegenübergestellt wird, der die endlose Folge des Nacheinanders gewissermaßen reinfängt . Ausgehend von der Funktionsweise der Zeitbestimmung definiert Elias die Zeit wie folgt:

»Der Ausdruck `Zeit` verweist also auf dieses >In-Beziehung-Setzen< von Positionen oder Abschnitten zweier oder mehrerer kontinuierlich bewegter Ceschehensabläufe [z.B. durch Uhren, Kalender, Naturabfolgen, R.K.]. Die Ceschehensabläufe selbst sind wahrnehmbar. Die Beziehung stellt eine Verarbeitung von Wahrnehmungen durch wissende Menschen dar. Sie findet ihren Ausdruck in einem kommunizierbaren sozialen Symbol, dem Begriff `Zeit‘, der innerhalb einer bestimmten Gesellschaft das erlebbare, aber nicht mit Sinnen wahrnehmbare Erinnerungsbild mit Hilfe eines wahrnehmbaren Lautmusters von einem Menschen zum anderen tragen kann. $\ll^{103}$

Resultat dieses standardisierten >Einfangens kontinuierlicher Geschehensabfolgen ist die Produktion von lesbaren und kommunizierbaren Sinneinheiten, die dadurch ermöglicht wird, weil konkrete Positionsbestimmungen im ständigen >Nacheinander $<$ sozialer und natürlicher Abläufe überhaupt sichtbar und damit vergleichbar gemacht werden können. Die daraus resultierende Sinnstiftung bildet nach Elias erst die Grundlage gesellschaftlicher Kernfunktionen der Koordination und Vereinheitlichung bzw. der Synchronisation verschiedenster gesellschaftlicher Akteure. Elias verdeutlicht hierbei eindrucksvoll, dass die Zeit vornehmlich als Symbolproduzent und damit als soziales Konstrukt $\mathrm{zu}$ verstehen ist, das funktional darauf ausgerichtet ist, notwendige Orientierungen zu schaffen. Bereits die mit der erstmaligen Systematisierung von Himmelskörperbewegungen eingeleitete Frühform der Zeitmessung ist für ihn dabei nicht unabhängig von gesellschaftlicher Normierung von Bezugsabläufen zu denken. Mit anderen Worten: Zeitmessung und Zeitbestimmung erfolgten für die längste Zeit stets soziozentrisch und in symbolhafter Absicht, das soziale Leben zu organisieren. Erst mit Galilei und Newton schob sich in den sozialen Zeitbegriff ein rein physikalischer Zeitbegriff, der sich immer mehr vom sozialen und menschenzentrierten Anwendungsbezug der Zeitbestimmung loslöste und schließlich den Charakter der Zeit als einer quantifizierbaren Größe forcierte. Trotz einer seit der Neuzeit wachsenden Bedeutung des physikalischen Zeitbegriffs beantwortet Elias die Frage nach der alltagspraktischen Möglichkeit zur Wirkungsweise von Zeit wie folgt:

»Die menschengeschaffenen Symbole der sich wandelnden Ziffernblätter von Uhren, die wechselnden Kalenderdaten sind die Zeit. Es ist jetzt 13 Uhr 10. Das ist die Zeit. « $^{104}$

Die Zeitfunktion der symbolischen Orientierung mittels Syntheseleistung mit der die Positionen im endlosen Nacheinander in Beziehung gesetzt werden können, erfolgt bspw. immer genau dann, wenn wir auf die Uhr sehen. Hier zeigt sich für Elias ganz

103 Ebd., 20.

104 Ebd., 24 [Herv. i. O.]. 
unverkennbar der instrumentelle Charakter der Zeit, weshalb er mit Blick auf die sprachlich begrenzten Angebote zur Zeitbestimmung das Verb »zeiten« (analog dem englischen »timing«) vorschlägt, aus dem die aktive Tätigkeit einer Positionsbestimmung auch sprachlich klarer hervorgehen würde. ${ }^{105}$ Die zeitimmanente Funktion der Sinnstiftung mittels symbolischer Syntheseleistungen wird jedoch nicht selbstevident wirksam, sondern muss erlernt werden, wobei das Erlernen und Verinnerlichen zeitlicher Bezugsrahmen nie freiwillig, sondern für Elias im Grunde als »Fremdzwang « ${ }^{106} \mathrm{zu}$ verstehen ist. Der Zivilisationszwang der Verinnerlichung der Zeitsynchronisation würde schließlich zur »Zweiten Natur ${ }^{107}$ reifen und einen Teil des sozialen Habitus ausbilden. In diesem Sinne erweitert Elias seine oben genannte Kerndefinition der Zeit als Funktion des Zusammenlebens schließlich um die Bedingung einer erst sozial zu erlernenden Synthese. $^{108}$

Die Rekonstruktion dieser Lernprozesse ${ }^{109}$ und der auf einem zeitbezogenen Wissensschatz basierenden Handlungen führt Elias zu weitreichenden (historischen) Analysen und Vergleichen zur Entstehung von Zeitmessung und Kalenderentwicklung, die im Befund einer historisch rasant wachsenden zeitlichen Selbstregulierung und Zeitsensibilität ufern. ${ }^{110}$ Zwar würden bereits in archaischen Gesellschaftsformen zeitliche Regulierungssysteme auffindbar sein, die Affekt- und Triebimpulse zu kontrollieren vermochten, doch die zeitliche Selbst- und Fremdregulierung hochentwickelter Gesellschaften würde aufgrund der stark erweiterten gesellschaftlichen Differenzierung das primäre Symptom des Zivilisationsprozesses ausbilden. ${ }^{111}$ Die zunehmende Komplexität der Gesellschaften und die wachsenden Interdependenzketten sind dabei jedoch nicht als statisch zu betrachten, sondern erfordern eine stetige Verfeinerung der zeitlichen Synchronisationsprozesse.

Elias betonte in einem Brief an Pierre Bourdieu aus den späten 1970er Jahren, dass die Forschung über die Zeit zu den schwierigsten Aufgaben seiner wissenschaftlichen Laufbahn überhaupt zähle. ${ }^{112}$ Dennoch ist es ihm gelungen, die Komplexität der Ausbildung des menschlichen Zeitbewusstseins in nachvollziehbarer Form vom Schleier des Metaphysischen und Transzendentalen zu befreien und die intrinsischen Funktionen, Motive und Entstehungslinien der Zeit offenzulegen. Diese können und sollen hier nicht vollends aufgezeigt werden, aber bilden einen weiteren wichtigen theoretischen Bezugsrahmen für die zeittheoretische Herleitung des Wartephänomens und dessen zeitgeschichtliche Verortung in der Moderne. So ist das allgemeine Unbehagen in der Erfahrung von Wartezeiten mit Rückgriff auf Elias zum einen evolutionär durch die

\footnotetext{
105 Vgl. ebd., 58.

106 Ebd., 20.

107 Ebd., 172.

108 Vgl. Elias, Über die Zeit, 42.

109 Elias sieht in Abgrenzung traditioneller erkenntnistheoretischer Herangehensweisen den für ihn einzig fruchtbaren analytischen Zugang zum Gegenstand `Zeit< in einer auf Temporalphänomene bezogenen »Theorie des menschlichen Wissens«. Vgl. ebd., 14.

110 Vgl. ebd., 36.

111 Vgl. ebd.

112 Vgl. Inken Hasselbusch, Norbert Elias und Pierre Bourdieu im Vergleich. Eine Untersuchung zu Theorieentwicklung, Begrifflichkeit und Rezeption. (Karlsruhe: PH Karlsruhe, 2014), 254.
} 
Zunahme der zeitbezogenen Selbst- und Fremdregulation in hochentwickelten Gesellschaften zu erklären, aber auch qualitativ durch die wachsende soziale Steuerungsfunktion von Uhren auf das Zeitempfinden. Das Warten lässt sich damit im Zuge des Elias'schen Zivilisationsprozesses als eines der kritischsten temporalen Nebenprodukte extrahieren, das einerseits den analytischen Blick auf die Mechanismen der offenlegt und andererseits selbst Produkt der in komplexen Gesellschaften zuweilen limitierten Synchronisationsfähigkeit ist.

\subsubsection{Dimensionen, Ebenen und Strukturen des subjektiven und sozialen Zeiterlebens}

Ausgehend vom funktionalen Verständnis der Zeit als Symbol- und Orientierungsinstitution im sozialen Miteinander bilden Fragen nach den Dimensionen, Ebenen und Strukturen alltäglichen Zeiterlebens einen weiteren Komplex, der bis heute das Interesse sozialwissenschaftlicher Zeitforschung prägt. Als wegweisender Theoriebaustein für die Operationalisierung eines lebensweltlichen Zeitbegriffs soll hier besonders die Arbeit von Schütz und Luckmann angeführt werden, die Durkheims Konzept der sozialen Zeit um ein umfassenderes Verständnis zu ergänzen versuchten. Inspiriert durch die neuerliche Rezeption philosophisch-phänomenologischer Perspektiven von Husserl, Bergson und Heidegger plädierten Schütz und Luckmann in den späten 1970er Jahren für eine Abwendung vom naturwissenschaftlichen Zeitbegriff und argumentierten für die komplexere Vertiefung der subjektiven Zeitperspektive« Im Rahmen ihrer Aufdeckung der elementaren Strukturen des alltäglichen Erlebens als der vornehmlichen und ausgezeichneten Wirklichkeit des Menschen gliedern Schütz und Luckmann das Phänomen der lebensweltlichen Zeit in drei Dimensionen, die durch das Individuum jeweils gelebt und erfahren werden können: Weltzeit, subjektive Zeit und intersubjektive (soziale) Zeit. Die »Weltzeit« beschreibt die irreversible, lineare Fortdauer der Welt, die folglich für das Individuum unaufhaltsam, übergeordnet und nicht modifizierbar ist. Resultat des Bewusstseins über die Weltzeit ist das Realisieren der eigenen Endlichkeit und einer daran geknüpften Notwendigkeit zur aktiven Lebensplanung, die zum Grundmotiv des Daseins wird. ${ }^{113}$ Die Handlungen innerhalb der Lebensplanung können jedoch nicht gleichzeitig, sondern müssen zwangsläufig in einer zeitlichen Abfolge, im Prinzip »first things first «114 , organisiert werden. Zudem umfasst der irreversible Charakter der Weltzeit das Bewusstsein darüber, in einen geschichtlichen Kontext bzw. eine Situation hineingeboren $\mathrm{zu}$ werden, wodurch die Sozialwelt immer auch zwangsläufig als "geschichtlich« (z.B. als Erfahrung des eigenen Daseins innerhalb einer Generationenfolge) erlebt wird. ${ }^{115}$

Demgegenüber beschreibt die »subjektive Zeit« eine in Anlehnung an Husserl und Bergson thematisierte »innere« Dauer, verstanden als "zeitliche Artikulation des Bewusstseinsstroms «. ${ }^{116}$ Diese subjektive Zeit artikuliert sich nicht in homogenen Maß-

113 Hier werden Schütz' und Luckmanns Bezüge zu Heideggers »Sorgestruktur « deutlich sichtbar.

114 Alfred Schütz und Thomas Luckmann, Strukturen der Lebenswelt, (Frankfurt a.M.: Suhrkamp, 1979), 77.

115 Vgl. ebd.

116 Ebd., 80. 
einheiten, sondern nur in nicht-homogenen Größen-Einheiten des Sinns. Hiermit ist gemeint, dass die »Einheiten« der subjektiven Zeitlichkeit vielmehr aus Erfahrungen und Erwartungshaltungen bestehen, nicht aber aus messbaren Größen oder (räumlichen) Ausdehnungen. Die subjektive Zeitwahrnehmung würde somit nur im relationalen Zusammenspiel gegenwärtiger und vergangener Erfahrungen sowie antizipierter Erwartungen ausgeprägt werden und sich artikulieren können. ${ }^{117}$ Die Rhythmik der relationalen Bezugnahmen auf Vergangenheit, gegenwärtiger Impression und zukunftsbezogener Antizipation wird dabei für Schütz und Luckmann von der vorherrschenden »Bewusstseinsspannung « geprägt, die schließlich die Größenordnungen des subjektiven Zeiterlebens bestimmen. ${ }^{118}$ Diese variierende Rhythmik mag erst begründen, warum auch kleinste Zeitspannen manchmal wie eine Ewigkeit anmuten und andere wiederum nur sehr kurz. In der Folge dieser variierenden Rhythmik bzw. der »Zirkularität im Bewusstseinsstrom « müsste der Tagesablauf individuell, ergo rhythmisierend gestaltet werden. Weil sich das Bewusstseinserleben eben nicht einfach in gleichmäßig homogene Raumzeit-Elemente teilen lässt, verlaufen auch Tagesabläufe nicht linear wie die kontinuierliche Weltzeit, sondern folgen deshalb bspw. Phasen höherer oder niedriger Leistungsfähigkeit. Die theoretischen Abgrenzungen zwischen Weltzeit und subjektiver Zeit gelten als wichtige Weiterentwicklung des Durkheim'schen Konzepts einer sozialen Zeit und bilden eine Erklärungsgrundlage zum Verständnis (und zur Komplexität) menschlicher Zeiterfahrung, die nicht zuletzt auch für ein Verständnis des Erlebens von Wartezeiten äußerst wichtig erscheint.

Zusätzlich zur Gestaltung des rhythmisierten Tagesablaufs begreifen Schütz und Luckmann unter dem Topos der subjektiven Zeit aber auch die langwelligeren Zeitzusammenhänge, die sich als biografische Zeitlichkeit im »Lebenslauf « artikulieren. Hierbei wird auf die gesellschaftliche Relevanz von Zeiteinheiten rekurriert, die keine Kategorien der inneren Dauer darstellen, sondern Kategorien, die intersubjektiv ausgeformt, festgelegt und gesellschaftlich lesbar sind. Sie umfassen die formalen Strukturen von Kindheit, Reife, Alter usw., die dem Einzelnen auferlegt werden und verinnerlicht werden müssen. Dieser größere Zeitzusammenhang bildet zusammengesetzt den individuellen Lebenslauf, der dem rhythmisierten Tagesablauf übergeordnet ist, aber ebenso wie der Tagesablauf zirkulären Motiven folgt (Wochenenden, Jahre, Meilensteine). Zusammenfassend wirken im Rahmen der subjektiven Zeiterfahrung des Menschen die biografische Zeit des Lebenslaufs und die Tagesrhythmik für Schütz und Luckmann nicht getrennt voneinander, sondern in folgendem Maße wechselseitig zusammen:

»Einerseits ist die biographische Artikulation dem Tagesrhythmus übergeordnet. [...] Andererseits sind aber die Interpretationen und Entwürfe, deren Sinnspannweit der Lebenslauf ist, in den Tageslauf der inneren Dauer eingefügt. «"119

Die dritte elementare Zeitdimension der lebensweltlichen Zeiterfahrung bildet nach Schütz und Luckmann schließlich die »intersubjektive Zeit«. Sie besorgt die Synchro-

117 Vgl. ebd., 83.

118 Vgl. ebd., 84.

119 Schütz und Luckmann, Strukturen der Lebenswelt, 86 [Herv. i. O.]. 
nisation und Anpassung der einzelnen individuellen Rhythmen an die soziale Umwelt. Sei es als direkt koordinierte Synchronisation mit dem Gegenüber oder durch abstrahierte und objektivierte Formen der Synchronisation (Kalender, Uhrzeiten), nur mittels dieser Anpassungen wird überhaupt erst eine soziale bzw. gemeinsame Zeit ermöglicht.

Resümierend stellt sich demnach die lebensweltliche Zeiterfahrung nach Schütz und Luckmann im Zusammenspiel der drei Zeitdimensionen von Weltzeit, subjektiver und intersubjektiver Zeit als »temporally-structured reality « ${ }^{120}$ dar, bei der sich jedoch die Zeitdimensionen nicht vollends getrennt und berührungslos gegenüberstehen. Vielmehr wird die tatsächliche Komplexität der menschlichen Zeiterfahrung für Schütz und Luckmann als Überkreuzung jener Dimensionen gedeutet:

»Die Struktur der lebensweltlichen Zeit baut sich auf in Überschneidungen der subjektiven Zeit des Bewußtseinsstroms, der inneren Dauer, mit der Rhythmik des Körpers wie der >biologischen Zeit überhaupt, mit dem Jahreszeiten wie der Welt-Zeit überhaupt und dem Kalender, der ssozialen Zeit«. Wir leben in all diesen Dimensionen zugleich. ${ }^{121}$

Diese Feststellung mag in ihrer Universalität unbefriedigend wirken, doch sie verdeutlicht, dass nicht allein eine innere, subjektive Zeitlichkeit die Zeitstruktur der belebten Welt formt, sondern offenbar erst ihre Wechselwirkung mit gesellschaftlich ausgehandelten, übergeordneten Zeitmaßen zum Zweck der sozialen Synchronisation und Koordination.

Als im Kontext dieser Arbeit besonders interessant erscheint dabei Schütz' und Luckmanns weiterführende Feststellung, dass innerhalb der Überschneidungen der Zeitdimensionen niemals eine Gleichzeitigkeit herrschen könne, niemals absolute Kongruenz. Stattdessen würde die resultierende Inkongruenz dem Menschen folglich die unausweichliche Grundverfassung des Wartens auferlegen. Das Warten, ob in der Schwangerschaft, der Landwirtschaft oder im Heilungsprozess, verstehen Schütz und Luckmann als subjektives Korrelat der Inkongruenz verschiedener Zeitdimensionen bzw. als einen Nachweis der Notwendigkeit zur Orchestrierung der drei diagnostizierten Zeitdimensionen. Das Warten formt somit schließlich die Daseinsform in der wir »einer uns auferlegten Zeitstruktur « ${ }^{122}$ begegnen, die, wenn auch nicht dauerhaft bewusst reflektiert, das Resultat der Überkreuzung jener drei Zeitdimensionen darstellt. Diese Erkenntnis ist für die weiterführende Analyse der Wartezeit von großer Bedeutung, da mit Rückgriff auf Schütz und Luckmann argumentiert werden kann, dass Wartezeiten zwar individuell erfahren, aber zugleich erst in der Kopplung an übergeordnete Zeitregime qualitativ aufgeladen werden.

Ähnlich wie Schütz und Luckmann differenziert auch Anthony Giddens die Ausbildung von akteursbezogenen Zeitperspektiven in drei Zeitebenen: der Alltagszeit, der biografi-

\footnotetext{
120 Bergmann, »The problem of time in sociology«, 84.

121 Schütz und Luckmann, Strukturen der Lebenswelt, 75.

122 Ebd., 76.
} 
schen und der historischen Zeit. ${ }^{123}$ Die Alltagszeit umfasst die tagtägliche Bewerkstelligung primärer Routinen in Form der Synchronisation der Rhythmen von Arbeit, Freizeit, Schlafen sowie der Reproduktion und Rekonstitution sozialer Strukturen. Die biografische Zeitebene wirft die zeitliche Perspektive auf die gesamte Lebenszeit und umfasst punktuelle Abgleichsmomente bzw. daraufhin die angepasste Taktung von Alltagsroutinen in Bezug auf übergeordnete biografische Zielorientierungen. Schließlich ist das Erleben der Alltags- und Lebenszeit nach Giddens stets zudem immer in einen noch weiter übergreifenden, intersubjektiven und epochalen Kontext einer jeweiligen historischen Zeit eingebettet. Alle drei Zeitebenen - in anderer Form auch artikuliert als Dasein, durée und longue durée - müssen dabei zusammenwirken und ständig durch Narrationen harmonisiert werden.

Die Frage nach der Architektur des menschlichen Zeiterlebens beschäftigte auch Eviatar Zerubavel. Er sieht die wesentlichen Strukturelemente der Organisation des Soziallebens in der zeitbezogenen Bestimmung von Dauer (quantitative oder qualitative Zeitrahmen in denen Ereignisse stattfinden), Timing (Datierung eines Ereignisses), Tempo (Ereignisdichte) und Sequenz (Trennung in Abfolgen des Davor und Danach) sozialer Ereignisse. ${ }^{124}$ Diese Elemente wirken institutionalisiert vor allem in Form von Zeitplänen (timetables) zusammen, die für Zerubavel daher als prädestinierte Objekte zur Untersuchung der sozialen Zeitorganisation gelten. Den Prozess der aktiven Realisierung von Zeitplänen mithilfe der vier Strukturelemente bezeichnet Zerubavel als Terminisierung (scheduling), die jedoch einer Vielzahl von natürlichen (bspw. Jahreszeiten), sozialen oder moralischen (bspw. Erwartung von Pünktlichkeit) Bedingungen unterworfen ist. ${ }^{125}$

Ähnlich wie Zerubavel sieht auch Helga Nowotny die Strukturierung zwischenmenschlicher Beziehungen im strategischen Einsatz zeitlicher »Intervalle«. Sie umfassen die vielfältigen Variationen und Kombinationen von Zeit(setzungen) im Spektrum von befristen, versprechen, beschleunigen, verlangsamen und - nicht zuletzt - dem warten und warten lassen. ${ }^{126}$ Jene oft konfliktbehafteten Zeitstrategien symbolisieren die Maske mit der die Zeit im gesellschaftlichen Leben auftritt und immer neu verhandelt wird. Sie bezeugen die unablässige Suche nach dem richtigen Moment, der in Macht, Kontrolle und reale Vorteile übersetzt werden soll. Die Intervalle werden deshalb auch häufig von der Sphäre zwischenmenschlicher Beziehungen in die Sphäre der Institutionen transportiert. Die zeitliche Wahrnehmung im institutionellen Zusammenhang tritt uns - anders als die soziale Zeit - jedoch wesentlich zähflüssiger gegenüber. In diesem Zuge werden Wartezeiten zu einem wichtigen Indikator im Verständnis des Wertes von Zeit innerhalb einer Organisation, denn in ihnen zeigt sich das »Intervall« in seiner Einbettung in Machtstrukturen. ${ }^{127}$

123 Vgl. Anthony Giddens, »Time and social organization«, in Social theory and modern sociology, hg. von ders. (Stanford: Stanford University Press, 1987), 144ff.

124 Vgl. Eviatar Zerubavel, »Timetables and Scheduling: On the Social Organization of Time«, Sociological Inquiry 46, Nr. 2 (April 1976): 89ff.

125 Vgl. ebd., $91 \mathrm{ff}$.

126 Vgl. Nowotny, Eigenzeit, $147 f$.

127 Vgl. ebd., 151. Vgl. auch Schwartz, »Waiting, exchange, and power: The distribution of time in social systems $\ll$. 


\subsubsection{Evolution und Charakteristik des modernen Zeitbewusstseins}

Der vierte Leitaspekt, der für ein Grundverständnis soziologischer Theoretisierungen des Zeitbegriffs aufgezeigt werden soll, behandelt die Frage nach der Entstehung und spezifischen Charakteristik des modernen Zeitbewusstseins, das besonders stark von den Dogmen der kapitalistischen Ökonomie beeinflusst wurde und wird. Für die Beantwortung werden beginnend mit einer Typologie der Evolution des Zeitbewusstseins (Rammstedt) zwei ältere (Weber, Marx) und zwei neuere (zeit-)soziologische Hauptwerke (Rosa, Nowotny) herangezogen, die Beiträge zur Offenlegung des historischen Entstehungsprozesses liefern können bzw. Gegenwartsdiagnosen des modernen Zeitbewusstseins anstellen. Erst auf diesem kontextuellen Verständnis soll die daran anschließende Engführung auf die historische Analyse verkehrsinduzierter Wartephänomene aufsetzen.

Wie hat sich das Verständnis von Zeit auf dem Weg in die Moderne entwickelt? Otthein Rammstedt unterscheidet in einem 1975 erschienenen, weit rezipierten Aufsatz idealtypisch vereinfacht vier Zeitbewusstseinsformen, die sich evolutionär ausbreiteten und jeweils mit korrespondierenden Formen der rationalen Zeiterfahrung einhergingen:

1) Einfache und funktional noch nicht ausdifferenzierte Gesellschaften besitzen ein »occasionales Zeitbewusstsein«, bei dem die rationale Form der Zeiterfahrung tendenziell nur zwischen einem `Jetzt « und einem >Nicht-Jetztく unterscheidet. Zeit wird dabei nicht als kontinuierlich messbare Bewegung verstanden, sondern wals erlebte Folge von nicht-kontinuierlichen Ereignissen. ${ }^{128}$ Das Zeitbewusstsein setzt sich demnach aus nicht-alltäglichen, zeitlich großräumigen Ereignissen zusammen, wodurch Zukunft, Gegenwart und Vergangenheit nicht scharf voneinander getrennt werden, sondern vergangene und zukünftige Ereignisse in einer gestreckten Gegenwart gleichwertig integriert werden. Synchronisationen unabhängig voneinander stattfindender sozialer Handlungen werden im occasionalen Zeitbewusstsein archaischer Gesellschaften unmöglich, da keine gesetzmäßige (numerische) Abfolge von Zeitveränderungen ermöglicht wird. Vielmehr bleibt die ausgeweitete Gegenwart das einzig denkbare Zeitsystem, da die Form der Zeit immer an einen konkreten Inhalt gebunden bleibt. Da ein occasionales Zeitbewusstsein den Naturabläufen kein eigenständiges Bezugssystem gegenüberstellt, können gesellschaftliche Veränderungen noch nicht von Veränderungen der natürlichen Umwelt unterschieden werden.

2) Segmentäre, früh ständische Gesellschaften (wie etwa die Stadtstaaten der griechischen Antike) zeigen nach Rammstedt die tendenzielle Dominanz eines »zyklischen Zeitbewusstseins« auf. In diesem würde die Zeit infolge der Messung immer gleicher Bewegungen als Kreislauf stets wiederkehrender Prozesse erfahren werden.

128 Otthein Rammstedt, »Alltagsbewußtsein von Zeit«, Kölner Zeitschrift für Soziologie und Sozialpsychologie 27, Nr. 1 (1975): 50. 
Zwar erfolgt dabei eine grundsätzliche Differenzierung in ein >Vorher und >Nachher , doch Vergangenheit und Zukunft sind darin strukturgleich, weil die Erinnerung an die Vergangenheit der Vorhersage der Zukunft entspricht, sodass Erfahrungsraum und Erwartungshorizont faktisch deckungsgleich sind. ${ }^{129}$ Der Mensch des zyklischen Zeitbewusstseins erfährt sich noch eins mit den Naturrhythmen. Er erfährt noch keine Subjekt-Objekt-Spaltung, keine reflektierende Distanzierung vom Sein. ${ }^{130}$

3) In einem dritten evolutionären Schritt der Zeitbewusstseinsausbildung brachten die seit der Neuzeit stärker ausdifferenzierten Gesellschaftsformen nach Rammstedt ein »lineares Zeitbewusstsein mit festgelegter Zukunft« hervor. Zeit wird darin als ein irreversibler und progressiver Ablauf auf ein finales teleologisches Ziel hin erfahren bzw. als Linie aus der Vergangenheit durch die Gegenwart in die Zukunft (Zeitpfeil-Logik). Die Ungerichtetheit des zyklisches Zeitbewusstseins erhält mit der Linearzeit nun eine eindeutige (Ziel)richtung. Vergangenheit, Gegenwart und Zukunft werden dabei erstmals zu dominanten Differenzierungsgrößen und prägen entsprechend die Zeiterfahrung. Die temporale Differenzierung wird nicht zuletzt deshalb konstitutiv, weil durch sie erst der Fortschritt zur Erreichung des Telos erfahrbar gemacht werden kann $^{131}$ bzw. erst eine »Synchronizität allen Geschehens als gleichzeitige Ungleichzeitigkeit im Hinblick auf das gemeinsame Ziel $\aleph^{132}$ organisiert werden kann. Als charakteristisch für das lineare Zeitbewusstsein mit festgelegter Zukunft sieht Rammstedt den erstmaligen Zwang zur Verinnerlichung der Zeitrechnung bzw. der Uhrzeit, um strukturierend auf das Erreichen des gesellschaftlichen Ziels einzuwirken. So erfolgt erstmals eine genaue Einordung aller Ereignisse an einen bestimmten Ort und in einem bestimmten Verhältnis zueinander. Stellvertretend für die linear-teleologische Zeitauffassung gelten etwa der Marxismus (Errichtung des Sozialismus) oder das Christentum (Erlösung).

4) Für die Hochmoderne mit ihren funktional stark ausdifferenzierten Gesellschaftsformen attestiert Rammstedt schließlich ein »lineares Zeitbewusstsein mit offener $\mathrm{Zu}$ kunft«. Hierbei ist der Ausgang der Zukunft nicht mehr auf ein gemeinsames Ziel ausgerichtet, sondern die Zukunft bleibt offen und ist dadurch permanent ungewiss. Zeit wird zum leeren objektiven Medium, in das beliebige Inhalte einsortiert werden können. Durch das damit erhöhte »Möglichkeitspotenzial« der Zukunft

129 Vgl. Rosa, Beschleunigung: die Veränderung der Zeitstrukturen in der Moderne, 27.; dazu auch vgl. Reinhart Koselleck, Vergangene Zukunft: zur Semantik geschichtlicher Zeiten (Frankfurt a.M.: Suhrkamp, 2000).

Vgl. Gloy, Philosophiegeschichte der Zeit, 29.

131 Gloy verdeutlich in Ergänzung zu Rammstedt die Weiterentwicklung der »Linearzeit « um eine reflexive Messbarkeit des Fortschritts mit folgender Feststellung: »Während die zyklische Zeit qualitativ bestimmt war und sich die Zeitgestalten in qualitativer Hinsicht unterschieden, erlaubt die unendliche, homogene, kontinuierliche Struktur der Linearzeit deren durchgängige Quantifizierung.«, ebd., 30 . 
(es gibt sozusagen mehrere mögliche `Zukünfte`) steigt zugleich die Gegenwartsbezogenheit, denn die Zukunft entscheidet sich quasi (bereits) in der Gegenwart durch eine Selektion der zukunftsrelevanten Möglichkeiten. Ferner wird anders als im teleologischen Zeitbewusstsein akzeptiert, dass es ein Nebeneinander mehrerer Wirklichkeiten bzw. Zielstellungen gibt, was insgesamt zu einer massiven Komplexitätssteigerung des Systems führt. Entscheidend für die Zeiterfahrung jener modernen Gesellschaftssysteme ist nun, dass das Handeln weniger auf ein teleologisches Ganzes ausgerichtet werden muss. Das Resultat sind eine Individualisierung bzw. Privatisierung der modernen Zeiterfahrung sowie die Ausbildung eines immanenten Veränderungsdrangs bis hin zur Entfremdung des Zeitbewusstseins.

Rammstedt zeigt mit der diachronen Systematisierung von vier Zeitbewusstseinsformen, dass die Zeit keineswegs epochenübergreifend ein natürlicher Bestandteil von Gesellschaften war, sondern dass Formen von Zeitbewusstsein mit stark variierenden Auffassungen über Rationalität korrelieren. Zeitbewusstsein und Zeitwahrnehmung stellen danach in höchstem Maße kulturabhängige Größen dar, die sich mit der jeweiligen Sozialund Wirtschaftsstruktur laufend verändern können und ihren Niederschlag vor allem im sich wandelnden Sprachgebrauch über Zeit hinterlassen. Wie jede idealtypische Generalisierung hat auch Rammstedts Darstellung der evolutionären Veränderungen des Zeitbewusstseins jedoch ihre Problemlagen, doch seine Typologie verdeutlicht dennoch, dass innerhalb einer Epoche keineswegs entweder alleinig zyklische oder lineare Zeitvorstellungen vorherrschen müssen, sondern er betont, dass diese jeweils nebeneinander bzw. - nach Ansicht Nowotnys - auch ineinander ${ }^{133}$ existieren können. So können auch in hochmodernen Kulturen occasionale Zeitbewusstseinsformen auftreten, etwa unter dem Einfluss von Drogen oder in existenziell bedrohlichen Extremsituationen, in denen sich der lineare Zeitfluss zum Eindruck des Stillstandes wandeln kann. Hierzu zählen mitunter auch Momente des langen Wartens.

Wenngleich das Zeitbewusstsein aus Sicht Rammstedts (als auch zuvor von Durkheim) strikt als kulturabhängige Größe verstanden werden muss, erscheint die Aufgabe der Ausbildung eines wie auch immer gearteten gesellschaftlichen Zeitbewusstseins generell als alternativlos. ${ }^{134}$ Die Bestimmung eines spezifischen gesellschaftlichen Zeitbewusstseins kann allein deshalb nicht umgangen werden, weil mit ihm das sich anthropologisch manifestierte Grundbedürfnis einhergeht, »die wahrgenommenen Veränderungen zeitlich zu ordnen und als zeitlich geordnet zu betrachten. ${ }^{135}$ Welche der idealtypischen Formen auch vorherrschen mögen, jede Zeitbewusstseinsform entspricht für sich genommen also dem menschlichen Ur-Bedürfnis nach subjektiver wie kollektiver Sinnstiftung.

133 Nowotny sieht einen uralten und zugleich unrealistischen Dualismus des Denkens über Zeit in entweder geraden Linien oder wiederkehrenden Bewegungen, doch konstatiert: 》]ede Konzeption von Zeit muß die Idee des irreversiblen Wandels unterbringen und die Idee der Wiederholung." Nowotny, Eigenzeit, 59.

Rammstedt bezeichnet die Relevanz der Ausprägung eines Zeitbewusstseins gar als »Ideologie des sozialen Geschehens«, Rammstedt, »Alltagsbewußtsein von Zeit«, 59. 
Rammstedt folgend bewegt sich das Zeitbewusstsein der westlichen Moderne - und somit auch der raum-zeitliche Bezugsrahmen dieser Arbeit - entsprechend im Modus einer »linearen Zeitlogik mit offener Zukunft«. Wodurch ist diese vorherrschende Beziehung des Menschen gegenüber der Zeit aber im Detail charakterisiert und woraus hat sich dieses bis heute noch grundlegend wirksame Zeitverständnis historisch entwickelt? Eine Analyse gesellschaftstheoretischer Standardwerke soll im Folgenden die Grundzüge jener Charakteristik ausfindig machen.

\section{Karl Marx}

Einen der frühsten Zugänge zur Beantwortung der Frage nach Evolution und Charakteristika des modernen Zeitbewusstseins eröffnet zweifelsohne Karl Marx' geschliffene Analyse der kapitalistischen Produktionsweise. Marx' Lebenswerk der kontinuierlichen Entzauberung des Kapitalismus als angeblicher Naturgesetzlichkeit und Naturgegebenheit erschließt den Faktor Zeit explizit als analytische Größe zur Bestimmung des Wertes einer Ware. Die Zentralität der `Zeit`verdeutlicht sich für Marx bereits im ersten Band seines dreiteiligen Kompendiums über das Kapital im Zusammenhang der Bestimmung eines Warenwerts:

»Ein Cebrauchswert oder Gut hat also nur einen Wert, weil abstrakt menschliche Arbeit in ihm vergegenständlicht oder materialisiert ist. Wie nun die Cröße seines Werts messen? Durch das Quantum der in ihm enthaltenen `wertbildenden Substanz Arbeit. Die Quantität der Arbeit selbst mißt sich an ihrer Zeitdauer, und die Arbeitszeit besitzt wieder ihren Maßstab an bestimmten Zeitteilen, wie Stunde, Tag usw. ${ }^{136}$

Nach Marx' Auffassung ist die Substanz eines jeglichen Wertes durch die sich darin kristallisierte Arbeit definiert. Als Größenmaß dieser Arbeitsleistung dient wiederum die Arbeitszeit. Der Faktor der (Arbeits-)Zeit wird in Marx' Werk folglich gleichbedeutend mit dem Wert eines Gutes, denn der Wert eines Gutes bemisst sich allein an der Zeit, die für dessen Produktion benötigt wurde. Ausgehend von jener Grundüberlegung, dass jegliche Warenwerte "nur bestimmte Maße festgeronnener Arbeitszeit « ${ }^{137}$ sind, wird (Arbeits-)Zeit in der marxistischen Theorie neben Kapital, Boden und Arbeit folglich zum Produktionsfaktor und zu einer indirekten Leitperspektive marxistischen Denkens.

(Arbeits-)Zeit wird aber nicht nur zum Indikator bzw. zur Bemessungsgrundlage eines Warenwertes, sie selbst wird auch zum aktiven Wettbewerbsfaktor, denn Zeitgewinne versprechen im ökonomischen System des Kapitalismus in direkte Marktvorteile umgewandelt werden zu können. Jene Gesetzmäßigkeit erklärt für Marx den für die Moderne so charakteristischen Drang nach technischen Beschleunigungsinnovationen, denn mit jeder Beschleunigung werden permanent wettbewerbliche Verbesserungen assoziiert. Resultat dieser zeitgebundenen Triebbewegung bildet für Marx die disruptive Erfahrung des späten 18. und vor allem des 19. Jahrhunderts in dem alles »Ständische

136 Karl Marx und Friedrich Engels, Das Kapital-Kritik der politischen Ökonomie (Erstes Buch: Der Produktionsprozeß des Kapitals) (Berlin: Dietz Verlag, 1962), 53.

137 Ebd., 54. 
und Stehende in Auflösung « und alles Heilige dem Stadium seiner Entweihung begriffen sei. ${ }^{138}$

Hochrelevant für die subjektzentrierte Zeiterfahrung in der Moderne ist hier Marx' Analyse, dass mit der Verinnerlichung der zeitlichen Logik im Bereich der Produktionsarbeit eine Unterwerfung des Proletariats unter das Zeitdiktat der Maschinen verbunden sei. Die Umwälzung der Produktionsprozesse von handwerklicher (Manufaktur) auf maschinelle Arbeitsweisen (Fabrik) ließ die Maschine zum Dreh- und Angelpunkt der Tätigkeiten der Arbeiterklasse werden. Die Maschine wurde dabei nicht nur »zum systematisch angewandten Mittel, mehr Arbeit in derselben Zeit zu erpressen «, sie bewirkte bzw. erzwang zudem erstmals in der Geschichte eine an die kontinuierliche und gleichförmige Bewegung der Maschine angepasste und zeitdisziplinierte Arbeitsweise. ${ }^{139}$ Auch wenn die aus der Maschinenarbeit resultierende Beschleunigung des Lebenstempos der Arbeiterklasse eher ein untergeordneter Nebenaspekt der marxistischen Theoriebildung bleibt, werden etwa mit der Verdichtung und Intensivierung der Arbeitszeit (im Resultat der Einführung des Normalarbeitstages) zeitrelevante Aspekte angeführt, die aufgrund ihrer lebensweltlichen Reichweite wohl zweifellos ein Grundcharakteristikum der modernen Zeiterfahrung seit dem frühen 19. Jahrhundert begründet haben dürften.

Zusammenfassend wird Zeit im Rahmen des marxistischen Theoriegebäudes von Wertschöpfungs- und Wettbewerbsmechanismen erstmals zum knappen Gut und zur Ressource erklärt. Charakteristisch für das Zeitbewusstsein der Moderne ist mit Rekurs auf Marx also eine durch die ökonomische Ordnung des Kapitalismus evozierte Zentralität der Zeit im Produktionsprozess, die sich von der Rhythmisierung des Lebens in definierte Arbeitstaglängen, über einen Zwang der Arbeiterschaft zur Verinnerlichung der Uhrzeit und sich im Kontext der >Produktion von relativem Mehrwert $<$ bis hin zur »Zusammenpressung einer größren Masse Arbeit in eine gegebene Zeitperiode ${ }^{140}$ staffelt.

\section{Max Weber}

Weitere Antworten zur Frage nach den Besonderheiten des modernen westlichen Zeitbewusstseins lassen sich aus Max Webers prominenten wissens- und religionssoziologischen Ausführungen zum historisch gewachsenen Zusammenhang zwischen den ethisch-religiösen Grundmotiven des Protestantismus und der Ausprägung eines »kapitalistischen Geistes « gewinnen. In Ergänzung zu Marx' reflektierender Denktradition zum Kapitalismus erkennt Weber als konstitutives Charakteristikum des Kapitalismus, aber auch der modernen Kultur überhaupt, eine aus der christlichen Askese geborene »rationale Lebensführung «. ${ }^{141}$ Im Übergang vom Mittelalter zur Neuzeit, so arbeitet Weber mithilfe der Analyse von Arbeiten führender protestantischer Theologen des 16. und 17. Jahrhunderts heraus, hätten sich die vormals innerweltlichen Ansätze der Askese (z.B. das Klosterleben) allmählich in einen nach außen getragenen Utilitarismus

138 Karl Marx und Friedrich Engels, »Manifest der Kommunistischen Partei«, in Karl Marx und Friedrich Engels, Werke (Berlin: Dietz Verlag, 1972), 465.

139 Vgl. Marx und Engels, Das Kapital, 433f.

140 Ebd., 432.

141 Vgl. Max Weber, Die protestantische Ethik und der»Ceist «des Kapitalismus (Wiesbaden: Springer VS, 2016), 170. 
aufgelöst und eine neuartige »Berufsethik« begründet, die in der »Berufsarbeit« das höchste asketische Mittel schlechthin sah. Abweichend vom Katholizismus erhielt die weltliche Alltagsarbeit im Zuge des Protestantismus somit eine zutiefst religiöse Bedeutung, welche die rationale Ausübung des »Berufs« als das

»einzige Mittel Gott wohlgefällig zu leben, nicht eine Überbietung der innerweltlichen Sittlichkeit durch mönchische Askese, sondern ausschließlich die Erfüllung der innerweltlichen Pflichten kennt, wie sie sich aus der Lebensstellung des einzelnen ergeben, die dadurch eben sein Beruf $«$ wird. $\ll^{142}$

Zeit erhält im Zuge dieser Entwicklung eine indirekt zentrale Bedeutung. Das Resultat der Ausbildung der historisch beispiellosen Berufsethik (insbesondere in Person des kapitalistischen Unternehmers) besteht unter anderem in einer >Ökonomisierung der Zeit<, die jedoch weniger existenziell als vielmehr religiös begründet wird. Die religiöse Motivlage für die Wahrnehmung der Zeit als ökonomischem Wert ist für Weber daraus zu erklären, dass, allen voran die Strömung des Calvinismus, in der möglichst rationalen und berufsmäßigen Mehrung des (privaten) Reichtums analog auch eine anzustrebende Mehrung des Ruhmes Gottes sah. Die Zielsetzung der ins Weltliche transferierten asketischen Lebensführung bildete demzufolge das größtmögliche >Erwirtschaften göttlichen Ruhmes innerhalb der gegebenen Begrenztheit der eigenen Lebenszeit. Als wesentliches Charakteristikum der modernen Zeiterfahrung ist mit Bezug auf Weber folglich eine Grunderfahrung der Zeitknappheit zu nennen. Diese Knappheit besteht zum einen aufgrund der Wahrnehmung der eigenen Endlichkeit, mehr noch aber aufgrund des skizzierten protestantischen Heilsversprechens, dessen Erfüllung direkt an den Grad der perfektionierten Berufs-Rationalität geknüpft wurde. Die für den Kapitalismus konstitutive sozialethische Verpflichtung des Einzelnen zu möglichst rationaler Berufsarbeit erzwang somit förmlich eine stärkere Bewusstwerdung der Zeit.

Je mehr nun die rastlose, stetige, systematische und zeitdisziplinierte Berufsarbeit zum religiösen Dogma des Protestantismus wurde, desto stärker formierte sich das korrespondierende Dogma der Vermeidung jeglicher Verschwendung von Zeit. Mit Rekurs auf die Direktiven calvinistischer Theologen vermerkt Weber:

»Die Zeitspanne des Lebens ist unendlich kurz und kostbar, um die eigene Berufung ,festzumachen<. Zeitverlust durch Ceselligkeit, ,faules Gerede<, Luxus, selbst durch mehr als der Cesundheit nötigen Schlaf -6 bis höchstens 8 Stunden - ist sittlich absolut verwerflich. ${ }^{143}$

Insbesondere der Calvinismus verachtete die Zeitvergeudung als »erste und prinzipiell schwerste aller Sünden. ${ }^{144}$ Äquivalent zur Ausbildung des Imperativs zum Handeln und zum aktiven Tun im Beruf werden in der protestantischen Berufsethik Kontemplation $^{145}$ und Müßiggang nicht nur rechtfertigungspflichtig, sie werden als Gefahr für

142 Ebd., 64 [Herv. i. O.].

143 Ebd., $143 f$.

144 Weber, Die protestantische Ethik, 143.

145 Kontemplation ist für die protestantische Berufsethik niemals als Selbstzweck zulässig, denn »sie ist Cott minder wohlgefällig, als das aktive Tun seines Willens im Beruf.« Ebd., 144f. [Herv. i. O.]. 
die methodische Systematik der Lebensführung und schließlich gar strafend als »Symptom fehlenden Gnadenstandes $\ll^{146}$ nach Ableben des Einzelnen eingestuft. Zeit wird somit im protestantischen Europa der Neuzeit erstmals offen zum kostbaren Gut bzw. zum spirituellen Wert stilisiert, »weil jede verlorene Stunde der Arbeit im Dienst des Ruhmes Gottes entzogen ist. ${ }^{147}$ Weil Zeit >kostbar ist, kann sie nunmehr auch >verloren werden. Um Zeitverschwendungen, etwa durch Kontemplation, zu verhindern, besteht ein weiteres zeitrelevantes Charakteristikum der protestantischen Berufsethik folglich im Zwang zur ständigen Überprüfung der eigenen Leistung gegen einen artifiziellen Referenzrahmen, der in Form der Uhrzeit stark an Bedeutung gewinnt. Weber sieht dabei in der zunehmend engeren Taktung von Schlägen der Kirchturmuhren im Viertelstundentakt eine neue Qualität gegenüber dem Mittelalter, in dem zwar bereits das Klosterleben durch Glockenschläge zeitlich getaktet war, dies jedoch in noch wesentlich größeren Zeiteinheiten und im Sinne des Klosterlebens. ${ }^{148}$ Demgegenüber besteht der qualitative Wandel der neuzeitlichen Taktverdichtung darin, dass damit das Maß der kapitalistischen Entwicklung selbst gemessen wird. Mit anderen Worten: Die Zeit transformiert sich zu einem von der menschlichen Erfahrung stärker abgetrennten Abstraktionslevel, in dessen Folge die Zeit dem Menschen nicht mehr dienen, sondern ihn zunehmend diktieren würde.

Zusammenfassend wird mit Webers historischer Analyse deutlich, wie eng das moderne Zeitbewusstsein an das jeweilig vorherrschende ökonomische Prinzip geknüpft und dieses wiederum - im Unterschied zu marxistischen Interpretationen - seinen Ursprung in religiösen Motivlagen findet. Webers Absicht bestand dennoch dezidiert nicht darin, eindeutige Kausalitäten zu belegen, vielmehr lag seine Absicht darin, eine sich gegenseitig bedingende Koevolution zwischen Protestantismus und der Herausbildung des >kapitalistischen Geistes` aufzuzeigen. Die Kennzeichen dieses durch den >kapitalistischen Geist ‘ geprägten und bis heute wirksamen Zeitbewusstseins liegen in einer erzwungenen Verinnerlichung der Uhrzeit, der intensiven Sensibilität des Zeitflusses, der Wahrnehmung der Begrenztheit und Knappheit von Zeit sowie in der sich daraus ergebenden handlungspraktischen Prämisse ihrer möglichst rationalen Nutzung. Affektkontrolle, Selbstbeherrschung und nicht zuletzt Zeitdisziplin. Sie bildeten aus Webers Sicht zusammengenommen die Grundpfeiler einer methodisch reglementierten Lebensführung, in der die rationale Lebensführung zur Existenzberechtigung des Menschen erklärt wurde. Die Zeit wurde damit im Zuge der protestantischen Berufsethik zur relationalen und zugleich das eigene und das Sozialleben disziplinierenden Größe, die sich in ih-

146 Ebd., 148.

147 Ebd., 144.

148 Zur Einführung von Uhrwerkmechanismen im klösterlichen Leben bemerkt der Historiker Cerhard Dohrn-van Rossum, dass das bloße Vorhandensein der frühen Uhrwerke allein noch keine Revolution des Zeitbewusstseins bedingt habe. Trotz einer gewissen Zeitstruktur war und blieb das Klosterleben auch nach Einführung von (oftmals notorisch unzuverlässigen) Uhrwerken zeitlich ungleich und elastisch. Idealisierte Vorstellungen eines durch Uhren organisierten Klosterlebens als »Uhrwerk-Cemeinschaften« seien daher unsinnig und stellten lediglich moderne Rückprojektionen dar. Cerhard Dohr-van Rossum, »Schlaguhr und Zeitorganisation«, in Im Netz der Zeit: menschliches Zeiterleben interdisplinär, hg. von Rudolf Wendorff (Stuttgart: S. Hirzel, 1989), 49-60. 
ren immer feineren Maßeinheiten immer mehr von sozialen Bedürfnissen abzutrennen und dafür als Entwicklungsmesser zu verselbstständigen schien.

Entscheidend für die alltags- und lebensweltliche Erfahrungswelt der Moderne ist dabei Webers abschließende Diagnose, dass die Strahlkraft und Expansion dieses für die Produktivität katalytischen Heilsversprechens keineswegs allein auf das Unternehmertum beschränkt blieb, sondern sich der Imperativ des puritanischen Geistes auf den modernen Menschen generell ausgebreitet und »den Lebensstil aller einzelnen (...) nichtnur den der direkt ökonomisch Erwerbstätigen « ${ }^{149}$ geprägt hätte. Trotz des Verblassens ehemals religiöser Motive hinter der weltlichen Berufsarbeit, übertrug sich die dogmatische Pflicht zur Behandlung der Arbeit als >Beruf gleichsam von Unternehmern auf die gemeine Arbeiterschaft. In der Konsequenz wurde Zeit in kapitalistischen Gesellschaftsformen fest und quasi-religiös als knappe Ressource internalisiert, die möglichst von allen Akteuren produktiv genutzt werden muss. ${ }^{150}$ Die dem Kapitalismus inhärente Zielstellung der maximalen Akkumulation von Reichtum umschreibt Weber mit seiner berühmten Metaphorik der verhängnisvollen Ausprägung eines »stahlharten Gehäuses «151 , das zwar im Laufe der Zeit seiner religiösen Grundmotivation beraubt wurde, aber dennoch nicht verlassen werden könne. Mit anderen Worten: Es gibt für Weber schlichtweg keine kulturelle Alternative zum (zeitsensitiven) Rationalismus.

Weber stellt ernüchtert fest, dass »die Sorge um die äußeren Güter dieser Welt zunehmende und schließlich unentrinnbare Macht über den Menschen, wie niemals zuvor in der Geschichte ${ }^{152}$ entwickelt habe, so sind damit nicht nur materielle Güter oder Kapitalbildung gemeint, sondern nicht zuletzt ist es doch auch die Zeit selbst, die zu einem äußeren Gut der Welt emporstieg und sich verselbstständigte. Auch wenn Weber die >Vergesellschaftung des `kapitalistischen Geistes` zeitlich nicht genauer eingrenzt, wird Zeit im koevolutionären Zusammenhang der sich säkularisierenden protestantischen Berufsethik wohl spätestens im Übergang vom 19. ins 20. Jahrhundert zu einem gesamtgesellschaftlichen Problem.

\section{Hartmut Rosa}

Webers Diagnose der Rationalisierung auf Grundlage einer asketischen Berufsidee beschreibt ein konstitutives und epochal auf individueller wie institutioneller Ebene wirkmächtiges Element des Modernisierungsprozesses. Die Zeit bleibt für Weber darin jedoch insgesamt nur sekundäre Beschreibungsebene der Veränderungsprozesse. Einen dezidiert temporalanalytischen Blick auf die Modernisierungsprozesse nimmt stattdessen Hartmut Rosa ein. Ausgehend von der Überzeugung, dass Modernisierung »nicht nur ein vielschichtiger Prozess in der Zeit ist, sondern zuerst und vor allem auch eine strukturell und kulturell höchst bedeutsame Transformation der Temporalstruk-

149 Weber, Die protestantische Ethik, 171. Er vermerkt an selber Stelle, dass dieser gesamtgesellschaftliche Imperativ im Übrigen so lange wirken würde »bis der letzte Zentner fossilen Brennstoffs verglüht ist.«

Zum Imperativ der >Vergesellschaftung « der rationalen Berufsethik vermerkt Weber schlicht: »Der Puritaner wollte Berufsmensch sein, - wir müssen es.«, ebd.

151 Ebd.

152 Ebd. 
turen und -horizonte selbst beinhaltet ${ }^{153}$, rückt Rosa die den Modernisierungsprozessen innewohnende zeitliche Struktur in den Mittelpunkt. Danach finden die zentralen Modernisierungsprozesse von Rationalisierung, Differenzierung, Naturbeherrschung und Produktivkraftentfaltung nicht nur zu einer bestimmten Zeit statt, sondern lassen sich zudem hinsichtlich ihrer Veränderungsrichtung beschreiben, die nach Rosas Auffassung bestmöglich mit dem Begriff der Beschleunigung erfasst werden kann. ${ }^{154}$ Rosa unterscheidet dazu technische, soziale und kulturelle Beschleunigungsformen, die komplex und bisweilen paradox zusammenwirken und schließlich im allgemeinen Befund einer aus Subjektsicht wahrgenommenen Zeitkrise ufern. ${ }^{155}$ Symptomatisch für die charakteristische Grunderfahrung des modernen Zeitbewusstseins ist für Rosa folglich die Doppeldiagnose der generellen Beschleunigungserfahrung, also der Verkürzung von Ablösungszyklen, bei gleichzeitiger Wahrnehmung des gefühlten Stillstandes. Dies hat zur Folge, dass in der Alltagsperspektive moderner Gesellschaften ein oftmals paradoxales Grundgefühl herrscht, durch immer effizientere Prozesse Zeit in immer größeren Mengen einzusparen und doch gleichzeitig das Gefühl des chronischen Zeitmangels zu haben.

Jene Beschleunigungserfahrung, die jeglichem sozialen Wandel unterliegt, definiert Rosa als "Steigerung der Verfallsraten von handlungsorientierenden Erfahrungen und Erwartungen und als Verkürzung der für die jeweiligen Funktions-, Wert- und Handlungssphären als Gegenwart zu bestimmenden Zeiträume. ${ }^{156}$ Warum aber verfällt die Moderne dem Grundmechanismus ihrer permanenten Beschleunigung, Dynamisierung und Mobilisierung und warum wird damit die Gegenwart zunehmend als `schrumpfend « wahrgenommen? Den Grund für diese Tendenzen sieht Rosa zum einen in der moderne-immanenten Verheißung der durch Beschleunigungen erzielten »Erweiterung des Möglichkeitshorizontes«, zum anderen im Zwang des modernen Individuums, sich der hohen Dynamik der technischen, sozialen und kulturellen Umwelt in Form der eigenen Steigerungsleistung anzupassen. ${ }^{157}$ In diesem Zusammenhang diagnostiziert Rosa ein entscheidendes Grundparadox des Zusammenhangs von Zeit und Moderne:

»Die Erhöhung des >Tempos des Lebens`, die Zeitknappheit der Moderne, entsteht nicht weil, sondern obwohl auf nahezu allen Gebieten des sozialen Lebens enorme Zeitgewinne durch Beschleunigung verzeichnet werden. « $^{158}$

In Ergänzung zu Webers zentraler Moderne-Diagnose der (zeitsensitiven) Rationalisierung bleibt an dieser Stelle festzuhalten, dass die Beschleunigung von Prozessen und Ereignissen ein zweites zentrales Grundcharakteristikum des modernen Zeitbewusstseins darstellt. Es ist die Wahrnehmung, dass salles immer schneller wird ‘, die nicht minder konstitutiv ist wie das Ethos der rationalen Arbeit. Rosa untermauert an dieser Stelle, dass das Beschleunigungselement zudem nicht erst ein kulturelles Phänomen der Spät- oder Postmoderne, sondern durchaus ein Symptom in all ihren Phasen,

153 Rosa, Beschleunigung: die Veränderung der Zeitstrukturen in der Moderne, 24.

154 Vgl. ebd.

155 Ebd., $15 f$.

156 Ebd., 133 [Herv. i. O.].

157 Ebd., $13 f$.

158 Ebd., 117. 
angefangen von der ersten Beschleunigungs- bzw. Dynamisierungswelle zu Mitte des 18. Jahrhunderts über die Industrialisierung bis hin zur Gegenwart, darstellt. Somit erscheint das Prinzip der Dynamisierung der Kultur der Moderne von Beginn an inhärent $\mathrm{zu}$ sein und dies erstaunlicherweise "noch bevor es sich in ihren materiellen Strukturen bemerkbar macht. « ${ }^{159}$ So lässt sich mit Rosa das für diese Arbeit fruchtbare Substrat ableiten, dass das Zeitbewusstsein der Moderne demnach nicht nur im Kontext technisch bedingter Beschleunigungen in der Gesellschaft, sondern zudem in Form sozialer Beschleunigungsprozesse auch als Beschleunigung der Gesellschaft selbst erfahren wurde und nach wie vor erfahren wird. ${ }^{160}$

\section{Helga Nowotny}

Als vierte selektive Quelle zur Identifikation der Charakteristik des modernen Zeitbewusstseins soll Helga Nowotnys Essay »Eigenzeiten« angeführt werden, der sich der Entstehung und Strukturierung des Zeitbewusstseins widmet. Ihre sozialwissenschaftliche Analyse des Agierens mit und der Wirkung von Zeit interessiert sich dabei für die Veränderungen des Zeitbegriffes und des Zeiterlebens sowie den Konflikten im Zusammenhang mit der Zeit entlang der epochalen Transformationen von der Industriezur Informationsgesellschaft. Ein zentraler Befund Nowotnys für die hier im Mittelpunkt stehende Frage nach der Ausbildung und der Charakteristik des modernen Zeitbewusstseins besteht dabei in der durch Kommunikationstechnologien ermöglichten Erfahrung der »Gleichzeitigkeit«, die das allgemeine Zeitempfinden bis heute stark beeinflusst. Gleichzeitigkeit - verstanden als die Wahrnehmung von Ereignissen und Prozessen, die zeitgleich an entfernten Orten der Erde stattfinden - bewirkt nach Ansicht Nowotnys auf Subjektebene in historisch wachsendem Maße den Wunsch nach Erlangung von Zeitsouveränität in Form der Abgrenzung einer »eigenen Zeit« von der weltumspannenden, technisch vermittelten Gleichzeitigkeit.

Stärker als bei Rosa oder zuvor bei Elias - wenngleich sichtlich inspiriert von dessen Postulat der Zeit als einem zutiefst symbolischen Koordinations- und Ordnungsprodukt - liegt Nowotnys Schwerpunkt auf der individuellen Erfahrungsebene des Zeiterlebens, die jeder Mensch in sich trägt. Jene »Eigenzeiten« ringen aus Sicht Nowotnys seit dem 19. Jahrhundert um ihre gesellschaftliche Anerkennung im standardisierten System der intersubjektiven und unwandelbaren Weltzeit. Neben dem verinnerlichten Streben des Menschen der modernen Industriegesellschaft, sein gesellschaftliches Dasein mittels seiner (beruflichen) Nützlichkeit auszuweisen, formierte sich demzufolge parallel ein allmähliches Bedürfnis und die allmähliche Anerkennung einer sfreien Zeitgestaltung. Dieses Ringen zeigt sich etwa in Form der ersten Forderungen der Industriearbeiterschaft nach notwendigen, institutionalisierten Erholungszeiten und erstreckt sich über das bürgerliche Dogma der »Zeit im Privaten« bis hin zum massenhaften Heraustreten der subjektiven Zeiten in die Öffentlichkeit, insbesondere im Rahmen von Unterhaltungsangeboten (Kino). Interessant erscheint hierbei der Zusammenhang zwischen Gleichzeitigkeit und Herausbildung von Eigenzeiten. So führte erst die Tendenz zur prozessualen >Vergleichzeitlichung〈der Welt zur >Entdeckungく einer 
inneren, subjektiven Zeitlichkeit, zunächst in elitär-avantgardistischen Kreisen, heute jedoch gesellschaftlich übergreifend. ${ }^{161}$ Mit Blick auf den von Ulrich Beck und Martin Mulsow postulierten Bruch zwischen einer `Ersten und einer `Zweiten Moderne im Laufe des 20. Jahrhunderts erscheinen die Eigenzeiten als Prozess der Tendenz zur Singularisierung zuvor pluralisierter Prozesse und damit als eine von vielen für die Zweite Moderne charakteristischen Entdifferenzierungsprozesse. ${ }^{162}$ Der prozentuale Anteil jener »Eigenzeiten« hat im Laufe der letzten zwei Jahrhunderte stark zugenommen, jedoch folgt aus Sicht der Psychologin Schräder-Naef auch die Gestaltung der freien Zeit einer gesellschaftlich stark standardisierten Erwartungshaltung, jene Zeit möglichst >sinnvolk zu nutzen. ${ }^{163}$

Gleichwohl bleibt die Erfahrung absoluter Gleichzeitigkeit seit Bestätigung Einsteins Relativitätstheorie bereits physikalisch illusionär. Die Gleichzeitigkeit ist lediglich approximativ. Dennoch prägt sie entscheidend unsere Zeitwahrnehmung im Arbeitsalltag, im Kommunikationsverhalten und in unseren sozialen Handlungen. Sie formiert einen Anschlusszwang und einen Imperativ, der nicht wenige >Außenseiter entstehen lässt, so etwa Arbeitslose oder Entwicklungsländer, die jeweils reine andere Zeit innehaben. So bleibt die technisch evozierte Gleichzeitigkeit auch eine soziale Illusion, damit ihr eine Vielzahl neuer Ungleichheiten ausgeprägt werden. Makrosoziologisch betrachtet sei die moderne Gesellschaft folglich geprägt durch das »Vorhandensein unterschiedlicher und widersprüchlicher Formen des Bewußtseins in der gleichen Zeit « ${ }^{164}$ Resultat sei eine zeitliche Ko-Präsenz von Eigenzeiten, »die durch die Illusion und die Norm der Gleichzeitigkeit technisch zusammengehalten und doch zeitlich differenziert wird. $\ll^{165}$ So entsteht der Eindruck, dass einige Menschen scheinbar sviel Zeit und manche nur sehr wenig haben. Hier entwickelt Nowotnys temporalanalytische Gesellschaftsbetrachtung eine politische Dimension, denn das daraus resultierende wachsende Nebeneinander unterschiedlicher Eigenzeiten kann zu sozialen Spaltungen führen, bei der »weite Teile der Bevölkerung zeitlich zurückgelassen werden. « ${ }^{166}$ Benötigt wird für das gesellschaftliche Zusammenleben also nicht zuletzt auch eine Balance zwischen der Vielzahl von Eigenzeiten, kurzum, ein Konsens in Form eines zeitlichen Miteinanders. Die Balance zwischen Eigen- und Fremdzeiten kann jedoch keineswegs rein technologisch erzeugt werden: »Technologien allein«, so Nowotny, »können niemals Zeit herstellen, genauso wenig, wie dies Uhren können, die Zeit zeigen. Dazu bedarf es der Interaktion zwischen Menschen, aus der heraus Koordinationsmechanismen erwachsen, funktional instrumentell, die aber auch als symbolische Orientierungsmittel verwendet werden. ${ }^{167}$

161 Insbesondere die Psychologie und die phänomenologische Philosophie, aber auch Kunst und Literatur, zählten im Übergang vom 19. ins 20. Jahrhundert zu den Triebfedern jener >Entdeckung des von der objektiven Zeit abweichenden inneren Zeitbewusstseins. Vgl. Nowotny, Eigenzeit, 22f.; dazu zur Rolle von Kunst und Kultur Kern, The culture of time and space, 1880-1918.

162 Vgl. Ulrich Beck und Martin Mulsow, Vergangenheit und Zukunft der Moderne (Berlin: Suhrkamp, 2014), 26.

163 Vgl. Regula D. Schräder-Naef, »Zeit als Belastung?«, in Im Netz der Zeit, 21.

164 Nowotny, Eigenzeit, 35.

165 Ebd., 43.

166 Ebd.

167 Ebd., 40. 
Nowotny sieht zudem einen weiteren Einflussfaktor auf die Veränderung der Zeiterfahrung des späten 20. Jahrhunderts in einer diagnostizierten Verschiebung der Beziehung zwischen Gegenwart und Zukunft. Nowotny argumentiert dabei für ein Verschwinden der Zukunft, die in der Langzeitbetrachtung zunehmend durch die Kategorie der »erstreckten Gegenwart ${ }^{168}$ ersetzt werden würde. Damit meint Nowotny eine allgemeine Vereinnahmung der Gegenwart, bei der die Zukunft näher an die Gegenwart rücken würde, was gravierende Folgen für die Ausbildung der Zeitwahrnehmung hätte. Diese werden zusammenfassend mit einem wachsenden Zeitdruck auf die Gegenwart beschrieben, wobei Problemlösungen nicht mehr wie noch in der Neuzeit auf die Zukunft als Erwartungshorizont geschoben werden können, ${ }^{169}$ sondern zunehmend im Jetzt gefunden werden müssten. ${ }^{170}$

Nowotnys These der Vergegenwärtigung der Zukunft ${ }^{171}$ nährt zudem noch eine weitere makrosoziologische Einflussgröße auf die Zeiterfahrung: die fortschreitende Individualisierung der Zeiterfahrung und deren Fragmentierung in immer kleineren Einheiten, die sich in Kurzzeitperspektiven und einer »Sehnsucht nach dem Augenblick « niederschlagen. So wird die Zeitwahrnehmung der westlichen Welt nicht selten vom Wunsch nach einer »Uchronie«, dem Verfolgen alternativer Zeitordnungen und Zeitnutzungen, die dem Zwang der von außen aufgezwängten Zeit (sei es ausgeübt durch Organisationen oder die Gesellschaft) entgegenwirken, getragen. ${ }^{172}$ Wohl auch dem Entrinnen des Bewusstwerdens der eigenen Endlichkeit geschuldet, die sich aber nie auflösen kann.

Zusammenfassend zeichnet Nowotny ein temporalanalytisches Gesellschaftsbild, in dem die Eigenzeit (die individuelle Ich-Zeit) sich stets mit der Fremd-Zeit (der Zeit der anderen) neu arrangieren muss. Hierin würde eine Tendenz zur Sozialisierung der Eigenzeit innerhalb der Weltzeit bestehen. Zeit wird zwar zunehmend flexibilisiert, bleibt dabei jedoch eng an die soziale Zeit geknüpft, denn trotz individualisierter Zeitmuster kann sich kein Mensch aus den Zeitstrukturen lösen, die ihn mit anderen verbinden. Eigenzeit wird vielmehr erst durch die anderen ermöglicht. Zeit, verstanden als kollektives Ordnungs- und Symbolsystem, wird damit für Nowotny zum analytischen Brennglas gesellschaftlicher Veränderungsdynamiken. Die wissenschaftlich-technische Innovation bildet für sie dabei indes die größte Triebfeder für die Veränderung der menschlichen Zeiterfahrung.

Zwar thematisiert Nowotny nicht explizit die Erfahrung von Wartezeiten, dennoch lässt sich aus ihrem Befund des Zuwachses der Erfahrung von »Gleichzeitigkeit« vermuten, dass erst innerhalb dieses Prozesses die Entdeckung und Erfahrung davon abweichender Zeitlichkeiten stärker als zuvor hervortreten konnte. Mit anderen Worten:

168 Ebd., 53.

169 Vgl. Koselleck, Vergangene Zukunft.

170 Vgl. Nowotny, Eigenzeit, 54.

171 Hartmut Rosa argumentiert hier vor dem Hintergrund der primatischen Grunderfahrung sozialer Beschleunigung abweichend von einer »Cegenwartsschrumpfung«, wonach Vergangenheit und Zukunft jeweils in immer kürzeren Abständen neu bewertet werden müssen. Vgl. Rosa, Beschleunigung: die Veränderung der Zeitstrukturen in der Moderne, $133 \mathrm{f}$. 
Je mehr im Laufe des 20. Jahrhunderts die Erscheinung der durch Kommunikationstechnologien beförderten »Gleichzeitigkeit« von Ereignissen sowie eine »erstreckte Gegenwart« die allgemeine Zeiterfahrung stärker auf eine Unmittelbarkeit hin ausrichten ließen, desto eher dürften die scheinbaren Anomalien - selbst in Form relativ kurzer situativer Wartesituationen - an Erfahrbarkeit und Problematisierung gewonnen haben.

\subsubsection{Kulturanthropologische Zeitstudien}

Rammstedts idealtypisches Evolutionsschema der Zeitauffassungen akzentuierte zweifelsfrei das westliche Primat einer seit der Neuzeit etablierten, stark zukunftsorientierten Zeitauffassung mitsamt einer Gliederung von Veränderungen im System von Vergangenheit, Gegenwart und Zukunft. Als Abschluss der theoretischen Grundlegungen und Vorklärungen zum Zeitbegriff soll nun aber gleichwohl betont werden, dass jenem P-P-F-Modell ${ }^{173}$ abweichende kulturelle Zeitvorstellungen gegenübergestellt werden können (und müssen). Fragestellungen der kulturellen Vielfalt von Zeitvorstellungen sowie der kulturellen Varianz der Messung und Wahrnehmung von Zeit werden dabei traditionell durch die Kulturanthropologie besetzt. Der anthropologische Fokus auf Temporalphänomene liegt folglich darauf, zeitbezogene Sinnstiftungen mittels phänomenologischer und ethnologischer Methoden in ihrer jeweiligen Abhängigkeit von gesellschaftlichen Sozialstrukturen zu erkennen und zu vergleichen.

Von der Vielzahl interkultureller Zeitstudien, die den Fokus auf kulturbasierte Bedeutungen und Zeitformen legen, sollen hier einige zentrale Arbeiten Erwähnung finden. Sie werden deshalb aufgeführt, weil mit ihnen eine Grundintention einhergeht, die sich durch diese Arbeit zieht. Der Analysefokus von verkehrsinduzierten Wartephänomenen liegt zunächst eindeutig im Kontext der westeuropäischen Eisenbahnkontextes und folglich im Rahmen der vierten evolutionären Stufe der Rammstedt'schen Typologie. Damit soll jedoch keineswegs das Bewusstsein für die mitunter gravierenden kulturellen Unterschiede in den Zeitauffassungen übergangen werden, die nicht selten vom allzu dominanten westlichen Modell der >linearen Zeitauffassung mit offener Zukunft< abweichen und für die es an dieser Stelle gleichwohl zu sensibilisieren gilt. ${ }^{174}$

\section{Edward T. Hall}

Als einer der Hauptakteure dieser zeitbezogenen Sensibilisierungsarbeit kann Edward T. Hall gelten. Seine Studie `The Dance of Life « stützte sich auf die leitende Annahme, dass das westliche Denken zu stark von der Diktion einer absoluten Zeit im Newton'schen Sinne geprägt sei. Stattdessen gebe es eine Vielzahl von Kulturen, die sich schlichtweg nicht unter Kategorien der linearen und absoluten Zeitauffassung subsumieren lassen und sich westlichen Zeitauffassungen gegenüber (noch) resistent zeigen. Die Ge-

173 P-P-F steht für Past - Present - Future.

174 Zum sich hier anschließenden umfangreichen Themenkomplex der Kolonialisierung des westlichen Zeitmodells, der Tendenz zur Missionierung anderer Kulturen zur Verinnerlichung eines linearen Zeitverständnisses, sei an dieser Stelle bspw. auf die traverse (2016, Nr. 3) mit ihrer Schwerpunktpunktausgabe »Zeiterfahrung - Untersuchungen über Beschleunigung und Entschleunigung von Geschichte« verwiesen. 
fahr der impliziten Vergleichsfolien auf Grundlage der westlichen Zeitauffassung sieht Hall folglich nicht nur in der Übersimplifizierung andersartiger Zeitkulturen, sondern auch in der Eliminierung der eigentlichen Vielfalt alternativer Zeitkonzepte, die jedoch erst beim Verlassen der traditionell westlichen Zeitauffassung erkennbar werden. ${ }^{175} \mathrm{Mit}$ Blick auf die Temporalkulturen vermerkt Hall kritisch und mahnend:

»(..) I am convinced that the West has made a great mistake in writing off the very special knowledge and abilities of the rest of the world simply because they don't conform to our standards for scientific paradigms. $\aleph^{176}$

Halls konzeptionell vielleicht wichtigster Beitrag liegt in der Kategorisierung der Vielfalt kultureller Zeitauffassungen. Er unterscheidet grundsätzlich monochrone (M-Zeit) und polychrone (P-Zeit) Kulturen zeitlicher Orientierung. Mitglieder monochroner Zeitkulturen sind stark an der Objektivität der Uhrzeit orientiert und tendieren zur Orientierung an Terminen, mitunter auch auf Kosten sozialer Beziehungen oder der Kommunikation. Die Arbeitsweise erfolgt wenig spontan, sondern in linearer Abfolge bis hin zu einem definierten Ende. Die monochronische Zeitauffassung ist ferner dadurch charakterisiert, dass so stark erlernt und kulturell verinnerlicht wird, dass sie schließlich als einzig logische und als natürliche Weise der Organisation des Lebens erscheint. Die Gefahr der westlichen Zeitauffassung, welche die Welt in segmentierte Einheiten aufteilt, besteht für Hall in der potentiellen Entfremdung vom Selbst und der Reduzierung des situativen Kontextes. Auch wenn Mitglieder des monochronischen Zeitverständnisses die Segmentierung in Zeiteinheiten als natürliche Realität begreifen, entspricht diese jedoch etwa keineswegs der Natürlichkeit biologischen Rhythmen. ${ }^{177}$ In dieser Charakterisierung entspricht die M-Zeit-Kultur im Wesentlichen der Auffassung der westlichen Zeitkultur.

Mitglieder von polychronen Zeitkulturen (bspw. in der arabischen oder lateinamerikanischen Welt) dagegen sind für Hall durch starke Beziehung zu ihren Mitmenschen und deren Bedürfnisse gekennzeichnet. Ihre Zeitauffassung ist durch geringeren Fokus auf die lineare Abfolge von Ereignissen und Zeiteinteilungen in ihrer Charakteristik insgesamt situativer und flexibler, jedoch im Falle der Bearbeitung von komplexen Vorgängen anfällig für Unproduktivität oder gar Chaos. ${ }^{178}$ Hall sieht eine Vielzahl menschlicher und ethnischer Konflikte in der Unvereinbarkeit jener beiden Zeitkulturen:

»Basic systems such as monochronic and polychronic time patterns are like oil and water and do not mix under ordinary circumstances. In a schedule-dominated monochronic culture like ours, ethnic groups which focus their energies on the primary groups and primary relationships, such as the family and human relationships, find it almost impossible to adjust to rigid schedules and tight time compartments. $\aleph^{179}$

178 »Matters in a polychronic cultures seem in a constant state of flux. Nothing is solid or firm, particularly plans for the future; even important plans may be changed right up to the minute of execution.«Ebd., 47. 
Exemplarisch für das Aufeinandertreffen konstratierender und zuweilen unvereinbarer Zeitauffassungen führt Hall jene der amerikanischen Ureinwohner und des sweißen Amerikas an. Die in Arizona beheimateten Hopi-Indianer und Navajo-Indianer bei denen Hall einige Jahre seines Lebens verbrachte - betrachten die Zeit nicht als ein vermitteltes Kontinuum von Vergangenheit, Gegenwart und Zukunft. Sie keine sprachlichen Ausdrücke, die einen Zeitfluss sspürbarı erscheinen ließen, weil dem Prozess des Zeitvergehens - im Gegensatz zum westlichen Zeitverständnis - kein numerischer Wert beigemessen werden kann. Sprachwissenschaftlich betrachtet, besitzen ihre Verben keinerlei Zeitformen, die Jahreszeiten sind keine Substantive, sondern Adverbien. Sommer oder Winter sind demnach kein Faktum, sondern sind Zustände. Die sprachliche Artikulation von Zeitphänomenen wird also nicht an einen Zeitfluss geknüpft, sondern im Fall der Najavo und Hopi vielmehr um Ablauf und Rhythmik wichtiger sakraler zeremonieller Tänze. So leben für Hall die Hopi und Navajo zusammenfassend in einem Zustand einer »eternal present ${ }^{180}$. Das Aufeinandertreffen dieser Zeitauffassung mit der westlichen ist dabei durchaus konfliktreich. Die divergierende Synchronisation sozialer Tätigkeiten produziert Probleme der Unpünktlichkeit und Unzuverlässigkeit und damit zu weitreichenden und sich vertiefenden Missverständnissen gegenüber der indigenen Bevölkerung. So werden nicht zuletzt auch Wartezeiten stark abweichend wahrgenommen. Während die von hoher Wertschätzung der Geschwindigkeit geprägte westliche Wahrnehmung von Zeit deren Ersparnis anstrebt, korrespondiert dagegen in der indianischen Zeitauffassung die Zeit, in der >nichts passiert, nicht mit Verlusten, sondern mit sakraler Notwendigkeit. Folglich appelliert Hall im Zusammenhang mit der kulturell divergierenden von Wartezeiten:

»Whites tend to think that because nothing overt is happening, nothing is going on. With many cultures there are long periods during which people are making up their minds or waiting for a consensus to be achieved. We would de well to pay more attention to these things. $\ll^{181}$

Resultierend aus dem Befund unzähliger Unvereinbarkeiten kultureller Zeitauffassungen besteht für Hall eine zentrale Herausforderung der Menschheit darin, die jeweilige Zeitkultur des Gegenübers verstehen zu lernen, um Missverständnisse im gegenseitigen Austausch abzubauen.

Um dem Vorwurf einer wiederum zu stark simplifizierenden Kategorisierung von polychronischer und monochronischer zu entgehen, weist Hall zudem auf die Verflechtungen von M-Zeit und P-Zeit hin, die auch innerhalb eines quasi-homogenen Kulturkreises nachweisbar seien. Zwar zeige sich oberflächlich eine Dominanz der monochronischen Zeitauffassung in Bereichen der Wirtschaft, Politik und Verwaltung, doch für den privaten Bereich diagnostiziert Hall durchaus das Nebeneinander monochronischer und polychronischer Zeitauffassungen, etwa im Bereich der Kindererziehung, die traditionell eher der Verantwortung der Mutter stand und darin stärker von polychronisch, also von gleichzeitig zu bearbeitenden Tätigkeiten, geprägt sei. Zudem seien auch in der westlichen Welt kulturabhängige Zeitpolitiken zu beobachten, so besitzt

180 Hall, The Dance of Life, 37.

181 Ebd., 42f. 
Frankreich eine stark zentralistische Zeitpolitik, bei der die zeitbezogenen organisationalen und institutionellen Entscheidungen in der Hand nur weniger Akteure liege. Anders dagegen seien die USA (als auch Deutschland) von einer stärker dezentralen Zeitpolitik geprägt, bei der die zeitrelevanten Entscheidungen weniger innerhalb eines klar zu identifizierenden Machtzentrums zu verorten seien. ${ }^{182}$

\section{Robert Levine}

Stellvertretend für eine Vielzahl weiterer Arbeiten, die alternative Muster der Zeitauffassung analysierten, ist der Sozialpsychologe Robert Levine $\mathrm{zu}$ nennen. Levine unterscheidet die weltweite Diversität unterschiedlicher Zeitauffassungen aggregiert zwischen 〉Uhrzeitkulturen $\prec$ und `Ereigniszeitkulturen $<$. In Ereigniszeitkulturen werden oftmals soziale Aktivitäten genutzt, um Zeiten festzulegen, während in Uhrzeitkulturen in umgekehrter Weise die Objektivität der Uhrzeit genutzt wird, um soziale Aktivitäten $\mathrm{zu}$ organisieren. ${ }^{183}$ Als stellvertretende Kulturen einer Ereigniszeit-Orientierung führt Levine mit Rückgriff auf anthropologisch-ethnologische Vorarbeiten etwa die Micmac-Indianer in Ostkanada ${ }^{184}$, die Nuer im Sudan ${ }^{185}$ oder die Zeitbestimmung des Kachin-Volkes ${ }^{186}$ im nördlichen Myanmar und Teilen Chinas auf. Mit Bezug auf das Kachin-Volkes sieht Levine einen beispielhaften Indikator für die interkulturelle Varianz der Zeitauffassungen gegenüber der westlichen Zeitauffassung in sprachlichen Niederschlägen bzw. deren Abwesenheit: »Während die meisten Menschen der westlichen Welt die Zeit als objektive Gegebenheit betrachten und ein Substantiv dafür gefunden haben, verwenden die Kachin ihre Begriffe für Zeit eher wie Adverbien. ${ }^{187}$ In Übereinstimmung mit Hall konstatiert auch Levine, dass oftmals gar kein einheitlicher Begriff von Zeit besteht, sondern diese, wie etwa bei den Sioux-Indianern, nur indirekt bezeichnet wird. So gibt es bspw. bei den Sioux keinen expliziten Ausdruck für 'spät< oder das >Warten ${ }^{188}$ Die Zeitbestimmung jener Volksgruppen der EreigniszeitOrientierung ist insgesamt stärker an sozialen Aktivitäten orientiert und ist damit weit weniger exakt als die uhrzeitliche Bestimmung. Sie kann diese ungenauere Zeitbestimmung aus Levines Sicht jedoch nur deshalb realisieren, weil der Regelungsanspruch ihres Zusammenlebens wesentlich weniger komplex ist als in uhrzeitlich orientierten Gesellschaften.

Trotz einer durch die Globalisierungsprozesse vermuteten Ausbreitung des uhrzeitlichen Orientierungsparadigmas betont Levine für einige Teile der Welt die persistente Dominanz von Ereigniszeiten gegenüber Uhrzeiten. Levine forciert damit ein für die Analyse von Zeitphänomen wichtiges Verständnis darüber, dass die ereigniszeitlichen Paradigmen vielerorts (noch) in starkem Kontrast zur Zeitauffassung der westlichen

\footnotetext{
182 Vgl. ebd., $110 f$.

183 Vgl. Levine, Eine Landkarte der Zeit, 135.

184 Vgl. Philip K. Bock, »Social structure and language structure«, Journal of Anthropological Research 42, Nr. 3 (1986): 427-37.

185 Vgl. Robert H. Lauer, Temporal man: The meaning and uses of social time (New York: Praeger, 1981), 22f.; Vgl. E. E. Evans-Pritchard, The Nuer (Oxford: Oxford University Press, 1940).

186 Vgl. E. R. Leach, Rethinking anthropology (London: Athlone P., 1966).

187 Levine, Eine Landkarte der Zeit, 180.

188 Vgl. ebd., 137.
} 
Welt stehen. Diese Dominanz sieht Levine insbesondere auch in Gestalt des unterschiedlichen Lebenstempos. Im Rahmen der empirischen Untersuchung unterschiedlicher Lebenstempi in 31 Nationen schlussfolgte Levine auf Grundlage seiner Erhebungen, dass Klima, Einwohnerzahl und kulturelle Werte die fundamentalen anthropologischen Einflussfaktoren für das lokale Lebenstempo bilden. Wärmeres Klima und höhere Einwohnerzahlen korrelieren dabei mit einem deutlich erhöhten Lebenstempo. Zudem seien am Individuum orientierte Gesellschaften tendenziell `schneller $<$ als jene, die vorwiegend am Kollektiv orientiert seien. Als wichtigste Determinante zur Bestimmung des Tempos eines Ortes sieht Levine aber die Wirtschaft des jeweiligen Ortes. Angesichts dieser Zusammenhänge weist Levine das weltweit höchste Lebenstempo in den westeuropäischen Staaten, das langsamste Lebenstempo in tropischen Staaten nach. ${ }^{189}$

Neben der dichotomen Unterscheidung von ereignis- oder uhrzeitlichen Orientierungen verdeutlicht Levine auch die noch in der Spätmoderne erfolgenden Unterschiede der kalendarischen Zeitbestimmung entlang von Naturphänomenen, so etwa bei den Luval in Sambia, die das Jahr in zwölf Vegetationsperioden teilen, den Bahan auf Borneo, die acht Jahresabschnitte je nach bäuerlicher Tätigkeit kennen oder den Mursi in Äthiopien, deren Kalender verhandelbar ist, da er je nach Auftreten wichtiger Ereignisse in der Landwirtschaft schwankt. ${ }^{190}$ Ergänzend zeigen die Studien von Bohannan oder Tedlock zur Zeitkultur der Tiv in Nigeria ${ }^{191}$ oder der Quiché-Indianer in Guatemala ${ }^{192}$ die aus westlicher Perspektive paradoxale Erkenntnis von Zeitkulturen, die Zeit zwar gewissermaßen als fortlaufend betrachten, aber die sich ergebenden Zeiteinheiten zugleich als unhintergehbar und statisch betrachten.

Als dritte wichtige Kontrastfolie zur westlichen Zeitauffassung dürfte schließlich auch die ethnologische Feldforschung zur balinesischen (Zeit-)Kultur von Clifford Gertz zu nennen sein. In seinem 1966 erschienen Essay >Person, time and conduct in Bali< deckte der Kulturantrophologe auf, dass die Zeitwahrnehmung paradoxerweise zur >Enttemporalisierung < der eigenen Lebenszeit neigt. Stattdessen zielt ein spezielles System der Namensgebung und Kommunikation darauf ab, mit der Zeit der jeweils anderen Person zu verschmelzen, woraufhin die Subjekte sentpersonalisiert< werden. Geertz zeigt, wie jene personellen Selbstwahrnehmungen an ein übergeordnetes Zeitverständnis geknüpft sind, die Zeit nicht als linear, sondern als punktuell und fragmentiert wahrnehmen. Zeit wird in der balinesischen Kultur tendenziell als simultan bzw. rein punktuell erfahren, was Geertz schließlich zusammenfassend als »contemporized view of time ${ }^{193}$ bezeichnet. Geertz sensibilisiert zusammenfassend dafür, dass kulturell eta-

189 Die Schweiz, Irland und Deutschland nehmen danach die ersten drei Positionen der Nationen mit dem schnellsten Lebenstempo ein. Das langsamste Tempo dagegen wurde für Mexiko, Indonesien und Brasilien erhoben. Vgl. ebd., 180. An dieser Stelle sei jedoch gleichsam auf einige methodische Defizite dieser häufig zitierten Untersuchung verwiesen, die unter anderem in einer nur sehr geringen Stichprobengröße, fehlender Kontrollgruppenmessungen, teils fragwürdiger Indikatoren oder fehlender Kontextualisierungen der Erhebungssituationen zu beanstanden sind.

190 Vgl. Levine, Eine Landkarte der Zeit, 99.

191 Paul Bohannan, „Concepts of time among the Tiv of Nigeria «, Southwestern Journal of Anthropology 9, Nr. 3 (1953): 251-62.

192 Barbara Tedlock, Time and the highland Maya (Albuquerque: University of New Mexico Press, 1992).

193 Clifford Geertz, The Interpretation of Cultures. Selected Essays by Clifford Ceertz. (New York: Basic Books, Inc., 1973), 392. 
blierte Zeitsysteme keineswegs zwangsläufig der Messung von Verläufen dienen müssen, sondern zuweilen allein der Unterscheidung und Klassifizierung von spezifischen (Feier-)tagen als gewissermaßen autarken und selbst-subsistierenden Zeiteinheiten. ${ }^{194}$

Neben diesen hier kurz vorgestellten, auf die unvoreingenommene Kontrastierung des westlichen Zeitmodells abhebenden kulturanthropologischen Studien, erzeugten jedoch viele andere Studien lediglich archetypische Grobkategorisierungen des Zeitbewusstseins. Diese erfolgten meist entlang der dichotomen Linien traditionell vs. modern oder agrarisch vs. industriell. ${ }^{195}$ Solche Kategorisierungen stellen jedoch oftmals zu einfache, stereotypische und nicht zuletzt kulturimperialistische Generalisierungen dar, die jegliche Interrelationen oder eigentliche Komplexitäten früherer (als auch gegenwärtiger) Zeitauffassungen schlichtweg übergehen. Bergmann vermerkt dazu kritisch: »Using this schematization, one achieves only very rough and stereotyped characterizations that modern societies are more future-oriented, while primitive societies are determined more by tradition (...). ${ }^{196}$ Jenseits dieser vereinzelt simplifizierenden Langzeitkategorisierungen besticht die Vielzahl zeitanthropologischer Studien jedoch insgesamt durch die Erzeugung von gleichberechtigten Kontrastfolien zum Narrativ der rastlosen westlichen Welt. Mitnichten sieht jede Kultur demnach die Zeit als eine quantitative Ressource, die gespart, kontrolliert, genutzt oder verkauft werden kann. Dazu verdeutlicht eine Vielzahl der Studien, dass bei weitem nicht jede Kultur die Zeitsphären von Vergangenheit, Gegenwart und Zukunft in ähnlich abstrahierter Form konzeptualisiert oder Begrifflichkeit für die Modalitäten der Zeit aufweist und benötigt. Zeitwahrnehmung, Zeitfunktionen oder auch die Zeitmessung - so die Postulate von Hall, Levine oder Geertz - sind vielmehr historisch gewachsene Konstrukte und sind ferner stets als kulturabhängige Größen zu verstehen.

\subsection{Was ist die Zeit? Fünf Kernbefunde für einen Orientierungsrahmen}

Die Beschäftigung mit dem Temporalphänomen Warten kann, so die einführende Überzeugung der vorangegangenen Ausführungen, nicht ohne eine Betrachtung der Zeit als Gegenstand philosophischer und sozialwissenschaftlicher Auseinandersetzungen auskommen. Ziel dieses Kapitels sollte es daher sein, einen grundlegenden Einblick in die Frage nach Funktionen, Strukturen und der Evolution des Zeitbegriffs sowie der Ausbildung von Zeiterfahrungen im Kontext der westlichen Moderne zu gewinnen, um die anschließende historische Erkundung des Wartephänomens im Verkehrskontext auf eine zeittheoretisch informierte Grundlage zu stellen.

194 Mit Blick auf die punktuelle Charakteristik des balinesischen Kalendersystems vermerkt Geertz an gleicher Stelle pointiert: »They don't tell you what time it is; they tell you what kind of time it is. « Ebd., 393.

Vgl. etwa A. Irving Hallowell, »Temporal Orientation In Western Civilization And In A Pre-Literate Society«, American Anthropologist 39, Nr. 4 (1937): 647-70. Dazu auch Leonard W. Doob, Patterning of Time (New York: Yale University Press, 1972). 
Das zurückliegende Panorama philosophischer, sozialwissenschaftlicher und anthropologischer Zeitforschungen konnte (und sollte) dazu gewiss nur einen Ausschnitt der immensen Breite und Komplexität der Zugänge verdeutlichen. Ausgehend von Durkheims Theoretisierung der Zeit als einer zuvorderst `sozialen` Größe, die Produkt als auch Diktat sozialer Verhältnisse ist, über die simultane Verschränkung erlebter Zeitdimensionen (Schütz/Luckmann, Giddens) bis hin zur Konzeptualisierung der sozialen Zeit als symbolische Synthese- und Orientierungsleistung (Elias) versuchten Soziologie und Anthropologie ihrerseits die von der Philosophie bereits in langer Tradition aufgeworfenen Rätsel um die Zeit auf verschiedenartigen Wegen zu entschlüsseln. Theoretisierende Pionierarbeiten und daran anknüpfende Synthesen beeinflussten sich dabei immer wieder wechselseitig, wobei die 1970er und 1980er Jahre eine wahre Blütephase der Beschäftigung mit Zeitfragen und -phänomenen markierten. Aus der sozialwissenschaftlichen Betrachtung heraus ließ sich deutlich extrahieren, dass Zeit und Zeitbestimmung primär auf die Hauptfunktionen der Integration, Koordination und Regulation sozialer Tätigkeiten abzielen und diese Funktionen parallel zu wachsender gesellschaftlicher Komplexität stärker in den Vordergrund des Bewusstseins rücken.

Die zeitphilosophischen Betrachtungen verlagerten das Zeitverständnis seit dem frühen 20. Jahrhundert zunehmend vom zyklischen zu einem immer stärker linear vermittelten bzw. von einem naturwissenschaftlichen zu einem subjektimmanenten Zeitverständnis. Dieser durch die phänomenologische und fundamentalontologische Philosophie Husserls, Bergsons oder Heideggers historisch begründete >Subjektivismus der Zeitauffassung < inspirierte seinerseits die sich etablierenden Sozialwissenschaften fortlaufend dazu, die Auffassung einer an die Subjektivität und einer Sozialzeit geknüpften Wandelbarkeit von Zeitauffassungen zu untersuchen. Im Verständnis der >Subjektivisten wird eine historische Variabilität von Zeit und damit schließlich auch ihre eigentliche Kontingenz der sozialen Konstruktion und ihrer Wahrnehmung angenommen, die in starkem Kontrast zur physikalischen Perspektive einer nicht wandelbaren, quantitativen Größe steht. So wird zusammenfassend im kulturanthropologischen und soziologischen Verständnis eine deutliche Abhängigkeit der Zeiterfahrung von kulturellen Einflüssen betont. Zeitauffassungen sind demnach weder definitiv festgelegt, noch als angeborene, natürliche oder apriorische Bedingung der Möglichkeit der Erkenntnis ausgeprägt. Vielmehr würde es sich bei der Ausprägung von Zeitauffassungen immer »um geschichtlich (bewußtseinsgeschichtlich), wissenschaftlich wie kulturell bedingte Sicht- und Interpretationsweisen ${ }^{197}$ handeln.

Wenngleich die Zeiterfahrung auch historisch variiert, prägt sich jegliche Zeiterfahrung - im Rekurs auf die evolutionäre Typologie Rammstedts - erst entlang der polaren Beziehungssetzungen von Kontinuität vs. Diskontinuität sowie in Bezug auf die Wahrnehmung einer zyklischen Wiederkehr und der Erfahrung aus. Elias sieht in der zivilisationsgeschichtlichen Rückschau die Natur der Zeit treffend als die Sehnsucht der Menschen »nach etwas Dauerndem hinter dem unaufhörlichen Wandel aller beobachtbaren Daten, aus der Suche nach etwas Unvergänglichem und Zeitlosem hinter ihrem 
vergänglichen Leben « ${ }^{198}$ Die Zeit(erfahrung) wird über die historische Variabilität dieser Suche nach Dauerhaftigkeit hinaus zusammenfassend im Spektrum eines semantisches Codesystems, als manipulierbare Größe der sozialen Praxis (mittels Beschleunigungen, Verlangsamungen oder Variationen der Dauer von Ereignissen), als Ressource, als mehrschichtiges Ordnungs- und Bezugssystem (auf individueller, interpersoneller und auf Makroebene) sowie als Ausdrucksmittel von Machtverhältnissen, Prioritäten und Hierarchien) theoretisiert. Darüber hinaus lassen sich in der Gesamtschau die sozialwissenschaftlichen Auseinandersetzungen des Begreifens von Zeit in Auseinandersetzungen über Zeitphänomene, Zeitmodelle, Zeitverhältnisse und Zeiterfahrungen systematisieren. ${ }^{199}$ Nach Maurer werden vier große Themenbereiche untergliedert: kulturkritische Abhandlungen, kulturhistorische Arbeiten, Arbeitszeitstudien und geschlechtsspezifische Zeitstrukturanalysen. ${ }^{200}$ Bergmann kategorisierte die soziologischen Zeitstudien ferner in sechs thematische Unterbereiche: 1) Zeitperspektiven und Zeitorientierung, 2) zeitliche Ordnungen der Sozialstruktur (Zeitmessung und Kalendererstellung), 3) Zeitstrukturen spezifischer Sozialsysteme und Berufsgruppen, 4) Evolution der Zeitwahrnehmung, 5) Zeit und der Bezug zum sozialen Wandel, 6) Zeit als Gegenstand sozialwissenschaftlicher Theoriebildung. ${ }^{201}$

\section{Grundproblematik: keine einheitliche Theoriebildung}

Die knappe Zusammenschau verdeutlichte dabei zugleich das schwerwiegendste Problem der Zeitforschung: die Heterogenität ihrer Ansätze. Zahllose Begriffsbestimmungen, Konzeptualisierungen, Abstraktionslevel und Strukturelemente der Zeit haben ein bis heute kaum überwundenes Kohäsions-Defizit verursacht, das einer einheitlichen Theoriebildung und einer allseits befriedigenden Definition des Zeitbegriffs entgegensteht. So stehen sich etwa im äußersten Falle eine phänomenologisch inspirierte Sichtweise über die Zeit und eine funktionalistische Sichtweise der Zeit als Orientierungsparadigma und Strukturprinzip moderner Gesellschaften (Luhmann) erkenntnistheoretisch weitestgehend unberührt gegenüber. Hartmut Rosa vermerkt dazu kritisch, dass bislang weder ein theoretischer oder praxisrelevanter Erkenntnisgewinn aus der Fülle der Studien erkennbar sei, noch die Erkenntnisse zu einer systematischen Zeitsoziologie zusammengefügt worden wären. Zwar postuliert die Mehrheit der Studien, dass soziale Phänomene temporal rekonstruiert und beschrieben werden können, jedoch bleibt diese Feststellung nach Ansicht Rosas meist eigenartig konsequenzlos. ${ }^{202}$ Das Grundproblem der Beschäftigung mit der Zeit-Thematik ufert damit schließlich in der Diagnose, dass die Sozialwissenschaften die Zeit zwar als »unverzichtbaren Grundbegriff ihrer Theoriebildung « ${ }^{203}$ begründen wollen, zugleich aber bislang die Integration der heterogenen Ansätze in bereits bestehende Perspektiven vermissen ließen. So wird

198 Elias, Über die Zeit, 162.

199 Vgl. Sabine Schmidt-Lauff, Zeit und Bildung. Annäherungen an eine zeittheoretische Grundlegung (Münster: Waxmann Verlag, 2012).

200 Vgl. Maurer, »Stand und Perspektiven der zeitsoziologischen Forschung «, 595.

201 Vgl. Werner Bergmann, »The problem of time in sociology«, 81.

202 Vgl. Rosa, Beschleunigung: die Veränderung der Zeitstrukturen in der Moderne, 19.

203 Rosa, Beschleunigung: die Veränderung der Zeitstrukturen in der Moderne, 22. 
trotz der seit den 1970er Jahren stark wachsenden sozialwissenschaftlichen Beschäftigung mit dem Zeitphänomen registriert, dass die meisten Studien rein »solipistisch « ${ }^{204}$ argumentierten und im Resultat mitunter gar ein »conceptual chaos ${ }^{205}$ begründet hätten.

Das Dilemma sozial- und geisteswissenschaftlicher Thematisierungen wird ferner darin gesehen, dass die Zeitphilosophie auf der einen Seite die Zeit mit ihrer dichotomen Einteilung in apriorischer Erfahrung oder quantitativer Naturgröße immer tiefer >verrätselt $<$ hätte, während die empirischen Studien die Zeit auf der anderen Seite allzu leicht als selbstevidente Größe hinnehmen und sie nicht theoretisch hinterfragen. ${ }^{206}$ Ontologische Fragen würden dabei weitegehend ausgeklammert. Stattdessen wird die Zeit entweder als soziale Tatsache oder Ergebnis eines sozialen Konstitutionsprozesses betrachtet. Ähnlich sieht auch Barbara Adam die Gründe einer unzureichenden Theoriebildung in der Verharrung und im Ausfechten denkgeschichtlicher Positionskämpfe. $\mathrm{Zu}$ sehr sei innerhalb der Betrachtung des Zeitbegriffs auf Dualismen und Dichotomien fixiert worden (Naturzeit vs. sozialer Zeit, apriorische Zeit vs. quantitative Größe, Spaltung von Struktur und Akteur etc.), zu wenig dagegen sei eine Beachtung der engen Verbindungen zwischen sozialer und natürlicher Zeit versucht worden. So besteht für Adam mit Rückblick auf die lange Tradition sozialwissenschaftlicher Zeitforschung zusammenfassend der Befund, dass die Zeit in der Sozialtheorie noch immer nicht ausreichend verstanden oder behandelt worden sei. ${ }^{207}$

Die Liste der Erklärungsversuche und der Klagen über die Heterogenität der Zeitforschung ließe sich leicht erweitern. Der selbstkritische Befund der verwirrenden Heterogenität bildet jedoch für sich genommen ebenfalls eine bedeutsame kultursoziologische Erkenntnis. Sie lässt auf eine wachsende Verunsicherung im Umgang mit der Zeit in der Spätmoderne schließen, die im Terminus der `Zeitkrise` ihren stärksten Ausdruck zu finden scheint. ${ }^{208}$ Unser Verhältnis zur Zeit erscheint darin alles andere als eindeutig, sondern als konfliktreich, zwiespältig, bisweilen gestört und insgesamt mehrdeutig. ${ }^{209}$

Das Rätsel der Zeit lässt sich allein auf Grundlage der Rückschau auf die sozial- und geisteswissenschaftlichen Bemühungen also mitnichten vollends lösen. Zugleich aber zeigte das skizzierte wissenschaftshistorische Panorama eine Reihe von wichtigen Fixpunkten auf, welche die Abstraktheit und Flüchtigkeit der Zeit einzugrenzen vermögen. Dazu soll im Folgenden erörtert werden, welche Kohärenzen sich innerhalb der Heterogenität des philosophischen sowie sozialwissenschaftlich-anthropologischen Zeitverständnisses erkennen lassen. Welche Orientierungspunkte und gemeinsame Erkenntnisnenner lassen sich auf Basis der Rückschau ausgewählter Arbeiten der zeitbezogenen sozialwissenschaftlichen Forschungstradition festhalten und extrahieren, welche

204 Werner Bergmann, »Das Problem der Zeit in der Soziologie. Ein Literaturüberblick zum Stand der zeitsoziologischen Theorie und Forschung. «, Kölner Zeitschrift für Soziologie und Sozialpsychologie 35, Nr. 3 (1983): 462.

205 Adam, Time and Social Theory, 15.

206 Vgl. Rosa, Beschleunigung: die Veränderung der Zeitstrukturen in der Moderne, 22.

207 Vgl. Adam, Time and Social Theory, 14.

208 Vgl. Rosa, Beschleunigung: die Veränderung der Zeitstrukturen in der Moderne, 451.

209 Vgl. Schräder-Naef, »Zeit als Belastung?«. 
die Diversität der Ansätze rudimentär zusammenhalten? Wie könnten diese Schnittmengen schließlich für ein Verständnis des Wartens sowie der anschließenden Längsschnittbetrachtung der historischen Verhandlung (verkehrsinduzierter) Wartephänomene nutzbar gemacht werden? Das Anliegen des folgenden Abschnittes besteht sonach darin, weder eine weitere (isolierte) Definition des Zeitbegriffs beizusteuern, noch in die »mystery trap « ${ }^{210}$ einer eigentlichen Unlösbarkeit der Zeitfrage zu tappen, sondern basale Bereiche der Theoriebildung herauszugreifen, die einen Orientierungsrahmen für die historische Analyse des spezifischen Temporalphänomens >Warten` besondere Beachtung ermöglichen können.

\section{Fünf Kernbefunde zum Zeitverständnis}

$\mathrm{Zu}$ aller erst lässt sich festhalten, dass das »conceptual chaos« der Zeitforschung zumindest durch einen übergeordneten anthropologischen Befund zum Verständnis der Zeit zusammengehalten wird, der sich meist implizit durch die Vielfalt der Zeitbetrachtungen zieht. Die Konstruktion und Reflektion über die Zeit repräsentieren den uralten Wunsch des Menschen nach einer vom Bewusstsein wahrnehmbaren Form von Abfolgen und Veränderungen, den Wunsch einer systematischen Einordnung des Daseins mittels Vergleichbarkeiten und relativer Fixierungen sowie den Wunsch nach Bestimmung von Synchronisation, Simultanität mittels der Messbarkeit von Zeit. Die Grundproblematik der schwierigen Orientierung und einheitlichen Theoriebildung entlang dieses Ur-Bedürfnisses mag insgesamt auch darin begründet sein, dass wir uns in der Zeit nicht wie im Raum bewegen können, »der auch bestehen bleibt, wenn wir ihn verlassen haben. «211 Jenseits dieser alle Arbeiten durchziehenden anthropologischen Grundmotivation sollen nun aber folgende fünf Orientierungspunkte als Destillate und zentrale Mitnahmen aus den zeittheoretischen Betrachtungen gelten.

1) Ontologischer Status: Kein tempus absolutum<, sondern hybrides Wesen der Zeit

Ein erster wichtiger Orientierungspunkt besteht in dem insbesondere durch die phänomenologische Philosophie vertretenen Grundsatz, dass eine einheitliche, objektive Zeitwahrnehmung, ein stempus absolutumく, schlichtweg nicht existiert. Zeit wird weder im Newton'schen Verständnis vollends als quantitative Messgröße verinnerlicht, noch ist das jeweilige subjektiv-individuelle Zeitempfinden intersubjektiv übertragbar. Die Existenz einer rein sobjektiven Zeit `ist damit für die lebensweltliche Praxis zunächst einmal als illusionär zu bezeichnen, wenngleich sie einen wichtigen Bezugspunkt bildet. Folglich ist >die Zeit< demnach dezidiert als hybrides Konstrukt zu verstehen, als Natur- und Kulturobjekt zugleich. Zwar ist die Zeit einerseits durch eine solide Faktizität (als physikalische Messgröße und Einheit von Stunden und Sekunden) gekennzeichnet, anderseits jedoch ist sie kulturell variabel, sozial geprägt und schließlich individuell variativ wirksam. Die erste Folgerung zum Grundverständnis von der Zeit lautet somit, dass sie mehr als nur das ist, was

210 Tabboni, »The Idea of Social Time in Norbert Elias«, 6.

211 Theo Rudolf Payk, »Zeit - Lebensbedingung, Anschauungsweise oder Täuschung?«, in Im Netz der Zeit, 77. 
uns Uhren und andere Messgeräte sanzeigen<. Eine Beschreibung von Zeitphänomenen muss daher deutlich über ihre objektive Messbarkeit hinausgehen.

2) Dialektische Ausbildung der Zeitwahrnehmung

Ausgehend von der Hybridizität der Zeit als Natur- und Kulturobjekt kann die Ausbildung einer Wahrnehmung von Zeitphänomenen gleichsam nicht als isoliert betrachtet werden. Zeitwahrnehmungen werden vielmehr erst im Dreieck einer intersubjektiven Ebene (Zeitkultur, >Weltzeit`), einer subjektiv-individuellen (Persönlichkeit, sSeele`) und einer objektiven Ebene (Uhrzeit, Kalenderzeit) ausgebildet. Zeiterfahrungen zeigen eine variierende Rhythmik des Bewusstseinsstroms (Schütz/Luckmann) und können damit stets nur kontextuell erklärt bzw. individuell rekonstruiert werden. Auch wenn uns die bildhafte Vorstellung der Zeit als einem linearen Fluss die Suggestion einer allumfassenden, objektiven Referenzgröße bereitet, wird die Zeit, so stellt erstmals Augustinus fest, auf alltagspraktischer Ebene subjektiv (und kulturell) mitunter stark abweichend von der Uhrzeit erlebt und verinnerlicht. Zugleich ist anzumerken, dass die Auffassung eines linearen, kontinuierlichen Fortschreitens von Zeit trotz des zeitphilosophischen Primats einer subjektimmanenten Zeitauffassung eine wesentlich längere Tradition aufweist und wohl daher nach wie vor stark kulturprägend ist. Die Zeitwahrnehmung innerhalb der westlichen Kultur erfolgt im Schnittpunkt einer objektiven Bezugsgröße und einer subjektiven Wahrnehmung, die sich entweder kontrastiv oder affirmativ zum objektiven Modell verhält und damit das objektive Bezugssystem subjektiv modifiziert. Die wahrgenommene Zeiterfahrung resultiert aus genau jenem Verhältnis. Wie kaum ein Zweiter hat Norbert Elias diesen dialektischen Zusammenhang im menschlichen Umgang mit der Zeit zu betonen versucht. Den Ort der Aushandlung dieses Verhältnisses bildet somit folglich das menschliche Subjekt bzw. das menschliche Gehirn. ${ }^{212}$ Dies bedeutet, dass sich die Zeit aus der neuzeitlichen Forschungstradition heraus somit niemals ohne das die Zeit erfahrende Subjekt verstehen lässt.

3) Wirkungsfeld und Ort der Entfaltung: Zeit als >soziale Zeit

Der dritte wichtige Orientierungspunkt besteht in der durch die Sozialwissenschaften etablierten Überzeugung, dass die Zeit insbesondere als ein soziales System und somit im Rahmen der Erzeugung und Nutzung von Zeitstrukturen verstehbar gemacht werden kann. Zeit und Zeitbestimmung werden demnach als Resultate sozialer Organisation verstanden. Die Erfahrbarkeit von Zeit konstituiert sich darin erst in sozialen Zusammenhängen und wird in der Ausbildung von Rhythmen, Takten oder Plänen analytisch greifbar sowie über Zeitbestimmungen, Zeitstrategien, Tempi oder Beschleunigungen qualitativ in Form der Veränderungen des Umgangs mit der Zeit beschreib- und analysierbar. Die Zeit bildet folglich ein zentrales Element des Soziallebens. Die dritte Folgerung zum Grundverständnis über den komplexen Gegenstand der Zeit umfasst damit, dass die Zeit als ein sozialer und anthropo- 
logischer >Fakt begriffen werden muss. Aus diesem Grund muss sie gleichsam als Dreh- und Angelpunkt sozialwissenschaftlicher Theoriebildung gelten. ${ }^{213}$

4) Funktionen: Zeit als Orientierungs-, Kommunikations- und Synchronisationsleistung Die vierte elementare Erkenntnis knüpft direkt an die zweite an und nimmt abermals Bezug auf Norbert Elias. Wenn die Zeit ein soziales System darstellt, muss sie zuvorderst in ihren Funktionen einer symbolischen Form sowie als ein Orientierungs- und Kontrollmittel gelesen werden. Zeit wird in diesem Verständnis durch ihren instrumentellen Charakter definiert, der zudem nicht apriorisch vorhanden ist, sondern erst erlernt werden muss. Das Erlernen erfolgt um den Preis des Fremdzwangs, der Selbstdisziplinierung und der Affektkontrolle, ermöglicht anschließend jedoch integrative Synchronisationsleistungen und die Kommunizierbarkeit des sozialen Symbols `Zeit<. Elias' leitende Betrachtung der ssymbolischen Natur der Zeit eröffnet den aufschlussreichsten und damit vielleicht vielversprechendsten Zugang, um die subjektive Flüchtigkeit des Zeitbegriffs objektiv-definitorisch einzufangen. Die Arbeit folgt mit dessen Zeitkonzeption einem Grundverständnis, nach der die Zeit als soziales Konstrukt zum Ziel gesellschaftlicher Orientierungsfunktionen verstanden wird, das jedoch gleichwohl an die Aristotelischen Auffassung einer kosmologischen, an Bewegungen im Raume gekoppelten Gründung bezogen bleibt. Zeit strukturiert das In-der-Welt-Sein, macht Vergleiche und Veränderungen erleb- und kommunizierbar. In ihr spiegelt sich der menschliche Wunsch, die endlose Abfolge von Ereignissen in eine sinnhafte Ordnung $\mathrm{zu}$ transferieren. Die Zeit fungiert nach diesem wesentlichen Begriffsverständnis demnach als ein quasi-linguistisches Bedeutungs- und Bezugssystem. ${ }^{214}$

Mit Rückgriff auf Norbert Elias und dessen für diese Arbeit als am aufschlussreichsten geltenden Zugang zum Verständnis der sozialen Zeit vermerkt Simonetta Tabboni zu deren Funktion und Wirkungsweise treffend:

»(..) what we sum up in the word stime< is the attribution of meaning to change, done by human collectivities but capable of individual construction, and its organization in terms of goals and other affirmation of values. The creation of time might be a uniquely social way of pronouncing on the $>$ meaning of lifer. It simultaneously satisfies organizational goals - establishing when to work, when to play, when to pray- and moral objectives for the collectivity - deciding what is most important to achieve in life (...). « $^{215}$

Zusammenfassend wird im Zuge dieser Arbeit somit Zeit als soziales, kommunikatives, verhaltensregulierendes und Orientierung und Vergleichbarkeit stiftendes Symbol und Zeichen der Syntheseleistung betrachtet. Dieser Ansatz ermöglicht es nicht zuletzt, die Dichotomie zwischen physikalischer und sozialer Zeit zu überwinden und die unter

213 Vgl. Adam, Time and Social Theory, 14.

214 Vgl. Eviatar Zerubavel, »The language of time: Toward a semiotics of temporality«, The Sociological Quarterly 28, Nr. 3 (1987): 354.

215 Tabboni, »The Idea of Social Time in Norbert Elias«, 9 [Hervorhebung des Verfassers, R.K.]. 
Punkt 2 angesprochene, wechselseitige Charakteristik der Zeit als Natur- und Sozialgröße zu erkennen.

5) Zeitqualitäten: Charakteristik westlicher Zeitkultur

Der fünfte leitende Orientierungspunkt betrifft die Erkenntnis, durch welche Charakteristik die Zeitauffassung der westlichen Welt geprägt ist und welchen Veränderungsdynamiken sie unterliegt. Die Rückschau zeitphilosophischer, zeitsoziologischer und vor allem die Kontrastierung zeitanthropologischer Studien identifizierte die westliche Zeitauffassung als konzeptionelle Dreiteilung von Vergangenheit, Gegenwart und Zukunft und entsprechender Parameter der Bestimmung eines >Davor<, >Jetzt $<$ und eines >Nachher $<$. Diese Dreiteilung bildet den Bezugsrahmen jeglicher Sinnsetzungen der westlichen Kultur. Die Zeit wird dabei als kulturell tradiert, als linearer Verlauf bzw. kontinuierlicher Fluss von der Vergangenheit über eine (stets flüchtige) Gegenwart hin zur Zukunft idealisiert. Genährt wird die Vorstellung eines linearen Verlaufs dabei durch die Wahrnehmung des biologischen Alterns oder durch Wachstumsprozesse. Indem sämtliche vom Bewusstsein wahrnehmbare Veränderungen gegen ein >objektives` Bezugssystem der Uhrzeit gehalten werden, verspricht sich die westliche Kultur die Ausbildung von Ordnung und Sinnhaftigkeit. Der in dieser Zeitauffassung idealisierte Zeitpfeil verläuft dabei zwar gerichtet, direktional und irreversibel, nicht jedoch in eine teleologisch definierte, sondern in eine explizit offene Zukunft, die folglich in der Gegenwart (und auf Grundlage der Vergangenheit) aktiv gestaltet werden muss.

Beginnend in der Neuzeit wurde die Zeit im Zuge der industriellen Rationalisierungsbestrebungen und intrinsischen Effizienzbestrebungen qualitativ zur knappen Ressource, zum Wert und nicht zuletzt zur monetarisierbaren Ware aufgeladen. Die Wahrnehmung der Begrenztheit und Knappheit von Zeit resultiert in der handlungspraktischen Prämisse ihrer möglichst rationalen Nutzung. Die zeitsensiblen Produktionsverhältnisse eines >kapitalistischen Geistes erzwangen eine Verinnerlichung der Uhrzeit und die Entwicklung einer intensiven Sensibilität für den Zeitfluss. Nicht nur Organisationen, auch Staaten haben damit ein zentrales Interesse an Fragen der Zeitnutzung, der Zeitbestimmung und der Kontrolle über sie. Zeit wird folglich als Machtinstrument gebraucht, weshalb in der Folge Zeitbudgets ungleich verteilt sein können.

Systemtheoretisch betrachtet, steht die Entwicklung des westlichen Zeitbewusstseins in der Tradition sich aufgrund wachsender Komplexität immer stärker erweiternder Synchronisationsanforderungen. Zeit wurde das entscheidende Organisationsprinzip. Das darin vielleicht prägendste Charakteristikum des modernen Verhältnisses zur Zeit besteht in der Wahrnehmung einer allgemeinen Beschleunigung, die durch Effizienzversprechen angetrieben und aufgrund anschließender Überkompensation abermals erforderlich wird. Das westliche Zeitverständnis wird ferner in der Doppeldiagnose einer wahrgenommenen Beschleunigung und einer resultierenden Zeitkrise verstanden. Auf individueller Ebene ist die Entwicklung der Moderne dazu vom Kampf um die Abgrenzung und Etablierung von Eigenzeiten, einer allgemeinen Sehnsucht nach dem Augenblick, der Individualisierung der Zeiterfahrung und deren Fragmentierung 
in immer kleineren Einheiten sowie der Gleichzeitigkeit und der Vergegenwärtigung der Zukunft geprägt.

Zusammenfassend übt die Zeit im westlichen Kulturkontext eine starke Zentralität aus. Das durch Bergson vertretene Postulat eines rein qualitativen Zeitbegriffs der reinen, gelebten Dauer scheint, mit Blick auf die Entwicklungen und daran geknüpften Zwänge zur Zeitrationalität der letzten zwei Jahrhunderte, schlichtweg ferner denn je. Das Zeit-Mensch bzw. das Zeit-Gesellschaft-Verhältnis gilt vielleicht auch deshalb gemeinhin als gestört und zwiespältig.

Trotz eines Primats jener westlichen Zeitvorstellung sind jedoch weitere, heterogene Formen der zeitgebundenen Sinnstiftung wirksam. Anthropologische Positionen haben deutlich gezeigt, dass die Orientierungs- und Kommunikationsfunktionen der Zeit auch andersartig realisiert werden können. Zwar stellen jegliche Völker basale Bezüge zum Umgang mit Zeit her, diese stehen jedoch in Abhängigkeit von kulturellen Leitbildern und Sozialstrukturen und resultieren in zum Teil gänzlich unterschiedlichen Zeitauffassungen hinsichtlich Tempi, Modalitäten, Messgenauigkeit, Synchronisationsbedürfnissen oder der stark variierenden Auffassungen über Rationalität.

Mit der Extrahierung der fünf theoretischen Kernbefunde zum ontologischen Status, der Erfahrbarkeit, dem Wirkungsfeld, den Hauptfunktionen sowie der Charakteristik der westlichen Zeitkultur soll nun der zeittheoretische Komplex auf den Spezialfall des Wartens sin der Zeit « verengt werden. Mit anderen Worten: Was macht vor dem Hintergrund des herausgearbeiteten philosophischen und sozialwissenschaftlich-anthropologischen Grundverständnisses von Zeit sowie der abgeleiteten fünf Kernbefunde die Zeit auf individueller und systemischer Ebene zur Wartezeit und was macht sie qualitativ überhaupt zu einem zeitlichen Sonderfall?

\subsection{Von der Zeit zur Wartezeit: Versuch einer Theoretisierung}

\subsubsection{Individuell-subjektive Grundbedingungen für die Erfahrung von Wartezeiten}

Basierend auf den beiden ersten Kernbefunden zum Zeitverständnis bildet sich jede Form der Zeitwahrnehmung (zumindest im westlichen Kulturkreis) im wechselseitigen Verhältnis zwischen subjektiver Erfahrung von Rhythmen und Abfolgen aus, die gegen eine objektive Referenzgröße der mechanisierten Uhr- oder Kalenderzeit gehalten werden. Im Regelfall wird diese dialektische Verhandlung als Abfolge von Einzelereignissen und damit als sinnstiftender Verlauf spürbar. Weist dieses komplexe dialektische Verhältnis nun aber ein Ungleichgewicht auf, das statt der Wahrnehmung einer >Füllung< des Verlaufs mit Einzelereignissen eine gefühlte >Leere der Zeit verursacht, wird Zeit zur Wartezeit. Die >Leere des Wartens wird demnach durch eine Störung des subjektivindividuellen, verinnerlichten Umgangs mit der Zeit verursacht, die es plötzlich nicht mehr wie gewohnt zulässt, die individuelle Zeitkonzeption an eine objektive Zeitkonzeption zu knüpfen. Der Spezialfall einer Wartezeit wird also immer dann wahrgenommen, sobald eine Inkongruenz in der dialektischen Verhandlung der Zeitkonzeptionen 
auftritt. Mit anderen Worten: Einzelereignisse können nicht mehr im Schema der Folge eines >Vorher< und >Nachher ausgemacht werden, das Ordnungsversprechen des Zeitflusses ist unterbrochen bzw. ist der Zeitfluss aufgrund einer »Nicht-Anwendbarkeit der Parameter einer chronologischen Sukzessionslogik ${ }^{216}$ nur noch schwerlich oder gar nicht mehr erkennbar. In der Folge sind auch die sonst üblich herangezogenen räumlichen Orientierungsgrößen abwesend, weshalb die individuelle Erfahrung des Wartens oftmals semantisch mit dem raumassoziativen Begriff des gefühlten >Stillstands aufgeladen wird. Zudem wird die seit der Antike etablierte Vorstellung der Zeit an im Raum geknüpfte Bewegungen im Modus des Wartens empfindlich gestört, womit die Zeit folglich ihrer räumlichen Ausdruckskraft entbehrt. Kurzum, die Ableitungszusammenhänge zwischen subjektivem Zeitempfinden und objektiven Bezugsgrößen werden im Warten gestört. Eine solche zeittheoretische Identifizierung der Wartezeit als problematischer Moment der Inkongruenz kann dadurch die mitunter starken psychologischen Modalitäten wartender Menschen erklären, die von Langeweile und Verdruss bis hin zu Angstzuständen reichen. Inkongruenz, fehlende Abfolge von Ereignispunkten sowie die Nicht-Anwendbarkeit räumlicher Orientierungsmuster bedingen damit zusammen auf der individuell-subjektiven Ebene die Erfahrung des Spezialfalls Warten in der Zeit.

Folglich sollen an dieser Stelle mit Rückgriff aus der Phalanx zeittheoretischer Studien fünf Grundbedingungen für die Erfahrung von Wartezeiten destilliert werden, wobei sich die ersten drei Grundbedingungen aus philosophischen Betrachtungen, die vierte Grundbedingung aus der zeitsoziologischen und die fünfte aus der zeitanthropologischen Forschung ableitet.

1) Wartezeit braucht ein die Zeit wahrnehmendes Subjekt

Erstens erfordert jedes Warten zunächst ein das die Zeit wahrnehmendes Subjekt, welches über die generelle Fähigkeit einer Zeitwahrnehmung verfügt.

»Warten existiert nicht ohne das wahrnehmende Subjekt, ebenso wenig wie die Zeit ohne ein wahrnehmendes Subjekt Objekt von Reflexion sein kann. «17 $^{217}$

Die Begründung dieser aus alltagspraktischer Sicht offenkundig erscheinenden Vorbedingung leisteten bereits im Ansatz Platon und Aristoteles. Insbesondere aber war es Augustinus' Zeittheorie der >dreifachen Gegenwart‘, der die Zeitwahrnehmung als subjektimmanente Leistung herleitete.

2) Nur gefühlte Zeit kann zu einem Modus des Wartens werden

Zweitens muss als Vorbedingung gelten, dass Zeit nicht im Sinne Newtons als vom Menschen unabhängige, objektive und externe Naturgröße verstanden werden kann, denn

216 Benz, (Erzählte) Zeit des Wartens, 42.

217 Ebd., 44. 
»Während das Warten die Zeit als solche bewusst und fühlbar macht, kann umgekehrt nur bewusst gefühlte Zeit kann überhaupt zu einem Modus des Wartens werden. « ${ }^{218}$

3) Notwendigkeit von Ereignis und antizipierendem Bewusstsein

Drittens wird Zeit erst dann zur Wartezeit, wenn ein zu erwartendes Ereignis besteht. Während die beiden erstgenannten Grundbedingungen den Grundvoraussetzungen der Ausprägung jeglicher Zeitwahrnehmung entsprechen, bildet diese dritte eine Sonderbedingung für den Spezialfall des Temporalphänomens Warten aus. Nur in der Erwartung kann das Bewusstsein eine Synthese aus der Wahrnehmung eines aktuellen Zustandes im Abgleich mit einer referenziellen Gegengröße (Ereignis) und dessen momentaner Abstinenz leisten. Die seelische Kompetenz einer Antizipation des Kommenden (Expectatio), noch Ausstehenden und noch nicht Seienden ist - mit Rückgriff auf Augustinus - demnach nur in einem von Aufmerksamkeit durchzogenen Geist möglich.

4) Notwendigkeit zweier Zeiterfahrungsebenen

Viertens besteht die Notwendigkeit einer Existenz zweier Zeiterfahrungsebenen (objektiv/subjektiv-individuell). Nur unter dieser Voraussetzung kann es überhaupt so etwas wie eine subjektiv gefühlte Leere geben, die sich im bereits skizzierten Störfall des Abgleichs der wahrgenommenen Folge von Einzelereignissen gegen einen objektiven Bezugsrahmen ausbildet. Der temporale Spezialfall der Wartezeit kommt somit nicht ohne Betrachtung einer objektiven und subjektiven Vermitteltheit von Wartezeit sowie nicht ohne eine an den Raum gebundene Vorstellung der Zeit aus.

5) Kulturelle Prägung von Zeit- und Wartezeiterfahrung

Fünftens zeigte die Betrachtung von mit dem westlichen Kulturkreis konstratierender Zeitauffassungen die Grundbedingung auf, dass der Modus der Wartezeit vorzugsweise im Rahmen eines linearen Zeitverständnisses und einer Kopplung mit der Ökonomisierung der Zeitnutzung überhaupt erst als spezifischer Modus wahrgenommen wird. So existieren neben der linearen Zeitauffassung auch kulturell etablierte Zeitsysteme, die keineswegs zwangsläufig der Messung von Verläufen dienen müssen oder in denen Zeit zyklisch gedacht wird. Erst wenn die Zeit als linearer Verlauf verinnerlicht wird, kann aber die Störung der dialektischen Ausbildung von Zeiterfahrung im Verfahren subjektiver Eindrücke und dem Abgleich gegenüber einer objektiv Referenzgröße überhaupt stattfinden. Nicht wenige Völker kennen keine explizite Begrifflichkeit für die Zeit. Diese Völker kennen folglich möglicherweise auch kein im Sinne der westlichen Zeitkultur konnotiertes Dasein im Modus des Wartens.

In Ergänzung dieser fünf ontologischen Vorbedingungen zur Ausbildung des Wartemodus zeigten sich in der Aufarbeitung einiger Wegmarken des zeitphilosophischen Denkens zudem punktuelle Hinweise zur weiteren Qualifizierung des Warte-Phänomens. 
Platon und Aristoteles lassen noch keine explizite Thematisierung des Wartens erkennen, vielmehr lagen zunächst die Versuche zum Verständnis von Zeit in der Veranschaulichung mittels von Bewegungen im Raum. In der Spätantike lässt Augustinus jedoch erstmals eine indirekte Verhandlung des Wartens im Rahmen seiner Zeitkonzeption der dreifachen Gegenwart erkennen, die unter anderem einen einzig und allein in der Seele realisierbaren erwartenden Zeitmodus umfasst. Das Warten wird hier jedoch noch keineswegs qualitativ beschrieben. Eine Problematisierung des Zustands ist nicht erkennbar, vielmehr erscheint im Modus des Wartens eine Voraussetzung der >Vergegenwärtigung des Zukünftigen gesehen zu werden. Weit mehr als der spätantike Vordenker des Antizipierens thematisierte Henri Bergson das Warten im Zuge seines rein qualitativen Zeitverständnisses. Indem Bergson das Warten als Inbegriff des qualitativen Übergangs und des aktiven Erlebens begreift, wird dieser spezifische Modus für ihn zur zentralen Erklärungsgröße der Subjektivität von Zeit, ja Bergson instrumentalisiert gar das Warten mithilfe seines vielzitierten Zuckerwürfel-Experiments der sgelebten Dauer . Auch wenn hier das Warten per se noch keine psychologische Problematisierung erfährt, wird es als >spannungsvoller Zustand ‘ deklariert, der aus Sicht Bergson jedoch nicht punktuell wirksam werde, sondern als >menschliche Grundverfassung`schlechthin zu gelten habe.

\subsubsection{Ursprünge und Entstehungsbedingungen des Wartens}

Aussagen zu Ursprung und Entstehungsbedingungen von Wartezeiten lassen sich aus den philosophischen Zeitbetrachtungen in nur sehr begrenztem Maße gewinnen. Zwar nutzen etwa Heidegger und Bergson das Warten entweder direkt oder indirekt als Beweisführung ihrer jeweiligen Zeitkonzeptualisierungen, jedoch werden - anders als in der sozialwissenschaftlichen Auseinandersetzung - keine systemischen Katalysatoren oder qualitativen Einblicke hinsichtlich der konkreten Erfahrung formuliert.

Heidegger nutzt den Modus des Erwartens - ähnlich wie Bergson - im Rahmen seines fundamentalontologischen Zeitansatzes als einen Beleg dafür, dass sich auch das uneigentliche Dasein im Kern aber auf ein eigentliches Dasein stützt, das sich seiner Endlichkeit bewusst ist und daraufhin im Rahmen seiner Möglichkeiten handelt. Alltägliche Wartesituationen könnten aus der Perspektive Heideggers somit womöglich als wichtige funktionale Schlüsselstellen zur Selbstbestimmung des eigentlichen Daseins interpretiert werden. Das Warten in Alltagssituationen könnte somit nach Heidegger'schen Lesart die im uneigentlichen Dasein stets verdrängte Erinnerung an die eigene Vergänglichkeit reaktivieren und damit die Erinnerung an das für erstrebenswerte, existenzielle eigentliche Sein ermöglichen.

Bergson hingegen nutzt den Modus des Wartens ganz explizit als Veranschaulichungsfolie der Ablösung vom mechanisierten Zeitdenken. Die Zeit wird, verdeutlicht durch das Zuckerwürfel-Experiment, nicht mehr, wie üblich, als Aneinanderreihung unbelebter Zeitpunkte gedacht wird, sondern als qualitative Veränderung, die durch Anpassung des Geistes an den Rhythmus des Ereignisses ein aktives Moment aufweist.

Gleichwohl wird jenseits dieser abstrakten >Auskünfteく nur wenig über den erlebten Modus des Wartens selbst bekannt. Konkretere >Mitnahmen für eine Theoretisierung der Wartezeit hinsichtlich ihrer Ursprünge und Entstehungsbedingungen ermöglichen 
dagegen erst die zeitsoziologischen und kulturanthropologischen Studien. Sie behandeln weniger die philosophische Frage der eigentlichen Erkenntnisbedingungen der Wahrnehmung von (Warte)zeit, sondern beleuchten stattdessen die inhaltlichen Ausformungen, die Strukturbedingungen und subjektiven Zuschreibungen. Aus der Rückschau dieser Studien sollen nun folglich sechs Kernpunkte extrahiert werden, die für eine Theoretisierung der Wartezeit hilfreich erscheinen.

1) SSozialer< Ursprung von Wartezeiten

Erstens lässt sich mit Rückgriff auf Sorokin und Mertons Postulat der Zeit als sozialer Orientierungsfunktion, in der alltägliches Handeln weit öfter an sozialen Referenzpunkten als an astronomischen festgemacht werden würde, die Vermutung folgern, dass im Laufe der Zeit auch Wartezeiten stärker durch soziale Referenzpunkte als durch natürliche Referenzpunkte verursacht worden sein dürften.

2) Warten repräsentiert eine elementare Zeitstrategie

Die Ausführungen von Nowotny zeigten zweitens, dass das Warten (und warten lassen) als nur eine von vielen Zeitstrategien zur Strukturierung sozialer Beziehungen dient. Nowotny sensibilisiert dabei für die zentrale Erkenntnis, dass Wartezeiten ein soziales Ausdrucksfeld der Ungleichverteilung von Zeitbudgets repräsentieren. Die Perspektive des Wartens als abhängige Variable von Machtverhältnissen wird hierbei durch Nowotnys frappierende Feststellung illustriert: »Die Sprache hat keinen Ausdruck für den, der warten läßt, sondern nur für den Wartenden. ${ }^{219}$

3) Warten muss serlernt werden

Drittens lässt sich mit Rekurs auf Elias' Überlegungen für das Phänomen des Wartens schließen, dass analog zur Notwendigkeit des Erlernens der Zeitnutzung zum Zweck der Positionsbestimmung auch im Besonderen das Warten der Notwendigkeit des Erlernens unterliegt. Das Warten lässt sich damit im Zuge des Zivilisationsprozesses als eines der kritischsten >Temporalprodukte extrahieren, das einerseits den analytischen Blick auf die Mechanismen der Zeitproduktion im Sinne Elias offenlegt und andererseits selbst Produkt der in komplexen Gesellschaften zuweilen limitierten Synchronisationsfähigkeit ist.

4) Inkongruenz von Zeitebenen

Eine entscheidende Entstehungsbedingung von Wartezeiten sehen Schütz und Luckmann im Auftreten von Inkongruenzen zwischen verschiedenen Zeitebenen. Da aus ihrer Sicht das Zeiterleben in der Verschränkung dreier Zeitebenen realisiert wird, die dauernd rhythmisiert und zusammengehalten werden müssen, entstehen Wartesituationen besonders an den Reibungspunkten der Zeitebenen von Weltzeit, subjektiver und intersubjektiver Zeit, die Ausdruck von Inkongruenzen sind und dem Menschen folglich die unausweichliche Grundverfassung des Wartens auferlegen. Damit wird jedoch auch deutlich, dass das Warten - in Korrespondenz zu 
Henri Bergsons >durée < - als aktive Tätigkeit der Harmonisierung jener Zeitebenen $\mathrm{zu}$ betrachten sein sollte.

5) Resultat der Inkongruenz zwischen Temporalsystemen

Luhmanns Systemtheorie liefert eine zwar abstrakte, aber zugleich gewichtige Erklärung der systemischen Entstehungsbedingungen von Wartezeiten in der modernen westlichen Kultur. Indem er die Zeit als entscheidende qualitative Erklärungsgröße begreift und die fortschreitende Differenzierung gesellschaftlicher Teilsysteme in der korrespondierenden Ausbildung differenzierter Temporalsysteme versteht, entstehen Wartezeiten in hochentwickelten und komplexen Gesellschaften insbesondere aufgrund temporaler Inkongruenzen der verschiedenen Teilsysteme. Ähnlich verortet auch Bergmann die (moderne) Entstehungsbedingung der Wartezeit in der fehlerhaften Synchronisierung der gesellschaftlichen Teilsysteme: »If all social behaviour were embedded in one single time order, as is the approximate case in primitive, less differentiated societies, there would be no problem of temporal synchronization; the flow of time would unobtrusively accompany the course of behaviour. Only when, through social differentiation, individual and social time must be distributed among various areas of behaviour do problems of coordination arise. The results of this lack of synchronization are the scarcity of time, waiting time and >time out ‘.« ${ }^{220}$ Je stärker die Ausdifferenzierung der gesellschaftlichen Teilsysteme fortschreitet, desto stärker wird demnach auch ihre Anfälligkeit, an den Berührungspunkten zu anderen Teilsystemen aufgrund unterschiedlicher Rhythmen, Abläufen und arbeitsbezogener Zeitauffassungen Wartezeiten zu produzieren. Als Beispiel sei hierfür etwa der temporal betrachtet eher schwergängige Bürokratieapparat angeführt, der bei Bearbeitung von Anfragen der beschleunigten Startup-Szene eine deutliche Inkongruenz zwischen den vorherrschenden Temporalsystemen offenbart.

\section{6) Zeitkulturelle Inkongruenzen}

Wartezeiten, so zeigte die kulturanthropologische Perspektive, sind in hohem Maße nicht nur sozialstrukturell- sondern ebenso kulturabhängig. Sie entstehen damit insbesondere an den Schnittstellen variierender Zeitwahrnehmungen. So vertritt etwa Stuart Hall die These, dass ein Aufeinandertreffen monochroner (M-Zeit) und polychroner (P-Zeit) Kulturen zeitlicher Orientierung zu divergierender Synchronisation sozialer Tätigkeiten führen und Probleme von Unpünktlichkeit, Unzuverlässigkeit und damit von Wartezeiten produzieren würde. Aber auch innerhalb derselben Zeitkultur würden divergierende Zeitauffassungen bestehen, die Inkongruenzen in sozialen Austauschbeziehungen hervorrufen und in Wartezeiten resultieren können. Die Kulturanthropologie liefert damit komplementär zur Luhmann'schen Systemtheorie der heterogenen Temporalstrukturen gesellschaftlicher Teilsysteme ein aus der jeweiligen Kultur abgeleitetes Verständnis zeitbezogener Inkongruenzen. Ähnlich wie komplexe Aufgabe Synchronisation der gesellschaftlichen Teilsysteme sieht die kulturanthropologische Perspektive auf Zeitphänomene die zentrale 
Herausforderung folglich darin, die jeweilige Zeitkultur des Gegenübers verstehen $\mathrm{zu}$ lernen, um Missverständnisse (und schließlich Wartezeiten) im gegenseitigen Austausch abzubauen.

Mit diesem Kapitel konnten aus der geistes- und sozialwissenschaftlichen Konzeptualisierungsgeschichte der Zeit nunmehr fünf grundlegende Erkenntnisse für die Frage des Verständnisses von Zeit aus der heterogenen Forschungslandschaft extrahiert sowie eine Reihe von Ursprüngen und Entstehungsbedingungen für die Ausprägung von Wartezeiten auf individueller und systemischer Ebene abgeleitet werden. Diese Perspektiven bilden den konzeptionellen Rahmen für die nun anschließende Spurensuche der historisch variierenden Verhandlung von verkehrlich bedingten Wartezeiten seit dem 19. Jahrhundert.

Damit wird nun der aporizitäre und steinige Pfad geistesgeschichtlicher Theoretisierungen des Zeitbegriffs verlassen. Zu solch einem Schritt bemerkt Simonetta Tabboni zuversichtlich.

»Unlike the philosopher, the sociologist can undertake the more modest task of tracing in collective life the nature of that human experience which we call temporal and the consequences of working through that experience: norms and ways of organizing time invented to satisfy prevailing needs, individual choices, and the values and priority meanings that are attributed to it. « $^{221}$

Tabboni bezieht ihre Aussage zwar disziplinär auf die Soziologie, doch es wird hier als nicht weniger ertragreich erachtet, einen >maßvollen Übertrag auf die kulturgeschichtliche Betrachtung des Zeitphänomens Warten zu vollziehen. Genau dieser Schritt soll nun im Anschluss erfolgen. Dazu wird im folgenden Kapitel zunächst das Warten als zeitgeschichtliches Temporalphänomen der Moderne sverortet<, um daran anschließend die Untersuchung zeithistorisch auf die konkreten Analysestränge der baulichbetrieblichen und rezeptionsgeschichtlichen Verhandlung von verkehrsinduzierten Wartezeiten zu verengen. 



\section{Die Wartezeit als Konfliktfall der Moderne}

Nachdem mit dem vorangegangenen Kapitel der Überblick zur Konzeptionalisierungsgeschichte der Zeit abgeschlossen wurde, kann nunmehr die Engführung auf die Beschäftigung mit Wartephänomenen hinsichtlich ihrer Verhandlungen im zeithistorischen Kontext sowie ihrer individuellen, symbolischen und sozialen Ausdrucksfelder in den Vordergrund erfolgen. Mit dem folgenden Kapitel wird daher in einem ersten Schritt zunächst die massive Zunahme alläglicher Wartesituationen als >modernes Phänomen charakterisiert. Indem Wartezeiten in den spezifischen Kontext des sich seit der Neuzeit etablierten Modernisierungsprozesses der Beschleunigung gestellt werden, wird einerseits deren relative Neuartigkeit verdeutlicht und andererseits deren zunehmende Aufladung zum >Konfliktfalk der Moderne hergeleitet. Anschließend werden Wartephänomene in einem zweiten Schritt ausgehend vom Befund ihrer Problematisierung in einem Exkurs entlang der vielfältigen disziplinären Auseinandersetzungen beleuchtet, um schließlich in einem dritten Schritt das Auftreten von Wartezeiten konkret auf das Handlungsfeld des modernen Verkehrswesens zu verengen und als explizit mobilitätsbezogenes Phänomen zu betrachten.

\subsection{Zeithistorische Verortung und Eingrenzung: Warten als temporales Phänomen inı der Moderne}

Die vorangegangenen zeittheoretischen Ausführungen machten deutlich, dass Menschen in allen Epochen ein mehr oder minder explizit ausgeprägtes Bedürfnis nach zeitlicher Orientierung entwickelten und daraufhin in Abhängigkeit gesellschaftlicher Komplexität und Synchronisationsansprüche Temporalstrukturen ausbildeten, welche die endlose Abfolge von Ereignissen in ein sinnstiftendes und kommunikatives Ordnungssystem entlang der Kategorien von Vergangenheit, Gegenwart und Zukunft übersetzen sollten. Als übergeordnetes Motiv der Zeitnutzung und -bestimmung soll daher nochmals konstatiert werden, dass die Existenz jeglichen Zeitsystems allgemein als Ausdruck dafür gelten kann, »daß Menschen Positionen, Dauer von Intervallen, Tem- 
po der Veränderungen und anderes mehr in diesem Flusse zum Zwecke ihrer eigenen Orientierung zu bestimmen suchen. $\aleph^{1}$

Über diese zivilisationsgeschichtliche Konstante eines Orientierungsmittels hinausreichend, können wir zudem mit Rückgriff auf Husserls Postulat eines inneren Zeitbewusstseins ${ }^{2}$ also zunächst davon ausgehen, dass nicht nur ein allgemeines Empfinden von Veränderungen zur anthropologischen Grundausstattung des Menschen gehört und die universelle Voraussetzung einer immer komplexer werdenden Temporalisierung des Erlebens bildet, ${ }^{3}$ sondern damit verbunden auch die mehr oder weniger spezifische Empfindung einer Anomalie in Form des Wartens oder des Aufschubs. Warten auf Rückkehr, auf das Ende des Winters oder auf das Jüngste Gericht repräsentierten zweifelsohne bereits in der Vormoderne lebenspraktische Erfahrungen, die im Abgleich zwischen Erwartung und Erfahrung mit einer situationsbedingt veränderten Zeitwahrnehmung einhergingen.

Das zeitliche Bewusstsein bzw. die Erfahrung eines relativen Stillstands kann an dieser Stelle keineswegs in der zivilisationsgeschichtlichen Breite beschrieben werden. ${ }^{4}$ Vielmehr soll hier jenes Zeitbewusstsein epochal im Kontext der Modernisierungstheorien verortet und anschließend im Handlungsfeld des modernen Verkehrswesens empirisch greifbar gemacht werden. Legitimiert wird diese Eingrenzung über eine quantitative und eine qualitative Zäsur, die im Zuge der Moderne deutlich wird. Erstens durch die quantitative Häufung und Vervielfachung von Wartesituationen. Zweitens durch ihre explizitere Wahrnehmung, ihre alltagspraktische Relevanz sowie durch ihre wachsende kulturelle Problematisierung. Die Verortung des Wartens in der Moderne< geschieht demnach nicht willkürlich, sondern fast zwangsläufig aufgrund ihrer in dieser Epoche außergewöhnlichen, systemischen Entfaltung und alltagspraktischen Bedeutung.

Der Versuch einer solchen Verortung trifft jedoch unmittelbar auf die Problematik, dass kaum ein Begriff derart schillernd und von Unschärfe geprägt ist, wie jener der >Moderne $<$. Der Begriff der >Moderne beinhaltet stets ein hohes Maß an Suggestivität und Assoziationspotential und erfreut sich vielleicht gar erst aufgrund dieser Unschärfe einer derart großen Attraktivität. ${ }^{5}$ Ausgehend von einer anfänglichen Folie zur Beschreibung philosophischer Strömungen seit der Renaissance im Allgemeinen und Descartes im Besonderen, wurde der Begriff der >Moderne im deutschsprachigen Raum erstmals 1886 durch ein Berliner Literaturkollektiv eingesetzt, um ein vollkommenen Neues und von traditionellen Regeln der Ästhetik abgelöstes Schreiben auszu-

2 Stephen Kern ergänzt dazu, dass die menschliche Existenz ohne eine gewisse Vorstellung der eigenen Vergangenheit nicht denkbar sei (Kern, The culture of time and space, 1880-1918, xxi.).

3 Vgl. Luhmann, »Die Zukunft kann nicht beginnen. Temporalstrukturen der modernen Gesellschaft«, 124.

$4 \quad$ Hierfür kann jedoch nochmals auf die punktuellen Interpretationen der Wartezeit im Rahmen der vorgestellten philosophischen und sozialwissenschaftlichen Zeittheorien in Kap. 2 verwiesen werden.

5 Vgl. Daniel Fulda, »Sattelzeit. Karriere und Problematik eines kulturwissenschaftlichen Zentralbegriffs«, in Sattelzeit: historiographiegeschichtliche Revisionen, hg. von Elisabeth Décultot und Daniel Fulda, Hallesche Beiträge zur Europäischen Aufklärung 52 (Berlin; Boston: De Gruyter, 2016), 1. 
drücken. Nur wenig später, im Jahr 1895, nahm der Brockhaus den Begriff auf und gab damit seine offizielle Verwendung frei. ${ }^{6}$ Zuschreibungen des >Modernen haben somit allgemein gesprochen seit dem 19. Jahrhundert Konjunktur und bezwecken dabei jeweils die deutliche Abgrenzung aktueller Entwicklungen von vorherigen Entwicklungen.

Was aber zeichnet die Programmatik der Moderne inhaltlich aus und wie lässt sich der Bruch gegenüber einer Vormoderne erklären? Welche Entwicklungen sind es, die sprachlich von vorherigen Entwicklungen so deutlich mit der Akzentuierung des >Modernen abgegrenzt werden sollten? Die Erlangung eines tieferen Verständnisses jedweder Phänomene der Neuesten Geschichte wird wohl kaum um die Beschäftigung mit solchen Fragen umhinkommen. Da im Mittelpunkt des Erkenntnisinteresses dieser Arbeit die Längsschnittbetrachtung der massiven Häufung verkehrsinduzierter Wartephänomene steht, die mit der Entstehung des Eisenbahnwesens in den 1830er Jahren ihren Anfang markiert, werden daher auch hier Einblicke in Evolution und Kerngehalt der Moderne benötigt.

\section{Definitionen, Prinzipien und Periodisierungen: Meisternarrative der Moderne}

Unter >Moderne wird zunächst allgemein mit Rekurs auf Giddens die seit dem 17. Jahrhundert in Europa einsetzende Epoche der Etablierung spezifischer Formen des Sozial-, Geistes- und Wirtschaftslebens verstanden, die sich von vormodernen Gesellschaften abzugrenzen vermochten und von Europa ausgehend eine mehr oder minder weltweite Verbreitung erfuhren. ${ }^{7}$ Giddens konkretisiert die Abgrenzung gegenüber vormodernen und traditionalen Gesellschaften über die Merkmale der Geschwindigkeit des Wandels, der globalen Reichweite dieses Wandels, der deutlichen Abhängigkeit der Produktion von unbelebten Energiequellen sowie der durch Industriekapitalismus vorherrschenden Transformation von Arbeitskraft und Erzeugnissen in Warenform (Komodifizierung). ${ }^{8}$ Ferner ist die Moderne nach Giddens durch die Entstehung eines besonderen Institutionenwesens geprägt, das vor allem in Form des Nationalstaates die soziale Interaktion in größeren territorialen Gebietszusammenhängen gewährleistet und durch demokratische Legitimation geprägt sei. All diese seit der Neuzeit entstandenen Institutionen stehen für Giddens im Zeichen einer >Diskontinuität<, also einer gegenüber traditionalen Ordnungen gänzlich einzigartigen Form der Gesellschaftsentwicklung, die insbesondere in der Stadt ihren markantesten Ausdruck findet. Giddens bemerkt zusammenfassend zum disruptiven Wesen der Moderne:

»Die durch die Moderne entstandenen Lebensformen haben uns in ganz beispielloser Weise von allen traditionalen Typen der sozialen Ordnung fortgerissen. ${ }^{9}$

Luhmann definiert, wie bereits ansatzweise oben herausgestellt, den Kerngehalt der Moderne in der Ablösung (und Überwindung) vormals hierarchischer und stratifikatorischer Gesellschaftsordnungen durch das fundamentale Strukturprinzip der »funktio-

6 Vgl. Christof Dipper, »Moderne«, Docupedia-Zeitgeschichte, 2010, 3.

7 Vgl. Anthony Giddens, Konsequenzen der Moderne (Frankfurt a.M.: Suhrkamp, 1996), 9.

8 Vgl. ebd., $14 f$.

9 Ebd., 13 [Herv. i. O.]. 
nalen Differenzierung «. ${ }^{10}$ Zwar unternimmt Luhmann keinen allzu konkreten Versuch einer zeitlichen Datierung dieses Übergangs, dennoch vermutet er, »daß irgendwann die Rekursivität der autopoietischen Reproduktion sich selbst zu fassen beginnt und eine Schließung erreicht, von der ab für Politik nur noch Politik, für Kunst nur noch Kunst, für Erziehung nur noch Anlagen und Lernbereitschaft, für die Wissenschaft nur noch Kapital und Ertrag zählen (...)«. ${ }^{11}$ Jener Selbstbezug der funktional ausdifferenzierten Systeme bildet für Luhmann eines der entscheidenden Wesensmerkmale der Moderne. Der funktionalen Differenzierung vorgelagert sieht Luhmann aus temporalanalytischer Sicht den entscheidenden Übergang in eine smoderne Zeitstruktur in der allgemeinen »Verzeitlichung des Seins $\aleph^{12}$, die wiederum Folge der gewandelten Betrachtung und Bewertung von Vergangenheit und Zukunft sei. Demnach änderte sich im Zuge der Ausbildung bürgerlicher Gesellschaften allmählich das Verständnis einer vormals allein mit einem historischen Ereignis (Christi Geburt) einsetzenden Vergangenheit hin zu einem Geschichtsverständnis, das erstmals auch eine rückwärtsgerichtete Zeitrechnung (vor Christi Geburt) erlaubte. Diese fundamental veränderte Zeitauffassung bewirkte ihrerseits, dass auch die Zukunft nicht länger als Annäherung an ein fixiertes Ereignis (z.B. die Erlösung), sondern vielmehr als offen und kontingent interpretiert werden musste. Moderne Temporalstrukturen zeichnen sich somit zusammenfassend durch eine relationale Betrachtung von Vergangenheit und Zukunft aus, die jeweils dem Zweck dient, Veränderungen wahrzunehmen und verändernd auf die Gegenwart einzuwirken. ${ }^{13}$ Funktionale Differenzierung und die Verzeitlichung des Seins bilden somit zusammenfassend zwei bis in die Gegenwart hinein wirksame Kerncharakteristika der Moderne.

Zapf sieht moderne Gesellschaften - besonders mit Blick auf jene des 20 . Jahrhunderts - ähnlich wie Giddens durch Ausprägung von Basisinstitutionen (Konkurrenzdemokratie, Marktwirtschaft, Wohlstandsgesellschaft mit Massenkonsum, Wohlfahrtsstaat) definiert. Auch er bezeichnet die Moderne in wirtschaftlicher Hinsicht mit dem Aufkommen des Industriekapitalismus sowie in politischer Hinsicht mit der Demokratisierung. ${ }^{14}$

Beck und Mulsow beschreiben die Epoche ergänzend als Phase der Verfestigung, >Ontologisierung und Naturalisierung vormals noch ambivalenter und doppelsinniger Prozesse. ${ }^{15}$ In Abgrenzung innerhalb der Moderne kontinuierlich anhaltender Epochenschwellen bezeichnen sie die Epochenschwelle des Übergangs von der Vormoderne zur Moderne als >Erste Moderne . Sie beginnt demnach im Zeitraum der Aufklärung

10 Niklas Luhmann, Die Gesellschaft der Gesellschaft, Teilbd.2 (Frankfurt a.M.: Suhrkamp, 1999), 678-743.

11 Ebd., 708.

12 Luhmann, »Die Zukunft kann nicht beginnen. Temporalstrukturen der modernen Gesellschaft«, 120.

13 Hierzu auch ergänzend Elias, der in Bezug auf die Relationalität der Zeitmodalitäten konstatiert: »Nur im Erleben der Menschen gibt es die gewichtigen Scheidelinien zwischen dem, was sheute`, was >gestern< oder was >morgen< ist. «Elias, Über die Zeit, 104.

Vgl. Wolfgang Zapf, »Entwicklung und Sozialstruktur moderner Gesellschaften«, in Einführung in Hauptbegriffe der Soziologie, hg. von Hermann Korte und Bernhard Schäfers (Wiesbaden: Springer Fachmedien Wiesbaden, 2016), 308ff. 
und wird in geistiger Nähe zum Luhmann'schen Modernitätsbegriff durch die allmähliche Ausbildung »trennscharfe[r] Grenzen zwischen Kategorien von Menschen, Dingen und Tätigkeiten« charakterisiert, wobei »Unterscheidungen zwischen Handlungssphären und Lebensformen, die die eindeutige institutionelle Zuschreibung von Zuständigkeit, Kompetenz und Verantwortung ermöglichen ${ }^{16}$ getroffen werden. Beck und Mulsow ermahnen jedoch gleichsam zur Vorsicht im Rückblick auf die Ausformung der sich auf dem Weg zu einer `Ersten Moderne ausbildenden Basisprinzipien ${ }^{17}$, die stark zeitversetzt und regional ungleich wirksam wurden.

Aus einer stärker erfahrungsbasierten und kulturgeschichtlichen Perspektive identifiziert Stephen Kern das Wesen der Moderne in der Ausbildung eines "positive negative space $\ll^{18}$, einer allgemeinen durch Technologieentwicklungen vermittelten Erfahrung von Simultanität sowie einer dramatischen Transformation des Distanzbezugs. Zudem sieht Kern - in Übereinstimmung mit Luhmann - die Moderne durch einen Generalangriff auf alles Ständische und Feudale gekennzeichnet, in dessen Folge tradierte soziale Hierarchien erodiert seien. ${ }^{19}$ Ähnlich sieht auch Conrad das Unternehmen der Moderne in der heroischen Ablösung, jedoch nicht nur von tradierten Formen des $\mathrm{Zu}$ sammenlebens, sondern von der bisherigen Geschichte überhaupt. Speziell der Beginn des 20. Jahrhunderts markierte danach ein nicht vergleichbares Streben nach Aufhebung von Distanz, Dauer oder Form unter der Prämisse der Erschaffung absoluter und präzedenzloser >Neuheit<, die sich bis auf die Ebene der radikalen Modifizierung der eigenen Körperlichkeit erstreckte. ${ }^{20}$

Die Theoretisierungsversuche der politischen, sozialen, wirtschaftlichen und kulturellen Basisprinzipien und -institutionen ließen sich, insbesondere auch hinsichtlich der Ambivalenzen und Schattenseiten der Modernisierungsprozesse, ${ }^{21}$ selbstredend erweitern. Die Mehrheit der Moderne-Diagnosen verbleibt dabei jedoch meist auf sehr abstrakter Ebene, was auf die Interpretation konkreter historischer Phänomene mitunter problematisch wirken kann. Als besonders fruchtbare Epochendeutung erscheint daher - speziell bezüglich der Frage des zeitlichen Beginns der allmählichen Etablierung moderner Basisprinzipien und seiner historischen Quellenevidenz - Kosellecks 1972

16 Ebd., 34.

17 Unter >Basisprinzipien < verstehen Beck und Mulsow »kognitiv-normative Problemstellungen, die sozusagen die treibende Kraft der Moderne ausmachen« (Ebd., 19.)

18 Hierunter versteht Kern ein in der Kunst auffälliges Prinzip der Neubetrachtung und Neunutzung von Räumen, die von der Kunst inspiriert gar die Kriegsführung (Erfindung des Camouflage) veränderte. Zuvor als störend oder unnütz empfundene Leerstellen rückten nunmehr ins Zentrum der Beschäftigung und etablierten eine neue Denkordnung. Für die Kunst gesprochen, stand, wie etwa im Kubismus Picassos, nicht mehr allein die ästhetische Wirkung im Vordergrund, sondern die Form selbst wurde zum Inhalt der Kunst (Kern, The culture of time and space, 1880-1918, xxvii und 315).

19 Vgl. ebd., 313-18.

20 Vgl. Peter Conrad, Modern Times, Modern Places: [Life \& Art in the 2oth Century (London: Thames \& Hudson, 1999), $14 \mathrm{f}$.

21 Eine gute Übersicht jener Schattenseiten im Spektrum von Ökokatastrophen und Vermassung liefert Rosa, Beschleunigung: die Veränderung der Zeitstrukturen in der Moderne, $107 \mathrm{ff}$. 
eher beiläufig eingeführte Metapher der `Sattelzeit oder auch `Schwellenzeit<. ${ }^{22}$ Koselleck bezeichnet mit diesen Begriffen eine Abgrenzungsphase von vormodernen Strukturen, die sich in der Erfahrung einer besonderen Krisenhaftigkeit der Zeit um 1800 auszeichnet und durch eine Vielzahl empirischer Funde Gewicht erlangt. Nach dieser bis heute weitläufig rezipierten (aber auch kritisierten) Auffassung lässt sich »zwischen rd. 1750 und rd. $1850 \ll^{23}$ in Europa ein begrifflicher Wandel und eine vornehmlich über ein gewandeltes Geschichtsverständnis artikulierte Reform der Selbstwahrnehmung erkennen. Gemeint sind hiermit eine aus dem theoretischen Fundament der Aufklärung entspringende zunehmende Säkularisierung, Verwissenschaftlichung und Professionalisierung, die sich nicht allein exklusiv auf die Sphäre einer reformierten Geschichtsschreibung bezogen, sondern darüber hinaus zu übergeordneten Maximen reiften, die in die gesamte politisch-soziale Semantik hineinwirkten. Mit den einsetzenden Entwicklungen wird eine rapide Veränderung der gesamten Weltdeutung und -Wahrnehmung vermutet, die schließlich als geistige Wegbereitung der bis in die Gegenwart wirksamen Modernisierungsprozesse interpretiert werden kann.

Die Metapher des Sattels symbolisiert hierbei den Übergang von einem alteuropäischen Geschichtsdenken in eine moderne Geschichtsauffassung, der jedoch keineswegs von einer linearen Entwicklung, sondern durch das gleichzeitige Nebeneinander von Beharrungs- und Modernisierungsimpulsen geprägt war. Demnach lassen sich auch noch bis weit ins 19. Jahrhundert hinein vielzählige vormoderne Merkmale ausmachen, von denen später im Kontext des Eisenbahnverkehrs - insbesondere im Kontext der Romantisierung der Postkutsche gegenüber der Eisenbahn - noch zu sprechen sein wird. Den Beharrungsbefunden zum Trotz, sieht Koselleck seit dem späten 18. Jahrhundert gleichwohl die übergeordnete Gerichtetheit jener neuen Weltdeutung und -Wahrnehmung. Begriffsgeschichtlich beinhaltet diese Gerichtetheit einen »Wandel vom vorneuzeitlichen zu unserem Sprachgebrauch ${ }^{24}$, den Koselleck wie folgt zusammenfasst:

»Alte Worte, etwa Demokratie, Freiheit, Staat bezeichnen seit rund 1770 einen neuen Zukunftshorizont, der den alten Begriffsgehalt anders umgrenzt; überkommene Topoi gewinnen Erwartungsgehalte, die ihnen früher nicht innewohnten. ${ }^{25}$

In geistiger Nähe zu Luhmanns Postulat einer allgemeinen Verzeitlichung des Seins, das die moderne Gegenwart nunmehr mittels einer relationalen Betrachtung von Vergangenem und Zukünftigem erzeugt, identifiziert Koselleck demnach die temporalstrukturelle Wegbereitung der Moderne als ein erstmaliges Auseinandertreten von Erfahrungen und gewandelter Erwartungshaltungen. ${ }^{26}$

Besonders interessant für die Explikation von Wartesituationen als spezifisch modernes und zunehmend problematisches Charakteristikum der alltäglichen Lebenspraxis erscheint hierbei Kosellecks These einer zeitgenössischen, allgemeinen >Dynami-

Reinhart Koselleck, »Einleitung «, in Geschichtliche Grundbegriffe, hg. von Otto Brunner, Werner Conze, und Reinhart Koselleck, Bd. 1 (Stuttgart: Klett-Cotta, 1972), xiii-xxvii.

23 Reinhart Koselleck, Zeitschichten: Studien zur Historik (Frankfurt a.M.: Suhrkamp, 2013), 303.

24 Ebd., 302.

25 Ebd., 303.

26 Koselleck, Vergangene Zukunft, 38-66 sowie 349-374. 
sierung licher Bewegungs- und Beschleunigungsmethapern zurückführt. Symptomatisch für den Übergang in die Moderne stellt Koselleck fest, dass ein gemeinsamer Nenner des politisch-sozialen Vokabulars darin bestand, »daß in steigendem Ausmaße Bewegungskriterien auftauchen «, die folglich in der Zeit um 1800 eine »Denaturalisierung der alten Zeiterfahrung « ${ }^{27}$ bedingt hätten. Diese Denaturalisierung bedeutet, dass die Zeit im epochalen Bruch der >Sattelzeit in den Stand eines hochrelevanten Mediums zur Messung des Fortschritts im Erreichen eines vielfach gewandelten Erwartungshorizontes gehoben wurde, was wiederum schließlich seinen deutlichsten Niederschlag in einer neuartig dynamisierten und bewegungsaffinen Sprachlichkeit zu finden schien.

In prinzipieller Befürwortung der Sattelzeit-These identifiziert Osterhammel den Übergang von Vormoderne zu Moderne in der Periode von 1770 bis 1830 noch etwas enger. ${ }^{28}$ Begründet wird dies damit, dass dieser Zeitraum aus Sicht der zeitgenössischen Historiker einen >revolutionären Zeitraum der Umbrüche spiegelte. Osterhammel hebt in Unterscheidung zu Koselleck jedoch die geografische Tragweite der revolutionären Veränderungen auf eine globalhistorische Perspektive und sieht die Epoche der revolutionären und krisenhaften Veränderungen zwischen 1770 und 1830 weniger exklusiv im Kontext einer europäischen Entwicklung als vielmehr auch im Kontext der durch Kolonialismus und Zusammenbruch außereuropäischer Großreiche bedingten Krisen in der Neuen Welt, in Afrika und Asien. ${ }^{29}$

Übergreifend wird demnach die Französische Revolution 1789 samt ihrer Vorbereitungen und Nachwirkungen als entscheidende Wegmarke für den Initialprozess der modernen Epoche begriffen. Die Betonung liegt hierbei dezidiert auf dem Initialprozess, denn die mit der Sattel- oder Schwellenzeit einsetzenden Modernisierungsprozesse bleiben bis in die Gegenwart hinein kontinuierlich >in Bewegung .

Die Modernisierung hat jedoch keinesfalls ihren Abschluss gefunden, sondern sie reformiert sich im andauernden Prozess. Um diesen Prozess nachvollziehbar zu machen, beinhaltet fast jede Reflektion über die Moderne somit auch den Versuch ihrer Periodisierung in Epochenphasen. Neben der zeitlichen Einordnung des Übergangs von Vormoderne zur Moderne zeigen sich dabei deutliche Schwierigkeiten in der Abgrenzung innerhalb einer an Komplexität wachsenden, durch fortlaufende Wandlungen, Ambivalenzen, Widersprüche und regionale Disparitäten gekennzeichneten Moderne. Am schwersten erscheinen dabei die Bestimmungen des Bruchs (oder der Brüche) zwischen einer >Ersten $<$ und >Zweiten $<$ Moderne bzw. einer `Spät $<$ - oder >Postmoderne $<\mathrm{zu}$

27 Koselleck, Zeitschichten, 303. Beck und Mulsow bezeichnen in Anschluss an Koselleck die einsetzende Epoche entsprechend als>Bewegungsmoderne< (Beck und Mulsow, Vergangenheit und Zukunft der Moderne, 39.)

28 Vgl. Jürgen Osterhammel, Die Verwandlung der Welt: eine Geschichte des 19. Jahrhunderts (München: Verlag C. H. Beck oHG, 2016), 102ff. An anderer Stelle vermerkt Osterhammel zur Besonderheit des Zeitraumes um die Französische Revolution: »(..) man hat als vergleichend arbeitender Historiker den Eindruck, dass sich selten innerhalb von etwa sechzig Jahren so viel veränderte wie zwischen etwa 1770 und 1830 « (Osterhammel, »Übergange ins 19.Jahrhundert - Anmerkungen eines Historikers«, 39). 
sein, da hier die scheinbar einfachere kategoriale Abgrenzung von modernen gegenüber traditionalen Gesellschaften nicht mehr zulässig ist.

Ohne hier nun tiefer in den Kanon der kontrovers diskutierten Periodisierungen einsteigen zu wollen, sei an dieser Stelle auf Christof Dippers kulturhistorische Perspektive zur Problematik der Schwellensetzungen verwiesen, die vielleicht trotz ihrer Abstraktion als aufschlussreichste Antwort auf die Frage der Periodisierungen dienen kann:

»Die Moderne besteht aus einer Kette von Epochen (...), die von Kulturschwellen eingeleitet werden, in denen sich die antagonistischen Ordnungsmuster ändern. $\ll^{30}$

Es bleibt somit schließlich festzuhalten, dass die Definitionen der Moderne jenseits des überwiegenden Konsenses eines konkreten Ausgangspunkts im Rahmen der Revolutionsphasen des späten 18. Jahrhunderts heterogen, ihre nachfolgenden Periodisierungen unscharf bleiben. Rammler vermerkt daher in gebotener Vorsicht, »daß Modernisierung als eine Gesamtentwicklung zu betrachten ist, die aus vielen verschiedenen, sich gegenseitig durchdringenden, beeinflussenden und überlagernden Teilprozessen besteht. ${ }^{31}$

Die skizzierten Beschreibungen und Theoretisierungen jener Teilprozesse haben teleologische Meisternarrative und gewichtige Axiome geschaffen. Aus wirtschaftlicher Perspektive erscheint die Moderne danach zuvorderst in der Ausbildung eines rationalen Industriekapitalismus unter der Prämisse der Zeitökonomie, Naturbeherrschung und Energieabhängigkeit. Politisch betrachtet umfasst ein weiteres Meisternarrativ die Etablierung des Nationalstaates, die Bürokratisierung und die allmähliche Ausbildung demokratischer Institutionen. Auf sozialer Ebene bilden Individualisierung, Urbanisierung und Freisetzung des Menschen aus feudalen Abhängigkeitsverhältnissen (bei Entstehung gänzlich neuer Abhängigkeitsverhältnisse) die wesentlichen Bestandteile dieser Meta-Narration. Auf kultureller Ebene schließlich sind es die durch wissenschaftlich-technische Innovationen induzierten Möglichkeitserweiterungen, die erfahrene Raum-Zeit-Verdichtung, ein damit verbundenes $>$ Neues Sehen ${ }^{32}$ sowie künstlerisch-ästhetische Neuentwürfe, die sich über ein Streben nach einem Bruch mit der Vergangenheit definieren. Diese Charakteristika der Moderne bilden die Hauptlinien geistes- und sozialwissenschaftlicher Erzählungen. Sie gaben (und geben) dem historischen Verlauf Tempo und Richtung.

Diese Meisternarrative können jedoch keinesfalls exklusiv als optimistische und linear wirksame Fortschrittserzählung verstanden werden. Keinesfalls kann das affirmative Telos der Moderne den Blick auf die inhärenten Ambivalenzen, Krisen und Irritationen verdecken. Ein Credo der sich reflektierenden Moderne besteht gerade darin, jene Tendenzen und Kräfte kritisch zu hinterfragen, etwa mit Blick auf die modernen

Christof Dipper, »Die Epoche der Moderne: Konzeption und Kerngehalt«, in Vergangenheit und Zukunft der Moderne, 179. 
Katastrophen zweier Weltkriege sowie der wirtschaftlichen, sozialen und ökologischen Krisen. Die Geschichtsschreibung, so Beck und Mulsow, hat sich daher heute »von linearen Meisternarrativen der Moderne verabschiedet « und sei »skeptisch gegenüber Erzählungen von Fortschritten hin zum Rechtsstaat, Konsumstaat, zur Wissensgesellschaft, zur säkularisierten Welt usw. ${ }^{33}$ Vielmehr war und ist die Moderne durch Ambivalenzen gekennzeichnet, weshalb positive oder negative Werturteile vorschnell und unterkomplex bleiben. ${ }^{34}$

$\mathrm{Zu}$ solchen vorschnellen und unterkomplexen Werturteilen zählt es etwa auch, die Moderne in Bezug auf das Meta-Narrativ der >Bewegungsmoderne verkürzt als Epoche der rastlosen Möglichkeitserweiterung und grenzenlosen Raum-Zeit-Vernichtung zu deklarieren, ohne dabei die komplementären Nebenwirkungen miteinzubeziehen. $\mathrm{Zu}$ diesen Nebenwirkungen zählt zweifelsohne das Aufkommen von einer Vielzahl durch die Modernisierungsprozesse selbst erst induzierter Retardierungsmomente. Erst vor dem Hintergrund der veränderten Zeitstrukturen der Moderne, jener Geistesepoche, in der Zeiteffizienz, Rationalisierung und Beschleunigung die entscheidenden ökonomischen und Subjektivität bzw. Zeitsensibilität die kulturell-sozialen Makro-Prozesse gesellschaftlicher Veränderung markieren, treten Reibungsprobleme in Gestalt von Wartezeiten überhaupt erst >spürbar in einer Vielzahl von Systemzusammenhängen hervor. Wenn das Warten in einem definitorischen Aspekt stets durch die Antizipation, Imagination und Erwartung von etwas Kommenden gekennzeichnet ist, so bieten die skizzierten Prozesse im Übergang von der Neuzeit bis hinein in die gegenwärtige >Zweite Moderner eine wachsende Ausdehnung an Gelegenheiten (und Zwängen!), kurzum eine sukzessive Potenzierung von Anlässen jeglicher Art, auf etwas zu warten.

Alltäglicher Ausdruck jener durch Reibungsprobleme entstehenden Dysfunktionalitäten und nicht intendierte Nebenfolgen bilden temporäre Stauungen, Knappheiten, Defekte oder - in pathologischer Form der Verlangsamung - auch Depressionen. Überall dort, wo die Nachfrage an Gütern oder Raum (für Bewegungen) ein Angebot übersteigt, treten Engpässe auf, die in Verzögerungen oder Wartezeiten resultieren. Nicht allein im Verkehrskontext, auch in Ämtern und Behörden, öffentlichen Einrichtungen (etwa Schwimmbäder oder Opernhäuser) gehören Wartezeiten - im Spektrum kurzzeitiger bis hin zu längerer Zeitdauer - und die korrespondierende Bereitstellung von Architekturen spätestens seit dem 19. Jahrhundert zu den signifikantesten Grunderfahrungen der modernen westlichen Lebenswelt.

Damit soll nun abschließend folgendes der Arbeit zugrundeliegendes Moderneverständnis das kontextuelle Gerüst der historischen Längsschnittinterpretation des Wartephänomens bilden: Einerseits wurde mit der weltgeschichtlichen Bruchphase der sSattelzeit`zunächst der modernitätstheoretische Einstieg für die diachrone Betrachtung verkehrsinduzierter Wartesituationen identifiziert. Die transformatorische Phase der sSattelzeit bietet die Vorteile, auf empirischer Seite insbesondere für die Aspekte einer um 1800 als revolutionär wahrgenommenen Verzeitlichung und Beschleunigung

33 Beck und Mulsow, Vergangenheit und Zukunft der Moderne, $15 f$.

34 Vgl. Dipper, »Die Epoche der Moderne: Konzeption und Kerngehalt«, in Vergangenheit und Zukunft der Moderne, 119. 
des Lebens zu sensibilisieren sowie auf methodischer Seite auf die enge Verzahnung von Zeit und Sprache aufmerksam zu machen. Darüber hinaus kann im Sinne der Analyse von Wartephänomenen ein mit der `Sattelzeit` einsetzender Doppeleffekt vermutet werden: Die in jener Bruchphase wachsenden Beschleunigungs- und Fortschrittserwartungen im Spektrum von Politik bis Wissenschaft lassen vermuten, dass der (temporäre) Stillstand komplementär eine bislang ungekannte Problematisierung zu erfahren begann und zudem die Beschleunigungserwartung selbst erst die Stillstände relational in Erscheinung treten ließ.

Daran angeschlossen bildet die Konzeptualisierung der >Ersten Moderne $<$ den weiterführenden Rahmen bis ins frühe 20 . Jahrhundert, in dessen Phase sich die politischen, wirtschaftlichen, sozialen und kulturellen Basisprinzipien der Moderne vollends durchzusetzen vermochten. Mit anderen Worten: Während die sSattelzeit den kontextuellen kulturgeschichtlichen Rahmen des Aufkommens und der Entdeckung verkehrsinduzierter Wartesituationen darstellt, bildet die >Erste Moderne deren nachfolgenden Hintergrund zur Interpretation der fortlaufenden Verhandlung von Wartesituationen und deren Modifikation in Form der Etablierung und Änderung von Ordnungsmustern bezüglich Zeitnutzung und Beschleunigungserwartung.

\subsubsection{Auf der Suche nach den Wurzeln des modernen Wartens: Wartezeiten als Komplementäreffekt von Beschleunigungsprozessen}

In jüngster Zeit wurden vermehrt Versuche unternommen, die Prinzipien zu identifizieren, die im historischen Verlauf eine Vielzahl der Modernisierungsprozesse untereinander verknüpft und die Janusköpfigkeit der Modernisierungsprozesse zwischen Fortschritt und Entfremdung befördert haben. Nach Ansicht von Stephen Toulmin liegt dieses verknüpfende Prinzip in der geteilten Auffassung des Strebens nach Rationalität. ${ }^{35}$ Das Rationalitäts-Prinzip hätte das westliche Denken seit dem 17. Jahrhundert primär dominiert und bildet nicht nur die Klammer der diversen Modernisierungsprozesse untereinander, sondern liefert darüber hinaus auch den vielversprechendsten methodischen Zugang zum Verständnis ihrer Negativerscheinungen. Hartmut Rosa dagegen geht hier noch einen Schritt weiter. Er sieht das jegliche Basisprozesse der Moderne - hierzu zählen mit Rückgriff auf einige der wichtigsten zeitgenössischen Theoretiker des 19. und frühen 20. Jahrhunderts Rationalisierung (Weber), Individualisierung (Simmel), Differenzierung (Durkheim), sowie Naturbeherrschung und Produktivkraftentfaltung (Marx) ${ }^{36}$ - verknüpfende Element im Metaprinzip der Beschleunigung. Jegliche Basisprozesse - und damit auch die Rationalisierung selbst - ließen sich demnach »konsistent als Strategien der Beschleunigung interpretieren. « $^{37}$ In diesem Verständnis erscheinen die skizzierten Hauptlinien der Modernisierung nicht als von der Beschleunigung unabhängig wirksame Prozesse, sondern gar gleichsam als Funktionsund Erscheinungsweisen der Beschleunigung. ${ }^{38}$ Rosa schlägt daher vor, Modernisie-

Vgl. Stephen Toulmin, Cosmopolis: the hidden agenda of modernity (Chicago: University of Chicago Press, 1992), 198.

36 Rosa, Beschleunigung: die Veränderung der Zeitstrukturen in der Moderne, $105 \mathrm{ff}$.

37 Ebd., 110.

38 Vgl. ebd. 
rungsprozesse wesentlich in ihrer inhärenten Logik der Beschleunigung zu reinterpretieren, nicht zuletzt um den Ursprung der Negativerscheinungen von Modernisierungsprozessen tiefergehend erklären zu können. Der Befund der prozessimmanenten Beschleunigung wird dabei von der weiterführenden (überzeitlichen) Annahme begleitet, dass die Beschleunigungslogik keine Sättigung erfährt, sondern vielmehr durch einen Selbstverstärkungseffekt gekennzeichnet ist. Einmal durch Beschleunigungen erfolgreich etablierte Gewinne an Zeit, Kapital, oder Mobilität bestätigen die Verheißung der Beschleunigung und reproduzieren zugleich die Hoffnung auf weitere sgeglückte< Beschleunigungen..$^{39}$ Diese Steigerungslogik bedingt schließlich einen fest geschlossenen >Akzelerationszirkel, der kaum gestoppt oder unterbrochen werden kann. Beschleunigung reift damit zu einem sich selbst antreibenden Prozess, der seine Niederschläge auf technischer, sozialer und kultureller Ebene findet.

Abbildung 1: Akzelerationszirkel (nach Rosa 2005, 251).

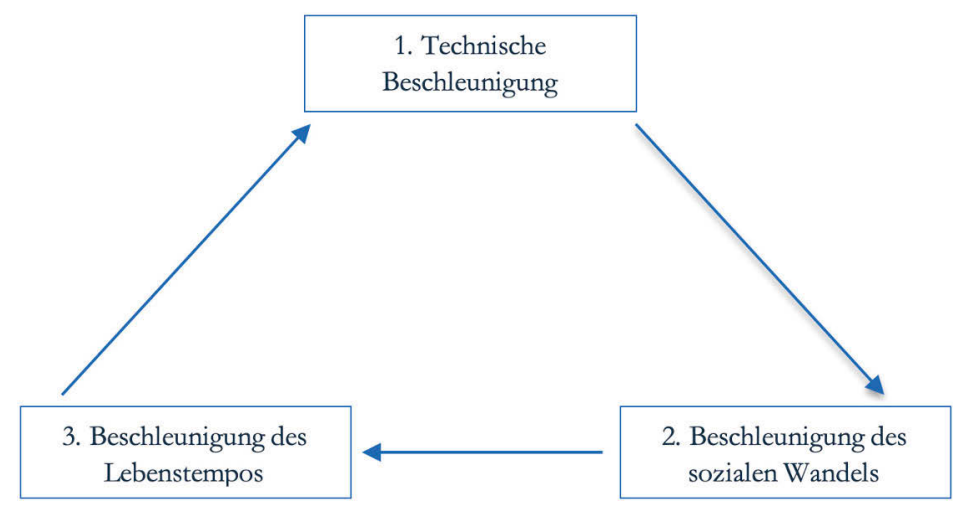

Rosa reiht sich mit der >Beschleunigungsthese $<$ in eine kanonische Epochenreflektion ein, die das Prinzip der Beschleunigung ebenfalls - wenngleich nicht derart strukturiert und theoretisch fundiert wie bei Rosa - als Ausdruck und Triebfeder der Moderne begreift. So betont etwa auch Koselleck die zentrale Stellung der Beschleunigung in Modernisierungsprozessen, die sich bis in die >Sattelzeit< zurückverfolgen lässt. Unter Beschleunigung wird für Koselleck zusammenfassend die allgemeine Verkürzung der Zeitspannen verstanden, die seit der Neuzeit zur »unbestreitbare[n] Erfahrung « ${ }^{40}$ avancierte. Der Wunsch nach Beschleunigung bzw. eine Beschleunigungserwartung wird zwar sprachlich schon vorneuzeitlich, etwa in der jüdisch-christlichen Apokalyptik, nachweisbar. ${ }^{41}$ Real erlebt und wirklichkeitsverändernd wird sie jedoch erst seit der Neuzeit. ${ }^{42}$ Den Grund für diese wachsende Erfahrbarkeit der Beschleunigung sieht Koselleck in einer historischen Zäsur, die für die zeithistorische `Entdeckungくvon Warte-

41 Vgl. Jürgen P. Rinderspacher, »Mit der Zeit arbeiten: Über einige grundlegende Zusammenhänge von Zeit und Ökonomie«, in Im Netz der Zeit, 93. 
phänomenen von entscheidender Bedeutung ist: dem Wandel bzw. der Säkularisierung prozesstreibender und handlungsleitender Heilserwartungen. Dieser Wandel vollzog sich zwischen dem 16. Jahrhundert und 18. Jahrhundert vom Heilsversprechen bzw. des Telos der sakralen Erlösung hin zu einem Heilsversprechen der Naturbeherrschung und politischen Selbstorganisation. Während die jüdisch-christlich Apokalyptik eine Beschleunigung(serwartung) im Rahmen von Religionsmotiven noch als »Vorziehen eines Weltendes, das als solches gewiß ist ${ }^{43}$ verfolgte, transformierte sich die neuzeitliche Beschleunigungserfahrung, insbesondere durch die verdichteten Entdeckungen und Erfindungen der Naturwissenschaften, zunehmend ins Weltliche. Mit dieser sich veränderten Zielstellung erneuerte sich auch die Beschleunigungserwartung, die als Vehikel zur Zielerreichung interpretiert werden kann.

Die im Rahmen der transformierten Zielerreichung realisierten immer schnelleren Ablösungszyklen neuen Wissens (Zwischenschritte auf dem Weg zur Zielerreichung) verstärkten dabei gleichzeitig wiederum das anthropologische Bedürfnis nach Einordnung und Vergleichbarkeit dieser Abfolgen. Erzielte Fortschritte wurden zunehmend 'berechnet und chronologisch gegen das Referenzsystem einer Newton'schen Naturzeit 'gemessen<, um Entwicklungen einordnen und vergleichen zu können. Infolge dieser Entwicklungen wuchsen in ungekanntem Ausmaß die Ausbildung einer erhöhten Zeitsensibilität im Allgemeinen und die Zentralität der Uhrzeit im Besonderen. Die relativen Begriffe der Geschwindigkeit und des Tempos stiegen in den Stand quasireligiöser Versprechen auf, wobei mit Blick auf die Hochphase der Industrialisierung nicht nur bei Zeitgenossen wie Marx und Engels der Eindruck entstand, dass die Gangart wichtiger als der Zielort geworden zu sein schien. ${ }^{44}$ Mit anderen Worten: Die Beschleunigungserwartung wurde immer häufiger aus den initialen Zielzusammenhängen gelöst und stattdessen als Selbstzweck betrachtet. ${ }^{45}$

Die wohl prominenteste Verknüpfung von Modernisierungsprozessen und Beschleunigung erfolgte im Lebenswerk des französischen Philosophen, Medientheoretikers und Stadtplaners Paul Virilio, der die Moderne, verdichtet zum Terminus der Dromologie, gänzlich als Herrschaft der Geschwindigkeit definierte. Geschwindigkeit wird innerhalb Virilios Dromologie als wesentlicher Faktor zur Veränderung gesellschaftlicher Machtverhältnisse verstanden, die zunehmend fatale Folgen im Spektrum des Verlustes der Geschichte und Erinnerung ${ }^{46}$ oder einer Implosion der Realzeit ${ }^{47}$ und schließlich trotz dieser astronomischen Umwälzungen zur vollständigen pathologischen Bewegungslosigkeit bzw. zum rasenden Stillstand ${ }^{48}$ führen würden. Die derart beschleunigte Moderne erfährt damit im Schlüsselbegriff der »Chronopolitik« auch eine zutiefst politische Dimension. Herrschaft, so Virilio, sei in historischer Rückschau überwiegend die Herrschaft des `Schnelleren` gewesen. Tempo und Geschwindigkeit

\footnotetext{
43 Ebd., 185.

44 Vgl. Nowotny, Eigenzeit, 86.

45 Vgl. Borscheid, Das Tempo-Virus, 12.

46 Vgl. Paul Virilio, Dergroße Beschleuniger, hg. von Peter Engelmann, übers. von Paul Maercker (Wien: Passagen, 2012), 17.

47 Vgl. ebd., 137.

48 Vgl. ebd., 152.
} 
wurden nicht nur im ökonomischen Verständnis zu Triebfedern der Überlegenheit, sondern auch im politischen Kontext. ${ }^{49}$

Auch Borscheid sieht die übergeordnete Charakteristik der Moderne in der Beschleunigung repräsentiert. Er argumentiert jedoch, dass sich mit der kontinuierlichen Etablierung von Beschleunigungstechnologien in der >Sattelzeit $<$ noch keinerlei Breitenwirkungen für Wirtschaft und Bevölkerung entwickelten. »Bis weit ins 19. Jahrhundert hinein«, so Borscheid, »waren für die Gesellschaft Mitteleuropas Beschleunigung und Tempo von eher nachgeordneter Bedeutung, ehe mit dem Bau der Eisenbahnen die Dromokratie begann, die Herrschaft der Geschwindigkeit. " $^{50}$ Erst das Industriezeitalter verursachte als entscheidender Geschwindigkeitsproduzent ein Beschleunigungsniveau, das spätestens im ersten Drittel des 20. Jahrhunderts »niemanden mehr ruhig sitzen $\aleph^{51}$ ließ.

\section{Dialektischer Zusammenhang zwischen Beschleunigung und Warten}

Der Leitperspektive der Beschleunigung als übergeordnetem Strukturprinzip der Moderne weiter folgend, stellt sich nun die Frage, welche systemischen Zusammenhänge zwischen Beschleunigung und dem Temporalphänomen des Wartens erkennbar werden. Inwieweit lassen sich in der Zunahme von Beschleunigungserwartungen Auskünfte für die Entstehung von Wartezeiten ableiten? Für eine Beantwortung dieser Kernfrage weist Rosa überzeugend darauf hin, dass ein Modus des Wartens im Rahmen der Modernisierungsprozesse dezidiert erst aus einem Wechselverhältnis von Beschleunigung und Verlangsamung entsteht. Danach werden "Akzelerationsprozesse fast immer von komplementären Tendenzen der Verzögerung, Retardierung und Verlangsamung begleitet. (...) Beschleunigung und Entschleunigung sind nach dieser Auffassung gleichberechtigte und universelle temporale Grundtendenzen. " $" 2$

Grundsätzlich, so hält Rosa zum Wechselverhältnis von Verlangsamung/Stauung und Beschleunigung fest, seien beide Temporalphänomene aufs Engste verzahnt:

»Wo immer in funktional ausdifferenzierten Cesellschaften Vorgänge miteinander synchronisiert bzw. zeitlich aufeinander abgestimmt werden müssen, führt eine zeitliche Veränderung wie die Beschleunigung von Prozessen zu potenziellen Reibungsproblemen an den Synchronisationsstellen. Problematisch und unmittelbar spürbar wird dies überall dort, wo hochakzelerierte Vorgänge auf »rückständige« Systeme treffen: Was schneller gehen kann wird durch das, was langsamer geht, immer wieder gebremst bzw. aufgehalten. ${ }^{53}$

Mit Blick auf den Verkehrskontext illustriert Rosa exemplarisch für die mit Retardierungsmomenten verzahnte Konstitution der Moderne, dass die Durchschnittsge-

49 Vgl. Paul Virilio, Ceschwindigkeit und Politik: Ein Essay zur Dromologie (Berlin: Merve-Verlag, 1980).

50 Peter Borscheid, »Zeit und Raum. Von der Beschleunigung des Lebens«, in Geschichte der deutschen Wirtschaft im 20. Jahrhundert, hg. von Reinhard Spree (München: Beck, 2001), 23.

51 Ebd., 34.

52 Rosa, Beschleunigung: die Veränderung der Zeitstrukturen in der Moderne, 51f. [Hervorhebung des Verfassers, R.K.].

53 Ebd., 144f. [Herv. i. O.]. 
schwindigkeit umso niedriger wird, desto mehr Menschen sich gleichzeitig fortbewegen wollen, ${ }^{54}$ da erwünschte Beschleunigungsprozesse mit erhöhten Synchronisationsanforderungen verbunden sind, die keineswegs immer in ausreichendem Maße (Raum, Ressourcen etc.) gewährleistet werden können, sondern punktuelle Verzögerungen benötigen. Jede Form der Beschleunigung folgt dennoch dem impliziten Versprechen einer Aufwertung und Verbesserung. Die Realisierung dieser Beschleunigung jedoch erfordert jedoch wiederum eine vergleichsweise stärkere Synchronisierung der Subsysteme. Gelingt diese Synchronisierung nicht, erhöht sich die Wahrscheinlichkeit der Entstehung von Anfälligkeiten für Inkongruenzen und damit der Entstehung von Wartezeiten.

Rosas Ausführungen bilden damit einen essentiellen Theorierahmen der Beschäftigung mit Wartephänomenen. Sie betonen, dass der wesentliche Ursprung für die Entstehung von Wartezeiten in der Moderne als eine dysfunktionale Folge von Beschleunigungsprozessen zu verstehen ist. So heisst es weiter: »Verlangsamung und Hemmung treten in der modernen Gesellschaft in zunehmend gravierendem Maße und immer häufiger als unbeabsichtigte Nebenfolge von Akzelerationsprozessen auf. ${ }^{55}$ Die massive Häufung von Wartesituationen kann hiernach nur aus einem Wechselverhältnis von Beschleunigung und Stilllegung bzw. Verlangsamung verstanden und beschrieben werden. Beide modernetypischen Phänomene sind damit dezidiert in seiner dialektischer Natur zu sehen oder wie es Borscheid treffend formuliert: »Beschleunigung und Bremsung gehören zusammen. ${ }^{56}$ Versuchte man Wartephänomene in die Epoche der Moderne mit einem dialektischen Dreischritt zu fassen, so wäre demnach das Warten als synthetisches Resultat der Verhandlung von Beschleunigung (These) und Stillstand/Verlangsamung (Antithese) zu begreifen, da sie nur in Verschränkung der beiden Sachverhalte von Beschleunigung und >Nicht-Beschleunigung< überhaupt zutage tritt (Synthese).

Als entscheidendes Zwischenresultat der zeithistorischen Verortung des Wartens kann demnach festgehalten werden, dass ein smodernes Warten nicht ohne die Komplementärgröße der Beschleunigung verstanden werden kann, ja die Beschleunigungsprozesse der Moderne das Zeitbewusstsein eines Wartens überhaupt erst >produziert und explizit wahrnehmbar gemacht haben. Die zeithistorische Verortung des Wartens steht demnach im Zeichen einer weiteren Doppeldiagnose: Zum einen sind auftretenden Wartezeiten ein systemisches Resultat der Beschleunigung, zugleich bilden sie den Ansporn und die Triebfeder weiterer Rationalisierung. Sie sind negative Folge und Treibstoff zugleich. Sie unterbrechen in langfristiger Betrachtung nicht etwa den skizzierten Wirkmechanismus des Akzelerationszirkels, sondern katalysieren ihn langfristig vielmehr. Prozessverzögerungen erzeugen einen abermals gesteigerten Erwartungshorizont zur Prozessbeschleunigung und mobilisieren eher Kräfte und Ressourcen zur technischen Überwindung der Verzögerung, als dass sie die Gerichtetheit der Modernisierungsprozesse aufhalten, eine Sättigung oder gar eine Kehrtwende dieser Prozesse bewirken würden.

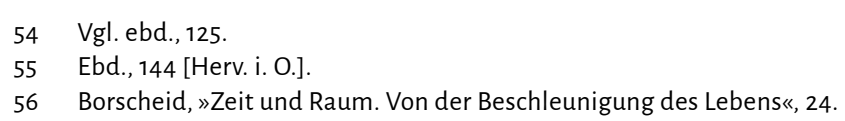


Abbildung 2: Erweiterung des Akzelerationszirkels (nach Rosa 2005, 251) um den Einfluss von Retardierungsmomenten.

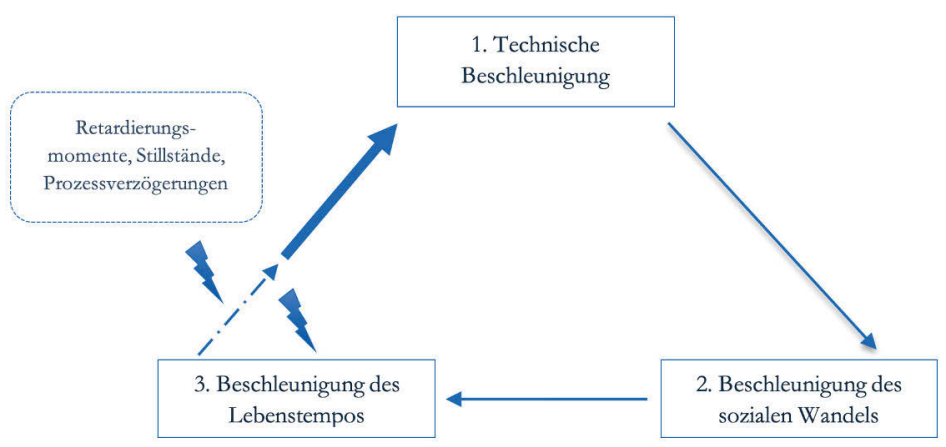

Die unter 2.4.2 erschlossenen Entstehungsbedingungen von Wartezeiten müssen folglich mit Blick auf die Zentralität der Beschleunigung innerhalb der Programmatik von Modernisierungsprozessen um eine wesentliche Bedingung erweitert werden. Die Modalität und die Erfahrung des Stillstands, die aus Wartezeiten resultieren, treten überhaupt erst vor der referentiellen Vergleichsfolie des modernen Telos einer fortwährend optimierten - und damit beschleunigten - Zeitnutzung hervor. Weil jene Beschleunigung eindeutig anthropogenen Charakter trägt, knüpft die Feststellung dieser wechselseitigen Abhängigkeit zudem deutlich an den aus der Zeitsoziologie Sorokins und Mertons abgeleiteten Aspekt einer allmählichen Verlagerung des Wartens in ein primär >soziales` Ursprungsgebiet an.

\subsubsection{Die Problematisierung des Stillstands und deren Voraussetzungen}

Folgen wir nun Kosellecks und Rosas Überlegungen einer effizienzgetriebenen Zeitauffassung der Moderne ${ }^{57}$, so kann im Umkehrschluss des Beschleunigungsaxioms vermutet werden, dass die Epoche in einem (wachsenden) Spannungsverhältnis gegenüber Stillstandsmomenten wie dem Warten stand, weil ihre an der Logik einer allgemeinen Beschleunigungserwartung orientierten Zeit- und Handlungsstrukturen im Warten ihre Hemmung bzw. gar ihre dauerhafte Gefährdung erfuhren. Die Inkongruenz zwischen Stillstand und Beschleunigungs- bzw. Bewegungserwartung und folglich die Unterbrechung des teleologischen Fortschrittsverständnisses, so ließe sich die Hypothese verdichten, hoben das Warten im Kontext der Moderne - angefangen von der institutionellen und schließlich auch auf der individuellen Ebene - , zunehmend in den Stand eines temporalen Problemfalls.

57 Rosa sieht die Besonderheit der modernen Kultur in den Triebfedern von Angst und Hoffnung, die - und dies stellt die eigentliche Besonderheit der Moderne dar - in historisch einmaliger Weise mit den Prinzipien der Zeiteffizienz verknüpft wurde. Vgl. Rosa, Beschleunigung: die Veränderung der Zeitstrukturen in der Moderne, 284. 
In der Tat durchlief die Wahrnehmung von Wartezeiten seit dem späten 18. Jahrhundert eine zunehmend negative Karriere, was bereits ein kurzer Blick auf den semantischen Wandel zeigt, den das Wort seit der >Sattelzeit< erfahren hat. In auffälliger Parallelität zu den gewandelten, sungeduldigen Erwartungshaltungen der Revolutionsjahre um 1800 vollzog sich ein Bedeutungswandel des Begriffs von seiner ursprünglichen Bedeutung des »Pflegens«, »Hütens«, "Auf etwas Schauens« in Richtung eines »Harrens « und damit verbunden in Richtung einer gewandelten emotionalen Aufladung. Zwar blieben die ursprünglichen Bedeutungen grundsätzlich erhalten, jedoch wurden sie zunehmend in Ergänzung adverbialer Bestimmungen genutzt. Folglich wartete man besonders seit der Literatur der Romantik immer häufiger »mit Verlangen«, »mit Ungeduld« oder »mit Schmerzen ${ }^{58}$

Der in der Neuzeit noch evident unkritische Begriff des Wartens einer aktiven, pflegenden und aufmerksamen Aktivität (hierzu zählt auch die seit dem 16. Jahrhundert etablierte Wendung, aufjemanden zu warten), avancierte somit erst im Zuge der neuzeitlich-modernen Beschleunigungs- und Zeitlogik zunehmend zum leidvollen Dasein. Kurzum: Erst im Laufe der `Sattelzeit`wurde die Beharrlichkeit gegenüber der Bewegung rechtfertigungspflichtig. Seit Hobbes, Friedrich Ancillon und Goethes Faust ist spätestens ab der Mitte des 18. Jahrhunderts ein modernes Zeitbewusstsein davon geprägt, dass nicht mehr die Veränderer die Begründungslast tragen, »sondern diejenigen, die an Bestehendem festhalten, im Alltag wie in der Politik oder der Kunst «. ${ }^{59}$ Darin wandelte sich der Zustand des Wartens - als ein Spezialfall der Unbeweglichkeit - allmählich zum ungeliebten, leidvollen Zustand und gar zum Feindbild. Im Warten sieht Friederike Gräff daher einen Zustand, »den das moderne Individuum scheut wie kaum einen anderen, weil er allem entgegen zu stehen scheint, was es sich erkämpft hat: Freiheit, Gleichheit, Selbstverantwortlichkeit. ${ }^{60}$ Die Grunderrungenschaften scheinen im Warten offenbar auf dem Spiel zu stehen und nähren abermals die leitende Vermutung, dass das Warten den vielleicht größten Konfliktfall unserer Beziehung zur Zeit vermittelt.

\section{Voraussetzung zur Problematisierung des Wartens: gesteigerte Zeitsensibilität}

Der Wahrnehmung eines temporalen Konfliktfalls gehen jedoch entscheidende kulturgeschichtliche Bedingungen voraus, deren systematische Zusammenhänge in Abbildung 3 in idealisierter Form zur Veranschaulichung gebracht werden. Bevor Wartezeiten überhaupt als krisenhaft und spannungsvoll aufgefasst werden konnten, musste zunächst ein tiefgreifender Wandel in den die Zeitauffassung gänzlich verändernden teleologischen Heilserwartungen erfolgen. Diese veränderten Zielstellungen speisten sich aus der bereits mit Rekurs auf Koselleck umrissenen Transformation des Erwartungshorizontes vom Telos der Erlösung (Wiedergeburt Christi) zum Telos eines aktiv

Vgl. Köhler, Lange Weile, 16.

59 Rosa, Beschleunigung: die Veränderung der Zeitstrukturen in der Moderne, 72. Auch Koselleck verweist auf die Verschiebung der Beweislast von der religiösen Heilserwartung auf jene des technischen Erfolges, woraufhin sich die christlichen Heilserwartungen am technischen Fortschritt (z.B. der Eisenbahn) »ankristallisieren« mussten (Koselleck, Zeitschichten, 194). 
steuerbaren, individuell und selbstverantwortlich erreichbaren Fortschritts. Im Resultat einer Säkularisierung der vormals sakralen Heilserwartung verschob sich auch die Zeitauffassung in Richtung einer kontingenten und offenen Zukunft in deren Folge die Zeit Vehikel, Maß und Faktor der Gestaltung jener offenen Zukunft wurde und somit entsprechend verinnerlicht, rational genutzt und problematisiert werden musste. Wie bereits im Zuge der Idealtypenbildung Rammstedts dargestellt, wurde die Zeit im Zuge der Entwicklung hochentwickelter westlicher Gesellschaften in diesem Zusammenhang folglich nicht mehr als zyklisch oder gar okkasional, sondern als linearer Lauf begriffen.

Die teleologische Neuausrichtung auf eine offene Zukunft schuf somit erst den Nährboden, auf dem eine grundlegend reformierte Ökonomie und Wissenschaft entstehen konnten. Da diese gesellschaftlichen Systeme aufgrund ihrer komplexeren Anforderungen wiederum eine gesteigerte Zeitsensibilität bzw. die Etablierung eines komplexen Zeitbezugssystems als Ordnungs- und Orientierungsfunktion benötigten, liegt hier der entscheidende evolutionäre Zusammenhang zur Ausbildung der bis in die Gegenwart wirksamen erhöhten Zeitsensibilität begründet, die in einer ihrer diversen Ausprägungen schließlich auch die erhöhte Sensibilität gegenüber Retardierungsmomenten umfasst.

Wissenschaft und Ökonomie bildeten nicht nur die entscheidenden Exekutivkräfte zur Gestaltung der nunmehr offenen und auf die Heilserwartung des Fortschritts ausgerichteten Zukunft, sondern wurden gleichwohl zu Vorreitern der Erfordernis eines erhöhten Zeitgefühls, wobei insbesondere die Ökonomie die wohl größte alltagspraktische Wirkung auf den Umgang mit Zeit ausübte. Während insbesondere die Naturwissenschaften die zeitsensitive Messung von Phänomenen etablierten und Zeit - angefangen mit den Beschleunigungsexperimenten Galileis - den eigentümlichen Charakter der naturgesetzlichen Zusammenhänge zu erklären vermochte, beinhaltete die Transformation des neuzeitlichen Wirtschaftswesens die konsequente Bewirtschaftung der Zeit. Jene sozioökonomische Transformation von der Bedarfsdeckungs- zur Marktwirtschaft umfasste folglich eine Erweiterung des vorherrschenden agrarwirtschaftlichen Denkens um ein kapitalwirtschaftliches Denken, das wiederum einen neuartigen, rechenhaften Umgang mit der Zeit erforderte, der spätestens im 19. Jahrhundert zum Allgemeingut geworden war. ${ }^{61} "$ Der revolutionäre Umbruch des Zeitbewußtseins von der Stufe gleichsam des passiven Sicheinfügens in die Rhythmen der Natur zum aktiven Zeitmanagement «, so stellt Rinderspacher dabei in näherer Betrachtung des ökonomischen Zusammenhangs heraus, »wurde ganz wesentlich durch die Praxis des Geldverleihens mitbewirkt. ${ }^{62}$ Der Geldverleih, - oder vielleicht mehr noch die Kapitalanlage (Investition) - repräsentiert die erhoffte Belohnung einer in die Zukunft projizierten Handlung. Diese elementaren Formen des Wirtschaftens beinhalten demnach das Verstreichen einer gewissen Zeitspanne, um diese Belohnung in Form von Kostenoder Arbeitsersparnis oder durch Zinserwirtschaftung zu realisieren. Hier zeigt sich einleuchtend der angesprochene Konnex, dass ein reformiertes kapitalwirtschaftliches 
Denken auf dem reformierten zeitkulturellen Verständnis einer nunmehr offenen $\mathrm{Zu}$ kunft basierte. Das Wirtschaften transformierte sich darin von der agrarischen Subsistenzwirtschaft, die ihre Erfahrungsgewissheit aus einer zyklischen Zeitauffassung der Jahreszeiten speiste, in Richtung einer in die Zukunft projizierten (unsicheren) Gewinnerwartung. Die Bedeutung des Faktors Zeit in der neuzeitlichen Wirtschaftsorganisation äußerst sich demnach vor allem darin, dass zentrale Elemente des kapitalwirtschaftlichen Denkens selbst hochgradig zeitsensitive Größen darstellen. ${ }^{63}$

Der Zeitfaktor rückte jedoch nicht nur über die Zukunftsorientierung des kapitalintensiven Wirtschaftens im Rahmen von Geldverleih, Kreditwesen oder der Investition ins Zentrum des Bewusstseins. Der Zeitfaktor selbst wurde im Rahmen des Industriekapitalismus gar zur alles entscheidenden Voraussetzung, um überhaupt an der sozialen Institution des Marktes bestehen zu können, weil die in eine Ware eingeflossene Arbeitszeit letztlich entscheidende Größe zur Bemessung ihres Wertes wurde. Dieser Wert wird zur Tauschrelation am Markt und schafft Vergleichbarkeiten, die nur auf der instrumentellen Funktion des Zeitfaktors basieren konnten. Waren, die einen reduzierten Zeitaufwand pro Wareneinheit aufweisen, so die grundlegende Wirkungsweise, werden am Markt belohnt. Der Warenwert steigt demnach äquivalent zum gering gehaltenen zeitlichen Input beim Herstellungsprozess. Kapitalwirtschaftliches Denken wurde - propagiert durch die Schriften von Adam Smith oder David Ricardo sowie dechiffriert von Marx und Engels - damit de facto zum Wettbewerb um den möglichst sparsamen Umgang mit Zeit. Der Markt, so ließe sich schlussfolgern, wurde damit indirekt zur wohl wirkmächtigsten Bühne des Zwangs zur Verinnerlichung des Zeitfaktors. Die Legitimität dieser Art des zeitsensitiven Wirtschaftens und damit die gesellschaftliche Tragweite der Zeitverinnerlichung konnte das neuzeitliche Europa mit Rückgriff auf Weber aber wiederum erst dadurch erhalten, »daß der effektive Umgang mit der Zeit in den Rang einer ethischen Norm erhoben wurde«. Erst auf jenem kulturellen Nährboden, so betont auch Rinderspacher die Tragweite dieser das Zeitbewusstsein radikal transformierenden Verschiebung, »konnte der Gedanke der ökonomischen Effizient [sic!] als ein Gebot der Alltagskultur massenwirksam werden. ${ }^{64}$

Zusammenfassend wurde die Zeit im Rahmen des reformierten Wirtschaftens also durch ihre zunehmende Komodifizierung zu einer Größe, die genutzt, gespart und schließlich möglichst selbst zur beschleunigten Innovation ${ }^{65}$ werden musste. Nicht allein die Wahrnehmung und Bewertung der Wartezeit als expliziter Fall der Synthese im Rahmen einer neuen rationalen Zeitdogmatik wurde dabei zum Problem, sondern die Zeit selbst wurde damit zu einer vulnerablen Größe, die zwar im Falle einer effizienten Nutzung zur Belohnung am Markt führen, aber zugleich im Falle einer >Fehlbewirtschaftung، gleichwohl zur existentiellen Gefahr reifen konnte.

Getrieben nicht zuletzt durch jene Bewirtschaftung der Zeit gewinnt in Europa zwischen dem 17. und dem 19. Jahrhundert die Etablierung eines universellen zeitlichen

63 Besonders interessant erscheint hierbei der semantische Befund, dass die Begrifflichkeiten kapitalwirtschaftlicher Prägung starke Analogien zur vormals sakralen Heilserwartung aufweisen. So finden sich etwa die religiösen Konnotationen des Glaubens im >Cläubiger als auch im >Kredit< (vom lateinischen credere für glauben) wieder.

Ebd.

65 Vgl. Nowotny, Eigenzeit, 11. 
Bezugssystems aufgrund sich stärker ausdifferenzierender Gesellschaftsformen, längerer Interdependenzketten sowie aufgrund der gewachsenen Notwendigkeit langfristiger Kalkulierbarkeit zunehmend an Bedeutung. Die wohlgemerkt für alle Zivilisationsepochen evidente Relevanz der Bestimmung >richtiger Zeitpunkte zur Festlegung von Anfängen und Endpunkten sozialer Tätigkeiten (etwa für Wahlen, Steuern, Feste, kultische Handlungen, Aussaaten) erhielt im Zuge der neuzeitlichen Entwicklungen ihre bedeutende Qualifizierung. Zeitkenntnis und Zeitnutzung entwickelten sich reziprok zum Wachstum bestimmter sozialer Erfordernisse von Wissenschaft und Wirtschaft zu neuartigen Fähigkeiten heraus, die Elias hinsichtlich ihrer zivilisationsgeschichtlichen Besonderheit in folgender Feststellung betont:

»Ein solches soziales Bedürfnis besteht durchaus nicht in allen menschlichen Gesellschaften. Es macht sich um so stärker bemerkbar, je größer, je menschenreicher, differenzierter und komplexer die Gesellschaften werden, die Menschen miteinander bilden. In früheren Gruppen von Jägern, Hirten und Ackerbauern ist das Bedürfnis nach einem aktiven >Zeiten oder >Datieren< von Ereignissen minimal, und minimal sind auch die Mittel dazu. In großen, urbanisierten Stadtgesellschaften, vor allem in solchen, wo die Spezialisierung sozialer Funktionen weit fortgeschritten ist, wo die Interdependenzketten, die die Träger dieser Funktionen aneinander binden, lang und hochdifferenziert sind und wo ein Croßteil der täglichen Lebensmühe von menschengeschaffenen Energien und Maschinen übernommen worden ist, wird das gesellschaftliche Bedürfnis nach Zeitbestimmung und den Mitteln zu seiner Befriedigung, den Signalen mechanischer Anzeiger der gemeinsamen Zeit, unausweichlich, und unausweichlich wird auch das Zeitgefühl der zugehörigen Menschen. ${ }^{66}$

Die Etablierung dieses »unausweichlichen Zeitgefühls« im Zuge der neuzeitlichen Moderne theoretisiert Elias ferner im allmählichen Übergang von einer partikulär-punktuellen zu einer kontinuierlichen Zeitregulierung, die ihren deutlichsten Ausdruck in der Institutionalisierung und Standardisierung der Zeitbestimmung in Form von Kalendern (Jahre, Monate, Tage) und den verfeinerten Zeiteinheiten der Uhrzeit (Stunden, Minuten, Sekunden) findet. ${ }^{67}$

Die eigentliche Folge und Radikalität der beschleunigten neuzeitlich-modernen Zeiterfahrung ist daher in deren alternativloser Verinnerlichung zu sehen. »Uhren, Kalender oder etwa auch (...) Fahrpläne«, so Elias, hätten in neuzeitlich-modernen Gesellschaften »in hohem Maße diejenigen Eigentümlichkeiten, die die Ausbildung individueller Selbstzwänge fördern. Der Druck dieser Fremdzwänge ist relativ unaufdringlich, mäßig, auch gleichmäßig und gewaltlos, er ist zugleich allgegenwärtig und unentrinnbar. ${ }^{68}$ Insbesondere die Symbolformen der Kalender und Uhren ermöglichten eine - gegenüber an die Unsicherheit von beobachtbaren Naturabläufen geknüpfte - stärkere Ereigniskontrolle und eine Erhöhung der Gewissheit über die immerwährenden Abfolgen der Ereignisse. Die durch Papst Gregor XIII. initiierte Kalenderreform von 1582 optimierte die Zeitregulation im Sinne einer gegenüber dem 
Julianischen Kalendersystem besseren Korrelation zwischen Sonne, Mond und wichtigen sozialen Ereignissen. Die gregorianische Kalenderreform ist somit zuvorderst als neuzeitliches soziales Bedürfnis einer stärkeren öffentlichen Zeitregulierung zu lesen.

Das neuzeitliche Europa steht damit aus zivilisationsgeschichtlicher Perspektive zusammenfassend für die Ausbildung eines komplexen Syntheseniveaus, das zugleich eine immense Erhöhung der mithilfe des Symbolsystems `Zeit induzierten individuellen Selbstregulierung einschloss. Die Ausbildung jenes Zeitgefühls nahm im Zuge der skizzierten Zusammenhänge gewandelter Heilserwartungen und daran geknüpfter Reform der Wissens- und Wirtschaftsgenese förmlich imperativen Charakter an und wurde ein zunehmend (unhinterfragter) Teil des sozialen Habitus. Nicht nur die Zeitbestimmung als solche erfolgte im Zuge dieser Entwicklung weniger punktuell und fluktuativ, sondern zugleich die persönliche Selbstkontrolle des neuzeitlichen und modernen Menschen. Das Erfordernis des erhöhten Zeitgefühls innerhalb moderner Gesellschaften, so ließe sich der Komplex der Voraussetzungen zur Problematisierung von Stillstandsmomenten zusammenfassen, kann nur im Zuge des Wandels einer generellen der Heilserwartung des Fortschritts zweckdienlichen Zeitauffassung erklärt werden, die korrespondierend auf die rationale Zeiterfahrung einwirkte. Erst dieser Wandel konnte überhaupt das Temporalphänomen des Wartens im Rahmen einer Syntheseleistung explizit als Abweichung erscheinen lassen. Diese Syntheseleistung soll nun näher beleuchtet werden.

\section{Syntheseleistung: Möglichkeit der Einordnung des Wandels}

Die Etablierung eines fortschritts- und beschleunigungsaffinen Telos und das daran geknüpfte Erfordernis einer Zeitverinnerlichung ermöglichten es, den gesellschaftlichen und wissenschaftlichen Wandel bzw. die Abfolge von Ereignissen gegenüber einem Referenzrahmen mittels einer Syntheseleistung zu beurteilen. Die mögliche Syntheseleistung eines Abgleiches zwischen fortschrittsorientierter Zielstellung auf der einen und gegenwärtigem Stand der Teloserreichung auf der anderen Seite ließ darin Retardierungsmomente als relatives Temporalphänomen überhaupt erst in Erscheinung treten. Anders ausgedrückt, je mehr die Beschleunigung zur (säkularen) Verheißung avancierte, desto stärker vermochten Retardierungsmomente innerhalb der teleologischen Idee des Fortschritts augenfällig zu werden und traten als Problemfälle auf. Mit Rekurs auf Kapitel 2.4.1 sei in diesem Zusammenhang dazu noch einmal an die Bedingungen der (individuellen) Erfahrbarkeit von Wartezeit erinnert. Zunächst muss ein die Zeit wahrnehmendes Subjekt vorhanden sein, das die Zeit bewusst >fühlbar als subjektive Größe (nicht als externe Naturgröße) wahrnimmt. Zudem müssen ein zu erwartendes Ereignis bzw. eine Zielorientierung existieren und schließlich ein Abgleich der wahrgenommenen Folge von Einzelereignissen gegen einen objektiven Bezugsrahmen vorgenommen werden können, der im Rahmen einer Syntheseleistung eine Inkongruenz aufzuzeigen in der Lage ist. Mit Blick auf das Veränderungspotential der Zeitwahrnehmung in der die Moderne vorbereitenden sSattelzeit< kann also in diesem Zusammenhang pointiert konstatiert werden: Das Subjekt war bereits vorhanden (und damit ein generelles Zeitbewusstsein). Neu hingegen sind die Zentralität der Zielbestimmung (säkulare Beschleunigungserwartung in einer offenen und kontingenten Zukunft) und die damit erzwungene Verinnerlichung des 
Bezugsrahmens einer objektiven Uhrzeit mit denen Abweichungen vom Telos identifiziert, vermessen und als problematisch rerlebt< werden konnten.

Fassen wir also die zeithistorische >Verortung « der Wartezeit im Kontext der Modernisierungstheorien noch einmal zusammen. Die Entstehung als auch die Problematisierung von Wartezeiten sind relatives Produkt einer zunehmenden Zeitstandardisierung, genauer der Evolution von einer an Naturphänomenen orientierten, partikulären Zeitbestimmung zu einer kontinuierlichen Zeitbestimmung. Ausschlaggebend für diesen Wandel sind Synchronisationszwänge aufgrund gewachsener Interdependenzketten einer gestiegenen funktionalen Differenzierung, die wiederum ihre Ursache in einer grundlegend reformierten Ausrichtung wirtschaftlichen und wissenschaftlichen Handelns haben. Eine reformierte Wissenschaft und Wirtschaft konnten wiederum ihrerseits erst im Zuge eines säkularisierten Erwartungshorizontes von Fortschritt und Rationalität ermöglicht werden, die seit der Neuzeit den vormals vorherrschenden Erwartungshorizont der sakralen Erlösung abzulösen begannen. Mit einem Wort: Während die Verheißung der Beschleunigung den kulturellen Motor der Modernisierungsprozesse repräsentierte, bildete die funktionale Differenzierung deren sozialstrukturellen Motor. ${ }^{69}$ Vor dem Hintergrund dieser hochgradig >zeitsensitiven< Entwicklungen Zeit wurde elementares und zu verinnerlichendes Werkzeug zum koordinierten >Erreichen als auch zur 〉Messung des gewandelten Telos - begannen Formen des Aufschubs komplementär im Widerspruch zur fortschritts- und bewegungsaffinen Programmatik der Moderne zu stehen. Sie wurden mindestens rechtfertigungspflichtig, wenn nicht gar problematisch. Die Phasenschwelle der Moderne fällt hieran parallel mit einer $>$ Entdeckung des Wartens zusammen. Beschleunigung und Verzögerung stehen insofern in einem dialektischen Verhältnis als dass zum einen mit der Beschleunigungserwartung die Retardierungsmomente bzw. Fehlstellen zwischen zeitlicher Erwartung und zeitlicher Erfahrung überhaupt erst >produziert wurden und zum anderen die intendierte Überwindung der Fehlstellen die Logik der Beschleunigung weiter legitimiert. Die Retardierungsmomente stören paradoxerweise die zirkuläre Ausweglosigkeit des modernen Beschleunigungsaxioms nicht, sondern treiben den Akzelerationszirkel bis in die Gegenwart hinein, trotz der Gefahr punktueller Unterbrechungen, langfristig weiter an. Jeder Stau sorgt im verinnerlichten Streben nach zeitsensitiver Effizienz, Beschleunigung und Akkumulation also nicht dafür, das Telos grundsätzlich in Frage zu stellen, sondern forciert vielmehr die Lösung des Staus durch - zuvorderst technische - Interventionen. Das Warten selbst erscheint aus diesem relationalen Verständnis heraus in definitorischer Korrektheit nicht als Phänomen, sondern vielmehr als eine Beziehung zwischen Phänomenen; einerseits dem Phänomen der Beschleunigung und andererseits dem Phänomen der gewachsenen Fähigkeit zur Zeitbestimmung und resultierenden Zeitsensibilität.

Vergleichbar mit dem geologischen Hebungsprozess eines Gebirges aus einer Ebene, produzierte das mit der >Sattelzeit $<$ reifende Zusammenspiel aus kulturell gewandeltem 
Erwartungshorizont und erhöhter Zeitsensibilität Bergspitzen als auch Taleinschnitte, die eine Mehrdimensionalität und vergleichsweise differenziertere (Zeit-)Topografie entstehen ließen. In solcher einer (Zeit-)Topografie konnte nunmehr der jeder Punkt des Gebirges wesentlich deutlicher in seiner relativen Lage und Entfernung zu anderen Punkten bestimmt werden als dies in der horizontalen Ebene möglich war. Diese symbolhafte Mehrdimensionalität bzw. Topografie repräsentiert eine allgemein mit der sattelzeit e einsetzende Verinnerlichung der Uhrzeit, die nicht intentional geplant wurde, sondern eher als Medium der Erschließung reformierter Felder gewandelten wirtschaftlichen und wissenschaftlichen Denkens einen bis zur unterbewussten Habitualisierung wirksamen Sekundäreffekt bildete. »Wir sind in ein allgegenwärtiges Zeitgefühl hineingeglitten«, stellt Elias frappierend fest. »Es ist ein Teil unserer Persönlichkeitsstruktur geworden. Als solcher wird es selbstverständlich. Es scheint, als könne man die Welt nicht anders erleben. ${ }^{70}$

Abbildung 3: Idealisiertes Schema zur Verortung des Wartens als ein Sekundäreffekt innerhalb der sich seit der Neuzeit wandelnden Erwartungshorizonte und Zeitauffassungen.

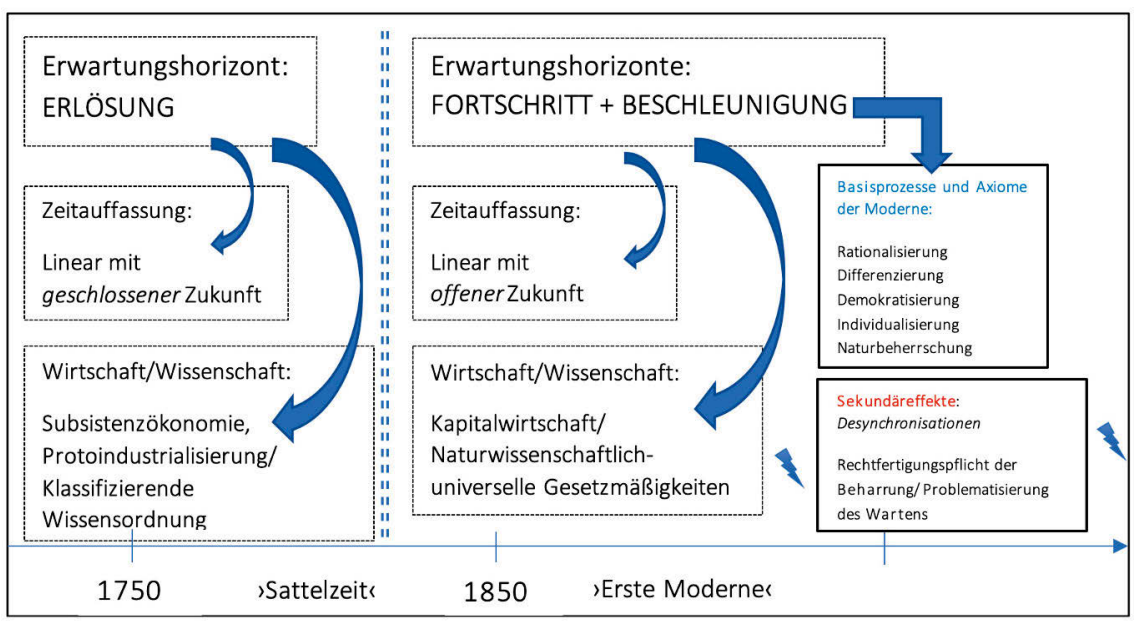

Sicherlich mag die referentielle Erfahrung der Wartezeit nur eine der vielen neuartigen Temporalerfahrungen einer allgemeinen Temporalisierung des Erlebens gewesen sein, die im Zuge der erhöhten Zeitsensibilität >spürbar wurden. Sie ist jedoch nicht weniger paradigmatisch und zugleich wirkmächtig als die weithin beschriebene Grunderfahrung der verheißungsvollen Beschleunigung. Der in der späten Neuzeit einsetzende Aufstieg der säkularisierten Beschleunigung wird somit korrespondierend von einem Aufstieg der Ungeduld flankiert. Die zeithistorische Verortung des Wartens im Kontext der Modernisierungsprozesse erfuhr aus diesem Zusammenhang seine Legitimität. Die hier skizzierte Rekapitulation der Entstehungsbedingungen des Wartens 
als problematisches Temporalphänomen erhält zudem eine Relevanz, um die scheinbare Alternativlosigkeit der überwiegend negativen Konnotation des Wartens zu erklären, aber auch zu relativieren. Oder anders ausgedrückt: es hätte es auch anders kommen können. Eine andere sSattelzeit und ein darin abweichender Erwartungshorizont hätten wohl mit Sicherheit auch eine andere Temporalkultur und eine andere Konnotation des temporären Stillstands erzeugt. Es war mit Sicherheit nicht die letzte sSattelzeit<.

Ausgehend von der zeithistorischen Verortung und Herleitung der einsetzenden Problematisierung des Wartens als Sekundäreffekt kultureller und sozialstruktureller Entwicklungen der späten Neuzeit soll nun im folgenden Kapitel der Aspekt der Problematisierung mittels einer disziplinären Zusammenschau an Evidenz gewinnen.

\subsection{Exkurs: Warten im Spiegel empirischer und theoretischer Forschung - Panorama disziplinärer Perspektiven}

Der folgende Forschungsüberblick erwächst aus der Motivation heraus, die in der Einführung dieser Arbeit skizzierte Vielfalt der forschungsseitigen Beschäftigung mit Wartephänomenen zu vertiefen, um dem Selbstverständnis einer interdisziplinär ausgerichteten Kulturgeschichte gerecht zu werden und einen bereits für sich genommen relevanten Aussagegehalt zu generieren. Dazu wird ein Panorama der disziplinären Zugriffe auf das Phänomen vorgestellt. Diese weit über das verkehrliche Warten hinausgehende Gesamtschau zum Forschungsstand wird nicht nur die psychologisch wie strukturell problematische Aufladung oder die Komplexität des Wartens verdeutlichen, sondern insbesondere die wahrliche Pluralität der Perspektiven und Zugriffe aufzeigen, die sich dem Temporalzustand insbesondere seit dem späten 20. Jahrhundert widmeten.

\section{Panorama und Synthese der disziplinären Perspektiven eines flüchtigen Phänomens}

Innerhalb der in den vorangegangenen Kapiteln skizzierten, immensen Fülle der Betrachtung von Zeitphänomenen erscheint die Thematik des Wartens zunächst als nischenhaft. Bei näherer Betrachtung jedoch ist die Forschung zu Wartephänomenen, insbesondere der letzten drei Jahrzehnte, durchaus umfassend und reicht punktuell bis in die Anfänge des 20. Jahrhunderts zurück. Angefangen von den Ursprüngen in der Mathematik reicht das disziplinäre Spektrum von der Sozialpsychologie und Soziologie bis in die Unternehmensforschung, in der die Problematik des Wartens in Schlangenformationen bis heute ein zentrales Schlüsselthema der Dienstleistungswelt darstellt.

Grundlegend lässt sich die Beschäftigung mit Wartephänomenen entlang zweier Zielstellungen rekonstruieren: Erstens, dem Bestreben nach der absoluten Reduktion von Wartezeiten mittels der Vermeidung von Stauungen durch mathematische Modellierung und stochastischer Vorausschau auf Netzwerkebene. Zweitens, dem Bestreben des Verständnisses der subjektiven Erfahrung des Wartens und einer daran geknüpften Suche nach Interventionsstrategien zur Minimierung der wahrgenommenen Wartezeit.

Die Vielzahl der Analysen ist jedoch heterogen, wenig systematisiert und aufgrund des allgegenwärtigen Auftretens von Wartesituationen von bisweilen geringer diszi- 
plinärer Trennschärfe. Eine integrative Theoretisierung des Wartens über diese disziplinären Sichtweisen hinaus ist bislang nicht verfügbar und nicht zuletzt vor diesem Hintergrund im vergangenen Kapitel in Ansätzen angestrebt worden. Dennoch lässt sich festhalten, dass die fragmentierten Sichtweisen durch eine übergeordnete Charakterisierung des Wartens als system- bzw. geschäftsschädigendem Problemfall, als Ausdrucksfeld sozialer Ungleichheiten oder zu bewältigende Managementherausforderung zusammengehalten werden. Bis auf wenige herauszustellende Ausnahmen, basierte dabei nahezu jede Studie zu Wartephänomenen ausnahmslos auf der impliziten Annahme, dass dieser temporale Zustand als negativ erfahren wird und ökonomische, soziale, psychologische bzw. objektive und subjektive Kosten verursacht. Somit verwundert die Feststellung kaum, dass Ökonomie und Psychologie die Forschungsgebiete markieren, die sich dem temporalen Phänomen des Wartens am eingängigsten gewidmet haben.

Aus dem nun beabsichtigten synthetisierenden Blick über die disziplinäre Beschäftigung ergeben sich wichtige Einblicke in die Vielfalt der Kontexte, Problemlagen und Zugriffsweisen, die eine Einordnung als auch die Anschlussfähigkeit der mit dieser Arbeit im Mittelpunkt stehenden mobilitätsgeschichtlichen Verortung des Wartens ermöglichen und es zudem gestatten, Parallelen und Verbindungslinien zu anderen Wartekontexten herzustellen. Um einen ganzheitlichen Blick auf Begriff und Charakteristika des Wartens zu erhalten, sollen zunächst die gewichtigsten disziplinären Schlüsselwerke der Beschäftigung mit Warte-Problematiken chronologisch skizziert werden, um anhand der Forschungsaktivitäten Entwicklungslinien zu identifizieren. Die Komplexität des Wartens wird mit diesem Kapitel entlang der folgenden zwei tabellarisch aufgezeigten Dimensionen systematisch erschlossen und synthetisiert.

Warten im Spiegel theoretischer und empirischer Forschung: Zugriffe und Programmatik des Exkurs-Kapitels.

\begin{tabular}{|l|l|}
\hline $\begin{array}{l}\text { Modelle des Wartens: } \\
\text { „Harte« Beschreibungsebenen bzw. } \\
\text { Abwendungsstrategien }\end{array}$ & $\begin{array}{l}\text { Erfahrung und Empfindung des Wartens: } \\
\text { "Weiche« Beschreibungsebenen } \\
\text { der Warteerfahrung }\end{array}$ \\
\hline $\begin{array}{l}\text { mathematisch, planerisch-operative und } \\
\text { technische Zugriffe (Queuing Theory } \\
\text { und Operations Management) } \\
\begin{array}{l}\text { Pünktlichkeitsstrategien und } \\
\text { Fahrplanmanagement }\end{array}\end{array}$ & $\begin{array}{l}\text { psychologische Wahrnehmungs- } \\
\text { zusammenhänge } \\
\text { Modelle der Warteerfahrung } \\
\text { Einflussfaktoren (temporal, situativ, } \\
\text { räumlich, gestalterisch) } \\
\text { Interventionsstrategien } \\
\text { (perception management) }\end{array}$ \\
\hline \multicolumn{2}{|l}{} \\
\hline \multicolumn{2}{|l|}{ Synthese: Wesen und Begriff des Wartens aus Sicht der bisherigen Forschung } \\
\hline
\end{tabular}




\subsubsection{Queuing Theory und Operations Management: Wartezeiten als stochastisches Problem und mathematische Beschreibung}

Die ersten theoretischen Auseinandersetzungen mit systemischen Verzögerungen, Staueffekten und Warteschlangenbildungen gehen nicht etwa auf das Verkehrswesen, sondern auf das Telefonwesen des frühen 20. Jahrhunderts und der daraus entstandenen Queuing Theory von Agner Krarup Erlang ${ }^{71}$ zurück. Der Mathematiker und Mitarbeiter der Kopenhagener Telefonaktiengesellschaft (KTAS) erforschte die theoretischen Notwendigkeiten für eine möglichst effiziente Dimensionierung von Telefonvermittlungsanlagen und entwickelte eine Reihe wichtiger mathematischer Formeln zur Reduzierung von Wartezeiten in Telefonnetzen, die zum Teil noch heute zur Betriebsgrundlage von Telefonleitungsaufkommen in Callcentern dienen. Mithilfe der sogenannten Erlang-Verteilung und der Warteschlangenmodelle Erlang-B und Erlang-C konnten aus einer bestimmten Anzahl bekannter Eingangsgrößen konkrete Verbindungskapazitäten und Personalbedarfe ermittelt werden. Aus wissenschaftsgeschichtlicher Sicht bemerkt Gillian Fuller dazu, dass mit diesen ersten mathematischen Beschreibungen von Wartephänomenen Verzögerungen nicht nur etwa als physischsichtbarer Aspekt großstädtischer Agglomerationen in der Industriegesellschaft thematisiert wurden (bspw. Verkehrsstau), sondern dass Wartephänomene zudem von Anbeginn auch Eingang in die moderne Informationsgesellschaft fanden. ${ }^{72}$

Die Relevanz solcher technischen Stauungen wurde offenbar als entscheidender Erfolgsfaktor eingestuft. So war etwa aus Sicht des schwedischen Elektroingenieurs Conny Palm die Servicequalität eines Telefonanbieters in allererster Linie vom Ausmaß der Verdichtung und Stauung des Telefonnetzes abhängig:

"service quality is measured uniquely by the magnitude of the congestion. ${ }^{73}$

In Ermangelung psychologischer Konzepte zum Warten, die in dieser Zeit noch nicht vorlagen, verfolgten die Ingenieure und Mathematiker demnach bereits erste grundsätzliche Annahme über das Verhältnis von Wartezeiten und Kundenzufriedenheit und mutmaßten für das Warten in Telekommunikationsnetzen:

»It is true that a 10 second delay on one occasion may be more disturbing than a 20 second delay on another occasion, but on the average a shorter delay time causes less annoyance than a longer. $\ll^{74}$

Interessant erscheint hier aus kulturgeschichtlicher Perspektive des Wartens, dass die Zeitsensibilität im Allgemeinen und der Wartezeit im Besonderen sich demnach zur Mitte des 20. Jahrhunderts bereits im Bereich von wenigen Sekunden zu bewegen schien. Abermals auf die modernetypische Relationalität von Bewegung und Bremsung rekurrierend, zeigt sich hierbei, dass der Impuls einer gesteigerten Sensibilität für

$71 \quad$ Erlang, »The theory of probabilities and telephone conversations «.

72 Vgl. Fuller, »The queue project«, 2.

73 Conny Palm, »Methods of judging the annoyance caused by congestion«, Tele 4 (1953): 189.

74 Ebd., 191. 
Zeitzwischenräume sich erst aus der allgemeinen Beschleunigung der Kommunikation nährte.

Seit dem Ursprungsfall der telefonnetzspezifischen Modellierung sind die Einsatzgebiete der Queuing Theory stetig gewachsen. So versuchte die Warteschlangentheorie nach dem Zweiten Weltkrieg mittels einer Vielzahl mathematischer Modelle und Formeln, eine abstrakte Beschreibung von Angebots- und Nachfragesituationen bzw. Verkehrs- oder Informationsflüssen in nahezu jeglichen Netzwerkgebilden (Militär, Internet, industrielle Fertigungsprozesse etc.) zu perfektionieren. ${ }^{75}$ Die Queuing Theory gehört damit heute, insbesondere dank computergestützter Berechnungsmöglichkeiten, die seit den 1970er Jahren zur Verfügung standen, zu einer festen Säule der Unternehmensforschung (Operations Research). Entsprechend sind Logistik, Prozessverwaltung oder Verkehrssysteme heute ohne die Modelle der Warteschlangentheorie kaum denkbar. ${ }^{76}$ Die Leistung der Queuing Theory besteht darin, in Systemen in denen Aufträge von Bedienstationen bearbeitet werden (bspw. Kassen in einem Kaufhaus), Fragen bezüglich der voraussichtlichen Wartezeit von Kunden (bzw. auch von Verkehrsteilnehmern), dem Ankunftsverhalten, der Warteschlangenlänge oder der Personalbedarfsplanung beantworten zu können. Mit anderen Worten: "Queueing theory is thus about reducing queues, probabilising the potential and possible chaos of traffic «. ${ }^{77} \mathrm{Die}$ Reduzierung der Wartezeit - etwa durch Schlangenstrukturen, Prioritäts- und Abfertigungsregeln oder frühzeitiges Antizipieren von Netzwerkengpässen - begründet hierbei den entscheidenden Impuls eines bis heute umfangreichen und einflussreichen Forschungsgebietes mit immenser Publikationstätigkeit.

Zentraler Meilenstein der mathematischen Beforschung des Wartens lieferte dabei auch die von Kendall 1953 formulierte Theorie der Warteschlange, ${ }^{78}$ deren sieben Abfertigungsprinzipien im Folgenden kurz aufgeführt werden sollen, da diese mitunter zur festen Terminologie der sozialwissenschaftlichen Auseinandersetzung mit Wartephänomenen geworden sind bzw. auch das alltägliche Sprechen über das Warten geprägt haben.

\section{- $\quad$ FCFS (First Come, First Served)}

Hierbei erfolgt die Bearbeitung der Elemente in der Reihenfolge ihrer Erscheinung. Dieser Modus gilt als besonders gerecht ${ }^{79}$ und ist die am meisten anzutreffende

75 Vgl. Felix Pollaczek, „Über eine Aufgabe der Wahrscheinlichkeitstheorie. I«, Mathematische Zeitschrift 32, Nr. 1 (1930): 64-100; Alexander Chintschin, »Mathematical theory of a stationary queue«, Matematicheskii Sbornik 39, Nr. 4 (1932): 73-84; John DC Little, »A proof for the queuing formula: $L=\lambda W \ll$, Operations research 9, Nr. 3 (1961): 383-87; James R. Jackson, »Jobshop-like queueing systems«, Management science 10, Nr. 1 (1963): 131-42.

76 Vgl. Jillian Dawes und Jennifer Rowley, »The Waiting Experience: Towards Service Quality in the Leisure Industry«, International Journal of Contemporary Hospitality Management 8, Nr. 1 (Februar 1996): 16.

77 Peter Adey u.a., »Introduction«, in The Routledge Handbook of Mobilities, hg. von Peter Adey u.a. (London and New York: Routledge, 2014), 208.

78 Kendall, D.G., 1953. "Stochastic processes occurring in the theory of queues and their analysis by the method of the imbedded Markov chain. «, The Annals of Mathematical Statistics 24, 338-354. Richard C. Larson, »Perspectives on Queues: Social Justice and the Psychology of Queuing.«, Operations Research 35, Nr. 6 (1987): 895-905; Rongrong Zhou und Dilip Soman, »Consumers « waiting in 
Organisationsform von Warteschlangen, denn jedes wartende Element wird - je nach Bearbeitungsdauer der vorderen Elemente - zu einem bestimmten Zeitpunkt sicher bearbeitet.

- LCFS (Last Come, First Served)

Dieses Verfahren repräsentiert das gegenteilige Prinzip zu FCFS. Hierbei werden die Elemente in entgegengesetzter Reihenfolge bedient, in der sie zuvor im Warteraum eingetroffen sind. Das als letztes eingetroffene Element wird als erstes bearbeitet. Da dieses Prinzip im Bedienungskontext mit Kunden als hochgradig unfair wahrgenommen wird, kommt es meist im nicht-personellen Kontext des Computings oder in der Lagerhaltung zum Einsatz.

- SIRO (Service In Random Order)

Hierbei werden wartende Elemente rein zufällig und unabhängig von ihrer Ankunft zur weiteren Bedienung ausgewählt.

- SJF (Shortest Job First)

In diesem Verfahren wird das Element bearbeitet, das am wenigsten Zeit für die Bedienung benötigt, um Elemente mit kurzer Bearbeitungsdauer nicht von jenen mit einer langen Bearbeitungsdauer blockieren oder unnötig aufhalten zu lassen.

- PRI (Priority Service)

Elemente mit hoher Priorität werden zuerst bedient, was voraussetzt, dass im Vorfeld alle Elemente eine Prioritätseinstufung erhalten müssen. Die Priorisierung einzelner Elemente kann dazu führen, dass weniger priorisierte Elemente erst sehr spät oder mitunter gar nicht bearbeitet werden.

- $\quad$ RR (Round Robin)

Basierend auf dem FCFS-Prinzip wird nach Ablauf einer bestimmten Bedienungszeit die Bedienung abgeschlossen oder das wartende Element muss sich wieder in der Warteschlange einreihen, um später den Vorgang mit der gegebenen Bedienungszeit abzuschließen.

- Deadline (Upper Time Limit)

Elemente, die eine nahende Deadline haben, werden frühzeitig und prioritär bearbeitet.

Mit Blick auf den Anwendungsfall des öffentlichen Verkehrssektors werden Interventionen zur Reduzierung oder Vermeidung von Wartephänomenen auf Netzwerkebene insbesondere durch eine mathematisch ausgereifte Fahrplangestaltung erzielt. Am erfolgreichsten gilt in diesem Zusammenhang die Implementierung sogenannter Integrierter Taktfahrpläne (ITF), international als Integrated Clockface Timetables bezeichnet, die zum einen die Wartezeit bei Umsteigesituationen als auch die gesamte Reisezeit verkürzen sollen. Kerngedanke dieser integrierten Fahrpläne ist, dass insbesondere Züge, aber auch Busse oder Fähren mehr oder minder gleichzeitig in größeren Stationen eintreffen und einen unmittelbaren Anschluss ermöglichen. 
Erstmals beschrieben in August Scherls 1909 erschienenen Buch >Ein neues Schnellbahnsystem ${ }^{80}$, gehen die Versuche im Aufbau solche Fahrpläne im Eisenbahnverkehr auf die in den 1940er Jahren durch John Frederick Pownall in Südengland vorangetriebenen Planungen zurück. Seit den 1970er Jahren wurde solche Systeme dann schrittweise in den Niederlanden ( SSpoorslag 70<), in der Schweiz ( $>$ Bahn 2000<) und in Österreich sowie auf regionaler Ebene (z.B. Südtirol) eingeführt. Insbesondere das Beispiel Schweiz zeigte, dass Wartezeiten bei Umsteigesituationen sowie Reisezeiten insgesamt deutlich verkürzt werden konnten und signifikant zur Attraktivierung und zunehmenden Nutzung des Bahnverkehrs beitrugen. Angesichts dieser Erfolgsbeispiele wundert es nicht, dass andere Länder aktuell die Einführung von Integrated Clockface Timetables vorantreiben, so etwa Deutschland (>Deutschland-Takt)) oder Dänemark.

Der Aufbau integrierter Fahrpläne wird dabei vor allem durch die haushaltsrelevante Versprechung genährt, Zeitvorteile ohne den Aufbau gänzlich neuer Infrastrukturen $\mathrm{zu}$ generieren. Integrated Clockface Timetables gelten damit als die effizientere Alternative $\mathrm{zu}$ prestigeträchtigen, aber ressourcenintensiven Hochgeschwindigkeitsplänen, die zwar den Verkehr auf einzelnen Strecken beschleunigen, aber auf Netzwerkebene keine flächendeckenden Verbesserungen und in manchen Fällen gar eine Anschlussverschlechterung in der Peripherie erzeugen. ${ }^{81}$

Die wartezeitrelevanten Nachteile integrierter Fahrpläne liegen jedoch zugleich in einer möglichen Erhöhung von Wartezeiten im Fall von Systemstörungen. Sollte der Anschluss einmal nicht erreicht werden, verdoppeln sich mitunter Warte- und Gesamtreisezeit deutlich. Jede Fahrplangestaltung steht damit vor einem Dilemma zwischen nomineller und robuster Fahrplangestaltung. Zwar lassen sich unter mathematischen Laborbedingungen die Wartezeiten klar noch weiter verkürzen, realpraktisch werden jedoch künstliche Pufferzeiten eingeplant, um Systemstörungen abfangen zu können. Im Dilemma zwischen nomineller und robuster Fahrplangestalt zeigt sich somit exemplarisch für die epochale Grundverfassung der Moderne in Form des engen Wechselverhältnisses von Beschleunigung und Verlangsamung. Mit anderen Worten: Die idealisierte Vorstellung eines »Traums vom Verkehrsfluss ${ }^{82}$ kann hier offenbar nur um den $>$ Preis`strategisch eingebauter Retardierungsmomente annähernd ideal realisiert werden. ${ }^{83}$

Jenseits solcher mathematischen Ansätze auf Systemebene sind aber auch unzählige kleinere Maßnahmen auf Ebene der konkret realisierten Verkehrsleistungen zu beobachten, die jeweils auf eine Prozessbeschleunigung und damit indirekt auf eine Reduktion von Wartephänomenen abzielen. Hierzu zählen die Verlagerung von Verkaufsautomaten von Haltestellen in die Verkehrsmittel hinein, die Einführung elektronischer

80 August Scherl, Ein neues Schnellbahn-System: Vorschläge zur Verbesserung des Personen-Verkehrs (Berlin: Scherl, 1909).

81 Tadej Brezina und Hermann Knoflacher, »Railway trip speeds and areal coverage. The emperor's new clothes of effectivity?«, Journal of Transport Ceography 39 (2014): 121-30.

82 Barbara Schmucki, Der Traum vom Verkehrsfluss: städtische Verkehrsplanung seit 1945 im deutsch-deutschen Vergleich (Frankfurt a.M.: Campus, 2001).

83 Andrew Davenport, Christophe Gefflot, und Chris Beck, »Slack-based techniques for robust schedules«, in Proceedings of the Sixth European Conference on Planning (Sixth European Conference on Planning, Toledo (Spain): AAAI Press, 2001). 
Tickets sowie die daran geknüpften Potentiale eines automatisierten Tarifsystems auf Grundlage von RFID- und NFC-Technologie. Die Vorteile dieser zum Teil kapitalintensiven Vertriebsstrategie werden auf Seiten der Betreiber in tagesaktuellem Wissen über Fahrgastströme, Effizienzsteigerungen oder Einsparpotentialen im Vertrieb sowie in der Erhöhung der Fälschungssicherheit von Fahrscheinen gesehen, wobei für die Nutzerseite neben der erwähnten Reduzierung von Wartezeiten eine Erhöhung der Reiseflexibilität oder etwa die Reduzierung von kognitiven Zugangshemmnissen propagiert werden. ${ }^{84}$ Die Ziele und Erwartungen des kombinierten Einsatzes von E-Tickets und RFID-gestützten Zugangskontrollsystemen liegen hoch und werden als »beträchtlicher Modernisierungsschritt für den ÖPV « ${ }^{85}$ gepriesen, insbesondere deshalb, weil sie die Wartezeiten im Verkehrszugang deutlich reduzieren sollen. Mittels dieser Zeitersparnis steht folglich die Hoffnung verbunden, den ÖPV für Kunden (insbesondere Spontan- und Gelegenheitsfahrer) attraktiver machen, zusätzliche Einnahmen durch marktübergreifende Verflechtungen generieren und nicht zuletzt Interoperabilität und überregionale Integration zu gewährleisten, sodass Fahrgäste zukünftig mit nur einem Ticket jedes beliebige Verkehrsunternehmen eines Landes nutzen können - und dies dezidiert ohne ein Schlangestehen an Vertriebsautomaten.

Zusammenfassend werden aus Sicht der Warteschlangentheorie Wartephänomene als dezidiert berechenbare Phänomene aufgefasst und in mathematischen Modellen beschrieben. Der (modernen) Problematik der Verzögerung kann durch stochastische Wahrscheinlichkeitsregeln und adäquates operations management begegnet werden kann. Retardierungsmomente werden aus Sicht der Queuing Theory schlichtweg als "stochastic disturbances ${ }^{86}$ begriffen, die mittels immer weiter verbesserter mathematischer Modelle und Simulationen vermieden oder zumindest vermindert werden können. Stillstände und Stauungen können demnach proaktiv verhindert und reibungslose Flüsse gewährleistet werden.

Trotz ihrer Errungenschaften sah sich die Warteschlangentheorie seit den 1980er Jahren zunehmend der sozialwissenschaftlichen und insbesondere der wirtschaftswissenschaftlichen Kritik ausgesetzt, denn die beabsichtigte Systemoptimierung zielte stets nur auf die Reduzierung der objektiven Dauer der Wartezeit, nicht jedoch auf das Verständnis davon, wie Wartezeiten individuell aus Sicht der wartenden Personen erfahren und wahrgenommen wurden. ${ }^{87}$ Besonders scharf argumentierten hierbei Carmon, Shanthikumar und Carmon gegen die Missachtung der psychologischen Dimension von Wartezeiten und warnten bezüglich der eindimensional normativen Betrachtung von Wartephänomenen gar vor entstehenden Ineffizienzen: »Failure

84 Vgl. Marc Langheinrich, »RFID and privacy«, in Security, Privacy, and Trust in Modern Data Management (Springer, 2007), 433-50; Andreas Kossak, »Quo vadis, elektronisches Ticketing.«, Der Nahverkehr, 2005, 7-8.

85 Kossak, »Quo vadis, elektronisches Ticketing.«, 14.

86 Leo G. Kroon, Rommert Dekker, und Michiel ]. C. M. Vromans, „Cyclic Railway Timetabling: A Stochastic Optimization Approach«, in Algorithmic Methods for Railway Optimization, hg. von Frank Geraets u.a. (Springer Berlin Heidelberg, 2007), 41-66.

87 Vgl. Winter Nie, »Waiting: integrating social and psychological perspectives in operations management«, Omega 28, Nr. 6 (2000): 611-29. 
to consider determinats of consumers' perception of queuing systems may at best result in inefficient systems, and in some cases lead to solutions of queuing related problems that simply do not work «. ${ }^{88}$ Darüber hinaus galt die Implementierung der theoretischen Grundsätze zur Reduzierung der objektiven Wartedauer oftmals als zu ressourcenaufwendig.

\subsubsection{Die Empfindung des Wartens: Psychologische Beschreibungsebenen}

\section{Sozialpsychologie und Soziologie des Wartens: Die Warteschlange als soziales System}

Waren die Beschreibungen von Wartephänomen aus Sicht der Queuing Theory auf die Reduzierung der objektiven Zeitdauer des Wartens oder dessen Abwendung beschränkt und somit noch rein mathematisch-operativer Natur, entstanden seit den späten 1960er Jahren erste explizite Beschreibungsversuche, die Wartesituationen in ihrer psychologischen und sozialen Dimension zu durchdringen versuchten. Während sich zuvor bereits zeitpsychologische Studien der experimentellen Erforschung subjektiver Zeitwahrnehmungen in Abhängigkeit sich verändernder Aktivitäten ${ }^{89}$ bzw. wechselnder visueller und auditiver Einflüsse ${ }^{90}$ gewidmet hatten, standen im vorherrschenden Erkenntnisinteresse sozialpsychologischer und soziologischer Studien empirische und phänomenologische Befunde zu vermehrt auftretenden Warteschlangenformationen westlicher Konsum- und Dienstleistungsgesellschaften. Es ist das Verdienst dieser Perspektiven, das Warten als anscheinende Selbstverständlichkeit des modernen Alltags in seiner tatsächlichen Komplexität erstmals tiefer ergründet zu haben und den Kosmos des kollektiven Wartens in seiner zuvor unerschlossenen Regelhaftigkeit als soziales System zu verstehen. In der Konsequenz dieses Perspektivwechsels wurden - etwa mit der pionierhaften, 1985 veröffentlichten Arbeit von Osuna, erstmals die psychologischen Kosten des Wartens wie Stress, Frustration oder Angst dem bisherigen Primat der ökonomischen Kosten des Wartens gegenübergestellt. ${ }^{91}$

Im Rahmen sozialpsychologischer Betrachtungen war es allen voran Leon Mann, der mit seinem 1969 erschienenen Artikel Queue Culture die Warteschlange als ein »embryonic social system «92 mit einer Vielzahl informeller Regeln, Freiheiten und Sanktionsmechanismen identifizierte. Trotz ihres informellen Charakters konstituierten die von ihm pionierhaft untersuchten Langzeit-Warteschlangen vor Footballstadien in Melbourne eine regelrechte Kultur des Wartens bzw. eine Gesellschaft in Miniaturform. Laut Mann würden solche Warteschlangen demnach mit ähnlichen funktionalen Schwierigkeiten konfrontiert werden wie andere Sozialsysteme und daher eine informelle, aber dennoch ebenso wirksame soziale Ordnung von quasi-institutionellem

Ziv Carmon, J. Ceorge Shanthikumar, und Tali F. Carmon, »A psychological perspective on service segmentation models: The significance of accounting for consumers < perceptions of waiting and service«, Management Science 41, Nr. 11 (1995): 1814.

89 John C. Loehlin, »The influence of different activities on the apparent length of time.«, Psychological Monographs: Ceneral and Applied 73, Nr. 4 (1959): 1.

90 I. J. Hirsh, R. C. Bilger, und B. H. Deatherage, »The effect of auditory and visual background on apparent duration«, The American Journal of Psychology 69, Nr. 4 (1956): 561-74.

91 Osuna, »The psychological cost of waiting «.

92 Mann, »Queue culture: The waiting line as a social system«, 340. 
Charakter ausbilden. Als Grund für die Regelhaftigkeit von Warteformationen bezeichnete Mann die Zentralität der Zeit in westlichen Gesellschaften. Die Kostbarkeit der Zeit und ihres erlebten Verlustes im Schlangestehen würde es unabdingbar machen, Regeln der Selbstkontrolle aufzustellen, die, getragen von der kulturellen Werteübereinkunft einer Schlangenordnung nach dem (gerechten) Prinzip der Ankunft (»first come, first serve«), die Formation dauerhaft stabil halten und somit in der Lage wären, das Leid des Zeitverlustes für jedes Mitglied einer Warteschlange minimieren zu können.

Jenseits dieser Feststellungen eröffnete diese bis heute vielbeachtete Untersuchung Aspekte einer Ökonomisierung des Wartens in Gestalt einer arbeitsteiligen Professionalisierung einzelner Schlangenmitglieder im Spektrum von »queue counters« (bezahlten Wartenden) bis hin zu systemgefährdenden Spekulanten oder Mittelsmännern. Darüber hinaus beleuchtete Mann entgegen der allgemein vorherrschenden Stigmatisierung des Wartens als zu vermeidender Zeitverlust den paradoxen Umstand, dass trotz der Zentralität der kostbaren Zeit und trotz alternativer Beschaffungsmöglichkeiten die Warteschlangen jedes Jahr länger wurden, das Warten demnach offenbar bewusst in Kauf genommen wurde. Den Grund dafür sah er im zunehmenden Eventcharakter des Ausharrens, der nicht zuletzt auch Reputation und Anerkennung der NichtWartenden außerhalb der Schlange einbringen würde. Anerkennung, Ereignischarakter und Gemeinschaft wurden somit für spezielle Wartesituationen als wichtige Gründe zur freiwilligen Entbehrung identifiziert. Mann resümierte diese Beobachtungen in der Einschätzung, dass die Warteschlange »almost becomes an end in itself, with its own intrinsic rewards and satisfactions $« .{ }^{93}$ Warten kann somit sinnstiftend wirken. Damit plädierte er dafür, dass der temporale Zustand des Wartens zusätzlich unter dem Aspekt der Belohnungsmechanismen gelesen werden müsste, was erstmals die soziale, kulturelle und emotionale Mehrdimensionalität von Wartephänomenen jenseits ihrer operativ-mathematischen Beschreibung als zu vernichtender Zeitzwischenraum aufzeigte.

Ab Mitte der 1970er Jahre widmeten sich die Sozialwissenschaften stärker der Thematik von Verzögerungen im Servicebereich und Fragen des institutionellen und sozialen Kontextes von Wartezeiten. Der US-amerikanische Psychologe Barry Schwartz legte dazu eine Reihe von Untersuchungen vor, die das beim Warten immanente Abhängigkeitsverhältnis zwischen Klienten und Anbietern in Hinblick auf die sozioökonomische Machtstellung der Akteure in den Blick nahmen. Schwartz leitete den systemischen Ursprung von Wartezeiten zunächst aus einem Missverhältnis zwischen Angebot und Nachfrage sowie - quasi im Luhmann'schen Sinne - aus der hochspezialisierten Arbeitsteilung moderner Gesellschaften ab, die zahlreiche Verknappungen und Engpässe bei der Bereitstellung von Spezialgütern oder der Inanspruchnahme von Dienstleistungen generieren würde. Trotz zahlreicher ideologischer Verweise auf die UDSSR als einer Nation im dauerhaften Wartezustand, räumte er dabei aber selbst für die kapitalistischen Gesellschaften die Unausweichlichkeit von Wartezeiten ein.

Ausgehend von dieser systemischen Unausweichlichkeit betonte Schwartz, dass die daraus resultierenden Wartezeiten jedoch keinesfalls für alle Menschen gleich verteilt 
seien, sondern mit den jeweiligen Machtverhältnissen der Akteure korrelieren, eindringlich betont im Leitsatz »Waiting is patterned by the distribution of power in a social system «. ${ }^{94}$ Wartezeiten werden demnach nicht einheitlich verteilt, sondern asymmetrisch. Während etwa mächtige Personen durch höheren Ressourcenaufwand relative Immunität gegenüber dem Warten besitzen (und mit Verweis auf Mann kaum in Schlangen anzutreffen seien), würden ressourcenärmere Personen je nach Abhängigkeitsgrad von der erwarteten Ware oder Dienstleistung wesentlich längere Wartezeiten in Kauf nehmen müssen.

Schwartz' Leistung besteht einerseits darin, Verzögerungen als wichtigen soziologischen Indikator erschlossen zu haben und andererseits darin, die negative Empfindung des Wartens nicht lediglich auf eine anthropologische Gesetzmäßigkeit zu reduzieren, sondern ein fundamentales Unbehagen im Warten auf die Problematik der sich im Warten kristallisierenden sozialen Ungleichheiten zurückzuführen. Die negative Empfindung des Wartens sei selbst zutiefst sozialer Natur. So wird das Warten etwa immer nur einseitig aus Sichtweise des Wartenden als Zumutung empfunden, nicht jedoch aus Sicht des Verursachers oder mit den Worten von Schwartz: »Waiting is therefore a negative condition only when we confine ourselves to the standpoint of the person who is delayed «. ${ }^{95}$ Während die zeitliche Verzögerung für die eine Seite zur unangenehmen Erfahrung wird, fördert es auf der anderen Seite unter Umständen sogar den Status des Verursachers. Diese Ungleichheiten seien es, die erst eine Verstärkung der intrinsischen und extrinsischen bzw. personellen und sozialen Kosten des Wartens verursachen würden, etwa in Prinzipien der objektiven Abhängigkeit, dem Unterordnungsgefühl oder im Eindruck, die eigene Zeit sei weniger wertvoll als die des Verursachers der Wartezeit. ${ }^{96}$ Die soziale Relativität dieses temporalen Zustands kristallisiert sich schließlich in einer Reihe von Spielarten und Typologien, die das Warten in den Rang eines machtpolitischen Mediums par excellence erheben würden. $\mathrm{Ob}$ als auferlegter (aggressiver) Zwang, als Sanktionierungs- und Bestrafungsmittel, als Akt der Selbstmystifizierung oder als Protest gegen höhergestellte Autoritäten, Schwartz identifizierte die Diskrepanz der Machtverhältnisse innerhalb der systemischen Knappheit von Angebot und Nachfrage als »the ultimate determinant of delay «. ${ }^{97}$

Neben der sozialen Differenzierung des Wartens beleuchtete Schwartz in späteren Arbeiten auch institutionelle und organisationale Gründe für ungleich verteilte Wartezeiten. Mit Blick auf die zeitliche Organisation sozialer Prozesse konstatierte er, dass im Grunde jegliche soziale Organisation aus einem Netzwerkgeflecht von »interlocking queues ${ }^{98}$ bestehen würde. Darin würden Wartezeiten keinesfalls ganzheitlich und umgehend eliminiert, sondern vielmehr auf unterschiedliche Prioritätsreihenfolgen verteilt, denn, so Schwartz, »because two activities usally cannot occupy the same place in time, choices, priorities, and queues are closely linked «. ${ }^{99}$ Die Priorisierung bzw. das

Barry Schwartz, »Waiting, exchange, and power: The distribution of time in social systems«, 843. Ebd., 844.

Vgl. ebd., $856 \mathrm{ff}$.

Ebd., 867.

Barry Schwartz, »Queues, priorities, and social process «, Social Psychology 41, Nr. 1 (1978a): 3

99 Ebd., 4. 
Warteschlangenmanagement sei demnach kein neutraler Akt, sondern als reflektierte Entscheidung stets moralisch aufgeladen. So kann bspw. die Beschleunigung eines Teils der Organisation nur durch die Verlangsamung eines anderen Teils gewährleistet werden. In Abhängigkeit von der Größe und Macht einer Organisation würde nur der gezielte und selektive Aufbau von bottlenecks in Organisationen jene paradoxen Pufferzonen schaffen (z.B. vorgeschaltete Sekretariate), die überhaupt erst die Voraussetzung für organisatorische Effizienz bilden. ${ }^{100}$ Kurzum: Der Schutz der Bearbeitung von Kernaufgaben kann nur durch punktuell erzeugte Verzögerungen gewährleistet werden. Mit dieser Sichtweise sprach sich Schwartz gegen eine zu stark mechanisierte Vorstellung der Beschreibung sozialer Systeme aus. Zudem bemängelte er die vorherrschende, rein ökonomische Sichtweise auf Wartesituationen als zu simplifizierend und unvollständig:

»The intention of many economists who have considered the problem is to reduce this duality [objektiver und subjektiver Eigenschaften des Wartens, R.K.] to a single plane. By adopting the assumption of an unrestricted convertibility of time and money, they have subsumed all vicissitudes in delay and its costs under a simple monetary model ${ }^{101}$

Um das Wesen von Verzögerungen im Dienstleistungssektor besser verstehen zu können, plädierte er stattdessen für eine differenziertere und duale Untergliederung von Wartezeiten in objektive und subjektive Eigenschaften bzw. der reinen Wartedauer und der daraus resultierend gefühlten Unzufriedenheit. Statt wie in der Queueing Theory Zeit lediglich auf eine mathematisch-physikalische Größe zu reduzieren und Wartezeit nur als rein monetäre Einbuße zu begreifen, argumentierte Schwartz für das Vorhandensein subjektiver Kosten, die in vielen Fällen von kulturellen und sozialen Faktoren ausgelöst würden und längere Wartezeiten bzw. negative Zeitwahrnehmung zur Folge hätten. Diese Überzeugung unterstrich er mit einer 1978 veröffentlichten Erhebung zur Wartedauer und Wahrnehmung von Wartezeiten afroamerikanischer US-Bürger im Gesundheitssystem. Die Untersuchung zeigte, dass Afroamerikaner nicht nur signifikant länger auf eine medizinische Behandlung warteten als weiße Patienten, sondern aufgrund der generellen gesellschaftlichen Frustration wesentlich größere Ungeduld und Zeitsensibilität aufwiesen, die insgesamt eine wesentlich negativere subjektive Zeitwahrnehmung prägte: »It is not the white, but, rather, the black who is most likely to complain about the time it takes to acquire service $«{ }^{102}$ Diese Ergebnisse widerlegten zwei weit verbreitete rassistische Vorurteile. Zum einen, dass Afroamerikaner aufgrund ihres attestierten »easy-going « Lebensstils ohnehin geduldiger wären und das Warten einfacher akzeptieren würden. Zum anderen widerlegte die Studie die weit verbreitete Annahme, dass insbesondere arme Afroamerikaner eine höhere Warte-Akzeptanz aufweisen würden, da sie ohnehin mit der gesparten Wartezeit nichts Produktives anstellen könnten. Schwartz zeigte damit pionierhaft auf, dass absolute Wartedauer und

100 Vgl. ebd., 5.

101 Barry Schwartz, »Time, Patience, and Black People: A Study of Temporal Access to Medical Care«, Sociological Focus 11, Nr. 1 (1978b): 18.

102 Schwartz, »Queues, priorities, and social process«, 19. 
subjektive Unzufriedenheit demnach in engem Zusammenhang standen bzw. subjektive Kosten nicht von den objektiven Kosten getrennt werden dürften.

Edgar Osuna erweiterte kurze Zeit später Schwartz' Forderung nach der Anerkennung subjektiver Kosten im Warten jenseits der ökonomischen Sichtweise des monetären Verlustes und verwies auf die umfangreichen und nicht minder relevanten psychologischen Kosten des Wartens. Er postulierte die Existenz einer "subjective cost (disutility) for waiting $^{103}$ und betonte:

»There are other costs, of a psychological nature, involved in the process of waiting, though their existence has not been fully explained. ${ }^{104}$

Als solche psychologischen Kosten wurden vordergründig ein erhöhtes Stresslevel und ein permanentes Beklemmungsgefühl des Wartenden identifiziert, Gefühle, die sich aus dem Bewusstsein einer generellen (Zeit-)Verschwendung und der erlebten Ungewissheit speisen würden und die dem Wartenden im Prozess explizit bewusst wären. Osuna konnte mit seinem mathematisch-theoretischen Stressevolutionsmodell aufzeigen, dass sich die Stressintensität mit zunehmender Wartedauer non-linear erhöht. So würde das Stresslevel bereits vor der Ankunft im Servicesystem steigen, weil Unsicherheit darüber bestünde, ob die Bedienung pünktlich und wie erwartet stattfinden kann. Wenn keine Wartezeit vorliegt, sinkt das Stresslevel auf null, wohingegen eine verlängerte Wartezeit - insbesondere dann wenn keine Informationen über das Eintreffen des zu Erwartenden bereitgestellt werden - das Stresslevel stetig steigen lassen und es selbst nach Abschluss des Leistungserhalts nicht auf Ausgangsniveau zurückfallen würde. ${ }^{105}$ Die sinnvollste Maßnahme zur Senkung der Stressintensität bestünde daher in der Bereitstellung von Echtzeitinformationen über die noch bevorstehende Wartedauer. Sei es im Verkehrskontext, an Fahrstühlen oder im Einzelhandel, Osuna plädierte als einer der ersten Autoren für eine stärkere Implementierung dieser aus heutigen Sicht vielerorts selbstverständlichen Maßnahme, denn »(...) merely informing the individual sometime in advance about the time he will be served, the psychological stress and anxiety associated to waiting is reduced. ${ }^{106}$ Osuna erbrachte somit einen ersten theoretisch fundierten Nachweis der Wirksamkeit von Echtzeitinformationen in Wartesituationen zur Reduzierung der immanenten psychologischen Kosten und plädierte für einen Brückenschlag zwischen mathematischen Modellen zur Wartezeitberechnung und den psychologischen Kosten des Wartens. ${ }^{107}$

103 Osuna, »The psychological cost of waiting «, 83 .

104 Ebd., 82.

105 Vgl. ebd., $92 \mathrm{ff}$.

106 Ebd., 100.

107 Ein weiterer Forschungsstrang, der sich seit den späten 1980er Jahren und bis heute besonders intensiv den psychologischen Kosten des Wartens widmet, besteht in sozialpsychologischen Studien zu Wartelisten von Patienten in Krankenhäusern innerhalb der Pflegewissenschaft (Health Studies), beginnend mit John Yates, Why are We Waiting?: An Analysis of Hospital Waiting-lists (Oxford: Oxford University Press, 1987). 


\subsubsection{Marketing und Management Studies: Attraktivierung eines ungeliebten Zustands}

Die Ansätze der (sozial)psychologischen Beschäftigung mit Wartesituationen wurden seit Ende der 1980er Jahre immer stärker von den Wirtschaftswissenschaften aufgegriffen und ausgehend von den USA zunehmend international und anwendungsorientiert erweitert. Katz et al. ${ }^{108}$ begründeten zu Beginn der 1990er Jahre dieses neue Forschungsinteresse mit der Veränderung sozioökonomischer Rahmenbedingungen in der Arbeitswelt der USA zum Ende der 1980er Jahre. Eine deutliche Zunahme von Zweitjobs und die Erhöhung der durchschnittlichen Wochenarbeitszeit (von 40,6 Stunden im Jahr 1973 auf 47 Stunden im Jahr 1988) hätten bei gleichzeitig sinkendem Freizeitanteil einen neuen Zeitdruck und dadurch einen bis heute spürbaren Rückgang der Wartetoleranz hervorgerufen, ${ }^{109}$ der nicht nur in den USA, sondern zunehmend auch in anderen postindustriellen Gesellschaften diagnostiziert wurde. Auch Carmon, Shanthikumar und Carmon begründeten in ihrer 1995 veröffentlichten Studie die gesunkene Wartetoleranz mit strukturellen Veränderungen und verwiesen auf den »phenomenal growth of the service sector in the American economy«, in denen "customers' satisfaction with the service has become a major concern for academics and practitioners alike«. ${ }^{110}$ Die Dienstleistungswirtschaft musste daraufhin erkennen, dass selbst kurze Wartezeiten seitens der Kunden nicht mehr akzeptiert wurden. Katz et al. fassen diese Gemengelage folgendermaßen zusammen:

»As consumers experience a greater squeeze on their time, short waits seem longer and more wasteful to them than ever before ${ }^{111}{ }^{11}$

Statt Wartezeiten zu tolerieren, richteten veränderte »consumer values« den Fokus der Arbeitnehmer nunmehr auf die noch verbliebene Freizeit und auf das Konzept der »quality time«. Wartezeiten avancierten dagegen zum kritischen Kulminationspunkt der Zeitknappheit, der von Seiten der Serviceanbieter nicht mehr ignoriert werden konnte, denn der übergeordnete Konsens der Managementliteratur bestand in der Auffassung, dass zu lange Wartezeiten die generelle Bewertung des Service negativ beeinflussen. ${ }^{112}$

Angesichts dieses Strukturwandels sahen sich verschiedene Subdisziplinen der Unternehmensforschung - insbesondere die Konsumenten- und Marketingforschung -

108 Karen L. Katz, Blaire M. Larson, und Richard C. Larson, »Prescription for the waiting-in-line blues: Entertain, enlighten, and engage«, MIT Sloan Management Review 32, Nr. 2 (1991): 44-53.

$109 \mathrm{Vgl}$. John McDonnell, »Music, scent and time preferences for waiting lines«, International Journal of Bank Marketing 25, Nr. 4 (2007): 224.

110 Carmon, Shanthikumar, und Carmon, »A psychological perspective on service segmentation models: The significance of accounting for consumers perceptions of waiting and service $\ll, 1806$.

111 Katz, Larson, und Larson, »Prescription for the waiting-in-line blues: Entertain, enlighten, and engage«, 44 .

112 Vgl. dazu unter anderem Katz, Larson, und Larson, »Prescription for the waiting-in-line blues: Entertain, enlighten, and engage«; Shirley Taylor, »Waiting for service: the relationship between delays and evaluations of service«, The journal of marketing, 1994, 56-69; Michael K. Hui und David K. Tse, »What to tell consumers in waits of different lengths: An integrative model of service evaluation«, The Journal of Marketing 60, Nr. 2 (1996): 81-90. 
zunehmend gezwungen, sich unter Einbezug psychologischer Theorieangebote erstmals explizit dem wartenden Kunden im Servicekontext (Restaurants, Handel, medizinische Versorgung, aber auch öffentlicher Verkehr) vor Empfang einer Leistung mit dem Ziel der Verbesserung der Servicequalität und daraus resultierender Steigerung der Kundenzufriedenheit zu widmen. Der neue Handlungsdruck bewirkte dabei einen historischen Paradigmenwechsel in der Servicewissenschaft. Statt sich wie traditionell auf Freundlichkeit und Kompetenz des Personals bzw. auf die Qualität der Leistung $\mathrm{zu}$ fokussieren, mussten angesichts dieser veränderten zeitsensiblen Kundenwahrnehmungen nun verstärkt integrative Konzepte von objektiver Wartezeitverkürzung und Qualitätssicherung im Mittelpunkt der Managementaktivitäten stehen. So plädierten etwa Katz et al. für die Loslösung vom konventionellen Qualitätsfokus zugunsten einer Erweiterung um ein stemporales Paradigma:

»Today this approach is insufficient. Consumers not only demand quality, they also demand speed. They do not tolerate waiting in line for long periods of time «. ${ }^{113}$

Dem neuen wirtschaftswissenschaftlichen Forschungsinteresse an diesem zuvor weitgehend vernachlässigten Aspekt der Servicewissenschaften lag dabei auch die Einsicht der Begrenztheit operationeller Lösungen im Rahmen der Queuing Theory zugrunde. Trotz der vielversprechenden Errungenschaften der mathematisch modellierten Verhinderung von Schlangenbildungen besteht heute Konsens darüber, dass eine Servicewelt ohne Wartezeiten reine Illusion wäre und nur allein die sharten $<$, normativen Beschreibungsebenen der Queuing Theory die Problematik der >neuen Ungeduld « nicht werden lösen können. Trotz weitreichender technologischer Hilfestellungen besteht heute Übereinkunft darin, dass Wartezeiten durch die Knappheit spezieller Dienstleistungen, durch volatile Nachfrageschwankungen und hohe Beratungsintensität auch in $\mathrm{Zu}$ kunft zu einem unvermeidbaren Bestandteil der Dienstleistungswelt gehören werden, so erklären Houston, Bettencourt und Wenger: »Ensuring that customers never wait is infeasible for most service firms. " $"$ Winter Nie betonte vielmehr, dass die Wahrscheinlichkeit des Auftretens von Wartezeiten im Servicebereich sogar generell höher sei als im Produktionsbereich. Zum einen weil sie oftmals erst in der Interaktion zwischen Anbieter und Kunde erzeugt, geliefert oder konsumiert werden sowie schwankender Nachfrage unterliegen und zum anderen weil die Interaktion von Anbieter und Kunde keinem standardisierten Muster folgt, sondern immer mit unvorhersehbaren Unsicherheiten verbunden ist, was zu unterschiedlichen langen Bearbeitungszeiten führt und die Anfälligkeit für zeitliche Engpässe erhöht. ${ }^{115}$ Die Prognose der Zunahme von Wartephänomenen im Servicebereich verstärkte damit eine ohnehin präsente Problematik. Im Vergleich zum Erhalt eines fertigen Produkts wird der Erhalt von Dienstleistungen

113 Katz, Larson, und Larson, »Prescription for the waiting-in-line blues: Entertain, enlighten, and engage $\ll, 44$.

114 Mark B. Houston, Lance A. Bettencourt, und Sutha Wenger, »The relationship between waiting in a service queue and evaluations of service quality: A field theory perspective«, Psychology \& Marketing 15, Nr. 8 (1998): 736.

115 Vgl. Nie, »Waiting: integrating social and psychological perspectives in operations management«, 612. 
oftmals unmittelbar erlebt und - sei es an Bankschaltern oder Kassen - als zeitlicher Prozess in einem räumlichen Setting erfahren. Die wirtschaftlichen Austauschbeziehungen in der Dienstleistungsgesellschaft werden stärker als zuvor verzeitlicht, mit der Konsequenz, dass Kunden die Servicequalität nicht mehr allein am Endergebnis bewerten »but also on the process of service delivery. ${ }^{116}$ Spätestens seit den 1990er Jahren sind Kundenzufriedenheit und Loyalität somit nicht mehr allein an der Qualität des Service geknüpft, sondern werden nunmehr auch an dessen zeitlicher Ausgabe bemessen. Zuvor ignoriert, konnten Wartezeiten nun zur geschäftsschädigenden Gefahr werden.

Dieses Bewusstsein der erhöhten Problemqualität des Wartens begünstigte folglich nicht nur ein wachsendes Interesse daran, den wartenden Kunden und dessen Zeitwahrnehmung innerhalb der Serviceumwelt besser zu verstehen, sondern ihn schließlich darin beeinflussen zu können. Nach der von Shirley Taylor formulierten Maxime "If you cannot control the actual wait duration, then control the customer's perception of it ${ }^{117}$ reiften insbesondere in den 1990er Jahren Wartephänomene zum facettenreichen Forschungsgegenstand der englischsprachigen Management- und Marketingforschung. Im Schnittfeld von Unternehmensforschung und angewandter Psychologie entstanden unzählige laborexperimentelle und feldbasierte Untersuchen, die sich meist rein exploratorisch der im Warten auftretenden emotionalen und affektiven Reaktionen widmeten und diese in stochastische Zusammenhänge mit objektiven Wartezeiten stellten. Vordergründig ging es zum einen darum, die psychologischen Kosten des Wartens anzuerkennen, zum anderen aber darum, die verschlungenen Wechselwirkungen zwischen wahrgenommener Wartezeit und Kundenzufriedenheit zu analysieren bzw. den Einfluss von Wartezeiten auf das zukünftige Kaufverhalten und die Loyalität zum Unternehmen zu bestimmen. ${ }^{118}$

Die Pluralität der Studien, die von europäischer Seite vorwiegend durch französische Beiträge bereichert wurde, reflektierte dabei zunehmend die Komplexität des temporalen Zustands selbst. Grob kategorisiert umfassten die Forschungsstränge nach Durrande-Moreau und Usunier in der Hochzeit der Wartezeit-Thematisierung in den 1990er Jahren a) Studien zur Warteerfahrung in Extremfällen (z.B. Reaktion und Verhalten bei Verspätungen), b) zum Warten in standardisierten Alltagssituationen, c) zur Einschätzung der Wartedauer aus Kundensicht sowie d) zum Einfluss von Warteschlangenregeln bezüglich der Kundenzufriedenheit. ${ }^{119}$ Auch wenn die aus Sicht der Kunden wahrgenommene Wartedauer einvernehmlich als entscheidende Einflussvariable zur Kundenzufriedenheit betrachtet wurde, ${ }^{120}$ untersuchte ein größerer Forschungsstrang auch den Einfluss von strukturellen Interventionsmaßnahmen (Musik, Farben, Düfte, Raumqualitäten, Designs, Komfort), den Einfluss des Zeitpunktes im Prozess, die

116 McDonnell, »Music, scent and time preferences for waiting lines«, 224.

117 Taylor, »Waiting for service: the relationship between delays and evaluations of service«, 56.

118 Vgl. Frédéric Bielen und Nathalie Demoulin, „Waiting time influence on the satisfaction-loyalty relationship in services«, Managing Service Quality: An International Journal 17, Nr. 2 (2007): 174-93; Ad Pruyn und Ale Smidts, »Effects of waiting on the satisfaction with the service: Beyond objective time measures «, International journal of research in marketing 15, Nr. 4 (1998): 321-34.

119 Durrande-Moreau, »Waiting for service: ten years of empirical research«, 175.

120 Houston, Bettencourt, und Wenger, »The relationship between waiting in a service queue and evaluations of service quality: A field theory perspective«. 
Bedeutung der Attraktivität des zu erreichenden Ziels ${ }^{121}$ oder den Einfluss von situationellen und persönlichen Variablen auf die wahrgenommene Wartedauer.

Als erste empirische Feldstudie zum Warten im Konsumbereich gilt Jacob Horniks 1984 veröffentlichte Untersuchung zu verschiedenen Zeitwahrnehmungen von Kunden im Einzelhandel unter Berücksichtigung wechselnder Rahmenbedingungen wie Schlangenlänge, Warteschlangenformation etc. Hornik verglich dazu die wahrgenommene Wartedauer von Kunden in Kassenschlangen mit der tatsächlichen Wartedauer und fand heraus, dass »individuals exhibit a tendency to overestimate waiting time. « ${ }^{122}$ Kunden überschätzten demnach ihre eigene Wartezeit im Durchschnitt um 2,65 Minuten, wobei die tatsächlich messbar verstrichene Zeit als wichtigster Referenzpunkt zur Abschätzung der wahrgenommenen Wartedauer fungierte. Dazu fand er heraus, dass entgegen der Ausgangshypothesen die Faktoren Warteschlangenlänge, Geschlecht, Alter oder Beruf keinen signifikanten Einfluss auf die subjektive wahrgenommene Wartezeit hatten, sondern es vielmehr die emotionalen Vorbedingungen waren, die, bezeichnet als »level of enjoyment«, zur entscheidenden Variable der Wartezeiterfahrung wurden. Kunden, die das Einkaufen genossen und solche, die regelmäßig einkauften, schätzten die Wartezeit deutlich kürzer ein als sie in Wirklichkeit war. Die deutliche Abweichung von wahrgenommener und tatsächlicher Wartezeit veranlasste Hornik zur Forderung eines reformierten »time perception approach ${ }^{123} \mathrm{im}$ Dienstleistungskontext jenseits des vorherrschenden Fokus auf die standardisierte Zeitmessung.

Kurz darauf war es David Maister, der als einer der ersten Autoren im Managementbereich den Übertrag psychologischer Verhaltenskonzepte in die Wirtschaftswissenschaften propagierte. Mit The Psychology of Waiting Lines kritisierte er als Wirtschaftsberater den traditionellen Fokus auf Methoden des operativen Warteschlangenmanagements und plädierte ähnlich wie Hornik für einen Perspektivwechsel in Richtung der subjektiven Erfahrungen des wartenden Kunden, denn, so zitiert Maister den US-amerikanischen Ökonomen Steven Levitt: »Products are consumed, services are experienced. ${ }^{124}$ Die Relevanz der Auseinandersetzung mit der Erfahrung des Wartens resultierte aber nicht nur aus der generell gestiegenen Bedeutung von Dienstleistungen gegenüber Produkten, sondern insbesondere aus der Gefahr, dass die Warteerfahrung kein unbedeutender Aspekt des Services darstellte, sondern die Bewertung des gesamten Services beeinträchtigen und herabsetzen könnte. Um diesem Zusammenhang entgegenzuwirken, schlug Maister acht theoretische Grundsätze zur Verbesserung der subjektiven Warteerfahrung und zur Erhöhung der Kundenzufriedenheit im Servicebereich vor, die in ihrer bisweilen anschaulichen Formelhaftigkeit bis heute als wichtige Referenz und als Ausgangspunkt empirischer Forschung im Managementbereich gelten. ${ }^{125}$

Thierry Meyer, »Subjective importance of goal and reactions to waiting in line«, The Journal of Social Psychology 134, Nr. 6 (1994): 819-27.

122 Jacob Hornik, "Subjective vs. objective time measures: A note on the perception of time in consumer behavior «, Journal of Consumer Research 11, Nr. 1 (1984): 617. Ebd. 
Managementgrundsätze zur Verbesserung der Warteerfahrung im Servicekontext nach Maister (1985).

\begin{tabular}{|l|l|}
\hline $\begin{array}{l}\text { Beschäftigtes Warten ist besser als unbeschäftig- } \\
\text { tes Warten }\end{array}$ & $\begin{array}{l}\text { Warten ohne Angabe von Cründen wird negativer } \\
\text { empfunden als mit Erklärungen }\end{array}$ \\
\hline $\begin{array}{l}\text { Pre-process Warten wird als länger empfunden } \\
\text { als in-process Warten }\end{array}$ & $\begin{array}{l}\text { Unfaires Warten wird negativer erfahren als } \\
\text { gleichberechtigtes Warten }\end{array}$ \\
\hline Angst lässt Warten länger erscheinen & $\begin{array}{l}\text { Je wertvoller der erwartete Service, desto größer } \\
\text { die Toleranz darauf zu warten }\end{array}$ \\
\hline $\begin{array}{l}\text { Ungewisses Warten erscheint länger als gewisses } \\
\text { und bestimmtes Warten }\end{array}$ & Cruppenwarten besser als isoliertes Warten \\
\hline
\end{tabular}

Das praktizierende Management als auch die Wissenschaft, so war Maister überzeugt, könnten unter Berücksichtigung der psychologischen Komplexität von Warteschlangen und des spezifischen Kontextes der Wartesituation lernen, das Warten nicht fatalistisch als unveränderliches Übel zu akzeptieren, sondern es aktiv zu gestalten. Auch wenn diese acht Grundsätze aus heutiger Sicht als triviale Selbstverständlichkeiten erscheinen mögen, formulierte Maister erstmals eine Theorie der Psychologie von Warteschlangen, die er selbst als "First Law of Service« bezeichnete und in der Formel $S=P-E$ zusammenfasste: Satisfaction = Perception - Expectation ${ }^{126}$ Mit dieser Formel definierte er die Kernvariablen Wahrnehmung und Erwartung als die wichtigsten Einflussgrößen für die Zufriedenheit und legte zugleich den Grundstein des Wahrnehmungsmanagements (perception management), das uns in den alltäglichsten öffentlichen Wartesituationen bis heute subtil beeinflusst.

Die empirischen und theoretischen Beiträge von Hornik und Maister stimulierten in den folgenden Jahren eine regelrechte Welle empirischer und anwendungsorientierter Studien zur Verfeinerung des psychologischen Managements von Warteschlangen. Katz et al. untersuchten etwa wie lang eine tolerierbare Wartezeit ist und welche Rahmenbedingungen die Zeitwahrnehmung positiv oder negativ verändern könnten. Sie quantifizierten diese Fragen mit einer weit rezipierten Untersuchung am Beispiel Bostoner Bankkunden. Dabei fanden sie heraus, dass Wartezeiten im speziellen Kontext der Bedienung an Bankschaltern maximal fünf Minuten betragen dürften um aus Sicht der Kunden als akzeptabel zu gelten. Über dieses Zeitmaß hinaus korrelierte die verlängerte Wartezeit klar mit einer sinkenden Kundenzufriedenheit, was die bereits zuvor vermutete Relevanz von Wartezeiten für die gesamte Serviceevaluation nun auch erstmals empirisch belegte. Zudem stellten sie, ähnlich wie zuvor Hornik heraus, dass die tatsächliche Wartedauer aus Sicht des Kunden um durchschnittlich eine Minute überschätzt wurde sowie dass Ablenkungen (distractions) und eine angenehme Warteumgebung die wahrgenommene Wartezeit messbar verkürzten. Das Anzeigen der voraussichtlichen Wartezeit hingegen konnte die Kundenzufriedenheit nicht entscheidend beeinflussen. ${ }^{127}$ Die empirischen Befunde wurden in zehn Anwendungsempfehlungen

126 Maister, »The Psychology of Waiting Lines«, 114.

127 Vgl. Hornik, »Subjective vs. objective time measures: A note on the perception of time in consumer behavior«, 51. 
übersetzt, die basierend auf den Prinzipien der Fairness (Einhalten der first come, first served-Regel), der Warteumgebung (Schaffung eines möglichst komfortablen Umfeldes) und der Ablenkung (Installation von Aufmerksamkeits-Tools) versuchten, Antworten auf die sneue Ungeduld im Dienstleistungsbereich zu geben. Entgegen zu starker Pauschalisierungsgesuche postulierten Katz et al. jedoch gleichzeitig »Every line is different ${ }^{128}$ und verwiesen so bereits klar auf die Komplexität des Wartens im Servicebereich jenseits einer idealtypischen Behandlung und betonten die zwingende Notwendigkeit der spezifischen Maßnahmenanpassung an die jeweilige Warteformation.

Im Zuge der Bestimmung von grundsätzlichen Prinzipien des Warteschlangenmanagements entstanden nun seit den 1990er Jahren dutzende empirische und theoretisierende Studien zur Relevanz einzelner psychologischer und materieller Variablen im Servicebereich mit dem Ziel, das bis dahin streng normative Warteschlangenmanagement psychologisch informiert durch ein Wahrnehmungsmanagement zu ergänzen. Die Potentiale solch eines Wahrnehmungsmanagements wurden nicht nur in einer preisgünstigen Implementierung gesehen, sondern auch darin, dass die subjektive Wahrnehmung des Kunden letztlich immer noch die entscheidende Variable zu dessen zeit- und servicebezogener Zufriedenheit darstelle: »If the customers think they are satisfied, then they are satisfied. Similarly, if customers think that their wait was short enough, then it was short enough, regardless of how long it actually was. ${ }^{129}$ Die forschungsleitende Forderung zielte deshalb darauf ab, dass sich Dienstleister besser in die Perspektive des wartenden Kunden versetzen sollten anstatt sich einzig und allein auf die operativen Lösungen der Queuing Theory zu verlassen. So insistierten etwa Carmon, Shanthikumar und Carmon auf eine reformierte Managementorientierung: »Although Queuing Theory considers the obvious costs of waiting in terms of time and money, it does not account for the psychological cost. ${ }^{130}$ Vielmehr würden aus Sicht der mathematisch ausgerichteten Betriebs- und Unternehmensforschung die psychologischen Kosten sogar bewusst ausgeklammert, weil sie als zu schwammig für analytische Modelle gelten oder ohnehin nicht qualitativ vom Ergebnis der mathematischen Modelle abweichen würden. ${ }^{131}$

Auch Dubé, Schmitt und Leclerc sahen in der Psychologie eine Schlüsseldisziplin zum Verständnis der Warteerfahrung und vermerkten: »Understanding the psychological experience of waiting is therefore vital to prevent, or at least reduce, the negative impact of service delays on consumer satisfaction and perceived quality. « $^{132}$ Wie Katz et al. räumten sie die erhöhte Komplexität dieses temporalen Zustands ein sobald die Affektebene einbezogen werde und untersuchten die affektiven Reaktionen auf Verzögerungen zu unterschiedlichen Zeitpunkten eines Prozesses. Sie fanden mit einer Feldstudie an Schülern heraus, dass das Warten innerhalb eines bereits begonnenen Prozes-

128 Katz, Larson, und Larson, »Prescription for the waiting-in-line blues: Entertain, enlighten, and engage«, 51.

129 Ebd., 44

130 Carmon, Shanthikumar, und Carmon, »A psychological perspective on service segmentation models: The significance of accounting for consumers < perceptions of waiting and service«, 1806.

131 Vgl. ebd., 1813.

132 Laurette Dubé, Bernd H. Schmitt, und France Leclerc, »Consumers`Affective Response to Delays at Different Phases of a Service Delivery«, Journal of Applied Social Psychology 21, Nr. 10 (Mai 1991): 810. 
ses (in-process) wesentlich positiver erlebt und wahrgenommen wurde als das Warten vor (pre-process) oder auch nach einem Prozess (post-process). Die affektiven Reaktionen unterschieden sich demnach stark je nach dem Zeitpunkt, in dem die Verzögerung stattfand:

»(...) delays occurring during the preprocess and the postprocess phases generate more intense negative affective responses than those occurring during the middle of the process. The in-process delay was similar to no delay and did not significantly alter subjects' affective state. ${ }^{133}$

Die Beobachtungen bestätigten damit frühere experimentelle Studien zu Kundenreaktionen bei Wartezeiten in Restaurants bei denen die Probanden stärker verärgert waren wenn die Wartezeit vor dem Bestellen des Essens auftrat als zu einem späteren Zeitpunkt des Aufenthalts im Restaurant. ${ }^{134}$ Zudem fanden sie heraus, dass »delays occuring in the preprocess phase can be as upsetting as a delay occuring in the postprocess phase. ${ }^{135}$ Bewertungen des Wartens vor und nach dem Prozess wichen nur insignifikant voneinander $\mathrm{ab}$ und interessanterweise wurden Verzögerungen des Ablaufs nur in diesen beiden Prozessphasen als Zeitverschwendung aufgefasst, nicht jedoch innerhalb des Prozesses. ${ }^{136}$ Als theoretisches Erklärungsangebot der zeitpunktabhängigen Affektdichte schlugen die Autoren die 1943 erstveröffentlichte Feldtheorie des Psychologen Kurt Lewins $\mathrm{s}^{137}$ vor. Der Feldtheorie zufolge würde das zielgerichtete Verhalten eines Menschen stets von den unmittelbar umgebenden psychologischen Kräften beeinflusst werden, die zu jeder Zeit auf ihn einströmen und entweder attraktivierend oder hemmend auf die Zielerreichung einwirken. $\mathrm{Zu}$ den hemmenden Kräften zählen Barrieren oder auch Verzögerungen und Verspätungen, die das Individuum davon abhalten, sein Ziel zu erreichen und zu Frustration oder anderen negativen Affekten führen. Diese Barrieren würden nach Lewin weniger aversiv wirken, wenn sie zumindest bereits in unmittelbarer Nähe der Zielerreichung, anstatt entfernt von ihr, auftreten würden. Dubé et al. fassen diese interessante Unterscheidung folgendermaßen zusammen:

»In other words, individuals are in distinct psychological states when inside or outside the goal region. When the individual is inside the region of the goal, pressure is relieved and a barrier produces little frustration. On the other hand, when the individual is outside the region, tension exists, either because the individual strives for the goal (as is the case before goal achievement) or because the individual has been satiated and strives for new goals (as is the case after goal achievement). $\ll^{138}$

133 Ebd., 817.

Dube-Rioux, Schmitt, und Leclerc, »Consumers reactions to waiting: when delays affect the perception of service quality«.

135 Dubé, Schmitt, und Leclerc, »Consumers Affective Response to Delays at Different Phases of a Service Delivery«, 816.

136 Vgl. ebd., 818.

137 Kurt Lewin, »Defining the >field at a given time.«, Psychological review 50, Nr. 3 (1943): 292-310.

138 Dubé, Schmitt, und Leclerc, »Consumers Affective Response to Delays at Different Phases of a Service Delivery«, 811. 
Wie bereits aus der Einführung (Kap. 1) hervor ging, ist jene Unterscheidung von Wartesituationen innerhalb oder außerhalb eines Prozesses insbesondere für die hier beabsichtigte Geschichte des Wartens im Mobilitätskontext von großer Bedeutung. Weil für Wartesituationen vor Beförderung vermutet werden kann, dass diese stärker problembehaftet wahrgenommen werden als solche während der Beförderung, beschränkt sich diese Arbeit im weiteren Verlauf des Hauptteils methodisch, wie bereits angesprochen, auf Wartesituationen vor Abfahrt des Verkehrsmittels. Diese Einschränkung gewinnt auch durch weitere Studien an Legitimität. So stellten etwa Benakavia und Lerman für das verkehrsbezogene Warten mit einer Beobachtungsstudie fest, dass das Warten auf einen um eine Minute verspäteten Bus am Straßenrand negativer wahrgenommen wurde als das Warten im Bus selbst. ${ }^{139}$ Angesichts des spannungsgeladeneren Wartens auf Beförderung müsste die Verhandlung dieses Teils der Warteerfahrung dementsprechend sichtbarere Niederschläge erzeugt haben, welche die höhere Aversion zu kompensieren versucht haben.

Auch Taylor untermauerte mit einer 1994 erschienenen Studie die Notwendigkeit der Beschäftigung mit Wartephänomenen vor Erhalt einer Dienstleistung und entwarf hierfür ein erstes konzeptionelles Modell der Warteerfahrung im Verspätungsfall. Darin definierte sie das Warten im Servicekontext als »(...) the time from which a customer is ready to receive the service until the time the service commences ${ }^{140}$ und kategorisierte das Warten vor Beginn einer Serviceleistung (pre-process) in die drei Unterarten von "pre-schedule waits, delays (that is post-schedule waits), and queue waits. $"{ }^{141}$ Während der erste und der letzte Typus von Seiten der Anbieter relativ gut steuerbar und von Seiten der Forschung bereits bekannt seien, würden sich Verspätungen oftmals jeglicher Kontrolle entziehen und damit der schwierigste und am wenigsten kontrollierbare Wartefall überhaupt sein. Taylor untersuchte daraufhin anhand von wartenden Fluggästen den Einfluss von Verspätungen auf die Servicebewertung. Ihr Resultat lautete unmissverständlich: » (...) delays affect service evaluations. «"42 Negative Servicebewertungen (bspw. fehlende Verlässlichkeit) würden demnach »mediated by negative affective reactions to the delay «, ${ }^{143}$ allen voran durch die Gefühlskategorien von Ungewissheit und Angst. Je länger die Verspätung andauerte, desto stärker wurden die negativen Affekte, die wiederum direkt auf die Servicebewertung wirkten. Die Affekte selbst würden direkt von der Länge und von der Aktivitätsdichte innerhalb der Verspätung beeinflusst werden. Diese durch die Verspätung ausgelösten Affekte seien ausschlaggebend für die Wartezeiterfahrung und prägen damit die Serviceevaluation. Basierend auf diesen $\mathrm{Zu}$ sammenhängen wurden Füllelemente und Überbrückungsstrategien bei verlängerten, außerplanmäßigen Wartezeiten als wichtige Managementinterventionen identifiziert. Wenn auch aus heutiger Sicht überraschend, rückte die lange Verspätung als kritischster Sonderfall des Wartens erst mit dieser Studie explizit in das Bewusstsein der Unternehmensführung. Der Aufbau eines Verspätungsmanagements rückte erst fortan auf

139 Moshe E. Ben-Akiva und Steven R. Lerman, Discrete choice analysis: theory and application to travel demand, Bd. 9 (MIT press, 1985).

140 Taylor, »Waiting for service: the relationship between delays and evaluations of service«, 56.

141 Ebd., 57.

142 Ebd., 56.

143 Ebd. 
die Agenda der Serviceanbieter und wurde - insbesondere im Verkehrskontext unter Strategien des Delaytainment ${ }^{144}$ auf Flughäfen oder unter Gesichtspunkten der monetären oder nicht-monetären Kompensation für Verspätungen ${ }^{145}$ - von Taylors Untersuchung ausgehend immer häufiger adressiert.

Für die Bedeutung des Informationsmanagements hinsichtlich der in Prozessen verbleibenden Wartedauer interessierten sich auch Hui und Tse. Sie fanden mit einer laborexperimentellen Untersuchung heraus, dass Wartezeitinformationen sich jedoch nicht bei allen Warteschlangenformationen positiv auf a) die wahrgenommene Wartezeit, b) die affektiven Reaktionen und c) die Wartezeitakzeptanz auswirken. Der Informationsgrad bzw. die Art der Information (voraussichtliche Wartezeit oder die Position in der Schlange), so ihre Kernaussage, müsste an die Wartezeitdauer angepasst werden. Während kurze Wartezeiten keine Informationen benötigen, wurden bei mittleren Verzögerungen von ca. 15 Minuten Informationen über die absolute Wartedauer für sinnvoller erachtet als Informationen über die Position des Wartenden in der Schlange. Bei langen Wartezeiten würde sich dieser Effekt umkehren, d.h. bei Verzögerungen ab 30 Minuten sollten Serviceanbieter über die Position in der Warteschlange informiert werden, nicht jedoch über die absolute Wartezeit, die als zu lang wahrgenommen werden würde. Hui und Tse stellten zudem ein Paradox heraus. Die wahrgenommene Wartezeit verlängerte sich durch die Bereitstellung von Informationen über voraussichtliche Dauer und/oder Position in der Schlange, wohingegen Personen ohne Warteinformationen die Wartezeit unterschätzten: » (...) subjects with either waiting-duration information or queuing information did not perceive a shorter waiting duration than subjects without the information. In contrast, subjects with waiting duration information appeared to report a longer perceived waiting duration than subjects without the information. ${ }^{146}$ Diese im Grunde negative Wirkung würde jedoch durch die positivere affektive Ansprache und eine dadurch verbesserte Servicebewertung kompensiert werden können, so heißt es weiter: »Although waiting-duration information leads to a significantly longer perceived waiting duration, the information has a positive effect on service evaluation through a more-positive affective response to the wait. $\aleph^{147}$ Warteinformationen seien demnach nur in kritischen Situationen und bei langen Wartezeiten sinnvoll und können bei kürzeren Wartezeiten gar kontraproduktiv wirken.

Baker und Cameron erweiterten in einer 1996 veröffentlichten Studie die Überlegungen zu subjektiven Beeinflussungsmöglichkeiten auf Ebene von Umwelt- und Raumfaktoren. Sie betonten die Bedeutung des »servicescape« als unerlässliche Komponente der Servicebewertung und untersuchten die Auswirkungen konkreter Maßnahmen zur Reduzierung subjektiv gefühlter Wartezeit von Kunden mithilfe der drei Gestaltungsebenen Raumambiente, Design und Bedienung. Die nahezu perfekte

144 Thomas Sauter-Servaes und Stephan Rammler, »Delaytainment an Flughäfen: Die Notwendigkeit eines Verspätungsservices und erste Gestaltungsideen«, WZB Discussion Paper (Berlin: Wissenschaftszentrum Berlin für Sozialforschung, 2002).

145 K. Douglas Hoffman, Scott W. Kelley, und Beth C. Chung, »A CIT investigation of servicescape failures and associated recovery strategies«, Journal of Services Marketing 17, Nr. 4 (2003): 322-40.

146 Hui und Tse, »What to tell consumers in waits of different lengths: An integrative model of service evaluation «, 87.

147 Ebd. 
Warteumgebung, in der die negativen Affekte entweder stark minimiert oder ganz verhindert werden könnten, sah ihrer Meinung nach wie folgt aus. Unterbewusst und non-sensual wirksame Elemente würden am effektivsten zur Reduzierung der Wartezeiterfahrung beitragen wenn das Licht nicht zu hell, die Musik niemals zu laut und die Temperatur nicht zu warm und nicht zu kalt sei. Das Raumprogramm würde am wirksamsten zur Affektreduzierung beitragen wenn die Farben im Warteraum nicht zu warm und die Möblierung möglichst komfortabel seien. Mitarbeiter sollten dazu im Dienst für den Kunden möglichst sichtbar bleiben, sich in einer Pause aber möglichst deutlich aus dem Sichtfeld der Kunden heraus bewegen. ${ }^{148}$

Hui, Dubé und Chebat widmeten sich ebenfalls dem Einfluss situativer Elemente und untersuchten die Wirkung von Musik auf Wahrnehmung und emotionale Verfasstheit des wartenden Kunden. Sie fanden heraus, dass Musik im Servicebereich zwar die wahrgenommene Wartezeit verlängert, dies jedoch nicht negativ auf die Servicebewertung zurückfallen würde, weil durch das Hören von Musik die emotionale Einstellung gegenüber der Wartezeit verbessert werden würde und diese Ebene die Servicebewertung stärker bestimmen würde als die wahrgenommene Wartezeit. Damit wurde aufgezeigt, dass die subjektive Zeitbestimmung im Hören von Musik aus dem hybriden Zusammenspiel von kognitiven und affektiven Prozessen bestimmt wird: » (...) music changes time estimates through both cognitive (amount of information processing) and affective (emotional response to the wait) processes. $\aleph^{149}$

Dawes und Rowley verfolgten in einer 1996 veröffentlichten Studie die Erweiterung der Wartemanagementprinzipien auf Grundlage der Analyse bereits erfolgreich implementierter Managementlösungen und verglichen dazu Wartemanagementkonzepte aus der Unterhaltungs- und Transportindustrie. Mittels teilnehmender Beobachtungen untersuchten sie die Fallstudien von Disneyworld Florida und dem internationalen Flughafen von Singapur. Disneyworld gilt bis heute als eines der weltweit wichtigsten Beispiele für erfolgreiches Wartemanagement, denn es kämpft mit der besonderen Problematik, dass der Besuch der Hauptattraktionen des Freizeitparks mit Wartezeiten von bis zu zwei Stunden verbunden sein kann. Diese stellen in der Freizeitindustrie eine besondere Herausforderung dar, da die Erwartungshaltung der Besucher aus dem Zusammenwirken hoher Eintrittspreise und zuvor angesprochenen knappen Freizeitbudget das Warten zum besonders kritischen Kulminationspunkt auflädt und aufgrund dieses Dilemmas ausgeprägte Maßnahmen erfordert. Disneyworlds Antwort auf diese Problematik besteht laut Dawes und Rowleys Analyse konzeptionell darin, die Warteerfahrung allerorts in die Freizeiterfahrung zu integrieren, also die alltäglich erfahrene Polarität des Wartens zum Nicht-Warten aufzulösen oder zumindest unkenntlich zu machen. Hinsichtlich der Bestrebungen des Freizeitparkmanagements vermerken sie:

148 Vgl. J. Baker und M. Cameron, »The Effects of the Service Environment on Affect and Consumer Perception of Waiting Time: An Integrative Review and Research Propositions«, Journal of the Academy of Marketing Science 24, Nr. 4 (1. September 1996): 340ff.

149 Michael K. Hui, Laurette Dube, und Jean-Charles Chebat, »The impact of music on consumers reactions to waiting for services«, Journal of Retailing 73, Nr. 1 (1997): $101 \mathrm{f}$. 
»The problem for the management is to absorb waiting into the leisure experience so that it becomes a positive part of the experience. ${ }^{150}$

Folglich würden die Verantwortlichen von Disneyland alles daran setzen, die von Maister und Katz et al. formulierten Prinzipien zu implementieren, so etwa, den Wartenden die Kontrolle über die Situation zu ermöglichen, ihnen die Ungewissheit durch permanente Echtzeitinformationen zur verbleibenden Wartezeit zu nehmen und unter allen Umständen das Prinzip der Warte-Gerechtigkeit (»first come, first served«) zu verfolgen. Flankiert würden diese Maßnahmen von dem Versuch, die Besucher möglichst frühzeitig in den Prozess zu integrieren (in-process Warten, statt pre-process Warten), kollektives Warten zu fördern, eine Vielzahl von Ablenkungsmechanismen zu integrieren (Videos, Sounds, Hinweise und Werbung) sowie eine verwinkelte Schlangenführung $\mathrm{zu}$ gestalten, die monotonen Blickperspektiven entgegenwirkt. ${ }^{151}$ Die verwinkelte Schlangenführung steht dabei sinnbildlich für das erfolgreiche Warteschlangenmanagement des weltgrößten Freizeitparks. Die Warteschlangen werden so konzipiert, dass sie bereits einen Teil der noch zu besuchenden Attraktion bilden. Die räumliche als auch die zeitliche Trennung zwischen innen (im Fahrgeschäft) und außen (vor dem Fahrgeschäft) wird absichtlich unscharf gestaltet womit das Warten selbst somit potentiell zum erlebnisorientierten und sinnstiftenden Spaßfaktor wird.

Im Gegensatz zu wartenden Besuchern in einem Freizeitpark warten Fluggäste weder freiwillig noch findet es in vergleichbaren Schlangenformationen statt. Das Wartemanagement von Flughäfen und insbesondere jenes von den Autoren analysierten Changi Airports in Singapur würde daher darauf abzielen, ein Management der passiven Warteerfahrung in Form vielfältiger Infrastrukturen zu vollziehen: »The backbone of the waiting experience is the extensive range of services which are available to meet the needs of different customers. ${ }^{152}$ Ein umfangreiches Dienstleistungsangebot von Restaurants, Bars und Geschäften würde demnach darauf abzielen, die zum Teil langen Transferzeiten der Fluggäste durch ein weitrechendes Dienstleistungsangebot zur Befriedigung physischer Befürdnisse und durch ein komplexes Raumprogramm mit Telekommunikationsdienstleistungen und hoher Informationsdichte über Anzeigetafeln das Warten tolerierbarer zu gestalten. Was die Autoren noch als scheinbar selbstlose Maßnahme des passiven Wartemanagements darstellen, entwickelte sich jedoch in jünster Zeit zu einem lukrativen Selbstzweck. Die kommerzielle, non-aeronautische Dienstleistungsdichte übersteigt auf vielen Flughäfen bei weitem die Schwelle der rudimentären Erfordernisse zur Befriedigung der primären Reisebedürfnisse. Vielmehr sind Flughäfen selbst zu umsatzstarken Wirtschaftsunternehmen geworden, die erst durch Wartezeiten genährt werden. So zeigte eine Studie von Torres et al. aus dem Jahr 2005, dass Touristen und Geschäftsreisende auf Flughäfen mit steigender Wartedauer deutlich mehr konsumierten als solche die nur kurze Wartezeiten hatten. ${ }^{153}$

150 Dawes und Rowley, »The Waiting Experience«, 17.

151 Vgl. ebd., $18 f$.

152 Ebd., 19.

153 E. Torres u.a., »Passenger waiting time in an airport and expenditure carried out in the commercial area«, Journal of Air Transport Management 11, Nr. 6 (2005): 363-67. 
Dennoch resümierten Dawes und Rowley als Lehre aus der Analyse zweier warteintensiver Fallbeispiele, dass die beste Lösung zum Wartemanagement darin bestünde, die Warteerfahrung in die zu erwartende Dienstleistung zu integrieren, »so that customers do not perceive any discontinuity, or indeed start to welcome the waiting experience in its own right. $\ll^{154}$

Hinsichtlich der operativen Reduktion der wahrgenommenen Wartezeit und der Erhörung der Warteschlangengerechtigkeit im Flugverkehr lassen sich jedoch zugleich auch eine Reihe weiterer Maßnahmen identifizieren. So zeigte etwa eine Studie von Larson aus dem Jahr 1987 bereits eindrucksvoll, wie es dem Flughafenmanagement von Houston gelang, nach einer Welle von Beschwerden über zu lange Wartezeiten bei der Gepäckausgabe, die Kundenzufriedenheit wiederherzustellen. Die Lösung der Problematik bestand darin, durch eine entferntere Parkposition des Flugzeugs den Weg vom Flugzeug zur Gepäckausgabe künstlich zu verlängern, um weniger `statische` Wartezeit am Gepäckförderband zu verbringen und zudem bei Passagieren mit Aufgabegepäck nicht die Wahrnehmung einer gegenüber Passagieren mit Handgepäck >ungerechteren Behandlung zu erzeugen. ${ }^{155}$

Auch der Einfluss der konkreten Warteumgebung lieferte in den 1990er Jahren immer wieder einen häufigen Befragungsgegenstand der Managementforschung. Pruyn und Smidts argumentierten in ihrer 1998 veröffentlichten Studie, dass die Warteumgebung die wichtigste Stellschraube zur Beeinflussung der Affekte des wartenden Kunden darstellt und unterstrichen: » (...) an alternative approach to queuing is to find ways to make time pass as quickly and pleasantly as possible. One may thus reduce the negative effects of waiting even when objective waiting times cannot be shortened. ${ }^{156}$ Sie plädierten jedoch nicht wie schon andere Autoren zuvor für die stärkere Konzentration auf eine psychologisch informierte Gestaltung von Warteumgebungen, sondern behaupten darüber hinaus, dass ein solcher Perspektivwechsel des Managements zu wesentlich größerer Kundenzufriedenheit führen würde als der bisherige Fokus auf die Verkürzung der objektiven Wartezeiten. Zur Relevanz der Warteumgebung konstatierten sie:

»The waiting environment proves to be a stronger determinant of service satisfaction than objective waiting time (...) Therefore, service managers can be advised to be less focused on shortening waiting times, but pay special attention to their customers' waiting conditions instead. « $^{157}$

Den Grund für die gewichtige Rolle der Warteumgebung zur Steigerung der Kundenzufriedenheit sahen sie in der Unterscheidung zwischen kognitiven und affektiven Reaktionen im Warten. Während die objektive Wartezeit `nur die kognitive Dimension in Form einer Bewertung über die Kürze oder die Länge der Wartezeit beeinflusst, würde dagegen die Attraktivität der Warteumgebung die Affekte direkt ansprechen und positive Stimmungen erzeugen können, die letztendlich ausschlaggebender für die Service-

154 Dawes und Rowley, »The Waiting Experience«, 20.

155 Vgl. Larson, »Perspectives on Queues: Social Justice and the Psychology of Queuing.«, 897.

156 Pruyn und Smidts, »Effects of waiting on the satisfaction with the service: Beyond objective time measures«, 321.

157 Ebd., 33of. 
bewertung seien. Die kognitive und die affektive Dimension wirken zwar wechselseitig zusammen, der gravierend stärkere Wirkungseffekt liegt nach Ansicht der Autoren aber in der affektiven Ebene, weil sie vielschichtiger ist und damit in der Läge wäre, die Servicebewertung in breiterem Spektrum zu beeinflussen. Pruyn und Smidts demonstrierten mit ihrer Erhebung, dass Interventionen bezüglich der objektiven Wartezeit nur lediglich für ein Zehntel der Varianz der Kundenzufriedenheit verantwortlich gemacht werden können: »In summary, objective waiting time by itself can only explain about $10 \%$ of the variance in satisfaction with the service. ${ }^{158}$ Statt der objektiven Wartedauer sollte daher vielmehr die wahrgenommene Wartezeit im Fokus der Managementmaßnahmen stehen, da sie die Kundenzufriedenheit indirekt über die kognitiven und affektiven Dimensionen beeinflusst. Die Gestaltung einer angemessenen Warteumgebung verdient hierbei besondere Aufmerksamkeit, denn mit ihr würden nicht nur direkt die Affekte angesprochen, die schließlich die Servicebewertung positiv beeinflussen, sondern solche Maßnahmen wären zudem »one of the easiest and perhaps one of the most effective means of improving customers' appraisal of the wait.«159

Ähnlich wie zuvor bereits Nie argumentierten auch Durrande-Moreau und Usunier mit ihrer 1999 veröffentlichten Studie für eine stärkere Differenzierung der Warteerfahrung. Sie plädierten weniger für kulturelle Einflussvariablen, sondern für das Einbeziehen individueller Zeitpsychogramme oder time styles, die personell verschiedene Warteerfahrungen der passiven oder der aktiven Ungeduld erzeugen würden. ${ }^{160}$ Während für Personen mit passiver Ungeduld die Zeit endlos lang zu vergehen scheint, würden Personen mit aktiver Ungeduld versuchen, das unkomfortable Gefühl der Leere mit Aktivitäten zu kontrollieren, ohne jedoch etwas an der Lage ändern zu können. Diese Kategorisierung von persönlichen Zeittypen sei sinnvoll für die Erforschung von Wartephänomenen, weil sie die komplexen Zusammenhänge zwischen objektiver Wartezeit und subjektivem Zeitempfinden noch realitätsnaher offenlegen könnte. DurrandeMoreau und Usunier wiesen mit ihrer Untersuchung im Nahverkehr der Stadt Grenoble zum einen diese zwei Formen der Ungeduld nach und zeigten Zusammenhänge zwischen persönlichen Zeitstilen und der Warteerfahrung nach. Demnach würde der Grad der passiven Ungeduld von der objektiven Wartedauer bedingt werden, der Grad der aktiven Ungeduld jedoch überwiegend vom persönlich gepflegten Zeitstil und der Gemütsverfassung mit dem der Fahrgast das Warten beginnt:

»Those who have a strong leaning toward quantitative time express more active impatience, tensely hoping for the occurrence of the event (being on the lookout, being aroused), whereas others first go through a state of passive impatience (plainly, being bored) before reaching a state of active impatience. « $^{161}$

Durrande-Moreau und Usunier zeigten mit ihrer Studie, dass persönliche Zeitstile mediatisiert durch den Grad des wahrgenommenen Zeitdrucks - die individuelle War-

160 Vgl. Durrande-Moreau, »Waiting for service: ten years of empirical research«, 176.

161 Ebd., $180 f$. 
teerfahrung signifikant prägen können. Die Akzeptanz der Wartezeit konnte jedoch nicht mit dem persönlichen Zeitstil in Verbindung gebracht werden, sondern wird vordergründig durch die objektive Wartedauer hervorgerufen.

Winter Nie erweiterte den integrativen Ansatz zur Erforschung der Wahrnehmung von Wartezeiten und plädierte zudem für die Einbeziehung kultureller Faktoren, die erst für die Unterschiedlichkeit der Zeitauffassungen verantwortlich seien. Für ein komplexeres Verständnis vom Warten in der Dienstleistungsgesellschaft hielt sie es daher für unabdingbar, Aspekte der psychologischen Verhaltensforschung und der kulturellen Prägung zu integrieren, denn, so begründet Nie die Notwendigkeit eines interdisziplinären Ansatzes, "since waiting involves people, time and environment, it is a social and psychological phenomenon. ${ }^{162}$ Das Warten bezeichnete sie zwar als »inescapable part of modern life ${ }^{163}$, doch noch immer würde die Forschung von mathematischen Modellen dominiert werden "that lack consideration of human factors. ${ }^{164}$ Weiter kritisierte Nie, dass normative Modelle stets die objektive Wartezeit als die wichtigste Komponente zur Kundenzufriedenheit bemessen würden, aber es die kulturell bedingten Werte, Normen, Rituale, Überzeugungen und Einstellungen sind, welche die Zeitauffassung entscheidend vorstrukturieren. Diese kulturellen Variablen sorgten dafür, dass Zeit an unterschiedlichen Orten der Welt mitunter stark abweichend wahrgenommen wird und sich so etwa auch die Toleranz gegenüber Wartezeiten in Japan von jener in Mexiko oder in Deutschland unterscheidet.

Nie verweist hierbei auf anthropologische Modelle der kulturellen Zeitwahrnehmung, die zum Teil auch bereits in Kapitel 2.2 .5 bereits zur Sprache kamen. Im $l i-$ nearen Separierungsmodell des euro-amerikanischen Raums fließt Zeit linear und wird in Vergangenheit, Gegenwart und Zukunft separiert. Die Zeit erscheint als knappe Ressource, die gespart oder gekauft werden muss, Zeitmanagement wird indes als rational und notwendig wahrgenommen. Das Warten wird im Kontext dieser kulturellen Zeitauffassung zur Zeitverschwendung und wird in vielen Fällen mit Geldverschwendung gleichgesetzt. Wartezeiten gilt es daher zu minimieren oder ganz zu eliminieren. Ganz anders können Wartezeiten in der zirkulär-traditionellen Zeitauffassung vieler spanischsprachiger Kulturen in Lateinamerika aufgefasst werden. Hier wird der Zeitlauf als zirkuläres System ohne Trennung zwischen Vergangenheit, Gegenwart und Zukunft verstanden, wobei die Wartetoleranz größer zu sein scheint und absolute Pünktlichkeit weniger Bedeutung zugemessen wird, da sich die Ereignisse aus der zirkulären Zeitauffassung heraus ohnehin wiederholen würden. Eine endlose Kontinuität der Dinge würde zudem bedingen, dass Pünktlichkeit mitunter sogar als Unhöflichkeit und Respektlosigkeit rezipiert wird und Planung als unnatürliche Aktivität eingestuft wird, die nicht unbedingt notwendig ist. Im Rahmen eines prozedural-traditionellen Zeitverständnisses wiederum könnte Zeiteffektivität einen größeren Stellenwert als die Zeiteffizienz einnehmen, so finden sich bspw. auf dem asiatischen Kontinent sehr heterogene Zeitwahrnehmungen zwischen Prozess- und Ergebnisorientierung. In Japan etwa kann eine längere Wartezeit durchaus als wichtiger Prozessbestandteil verstanden werden,

162 Nie, »Waiting: integrating social and psychological perspectives in operations management«, 612.

163 Ebd., 611.

164 Ebd., 627. 
was die Toleranz gegenüber Wartezeiten deutlich erhöht: » (...) the Japanese view quality management as a process. The process (including waiting, anticipation etc.) required to achieve a goal is treated as a unique, rich, and necessary experience. ${ }^{165}$

Nach der Jahrtausendwende lassen sich Kontinuitäten, aber auch neue Trends in der Beschäftigung mit Wartephänomenen durch die Marketing- und Managementforschung identifizieren. Die Kontinuität besteht in der anhaltend redundanten Betonung der Notwendigkeit des Verständnisses der individuellen Wahrnehmung von Wartezeiten, die erheblich von der eigentlichen objektiven Zeitdauer abweichen kann. Neue Trends bestehen dagegen in komplexeren Beschreibungsversuchen bzw. der Messung von Wartezeitvariablen, in der stärkeren Einbeziehung kontextueller Variablen der Warteerfahrung (etwa Musik, Raumgestaltung oder gar Düfte) sowie im Trend zur Anpassung der Warteproblematiken an spezifische Dienstleistungskontexte. So wurde auch das Internet zunehmend zu einem Forschungsfeld für Wartephänomene. ${ }^{166}$ Trotz des wachsenden Interesses am Warten im Netz finden bis heute forschungsseitig jedoch noch immer physische Schlangenbildungen stärkere Berücksichtigung als digitale oder virtuelle Warteschlangenbildungen. Zudem verabschiedete man sich in der jüngeren Forschung von der verallgemeinernden Betrachtung der Kundenwahrnehmung zugunsten größerer Heterogenität. So besteht heute Konsens darin, dass nicht alle Kunden im Hinblick auf ihre Wartetoleranz gleich behandelt werden können, sondern verschiedene Kundengruppen identifiziert werden müssen, die mit zielgerichteten Interventionen angesprochen werden sollten. ${ }^{167}$ Punktuell lässt sich darüber hinaus punktuell zudem das Plädoyer zur stärkeren Berücksichtigung kultureller Unterschiede beobachten, die, ähnlich wie bei Winter Nie, als nötig erachtet wird, um das Verhalten der Kunden und Passagiere überhaupt wirksam beeinflussen zu können. ${ }^{168}$

Die Betonung der Heterogenität beinhaltet dabei nicht zuletzt auch neue Erkenntnisse bezüglich der grundsätzlichen Konnotation des Wartens. So lieferte etwa jüngst Margareta Friman einen Einblick in die eigentliche Vielschichtigkeit der erlebten Wartesituation im öffentlichen Verkehrswesen. Bezüglich der affektiven Reaktionen verkehrsinduzierten Wartens fand die Psychologin dabei erstmals heraus, dass unter bestimmten Voraussetzungen Wartesituationen gar als Bereicherung der Serviceerfahrung dienen können und somit durchaus auch positiv aufgeladen werden können. ${ }^{169}$

Bis in die Gegenwart hinein besteht der übergeordnete Konsens der betriebswirtschaftlichen Beschäftigung mit temporären Stauphänomenen jedoch ganz deutlich darin,

165 Ebd., 623.

166 Benedict GC Dellaert und Barbara E. Kahn, »How tolerable is delay? Consumers evaluations of internet web sites after waiting «, Journal of interactive marketing 13, Nr. 1 (1999): 41-54; Bruce D. Weinberg, »Don't keep your internet customers waiting too long at the (virtual) front door «, Journal of Interactive Marketing 14, Nr. 1 (2000): 30-39.

167 Vgl. McDonnell, »Music, scent and time preferences for waiting lines«.

168 Vgl. Leonard L. Berry, Kathleen Seiders, und Dhruv Grewal, »Understanding service convenience«, Journal of Marketing 66, Nr. 3 (2002): 1-17.

169 Vgl. Friman, »Affective dimensions of the waiting experience«. 
dass sich das Warten im Servicekontext nachteilig auf Servicebewertung und Kundenzufriedenheit auswirkt und daher zu einer der wichtigsten Determinanten im Management gehört. Konsens besteht bis heute ebenfalls in der Einsicht, dass trotz vieler technisch unterstützter Verbesserungen Schlangenbildungen im Servicebereich ein fester Bestandteil bleiben werden bzw. sogar weiter auf dem Vormarsch sind. Einen entscheidenden Einflussfaktor für die Prognose der zukünftigen Permanenz von Wartephänomenen bildet dabei der Sicherheitsaspekt. So können die Terroranschläge des 11. September 2001 oder auch die weltweite Corona-Pandemie als Katalysator des Wartephänomens (insbesondere im Flugverkehr) verstanden werden, die aufgrund der seitdem massiv verschärften Sicherheitsvorkehrungen das Warten als dialektische Komplementärgröße wiederum erneut fest verankert und - mit Blick auf die den Fluss von Passagieren verlangsamenden Sicherheitsregimes - das Warten re-institutionalisiert haben.

\subsection{Synthese: Warten im Spiegel theoretischer und empirischer Zeitforschung}

Die wissenschaftliche Thematisierung von Wartephänomenen wurde seit Beginn der 1990er Jahre zu einem festen Gegenstand der Marketinglehre bzw. der Managementund Konsumverhaltensforschung, blieb im Beschäftigungsumfang jedoch weit hinter der operativ-mathematischen Beschäftigung der Queuing Theory und ihren normativen Modellen zurück. Dennoch rückte das Verständnis des temporär passiven Kunden in den Stand einer elementaren Managementaufgabe, deren Ziel es bis zum heutigen Tage ist, die ökonomischen und psychologischen Kosten, aber auch die »Möglichkeitskosten ${ }^{170}$ des Wartens zu minimieren. Die empirischen und theoretischen Forschungsaktivitäten durchliefen dabei - nicht anders als in anderen Forschungsbereichen - wechselnde Schwerpunkte und Ansätze, die ein wachsendes Inventar von Managementmaßnahmen hervorbrachten und darin das ganze Ausmaß der Komplexität dieses temporalen Zustands reflektieren.

Nachdem jüngere Studien zunächst auf die Relevanz subjektiver Zeitwahrnehmungen des Kunden aufmerksam machten, die wesentlich von der tatsächlichen Wartezeit abweichen konnten (Hornik 1984) und die Einbeziehung psychologischer Aspekte erforderlich machten (Maister 1985), wurde mit den durch die Servicewissenschaft erstmals ein Perspektivwechsel vom mathematischen zum psychologischen Wartemanagement vollzogen. Die Betrachtung der Zusammenhänge von Wartezeiten und Kundenzufriedenheit offenbarten dabei, dass das Warten demnach nicht nur ökonomische Kosten des Zeitverlustes, sondern auch psychologische Kosten wie Stress, Verunsicherung oder Angst beinhaltete, die es mit gezielten Interventionen abzuschwächen galt. Motiviert wurde dieser Perspektivwechsel von veränderten Rahmenbedingungen, genauer genommen von zwei Punkten. Zum einen bewirkte der Wandel zur Dienstleistungsgesellschaft in westlichen Industrienationen nicht nur eine Häufung von Wartesituationen,

170 France Leclerc, Bernd H. Schmitt, und Laurette Dubé, »Waiting time and decision making: Is time like money?«, Journal of Consumer Research 22, Nr. 1 (1995): 110-19. 
sondern auch einen Wandel der Zeitsensibilität (time values) seitens der Kunden, für die das Warten in Servicesituationen offenbar weniger tolerierbar als jemals zuvor wurde.

Zum anderen bestand Konsens darin, dass die Häufung von Wartezeiten die gesamte Servicebewertung als auch die Kundenloyalität negativ beeinflussen würden und zur nachhaltigen Gefahr reiften. Seit Ende der 1980er Jahre schien somit ein erhöhtes Zeitdefizit auf einen wachsenden Dienstleistungssektor zu stoßen, der das Aufeinandertreffen von Kunden und Anbietern räumlich und zeitlich zunehmend neu strukturierte. Dieses Zusammenspiel bewirkte eine historische Zäsur in Form einer sensibleren Zeitwahrnehmung für Zeitzwischenräume. Im strukturellen Übergang zur Dienstleistungsgesellschaft lässt sich somit eine deutliche Beschleunigungswelle bzw. die Herausbildung einer sneuen Ungeduld identifizieren. Einfachheit und Zweckmäßigkeit wurden daraufhin unter der Losung convenience für große Teile der Konsumenten zur primären Entscheidungsgrundlage und bewirkten ein bis heute anhaltend exzessives Wachstum von >convenience stores` oder dem Konsum von sconvenience food ${ }^{171}$ Mit anderen Worten: Zeit wurde noch einmal mehr zum absoluten Wettbewerbsfaktor erklärt, die kundenseitig gewachsene Ungeduld schien zur Achillesferse des Dienstleistungssektors zu reifen.

Um diese diagnostizierte sneue Ungeduld besser verstehen und kompensieren $\mathrm{zu}$ können, wurde die Psychologie zur Schlüsseldisziplin erklärt, wobei im Idealfall mathematische und psychologische Konzepte des Warteschlangenmanagements integrativ zusammenwirken sollten. Zusammenfassend spielte sich die Beschäftigung mit der Warteerfahrung dazu innerhalb der vier folgenden Dimensionen ab: objektive Zeitdauer, subjektive Zeiteinschätzung sowie kognitive (Akzeptanzgrad, Einschätzung über Länge und Kürze des Wartens) und affektive Reaktionen (emotionale Ansprachen wie etwa Irritation, Langeweile, Ärger, Angst) auf Wartezeiten.

Die umfangreiche und langjährige Erkundung von Einflussmöglichkeiten zur positiven Veränderung der wahrgenommenen Wartezeit endete in den späten 1990er Jahre jedoch vorerst in der Ernüchterung bezüglich der begrenzten Wirksamkeit situativer Beeinflussungsmaßnahmen und der Schwierigkeit, seitens der Serviceanbieter adäquat auf die Heterogenität der menschlichen Verfassungen einzugehen. Basierend auf einer qualitativen Literaturauswertung von 18 empirischen Studien zum Wartemanagement in der Hochzeit zwischen 1984 und 1997 hierarchisierte Durrande-Moreau die Einflussfaktoren auf die Warteerfahrung. Sie stellte dabei ernüchternd fest, dass die signifikantesten Effekte nach wie vor temporaler Natur waren, also in der tatsächlichen, objektiven Wartedauer sowie in der Erwartungshaltung der Kunden liegen. Weniger signifikant, aber dennoch stark beeinflussend, waren individuelle Faktoren des wartenden Kunden vor dem Anstellen in der Schlange, also dessen Motivation, Habitus, Stimmung, Zeitdruck. Enttäuschend dagegen waren die Effekte der Veränderung situativer Faktoren während des Wartens (physisches Warteumfeld, Musik, Licht, Ablenkungseinrichtungen, TV-Geräte, Zeitpunkt des Wartens, alleiniges oder kollektives Warten), die zwar die meiste Forschungsaktivität erfahren hätten, aber kaum nachweisbaren Einfluss auf die Warteerfahrung nehmen würden. Die Beeinflussung der Wartesituation, so konstatiert Durrande-Moreau überraschend, "has still not been proved to be efficient in 
changing customers' perceptions. ${ }^{172}$ Die Analyse zeigte, dass die absolute Wartezeit im Laufe der 1990er Jahre immer mehr zu einer neutralisierten Größe wurde und man stattdessen die nicht-zeitlichen psychologischen Aspekte des Wartens besser verstehen wollte. Tatsächlich aber wurde zum Ende der 1990er wiederum erklärt, dass die objektive Wartedauer nach wie vor fundamental für die Warteerfahrung sei und deren »central stimulus $\aleph^{173}$ bilden würde. Mit anderen Worten: Je länger das Warten andauert, desto negativer wird es erfahren und kann durch situative Interventionen nur noch marginal beeinflusst werden. Damit wurde die Forderung laut, dass objektive Zeit wieder in den Mittelpunkt der Erforschung von Wartephänomenen rücken sollte und man sich wieder mehr den Zugriffen der klassischen Unternehmensforschung bzw. der Queuing Theory im Begriff der objektiven Wartezeitminimierung zuwenden sollte. Statt zu stark auf das psychologische Wahrnehmungsmanagement zu setzen, sprach sich Durrande-Moreau für neue Beschleunigungstechnologien oder operative Maßnahmen aus, die sofortige Zeitersparnis bieten können, bspw. Die Installation von Fahrkartenautomaten in Verkehrsmitteln. Zudem sollten Kunden stärker nach ihren Bedürfnissen klassifiziert und Wartesysteme daraufhin diversifiziert werden, mit der Konsequenz einer heterogenen Wartelandschaft mit einer Vielzahl von »special lanes «. ${ }^{174}$

Der zurückliegende Exkurs in eine Auswahl disziplinärer Zugriffe verdeutlichte nicht nur, dass das Warten zunehmend als fester Bestandteil des modernen Lebens verhandelt wurde, sondern das Temporalphänomen nachweislich insbesondere mit Beginn des Aufstiegs von Kommunikationstechnologien erstmals systematisch problematisiert wurde. Die anfänglich `harten` Beschreibungs- und Lösungsebenen wichen dabei im Laufe des 20. Jahrhunderts zunehmend ‘weichen<, akteursbezogenen Beschreibungsebenen. Zeitphänomene wurden dabei seit Ende des 20. Jahrhunderts zunehmend versucht in ihrer subjektiven Wahrnehmung in Abhängigkeit von vielzähligen Einflussfaktoren zu erfassen und daraufhin die Zeitwahrnehmung mittels eines perception managements positiv beeinflussen zu können.

Aus diesen wissenschaftshistorischen Befunden erwächst nun ein weiterführendes, leitendes Interesse: Wenn die Problematisierung des Wartens mit Blick auf die Fülle der durch psychologische Zugriffe inspirierten Managementliteratur den vorläufigen Endpunkt der Problematisierung des Wartens bildet, wo liegt ihr Anfangspunkt? Gibt es jenseits der frühesten bislang identifizierten, expliziten Arbeiten zum Wartephänomen im Rahmen der Queuing Theory bereits zeitlich vorgelagert weitere Reflektionen über das Warten, die bislang verborgen geblieben sind? Die Beantwortung dieser Frage führt nun final in historische Analyse von Wartephänomenen im konkreten Feld des Wartens auf Eisenbahnen. Damit wird nun nach den ersten eingrenzenden Präzisierungen des Wartephänomens der zeithistorischen >Verortung innerhalb der durch das Prinzip der Beschleunigung zusammengehaltenen Modernisierungsprozesse - die angekündigte zweite Präzisierung in Form der analytischen Verengung auf den Verkehrskontext vollzogen.

172 Durrande-Moreau, »Waiting for service: ten years of empirical research«, 180.

173 Ebd., 175.

174 Vgl. Gasparini, »On Waiting«, 35. 


\subsection{Verkehrsinduziertes Warten}

»Unser Verhältnis zur Geduld, also der Fähigkeit zu warten, ist hoch ambivalent. Theoretisch betrachten wir sie als Tugend, praktisch besitzen wir sie nicht. $\ll^{175}$

Der vorangegangene Exkurs konnte nur einen Ausschnitt der Breite von Erscheinungsfeldern des Wartens aufzeigen, das grob kategorisiert virtuell in technischen Netzen, physisch realisiert vor Empfang von Gütern und Dienstleistungen oder als eingesetzte Zeitstrategie in sozialen Systemen und daran geknüpft als Folge ungleicher Machtverhältnisse auftritt. Innerhalb dieser Kategorisierung bildet das Verkehrswesen zweifelsohne ein zentrales Auftrittsfeld, das im Folgenden aufgrund seiner Sonderstellung für die Ausbildung, Verhandlung und Erfahrung von Wartephänomenen herausgegriffen werden soll. Die Legitimation dieses Herausgreifens erfolgt aus dem engen und bereits frühzeitig etablierten Nexus zwischen Moderne und Verkehr, der bisweilen im Weber'schen Duktus überzeugend als >Wahlverwandtschaft< charakterisiert wurde. ${ }^{176}$ Der Verkehr, allgemein definiert als physisch realisierte Mobilität und als Ortsveränderung von Menschen, Gütern und Informationen, gilt seit Anbeginn der Moderne als »eine der zentralen Stoßrichtungen der Beschleunigung ${ }^{177}$, wenn nicht gar als ihr dominantestes Ausdrucksfeld. So galt die Förderung des Verkehrs in den letzten zwei Jahrhunderten als ein »weitgehend positiv konnotierter Bereich sozioökonomischen und politischen Handelns«, der mit "gesellschaftlicher Emanzipation, (...) ökonomischer Prosperität, als Steigerung von Freiheit und Modernität verstanden und begrüß $\iota^{178}$ wurde.

Jegliche Ideen der politischen, sozialen oder wissenschaftlichen Modernisierung rekurrieren direkt oder indirekt auf das Zieltelos der >Bewegung und der >Beweglichkeit<, denn nur sie repräsentierten die zur Zielerreichung notwendigen >Vehikek der Veränderung. Mit anderen Worten: Keine Revolution, keine Kapitalwirtschaft, kein naturwissenschaftliches Streben waren und sind ohne >Bewegungs- und Beweglichkeitsschübe denkbar. Während im Zuge der Aufklärung zunächst insbesondere die Modalität einer >Beweglichkeit` des Geistes und der >Bewegung`von Gedanken im Sinne eines dialektischen Dreischritts (Hegel) ${ }^{179}$ proklamiert wurde, stand die Moderne seit dem 19. Jahrhundert zusätzlich und ganz entscheidend im Zeichen der physisch realisierten >Bewegung « und damit verbunden letztlich stets im Zeichen eines nie dagewesenen Bestrebens nach möglichst erleichterter Raumüberwindung. Das Zieltelos der Bewegung fand somit seinen Ausdruck in der Überlagerung mehrerer bewegter bzw. zunehmend beschleunigter Sphären: der politisch-sozialen Bewegung/Beschleunigung seit

175 Gräff, Warten: Erkundungen eines ungeliebten Zustands, 41.

176 Vgl. Rammler, Mobilität in der Moderne.

177 Borscheid, »Zeit und Raum. Von der Beschleunigung des Lebens«, 23.

178 Hans-Liudger Dienel und Helmuth Trischler, »Ceschichte der Zukunft des Verkehrs: Eine Einführung. «, in Geschichte der Zukunft des Verkehrs: Verkehrskonzepte von der frühen Neuzeit bis zum 21. Jahrhundert, hg. von Hans-Liudger Dienel und Helmuth Trischler (Frankfurt a.M.; New York: Campus, 1997), 11.

179 So betont Hegel hinsichtlich der Bedeutung der Bewegung für die Realisierung der dialektischen Methode: »Das bewegende Prinzip des Begriffs [...] heiße ich die Dialektik.« Ceorg Wilhelm Friedrich Hegel, Grundlinien der Philosophie des Rechts, Bd. 7 (Frankfurt a.M.: Suhrkamp, 1979), Einleitung. $\S 31$, S. 83 [Herv. i. O.]. 
der Französischen Revolution, aber nicht zuletzt eben auch ganz konkret der bewegten/beschleunigten Erfahrung der Raumüberwindung. Hier materialisieren sich die gewandelten Vorstellungen und Zielstellungen des modernen Denkens besonders deutlich, hier treten sie an die Oberfläche. Die mit der dampfgetriebenen Eisenbahn einsetzende Transportrevolution in der ersten Hälfte des 19. Jahrhunderts stellt darin zwar wahrlich nur eines von vielen Ausdrucksfeldern der Beschleunigung des modernen Lebens dar, jedoch »spielen sich hier die spektakulärsten Szenen in diesen in vielfacher Hinsicht revolutionären Zeiten $a b . «^{180}$

Wie bereits zu Beginn dieses Kapitels beleuchtet, tritt jedoch gleichwohl mit dem beschleunigten Aufstieg der (verkehrlichen) Moderne eine Art Gegenbewegung auf den Plan, eine erst durch die veränderten Zielbestrebungen relationale Herausbildung (und Erfahrung) von (antimodernen) Stillstandsmomenten, die als genuines Merkmal die Ausbildung der Beschleunigungsprozesse begleiten. Die an dieser Stelle nochmals in Erinnerung zu rufende Doppeldiagnose der Moderne lautete, dass zwar einerseits Beschleunigungsprozesse eine ungeahnte Verkürzung von Wartezeiten (Prozesse, Bezüge, Raumüberwindung) bedingten, andererseits das moderne Telos der Bewegung und Beschleunigung aber überhaupt erst eine stärkere Bewusstwerdung relationaler Situationen des Stillstands erzeugten und sspürbar werden ließen. Denken wir diese Doppeldiagnose weiter fort, so führt hinsichtlich der Suche nach den Schauplätzen jener Gegenbewegung paradoxerweise kein Weg am Verkehrswesen vorbei, denn hier bildet das genuine Begleitmerkmal zur Beschleunigung den wohl sichtbarsten wie regelmäßigsten Referenzpunkt. Zwar ermöglicht das moderne Verkehrswesen eine historische Zäsur der Reisezeitverkürzung und der Raumüberwindung, doch zugleich liefern die Millionen von Reisenden, die regelmäßig gezwungen waren, verkehrsinduzierte Wartesituationen zu erfahren und zu verhandeln, folglich den konkreten historischen Tatsachenbefund der >Entdeckung eines Gegenmoments zur beschleunigungsaffinen Moderne. Nicht ohne Grund sieht wohl daher auch Virilio das Verkehrswesen als wichtigen Kulminationspunkt seiner Modernitätstheorie an, die im Zuge der Erfindung des beschleunigten Massenverkehrs zugleich die komplementäre >Entdeckungくvon systemischen Gegenmomenten des >Unfalls` (Eisenbahn), des `Absturzes` (Flugzeug) oder des >Untergangs` (Titanic) erzeugte. ${ }^{181}$

Das Verkehrswesen repräsentiert nicht nur eine dominante Schnittstelle von Zeit und Raum, es bildet zugleich den prominenten Austragungsort des skizzierten Spannungsverhältnisses zwischen Verlangsamung und Bewegung, zwischen Beschleunigung und Stillstand. So waren es vor allem die transitorischen Verkehrsorte der Moderne, die zu Orten des Erlernens, Einübens und der Auseinandersetzung mit dem speziellen Temporalstatus des Wartens wurden. Hier wurde durch die strukturelle und zunehmend standardisiert-vereinheitlichte Organisationsform der Zeit in Gestalt von statischen (Fahr-)Plänen ${ }^{182}$ ein modernes Zeitdenken bzw. die Verinnerlichung der Uhrzeit oktroyiert. Hier wurde durch den realisierten Transport die Verinnerlichung

180 Borscheid, Das Tempo-Virus, 143.

181 Vgl. Paul Virilio, Der eigentliche Unfall (Wien: Passagen, 2009).

182 Vgl. Zerubavel, »Timetables and Scheduling«. 
Abbildung 4: Dresden Postplatz (1946): Straßenbahnhaltestellen mit Wartehalle, sogenannte "Käseglocke«.

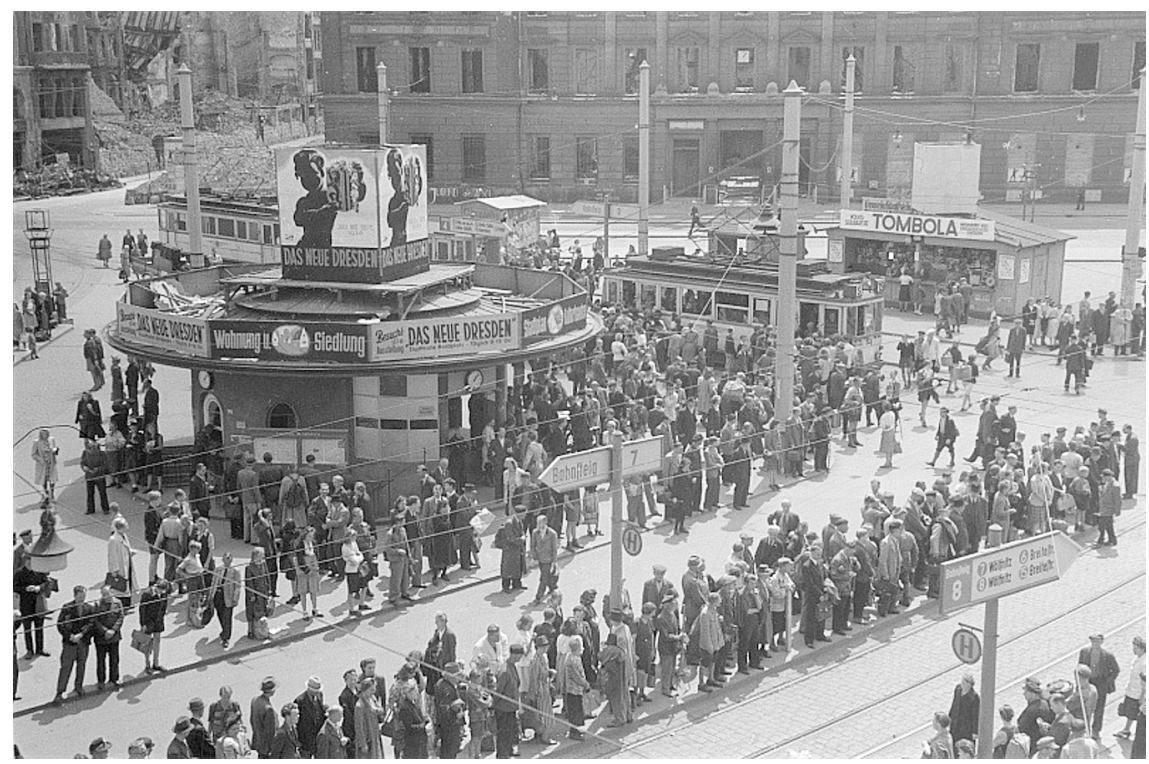

Quelle: Deutsche Fotothek, Inventarnummer: df_ps_0000343.

eines gewandelten Verhältnisses zur Distanz praktiziert. Hier wurde eine Änderung des Rhythmus evoziert, der zur allgemeinen Temporalisierung des Erlebens beitrug und innerhalb einer erhöhten Sensibilität der Zeitwahrnehmung auch die Sensibilität für neuartige Zeitzwischenräume einschloss. Konkrete Beispiele des verkehrsinduzierten Wartens umfassen im öffentlichen Verkehr die vielzähligen prozessimmanenten Aufenthalte an Bahnhöfen, Flughäfen oder Haltestellen, die beim Erwarten von regulären Abfahrten, bei Umsteigesituationen oder im Falle von Verspätungen auftreten. Im Individualverkehr dagegen sind es die Aufenthalte an Ampeln, Kreuzungen und insbesondere in Stausituationen, die das Verkehrswesen als besonderes Auftrittsfeld des Spannungsverhältnisses von Bewegung und (temporärer) Stauung auszeichnen.

\section{Zur Notwendigkeit des Wartens auf öffentlichen Verkehr (subjektive und operative Perspektiven)}

Die Notwendigkeit solcher Wartesituationen wird im öffentlichen Verkehr im Vergleich zum Individualverkehr durch eine formale Besonderheit bedingt. Mit öffentlichen Verkehrsmitteln zu fahren bedeutet, »zu vorgegebenen Zeiten nach Fahrplan, mit Mitreisenden, die man sich nicht ausgesucht hat, zu einer Haltestelle zu fahren, die nicht das eigentliche Endziel des Weges ist. ${ }^{183}$ Fahrgäste nutzen gemeinsam mit anderen Mit-

183 Katrin Dziekan und Meinhard Zistel, »Öffentlicher Verkehr«, in Verkehrspolitik, hg. von Oliver Schwedes (Wiesbaden: Springer, 2018), 348. 
fahrern ein geteiltes Beförderungsmittel, in welchem die Reisenden einen ähnlichen Weg oder Teilweg zurücklegen. Die dadurch ermöglichte »örtliche und zeitliche Bündelung von Fahrtwünschen ${ }^{184}$ kann jedoch nur dann effizient und verlässlich realisiert werden, wenn sich Reisende dazu einem gewissen Orts- und Sachzwang unterstellen. Sie müssen sich - um in Bussen, Bahnen und Flugzeugen gemeinsam transportiert zu werden - schlicht zu einem bestimmten Zeitpunkt an einem bestimmten Ort einfinden, um den Raum überhaupt beschleunigt überwinden zu können bzw. die Abfahrt nicht zu verpassen. Mit anderen Worten erfordert der öffentliche Personenverkehr gegenüber dem Individualverkehr damit ein Mehr an Regelungs- und Informationsaufwand vor der Abfahrt. Um aus Sicht der Verkehrsanbieter diese effiziente Bündelung von Fahrtwünschen gewährleisten zu können, müssen Reisende dazu zeitliche und örtliche Informationen erhalten, um überhaupt eine zeit- und ortsgenaue Synchronisation zwischen Fahrgast und technischem Betriebssystem herstellen zu können. Während dafür die Institution des Fahrplans die Kontingenz der unendlichen Ereignisabfolgen in zeitlicher Hinsicht zugunsten fester Determinationen auflöst, wird in Ergänzung dazu jegliche Kontingenz des (Abfahrts-)Ortes durch die Errichtung und Denomination eines Bahnhofs in örtlicher Hinsicht eindeutig bestimmt.

Ob heute oder im frühen 19. Jahrhundert, Reisende müssen somit zunächst zu einem Sammelpunkt, einer Station, gelangen, um anschließend zunächst ein mehr oder weniger langes, stationäres und unmittelbares Warten im Transitraum von Wartehallen oder Bahnsteigen oder ein indirektes Warten in Restaurants oder Geschäften zu absolvieren, bevor schließlich ein Verkehrsmittel bestiegen werden und im Weitertransport eine Bündelung von Fahrtwünschen realisiert werden kann. Insbesondere die ersten Jahrzehnte des Eisenbahnwesens stehen dabei, wie noch zu zeigen sein wird, im Zeichen der temporären Sammlung bereits abgefertigter Reisender, die vielerorts "aus Gründen der Sicherheit und Kontrolle noch nicht auf den Bahnsteig durften. ${ }^{185}$ Auch wenn dieser Umstand eines »organisatorischen Zwangs « ${ }^{186}$ nur allzu selbstverständlich erscheinen mag, so bildet er doch gegenüber dem Individualverkehr eine bis in die Gegenwart hinein strukturelle Besonderheit des öffentlichen Verkehrs, die zugleich als ein entscheidender Wettbewerbsnachteil gegenüber dem Individualverkehr identifiziert wird. ${ }^{187}$

Dieser meist situative, stationäre Aufenthalt vor Abfahrt eines öffentlichen Verkehrsmittels wird jedoch nicht nur seitens der Passagiere benötigt, um die angesprochenen Raum- und Sachzwänge zu erfüllen, also ein Verkehrsmittel zu einem definierten Zeitpunkt an einem definierten Ort überhaupt besteigen zu können. Der situative Aufenthalt erfüllt zugleich aus Sicht der verkehrsanbietenden Seite einen funktionalen Zweck. Die Bereitstellung eines effizienten, verlässlichen und für unterschiedlichste Fahrtwünsche gebündelten Verkehrsangebots stellt aus operativer Sicht eine enorme Herausforderung dar oder anders ausgedrückt: Die mit höherer Geschwindigkeit

184 Ebd.

185 Radlbeck, »Bahnhof und Empfangsgebäude«, 13.

186 Ebd.

187 Yingling Fan, Andrew Guthrie, und David Levinson, »Waiting Time Perceptions at Transit Stops and Stations: Effects of Basic Amenities, Gender, and Security«, Transportation Research Part A: Policy and Practice 88 (Juni 2016): 252. 
erzeugte erleichterte Raumüberwindung stellt nicht allein ein technisches oder infrastrukturelles, sondern nicht zuletzt ein organisatorisches Problem dar, das zudem bezüglich des Organisationsaufwandes mit dem Geschwindigkeitsniveau des jeweiligen Verkehrsmittels zu korrelieren scheint. ${ }^{188}$ Eine geregelte Bereitstellung öffentlicher Verkehrsangebote erfordert daher ein mehr oder weniger intensives Maß zeitlicher und räumlicher Kontrolle vor Beginn der eigentlichen Abfahrt, um Ströme (sicher) zu lenken, Fahrberechtigungen zu prüfen oder Passagiere (klassenspezifisch) gruppieren zu können. Dieser organisatorischen Herausforderung in der Bereitstellung beschleunigter Verkehrsangebote wurde mit der Einrichtung räumlicher und zeitlicher Kontrollund Transferzonen bzw. Zonen des Übergangs vom Verkehrsraum der Stadt zum Verkehrsraum der Eisenbahn begegnet. ${ }^{189}$ Verkehrsflüsse wurden und werden somit überhaupt erst mittels der komplementären Einrichtung von Brems- und Reibungszonen realisierbar. In diesem Sinne übernehmen Wartesituationen - wenn auch kaum aus Sicht der Reisenden dann doch zumindest aus operativer Sicht - ebenso eine integrative Funktion, denn sie gewährleisten Übergänge und Synchronisationen, die ohne die Einrichtung von Zwischenebenen schwieriger realisierbar wären. Wohl kaum wurde dieser für die sozialwissenschaftliche Mobilitätsforschung essentielle Zusammenhang bislang pointierter betont als durch den Soziologen John Urry und damit durch einen Gründungsvater der mobility studies selbst:

»The relationality between mobilities and immobilities is a typical complexity characteristic. There is no linear increase in fluidity without extensive systems of immobilities. Thus the so-far most powerful mobile machine, the aeroplane, requires the largest and most extensive immobility (...). The least powerful machine, human legs, requires almost no such immobilities (except maybe the armchair!). $\ll^{190}$

drawingml2svgZusammenfassend können somit die Motive der Entstehung verkehrsinduzierter Wartezeiten im öffentlichen Verkehr wie folgt festgehalten werden: Aus operationaler Sicht entstehen Wartezeiten durch die kontrollintensive Organisation von Geschwindigkeit, die innerhalb von immobilen Infrastrukturen (Bahnhöfe, Flughäfen, Haltestellen) Prozesszonen der Retardierung erfordert. Aus Sicht der Reisenden wiederum werden Wartezeiten - wenngleich weit weniger intendiert - im notwendigen Einräumen von Zeitkapazitäten zur Bewerkstelligung des Übergangs vom privaten oder öffentlichen Raum in den Verkehrsraum der Eisenbahn oder des Flugverkehrs erforderlich. Abstrahiert gesprochen können somit (öffentliche) Verkehrsflüsse, die unterschiedliche Fahrtwünsche bündeln, nur mittels punktueller Immobilitäten - räumlicher Stauungszonen als auch zeitlicher Retardierungsmomente - realisiert werden.

Als Resultat der formalen Besonderheit des öffentlichen Verkehrs mag das situative Mikro-Warten an Haltestellen und Bahnsteigen im modernen, hochmobilen Leben wie eine weithin übersehene Alltagsbanalität erscheinen. Historisch betrachtet stellt

188 So erfordert etwa das Warten auf einen relativ betrachtet langsamen Bustransport an einer Haltestelle seitens der Reisenden als auch des Anbieters gänzlich weniger organisatorischen Aufwand als das Warten auf den ungleich beschleunigteren Transport per Flugzeug. 
Abbildung 5: Schema des Reiseverlaufs (eigene Darstellung).

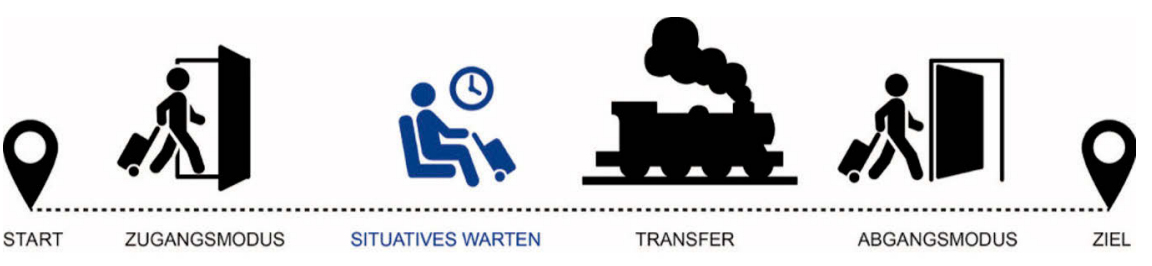

das verkehrsinduzierte Warten jedoch eine kulturelle Praxis dar, die erst im Zuge eines psychischen Zivilisationsprozesses erlernt und aus Sicht der Verkehrsanbieter in den Betriebsablauf eingefügt und mit einem entsprechenden Raumprogramm planerisch gerahmt werden musste. Wenngleich mit der Entstehung moderner Verkehrssysteme die Erfahrung solcher Wartezeiten wohl kaum dem »Wahrnehmungsschock « ${ }^{191}$ des gesteigerten Geschwindigkeitsniveaus ebenbürtig erschien, so bleibt zu vermuten, dass sie doch zumindest als Irritation und Desorientierung wahrgenommen worden sind, die entsprechende Umgangsstrategien erforderten. In jedem Fall aber müssen jene an Beschleunigungsphänomene gekoppelten Retardierungseffekte, so die Grundüberzeugung dieser Arbeit, als wirkmächtige, spezifisch `moderne`Charakteristika der Lebenswelt seit der Mitte des 19. Jahrhunderts gelesen und damit in ihrer relativen Neuheit herausgestellt werden. Diese relative Neuheit soll mit der begrifflichen Qualifizierung eines systemischen Wartens eingefangen werden, die es nun näher zu beleuchten gilt.

\subsection{Systemisches Warten}

Das Warten ist wie bereits an anderer Stelle erwähnt, zunächst rein objektiv betrachtet eine >zeitlose<, anthropologische Grundverfassung des Menschen, die innerhalb eines mehr oder minder komplex ausgeprägten Zeitbewusstseins als krisenhafte Fehlstelle erfahren wurde. Wenn wir Maslows These folgen und annehmen, dass Menschen ein psychisches Motivationssystem besitzen, das sie zum Streben nach zunächst existentiellen und zunehmend komplexeren Bedürfnisbefriedigungen veranlasst ${ }^{192}$ und diese Eigenschaft eine überzeitliche Kategorie der Menschheitsgeschichte darstellt, so müssen wir davon ausgehen, dass Menschen seit jeher natürlich oder sozial bedingte Verhinderungen ihrer Bedürfnisbefriedigungen erfahren haben. Selbstverständlich sind rückwärtige Zuschreibungen gegenwärtiger Phänomene und Bewusstseinslagen auf frühere Epochen äußerst fraglich, wenn nicht gar gänzlich unzulässig. Wenngleich die Ägypter noch kein feingliedriges, modernes Zeitdenken im Sekundentakt verinnerlicht haben mögen, ist dennoch davon auszugehen, dass Menschen ein mehr oder minder explizites, überzeitliches Bewusstsein der Antizipation des Kommenden besessen haben

191 Schivelbusch, Ceschichte der Eisenbahnreise, 46.

192 Vgl. Abraham Harold Maslow, »A theory of human motivation. «, Psychological review 50, Nr. 4 (1943): 370-96. 
müssen. So warteten Menschen ohne Zweifel schon immer auf ernährungsrelevante Ernten, auf transportrelevante Winde, auf spirituelle Erlösung und vieles mehr.

Die in Kapitel 2.4 hergeleiteten Kriterien zur Ausbildung von Wartezeiten die Wahrnehmung einer Inkongruenz innerhalb der dialektischen Verhandlung von Zeitkonzeptionen sowie die resultierende Unterbrechung des gewohnten Ordnungsversprechens des Zeitflusses - sind somit als Teilaspekte des menschlichen Zeitbewusstseins keineswegs neu, jedoch begründen die Ausdifferenzierung der Wartephänomene, die Warteanlässe und die Veränderung der Warteerfahrungen seit spätestens Mitte des 19. Jahrhunderts ein >modernes Element<.

Insbesondere mit Blick auf den modernen öffentlichen Massenverkehr bildet sich in diesem Zeitraum erstmals die skizzierte Notwendigkeit eines situativen Aufenthalts zur Bündelung von Fahrtwünschen aus, der sich quasi zwischen den Empfang von Dienstleistungen schiebt und letztlich die Wahrnehmung einer neuartigen, interstitiellen und liminalen Temporalregion erzeugt.

Um nun die Eigenart jener Retardierungsmomente von der Vielzahl parallel auftretender als auch von vormodernen Wartesituationen abzugrenzen, wird hiermit im Sinne der besseren Erfassung der sich im Zuge der Moderne ausdifferenzierenden Wartephänomene der Begriff des systemischen Wartens vorgeschlagen.

Die adjektivische Ergänzung systemisch erfolgt aus drei Gründen:

1) weil diese Form des Wartens speziell im Kontext der sich in komplexen Gesellschaften zunehmend ausdifferenzierenden Subsysteme in Erscheinung tritt bzw. erforderlich wird. Erst die in der Moderne massive Zunahme der Interdependenzketten erhöht das Risiko für systemisch bedingte Desynchronisationen, die schließlich in Wartezeiten resultieren.

2) weil das Erwarten einer Zugabfahrt systemrelevante Funktionen erfüllt (subjektive und operative Synchronisierung der Reisenden an Verkehrsraum). Reziprok gesprochen, würde es ohne die fahrplanmäßige Organisation des Eisenbahnverkehrs keinen situativen Aufenthalt in Wartesälen geben, der den Reisenden eine Zentralität der Zeiterfahrung förmlich aufzwingt.

3) verweist die Nutzung des Adjektivs systemisch darauf, den Blick im Sinne einer methodischen Perspektivierung auf eine ganzheitliche Betrachtung jener Systeme zu richten, in denen Wartesituationen auftreten. Mithilfe dieser methodischen Perspektivierung wird es erst möglich, Ursachen und die Funktionen von Wartesituationen im Kontext der Moderne jenseits ihrer phänomenologischen Betrachtung aufzudecken. Mit spezifischem Blick auf das Verkehrswesen wird hierbei insbesondere konkret auf das relationale Verhältnis bzw. die gegenseitige Bedingtheit von Beschleunigung und Retardierung rekurriert.

Systemisches Warten steht somit für ein Begriffsangebot, das zusammengenommen aufgrund seiner Erscheinungsformen, seiner Funktion, aber auch aufgrund seiner einzunehmenden Betrachtungsweise eine systemische und damit dezidiert moderne Charak- 
teristik besitzt. Jene moderne Charakteristik schließt dabei ein, dass mit Beginn der Modernisierungsprozesse eine allmähliche Verlagerung von Warteanlässen und Warteerfahrungen in eine soziotechnische Systemebene erfolgt und damit verbunden eine massive Verlagerung der Warteanlässe und -erfahrungen von vormals naturbezogenen auf anthropogene Ursachenebenen. So werden die vormals überwiegend existenziellen Warteanlässe im Kontext agrarwirtschaftlich ausgerichteter Gesellschaften (Erwarten günstiger Wetterereignisse oder astronomischer Phänomene) durch Ursachen der technisch-operativen Notwendigkeit und der Knappheit im Bezug von Gütern und Dienstleistungen ergänzt und schließlich überlagert. Überspitzt formuliert ließe sich festhalten, dass der moderne Mensch zwar noch immer den Frühling wartet, doch in der Zwischenzeit wesentlich häufiger und kleinteiliger auf Bahnen, in Telefonschleifen, beim Upload von Content auf Webseiten oder auf freie Plätze in Kindertagesstätten.

Die hier vertretende These einer sich im Laufe des 19. Jahrhunderts herauskristallisierenden Modernität des Wartephänomens ließe sich zweifelsfrei entgegenhalten, dass es auch bereits in vorindustriellen Gesellschaften kleinteiligere Wartesituationen gegeben hat, die sich von den langwelligen und naturbezogenen Anlässen des Wartens unterschieden und Schnittmengen mit der Charakteristik des systemisches Wartens aufweisen könnten. So wissen wir, dass an französischen Höfen des Barock stets Vorzimmer zum König, sogenannte Antichambres, bestanden, an denen Besucher des Königs ausharren mussten, bis ihnen Audienz gewährt wurde. ${ }^{193}$ Das in napoleonischer Zeit erbaute Théatre de Vaudeville in Paris verfügte über einen Wartesaal, in dem sich das königliche Gefolge für den Zeitraum der Aufführung aufzuhalten hatte. Zudem sind auch in Badehäusern, Rathäusern, Gerichtsgebäuden und vor den Eingängen von Stadttoren Wartezonen nachweisbar. Auch hier wurden die Warteanlässe von der Sphäre des Natürlichen zunehmend in die Sphäre des Sozialen verlagert, die für die Charakteristik des systemischen Wartens typisch sind. Die entscheidende Abgrenzung gegenüber diesen vormodernen Wartesituationen zeigt sich jedoch darin, dass die angesprochenen Warteorte allesamt Orte sind, an denen die Zeitlichkeit des Wartens am Referenzsystem einer sozialen Uhrzeitlichkeit jedoch nicht an einer - wie etwa ganz besonders im Eisenbahnverkehr - objektiven Zeitlichkeit (Uhr- bzw. Eisenbahnzeit) ausgerichtet war. Im Gegensatz zur durch Fahrpläne eindeutig determinierten Abfahrt, die es mittels einer Wartezeit zu überbrücken und deren Länge mittels der Differenz von Abfahrt und aktuellem Zeitpunkt deutlich begrenzt, gewiss und damit besser abzusehen war, waren die Wartesituationen in den Antichambres oder vor Stadttoren weit weniger berechenbar, denn sie waren weniger an objektiven als vielmehr an sozialen Referenzbezügen orientiert. Mit anderen Worten: Wann der Einlass in eine Stadt oder ein Königszimmer gewährt wurde, hing weit weniger von einer objektiven Zeitlänge ab, als vielmehr von individuellen oder institutionellen Entscheidungen der Personen oder Organisationen bzw. von deren Macht- und Anspruchsverhältnissen gegenüber den Wartenden.

193 Helmut Puff, »Waiting in the Antechamber«, in Timescapes of Waiting: Spaces of Stasis, Delay and Deferral, hg. von Christoph Singer, Robert Wirth, und Olaf Berwald (Leiden \& Boston: Brill, 2019), 1734. 
Zur weiteren Präzisierung und Abgrenzung des Auftretens und der Erfahrung des systemischen Wartens in den Fugen der Modernisierungsprozesse werden im Folgenden Dauer, Rhythmus und Modalität verglichen.

\section{Charakteristik des systemischen Wartens}

Zunächst ist das systemische Warten meist wesentlich kürzer als etwa ein Langzeitwarten auf jahreszeitlichen Wandel, das Erscheinen astronomischer Konstellationen zur Zeitbestimmung oder gar eine spirituell ersehnte Erlösung. Wenngleich auch die Moderne neue Formen des Langzeitwartens erzeugt haben mag (Erhalt von Spenderorganen, Langzeitarbeitslosigkeit), die Parallelitäten zu einem längeren vormodernen Warten aufzeigen, spielt sich das systemische Warten bezüglich seiner absoluten Dauer meist im Bereich von Stunden und Minuten, nicht jedoch im Bereich von Tagen, Monaten oder gar Jahren ab. Auch wenn es sich aus Sicht der Wartenden wie eine Ewigkeit anfühlen mag, ist es verglichen mit vormodernen Wartesituationen von vergleichsweise begrenzter Dauer.

Es ist damit verbunden im Grundcharakter wesentlich profaner und weniger existenziell, weil es weit weniger auf den Erhalt grundsichernder Maßnahmen abzielt, als oftmals vielmehr ein notwendiges Übel zur Synchronisierung im Übergangs- und Kontaktbereich zweier Systeme darstellt. Beispielhaft kann diese Profanität darin illustriert werden, dass das im Zuge der Moderne massenhafte Phänomen des (systemischen) Erwartens eines öffentlichen Verkehrsmittels vor Abfahrt oder bei Umsteigesituationen grundsätzlich vollkommen anderer Natur als das Erwarten eines Kindes in der Schwangerschaft ist. Selbst wenn die mit dem Transport verfolgten Bedürfnisbefriedigungen höchste Relevanz entwickeln, ist die Lebensnotwendigkeit des unmittelbaren Erwartens weit weniger existenziell, denn es müssen prinzipiell keine unkontrollierbaren Knappheiten überwunden werden, sondern es muss lediglich ein Transfer zwischen technischer und belebter Sphäre gewährleistet werden. Aus dieser Charakteristik heraus können situative Wartesituationen, wie sich im Hinblick auf die Frühphase der Rezeption des verkehrsinduzierten Wartens auf Eisenbahnen zeigen wird, in einigen Fällen gar als aufregende Bereicherung oder Repräsentationsebene und damit positiv als vergleichsweise privilegiertes Warten erfahren werden. Die Abgrenzung gegenüber andersartigen Wartesituationen ist also nicht zuletzt auch darin zu sehen, dass systemisches Warten bei individuell günstigen Rahmenbedingungen durchaus als spannende Aktivität und letztlich als Bereicherung betrachtet werden kann.

Das systemische Warten ist zudem vergleichsweise weniger unsicher bzw. von weniger Ungewissheit gezeichnet. Wartende in modernen Systemzusammenhängen verfügen trotz überwiegend negativer Affekte im Warten - insbesondere im Sonderfall der nicht kalkulierten Verspätung - insgesamt über eine gewisse Prozesssicherheit, weil sie sich bereits im System befinden bzw. informatorische Unterstützung durch Pläne oder Auskünfte erhalten, welche die Ungewissheit des Wartens, die immer auch ein situatives Informationsdefizit darstellt, kompensieren können. Systemisches Warten ist zudem stärker im Vorfeld plan- und absehbar und tritt dadurch weniger überraschend oder unvorbereitet in Erscheinung. 
Darüber hinaus tritt das systemische Warten vergleichsweise häufiger und regelmäßiger auf als etwa das Langzeitwarten. Die Rhythmik der Entstehung, Erfahrung und Auflösung systemischer Wartesituationen gehört im Leben der Moderne zur Alltagsroutine und ermöglichen eine stärkere Routinisierung des Verhaltens.

Obwohl die Charakteristik des systemischen Wartens somit insgesamt weniger kritisch erscheint als etwa ein Warten auf einen ernterelevanten Regen, der im Falle des Ausbleibens eine existenzielle Bedrohung darstellt, sind die systemischen Wartesituationen keineswegs psychologisch unproblematisch, denn die selbst im situativen Kurzzeitwarten erzwungene Taktunterbrechung bildet unweigerlich den Wahrnehmungsmittelpunkt und kann negative Affektreaktionen hervorrufen, insbesondere im Sonderfall der Verspätung. Die sonst subtil wirksame Orientierungsfunktion der Zeit ist auch im systemischen Warten aufgehoben und bewirkt unter Wartenden mitunter eine situativ unterbrochene Produktion zeitbezogener Sinnstrukturen. So hebt auch Gasparini die Relevanz der selbst kleinsten Wartesituationen wie folgt hervor:

»Micro-waiting experiences of everyday life can in fact be interpreted as a sign and a metaphor of a global sense of waiting with reference to the achievement and realization of each individual life. Aside from different ideological or religious beliefs, waiting, even when it is experienced at an everyday or micro level, relates to the value of time and therefore, from the actor's point of view, to the general meaning of life. « $^{194}$

Zusammengenommen können damit die in der Moderne gehäuft auftretenden systemischen Wartesituationen im Wesentlichen auf drei Ebenen von vormodernen Wartesituationen unterschieden werden: einer referentiellen, einer sozialen und einer qualitativen Ebene. Die referentielle Unterscheidung erwächst dadurch, dass im Vergleich zu den skizzierten Wartesituationen der Vormoderne das Warten nicht mehr auf das Eintreten von Naturereignissen oder spirituellen Ereignissen, sondern auf die Abläufe eines anthropogenen Systems bezogen wird. Auf der sozialen Ebene besteht die Spezifik des systemischen Wartens darin, dass die Wartenden - etwa im Vergleich des Wartens in den Antichambres barocker Höfe - nicht mehr als Bittsteller auftreten, über deren Wartezeit aufgrund sozialer Hierarchieunterschiede beliebig verfügt werden kann. Stattdessen erfahren die Wartenden im Kontext des öffentlichen Verkehrs trotz ihrer vorherigen Trennung in klassenspezifische Wartesäle, dass, erzwungen durch die beabsichtigte Bündelung unterschiedlicher Fahrtwünsche, alle Reisenden auf denselben Zug warten, der auch trotz der Trennung unterschiedlicher Wagenklassen für alle Reisenden zur selben Zeit eintrifft.

An diesen Aspekt der Nivellierung unterschiedlicher Wartezeitlängen geknüpft ist das systemische Warten von einer Requalifizierung und Reperspektivierung geprägt. Die Wartenden treten nicht mehr als Antragsteller auf, sondern müssen vielmehr als Kunden behandelt werden. Die Verursachung des Wartens wird nicht mehr allein durch den Wunsch des Reisenden zu seiner Bedürfnisbefriedigung erzeugt, sondern wird auch durch die operative Notwendigkeit der Einführung von Kontrollzonen seitens der Anbieterseite bewirkt. Das Warten wird den Kunden (Fahrgästen) zu einem gewissen 
Grad auferlegt, weshalb die Anbieterseite im Sinne einer Kompensation dieses organisatorischen Zwangs die Perspektive des Wartenden einnehmen muss. Auf mindestens diesen drei Ebenen wird eine >moderne Erweiterung des anthropologischen Grundmodus >Warten< bewirkt.

Auch wenn die skizzierte Charakteristik des systemischen Wartens insgesamt weit weniger existenziell anmutet, heißt dies keineswegs, dass das alltägliche Warten auf Busse und Bahnen keinen Referenzpunkt der Reflektion über Werte und Bedeutungen der Zeit und des Lebens erzeugen würde. Im Gegenteil könnte die regelmäßige Häufung systemischer Wartesituationen überhaupt erst im Sinne einer Heidegger'schen Fundamentalontologie zur verstärkten Auseinandersetzung mit der eigenen Lebenszeit beigetragen haben. Diese Frage mag dabei allein durch die schiere Quantität des systemischen Wartens an Gewicht gewinnen. Genährt nicht nur durch die Notwendigkeit des frühzeitigen Aufenthalts an Bahnhöfen, sondern auch durch das Schlange stehen an Kassen, in Behörden oder in öffentlichen Einrichtungen wie Badehäusern oder Arztpraxen wurde das systemische Warten im Laufe des 19. Jahrhunderts zu einer konstitutiven Massenerfahrung, der sich der moderne Mensch kaum entziehen kann. Vor diesem Hintergrund müssten folglich die großen Wartesäle der Bahnhöfe oder die raumgreifenden Flugsteige als gleichwertig transitorische Niederschlagsorte der Moderne gelten, wie etwa die bereits ausgiebig beforschten Transitorte des Hotels, des Flughafens oder des Kaufhauses. ${ }^{195}$ Jene an diesen Orten praktizierten situativen Wartesituationen repräsentieren wesentliche Indikatoren einer Epoche, die neben der Kompression von Raum und Zeit neue Zeitzwischenräume hat entstehen lassen, die stets und ständig mit Warten sgefüllt‘ werden mussten. Die resultierenden Wartesituationen sind das Produkt der Notwendigkeit gewandelter raum-zeitlicher Organisationsund Synchronisationsansprüche, die schließlich ein inhärentes Grundparadox der teleologischen und auf die Bewegung und Raumüberwindung hin abzielenden Moderne erzeugten: Das Verkehrswesen ermöglicht einerseits neue Dimensionen der Raumüberwindung, kreiert jedoch gleichzeitig permanent die dialektische Notwendigkeit eines übergeordneten Zeitregimes, das in Form von temporären Retardierungsmomenten relationaler Bestandteil des Massenverkehrs, aber auch relationaler Bestandteil des Modernisierungsdiskurses selbst geworden ist.

Wenn wir uns darauf einlassen, das systemische Warten im Allgemeinen und das Warten auf öffentliche Verkehrsmittel im Besonderen als historische Gegebenheit auf der Rückseite der modernistischen Teleologie von Bewegung und Beschleunigung zu betrachten, stellt sich die entscheidende Frage, inwieweit die zeitgenössischen Protagonisten im Zeichen einer Entdeckung und anschließenden Verhandlung dieses systemischen Wartens gestanden haben mögen und wie sich diese mit kulturgeschichtlichen Herangehensweisen nachvollziehen lässt. Diese Frage soll anschließend mithilfe des historiografischen Hauptteils diachron nachgezeichnet werden. In Erweiterung der

195 Vgl. Alexa Geisthövel, Habbo Knoch, und Christian W. Cottwaldt, Hg., »Der Bahnhof «, in Orte der Moderne: Erfahrungswelten des 19. und 20. Jahrhunderts (Frankfurt a.M.; New York: Campus, 2005), 17-26; Lars Wilhelmer, Transit-Orte in der Literatur: Eisenbahn-Hotel-Hafen-Flughafen (Bielefeld: transcript Verlag, 2015). 
160 Im Zwischenraum der beschleunigten Moderne

geleisteten systematischen Erschließungen der Wartezeit im Rahmen zeit- und modernisierungstheoretischer Ansätze soll damit finalisierend die Geschichte des Wartens erörtert werden. Mit Verengung auf den Mobilitätskontext der Eisenbahn werden da$\mathrm{zu}$ im Sinne einer historischen Außenperspektive die planerischen Verhandlungen des wartenden Passagiers sowie im Sinne einer Innenperspektive das Erleben verkehrsinduzierter Wartesituationen herausgearbeitet. 


\title{
4. Die Eisenbahn als zentrales Verkehrsmittel der Moderne: Eine Kontextualisierung
}

\subsection{Verkehrs- und technikgeschichtlicher Überblick: Aufstieg, Blüte und beginnender Rollenverlust des Eisenbahnwesens}

\author{
»[...] the railway is central to understanding \\ modern everyday life. «'
}

Die Eisenbahn repräsentiert das zentrale Verkehrsmittel des Industriezeitalters. Angetrieben durch den für die Epoche sinnbildlichen Impuls- und Taktgeber der Dampfmaschine wurde sie zum Symbolträger der sozioökonomischen und raumzeitlichen Umwälzungen des 19. Jahrhunderts und bildete - begleitet von politischen, aufklärerischen und wirtschaftlichen Heils- und Fortschrittsversprechen, aber auch von massiven Widerständen - das ikonisierte Medium des Aufbruchs in ein beschleunigtes Zeitalter. Die Schilderungen und Begründungen ihrer gesellschaftlichen und kulturellen Bedeutung nahmen bereits zeitgenössisch mitunter kolossale Formen an. So vermerkte etwa Frederick Williams im Jahr 1883:

»They mean the more frequent intercourse of families who otherwise would be separated, perhaps, for months or years; the promotion of the domestic happiness of hundreds of thousands of homes. They mean the increased activity and intelligence of society. They mean that business is done better, more effectively, cheaply, and widely. They mean that trade, manufacture, and commerce become possible that otherwise would have been impossible. $\ll^{2}$

Mit diesem Kapitel soll der gigantische soziotechnische Komplex des Eisenbahnwesens entlang systematischer Positionen aufgebrochen und beleuchtet werden, um einen enzyklopädischen Überblick des ersten Jahrhunderts des Eisenbahnwesens zu schaffen. 
Dieser Überblick erzeugt folglich einen Wissensspeicher, auf den im Rahmen der anschließenden Betrachtung des Wartephänomens im Sinne einer besseren Einordnung und Kontextualisierung einzelner Aspekte zurückverwiesen werden kann. Dieser systematische Überblick hat somit nicht zum Ziel, die Gesamtgeschichte des Eisenbahnwesens zu rekonstruieren. Vielmehr zielt er darauf ab, multiperspektivische Einblicke in den Gegenstand zu gewähren, um ein Rahmenwissen zu quantitativen und qualitativen Entwicklungslinien des Eisenbahnwesens zu schaffen. Mittels eines schwerpunkthaften Blicks auf das deutsche Eisenbahnwesen soll ein Rahmen für die technischen Hintergründe und Entwicklungen, die Akteursgefüge, Heilsversprechen, Widerstände und die Sozialität der Eisenbahnreise geschaffen werden, ohne den die Bau- und Kulturgeschichte des wartenden Passagiers nicht vollends verständlich gemacht werden könnte. Mithilfe dieser Rahmung soll schließlich das Transportsystem der Eisenbahn als soziotechnisches System erschlossen werden, das wie kein zweites Feld Produktions- und Erfahrungsort des systemischen Wartens wurde.

Die Auswahl des Betrachtungszeitraums 1830-1935 wird dabei auf Grundlage dreier heuristischer Vorüberlegungen getroffen, die für die Analyse des Wartens als aufschlussreiche Kontextbedingungen angenommen werden. Zunächst lenkt das Interesse

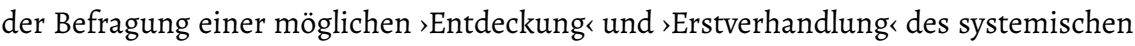
Wartens mit Beginn des Personenverkehrs den Fokus zweifellos auf die Frühphase des Eisenbahnwesens in den 1830er und 1840er Jahren. Wenn dem systemischen Warten (auf Eisenbahnen), wie bereits oben skizziert, eine moderne Modifizierung des eigentlich anthropologischen Grundmodus >Warten innewohnt, muss die Bruchkante bzw. die Übergangsphase in das moderne Verkehrswesen besondere analytische Aufmerksamkeit verdienen. Im zweiten Schritt soll aufgedeckt werden, ob und wie sich das Phänomen des verkehrsinduzierten Wartens innerhalb der Etablierung der Eisenbahn als unangefochtenes Massenverkehrsmittel und der Etablierung von Bahnhofsbauten zu Kathedralen der Mobilität bis zum Ende des 19. Jahrhunderts bezüglich routinierterer Praktiken, veränderter Formalität und räumlichen Settings gegenüber seinen Ursprüngen veränderte. Schließlich bildet der sich parallel zur Etablierung der großen Staatsbahnen (Deutsche Reichsbahn-Gesellschaft ab 1920, SNCF in Frankreich ab 1937, >Big Four-Zusammenschluss in England seit 1923) abzeichnende Aufstieg alternativer Verkehrsmittel, der allmähliche Bedeutungsrückgang der Eisenbahnen und der Festigung der Betriebsführung bis zur Mitte des 20. Jahrhunderts eine dritte Kontextbedingung, die Modifikationen der Erfahrung und Verhandlung des Wartens bewirkt haben könnten. Zusammen kann somit der gewählte Betrachtungszeitraum mit den drei Kernphasen des Aufstiegs, der Konsolidierung und des einsetzenden Bedeutungsverlustes des Eisenbahnwesens umrissen werden.

\subsubsection{Vorläufertechnologien auf dem Weg zur Eisenschiene}

In technikgeschichtlicher Hinsicht stellt sich die Entwicklung der Eisenbahnen in die jahrtausendealte Traditionslinie des Straßenbaus, der spätestens seit Entstehung der ersten Hochkulturen im Nahen Osten darauf abzielte, die Oberfläche von Straßen möglichst der horizontalen Linie anzugleichen, um Energieersparnisse beim durch permanente Reibungsverluste gekennzeichneten Bewegen von Gütern und Personen zu er- 
zielen. Zwar bewirkte die Innovation, Lasten nicht mehr gleitend, sondern mithilfe von Rädern rollend zu transportieren bereits eine deutliche Effizienzsteigerung, ${ }^{3}$ doch besonders die Kombination des Transports schwerer Güter über lange Distanzen und in bergreichen Regionen stellte eine anthropologische Kernproblematik des Transportwesens dar, da die Energiequelle zum Transport jenseits der menschlichen Muskelkraft auch im Einsatz tierischer Muskelkraft seine natürlichen Grenzen fand.

Die wirkungsreichsten Versuche eines optimierten Straßenbaus gehen auf das Römische Reich zurück. Auf einer Vielzahl römischer Handelsstraßen (Pompeji, Brennerpass, Fernpass) sind spezielle Gleisstraßen gefunden worden, die den Reibungswiderstand der Fuhrwerke deutlich minimieren konnten. Zwar verfügte bereits auch das antike Griechenland über Straßen mit solchen ausgemeißelten Radrillen in konstanter Spurweite, doch die Etablierung gleisähnlicher Straßen geht erst auf die Zeit des Ausbaus des römischen Straßensystems zurück. ${ }^{4}$ Auch wenn im Einzelfall mancherorts ungeklärt bleibt, ob die Vertiefungen in der Straßenoberfläche im Vorfeld intentional ausgehöhlt wurden oder mancherorts vielmehr als »Gebrauchsrillen $\aleph^{5}$ das seingeschriebene< Resultat der Verkehrsbewegungen selbst waren, verdeutlichen die gesicherten Fälle eine long-durée-Tradition der zivilisatorischen Anstrengungen zur Reibungsminimierung, die den modernen Überlegungen zum Aufbau von Eisenbahnen bereits weit vorausgingen.

Das englische Bergbauwesen des 18. Jahrhunderts markierte den für die hiesige Betrachtung entscheidenden Wendepunkt der traditionellen Beschränkungen des Transportwesens. Hier erfolgte erstmals das Zusammenwirken dreier Innovationen: einerseits einer neuartigen Form des Antriebs auf Basis von Dampfkraft, die es Wagen ermöglichte, einen für die Menschheitsgeschichte disruptiven »Prozeß der Emanzipation der modernen Produktionsweise von den Schranken der organischen Natur ${ }^{6}$ einzuleiten. Zum anderen die Nutzung von Spurkranzrädern, die im Zusammenwirken ein Rad-Schiene-System erzeugten. Drittens schließlich die Nutzung der Dampfkraft für die Umwandlung thermischer Energie in mechanische Energie und damit in Bewegungsprozesse. Diese Bewegungsprozesse wurden zunächst noch exklusiv für die Wasserhaltung, dem im Bergbau obligatorischen Abpumpen von Wasser aus tiefliegenden Schächten, eingesetzt, allmählich aber auch für das zuvor von Pferdekraft verrichtete Bewegen von Grubenwagen auf einer glatten Oberfläche aus Holzschienen. Diese glatte Oberfläche gewährleistete es nunmehr, dank eines relativ kleinen Reibungswiderstandes schwere Lasten mit relativ geringem Kraftaufwand zu bewegen, was insbesondere eine Anwendung im Bergbau begünstigte.

Die ältesten bislang gefundenen Darstellungen von Rädern gehen auf das sumerische Reich (um 3500 v. Chr.) zurück. Einen in jüngerer Zeit erschienenen Überblick zur (Technik-)Ceschichte des Rades gibt Norbert Oberschmidt, Das Rad: eine bewegte Geschichte (Heidelberg: Verlag Regionalkultur, 2015).

$5 \quad$ Heinrich Bulle, »Celeisestraßen des Altertums«, Sitzungsberichte der bayerischen Akademie der Wissenschaften, Nr. Heft 2 (1947), 8. 
Während solche Gruben- und Riegelbahnen ${ }^{7}$ innerhalb des Berges überwiegend noch auf Holzschienen fuhren, wurden die außerhalb der Bergwerke liegenden Streckenabschnitte zu umliegenden Orten und Seehäfen an besonders belasteten Stellen seit Mitte des 17. Jahrhunderts zunehmend mit schmiedeeisernen Abschnitten verstärkt. ${ }^{8}$ Fuhrwerke auf dieser entstehenden >Eisenspur< wurden zunächst noch von tierischer oder menschlicher Kraft bewegt, bald darauf jedoch wurden Dampfmaschinen - zunächst statisch montierte und durch Seilzüge mit den Wagen verbundene, dann zunehmend als mobile Versionen (Lokomotiven) installierte Dampfmaschinen auf Bergwerkszügen selbst eingesetzt.

Im Jahr 1712 demonstrierte Newcomen eine erste funktionsfähige Anwendung einer Dampfmaschine, die in der Folge entscheidend von Watt $(1769,1784)$, Trevithick und Evans ( $a b$ 1800) in puncto Leistung und Rohstoffeffizienz weiterentwickelt und zunehmend in der gewerblichen Industrieproduktion, in Dampfschiffen und bald darauf in Dampflokomotiven eingesetzt wurde. Trevithick präsentierte 1804 eine erste in einem Walisischen Bergwerk auf Schienen fahrende, von Dampfkraft angetriebene Lokomotive, doch der eigentliche Beginn des Eisenbahnzeitalters und damit der sich anbahnende disruptive Moment einer umfassenden »Mechanisierung der Triebkräfte « ${ }^{9}$ sollte noch einige Jahrzehnte in Anspruch nehmen. Problematisch erschien im Einsatz der Dampfkraft auf Schienen zunächst, dass die Reibung von glatten Rädern auf glatten Oberflächen als nicht ausreichend kohäsionsfähig und dadurch als unsicher (insbesondere bei Kurvenfahrten, Steigungen und großen Lasten) betrachtet wurde und erst Wege gefunden werden mussten, wie sich die Bewegungsenergie sicher auf der Schiene entfalten ließ. Der englische Ingenieur George Stephenson, der in Fachkreisen des 19. Jahrhunderts angesichts seiner Rolle eines Hauptbegründers des Eisenbahnwesens nicht selten als »einer der größten Männer aller Zeiten ${ }^{10}$ verehrt wurde, stellte im Zusammenhang mit der mehr als ein Jahrzehnt ungelöst gebliebenen Reibungsproblematik ab 1814 vermehrt Versuche auf Kohlebahnen bei Newcastle auf. Ziel dieser Versuche war es, durch Dampfkraft angetriebene Wagen auch auf glatten, harten und eisernen Oberflächen fahren zu lassen. Entgegen der zu jener Zeit in Fachkreisen verbreiteten Überzeugung, dass die Haftungskraft der Räder auf den Gleisen noch weiter erhöht werden müsse, konnte Stephenson zeigen, dass die Haftungskraft glatter Räder sogar für den Transport schwerer Güter genügte. Stephensons Nachweis schuf den Beginn des bis heute im Wesentlichen angewendeten Prinzips der Eisenbahntechnik und markierte damit eine entscheidende technische Voraussetzung zur wirtschaftlichen und gesellschaftlichen Durchdringung der Eisenbahnen.

Auf Holzbohlen gelagerte Bahnen wurden bereits im 16. Jahrhundert in deutschen Bergwerken eingesetzt.

8 Eine partielle > Eisenspur « wurde erstmals im Jahr 1767 in den Kohlewerken von Coalbrookedale verlegt, eine durchgängige 1776 in den Kohlewerken von Sheffield. Solche eisernen Beschläge auf Holzbohlen wurden erstmals als > railroads، bezeichnet.

10 Max Maria von Weber, Schule des Eisenbahnwesens: Ceschichte, Technik, Administration und Statistik der Eisenbahnen, Dritte, vermehrte Auflage, neu bearbeitet von Eduard Schmitt (Leipzig: Verlagsbuchhandlung von J. J. Weber, 1873a), $16 f$. 


\subsubsection{Anfänge des Personenverkehrs}

Als erste explizit auch für den Personenverkehr freigegebene Bahnstrecke gilt die 1825 zwischen den nordostenglischen Städten Stockton und Darlington fertiggestellte Verbindung, die eine Länge von 38 englischen Meilen (ca. 18 Kilometer) erreichte und die erste in England »unter allgemeinen Gesichtspunkten «" ${ }^{11}$ gebaute, also auch für den Transport von Personen bestimmte, Strecke des Eisenbahnwesens darstellte. Mit der Eröffnung 1825 vergingen nach Präsentation der ersten Dampflokomotive zunächst also noch mehr als 20 Jahre, um die Dampftechnologie für Verkehrszwecke auch außerhalb des Bergbauwesens zu erschließen. Ein wesentlicher Grund für die anfangs zögerliche Funktionalisierung im Rahmen des Personenverkehrs kann damit begründet werden, dass die mit der Dampfmaschine im Bergbau generierten Zugbewegungen von Wagen zunächst nur sehr kleine Geschwindigkeiten erzeugten und daher der dampfbetriebene Personentransport - trotz der potentiellen Zweckmäßigkeit - anfangs gar nicht in Erwägung gezogen wurde. Vielmehr galt vor diesem Hintergrund das englische Postverkehrssystem der stage coaches ${ }^{12}$ noch lange Zeit als das vergleichsweise schnellere Transportmittel. So beschränkte sich das früheste Eisenbahnwesen vor 1830 im Resultat noch fast überwiegend auf den Transport von schweren Gütern wie Steinen, Kohlen oder Holz. ${ }^{13}$

Auf der nunmehr 1825 eröffneten Strecke wurden Personen und Güterwagen teils mit Pferdekraft und teils mit einer Dampflokomotive bewegt. Am 27. September 1825 setzte George Stephenson auf dieser Strecke mit der von ihm benannten >Experiment< erstmals eine Dampflokomotive ein, die 500 auf Kohlewagen platzierte Personen transportierte und als Initialzündung der Erschließung der Eisenbahn für den Personenverkehr gelten kann. Das Experiment mit der >Experiment « glückte und diese mit einer Geschwindigkeit von sechs englischen Meilen in der Stunde absolvierte Pionierfahrt gilt damit als erste Personenbeförderung des Eisenbahnwesens. Sie zeigte in technischer Hinsicht die Lösung der Haftungsproblematik auf, ließ erstmals das Geschwindigkeitsmonopol der Postkutschen einbüßen und eröffnete schließlich einen fulminanten epo-

11 Karl Hartmann, Praktisches Handbuch über die Anlage von Eisenbahnen, ihre Kosten, Unterhaltung und ihren Ertrag, über die Anfertigung und Prüfung guß-und stabeiserner Schienen, und die Einrichtung der Dampf-und anderen Eisenbahnwagen: nebst anhangsweisen Betrachtungen über die Anwendung der Dampfwagen auf gewöhnlichen Kunst-Straßen (Augsburg: Jenisch- und Stage'sche Buchhandlung, 1837), 18.

12 Das englische Postkutschenwesen des späten 18. Jahrhunderts wird bereits als Transportrevolution bezeichnet, da Reisezeiten zwischen 1750 und 1830 um bis $80 \%$ reduziert wurden, sich die Anzahl der Unternehmen vervielfachte und sich die Anzahl der Reisenden in diesem Zeitraum verfünfzehnfachte. Vgl. Philip Bagwell, The transport revolution 1770-1985 (London: Routledge, 2002), $42 \mathrm{ff}$.

13 Wichtige Ausnahmen stellen hierbei jedoch zwischen 1820 und 1830 gebaute, von Pferden betriebene, interregionale Eisenbahnstrecken dar, die unter Nutzung des etablierten und effizienten Rad-Schiene-Systems bereits Transportdienstleistungen für den Personenverkehr verrichteten, so etwa auf der 1827 teileröffneten Strecke Budweis - Linz (128km). Diese Bahnen nutzten demnach bereits die Eisenbahninfrastruktur, repräsentierten durch die Nutzung rein tierischer Antriebskraft jedoch noch die vormoderne Verkehrswelt und bildeten damit eine hybride Übergangsphase zwischen vormodernem und modernem Verkehrswesen. 
chalen Wettbewerb, der in der Frage gipfelte, »ob fernerhin Lebenskraft oder Dampf den Menschen von Ort zu Ort fördern sollte. $\aleph^{14}$

Abbildung 6: Sinnbild der durch die Eisenbahn erzeugten Umkehrung des Kräftespiels und der Mechanisierung der Triebkräfte: Schnitt durch einen englischen Luxuspferdewagen.

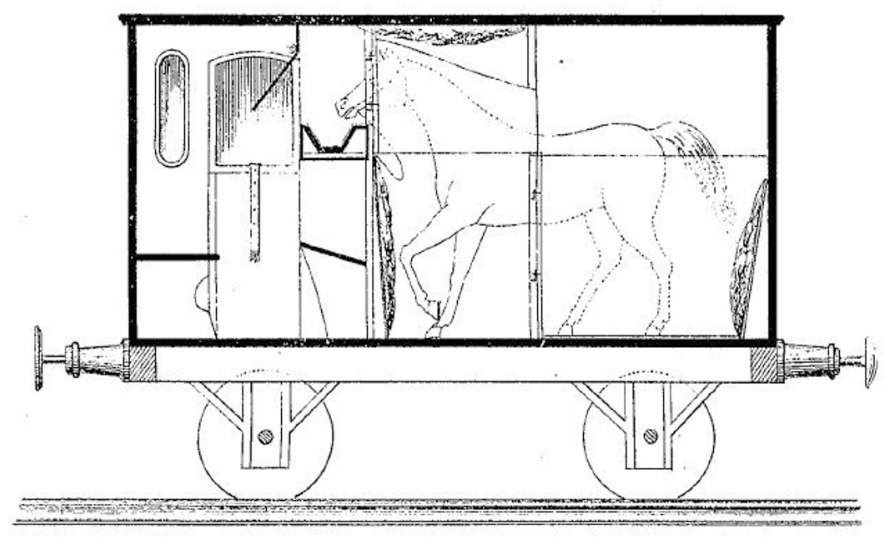

Quelle: Zeitschrift für Bauwesen 1876, S. 529, Blatt 5.

Die pionierhaften Erfahrungen der Strecke Stockton-Darlington dienten als experimentelles Versuchsfeld und stimulierten noch während des Streckenbaus den Bau einer zweiten Linie auf englischem Boden zwischen Manchester und Liverpool, zwei der bedeutendsten Kernzentren der Industrialisierung. Die insbesondere von der Baumwollund Textilindustrie geprägten Städte pflegten weitreichende Handelsbeziehungen über den gesamten Globus. Während Liverpool direkt an der Englischen See gelegen über einen Meereshafen verfügte, hatte Manchester mit dem geografischen Nachteil der Lage im Hinterland zu kämpfen. Beide Städte waren bis zum Bau der Eisenbahnlinien über die Wasserstraße des Mersey River und über Kanäle verbunden, die jedoch witterungsanfällig waren, da sie in der Sommerzeit oftmals zu wenig Wasser führten und im Winter zufroren. Folglich entwickelten die Städte den dringenden Bedarf einer witterungsunabhängigen, ganzjährig nutzbaren Verkehrsverbindung, die insbesondere im Interesse Manchesters als der größeren und gemessen am industriellen Output bedeutenderen Stadt lag. Mit Eröffnung am 16. September 1830 gilt diese knapp 50 Kilometer lange Strecke zwischen Liverpool und Manchester aufgrund der erstmals ausschließlich durch Lokomotiven angetriebenen, nach regelmäßigem Fahrplantakt verkehrenden

14 Max Maria von Weber, »Einleitung«, in Handbuch für Specielle Eisenbahn-Technik, hg. von Edmund Heusinger von Waldegg, Dritte, verbesserte Auflage, Bd. 1: Der Eisenbahnhochbau (Leipzig: Wilhelm Engelmann, 1873b), 8. 
Züge und einem gegenüber >Stockton-Darlington` fest umrissenen Dienstleistungsangebot für Reisende als die weltweit erste Personenverkehrsstrecke. ${ }^{15}$

Auf Grundlage einer 1826 durch das britische Parlament (Railway Act) vergebenen Konzession war es der Liverpool \& Manchester Railway Company (L\&M) als erster Gesellschaft überhaupt nach Recht und Gesetz ermöglicht worden, einen Eisenbahnbetrieb zu etablieren. Die auf der neuen Bahn erreichten Geschwindigkeiten mit vollbesetzten Wagen lagen anfangs bei ca. $30 \mathrm{~km} / \mathrm{h},{ }^{16}$ was trotz eines aus heutiger Sicht relativ geringen Geschwindigkeitsniveaus einer drastischen Verkürzung der Reisezeit um zweieinhalb Stunden gegenüber der Fahrt mit dem damals schnellsten Verkehrsmittel, den stage coaches, entsprach. Die Reisezeit zwischen Manchester und Liverpool wurde mit Eröffnung der Strecke somit von ca. vier Stunden auf anderthalb Stunden reduziert. ${ }^{17}$ Die erwähnte anfängliche Zurückhaltung der Nutzung mechanisierter Triebkräfte für den Personentransport wurde mit dem Betrieb dieser durch Tunnel, Brücken und Einschnitte der horizontalen Linie angeglichenen Strecke und der damit vermiedenen Steigungen zugunsten einer öffentlichkeitswirksamen Entdeckung der Geschwindigkeit aufgegeben.

Die Popularität des neuen Verkehrsmittels war immens. Zehntausende Zuschauer verfolgten am Streckenrand die Jungfernfahrt im September 1830 und bereits am Ende der ersten Woche nach Eröffnung der Strecke wurden mehr als 6.000 Fahrgäste gezählt. ${ }^{18}$ Die quantitativen Niederschläge der technologischen Innovation stellten alle bis dahin erlebten Kategorien der Raumüberwindung in den Schatten. Die mit der Eisenbahn demonstrierte verkehrsgeschichtliche Zäsur lag demnach im doppelten Sinne nicht allein im Umstand, dass Personen und Güter deutlich schneller (und komfortabler) als je zuvor, sondern zugleich in wesentlich größerer Kapazität transportiert werden konnten. Während vor der Eröffnung der Eisenbahnstrecke täglich 29 zwischen den Städten verkehrende Kutschen täglich ca. 600 Personen beförderten, wurden nach Eröffnung der Bahn täglich durchschnittlich ca. 1400 Reisende befördert. ${ }^{19}$ Die rasante Entwicklung der Fahrgastzahlen und der erlebte Geschwindigkeitszuwachs legten neue Maßstäbe. Tradierte Relationen von Nähe und Ferne begannen - wenn auch vorerst nur von einem Bruchteil der Bevölkerung erfahrbar realisiert - schlagartig zu erodieren. In materieller Gestalt der dampfbetriebenen Eisenbahnen zwischen Manchester und Liverpool wurde die Verkehrsbewegung damit in historisch einmaliger Weise breitenwirksam »aus ihrer organischen Bindung gelöst. « $^{20}$

Aufgrund ihres einschneidenden Erfolges erfuhr die Bahnstrecke schon während der dreijährigen Bauzeit 1827-30 ein immenses internationales Fachinteresse und wur-

15 Vgl. Ralf Roth, Das Jahrhundert der Eisenbahn: die Herrschaft über Raum und Zeit 1800-1914 (Ostfildern: Thorbecke, 2005), 33.

16 Stephensons >Rocket--Lokomotive erreichte ohne angekoppelte Wagenmasse beim Lokomotivwettlauf von Rainhill 1829, der der Streckeneröffnung Liverpool-Manchester vorausging, sogar bereits eine Höchstgeschwindigkeit von $55 \mathrm{~km} / \mathrm{h}$.

17 »From Liverpool to Manchester in 1830«, zugegriffen 21. August 2020, www.historyhome.co.uk/readings/smiles.htm.

18 Simon Garfield, The last journey of William Huskisson: how a day of triumph became a day of despair at the turn of the wheel (London: Faber, 2002), 188.

19 Hartmann, Praktisches Handbuch über die Anlage von Eisenbahnen, 9.

20 Schivelbusch, Geschichte der Eisenbahnreise, 15. 
de bald zum Referenzmodell der weltweiten Eisenbahnentwicklung. Ingenieure, Politiker und Geschäftsleute aus den USA, Kanada, Deutschland, Frankreich, Belgien und vielen anderen Nationen pilgerten in Scharen nach England, um die neue Technologie im praktischen Einsatz zu erleben und die Vorzüge des Transportmittels in Augenschein zu nehmen. ${ }^{21}$ Bürgerlich-liberale Vordenker des Eisenbahnwesens, die mit einer Vielzahl von Denkschriften bereits vor oder unmittelbar nach den englischen Pionierfahrten von 1825/30 den theoretisch-konzeptionellen Nährboden zur Implementierung der Eisenbahnen bereiteten - darunter im deutschen Kontext etwa Joseph von Baader ${ }^{22}$, Friedrich Harkort ${ }^{23}$ oder Friedrich List ${ }^{24}$ - sahen mit Eröffnung dieser Strecke(n) einen Meilenstein der von ihnen vertretenen visionären Heilsversprechen verwirklicht.

Mit Eröffnung eines Teilstücks der Dampfeisenbahnstrecke zwischen Lyon und St. Étienne im Jahr 1828 erfolgte nur wenig später die Ankunft der Dampfeisenbahn auf dem europäischen Festland. Ihr ging bereits die Eröffnung von überregionalen Bahnstrecken (Linz-Budweis, 1827-1832) voraus, auf denen jedoch ausschließlich von Pferden gezogene Wagen eingesetzt wurden. Belgien zeigte sich hierbei im Hinblick auf die Implementierung der neuen (englischen) Technologie am offensten und schuf innerhalb nur weniger Jahre ein staatlich finanziertes, dampfgetriebenes Eisenbahnnetz und wurde zum frühen Vorreiter eines nationalen Eisenbahnsystems, das im Ergebnis schließlich gar eine höhere Netzdichte als in England erzeugte. ${ }^{25}$ Im weiteren Verlauf der 1830er Jahre erfolgten zahlreiche Streckenöffnungen in Nordamerika (Baltimore 1830) und auf dem europäischen Festland. ${ }^{26}$ Getrieben durch die Wechselwirkungen wachsender Passagierzahlen, günstiger Preise für den Hauptenergieträger Kohle, technischer Verbesserungen und nicht zuletzt der durch lukrative Renditen forcierten priva-

21 Vgl. Meeks, The Railroad Station: An Architectural History, xiii.

22 Joseph von Baader plädierte bereits ein Jahr nach Eröffnung der Strecke Stockton-Darlington dafür, dass Eisenbahnen es verdienen, »als eine der nützlichsten Erfindungen die höchste Aufmerksamkeit aller kultivirten Staaten und Völker in Anspruch zu nehmen. "Joseph von Baader, Ueber die Vortheile einer verbesserten Bauart von Eisenbahnen und Wagen (München: E.A. Fleischmann, 1826), 3. Harkort propagierte bereits 1825 in seiner selbst gegründeten Zeitschrift den Bau von Eisenbahnen in den deutschen Staaten zum Zwecke des schnelleren und günstigeren Warenverkehrs zu verfolgen. Der Pathos jener Phase der dem Eisenbahnzeitalter vorausgehenden Denkschriften geht exemplarisch etwa aus folgender seiner Ausrufe hervor: »Möge auch im Vaterlande bald die Zeit kommen, wo der Triumphwagen des Cewerbfleißes mit rauchenden Kolossen bespannt ist, und Gemeinsinn die Wege bahnen!«Friedrich Harkort, „Eisenbahnen (Railroads)«, Hermann. Zeitschrift von und für Westphalen, die Lande zwischen Weser und Maas, Nr. 26 (März 1825).

24 List prägte mit seinen Schriften über die wirtschaftlichen Vorteile von Fernbahnstrecken wie kaum ein anderer den Ausbau des deutschen Eisenbahnwesens. Durch seinen Aufenthalt in Amerika waren Lists Vorstellungen dabei stark vom Prinzip eines möglichst ökonomischen Verkehrswesens geprägt. Vgl. Friedrich List, Ueber ein sächsisches Eisenbahn-System als Crundlage eines allgemeinen deutschen Eisenbahn-Systems und insbesondere über die Anlegung einer Eisenbahn von Leipzig nach Dresden (Leipzig: Liebeskind, 1833).

25 Williams, Our Iron Roads: Their History, Construction, and Administration, 487.

26 Fast zeitgleich mit der Eröffnung Liverpool-Manchester wurde 1830 die erste Strecke zwischen Baltimore und Ellicot Mills in den USA eröffnet. 1834 wurde mit London-Birmingham die zweite englische Fernbahnstrecke eröffnet. 1835 eröffnete die mit sechs Kilometern Länge erste Strecke auf deutschem Boden zwischen Nürnberg und Fürth. 1837 erfolgten Streckenöffnungen in Russland, Australien, in Österreich und auf Kuba. Seit 1839 verfügte auch Italien über eine erste Bahnstrecke zwischen Neapel und Portici. 
ten Bautätigkeit, ${ }^{27}$ wuchs das Streckennetz der Eisenbahnen, insbesondere in England, innerhalb weniger Jahrzehnte rapide an. 1840 umfasste die Länge des von 76 privaten Gesellschaften betriebenen britischen Eisenbahnnetzes bereits $3500 \mathrm{~km}$, das deutsche dagegen erst $548 \mathrm{~km}$. Die sich überschlagende Spekulationstätigkeit mit Aktien privater Eisenbahnunternehmen prägte zeitgenössische Begriffe der "railway mania und des »Eisenbahnfiebers « und erzeugte binnen kurzer Zeit einen überhitzten Verkehrsmarkt, der aber letztlich trotz seiner ökonomischen Volatilität und Krisenhaftigkeit einen beispiellosen Bauboom und schließlich eine Expansion der Netze bewirkte. Während England die Frühphase des Eisenbahnwesens durch technologische, wirtschaftsstrukturelle und förderpolitische Rahmenbedingungen - aber auch begünstigt durch eine hohe Technikakzeptanz der Bevölkerung ${ }^{28}$ - deutlich dominierte, ${ }^{29}$ holten insbesondere die USA, Deutschland und Frankreich seit den 1850er Jahren zunehmend auf und entwickelten großdimensionierte nationale Eisenbahnnetze. Ab 1850 wurden zugleich auch Bestrebungen für den Ausbau eines kontinentalen Netzes verfolgt, was vielerorts - jedoch mit Ausnahme bspw. Russlands - die notwendige Vereinheitlichung der Spurweiten nach sich zog.

Bis ca. 1860 waren alle großen Städte Deutschlands durch Hauptverbindungslinien miteinander verbunden. Seiner spezifischen politischen Geografie geschuldet, wurde das deutsche Eisenbahnwesen bis zur Gründung des Deutschen Reiches 1871 vorwiegend in zwei große Gruppen geteilt. Zum einen im Norden in eine preußische Gruppe bestehend aus einem Gemenge privater und staatlicher Bahnen sowie einiger Kleinstaatennetze. Zum anderen in eine süddeutsche Gruppe bestehend aus vier Mittelstaaten, die allesamt Staatsbahnkomplexe aufwiesen. Zwar wurde die politische Fragmentierung überwiegend als hinderliche Bedingung zur Integration des deutschen Eisenbahnwesens betrachtet, doch einige Stimmen sahen genau in diesem Umstand einen Grund der deutschen Aufholjagd in Bezug auf die Industrialisierung. So vermutete ein Autor in einem 1879 erschienenen Aufsatz mit Rückblick auf die divergierenden nationalen Entwicklungslinien des staatlich vorangetriebenen Eisenbahnwesens:

27 Die >ungeduldige`Atmosphäre einer mit Beginn des Eisenbahn-Baubooms genährten Verheißung auf schnelle Profite wird durch einen symptomatischen Satz in einem der zu jener Zeit wichtigsten Organe des Bauwesens widergespiegelt: »]eder Theilnehmer an einem industriellen Unternehmen hat zu seinem nächsten Zwecke einen sicheren und baldigen Gewinn. Er säet, um schnell zu ernten. Sein Leben ist kurz, er eilt es zu genießen. «Auguste Perdonnet, »Von dem Nutzen der Eisenbahnen.«, Allgemeine Bauzeitung 1, Nr. 48 (1836): 400.

28 Aus kontinentaleuropäischer Sicht wurden die für die Entwicklung des Eisenbahnwesens »nationalen Eigenschaften seiner Bewohner«immer wieder als ein Faktor (neben vielen anderen) ins Feld geführt, die England zum Mutterland des Eisenbahnwesens beförderten. Zu diesen besonderen nationalen Eigenschaften zählte etwa aus Sicht von Max Maria von Weber insbesondere das »Interesse der Engländer an der Schnelligkeit in jeder Form. « Verein für Eisenbahnkunde zu Berlin. Protocoll der Versammlung vom 11. Februar 1879«, Zeitschrift für Bauwesen XXIX. (1879): 463. Einen gewichtigen Crund der englischen Dominanz sieht Schivelbusch in den in England fast unendlichen Kohlevorkommen: »Auf dieser Realität [...] und diesem Bewußtsein basiert die Leichtigkeit, fast möchte man sagen Naturwüchsigkeit, mit der in England die Mechanisierung der Triebkräfte vollzogen wird.«Schivelbusch, Geschichte der Eisenbahnreise, 13. 
»Unter dieser geographischen Configuration sieht die Welt das, in seinen Consequenzen ungemein lehrreiche, noch nicht dagewesene Schauspiel des Concurrenzkampfes zwischen unbegrenzt zahlungsfähigen Gegnern sich entwickeln. Staat ringt hier mit Staat, wie sonst Bahn mit Bahn, mit dem Unterschiede, daß hier der Kampf nicht durch den Bankerott des einen Gegners enden kann. ${ }^{30}$

\subsubsection{Statistische Befunde zur Verkehrsentwicklung}

War die Anfangsphase des Eisenbahnwesens klar von den baulichen, technischen und verkehrlichen Entwicklungen Englands dominiert, änderten sich zum Ende des 19. Jahrhunderts insbesondere die Größenverhältnisse der nationalen Bautätigkeit. Mit knapp 40.000 Kilometern besaß das Deutsche Reich im Jahr 1885 die europaweit größte Streckenlänge vor England, Frankreich, Russland und Österreich-Ungarn. Bis 1901 umfasste das Streckennetz weltweit ca. 800.000 Kilometer, davon 300.000 in Europa und allein 51.000 in Deutschland. ${ }^{31}$

Abbildung 7: Entwicklungen des Personenverkehrs in Deutschland (kumuliert aus Daten der preußisch-hessischen Staatseisenbahnen, Elsaß-Lothringer, Bayerischer, Sächsischer, Württembergischer und Badischer Staatseisenbahnen, eigene Darstellung).

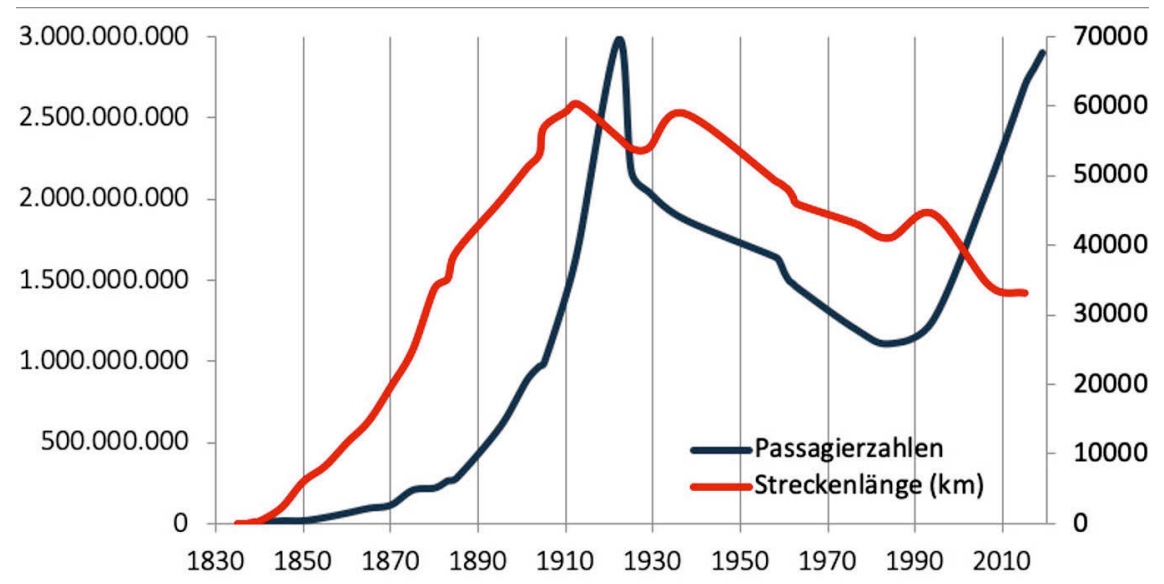

Quellen: Geschäftsberichte der Deutschen Reichsbahn, Deutschen Bundesbahn und Deutschen Bahn.

Abbildung 7 zeigt zudem die Entwicklung der Passagierzahlen in Deutschland, die trotz einiger Stagnations- und Rückgangsphasen in der historischen Betrachtung ein Bild der massiven Verkehrszunahme zeichnet. Während die Ludwigsbahn zwischen

30 »Verein für Eisenbahnkunde zu Berlin. Protocoll der Versammlung vom 11. Februar 1879«, 465.

31 Meyers Großes Konversations-Lexikon, 6. Aufl., Bd. 5 (Leipzig und Wien: Bibliographisches Institut, 1903), 500. 
Nürnberg und Fürth schon im ersten Betriebsjahr 1835/36 eine gegenüber dem Postkutschenwesen berauschende Anzahl von 449.399 Passagieren registrierte, ${ }^{32}$ wurden im Verkehrsjahr 1859 allein in Preußen bereits ca. 20 Millionen Fahrgäste gezählt. ${ }^{33}$ 1868, kurz vor Gründung des Deutschen Reiches wurden im Deutschen Bund fast 87 Millionen Fahrgäste gezählt ${ }^{34}$ und im Verkehrsjahr 1906 wurde erstmals die Marke von einer Milliarde Reisenden durchbrochen. Das Verkehrsjahr 1922 schließlich stellte die bis heute unübertroffene Passagierzahl von knapp drei Milliarden Passagieren auf den Bahnen des deutschen Reiches und damit den Höhepunkt der gesellschaftlichen Bedeutung der Eisenbahnen dar. Die Erfahrung der Ortsveränderung, ob erzwungen durch Pendlerwege, Migration und Kriege oder aber aus touristischen Motiven, avancierte spätestens zum Ende des 19. Jahrhunderts zu einer Massenerfahrung und damit zu einer Grunderfahrung der Moderne.

Abbildung 8: Bahnkarte Deutschlands und angrenzender Länder (1899).

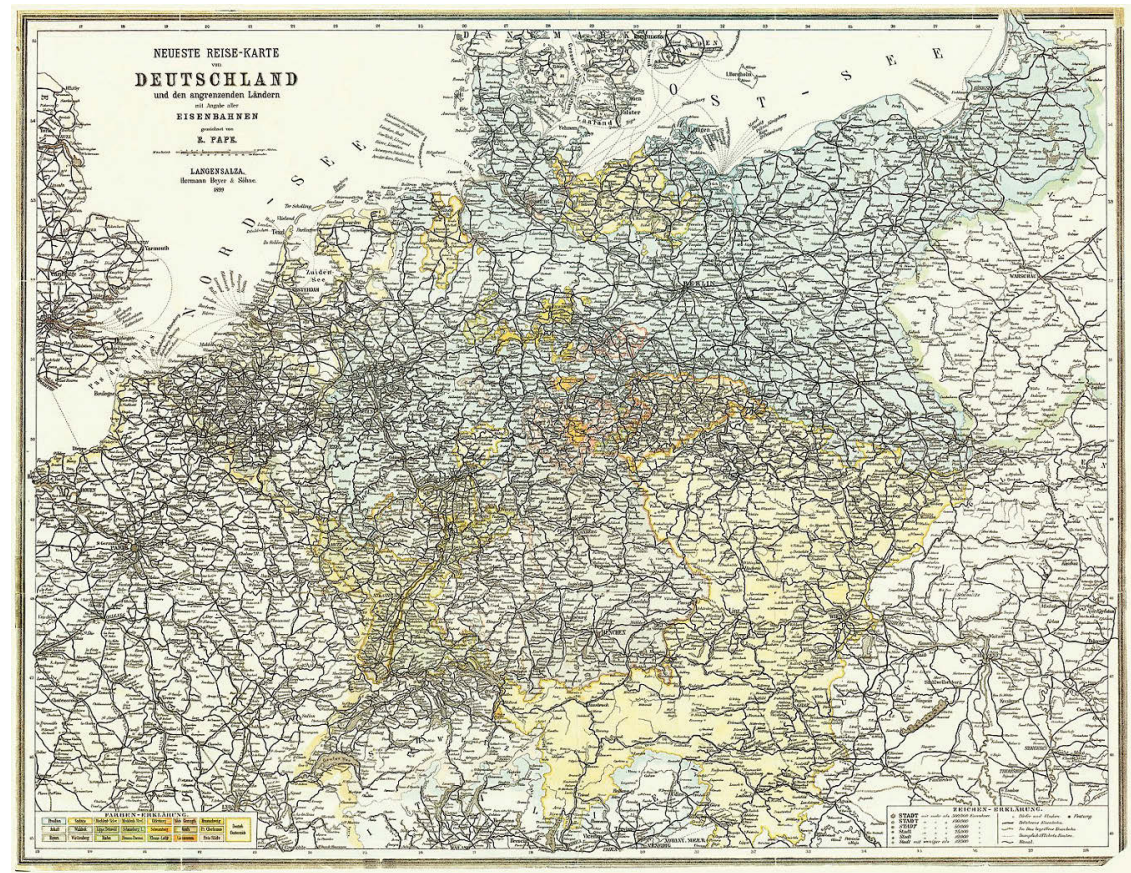

Quelle: Karten- und Luftbildstelle der DB Mainz.

32 Johannes Scharrer, Deutschlands erste Eisenbahn mit Dampfkraft oder Verhandlungen der LudwigsEisenbahn-Cesellschaft in Nürnberg (Nürnberg: Riegel und Wießner, 1837), 10.

33 »Verein für Eisenbahnkunde zu Berlin. Protocoll vom 8. Januar und vom 12. Februar 1861«, Zeitschrift für Bauwesen XI. (1861): 541.

34 von Weber, Schule des Eisenbahnwesens: Geschichte, Technik, Administration und Statistik der Eisenbahnen, 45 . 
Um das rapide Verkehrswachstum bis zum Ende des 19. Jahrhunderts noch etwas stärker zu verdeutlichen und eine Vorstellung der gesellschaftlichen Durchdringung des Eisenbahnwesens zu erzeugen, seien hier nur stellvertretend die Beispiele der verkehrlichen Entwicklungsdaten von Berlin und London aufgeführt. Die Summe der an allen Berliner Bahnhöfen angekommenen und abgefahrenen Reisenden betrug 1853 etwas mehr als 1,4 Millionen Reisende bei einer Einwohnerzahl von knapp mehr als 400.000 . Zehn Jahre später (1863) wurden bei ca. 600.000 Einwohnern bereits 2,9 Millionen Reisende registriert. Nochmalig zehn Jahre später (1873), und damit in den politischen Kontext der Reichsgründung und in den verkehrspolitischen Kontext diverser Streckenneubauten fallend, wurden bei einer Einwohnerzahl von ca. 900.000 bereits mehr als 9,2 Millionen Reisende registriert, was innerhalb eines Jahrzehnts die Verdreifachung des Personenverkehrsvolumens darstellt. Während 1853 die Zahl der Reisenden dem Vierfachen der Einwohnerzahl entsprach, passierten 1873 bereits zehn Mal mehr Reisende als Einwohner die Bahnhöfe der (neuen) deutschen Hauptstadt. ${ }^{35}$ Noch größere Wachstumsraten konnte hingegen London aufweisen. Die Metropolitan-Bahn zählte 1866 noch etwas mehr als 21 Millionen Reisende, 1874 jedoch bereits 70 Millionen, was einer 19-fachen Menge der damaligen Einwohnerzahlen von ca. vier Millionen Menschen entsprach. ${ }^{36}$ Exemplarisch kann mit Blick auf diese beiden metropolitanen Beispiele aufgezeigt werden, dass das Wachstum des Personenverkehrs auf Eisenbahnen in direktem Zusammenhang mit dem korrespondierenden Urbanisierungsprozess stand bzw. die Frequenz der Verkehrsanlässe mit Zunahme der Einwohnerzahl rasant anwuchs.

Für den hier beabsichtigten Zweck einer zunächst grundlegenden Kontextualisierung kann also festgehalten werden, dass die Eisenbahn im deutschen Raum spätestens seit den 1870er Jahren zum Massenphänomen wurde. Indem das Streckennetz immer mehr Anschlüsse generierte, die Fahrpreise der unteren Wagenklassen staatlich gesteuert und für größere Bevölkerungsgruppen zugänglich gemacht wurden und die Verkehrsanlässe in Wechselwirkung mit einer sich rasch diversifizierenden Wirtschaftsund Sozialstruktur zunahmen, zeigte die Entwicklung der Passagierzahlen im Laufe des 19. Jahrhunderts ein zuweilen exponentielles Wachstums auf. Beginnend mit dem Impuls der Reichsgründung 1871 entfaltete sich bis in die 1920er Jahre hinein eine Verkehrsepoche, die angesichts des Passagieranstiegs auf fast drei Milliarden Fahrgäste und der entsprechenden gesellschaftlichen Durchdringung folglich als das goldene Zeitalter der Eisenbahnen bezeichnet wird.

\subsubsection{Wirtschaftsfaktor und Widerstandsobjekt}

Die Rolle der Eisenbahn für die Entwicklung des 19. Jahrhunderts wurde zumeist besonders deutlich in ihrer Rolle als treibender Wirtschaftsfaktor akzentuiert. Das Gros wirtschaftsgeschichtlicher Forschung betont dabei das enge Wechselverhältnis zwischen Ei-

»Verein für Eisenbahnkunde zu Berlin. Protocoll der Versammlungen am 13. October und 10. November 1874.«, Zeitschrift für Bauwesen XXV. (1875): 282. 
senbahn und Industrialisierung. Mit prominenter Ausnahme der These Robert Fogels, nach der die Industrialisierung der US-amerikanischen Wirtschaft im 19. Jahrhundert nicht vorwiegend auf den Bau der Eisenbahnen zurückgeführt werden könne, sondern vielmehr auf einem breiteren Spektrum von Innovationen und ökonomischen Prozessen basierte, ${ }^{37}$ wurde dem Eisenbahnsektor mehrheitlich - insbesondere durch dessen rückwärtige Verkettungseffekte bzw. Rückwärtsverknüpfungen (backward linkages) die Bedeutung des "most powerful single intitiator of take-offs $\aleph^{38}$ zugesprochen. Vertreter der ssingle-intiator-These argumentieren, dass etwa der Neubau von Strecken und Lokomotiven einen deutlichen Aufschwung der Wirtschaftszweige von Montanund Maschinenbauindustrie bewirkte, deren schwere Güter wiederum auf einer sich ständig ausweitenden und verbessernden Infrastruktur leichter und günstiger transportiert werden konnten. Dies führte wiederum zur allgemeinen Verbilligung der Waren und damit zur Nachfrageerhöhung bzw. zu rückwärtigen Wachstumsimpulsen in anderen Wirtschaftszweigen. ${ }^{39}$ Die Eisenbahnen bildeten demnach für eine Vielzahl von Nationen (England, Deutschland, Frankreich, die USA und Russland) den schwerindustriellen Leitsektor schlechthin, der nicht allein dadurch bestimmt wurde, dass er zu einem der beschäftigungsintensivsten Wirtschaftszweige wuchs, sondern zudem vor allem hohe Kapitalnettoinvestitionen in sich binden konnte. Fremdling sieht bspw. die Modernisierung der deutschen Eisenindustrie und zu geringerem Maße auch des Ingenieurwesens als direkte Auswirkung der Eisenbahnen. Gemessen am Kriterium des Anteils am Kapitalstock der Gesamtwirtschaft konnte zwischen 1840 und 1880 kein moderner Wirtschaftssektor mehr Kapital akkumulieren als die Eisenbahnen. Auch unter dem Kriterium der Beschäftigtenzahlen zeigte sich die Dominanz des Eisenbahnsektors. Bereits in den frühen 1840er Jahren überstieg die Anzahl der Beschäftigten im Eisenbahnbau die Anzahl der Beschäftigten im Steinkohlenbergbau. ${ }^{40}$ Darüber hinaus wurden der Grad der Produktivitätsfortschritte und das hohe Maß der Generierung von Vorwärtskopplungseffekten als entscheidende Kriterien der Herausbildung zum wirtschaftlichen Führungssektor identifiziert. Entgegen der generalisierenden These Fogels, den Eisenbahnbau in seiner Relevanz für Industrialisierungsprozesse nicht $\mathrm{zu}$ hoch zu bewerten, sieht Fremdling den Eisenbahnsektor daher insbesondere mit Blick auf den deutschen Industrialisierungskontext als den unangefochtenen Leitsektor, der nicht zuletzt Rezessionsphasen der Gründerkrise in den 1870er Jahren und die damit

Robert Fogel, Railroads and American Economic Growth: Essays in Econometric History (Baltimore: Johns Hopkins Press, 1964).

38 Walt W. Rostow, The Process of Economic Growth (New York: Norton Library, 1962), 302f.

39 Die Verbesserung der Infrastruktur und die resultierende Verbilligung des Warentransports stimulierte zudem eine erhöhte Exportorientierung der Eisenindustrie. Seit 1860 führten die Wechselwirkungen zwischen der durch den Eisenbahnausbau generierten Nachfrage nach Eisenprodukten und der durch die Eisenbahnen generierten Transportvereinfachungen zu einem deutlichen Exportüberschuss von Eisenprodukten. Vgl. Rainer Fremdling, »Railroads and Cerman Economic Growth: A Leading Sector Analysis with a Comparison to the United States and Great Britain«, The Journal of Economic History 37, Nr. 3 (1977): 531.

40 Vgl. Rainer Fremdling, Eisenbahnen und deutsches Wirtschaftswachstum, 1840-1879: ein Beitrag zur Entwicklungstheorie und zur Theorie der Infrastruktur, Bd. 2 (Dortmund: Cesellschaft für Westfälische Wirtschaftsgeschichte, 1975), 23. 
verbundenen Arbeitsplatzverluste zu einem gewissen Teil kompensieren konnte. ${ }^{41}$ Der Eisenbahnbau wird ferner zusammenfassend zum einen als entscheidender Stimulus zur Adaption moderner englischer Technologieprodukte und zum anderen als Feld der Verdrängung englischer Kohle durch deutsche Kohleförderung eingestuft. ${ }^{42}$ Ein Verständnis der industriellen Revolution in Deutschland ist damit ohne diese beiden eng mit der Eisenbahn verbundenen Prozesse schlichtweg undenkbar. Auch bereits zeitgenössische Beobachter des Eisenbahnbooms wie Werner Sombart betonten die Sonderstellung der Eisenbahnen. So glorifizierte Sombart den Eisenbahnbau als riesenhafte Erscheinung und als »die - mit Abstand - größte produktive Leistung (...), die die Menschheit bisher vollbracht hat. ${ }^{43}$

Bau und Betrieb von Eisenbahnen und die Industrialisierung standen dabei jedoch nicht in einem monokausalen Verhältnis, sondern befruchteten sich wechselseitig. Während die Dampfmaschine im industriellen Produktionsprozess eine gesteigerte Zahl von Gütern erzielte, sorgte ihr Einsatz auf Eisenbahnen für die erleichterte Zirkulation der erzeugten Güter. Diese beiden Elemente - Produktion und Zirkulation wirkten direkt als auch indirekt zusammen und schufen damit den kulturgeschichtlichen Evolutionsschritt einer »Neukomposition der kapitalistischen Welt auf der Grundlage des modernen Verkehrs «. ${ }^{44}$ Die durch Zirkulation der Eisenbahnen ermöglichten Prozesse des Austauschs schufen das Rückgrat gesellschaftlicher Stratifikation, Diversifizierung und damit letztlich die Voraussetzung des Funktionierens immer komplexerer moderner Gesellschaften. "Die Eisenbahnen«, so resümiert Roth ihre immense Bedeutung, »setzten nicht nur vorwärtstreibende Wechselwirkungen zwischen Wirtschaft und Transportgewerbe in Gang, sie beförderten auch den Auf- und Ausbau von Kommunikationsnetzen, die die Informationsübertragung in Wirtschaft, Politik und Alltag revolutionierten. $\ll^{45}$

Stärkster räumlicher Ausdruck dieses Wechselverhältnisses von Industrialisierung und Eisenbahnen ist neben den physischen Infrastrukturnetzen das Phänomen der Urbanisierung bzw. des rapiden Städtewachstums von Orten, die an die Eisenbahn angebunden wurden. Reulecke betont in diesem Zusammenhang, dass die Eisenbahnen das Städtewachstum in mehrfacher Hinsicht prägten. Zum einen wurden durch den seit Mitte der 1840er Jahre zunehmenden Bau von Lokomotiven und Waggons aus deutscher Produktion (Importsubstitution englischer Fabrikate) neue Fabrikanlagen und ganze Industrieviertel errichtet. Zum anderen wurde durch den Umstand, dass jene neuen Strukturen oftmals in Residenzstädten errichtet wurden, die lokale Wirtschaftsstruktur deutlich von der vormaligen Abhängigkeit eines Großteils der Bevölkerung vom Hof in die Richtung neuer Fabrikarbeitsplätze verschoben. Der durch die Eisenbahnen beförderte Prozess der wechselseitigen Stimulation von Phänomenen zeigt sich hierbei insbesondere in den durch die Eisenbahnen ausgelösten Wanderungsbewegungen. Die Eisenbahnen bewirkten nicht nur die Stadterweiterung und die Diversifizierung der

41 Vgl. Fremdling, »Railroads and Cerman Economic Growth«, $585 f$.

42 Vgl. Fremdling, Eisenbahnen und deutsches Wirtschaftswachstum, 1840-1879, 3.

43 Werner Sombart, Der moderne Kapitalismus, Bd. 3: Das Wirtschaftsleben im Zeitalter des Hochkapitalismus (München und Leipzig: Duncker \& Humblot, 1927), 289.

44 Schivelbusch, Geschichte der Eisenbahnreise, 171.

45 Roth, Das Jahrhundert der Eisenbahn: die Herrschaft über Raum und Zeit 1800-1914, 67. 
Wirtschaftsstrukturen, sondern unterstützten ihrerseits überhaupt erst die erleichterten Wanderungsströme der Landbevölkerung in die Städte, in denen dann die eisenbahnbezogenen Arbeitsplätze bekleidet wurden. So lässt sich neben der wirtschaftsgeschichtlichen Perspektive schließlich auch aus Sicht der Stadtgeschichtsforschung kontextualisierend festhalten, »daß die Bedeutung des Eisenbahnbaus nicht nur für die deutsche Industrialisierung, sondern auch für die deutsche Urbanisierung nicht hoch genug eingeschätzt werden kann. ${ }^{46}$

Zwar suggerieren die Impulse für Wirtschaft und Stadtwachstum sowie die skizzierten quantitativen Passagierdaten eine mitunter exponentielle Bedeutungszunahme des Eisenbahnverkehrs, doch dieser Prozess fand keineswegs in linearer Form statt. Vielmehr wechselten sich im 19. Jahrhundert immer wieder Phasen der starken Verkehrszunahme (nach 1870) und des Streckenausbaus mit Phasen der Stagnation oder gar des Rückgangs der Passagierzahlen (etwa 1850-1860) ab. Nicht nur im deutschen Kontext bewirkten politische Umwälzungen (bspw. der Vormärz 1848 oder der Deutsche Krieg 1866), die Entstehung kollektiver Angstmomente nach verheerenden Unfällen (etwa der Unfall zwischen Paris und Versailles 1842 oder der Einsturz der Eisenbahnbrücke über den Firth-of-Tay 1879$)^{47}$ sowie mit dem Platzen von Spekulationsphasen einsetzende wirtschaftliche Rezessionsphasen (z.B. Gründerkrise) eine temporäre Bremsung des insgesamt unstrittigen Wachstumstrends. Politische Spannungen und kriegerische Auseinandersetzungen führten somit zu zwischenzeitlichen Rückgängen der Verkehrsnachfrage sowie zur Beschädigung und Zerstörung der Verkehrsinfrastruktur.

Innerhalb der Entwicklung zum vorherrschenden Massenverkehrsmittel war dabei insbesondere die Frühphase des Eisenbahnwesens (1825-1850) von zahlreichen Unwegsamkeiten geprägt. Mit Blick auf England etwa lässt sich festhalten, dass die Entwicklungen der Pionierphase von ständigen technischen (fehlende Leistungsfähigkeit und Zuverlässigkeit der Lokomotiven oder Gleisanlagen), finanziellen (hoher Kapitalaufwand ohne historische Vorerfahrungen, harte Wettbewerbskämpfe) oder genehmigungsrechtlichen Problemen (Enteignungen, Gebietsverletzungen) geprägt war, die den Wachstumstrend des Eisenbahnverkehrs immer wieder punktuell zurückwarfen.

Gegen die irrtümliche Annahme eines streng linearen Verkehrswachstums ist zudem festzuhalten, dass der Aufstieg des Eisenbahnwesens seit seinem Beginn von zahlreichen politischen, wirtschaftlichen und kulturellen Widerständen flankiert wurde. Noch vor Eröffnung der ersten für den Personenverkehr freigegebenen Strecke zwischen Stockton und Darlington 1825 wurde der Streckenbau durch angrenzende Landbesitzer und Fuhrunternehmer vehement behindert und sabotiert. Der Ingenieur Stephenson wurde gar mit Steinen beworfen und körperlich bedroht. Bei weitem nicht alle gesellschaftlichen Gruppen waren der neuen Verkehrstechnologie gegenüber aufge-

46 Jürgen Reulecke, Geschichte der Urbanisierung in Deutschland (Frankfurt a.M.: Suhrkamp, 1985), $30 \mathrm{f}$. Für eine exemplarische Betrachtung der bereits in der Frühphase der Eisenbahn evozierten Urbanisierungseffekte im Nordosten Englands: Williams, Our Iron Roads: Their History, Construction, and Administration, $499 \mathrm{f}$. 
schlossen, sondern viele befürchteten den Verlust bestehender Privat- und Wirtschaftsinteressen oder etablierter Privilegien.

Für den deutschen Kontext wurde geheimhin keine einheitliche Kritikergruppe oder geschlossene Opposition identifiziert, vielmehr stammten die Stimmen gegen den Eisenbahnbau aus ganz unterschiedlichen Lebens- und Sozialbereichen, die mitunter sehr verschiedene Gründe gegen den Eisenbahnbau vorbrachten. ${ }^{48}$ Abstrahiert lassen sich jedoch zwei zentrale Widerstandsgruppen benennen, die sich besonders im Zeitraum zwischen 1830 und 1850 formierten. Auf der einen Seite die traditionell orientierte Landbevölkerung und auf der anderen Seite sich in Anhängerschaft der literarischen Romantik formierenden Eliten und Intellektuellen. Während die erste Gruppe ihre Ablehnung der Eisenbahnen aus der Angst vor unerklärlichen und bisweilen dämonischen Kräften speisten, die im Anblick der feuerspeienden Dampflokomotive entstanden, beklagte die zweite Widerstandsgruppe die Eingriffstiefe der technischen Überformung in die Natur sowie die positivistische Haltung der Technikoptimisten, die Raumwiderstände der Natur nunmehr beherrschen zu können. ${ }^{49}$ Diese zweite Gruppe fand in der deutschen Poesie eine starke Plattform der Kritikäußerung. Hier wurde mit den Mitteln der Dichtung teils - wie sich später noch zeigen wird - drastisch gegen den vermuteten Zwang des beschleunigten Daseins und einer allgemeinen Rastlosigkeit der Welt argumentiert. ${ }^{50}$

Prominente Eisenbahnkritiker waren aber auch im Mutterland der Industrialisierung und der Eisenbahnen zu finden. Thomas Carlyle, John Ruskin oder Matthew Arnold gehörten zu den wichtigsten (technikkritischen) Stimmen des Jahrhunderts, das Carlyle 1829 vor dem Hintergrund der ersten Streckeneröffnung zwischen Stockton und Darlington bzw. der fast fertiggestellten Strecke zwischen Manchester und Liverpool vorausschauend als »Mechanical Age« bzw. »Age of Machinery « ${ }^{51}$ bezeichnete. Carlyles zentrale Kritik bestand in der Anklage der zur Mitte des 19. Jahrhunderts registrierten gesellschaftlichen Durchdringung des >mechanischen Prinzips`, das zuvorderst durch die Dampfkraft ausgebildet wurde. Die mechanische Bewegung, ihre »Gleichförmigkeit, Regelmäßigkeit, beliebige Dauer und Steigerung (Unermüdlichkeit) « ${ }^{52}$ schienen für Carlyle nicht nur im Verkehrswesen, sondern auch in Erziehung, Religion oder im menschlichen Zusammenleben das >dynamische Prinzip « der großen historischen Ideen (Christentum, Französische Revolution) abzulösen. Dieses mechanische Prinzip, das auch die Schrumpfung der Distanz einschloss, sei jedoch der menschlichen Natur nicht angemessen. ${ }^{53}$ Ruskin dagegen prangerte in seinen vielgelesenen Schriften aus geschichtsphilosophischer und kunsthistorischer Perspektive die faktischen und psychologischen Begleiterscheinungen der Eisenbahnreise - insbesondere die Entfrem-

\footnotetext{
48 Vgl. Roth, Das Jahrhundert der Eisenbahn: die Herrschaft über Raum und Zeit 1800-1914, 50.

49 Vgl. ebd.

50 Vgl. Johannes Mahr, Eisenbahnen in der deutschen Dichtung (München: W. Fink, 1982), $57 \mathrm{ff}$.

51 Thomas Carlyle, The Works, hg. von H.D. Traill, Bd. 27 (New York: AMS Press, 1974), 59.

52 Schivelbusch, Geschichte der Eisenbahnreise, 15.

53 Vgl. Alfred Christoph Heinimann, Technische Innovation und literarische Aneignung: die Eisenbahn in der deutschen und englischen Literatur des 19. Jahrhunderts (Bern: Francke, 1992), $155 f$.
} 
dung, Entmündigung und erlebte Monotonie des zu Erwartenden - an. ${ }^{54}$ Als dritter maßgeblicher Kulturkritiker des 19. Jahrhunderts gilt Matthew Arnold und dessen im Kontext der Eisenbahn formulierten Vorwurf gegen seine Zeitgenossen, materielle Werte den geistigen und ideellen Werten vorzuziehen. Die Eisenbahn verkörperte für Arnold einen auf die Maschine reduzierten Glauben, einen Materialismus, der sich den ethischen Geboten der Gegenwart verschließen und letztlich zur Anarchie führen würde. ${ }^{55}$ In der Art wie Arnold offen die Gleichsetzung von Fortschrittsdenken, Zahlengläubigkeit und Mobilität - und damit eine Grundüberzeugung der Moderne - angreift, bemerkt der Literaturhistoriker Heinimann, wie aktuell auch heute noch die sich an Technologieinnovationen entzündende Gesellschaftskritik des 19. Jahrhunderts anmutet. $^{56}$

Neben den technikfeindlichen Stimmen des Bildungsbürgertums wendeten sich aber auch nicht zuletzt Teile der Monarchie entschlossen gegen die Eisenbahn. König Wilhelm III. von Preußen etwa konnte sich angesichts der Streckenöffnung zwischen Berlin und Potsdam 1838 »keine große Seligkeit davon versprechen, ein paar Stunden früher in Berlin und Potsdam zu sein. ${ }^{57}$ Ernst August von Hannover stellte sich getrieben vom Willen, das feudale Privileg (des Reisens) exklusiv in den Händen der Aristokraten halten zu wollen, gegen den Bau einer Bahnstrecke in seinem Herrschaftsgebiet indem er offen vermerkt haben soll: »Ich will keine Eisenbahn im Lande [Hannover, R.K.]; ich will nicht, dass jeder Schuster und Schneider so rasch reisen kann, wie ich. ${ }^{58}$

Trotz der prominenten und einflussreichen Kritiker sorgten jedoch die praktischen Erfahrungen der ersten fahrenden Bahnen im Laufe der Frühphase bis 1850 immer stärker dafür, dass die anfänglichen Debatten der möglichen kulturellen und moralischen Konsequenzen zunehmend von den realen Konsequenzen überformt wurden. ${ }^{59}$ Die Nutzerzahlen stiegen schnell in die Millionenhöhe, die Vorteile der leichteren Warenbeschaffung und rückwärtigen Wirtschaftseffekte schufen trotz der Eingriffstiefe in Natur und Siedlungsraum sowie der bedrohlichen Anmutung der neuen Maschinen überzeugende Argumente und führten schließlich seit den 1850er Jahren zunehmend zum Überschreiten der Diskursschwelle zugunsten einer mehrheitlichen Befürwortung der Eisenbahnen.

\subsubsection{Nebeneinander der Verkehrsträger}

Der Siegeszug der Eisenbahnen vermittelt nur allzu leicht den Eindruck einer allumfassenden >Einnahme und der Verdrängung alternativer Verkehrsideen. Doch vielmehr

54 Zwei der besonders eisenbahnkritischen Werke Ruskins: John Ruskin, The Stones of Venice, Bd. 2: The Sea Stories (London: Smith, Elder, and Co., 1853) und John Ruskin, The Seven Lamps of Architecture (New York: John Wiley \& Son, 1866). Von ihnen wird an späterer Stelle (Kap. 7.4.2) noch zu berichten sein.

55 Vgl. Heinimann, Technische Innovation und literarische Aneignung, $163 \mathrm{f}$.

56 Vgl. ebd., 164.

57 Zitiert nach Louis Berger, Der alte Harkort: ein westfälisches Lebens- und Zeitbild (Leipzig: Julius Baedeker, 1891), 234.

58 Zitiert nach Rolf Peter Sieferle, Fortschrittsfeinde? Opposition gegen Technik und Industrie von der Romantik bis zur Gegenwart (München: Beck, 1984), 112.

Vgl. Roth, Das Jahrhundert der Eisenbahn: die Herrschaft über Raum und Zeit 1800-1914, 56. 
herrschte in infrastruktureller Hinsicht bis fast zur Mitte des 19. Jahrhunderts keineswegs Konsens darüber, welchem Verkehrsweg die Zukunft des dampfgetriebenen Verkehrs eigentlich gehören sollte. Mindestens für das erste Jahrzehnt des sich formierenden Eisenbahnzeitalters entbrannte zunächst noch eine Diskussion darüber, ob die Zukunft des dampfgetriebenen Transportwesens den bereits bestehenden Wasserstraßen, den Chausseen oder eher der geführten Schiene gehören sollte. Dampfschiffe auf Kanälen und Flüssen ermöglichten einen zwar vergleichsweise langsamen Transport, aber ermöglichten zugleich den Transport weit größerer Güterkapazitäten als auf der Schiene. Die geringere Geschwindigkeit ließ wiederum den Personenverkehr auf Wasserstraßen als nicht adäquat erscheinen. Wenngleich das Pendel nach gut einer Dekade mehrheitlich zugunsten der Eisenbahnen auf einer separaten Schieneninfrastruktur auszuschlagen begann, stand auch dieses Ergebnis am Ende eines weiteren Aushandlungsprozesses zwischen straßen- oder schienengebundenen Verkehrsräumen. Für den Einsatz von >Dampfmobilen sprach, dass bereits bestehende und für das Postwesen etablierte Chausseen genutzt werden konnten, die zudem flexibler waren und auf den Straßen im Gegensatz zur schienengebundenen Eisenbahn einander ausweichen konnten. Die Eisenbahnen dagegen konnten bei einer gegenüber den Chausseen wesentlich geringeren Reibung höhere Geschwindigkeiten erzielen und gleichzeitig größere Volumina transportieren. Zudem würde der Schnellverkehr (Eisenbahnen) vom gemächlichen Landverkehr auf den Chausseen getrennt werden, was eine Erhöhung der Sicherheit des Verkehrswesens gewährleisten würde. Angesichts dieser Vorteile setzten sich schließlich im Laufe der 1820er und 1830er Jahre die Ideen der Eisenbahnpioniere gegenüber den Ideen der >Dampfmobilisten $<$ durch. ${ }^{60}$

Auch wenn die Eisenbahn zur Mitte des 19. Jahrhunderts immer stärker an Deutungshoheit gewann, bedeutet dies keinesfalls, dass die traditionellen Verkehrsträger für den Güter- und Personentransport reziprok an Bedeutung verloren. Vielmehr ist die Transportrevolution des 19. Jahrhunderts dezidiert als ein Nebeneinander traditioneller und neuer Verkehrsarten zu denken, in dem die absolute Zunahme der Verkehrsleistungen nicht allein von der neuen Verkehrsart der Eisenbahnen geleistet werden konnte. Das Kutschensystem als auch die Dampfschifffahrt, ja selbst die Segelschifffahrt existierten weiter, wenn auch mit relational zur Eisenbahn kleiner werdender Verkehrsleistung. Somit waren mit dem Aufstieg der Eisenbahn keineswegs ausschließlich Substitutionseffekte zu verzeichnen, sondern ebenso Komplementäreffekte verbunden. So bewirkte bspw. die Problematik, dass immer mehr Waren, Rohstoffe und Menschen aus dem Umland überhaupt erst zu den Bahnstrecken gebracht werden mussten, die Gründung zahlreicher Fuhrunternehmen in der zweiten Hälfte des 19. Jahrhunderts.

\subsubsection{Einsatzfelder und Heilsversprechen}

Die primären Einsatzfelder der Eisenbahn lagen seit ihrer Pionierzeit im Güter- und Personenverkehr. Zwar wurde mit der Dampftechnologie anfangs zunächst mehrheitlich vor allem der wirtschaftlichere Transport von Gütern intendiert, doch der Personenverkehr entwickelte sich bald als ähnlich nachfragestarke und damit lukrative 
Einnahmequelle. Im Allgemeinen waren die Schwerpunkte des Einsatzzweckes jedoch stark von ortsspezifischen Variablen abhängig. Während auf einigen Strecken von Beginn an der Güterverkehr dominierte, wurden andere Strecken vorzugsweise mit Personenverkehren bewirtschaftet. Als dritter Einsatzzweck ist das Militär zu nennen, dass mit den Eisenbahnen eine schnellere Verteidigung bzw. eine bessere Logistik und Truppenbewegung verfolgte. Weil die Truppenbewegung traditionell als eine der größten Herausforderungen der Kriegsführung galt, wuchs die Eisenbahn im Laufe des 19. Jahrhunderts zu einem kriegsrelevanten Faktor heran. Im Deutschen Krieg 1866 wurde die Eisenbahn in der Schlacht bei Königgrätz erstmals zur Verlagerung großer Truppenkontingente eingesetzt, was nach Ansicht des Generals Moltke einen wesentlichen Beitrag zum preußischen Sieg gegen den Deutschen Bund unter Führung Österreichs geleistet haben soll und damit der Eisenbahn die neuartige militärische Bedeutung des Verkehrsmittels explizierte.

Neben dem strategischen Vorteil der beschleunigten Truppenmobilität galten die Eisenbahnen aber gleichwohl auch als shumanistischer Fortschritt innerhalb der Kriegsführung, da die Eisenbahn »die Dauer der Kriege von Jahren auf Tage zurückgeführt hat. ${ }^{61}$ Letztlich sogar wurden die Eisenbahnen damit nicht selten als Friedensstifter deklariert, da sie nach Auffassung der bürgerlich-liberalen Eisenbahnlobby sinnlos erscheinen ließen, einen Angriffskrieg zu führen, da deren militärische Nutzung eine ebenso schnelle Verteidigung möglich machen und eine gegenseitige Auskürzung strategischer Vorteile bewirken würde. So würde die Eisenbahn einen Beitrag zum Frieden der Völker leisten können. Wenngleich diese militärpolitischen Handlungsmotivationen evident erscheinen, ist mit Blick auf die frühen Entwicklungen im preußischen Staat deutlich aufgezeigt worden, dass diese Erwägungen jedoch nur eine untergeordnete Rolle beim Zustandekommen neuer Eisenbahnprojekte gespielt haben und sich im Fall des militärischen Interesses vielmehr schwerwiegende Hemmnisse für die Betreibergesellschaften ergaben. ${ }^{62}$

Das zentrale Zukunftsversprechen ging jedoch eindeutig von den wirtschaftlichen Effekten der Eisenbahn aus. Der vereinfachte und verbilligte Transport von Rohstoffen und Gütern aller Art wurde noch vor den ersten fahrenden Bahnen als Katalysator für Handel und Gewerbe und damit als Triebfeder nationaler Prosperität herbeigesehnt. ${ }^{63}$ In den Denkschriften der 1820er und 1830er Jahre wurde dabei auch immer wieder deutlich auf ein daran geknüpftes soziales Erlösungsversprechen verwiesen. List preiste die Eisenbahn als Erlösung der Völker von der »Plage des Krieges, der Theuerung und Hungersnoth, des Nationalhasses und der Arbeitslosigkeit, der Unwissenheit und des Schlendrians. « ${ }^{64}$ Zudem konnten die Eisenbahnen aus Sicht der liberalen Wirtschaftstheoretiker einen Beitrag dazu leisten, eventuelle Engpässe landwirtschaftlicher Gü-

61 »Verein für Eisenbahnkunde zu Berlin. Vortrag zum Stiftungsfest am 8.October 1867«, Zeitschrift für Bauwesen 18, Nr. Heft IV-VII (1868): 332.

62 Dietrich Eichholtz, Junker und Bourgeoisie vor 1848 in der preußischen Eisenbahngeschichte. (Berlin, 1962), 100 ff.

63 Vgl. von Weber, Schule des Eisenbahnwesens: Ceschichte, Technik, Administration und Statistik der Eisenbahnen, 29.

64 Friedrich List, Das deutsche National-Transport-System in volks-und staatswirthschaftlicher Beziehung (Altona und Leipzig: Johann Friedrich Hammerich, 1838), 6. 
ter in der einen Region mit Überschüssen einer anderen Region auszugleichen. Mit Blick auf die Volatilität des frühmodernen Getreidemarktes und die mitunter hohe Besteuerung auf Importgetreide ${ }^{65}$ verursachte eine tradierte, orts- und regionalgebundene Wirtschaftsform nur allzu oft Hungersnöte, die allein aufgrund fehlender Transportkapazitäten nicht verhindert werden konnten. Angesichts der durch die Eisenbahnen bewirkten grenzüberschreitenden Erweiterung wirtschaftlicher Austauschbeziehungen und der regionalen Ausgleichsmöglichkeiten sollten diese Katastrophen aus Sicht der frühen Verfechter des Eisenbahnwesens daher bald der Vergangenheit angehören. Zudem konnte allein schon die Verbilligung der Waren durch erleichterten Transport dafür sorgen, dass sie größere Bevölkerungsschichten mit Waren versorgen und damit Hungersnöten vermindern konnten. ${ }^{66}$ Allein die Ersetzung tierischer Kräfte durch mechanische Kräfte konnte aus Sicht der Eisenbahnverfechter schon einen wichtigen Beitrag zur Sicherung des Nahrungsmittelangebots leisten. So errechnete Adam Smith, dass der Unterhalt eines Pferdes der Menge von Lebensmitteln für acht Arbeiter entsprechen würde. Die Substitution von einer Million zu Transportzwecken eingesetzter Pferde würde damit zusätzliche Lebensmittel für acht Millionen Arbeiter absondern. ${ }^{67}$ Das Heilsversprechen des technischen Fortschritts und der Mechanisierung der Triebkräfte adressierte damit nicht zuletzt auch zutiefst existentielle Primärbedürfnisse.

Neben der Linderung existentieller Problemlagen wurde die Eisenbahn auch zum Heilsbringer der Bildung und der (seelischen) Gesundheit aufgeladen. Der Transport mit Dampfwagen würde demnach nicht nur die Felder der Völker befruchten, sondern zugleich »auch den Niedrigsten unter ihnen Kraft verleihen [...], sich durch den Besuch fremder Länder zu bilden, in entfernten Gegenden Arbeit und an fernen Heilquellen und Seegestaden Wiederherstellung ihrer Gesundheit zu suchen. ${ }^{68}$ Diese frühe Erwartungshaltung der Linderung von Problemlagen durch Mobilitätszuwächse kann nicht nur als ein Vorreiter des Massentourismus interpretiert werden, sondern sie illustriert vielmehr exemplarisch den Geist der Moderne, der durch die enge und bis heute wirksame Wahlverwandtschaft der Epoche mit neuen Transporttechnologien besticht.

Die Hoffnungen der Eisenbahnen umfassten aber insbesondere im deutschen Kontext auch zusätzlich die Adressierung einer potentiellen politischen Kraft, die ebenfalls wesentliche Hauptlinien der Moderne verkörpert. Die allgemeine Aufbruchsstimmung und das Technikvertrauen in die Eisenbahnen markieren wesentliche Charakteristika der Moderne, die bis heute aktuell erscheinen. Im Zuge des Vormärz in den 1830er und 1840er Jahren wurde die Eisenbahn immer häufiger politisch als Besiegelung des Despotismus, überkommener Feudalstrukturen, der Kleinstaaterei und des Partikularismus und so zusammenfassend als Hebel der bürgerlichen Gesellschaft schlechthin instrumentalisiert. ${ }^{69}$ Max Maria von Weber, einer der wichtigsten und wortgewaltigs-

So bewirkte etwa das britische >Corn Law < von 1815, dass durch die Besteuerung von Importgetreide zwar der einheimische Markt geschützt werden konnte, aber zugleich der Getreidepreis deutlich in die Höhe getrieben wurde und damit die nationale Versorgungssicherheit gefährdete.

Vgl. von Weber, Schule des Eisenbahnwesens: Ceschichte, Technik, Administration und Statistik der Eisenbahnen, 29.

67 Vgl. Schivelbusch, Ceschichte der Eisenbahnreise, 12.

68 List, Das deutsche National-Transport-System in volks-und staatswirthschaftlicher Beziehung, 6.

69 Vgl. Roth, Das Jahrhundert der Eisenbahn: die Herrschaft über Raum und Zeit 1800-1914, 42. 
ten Fürsprecher des Eisenbahnwesens in der Aufbruchs- und Etablierungsphase des neuen Verkehrsmittels, fasst das Spektrum kultur- und friedensstiftender Wirkungen der Eisenbahnen in einem flammenden Plädoyer zusammen:

» (...) wenn der Verkehr der Menschheit ein Hauptmittel zur Verbreitung von Humanität und Cultur ist, so haben die Eisenbahnen eine starke Hand zur Anwendung dieses Mittels geliehen. Die große Nähe der blühenden Städte Griechenlands war Ursache der hohen Cultur von Hellas; die Eisenbahnen haben es eben so leicht gemacht, sich vor, London nach Paris oder Rom zu begeben, als es zu den Zeiten des Perikles war, von Athen nach Corinth zu wandern. Ihre Einwirkung vermindert offenbar die Hemmung der trägen Masse des Körpers und gewährt den Geistern freiern Verkehr; die Völker lernen sich kennen, der Nationalhaß nimmt ab, die gegenseitige Achtung steigt, die Privatbeziehungen eines Volkes spinnen sich tiefer in das Leben des andern hinein. Die Kriege verletzen fortan immer mehr und mehr den Sieger mit dem Besiegten, werden daher immer seltener werden; kein Vortheil, welchen Erfindungen und Fortschritte in Wissenschaft und Kunst bieten, bleibt lange Eigenthum eines Volkes und die gleiche Form der Fortbewegung hilft die Unterschiede der Stände ausgleichen. ${ }^{70}$

Ob mit dem Motiv politischer Einigung oder kultureller und gesellschaftlicher Weiterentwicklung, mit den Eisenbahnen wurde demnach übergreifend der Aspekt der verbesserten Raumüberwindung assoziiert. Max Maria von Weber summiert den Zusammenhang von Fortschritt und Raumüberwindung folgendermaßen:»Der Mensch ist ein Wesen, das sich seinen letzten Zwecken nur durch Vergesellschaftung mit Seinesgleichen nähern kann; deshalb begünstigt die Erleichterung des Verkehrs den allgemeinen Fortschritt $\mathrm{zu}$ allermeist. "7 $^{71}$

Zusammenfassend kann mit Blick auf die Frage der Motivationen und Heilserwartungen festgehalten werden, dass den Eisenbahnen kein geringerer als der Status eines »ausgleichende[n] Element[s] und wahrhafte[n] Regulator[s] aller Missverhältnisse, welche die Natur dieser Cultur entgegensetzt $\ll^{72}$ zuteil wurde.

\subsubsection{Treibende Akteure}

Die propagierten Erlösungen durch die Eisenbahn gingen meist vor allem vom liberalen Bürgertum und - bis auf wenige Ausnahmen - anfangs nicht von staatlichen Akteuren aus. Bau und Betrieb der ersten Generation von Bahnstrecken wurde von neugegründeten Eisenbahnkomitees organisiert, die mit Aktionenausschüttungen Kapital für den ressourcenintensiven Streckenbau akkumulierten. Wenn auch viele Pläne nicht in die Tat umgesetzt wurden, so fußte doch die Inbetriebnahme der ersten Strecken in Nürnberg, Wien, Mannheim, Leipzig oder Frankfurt a.M. auf der Gründung solcher privater Komitees, die anschließend zu Eisenbahngesellschaften umgewandelt wurden. Sie

von Weber, Schule des Eisenbahnwesens: Ceschichte, Technik, Administration und Statistik der Eisenbahnen, 28.

von Weber, Schule des Eisenbahnwesens: Ceschichte, Technik, Administration und Statistik der Eisenbahnen, 3 .

»Verein für Eisenbahnkunde zu Berlin. Protocoll vom 8. Januar und vom 12. Februar 1861«, 332. 
bildeten die entscheidenden Organe der bürgerlichen Kräfte, die den Eisenbahnbau jenseits des Staates förderten. Weniger also der Staat, als vielmehr Bürger, Fabrikanten und Kaufleute betrieben somit die frühesten Bahnpläne, die erst als Pferdebahnen ausgeführt und schließlich dampfbetrieben erweitert wurden. ${ }^{73}$ Bis ca. 1850 wurden besonders in Preußen nur sehr vereinzelt Neubaustrecken auf Staatskosten finanziert (Schlesische Bahn ab 1852, Ostbahn von Berlin nach Königsberg ab 1857). Das Gros der Verkehrsleistung erbrachten private Eisenbahnunternehmen, die eigene Fahrzeuge und eine jeweils eigene Betriebsorganisation besaßen.

Während somit zu Beginn des Eisenbahnzeitalters besonders private Unternehmungen den Bau und Betrieb dominierten, weil der Staat mit prominenten Ausnahmen in Belgien oder einzelnen deutschen Teilstaaten (Herzogtum Braunschweig oder süddeutscher Raum) die hohen Investitionen scheute, wurde die Akteurslandschaft insbesondere mit Blick auf Deutschland aber auch in Belgien - im Laufe des 19. Jahrhunderts zunehmend um staatliche Akteure erweitert. Mit der Verstaatlichung einer Vielzahl von Eisenbahnunternehmen seit den späten 1840er Jahren wurde das Eisenbahnverkehrswesen zunehmend zu einer öffentlichen Aufgabe. 1848 waren in Preußen bereits 48 Prozent der Unternehmen verstaatlicht, Neubaustrecken wurden zunehmend rein durch staatliche Investitionen vorangetrieben. Der Bau und Betrieb von Eisenbahnen wurde damit nicht zuletzt ein Feld der mitunter drastischen Auseinandersetzungen zwischen privater und öffentlicher Hand, die teils in langen gerichtlichen Auseinandersetzungen von Strafandrohungen bis hin zu Enteignungen reichten. ${ }^{74}$ Doch auch hier folgten die Entwicklungen auf dem Weg zum Zenit des Eisenbahnzeitalters keinem linearen Verlauf. Vielmehr wechselten sich Phasen der zunehmenden Verstaatlichung (1840-1860) mit wirtschaftsliberalen Phasen des Privatbahnbau oder gar der RePrivatisierung verstaatlichter Linien ab (1860-1880). Zwischen 1880-1888 erfolgte wiederum eine große Verstaatlichungswelle. Im Verkehrsjahr 1888/89 waren bereits 88 Prozent der deutschen Eisenbahngesellschaften in staatlicher Hand.

Als einer der frühesten Befürworter des Staatsbahnwesens erwies sich Joseph von Baader, der im Hinblick auf die für jede Staatsführung zentrale Zielstellung der wirtschaftlichen und gesellschaftlichen Entwicklung die mögliche Zurückhaltung staatlicher Investitionstätigkeit von vornherein versuchte zu unterbinden:

»Celdmangel kann hier nicht als ein unübersteigliches Hinderniss angeführt werden, wo es auf die wohlthätigste Beförderung des Ackerbaues, des Cewerbfleisses, des Handels, des wahren innern Reichthums einer ganzen Nation ankömmt, wo es sich nicht um eine reine Auslage von Millionen auf einen Bau handelt, welcher Nichts einträgt, und von welchem die Zinsen für immer verloren sind, sondern darum: ein bedeutendes Capital zu den gemeinnützigsten Zwecken anzulegen (...). $\ll^{75}$

Vgl. Roth, Das Jahrhundert der Eisenbahn: die Herrschaft über Raum und Zeit 1800-1914, 59ff. 
Auch Friedrich List richtete sich im Zuge seines Entwurfs eines sächsischen Eisenbahnsystems an den Staat und betonte:

»Was sind aber vier Millionen, ja ich frage, was sind sechs und zehn Millionen Aufwand, bei so großen National-Interessen, wo zumal das verwendete Capital so außergewöhnliche Interessen trägt? Je mehr unter solchen Umständen verwendet werden kann, desto besser. ${ }^{76}$

Lists Plädoyer sollte nur partiell gehört werden. Insbesondere in Preußen zeigte sich zunächst eine deutliche Zurückhaltung staatlicher Investitionstätigkeit. ${ }^{77}$ Erst der preußische Handelsminister von der Heydt äußerte 1852 die gewachsene Überzeugung, dass die Eisenbahnen "nur unter der Verwaltung des Staats die Wirksamkeit entfalten können, zu der sie fähig und bestimmt sind $\aleph^{78}$ und begründete damit den Aufstieg des Staates als bis zum Ende des 19. Jahrhunderts letztlich wichtigsten Akteur des Eisenbahnwesens.

Die Verstaatlichung erfolgte aus vielfachen Motivlagen heraus. Zum einen wurde dem Staat durch den privatwirtschaftlichen Betrieb frühzeitig vor Augen geführt, welch lukratives Geschäftsfeld die Eisenbahn aufweisen konnte. Zudem wurde die graduelle Verstaatlichung mit der Erhöhung der Sicherheit begründet. Die Betriebsorganisationen der Privatbahnen wurden zwar frühzeitig durch staatliche Eisenbahngesetze geregelt, doch fehlte es der Fülle an Privatbahnen an interorganisationaler Standardisierung bzw. war diese teils aus protektionistischen Überlegungen nicht gewünscht. Aus Sicht des Staates konnte daher erst eine zentralisierte Betriebsführung eine wirksame Erhöhung der Sicherheit gewährleisten. Zudem sah der Staat in den Eisenbahnen wie erwähnt eine wichtige militärstrategische Funktion. Bahnen und Netze in staatlicher Hand würden die Truppenbewegungen gegenüber der Nutzung privater Bahnen und Netze flexibilisieren und erleichtern. Ferner sollte mit den Initiativen der Verstaatlichung das Spekulationswesen eingedämmt und nicht zuletzt im Sinne einer Sicherung gleichwertiger Lebensbedingungen auch jene Landesteile durch Bahnen erschlossen werden, die aus einer privatwirtschaftlichen Perspektive der bestmöglichen Rentabilität gar nicht erst erschlossen worden wären. Die Nutzung der Überschüsse lukrativer Hauptlinien sollte im Sinne eines staatlich verantworteten Eisenbahnwesens die Subventionierung von Nebenstrecken ermöglichen. ${ }^{79}$

Die Akteursgeschichte der wesentlichen Treiber des Eisenbahnwesens stellt sich somit im Wesentlichen als kontinuierliches Wechselspiel privater Initiativen und staatlicher Interventionen dar, wobei sich bereits in der Frühphase nationale Spezifika hinsichtlich des Gewichtes der einen oder anderen Akteursgruppe herausbildeten. Während das Eisenbahnwesen Englands wie bereits erwähnt überdeutlich von privaten Un-

76 List, Ueber ein sächsisches Eisenbahn-System, 23.

77 Staatliche Investitionen beschränkten sich in der Frühphase des preußischen Eisenbahnwesens auf das Einbringen eines Bruchteils des Aktienkapitals.

78 Schreiben an den preußischen Ministerpräsidenten Freiherr von Manteuffel vom 4. Januar 1852. Zitiert in Königlich Preussisches Ministerium für Öffentliche Arbeiten, Berlin und seine Eisenbahnen 1846-1896, Bd. 1 (Berlin: Julius Springer, 1896), 195.

79 Vgl. von Weber, Schule des Eisenbahnwesens: Ceschichte, Technik, Administration und Statistik der Eisenbahnen, $74 f$. 
ternehmen geprägt wurde, bestanden dagegen etwa in Frankreich bereits frühzeitig erhebliche Zweifel des Staates an einer rein privaten Organisation, wodurch in der Konsequenz etwa sämtliche Anlagen des Eisenbahnwesens als Staatsbauten errichtet wurden, die von Ingenieuren stattlicher Schulen realisiert wurden. ${ }^{80}$ Die Akteursgeschichte des deutschen Kontexts schiebt sich in etwa zwischen die polarisierenden Fälle Englands und Frankreichs. Während insbesondere in der Frühphase des deutschen Eisenbahnwesens private Akteure die Entwicklungen vorantrieben, wurden Betrieb, Bau und Verwaltung zur Hochphase des Eisenbahnwesens (1880-1930) wiederum deutlich durch staatliche Interventionen dominiert, wobei auch hier weiterhin private Anbieter neben übermächtigen staatlichen Anbietern koexistierten.

\subsubsection{Verlauf der Technikentwicklung und Betriebsorganisation}

Im Zuge der gigantischen Verkehrszunahmen des 19. Jahrhunderts diversifizierten sich nicht nur die Lokomotiv-Technik, sondern auch die Betriebsanlagen. Personen- und Güterverkehr bzw. Nah- und Fernverkehr wurden zunehmend voneinander getrennt, womit neben den sukzessiv erweiterten Bahnhofsbauten zusätzlich große Güter- und Rangierbahnhöfe entstanden. Neben spektakulären Ingenieursbauten wie Tunneln, Brücken, Eisenbahnfähren, Gebirgspassagen und dem Einsatz von Zahnradbahnen in besonders steilem Gelände wurde mit der Telegrafie seit den 1840er Jahren ein Kommunikationssystem (Zugmeldeverfahren mit längs der Bahnstrecken angeordneten Zeigertelegrafen) etabliert, das eine nochmalige Übertragungsbeschleunigung von Informationen und damit eine Zunahme der Betriebssicherheit gewährleistete. Während die technische Entwicklung der Lokomotiven immer größere Zuggeschwindigkeiten ermöglichte, erhöhten die korrespondierenden Technologien wie die Druckluftbremse, das Signal- und Stellwerkswesen oder die Verbesserung von Wagenkupplungen zunehmend die Betriebssicherheit und damit die Effizienz des Bahnsystems.

Die durch Kohlebrennstoff befeuerte Dampfmaschine repräsentierte zweifelsohne die dominierende Antriebstechnologie des ersten Jahrhunderts der Eisenbahn, doch bereits vor der Wende vom 19. zum 20. Jahrhundert reiften Überlegungen zu alternativen Antriebstechnologien. Seit den 1870er Jahren wurden durch Werner von Siemens erste Versuche zur Elektrifizierung des Bahnbetriebs unternommen, indem Lokomotiven elektrischen Strom über Oberleitungen oder neben den Gleisen installierte Stromschienen aufnahmen. Die City and South London Railway (CSLR) nahm 1890 als erste Strecke den mit Elektrolokomotiven betriebenen U-Bahn-Betrieb auf, die Berliner S-Bahn fuhr testweise ab 1901 elektrisch. Parallel wird 1887 erstmals eine mit einem Verbrennungsmotor betriebene Lokomotive eingesetzt. Bis zur Jahrhundertwende erfolgte damit eine weitreichende Diversifizierung der Antriebssysteme, die wiederum in einer sich ausdifferenzierten Systematik von Schmalspurbahnen, Hochbahnen, Untergrundbahnen, Stadtbahnen und schließlich auch im innerstädtischen Einsatz in Straßenbahnen (1882 erstmals elektrisch in Berlin) realisiert wurden.

Die kontinuierlichen Verbesserungen in der Lokomotivtechnik generierten zudem eine sukzessive Erhöhung der Geschwindigkeitskapazitäten. Waren 1830 noch Durch-

»Verein für Eisenbahnkunde zu Berlin. Protocoll der Versammlung vom 11. Februar 1879«, 464. 
schnittsgeschwindigkeiten von $30 \mathrm{~km} / \mathrm{h}$ erreicht worden, wurden sie bis zur Jahrhundertwende mehr als vervierfacht. 1903 erreichte eine preußische Dampflokomotive eine Geschwindigkeit von bereits $137 \mathrm{~km} / \mathrm{h}$, ein elektrischer Triebwagen auf einer Teststrecke bei Berlin gar eine Geschwindigkeit von $210 \mathrm{~km} / \mathrm{h}$. Wie bereits zur Sprache kam, ist die Realisierung großer Geschwindigkeiten nicht allein als technisches Problem zu betrachten, sondern stellt nicht zuletzt eine organisatorische Herausforderung dar, die überhaupt erst den Rahmen der (sicheren) Gewährleistung bietet. So konnten die erzielten Geschwindigkeitszuwächse überhaupt erst auf Grundlage der korrespondierenden Erhöhung der allgemeinen Betriebssicherheit, der verbesserten Gleisanlagen und eines durchorganisierten Betriebsablaufs erzielt werden.

Mit den seit 1850 durch die Eisenbahntechniker-Versammlung aufgestellten »Grundzügen für die Gestaltung und der Eisenbahnen Deutschlands« und später durch den Verein Deutscher Eisenbahnunternehmen (VDEV) laufend aktualisierten »Technischen Vereinbarungen" wurden Betriebsführung, Betriebsmittel und Konstruktion von Neubaustrecken einem kontinuierlichen Streben nach Standardisierung unterzogen. Ziel des einheitlichen Regelwerks war neben der allgemeinen Erhöhung der Betriebssicherheit insbesondere auch die übergreifende Nutzung von Betriebsmitteln auf fremden Bahnen. ${ }^{81}$

Im Hinblick auf die Entwicklung der Wagenarchitektur und -ausstattung erfolgten die zentralen Schritte über die Einführung des Pullman-Schlafwagens (erstmals 1859 in den USA, ab 1874 auch in Europa eingesetzt), der Einführung von Durchgangswagen (DWagen, ab 1870 in Deutschland) bis hin zu Luxuszügen (»Orient-Express«ab 1883). Die Beleuchtung im Inneren der Wagen erfolgte anfänglich mit Kerzen und Öllampen und wurde über den Zwischenschritt der Ölgasbeleuchtung und der Gasglühbeleuchtung ab dem frühen 20. Jahrhundert elektrisch über Batteriebetrieb hergestellt.

Die technische Weiterentwicklung der Anlagen und Betriebsmittel und die Verkehrszunahme bedingten sich hierbei wechselseitig - analog der skizzierten $\mathrm{Zu}$ sammenhänge von Wirtschaftsentwicklung, Städtewachstum und Zunahme des Eisenbahnverkehrs. Die Verkehrszunahme erforderte zum einen technische und betriebliche Anpassungen in Form von ausgereifteren Technologien oder gesetzlich verankerten und oftmals international gültigen Standardisierungen. Zum anderen katalysierten die technischen und betrieblichen Weiterentwicklungen wiederum die Verkehrskapazität und generierten die Zunahme der Verkehrsnachfrage.

Wie viele Bereiche des Eisenbahnwesens orientierte sich auch das Tarifwesen in der Frühphase an den etablierten Vorgängersystemen des Postkutschen- und Fährwesens. ${ }^{82}$ Zugleich aber belebte die technische Revolution der Eisenbahn eine gänzliche Neuausrichtung des Tarifwesens, etwa in Form nachfragesensitiver oder tageszeitabhängiger

81 So heißt es in einer 1849 den verabschiedeten `Grundzügen< vorausgehenden Schrift des Bauraths Mohn der Königlich-Hannoverschen Staatsbahn, dass die Vorschriften »sich vorzüglich darauf beschränken müssen, die Benutzung aufbenachbarten, unter ähnlichen Terrainverhältnissen liegenden Bahnen möglich zu machen. Zitiert in Königliche Eisenbahndirektion zu Berlin, Festschrift über die Thätigkeit des Vereins Deutscher Eisenbahn-Verwaltungen in den ersten 50 Jahren seines Bestehens, 1846-1896 (Berlin: Nauck, 1896), 46 [Herv. i. O.].

82 Emil Rank, Das Eisenbahntarifwesen in seiner Beziehung zu Volkswirtschaft und Verwaltung (Wien: A. Hölder, 1895). 
Tarifmodelle zur Optimierung der Auslastung oder Stimulanz der Verkehrsnachfrage. ${ }^{83}$ Zudem ermöglichte der Aufbau zentraler Einrichtungen zur Koordination und Schlichtung zwischen verschiedenen Eisenbahnunternehmen, wie etwa das 1842 in England eingeführte Clearing House, erstmals die Verrechnung und Einnahmenaufteilung bei Nutzung unterschiedlicher Bahnunternehmen. ${ }^{84}$ Darüber hinaus kartografierten solche Clearingstellen die bestehenden Netze in thematischen Karten, quantifizierten die Fahrtzeiten und legten wichtige Standardisierungen für den Eisenbahnbetrieb fest. $\mathrm{Zu}$ diesen Standards gehörte insbesondere auch die Einführung einer für alle Orte innerhalb eines überregionalen Netzes verbindlich geltenden »Eisenbahnzeit«, die sich von der »Lokalzeit« der jeweiligen Orte unterschied. Die Lokalzeit eines jeden Ortes resultierte aus seiner relativen Lage zur Sonne. Die Bestimmung der lokalen Zeitrechnung richtete sich nach dem höchsten Sonnenstand, der jedoch je nach Lage auf dem Längengrad zu unterschiedlichen Zeitpunkten erfolgt. Die Zeitdifferenzen betrugen zwar etwa im Großherzogtum Baden lediglich maximal acht Minuten, summierten sich aber in der Entfernung zwischen den exponiertesten Punkten des Geschäftsgebietes des Vereins Deutscher Eisenbahn-Verwaltungen in den 1850er Jahren (zwischen der Grenze Ungarns und Belgiens) auf fast eine ganze Stunde. ${ }^{85}$ Diese Differenzen wirkten äußerst problematisch auf die geregelte Betriebsführung, da die Uhren zwischen Abfahrtsort und Zielbahnhof fortwährend umgestellt werden mussten. Die Standardisierung des eisenbahnbezogenen Zeitwesens wurde folglich zur Grundvoraussetzung eines überregionalen Fahrplanwesens und wurde erstmals mit Einführung der Greenwich Mean Time im Jahr 1847 in England vollzogen. Die Einführung erzeugte einen international wirksamen Prozess der allmählichen Überformung tradierter Zeitbezugssysteme durch das Zeitregime des Eisenbahnbetriebs. Im Laufe des 19. Jahrhunderts erarbeiteten internationale Verbände (bspw. IEV - Internationaler Eisenbahn-Verband, UICUnion Internationale des Chemins des Fer) zum einen wegweisende Übereinkommen, die etwa eine gegenseitige und grenzüberschreitende Nutzung von Personen- und Güterwagen und zum anderen auch die Standardisierung des zeitlichen Bezugsrahmens der Betriebsführung regelten. Zwar gilt die Eisenbahnzeit bis in die 1880er Jahre hinein lediglich als Bezugssystem zur den Bahnverkehr, doch je mehr die Bahnnetz verdichtet und je mehr Räume in den Bahnverkehr einbezogen werden, desto »hoffnungsloser ${ }^{86}$ wird die tradierte Position der Lokalzeit gegenüber der Eisenbahnzeit, denn »ein geregelter Verkehr«, so bemerkt Schivelbusch, »erfordert eine Vereinheitlichung

83 Norman Kellermann, Searching for a Path out of Distance Fares: A Review of Historical Passenger Railway Pricing and an Agent-Based Simulation Study on Possible Fare Amendments (Köln: Kölner Wiss.-Verlag, 2014), $49 f f$.

84 Hierzu insbesondere Philip Bagwell, The railway clearing house in the British economy 1842-1922 (London: Allen \& Unwin, 1968).

85 Königliche Eisenbahndirektion zu Berlin, Festschrift über die Thätigkeit des Vereins Deutscher Eisenbahn-Verwaltungen in den ersten 50 Jahren seines Bestehens, 1846-1896, 352. Auch wenn die Abweichungen zwischen Lokal- und Eisenbahnzeit mitunter nur wenige Minuten betrugen, bewirkten sie aus Sicht der Reisenden, dass Fahrpläne nur mit großen Schwierigkeiten gelesen werden konnten und damit die exakte Einschätzung der Reisezeit nur schwerlich bestimmt werden konnte.

Schivelbusch, Geschichte der Eisenbahnreise, 44. 
der Zeit«. ${ }^{87}$ In der Folge dieses Zeitkonflikts zwischen Lokal- und Eisenbahnzeit etablierte sich ab 1880 die Eisenbahnzeit als temporales Hauptbezugssystem. 1880 wird die Eisenbahnzeit in England zur Standardzeit erklärt. 1893 folgt das Deutsche Reich nach dem Scheitern vorheriger Initiativen aus den $1850 e r$ Jahren ${ }^{88}$ mit der Einführung einer »Zonenzeit« und folgt damit der bereits zuvor 1884 in Washington beschlossenen Einteilung der Welt in ein Zeitzonensystem. Die nunmehr geltende »Zonenzeit« entspricht der Mitteleuropäischen Zeit (MEZ) löst damit die zuvor zehn verschiedenen Zeiten in Deutschland ab.

\subsection{Abschluss der Kontextualisierung}

Angesichts der durch das Eisenbahnwesen ausgelösten Veränderungsdynamiken kann die kulturgeschichtliche Bedeutung der Eisenbahnen wohl kaum groß genug eingeschätzt werden. Ob aus wirtschaftlicher, politischer oder wahrnehmungspsychologischer Betrachtung, das Aufkommen der Eisenbahn muss als eine zivilisationsgeschichtliche Zäsur bzw. als sgame changer eingestuft werden, der die etablierten Regeln des gesellschaftlichen >Spiels` deutlicher veränderte als es die kühnsten und optimistischsten Zeitgenossen des frühen 19. Jahrhunderts wohl je vermutet hätten. Die für Transportzwecke eingesetzte Dampfmaschine legte den technischen Grundstein einer kulturellen Wende der Raumüberwindung, die den Menschen innerhalb weniger Jahrzehnte aus seiner organischen Bindung löste, das Wirtschaftsleben transformierte und eine sich erweiternde Erfahrung und Bemessung von Raum und Zeit begründete. Die Eisenbahn steht damit stellvertretend für einen Übergang in eine nicht zuletzt verkehrlich vermittelte Moderne, die uns bis in die Gegenwart hinein in Gestalt eines fortwährenden Strebens zur Erweiterung der Möglichkeitsräume und in Gestalt eines ausgeprägten Grundbedürfnisses nach Mobilität entgegentritt. Diese parallel mit der Eisenbahn einsetzenden und durch sie mitgetragenen Modernisierungsprozesse erscheinen uns heute als selbstverständlich, doch sie sind vergleichsweise junge Phänomene. Wenngleich sie simplifiziert in den ersten Streckeneröffnungen Englands nicht ihren alleinigen Ursprung genommen haben mögen, so erhalten sie doch hiermit einen entscheidenden Impuls in Richtung der Charakteristik eines >modernen Lebens.

87 Ebd., 43.

88 Bereits 1852 regte der Heidelberger Professor Erb mit einem Antrag an den Verein Deutscher Eisenbahn-Verwaltungen an, eine definierte Normalzeit einzuführen, die »nicht blos [sic!] auf den Dienst der Kommunikationen im Vereinsgebiete beschränkt bleibe, sondern dass derselbe überall auch als allgemeine bürgerlich und gesetzlich allein anerkannte Zeit eingeführt und endlich die Annahme dieser Normalzeit auch in den benachbarten, nicht zum Territorium des Vereins gehörigen Staaten erstrebt werde.« (Königliche Eisenbahndirektion zu Berlin, Festschrift über die Thätigkeit des Vereins Deutscher Eisenbahn-Verwaltungen in den ersten 50 Jahren seines Bestehens, 18461896, 351.)

Erbs Antrag wurde jedoch nach eingängiger Prüfung unter anderem aufgrund seiner zu starken Wirkung auf das alltägliche Leben abgelehnt. Vielmehr galten die kleinen Zeitdifferenzen der im Kontext der in den $1850 e r$ Jahren noch vergleichsweise geringen Verkehrsintensität als eine allgemein tolerierbare Geringfügigkeit. 
Im Ergebnis der selektiven und dem Ziel der allgemeinen Kontextualisierung folgenden Zusammenschau der Entwicklungslinien des ersten Jahrhunderts des Eisenbahnwesens zeigen sich weitreichende und komplexe Folgewirkungen, die sich im $\mathrm{Zu}$ ge der Mechanisierung der Triebkräfte ergaben. Die technische Innovation der Eisenbahn löste auf der einen Seite anthropologische Ur-Probleme (Limitationen menschlicher und tierischer Energieressourcen) und erzeugte zugleich neue kulturethische Fragen und Problemfelder, die von physischen Sicherheitsbedenken über Verschiebungen tradierter makrosozialer Konstellationen bis hin zu psychologischen Wahrnehmungsschocks reichten. ${ }^{89}$ Die sozialen, politischen, wirtschaftlichen und kulturellen Implikationen der Etablierung des Eisenbahnwesens zeigen dabei keine eindimensionale Trajektorie, sondern sind durch wechselseitige Prozessdynamiken, heterogene Akzeptanzlagen und vielfältige, konkurrierende Erwartungshaltungen gekennzeichnet, die sich im Laufe des 19. und frühen 20. Jahrhunderts abschwächten, verstärkten oder immer wieder von anderen Aspekten überlagert oder abgelöst werden konnten.

Als direkte Folgewirkungen des Eisenbahnwesens sollen hiermit festgehalten werden, dass die Einführung der neuen Transporttechnologie eine bis dahin nie erlebte Schrumpfung von Distanzen und einen allgemeinen Mobilitätszuwachs bewirkte, die im Laufe des 19. Jahrhunderts nicht nur eine drastische Zunahme räumlicher Erreichbarkeiten (durch bedeutende Zeitverkürzungen) mit sich brachte, sondern diese Erweiterung der Möglichkeitsräume bei gleichzeitiger Senkung der dafür traditionell erforderlichen Kosten realisierbar wurde. Frederick Williams, ein bekannter EisenbahnPublizist, resümiert im Jahr 1883 im Rahmen eines Rückblicks auf die ersten fünf Jahrzehnte des englischen Eisenbahnwesens die (ökonomische) Bedeutung wie folgt:

»The construction of every mile of every railway—unlike money lavished in war-has at almost every stage enriched somebody, has enriched the nation and the world. Wealth employed on armies and fleets, or squandered in the destruction of life or property, or wasted in the luxuries of despotic rulers, is unproductive. Not so with railways, every pound of which honestly spent, in due time yields a reward. ${ }^{90}$

Bestehende Kommunikationsbeziehungen wurden verstärkt und gänzlich neue geschaffen. Diese Transformationen benötigten insbesondere auf Seiten der Reisenden vielfältige psychologische, kommunikative und organisatorische Anpassungsprozesse und das Erlernen neuer Kulturtechniken, zu denen nicht zuletzt auch das Erwarten der Abfahrt in einem speziell dafür geschaffenen Raumprogramm gehörte.

Als sekundäre Folgewirkungen des Eisenbahnwesens lassen sich unter anderem der Aufbau gänzlich neuer Organisationsprinzipien, die Entwicklung innovativer Preispolitiken, eine veränderte Kriegsführung, sowie eine neue Art des wechselseitigen Zusammenwirkens staatlicher und bürgerlicher Akteure festhalten.

Für all diese Prozesse bildet die Zeit das ordnende und strukturierende Element schlechthin, weswegen die aus Sicht dieser Arbeit entscheidende Folgewirkung der Verbreitung der Eisenbahn in der Nutzung, Etablierung und der Verinnerlichung der mechanisierten Uhrzeit als gesamtgesellschaftliches Ordnungs- und Strukturprinzip ge- 
sehen wird. Natürlich verhilft nicht alleinig die Eisenbahn dieser Verinnerlichung zu ihrem entscheidenden Durchbruch, doch sie trägt mit jeder einzelnen Bereitstellung und Nutzung in Form ihrer durch die Uhrzeit vermittelten Synchronisation von Kundenwünschen und Verkehrsmitteln an Bahnhöfen entscheidend zu dieser Verinnerlichung bei. Das Zusammenspiel der Organisation des Eisenbahnsystems auf Grundlage zeitbasierter Fahrpläne und deren zeitsensitiv informierte Nutzung bewirken eine bislang unerreichte (weil in Dichte und Präzision nicht oder nur selten notwendige) Verinnerlichung der Zeit als Hauptbezugssystem der Synchronisation und Orientierung. Mit anderen Worten: Wenn die Kohle die Hauptenergieressource des neuen Verkehrsmittels darstellt, so muss zugleich das Bezugssystem einer mechanisierten Uhrzeit als komplementärer Rohstoff bzw. als Ressource betrachtet werden, denn nur sie ermöglichten es überhaupt erst eine auf Synchronisierung ausgerichtete Betriebsorganisation $\mathrm{zu}$ etablieren.

In der Folge des Betriebs und ihrer Nutzung befördern die Eisenbahnen seit den 1830er Jahren damit nicht nur Millionen von Menschen und Gütern, sondern zudem ein neues Zeitgefühl, das gleichwohl einem Zwang unterliegt und damit die Zeit - ähnlich wie im wirtschaftlichen Kontext der kapitalistischen Produktionsweise - in den Stand einer kritischen Größe hebt, die entweder zielführend genutzt (rechtzeitiger Zugang zum Verkehrsmittel) oder fälschlich eingesetzt (Verpassen eines Zuges) werden kann. Im Folgenden wird nun mit der erzwungenen Verhandlung von Zeitzwischenräumen in Form des systemischen Wartens eine jener komplexen temporalen Folgewirkungen des Eisenbahnwesens herausgegriffen und in seiner Rolle einer (modernen) Kulturtechnik eingehend untersucht. 



\section{Warten auf Eisenbahnen: Räume und Rezeptionen (1830-1935)}

Der im vorangegangenen Kapitel geschaffene Überblick verdeutlichte, wie sehr die verkehrliche Moderne wahrhaftig im Zeichen einer gegenüber früheren Epochen massiven Beschleunigungszunahme stand. Gleichwohl erscheint sie bei näherer Betrachtung als Epoche der komplementären Produktion und Erfahrung einer Vielzahl situativer Momente des Stillstands, die in engem Verhältnis zur Beschleunigung stehen, ja durch sie überhaupt gar erst als relativer Stillstand hervorgerufen und wahrnehmbar wurden. Der inhärente Zusammenhang einer mit der Beschleunigungserfahrung verbundenen Entdeckung der >Gegenmomente des Wartens könnte dabei wohl nicht treffender illustriert werden, als durch die Ereignisse auf der Jungfernfahrt bei der Streckenöffnung zwischen Liverpool und Manchester am 15. September 1830, die den triumphalen Auftakt in ein neues Zeitalter der revolutionierten Raumüberwindung darstellen sollte. Nicht nur mussten die ca. 600 Passagiere in Liverpool vor Zustieg in die Wagen bereits vor Abfahrt eine (systemische) Wartezeit von ca. 70 Minuten verbringen, um überhaupt beschleunigt transportiert werden zu können, ${ }^{1}$ sondern vielmehr traf der Zug, bedingt durch einen Unfall des britischen Ministers William Huskisson mit Todesfolge, erst mit zweieinhalb Stunden Verspätung im Bahnhof von Manchester ein. ${ }^{2}$ Huskisson wurde nicht nur das erste prominente Todesopfer eines Eisenbahnunfalls, sondern verdeutlichte auf bittere Weise, dass Beschleunigung und Retardierung von Anbeginn des modernen Verkehrswesens auf Engste verwoben waren und die Verkehrsgeschichte des Wartens gar eine im Grunde um zweieinhalb Stunden ältere Geschichte aufweist, als jene der planmäßigen, beschleunigten Ankunft eines modernen Verkehrsmittels.

1 Die L\&M Railway Company bat die Gäste der Jungfernfahrt, sich am 15. September 1830 spätestens um 9:30 Uhr am Bahnhof Liverpool einzufinden. Die Abfahrt fand aber letztlich erst um 10:40 Uhr statt. Vgl. Joseph Kirwan, A Descriptive and Historical Account of the Liverpool and Manchester Railway, From Its First Projection to Present Time (Clasgow and London: M'Phun, Simpkin and Marshall, 1831), $16 \mathrm{f}$.

2 James Scott Walker, An Accurate Description of the Liverpool and Manchester Railway (Liverpool: JF Canneli, 1832), 68. 
Die Moderne, so die leitende These des nun folgenden Hauptteils, steht zurecht im Zeichen einer Entdeckung und Verinnerlichung der Beschleunigung, sie muss jedoch gleichwohl als die Entdeckung und Verinnerlichung des situativen Wartens eine Erweiterung und Reinterpretation erfahren. Diesem Komplementär des modernen Verkehrs gilt es nun mit den folgenden historiografischen Kapiteln im Kontext des Eisenbahnwesens näher auf die Spur zu kommen. In knapper Rekapitulation des im Einführungskapitel geschilderten Vorgehens werden dazu zwei sich wechselseitig beeinflussende Perspektiven als Zugänge gewählt, um das Phänomen in seinem historischen Wandel zu erschließen: zum einen die Aufarbeitung baulich-betrieblicher Verhandlungen des Passagiers aus Sicht von Eisenbahngesellschaften, Architekten, Ingenieuren (Außenperspektive) und zum anderen die konkret aus Sicht der Passagiere erlebten Rezeptionen und Erfahrungen des Wartens an Bahnhöfen (Innenperspektive).

Dabei wird folgende Leitfragestellung das wechselseitige Verhältnis von Betriebsorganisation/Raumprogramm und Wartepraktik bzw. von Außen- und Innenperspektive des Wartens zusammenhalten: Zeichnet sich innerhalb des Betrachtungszeitraums eine qualitative Transformation der Räume des Wartens und der organisatorisch-betrieblichen Gestaltung des Wartens ab, die darüber hinaus Rückschlüsse auf den affektiven Umgang der Reisenden mit diesen Umgebungen und damit auf gesellschaftliche $\mathrm{Zu}$ schreibungen des Phänomens eröffnen? Anders ausgedrückt: Wenn die Synchronisation von Verkehrsmitteln und Reisenden an neuralgischen Verkehrsknotenpunkten im organisatorischen Zwang des Wartens mündete, in welchen räumlichen Settings sollte und wurde dieser neuartige Zwang realisiert bzw. erlebt? Ferner, wurde das Warten als Stiefkind der beschleunigten Moderne von Anbeginn des modernen öffentlichen Verkehrs als problematisch interpretiert?

Der mit dem modernen öffentlichen Verkehr untrennbar verbundene organisatorische Zwang des Wartens vor Abfahrt eines Verkehrsmittels fand im 19. Jahrhundert (wie auch heute) an konkret für diesen interimistischen Zweck definierten Orten statt. Lage, Ausstattung und Anmutung dieser Orte des Wartens wandelten sich im Laufe des Eisenbahnwesens und bildeten damit nicht nur jeweils einen zeitspezifischen Kristallisationspunkt der jeweilig vorherrschenden Betriebsorganisation, sondern, so die leitende Vermutung, nahmen auch Einfluss auf die jeweilige Wahrnehmung der Wartezeit an jenen Orten. Folgendes Kategoriensystem wird dazu als ein Gerüst der bauund rezeptionsgeschichtlichen Erschließung des verkehrlichen Wartens dienen, um das Phänomen im historischen Wandel zu beleuchten:

- Raumangebote und Ausstattungen (der Warteräume selbst, aber auch der umliegenden Serviceinfrastrukturen)

- Stellung des Wartens innerhalb der Gebäudestruktur

- Dauer des Wartens (traditionell wichtigste Einflussgröße für die Wahrnehmung der Wartezeit)

- Formalität des Wartens (Freiheitsgrad bezüglich der Bewegungen auf dem Bahnhof)

- Sozialität des Wartens (Klassentrennungen, Kommunikationsmöglichkeiten).

Der betriebsorganisatorische Umgang mit wartenden Passagieren und deren passende materielle Rahmung bildeten innerhalb der übergeordneten Problemstellung des Baus 
neuer Verkehrsplätze und Knotenpunkte für Reisende nur zwei von vielen Problemen. Entsprechend waren Überlegungen zur Anlage und Gestaltung von Warteräumen auf Engste mit den Überlegungen zur Lösung der Gesamtaufgabe des Bahnhofsbaus und der Betriebsorganisation verwoben und lassen sich demnach nicht getrennt voneinander betrachten. Eine Erschließung der materiellen und konzeptionellen Niederschläge des wartenden Passagiers ist somit unmittelbar in die historische Entwicklung des Bahnhofsbaus als einer der komplexesten und signifikantesten Bauaufgaben der Moderne eingebettet und kann davon nicht losgelöst betrachtet werden. Somit muss sich die Kulturgeschichte des Wartens im spezifischen Kontext des Eisenbahnwesens unter anderem aus dem Verständnis der Bau- und Architekturgeschichte des Bahnhofswesens speisen. Aus dieser heuristischer Vorüberlegung heraus wird für die Analyse des Wandels der räumlichen Dimension des Wartens auf Carroll Meeks' Periodisierungsangebot baulicher Diskursphasen im Bahnhofsbau zurückgegriffen, das zugleich einen chronologischen Rahmen für die Betrachtung der subjektbezogenen Innenperspektive des wartenden Passagiers aufspannt. Der Architekturhistoriker Meeks teilt die entscheidenden Veränderungslinien des internationalen Bahnhofsbaus vom Aufstieg bis zum Höhepunkt des Eisenbahnwesens (im frühen 20. Jahrhundert) in vier Phasen ein:

- Pionier- und Explorationsphase (1830-1845)

- Standardisierung (1850er)

- Kultivierung (1860-1890)

- Megalomanie (1890-1914). ${ }^{3}$

Die Orientierung an jenen übergeordneten Bauphasen ermöglicht einen strukturierten Zugang, um innerhalb der baugeschichtlichen Entwicklung einerseits Veränderungslinien der Orte und Ausstattungen des Wartens und andererseits mögliche erfahrungsund rezeptionsgeschichtliche Niederschläge des Wartens aufzudecken. Allerdings erfolgt für die vorliegende Arbeit eine gegenüber Meeks leicht angepasste Periodisierung, die durch einen erweiterten Kernbetrachtungszeitraum, durch den geografischen Fokus auf das deutsche Eisenbahnwesen und darin spezifischer Meilensteine des Bahnhofsbaus sowie durch den Fokus auf die Veränderungen des spezifisch wartebezogenen Raumprogramms begründet wird. Die vier Phasen des Gesamtbetrachtungszeitraums stellen sich demnach wie folgt dar:

- Pionier- und Explorationsphase (1830-1845)

- Standardisierung und Konsolidierung (1845-1870)

- Blütephase (1870-1900)

- Marginalisierung und moderne Zweckorientierung (1900-1935).

3 Meeks, The Railroad Station: An Architectural History, 29. Meeks führt die Periodisierung mit dem »20th Century Style« (1914-1956) noch bis ins Erscheinungsjahr seines Buches weiter. Da aber im Rahmen dieser Arbeit aus angesprochenen Gründen der Betrachtungszeitraum des ersten Eisenbahnjahrhunderts gewählt wurde, wird diese fünfte Bauperiode im Folgenden nicht im Vordergrund stehen. Meeks Periodisierungsangebot erhielt im Laufe des 20. Jahrhunderts durch eine Reihe von Bestätigungen weitere Glaubwürdigkeit, so etwa durch den Architekturhistoriker Steven Parissien: Bahnhöfe der Welt: eine Architektur-und Kulturgeschichte (München: Knesebeck, 1997), 37. 
Innerhalb dieser Verlaufsphasen bilden die oben genannten Kategorien das zentrale Erkenntnisinteresse und strukturieren das analytische Vorgehen in Form thematischer Betrachtungen (Direktiven, Baudiskurse, Bahnhofsbeispiele). Während dabei für die Analyse der Pionier- und Frühphase (1830-1845) das Vorgehen stärker von einer Beleuchtung konkreter Bahnhofsbeispiele geprägt sein wird, liegt das Vorgehen der späteren Entwicklungsphasen stärker auf der Analyse der baulich-betrieblichen Rahmenentwicklungen des Bahnhofsbaus, die breitere Rückschlüsse auf die allgemeine Entwicklung der Wartezeiterfahrung am Bahnhof ziehen lassen. 


\section{Pionier- und Explorationsphase (1830-1845)}

Bevor Eisenbahnen über Schienen rollten, um Personen und Güter zu transportieren, standen die Architekten und Ingenieure des frühen Eisenbahnwesens zunächst vor einer Phalanx an Herausforderungen. Wie etwa musste der Unterbau einer Trasse beschaffen sein, um das gewaltige Gewicht der Lokomotiven und Wagen sicher und zugleich vergleichsweise schnell auf einer glatten Eisenschiene beschleunigen und jederzeit abbremsen zu können? Durch welche baulichen Maßnahmen (Tunnel, Brücken, Einschnitte) konnte die Streckenführung optimiert werden, um Anstiege oder Umwege $\mathrm{zu}$ vermeiden? Wie konnte mithilfe von Signalen entlang der Strecke eine Kommunikation während der Fahrt erfolgen? Die Errichtungen der ersten rein dampfbetriebenen Eisenbahnlinien in England (1830), den USA (1830) und Kontinentaleuropa (ab 1835) stellten sich somit zunächst vorrangig als technische Herausforderungen dar, die es zwischen den eigentlichen Abfahrts- und Ankunftsorten zu meistern galt. Die primäre Aufgabe bestand zunächst in der Erschließung und Errichtung eines infrastrukturellen Zwischenraums, der Durchmessung und Durchkreuzung des Naturraums mithilfe eines eisernen Schienenweges und komplementärer Technologien. ${ }^{1}$ Entsprechend ist der Blick auf die Bau- und Technikentwicklung der Frühphase des Eisenbahnwesens gemeinhin von erzielten Geschwindigkeiten, verkürzten Reisezeiten und einer damit einsetzenden Schrumpfung des Raumes geprägt. Doch wie im Rahmen dieser Arbeit bereits hinsichtlich der komplexen Relationalität von Beschleunigung und Verlangsamung angeführt wurde, benötigt jede Form der physischen Mobilität, ob individuell oder in kollektiver Form absolviert, Infrastrukturen der Immobilität, die den Bewegungsfluss überhaupt erst physikalisch (Reibung) oder organisatorisch (Abfertigung vieler Reisender mit unterschiedlichen Fahrtwünschen in ein und demselben Verkehrsmittel) ermöglichen. ${ }^{2}$ Obwohl der Fokus insbesondere auf die Funktion der Gewährleistung einer sicht- und spürbaren Fortbewegung fiel, glich die Etablierung eines neuen

Der für die neue Transportart gewählte Terminus `Eisenbahn` und seine entsprechenden Bezeichnungen in den romanischen Sprachen verweisen auf eben jene Zentralität der Schaffung einer eigener, vom bisherigen Straßensystem unabhängigen Infrastruktur, die als seiserne Wege (franz. schemin de fers, ital. sferrovia`) in Erscheinung treten und fortan die begriffliche Fassung der neuen Verkehrstechnologie prägten. 
Wegesystems mit tausenden Kilometern fest verlegter Gleise, unzähligen Brücken oder Telegrafenmasten aus Sicht der Verkehrsunternehmen im Grunde der Schaffung eines gewaltigen Netzwerks immobiler Infrastrukturen, die jene Fluidität überhaupt erst gewährleisten sollten. ${ }^{3} \mathrm{Zu}$ einer der wohl eindrucksvollsten wie wichtigsten immobilen Infrastrukturen der Gewährleistung von Bewegung wurde dabei der Bahnhof in seiner Funktion einer Schleuse und Übergangszone zwischen belebter und technischer Welt.

\subsection{Der Bahnhofsbau zwischen Persistenz und neuheitlicher Bauaufgabe}

Die Frage nach Form der geeigneten Gewährleistung des $\mathrm{Zu-} \mathrm{und} \mathrm{Abgangs} \mathrm{zum} \mathrm{bzw.}$ vom neuen Verkehrssystem der Eisenbahnen stellte für Architekten und Ingenieure eine vollkommen neue Bauaufgabe dar, für die Anfang des 19. Jahrhunderts auf kein fest etabliertes Vorgängermodell zurückgegriffen werden konnte. So betont Carroll Meeks eindrücklich:

»Neither of the two preceding modes of transportation - the canal and the centuryold turnpike system - had developed special buildings for the use of passengers. $\aleph^{4}$

Die einzigen transitorischen, an landgebundene Verkehrsflüsse orientierten Gebäudestrukturen, auf die überhaupt zurückgegriffen werden konnte, waren die rudimentären Einrichtungen von Dampfschifffahrtsgesellschaften ${ }^{5}$ oder Zollhäuser an gebührenpflichtigen Chausseestraßen (turnpikes). Zudem konnten vor allem Wirtshäuser und Posthaltereien als mögliche Schlüsselreferenzen des Bahnhofsbaus gelten, die bereits in vorindustrieller Zeit als Start- und Zielpunkte und damit als die immobilen Infrastrukturen des per Postkutsche absolvierten, öffentlichen Reiseverkehrs dienten. ${ }^{6}$ Dass

Zusätzlich muss auch die Festsetzung regulatorischer Rahmenwerke für den Eisenbahnbetrieb als simmobile` Infrastruktur der Cewährleistung von Bewegung und Fluidität gelten.

4 Meeks, The Railroad Station: An Architectural History, 27. Diese Einschätzung teilten bereits auch jene Zeitgenossen, die den Aufstieg des Eisenbahnwesens selbst miterlebten, wie etwa der einflussreiche deutsche Eisenbahningenieur Eduard Schmitt. Auch er betonte bezüglich der Neuartigkeit der Bauaufgabe >Bahnhof $«$ » Während unsere übrigen Hochbauten meist Gegenstände langer Erfahrungen sind, sie von den früheren Bauten oft nur durch Nuancen unterscheiden und ebenso der Vergangenheit, wie der Cegenwart angehören, sind die Eisenbahn- Hochbauten durch unsere Ceneration ganz neu geschaffen und das spontane Product einer der bedeutendsten Erfindungen unserer Epoche, geschaffen, um Bedingungen zu erfüllen, an welche unsere Vorfahren nicht dachten. Diese neue Art von Bauwerken ist daher in jeder Beziehung von der größten Wichtigkeit." Eduard Schmitt, Vorträge Bahnhöfe und Hochbauten auf Locomotiv-Eisenbahnen: Zweiter Theil. Hochbauten für die Zugförderung und Bahnbewachung (Leipzig: Arthur Felix, 1882), 3.

5 Die Existenz solcher Einrichtungen, die sich baulich und funktional wiederum stark an Gasthäusern orientierten, sind bspw. im englischen Dampfschiffwesen nachgewiesen worden, wenngleich keine konkreten Überlieferungen dieser Strukturen vorliegen: Charles Hadfield und Cordon Biddle, The Canals of North West England (Newton Abbot: David \& Charles, 1970), 39.

6 Auch Arschavir sieht in den baulichen Strukturen des Postkutschenwesens den zentralen Orientierungsrahmen der ersten Hochbauten des Eisenbahnwesens: »In almost every case these stations [of the early 1830 s, R.K.] were adapations of existing forms put to new uses with minimum alteration« (A. Arschavir, »The Inception of the English Railway Station«, Architectural History 4 (1961): 67). 
insbesondere die Strukturen des Postkutschenwesens einen wichtigen Orientierungsrahmen für den Ausbau des Eisenbahnwesens bildeten, vermag dabei allein schon der Blick auf die gemeinsamen semantischen Bezüge des Post- und Eisenbahnwesens verraten, denn die Bezeichnungen der Wegpunkte des Postkutschenwesens wurden kurzerhand auch für die Eisenbahn übernommen. Beide Verkehrssysteme nutzten - insbesondere im englischen Sprachraum - jeweils den Begriff der >Station ${ }^{7}$.

Nicht nur begrifflich zeigte sich eine enge Orientierung am Postkutschenwesen. Auch in personeller und technischer Hinsicht zeigte sich die Beharrlichkeit des bereits etablierten Verkehrssystems der Postkutsche im Gewand der dampfgetriebenen Eisenbahnen. So waren viele der frühen Lokomotivführer, Bremser oder Kontrolleure vormals Postkutscher oder erinnerten die einzelnen Waggons der Eisenbahn deutlich einer auf die Schiene transferierten Postkutsche. ${ }^{8}$ Doch jenseits dieser vielen betriebstechnischen, personellen und begrifflichen Persistenzen mussten für den Eisenbahnbetrieb in baulicher Hinsicht massive funktionale Erweiterungen gegenüber den stationären Infrastrukturen des Postkutschenwesens erfolgen, denn weder die Zollhäuschen noch die Wirtshäuser oder Posthöfe verfügten über derartige Empfangsgebäude, die speziell auf eine Abfertigung von hunderten Reisenden in einem eng begrenzten Zeitraum ausgerichtet waren. Auch wenn Wirtshäuser und Posthöfe bereits im Kern die Funktion eines Verkehrsplatzes, also der organisatorisch notwendigen zeitlichen und räumlichen Synchronisierung von Betriebsmitteln und Reisenden erfüllten und in ihnen bereits ähnliche Sub-Funktionen untergebracht waren, die auch für das neue Transportsystem der Eisenbahn relevant waren, so fand in ihnen noch keinerlei baulich-funktionale Differenzierung im Sinne der Gewährleistung einer Abfertigung oder etwa der Trennung des Güter- und Personenverkehrs statt. Bedingt durch die auf wenige Passagiere begrenzte Platzkapazität von Postkutschen war diese funktionale Trennung auch schlichtweg nicht nötig. Zudem traten betriebliche Störungen durch Kreuzungsverkehre oder Stauungen aufgrund der vergleichsweise geringen Passagierkapazität nicht auf. Abfertigung, Aufenthalt und Gepäckverwahrung konnten somit im Posthof zuvor meist in derselben Räumlichkeit untergebracht werden.

7 Zur Bedeutung des Postwesens für die schon in der Neuzeit einsetzenden Modernisierungsprozesse sei insbesondere verwiesen auf: Wolfgang Behringer, Im Zeichen des Merkur: Reichspost und Kommunikationsrevolution in der Frühen Neuzeit (Göttingen: Vandenhoeck \& Ruprecht, 2003). Zum Stellenwert des Postwesens für die Transformation des Subjekts zur Figur des >Passagiers $<$ Alexandra Bekasova, »The Making of Passengers in the Russian Empire: Coach-Transport Companies, Guidebooks, and National Identity in Russia, 1820-1860s «, in Russia in Motion: Cultures of Human Mobility since 1850, hg. von John Randolph und Eugene M. Avrutin (Chicago: University of Illinois Press, 2012), 199-217. In den USA fand zudem für die Bezeichnung des Bahnhofs häufig der Begriff des >depot Verwendung, der damit im Hinblick auf die Bedeutung des Bahnhofes stärker als anderswo auf die Funktion der (sicheren) Unterbringung des Betriebsmaterials abhob und damit zugleich stärker als anderswo die technische Dimension des Eisenbahnwesens betonte.

8 Vgl. Meeks, The Railroad Station: An Architectural History, 28; Vgl. Roth, Das Jahrhundert der Eisenbahn: die Herrschaft über Raum und Zeit 1800-1914, 134. 
Gekoppelt an den deutlichen Unterschieden bezüglich Passagierkapazität und -frequenz ${ }^{9}$ zeigten sich zudem auch temporale Differenzen, die einen leichtfertigen Transfer der Bauprinzipien von Posthöfen auf die Bauaufgabe >Bahnhofsbau< erschwerten. So waren Wirtshäuser und Posthöfe weit mehr als die späteren Bahnhöfe auf einen wesentlich längeren Aufenthalt - meist über Nacht - ausgerichtet, der damit begründet war, dass Pferde Ruhezeiten benötigten oder die Kutschen bei Dunkelheit nicht weiterfahren konnten und den kommenden Tag abwarten mussten. Die Eisenbahn dagegen beseitigte mittels ihrer Mechanisierung der Triebkräfte eine Reihe natürlicher Abhängigkeiten und konnte theoretisch rund um die Uhr betrieben werden. Die Bahnhöfe mussten somit einer gänzlich veränderten raumzeitlichen Verfasstheit des Eisenbahnwesens entsprechen und zusammengenommen auf einen zum Postwesen vergleichsweise transitorischen Kurzaufenthalt bzw. auf die mehr oder minder gleichzeitige >Passage< einer Vielzahl von Reisenden ausgerichtet werden.

Abbildung 9: Postpassagierstube in Schottland: Vereinigung unterschiedlicher Dienstleistungseinrichtungen in nur einem Raum (Kochstelle/Restauration, Gepäckdepot, Warteraum). Zeichnung von Henry Ritter, Datum unbekannt.

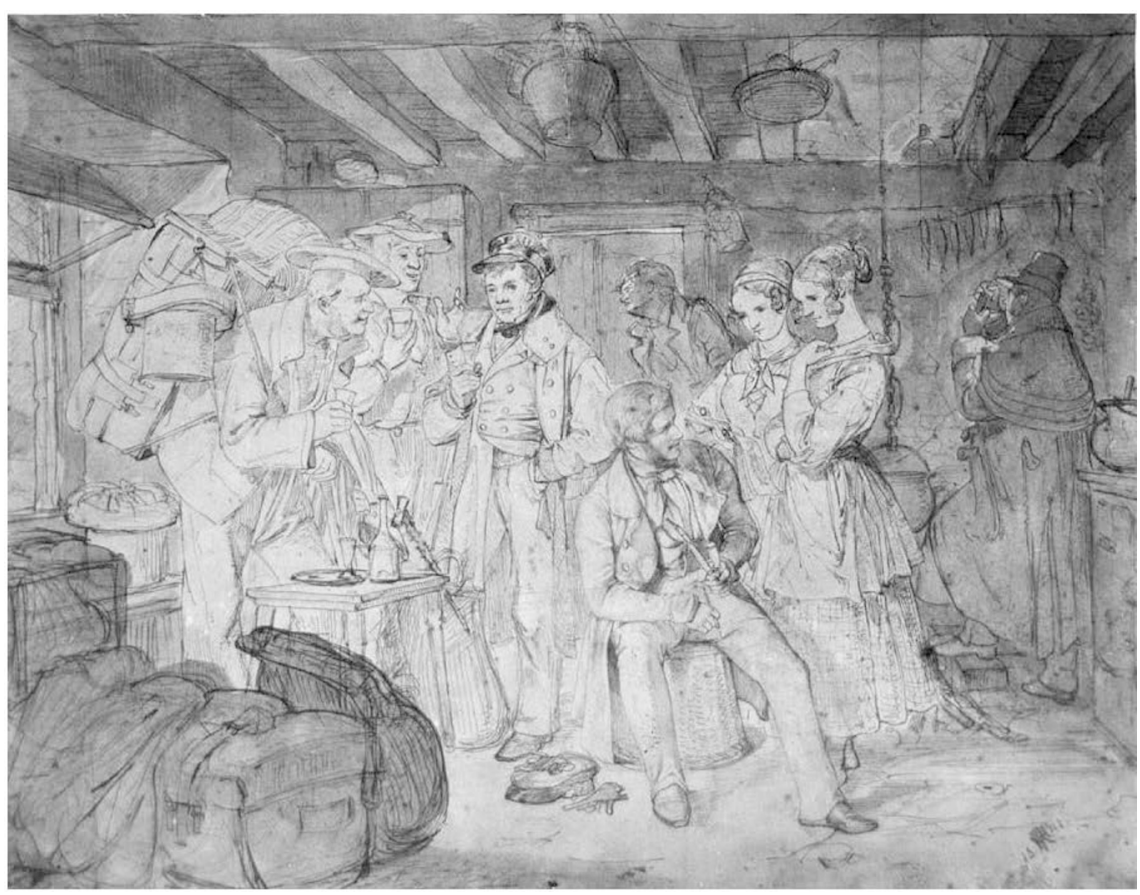

Quelle: Henry-Ritter-Album, Königswinter und Achenbach, 1863, @Michael Venator.

9 》If the average road coach carried between ten and fourteen people the Railway would need to multiply this figure by a factor of ten at least« (Hadfield und Biddle, The Canals of North West England, 1: 49ff.) 
Abbildung 9 zeigt exemplarisch die Ansicht einer Postpassagierstube, die als Vorläufer baulicher Einrichtungen für den Personenverkehr und als rudimentärer Bezugspunkt des späteren Bahnhofsbaus angesehen werden kann. ${ }^{10}$ Wenngleich, wie in dieser Zeichnung zu sehen, bereits in der Poststation verschiedene Funktionen und Dienstleistungen eines institutionalisierten Verkehrsangebots - bspw. Restauration, Warteraum, Gepäckaufbewahrung - zu finden waren, ${ }^{11}$ erforderte das Eisenbahnwesen durch seine zum Postkutschenwesen vergleichsweise großmaßstäblichere Personenfrequenz sowie der infrastrukturellen Besonderheit, dass nicht ein bestehender Straßenraum genutzt, sondern ein fixierter Schienenweg unter dem Einsatz schwerer Dampfmaschinen befahren wurde, gänzlich neuartige Baulösungen. So bleibt schließlich trotz der vielfältigen Bezüge und punktueller betrieblicher und personeller Persistenzen zum etablierten Verkehrssystem der Postkutschen in funktionaler Beziehung zusammenfassend festzuhalten, dass fast jede Lösung für die erweiterten funktionalen Herausforderungen der Eisenbahn neu entwickelt werden musste.

Die vielfältigen Lösungen der Bauaufgabe >Bahnhofsbau beanspruchten zwar jeweils nur einen Bruchteil der Gesamtbaukosten einer Eisenbahnlinie, ${ }^{12}$ doch die geschaffenen Bauwerke repräsentierten wie kaum ein anderer Aspekt des Eisenbahnwesens die Ankunft einer neuen Verkehrsepoche. ${ }^{13}$ Insbesondere aus Sicht der Reisenden repräsentierten sie die Bahnfahrt selbst, da diese jenseits des Bahnhofs meist nur auf freier Strecke stattfand bzw. als Raumdurchquerung wahrgenommen wurde. ${ }^{14}$ Der Bahnhof mit seinem Empfangsgebäude wurde zum weithin sichtbaren Ausdruck der dampfgetriebenen Transportrevolution und der mit ihr stimulierten gesellschaftlichen, kulturellen und wirtschaftlichen Veränderungen. Was sich zunächst als triviale Gewährleistung zum Zweck entpuppte, »den Verkehr von Personen und Gütern auf Eisenbahnen $\mathrm{zu}$ vermitteln [und] diesen Verkehr überhaupt möglich $\mathrm{zu}$ machen ${ }^{15}{ }^{15}$ sollte im Laufe des 19. Jahrhunderts die symbolische Aufladung zum bedeutungsvollen »Verdichtungsraum von Modernität, Urbanität und Industrialisierung « ${ }^{16}$ schlechthin erfahren.

10 Diese räumliche Disposition einer Sammelstelle von Reisenden vor Abfahrt im Verkehrsmittel kann durchaus auch als ein früher Vorläufer heutiger Gate-Bereiche auf Flughäfen interpretiert werden.

11 Wohlgemerkt meist in nur einem einzigen Raum.

12 Bezüglich der konkreten Baukosten verweist ein Handbuch aus den frühen 1870er Jahren verweist darauf, dass der Bau von Bahnhöfen und Wärterhäuschen entlang der Strecke im Durchschnitt $11 \%$ der Gesamtinvestitionskosten des Streckenneubaus im Deutschen Reich ausmachen würde (Eduard Schmitt, Vorträge Bahnhöfe und Hochbauten auf Locomotiv-Eisenbahnen: Erster Theil. Die Anlage der Bahnhöfe (Leipzig: Arthur Felix, 1873), 360). Zugleich darf dieser gering erscheinende Anteil nicht verdecken, wie kostenintensiv damit die Schaffung der im Verhältnis zur Gesamtstrecke kleindimensionierten Wegpunkte war.

13 Neben der Errichtung von Bahnhöfen stellten wohlgemerkt auch die Errichtung von Opern, Parlamentsgebäuden, Markthallen oder öffentlichen Bibliotheken paradigmatische Bauaufgaben des 19. Jahrhunderts dar, die aufgrund ihrer Funktion oder Dimension kaum oder auf gar keinen Vorgängermodellen aufbauen konnten.

14 Vgl. Radlbeck, »Bahnhof und Empfangsgebäude«, 1.

15 Schmitt, Vorträge Bahnhöfe und Hochbauten auf Locomotiv-Eisenbahnen, 3.

16 Markwart Herzog und Mario Leis, »Der Bahnhof: Kathedrale, Erlebniswelt, Sozialstation und Konsumparadies«, in Der Bahnhof: Basilika der Mobilität - Erlebniswelt der Moderne, hg. von Markwart Herzog und Mario Leis (Stuttgart: W. Kohlhammer, 2010), 7. 
Bahnhöfe repräsentierten und bündelten nicht allein den gesellschaftlichen Wandel und kulturellen Zeitgeist des 19. Jahrhunderts, sie gestalteten ihn zugleich auch. Bahnhöfe, resümiert Meeks den Zusammenhang zwischen neuer Transporttechnologie und der dafür zu errichtenden Verkehrsplätze, »were becoming the symbol of the age. « ${ }^{17}$

Mit welchem Raumprogramm, welchen funktionalen Einrichtungen und nicht zuletzt mit welchen gestalterischen Mitteln aber sollten die Bahnhöfe - oder trefflich im technischen Ingenieurs-Duktus ausgedrückt, die »Vermittlungsstellen zwischen der Transportanstalt und der Bevölkerung ${ }^{18}$ - ausgebildet werden und welche Auswirkungen mag dieses bauliche Gefüge auf die Wahrnehmung von darin erlebten verkehrsinduzierten Wartezeiten genommen haben?

\section{Anforderungen und Elemente der neuen Bauaufgabe}

Bahnhöfe bilden den punktuellen und im Grunde einzigen Übergangsbereich von Personen auf die Bahn. Als einer der federführenden Ingenieure des deutschen Eisenbahnwesens im 19. Jahrhundert stellte Eduard Schmitt zur Bedeutung des Bahnhofsbaus fest: »Die Bahnhöfe spielen, in der Gesammtheit einer Eisenbahn, eine äusserst wichtige Rolle. Sie erfordern ein sehr sorgfältiges Studium, weil durch ihre gute Anlage grosse Ersparnisse im Betriebe der Bahn erzielt werden können, und weil die Wahl ihrer Stellung allein einen sehr grossen Einfluss auf die Zukunft der Bahn ausüben kann. ${ }^{19}$ Angesichts der relevanten Stellung innerhalb des Eisenbahnwesens wundert es kaum, dass die Lösung dieser neuen Bauaufgabe von Anbeginn hitzige Diskussionen unter Architekten, Ingenieuren und Politikern erzeugte, die über Jahrzehnte hinweg Lehrbücher und Fachzeitschriften füllten.

Den betrieblichen Erfordernissen des Bahnverkehrs entsprechend galt es grundsätzlich jeweils die folgenden Bauelemente orts- und budgetabhängig in möglichst effizienter Form miteinander in Verbindung zu bringen:

- Empfangsgebäude mit Serviceeinrichtungen für die Reisenden und Diensträumen der Bahnverwaltung (insbesondere der Verkaufsstelle für Fahrscheine)

- Bahnsteige bzw. Plattformen zum Besteigen und Verlassen der Züge

- Überdachte Wagen-, Personen- oder Gleishalle mit Einrichtungen zum Bewegen der Wagen (Drehscheiben)

- Optional: Vorgelagerter Hotelbau (vorwiegend in England und den USA realisiert).

Bahnhöfe wurden dazu ferner in der Regel in drei hintereinander liegende systemische Zonen gegliedert. Auf der Stadtseite schloss sich ein vorgelagerter Vorplatz dem örtlichen Straßensystem an und ermöglichte den Zubringerverkehr zum Bahnhof. ${ }^{20}$

17 Meeks, The Railroad Station: An Architectural History, 39.

18 A. Goering und M. Oder, Der Eisenbahnbau, Bd. 4: Anordnung der Bahnhöfe, Handbuch der Ingenieurwissenschaften 5.Teil (Leipzig: Engelmann, 1907), 1.

19 Schmitt, Vorträge Bahnhöfe und Hochbauten auf Locomotiv-Eisenbahnen, 3.

20 Lagen eine Vielzahl von Bahnhöfen zu Beginn des Eisenbahnzeitalters noch zum Teil weit vor den Ortschaften (besonders in Deutschland, weniger dagegen in England), entwickelte sich die Einbindung der Bahnhöfe in den Stadtraum zu einer der komplexesten Aufgaben des Eisenbahnwesens. Die Verbindung von Stadt und Eisenbahn bildete damit letztlich einen der wichtigsten Kris- 
Auf der Bahnseite ermöglichten erhöhte und überdachte Bahnsteige den direkten $\mathrm{Zu}$ gang in die Wagen und boten Witterungsschutz. Dazwischen schob sich das Empfangsgebäude mit seinen Einrichtungen als Bindegliedzone zwischen Stadtraum und Zug. ${ }^{21}$ Die Zusammenführung der Einzelelemente entlang dieser Zonen schuf schließlich ein bau- und verkehrshistorisch einzigartiges Ensemble, eine durch Zäune und Hochbauten abgeschlossene Anlage, die angesichts ihrer eingefriedeten und abgeschlossenen Charakteristik die Bezeichnung >Bahnhof $<$ durchaus verdiente. ${ }^{22}$ Auch hier zeigten sich angesichts der Charakteristik einer abgeschlossenen Anlage wiederum enge sprachliche als auch funktionale Bezüge zu den bereits vor dem Eisenbahnzeitalter bestehenden Posthöfen, die teils - wie etwa beim Thurn und Taxis Posthof in Frankfurt a.M. bereits überdachte Abfertigungsbereiche aufwiesen und ein gewisses Maß an Witterungsschutz und Komfort boten. ${ }^{23}$

\section{Vielfalt der Ausführungen: Typologie des Bahnhofsbaus}

Jenseits der Gemeinsamkeit, dass die genannten Bauelemente des Bahnhofes in irgendeiner Form vorhanden sein mussten, zeigten sich in der Praxis mitunter stark abweichende Lösungen, die sich insbesondere aus den unterschiedlichen relativen Lagen der Bahnhöfe zur Stadt und den Gleiskörpern, aus spezifischen topografischen Gegebenheiten, der hierarchischen Funktion des jeweiligen Bahnhofes im Gesamtnetz (Endpunkt, Startpunkt, Zwischenstation) sowie aus der dem Bahnunternehmen verfügbaren Grundstücksgröße ergaben. Bedingt durch die Varianz dieser und weiterer Einflussfaktoren schufen die realisierten Pionierprojekte der 1830er und 1840er Jahre zunächst eine breite Vielfalt von Entwürfen und Vorschlägen im Spektrum von Längen-, Quer-, Umschließungs-, Anschluss- oder Übergangsbahnhöfen. ${ }^{24}$ Meeks typologisiert allein bis Anfang der 1840er Jahre fast ein Dutzend weltweiter Stationsausführungen, die von einer seitlichen Erschließung (Durchgangsbahnhof) bis hin zum besonders bekannten und monumentalen Typus des Kopfbahnhofs reichen (Abbildung 10). All jene Bahnhofstypen wiesen ihre jeweiligen Vor- und Nachteile bezüglich Betriebsführung, Baukosten und Komfort auf, die an dieser Stelle aufgrund ihrer erschöpfenden Tiefe nicht näher ausgeführt werden sollen. Zusammengenommen zeigten sie jedoch das tendenzielle Dilemma auf, dass jene Formen, die bequemer für die Reisenden waren (bspw. durch besonders kurze Wege vom Eingang zum Zug, wenige sverlorene Steigungen durch Treppen), sich für die privaten oder stattlichen Bahnunternehmen zugleich als vergleichsweise teurer und personalaufwendiger erwiesen. Die aus Sicht des

tallisationspunkte städtebaulicher Entwicklung des 19. Jahrhunderts. Vgl. Christian W. Thomsen, "Kathedralen der Moderne? Bahnhofsarchitektur - gestern, heute und morgen«, in Der Bahnhof: Basilika der Mobilität - Erlebniswelt der Moderne, 19.

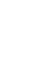
gar Souvenirshops für die Versorg Vgl. ebd., 23. Später erbaute oder erweiterte Posthöfe standen den parallel errichteten Bahnhö-
fen in puncto Komfort mancherorts in nichts nach. So verfügte etwa der 1846 errichtete zentrale Vgl. Schmitt, Vorträge Bahnhöfe und Hochbauten auf Locomotiv-Eisenbahnen, $61 \mathrm{ff}$. gar Souvenirshops für die Versorgung der Abreisenden (Vgl. Bekasova, »The Making of Passengers 
Bahnbetriebs effizientesten und sichersten Lösungen kollidierten demnach oftmals mit Unannehmlichkeiten für die Reisenden. ${ }^{25}$

Ausgehend vom Prototypen des Bahnhofsbaus - der Liverpool Crown Street Station (1830) - avancierte der Durchgangsbahnhof mit seitlicher Erschließung (Typus Nr.4 in Abbildung 10) schließlich zum insgesamt meistgebauten Bahnhofstypus, der bis in die Gegenwart allen Standardisierungs- und Rationalisierungswellen standgehalten hat. In der Ausprägung des Durchgangsbahnhofs wurde bei diesem Typus das Empfangsgebäude parallel zum Bahnkörper angeordnet, was einen ungehinderten Durchfluss des Bahnverkehrs durch die Ortschaft ohne betriebliche Notwendigkeit zusätzlicher Wendemanöver (wie etwa im Kopfbahnhof) ermöglichte. Jener Typus des >one-sided-style galt aus zeitgenössischer Sicht als die natürlichste denkbare Form, die, um den noch geringen Betrieb sicherzustellen, zugleich (noch) keinen Bruch mit bestehenden Bautraditionen nötig machte. ${ }^{26}$

Die Etablierung geeigneter Lösungen in Abhängigkeit von lokalen Betriebsverhältnissen, dem verfügbaren Kapital oder gar der kulturellen Besonderheiten der Reisenden nahm Jahrzehnte in Anspruch und schuf ein eigenes bau- und ingenieurswissenschaftliches Diskursfeld und - wie zu zeigen sein wird - um 1900 eine eigene Wissenschaftsdisziplin. Mit dem Bau der ersten Bahnhofsgeneration wurde die Suche und Diskussion geeigneter Baulösungen - zusammen mit unzähligen Schilderungen bisheriger nationaler und internationaler Erfahrungen und Prognosen des Bahnhofsbaus zu einem festen Bestandteil der Debatten in den Fachkreisen des Architektur- und Ingenieurswesens. Ausdruck dieser sich ausbreitenden Fachdebatten war die Professionalisierung des Eisenbahningenieurswesens, die Gründung neuer Publikationsorgane, Vereine oder die Einrichtung fester Rubriken in den bereits vor dem Eisenbahnwesen bestehenden einschlägigen Fachzeitschriften.

\section{Probleme und Unsicherheiten}

Die neue Aufgabe des Bahnhofsbaus stand bereits in ihrer Frühphase vor Schwierigkeiten, die aus der hohen Veränderungsdynamik des Eisenbahnwesens selbst und daran gekoppelt aus konstruktionstechnischen Schwierigkeiten der stetigen Bedarfsanpassung resultierten. Entscheidendes Hauptproblem für den Bahnhofsbau bestand in der allgemeinen Unklarheit über die Verkehrsentwicklung und der damit verbundenen Dimensionierung der Räumlichkeiten, die wiederum Einfluss auf die baustatistische Umsetzung und den geeigneten Materialeinsatz nahmen. Welchen Bedarf würde die neue Transporttechnologie entwickeln? Wie viele Menschen würden die Eisenbahnen nach Eröffnung tatsächlich nutzen? Sollte die Dimensionierung und Ausstattung neu zu erbauender Bahnhofsgebäude bereits eine optimistische Verkehrsentwicklung berücksichtigen oder im Sinne größtmöglicher Wirtschaftlichkeit und allgemeiner Ungewissheit der zukünftigen Entwicklung zunächst noch kleiner dimensioniert und spartanisch ausgestattet werden? Wie sollten generell die Räumlichkeiten und Wegeführungen beschaffen sein und welche neuen Bedarfe würden sich im Verlauf einer Bahnreise

Hierzu sei beispielhaft auf den Neubau des Hannoveraner Hauptbahnhofes von 1881 verwiesen, siehe Kap. 8.1.1.

Vgl. Meeks, The Railroad Station: An Architectural History, 31. 
Abbildung 10: Typologie der Bahnhofsbauten in der Frühphase des Eisenbahnwesens.
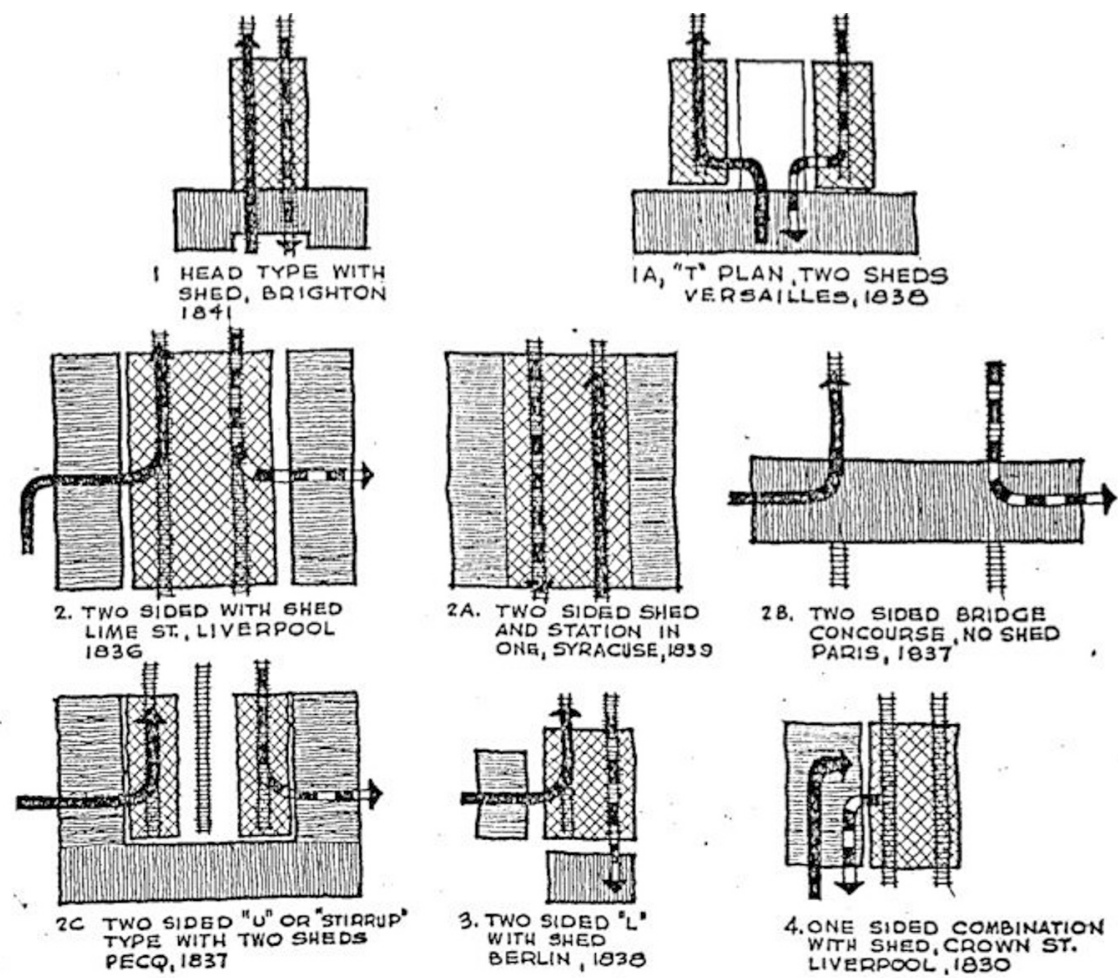
4. ONE SIDED COMBINATION
WTH SHED, CROWN ST. LIVERPOOL, 1830

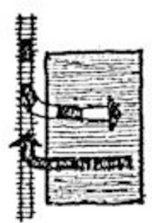
4A. ONE SIDE
NO SHED

PLAN KEY

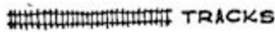

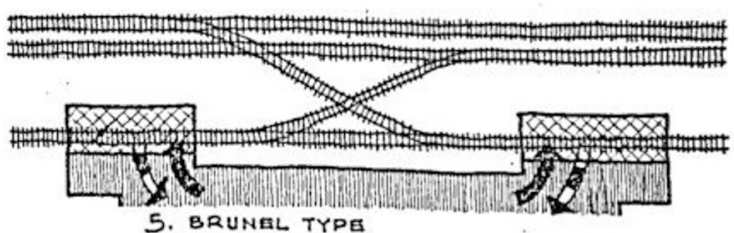

5. BRUNEL TYPE

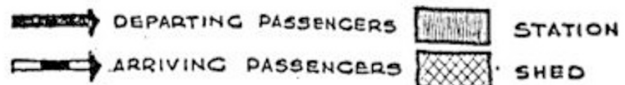

Quelle: Meeks 1956, S. 30.

entwickeln, die im Bahnhof Berücksichtigung finden mussten? Was aus heutiger Sicht als trivial erscheinen mag, formte für die Zeitgenossen der 1830er und 1840er Jahre eine Gleichung mit vielen Unbekannten, die zusätzlich dadurch erschwert wurde, dass die einmal gebauten Strukturen mitunter nur wenig Spielraum besaßen, um sich dem hochdynamischen Feld der Eisenbahnentwicklung in Form baulicher Erweiterungen anzupassen. 
Wenngleich jegliche dieser Fragen direkte und indirekte Auswirkungen auf die neue Bauaufgabe des Bahnhofshofes nahmen, bildete das besonders aus Sicht der Ingenieure wohl herausforderndste Element die Schaffung einer Bahnsteige und Gleise überspannenden Bahnsteig- oder Perronhalle zum Witterungsschutz, die mittelfristig nicht nur gänzlich neue Materialien (Eisen statt Holz), sondern auch neue Konstruktionsmethoden erforderte. Neben diesem großflächigen Bauelement, das in der Folgezeit zusammen mit dem Empfangsgebäude zum ikonischen (Unterscheidungs-)Merkmal eines jeden (Großstadt-)Bahnhofs wurde, mussten jedoch mit zunehmendem Reiseverkehr auch viele kleinteilige Lösungen gefunden, adaptiert oder weiterentwickelt werden. Hierzu gehören die für die Reisenden bestimmten Vordächer, Windfänge, Fahrkartenschalter, Gepäckorganisationen, Uhrentürme, Speiseräume, sanitäre Einrichtungen als auch die für die Verwaltung und das Bahnpersonal dienenden Büro- und Wohnräume. Die Architekten und Ingenieure des frühen Eisenbahnwesens standen damit zusammengenommen gleich vor zwei Problemfeldern: Zum einen vor dem Problemfeld der konkreten ortsspezifischen Baulösung und zum anderen vor dem Problemfeld der gleichzeitig notwendigen Skalierung einer ohnehin unsicheren Bauaufgabe in Form der Errichtung hunderter oder (im nationalen Kontext) gar tausender Stationen innerhalb weniger Jahre.

\section{Erste Bahnhöfe: Reallabore mit noch vergleichsweise lösbaren Aufgaben}

Die jüngste Generation der Bahnhöfe und Empfangsgebäude sah sich mit diesen wachsenden Problemen jedoch zunächst erst nur in abgeschwächter Form konfrontiert. Entsprechend der eisenbahntechnischen Vorreiterrolle war wiederum England der Schauplatz des Aufbaus der jüngsten Generation von Bahnhöfen und Empfangsgebäuden. Hier konnten vor allem die bestehenden Vorkenntnisse der teilweise noch pferdebetriebenen Strecke Stockton-Darlington (seit 1825) mit ihren noch vergleichsweise handhabbaren Passagierzahlen dafür sorgen, dass keine allzu großen kapazitären Schwierigkeiten in der Errichtung der ersten Bahnhofs-Prototypen zu erwarten waren. Die ersten Strecken bildeten zudem noch keine Netze aus, sondern stellten sich als punktuelle und relativ kurze Verbindungen zwischen wichtigen Zentren oder Verbindungen von Zentren zu bedeutenden Vororten dar. Dieser noch fehlende Netzcharakter bewirkte eine gewisse Komplexitätsreduktion bezüglich der Prognose der Passagierzahlen, die sich damit zuvorderst aus der Maximalkapazität nur eines einzigen Zug ergab und bspw. noch keine aus zusätzlichen Umsteige- und Anschlusssituationen resultierenden Nachfragespitzen berücksichtigen musste. Darüber hinaus legten die Eisenbahnunternehmen ihren Fokus auf die Errichtung der Strecke und damit auf vorwiegend technische Aspekte, sodass den ersten Bahnhöfen zunächst eine noch vergleichsweise untergeordnete Bedeutung im Gesamtsystem beigemessen wurde. So entfielen etwa beim Bau der Strecke Liverpool-Manchester nur insgesamt etwas mehr als 5 Prozent der Gesamtbaukosten auf die Errichtung von Hochbauten (End- und Zwischenstationen, Lagerhäuser, Büroräume und Depots). ${ }^{27}$

27 Berechnet auf Grundlage der geschilderten Kostenpositionen des entsprechenden Streckenbaus in Kirwan, A Descriptive and Historical Account of the Liverpool and Manchester Railway, 8. Der geringe Anteil an den Baukosten lässt sich zum einen durch die noch geringe Menge an Zwischenstatio- 
Folglich dominierten in den $1830 e r$ Jahren zunächst noch einfachste Bauten, die nur das Notwendigste bereithielten, um den Übergang von der Stadt auf die Bahn überhaupt erst einmal grundsätzlich zu ermöglichen. Der Architekt Lichthammer trifft in einem in der österreichischen Allgemeinen Bauzeitung erschienenen Reisebericht aus dem Jahr 1842 über das nationale Bahnsystem Belgiens bezüglich der baulichen Gestaltung der dortigen Bahnhöfe eine Feststellung, die durchaus als repräsentativ für jegliche Eisenbahnnationen der Frühphase einzustufen ist. So ging man beim Entwurf des Bauplanes der ersten belgischen Stationen zunächst »von dem Grundsatze aus, erst durch Anlegung provisorischer Bahnhöfe die Bedürfnisse kennen zu lernen, da dieselben im Voraus nie so genau bestimmt werden können. $\aleph^{28}$ Diese Strategie des >Trial and Error v verdeutlicht abermals die Neuheit der Bauaufgabe, die direkt an die Ungewissheiten der Betriebsführung selbst gekoppelt waren.

Die Frühphase des Bahnhofsbaus, so resümierten im frühen 20. Jahrhunderts Goering und Oder im Rückblick auf das erste Jahrhundert der Eisenbahn, hatte »noch keine Vorstellung vom Anwachsen des Verkehrs (...). Es war daher natürlich, daß fast überall die ersten Anlagen der Bahnhöfe sich bald als unzureichend erweisen, trotzdem man sie nach damaliger Meinung wohl schon reichlich bemessen zu haben glaubte und sie in Deutschland von vornherein, namentlich bei Staatsbahnen, mit einer gewissen Vorliebe behandelt und ausgestattet hatte. ${ }^{29}$ Zugleich bestand die Frühphase des Bahnhofsbaus im Zeichen breiter Experimentierfreude. So fasst Meeks mit Blick auf die ersten zwei Jahrzehnte der Typisierung des Bahnhofsbaus zusammen: "Station types elude ready classification. Some stations bore in them the patterns for the great terminals of the future, others proved abortive. ${ }^{30}$ Die frühen Bahnhöfe von Liverpool (1830), Manchester (1830), Nürnberg (1835) oder Berlin (1838) entsprachen damit wahrlichen Reallaboren. An und in ihnen wurden die betrieblichen und baulichen Bedürfnisse des neuen Transportmittels quasi realexperimentell erkundet. Diese Reallabore können in baulicher Hinsicht unter dem Slogan einer "simple, logical solution to a purely practical problem ${ }^{31}$ subsumiert werden, denen die Architekturgeschichte trotz ihres funktionalen auf "sound construction and unpretentious honesty « ${ }^{32}$ ausgerichteten Charakters zugleich eine würdevolle Ausstrahlung attestiert hat.

Wenn damit der Grundcharakter der Frühphase des Eisenbahnwesens als betrieblicher Experimentierraum in einer baulich pragmatisch-funktionalen Umgebung umrissen werden kann, stellt sich nun die Frage, wie an diesen Orten der erstmals notwendige situative Aufenthalt bzw. das systemische Warten verhandelt wurde. Um dem Charakter des Wartens zum Zeitpunkt der frühesten baulichen Situation des Eisenbahnwesens nun näher auf die Spur zu kommen, sollen im Folgenden eine Reihe ausgewählter englischer und deutscher Bahnhöfe der Frühphase des Eisenbahnwesens beleuchtet

nen und Wärterhäuschen begründen, jedoch auch durch die noch sehr pragmatische und wenig repräsentative Gestaltung und Ausführung der Stationen.

Lichthammer, »Ueber einige Bahnhöfe des westlichen Deutschlands und Belgiens«, Allgemeine Bauzeitung 7 (1842): 354.

29 Goering und Oder, Der Eisenbahnbau, 4: Anordnung der Bahnhöfe:2.

30 Meeks, The Railroad Station: An Architectural History, 29.

31 Arschavir, »The Inception of the English Railway Station«, 72.

32 Ebd., 67. 
werden, um an jenen Orten eine Archäologie des Wartens zu betreiben. Beginnend mit einer kurzen einleitenden Beschreibung der Entstehungsgeschichte, gestalterischer Aspekte und Auffälligkeiten des jeweiligen Bahnhofs schwenkt die Betrachtung dazu im Anschluss auf die Analyse der baulich-betrieblichen Rahmung des Wartens (Außenperspektive) und der Interpretation der möglichen sozialen und kommunikativen Auswirkungen dieser baulich-technischen Rahmungen für den wartenden Reisenden (Innenperspektive). Die Analyse der Orte des Wartens speist sich dazu aus grafischen Quellen (Baupläne, Grundrisse), aus schriftlichen Quellen (Reiseberichte, Zeitungsartikel) sowie aus Sekundärquellen und wird entlang des bereits erwähnten, deduktiven Kategorienrasters strukturiert:

- Wartebezogenes Raumprogramm (Lage, Stellung, Ausstattungen)

- Sprachliche Repräsentation des Wartens

- Dauer des Wartens

- Formalität des Wartens

- Sozialität des Wartens

Um hierbei eine narrative Verschränkung der Innen- und Außenperspektive des verkehrlichen Wartens zu erreichen, werden die gesammelten Erkenntnisse - wenn vorhanden - von Quellenaussagen zur Rezeptionsgeschichte des Wartens in der jeweiligen Zeitebene flankiert und von zusammenfassenden Betrachtungen bzw. dem Versuch einer Rekonstruktion der frühesten Wartezeiterfahrung abgeschlossen.

\subsection{Die Orte des (frühen) Wartens: Bahnhöfe der ersten Generation}

\subsubsection{Liverpool - Crown Street Station (1830)}

\section{Bauliche Kurzbeschreibung}

Die am 15. September $1830 \mathrm{im}$ Rahmen der Streckeneröffnung Liverpool-Manchester eingeweihte Crown Street Station in Liverpool bildete den Urtypus des Bahnhofsbaus. ${ }^{33}$ Er gilt aus Sicht der Architektur- und Eisenbahngeschichte als "probably the first building of any substance to be designed specifically to meet the needs of railway travel. $\ll^{34}$ Mit seiner dominanten hölzernen Überdachung, die durch eine gegenüber dem Empfangsgebäude errichteten Stützmauer gehalten wurde, vereinte dieser Bahnhof (Typus

33 Zwar verfügte bereits auch die Strecke Stockton-Darlington über bauliche Strukturen für Zu- und Abgang zur Eisenbahn, jedoch wurden hierfür vorwiegend bereits zuvor bestehende Strukturen insbesondere Pubs, Inns oder bestehende Lagerhäuser - genutzt. Die Gebäude der Linie StocktonDarlington wurden erst im Laufe der 1830er Jahre durch funktional dem Eisenbahnverkehr gewidmete Strukturen erweitert und damit zeitlich nach den Eröffnungen in Liverpool und Manchester. Weil die Bahnhofsgebäude von Liverpool und Manchester als Neubauten errichtet wurden, die funktional auf den dampfbetriebenen Regelverkehr nach festem Fahrplan ausgerichtet wurden, können diese beiden Bahnhöfe folglich als die weltweit ersten Bahnhofsgebäude betrachtet werden.

Arschavir, »The Inception of the English Railway Station«, 67. 
sseitliche Erschließung`) trotz seiner noch vergleichsweise bescheidenen Dimensionen bereits alle wesentlichen Elemente des modernen Bahnhofs im Embrionalstadium. ${ }^{35}$ Diese Elemente umfassten - wie bereits oben geschildert - die Troika aus Empfangsgebäude, Bahnsteig bzw. Plattform und einer Wagen-, Personen- oder Gleishalle. Im Gegensatz zum baulichen Novum der überdachten dreigleisigen Halle aus einem hölzernen Hängewerk wurde jedoch das zeitgenössisch noch oft als >warehouse < oder >railway office < bezeichnete Empfangsgebäude selbst in Form eines einfachen, zweigeschossigen Massivbaus in klassizistischer Formensprache ausgebildet. Klammert man also die angeschlossene Gleishalle von der Betrachtung aus, konnte dieses eher unspektakuläre und zugleich zeitgenössisch als »handsome building « ${ }^{36}$ bezeichnete Empfangsgebäude demnach wohl noch kaum explizit als ein originär dem Eisenbahnwesen bestimmtes Gebäude ausgemacht werden. Es unterschied sich schlichtweg nur wenig von der Architektur der städtischen Bebauung Liverpools. Mit Blick auf das Gesamtensemble dieses >Pionier-Bahnhofs‘, das uns bis heute dank einer zeitgenössischen Darstellung von T.T. Bury aus dem Jahr 1833 (Abbildung 11) überliefert wird, kommt damit deutlich der bereits angesprochene architekturhistorische Befund des frühen Bahnhofsbaus in seiner Charakteristik zwischen der relativ unkritischen Fortführung bestehender Bautraditionen einerseits und der schwierigeren Aufgabe zur Lösung neuer Funktionsansprüche andererseits zum Ausdruck. Während das einem Wohnhaus ähnelnde Empfangsgebäude eine deutliche Kontinuität des (bekannten) Bauens verdeutlichte, bildete die Konstruktion des angeschlossenen Hallendaches die Erweiterung um ein gänzlich neues, in dieser Form bislang nie zuvor realisiertes Bauelement. ${ }^{37}$ Es steht hierbei zu vermuten, dass der Chef-Ingenieur der Liverpool \& Manchester Eisenbahngesellschaft George Stephenson und der mutmaßliche Architekt John Foster Junior ${ }^{38}$ für diesen $>$ Hybriden aus Wohnhaus und Gleishalle in engem Austausch standen, insbesondere um eine adäquate Lösung für die neue Bauaufgabe einer weitgespannten Überdachung zu finden. ${ }^{39}$ Diese Kooperation zwischen Architekt und Ingenieur sollte sich im weiteren Verlauf des 19. Jahrhunderts zu einer zentralen Kooperation und zugleich zu einem der zentralsten Machtkämpfe moderner Bautätigkeit entwickeln. ${ }^{40}$ Empfangsgebäude und Wagenhalle bildeten - angefangen mit Liverpools erstem Bahnhof - zwei oftmals oppositionäre Elemente, die jeweils entweder in der Verantwortung des Architekten oder des Ingenieurs standen und die aus architekturhistorischer Sicht in folgenden Generationen des Bahnhofsbaus nie gänzlich vereint werden konnten.

In bahnbetrieblicher Hinsicht ist mit Blick auf die Crown Street Station weiterhin zu bemerken, dass sich unter der an den Stirnseiten offenen Überdachung zudem

35 Vgl. Meeks, The Railroad Station: An Architectural History, 28.

36 Walker, An Accurate Description of the Liverpool and Manchester Railway, 18.

37 Der Architekturhistoriker Chris Barman vermerkte gar bezüglich der historisch zäsuralen Herausforderung des Überspannens großer Raumflächen in den Gleishallen: »Not since the days of the great cathedrals had the constructor of buildings been faced with such a challenge. «Christian Augustus Barman, An introduction to railway architecture (London: Art and Technics, 1950), 14. Vgl. Meeks, The Railroad Station: An Architectural History, xiii.

39 Vgl. ebd., 28.

40 Vgl. Arschavir, »The Inception of the English Railway Station«, 69. Hierzu auch Cordon Biddle, Victorian Stations: Railway Stations in England and Wales, 1830-1923 (Newton Abbot: David and Charles, 1973), 89. 
Abbildung 11: Ansicht des Bahnhofs Liverpool mit Empfangsgebäude und überdachter Wagenhalle.

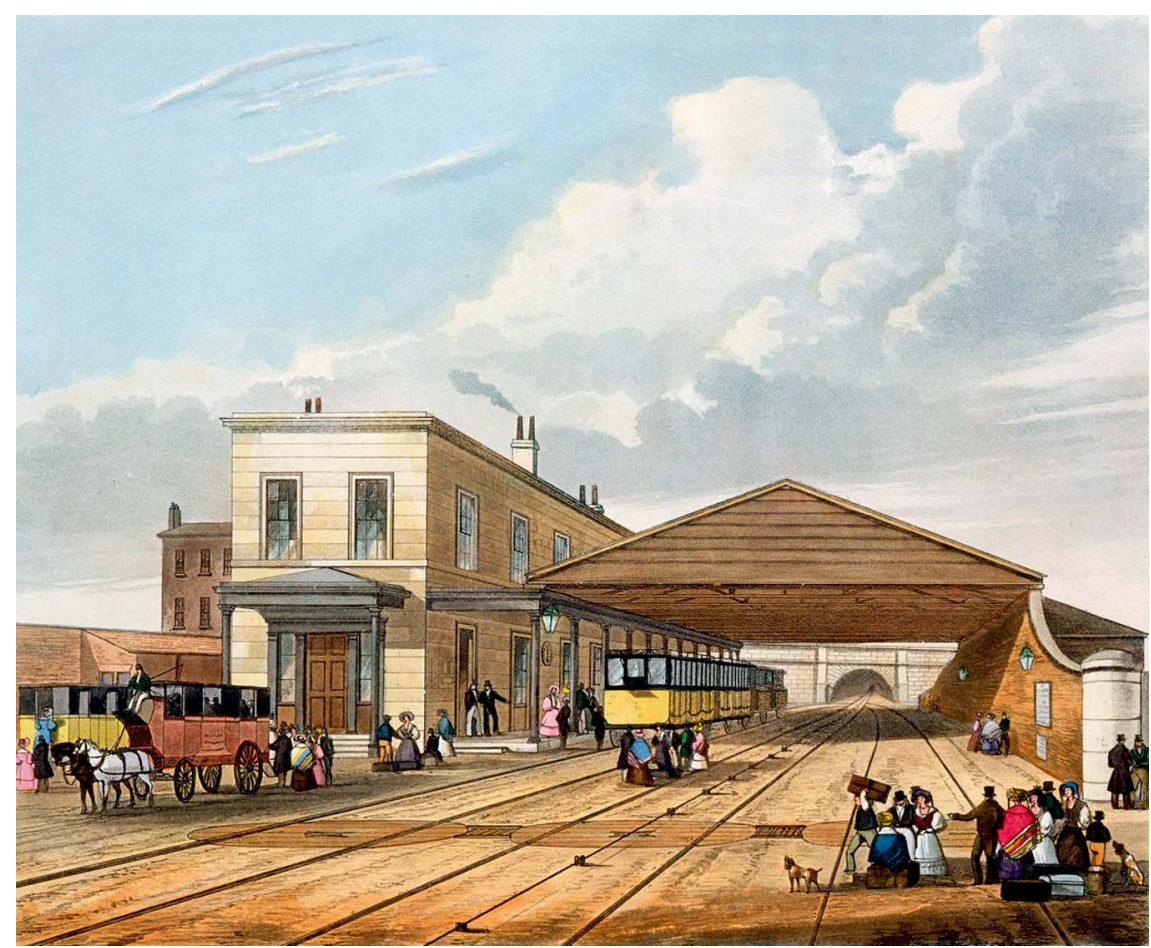

Quelle: T.T. Bury, Coloured Views on the Liverpool and Manchester Railway (London: Ackermann \& Co., 1833), Tafel 8.

bereits eine klare, für moderne Massenverkehrssysteme typische Trennung von abfahrenden und ankommenden Passagieren befand. Während die aus Liverpool abfahrenden Passagiere eine dem Empfangsgebäude angeschlossene, von Kolonnaden gesäumte Veranda - die Vorstufe eines Bahnsteigs - für das Erwarten der Züge nutzten, stiegen die aus Manchester anreisenden Passagiere auf der gegenüberliegenden Seite aus. Mithilfe dieser Trennung konnten Wegekreuzungen verringert und der Betriebsablauf im wahrsten Wortsinn relativ reibungslos gestaltet werden. Zudem zeigte sich mit diesem Pionierbahnhof bereits der auch für die Passagiererfahrung so relevante Schleusencharakter des Empfangsgebäudes, indem sich das Gebäude - wie in Bury's Illustration gut $\mathrm{zu}$ erkennen - zwischen den öffentlichen Verkehr des städtischen Straßenraums auf dem Vorplatz und den Eisenbahnverkehr schob. Beide Bereiche wurden damit deutlich voneinander getrennt. Das Empfangsgebäude erfährt hiermit bereits im Urtypus seine vermittelnde und damit transitorische Grundausrichtung zwischen Stadt- und Verkehrsraum, die es bis in die Gegenwart hinein behalten sollte.

Angesichts der beschriebenen Unsicherheit, wie die neuartige Bauaufgabe des Bahnhofsbaus zu lösen sei, muss die Crown Street Station als baulich wie betrieblich 
gelungener Auftakt bezeichnet werden. Ihr Empfangsgebäude ermöglichte den geforderten Übergang auf das Bahnsystem durch Gewährleistung einer Doppelfunktion: die Schaffung eines Schutzraumes für das (nunmehr) systemische Warten bzw. den situativen Kurzaufenthalt und - damit verbunden - den geordneten und kontrollierbaren Zugang auf die Bahn selbst. ${ }^{41}$ Dieser Ort muss damit als einer der ersten Schauplätze für die Ausbildung einer neuen Kulturtechnik verstanden werden, die nicht allein das beschleunigte Reisen in einem Dampfwagen, sondern ebenso die systemisch und psychisch neuartige Disposition des Antizipierens jener beschleunigten Raumüberwindung in eigens dafür vorgesehen, transitorischen Strukturen beinhaltete. Trotz ihrer weltweiten Strahlkraft als Musterbeispiel für den Bahnhofsbau musste die Crown Street Station ihren Dienst bereits nach sechs Jahren aufgrund des enorm gewachsenen Verkehrsvolumens - die durchschnittlichen Anzahl Tagesreisender verdoppelte sich bereits nach wenigen Monaten - zugunsten der Liverpool Lime Street Station einstellen, die nicht nur größere Kapazitäten, sondern zudem eine geringe Entfernung zum Stadtzentrum von Liverpool aufwies. Das Empfangsgebäude wurde wahrscheinlich wenige Zeit später abgerissen und wich einem Güterzentrum.

\section{Wartebezogenes Raumprogramm (Liverpool)}

Vor dem Hintergrund der verkehrsgeschichtlichen Bedeutung als weltweit erster vollwertiger Bahnhof stellt sich nun die Frage, welches bauliche Gefüge für den neuerlichen organisatorischen Zwang des Wartens in diesem Mutterbau des Eisenbahnwesens bereitgestellt wurde. Wahrhaftig stellt sich gar die Frage, ob es überhaupt bereits ein wartebezogenes Raumprogramm gab. Bis auf die aufgeführte Darstellung von T.T. Bury sind hierzu keinerlei Bauakten überliefert, was die Quellenlage deutlich einschränkt. Dennoch vermutet Meeks in Rückgriff auf jene Darstellung: »On entering the building he [the passenger, R.K.] found himself in a room which combined the functions of ticket-selling and waiting, as in the great concourses of today's terminals. From the waiting room he passed onto the platform and into his carriage under the cover of a train-shed. $\aleph^{42}$

Nach Meeks' Auffassung waren im Pionierbahnhof von Liverpool demnach die Funktionen des Wartens, des Ticketverkaufs und der Gepäckabfertigung in einem großen zusammenhängenden Raum organisiert, was damit der bereits oben erwähnten Orientierung der Bahnhöfe an den Strukturen von Posthöfen entsprechen würde (siehe Abbildung 9). Auch eine zeitgenössische Beschreibung von Walker, die wenige Jahre nach Streckenöffnung verfasst wurde, stützt Meeks' These des frühen Vorhandenseins einer rudimentären räumlichen Struktur, die dem verkehrsinduzierten Phänomen des Wartens Raum bot. Walker beschreibt das Stationsgebäude 1832 folglich als

»(..) a handsome building, used as offices for the clerks of the Company, coach-of-

fices, and apartments for the reception and accommodation of passengers, who are conveyed there in omnibuses from Liverpool (...). « $^{43}$ 
Abbildung 12: Situationsplan und (vermuteter) Grundriss der Crown Street Station Liverpool.

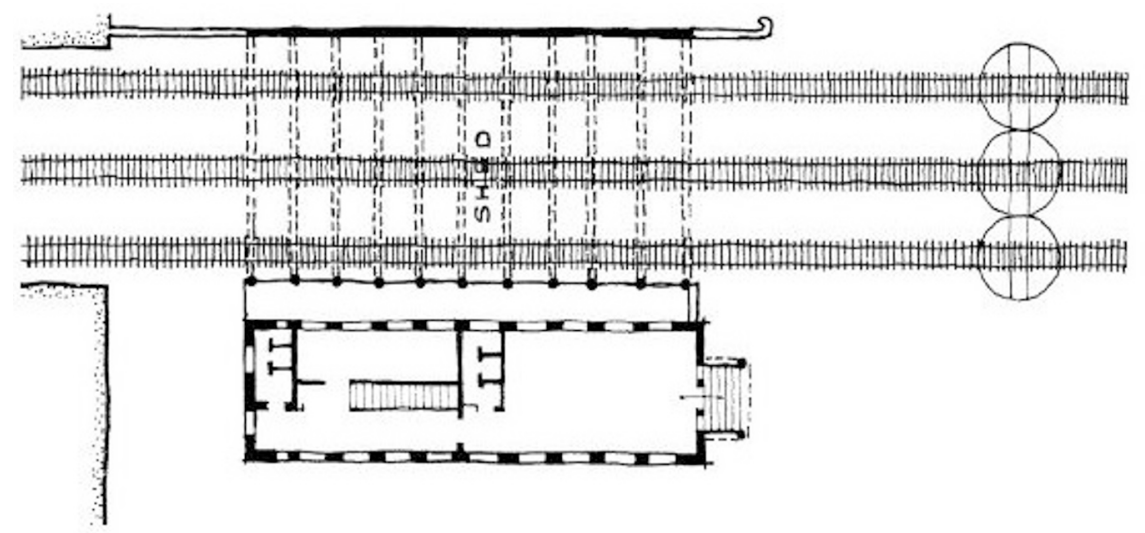

Quelle: Meeks 1956, Annex Fig. 7.

Aus dieser frühen Schilderung lassen sich folglich vier zentrale Punkte ableiten, die für eine Rekonstruktion der baulichen, sozialen und sprachlichen Verhandlung des verkehrlichen Wartens von Interesse erscheinen.

Erstens wird deutlich, dass das Warten bereits von Anbeginn ein Bestandteil der Reiseerfahrung war und eine - wenngleich noch undifferenzierte - bauliche Rahmung erfuhr.

Zweitens steht zu vermuten, dass es aufgrund der undifferenzierten räumlichen Disposition (alle Funktionen in einem Raum) vor der Abfahrt noch keinerlei Klassentrennung bestand, obwohl die L\&M-Eisenbahngesellschaft von Anbeginn zwei unterschiedliche Wagenklassen anbot. Das Warten auf Abfahrt des Zuges war damit - zumindest in Liverpool - noch `klassenlos`, was wiederum soziale und kommunikative Auswirkungen erzeugt haben könnte, die an späterer Stelle noch zur Sprache kommen werden.

Drittens wurde offenbar anfangs weder eine konkrete Begrifflichkeit des >Wartens genutzt noch wurden etwa die "apartments for the reception and accommodation of passengers « als >Warteräume bezeichnet, sondern vielmehr wurde die Praxis des situativen Aufenthalts noch mit der betriebstechnischen Funktion des Wartens innerhalb des Eisenbahnwesens (Empfang und Unterbringung) umschrieben.

Viertens liefert Walkers Beschreibung schließlich einen zentralen Hinweis darauf, dass das verkehrliche Warten seinen originären Ursprung bereits offenbar an anderer Stelle als am Bahnhof fand. So verweist Walker darauf, dass die Reisenden mit Omnibussen aus der Stadt zum Bahnhof transportiert wurden. Der früheste Ort der Erfahrung und Verhandlung des verkehrsinduzierten Wartens war also nicht unbedingt nur der Bahnhof selbst, sondern bereits das Warten auf den Zubringerverkehr zum Bahnhof an Omnibus-Stationen in der Stadt. Dass die Ersterfahrung des systemischen Wartens für die meisten Reisenden nur partiell am Bahnhof stattfand, erhält weitere Unterstützung durch den Befund einer meist im Fahrpreis enthaltenen Transportdienstleistung 
zum und vom Bahnhof in die angrenzende Stadt. Die ersten Bahnhöfe lagen oft der Kernstadt leicht vorgelagert, ${ }^{44}$ weshalb in der Regel ein Zubringerverkehr eingerichtet wurde. Somit kann vermutet werden, dass der Großteil der Reisenden von diesem (kostenlosen) Service Gebrauch gemacht haben dürfte und die Warteerfahrung bereits ihren räumlichen Anfang >in der Stadtく nahm. Auch eine Schilderung des Betriebsablaufs an der Crown Street Station berichtet hierzu passend vom kritischen Umstand, dass viele Reisende mit den Omnibussen erst unmittelbar vor Abfahrt des Zuges am Bahnhof erschienen, was dazu führte, die Wagen oftmals überstürzt zu besteigen. ${ }^{45}$ Dies lässt weiter vermuten, dass die Warteräume am Bahnhof selbst gar nicht zwangsläufig aufgesucht wurden und nährt den Eindruck, dass das früheste verkehrliche Warten für einen Teil der Reisenden im Grunde an vorgelagerten Orten und nicht am Bahnhof selbst stattfand. ${ }^{46}$

Neben jenen aus Walkers kurzer Schilderung ableitbaren Erkenntnissen, lassen sich Einblicke in die früheste Warteerfahrung des Eisenbahnwesens zudem aus den betrieblichen Herausforderungen der Eisenbahngesellschaft gewinnen. Das größte Problem bestand darin, einer ungekannt großen Menschenmenge innerhalb eines kurzen Zeitraums den Übergang von der Stadt auf das (komprimierte) Bahnsystem zu ermöglichen: oder wie Donaghy es ausdrückt: »(...) handling such large crowds, the greatest problem was to get the trains started at their schedulded time. $\aleph^{47}$ Um dieser Herausforderung $\mathrm{zu}$ begegnen, führte die L\&M-Eisenbahngesellschaft einen Maßnahmenkatalog ein. Darin wurden die Kutscher dazu angehalten, spätestens zehn Minuten vor Abfahrt am Bahnhof einzutreffen und damit den Reisenden (und vor allem den Betreibern) einen Zeitpuffer zu verschaffen, der für den geordneten, kontrollierten und sicheren Übergang auf die Wagen benötigt wurde. Diesen Zeitpuffer, der als ein Ursprung des systemischen Wartens gelten kann, sollten die Reisenden im Warteraum verbringen, aus dem sie erst fünf Minuten vor Abfahrt durch ein Glockensignal herausgebeten wurden. Im Anschluss wurde dann für einige Minuten eine kleinere Handglocke geläutet, um die Passagiere zum Einsteigen zu bewegen. ${ }^{48}$ Zudem durften den Warteraum nur Inhaber eines Fahrscheins nutzen, sodass hier keine Angehörigen Platz fanden, die Reisende und ihr Gepäck zum Bahnhof brachten. ${ }^{49}$

Für eine weiterführende Rekonstruktion der frühesten Wartesituation des Eisenbahnzeitalters kann bzw. muss aufgrund der fehlenden Quellenlage eine Interpretation der Illustration T.T. Bury's unternommen werden. Bury's Ansicht der Crown Street Station untermauert mit den im linken Bildrand sichtbaren, pferdegezogenen Omnibussen nicht nur den zuvor besprochenen Umstand des starken Zubringerverkehrs zum weit

In Falle von Liverpool etwa lag der Crund für die etwas vorgelagerte Position des Bahnhofs in der behördlichen Auflage, dass die Dampflokomotiven nicht in das Stadtgebiet einfahren durften.

Paul Wright, »Disused Stations: Liverpool Crown Street Station«, 2014, www.disused-stations.org.uk///liverpool_crown_street/, zugegriffen am 15.08.2018.

Bzw. sich das früheste verkehrliche Warten gestaffelt auf mehrere Warteorte (Stadt und Bahnhof) verteilte. 
vom Liverpooler Stadtzentrum entfernten Bahnhof. Die Illustration zeigt darüber hinaus vor allem die räumliche Verteilung der Reisenden im Bahnhofsgelände, die Rückschlüsse auf den möglichen Bewegungsradius und damit der Formalität des Wartens in der Frühphase ermöglicht. In der dargestellten Szene sind Reisende in fast allen Bereichen des Bahnhofs zu sehen, die sich wahrscheinlich in zwei Gruppen unterteilen lassen. $\mathrm{Zu}$ sehen sind zum einen Reisende, die mit einem gerade zuvor eingetroffenen $\mathrm{Zug}$ aus Manchester in Liverpool eingetroffen sein könnten (die Ankunftsseite befand sich wie erwähnt am rechten äußeren Gleis) und sich dem Anschein nach in Richtung der bereitstehenden Omnibussen orientieren - bzw. sie bereits besteigen (linker Bildrand) -, um das Stadtzentrum zu erreichen. Zum anderen ist eine Gruppe Reisender zu sehen, die aufgrund ihrer Nähe des auf der Abfahrtsseite bereitstehenden Zuges (unmittelbar am Empfangsgebäude) die Abfahrt ihres Zuges nach Manchester erwarten. Während sich einige Reisende dieser zweiten Gruppe - in Nähe zu einer Stationsuhr - im eigens dafür vorgesehen Bereich der überdachten Veranda aufhalten, scheinen andere Reisende diese räumliche Struktur gar nicht zu nutzen. Sie warten, zum Teil auf Koffern sitzend, vor dem Gebäude oder zwischen den Gleisen (Gruppe in Bildmitte). Bei aller Vorsicht der Verallgemeinerung dieser punktuellen Darstellung ${ }^{50}$ entsteht damit jedoch der Gesamteindruck eines relativ liberalen, wenig reglementierten, wenig formalisierten und bisweilen ungeregelten Wartens, das weder von Stationspersonal noch von Einzäunungen oder anderen baulichen Hindernissen gelenkt wurde. Die ersten Eisenbahnpassagiere verbrachten damit das systemische Warten auf Abfahrt wohl keineswegs rein statisch im dafür vorgesehen Warteraum der Station (hier entlang des Bahnsteigs gelegen), sondern - wohl auch in Abhängigkeit der Wetterlage - im gesamten Bahnhofsumfeld. Trotz zweier bestehender Wagenklassen der L\&M-Eisenbahngesellschaft (first class, second class) sind in Bury's Darstellung zudem keinerlei räumliche Trennungen auf dem überdachten Bahnsteig auszumachen, sodass der Eindruck entsteht, dass die später in anderen Bahnhofsgebäuden obligatorisch werdende Klassentrennung im Pionierbahnhof von Liverpool noch keine Realisierung erfuhr. Im Zusammenspiel mit der freien Raumnutzung stellt sich somit das Warten in der absoluten Frühphase des (englischen) Eisenbahnwesens als situativer Aufenthalt mit einem relativ hohen Grad an sozialem, kommunikativem und klassenübergreifendem Austausch dar.

Zusammenfassend kann so für die Kulturgeschichte des (frühen) verkehrlichen Wartens zunächst abstrahiert festgehalten werden, dass die >Erstverhandlungく des situatives Aufenthalts sich räumlich flexibel, stark informell, sozial durchlässig - und unter Berücksichtigung der vielen Zubringerverkehre - mitunter für einige Gruppen bezüglich der absoluten Dauer relativ kurz gestaltete. Dass diese Ableitungen jedoch stark mit ortsspezifischen Gegebenheiten variierten und eine Verallgemeinerung der frühen Warteerfahrung damit wiederum erschwert wird, zeigt bereits der Blick auf den korrespondierenden Endpunkt der >Mutterstrecke< im benachbarten Manchester.

50 Die kritisch-reflektierte Bildinterpretation ist traditionell eine Domäne der Kunstgeschichte, erfuhr jedoch im Zuge des cultural und iconic turn auch stärkeren Eingang in die Kultur- und Sozialwissenschaften. Dazu z.B. Winfried Marotzki und Horst Niesyto, Hg., Bildinterpretation und Bildverstehen: methodische Ansätze aus sozialwissenschaftlicher, kunst-und medienpädagogischer Perspektive (Wiesbaden: VS Verlag für Sozialwissenschaften, 2006). 


\subsubsection{Manchester - Liverpool Road Station (1830)}

\section{Bauliche Kurzbeschreibung}

Die Liverpool Road Station im westlichen Innenstadtbereich Manchesters bildete das Gegenstück zur Crown Street Station in Liverpool. Sie wurde nach langen Standortdiskussionen erst kurz vor Streckenöffnung im Jahr 1830 als ein 80 Fuß langer, stuckverputzter Backsteinziegelbau fertiggestellt. Das Empfangsgebäude unterschied sich gegenüber dem Liverpooler Pendant durch ein hochgelegenes Abfahrtsgleis, das ein Stockwerk über dem Straßenniveau lag. Das zweistöckige Gebäude musste somit nicht nur Geschäftsräume für die Bahngesellschaft und Schutzräume für die Reisenden schaffen, sondern in seinem Inneren den Übergang auf die Bahn zusätzlich durch Treppen vermitteln. Wie in Liverpool schob sich auch in Manchester das Empfangsgebäude bereits deutlich als transitorischer Übergangsbereich und Scharnier zwischen den öffentlichen Stadtraum und den (neuen) Verkehrsraum des Schienenweges.

Abbildung 13: Ansicht der Manchester Liverpool Road Station aus dem Jahr 1905 im Bauzustand des Entstehungsjahres 1830. Das eigentliche Empfangsgebäude befindet sich in der rechten Bildhälfte, das Eckgebäude aufder linken Seite war bereits vorhanden. Im Empfangsgebäude sind die beiden erstmals klassenspezifisch getrennten Eingänge zu erkennen (first class mit leicht hervorspringendem Eingangsportal, rechts daneben: second class, ganz rechts außen: Frachteingang).

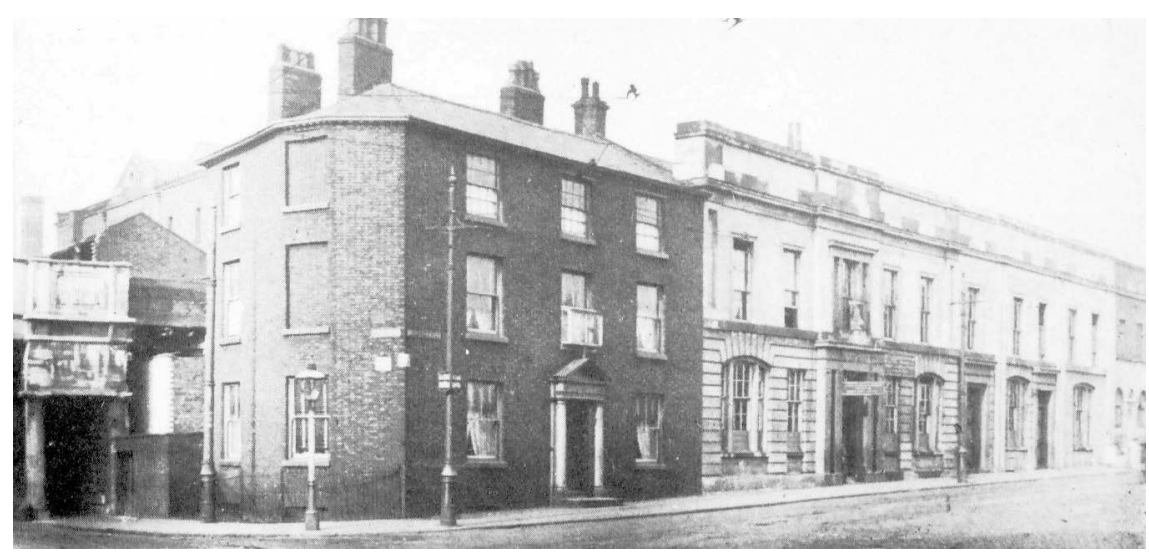

Quelle: Fitzgerald 1980, S. 55.

In gestalterischer Hinsicht wurde die straßenseitige Fassade des Empfangsgebäudes ähnlich wie in Liverpool mit aufwendigen Fenster- und Türumrandungen bekleidet, wenngleich der Bau, eingefasst in einen angrenzenden Bestandsbau, im Gesamten weniger erhaben erschien. Ein Gurtgesims trennte die zwei Stockwerke, die Attika wurde erhöht, um den Dachaufbau zu verdecken. Walker, dessen Schilderung bereits für den Bahnhof in Liverpool Erwähnung fand, beschreibt das Empfangsgebäude im Jahr 1832 erstaunlich knapp und randständig als »spacious building« mit griechischer Eingangs- 
front, das im Vergleich zum Endbahnhof in Liverpool zusätzlich mit einer Reihe von Geschäftsräumen auf Straßenniveau ausgestattet war. ${ }^{51}$

\section{Lagerhaus oder Empfangsgebäude?}

Trotz im Grundsatz ähnlich gelagerter funktionaler Ansprüche - Vermittlung der Reisenden auf den Eisenbahnverkehr - unterschied sich der Endbahnhof von Manchester dennoch nicht nur gestalterisch von seinem Pendant in Liverpool, sondern auch hinsichtlich seiner städtebaulichen Einbindung. Das Bahnhofsgelände in Manchester lag inmitten eines innenstadtnahen Industriegeländes mit Fabriken und Lagerhäusern, die wiederum in unmittelbarer Nähe zu den für Manchester lebenswichtigen Wasserstraßen des Irwell und des Bridgewater-Kanals errichtet worden waren. Diese Nähe zum industriellen Kern und den Wasserstraßen sollte auch die bauliche Charakteristik dieses weltweit ältesten bis heute noch erhaltenen Endbahnhofs bestimmen. Fitzgerald bemerkt hinsichtlich dieser sindustriellen< Einbindung, dass die Leitungsebene der Liverpool \& Manchester Railway über vielfältige Erfahrungen im gewerblichen Bereich verfügte, nicht jedoch über Erfahrungen im großmaßstäblichen Transportwesen. Notgedrungen orientierten sich aus Fitzgeralds Sicht die Verantwortlichen beim Bau des Passagiergebäudes in Manchester daher ganz anders als in Liverpool an den lokal bestehenden Verkehrsbauten des mit der Eisenbahn konkurrierenden Kanalwesens und damit schließlich am baulichen Typus des Lagerhauses. ${ }^{52}$

Das Bahngelände in Manchester setzte sich folglich primär aus einem großen dreistöckigen Lagerhaus zusammen, im das Passagiergebäude nicht als bauliches Spezifikum herausstach, sondern sich einem vergleichsweise stärker industriell-gewerblich geprägten Umfeld unterordnen musste. Selbst in der Eröffnungszeremonie spielte das auf der Ankunftsseite gelegene Lagerhaus die entscheidendere Rolle als das Empfangsgebäude, ${ }^{53}$ was zwar sicherlich der gegenüber dem Empfangsgebäude größeren Kapazität geschuldet war, aber insgesamt auch sinnbildlich für die stärkere bauliche Orientierung an einem >Warenumschlagplatz und der weniger starken räumlichen Trennung von Güter- und Personenverkehr steht. Mit dieser gegenüber Liverpool unterschiedenen kontextuellen Einordnung einer in Manchester stärker am Güterverkehr orientierten Anlage lässt sich wohlmöglich auch der aus heutiger Sicht etwas befremdliche Befund erklären, warum die frühesten Passagiergebäude - etwa in einer der ersten deutschsprachigen Schilderungen der neuen Bahnstrecke - mancherorts als »Gesellschaftswaarenhäuser ${ }^{54}$ bezeichnet wurden.

51 Walker, An Accurate Description of the Liverpool and Manchester Railway, 38.

$52 »(.$.$) it is reasonable to suggest that the committee was inclined to adapt the experience of wa-$ terways to its own situation« (Fitzgerald, Liverpool Road Station, Manchester, 30). Raumgreifende Warenhäuser wurden insbesondere deshalb benötigt, weil die mit der Eisenbahn angelieferten Waren oftmals nicht unmittelbar abgeholt wurden. Die Eisenbahngesellschaft musste daher eine zwischenzeitliche Verantwortung für die Waren übernehmen und sie zwischenlagern. Um zudem gegenüber dem etablierten Kanalwesen konkurrenzfähig zu sein und den Kunden ähnliche Services zu bieten, mussten die Eisenbahngesellschaften in großräumige Lagerhäuser investieren. Vgl. Donaghy, Liverpool \& Manchester Railway Operations, 1831-1845, 38.

53 Kirwan, A Descriptive and Historical Account of the Liverpool and Manchester Railway, 19.

54 Das grösste Wunderwerk unserer Zeit, oder, Die Eisenbahn für Dampfwägen zwischen Liverpool und Manchester in England (Nürnberg: Friedrich Campe, 1832), 7. 
Der Eindruck einer in Manchester vergleichsweise pragmatischeren und bisweilen stiefmütterlicheren Behandlung des Themas Empfangsgebäude kann weiterhin dadurch bekräftigt werden, dass in Manchester keine für die Eisenbahnarchitektur so prägende Personen- bzw. Wagenhalle, sondern lediglich ein kleines »departure-shed « ${ }^{55}$ errichtet wurde. Stattdessen bestanden auf der Bahnseite lediglich kurze und schmale Kolonnaden, die den Einstieg in die Wagen vermittelten. Entsprechend deklarierten zeitgenössische Presseberichte den Bau des Empfangsgebäudes als »coach office ${ }^{56}$, was eher auf den Bau eines Gebäudes für die Eisenbahngesellschaft als auf ein Gebäude für die Unterbringung von Passagieren verweist. Der Architektur- und Eisenbahnhistoriker Gordon Biddle führt den geringeren Gestaltungsanspruch ${ }^{57}$ an den zweiten Endbahnhof dieser Mutterstrecke dabei - ähnlich wie Fitzgerald - interessanterweise auf den damaligen sgenius loci< der Industriestadt Manchester zurück, der in Kontrast zu Liverpools Selbstauffassung einer stärker kulturell orientierten Hafenstadt zu stehen schien. Im vergleichenden Blick auf die beiden ersten, speziell für den Passagiertransport erbauten Endbahnhöfe des Eisenbahnwesens vermutet Biddle zusammenfassend:

»These termini symbolised the difference between the two towns at that time. Both were mixtures of affluence and poverty, but Liverpool's affluence was expressed culturally (...). Manchester, on the other hand, the growing >cottonpolis< (...) was run by manufacturers, and for them a station at the bottom of Liverpool Road was good enough. $\ll^{58}$

\section{Wartebezogenes Raumprogramm (Manchester)}

Hinsichtlich der Frage vorhandener Raumangebote für das verkehrliche Warten verweist eine knappe Bahnhofsbeschreibung von Walker aus dem Jahr 1832 auf ein Empfangsgebäude "for the reception of passengers. ${ }^{59}$ Was bei Walker noch relativ unspezifisch klingt, erfährt durch eine Schilderung des österreichischen Eisenbahn-Ingenieurs Luigi Negrelli und dessen Eindrücke der Water Street Station ${ }^{60}$ weitere Präzisierung. Der Ingenieur unternahm Ende der 1830er Jahre eine Reise, die ihn nach Frankreich und Belgien und schließlich (natürlich) auch ins Mutterland der Eisenbahnen führte, um die Wirkungen des »höchste[n] Communicationsmittel[s] unserer Zeit« zu studieren und diese Eindrücke für den Aufbau eines heimischen Eisenbahnsystems nutzbar $\mathrm{zu}$ machen. Angekommen in Manchester beschreibt er den Bahnhof wie folgt: 
»Das große Plateau, zu welchem man durch verschiedene Rampen und Scalinaden gelangt ist von den Administrationsgebäuden, den Passagierzimmern und Remisen umgeben (...). « ${ }^{61}$

Schließlich berichtet auch Whishaw in seinem 1842 veröffentlichten Kompendium des frühen englischen und irischen Eisenbahnwesens in noch größerer Deutlichkeit von »waiting-rooms, which are [...] on the same level as the railway, and are approached by wide staircases from the ground-floor. ${ }^{62}$

Aus Walkers, Negrellis und Whishaws zeitgenössischen Berichten wird somit klar ersichtlich, dass Räumlichkeiten für den Empfang und Aufenthalt von Passagieren intentional angelegt worden waren. Dank des bis in die Gegenwart erhalten gebliebenen Gebäudekomplexes ${ }^{63}$ kann der ursprüngliche Grundriss zudem auch heute noch klar nachvollzogen werden (siehe Abbildung 15). Darin bestätigen sich die zeitgenössischen Schilderungen über Räumlichkeiten für den situativen Aufenthalt, sodass festgehalten werden kann, dass auch der Endbahnhof in Manchester bereits von Beginn an über ein vorhandenes Raumprogramm für das systemische Warten verfügte. Damit zeigte die Liverpool Road Station in Manchester weit deutlicher als ihr Pendant in Liverpool das Vorhandensein eines auf das verkehrliche Warten ausgerichteten Raumprogramms.

Abbildung 14: Grundriss des Empfangsgebäudes mit einer innerhalb des Raumprogramms erstmals deutlich sichtbar verfolgten Klassentrennung.

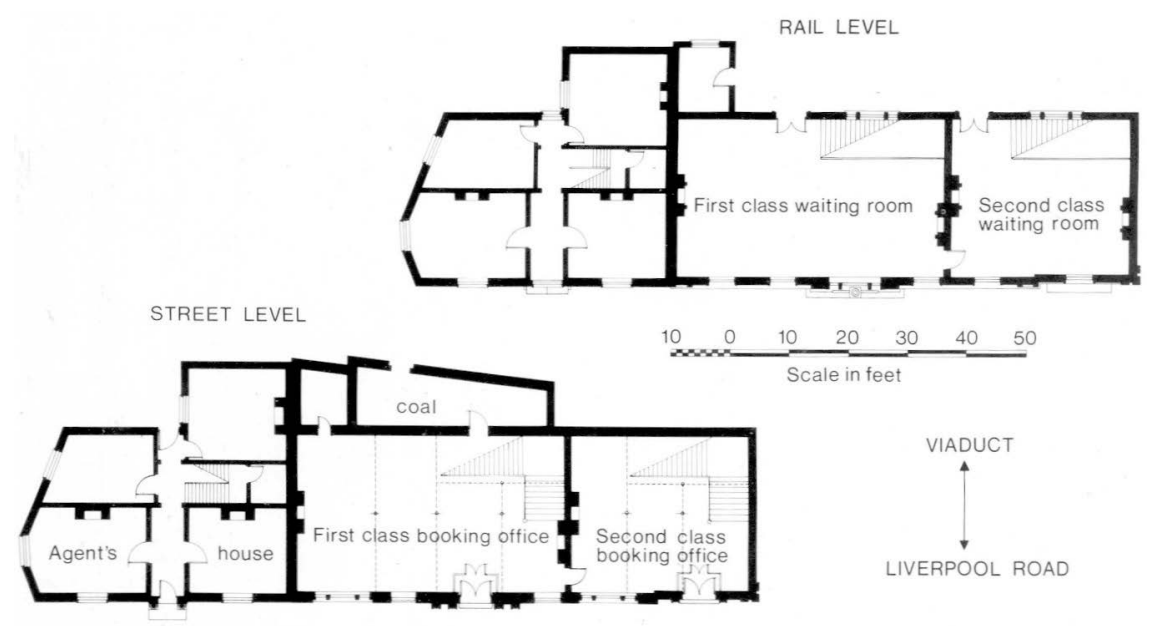

Quelle: Fitzgerald 1980, S. 51.

61 Luigi Negrelli, Ausflug nach Frankreich, England und Belgien zur Beobachtung der dortigen Eisenbahnen, mit einem Anhange über Anwendung von Eisenbahnen in Cebirgsländern (Frauenfeld: Beyel, 1838), 163f.

62 Whishaw, The Railways of Great Britain and Ireland, 199.

63 Der ehemalige Bahnhof ist heute Teil des Museum of Science and Industry von Manchester. 


\section{Formalität und Soziabilität des Wartens}

Zwar ist die Liverpool Road Station in gestalterischer Hinsicht als pragmatischere Lösung zu bezeichnen, doch zeigt sie ein Novum, das für die kulturgeschichtliche Betrachtung des verkehrlichen Wartens von großer Bedeutung erscheint: die klassenspezifische Trennung der Reisenden. Bereits bei Zutritt ins Gebäude wurden die Reisenden entsprechend ihrer Wagenklasse voneinander separiert und verblieben bis zur Abfahrt in ihren jeweiligen Wartebereichen. Der Eingang zur 1. Klasse wurde dazu statusgerecht durch einen leicht hervorspringenden Eingangsbereich, Lisenen, aufwendigere Fensterdekorationen und schließlich durch einen urnenhaften Baluster über dem Eingang versucht entsprechend gegenüber dem Eingang der 2. Klasse distinguierend zu gestalten. Anders als in Liverpool wurden die Wagenklassen in Manchester damit bereits mit Betreten des Empfangsgebäudes und damit bereits vor Beginn der Abreise separiert und es bestanden während des Wartens weniger Möglichkeiten des klassenübergreifenden Austauschs. Angesichts der gegenüber der Liverpool Crown Street Station späteren Bauzeit der Manchester Liverpool Road Station zeigte damit das Raumprogramm bereits eine deutlich stärkere Differenzierung hinsichtlich der Wartepraxis. Warum noch vor Eröffnung der Strecke - und damit vor der eigentlichen betrieblichen Erfahrung des alltäglichen Eisenbahnverkehrs - bereits zwei in puncto Warteinfrastrukturen so unterschiedliche Empfangsgebäude errichtet wurden, bleibt jedoch fraglich und ist aus der bestehenden Quellenlage nicht zu beantworten.

\section{Rekonstruktion der Warteerfahrung}

Anders als im Beispiel des Endbahnhofs von Liverpool sind für die Liverpool Road Station keine Illustrationen überliefert, die es erlauben würden, beispielhaft eine konkrete Abfahrtssituation nachzuvollziehen. Zwar sind Darstellungen einfahrender oder abfahrender Züge über die angrenzende Irwell-Brücke vorhanden, sie lassen aber keine Interpretation des frühen Wartens im unmittelbaren Umfeld des Empfangsgebäudes zu. Eine Rekonstruktion der frühen Warteerfahrung in Manchester kann daher nur auf Grundlage der wartebezogenen Grundrissdisposition erfolgen.

Angesichts der spezifischen Verhältnisse eines gegenüber Liverpool hochgelagerten und schmalen Abfahrtsgleises und der zentralen Einrichtung dezidierter Warteflächen, kann zunächst davon ausgegangen werden, dass das verkehrliche Warten für Reisende mit Abfahrtsort Manchester deutlich beengter und weniger liberal erfahren worden war. Die nur sehr kleine überdachte Bahnsteigfläche, die laut Whishaw lediglich dafür bestimmt war, die Passagiere für den Moment des Einstiegs in die Wagen vor Wettereinflüssen zu schützen, ${ }^{64}$ ließ keine vergleichbar freie Raumnutzung wie in Liverpool zu. Damit wurde der Großteil der Wartezeit - anders als in Liverpool - vermutlich stärker raumgebunden bzw. stationär in den Warteräumen und nicht im weiteren Umfeld der Bahnhofsanlage verbracht.

Ein umgerechnet ca. $69 \mathrm{~m}^{2}$ großer Warteraum für die zweite Klasse und ein ca. $104 \mathrm{~m}^{2}$ großer Raum für die erste Klasse mussten hierbei genügen, um die Reisenden eines Zuges (je nach Auslastung durchschnittlich zwischen 80 und 100 Personen) ${ }^{65}$

64 Whishaw, The Railways of Creat Britain and Ireland, 199.

65 Berechnet auf Grundlage der Angaben zur Fahrplangestaltung von ebd., 206. 
aufzunehmen. Zieht man zudem in diesen Räumen die Flächenanteile der Treppenerschließung ab und berücksichtigt dazu noch die starken saisonalen Schwankungen der Passagierzahlen, lässt sich damit eine Situation rekonstruieren, die im Falle zweier vollbesetzter Warteräume während der Sommermonate eine überaus beengte Atmosphäre geschaffen haben dürfte.

Dieser ortsspezifische Zwang zur Nutzung der knapp bemessenen Wartesäle in Manchester mag damit eine Erklärung für die zeitgenössische Schilderung Walkers liefern, der trotz sonst überaus knapper Notizen über diesen Bahnhof bezüglich der Nutzungspraxis der Reisenden festhält: "who pass immediately through it [the waiting rooms, R.K.] to and from the carriages. ${ }^{66}$ Offenbar zeigte sich hiermit auch in Manchester eher eine Nutzungspraxis der schnellen Durchquerung der Warteräume, zumindest jener Reisender, die mit der Kutsche am Bahnhof ankamen. Ob es daneben eine Wartepraxis eines langen, stationären Wartens auf die Abfahrt gab und welche Gruppen diese Praxis in Anspruch nahmen, ist nicht überliefert.

\section{Sprachliche Repräsentationen und Semantik des Wartens}

Im Hinblick auf die sprachliche Repräsentation des (frühen) Wartens erhärtet sich wie bereits in der Betrachtung der Liverpool Crown Street Station der Befund, dass das Warten als ein routinierter Teilaspekt des Reisens zumindest begrifflich noch keine eigenständige Form erhielt. Die später fast überwiegend benutzte Bezeichnung der Wartesäle oder Warteräume wird bei Walker (»rooms for accomodation«) als auch bei Negrelli (»Passagierzimmer«) eher mit der Nutzergruppe als mit ihrer erlebten Tätigkeit bzw. Praxis bezeichnet. Wahrscheinlich geschah diese Umschreibung nicht zuletzt deshalb, weil diese Praxis des systemischen Kurzaufenthalts noch gänzlich neu war. Dagegen wird weniger Jahre später in den weitrezipierten Berichten Whitshaws bereits von >waiting rooms gesprochen, was vermuten lässt, dass - zumindest im englischen Kontext - nach einem Jahrzehnt der Eisenbahnnutzung der situative Aufenthalt einen zentralen und weithin verinnerlichten Aspekt der Reiseerfahrung ausmachte, der auch sprachlich konkret als Praxis des >Wartens` gefasst wurde.

\subsubsection{Nürnberg - Ludwigsbahnhof (1835)}

\section{Bauliche Kurzbeschreibung}

Der Ludwigsbahnhof von Nürnberg gilt als das erste Bahnhofsensemble auf deutschem Boden. Es bildete einen der beiden Endpunkte der ersten deutschen Eisenbahnstrecke zwischen Nürnberg und Fürth, die Ende des Jahres 1835 im euphorisierten Windschatten der pionierhaften Erfahrungen in England und den USA als rein privatfinanzierte Bahn eröffnet wurde. Mit der nur knapp sieben Kilometer langen Strecke, auf der neben den neuen Dampfwagen überwiegend noch von Pferden gezogene Wagen verkehrten, wurden zwei Städte miteinander verbunden, die bereits über historisch enge Austauschbeziehungen verfügten. Eine im Vorfeld der Eröffnung unternommene 40tägige Verkehrszählung extrapolierte eine jährliche Frequenz von mehr als 612.000 Per- 
sonen, die »zu Fuß und zu Wagen« zwischen den Städten verkehrten ${ }^{67}$ und damit als eine der meistfrequentierten Verkehrsverbindungen in ganz Deutschland angesehen wurde. Entsprechend groß wurde das Nutzerpotential einer installierten Eisenbahnverbindung eingeschätzt. Weil für die Realisierung solch eines Vorhabens bis zu diesem Zeitpunkt jedoch nur geringe Vorerfahrungen vorlagen, waren die Bezüge zu den englischen Mutterbahnen omnipräsent. »Die Bahn«, so hieß es demonstrativ in der Gründungseinladung der neuen Eisenbahngesellschaft, »soll nach dem Muster der Schienenwege zwischen Liverpool und Manchester, und zwischen Darlington und Stockton in England gebaut, jedoch jede Verbesserung, welche seitdem die Erfahrung gelehrt hat, dabei in Anwendung gebracht werden. ${ }^{68}$ Nicht nur der Streckenbau oder die gewählte Spurweite von $1435 \mathrm{~mm}$ orientierten sich dazu an den zum Teil selbst in England in Augenschein genommenen Erfahrungen, auch Lokomotiven und der erste Lokführer ${ }^{69}$ kamen zunächst noch von der Insel.

\section{Abbildung 15: Ludwigsbahnhof in Nürnberg (um 1836, Stich von J.Hintz).}

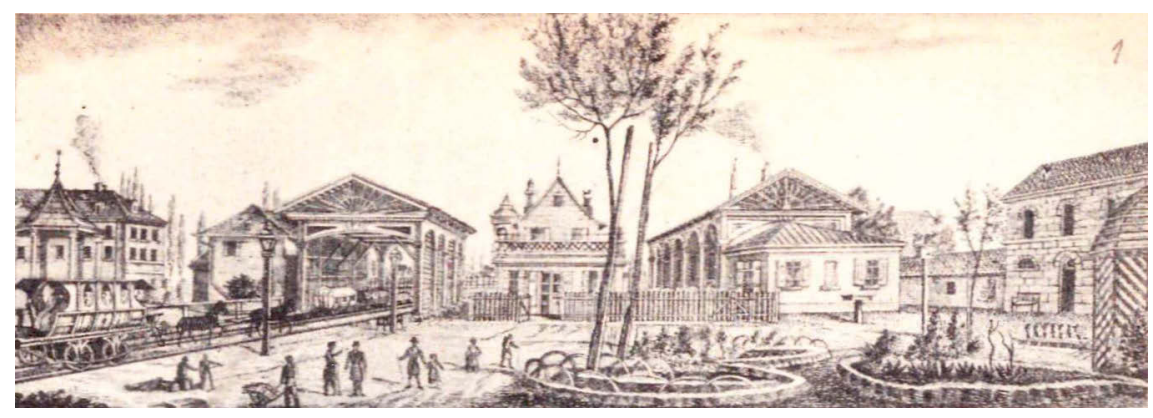

Quelle: Schulz 1935.

Analog zu den betrieblichen Merkmalen war auch die Konzeption der Passagiergebäude offenbar deutlich vom Wissenstransfer aus England geprägt. So wurde in Adaption des Bahnhofs-Archetypus der Liverpooler Crown Street Station auch der erste deutsche Bahnhof ebenfalls als einseitige Anlage gestaltet, die später wiederum die Vorlage ähnlicher Bauten, etwa in St. Petersburg (1837), Potsdam (1838), Berlin (1838), Wien (1839) oder Amsterdam (1839) bildete. Da zunächst nur wenige Züge abgefertigt werden mussten und der Bahnhof keinen Durchgangsverkehr aufwies, erschien dieser Typus der Königlich privilegierten Ludwigs-Eisenbahn-Gesellschaft (LEG) als effizienteste Lösung der neuen Bauaufgabe. ${ }^{70}$ Anders jedoch als bei vielen der ersten englischen Stationen wurde das gesamte Bahnhofsgelände durch eine Umzäunung eingefriedet und

67 Vgl. Scharrer, Deutschlands erste Eisenbahn mit Dampfkraft oder Verhandlungen der Ludwigs-EisenbahnGesellschaft (Nürnberg: Riegel und Wießner, 1837), 3.

68 Ebd.

69 Als anekdotische Randnotiz sei hier erwähnt, dass dieser englische Lokführer mit Namen William Wilson trotz einer ursprünglich nur kurzfristig angedachten Anstellung in Nürnberg nicht nach England zurück ging, sondern bis zu seinem Lebensende (1862) in Nürnberg blieb und dort mitunter in den Stand einer Kultperson erhoben wurde.

Vgl. Biddle, Victorian Stations: Railway Stations in England and Wales, 1830-1923, 107. 
entsprach damit stärker dem Charakter eines abgeschlossenen Geländes, das anfangs zeitgenössisch lediglich als »Hof« bezeichnet wurde.

Abbildung 16: Situationsplan des Bahnhofs Nürnberg (1835).

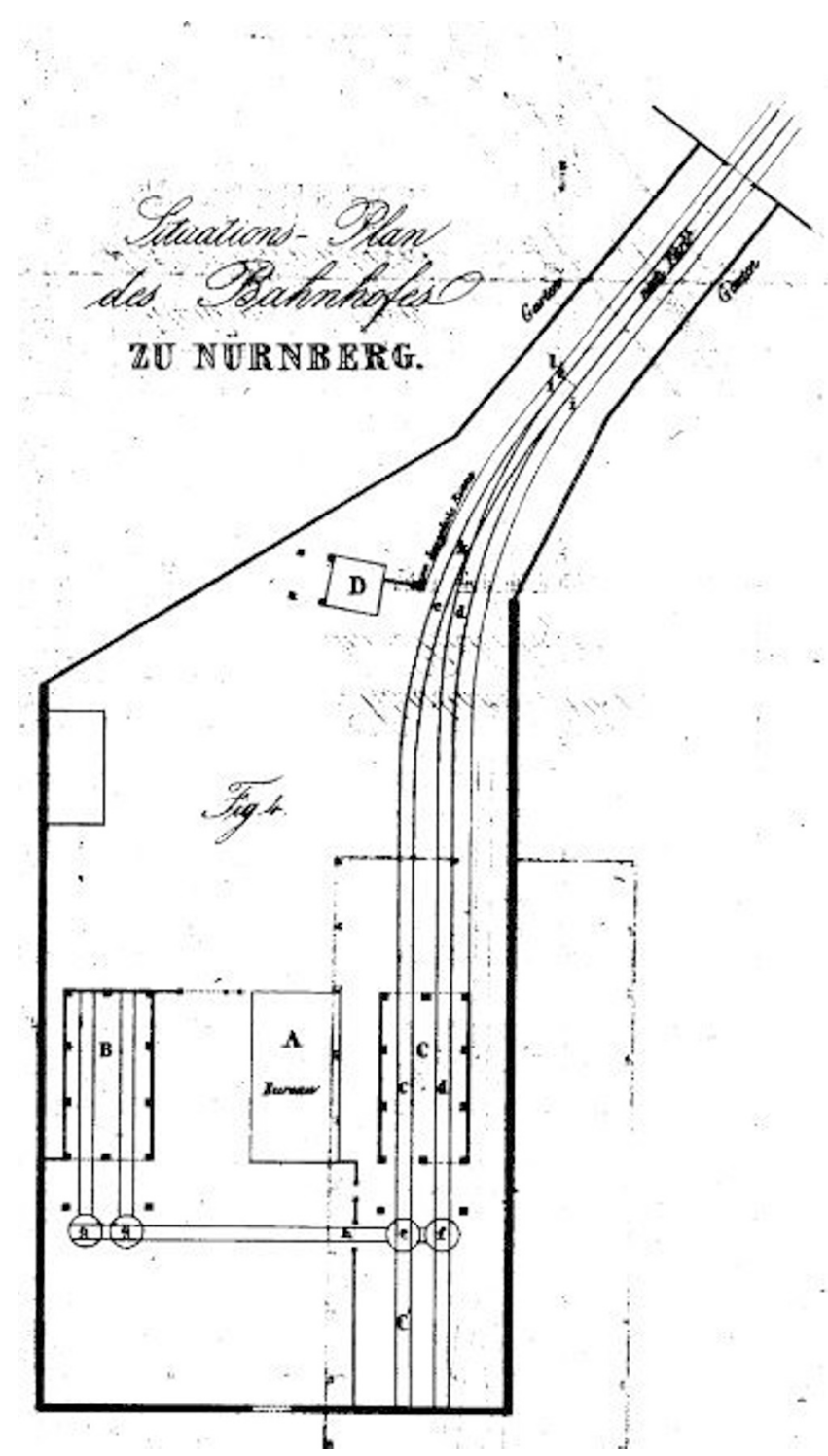

Quelle: Allgemeine Bauzeitung 1838, Blatt CCVI.

Musterhaft für die Anfangsjahre des Eisenbahnwesens wurde auch das Nürnberger Stationsgebäude, wie sein Pendant in Liverpool, im Stile eines einfachen, zweigeschossigen Wohnhauses errichtet, das im Grunde keine eigenständigen Merkmale aufwies, die es von einer umliegenden Wohnbebauung unterscheiden ließ. Ange- 
sichts der Anmutung eines »Fränkische[n] Häuschen[s] mit Giebeldach und Fensterläden, das ein schön verzierter gußeiserner Zaun umrahmte « ${ }^{71}$, kann damit nicht $\mathrm{zu}$ Unrecht von einem biedermeierlichen Beginn des deutschen Eisenbahnhochbaus gesprochen werden. Dennoch verfügte dieser einfache Hochbau, der zusammen mit seinem Pendant in Fürth einen der ersten Schauplätze der Beschleunigungserfahrung als auch des verkehrsinduzierten Wartephänomens auf deutschem Boden bildete, nachweislich bereits über ein angeschlossenes, noch komplett aus Holz gefertigtes »überdecktes Bahnstück « ${ }^{72}$. Wie aus einem in der Allgemeinen Bauzeitung veröffentlichten Situationsplan hervorgeht (Abbildung 16), entstanden links und rechts des kleinen Empfangsgebäudes von Nürnberg zwei Remisen zum Abstellen der Wagen, die über Gleise und Drehscheiben erreichbar und miteinander verbunden waren. Somit verfügte der Nürnberger Bahnhof bereits in äußerst vereinfachter Form auch über das eisenbahntypische Bauelement einer Gleishalle, das Reisenden ein witterungsgeschütztes Ein- und Aussteigen ermöglichte (im Grundriss als Gebäude C bezeichnet).

\section{Wartebezogenes Raumprogramm (Nürnberg)}

Entsprechend des Vorbildes der Liverpool Crown Street Station waren auch in Nürnberg die Funktionen des Fahrkartenverkaufs und des Warteraums in unmittelbarer räumlicher Nähe zueinander untergebracht. Alexander Lips, ein zunächst eisenbahnkritischer und sich nach Eröffnung dieser ersten deutschen Mutter- und Pionierbahn zum Eisenbahnunterstützer wandelnder Schriftsteller, schildert das funktionale Raumgefüge des ersten deutschen Bahnhofs wie folgt:

»In dem Hauptgebäude befindet sich der Cassier, die Wartzimmer und besonders der Bahninspektor und der Direktorial-Comissar, welchem die Aufsicht auf die Fahrten und die dafür nöthige Controlle in allen Theilen übertragen ist. ${ }^{73}$

Auf Basis dieser Schilderung ist davon auszugehen, dass für das verkehrsinduzierte Warten zwar ein auf die rudimentärste Form reduziertes Raumangebot existierte, dieses jedoch noch keinerlei spezifische Differenzierung in unterschiedlichen Wagenklassen aufwies. Wenngleich weiterreichende Einblicke in Gestaltung und Ausstattung dieser frühesten Formen des wartebezogenen Raumprogramms leider nicht überliefert sind, lässt sich dennoch auf Grundlage der Schilderung von Lips schlussfolgern, dass hier noch keine besonders raumgreifende oder komplexe bauliche oder betriebliche Verhandlung und Rahmung des wartenden Passagiers stattfand. Vielmehr war der Nürnberger Ludwigsbahnhof auch in dieser Hinsicht als Provisorium zur Erprobung der Betriebsverhältnisse zu bezeichnen. Dies wird indirekt durch einen Zwischenbericht der Eisenbahnverwaltung verdeutlicht, der nach dem ersten mehrmonatigen Betrieb während des Winters 1835/36 den Bau einer (neuen) Warteinfrastruktur anregt

71 Hermann Claser, »Topos Bahnhof «, in Renaissance der Bahnhöfe, hg. von Bund Deutscher Architekten BDA, Deutsche Bahn AG, und Förderverein Deutsches Architekturzentrum DAZ in Zusammenarbeit mit Meinhard von Gerkan (Wiesbaden: Vieweg+Teubner Verlag, 1996), 281.

72 Üeber Depots und Sammelplätze für Waaren und Reisende (Stazionsplätze) bei Eisenbahnen«, Allgemeine Bauzeitung 3, Nr. 19, 20, 21 (1838): 195.

73 Alexander Lips, Die Nürnberg-Fürther Eisenbahn in ihren nächsten Wirkungen und Resultaten (Nürnberg: Riegel und Wießner, 1836), 16. 
und diese schließlich auch veranlasst. Der Direktor Scharrer selbst vermerkt zu dieser neuen Notwendigkeit:

»Heitzbare Warthallen in den innern Hofräumen erscheinen bei dem großen Andrang der die Abfahrten erwartenden Passagiere als dringendes Bedürfniß. ${ }^{74}$

Zwar bleibt hierbei im Unklaren, ob mit diesen beheizbaren Warthallen die kleinen bereits bestehenden Räumlichkeiten innerhalb des Empfangsgebäudes gemeint waren von denen Lips berichtet oder aber eine gänzlich neue Wartehalle außerhalb des Gebäudes realisiert wurde. Unabhängig davon wird damit aber deutlich, dass in der Konzeption des Betriebsablaufs und der dazu benötigten Gebäudestrukturen zum einen das Raumangebot für den interimistischen Aufenthalt von Passagieren (großer Andrang), als auch deren minimalste Ansprüche (beheizbare Räume) weit unterschätzt wurden. Das durch die Organisation des öffentlichen Massenverkehrs induzierte Phänomen eines systemischen Zwischenaufenthalts wurde demnach von vornherein nicht vollends in seiner Tragweite und seinen Notwendigkeiten vorausgesehen, sondern das Phänomen wurde im Grunde erst im Resultat selbstkritischer Beobachtungen, Erfahrungen und nicht zuletzt der Rückmeldungen seitens der Passagiere erkannt und thematisiert. Das verkehrsinduzierte Warten bzw. der transitorische Aufenthalt samt seiner Anforderungen kann damit im Nürnberger Kontext durchaus als Erfahrungs-Novum aller beteiligten Akteure bezeichnet werden.

Dennoch bleibt an dieser Stelle abermals festzuhalten, dass das systemische Warten zumindest bereits eine rudimentäre Form innerhalb der baulichen Struktur aufwies, die - wie die Reflektion der >lernenden Nürnberger Eisenbahnverwaltung in den Versammlungsprotokollen zeigt - wenn nicht vor Eröffnung der Bahn, dann doch spätestens nach kurzer Zeit explizit ins Bewusstsein gerufen und schließlich konkret erweitert wurde.

Rekonstruktion der Warterfahrung in Nürnberg

Anders als in den vorangegangenen Bahnhofsbeispielen soll die Rekonstruktion der lokalen Warteerfahrung am ersten deutschen Bahnhof nunmehr stärker über orts- und streckenspezifische Besonderheiten der ersten deutschen Eisenbahnstrecke zu erzeugen versucht werden. Hierzu werden die betrieblichen Spezifika der Organisation des Eisenbahnverkehrs zwischen den beiden fränkischen Nachbarstädten herangezogen, die mögliche Anhaltspunkte liefern. Hierzu zählen die Besonderheiten des Fahrtkartenerwerbs, die Betriebsform einer vergleichsweise kurzen, eingleisigen Strecke sowie die geforderten Verhaltensregeln vor Abfahrt.

\section{Fahrkartenkauf}

Der Fahrkartenverkauf erfolgte in Nürnberg und Fürth direkt am Bahnhof und nicht wie in England an in der Stadt gelegenen Verkaufsplätzen. Unter der Annahme, dass die Reisenden ihre Fahrkarten hintereinander an den Schaltern erwarben und mitun- 
ter nahezu 200 Personen einen Zug besteigen wollten, ${ }^{75}$ mussten die Reisenden aller Wahrscheinlichkeit nach frühzeitig am Bahnhof erscheinen, um pünktlich vor Abfahrt eine Fahrkarte zu erwerben. Die Reisenden standen somit entweder längere Zeit in der Warteschlange der Kasse oder aber verfügten nach Fahrkartenkauf über überschüssige Zeit, die sie im >Wartzimmer oder am >überdeckten Bahnstück verbringen mussten. Hinsichtlich der durchschnittlichen Dauer des Wartens kann aufgrund der individuell unterschiedlichen Ankunftszeiten am Bahnhof natürlich nur spekuliert werden, aber der Umstand des geschilderten Fahrkartenerwerbs dürfte im Zusammenspiel mit der von großer Neugierde geprägten Wahrnehmung der Eisenbahn als einer allgemeinen Neuheit sowie den Unsicherheiten mit dem Betriebsablauf dafür gesorgt haben, dass sich Reisende eher weit vor der terminierten Abfahrt des Zuges (30-60 Minuten) am Bahnhof eingefunden haben mögen und damit eine insgesamt lange Wartezeit absolvierten.

\section{Abfahrtsorganisation und Raumnutzung}

Wenngleich die durchschnittliche Wartedauer in der Frühphase des deutschen Eisenbahnwesens aufgrund fehlender Statistik-Quellen Gegenstand der Spekulation ist, kann dagegen als sicher gelten, dass fünf Minuten vor Abfahrt eine Glocke läutete, die Reisende dazu aufforderte sich im Verwaltungsgebäude einzufinden. Ein zweites Läuten signalisierte den Passagieren anschließend - unter Führung des Bahnpersonals -, die Wagen zu besteigen. ${ }^{76}$ Ob bis zum Zeitpunkt des ersten Abfahrtssignals den Reisenden das gesamte Bahnhofsgelände zur freien Raumnutzung zur Verfügung stand, bleibt nicht vollends aufzuklären, jedoch steht $\mathrm{zu}$ vermuten, dass die Passagiere so lange aufgefordert wurden im Wartesaal zu verbleiben, bis das Glockensignal ertönte, um einerseits die Betriebssicherheit zu erhöhen und andererseits die aus Sicht der Verantwortlichen als fragil wahrgenommene Technik zu schützen. Der Schauplatz des frühen verkehrlichen Wartens müsste hiermit also vor allem in den beengten Räumlichkeiten der >Wartzimmer gelegen haben, die trotz der drei angebotenen Wagenklassen noch keinerlei klassenspezifische Trennung aufwiesen und damit einen (noch) hohen Grad an sozialem, kommunikativem und sklassenübergreifenden Austausch ermöglicht haben dürften.

Aus dem Bauprogramm des Ludwigsbahnhofes wird zudem ersichtlich, dass das Erwarten der Abfahrt in den relativ kleinen Räumlichkeiten ohne jegliche gastronomische Versorgung erfolgte. Diese anfangs fehlende Versorgungslage bewirkte wohl auch die häufige Verlagerung des Wartens auf alternative Schauplätze. Insbesondere die Gasthöfe spielten hier entsprechend eine zentrale Rolle. Sie markierten jenseits des Bahnhofes selbst die wichtigsten Alternativorte des Wartens. So bemerkt etwa Lips:

»(...) die in der Nähe der Abfahrts-Lokalitäten befindlichen Gasthöfe und Wirthshäuser haben, abgesehen von dem außerordentlichen Besuch, dessen sie sich zur Zeit der Eröffnung und Einweihung der Bahn erfreuten, beständig Zuspruch von Personen, die

75 Das höchste Vekehrsaufkommen wurde insbesondere bei den Dampffahrten an Sonntagen verzeichnet (Vgl. Johannes Scharrer, Deutschlands erste Eisenbahn mit Dampfkraft, 23f.).

76 Vgl. Glaser, »Topos Bahnhof«, 281; Vgl. Lips, Die Nürnberg-Fürther Eisenbahn in ihren nächsten Wirkungen und Resultaten, 17. 
theils die Frequenz der Institution beobachten oder aber selbst davon Gebrauch machen wollen und dort bis zur nächsten Abfahrt verweilen. Ferner wird sich künftig wohl eine Restauration im Lokale des Instituts [der Eisenbahn, R.K.] selbst bilden (...). «" ${ }^{77}$

Auch in diesem Befund scheint sich wiederum ein gewisser Überraschungseffekt der Bahnverwaltung hinsichtlich der passagierseitig zu verbringenden Wartezeit zu spiegeln. Obwohl mit einer großen Personenfrequenz kalkuliert wurde, wurden den Reisenden offenbar zunächst keine unmittelbar am Bahnhof zur Verfügung stehenden Versorgungsmöglichkeiten geschaffen. Das Element des temporären Aufenthalts der Reisenden wurde - wohl angesichts des nachvollziehbaren Fokus auf Streckenbau und Gewährleistung der sicheren Bewegung der Dampflokomotive - zunächst kaum als relevanter Teilaspekt der Transportdienstleistung erachtet.

Betriebsform (eingleisige Strecke): Quelle des Wartens

$\mathrm{Zu}$ den Quellen der Entstehung systemischer Wartezeiten muss auch zweifelsohne die Fahrplangestaltung gezählt werden. Im Falle der Strecke Nürnberg - Fürth fanden nur relativ wenige Fahrten statt, da auf ihr die spezifische Betriebsform einer eingleisigen Strecke vorlag. Diese aus der Sicht der Reisenden ungünstige Situation galt als Quell langer Wartezeiten, was bereits früh als potentiell problematischer Umstand prognostiziert wurde:

»Die Einfachheit ${ }^{78}$ der Bahn aber hat einen großen Zeitverlust zur Folge, der nicht für die Bahn benutzt werden kann, indem, um einen neuen Curs machen zu können, immer erst die Rückkehr des ersten Wagenzugs abgewartet werden muß, was denn doch vielen Reisenden nicht zusagt, die deshalb lieber gewöhnliches Spannfuhrwerk wählen, um sogleich abgehen zu können (...). « ${ }^{79}$

Die zeitgenössische Vermutung bestand also interessanterweise bereits darin, dass der Betrieb auf einer eingleisigen Strecke neue, bislang ungekannte Wartezeiten produziert, die zum Wettbewerbsnachteil gegenüber traditionellen Verkehrsmitteln (Spannfuhrwerke) reifen könnten. Das durch die Synchronisation von Reisenden und Betriebsmitteln bedingte systemische Warten auf öffentlichen Verkehr wurde hier demnach unumwunden als Nachteil gegenüber der spontan organisierbaren, (privaten) Mobilität thematisiert, was im Grunde eine bis in die Gegenwart hinein wirksame Differenz zwischen öffentlichem und privatem Verkehr markiert. Tatsächlich verkehrten in den ersten Jahren täglich zunächst neun (sonntags bis zu 12) Züge, ${ }^{80}$ was bei einem spontanen Abfahrtswunsch aus Nürnberg oder Fürth eine Wartezeit von mehr als einer Stunde erzeugen konnte. Diese mitunter lange Wartezeit stand folglich in starker Diskrepanz zu einer recht kurzen Fahrzeit. Mehr noch wurde das systemische Warten im Zuge dieses

77 Ebd., 22. [Hervorhebung des Verfassers, R.K.].

78 Gemeint ist hier die Eingleisigkeit der Strecke.

79 Lips, Die Nürnberg-Fürther Eisenbahn in ihren nächsten Wirkungen und Resultaten, 16. [Hervorhebung des Verfassers, R.K.].

Scharrer, Deutschlands erste Eisenbahn mit Dampfkraft, $23 \mathrm{f}$. 
lokal ungünstigen Raum-Zeit-Verhältnisses womöglich überhaupt erst explizit ins Bewusstsein gerückt. In der Folge fürchtete Lips gar den durch den Zeitverlust bewirkten Nachteil als dermaßen betriebsschädigend, als dass

»Alle diejenigen, welche den Moment des Abgangs der Eisenbahn-Wagen versäumen, und geschäftig wie sie sind, keine Stunde bis zum Abgang eines zweiten Curs verlieren wollen, dem Fiaker anheim fallen. ${ }^{81}$

Entsprechend dieses direkt mit einer Wartezeit in Verbindung stehenden Missstandes wird, so Scharrer in der Bestandsaufnahme am Ende der ersten Betriebsmonate, »im Publikum viel von der Nothwendigkeit eines Ausweicheplatzes für die Bahn gesprochen, um dadurch in den Stand gesetzt zu seyn, halbstündlich abfahren zu können.« ${ }^{82}$

\section{Sprachliche Repräsentationen}

In Betrachtung der sprachlichen Repräsentationen des Wartens ist auffällig, dass im Kontext der überaus knappen zeitgenössischen Beschreibungen der Bahnhofssituation und der Hochbauten das Verb swarten bereits deutliche Verwendung erfährt. Während wenige Jahre zuvor die Wartesäle der ersten englischen Bahnhöfe noch deutlich im Sinne der Funktion jener Räume innerhalb des Bahnbetriebs oder der Nutzergruppe bezeichnet wurden (rooms for accomodation of passengers), wird - zumindest im Falle der beiden ersten deutschen Bahnhofsbauen in Nürnberg und Fürth - mit Begriffen der >Warthallen $<$ und >Wartzimmer operiert und damit bereits direkt auf die in diesen Räumen stattfindende Praxis rekurriert. Damit wird auf der sprachlichen Ebene das Warten bereits aus der Perspektive des Passagiers betrachtet. Bezüglich der sprachlichen Repräsentation des Temporalphänomens lässt sich somit bereits im Frühstadium des deutschen Eisenbahnwesens ein deutlicher Bezug auf ein durch das Verkehrswesen temporär erzwungenes Zwischenstadium ausmachen. Dagegen wird jedoch das Bahnhofsgebäude selbst zeitgenössisch noch als »Bureau« oder »Verwaltungs-Lokal« bezeichnet und demnach anfangs noch primär nur die bereitstellende Organisation, jedoch nicht die das Gebäude nutzenden Passagiere und deren Handlungen innerhalb dieses Gebäudes repräsentiert.

Abschließend kann auf Grundlage der überlieferten Belege im Zusammenspiel von Raumprogramm und Betriebsorganisation hinsichtlich der Warteerfahrung in Nürnberg geschlussfolgert werden, dass die Reisenden auf Deutschlands erster Bahnstrecke zunächst recht frühzeitig am Bahnhof eintrafen und das längere Zeitfenster in verhältnismäßig kleinen Räumlichkeiten ohne jegliche gastronomische Versorgung verbrachten. Die Schilderungen der ersten Betriebserfahrungen verweisen zugleich darauf, dass das verkehrsinduzierte Warten seitens der Reisenden bereits in der absoluten Frühphase des Eisenbahnwesens offenbar teilweise problematisiert wurde. Diese aus den Forderungen des >Publikums hervorgehende geringe Toleranz gegenüber der unter anderem durch den eingleisigen Betrieb generierten Wartezeiten (aber auch

81 Lips, Die Nürnberg-Fürther Eisenbahn in ihren nächsten Wirkungen und Resultaten, 25.

82 Scharrer, Deutschlands erste Eisenbahn mit Dampfkraft, 99. 
fehlender adäquater Warteeinrichtungen) könnte hier insbesondere aus dem spezifischen Kontext der Bahnlinie erklärt werden. Zum einen erzeugte die mit knapp sieben Kilometern relativ kurze Strecke sowie der noch überwiegende Einsatz von Pferden den Charakter eines öffentlichen Personennahverkehrs und kaum den eines Fernverkehrs. Zudem waren beide Städte bereits vor der Eisenbahn eng und hochfrequentiert miteinander verbunden. Dies erzeugte eine temporale Erwartungshaltung, die wahrscheinlich insgesamt in der Beschleunigung einer bereits etablierten und vertrauten Verkehrsverbindung uferte. Entsprechend einfach konnte die Vergleichsmöglichkeit gegenüber den mit Fuhrwagen organisierten, bestehenden Verbindungen gewesen sein und entsprechend stark die Wahrnehmung einer `Störgrößeく.

Als eine solche Störgröße konnte das durch Betriebsorganisation und Fahrkartenerwerb bedingte verkehrliche Warten auf die Abfahrt gelten. Im Falle der gegenüber dem Pferdebetrieb wesentlich schnelleren Dampffahrt konnte die Strecke in 12 bis $15 \mathrm{Mi}$ nuten absolviert werden. Wenn Passagiere jedoch teilweise durch Fahrkartenkauf und die zeitintensivere Synchronisation von Reisenden und Betriebsmitteln bereits frühzeitig am Bahnhof erscheinen mussten, zeigte sich folglich ein deutliches Missverhältnis zwischen reiner (beschleunigter) Fahrtzeit und der dafür benötigten >präparatorischen Wartezeit. Entsprechend konnte der >Preis $<$ der vorgelagerten Wartezeiten gar die durch die neue Dampftechnologie erzielten Geschwindigkeitsvorteile zunichtemachen. Somit steht zusammenfassend zu vermuten, dass die Charakteristik der ersten deutschen Eisenbahnstrecke die Sensibilisierung und Reflektion über absolute Zeitmaßstäbe im Allgemeinen und der verkehrlichen Wartezeit im Besonderen stark befördert haben mag und dies aufgrund der geschilderten Rahmenbedingungen womöglich weit stärker als anderswo. Mit anderen Worten: Neben der durch die Dampflokomotive erzeugten >Entdeckung der Geschwindigkeit d dürfte eine >Entdeckung des Wartens ‘ für die Bewohner von Nürnberg und Fürth somit stark durch die Kürze der Fahrtzeit genährt worden sein. Zudem war diese Komplementärerfahrung zur Beschleunigung angesichts der starken Personenfrequen $z^{83}$ und der drei preislich gestaffelten Wagenklassen kein rein elitär-bürgerliches Erlebnis, sondern wurde von Beginn an für viele Bevölkerungsteile serlebbar<.

Die Bedeutung dieser Eisenbahnlinie kann somit nicht nur in der objektiv beschleunigten Verkehrsverbindung und der Signalwirkung für andere Regionen gesehen werden, sondern übergeordnet auch in der damit einsetzenden Verdichtung der Zeitintervalle und ein damit wachsendes Bewusstsein für eine moderne Taktung und Synchronisation des Lebens.

\subsubsection{Berlin - Potsdamer Bahnhof (1838)}

\section{Bauliche Kurzbeschreibung}

Der 1838 eingeweihte Potsdamer Bahnhof in Berlin gilt als das älteste Bahnhofsensemble Preußens. Der Bahnhof bildete einen der beiden Endpunkte einer knapp 27 Kilometer langen Bahnstrecke zwischen Berlin und der Residenzstadt Potsdam. Wie Nürnberg 
und Fürth verfügten auch diese Städte über eine historisch gewachsene Verkehrsverbindung und enge Austauschbeziehungen, die sich insbesondere aus dem Status Potsdams als Sitz des preußischen Königshauses ergaben. Das großzügige Bahngelände ${ }^{84}$ lag am Potsdamer Tor und damit außerhalb der damaligen Berliner Stadtmauer ${ }^{85}$. Wie in Nürnberg wurde auch in Berlin das gesamte Gelände eingefriedet, was den für den deutschsprachigen Raum typischen Charakter eines Bahnhofes erzeugte. Er verfügte über drei Gleise, von denen nur eines ausschließlich dem Personenverkehr diente. Das durch die rein privatfinanzierte Berlin-Potsdamer-Eisenbahngesellschaft für den Personenverkehr errichtete Empfangsgebäude orientierte sich wie seine deutschen Pionierbauten in Nürnberg und Fürth deutlich an englischen Vorbildern, ganz konkret wiederum am Liverpooler Prototypen einer Anlage in >seitlicher Erschließung . Zudem wurde auch hier entsprechend der deutlichen englischen Prägung bereits eine räumliche Trennung der Abfahrts- und Ankunftsbereiche vorgenommen.

Abbildung 17: Erster Potsdamer Bahnhof in Berlin (1843) mit Empfangsgebäude und überdachter Gleishalle (Zeichnung von Emil Henning).

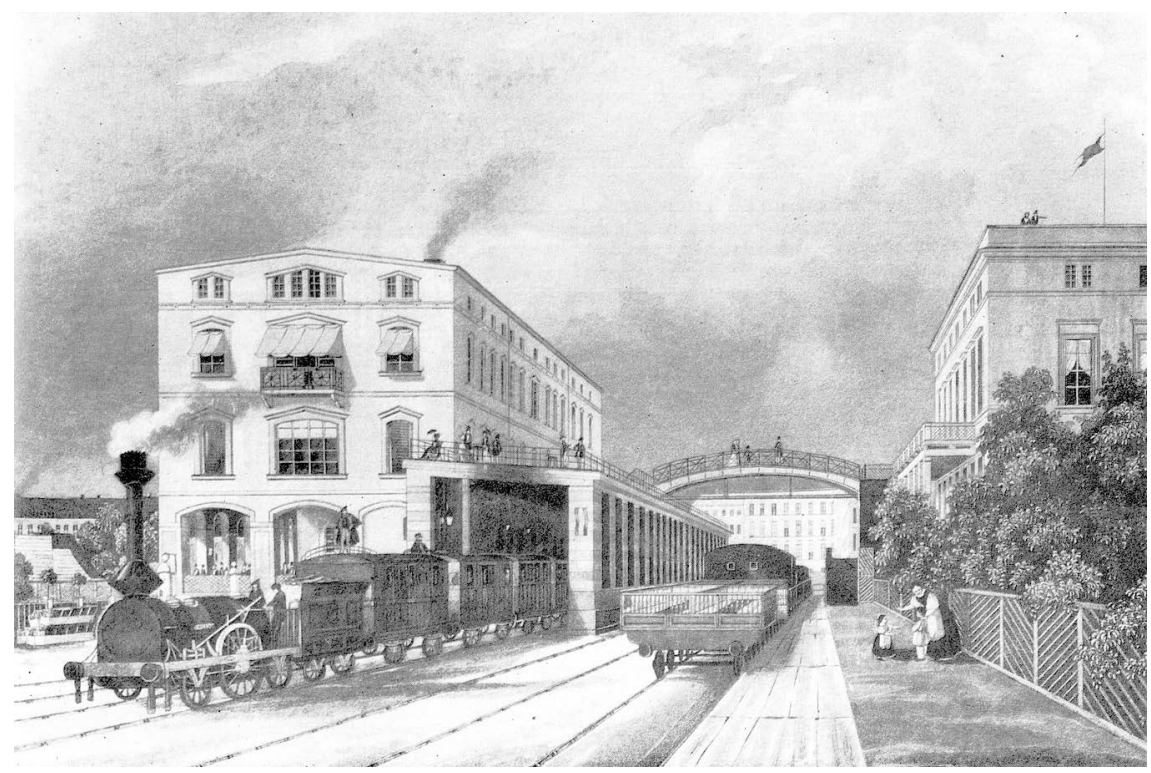

Quelle: Architekturmuseum der Technischen Universität Berlin.

Das Bahnhofsgebäude wurde als ein dreistöckiger Kopfbau errichtet, dessen Haupterschließung über die Westseite erfolgte. Durch seine langgestreckte Form und einer

84 Die Bahndirektion musste nach Auflage der preußischen Behörden ein besonders weiträumiges Grundstück erwerben, um den Abstand zur umliegenden Wohnbebauung möglichst groß bemessen zu können, vgl. Deutschland und seine Eisenbahnen. (Leipzig: Wigand, 1838), 12.

85 Das Aufeinandertreffen moderner und vormoderner städtebaulicher Elemente zeigte sich in Berlin insbesondere dadurch, dass Berlin erst etwas mehr als 30 Jahre vor Eröffnung der Eisenbahn eine neue Stadtmauer erhalten hatte. 
insgesamt dreiteiligen Gebäudestruktur (Empfangsgebäude, Verbindungsbau/Veranda, Magazin/Lagerhaus) ähnelte das Gebäude weniger als andere Gebäude der Pionierphase des Eisenbahnhochbaus dem Charakter eines solitären Wohnhauses. Im Gegensatz zu Liverpool oder der deutschen Pionierbahn in Nürnberg und Fürth erfuhr das Empfangsgebäude von Berlin ohnehin insgesamt eine bereits aufwendigere Gestaltung, was nach Ansicht von Krings den Repräsentations- und Verwaltungsbedürfnissen der Bahngesellschaft entsprach, »welche das Privileg zu schätzen wußte, die vom königlichen bzw. kaiserlichen Hof am stärksten frequentierte Linie (zu den Potsdamer Schlössern) bedienen zu können. ${ }^{86}$ Der Kopfbau wurde mit einem wettergeschützten Laubengang bzw. einer Arkade umgeben, die, typisch für unzählige weitere Bahnhofsbauten des 19. Jahrhunderts die Funktion eines öffentlichen Aufenthaltsraumes mit der eines geschützten Vordachs und einer Verteilung der Reisenden erfüllte. Mehr noch wurde damit insgesamt der stadttorartige Charakter zur Vermittlung auf das Bahnsystem repräsentiert. ${ }^{87}$

Auf seiner Bahnseite im Osten wurde dem ersten Berliner Empfangsgebäude ein in Massivbauweise ausgeführter überdachter Bereich angeschlossen, der den Reisenden auf einer »Plateform ${ }^{88}$ einen geschützten $\mathrm{Zu}$ - und Ausstieg aus den Wagen ermöglichte. Mit dieser schmalen, langgestreckten und überdachten Wagenhalle liegt auch im ersten Bahnhof Preußens das formale Charakteristikum des eisenbahnspezifischen Bauprogramms aus Vorplatz, Empfangsgebäude und Halle vor. Die vergleichsweise kleine Überdachung nur eines Gleises samt angeschlossener Veranda wurde gewählt, weil es wie in Liverpool 1830 angesichts der noch geringen Frequenz genügte, jeden Zug nur von einem Gleis abfahren zu lassen. ${ }^{89}$

Im Gegensatz zu den bereits vorgestellten Beispielen der Pionierphase des Eisenbahnhochbaus erfolgte in Berlin eine deutliche räumliche als auch sprachliche Trennung von Passagier- und Verwaltungsgebäuden. Während das Verwaltungs- und Wohngebäude der Bahngesellschaft separat südlich vorgelagert errichtet wurde, bildete das funktional primär den Reisenden dienende, als »Empfangshaus «" ${ }^{\circ}$ bezeichnete Gebäude, den eigentlichen Kern der Anlage. Das Bauprogramm des Berliner Bahnhofs erscheint damit erstmals deutlich stärker auf die Passagiernutzung ausgerichtet bzw. streng funktional zwischen administrativer und betrieblicher Trennung aufgeteilt worden zu sein.

Analog der Erfahrungen anderer früher Streckenöffnungen war auch die erste Strecke Preußens ein voller Erfolg. Allein in der ersten Betriebswoche Ende September 1838 verkehrten laut Direktionsangaben bereits 26.304 Personen zwischen Potsdam

86 Ulrich Krings, »Bahnhofsarchitektur: deutsche Großstadtbahnhöfe des Historismus« (Dissertation, TU München, 1981), 69.

87 Vgl. Radlbeck, »Bahnhof und Empfangsgebäude«, 16.

88 August L. Crelle, »Einige techn. Nachrichten v. d. Eisenbahn zwischen Berlin u. Potsdam.«, Journal für die Baukunst: in zwanglosen Heften 15 (1841): 222.

89 Vgl. Mihály Kubinszky, Bahnhöfe Europas: Ihre Geschichte, Kunst und Technik. Für Eisenbahnfreunde, Architekten und kulturgeschichtlich Interessierte (Stuttgart: Franck'sche Verlagshandlung, 1969), 26.

90 George Gropius, Die Berlin-Potsdamer Eisenbahn: Mit einer Abbildung und einer Charte (Berlin: Weidle, 1838). 
und Berlin-Zehlendorf. ${ }^{91}$ Trotz eines leichten Rückgangs der zu diesem Zeitpunkt stark wachsenden Fahrgastzahlen - Grund war die Öffnung weiterer Eisenbahnstrecken in Berlin ab 1841 - fuhren in den ersten fünf Betriebsjahren fast 3 Millionen Fahrgäste mit der Bahn und damit genauso viele Reisende, wie in einem Zeitraum von 50 Jahren vor der Eisenbahn auf der Chaussee zwischen Berlin und Potsdam reisten. Wohlgemerkt lagen hierbei die Fahrpreise für die meisten Menschen, insbesondere für die Berliner Unterschicht, im Bereich des Unerschwinglichen Fahrpreise. ${ }^{92}$ Entsprechend dieser Passagierentwicklungen erwiesen sich die Kapazitäten der Bahnhofsanlage bereits nach kurzer Zeit als unzulänglich, sodass der Bahnhof von 1846-48 eine erste und von 1868-72 eine zweite umfassende Erweiterung sowie in diesem Zusammenhang eine gänzliche Verlagerung erfuhr.

\section{Wartebezogenes Raumprogramm (Berlin 1838)}

Die Rekonstruktion des Bauprogramms von 1838 zeigt eine bereits deutliche Verankerung des verkehrlichen Wartens innerhalb der Grundrissdisposition. Den Zugang zum Bahnsystem vermittelte im Ursprungsstadium der dreistöckige Kopfbau des Empfangshauses. Darin umgab eine U-förmige, nach außen hin offene Schalterhalle offenbar eine Reihe von Warteräumen. Bestätigt wird das Vorhandensein dieser Strukturen durch eine überlieferte Grundrisszeichnung von August Crelle, der als Chefingenieur der Bahnstrecke fungierte. Warteräume sind indes nicht für nur den Berliner Endbahnhof nachweisbar, sondern auch für das Pendant in Potsdam. Eine zeitgenössische Schilderung von Ludwig Rellstab in der Königlich privilegierten Berlinischen Zeitung, die in einem anlässlich der Streckenöffnung erschienenen Artikel von einem zunächst interimistischen Aufbau berichtet, beschreibt den Bahnhof von Potsdam als ein Gebäude, "welcher einen größeren Salon und zwei kleinere elegant eingerichtete Gemächer, als Versammlungsorte für die Abreisenden bei üblem Wetter, enthält. « ${ }^{93}$

Abbildung 18: Grundriss des Potsdamer Bahnhofs in Berlin, 1838. A - Empfangsgebäude; B - Bahnsteig mit Veranda für Wartende, aufgeteilt nach drei Wagenklassen; C-Magazin; 1 - Flur mit Schalterhalle; 2 - Warteräume.

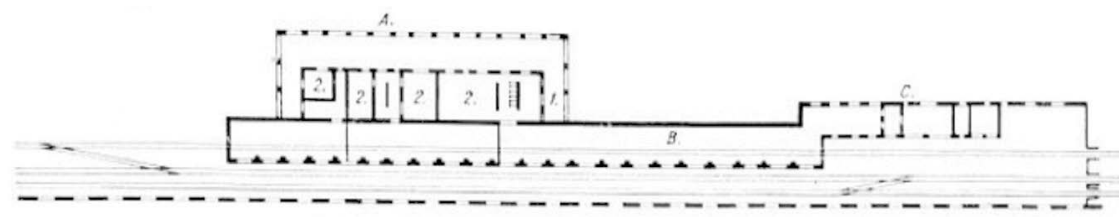

Quelle: Kubinszky 1969, S. 83.

91 »Königlich privilegirte Berlinische Zeitung von Staats- und gelehrten Sachen«, 25. September 1839,5 .

92 Vgl. Reiner Schipporeit, Berlin-Potsdamer Eisenbahn: Bau, Technik, Betrieb (Berlin: Museumspädagogischer Dienst, 1988), $20 f$.

93 Zitiert aus Peter Bley, 150 Jahre Eisenbahn Berlin-Potsdam: aus d. Ceschichte d. ältesten Eisenbahn in Berlin u. Preussen (Düsseldorf: Alba, 1988), 29. [Hervorhebung des Verfassers, R.K.]. 
Abbildung 19: Grundriss des Empfangsgebäudes des Potsdamer Bahnhofs 1838. 1 - Vorhalle;2, 4, 5, 7-Klassenspezifische Warteräume; 3, 8-Flure; 9-Kassenzimmer; 10 - Vorraum der Kasse.

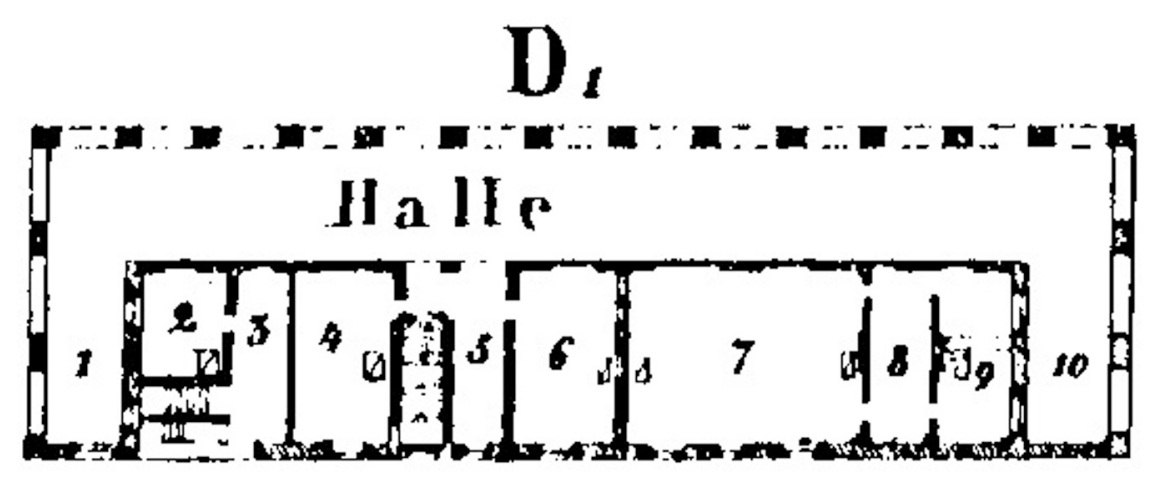

Quelle: Handke 1988, S. 58.

Nähere Informationen $\mathrm{zu}$ den konkreten Ausstattungen (Möblierungen, Wandoder Farbgestaltungen etc.) sind leider nicht überliefert, jedoch sind in Crelles Grundrisszeichnung (Abbildung 19) in fast allen Räumen Schächte eingezeichnet, die Kaminen oder gusseisernen Öfen entsprochen haben dürften. Die >Transiträume waren demnach - anders im Beispiel des Ursprungsbahnhofes von Nürnberg - beheizbar. Erwähnenswert ist hierbei zudem nicht nur der Befund, dass der temporäre Aufenthalt der Reisenden bereits wesentlich deutlicher als in den anderen vorgestellten Beispielen der Eisenbahnfrühphase (mit Ausnahme Manchesters) eine baulich-räumliche Entsprechung erfuhr. Erwähnenswert ist vielmehr auch, dass diese »Gemächer« streng getrennt nach Wagenklassen angeordnet waren. Von den separierten Räumen aus konnten die Reisenden unmittelbar die überdachte Bahnsteighalle erreichen, in der sich die Klassentrennung in Form separater, klassenspezifischer Wartebereiche weiter fortsetzte. Damit waren wie im Ursprungsbau der Liverpool Road Station von Manchester Warteräume und Bahnsteig bereits von Beginn an - und damit anders als in Liverpool oder Nürnberg - in (drei) klassenspezifische Wartezonen unterteilt worden. ${ }^{94}$ Der präparatorische Aufenthalt vor Abfahrt wurde somit in Berlin deutlich stärker formalisiert, die klassenübergreifende Austauschmöglichkeit im >liminalen Moment des Wartens durch eine bereits bei Zugang in die Warteräume vorgenommene Personentrennung deutlich eingeschränkt. Nach Erwerb einer Fahrkarte war das räumliche Setting folglich derart gestaltet, dass sich die Reisenden der verschiedenen Klassen an keiner weiteren Stelle mehr begegneten, wobei insbesondere die Reisenden dritter Klasse mittels einer durchgehenden Wand von den anderen Warteräumen separiert wurden.

94 Vgl. Kubinszky, Bahnhöfe Europas, 83. Um die Trennung der Reisenden noch deutlicher zu machen, wurden in Berlin die Warteräume zum Teil nicht mehr - wie noch in Manchester - mit Türen verbunden. 
Eine weitere Besonderheit des wartebezogenen Raumprogramms bestand in einem zeitweise royalen Nutzerkreis. Für den Fall, dass sich der Königliche Hof in Potsdam aufhielt, musste ein eigens für königliche Gäste bestimmter Warteraum vorgehalten werden, der vom Rest der drei Warteklassen streng separiert werden musste. So war der im Grundriss linke äußere Raum (Abbildung 19, Nr. 2) nur dem Königshaus bzw. dem Hofstaat vorbehalten. Diese >Königszimmer wurden allerdings nur äußerst selten genutzt, erstmals wohl im Mai 1839. Der preußische König Friedrich Wilhelm III, bekannt durch seine (angebliche) bereits zuvor erwähnte Skepsis gegenüber der Eisenbahn, reiste erst fast ein Jahr nach Streckenöffnung erstmals in Begleitung seiner Gemahlin und Prinz Karl mit der Eisenbahn in einer Fahrzeit von 38 Minuten von Berlin nach Potsdam. Im Verkehrsjahr 1844 waren gerade einmal 1,5 Prozent aller Reisenden Mitglieder des Königlichen Hofes. Die vorzuhaltende Fläche im Empfangsgebäude stand somit in deutlichem Widerspruch zum absolut betrachtet marginalen Verkehrsaufkommen dieser Nutzergruppe. Das Raumprogramm des Potsdamer Bahnhofs von Berlin spiegelte damit letztlich erstmals in einem Bahnhofsgebäude deutlich das noch vollends feudale Herrschaftssystem des preußischen Staates.

\section{Rekonstruktionsversuch der frühen Warteerfahrung im Potsdamer Bahnhof (1838)}

Die Quellenlage über die Anfangszeit der Berlin-Potsdamer-Bahn ist äußerst spärlich. Bis auf einen Brücken-Gedenkstein, einige Fahrscheine und Zeitungsberichte sind kaum mehr greifbare Belege vorhanden. ${ }^{95}$ Im Versuch einer Rekonstruktion der früheren Warteerfahrung am Potsdamer Bahnhof sollen daher nun wiederum einige Elemente des Betriebsablaufs betrachtet werden, die als Einflussfaktoren für Länge, Ort und Empfindung der Wartezeit herangezogen werden können.

\section{Allgemeine Betriebsanordnungen}

Der vielleicht deutlichste Hinweis auf die objektive Wartedauer findet sich in den Anordnungen zum Verhalten der Passagiere für Fahrten auf der Berlin-Potsdamer Eisenbahn. Hier wird vor dem Hintergrund des Verlustes der Fahrtberechtigung im Falle des zu späten Eintreffens am Bahnhof eindringlich bezüglich der empfohlenen Ankunftszeit am Bahnhof vor Abfahrt des Zuges vermerkt:

»Da die durch dies Verspäten unbrauchbar gewordene Billets nicht ersetzt werden, so werden die geehrten Reisenden ersucht, sich möglichst 10 Minuten vor der Abfahrt einzustellen. ${ }^{96}$

Ob sich die Reisenden an diese Anforderungen hielten, bleibt offen, jedoch zeigt dieser Zeitrahmen eine aus Sicht der Betriebsgesellschaft verhältnismäßig zeitliberale Regelung an, denn es wurde damit ein relativ kurzfristiger Zeitvorlauf eingeräumt. Das mindestens 10-minütige Ankunftsfenster dürfte jedoch insbesondere bei einem noch nötigen Fahrkartenerwerb knapp bemessen gewesen sein, zumindest für Reisende, die

Vgl. Schipporeit, Berlin-Potsdamer Eisenbahn: Bau, Technik, Betrieb, 4. (Vorwort von Alfred Cottwaldt). 
noch keine Fahrkarte besaßen. Dass für die Passagiere das frühzeitige Erscheinen für den noch rechtzeitigen Fahrkartenkauf sichergestellt werden musste, dürfte nach kürzester Zeit in aller Munde gewesen sein. So handelte etwa eine Szene in Adolf Glasbrenners 1844 erschienener Trivialliteratur >Herr Buffey auf der Berlin-Leipziger Eisenbahn amüsiert von einem handfesten Streit beim Warten an den Fahrkartenschaltern in Berlin, der schließlich sogar in einer körperlichen Auseinandersetzung uferte. ${ }^{97}$

Im weiteren Versuch der Rekonstruktion der absoluten, durch den Fahrkartenerwerb verursachten Wartezeit vor Abfahrt kann ferner eine Bekanntmachung der Eisenbahndirektion vom 27.10.1838 herangezogen werden, in der die Kaufoptionen für eine private Vorkaufsstelle oder am Bahnhof offeriert werden:

»Die Billetts zu den ordentlichen Fahrten werden sowohl in Berlin als in Potsdam, Tages vorher, auf die Hin- und Rückfahrt von und nach beiden Orten, am Tage der Fahrten nur auf die Hinfahrt von jedem Ort ab ausgegeben. Der Verkauf geschieht in Berlin am Tag der Fahrten in der Kasse am Bahnhofe und Tages vorher, mithin zuerst am 29. September (von welchem Tage ab ausnahmsweise in Berlin auch schon Billetts bis zum 4. November einschließlich gelöst werden können) im Lokal des Herrn Ceorge Cropius, in der neuen Bau-Akademie; in Potsdam nur in der Kasse am Bahnhofe. In der letzten halben Stunde vor jeder Fahrt, werden an den Kassen nur Billetts zur nächsten Fahrt verkauft. ${ }^{98}$

Aus diesen Regelungen geht leider nicht klar hervor, ob die Reisenden zu einer bestimmten Uhrzeit am Bahnhof erscheinen sollten, um ihre Fahrkarten zu lösen. Ähnlich wie in der Rekonstruktion der Warteerfahrung in Nürnberg kann hier jedoch vermutet werden, dass für den Fahrkartenerwerb am Bahnhof aufgrund der seriellen Abarbeitung am Schalter bei hohem Andrang ein eher größeres Zeitpolster als die empfohlenen 10 Minuten eingeplant worden sein dürfte. Der knappe 10-minütige Vorlauf konnte, wenn überhaupt, somit wahrscheinlich nur von bereits mit Fahrkarten ausgestatteten Reisenden in Anspruch genommen worden sein. Alle anderen Reisenden erschienen vermutlich wesentlich früher am Bahnhof.

Eine Reihe weiterer aufschlussreicher Hinweise zur Wartedauer (und damit indirekt zur Warteerfahrung) bietet ferner das Bahn-Polizei-Reglements für die BerlinPotsdamer Eisenbahn vom 19. Januar 1839, das deutliche Anordnungen für die Reisenden formulierte. $\$ 18$ des Reglements thematisierte darin die Abfahrtsmodalitäten, die in direktem Zusammenhang einer verkehrsinduzierten Wartezeit stehen. »Der Ort, wo die Wagen stehen«, so die Bekanntmachung, »ist dem Publikum bis 10 Minuten vor der zum Abgange bestimmten Stunde geschlossen«. Mit diesem angesprochenen Ort kann nur die schmale Wagenhalle samt dem klassenspezifisch separierten Bahnsteig gemeint sein. Die Anweisungen lauteten weiter: »Erst 10 Minuten vor Abfahrt wird der Zeit wird der Verschluß geöffnet, und dies durch einmaliges Läuten der Glocke angedeutet. Es treten hierauf die mit einem Billet zur nächsten Fahrt versehenen Personen

97 Adolf Clasbrenner, »Herr Buffey auf der Berliner-Leipziger-Eisenbahn«, Berlin wie es isst-und trinkt, Heft XXI. (1844).

98 Direktions-Annonce der Berlin-Potsdamer-Eisenbahngesellschaft vom 27.10.1838, zitiert nach Bley, 150 Jahre Eisenbahn Berlin-Potsdam, 37. 
ein und nehmen nach Anweisung der die Aufsicht führenden Wagenmeister und Wärter, ihre Plätze in den Wagen ein. Nach 5 Minuten, also 5 Minuten vor dem Abgange, wird zum zweiten Male geläutet, um die etwa noch zurückgebliebenen Reisenden auf die Abfahrt aufmerksam zu machen (...). «Sobald sich der Zug dann in Bewegung setzte, wurde »der zu den Wagen führende Eingang wieder geschlossen und niemand weiter zum Mitfahren zugelassen. «99

Der mit dieser Anordnung formulierte organisatorische `Zwang〈 zum räumlich eingeschränkten Aufenthalt bildet einen der frühesten Niederschläge des Ursprungs des Temporalphänomens, das bereits mehrfach als systemische Wartezeit qualifiziert wurde. In der Betriebsanordnung zeigt sich deutlich, dass ein temporärer Aufschub aus Sicht der Betriebsorganisation als Synchronisations-, Sicherheits- und Kontrollpuffer intentional installiert wurde, um die Synchronisation von Menschen und Betriebsmitteln zu gewährleisten. Ferner lassen sich aus diesen Betriebsanordnungen drei für die Rekonstruktion der verkehrshistorisch gesehen erstmalig in großem Umfang auftretenden Wartezeiten wesentliche Punkte ableiten.

Erstens, die pionierhafte Warteerfahrung erfolgte hinsichtlich des vorhandenen Raumangebots stark eingeschränkt und reglementiert. Der Bahnsteig war vor Abfahrt offenbar nicht frei begehbar, sondern stand den Reisenden erst unmittelbar vor Abfahrt zur Verfügung. Zweitens bildeten die Warteräume aufgrund des Verschließens der Räume bis vor Abfahrt den primären Ort des Wartens, zumindest für jene Reisende, die bereits frühzeitig am Bahnhof ankamen und die Öffnung der Bahnsteighalle abwarten mussten. Drittens wurde aus bahnpolizeilicher Sicht die Betriebsgesellschaft dazu aufgefordert, die Türen zum Bahnsteig bis 10 Minuten vor Abfahrt geschlossen zu halten, die Bahngesellschaft wiederum kommunizierte diesen zehnminütigen Vorlauf an ihre Kunden weiter. Aus der direkten Übernahme der bahnpolizeilichen Sperrfrist könnte interpretiert werden, dass die Betriebsgesellschaft den Reisenden bei ihrer Ankunft den direkten Zugang auf den Bahnsteig ermöglichen wollte, möglicherweise aus dem Grund, Wartezeiten in den Räumen des Empfangshauses zu vermeiden und mehr räumliche Kapazitäten bzw. eine bessere Verteilung des wartenden Publikums $\mathrm{zu}$ erreichen und dessen Unzufriedenheit zu vermeiden.

Dass die ungewohnte Situation vor Abfahrt zu Unzufriedenheit geführt haben und die Bahngesellschaft den zeitlichen Vorlauf daher besonders knappgehalten haben könnte, lässt auch ein Blick auf die konkreten Raumverhältnisse vermuten. Ausgehend von den Abmaßen aus überlieferten Grundrissplänen standen im Warteraum 3. Klasse ca. $80 \mathrm{~m}^{2}$ zur Verfügung, im Warteraum 2. Klasse ca. $48 \mathrm{~m}^{2}$ und jenem 1. Klasse ca. $30 \mathrm{~m}^{2}{ }^{100}$ Zieht man den Platz für Möblierungen und sonstige Gegenstände und Flure ab, wird schnell deutlich, dass bei einer Abfahrt von 300-500 Passagieren je Wagenzug $^{101}$ die Raumkapazitäten im Verhältnis zum Passagieraufkommen unzulänglich

99 Abgedruckt in G.M. Kletke, Die Preußischen Eisenbahnen, Bd. Dritter Abschnitt: Über Spezielle Vorschriften zur Benutzung der Eisenbahnbeförderung (Berlin: Mhlius'sche Buchhandlung, 1844), $131 f$.

100 Berechnet auf Crundlage des Situationsplans aus Manfred Berger, Historische Bahnhofsbauten, Bd. 1: Sachsen, Preussen, Mecklenburg und Thüringen (Berlin: transpress, 1980), 138.

101 Täglich verkehrten in den Anfangsmonaten täglich 1500-2000 Personen bei vier angebotenen Fahrten nach Potsdam. 
waren bzw. die Warteerfahrung durchaus als beengt interpretiert werden dürfte. Selbst wenn die heutige Versammlungsstättenrichtlinie (eine Person je $\mathrm{m}^{2}$ Grundfläche) ${ }^{102}$ natürlich nicht ohne Weiteres als Referenzpunkt einer historischen Realität herangezogen werden kann, zeigt sich hier doch, dass im ersten preußischen Bahnhof nicht einmal die Hälfte der Passagiere eines vollbesetzten Wagenzuges in den Warteräumen Platz gefunden haben dürfte.

Eine solche Menschenmenge in derart beengten Verhältnissen und die sich daraus entwickelnde Wahrnehmung eines polizeilichen Kontrollmangels motivierte die Königliche Regierung und das Königliche Polizeipräsidium nach einer einmonatigen Betriebserfahrung schließlich dazu, feste Regeln für das Verhalten der Passagiere im Empfangshaus (und der anschließenden Fahrt) auszugeben, die laut einer Veröffentlichung vom 27. Oktober 1838 in den Empfangshäusern von Berlin und Potsdam ausgehängt wurden:

»5) Ueber das Verhalten der Fahrgast im Empfangshause, bei dem Einsteigen in die Wagen zur Fahrt, während derselben, und bei dem Aussteigen, ist das Erforderliche von der Cesellschaft durch besondere Anschläge auf dem Bahnhofe und in den Empfangszimmern bekannt gemacht. ${ }^{103}$

Bis auf diese Ankündigung sind die Aufforderungen, die uns noch konkretere Rückschlüsse auf die Disziplinierung der Reisenden im Augenblick des temporären Aufenthalts geben könnten, jedoch leider nicht überliefert. Es steht aber zu vermuten, dass die im zweiten Stock des Empfangshauses gelegene Bahnhofswirtschaft einen großen Teil der Reisenden aufgenommen haben dürfte. Der Wirtschaft war eine Dachterrasse auf dem Dach der Bahnsteighalle angeschlossen, die sicherlich als Attraktion gegolten haben muss, da sich von hier ein sehr guter Blick auf die ab- und anfahrenden Züge bot. Diese erst nachträglich eingerichtete Bahnhofswirtschaft ${ }^{104}$ ermöglichte nicht nur eine Ausweichkapazität der knapp bemessenen Warteräume, sondern es zeigte sich vielmehr, dass im Falle Berlins das verkehrliche Warten vom frühesten Zeitpunkt an mit kommerziellen Angeboten gekoppelt war bzw. der erzwungene temporäre Aufenthalt als eine Quelle der wirtschaftlichen Verwertung erkannt wurde.

Weitere Aufschlüsse über die Rekonstruktion der Warteerfahrung könnte dagegen die Analyse der Nutzerschaft der ersten preußischen Bahn versprechen. Die Bahn wurde offensichtlich ganz überwiegend für den touristischen Ausflugsverkehr von und nach Potsdam genutzt. Da für die Großstadt Berlin im Grunde nur der Thiergarten in fußläufiger Nähe lag, wurde Potsdam mit seiner attraktiven Lage zwischen Seen und Hügeln schnell zum attraktivsten Reiseziel für die Berliner Naherholenden. Dieser sich rapide

102 Berliner Senatsverwaltung für Stadtentwicklung, »Verordnung über den Betrieb von baulichen Anlagen«, 2007, 9, www.versammlungsstaettenverordnung.de/bundeslaender/downloads/BERLIN/BetrVO_07.pdf zugegriffen am 20.06.2019.

103 Anordnung der Königlichen Regierung zu Potsdam (Böttger) und des Königlichen Polizeipräsidenten zu Berlin (Gerlach) vom 27.10.1838, zitiert aus Bley, 150 Jahre Eisenbahn Berlin-Potsdam, 31.

104 Crelle berichtet 1841 indirekt von den baulichen Erweiterungen um eine Bahnhofswirtschaft: »Im Innern des Cebäudes ist Vielerlei verändert worden; zum Theil in Folge veränderter Beschlüsse darüber, ob und in welcher Art ein Restaurateur in dem Hause sein sollte.« Crelle, »Einige techn. Nachrichten v. d. Eisenbahn zwischen Berlin u. Potsdam.«, 222. 
entwickelnde Ausflugsverkehr wird durch die lebhafte Eröffnung von Bahnhofswirtschaften im unmittelbaren Umfeld des Endbahnhofes in Potsdam belegt, die mitunter versuchten die Reisenden bis zur Rückfahrt nach Berlin in ein und demselben Etablissement verbleiben zu lassen. Die Königlich privilegirte Berlinische Zeitung von Staatsund gelehrten Sachen (später Vossische Zeitung) berichtete noch kurz vor der Gesamtstreckenöffnung, dass diese Orte zu zentralen Orten des verkehrlichen Wartens gereift seien:

»Der bei Zehlendorf durch Herrn Heinzelmann erbaute Salon, so wie das elegante von demselben eingerichtete Lokal in Potsdam nächst dem Bahnhofe, bieten den Spazierfahrern auch zugleich angenehme Aufenthaltsplätze dar, um die Zeit der Abfahrt abzuwarten. $\ll^{105}$

Entsprechend der primär touristischen Nutzerschaft steht damit zu vermuten, dass ein touristisches Publikum eine vermutlich im Vergleich zu Geschäftsreisenden oder Staatsdienern eher geringere Zeitsensibilität mitbrachte. Es steht damit zu vermuten, dass die Mehrheit der Reisenden durch ihren Reiseanlass eine vergleichsweise größere Wartetoleranz entwickelt haben könnte. Diese Vermutung speist sich dabei nicht zuletzt auch durch den Befund, dass trotz des Betriebs auf einer nur eingleisigen Strecke keine Beschwerden zu den dadurch langen Wartezeiten zwischen den Zügen überliefert sind, wie sie dagegen in sehr deutlicher Weise in Nürnberg und Fürth auftraten. Dies mag daran liegen, dass die $27 \mathrm{~km}$ lange Städteverbindung zwischen Berlin und Potsdam anders als die weit kürzere zwischen Nürnberg und Fürth (knapp $7 \mathrm{~km}$ ) weniger als eine Art Vorortverkehr wahrgenommen wurde. Mit anderen Worten: Die absolute Reisedauer stand im Berliner Kontext in einem möglicherweise akzeptableren Verhältnis zur investierten >präparatorischen $<$ Wartezeit vor Abfahrt.

\section{Sprachliche Repräsentationen}

Hinsichtlich der Analyse sprachlicher Repräsentationen ist auffällig, dass im Rahmen der zeitgenössischen Schilderungen der ersten preußischen Bahnstrecke an (noch) keiner Stelle der Begriff des >Wartens« konkrete Verwendung gefunden zu haben schien. $\mathrm{Ob}$ in Zeitungsberichten oder Publikationen der für den Bau verantwortlichen Bahningenieure oder auch seitens der Bahnverwaltung, stets wurde das Warten positiv konnotiert in die Dimension des `Empfangs gewendet. In Kontrast zur wenige Jahre zuvor offenen Verwendung des Begriffs im Kontext der Strecke Nürnberg - Fürth schien bis Ende der 1830er Jahre die sprachliche Fassung der >Praxis des Wartens offenbar im deutschen Sprachraum damit noch keineswegs einheitlich verwendet worden zu sein, was dem Umstand einer allgemein neuen Erfahrung entsprochen haben könnte.

105 Bericht von L.Rellstab in der Königlich privilegirten Berlinischen Zeitung von Staats- und gelehrten Sachen vom 21.09.1838, zitiert aus Bley, 150 Jahre Eisenbahn Berlin-Potsdam, 29. 


\subsection{Zur baulichen, betrieblichen und kollektiven sEntdeckunge des Wartens in der Pionierzeit der Eisenbahnen}

»Der Aufenthalt in den Warteräumen, dieses Innehalten der Verkehrsbewegung von der Stadt in die Eisenbahn, macht vielleicht den Schleusencharakter des Bahnhofs am deutlichsten. ${ }^{106}$

Die bauliche Rahmung, der operative Umgang und die erlebte Praxis bzw. Reflektion der Passagiere bedingen mit Beginn des Eisenbahnwesens eine jeweilig auf unterschiedlichen Ebenen gelagerte Erstverhandlung des Wartens, die in einer jeweils genuinen >Entdeckung des Phänomens mündete. Diese drei Ebenen der Erstverhandlung sollen nun im Folgenden näher beleuchtet werden. Während hierbei die bauliche und operative Betrachtung dem ersten Analysestrang der Arbeit entspricht (Außenperspektive), entspricht die Beleuchtung der erlebten Praxis bzw. der Reflektion des Phänomens entsprechend dem zweiten Analysestrang (Innenperspektive).

\subsubsection{Bauliche Entdeckung des Wartens: Räume und Orte}

Die Früherfahrung des verkehrlichen Wartens vollzog sich in den 1830er und frühen 1840er Jahren innerhalb einer nachweislichen Dominanz baulicher Provisorien und Versuchsaufbauten. Es waren Transitbauten, die nicht viel mehr als die rudimentäre Funktion der Gewährleistung eines Übergangs auf das Bahnsystem erfüllen sollten. Die Empfangsgebäude der ersten Bahnhöfe orientierten sich dazu noch vordergründig am bekannten und etablierten Bautypus gewöhnlicher Wohnhäuser (Liverpool, Nürnberg) mit einfachsten Konstruktionen und Konstruktionsmitteln, ${ }^{107}$ an Zollhäusern (Baltimore), Lagerhäusern (Manchester) ${ }^{108}$ und insbesondere an Posthöfen, welche die Vorläuferbauten des vorindustriell dominierenden Landverkehrssystems der Postkutsche darstellten. Die Herstellung einfacher Verkehrsbauten erschien aus der Vorgängererfahrung der Posthöfe heraus zunächst auch für den Bau von Bahnhöfen zweckmäßig und anschlussfähig zu sein. So zeigten die Empfangsgebäude der Pionierbahnhöfe mit Ausnahme der angeschlossenen, überdachten Wagenhalle ${ }^{109}$ - ihrer äußerlichen Form nach entsprechend zunächst keine neuen Auffälligkeiten. Vielmehr vermittelten sie für die vielen Millionen Menschen, die allein innerhalb der ersten Betriebsjahre in Kontakt mit der neuen Technologie kamen, eine gewisse Anmutung des Vertrauten.

106 Schivelbusch, Ceschichte der Eisenbahnreise, 157.

107 Julius Rasch, »Die Eisenbahn-Hochbauten auf den Bahnhöfen und ausserhalb derselben.«, in Handbuch für Specielle Eisenbahn-Technik, hg. von Edmund Heusinger von Waldegg (Leipzig: Wilhelm Engelmann, 1873), 561.

108 Die baugeschichtliche Weiterentwicklung einer Tradition des Baus von Lagerhäusern zu Empfangsgebäuden lässt sich besonders mit Blick auf den englischen Anfangskontext des Eisenbahnhochbaus verzeichnen. Räume für vormals unbelebte Güter wurden nunmehr zu `Zwischenlagern von Passagieren und damit zu belebten Transiträumen weiterentwickelt.

109 Das Novum der Überdachung, das später als Perron- oder Wagenhalle mit riesigen Spannweiten zum ikonischen Element der Großbahnhöfe moderner Metropolen reifen sollte, findet sich bereits in recht stattlicher Form im Bahnhof von Liverpool und ermöglichte somit bereits auf dem ersten Bahnhof der Welt den witterungsgeschützten Ein- und Ausstieg. 
Dennoch war die bloße Adaption von Posthöfen für die neuen Anforderungen des Eisenbahnwesens nicht ausreichend. Wenngleich die Kubatur des Empfangsgebäudes keiner zwingenden Anpassung bedurfte, war es hingegen vielmehr das innere Raumprogramm, das erweitert werden musste. In genau jener Notwendigkeit kann die >bauliche Entdeckung des Wartens« verortet werden. Diese >Entdeckungく bestand darin, das primäre Referenzsystem der Posthöfe zum einen wesentlich in seiner Größe erweitern und zum anderen insbesondere die Funktion des Wartens von anderen Funktionen räumlich differenzieren zu müssen. Wurde innerhalb von Posthöfen zuvor lediglich eine Fläche geschaffen, die jegliche Funktionen in sich verband, wurde selbst das Raumprogramm der jüngsten Empfangsgebäude stärker aufgetrennt, das Warten als (notwendige) Verkehrspraxis damit indirekt anerkannt bzw. auch erst >produziert

Kein bis dahin bestehender Gebäudetyp erforderte zudem eine derart kontrollierte und schnelle Schleusung vieler Menschen vom öffentlichen Stadtraum auf einen Verkehrsträger. Eine zentrale Anforderung des inneren Raumprogramms der Empfangsgebäude bildete daher die neuartige Einrichtung von Sammelflächen, denn, so resümiert Arschavir, »The first obvious requirement for passengers, after the purchase of a ticket, was waiting space (...). « ${ }^{110}$ Entsprechend der Anforderung einer kontrollierbaren Schleusung nahmen Warteräume und Bahnsteige bereits in der Pionierphase einen einfachen, aber dennoch prominenten Bestandteil des Raumprogramms ein. So zeigten alle vier exemplarisch untersuchten Bahnhöfe der Frühphase das Vorhandensein von Warteräumen. Auch wenn das Warten mancherorts noch weniger differenziert innerhalb nur eines einzigen Raumes stattfand (Liverpool) ${ }^{111}$ und nähere Details $\mathrm{zu}$ jeweiligen Ausstattungen dieser Räume nicht mehr vorliegen, bleibt mit Blick auf die Stellung innerhalb der Grundrisse festzuhalten, dass die Warteräume (die teilweise noch nicht explizit als solche bezeichnet wurden) innerhalb der Empfangsgebäude der Pionierphase bereits ein zentrales bauliches Element darstellten. Auch wenn Christian Barman mit Blick auf die frühen Warteinfrastrukturen in England lakonisch bemerkt, dass die Reisenden in London oder Birmingham unter Bedachungen warteten, die genauso gut für die Behausung von Rindern oder Fuhrwerken auf einer Farm herhalten konnten, ${ }^{112}$ nahmen die baulichen Wartestrukturen trotz ihrer Simplizität und vorerst mageren Ausstattung bereits einen wesentlichen Teil des Raumprogramms ein. Innerhalb der vorgestellten Beispiele machen die Warteräume zusammengenommen sogar die flächenmäßig größte Raumgruppe aus.

Ausgehend von einer aus neuartigen Anforderungen geborenen >baulichen Entdeckung des Wartens« sollen nun weitere zentrale Befunde sowie Gemeinsamkeiten und Unterschiede zwischen den analysierten Pionierbahnhöfe herausgestellt werden.

1) Beengte Räumlichkeiten ohne jeglichen Komfort

Ein für die Frühphase charakteristischer Befund liegt darin, dass die Warteräume

110 Arschavir, »The Inception of the English Railway Station«, 65.

111 Von allen untersuchten Bahnhöfen der Frühphase bestanden hinsichtlich der inneren Raumorganisation in Liverpool noch am ehesten Bezüge zum Posthof.

112 Barman, An introduction to railway architecture, 16. 
im Verhältnis zur tatsächlichen Personenfrequenz meist viel zu klein bemessen waren, da der Erfolg der Bahnen oftmals selbst die optimistischsten Prognosen übertraf. Schauplatz des Wartens waren daher aller Wahrscheinlichkeit nach auch Bereiche, die außerhalb der Warteräume selbst lagen. Vor allem dürfte hierfür auch der Gleiskörper (Liverpool) als zentrale Wartezone gedient haben. Darüber hinaus bestand ein verbindendes Charakteristikum darin, dass die Passagiere zunächst nur wenig Komfort genossen, weil den Warteräumen etwa - wie in Nürnberg - rudimentäre Einrichtungen fehlten.

2) Klassentrennungen

Wie bereits an anderer Stelle erwähnt, besteht eine entscheidende Besonderheit des öffentlichen Verkehrs der Eisenbahnreise darin, dass die Fahrtwünsche unterschiedlicher Reisender mit unterschiedlichen Abfahrts- und Zielorten in ein und demselben Fahrzeug gebündelt werden müssen. Dieser zum Individualverkehr kontrastierende Aspekt wurde von einigen Zeitgenossen bereits frühzeitig in seiner potentiell demokratisierenden Wirkung erkannt. Der Saint-Simonist Pecqueur betonte etwa, dass die Eisenbahn mehr für die Gleichstellung der Klassen getan hätte als sämtliche andere Bereiche:

»Die gemeinschaftlichen Reisen in der Eisenbahn und auf den Dampfschiffen sowie die großen Ansammlungen der Arbeiter in den Fabriken befördern außerordentlich das Gefühl und die Cewohnheit der Cleichheit und Freiheit. Die Eisenbahnen werden in wunderbarer Weise für die Herrschaft wahrhaft brüderlicher sozialer Beziehungen wirken und mehr leisten für die Cleichheit als die übertriebenen Prophezeiungen der Volksredner der Demokratie; und all dies wird möglich werden, weil man gemeinsam reist, weil alle Klassen der Cesellschaft hier zusammenkommen, weil sich eine Art lebendiges Mosaik bildet, das sich zusammensetzt aus den verschiedensten Schicksalen, gesellschaftlichen Positionen, Charakteren, Verhaltensweisen, Gebräuchen und Trachten, die jede Nation beisteuert. So verringern sich nicht nur die Entfernungen zwischen den Orten, sondern gleichermaßen die Abstände zwischen den Menschen. ${ }^{113}$

Nicht allein die wirtschaftlichen Folgewirkungen der Eisenbahnen (Minderung von Hungersnöten, verbilligte Bezugsmöglichkeiten von Waren) hatten demnach sozialpolitische Implikationen, sondern allein schon die Reise selbst. War es vor dem Eisenbahnzeitalter nur vorwiegend höheren Ständen vorbehalten Reisen zu unternehmen und sich aus einer vorwiegend sedentaristisch-ortsgebundenen oder kleinräumigzirkulären Grundverfassung des vormodernen Lebens zu lösen, ${ }^{114}$ so wurde das Privileg der Ortsveränderung jenseits lokaler und kleinräumiger Verhältnisse durch das Aufkommen der Eisenbahnen nunmehr erstmals für größere Bevölkerungsteile ermöglicht. Diese betriebliche Notwendigkeit der Bündelung unterschiedlichster

113 Pecqueur in Schivelbusch, Geschichte der Eisenbahnreise, $67 \mathrm{f}$.

114 Sven Kesselring und Wolfgang Bonß, »Mobilität und Moderne. Zur gesellschaftstheoretischen Verortung des Mobilitätsbegriffs«, in Erziehung zur Mobilität. Jugendliche in der automobilen Cesellschaft., hg. von Claus Tully (Frankfurt a.M.: Campus, 1999), 39-66. 
Fahrtwünsche in nur einem Fahrzeug konnte somit durchaus als Angriff auf eine klassenbewusste Gesellschaftsordnung interpretiert werden. Die Eisenbahnreise im Allgemeinen und das Warten im Besonderen standen angesichts ihrer vereinheitlichenden Charakteristik im Widerspruch einer streng hierarchisch organisierten Gesellschaft. Einer frühen, anarchischen Anfangsphase in der mancherorts Reisende erster, zweiter und dritter Klasse sich in denselben (beengten) Räumlichkeiten auf die Abfahrt vorbereiteten, wich daher schnell einer strengen räumlichen Separierung, die versuchte, dem egalisierenden Charakter wiederum aktiv entgegenzutreten. Mit Einrichtung der festen Wartezonen sollte der Bahnhof nicht zu einem Kontrastort, sondern zu einem Ort der Spiegelung gesellschaftlicher Gesamtverhältnisse werden. Dem vereinheitlichenden >Angriff^der Eisenbahn wurde damit bereits frühzeitig mit der sozialdistinktiven Einrichtung klassenspezifischer Wagenklassen und äquivalenter Wartebereiche begegnet. Um die soziale Unterscheidung der Wagenklassen noch weiter künstlich zu unterstreichen, erfolgte zudem die Abfertigung der Wagenklassen oftmals zeitlich getrennt, sodass sich die unterschiedlichen Reisenden auf dem Bahnsteig nicht begegnen mussten.

Die räumliche Trennung unterschiedlicher Wagenklasse wurde jedoch offenbar nicht überall von Beginn an vollzogen. Zum Teil wurde die Frage der Klassentrennung selbst entlang ein und derselben Bahnstrecke örtlich verschieden behandelt. So warteten trotz der bereits anderswo frühzeitigen Etablierung unterschiedlicher Wagenklassen die Passagiere in Liverpool und Nürnberg demnach offenbar noch in gemeinsamen Räumlichkeiten, wohingegen das Raumprogramm von Manchester und Berlin bereits eine deutliche Separierung zeigte. Doch auch die >klassenlosen< Verhältnisse der beiden exemplarischen Beispiele von Liverpool und Nürnberg wurden bereits nach kurzer Zeit als problematisch angesehen und innerhalb der Nachfolgebauten im Sinne der sozialen Distinktion reorganisiert. Carol Meeks sieht diese charakteristische Separierung der Fahrklassen mit Fertigstellung der ikonischen Station von London Euston Square erstmals im Jahr 1838 realisiert. Hier wurden ihm zufolge die Reisenden erstmals beim Zutritt ins Empfangsgebäude voneinander getrennt und anschließend auf separierte Warteräume und Bahnsteigzonen verteilt. ${ }^{115}$ Dieser These ist jedoch wie sich mit Blick auf die Analyse von Manchester Liverpool Road Station zeigte - zu widersprechen, da in Manchester bereits ein halbes Jahrzehnt zuvor die Klassentrennung räumlich und in puncto separierter Wegeführungen deutlich und zweifelsfrei intendiert vollzogen wurde.

\section{3) Restaurationen}

Ein dritter auffälliger Befund liegt im Umstand oftmals fehlender Versorgungseinrichtungen oder Restaurationen im Empfangsgebäude. Obwohl das Postkutschenwesen oftmals als entscheidender Referenzpunkt für den Aufbau der Verkehrsbauten angeführt wurde, ${ }^{116}$ fehlte es mehrheitlich an gastronomischen Einrichtungen.

115 Vgl. Meeks, The Railroad Station: An Architectural History, 32.

116 August Crelle etwa orientiert sich in seinen 1839 veröffentlichten Cestaltungsprinzipien für Empfangsgebäude im Zusammenhang mit der neu zu projektierenden Strecke zwischen Berlin und Frankfurt/Oder direkt an der gastronomischen Referenz des Postwesens: »Die Gebäude auf den 
Anders als die frühesten Empfangsgebäude verfügten die Posthöfe stets über Versorgungsmöglichkeiten, auch deshalb, weil in ihnen oftmals ein längerer Aufenthalt (über Nacht) stattfand. Möglicherweise ist das Fehlen solcher gastronomischen Angebote der Grund für die punktuellen zeitgenössischen Schilderungen über Passagiere, die die Abfahrt ihres Zuges nicht am Bahnhof selbst, sondern in angrenzenden Gasthäusern verbrachten.

Zusammenfassend lässt sich für die Frühphase des Eisenbahnwesens festhalten, dass die eigentlichen Notwendigkeiten des (wartenden) Passagiers erst im Laufe des Betriebs festgestellt wurden, da zum einen der Investitionsfokus zunächst stärker auf den Streckenbau und die Betriebsmittel als auf die Übergangspunkte zur Bahn gelegt wurde. Zum Ende 1830er Jahre schienen die Erfahrungen jedoch bereits so weit fortgeschritten und gesättigt zu sein, dass erste Gestaltungsmaximen veröffentlicht wurden, die auch dezidiert das (neuartige) Element des temporären Aufenthalts betrafen. Als wohl früheste programmatische Erwähnung der Einrichtung von Wartebereichen im deutschsprachigen Raum hierbei ein Artikel zu funktionellen Gesichtspunkten des Bahnhofsbaus in Försters Allgemeiner Bauzeitung aus dem Jahr 1838 gelten. In ihm werden erstmals die vielen pionierhaften Erfahrungen aus England und Kontinentaleuropa zur Empfehlung einer Anlage mit getrennten Abfahrts- und Ankunftsbereichen, getrennten Einrichtungen zur Gepäckannahme und -aufbewahrung sowie der dezidierten Anforderung einer Einrichtung von bequemen ${ }^{117}$ und zugleich klassenspezifischen Wartemöglichkeiten für Reisende verdichtet. Handlungsleitend für den Bau jeglicher neuer Bahnhöfe heißt es dazu:

»Bei einem wohl eingerichteten Depot für Reisende und Waren [...] Muß für die Unterkunft der Passagiere bis zur Abfahrt durch eigene Lokale gesorgt sein, wobei der Bequemlichkeit der Kontrolle halber die Reisenden der verschiedenen Klassen, d. i. die Inhaber der im Preise verschiedenen Fahrkarten, wieder von einander zu trennen sind. $^{118}$

Eines der zu jener Zeit wichtigsten (deutschsprachigen) Organe des Bauwesens lenkte damit die bislang noch kleinmaßstäbliche, aber bereits heterogene Entwicklung des Eisenbahnhochbaus erstmals in Richtung einer Programmatik, die im Sinne der Gewährleistung von Betriebseffizienz, Sicherheit und Komfort eine streng funktionale Differenzierung sowie die verbindliche Schaffung von Aufenthaltsflächen beabsichtigte. Mit anderen Worten: Mit dieser Veröffentlichung erfuhr das systemische Warten eine erste Form der >Anerkennung bzw. der baulichen Institutionalisierung innerhalb des Raumprogramms.

Bahnhöfen müssen die nöthigen Räume zum Empfange der Passagiere, so eingerichtet, daß die Reisenden, etwa wie auf den Poststationen, zugleich die nothwendigste Bewirthung finden.« $\mathrm{Au}$ gust L. Crelle, »Zum uberschläg. Entwurf e. Eisenbahn zwischen Frankfurt a. d. O. und Breslau.«, Journal für die Baukunst: in zwanglosen Heften 13 (1839): 14.

117 Ohne näher zu erklären, was diese Bequemlichkeit ausmachen würde, wurde explizit empfohlen, den Reisenden nach Möglichkeit eine Restauration zur Verfügung zu stellen.

118 Üeber Depots und Sammelplätze für Waaren und Reisende (Stazionsplätze) bei Eisenbahnen«, 163. 
Diese ersten Ausführungen blieben jedoch überaus allgemein und konnten kaum als hinreichende Kriterien des standardisierten Bahnhofsbaus dienen. So formierte sich in den frühen 1840er Jahren zunehmende Kritik an fehlenden synthetisierenden Gedanken, wie sie etwa vom Architekt Lichthammer 1842 in der Allgemeinen Bauzeitung vorgetragen wurde:

»Es ist der neuern Zeit bei der Anlegung von Eisenbahnen und deren Beschreibungen fast gar nichts oder wenig über die Hauptgrundsätze, welche bei dem Baue von Bahnhöfen zu beachten sind, öffentlich bekannt geworden. Eine zweckmäßige Einrichtung der Bahnhöfe gereicht nicht allein zur Bequemlichkeit der Reisenden, sondern sie bildet auch die Hauptgrundlage eines geregelten Geschäftsganges. Wenn der Reisende nicht ohne Zurechtweisung die betreffenden Bureau's, die Ceschäftshallen etc. finden kann, wenn die ankommenden und abgehenden Reisenden sich miteinander vermischen und sich um ihr Gepäck streiten müssen, dann ist an die nothwendige Aufrechterhaltung der Ordnung natürlich nicht zu denken. Und dennoch scheint man auf dem Kontinente lange Zeit die Hauptbedingungen einer zweckmäßigen Einrichtung der Bahnhöfe entweder nicht gekannt, oder doch ziemlich vernachlässigt zu haben. ${ }^{119}$

Um dieser Wissenslücke zu begegnen, formulierte Lichthammer daher zehn Grundsätze, die sich auf Grundlage eigener Beobachtungen als am zweckmäßigsten herausstellten. Sie entsprechen dabei zum Teil den 1838 in der Allgemeinen Bauzeitung veröffentlichten Maximen, erweiterten sie jedoch im Detail. Die für das Warten relevanten Grundsätze umfassen die folgenden:

»2. Die Bureaus für Bagage- und Personenbillets müssen neben einander liegen und Reisende muß mit Sicherheit sein Cepäcke bis zur Lösung einer Personenkarte, in einem gedeckten Raume niederlegen können.

3. Die Wartesäle müssen an die oben genannten Bureaus sich unmittelbar anlehnen, damit der Weg der Reisenden so viel wie möglich abgekürzt wird.

4. Ebenso sind die Einsteighallen an diese Wartesäle dicht anzuschließen. ${ }^{120}$

Die frühen Programmatiken von 1838 und 1842 verweisen somit zusammengenommen bereits auf eine enge Einbindung des wartenden Passagiers in den Betriebsablauf vor Abfahrt und präzisieren die bloße Notwendigkeit von Wartestrukturen in Richtung einer funktionellen und räumlichen Nähe zu anderen Einrichtungen innerhalb des Empfangsgebäudes. Die Programmatiken verfolgten dabei zudem nicht allein die Betrachtung von Einzelaspekten, sondern der Bahnhof wurde dabei als gestalterische Einheit verstanden, denn "Nur dann, wenn allen diesen Bedingungen gehörig entsprochen ist «, so hieß es, »wird die Zirkulazion der Reisenden und Güter ohne Hemmnisse und Störungen geschehen können. «21 Wenngleich darin noch keine konkreteren Aussagen zur Größe, Ausstattung oder Lage der Warteräume getroffen wurden, wurde dem organisatorischen Novum des temporären Sammelns von Passagieren damit offenbar früh

119 Lichthammer, »Ueber einige Bahnhöfe des westlichen Deutschlands und Belgiens«, 354.

120 Ebd., 363.

121 »Ueber Depots und Sammelplätze für Waaren und Reisende (Stazionsplätze) bei Eisenbahnen«, 163. 
begegnet. Konkreter angesprochen wird dagegen jedoch die Empfehlung einer Klassentrennung und - wiederum ganz in anknüpfender Tradition zum Postkutschenwesen die Notwendigkeit einer gastronomischen Versorgung. Diese für die Bauentwicklung der kommenden Phasen maßgebliche Maxime von 1838 finalisiert und institutionalisiert mit ihrer betonten Einrichtung von Passagierlokalen gewissermaßen die >bauliche Entdeckung des Wartens $\triangleleft$, die von dort an zum festen Bauprogramm gehören sollte.

\subsubsection{Betriebliche Entdeckung des Wartens: Herausbildung eines stationären Warteimperativs in Betriebsorganisation und Passagierabfertigung}

Der Befund einer deutlichen Zentralität des Wartens innerhalb des skizzierten Bauprogramms ausgewählter Bahnhöfe der Pionierphase wirft die Grundfrage auf, ob sich diese Zentralität aus den Anforderungen der Betriebsorganisation ergab oder sich die Betriebsorganisation umgekehrt vielmehr nach den aus Sicht von Ingenieuren und Architekten als (einzig) denkbar erachteten baulich-räumlichen Möglichkeiten zur Synchronisation von Mensch und Betriebsmitteln richtete. Mit anderen Worten: Welcher Akteur prägte primär die Entwicklung, die in der Ausbildung jener in jedem Beispiel vorhandener Wartesäle mündete?

Mit Blick auf die Vielzahl der betrieblichen Anforderungen vor Abfahrt steht hier in der Rückschau der Frühphase zu vermuten, dass es vor allem die Betreiberseite war, die als treibende Kraft dieser Entwicklung angesehen werden muss. Die Wünsche nach einer praktischen Kontrollierbarkeit des Passagierstroms, der Prüfung von Fahrtberechtigungen, der Wahrung von Betriebssicherheit, Pünktlichkeit, Aufrechterhaltung der Ordnung oder auch einer Klassenteilung sind allesamt originär Wünsche der Bahnverwaltung, die diese wiederum zum Teil auf Anforderung bahnpolizeilicher Vorgaben umzusetzen hatte. Die sich bereits in der ersten Bahnhofsgeneration ausbildende Vielfalt von Formen bildete demnach den baulichen Niederschlag einer Vielzahl vorgelagerter betrieblicher Anforderungen, die in einem solchen Gebäude Berücksichtigung finden mussten. Anders ausgedrückt: Ohne die betrieblichen Anforderungen der Fahrkartenkontrolle oder eines zeitlich versetzten Einstiegs unterschiedlicher Wagenklassen hätten die Ingenieure und Architekten womöglich andere, einfachere bauliche Lösungen gefunden, die die Synchronisation von Passagier und Betriebsmittel gewährleistet hätten. Dass die in der Pionierphase nachweisbaren Warteräume aus Sicht der Planung bereits frühzeitig zu einem solch raumgreifenden Bauelement gereift waren, konnte aber offenbar nur auf Grundlage einer Betriebsphilosophie entstehen, nach der die geordnete Abfertigung der Reisenden vor Abfahrt nicht denkbar erachtet wurde, ohne die 'Zwischenebene< eines (oktroyierten) temporären Aufenthalts in den Wartesälen einzuziehen.

Wieso aber wurden diese Warteräume und -säle überhaupt als derartig unumgänglich angesehen? Wieso konnten Reisende die Züge nicht unmittelbar besteigen? Mit Rückgriff auf die Entstehungsbedingungen eines systemischen Wartens (siehe Kap. 3.4) kann hierzu nochmals rekapituliert werden, dass Wartezeiten aus operationaler Sicht durch eine generell kontrollintensive Organisation des Verkehrs begründet und benötigt werden, die innerhalb der Verkehrsbauten unter anderem die Einrichtung von Prozesszonen der Retardierung erfordert. Aus Sicht der Reisenden wiederum wird die 
Nutzung des öffentlichen Verkehrs nur mittels eines Orts- und Sachzwangs ermöglicht (Abfahrt am Bahnhof, zu einem bestimmten Zeitpunkt). Für den Übergang vom privaten oder öffentlichen Raum in den Verkehrsraum müssen dazu gewisse Zeitkapazitäten bzw. - puffer eingeräumt werden, die in überschüssiger Zeit am eigentlichen Abfahrtsort resultieren können. Operative und subjektive Zeitfaktoren wirken also einerseits in der Organisation als auch in der Nutzung von öffentlichem Verkehr zusammen, die jeweils im selben Phänomen, der Entstehung systemischer Wartezeiten, münden.

Indirekte Hinweise für eine solche von operativer Seite vorgenommene Einrichtung systemischer Wartezeiten zeigen sich bereits in den Betriebsreglements der Frühphase des Eisenbahnwesens, genauer im Zusammenhang mit den Bestimmungen zur Abfahrtsorganisation. Hierbei kann das akustische Signal des Glockenschlags vor Abfahrt gewissermaßen als ein Indiz für die bewusste Einrichtung eines zeitlichen Zwischenraums herangezogen werden. Bereits auf der ersten Personenstecke zwischen Liverpool and Manchester läutete zunächst eine Glocke, um die Reisenden aus dem Wartesaal zu rufen und zum Einstieg zu bewegen. Auch auf den ersten deutschen Bahnen läuteten Glocken in mehrfachen Intervallen und forderten zum Einstieg auf (so bereits in Nürnberg 1835 oder Berlin 1838). Im Vereins-Reglement des VDEV zum Personenverkehr von 1847 wird in einem Entwurf zur Vereinheitlichung der Betriebsführung vorgeschlagen, dass »das Zeichen zum Einsteigen« erst durch »zwei unterschiedene Schläge auf die Glocke $\ll^{122}$ gegeben wird, was ab 1865 schließlich als verbindlicher Bestandteil der Betriebsführung in die Vereins-Reglements aufgenommen wird.

Die nachweisliche Nutzung dieses akustischen Signals vermag zunächst trivial anmuten, doch sie verrät, dass diesem akustischen Signal offenbar eine Situation vorausgehen musste, in der eine Vielzahl der Reisenden sich bis zu diesem Zeitpunkt bereits in einem speziellen Raum versammelt hatte, die zu Empfängern dieses Signals wurden. Die bereits am Bahnhof eingetroffenen Reisenden wurden demnach erst für eine bestimmte Zeit vom Bahnsteig und vom Einstieg in die Wagen zurückgehalten, was, wie sich noch in den späteren Entwicklungsphasen zeigen wird, einer immer raumgreifenderen baulichen Entsprechung bedurfte, die schließlich mit Wachstum der Passagierfrequenz in den gigantischen Wartesälen der Kopfbahnhöfe resultierte.

Was sich demnach zum einen vermittelt durch die akustischen Signale und baulich vermittelt über das mehr oder weniger ausdifferenzierte Vorhandensein von Warteraumstrukturen in den Pionierbahnhöfen abzeichnete, war die Herausbildung einer operativen Bewusstwerdung und Nutzung des Wartens als organisatorischer Aspekt des Betriebsablaufs. Diese Bewusstwerdung in der Phase des Aufstiegs der Eisenbahn zum Massenverkehrsmittel wurde dabei nicht allein durch das Vorhandensein von Warteflächen charakterisiert, sondern vielmehr über eine entscheidende inhaltliche Qualifizierung, die wohl am treffendsten als Ausbildung eines stationären Warteimperativs bezeichnet werden dürfte.

Dieser Imperativ zeigte sich darin, dass Reisende an den Bahnhöfen häufig in den Wartesälen sprichwörtlich `festgehalten « wurden. Gemeint ist hiermit, dass es den Reisenden in vielen Ländern und Regionen nicht erlaubt war, sich vor Abfahrt frei im

122 Königliche Eisenbahndirektion zu Berlin, Festschrift über die Thätigkeit des Vereins Deutscher Eisenbahn-Verwaltungen in den ersten 50 Jahren seines Bestehens, 1846-1896, 248. 
gesamten Bahnhofsbereich zu bewegen. ${ }^{123}$ Exemplarisch sei dazu in Rekapitulation des Betriebsreglements der ersten preußischen Eisenbahnstrecke zwischen Berlin und Potsdam noch einmal darauf verwiesen, dass »Der Ort, wo die Wagen stehen « dem $\mathrm{Pu}$ blikum »bis 10 Minuten vor der zum Abgange bestimmten Stunde geschlossen« zu halten ist. Diese knappe, aber für die historische Betrachtung des verkehrlichen Wartens hochrelevante Bemerkung deutet darauf hin, dass ein freies Betreten des Bahnsteigs oder der Gleisanlagen vor dem Ertönen des Glockensignals in der Regel nicht gestattet war. Nach Erwerb der Fahrkarte und Aufgabe des Reisegepäcks wurden Reisende daher nicht direkt zum Bahnsteig bzw. direkt zum Zug, sondern zunächst zu den Wartesälen geführt. Erst von hier aus, nach mehr oder weniger langem Aufenthalt, konnten Bahnsteig und Zug bestiegen werden.

Die Herausbildung dieses raumgebundenen, stationären Warteimperativs resultierte aus der operativen Herausforderung angesichts der Abfertigung hunderter Reisender eine ausreichende Ordnungs- und Kontrollfähigkeit von Strömen, Zugangsberechtigungen und insbesondere dem betriebsgerechten Timing dieser Prozesse zu gewährleisten. Für diese Formen lieferte die Schleuse eines vorgeschalteten und abschließbaren Wartesaals bzw. Transitraums oftmals das geeignete Mittel, denn sie ermöglichte die störungsfreie Bearbeitung bzw. Vorbereitung von Prozessen im Hintergrund, die eine pünktliche und sichere Abfahrt offenbar erst möglich machten. Egal ob in Liverpool oder Berlin, die Zweckmäßigkeit des temporären Sammelns von Reisenden, die über die skizzierten Beispiele hinaus ein zentrales Prinzip der Passagierabfertigung darstellte, kann als eine Art der >betrieblichen Entdeckung des Wartens verstanden werden. Dass dieses Prinzip zu einem grundsätzlichen Prinzip der Moderne wurde, welches bis heute wirksam ist, lässt sich leicht mit Blick auf die Funktion von Sekretariaten und Vorzimmern erkennen. Auch diese vorgeschalteten (Raum-)Elemente sollen eingehende Ströme (Anfragen, Personen etc.) filtern bzw. vorstrukturieren, um die Effizienz der Kernprozesse im Hintergrund nicht durch permanente Ablenkungen und Störungen zu gefährden. ${ }^{124}$

\subsubsection{Kollektive Entdeckung des Wartens: Rezeptionen und Praktiken}

Der Blick auf die Innenperspektive des Wartens und dem damit verbundenen Versuch der Rekonstruktion der frühesten Erfahrung dieses Reisebestandteils gestaltet sich weit schwieriger als die Rekonstruktion einer baulichen und betrieblichen >Entdeckung des Wartens. Nur sehr wenige literarische Quellen lassen indirekte Rückschlüsse auf die Wahrnehmung und Rezeption des Temporalphänomens in der Frühphase bis $1845 \mathrm{zu}$.

Die literarische Verhandlung der neuen Eisenbahnen stellte sich in der Pionierphase laut dem Literaturhistoriker Johannes Mahr vor allem im polarisierten Spektrum zwischen Heroisierung und Furcht dar. Der Lyrik kam hierbei als eine der meistrezipierten Gattungen des 19. Jahrhunderts eine bedeutende Rolle zu. Mahr attestiert den Eisenbahngedichten eine lückenlose Traditionskette, die es als einzige literarische Gattung

123 Auf die nationalen und regionalen Unterschiede des Aspekts der Bewegungsfreiheit der Reisenden wird an späterer Stelle noch ausführlich eingegangen (Kap. 7.2.1). 
erlauben würde, »das wechselnde Bild der Bahn zu verfolgen. " $^{125}$ Die Lyrik gilt demnach als jene literarische Gattung, in dem Eisenbahnen am häufigsten erscheinen, weil sich die kurze lyrische Form besonders anbieten würde, um das neue subjektive Welterleben $\mathrm{zu}$ verarbeiten. ${ }^{126}$ Doch trotz dieser literaturwissenschaftlich vielversprechenden Ausgangslage findet sich weder in den Eisenbahngedichten von Adalbert von Chamis$\mathrm{so}^{127}$, Friedrich Rückert ${ }^{128}$, Anastasius Grün ${ }^{129}$, Karl Beck ${ }^{130}$, noch in jenen von Nikolaus Lenau ${ }^{131}$ oder Theodor Mundt ${ }^{132}$ auch nur eine schmale Thematisierung des präparatorischen Aufenthalts. Dieser Befund greift für die heroisierenden Ansätze genauso, wie für jene Gedichte, die im Eisenbahnwesen im Allgemeinen und der Lokomotive im Besonderen ein bedrohliches Fabelwesen sahen. Vielmehr werden in den Gedichten die mit der Eisenbahn evozierten Tendenzen der Beschleunigung, Raumschrumpfung sowie der neuen Erreichbarkeiten im Spektrum ihrer Befürwortung oder Ablehnung behandelt. Gattungsgemäß wird dabei zudem das subjektive Welterleben nur selten von einer wirklichen Situationsbeschreibung begleitet. Stattdessen bleibt der Blickpunkt der Gedichte oftmals abstrakt und referiert auf die Metaebene der raumzeitlichen Veränderungen.

Laut Kistenmacher könne die deutsche Lyrik jener Zeit ohnehin nur schwerlich für eine Rekonstruktion der frühen Warteerfahrung herangezogen werden, da sich die Autoren in der Zeit von 1830-1844 aus seiner Sicht allgemein »nicht viel mit den aktuellen Fragen der Industrie und des Verkehrs ${ }^{133}$ befassten. Stattdessen beschäftigten sie sich in der Frühphase des Eisenbahnwesens überwiegend mit politischen Themen und verlagerten ihr reformatorisches Bestreben fast gänzlich in dieses Gebiet. Wenn von Eisenbahnen gesprochen wurde, dann wiederum oftmals im politischen Zusammenhang eines Freiheitsgedankens, der `sozialen Frage`, als Mittel zur Vereinigung der Völker oder der Überwindung der deutschen Kleinstaaterei.

Jenseits dieser unterschiedlichen Positionsbestimmungen der Lyrik zum Eisenbahnmotiv herrscht jedoch Konsens darin, dass liberale Zeitschriften und Zeitungen das stärkste Interesse an den neuen Entwicklungen der verbesserten Verkehrsverhältnisse zeigten. Mit Berichterstattungen über Streckenöffnungen prägten sie als zentraler Meinungsträger das öffentliche Bild der neuen Verkehrstechnologie. ${ }^{134}$ So wimmelte es in den 1840er Jahren wahrlich an Titeln von >Dampfbooten<, >Eisenbahnen $<$, >Dampfwagen $<$ und >Lokomotiven $<.{ }^{135}$ Doch auch hier lag die gesamte inhaltliche Aufmerksamkeit dieser Erscheinungen nachvollziehbarerweise nicht auf dem temporären Aufenthalt vor Abfahrt, sondern auf der als viel wesentlicher empfundenen

125 Mahr, Eisenbahnen in der deutschen Dichtung, 51.

$126 \mathrm{Vgl}$. Mahr, Eisenbahnen in der deutschen Dichtung, $55 \mathrm{f}$.

127 »Das Dampfroß« (1830)

128 »Die Eilfahrt« (1833)

129 »Poesie des Dampfes« (1837)

130 »Die Eisenbahn« (1837)

131 »An den Frühling 1838« (1838)

132 »Brief aus London« (1837)

133 Hans Werner Kistenmacher, Maschine und Dichtung: ein Beitrag zur Geschichte der deutschen Literatur im 19. Jahrhundert (Greifswald: Hartmann, 1914), 72.

134 Vgl. Mahr, Eisenbahnen in der deutschen Dichtung, $25 \mathrm{ff}$.

135 Vgl. Kistenmacher, Maschine und Dichtung, 53. 
Neuheit einer bis dahin unvergleichlich schnellen Raumüberwindung sowie auf detaillierten Beschreibungen der neuen Technologie. Es ließen sich unzählige Beispiele dieser auf die Bewegung und die Lokomotiven fixierten Berichterstattung anführen, eine Schilderung der neuen Bahnhofsgebäude ist dabei jedoch nur äußerst selten, eine Thematisierung des Aufenthalts in Wartesälen oder auf Bahnsteigen darin (noch) nicht auszumachen.

Exemplarisch sei hierzu etwa auf Heinrich Heines berühmte Schilderung der Eröffnung einer neuen Bahnstrecke in Frankreich des Jahres 1843 verwiesen, in der die transformatorische Kraft der Eisenbahnen klar im Vordergrund steht:

»Die Eröffnung der beiden neuen Eisenbahnen, wovon die eine nach Orléans, die andere nach Rouen führt, verursacht hier eine Erschütterung, die jeder mitempfindet, wenn er nicht etwa auf einem sozialen Isolierschemel steht. Die ganze Bevölkerung von Paris bildet in diesem Augenblick gleichsam eine Kette, wo einer dem andern den elektrischen Schlag mitteilt. (...) Die Eisenbahnen sind wieder ein solches providentielles Ereignis, das der Menschheit einen neuen Umschwung gibt, das die Farbe und Cestalt des Lebens verändert; es beginnt ein neuer Abschnitt in der Weltgeschichte, und unsre Generation darf sich rühmen, daß sie dabeigewesen. $\ll^{136}$

Die allgemeine Quellenlage zur Erkundung passagierbezogener Reflektionen des Wartens gestaltet sich damit innerhalb einer zeitgenössisch von großen Fragen und Gesten geprägten Literatur äußerst schwierig. Der folgende Versuch einer Rekonstruktion der frühesten verkehrlichen Warteerfahrung soll daher in Form von drei zentralen Thesen erfolgen.

1) Warten als Subsumption unter einer neuen Gesamterfahrung und Katalysator des Eisenbahnfiebers

Die Erfahrung des verkehrlichen Wartens auf Eisenbahnen kann wahrscheinlich insgesamt nur im Zusammenhang einer übergeordneten Pioniererfahrung der Bahnreise betrachtet werden. Ob Betriebsmittel, Gebäude oder Abläufe, jeglicher Aspekt der Eisenbahnreise erschien den Beteiligten gänzlich neu. Verantwortliche der Bahnverwaltungen, Behörden oder die Reisenden selbst; sämtliche Akteure, die mit der Eisenbahn sympathisierten waren voller Aufregung ob der politischen, wirtschaftlichen und gesellschaftlichen Potentiale der neuen Verkehrstechnologie. Weltweit kursierte der Begriff des >Eisenbahnfiebers $<$, der diese Aufbruchsstimmung einzufangen versuchte. ${ }^{137}$ Angesichts der epochalen Veränderungen, der leibhaftigen Erfahrung des beschleunigten Transports, der geschwindigkeitsbedingten, >panoramatischen $<$ Wahrnehmungsveränderungen $>$ vom Punkt zur Linie ${ }^{138}$ und der Erschließung neuer Möglichkeitsräume mag

136 Heinrich Heine, Werke und Briefe in zehn Bänden, hg. von Hans Kaufmann (Berlin und Weimar: Aufbau, 1972), 477.

137 Der Begriff des > Eisenbahnfiebers < umfasste dabei zum einen Passagiere, die bereits vor Antritt der Fahrt in einen Aufregungszustand verfielen, er umfasste aber auch die Dimension der krankhaften Überspekulation mit Eisenbahnaktien. Viktor von Röll, Enzyklopädie des Eisenbahnwesens (Wien: Urban \& Schwarzenberg, 1913), 57.

138 Schivelbusch, Ceschichte der Eisenbahnreise, $51 \mathrm{ff}$. 
das eigentliche Erwarten der Abfahrt aus Perspektive der Passagiere während der 1830er und frühen 1840er Jahre schlichtweg noch nicht explizit wahrgenommen worden sein.

Wenn das Warten überhaupt implizit als eine gewisse Abweichung oder besondere Situation spürbar war, dann möglicherweise vielmehr als ein Katalysator der ohnehin vorhandenen Aufregung. Diese These einer Katalysatorfunktion des Wartens wird dabei von einer zeitgenössischen Schilderung des dänischen Dichters Hans-Christian Andersen genährt, der einen der wenigen direkten Befunde liefert, die auf die zeitgenössische Atmosphäre an den Bahnhöfen der Frühphase vor Abfahrt schließen lassen. Andersen unternimmt um 1840 eine lange Reise, die ihn durch halb Europa führen sollte. $\mathrm{Zu} \mathrm{Be-}$ ginn dieser Reise besteigt er auf der Durchreise von Norddeutschland nach Dresden in Magdeburg erstmals eine Dampfeisenbahn und schildert seine Empfindungen während einer offenbar einstündigen Wartezeit am gerade erst eröffneten Bahnhof der Stadt, welcher den Endpunkt der ersten deutschen Fernverbindung (Magdeburg - Leipzig Dresden) markierte:

»Zum ersten Mal in meinem Leben sollte ich eine solche sehen. Einen halben Tag, und die darauf folgende Nacht, war ich mit der Diligence den furchtbar schlechten Weg von Braunschweig nach Magdeburg gereist. Ermüdet kam ich hier an, und eine Stunde später sollte ich wieder fort mit dem Dampfwagen. Ich will nicht leugnen daß ich vorher eine Empfindung hatte, die ich Eisenbahnfieber nennen will, und dieses war am stärksten als ich in das großartige Gebäude trat wovon aus die Wagenreihe fahren sollte. Hier war ein Cedränge von Reisenden, ein Laufen mit Koffern und Nachtsäcken, ein Sausen und Brausen der Maschinen, aus welchen der Dampf hervordrang. Man weiß zum ersten Mal nicht recht wo man stehen darf, daß nicht ein Wagen, oder Dampfkessel, oder ein Lade mit Reisesachen über uns stürze; freilich steht man auf einem vorspringenden Altan [Balkon/Bahnsteig, R.K.] sicher; die Wagen in welche man soll, liegen in einer Reihe bis dicht hinauf, gleich den Condeln bei einem Kai aber unten im Hofe kreuzt, gleich Zauberfäden, die eine Elsenschiene die andere. (...) Ist man nun, wie gesagt, zum ersten Mal hier, dann glaubt man umzuwerfen, Arme und Beine zu brechen, in die Luft gesprengt, oder durch Zusammenstoßen mit einer andern Wagenreihe gequetscht zu werden; aber ich glaube daß man nur beim ersten Male daran denkt. « $^{139}$

Aus Andersens Worten wird deutlich, dass sein faktisches Warten innerhalb der offensichtlichen Aufregung über den neuen Bahnhofskosmos und der allgemeinen Neugier subsumiert wird. Der organisatorische Zwang des Aufenthalts wird hier keinesfalls negativ konnotiert, sondern ganz im Gegenteil wird der Bahnhof hier vielmehr zum Kristallisationspunkt des `Eisenbahnfiebers $`$. Das Warten fungierte hier als Spannungsaufbau und offenbar auch als Möglichkeit zur Inspektion der Technik und der Betriebsabläufe. Demnach rückt das Warten hier (noch) nicht in den Stand einer Bürde, sondern vielmehr in den Stand einer katalytischen Kraft eines ohnehin positiven Grundgefühls.

139 Andersen Hans-Christian, Eines Dichters Bazar, Bd. 1 (Leipzig: Eduard Kummer, 1843), 24f. [Hervorhebungen des Verfassers, R.K.]. 
Diese Vermutung einer positiven, die Aufregung noch weiter steigernden Grunderfahrung des Wartens wird auch über einen überlieferten Brief einer englischen Dame gestärkt, die im Juni 1831 kurz nach Eröffnung der Strecke zwischen Liverpool und Manchester erstmalig die Eisenbahn nutzt.

»Das wundervolle Wetter, welches am Montag herrschte, veranlasste mich, einen Platz in einem offenen Wagen der Eisenbahn zu nehmen. Wir kamen daselbst eine Stunde zu früh an; da ich aber die neue Art des Betriebes noch nicht gesehen hatte, so war ich begierig, die Wagen und die Locomotive zu sehen (...). « $^{140}$

Dieser Brief gehört zu den wenigen Quellen, die implizit auf die Verhandlung eines zu großen Zeitpolsters am Bahnhof berichten. Hieraus geht nicht nur hervor, dass sich die Reisenden - wie noch in Kapitel 7.2.1 zu berichten sein wird - im englischen Kontext völlig frei am Bahnhof bewegen konnten. Vielmehr geht hier wiederum heraus hervor, dass die Wartezeit der Neugier Raum gibt und sie zugleich noch weiter verstärkt. Warten ist Vorfreude, Plattform gesellschaftlicher >Massenerfahrung< und vermutlich auch ein Element sozialer Repräsentation. Andersens Schilderungen und jene der englischen Dame dürften sich durchaus als eine exemplarische Grunderfahrung des frühen Eisenbahnzeitalters darstellen. Die Subsummierung der Warteerfahrung unter einer Grunderfahrung des >Neuen mag dabei so lange angehalten haben wie eine fehlende Vertrautheit und Routinisierung im Umgang der neuen Verkehrsmittelnutzung bestand.

\section{2) Warten als unbewusstes Erlebnis aufgrund fehlender Vergleichserfahrungen}

Als zweite These zur Rekonstruktion der frühen Warteerfahrung soll die Vermutung eines weitgehend nur subtil erfahrenen Warteerlebnisses angeführt werden. Nach dieser Überlegung konnte das Warten nicht explizit thematisiert werden, weil aufgrund des allgemeinen »Mangels an Erfahrungen des Publikums ${ }^{141}$ schlichtweg keine vergleichbaren Vorgängererfahrungen existierten, die das Phänomen einordnen ließen. Diese These wird aus dem herausgearbeiteten sprachlichen Befund genährt, dass die Begriffsbezeichnung des Wartens international anfangs äußerst heterogene Verwendungen bzw. Umschreibungen findet. Die Neuheit des Phänomens (und damit die Unerfahrenheit in Umgang und Reflektion) erhält dadurch Ausdruck, dass sprachlich oftmals weniger die Tätigkeit selbst als vielmehr die räumliche Funktion des Aufenthaltsraums genutzt wurde. Während in Nürnberg zwar direkt von >Wartsälen gesprochen wurde, ist im englischen Kontext zunächst von >rooms for accomodation of passengers' und in Berlin mehrheitlich von >Empfangszimmern « die Rede. Erst nach einiger Zeit wird auch in England die Bezeichnung swaiting rooms < etabliert (spätestens mit Whishaw 1842) und damit eine sprachliche Wendung von der betrieblichen Sichtweise zur Repräsentation der Tätigkeit aus Sicht der Passagiere vollzogen. In dieser sprachlichen Stabilisierung könnte ein Hinweis liegen, dass in den Jahren zuvor die Praxis

140 »Brief einer englischen Dame«, abgedruckt in Carl Löper, Stammbuch der neueren Verkehrsmittel, Eisenbahnen, Dampfschiffe, Telegraphen und Luftschiffe (Heidelberg: Decker, 1984), 148f.

141 Ëisenbahn von Paris nach St. Germain.«, Allgemeine Bauzeitung 3, Nr. 27 (1838): 247. 
des Wartens aufgrund fehlender Vorerfahrungen noch nicht explizit als solche thematisiert, bezeichnet und erlebt wurde. Mit anderen Worten: Das Warten musste zunächst einmal erlernt werden, um es explizit thematisieren zu können.

Die These eines eher unbewussten Warteerlebnisses könnte zudem dadurch erhärtet werden, dass die für die Wahrnehmung von Wartezeiten so wesentliche Vorbedingung einer wahrgenommenen Anomalie des sonst vertraut linearen Zeitflusses ${ }^{142} \mathrm{zu}$ Beginn des Eisenbahnwesens schlichtweg noch nicht gegeben war, weil sich das mechanisierte Zeitbezugssystem der Eisenbahnen auf Seiten der Reisenden erst allmählich auszuprägen begann.

Zweifelsohne fungierte hierbei der Bahnhof als zentraler gesellschaftlicher Schauplatz und Lernort der Verinnerlichung des neuen Zeit-Regimes einer physikalisch-mechanisierten Zeitordnung, die ihre Rhythmen von den natürlichen Referenzgrößen abzuschütteln begann. In den Bahnhöfen manifestierte sich die Präsenz einer neuen Temporalkultur, die ganz im Elias'schen Sinne auf ein "In-Beziehung-Setzen von Positionen oder Abschnitten zweier oder mehrerer kontinuierlich bewegter Geschehensabläufe ${ }^{143}$ und damit auf deren Synchronisation abzielte. Diese Synchronisation von Menschen und Betriebsmitteln am Bahnhof erzwang seitens der Passagiere, sich nunmehr nach Abfahrtszeiten zu richten und sich zeiträumlich entsprechend im Vorfeld $\mathrm{zu}$ organisieren. Um den Zeitpunkt der Abfahrt nicht zu verpassen, wurde der ständige Abgleich mit der aktuellen Uhrzeit zu einer zentralen wie notwendigen Praxis. Zweifelsohne war auch das Postkutschenwesen bereits stark zeitlich >getaktet und hatte mit der Etablierung des minutengenauen Fahrplans eines der bis heute zeitsensitivsten Medien geschaffen. ${ }^{144}$ Jedoch bewirkte das wesentlich stärker durch ein objektiv-mechanisiertes Zeitsystem organisierte Eisenbahnwesen einerseits einen qualitativen Bedeutungszuwachs der Zeitkategorie. Zum anderen bewirkte die ungleich größere Anzahl an Reisenden eine immense quantitative Bedeutungszunahme des objektiv-mechanisierten Zeitbegriffs, weil sich ihm nun wesentlich mehr Menschen unterstellen mussten. Das Bewusstsein von und über Zeit dürfte so im Kontext der frühen Bahnreise - wenngleich überdeckt vom Anblick und der aufgeregten Erwartung des Neuen - einen subtil wirksamen, aber zentralen (und vom alltäglichen Leben unterschiedenen) Bewusstseinsaspekt gebildet haben. Prominentestes Sinnbild für die Zentralität des Zeitlichen und der normativen Verinnerlichung des Uhrzeitregimes ist wohl zweifelsohne die Bahnhofsuhr. Sie wurde im deutschen Kontext gar bahnpolizeilich vorgeschrieben, so etwa für den Betrieb der Berlin-Potsdamer Bahngesellschaft (1839):

»§. 20. Es soll auf jedem der beiden Bahnhöfe eine dem Publikum außerhalb des Hofes sichtbar große Uhr vorhanden sein, nach welcher der Betrieb der Eisenbahnbeförderung überall geleitet wird und welche daher auch für alle Reisende maßgebend ist.

142 Vgl. Kap. 2.4.

143 Elias, Über die Zeit, 20.

144 Zum Übergang der stundenbasierten zur minutengenauen Fahrplangestaltung im Postwesen sei auf eine jüngst erschienene Arbeit von Catherine Herr-Laporte verwiesen: Catherine Herr-Laporte, »Rien ne sert de courir; il faut partir à point: temps et mobilité dans un long xviiie siècle«, in Les Débuts du Conservatoire des Arts et Métiers, hg. von Liliane Hilarie-Pérez, Stéphane Lembré, und Delphine Spicq (Toulouse: Presses Universitaires du Midi, 2019), 119-42. 
Beide Uhren sollen nach der Uhr der Königl. Akademie zu Berlin reguliert werden, und es ist dies täglich zu kontrolliren. ${ }^{145}$

Wie aus dieser behördlichen Anordnung hervorgeht, existierten bis zu diesem Zeitpunkt nur wenige Orte an denen die mechanische Uhrzeit sausgestellt wurde. Der Bahnhof verdichtete somit das Netz sichtbarer Zeitanzeiger in der Stadt. Bahnhöfe wurden neben Kirchtürmen zu den wichtigsten Zeitanzeigern, faktisch deshalb, weil sich die Organisation des Eisenbahnwesens zutiefst als Organisation von Zeit und Raum darstellte. Auch Gottwaldt führt den Wandel der Temporalkultur des frühen 19.Jahrhunderts auf die Bahnhofsuhr zurück und vermerkt:

»Die am Bahnhof allgegenwärtige Uhr und der sich täglich wiederholende Fahrplan weisen unerbittlich darauf hin, dass es neben dem zyklischen Zeitbegriff der regelmäßigen Erneuerung von Tageslauf und Jahreszeiten immer auch einen linearen Zeitbegriff der Vergänglichkeit geben wird. $\aleph^{146}$

Diese Verinnerlichung eines durch die Eisenbahnen oktroyierten linearen Zeitbegriffs war jedoch ein Prozess und musste gesamtgesellschaftlich erst über einen langen Zeitraum hinweg erlernt werden. Ungeachtet der Tatsache, dass die Bahnhöfe zu Kristallisationspunkten der modernen, von Naturrhythmen abgelösten Zeitordnung wurden, brauchte diese Entwicklung selbst `Zeit<, um verstanden und praktiziert zu werden. Zudem trat zu Beginn des Eisenbahnwesens trotz der rasant steigenden Passagierzahlen ohnehin nur ein Bruchteil der Bevölkerung in direkten Nutzungskontakt mit der Eisenbahn.

Abschließend kann die These einer primär unbewussten Verhandlung des verkehrlichen Wartens in der Pionierphase der Eisenbahnen zudem durch die Beharrungskräfte einer alten, langsameren Zeitkultur gestützt werden. Trotz der Verbreitung von öffentlichen Zeitanzeigern $^{147}$ und der auf einem linearen Zeitregime basierenden Organisation der Eisenbahnen blieb die Zeitwahrnehmung im Kontext der 1830er und 1840er Jahre noch stark an natürlichen Rhythmen verhaftet. Die >Sattelzeit` war gerade erst am Ende ihres Wirkens, der Übergang in die moderne Zeitordnung noch stark personen- und gruppenspezifisch. Dass die Zeitwahrnehmung zumindest im deutschsprachigen Kontext zur Entstehungszeit der Eisenbahn noch weniger von einer Zeitökonomie geprägt gewesen sein dürfte, wird hierbei durch einen vergleichenden Hinweis zur Evolution der Bahn in England und Deutschland deutlich, den Max Maria von Weber im Jahr 1873 verfasste. Im Zusammenhang mit unterschiedlichen nationalen Ansätzen und Charakteristika des Streckenbaus vermerkte von Weber aufschlussreich für den deutschen Raum:

»Man schmiegte sich den Unebenheiten des Terrains mit stärkeren Steigungen, Krümmungen und Cefällen, unter Aufopferung eines Theiles der Ceschwindigkeit, an, was

145 Kletke, Die Preußischen Eisenbahnen, Dritter Abschnitt: Über Spezielle Vorschriften zur Benutzung der Eisenbahnbeförderung:110.

146 Geisthövel, Knoch, und Gottwaldt, »Der Bahnhof«, 26.

147 Diese funktionierten jedoch zum Teil nur bei Tageslicht (Sonnenuhren). 
um so zulässiger war, als, bei den weniger angespannten Lebensverhältnissen, die Zeit noch weniger werthvoll als in England ist. ${ }^{148}$

Die 1830er Jahre standen demnach aus dem Rückblick der 1870er Jahre noch nicht unter dem gleichen `Zeitdruck wie im merkantilistischen England. Eine mäßigere Geschwindigkeit wurde offenbar billigend in Kauf genommen. Vor dem Hintergrund dieser grundsätzlich gemäßigteren Temporalkultur steht wohl auch zu vermuten, dass reziprok zur geringeren Beschleunigungserwartung auch Wartezeiten weit weniger problematisiert, sondern stärker toleriert, akzeptiert bzw. gar nicht erst als Abweichung oder Wartezeit empfunden wurden. Ohnehin diente die Eisenbahnreise der Anfangszeit überwiegend dem Ausflugs- und Freizeitverkehr. Zwar wurde die erste Personenverkehrsstrecke zwischen Liverpool und Manchester dafür gefeiert, dass es nunmehr für Geschäftsleute möglich wurde am selben Tag hin- und zurückzureisen, ${ }^{149}$ doch insgesamt waren der Berufsverkehr oder gar ein Pendlertum noch randständige Erscheinungen. Damit steht zu vermuten, dass auch in Bezug auf die Reiseanlässe eine vermutlich ohnehin größere zeitliche Toleranz bzw. eine noch geringere Zeitökonomie vorherrschten.

\section{3) Explizierung der Warteerfahrung in Form von Beschwerden}

Als dritte These zur frühen Warteerfahrung lässt sich aus der vorangegangenen Analyse der Pionierbahnhöfe formulieren, dass in bereits punktuell auch (moderne) Anzeichen bestanden, die im verkehrlichen Warten explizit den Grund eines Ärgernisses sahen. So zeigt sich etwa in den Beschwerden Reisender über die ungünstige Fahrplangestaltung zwischen Nürnberg und Fürth, dass die dadurch entstehenden (langen) Wartezeiten durchaus offen problematisiert wurden. Dies konnte offenbar besonders dort geschehen, wo zum einen der Reiz des Neuen allmählich von einem routinierten Umgang und einer Gewöhnung abgelöst wurde ${ }^{150}$ und wo bereits vor Bau der Eisenbahn etablierte Verkehrsverbindungen eine stärkere zeitsensitive Erwartungshaltung erzeugten oder aber auch schlichtweg das verfügbare Angebot der Verkehrsnachfrage nicht gerecht wurde.

Die Relation zwischen am Bahnhof verbrachten Wartezeiten und der Zugangs- und Abfahrtszeit mit der eigentlichen Reisezeit im Zug bildeten demnach einen weiteren wichtigen Einflussfaktor für die explizite Erfahrung des systemischen Wartens. Da die ersten Bahnhöfe zwar nicht im Stadtzentrum, aber doch meist in unmittelbarer Nähe

148 von Weber, Schule des Eisenbahnwesens: Geschichte, Technik, Administration und Statistik der Eisenbahnen, 41.

149 »The traveller will live double times: by accomplishing a prescribed distance in five hours, which used to require ten, he will have the other five at his own disposal. The man of business in Manchester will breakfast at home - proceed to Liverpool by the Railway, transact his business, and return to Manchester before dinner. A hard day's journeying is thus converted into a morning's excursion." Henry Booth, An account of the Liverpool and Manchester Railway (Liverpool: Wales and Baines, 1830), 91.

150 Die Passagierfrequenz zwischen Nürnberg und Fürth übertraf gar noch die von Liverpool und Manchester, sodass hier bereits nach kurzer Zeit von einer Gewöhnung an das Eisenbahnsystem ausgegangen werden kann. 
vor den Stadtmauern errichtet wurden, waren die Zugangszeiten - selbst als Fußgänger - noch vergleichsweise gering, sodass die am Bahnhof verbrachte Zeit relativ lang erschienen sein könnte. So ist insgesamt davon auszugehen, dass sich ortsspezifisch in die aufgeregt positive Grunderfahrung der Eisenbahnreise bereits punktuell auch negative Konnotationen eingeschlichen haben könnten, die - mit Blick auf die Problematik in Nürnberg - sogar Einfluss auf die attestierte Zukunftsfähigkeit des Eisenbahnwesens nehmen sollten. Wenngleich der Nürnberger Einzelfall den Unmut über die langen Wartezeiten zum Ausdruck brachte, muss angesichts der sonst aber fehlenden Quellen, die über eine mögliche Problematisierung des verkehrlichen Wartens berichten würden, betont werden, dass zu Beginn des Eisenbahnwesens insgesamt noch keine kollektiv irritierende Problemerfahrung erkennbar wird.

\section{Zur 'kollektiven Entdeckungr des Wartens}

Zusammenfassend traf das zeitsensitive System der Eisenbahnen in den 1830 und 1840er Jahren auf eine gesellschaftliche Temporalkultur, die noch recht stark von zyklischen und naturgebundenen Rhythmen geprägt war. Wartezeiten, wie sie die Organisation des neuen Massenverkehrsmittels erzwang (und verursachte), waren weder bekannt, noch wurden sie offen als Anomalie oder Störfaktor thematisiert. Selbst wenn wie im Falle der ersten Streckenöffnung in England die Wahrnehmung einer Verspätung sälter als jene der planmäßigen Ankunft war, dürfte sich die Wahrnehmung einer artifiziellen, von Naturrhythmen oder sozialen Ursachen abgekoppelten systemischen Wartezeit vor Abfahrt zu Beginn des Eisenbahnzeitalters innerhalb einer Erfahrung des Neuen und einem allgemeinen Grundgefühl der Aufregung verloren haben.

Dennoch kann für die Millionen von Passagieren eine >kollektive Entdeckung des Wartens konstatiert werden, die sich weniger explizit als vielmehr subtil und unterbewusst ins Gedächtnis einzuschreiben begann. Ähnlich wie im Kontext der baulichen Entdeckung des Wartens stehen auch hier Persistenz und Neuheit nah beieinander. Zum einen waren es die Menschen wohlgemerkt aus anderen Zusammenhängen gewohnt zu warten. Knappheiten an Gütern und Informationen oder auch soziale Hierarchien bewirkten, dass sich Menschen bereits vor dem Eisenbahnzeitalter zweifelsohne stets auch mit (oftmals existenziell bedrohlichen) Wartesituationen konfrontiert sahen. Das Warten bildet - wie bereits an anderer Stelle erwähnt - einen anthropologischen Ur-Modus und ist daher keine Neuerfindung des modernen Lebens. Neuartig jedoch, und damit zumindest subtil als Andersartigkeit verinnerlicht, war, dass das Warten in spezifischen Räumlichkeiten abgehalten wurde, von relativer kurzer und zugleich mehr oder weniger verlässlicher Dauer war und eine Vielzahl unterschiedlicher, sich fremder Menschen allein aufgrund desselben Anlasses das gleiche Erlebnis teilten.

Die Quelle dieses kollektiv erlebten Zwischenstadiums lieferte - wie erörtert - ein Zusammenspiel behördlicher und betrieblicher Sicherheitsbestimmungen sowie das organisatorische Kontrollproblem einer zeitgleichen Synchronisation von Mensch und Betriebsmitteln. Diese Synchronisation mit dem anschließenden Ziel der Beschleunigung erschien nur handhabbar durch ein vorheriges Sammeln und Festhalten der Reisenden in transitorischen Zwischenräumen. Allein die Schaffung eines spezifischen Raumprogramms für diesen erzwungenen Kurzaufenthalt lässt vermuten, dass die Rei- 
senden in physischer Anwesenheit in jenen Räumlichkeiten ein Bewusstsein von Zeitlichkeit im Allgemeinen und dem Warten im Besonderen zu entwickeln begannen. Doch auch wenn zu vermuten steht, dass der Kurzaufenthalt der vielen Millionen Reisenden des frühen Eisenbahnzeitalters sich erst langsam und subtil als ein neues Phänomen in das kollektive Gedächtnis einzuschreiben begann, darf an dieser Stelle nicht unerwähnt bleiben, dass die zeitgenössische Literatur und Lyrik der ersten Eisenbahnjahre keine nachweisbaren Rezeptionen des Wartephänomens zeigen. Stattdessen finden sich ausschließlich Thematisierungen der Geschwindigkeitserfahrung oder der (oppositionellen) Romantisierung der mit der Eisenbahn bedrohten Zeit als Form des Widerstands gegen die Veränderungen der Eisenbahn. Zusammenfassend lässt sich also festhalten: Das Warten wird anfänglich noch nicht explizit behandelt, denn es gab zunächst schlichtweg wichtigere Phänomene und Implikationen, die mit der Eisenbahn in Verbindung standen. 



\section{Standardisierung und Konsolidierung (1845-1870) Etablierung und erweiterte Rahmung des stationären Warteimperativs}

Spätestens zum 20. Jahrestag der historischen Pionierfahrt zwischen Liverpool und Manchester war das Verkehrswesen von einer Atmosphäre geprägt, in welcher der Erfolg der Eisenbahnen nicht mehr aufzuhalten war. Nach anfänglich massiven Ungewissheiten bezüglich der Zukunft des Eisenbahnwesens, die sich aus wirtschaftlichen Rückschlägen (Spekulationsblasen), modalen Richtungsentscheidungen (Nutzung von Straße, Kanal oder Schiene), politischen Spannungen (Vormärz) und kulturellen Ängsten und Bedenken sowie dem teilweise starken Widerstand von Grundbesitzern und Versorgungsunternehmen speisten, setzte sich vor allem der wirtschaftliche Nutzen der Eisenbahn immer deutlicher durch. In der Folge sollte die Phase der experimentellen Früherkundung des Eisenbahnwesens am Ausgang der 1840er Jahren ihr Ende finden.

Ein jährlich wachsendes Streckennetz mit zunehmenden Kreuzungspunkten bewirkte eine sukzessive Verkehrszunahme des Personen- und Güterverkehrs. Immer mehr neue Strecken verbanden die bereits älteren und schufen in der Folge ein Netzwerk, das eine ohnehin bereits steigende Nachfrage nochmals verstärkte und vervielfachte. Bis 1860 waren alle deutschen Städte mit mehr als 100.000 Einwohnern miteinander verbunden und im Jahr 1859 reisten allein in Preußen bereits 20 Millionen Menschen mit der Eisenbahn. Selbst die optimistischsten Vertreter des Eisenbahnwesens, darunter die Verwaltungen und Aktionäre selbst, zeigten sich regelmäßig vom Zuwachs des Verkehrszuwachses überrascht. Nicht zuletzt deshalb, weil die Verkehrszunahme nur schwerlich antizipiert und auch in dieser Hinsicht nicht auf vergleichbare historische Erfahrungswerte zurückgegriffen werden konnte. Die komplexen Wirkungszusammenhänge zwischen den Faktoren Netzausbau, Tarifgestaltung, Nutzerverhalten und -akzeptanz (auch im jahreszeitlichen Wandel) oder der Einfluss von Komfort- und Zeitgewinnen durch verbesserte Technik ließen sich nur schwerlich quantifizieren und bleiben zum Teil bis in die Gegenwart hinein nicht vollends modellierbar. Zudem wurde der Aufbau des Eisenbahnwesens zunächst primär von privatwirtschaftlichen Akteuren vorangetrieben, wodurch ein heterogenes und partikulares Erfahrungswissen bzw. 
stark unterschiedliche Zielsetzungen vorherrschten. Private Eisenbahngesellschaften arbeiteten nicht selten gegeneinander und versuchten ihre jeweiligen Strecken vor Konkurrenten zu schützen, was den Aufbau eines großflächigen Erfahrungswissens oder einer breiten Standardisierung des Betriebswesens zunächst erschwerte.

Der Schienenverkehr, der zwar noch nicht für alle Mitglieder der Gesellschaft erschwinglich war, entwickelte sich zur Mitte des 19. Jahrhunderts jenseits der allerorten vorherrschenden Nahmobilität ${ }^{1}$ zu einer zentralen Mobilitätserfahrung. Der Erfolg der Eisenbahnen führte dabei mancherorts bereits nach kurzer Zeit zum Erreichen der Kapazitätsgrenzen für die Personen-, Gepäck- und Güterabfertigung und damit oft zur Erweiterung von Stationen der ersten Generation durch größere Neuanlagen, insbesondere an Endstationen in Großstädten. Trotz der optimistischsten Erwartungen an die Entwicklung des Fahrgastaufkommens waren viele Bahnhöfe bereits nach wenigen Betriebsjahren ungeeignet. Der rasant wachsende Eisenbahnverkehr bewirkte, dass die Erstgeneration der Bahnhöfe sich spätestens im Laufe der 1840er Jahre als oftmals unterdimensioniert darstellte und viele Stationen bis 1860 nicht nur eine zweite, sondern gar bereits eine dritte Erweiterung erlebten. Paradigmatisch für die in der Moderne oftmals durch neue, disruptive Technologien ${ }^{2}$ ausgelöste Veränderungsdynamik, war auch die Errichtung von Bahnhöfen von einer Inkongruenz zwischen gegenwärtigen Wissensständen und dessen zwischenzeitlicher Weiterentwicklung betroffen. In der Folge entsprachen die immobilen Infrastrukturen der Bahnhöfe oftmals bereits bei ihrer Eröffnung schon nicht mehr dem sich während der Bauzeit weiterentwickelten Eisenbahnwesen. Vielmehr bildete die Eröffnung von Bahnhöfen des 19. Jahrhunderts in vielen Fällen den Entwicklungsstand früherer Jahre ab, der den zwischenzeitlich gewachsenen Ansprüchen bezüglich Kapazität, Betriebsorganisation, Komfort oder Sicherheit oftmals schon nicht mehr entsprach.

Um diese Dynamik nachvollziehbar zu machen, seien hierzu nur einige Beispiele genannt. Die bereits vorgestellte Crown Street Station in Liverpool wurde 1836 nach nur sechs Betriebsjahren von der an anderer Stelle erbauten und wesentlich größeren Lime Street Station abgelöst, die ihrerseits bis 1867 nochmals zwei umfassende Erweiterungen erfuhr. Der Potsdamer Bahnhof in Berlin wurde ebenfalls nach nur wenigen Betriebsjahren 1846 umfassend erweitert und erlebte bis 1872 die Fertigstellung eines großdimensionierten Neubaus an gänzlich anderer Stelle. Unzählige weitere Beispiele ließen sich anführen, um die in jener Zeit vorherrschende Entwicklungsdynamik zu verdeutlichen. Die Bahnhöfe der Standardisierungs- und Konsolidierungsphase des Eisenbahnwesens sind somit im Kontext ihrer ständigen Veränderung zu verstehen, die wohl am besten dadurch verdeutlicht werden kann, dass, wie im Beispiel des Baus von

1 Die deutliche Mehrzahl der absolvierten Wege bildete im 19. Jahrhundert zweifelsohne noch ganz deutlich der Fußverkehr. Dazu: Colin C. Pooley, »Travelling through the City: Using Life Writing to Explore Individual Experiences of Urban Travel c1840-1940«, Mobilities 12, Nr. 4 (2017): 598-609. Basierend auf der Definition disruptiver Technologien kann die Eisenbahn durchaus als eine solche bezeichnet werden: »Disruptive technologies can be considered scientific discoveries that break through the usual product/technology capabilities and provide a basis for a new competitive paradigm. « Ronald N. Kostoff, Robert Boylan, und Gene R. Simons, »Disruptive Technology Roadmaps«, Technological Forecasting and Social Change 71, Nr. 1-2 (Januar 2004): 142. 
Liverpool Lime Street Station, für den Bahnhofsbau mancherorts sogar mehrmals Kirchen umgesetzt wurden.

Typologisch betrachtet dominierten zur Mitte des Jahrhunderts zweiseitige Anlagen mit getrennten Gebäuden für ab- und anfahrende Reisende. Daneben formierte sich ausgehend vom Gare de l'Est in Paris (1847-1852) jedoch auch bereits der Typus des Kopfbahnhofs, der im späten 19. Jahrhundert die wohl ikonischste Form des Übergangs zwischen Stadt- und Bahnkosmos darstellen sollte. Zusammenfassend gelangte mit den späten 1840er Jahren der Bau von Bahnhöfen an das Ende seiner experimentellen Frühphase. Empfangsgebäude wurden stärker standardisiert und wuchsen zugleich hinsichtlich Größe und funktionaler Komplexität. ${ }^{3}$

Für die nun folgende Analyse des verkehrlichen Wartens im Kontext der zweiten Entwicklungsphase des Eisenbahnwesens (Aufstieg zum dominierenden Massenverkehrsmittel) wechselt die zuvor induktiv ausgerichtete, hypothesengenerierende Betrachtung von Einzelfällen nun stärker auf eine deskriptive Betrachtung. Nicht mehr allein die dichte Beschreibung einzelner Bahnhöfe steht damit im Vordergrund, sondern das Aufdecken übergeordneter Bau- und Erfahrungskonjunkturen, die Einfluss auf die Erfahrung verkehrsinduzierter Wartezeiten am Bahnhof nahmen. Dieser Perspektivwechsel kann zum einen damit begründet werden, dass die Entwicklung des Eisenbahnwesens durch dessen immenses Wachstum nicht mehr durch Betrachtung von Einzelbeispielen heraus darstellbar bzw. der wachsenden Komplexität und Kleinteiligkeit nicht mehr gerecht wird. Zum anderen eröffnet eine wesentlich verbreiterte Quellenlage ab ca. 1850 die Möglichkeit eines abstrahierenden Vorgehens, das eine größere Verallgemeinerbarkeit von Tendenzen und Konjunkturen des Wartens zulässt. Um die übergeordneten Tendenzen und Konjunkturen dennoch an konkrete Räume rückzubinden, werden an geeigneter Stelle punktuell konkrete Bahnhöfe näher beleuchtet, in denen jene Entwicklungen in besonderer Deutlichkeit aufgezeigt werden können. Kurzum: Die bereits für die Frühphase herangezogenen Analysekategorien werden beibehalten, jedoch in den folgenden Kapiteln stärker von übergeordneten baulich-betrieblichen Rahmenentwicklungen informiert und auf einen größeren Zeitraum ausgebreitet.

\subsection{Bauliche und betriebliche Rahmenentwicklungen}

Zur Stimulierung eines stetigen Wachstums des Eisenbahnverkehrs, aber auch als Reaktion auf dasselbe, mussten zunächst hunderte, dann tausende Bahnhofsneubauten errichtet werden. Dies betraf nicht nur die Endpunkte der Bahnlinien in den großen Städten, sondern insbesondere auch zunehmend die Errichtung von Zwischenstationen auf jenen Bahnlinien. Wie bereits an anderer Stelle erwähnt, mussten die geeigneten Lösungen der neuen Bauaufgabe jeweils in Abhängigkeit von lokalen Betriebsverhältnissen, topografischen Gegebenheiten, der (erwarteten) Personenfrequenz, dem verfügbaren Kapital oder gar kulturellen Besonderheiten gesucht und gefunden werden. Die Vielfalt dieser individuellen Lösungen spiegelte sich innerhalb 
der Standardisierungs- und Konsolidierungsphase des Eisenbahnwesens (ab spätestens 1850) vor allem entlang zweier Dimensionen: in der strukturellen Organisation des Bahnhofes (Lage des Empfangsgebäudes und der anderen Bahnhofsbauten, Grundriss des Empfangsgebäudes etc.) sowie in seiner baukünstlerischen Gestaltung. Da in der Anfangszeit des Eisenbahnhochbaus keinerlei Erfahrungen und damit auch kaum verbindliche Baumaximen vorlagen, hatten die von den Bahnverwaltungen beauftragten Architekten und Ingenieure oftmals für beide Gestaltungsdimensionen völlig freie Hand. In der Folge glich bei genauerer Betrachtung im Grunde kaum ein Bahnhof dem anderen. Es dauerte mindestens zwei Jahrzehnte bis sich aus den vielen individuellen Lösungen die brauchbarsten und praktischsten entwickelten. ${ }^{4}$

Die Entwicklung dieser beiden Gestaltungsdimensionen soll im Folgenden mithilfe einer chronologischen Aufarbeitung einer Auswahl internationaler Schlüsselwerke des Bahnhofsbaus vertieft werden, da mit ihnen nicht nur wichtige Rahmenbedingungen für die Warteerfahrung der Reisenden einhergehen, sondern sich zudem zeigt, wie sehr das durch den Bahnverkehr selbst sproduzierte systemische Warten der Reisenden zu einem leitenden Strukturelement des Bahnhofsbaus avancierte. Im Sinne der Rekonstruktion einer Außenperspektive des Wartens ist hierbei wiederum insbesondere die Frage leitend, welche Rolle die Wartesäle innerhalb des vorgeschlagenen Raumprogramms und der sich zunehmend standardisierenden Grundrissgestaltungen einnahmen bzw. über welche Ausstattungen und baukünstlerische Gestaltungselemente sie verfügten.

\subsubsection{Auf dem Weg zu einer Normalform ‘: Direktiven und Anforderungen des Bahnhofsbaus (1845-1870)}

Die Fachdebatten der 1840er Jahre standen im Zeichen eines übergreifenden Bewusstseins, dass es trotz vielfacher internationaler Baubeschreibungen keine ausreichenden Systematisierungsversuche gab, um die Bauaufgabe >Bahnhof^effizient und ortspezifisch zweckmäßig zu lösen. Im Zuge der anschließenden Suche nach Systematisierungen und der Entwicklung funktioneller Gesichtspunkte des Bahnhofsbaus kamen zunächst die wichtigsten Impulse aus Frankreich.

\section{Revue General d'Architecture et des travaux publics (1846)}

Im Kontext einer allgemeinen Aufbruchsatmosphäre (Eisenbahnfieber) verdichtete César Daly in der französischen Fachzeitschrift >Revue Générale d'Architecture et des travaux publics von 1846 die Erfahrungen der Frühphase des Eisenbahnwesens in einem der ersten Typologisierungsversuche bestehender Bahnhofsbauten. Für Daly hatten sich mit Blick auf die ersten in Frankreich und England errichteten Bahnhöfe insgesamt vier Grundformen herauskristallisiert, die sich jeweils insbesondere auf Grundlage des heuristischen Kriteriums der Organisation von $\mathrm{Zu}$ - und Abwegen für Reisende, Güter und Gepäck ergaben. Für die innere und äußere Gestaltung dieser Hauptformen wurden dabei ganz ähnliche formale Anforderungen wie zuvor in der 
Allgemeinen Bauzeitung (1838) formuliert. So wird sich etwa erneut für eine klare Trennung von abfahrenden und ankommenden Reisenden ausgesprochen. Übergeordnet sei für jegliche Wahl der Disposition ferner zu beachten, dass die Zirkulation gewährleistet, die Wege von Gepäck und Mensch möglichst kreuzungsfrei und die Wege zum bzw. vom Zug möglichst kurz und ohne Überschreiten von Gleisen zu ermöglichen. Jenseits dieser allgemeinen Prämissen sei die Wahl jeder dieser Dispositionen jedoch immer mit Vor- und Nachteilen verbunden. Keiner der vier Typen wurde daraufhin favorisiert, sondern Daly merkte an, dass es jeweils einer ortsspezifischen Einpassung bedarf. Hinsichtlich der Rolle des temporären Sammelns von Reisenden wird jedoch herausgestellt, dass Wartesäle in jeder der vier Formen ein zentrales Element des Bauprogramms bilden. Damit erhält diese Raumgruppe eine noch stärkere bauprogrammatische Institutionalisierung, als zuvor in der Allgemeinen Bauzeitung. Ob zentral im Empfangsgebäude von Kopfbahnhöfen eingerichtet (Paris, Gare du Nord) oder bei Anlagen mit seitlicher Erschließung in die Tiefe des Eingangsvestibüls gelegt, die Wartesäle bildeten spätestens nach Dalys einflussreicher Studie einen Dreh- und Angelpunkt der formalen Anforderungen des Bahnhofsbaus. Ferner werden Wartesäle wohl erstmals mit einer aus Sicht der Reisenden elementaren Qualifizierung versehen. So sollten die Wartesäle im Typus eines Kopfbahnhofes mit Aus- und Eingang durch den Kopfbau (Typus 1 der vier Grundformen) derart im Grundriss platziert werden, dass man aus ihnen einen Überblick über das gesamte Geschehen im Bahnhof erlangen kann. In offenbar vollem Bewusstsein der psychologisch mitunter problematischen Abfahrtssituation sollte es nach Dalys Ansicht das Ziel sein, solche Räume möglichst "fröhlich « erscheinen zu lassen. ${ }^{5}$ Dieser Hinweis deutet damit interessanterweise auf die Anerkennung der besonderen Situation des systemischen Wartens hin, der in Form der Platzierung innerhalb des Gebäudes Rechnung getragen werden sollte.

\section{Grundzüge für die Gestaltung der Eisenbahnen Deutschlands (1850)}

Die Zunahme des grenzüberschreitenden Eisenbahnverkehrs bewirkte auch in Deutschland, sich auf Grundlage der internationalen Erfahrungen aktiv mit Fragen der Standardisierung und Regelhaftigkeit des Bahnverkehrs zu beschäftigen. Wichtigstes Organ dieser Bestrebungen wurde der Verein Deutscher Eisenbahnverwaltungen (VDEV). 1846 zunächst aus den zehn größten preußischen Eisenbahnverwaltungen als ,Verein preußischer Eisenbahnverwaltungen ‘ gegründet, wurde der Zusammenschluss 1847 zum besagten VDEV umbenannt. 1850 waren fast 50 Eisenbahnverwaltungen (darunter auch solche aus Österreich und Ungarn) Mitglied des VDEVs. Das Interesse der Mitglieder dieses Dachverbandes bestand vor allem darin, die vielen Netzfragmente innerhalb der vielen Gliedstaaten des Deutschen Bundes miteinander in Verbindung zu bringen sowie die Grenzübertritte und Transitverkehre zu regeln. Da zwischen den einzelnen Verwaltungen in technischer Hinsicht kaum Einheitlichkeit bestand, war das 
erklärte Ziel des Vereins, uniforme Regelungen zu schaffen, die »das eigene Interesse und dasjenige des Publikums $\aleph^{6}$ fördern.

Auf Anregung des Baurates der Königlich Hannoverschen Staatsbahn (Mohn), der 1849 einen ersten Vorstoß zur Schaffung einheitlicher Regelungen für Bahnbau und -betrieb an den Verein heran trug, wurden im Jahr 1850 im Ergebnis der >TechnikerVersammlung، des VDEV in Dresden die Grundzüge für die Gestaltung der Eisenbahnen Deutschlands verfasst. Sie gelten als erstes zusammenhängendes Regelwerk des deutschen Eisenbahnwesens. In insgesamt 165 Paragrafen finden sich neben zahlreichen Festlegungen zu Oberbau, Planum, Signalwesen oder Lokomotiven auch einige, wenngleich recht allgemein gehaltene Richtlinien zum Bau von Bahnhofsanlagen, die wiederum direkte Auswirkung auf die bauliche Rahmung des wartenden Passagiers hatten.

Ort der Abfahrt sollten stets bedeckte Hallen bilden, wobei abfahrende und ankommende Züge abermals streng getrennt werden sollten. Zum Raumprogramm im Empfangsgebäude wurde vermerkt:

»Im Empfangsgebäude sind folgende Räume erforderlich: Eine geräumige Vorhalle welche gegen die Strasse abgeschlossen werden kann, in Verbindung mit der Billetund Cepäckexpedition, der Post und wenigstens zwei Wartesälen mit Restauration. (...) Die Wartesäle und die Cepäckexpedition müssen mit der Wagenhalle in directer Verbindung stehen. Im Gebäude selbst oder in directem bedachtem Zusammenhange mit demselben sind Retiraden anzulegen. ${ }^{7}$

Die Entwicklung der nach 1838 in der Allgemeinen Bauzeitung formulierten (warterelevanten) Baudirektiven zeigte sich damit zum einen darin, dass die Einrichtung einer Restauration und von Toiletten nunmehr zur Pflichtaufgabe erklärt wurde. Darüber hinaus wurde mit der bereits von Lichthammer geäußerten Maxime der Verbindung von Wartesaal und Gleishalle die Lage der Wartesäle innerhalb des Grundrisses stärker spezifiziert. Wie bereits aus Dalys Ausführungen ersichtlich wurde, sprach man sich damit nun auch im deutschen Kontext dafür aus, Wartesäle möglichst über eine Sichtverbindung zum Zug verfügen zu lassen.

Interessanterweise schien sich der Übergang von der ersten zur zweiten Generation der Bahnhofsbauten also auch gerade im Hinblick auf die Gestaltung der Wartestrukturen abzuzeichnen. So scheint sich für die Zeitgenossen etwa beim Bau der Hannoverschen Eisenbahnbauten im Jahre 1842 auf Grundlage der internationalen Erfahrungen offenbar bereits ein fortgeschrittenes Wissen über die richtige Dimensionierung der Wartezimmer, Gepäckexpeditionen und anderer Räume gefestigt zu haben, für die sich - anders als in den Pionierbauten - nunmehr bereits "ein annähernder Maßstab « ${ }^{8}$ auffinden ließ. Die Bestrebungen einer Standardisierung des Baus von Empfangsgebäuden war damit jedoch nur in Ansätzen erfüllt und wurden jeweils durch eine weitere Verkehrszunahme überholt. Die Suche nach der idealen und zweckmäßigen Form musste demnach unnachgiebig weitergeführt werden.

6 Viktor von Röll, Enzyklopädie des Eisenbahnwesens (Wien: Urban \& Schwarzenberg, o.J.), 94.

7 zitiert aus ]. Frank, Der praktische Eisenbahnbeamte (Magdeburg: Emil Baensch, 1851), 509.

8 »Die Eisenbahnen im Königreich Hannover«, Allgemeine Bauzeitung, Nr. 16 (1851): 257. 


\section{Traité élémentaire des chemins de fer (1856)}

Der französische Ingenieur Auguste Perdonnet (1801-67) gehörte zweifellos zu einem der einflussreichsten Impulsgeber des frühen Eisenbahnwesens. Er befasste sich in seinem Wirken nicht nur allein mit der Eisenbahntechnik und Konstruktionsfragen, sondern nahm innerhalb der Suche nach der idealen Disposition von Bahnhofsgebäuden auch die Perspektive der Reisenden ein. Wegweisend bemerkte Perdonnet, dass Reisende »eine gewisse Oekonomie, verbunden mit Schnelligkeit, Regelmäßigkeit, Sicherheit und Annehmlichkeit « ${ }^{9}$ verlangen würden. Damit leitete er eine Perspektivierung ein, die nicht ausschließlich auf den Betrieb beschränkt blieb. Wenn zunächst auch nur geringfügig und unspezifisch, wie sich im Ausdruck einer "gewissen Annehmlichkeit« zeigt, wird die Perspektive hier auch (erstmals) durch die konkreten Bedürfnisse der Reisenden beeinflusst.

Im 1856 erschienenen Traité élémentaire des chemins de fer, einem Standardwerk des französischen Eisenbahnwesens, das aber auch international durch Übersetzungen rezipiert wurde, nimmt Perdonnet auf der Suche nach übergeordneten Grundsätzen und einer idealen Form des Bahnhofsbaus wiederum (wie zuvor Daly) eine vergleichende Übersicht der Grundrissdispositionen und Lagevarianten einzelner Gebäudeteile großer Bahnhöfe Frankreichs, Englands, Belgiens und Deutschlands vor. Auch hier wurden Wartesäle neben der Gepäckaufbewahrung, den Verwaltungsbüros und dem Fahrkartenverkaufsbüro direkt zum benötigten Raumprogramm eines jeden Bahnhofs gezählt. Doch die Wartesäle nahmen hier nunmehr auch aus einem anderen Grund einen wichtigen Stellenwert ein, denn bei der Abwägung unterschiedlicher Formen der Platzierung von Empfangsgebäuden an Kopfbahnhöfen (am Kopf oder seitlich der Gleise) wird das organisatorisch erzwungene Phänomen des Wartens zum strukturierenden Element. So fällt Perdonnets Plädoyer im Traité schließlich für die Anlage der Gebäude in seitlicher Lage aus, weil nur dadurch größere Räumlichkeiten in der Länge des Bahnhofes und damit größere Kapazität zur Aufnahme von Passagieren (vor allem bei hohem Passagieraufkommen) erzeugt werden könnten. Zudem sei durch die seitliche Erschließung eine bessere Klassenaufteilung in der Länge sowie ein direkter Zugang $\mathrm{zu}$ den Wagons aus den Wartesälen entlang einer Achse ermöglicht. ${ }^{10}$ Auch wenn diese Entscheidung einen Kostennachteil nach sich zog, zwei Hauptfassaden, eine svor Kopf< und eine an der Seite ausgestalten zu müssen, wurde hiermit in den $1850 e r$ das betriebliche als auch bauliche Problem des zwischenzeitlichen Sammelns von Reisenden offensichtlich zum einflussreichsten Faktor innerhalb der fortwährenden Suche nach einer idealen Bahnhofsdisposition.

Perdonnet entwickelte darüber hinaus auch wichtige Kriterien für die Gestaltung dieser Räume selbst. So vermerkte er etwa hinsichtlich der Belüftung von Wartesälen: »Il est très-important que les salles d'attente soient bien aérées, car c'est en été surtout

$9 \quad$ Perdonnet, »Von dem Nutzen der Eisenbahnen.«, 400.

10 »Les bâtiments étant placés sur le côté, on peut donner immédiatement, des salles d'attente sur le trottoir de départ, issue à un nombre considérable de voyageurs à la fois, ce qui est fort important les jours de grande affluence. Les voyageurs se rendant plus directement des salles dans les wagons, le classement se fait plus facilement et avec plus d'ordre que si les salles d'attente étaient en tête. «Auguste Perdonnet, Traité Élémentaire des Chemins de Fer., Bd. 2 (Paris: Langlois et Leclercq, 1856), 16. 
qu'elles se remplissent. «" Zudem etablierte Perdonnet die Maxime, die Dimensionen dieser Räume - zumindest für den französischen Kontext - stets an der größtmöglich erwartbaren Auslastung auszurichten, etwa an Tagen in den Sommerferien oder an Feiertagen. ${ }^{12}$ Dabei empfahl er jedoch, die Raumfläche der Wartesäle jeweils klassenspezifisch anzupassen, sodass der für jeden Reisenden in den Warteräumen reservierte Platz von der ersten und zweiten zur dritten Klasse proportional größer werden sollte. ${ }^{13}$

Perdonnets über Jahrzehnte hinweg in mehreren Bänden und Ausgaben veröffentlichte Traité betonte damit abermals die Zentralität des Wartens innerhalb des Bahnsystems. Es bewirkte aus Sicht einer kulturgeschichtlichen Perspektivierung des Wartephänomens nicht nur eine weitere bauliche Institutionalisierung des Wartens, sondern zeigte darüber hinaus erste nationale Schwerpunktsetzungen bezüglich der Organisation und Rahmung des wartenden Passagiers, der in Frankreich offenbar wesentlich größere Aufmerksamkeit genoss als andernorts. Auf diese nationalen Unterschiede wird im Folgenden weiter eingegangen werden. Mit der Empfehlung die Empfangsgebäude seitlich der Gleise zu platzieren, rückt zudem die betriebliche Notwendigkeit des Wartens in den Stand eines strukturgebenden Elements innerhalb der Suche nach einer idealen Bahnanlage. Das moderne Phänomen des situativen Wartens strukturierte und informierte somit ganz entscheidend das Architekturprogramm der neuen Verkehrsbauten.

\section{Technische Vereinbarungen über den Bau und die Betriebseinrichtungen der Eisenbahnen 1866}

Der 1847 gegründete VDEV trug in den späten 1860er Jahren wohl am maßgeblichsten zur fortschreitenden (internationalen) Standardisierung bei und spezifizierte mit den ab 1866 und bis 1930 herausgegebenen >Technischen Vereinbarungen f für seine Mitgliedsbahnen den Eisenbahnbetrieb in technischer Hinsicht. Trotz des Umstands, dass die Mitgliedsbahnen des VDEVs mehrheitlich im deutschsprachigen Raum angesiedelt waren, war der VDEV für die Entwicklung eines internationalen Regelwerks zur technischen Harmonisierung von großer Bedeutung. So wurde auf starke Mitwirkung des Vereins 1882 in Bern eine erste >Internationale Konferenz betreffend die Technische Einheit im Eisenbahnwesen (TE)< abgehalten. Diese mündete 1886 schließlich in einem Staatsvertrag zur technischen Harmonisierung, welchem sich bis 193820 Nationen anschlossen. ${ }^{14}$ Trotz der überwiegend technischen Spezifikationen wird an einer Stelle knapp auf einen verbindlichen Standard für die Planung und Errichtung von Empfangsgebäuden eingegangen. $\$ 80$ der Vereinbarungen besagte, dass in Empfangsgebäuden »wenigstens zwei Wartesäle mit Restauration, ein Damen- und ein Toilettezimmer $(. ..) \ll^{15}$ veranschlagt werden müssen, die wiederum in direkter Verbindung zum

\footnotetext{
11 Ebd.

12 Ebd., 32

13 Ebd., 33.

14 Vgl. Corinna Salander, Das Europäische Bahnsystem: Akteure, Prozesse, Regelwerke (Wiesbaden: Springer, 2018), 3.

15 Edmund Heusinger von Waldegg, »Technische Vereinbarungen des Vereins Deutscher Eisenbahnverwaltungen über den Bau und die Betriebseinrichtungen der Eisenbahnen«, Organ für die Fortschritte des Eisenbahnwesens Erster Supplementband (1866): 5.
} 
Bahnsteig stehen sollen. Zudem sind - in Erweiterung vorheriger Bestimmungen seit den späten 1860er Jahren - nunmehr verbindlich »Abtritte« anzulegen und wenn möglich sind in der Nähe der Bahnsteige »für das reisende Publicum zugängliche Trinkbrunnen ${ }^{16}$ einzurichten.

Mit diesem spezifischen Passus zeigte sich nicht nur, dass die technische Standardisierung auch in Teilen die Standardisierung eines 'warterelevanten Bauprogramms umfasste, sondern es markierte auch eine aus kulturhistorischer Sicht entscheidende Entwicklung. So wird mit den >Technischen Vereinbarungen von 1866 offenbar erstmals in einem der zentralen Organe des Eisenbahnwesens die Einrichtung spezieller >Damenzimmer angewiesen, die damit das Phänomen des verkehrlichen Wartens einer räumlichen und sozialen Differenzierung unterzieht. Das Warten auf Abfahrt wurde nicht mehr allein, wie bereits zuvor, klassenspezifisch differenziert, sondern erhielt nun offenbar auch eine zusätzlich geschlechtsspezifische Dimension. Da diese `Qualifizierung besondere Aufmerksamkeit verdient und zu weit von der hier zunächst interessierenden Frage der Entwicklung einer Standardisierung des Bahnhofsbaus in der Konsolidierungsphase abweichen würde, wird sie an anderer Stelle noch einmal gesondert betrachtet werden. ${ }^{17}$

\subsection{2 sormalforms}

Die Entwicklung von Direktiven und Anforderungen an den Bahnhofsbau kommt im deutschsprachigen Raum in den späten 1860er Jahren im zeitlichen Umfeld der Veröffentlichung der >Technischen Vereinbarungen $`$ an einen ersten Sättigungspunkt. Bis 1870 wurden allein auf dem Gebiet des Deutschen Bundes Eisenbahnstrecken in einer Länge von fast $20.000 \mathrm{~km}$ eröffnet, tausende Bahnhofsgebäude errichtet und jährlich Passagiere im zweistelligen Millionenbereich transportiert. Durch die zahlreichen Beobachtungen und Systematisierungsversuche, die langjährigen Praxiserfahrungen, aber auch dank der Institutionalisierung und Professionalisierung des Eisenbahningenieurswesens und dessen internationalem Austausch, konnten zentrale bauliche, technische und betriebliche Probleme gelöst bzw. in Regelwerken verbindlich festgehalten und disseminiert werden. Die Sättigung dieser Erfahrungen mündete in baulicher Hinsicht in der Herausbildung einer Disposition, die an den Endpunkten der Bahnlinien meist die Anlage eines Empfangsgebäudes mit getrennter Abfahrts- und Ankunftsseite entstehen ließ, das übergeordnet in den Typus eines Kopfbahnhofs eingebettet war. ${ }^{18}$ Die seitlichen Gebäude wurden dazu mittels eines vor die Gleisenden geschalteten Querbahnsteiges verbunden und zunehmend auch von einem Kopfgebäude flankiert, das in der Regel jedoch stärker der Verwaltung, als dem Publikumsverkehr diente. Materieller Ausdruck dieser >Normalform sind mit Blick auf den deutschen Kontext insbesondere die Entstehung bzw. die Umbauten der großen Endbahnhöfe in der preußischen Hauptstadt zwischen 1860 und 1880 (Ostbahnhof 1866-67, Görlitzer Bahnhof 1866-68, Schlesischer Bahnhof 1867-69, Potsdamer Bahnhof 1868-72 etc.). Jegliche Bahnhofsgroßbauten

16 Ebd.

17 Siehe Kap. 8.2.1

18 Vgl. Kubinszky, Bahnhöfe Europas, 26. 
Berlins entsprachen folglich mehr oder weniger einer solchen in Abbildung 20 dargestellten idealtypischen Form. ${ }^{19}$ In diesen Bahnhöfen fanden die in den Jahrzehnten zuvor entwickelten zentralen Forderungen einer strikten Trennung von Abfahrts- und Ankunftsseite, der Trennung von Gepäck- und Personenströmen sowie das Vorhandensein von großräumigen Wartebereichen und Restaurationen mit Sichtbeziehung zum Gleis ihre bauliche Entsprechung. Einer zu jener Zeit populären klassizistischen Grundauffassung folgend, wird dabei in dieser sich etablierenden Form - vor allem in Deutschland - innerhalb des seitlich der Gleise platzierten Empfangsgebäude in baukünstlerischer Hinsicht eine Symmetrie des Grundrisses angestrebt, in der das Vestibül (A) in den Stand eines zentralen Zirkulationsorts tritt und der nach Kauf der Fahrkarte (b) und der Gepäckaufgabe (f) den Weg zu den Wartesälen vermittelt (d).

Abbildung 20: Idealtypischer Grundrissentwurf für Kopfstationen mit seitlich der Gleise angeordnetem Empfangsgebäude, A - Vestibül, b-Fahrkartenschalter, f-Gepäckabgabe, $c$ - Korridor, d-»Wartsäle«, e-Restauration, P-Bahnsteig.

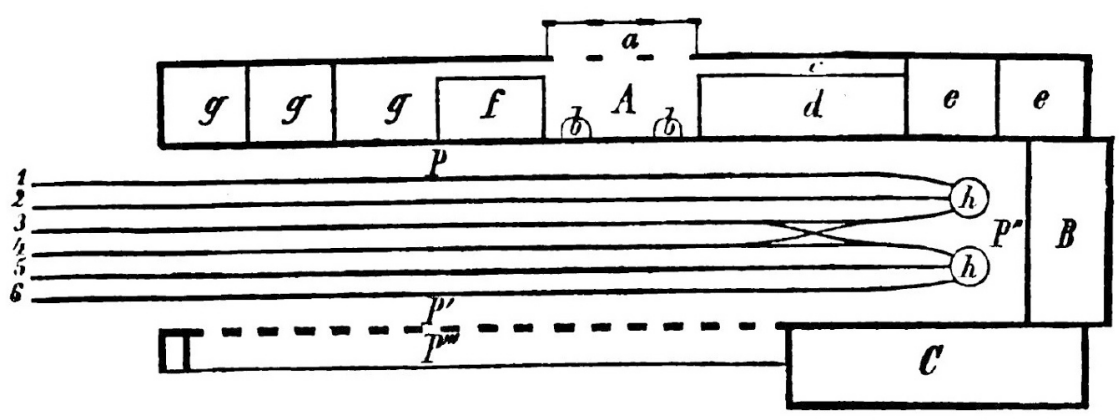

Quelle: Paulus 1872, S. 322.

Nach Ansicht von Radlbeck sind jegliche von dieser Urform abweichenden Empfangsgebäudeformen nur Abwandlungen dieses >Normaltyps ‘, denn auch in ihnen fanden sich trotz äußerlicher Verschiedenheiten stets die drei folgenden zentralen Funktionsgruppen wieder: »Zugang und Kundenverkehr, Schalter und Dienste/Verwaltung, Warten. $\ll^{20}$ Unabhängig von Form und äußerer Anmutung oberflächlich andersartiger Bahnhofstypen - später vor allem der Durchgangsbahnhof, der die stumpfen Gleisenden im Sinne eines ungehinderten Verkehrsdurchflusses beseitigte - bildet sich nach Ansicht Radlbecks durch jene Empfangsgebäude mit seitlicher Erschließung um 1870 eine Form heraus, die im Hinblick auf Wegeführung und Zuordnung der wichtigsten Raumgruppen bis ins späte 20. Jahrhundert hinein wirksam bleiben sollte.

Bis auf den Görlitzer Bahnhof und Potsdamer Bahnhof, die diesem idealtypischen Crundriss fast exakt entsprechen zu schienen, wichen die anderen Berliner Großbahnhöfe in ihrer Grundrissdisposition nur insofern ab, als dass die Mehrheit von ihnen auf der Ankunftsseite $\left(P_{<}, P_{\iota}\right)$ keine offenen Hallen, sondern massive Gebäude für den Empfang der ankommenden Reisenden aufwiesen. 
Ausgehend von Radlbecks These ist hiermit als zusammenfassender Zwischenbefund zur baulichen Suche nach einer Standardisierung festzuhalten, dass innerhalb der Entstehung der >Normalform räre Aufenthalt bzw. das systemisch durch den Bahnverkehr selbst verursachte Warten der Passagiere deshalb einen zentralen Stellenwert erhielt, weil es zu einem prägenden Strukturmoment des Bauprogramms wurde. Die Überlegungen zur Unterbringung großer Menschenmengen wurden zu einer Frage, die verstärkt seit den Ausführungen von Perdonnet dazu führten, die Empfangsgebäude neuer Bahnhöfe (in den großen Städten) tendenziell parallel zu den Gleisen und nicht an deren Kopfseiten zu platzieren. Die Begründung dafür lag in der Verkürzung der Wege, der Gewinnung größerer Raumflächen und die dadurch resultierende Gewährleistung klassenspezifischer Trennung und Kontrolle.

"Der Grundriss«, so heißt es Anfang der 1870er Jahre in einer ersten Rückschau der Erweiterungs- und Neubauphase, »hat vor Allem den praktischen Bedürfnissen des Publikums und des Betriebes zu genügen. « $^{21}$ Neben der Wegeführung und den Diensträumen bildete dafür die Bereitstellung von Warteräumen aus Sicht der Planung offenbar eine der drei wichtigsten Bauaufgaben. Die gegenüber der Frühphase des Eisenbahnwesens explizitere Thematisierung und die damit gewachsene Stellung des Wartens wird in Ablösung der ersten Bahnhofsgeneration von einer zweiten innerhalb der Grundrisse folglich durch eine deutliche Vergrößerung der Warteflächen markiert. Vormals bloße Räume wurden nunmehr zu Sälen und Hallen. Solche Wartesäle, die zum Teil viele hundert Passagiere aufnehmen mussten, wurden im Rahmen der Ausbildung des städtischen Kopfbahnhofs - etwa jener Berliner Prägung - abermals zur größten Raumgruppe innerhalb neu errichteter Empfangsgebäude. Entsprechend ihrer größer gewachsenen Größe wurde folglich empfohlen, sich für die »Einrichtung der Wartesäle im Allgemeinen [an der Einrichtung, R.K.] anderer grosser Säle [zu orientieren, R.K.], bei denen Säulen zu vermeiden sind. « $^{22}$ Angesichts der Zentralität der sich darin befindlichen Wartesäle wurde der Seitenflügel der Abfahrtseite treffend als »Wartesaaltrakt ${ }^{23}$ bezeichnet.

Der seitens der Bahnbetreiber als offenbar notwendig erachtete systemische Zwischenaufenthalt der Reisenden wird demnach im Zuge der zweiten Bahnhofsgeneration im deutschen und französischen Kontext nicht nur verstetigt, sondern weiter ausgebaut. Mit anderen Worten: Der stationäre Warteimperativ wird hier als ein fester betrieblicher Bestandteil installiert und damit verbunden auch der Produktionsort einer modernen Massenerfahrung.

21 W. Housselle, »Ueber Kopfstationen«, Deutsche Bauzeitung VI., Nr. 1 (1872): 2.

22 Rasch, »Die Eisenbahn-Hochbauten auf den Bahnhöfen und ausserhalb derselben.«, 580. Wie Rasch sprach sich auch der Architekt Eberhard Wulff in der Folgezeit dafür aus, die Wartesäle »bezüglich ihrer Tiefe und Länge am besten als gewöhnliche Versammlungssäle«zu behandeln. Eberhard Wulff, Das Eisenbahn-Empfangs-Cebäude nach seinen praktischen Anforderungen und seiner künstlerischen Bedeutung: an den Bauausführungen der Rheinischen Eisenbahn erläutert (Leipzig: Scholtze, 1882), 18. 


\subsubsection{Verstetigung und Etablierung des stationären Warteimperativs}

Mit Etablierung der >Normalform $\prec$ hatte sich keine betriebliche Wendung des wartenden Passagiers vollzogen, sondern das vorhandene Prinzip des an einen spezifischen Raum gebundenen, stationären Warteimperativs wurde vielmehr weiter ausgebaut und unterstrichen. So zeigt sich auf Basis einer Schilderung von Julius Rasch aus dem Jahr 1873, dass das Betreten des Bahnsteigs oder der Gleisanlagen vor dem Ertönen des Glockensignals auch in der zweiten Phase der Bahnhofsgeneration oftmals noch immer nicht gestattet war. Im Rahmen einer international vergleichenden Betrachtung der Abfahrtsorganisation vermerkt Rasch mit Blick auf den deutschen Kontext, dass der Zugang zu den Wartesälen zwar auch Personen ohne Fahrtwunsch offen steht, man jedoch

»(...) die Thüren an der Perronseite meistens geschlossen [hält, R.K.], bis das Signal zum Einsteigen gegeben wird. ${ }^{24}$

Eisenbahnreisende betraten demnach vor Abfahrt an einer der großen Stadtbahnhöfe nicht mehr nur einen einzigen Raum, der jegliche Funktionen (Fahrtkartenschalter, Gepäckabgabe, Warteraum etc.) in sich verband, sondern sie betraten zunächst ein geräumiges Vestibül, an dem seitlich oder in der Tiefe gestaffelt die Fahrkarten- und Gepäckschalter angeordnet waren. Nach Erwerb der Fahrkarte und Aufgabe des Reisegepäcks führten sie Zirkulationsflächen (das Vestibül selbst sowie Flure, Passagen oder Korridore) jedoch nicht direkt zum Bahnsteig bzw. direkt zum Zug, sondern zunächst zu den Wartesälen. Erst von hier aus, nach mehr oder weniger langem (Pflicht-)Aufenthalt, konnten Bahnsteig und Zug nach Ertönen eines Signals und unter Führung von Bahnbeamten bestiegen werden. Da dieses Prinzip - etwa in Berlin (1838) - bereits in der Frühphase des Eisenbahnwesens Anwendung fand, erfährt die Geschichte des verkehrlichen Wartens in der Phase des Aufstiegs der Eisenbahnen demnach keine entscheidende Zäsur. Vielmehr ist die zweite Phase dadurch gekennzeichnet, dass sich im Zuge der stärkeren Formalisierung des Verkehrszugangs der Wartesaal aus betrieblicher Sicht noch deutlicher als Schleuse zwischen Eingangs- und Abfahrtszone bzw. zwischen Stadt- und Verkehrsraum schiebt. Diese stärkere Formalisierung war nötig geworden, weil die Synchronisation von Betriebsmitteln und Passagieren insgesamt komplexer geworden war. Die Komplexitätssteigerung bestand dabei in erster Linie im quantitativen Wachstum der Verkehrsnachfrage und der sich daraus ergebenden Herausforderung, wesentlich mehr Reisende als zuvor pünktlich abfahren lassen zu müssen. Die Lösung dieser gewachsenen Herausforderung erforderte operativ vor allem die Erhöhung der Ordnungs- und Kontrollfähigkeit von Strömen, Zugangsberechtigungen und insbesondere dem betriebsgerechten Timing dieser Prozesse. Für diese Formen lieferte die Schleuse eines vorgeschalteten und abschließbaren Wartesaals bzw. Transitraums ein geeignetes Mittel, denn sie ermöglichte die störungsfreie Bearbeitung von Prozessen im Hintergrund, die eine pünktliche und sichere Abfahrt offenbar erst ermöglichten. 
Aus Sicht der Reisenden rückt damit verbunden das Warten in Form eines stationären `Zwangs`, deutlicher als ohnehin zuvor, in den Mittelpunkt der Mobilitätspraxis. Zugleich lassen sich einige Unterschiede gegenüber der Frühphase vermuten. So konnte etwa das Warten auf die Abfahrt zu Beginn des Eisenbahnwesens trotz bereits vorhandener Wartestrukturen und strenger Betriebsreglements insgesamt wahrscheinlich in freieren, informelleren und weniger stationären Kontexten verbracht werden. So kann ferner vermutet werden, dass die nunmehr etablierte Raumbindung des Wartens an den Wartesaal - wie etwa ganz deutlich materialisiert in den großen Kopfbahnhöfen Berlins um 1870 - das Phänomen auf eine neue Konnotationsstufe gestellt hat, wenn nicht gar überhaupt erst spür- und sichtbar gemacht haben dürfte.

Zusammenfassend kann damit an dieser Stelle festgehalten werden, dass sich ab Mitte des 19. Jahrhunderts parallel zur Entwicklung einer baulichen >Normalform $>$ des Empfangsgebäudes in Seitenlage, der stationär-raumgebundene Warteimperativ zur operativen und erfahrungsrelevanten $>$ Normalform $>$ der Passagierabfertigung entwickelte. Durch die zentrale Installation von Prozesszonen der Retardierung, die nunmehr obligatorisch >genutzt< oder zumindest durchschritten werden mussten, hob sich das Warten damit deutlicher als zuvor von der Atmosphäre der allgemeinen Mobilitätszunahme ab. Wartesäle wurden zur >Bremszone im zunehmend Transitorischen, einerseits des Bahnhofs selbst, aber zugleich des allgemeinen Lebenstempos des industriellen Zeitalters.

\subsection{Räumliche und betriebliche Differenzierungen des verkehrlichen Wartens (1845-1870)}

\subsubsection{Nationale und regionale Unterschiede}

Ausgehend vom Befund der Verstetigung und des Ausbaus eines raumgebundenen Warteimperativs als operative >Normalform der Passagierabfertigung innerhalb der zweiten Bahnhofsgeneration (1845-1870), soll nun der Blick auf mögliche nationale und regionale Unterschiede in der konkreten Ausgestaltung dieses Prinzips gelenkt werden. Motiviert wird dieser analytische Exkurs durch eine Aussage von Julius Rasch aus dem Jahr 1873, der angibt, dass die Abriegelung der Wartesäle vor Abfahrt am drastischsten in Bayern und Frankreich praktiziert wird. Hier, so Rasch, »schließt man die Reisenden in die Wartesäle ein. ${ }^{25}$

Tatsächlich wird dieses >Einschließen im französischen Eisenbahnkontext durch Berichte aus den $1850 e r$ Jahren mit großer Deutlichkeit bestätigt. So widmet sich etwa kein Geringerer als der schon erwähnte, einflussreiche Eisenbahningenieur Auguste Perdonnet in der Traité Élémentaire diesem Thema in auffallend kritischer Form. Perdonnet weist im Zuge eines Vergleichs der Abfahrtsorganisation zwischen Frankreich und England erstaunt auf die wartebezogene Besonderheit des französischen Bahnsystems hin und konstatiert: 
»En emprisonnant au contraire les voyageurs qui attendant les convois dans les salles où on ne laisse ordinairement pénétrer le jour que par les combles, les compagnies paraissent douter de leur force et n'avoir de confiance que dans les murs les plus élevés pour faire respecter leur propriété. Elles semblent vouloir cacher à tous les regards ce moteur, qui n'est réellement redoutable que pour ceux qui ne le connaissent pas. $\aleph^{26}$

Demnach war es für Bahnreisende in Frankreich nicht ohne Weiteres möglich, den Perron zu betreten bzw. sich in der Gesamtheit des Bahnhofs frei zu bewegen. Vielmehr waren die Reisenden in Frankreich besonders deutlich dazu angewiesen, sich vor Abfahrt dezidiert nur in den Wartesälen aufzuhalten, was sich entsprechend auch in den Grundrissdispositionen der Empfangsgebäude der ersten und zweiten französischen Bahnhofsgeneration - etwa dem Gare de l'Est in Paris - nachvollziehen lässt. Da der Bahnsteig nicht zum temporären Aufenthalt bereitgestellt werden sollte, mussten die Wartesäle dermaßen dimensioniert werden, dass sie sämtliche Reisende zweier vollbesetzter Züge aufnehmen konnten. ${ }^{27}$ In französischen Bahnhöfen wuchsen die Wartesäle daher bereits noch früher als im deutschen Kontext zur mit Abstand größten Raumgruppe heran, was eine absolut zentrale Funktion des stationären Wartens innerhalb der französischen Betriebsorganisation markiert.

Perdonnets Wortwahl einer solchen >Inhaftierung « wartender Reisender im französischen Bahnsystem verdeutlicht, dass die hier im Zuge einer übergeordneten Charakterisierung der Passagierabfertigung vorgenommene Klassifikation eines Warteimperativs durchaus nicht zu überspitzt gewählt ist, sondern bereits von einigen Zeitgenossen mitunter genau treffend als solche empfunden wurde. Interessant erscheint hierbei zudem Perdonnets anschließender Erklärungsversuch dieser >Gefangennahmeく. So hatten aus seiner Sicht die Bahnverwaltungen im französischen Kontext offenbar zu wenig Vertrauen in ihre Kunden. Von ihnen wurde vielmehr vermutet, dass sie im Angesicht der neuen Technik auf dem Bahnsteig erschrecken, sich verletzen oder die fragile Technik möglicherweise gar beschädigen würden. So würden die Unternehmen ihr wertvolles Eigentum zum Leid der Reisenden lieber hinter »den höhsten Mauern« schützen wollen. In der Folge sieht Perdonnet die Wartesäle Frankreichs zwar als sehr großzügig an, aber zugleich kritisiert er sie harsch als dunkle Räume, die ein Gefühl der Beklommenheit vermitteln. ${ }^{28}$

Auf der Suche nach Lösungen gegen diesen attestierten Missstand eines >Inhaftierungs-Prinzips zeigt Perdonnet mit dem englischen Bahnsystem in aller Deutlichkeit eine prominente Kontrastfolie auf. Ganz im Gegenteil zum heimischen Frankreich würde den Reisenden im Mutterland der Eisenbahnen keinerlei falscher Paternalismus der Bahnverwaltungen entgegenwehen, der sich in einer übermäßigen Sorge um den Schutz der Reisenden oder einer Kultur des Misstrauens äußern würde. Für England, so äußerte sich Perdonnet in einem ins Deutsche übersetzten Fachbeitrag in der Allgemeinen Bauzeitung, sei es vielmehr charakteristisch, »daß das Publikum unmittelbar

26 Perdonnet, Traité Élémentaire des Chemins de Fer., 30.

27 »En France, on les enferme dans des salles d'attente dont les dimensions sont calculées de manière qu'elles puissent con tenir les voyageurs de deux convois les plus chargés que l'on conduise, et tous les voyageurs d'une même classe sortent à la fois de ces salles au moment du départ. «Ebd., 29. 
auf die Trottoirs [Bahnsteige, R.K.] oder in die Wagen gelangt. ${ }^{29}$ Kontrastierend zur französischen Erfahrung seien die Wartesäle daher »sehr klein « ${ }^{30}$ und könnten kaum alle Reisende eines Zuges aufnehmen. Die vergleichsweise winzigen Warteräume seien dabei jedoch keineswegs problematisch, weil in England dafür Sorge getragen würde, dass die Bahnsteige für eine vermehrte Nutzung entsprechend breiter gestaltet und immer überdacht seien. Anstatt also in »den sehr geräumigen Wartesälen Frankreichs (...) das Publikum wie in einem Gefängnisse eingesperrt« zu lassen, gebe es in England demnach die Annehmlichkeit »sich auf den Rampen bewegen zu können «. ${ }^{31}$

Diese charakteristische $>$ Bewegung $<$ der Reisenden auf dem Bahnsteig entlaste nicht nur das begrenzte Raumangebot in den englischen Wartesälen, sondern sie mündete im englischen Kontext offenbar in der allseits beliebten >Wartepraxis des Auf-und-AbSpazierens. Perdonnet berichtet dazu aus seinen Beobachtungen in England:

»Lorsque les voyageurs ne sont pas en très-grand nombre, il leur est loisible de s'y promener et d'examiner le chemin jusqu'au moment du départ, ou d'entrer dans les voitures dont les portières sont ouvertes. $\ll^{32}$

In der Regel konnten sich demnach Reisende in England bei normalem Passagieraufkommen bereits weit vor Abfahrt während eines Spaziergangs, ja einer Flanerie, die Technik in Augenschein nehmen und sich mit ihr vertraut machen. In Fällen höheren Passagieraufkommens (und im Falle eines schon bereitstehenden Zuges) wurden die Türen der Wagon bereits frühzeitig geöffnet und die Reisenden dazu seingeladen<, die Wagen schon ab zehn Minuten vor der eigentlichen Abfahrt zu besteigen. ${ }^{33}$ In deutlicher Unterscheidung zur auch im deutschsprachigen Raum geheimhin praktizierten Regel eines Glockenschlages, der überhaupt erst das Betreten des Bahnsteiges erlaubte, verlief der Zugang zum Verkehrsmittel in England damit offenbar weitaus freier, unmittelbarer und weniger an den konkret-stationären Ort des Wartesaals gebunden. Während in Frankreich das Publikum mittels Barrieren und Hindernissen absichtlich davon abgehalten wurde, die Bahnsteige zu benutzen, um »die Mitarbeiter nicht in ihren Aufgaben zu stören «, ${ }^{34}$ war die englische Betriebsorganisation somit zusammenfassend um ein Vielfaches liberaler ausgerichtet, ohne dabei Abstriche in puncto Betriebssicherheit oder Pünktlichkeit zu erleiden. Mehr noch, der Verkehrszugang und das daran geknüpfte Warten wirkte auf Perdonnet damit insgesamt seinladender und auch kundenorientierter. Angesichts dieser fast schon glorifizierenden Schilderungen der englischen Abfahrtsorganisation wundert es kaum, dass sich Perdonnet schließlich klar und deutlich für die Übernahme des englischen Systems in Frankreich ausspricht:

29 Auguste Perdonnet, »Ueber den Raum, den die verschiedenen Theile der Eisenbahnen einnehmen müssen.«, Allgemeine Bauzeitung 23 (1858): 275.

30 Ebd..

31 »Der Bahnhof der Lyoner Eisenbahn in Paris. «, Allgemeine Bauzeitung 24 (1859): 76.

32 Perdonnet, Traité Élémentaire des Chemins de Fer, 29.

33 »Lorsqu'au contraire il y a foule, on les invite à monter dans les voitures dix minutes auparavant. «. Ebd.

34 Im Original: „Souvent on limite l'espace dans lequel les voyageurs peuvent se promener sur le trottoir, par des barrières, et on les empêche ainsi de gêner les employés dans leurs fonctions.« Ebd. 
"Des deux modes adoptés pour l'embarquement des voyageurs, le mode anglais nous paraît incontestablement préférable. «35

Perdonnet, der wie bereits an anderer Stelle erwähnt, als früher Vordenker im Eisenbahnwesen gelten kann, der bereits Ansätze einer kundenorientierten Perspektive für Bedarfe, Wünsche und Anforderungen der Reisenden zeigte, präferierte das freie englische System zum einen aus psychologischen und zum anderen aus eher ideologischen Gesichtspunkten. Den psychologischen Vorteil des englischen Systems sah .offensichtlich darin, das Unbehagen des systemischen Wartens, wenn es, wie in Frankreich, derart statisch und vom Verkehrsmittel entfernt in (dunklen) Wartesälen praktiziert werden musste, zu mildern. Die freie Bewegung sowie die unmittelbare Nähe zum Erwartungsobjekt konnten die emotional-affektiv ungewohnte und mitunter irritierende Situation des Wartens positiv beeinflussen. Bezüglich einer ideologischen Dimension favorisierte Perdonnet das englische System aber vor allem deshalb, weil die Bewegungsfreiheit und die Offenheit der Strukturen für ihn sinnbildlich den liberalen Geist Englands verkörperten:

»Ces magnifiques trottoirs sur lesquels se promène paisiblement la foule des voyageurs, ces portes toujours ouvertes au public, ces voies nombreuses avec leurs locomotives qui s'arrêtent comme par enchantement dans les gares lorsqu'elles semblent entraînées par une force indomptable, c'est là vraiment un grand et beau spectacle qui donne une juste idée de la puissance et du libéralisme des compagnies qui ont doté leur pays de ces merveilleux instruments de travail. « ${ }^{36}$

Einen weiteren entscheidenden Vorteil dieser liberalen Betriebsführung sah Perdonnet zudem in der damit verbundenen Chance einer öffentlichen Technikbildung, die bereits am Bahnsteig ihren Anfang nahm:

»Les voyageurs qui pénètrent librement dans la gare à toute heure, se familiarisent avec les machines en les étudiant. Ils cessent, en les admirant, de les craindre, et c'est ainsi que les chemins de fer deviennent populaires. ${ }^{37}$

Dank des Umstands, dass Reisende sich an den Bahnsteigen in England frei und jederzeit mit der neuen Dampftechnologie vertraut machen konnten, sah Perdonnet einen entscheidenden Grund für die Ausbildung der im Vergleich zu anderen Nationen beispiellos großen Technikakzeptanz der englischen Bevölkerung gegenüber den Eisenbahnen. Durch Perdonnets Reflektionen wurde das verkehrsinduzierte Warten auf Abfahrt hiermit nicht mehr nur in den Stand einer betrieblichen Notwendigkeit gerückt, die adäquater räumlicher Strukturen bedurfte, sondern erhielt hiermit eine gesellschaftspolitische Dimension. Anders ausgedrückt: die Organisation des verkehrlichen Wartens reifte hier erstmals zum Indikator und Seismografen der soziotechnischen Dispositionen und Selbstauffassungen einer ganzen Nation.

Die wesentlich liberalere englische Abfahrts- und Wartekultur wird dabei den Briten nicht nur von Seiten der Festlandeuropäern attestiert, sondern in umgekehrter Weise 
auch von den Briten selbst bestätigt. So heißt es etwa in der dritten Auflage von E.B. Ivatts Railway Management at Stations aus dem Jahr 1898, dass britische Reisende gerne an Bahnsteigen entlangschlendern, während französische Reisende (lieber) in einem geschlossenen Raum warten würden. Mit Blick auf einen Pariser Großbahnhof vermerkte Ivatt $\mathrm{zu}$ dieser aus britischer Perspektive sonderbaren Warte-Situation: »(...) passengers are completely boxed up in them [den Wartesälen, R.K.] and cannot even see on the platform. $\ll^{38}$

Auch der prominente Publizist und Eisenbahnhistoriker Frederick Williams berichtete in seinem vielgelesenen Werk 〉Our Iron Roads` nicht ohne eine gewisse Spur von Stolz und Häme gegenüber seinen Landsleuten:

»Continental railways have peculiarities unknown in this country, which appear strange, and are sometimes annoying (...). In England, the traveller goes to the station when he pleases; lounges in the waiting-room, eats and drinks when he pleases; wanders about the platform, and superintends his luggage as he pleases; and, in fact, so long as he does not interfere with the convenience of other people, and does not violate the »bye-laws of the company, he may do what he likes. In France, instead of the traveller managing himself, he is managed. On procuring his ticket, he delivers up his luggage, is marched into a waiting-room, according to the class of his fare; as if the company were afraid that, having paid his money, he should not have his ride. When the train is ready, the first-class passengers are liberated, and every one scrambles to his seat with as much agility as circumstances will admit; and then the second-class and the third are allowed to follow. ${ }^{39}$

Symptomatisch für die unterschiedlichen Betriebsauffassungen zwischen England und Frankreich kann hier Williams' Nutzung der Passivform (is marched into a waiting-room) gelten, die aus englischer Sicht offenbar wie der Verlust persönlicher Handlungsspielräume bzw. wie eine Fremdsteuerung anmutete. Die skizzierte Vergleichsfolie dürfte die Leser wohl darin bestärkt bzw. ihnen überhaupt erst vor Augen geführt haben, welch hohes Gut das in England vorherrschende Prinzip der liberalen und zugleich respektvollen Selbstbestimmung darstellt. Williams, der in seinem Buch das englische Eisenbahnwesen immer wieder als überlegen und am weitesten entwickelt glorifiziert, dürfte mit seiner Beobachtung zum französischen System damit auch bewiesen haben, dass im Laufe des 19. Jahrhunderts - dem Jahrhundert der Nationalstaatenbildung und Nationalisierungsprozese ${ }^{40}$ - mitunter selbst das verkehrliche Warten für Zwecke der nationalen Selbstüberhöhung und -vergewisserung instrumentalisiert werden konnte.

Doch nicht nur Perdonnet und die Briten selbst sahen in der sselbstbestimmten Betriebsorganisation den liberalen Geist des innovationsstarken Englands bestätigt, auch viele deutsche Beobachter teilten seit den 1850er Jahre immer wieder solche Einschätzungen. Dutzende Berichte schilderten die besondere englische Situation, nach der »der Zutritt zu dem Perron (...) dem Publicum in der Regel frei [steht, R.K.]« und man 
häufig überhaupt erst zu den Wartezimmern über den Bahnsteig gelangt. Ferner wurde das Vorhandensein der vergleichsweise kleinen Warteräume angesichts der Größe des englischen Personenverkehrs nur dadurch begründbar erklärt, »weil das Publicum gewöhnt ist, alsbald seinen Platz im Wagen einzunehmen oder sich auf dem Perron der Einstieghalle aufzuhalten. $\aleph^{41}$

Die Wartestrukturen im englischen Bahnwesen wurden als »elegante, aber verhältnismäßig kleine Räume für die Passagiere ${ }^{42}$ beschrieben, wobei sich die Reisenden vom Vestibül kommend »meist direkt zum Perron begeben, denn die Wartesäle haben geringe Dimensionen und genügen nicht für den Verkehr. « ${ }^{43}$ Für die deutschen Berichterstatter war die wartebezogene Charakteristik des englischen Publikums demnach vor allem dadurch geprägt, dass ein präparatorischer Aufenthalt in Wartesälen kaum oder überhaupt gar nicht stattfand. So wurde in einer Mischung aus Erstaunen und Anerkennung deklariert, dass es die Gewohnheit der englischen Publikums sei, "ohne Aufenthalt in den Wartesälen mit dem geringsten Zeitverluste und auf dem kürzesten Wege nach und von der Bahn zu gehen. «44 Habitus der englischen Reisenden war es vielmehr, »erst möglichst kurze Zeit vor der Abfahrt des Zuges nach der Station $\mathrm{zu}$ kommen und entweder, falls der Zug bereit steht, in denselben einzusteigen, oder bis zur Abfahrt des Zuges sich gewöhnlich in dem vorderen Theile der Halle aufzuhalten. $\aleph^{45}$ Ein stationärer Warteimperativ, wie in Frankreich oder Deutschland, ist damit für den englischen Kontext nicht auszumachen. Vielmehr schienen sämtliche Eisenbahnhochbauten von der "Absichtlichkeit« getrieben zu sein, »bei allen Constructionen auf Beschleunigung des Verkehres $\aleph^{46} \mathrm{zu}$ setzen, was seine bauliche Entsprechung im ermöglichten Direktzugang zum Zug und größerer Bewegungsfreiheit fand.

Ähnlich wie in England war auch das Eisenbahnwesen der USA stark von einer pragmatisch-ökonomischen Logik geprägt, die insbesondere auch Auswirkungen auf die Rahmung und die Praxis des Wartens selbst hatte. So hieß es stellvertretend für viele Reisebeobachtungen des US-Systems zur Mitte des 19. Jahrhunderts:

»Die Räume für den Aufenthalt der Reisenden auf den Bahnhöfen sind äußerst beschränkt, und Restaurationen höchst selten und dürftig; die Passagiere steigen auf den Ausgangsstationen sofort in die bereitstehenden Wagen. ${ }^{47}$

Auch in den USA war somit der stationäre Warteimperativ weit weniger raumgebunden bzw. verfügten die Reisenden am Bahnhof über absolute Bewegungsfreiheit. Anstatt an

41 Ënglische Eisenbahn-Einrichtungen«, Zeitschrift für Bauwesen XIII. (1863): 610.

42 Schmitt, Vorträge Bahnhöfe und Hochbauten auf Locomotiv-Eisenbahnen, 23.

43 Conrad Busse, »Englische Bahnhöfe«, Deutsche Bauzeitung 2, Nr. 34 (1868): 359.

44 Schmitt, Vorträge Bahnhöfe und Hochbauten auf Locomotiv-Eisenbahnen, 57.

45 H. Schwabe, »Über Englische Bahnhofs-Anlagen«, Allgemeine Bauzeitung 41 (1876): 70.

46 von Weber, Schule des Eisenbahnwesens: Ceschichte, Technik, Administration und Statistik der Eisenbahnen, 37.

47 A. Bendel, »Aufsätze, zusammengestellt aus den von dem verstorbenen Ceh. Regierungsrath Henz während seiner Reise in Nord-Amerika im Jahre 1859 gesammelten Notizen. «, Zeitschrift für Bauwesen XI. (1861): 476. 
den Stationen in reich ausgeschmückten Wartesälen zu verharren, zogen es die Amerikaner vor, möglichst frühzeitig in die Wagen einzusteigen und nahmen dafür jeglichen fehlenden Luxus an den Stationen in Kauf. Die Erwartungshaltung der Fahrgäste beanspruchte jedoch dagegen im Vergleich zur restlichen Eisenbahnwelt, aufgrund der vergleichsweise riesigen Distanzen im US-System, eine umso komfortablere Ausstattung der Wagen.

Doch nicht nur in England oder in den USA ist der für den deutschen und französischen Kontext so prägsame stationäre Warteimperativ obsolet. Auch Belgien, die erste Eisenbahnnation auf dem europäischen Festland, schien sich dem englischen und USamerikanischen Muster der Abfahrtsorganisation zu ähneln. So wird bspw. über das Passagierverhalten auf der wichtigen Knotenstation Mechelen berichtet, dass die Reisenden sich nicht in den Wartesälen aufzuhalten pflegen, sondern »sie bleiben auf der Rampe oder steigen in die Wagons wie in England. $\aleph^{48}$ Auch Eduard Schmitt bestätigte einige Jahre später diesen Eindruck einer liberalen Wartezeitgestaltung und vermerkte für die belgische Reisekultur: »die Reisenden halten sich nicht in den Wartesälen auf; sie bleiben auf dem Perron oder steigen in die Wagen, wie in England. ${ }^{49}$

Zwischen die englische, belgische und französische Abfahrtsorganisation schien sich aus Sicht Perdonnets die Passagierabfertigung in Österreich zu schieben. In der Beschreibung des Wiener Südbahnhofes vermerkt er, dass die Gebäude für die Reisenden verhältnismäßig klein seien, es den Reisenden aber gestattet sei, »die Züge unter der bedeckten Halle abzuwarten. $\varkappa^{50}$

Im Bewusstsein der Vorteile des englischen Systems sahen einige deutsche Eisenbahningenieure in den 1870er Jahren die Zeit für eine Anpassung des deutschen Systems gekommen. »Von allen diesen Methoden«, so betonte etwa Julius Rasch 1873 in einem der in dieser Zeit zahlreich erscheinenden Handbücher zum Eisenbahnwesen, »dürfte die englische als die dem Publicum angenehmste auch deshalb den Vorzug verdienen, weil sie wesentlich dazu beiträgt, das Publicum mit dem Eisenbahnbetriebe vertraut zu machen. ${ }^{51}$ Perdonnets bereits fast zwanzig Jahre alte These der Erhöhung der Technikakzeptanz durch erhöhte Bewegungsfreiheit während des Wartens, schienen nun also auch in Deutschland Verbreitung zu finden. Zudem gewährte die Nutzung des liberalen englischen Systems aber auch noch einen Vorteil in puncto einer Verteilungsgerechtigkeit. So prognostizierte Rasch für den Fall der Gewährleistung eines vor Abfahrt frei begehbaren Bahnsteiges:

»Auch erhalten die Reisenden, welche zuerst kommen, meistens die besten Plätze, während bei den anderen Methoden die, welche am stärksten und gröbsten sind, dieses Vortheils theilhaftig werden. ¿52 $^{2}$

Auguste Perdonnet, »Ueber den Raum, den die verschiedenen Theile der Eisenbahnen einnehmen müssen.«, Allgemeine Bauzeitung 23 (1858): 279.

49 Schmitt, Vorträge Bahnhöfe und Hochbauten auf Locomotiv-Eisenbahnen, 127.

50 Perdonnet, »Ueber den Raum, den die verschiedenen Theile der Eisenbahnen einnehmen müssen.«, 282.

51 Rasch, »Die Eisenbahn-Hochbauten auf den Bahnhöfen und ausserhalb derselben.«, 580.

52 Ebd. 
Besonders mit Blick auf die Betriebsführung der Königlich Bayerischen Staatsbahn etwa sah die Realität zum Zeitpunkt solcher Überlegungen allerdings noch gänzlich anders aus. Hier wurden die Reisenden wie im französischen Kontext vor der Abfahrt in den Wartesälen vorübergehend für einige Zeit festgehalten. Diese Praxis des >Einsperrens` in die Wartesäle dürfte aber auch in vielen anderen nationalen und regionalen Kontexten stattgefunden haben. Allein mit Blick auf die Rekonstruktion der Warteerfahrung im ersten Berliner Potsdamer Bahnhof kann davon ausgegangen werden, dass die Etablierung eines stationären Warteimperativs auch im preußischen Kontext zum betrieblichen Prinzip erhoben wurde. Zum anderen wird diese Etablierung aber durch eine Vielzahl indirekter Hinweise aus den literarischen Niederschlägen zum Phänomen deutlich, auf die das rezeptionsgeschichtliche Kapitel 7.4 noch näher eingehen wird.

Zusammenfassend zeigt sich mit der kurzen Betrachtung nationaler Unterschiede hinsichtlich der Passagierabfertigung, dass sich mit Aufstieg der Eisenbahn zum Massenverkehrsmittel und trotz der Ausbildung einer standardisierten Raumfolge innerhalb der Bahnhöfe nicht nur nationale und kulturelle Eigenheiten im Umgang mit wartenden Passagieren herausbildeten, sondern der stationäre Warteimperativ sich offensichtlich nicht homogen und flächendeckend ausbreitete. Frankreich und England bildeten dabei das wohl deutlichste Oppositionspaar, wohingegen die Betriebsorganisationen in Deutschland und Österreich dazwischen anzusiedeln sind. Das Betriebsreglement der Bayerischen Staatsbahn sticht hierbei jedoch bezüglich seiner besonders stark reglementierten und an Frankreich orientierten Abfahrtsorganisation heraus.

Zwar verbindet die vorgestellten nationalen Beispiele der übergeordnete Modus eines gewissen Wartens vor Abfahrt, doch wurde es bei genauerer Betrachtung von ganz unterschiedlichen räumlichen Imperativen begleitet. In der Folge erscheint es statthaft, seit spätestens der Mitte des 19. Jahrhunderts zwischen einem >fluiden und einem >stationär-raumgebundenen Warteimperativ zu unterscheiden. Somit verfügten Reisenden in Europa zur Zeit der Standardisierung und Konsolidierung des Eisenbahnwesens je nach Abfahrtsort über ganz verschiedene Grade der Bewegungsfreiheit. Während sie in Frankreich und Bayern fest im raumgebundenen Korsett eines stationären Warteimperativs die Wartesäle verpflichtend nutzen mussten, wurden diese von einer Vielzahl englischer Reisender zum Teil gar nicht erst betreten. Diese damit deutlich gewordenen Differenzierungen sind deswegen von kontextueller Relevanz, weil die jeweilig vorherrschenden Betriebsmodi unmittelbaren Einfluss auf die Wahrnehmung der verbrachten Wartezeit nehmen konnten. Angesichts der liberalen, frei und selbstbestimmten Gestaltung der Wartezeit lässt sich somit aus zeitpsychologischer Sicht argumentieren, dass das Warten an englischen, amerikanischen oder belgischen Bahnhöfen für die Reisenden von weit weniger affektiven Reaktionen wie Stress und Nervosität begleitet worden sein dürfte als im französischen oder deutsch-bayerischen Kontext.

Diese für die Kulturgeschichte des verkehrlichen Wartens strukturbildende Einschätzung wird dabei von einer zeitgenössischen Beobachtung des Julius Rasch gestützt, der sich schließlich erfahrungsgesättigt und psychologisch argumentierend für die allgemeine Öffnung des raumgebundenen Warteimperativs ausspricht, denn: 
»Die Erfahrung lehrt auch, dass das in den Wartesälen häufig ungeduldige und unruhige Publicum sich beruhigt, wenn die Thüren derselben geöffnet werden und dasselbe auf dem Perron die Abfahrt erwarten kann. ${ }^{53}$

Damit zeigt sich an dieser Stelle zudem eine historische Argumentation der in 2.4.1 herausgearbeiteten zeitkulturellen Inkongruenzen, die als eine Entstehungsbedingung von Wartezeiten gelten. Auch innerhalb derselben Zeitkultur, so Stuart Hall, würden demnach divergierende Zeitauffassungen bestehen können. Eben jene Divergenzen zeigen sich mit Blick auf die ganz unterschiedlichen Handlings des wartenden Passagiers in den einzelnen west- und mitteleuropäischen Betriebskontexten, die das (stationäre) Warten auf der einen Seite marginalisierten (England, Belgien) und es andernorts zum zentralen Reisebestandteil vor Abfahrt formierten.

\subsubsection{Erweiterte Rahmung und Kompensation des stationären Warteimperativs: Kulinarisierung, Mediatisierung und Kommerzialisierung des Wartens}

»Ein Stand für Zeitungsverkäufer oder ein größerer Buchhändlerstand fehlt auf größeren Bahnhöfen nur selten. $\aleph^{54}$

Ein weiteres zentrales Merkmal der zweiten Baugeneration von Empfangsgebäuden war im deutschen Kontext, neben der Etablierung des stationären Warteimperativs vor Abfahrt als operativem Standard und subjektivem Teilaspekt der Eisenbahnreise, die Zunahme bzw. Schaffung rahmender Serviceeinrichtungen im Bahnhof. Erweiterung und Aufbau rahmender Angebote für Reisende umfassten dabei insbesondere den Bereich der gastronomischen Versorgung, aber auch die Deckung weiterer Reisebedarfe, die durch die neue Verkehrsform erst entstanden waren.

Der Aufbau solcher Serviceinfrastrukturen kann als Folge einer allgemeinen Normalisierung des Eisenbahnverkehrs als auch der stärkeren Routinisierung seitens der Reisenden verstanden werden. So war es zur Mitte des 19. Jahrhunderts angesichts des wachsenden Netzes und der sich dadurch verstärkenden Verkehrsnachfrage nicht mehr die Frage, $o b$ die Zukunft den Eisenbahnen gehören würde, sondern wie diese Zukunft ausgestaltet werden sollte. Während diese Frage in baulicher Hinsicht durch die allmähliche Etablierung von stärker standardisierten Planungsformaten und Grundrissdispositionen (>Normalform`) beantwortet wurde, war diese Frage aus Sicht der Passagiere nur mit der Berücksichtigung der erhöhten Ausstattungs- und Dienstleistungsansprüche zu beantworten. Mit anderen Worten: Die zukünftige Nutzung des Bahnverkehrs wurde aus Sicht der Reisenden nunmehr immer stärker an konkrete Bedingungen hinsichtlich Bequemlichkeit und Komfort geknüpft.

>Komfort bezeichnet aus Sicht der psychologischen Forschung einen Zustand des Wohlbefindens, in dem sich die physiologischen, psychologischen und physikalischen 
Bedingungen eines Subjekts im Zustand der Harmonie befinden..$^{55}$ Die Wahrnehmung von Komfort (oder respektive Diskomfort) wird dabei durch Abgleich einer jeweiligen Situation mit bereits erlebten Situationen erzeugt. Komfort wird somit als eine im Grunde neutrale Gefühlslage konzeptualisiert, die so lange nicht bewusst wahrgenommen wird, bis diese harmonisierte Situation von unangenehmen Empfindungen gestört wird, weil die erlebte Situation und die aus Erfahrungen gespeiste Erwartung jener Situation eine Diskrepanz bilden. Komfort kann daher nur schwer gemessen werden, sondern ist entweder aufgrund harmonisierter Verhältnisse gegeben oder aus Sicht eines Subjektes nicht vorhanden und erst dadurch spürbar. ${ }^{56}$

Ausgehend von diesem theoretischen Komfortverständnis ist es kaum verwunderlich, dass die Reisenden des frühen Eisenbahnwesens vielerlei Anlässe hatten, keine Harmonisierung ihrer psychischen, physiologischen oder physikalischen Dispositionen vorzufinden. So war die Abfahrtssituation an den Bahnhöfen - ganz zu schweigen von den Verhältnissen während der Fahrt - zur Mitte des Jahrhunderts zunächst noch von unzureichenden physikalischen (keine Heizungen in den Warteräumen in Nürnberg) oder physiologischen Bedingungen (keine Restaurationen in Liverpool oder Manchester) geprägt, die überwiegend eine Wahrnehmung von Diskomfort prägten. Diese unkomfortable Grunderfahrung erklärt wohl, warum die zweite Phase der Bahnhofsbaugeneration im Zeichen der gewachsenen Passagieranforderungen stand, die zum Ziel hatte, die außerhalb des Eisenbahnwesens erfahrene, bessere Harmonisierung von Grundbedürfnissen nun auch für die Zugreise einzufordern. In bezeichnender Weise bemerkte der Architekt Eduard Schmitt 1873 den gewachsenen Komfort- und Dienstleistungsbedarf der Reisenden im Rückblick auf die zweite Baugeneration von Empfangsgebäuden:

»Man giebt gegenwärtig für denselben Verkehr den Stationen grössere Dimensionen als ehemals, und zwar nicht immer aus dem Grunde, dass dieselben absolut nothwendig sind, sondern um den sich immer steigernden Anforderungen des Publikums zu genügen. ${ }^{57}$

Demnach sei das Größenwachstum der deutschen Bahnhöfe interessanterweise weniger auf etwaig notwendige technische oder betriebliche Entwicklungen des Eisenbahnwesens zurückzuführen, sondern vielmehr auf die gesteigerten Komfort- und Dienstleistungsbedarfe der Reisenden. Diese Bedarfe umfassten zum einen die Einrichtung besserer Versorgungsmöglichkeiten mit Speisen und Getränken, als auch den Erwerb von Reisebedarf zur Information oder Zerstreuung (Zeitungen, Bücher, Tabakwaren). Im Resultat wurden jegliche größere Neu- oder Umbauten von Empfangsgebäuden der zweiten Generation durch Einrichtung von Bahnhofswirtschaften (Restaurationen), Büffets und kleineren Geschäften flankiert. Ziel dieser Maßnahmen war es dabei sicher nicht nur, den seit Mitte des 19. Jahrhunderts gesteigerten Passagieransprüchen gerecht

Vgl. Keith Slater, Human Comfort (Springfield: CC Thomas, 1985), 4.

56 Luian Zhang, Martin C. Helander, und Colin C. Drury, »Identifying Factors of Comfort and Discomfort in Sitting «, Human Factors: The Journal of the Human Factors and Ergonomics Society 38 , Nr. 3 (1996): $377 f$. 
zu werden, sondern nicht zuletzt auch den durch die Bahnverwaltungen selbst auferlegten organisatorischen Zwang des stationären Warteimperativs zu kompensieren bzw. weniger >spürbar $<$ zu machen.

Jene Entwicklungen fielen jedoch international wiederum stark unterschieden aus. Schmitt resümierte hinsichtlich der Entwicklungen der späten 1860er Jahre, dass in Deutschland »grosse Eleganz und Bequemlichkeit in den für die Passagiere bestimmten Räumlichkeiten« herrsche. Dagegen würden in England »nur Endstationen reich ausgeschmückt werden«, wobei ansonsten das »Prinzip absoluter Sparsamkeit« herrsche. Französische Bahnhöfe würden dabei hinsichtlich ihrer Größe und Ausstattung eine Mittelstellung zwischen Deutschland und England einnehmen. »Die Bahnhöfe Frankreichs«, so Schmitt, würden »die technisch vollkommenen Hilfsmittel der Englischen [Bahnen, R.K.]« besitzen, »ohne in die bedrückende Enge der Localitäten derselben $\mathrm{zu}$ verfallen oder andererseits den räumlichen Luxus der Deutschen nachzuahmen. ${ }^{58}$ Auch wenn die Einschätzungen des deutschen Systems aus Sicht eines Deutschen zu jener Zeit durch einen gewissen stechnologischen Nationalismus ${ }^{59}$ gefärbt gewesen sein dürften, so sticht zumindest die besondere Größe deutscher Bahnhofseinrichtungen empirisch unverklärt ins Auge.

Die Erweiterung von Komfort- und Dienstleistungsangeboten innerhalb der zweiten Bahnhofsgeneration bedingte damit seit Mitte des 19. Jahrhunderts die Entstehung eines >würdevollen Wartens`, das durch eine Erhöhung der Aufenthaltsqualität im Allgemeinen und einer Kulinarisierung, Mediatisierung und damit insgesamt zu einer Kommerzialisierung des Wartens im Besonderen bewirkt wurde. Die Rekonstruktion der Veränderungen entlang dieser drei übergeordneten Tendenzen soll nun im Folgenden kurz angeschnitten werden. Diese Betrachtung wird deshalb verfolgt, weil Komfort und Bedürfnisbefriedigungen der Passagiere als zentrale Einflussfaktoren für die Ausbildung eines subjektiven Wohlbefindens gelten, das wiederum direkten Einfluss auf die Wahrnehmung und Verhandlung des systemischen Wartens genommen haben dürfte.

\section{Kulinarisierung: Die Bahnhofswirtschaft}

Eine der Besonderheiten der (öffentlichen) Reisesituation besteht in der Problematik eingeschränkter Handlungsmöglichkeiten der Reisenden während der Fahrt. So kann öffentlicher Verkehr nur unter der Bedingung organisiert werden, dass eine Vielzahl von Menschen während der Fahrt für eine gewisse Zeit ihre individuellen Wünsche einem gemeinschaftlichen Ziel der Ankunft unterordnet. In der Konsequenz bedeutet dies, dass während der Fahrt die Bewegungsfreiheit sowie Möglichkeiten zur Bedürfnisbefriedigung vergleichsweise eingeschränkt sind. Diese Raum- und Sachzwänge hatten und haben bis heute insbesondere Auswirkung auf eine essenzielle Bedürfnisbefriedigung des Menschen: die Versorgung mit Essen und Getränken.

Um dieser Problematik beizukommen, wird das Reisen seit jeher von Fragen der leiblichen Versorgung begleitet bzw. stehen Verkehrs- und Gastronomiegeschichte seit jeher in engstem Zusammenhang. So waren bereits die vormodernen Verkehrshäuser

59 Hierzu auch: Joachim Radkau, Technik in Deutschland: vom 18. Jahrhundert bis heute (Frankfurt a.M.; New York: Campus, 2008), 161-69. 
der Poststationen explizit mit einer Versorgungsfunktion verbunden, boten in ihrer Funktion als Gasthäuser Speisen, Getränke sowie Übernachtungsmöglichkeiten an. Wie in anderen Zusammenhängen orientierte sich auch in dieser Hinsicht das Eisenbahnwesen stark am Postkutschenwesen. ${ }^{60}$ Die langen Zugreisen des 19. Jahrhunderts, die sich durch nur allmählich zunehmende Geschwindigkeitsniveaus verkürzten, machten eine ausreichende Versorgung vor Fahrtantritt bzw. eine ausreichende Selbstverpflegung für die Fahrt nötig. Anders als in der Gegenwart war die Fremdversorgung während der Fahrt aber nicht möglich, weil es bis ca. 1900 keine Speisewagen gab und entsprechend der geschilderten Raum- und Sachzwänge des öffentlichen Verkehrs Reisende bei Hunger und Durst nicht unvermittelt die Türen und Fenster des Zuges öffnen, den Zug zum Stehen bringen durften oder ihre eigene Fahrt unterbrechen wollten, um ihre Grundbedürfnisse zu befriedigen.

Vor diesem Hintergrund scheint die im Zuge des Verkehrswachstums einsetzende Entstehung großer Bahnhofsrestaurationen ab Mitte des 19. Jahrhunderts als ein konsequenter wie notwendiger Entwicklungsschritt. Zwar wurde die Relevanz der Einrichtung von Versorgungsmöglichkeiten im deutschsprachigen Raum bereits seit den ersten programmatischen, in der Allgemeinen Bauzeitung veröffentlichten Empfehlungen zum Bahnhofsbau von 1838 betont, verpflichtend wird die Errichtung einer »Restauration « - zumindest für größere Stationen - jedoch erst mit den >Technischen Vereinbarungen von 1850 verankert. Bis zu diesem Zeitpunkt übernahmen zumeist Gastwirte in unmittelbarer Umgebung des Bahnhofs die Versorgung vor Fahrtantritt oder bei Ankunft. Spätestens mit den Großbahnhöfen der 1860er Jahre aber wanderten die Restaurationen ins Innere der Bahnhofsbauten, genauer ins Innere der Wartesäle. So fungierten, besonders deutlich im deutschen Eisenbahnkontext, die Wartesäle zugleich als Warte- und Erfrischungsräume. ${ }^{61}$ Das Spektrum der häufigsten Anordnungen umfasste dabei folgende Formationen: ${ }^{62}$

\section{Schanktisch (Büffet)}

Bei dieser Minimalvariante einer Versorgungseinrichtung mussten Speisen und Getränke selbstständig an einer Theke bestellt, bezahlt und in Empfang genommen werden. Der Schanktisch wurde an einer Wandseite des Wartesaals und dabei möglichst zwischen zwei verschiedene Warteräume angeordnet, um es dem Wirt zu ermöglichen, den Betrieb in beiden Räumen leicht zu übersehen und zu überwachen. Diese Formation galt als Standardvariante für die unteren Wagenklassen und stellte die Versorgungserfahrung des weit größten Teils der Reisenden des 19. Jahrhunderts und frühen 20. Jahrhunderts dar.

60 Dieser enge Zusammenhang zeigte sich insbesondere im englischen und US-amerikanischen Eisenbahnwesen, weil dort an großen Kopfstationen oftmals zusätzlich ein großes Hotel errichtet wurde (London St. Pancras). Stationen wie London St. Pancras oder St. Louis Union Station zeigen damit noch stärker als in anderen nationalen Kontexten auf, dass der moderne Bahnhof zu einem Reproduktionsort bereits im Postkutschenwesen etablierter Funktionen (Essen, Trinken, Übernachtung) geworden war.

61 Vgl. Schmitt, Anlage und Einrichtung der Cebäude, 75.

62 Ebd., $75 \mathrm{ff}$. 


\section{Wartesaal als Restaurant}

Bei dieser Formation waren Wartesaal und Restaurant miteinander vereinigt, wobei der Saal durchgehend mit Tischen und Stühlen möbliert war. Der Nachteil dieser im Vergleich zum Büffet gehobeneren Versorgungssituation war der, dass Reisende, die nichts konsumieren wollten, sich durch den Wirtschaftsbetrieb gestört fühlen konnten und so wurde »der Wartesaal seinem eigentlichen Zweck zum nicht geringen Teile entzogen ${ }^{63}$. Zur Lösung dieses Problems wurde im frühen 20. Jahrhundert eine Trennung des Wartesaals mit Säulenstellungen (z.B. in Wiesbaden) realisiert. Diese Säulen separierten den Wartesaal in unterschiedliche Funktionszonen, die einen Aufenthalt mit oder ohne Essen ermöglichten und dadurch die kritisierte Konvergenz von Verzehr und Warten zur Option und nicht zur Norm werden ließen.

\section{Separater Speisesaal}

Die Einrichtung eines separaten Speisesaals in Form eines vollwertigen Restaurantbetriebs galt als die gehobenste Form der Bahnhofsgastronomie. Sie wurde nur in sehr großen Bahnhöfen, bei umfangreicher Bewirtschaftung und einer Trennung der Wartesäle eingerichtet.

\section{Speisehallen für Durchreisende}

Ein vierter gastronomischer Bautypus bildete die Einrichtung von Restaurationen auf Bahnsteigen, die nicht von abfahrenden und ankommenden Reisenden, sondern einzig von Durchreisenden benutzt wurden. Diese Speisehallen fungierten als Zwischenaufenthalte für Reisende, die auf langen Zugverbindungen verkehrten. Solche gastronomischen Transit- und Warteräume bestanden prominent etwa zum Beispiel im Hauptbahnhof von Hannover, in dem Reisende auf dem Weg zwischen Berlin und Köln ihre Mittagsmahlzeit in einem 30-minütigen Zeitfenster einnahmen. Diese planmäßigen Versorgungsaufenthalte - für viele Jahrzehnte der Frühphase des Eisenbahnwesens ein fester Bestandteil der Reiseerfahrung - wurden erst zum Ende des 19. Jahrhunderts mit Einführung von Speisewagen obsolet, die den Verzehr von Speisen und Getränken während der Fahrt ermöglichten.

\section{Speiseräume für Kutscher und Chauffeure}

Diese gastronomische Einrichtung adressierte nicht die Reisenden selbst, sondern speziell nur das Dienstleistungspersonal am Bahnhof, das in der Regel mehr mit dem Phänomen des Wartens beschäftigt war als die Reisenden selbst, da die Fuhrwerksarbeiter - ähnlich dem heutigen Taxigewerbe - stets die Ankunft eines Zuges mit potentiellen neuen Kunden erwarten mussten. Solche Speiseräume für das Fuhrpersonal, wie etwa in Halle (Saale), bildeten daher an den Bahnhöfen eine nicht unwichtige Erweiterung des wartebezogenen Raumprogramms.

\section{Schanktisch/Büffet am Bahnsteig}

Diese einfache Form des Gastronomiebetriebs war in erster Linie typisch für den englischen Eisenbahnkontext. Entsprechend der bereits geschilderten Affinität und Praxis 
englischer Reisender, die Abfahrt direkt auf dem Bahnsteig in unmittelbarer Nähe zum Zug abzuwarten bzw. die Wartesäle im Innern des Empfangsgebäudes nur selten aufzusuchen, wurden die Zugänge der gastronomischen Einrichtungen (>refreshment rooms bzw. >bars ) als auch jeglicher anderer Serviceeinrichtungen an die Bahnseite und nicht an die Stadtseite verlegt. Der Bahnsteig fungierte damit als Hauptzirkulations- und Wartezone in der auch vorwiegend (im Stehen) konsumiert wurde.

\section{Öffentliche Speiseräume auf Stadtseite}

Eine weitere Anordnung der gastronomischen Einrichtungen bildete die Anlage von Speiseräumen, die nur von der Straße oder vom Vorplatz aus erreichbar waren und auch dezidiert vom nicht-reisenden Publikum benutzt werden konnten. Prominente Beispiele der Blütephase des Eisenbahnwesens waren hierfür die Bahnhofsgaststätten von Frankfurt, Hannover, Wiesbaden oder jene des Wiener Südbahnhofs.

\section{Restauration/Büffet auf Ankunftsseite}

Häufig wurden in Großbahnhöfen auch Wartesäle auf der Ankunftsseite errichtet, »um denjenigen Personen, welche Reisende erwarten oder sich vor der Abfahrt zur Stadt einige Zeit aufzuhalten wünschen, einen geschützten Aufenthaltsraum zu gewähren. « ${ }^{64}$ In den seltensten Fällen jedoch wurden dazu auch gastronomische Strukturen errichtet. Im Beispiel des Neubaus des Bahnhofs der Königlichen Ostbahn in Berlin (1870) jedoch erschien die Einrichtung eines Büffets »auf dieser Seite ebenfalls unentbehrlich «. ${ }^{65}$

Unabhängig von der im Einzelfall konkret realisierten Form wurde die Bahnhofsrestauration im Zuge der 1860er Jahre zu einer zentralen, aus Sicht der Reisenden eingeforderten Institution. Diese Entwicklung bewirkte damit eine neuartige Kulinarisierung der Reiseerfahrung im Allgemeinen und - zumindest bis zur Einführung der Speisewagen - eine Kulinarisierung des präparatorischen Wartens im Besonderen. ${ }^{66}$ Die enge Wechselbeziehung zwischen Warten und Gastronomie illustrierend wurde die Entstehung solcher Restaurants überhaupt erst auf der Grundlage der Existenz des Phänomens des systemischen Wartens möglich. In Abhängigkeit von ortspezifischen Gegebenheiten, der Größe der Station, aber vor allem auch abhängig von dem an die Wagenklasse gekoppelten Budget der Reisenden, reichte die Versorgung dabei von einer kleinen Erfrischung im Stehen bis hin zum Gängemenü an Tafeln mit gestärkten Tischdecken. Wie wohl kaum eine zweite Bahnhofsrestauration, zeigt das Restaurant Le Train Bleu im Pariser Gare de Lyon mit seiner Fin-de-siècle-Ausstattung das obere Ende dieser Kulinarisierung an, in der das systemische Warten - zumindest für wohlhabendere

64 »Das Empfangsgebäude der Königlichen Ostbahn zu Berlin.«, Zeitschrift für Bauwesen XIX. (1870): 7.

65 Ebd.

66 Der Begriff der Kulinarisierung mag angesichts der einfachen Speisen und Getränke an den Schanktischen der Wartesäle der dritten und vierten Wagenklasse etwas überzogen erscheinen. Er wird hier aber bewusst gewählt, um die deutliche Zäsur der Zunahme gastronomischer Angebote seit den $1850 e r$ Jahren zu unterstreichen, die - wie aufgezeigt - in den oberen Wagenklassen durchaus den Charakter von Spitzenrestaurant annahmen und insbesondere hier den Begriff der Kulinarisierung sinnvoll erscheinen lassen. 
Reisende - in den Stand eines überaus würdevollen und nicht zuletzt gesellschaftlich repräsentativen Teilaspekts der Reiseerfahrung gehoben wurde.

Die Existenz solcher Spitzenrestaurants darf jedoch keinesfalls darüber hinwegtäuschen, dass die häufigsten konsumierten Speisen in den Wartesälen ganz anderer Natur waren. Statt dem Gängemenü lag das vorwiegende Konsumverhalten an den Büffettischen auf dem Verzehr von Butterbroten und alkoholischen Getränken, wie unter anderem aus einer Passage des humoristischen Gedichts Aufden Preuß'schen Eisenbahnen von Frank Wedekind (1898) zu berichten weiß.
»Auf den Preuß'schen Eisenbahnen
Und besonders in Berlin
Fahren fromme Untertanen
Cottesfürchtig her und hin.
Überall zum Butterbrote
Findet jeder ein Glas Bier (...). $\ll^{67}$

Zusätzlich zu schnellen und preiswerten Imbissen wurden aber auch einfache warme Speisen, insbesondere Suppen konsumiert. Deren Verzehr war jedoch nicht selten von der (modernen) Problematik des `Zeitdrucks geprägt, wie etwa aus einigen satirischen Ratschlägen zur Nutzung der Eisenbahn aus dem Jahr 1864 hervor geht, die in der Satirezeitung Kladderadatsch abgedruckt wurden.

»(..)
Vom Aufenthalt auf der Station.
Was du auch thust auf der Station,
Beeile dich, mach schnell, mein Sohn!
Bewege dich im schärfsten Trab,
Man wartet nicht - der Zug geht ab.
Weh dir, wenn du erst fertig bist,
Wenn schon der Zug im Fortgeh'n ist.
Dein Koffer fährt dann ohne dich,
Du bleibst zurück elendiglich.
(...)
Vom Warmessen auf der Station.
Schwer ist's, dass du den Hunger stillst,
Wenn du was Warmes essen willst.
Die Zeit ist kurz, hoch ist der Preis,
Und Alles ist entsetzlich heiss.
Der Kellner grinst dich an mit Hohn:
Schnell, schnell, mein Herr! Es läutet schon. « ${ }^{68}$

Mit dem seit Jahrhundertmitte wachsenden Bedarf nach Versorgungsmöglichkeiten im Bahnhof stieg interessanterweise der Wirt in den Rang eines Repräsentanten des Bahn-

67 Frank Wedekind, Cedichte aus dem »Simplicissimus« (Göttingen: Wallstein Verlag, 2019), 91.

68 >Reisen auf der Eisenbahn< (1864), abgedruckt in Löper, Stammbuch der neueren Verkehrsmittel, Eisenbahnen, Dampfschiffe, Telegraphen und Luftschiffe. 
betriebs selbst. So stellte der Bahnhofsarchitekt Eberhard Wulff im Jahre 1882 offenbar sichtlich beeindruckt und überrascht vom Anwachsen der Bahnhofsgastronomie im deutschen Kontext fest:

»Nachdem einmal die leibliche Verpflegung der Reisenden innerhalb der Warteräume in das feststehende Programm der deutschen Empfangsgebäude aufgenommen ist (in Frankreich ist dieselbe ausgeschlossen), tritt der Restaurateur dem Publicum gegenüber in eine nicht viel weniger wichtige Stellung als die im Empfangsgebäude beschäftigten Beamten. ${ }^{69}$

Nicht mehr allein die Bahnverwaltung wurde damit zum exklusiven Aushängeschild des lokalen Verkehrswesens, sondern offenbar auch die jeweilige Dienstleistungsstruktur. Da die Bahnhofswirte die Flächen von den Bahnverwaltungen pachteten und nicht selbst von den Verwaltungen angestellt wurden, kann vermutet werden, dass somit die Auswahl des geeigneten Bahnhofswirtes mancherorts in den Stand einer strategischen Unternehmensentscheidung rückte.

\section{Kritik an der Kulinarisierung: Das Unbehagen der Planer und Architekten}

Die deutliche Entwicklung zur Kulinarisierung des Wartens in der zweiten Hälfte des 19. Jahrhunderts erzeugte einen sich entwickelnden Konflikt zwischen den legitimen Interessen und Forderungen der Reisenden auf der einen und den Architekten und Planern auf der anderen Seite. So wurden die großen Restaurationslokale, die mancherorts innerhalb eines Bahnhofes in der gesamten Breite der oben skizzierten Typologie auftraten, von Seiten der Planer zu einem Hindernis des laufenden Betriebs und als wuchernder Flächenverbrauch kritisiert. Von Weber, zweifellos einer der einflussreichsten Eisenbahntheoretiker des Deutschen Reiches, vermerkte etwa bezüglich dieser Entwicklung, dass in Deutschland »durch die Einrichtung der Warteräume, die Eisenbahnhöfe an sehr vielen Orten, zu großer Unbequemlichkeit des Betriebes, zu den beliebtesten Restaurants der Städte, an denen sie liegen, geworden « $^{70}$ waren. In der Folge hätten die Wartesäle »den Charakter als solche fast verloren« und seien zu großen Restaurations-Lokalen mit prächtiger Ausstattung mutiert, die »über das wahre Bedürfniß weit hinausgehende Dimensionen ${ }^{71}$ aufweisen würden.

Auch bei den Überlegungen zum Bau eines Zentral-Bahnhofes für Berlin kurz nach Reichsgründung zeigt sich indirekt das deutliche Missfallen der Architekten an der jüngsten Kulinarisierung des Wartens in Materialität und Form großer Speisesäle. So prognostiziert Schwabe für den Bau eines solchen Großbahnhofes keinerlei schwerwiegende Probleme, wären da nicht die neuen Bedürfnisse der Reisenden:

»Die Anlage könne einfach und kompendiös genug gemacht werden, falls nur eine absolute Trennung der Personen-, Stückgut- und Kohlen Bahnhöfe festgehalten werde

69 Wulff, »Das Eisenbahn-Empfangs-Cebäude nach seinen praktischen Anforderungen und seiner künstlerischen Bedeutung«, 36.

von Weber, Schule des Eisenbahnwesens: Ceschichte, Technik, Administration und Statistik der Eisenbahnen, $246 f$. 
und falls man bei Disponirung der ersteren nicht von den gegenwärtigen Cewohnheiten unseres Publikums ausgeht, das bei einem Bahnhofe ausgedehnte RestaurationsRäumlichkeiten verlangt und jedem einzelnen Reisenden ein Geleit mehrer Freunde und Verwandten bis an die Wagen folgen lässt. $\ll^{72}$

Was sich somit einerseits als Zugewinn an Angebotsqualität für Reisende, respektive als Zugewinn städtischer Lebensqualität für Nicht-Reisende darstellte, wurde von Seiten der Architekten und Bahnverwaltungen als Betriebsschädigung angesehen, nicht zuletzt auch deshalb, weil die Reisenden im Falle von allein stadtseitig gelegenen Restaurants aufgrund der Fremdnutzung kaum mehr freie Sitzplätze erhielten. Auch im österreichischen Kontext lassen sich solche Diskussionen erkennen. Auch hier war das Bahnhofsrestaurant von hoher Relevanz, da es von den Reisenden stark nachgefragt wurde. Zugleich war es aber auch hier aus Sicht der Bahnverwaltung Fluch und Segen zugleich, wie etwa Flattich $1870 \mathrm{zu}$ berichten weiß:

»Den Anlagen von Restaurationen in Stationen und Bahnhöfen ist eine besondere ,Wichtigkeit beizulegen; weil einerseits das Publikum nahezu in allen Stationen derartige Anlagen verlangt, anderseits dieselben nicht selten eine wahre Plage für die Eisenbahn-Verwaltung werden, weil die Anlage durch den schlechten Betrieb der Restauration in kurzer Zeit derart verdorben werden kann, dass ein Umbau, folglich eine grosse Neuausgabe für die Verwaltung sich als nöthig erweist, um die Anlage wieder in Stand zu setzen. $\ll^{73}$

Noch stärker als im deutschen Kontext wurde in Österreich demnach offenbar die raumgreifende Kulinarisierung des Wartens als geschäfts- bzw. gar als bauwerksschädigend kritisiert. Dass die Bahnhofsanlage durch schlechten Betrieb sogar schnell gänzlich `verdorben « werden konnte, war in diesem Zusammenhang eventuell auch der österreichischen Eigenart geschuldet, denn bspw. wurde in Wiener Bahnhofsrestaurants weit öfter warm gegessen als in Berlin. ${ }^{74}$

Als aus Sicht der Planer und Verwaltungen positives Gegenbild wurde an dieser Stelle vor allem die englischen und französischen Bahnsysteme angeführt, in denen sich Restaurants nur auf Stationen mit Speisehallen für den Durchgangsverkehr befanden und diese deutlich von den Wartesälen abgetrennt lagen. $\mathrm{Zu}$ diesen Zwischenhalten, die im Laufe des 19. Jahrhunderts bis zur Einführung von rollenden Speisewagen zu legendären kollektiven Erinnerungsorten gereift zu sein schienen, zählten in England bspw. die refreshment rooms in Wolverton oder Swindon. An solchen Verzehrstationen regierte - wie überall im englischen Eisenbahnwesen - das Prinzip der Schnelligkeit. So wurden in Wolverton, dem Verzehrhalt auf halber Strecke zwischen London und Birmingham, offenbar innerhalb weniger Minuten hunderte Reisende mit Kaffee, Tee, 
Sandwiches und Kuchen versorgt. Allein hier wurden durch einmal in einem Verkehrsjahr 182.000 Banbury cakes, 45.000 Flaschen Stout und 85 Schweine konsumiert. ${ }^{75}$ Die von Hast und Eile geprägte Atmosphäre bei diesen Zwischenhalten an Verzehrstationen wird in einem 1862 veröffentlichten Reiseratgeber eingängig und zugleich äußerst humorvoll geschildert. Zum Oberthema >refreshment« wird darin vermerkt:

»The rule generally is for the train to stop five or ten minutes for the purpose of taking refreshment; in such cases, especially with anything like a heavy train, a rush of passengers is made simultaneously to wards the refreshment-room, and the counter is be sieged by hungry and thirsty applicants, urging their various requests for sandwiches, buns, biscuits, wine, brandy, ale etc. But inasmuch as there are usually some two or three hundred persons requiring refreshments, and only about dozen hands to supply them, it stands to reason that the task of serving out the viands is no easy one, and many are the disappointments accordingly. Let the traveller remember that he has only the short space of five or ten minutes to gain the refreshment counter, to obtain the refreshment, to pay and perhaps receive change, to perform the operation of eating and drinking, and regain the seat in the carriage. It is obvious, there fore, that a person must exercise his utmost ingenuity and energy in order to accomplish this edible feat. " $^{76}$

Angesichts der enormen Zeitknappheit wird im Weiteren folgende Strategie vorgeschlagen, die bei aller humoristischen Anmutung als durchaus ernst gemeinter Ratschlag gedient haben dürfte.

»When the train is on the point of stopping, mark well the place where the words »Refreshment-Room « are written up, so that directly the train stops, you may make at once for this place without wasting your time in looking about for it. Walk straight to that part of the counter where one of the attendants is stationed, and having, in parliamentary phraseology, »caught her eye, « declare your wants. But in doing this, be quick and concise. If you desire a basin of soup, never mind the words »a basin of, «but simply utter the mono syllable »soup« so with a cup of tea, content yourself with calling out the latter word ; a bottle of ale, »ale, « etc. (...) Beware of taking hot refreshments; (...) the fluids supplied are so excessively hot, and so long in forthcoming, that it is utterly impossible for a person to swallow them, unless his throat be sheathed with - iron. (...) On the whole, we should advise the railway traveller to take his refreshment with him (...) by this means a double advantage will be secured, for a person may partake of his refreshment at any moment he pleases, without being obliged to eat and drink at a particular moment dictated by the railway company; he will also obtain his refreshment at a much more moderate charge, and, further, he will have the interval to stretch his legs in, and to breathe a little fresh air, which he will find far more advantageous than being huddled and pushed about amidst a hungry and impatient crowd. ${ }^{77}$ 
Insgesamt eilte den englischen refreshment rooms wegen des erlebten Gedränges und der minderwertigen Qualität der Speisen ein denkbar schlechter Ruf voraus, der nicht zuletzt auch durch Charles Dickens Kurzgeschichtenband >Mugby Junction` genährt worden sein dürfte. Auf schärfste und ironischste Weise bezeichnete er die englische Bahnhofsgastronomie als >Tyrannei<.

Mit Einführung von Speisewagen, die um die Jahrhundertwende auf immer mehr (Fern-)Verbindungen eine >rollende Verpflegung ermöglichten, zeichnete sich jedoch der allmähliche Untergang der raumgreifenden Bahnhofsgastronomie ab. In Folge der technischen Entwicklung zum Speisewagen, stiegen die Bahnhofswirte aus Sorge um ihr langsam schwindendes Geschäft mancherorts gar selbst zu Speisewagenbetreibern auf. ${ }^{78}$ Die seit 1850/60 etablierte, stationäre Kulinarisierung des Wartens am Bahnhof transformierte sich somit seit der Jahrhundertwende - vielleicht symptomatisch für die Verflüssigungstendenzen der Moderne - stärker in Richtung einer mobilen Form der Versorgung.

\section{Mediatisierung, Information und Zerstreuung: Reisebuchhandlungen und -bibliotheken}

Neben der gastronomischen Versorgung bewirkte der Aufbau von umfangreichen Reisebibliotheken und Leihstellen eine weitere signifikante Erweiterung des Dienstleistungsangebotes an Bahnhöfen, die großen Einfluss auf die Praxis des Wartens hatte. Auch hier zeigte sich der konstitutive Zusammenhang zwischen der Existenz des Wartephänomens und der Entwicklung rahmender Angebotsstrukturen, der schon zuvor bei der Etablierung eines bis 1870 stärker standardisierten Raumprogramms griff. Zum einen hatten die literarischen Angebote direkte Auswirken auf die Wahrnehmung des systemischen Wartens, zum anderen bildet die Existenz des Wartephänomens - in diesem Fall speziell das lange Warten im Zug - überhaupt erst den Anlass für die Schaffung einer erweiterten Angebotslage. Diese neue Angebotslage entstand auf Grundlage einer allgemeinen Erfahrungssättigung zum Zeitpunkt der wachsenden Massenwirksamkeit der Eisenbahnen. Die neue Form der Zugreiseerfahrung wurde im Vergleich zur Reise mit der Postkutsche aufgrund der geschwindigkeitsevozierten Ablösung vom durchkreuzten Naturraum von vielen Zeitgenossen nach der allgemeinen Aufregung der Anfangsjahre immer mehr als artifizielles, von der ursprünglichen Landschaftserfahrung vollends abgekoppeltes Erlebnis wahrgenommen. Zwar ermöglichte die Eisenbahnreise zweifellos eine weit komfortablere und wesentlich schnellere Reise, jedoch reiften darin Monotonie, Müdigkeit, Anonymität und Langeweile zu wirkmächtigen >Reisebegleitern<.

Jene neue psychologische Verfasstheit bedingte eine neuartige Nachfrage nach Zerstreuung und Unterhaltung oder - wie Schivelbusch es angesichts der veränderten Raum-Zeit-Erfahrung nennt - eine Nachfrage nach »imaginären Ersatzlandschaften $\aleph^{79}$, in denen sich der Blick von der durchreisten Landschaft vollends emanzipieren und die Monotonieerfahrungen kompensiert werden konnten. Geschäftstüchtige Verleger, Buchhändler und Leihbibliothekare, aber auch Literaten selbst erkannten 
das novierte Bedürfnis nach solchen >Ersatzlandschaften $<$ und produzierten zwischen den 1850er und 1860er Jahren ausgehend von England und Frankreich spezielle literarische Werke, die zusammen mit neuartigen Vertriebsstrukturen ein System der »organisierten Reiselektüre ${ }^{80}$ schufen.

In Erweiterung der bereits $\mathrm{zu}$ diesem Zeitpunkt etablierten Gattung der Reisehandbücher umfasste die >Reiselektüre zeitgenössische, auf ein Massenpublikum ausgerichtete Unterhaltungsliteratur, die zwar oftmals von Künstlern und Schriftstellern aufgrund ihrer literarischen Qualität belächelt und parodiert wurde, aber reißenden Absatz fand. In historisch ungekannter Dimension evozierte die Nutzung des Massenverkehrsmittels der Eisenbahnen den Konsum von literarischen Massenprodukten und verschaffte dem bis heute anhaltenden Metaprozesses der Mediatisierung einen gewaltigen Schub. ${ }^{81}$ Ob Reisebeschreibungen und -berichte, Lyrik- und Liedanthologien, Novellen, Erzählungen oder als Skandalgeschichten aus aristokratischen Kreisen, Grundbedingung für die Herstellung solcher Werke war es, dass sie auf Leser kurzweilig, unterhaltend oder belehrend wirken konnten. ${ }^{82}$

Namhafte Akteure dieser Dienstleistungserweiterungen am Bahnhof, die aus dem Wartephänomen heraus entstanden waren und es zugleich um den Faktor der Zerstreuung und Information modifizierten, waren in England unter anderem das Verlagshaus William Smith \& Son, das 1849 das Monopol zur Unterhaltung von Kiosken und Buchläden auf allen englischen Stationen erhielt, sowie auf französischer Seite das Verlagshaus Louis Hachette, das ab 1854 die französischen Stationen mit Reiselektüre versorgte. Die Distribution der Reiselektüre erfolgte entweder in Form des Verkaufs oder des Verleihs, wobei der Bahnhof jeweils zum zentralen Vertriebsschauplatz wurde. Der Verkauf erfolgte im deutschen Kontext bis Anfang der 1860er Jahre meist durch ambulante bzw. ^fliegende< Verkaufsstände an Bahnsteigen oder direkt in den Wartesälen durch ortsansässige Buchhändler. Im Zuge des kommerziellen Erfolgs des Verkaufs von Reiselektüre transformierten sich die provisorischen Verkaufsstände im letzten Drittel des 19. Jahrhunderts immer mehr in stationäre Verkaufsstände, die als beheizbare und begehbare Verkaufspavillons in den Bahnhofshallen aufgestellt wurden. ${ }^{83}$ Der lukrative

80 Christine Haug, Reisen und Lesen im Zeitalter der Industrialisierung: die Geschichte des Bahnhofs-und Verkehrsbuchhandels in Deutschland von seinen Anfängen um 1850 bis zum Ende der Weimarer Republik (Wiesbaden: Harrassowitz, 2007), 366.

81 Entgegen der Annahme einer erst in der Spätmoderne durch elektronische Medien einsetzenden Mediatisierung führt Friedrich Krotz zur überzeitlichen Bedeutung der Mediatisierung des Menschen an: »Mediatisierung als Metaprozess sozialen und kulturellen Wandels beinhaltet eine Vielfalt von übergreifenden, zum Teil bereits Jahrhunderte dauernden Entwicklungen, die schon vor der Erfindung der Schrift begonnen haben und mit der Erfindung der heute vorhandenen Medien noch lange nicht beendet sind. «Friedrich Krotz, Mediatisierung: Fallstudien zum Wandel von Kommunikation (Wiesbaden: VS Verlag für Sozialwissenschaften, 2007), 12.

82 Vgl. Christine Haug, »Das halbe Geschäft beruht auf Eisenbahnstationen...«. Zur Entstehungsgeschichte der Eisenbahnbibliotheken im 19. Jahrhundert«, Internationales Archiv für Sozialgeschichte der deutschen Literatur (IASL) 23, Nr. 2 (1998): 72.

83 Vgl. Christine Haug, „Ëin Buchladen auf Stationen, wo sich zwei Linien kreuzen, müsste gute Geschäfte machen...«: Der deutsche Bahnhofs- und Verkehrsbuchhandel von 1850 bis zum Ende der Weimarer Republik im internationalen Vergleich «, in Die Internationalität der Eisenbahn, 1850-1970, hg. von Monika Burri, Kilian T. Elsasser, und David Gugerli (Zürich: Chronos, 2003), 77. 
Markt bewirkte aber zudem, dass neben diesen offiziellen Vertriebsstrukturen auch informelle, nicht-legitimierte Händler Reiselektüre direkt in den Wartesälen oder an den Bahnsteigen anboten, was zunehmend eine Kontrolle und Einflussnahme der Eisenbahngesellschaften hinsichtlich des Literaturangebots bewirkte. ${ }^{84}$

Eine zweite Distributionsform stellte der Verleih von Büchern dar, der für die Reisenden den Vorteil hatte, das Buch nicht kaufen zu müssen, sondern Reiselektüre gegen eine geringere Gebühr am Abfahrtsbahnhof auszuleihen und sie am Zielbahnhof wieder abgeben zu können. Solche >rollenden Bibliotheken standen dabei in direkter Konkurrenz zu den Verlagshäusern und ihren Buchverkäufen und wurden auch von den Autoren selbst wegen potentieller Honorareinbußen zur ungeliebten Absatzform der Reiselektüre. Solche Leihsysteme existierten in England bereits seit den 1850er und wurden in Deutschland erst in den späten 1880er Jahren etabliert.

Weitere Konkurrenz erhielt der Reiselektüremarkt durch den Verkauf von Zeitungen und Zeitschriften, die die unterhaltende Zerstreuung stärker mit der Funktion der Information über aktuelle Ereignisse verbanden. Dass solche Verkaufseinrichtungen nicht allein auf großen Bahnhöfen, sondern auch im Nahverkehrsbereich eingerichtet wurden, verrät eine Beschreibung der neuen Pariser Gürtelbahn aus dem Jahr 1870, in der es heißt:

»Von Restaurationen ist in diesen Stationen natürlich nicht die Rede. Dagegen fehlt in den nur einigermaßen bedeutenden nicht ein kleiner Buch- und Zeitungsladen. ${ }^{85}$

Als dritte, aber eher marginale Distributionsform etablierte sich in den 1890er Jahren der Verkauf von Reiselektüre an speziellen Automaten, die es erlaubten, unabhängig von Öffnungszeiten die ganze Bandbreite kurzweiliger Geschichten und KlatschNachrichten in die Wartesäle und anschließend in den Zug mitzunehmen.

Die seit den 1850er Jahren etablierte Erfolgsgeschichte der literaturwissenschaftlich und verkehrshistorisch vergleichsweise wenig erfassten ${ }^{86}$ bzw. nur schwerlich anerkannten Gattung der Reiselektüre, kommt erst in den 1920er Jahren durch den Vertrieb von Taschenbüchern und Feldbüchereien allmählich zum Erliegen. Doch trotz der veränderten Literaturformen griff auch hier zweifellos nach wie vor das Prinzip der Schaffung von >Ersatzlandschaften . Unabhängig vom konkreten Medium zielt die Lektüre während der Reise bis in die Gegenwart hinein auf die kompensatorische Funktion, eine aufkommende Monotonie während der Zugfahrt ${ }^{87}$ oder während des Wartens auf Abfahrt zu minimieren. Walter Benjamin sah zudem aber auch noch eine weitere

84 Vgl. Haug, »Das halbe Geschäft beruht auf Eisenbahnstationen...«. Zur Entstehungsgeschichte der Eisenbahnbibliotheken im 19. Jahrhundert«, 112ff.

85 W. Housselle, »Die Pariser Gürtelbahn.«, Zeitschrift für Bauwesen XIX. (1870): 252.

86 Vgl. Haug, »Ëin Buchladen auf Stationen, wo sich zwei Linien kreuzen, müsste gute Geschäfte machen...«: Der deutsche Bahnhofs- und Verkehrsbuchhandel von 1850 bis zum Ende der Weimarer Republik im internationalen Vergleich«, 86.

87 An dieser Stelle sei jedoch erwähnt, dass die Zugreise keineswegs von allen Reisenden gleichsam als visueller Verlust wahrgenommen wurde, sondern durchaus auch neue Sichtbarkeiten und Sehqualitäten geschaffen wurden, für die insbesondere eine neue Art von Reiseführern sensibilisierte. Hierzu: Daniel Speich, »Rechts und Links der Eisenbahn: Zur visuellen Standardisierung der touristischen Eisenbahnfahrt«, in Die Internationalität der Eisenbahn, 1850-1970, 91-109. 
Funktion des Lesens von Reiselektüre, insbesondere von Kriminalromanen. Benjamin vermutete, dass die Motivation des kollektiven Griffs zur Reiselektüre »weniger aus Lesefreude« geschehen würde, »als im dunklen Gefühle, etwas zu tun, das den Göttern der Eisenbahn wohlgefällt. $\ll^{88}$ Die Lektüre diene somit gleichsam der Beschwichtigung einer Vielfalt von inneren Ängsten. Statt selbst zum Protagonisten von Unheil und Gefahr zu werden, würde sich der Reisende mittels der gelesenen Handlung in Krimis, Dramen oder Boulevardpresse lieber zum Zeugen eines gefahrvollen Lebens machen: "Die Betäubung der einen Angst durch die andere ist seine Rettung. ${ }^{89}$

Waren es im 19. Jahrhundert vorwiegend in langen Buchreihen herausgegeben Kurzgeschichten und Reiseberichte, so bilden heute die portablen Screens der Smartphones jene >Ersatzlandschaften<, die unseren Blick von der geschwindigkeitsevozierten "Verflüchtigung der Wirklichkeit « ${ }^{90}$ und der impressionistischen Wahrnehmung der vorbeiziehenden Außenwelt auffangen, uns Zerstreuung wie Information bieten. ${ }^{91}$ Seit Mitte des 19. Jahrhunderts erhält damit das verkehrsinduzierte Warten das Charakteristikum einer Mediatisierung, die seither zum festen Bestandteil der modernen Reiseerfahrung gehört. Jene mit dem Konsum von Reiselektüre einsetzende Mediatisierung muss darüber hinaus als entscheidendes psychologisches Korrektiv der ersten Krise der modernen Reiseerfahrung verstanden werden. Mit anderen Worten: Ohne die unzähligen an den Bahnhöfen verkauften Klatschnachrichten und Adelsgeschichten, ohne die ulkigen Lokalpossen und Reisebeschreibungen ferner Länder wäre die Verstetigung des modernen, beschleunigten Verkehrs - zumindest aus Sicht der Reisenden nicht - zukunfts- bzw. akzeptanzfähig gewesen. Die Bedeutung der Mediatisierung des Wartens kann demnach für die Entwicklungsgeschichte des modernen öffentlichen Verkehrs nicht zu geringgeschätzt werden. In diesem Verständnis wundert es kaum, dass die Bahngesellschaften den Bahnhofsbuchhändlern anfangs sogar Zuschüsse für den Betrieb der Verkaufsstände gewährten. ${ }^{92}$

\section{Kommerzialisierung: Geschäfte für Reisebedarf}

Der Erwerb von Reiselektüre, Zeitungen und Zeitschriften machte innerhalb der Phase der Standardisierung und Konsolidierung des Eisenbahnwesens den größten Anteil der am Bahnhof verkauften Produkte und Dienstleistungen aus. Parallel zur großen Nachfrage nach kompensatorischen >Ersatzlandschaften in Form von Literaturformaten oder dem Konsum von Speisen und Getränken in Bahnhofsgastronomien entwickelte sich jedoch zugleich die Entstehung weiterer Konsumangebote, die das verkehrsinduzierte Warten flankierten und modifizierten. Hierzu zählte der Verkauf kleinerer Waren, die nach heutiger Definition als >Reisebedarf^ zusammengefasst werden und

88 Walter Benjamin, »Kriminalromane, auf Reisen«, in Gesammelte Schriften, hg. von Rolf Tiedemann und Hermann Schweppenhäuse, Bd. IV: Kleine Prosa (Frankfurt a.M.: Suhrkamp, 1972), 88.

89 Ebd., 89.

90 Schivelbusch, Ceschichte der Eisenbahnreise, 62.

91 Auch in den 1980er Jahren zeigten Studien, dass etwa noch dreißig Prozent der Reisenden sich in den DB-Bahnhöfen Reiselektüre erwarben (Radlbeck, »Bahnhof und Empfangsgebäude«, 45).

92 Vgl. Haug, »Ëin Buchladen auf Stationen, wo sich zwei Linien kreuzen, müsste gute Geschäfte machen... «: Der deutsche Bahnhofs- und Verkehrsbuchhandel von 1850 bis zum Ende der Weimarer Republik im internationalen Vergleich«, 80. 
Schreibmaterialien, Andenken, Blumen, Reisehygieneartikel und vor allem Tabakwaren umfassten. Im frühen 20. Jahrhundert folgten diesen Produkten auch Artikel aus Apotheken und Fotogeschäften. Nicht selten wurden in den frühen Bahnhofsneubauten des 20. Jahrhundert an Orten mit hoher Fremdenverkehrsdichte zudem auch Friseurgeschäfte eingerichtet, so etwa im Neubau von Wiesbaden (1906).

Bereits 1846 gewährt ein Bericht von César Daly Einblick in die Vielfalt, der am Pariser Bahnhof Gare du Nord verkauften Waren, der hier nur stellvertretend für eine Vielzahl solcher Schilderungen herangezogen werden soll. Laut Dalys wurden im Bahnhof »tausend Dinge verkauft, die der Reisende im Moment der Abreise benötigt, Zigarren, Tageszeitungen, Ficelles [dünne Baguettes, R.K.], Taschenmesser, Kuchen und Gebäck. «93 Das Spektrum der angebotenen Waren reichte dabei offenbar von praktischen Gebrauchsgegenständen und Werkzeugen auf der einen Seite bis hin zu Genussmitteln auf der anderen. Während Taschenmesser als alltagsrelevantes Multifunktionswerkzeug erworben werden konnten, vermochten dagegen Tabakwaren und Süßigkeiten als zentrale »Ablenkungs- und Beruhigungsmittel «" ${ }^{94}$ fungieren, um die ungewohnte Abfahrtssituation an den Bahnhöfen zu kompensieren und der erzwungenen Passivität der anschließenden Fahrt etwas entgegenzusetzen. Die verblüffende Warenvielfalt deutet zudem an, dass der Bahnhof bereits offenbar im Zuge seiner zweiten Erweiterungsphase mancherorts zu einem zentralen Verkaufsschauplatz geworden war. In ihm werden die Bedarfe tausender Menschen, die sich ähnlich wie in der Markthalle konzentriert an einem Ort aufhalten, befriedigt. Jedoch besteht hier ein wesentlicher Unterschied zur Markthalle, denn die Bahnhöfe - verstanden als oberste Repräsentanten des Eisenbahnwesens - schufen wiederum selbst erst die Bedarfe, die dann mit den Verkaufsangeboten in den Kathedralen der Mobilität befriedigt wurden. So trägt die Bahn durch Einrichtung von Läden und Geschäften seit langem einem im Grunde "von ihr ausgelösten Bedarf Rechnung. «"

Dieser Zusammenhang lässt das Verständnis der Modernität der Bahnhöfe um eine Dimension erweitern, die nicht allein mit Vorhandensein neuer Technologien in neuen räumlichen Arrangements umrissen wird. Die Modernität des Bahnhofes zeigt sich mit Blick auf die Kommerzialisierung des Wartens vielmehr darin, dass moderne Entwicklungen nicht nur die Entstehung von neuartigen Zeitnischen und -zwischenräumen generieren, sondern zugleich ihre unmittelbare Verwertung beinhalten. Dieser Doppelprozess von Problemerzeugung und simultaner Problemlösung lässt den Bahnhof zu einem signifikanten Ausdrucksort des Verständnisses der modernen (kapitalistischen) Wirtschaftslogik werden.

Eine weitere moderne Besonderheit des Bahnhofes im Zusammenhang mit der Befriedigung nach Reisebedarf besteht zudem in einer zeitlichen Dimension. Die Versorgung mit Reisebedarf war während der gesamten Tageszeit erforderlich. Insbesondere mit Einführung von Nachtzügen dehnte sich das Warenangebot am Bahnhof in allen hier beschriebenen Komponenten bis in die Nacht hinein aus, sonst übliche Ladenschlusszeiten wurden aufgehoben. Diese Besonderheit, die sich weniger zur Mitte des 
19. Jahrhunderts als vielmehr seit der Jahrhundertwende abzeichnete, unterstrich dabei zudem die Charakteristik des Bahnhofs als Ort einer von anderen Alltagsorten distinguierten Temporalität.

Nach 1945 wird die Kommerzialisierung der Bahnhöfe aufgrund des wachsenden Konkurrenzdrucks der motorisierten Verkehrsträger weiter vorangetrieben. Im Sinne einer Überlebensstrategie werden die Bahnen aus einem neuen Kostendruck heraus veranlasst, »der Verlockung durch die Pachteinnahmen mehr und mehr nachzugeben. ${ }^{96}$ Die Entwicklung zur Kommerzialisierung des Bahnhofes im Allgemeinen und des Wartens im Besonderen erreichte in Form der Umgestaltung von Bahnhofsgebäuden $\mathrm{zu}>$ Einkaufsbahnhöfen seit dem späten 20. Jahrhundert im Rahmen einer >Renaissance der Bahnhöfe i ihre vorläufige Spitze. Bahnhöfe reiften darin zu Konsumtempeln und erhielten eine "zweite Haut «" ${ }^{97}$. Auch wenn die Erlebniswelt des Konsums in Form des Berliner, Leipziger oder Frankfurter Hauptbahnhofs keineswegs vergleichbar mit der Angebotslage der Bahnhöfe zwischen 1845 und 1870 ist, nimmt diese Entwicklung nichtsdestotrotz zur Mitte des 19. Jahrhunderts ihren Anfang.

\section{Abschluss: Auswirkungen der Komfortsteigerung, Mediatisierung und Kommerzialisierung des Wartens}

Zusammenfassend sollte mit den vorangegangenen Ausführungen deutlich gemacht werden, dass die Erweiterung des Komfort- und Dienstleistungsangebots an Bahnhöfen der zweiten Generation nur aus der engen Wechselbeziehung zum Vorhandensein einer systemischen Wartezeit stand. Die Reisezeit im Zug sowie der ihr vorausgehende präparatorische Aufenthalt an den Bahnhöfen erzeugten eine Nachfrage nach kompensatorischen Maßnahmen zur Zeitfüllung. Ob im Dekor der Wartesäle, dem Warenangebot in den Vorhallen oder den Speiseangeboten in den Bahnhofswirtschaften, in all diesen materiellen Angebotszunahmen spiegelt sich ein gesteigertes Bewusstsein für eine andersartige Zeitlichkeit der Eisenbahnreise, die auch eine Reihe neuartiger Bedarfe schuf und die es direkt im Bahnhof selbst zu befriedigen galt.

Die Erfahrung eines beschleunigten Transports ging mit psychologischen und physiologischen Defiziten einher, die konsumistisch kompensiert werden mussten. Beschleunigung, Zeiterfahrung und Konsumption standen dabei wohlgemerkt nicht erst seit Mitte des 19. Jahrhunderts in engster Beziehung zueinander, sie wurde aber $a b$ diesem Zeitpunkt weit bewusster und von weit mehr Menschen als zuvor erfahren. In der Folge dieses Bewusstseins stiegen die Bahnhofsgebäude von ihrer vormalig rudimentären und provisorischen Funktion der bloßen technisch-funktionalen Vermittlung von Menschen auf das Bahnsystem, in den Stand komplexer, hochverdichteter Dienstleistungs- und Erfahrungslandschaften, die Analogien zur parallelen Entstehung städtischer Kaufhäuser aufwiesen. Schivelbusch vergleicht nicht zu Unrecht den auf der Eisenbahnreise benötigten "panoramatischen Blick aus dem Abteilfenster« mit dem Erlebnis des Durchstreifens von Kaufhäusern, in denen die Erscheinung der Waren

Ebd. Die Zunahme der Verkaufsläden und der Ladenflächen war nach dessen Berechnungen im deutschsprachigen Raum in folgenden Bahnhofsbauten besonders massiv: Hamburg-Altona, Luzern, Bern, Essen, München, Wuppertal-Elberfeld, Hannover. 
genauso impressionistisch im Vorübergehen erfahren wurde wie die vorbeiziehende Landschaft auf der Bahnreise. ${ }^{98}$

Gesteigerte Konsumption und gesteigerter Komfort wurden dabei aber weniger $\mathrm{zu}$ freiwilligen Leistungen, als vielmehr zu Überlebensbedingungen der weiteren $\mathrm{Zu}$ kunftsfähigkeit des Verkehrsmittels Eisenbahn. Die Warteerfahrung erhielt durch die vielfältige Rahmung von Angeboten zwar einerseits Optionen zur positiveren und würdevollen Zeitwahrnehmung, zugleich jedoch trat damit die Verhandlung und das (erträgliche) Erlebnis des stationären Aufenthalts seit Mitte des 19. Jahrhunderts in deutliche Abhängigkeit zum Konsum von Waren und Dienstleistungen.

\subsection{Exemplarische Bahnhofsbauten der Wachstums- und Standardisierungsphase}

Nachdem die wartezeitrelevanten Hauptentwicklungen der zweiten Generation von Empfangsgebäuden aufgezeigt wurden (Herausbildung einer baulichen >Normalform<, Verstetigung und Ausbau eines stationären Warteimperativs sowie Zunahme rahmender Komfort- und Serviceangebote), sollen diese im Folgenden knapp anhand zweier exemplarischer Bahnhofsgebäude der Wachstums- und Standardisierungsphase nachgezeichnet werden. Es ließen sich dazu fraglos unzählige Beispiele heranziehen, um die baulichen und komfortorientierten Entwicklungen des Eisenbahnhochbaus an konkrete Orte rückzubinden. Die Wahl der beiden Beispiele Elberfeld (Wuppertal) und Berlin Potsdamer Bahnhof wurde jedoch deshalb getroffen, weil in ihnen zum einen die wartebezogenen Entwicklungen dieser Phase besonders deutlich zum Ausdruck kommen und zum anderen die charakteristischen Entwicklungen im gesamten zeitlichen Spektrum der Phase der >zweiten Bahnhofsgeneration` abgebildet werden können. So steht Elberfeld für ein sehr frühes Beispiel der Etablierung des stationären Warteimperativs am Beginn der zweiten Bahnhofsgeneration, der Potsdamer Bahnhof in Berlin dagegen für ein eher spätes Beispiel. Während somit Elberfeld insbesondere die baulich-betriebliche Maxime der Zwischenphase spiegelt, zeigt der Neubau des Potsdamer Bahnhofs in Berlin zudem auch die passagierbezogene Erweiterung durch kompensatorische Infrastrukturen, die in einer charakteristischen >Würde des Wartens $<$ mündeten.

Ohne die Bahnhofsbauten zu sehr im Detail zu beleuchten, wird in der nun folgenden kurzen Rekonstruktion insbesondere verfolgt, anhand des vorgegebenen Bauprogramms die Stellung des Wartens sowie an diesen Orten die Rolle des Wartens innerhalb einer konkreten Rekonstruktion der Situation vor Abfahrt des Zuges nachzuvollziehen.

\subsubsection{Elberfeld (1850)}

Zwischen 1848-50 wurde in der Industriestadt Elberfeld (später Wuppertal) eine Station errichtet, die exemplarisch für die skizzierte Standardisierungs- und Konsolidierungsphase angesehen werden kann, da es sich bei ihr um eine der ersten großen Stationen 
Abbildung 21: Empfangsgebäude des Bahnhofs Elberfeld (um 1850).

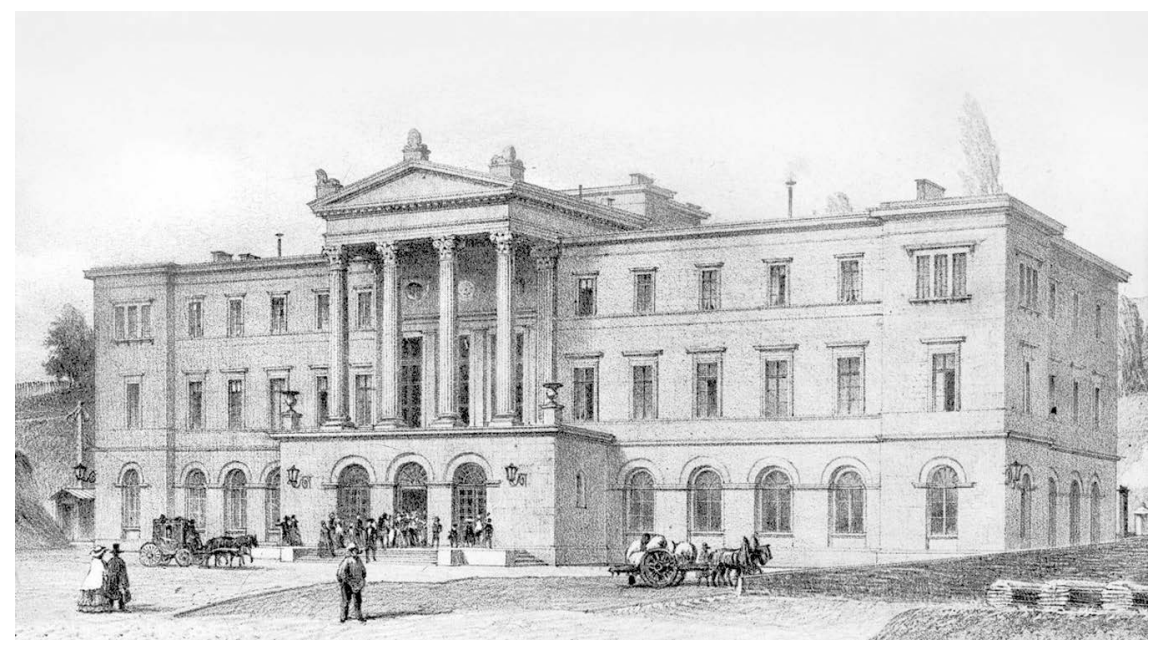

Quelle: Historisches Zentrum Wuppertal.

des deutschen Eisenbahnwesen handelt, die im Zuge ihrer Erweiterung eine bezüglich ihres Raumprogramms neue Generation von Stationen repräsentierte. Sie bildete neben dem Bahnhof in Dortmund einen der beiden Anfangs- und Endpunkte der BergischMärkischen Eisenbahngesellschaft und entsprach wie viele andere Stationen zu jener Zeit bereits nach wenigen Betriebsjahren nicht mehr der gewachsenen Verkehrsnachfrage. Im Zuge der daraufhin erforderlichen Modernisierung zeigten sich in Elberfeld die Charakteristika, die für den zweiten evolutionären Schritt des Baus von Empfangsgebäuden typisch waren, besonders deutlich. Dazu gehörte, dass die Grundrissdisposition von einem streng symmetrischen Raumprogramm beherrscht wurde, in dessen Mittelpunkt ein für damalige Verhältnisse großräumiges Vestibül stand, das als zentrale Verkehrs- und Zirkulationszone fungierte. Dem klassizistischen Vokabular jener Zeit folgend, wurden die Wartesäle im symmetrischen Grundriss zu beiden Seiten des Vestibüls eingerichtet, wobei dasselbe zugleich dazu diente, die Wartesäle der ersten und zweiten Klasse streng vom Wartesaal der dritten Wagenklasse abzusondern.

Mit Blick auf den Grundriss (Abbildung 22) wird deutlich, dass die Wartesäle nicht nur gegenüber der vorherigen Bahnhofsgeneration deutlich an Fläche gewonnen hatten, sondern sie trotz des Wachstums anderer Flächen auch innerhalb der zweiten Bahnhofsgeneration wiederum zur größten Raumgruppe reiften. Die Grundrissgestaltung des Neubaus von Elberfeld macht deutlich, dass am zuvor bestimmenden betrieblichen Prinzip eines stationären Warteimperativs nicht nur nahtlos angeschlossen wurde, sondern das Prinzip im Rahmen der zweiten Bahnhofsgeneration nochmals räumlich unterstrichen und verstärkt wurde.

Ferner lässt die Grundrissgestaltung darin vermuten, dass der Weg der Reisenden im Anschluss des Fahrtkartenerwerbs an der »Casse « und der Gepäckaufgabe in der Ein- 
gangshalle zunächst in die Wartesäle führte. Zwar bestand eine direkte Verbindung von der Eingangshalle zum "Perron", doch die Zentralität des wartebezogenen Raumprogramms weist darauf hin, dass die Reisenden zunächst in den Wartesälen Platz nahmen, bevor Sie den Bahnsteig betreten konnten. Zudem war die Bergisch-Märkische Eisenbahngesellschaft noch im Zuge ihres Streckenbaus im Jahr 1844 in den VDEV eingetreten, ${ }^{99}$ sodass sie sich dem allgemeinen Betriebsreglement der Mitgliedsbahnen anschloss, dass bezüglich der Abfahrtsorganisation wie bereits erwähnt ein zweifaches Glockensignal beinhaltete. Folglich kann auch hier davon ausgegangen werden, dass sich die Reisenden einem stationären Warteimperativ gegenübersahen, wonach die Wartesäle zunächst erst aufgesucht werden (mussten) bis das Glockensignal ertönte und erst daran angeschlossen der Bahnsteig bzw. die bereitstehenden Wagen bestiegen werden konnten.

Abbildung 22: Grundriss Bahnhof Elberfeld (um 1850).

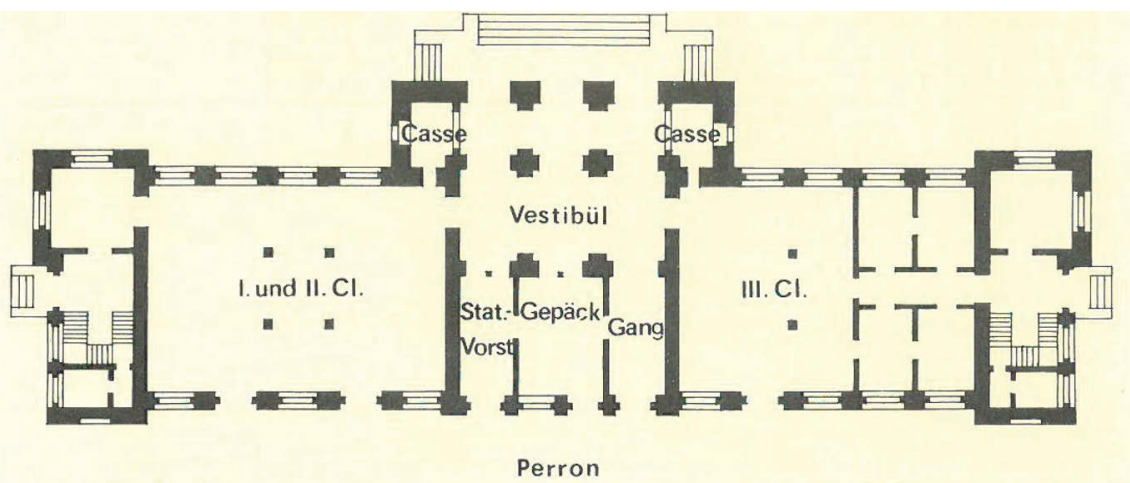

Quelle: Berger 1987, S. 125.

Die in Elberfeld etablierte Grundrissdisposition trägt damit bereits die Züge der erst einige Jahrzehnte später von Eberhard Wulff als >baulichen Organismus bezeichneten Programmatik (1882), die versuchte den Dreiklang von Hineinschleusung, (zwischenzeitlicher) Absorption und Weiterbeförderung möglichst zweckgemäß im Grundriss abzubilden. So stellt sich der Elberfelder Bahnhof mit Blick auf dessen Grundrissdisposition durchaus in den Dienst einer organischen Durchbildung, die das stationäre Warten explizit als eine der Grundbedingungen der effizienten Verkehrsorganisation erklärt. So stellt Wulff im Übertrag des menschlichen Verdauungssystems auf das System der Prozessierung von Passagieren durch das Bahnhofsgebäude fest:

»Die Haupteingangsthüre bildet den Mund, welcher in das Vestibul, die Mundhöhle, führt. Innerhalb letzterer befinden sich die einzelnen Organe, welche die Verarbeitung der einzelnen Consumtibilien (Personen, Gepäck, Depeschen) besorgen, um sie dann in die betreffenden Abtheilungen allzuführen. Den Hauptantheil erhalten die

99 Königliche Eisenbahndirektion zu Berlin, Festschrift über die Thätigkeit des Vereins Deutscher Eisenbahn-Verwaltungen in den ersten 50 Jahren seines Bestehens, 1846-1896, xii. 
Warteräume, die sich daher als Magen charakterisiren, der durch Magenwände in verschiedene Abtheilungen getheilt ist, während der Hauptcorridor die Speiseröhre repräsentiert. ${ }^{100}$

Zweifellos fanden sich auch in Elberfeld die Reisenden nach kurzer Zeit in einem solchen >Magen wieder. Neben Fahrkartenkauf und Gepäckaufgabe gehörte damit für den Fahrgast der Aufenthalt in diesen Räumen zur wichtigsten präparatorischen >Aufgabeく vor Antritt der Fahrt. Eingerahmt vom gewachsenen Selbstverständnis der Eisenbahngesellschaften, das sich architektonisch in einer repräsentativ-klassizistischen Gestaltung ausdrückte, wurde hier das systemische Warten zum obligatorischen Aspekt der Reiseerfahrung. Wenngleich die konkreten Ausstattungsmerkmale der gewachsenen Wartesäle nicht überliefert sind, so zeigt sich doch, dass das betriebliche Prinzip des temporären Aufenthalts im Zuge der Bahnhofsneubauten nicht eliminiert, sondern verstetigt und kultiviert wurde. Die Entdeckung des (verkehrlichen) Wartens, die bereits in der Frühphase für eine noch vergleichsweise kleine Anzahl von Reisenden erfahrbar wurde, fand damit im Zuge der allgemeinen Verkehrszunahme seitens der Passagiere eine endgültige Verankerung.

Interessant ist das Beispiel Elberfeld jedoch noch in einer anderen Hinsicht. Zwar ist zweifelsohne die zentrale Stellung der Wartesäle im Grundriss auszumachen, jedoch (noch) nicht die für diese Phase ebenfalls typische Kompensation des organisatorischen Zwangs durch die Einrichtung von Restaurationen. So ist im überlieferten Grundriss kein separater Speisesaal zu erkennen, auch nicht die Minimalvariante eines Büffets oder Schanktisches. Eine Fotografie aus der Mitte des 20. Jahrhunderts (Abbildung 23), die den Wartesaal dritter Klasse zeigt, verdeutlicht bei näherer Betrachtung vielmehr, dass die gastronomischen Einrichtungen an der Wand des Saales erst zu einem weit späteren Zeitpunkt eingerichtet worden sind und im Ursprungsstadium noch nicht vorhanden waren. ${ }^{101}$ Die so typische Kulinarisierung des Wartens war zum Beginn der zweiten Bahnhofsgeneration somit noch nicht flächendeckend ausgeprägt und wurde anfangs wahrscheinlich noch durch außerhalb des Bahnhofs liegende Gasthäuser abgedeckt. Der Grund für das Fehlen von Restaurationen könnte ferner darin gelegen haben, dass Konzeption und Bauzeit des Bahnhofes in Elberfeld zeitlich vor der Veröffentlichung der Grundzüge für die Gestaltung der Eisenbahnen Deutschlands (1850) lagen, in denen die Einrichtung von Versorgungsmöglichkeiten fest verankert worden war.

100 Wulff, Das Eisenbahn-Empfangs-Cebäude nach seinen praktischen Anforderungen und seiner künstlerischen Bedeutung, 19.

101 Abgesehen von Materialität und Form des Schanktisches wird mit Anblick des Fensters auf der linken Seite deutlich, dass die Aufbauten erst aus wesentlich späterer Zeit stammen, weil die Fensterflächen im Ursprungsstadium kaum denkbar derart verdeckt gewesen sein dürften. 
Abbildung 23: Innenansicht des Wartesaals 3. Klasse im Hauptbahnhof Wuppertal (ehemals Elberfeld), um 1960.

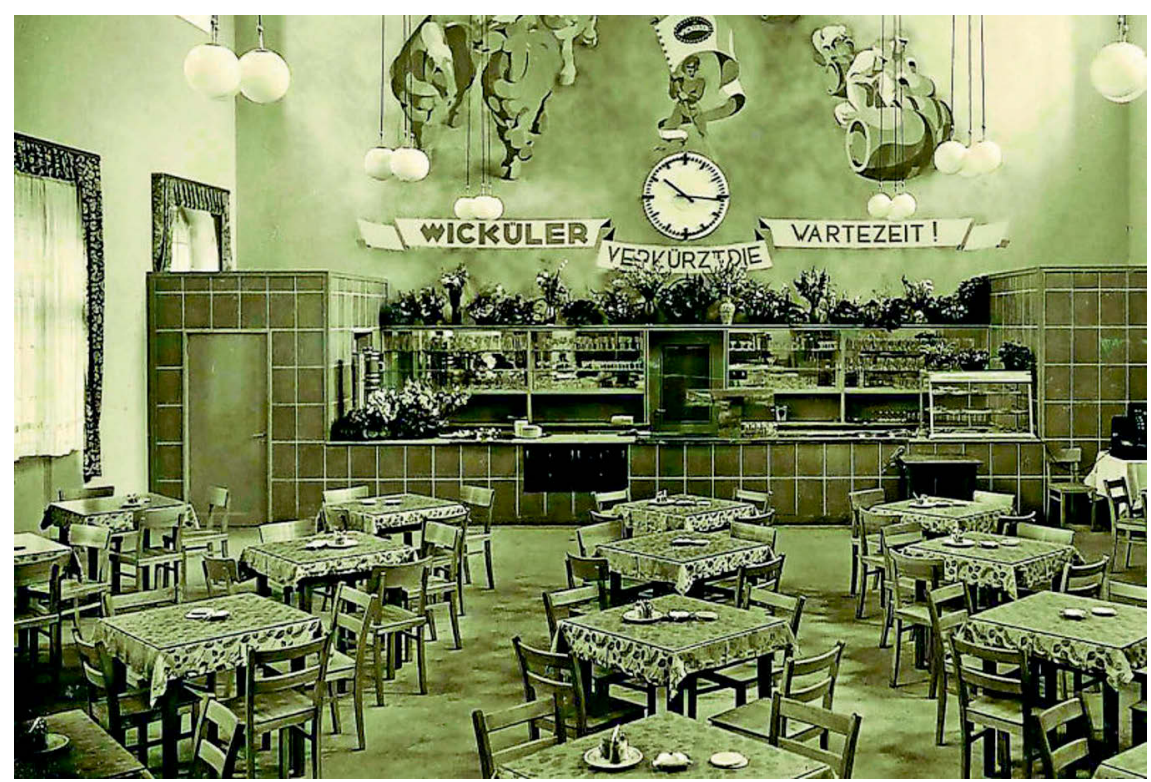

Quelle: Privatbestand Rita Mattke.

\subsubsection{Berlin - Görlitzer Bahnhof (1866)}

Die 1860er Jahre markierten in Berlin den Beginn einer massiven Planungs- und Bauperiode, die zum Ziel hatte, der preußischen Hauptstadt (ab 1871 Reichshauptstadt) eine >zweite Generation von Bahnhöfen zu bescheren, die nicht zuletzt den gewachsenen Status der Stadt im nationalen und internationalen Kontext repräsentieren sollte. Bis 1880 wurden dazu sieben große Endbahnhöfe geschaffen, die teils ältere Vorgängerbauten ersetzten oder die Start- und Zielbahnhöfe gänzlich neu trassierter Strecken bildeten. $^{102}$

$\mathrm{Zu}$ einem der ersten realisierten Bahnhöfe gehörte der Görlitzer Bahnhof in der südwestlichen Innenstadt Berlins, der im Auftrag der privatwirtschaftlich organisierten >Berlin-Görlitzer-Eisenbahngesellschaft‘ zwischen 1866 und 1868 durch den Architekten August Orth erbaut wurde. Die Station markierte den Anfangs- und Endpunkt der vergleichsweise spät erbauten Hauptstrecke zwischen Berlin und Görlitz (1865), die aufgrund ihrer Kriegsrelevanz im Rahmen des >Deutschen Krieges` (1866) bis 1867 einen beschleunigten Ausbau erfuhr. Von militärischer wie wirtschaftlicher Bedeutung war der Streckenbau insbesondere deshalb, weil mit ihm die Reisedauer nach Wien bedeutend verkürzt werden konnte.

102 Vgl. Krings, »Bahnhofsarchitektur: deutsche Großstadtbahnhöfe des Historismus«, 53ff. 
Abbildung 24: Görlitzer Bahnhof zur Zeit seiner Eröffnung (um 1868).

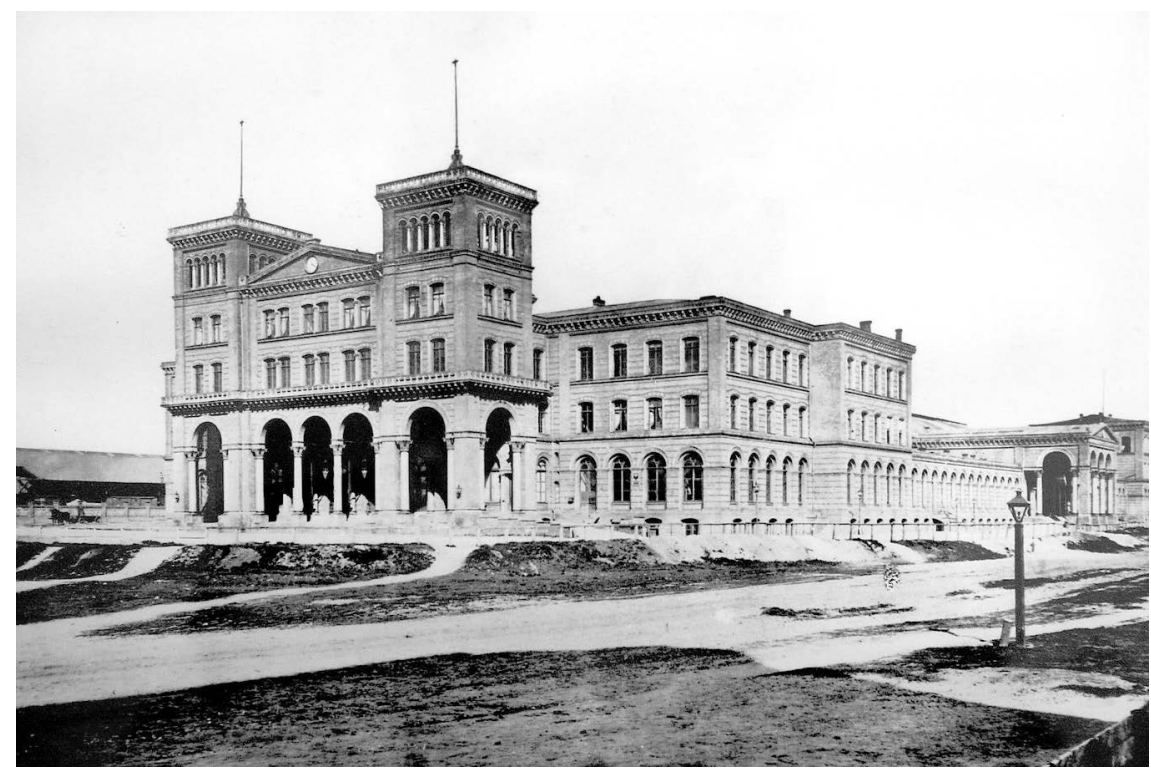

Quelle: Eisenbahnmuseum Bochum-Dahlhausen.

Der Görlitzer Bahnhof wurde als zweitseitige Anlage errichtet, die mit einem viergeschossigen Kopfbau mit Doppelturmfassade abschloss. Der Kopfbau fungierte jedoch nicht als zentraler Eingangsbereich, sondern beherbergte lediglich die Büros der Bahnverwaltung, die Post und diente bei Bedarf als separierter Warteraum für den Königlichen Hof. Die Hauptzirkulation der Reisenden - und damit der geschilderten >Normalform < entsprechend - erfolgte dagegen über parallel zu den Gleisen errichtete Seitenflügel. Dazu wurde auf der südlichen Abfahrtsseite ein eingeschossiges Gebäude in "Ziegelbauweise von hellen Verblendsteinen mit farbigen Thonplatten, Gesimsen und Formsteinen errichtet. ${ }^{103}$ Das in seiner Mitte von einem Risalit mit RundbogenPortikus und einem dreigeschossigen Pavillon abgeschlossene Empfangsgebäude beherbergte Wartesäle, Flure, Fahrkarten- und Gepäckabfertigung und war - wie auch die Bahnsteighalle selbst - 3m über dem Niveau der Zufahrtsstraße untergebracht, um den angrenzenden Landwehrkanal in ausreichender Höhe überqueren zu können. Den Geländeunterschied vermittelte dabei eine dem Hauptvestibül vorgelagerte Rampe, die als Säulenhalle ausgeführt wurde. Das Souterrain beherbergte zudem Wohnungen »für das niedere Beamtenpersonal ${ }^{104}$.

Ohne sich in der Fülle architektonisch-baulicher Details zu verlieren, sollen im Folgenden konkret die wartebezogene Raumdisposition und die Erweiterung des Service-

103 Königlich Preussisches Ministerium für Öffentliche Arbeiten, Berlin und seine Eisenbahnen 1846$1896,260$.

104 »Verein für Eisenbahnkunde zu Berlin. Protocoll der Versammlung vom 10. November 1866«, Zeitschrift für Bauwesen XVII. (1867): 289. 
angebotes beleuchtet werden. Sie erscheinen im Kontext dieser Arbeit besonders deshalb relevant, weil mit Planung und Bau des Görlitzer Bahnhofs proklamiert wurde, dass dieses Bahnhofsgebäude »in seiner Raumdisposition dem modernen Bedürfniss Rechnung getragen und dazu wesentlich beigetragen hat, einen grösseren Maasstab für derartige Aufgaben ${ }^{105} \mathrm{zu}$ schaffen. Zwar stammt diese lobpreisende Einschätzung aus der Feder des Architekten August Orth selbst, dennoch zeigt diese für den deutschen Kontext besonders großräumige Weiterentwicklung des Bahnhofsbaus mögliche Kontinuitäten und Veränderungslinien des wartebezogenen Umgangs mit Passagieren auf, die auch für andere folgende Bahnhofsprojekte richtungsweisend geworden sein dürften.

Abbildung 25: Grundriss des Görlitzer Bahnhofs in Berlin.

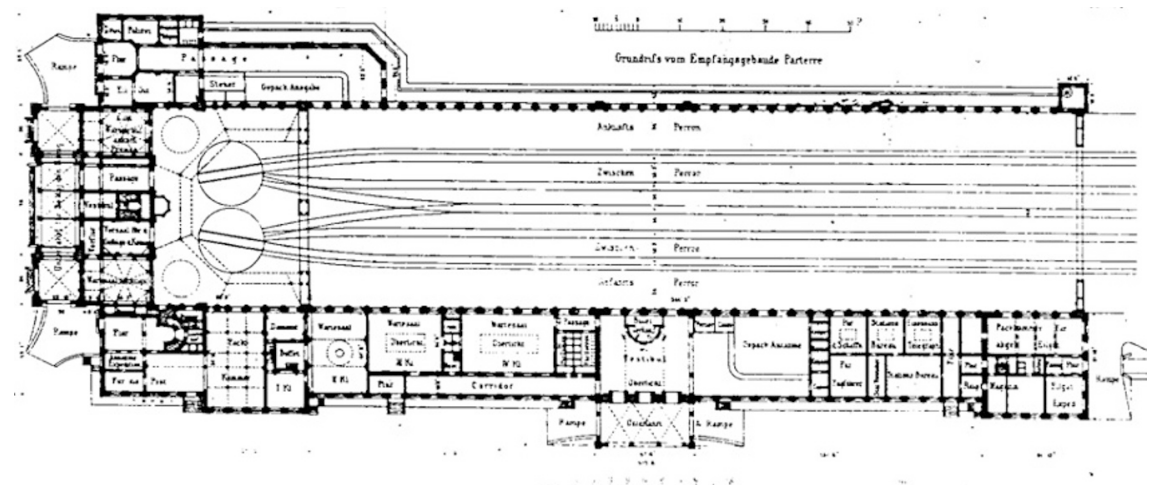

Quelle: Zeitschrift für Bauwesen, 1872, XXII. Blatt 63.

Am Görlitzer Bahnhof angelangt erreichten die Reisenden vom Hauptflur des Eingangsvestibüls aus zunächst die drei in der Tiefe der Eingangshalle eingerichteten Fahrkartenschalter von denen einer fest für Reisende erster und zweiter Klasse reserviert war. Sie durchquerten anschließend das Vestibül zu einer geräumigen Halle, in der sie ihr Gepäck aufgaben, bevor sie auf der gegenüberliegenden Seite des Vestibüls einen stattlichen 34 Meter langen und ca. 3,50m breiten asphaltierten Korridor in Richtung der vier klassenspezifisch getrennten Wartesäle betraten.

Mit dieser kurzen Rekonstruktion der Wegeführung, die auch mittels des Grundrisses (Abbildung 25) nachvollzogen werden kann, wird deutlich, dass die Reisenden in der von Orth beschriebenen >modernen Raumdisposition dieses wegweisenden Vertreters der szweiten Bahnhofsgeneration a auf dem Weg zum Abfahrtsgleis nach wie vor die Wartesäle nutzten oder sie zumindest durchschritten. Zwar bestanden auch hier wie in Elberfeld zwei Türverbindungen, die den Strom der Reisenden direkt von der Eingangshalle auf den Bahnsteig vermitteln konnten, doch angesichts der massiven Größe

105 August Orth, »Der Bahnhof der Berlin-Görlitzer Eisenbahn zu Berlin«, Zeitschrift für Bauwesen XXII., Nr. 1-3 (1872): 552. 
der Wartesäle und ihrer nur dort nutzbaren Serviceeinrichtungen (Restaurant, Büffet) ist auch für das Berliner Beispiel davon auszugehen, dass die Reisenden vor Abfahrt zunächst den Weg über die Wartesäle genommen haben dürften bzw. sie auf Grundlage des VDEV-Vereinsreglements auch dazu angehalten waren. Wie im Beispiel des Elberfelder Bahnhofs blieb die innere Organisation der Raumfolgen somit auch zwei Jahrzehnte später stark auf eine zwischenzeitliche (Zwangs-)Unterbringung der Passagiere bezogen. Mit anderen Worten: Der stationäre Warteimperativ wird im Zuge des allgemeinen Verkehrswachstums und gewachsener Betriebserfahrungen nicht etwa aufgelöst, sondern wird weiter verstetigt und etabliert bzw. im Zuge der Einrichtungen von Bahnhofsrestaurationen regelrecht auch >kultiviert<. Der Görlitzer Bahnhof verfügte über zwei Büffets, die zum einen zwischen dem Wartesaal vierter und dritter Klasse und zum anderen zwischen dem Wartesaal erster und zweiter Klasse eingerichtet wurde. Im Vergleich zu Elberfeld verfügte der Görlitzer Bahnhof damit bereits über das für die zweite Hälfte des 19. Jahrhunderts so charakteristisch stark erweiterte Dienstleistungs- und Versorgungsangebot.

Bezüglich einer weiteren Rekonstruktion der betrieblichen und baulichen Rahmung des Wartens im ersten Berliner Großbahnhof kann darüber hinaus festgehalten werden, dass die Reisenden vom Vestibül kommend den langen Korridor in absteigender Reihenfolge verließen: zunächst Reisende vierter Klasse, dann jene dritter, zweiter und erster Klasse. Housselle kommentiert hinsichtlich dieser Reihenfolge im Görlitzer Bahnhof, dass diese »da, wo der Zutritt zu den Wartesälen Jedermann freisteht, beibehalten werden muss «, sie jedoch »den Nachteil [hat], dass die Passagiere II. und I. Klasse oft einen ziemlich weiten Weg nach ihren Wartesälen zurückzulegen haben. « ${ }^{106}$ Aus dieser Aussage geht indirekt hervor, dass im preußisch-deutschen Kontext der 1860er und 1870er Jahre an den Wartesälen angelangt die Fahrkarte nicht bereits am Eingang der Wartesäle kontrolliert wurde. Somit konnten auch Begleitpersonen ohne eigentlichen Fahrtwunsch die Wartesäle betreten. Der Görlitzer Bahnhof war somit quasi ein öffentlicher Ort. ${ }^{107}$

Um die Reisenden vor Abfahrt nach Görlitz oder Wien aufzunehmen, verfügte der Wartesaal vierter Klasse über eine Fläche von $174 \mathrm{~m}^{2}$, jener dritter Klasse über $140 \mathrm{~m}^{2}$ und die Wartesäle zweiter und erster Klasse über 146 bzw. $38 \mathrm{~m}^{2}$. Zudem war dem Wartesaal zweiter Klasse ein ca. $30 \mathrm{~m}^{2}$ großes Damenzimmer angeschlossen. Die Beleuchtung dieser Säle erfolgte über zentral in der Raummitte platzierte Oberlichter. Anders als die Wartesäle dritter und vierter Klasse, die »Holzdecken mit sichtbarer Konstruktion und eine einfache dekorative Ausbildung erhalten ${ }^{108}$ hatten, wurden die Wartesäle zweiter und erster Klasse wesentlich aufwendiger dekoriert. Die als würdevolles Warten umschriebene Charakteristik des situativen Aufenthalts jener Entwicklungsphase kommt hier vollends zur Geltung. Alle Wartesäle verfügten zudem durch Fenster- und Türöffnungen über eine direkte (Sicht-)beziehung zum Gleis bzw. zum Zug, was aus

106 Housselle, »Ueber Kopfstationen«, 3.

107 In Österreich wurde dagegen etwa die Fahrtkarte direkt beim Betreten der Wartesäle kontrolliert, sodass es Begleitpersonen bis zur unmittelbaren Abfahrt des Zuges nicht möglich war, in der Nähe der Reisenden zu bleiben, es sei denn sie zahlten eine zusätzliche >Bahnsteigkarteく.

108 »Der Bahnhof der Berlin - Cörlitzer Eisenbahn in Berlin«, Wochenblatt des Architekten-Vereins zu Berlin 1, Nr. 45 (1867): 434. 
psychologischer Perspektive einen essentiellen Faktor für die Minderung des Nervositätsgrades während des Wartens darstellte.

Weiterhin dürfte psychologisch begünstigend gewirkt haben, dass der Görlitzer Bahnhof im Vergleich zu den anderen Berliner Bahnhöfen zu den weniger verkehrsstarken Abfahrts- und Ankunftsorten zählte. Die Zahl der an diesem Bahnhof abreisenden und ankommenden Reisenden bezifferte sich im Verkehrsjahr 1873 >nur auf ca. 367.500 Personen wohingegen den Potsdamer Bahnhof im gleichen Verkehrsjahr bereits 2,23 Millionen Reisende durchströmten. ${ }^{109}$ In den Anfangsjahren fuhren am Görlitzer Bahnhof täglich nur sechs Personenzüge, ${ }^{110}$ sodass im Tagesdurchschnitt ca. 1.000 Personen abgefertigt werden mussten. In Abhängigkeit der Jahres- und Tageszeit dürften sich demnach pro Zug 100 bis 200 Reisende im Bahnhof befunden haben. Trotz der zusätzlichen Anwesenheit von Begleitpersonen, die den Reisenden dabei halfen das Gepäck zu tragen ${ }^{111}$ oder vor einer damals noch als aufregend empfundenen Reise und begrenzter Kommunikationsmöglichkeiten in der Ferne so lang wie möglich in der Nähe ihrer Angehörigen bleiben wollten, dürften die Wartesäle im Görlitzer Bahnhof daher in dessen Anfangszeit wohl nur im Bereich der dritten und vierten Wagenklasse zu Orten großer Menschenansammlungen avanciert sein.

Mit Rückgriff auf die statistischen Nachrichten für den Bahnverkehr in Preußen verteilte sich die Benutzung verschiedener Wagenklassen 1871 anteilig wie folgt:

- I. Klasse: $1,7 \%$

- II. Klasse: $17 \%$

- III. Klasse: $52 \%$

- IV. Klasse: $34 \%{ }^{112}$

Geht man nun beispielhaft von einer durchschnittlich errechneten Fahrgastzahl von 167 Reisenden pro Zug im Verkehrsjahr 1873 aus, ${ }^{113}$ so verteilte sich die Nutzung der Wartesäle im Görlitzer Bahnhof der Anfangsjahre ca. ungefähr wie folgt: erste Klasse (3 Pers.), zweite Klasse (28 Pers.), dritte Klasse (86 Pers.), vierte Klasse (56 Pers.). Daraus ergibt sich, dass Reisende dritter Klasse vermutlich am stärksten die Erfahrung beengter Raumverhältnisse gemacht haben dürften, da dieser Saal mit einer Fläche von $140 \mathrm{~m}^{2}$ zwar der zweitgrößte war, jedoch verhältnismäßig viele Reisende aufnehmen musste. Die Nutzergruppe, die am ersten Berliner Großbahnhof den betrieblichen Zwang des Wartens damit am deutlichsten als >beengt` erfahren haben dürfte, waren folglich mittelbürgerliche Bevölkerungsschichten, die typischerweise die dritte Klasse nutzten. Dazu zählten »Angestellte, kleinere Geschäftsleute, Handwerker und Soldaten,

109 »Verein für Eisenbahnkunde zu Berlin. Protocoll der Versammlung vom 10. November 1874«, Zeitschrift für Bauwesen XXV. (1875): $282 \mathrm{f}$.

110 Hermann Schwabe, Ueber das englische Eisenbahnwesen (Berlin: Ernst \& Korn, 1871), 27.

111 Insbesondere Reisende der 4.Klasse nahmen offensichtlich große Mengen Handgepäck mit auf die Reise und trugen es entsprechend vor Abfahrt zunächst in die Wartesäle hinein: »Der Bahnhof der Berlin - Görlitzer Eisenbahn in Berlin«, 434.

112 »Verein für Eisenbahnkunde zu Berlin. Protocoll der Versammlungen am 11. März 1873.«, Zeitschrift für Bauwesen XXIII. (1873): 532.

113 1873: 367.500 Reisende geteilt durch 365 Tage, geteilt durch sechs Verbindungen/Tag. 
also diejenigen, die weder arm noch reich waren ${ }^{114}$ Dagegen wartete die mengenmäßig marginale Nutzergruppe des wohlhabenden Bürgertums in vergleichsweise überdimensionierten Räumlichkeiten, auch weil die Anteile der Klassennutzung der ersten und zweiten Klasse seit den frühen 1860er doch insgesamt »ziemlich constant geblieben ${ }^{115}$ waren.

\section{Abschluss: Exemplarische Bahnhofsbeispiele der Wachstums- und Standardisierungsphase}

In der Betrachtung des Raumprogramms der beiden vorgestellten, exemplarischen Beispiele des Bahnhofsbaus in der Wachstumsphase des Eisenbahnwesens lässt sich zusammenfassend festhalten, dass sich mit dem Bau von neuen Bahnhofsgebäuden zwischen den späten 1840er und 1860er Jahren abzeichnete, dass sich der stationäre Warteimperativ nicht nur eine Verstetigung, sondern vielmehr einen massiven Ausbau erfuhr. Innerhalb einer sich grundsätzlich vergrößernden Bahnhofsfläche treten nunmehr Zirkulationsräume (Vestibüle, Korridore) und Räume des temporären Festhaltens stärker auseinander. Dennoch wird - repräsentiert durch Flächen- und Ausstattungswachstum der Wartesäle - dabei insgesamt an der betrieblich erforderlich gehaltenen Funktion des Zwischenaufenthalts der Reisenden festgehalten und damit die Zentralität des Wartens innerhalb des Betriebsablaufs und innerhalb der Reiseerfahrung nochmals unterstrichen. Während in einigen Beispielen der Frühphase der stationäre Warteimperativ noch punktuell weniger deutlich ausgelegt worden sein mag, kommt er nun spätestens zu Mitte des 19. Jahrhunderts zur vollen Blüte. Flankiert wurde diese Entwicklung mit dem Aufbau kompensatorischer Service- und Dienstleistungseinrichtungen, die sich im Grundriss in Form der Einrichtung von Büffets und Restaurationen niederschlugen. Wenngleich sie um 1850 noch nicht vorhanden waren, gehören sie spätestens seit den späten 1860er Jahren zum festen Raumprogramm der Verkehrsbauwerke, die damit das Warten in den Stand eines würdevollen Aufenthalts rücken.

Mit Blick auf die beiden skizzierten Bahnhofsbeispiele der Konsolidierungsphase wird zudem deutlich, wie sich im Zuge des Aufstiegs der Eisenbahn zum Massenverkehrsmittel innerhalb der Organisation der Verkehrsbauten ein Prinzip verfestigte, das im Grunde auch der Organisation heutiger Flughäfen gleicht. Ob im Görlitzer Bahnhof im Jahr 1868 oder im Berliner Flughafen BER des frühen 21. Jahrhunderts; der Reisende kann das Verkehrsmittel nicht direkt besteigen, sondern ist in der Regel dazu verpflichtet, sich zunächst für eine mehr oder lange Zeitspanne im Zwischen- und Transitraum von Sicherheitskontrollen und Flugsteigen aufzuhalten. Grund ist hierbei wiederum die organisations- und kontrollintensive Synchronisation großer Passagierströme mit dem Verkehrsmittel, die in der (intendierten) Entstehung zeitlicher Pufferzonen resultieren. Die Mitte des 19. Jahrhunderts markiert damit zwar nicht die Geburtsstunde, aber doch den Ausbau und die Etablierung eines bereits zuvor entstandenen Prinzips der Abfahrtsorganisation, das in (öffentlichen) Verkehrskontexten bis in die Gegenwart hinein zu einem zentralen Bestandteil der Reiseerfahrung gehört. Während - wie sich noch zeigen wird - das Prinzip des situativen Festhaltens im Bahnwesen seit Anfang des

114 Roth, Das Jahrhundert der Eisenbahn: die Herrschaft über Raum und Zeit 1800-1914, 136.

115 »Verein für Eisenbahnkunde zu Berlin. Protocoll der Versammlungen am 11. März 1873.«, 532. 
20. Jahrhunderts allmählich aufzulösen begann, wird das Prinzip im öffentlichen Flugverkehr nach wie vor ungebrochen praktiziert und erfährt aktuell durch immer weiter steigende Sicherheits- und Kontrollansprüche im Kontext des internationalen Terrorismus oder weltweiter Pandemiephänomene (jüngst Corona) sogar noch zunehmend an Bedeutung. ${ }^{116}$

\subsection{Rezeptionsgeschichte des verkehrlichen Wartens (1845-1870)}

Im Sinne des zweiten Analysestrangs dieser Arbeit sollen nun die literarisch-künstlerischen Niederschläge rekonstruiert werden, die die Rückschlüsse auf die Rezeptionen, Erfahrungen und Praktiken des Wartens jener Zeit liefern könnten. Dazu wurde eine Vielzahl literarischer und bildkünstlerischer Quellen zum Eisenbahnwesen hinsichtlich möglicher direkter oder indirekter Aussagen zum Temporalphänomen des Wartens untersucht. Den Korpus bildeten dutzende Anthologien, Sammelwerke und Monografien der betreffenden Zeitspanne, die sich in mit dem Motiv der Eisenbahn befassten. Der Fokus lag dabei auf sprachlichen und forschungspragmatischen Gründen vorwiegend aus dem deutschsprachigen - und seiner eisenbahntechnischen Pionierrolle entsprechend - dem englischsprachigen Raum. Trotz eines umfangreichen Korpus kann für diese Analyse kein Anspruch auf Vollständigkeit geltend gemacht werden.

Das jeweilige Extrakt relevanter Befunde wird im Folgenden entlang der Unterteilung von Lyrik, Prosa (Reisehandbücher, Romane, Unterhaltungsliteratur, Essays), Liedern sowie Zeichnungen aufbereitet.

\subsubsection{Lyrik}

Wie schon für die Pionierphase der Eisenbahnen scheint das Feld der Lyrik auch in der anschließenden Phase zunächst wenig ertragreich für die Rekonstruktion möglicher Niederschläge der Warteerfahrung zu sein. So attestierte Kistenmacher den 1850er bis 1880er Jahren übergeordnet, dass »in dieser Zeit die Ernte für den, der ausgeht Eisenbahn- und Fabriklyrik zu suchen, nur gering [ist].« ${ }^{117}$ Den Grund sah Kistenmacher in einer allgemeinen Beruhigung der Verarbeitung des Eisenbahnmotivs und in einer neu herangewachsenen Generation, die »nicht mehr die persönliche Fühlung mit den Ideen [hatten], die die Gemüter von 1830-1848 so erregte. ${ }^{118}$ Gegenüber der aufgeregten Anfangszeit der Eisenbahnen sollte die Lyrik in den darauffolgenden drei Jahrzehnten das Thema also weit weniger bearbeiten. Stattdessen war die deutsche Dichtung jener Zeit - maßgeblich beeinflusst von der >Münchner Schuleく um Lingg, Geibel oder Greif - aus literaturhistorischer Sicht wieder stärker durch das Abrücken von der realen Gegenwart geprägt.

116 Vgl. Menno Hubregtse, Wayfinding, consumption, and air terminal design (New York: Routledge, 2020).

117 Kistenmacher, Maschine und Dichtung: ein Beitrag zur Ceschichte der deutschen Literatur im 19. Jahrhundert, 64.

118 Ebd. 
In der Tat zeigte die Analyse, dass die wartezeitspezifischen Niederschläge jener Zeit sehr geringfügig sind, doch wird mit dem 1852 entstandenen und 1878 publizierten Gedicht Schienenweg von Gustav Mühl (1819-1880) zumindest in Ansätzen ein Zugang zur Rekonstruktion der zeitgenössischen Warteerfahrung ermöglicht. Gustav Mühl, ein elsässischer Dichter und Bibliothekar, entwirft in jenem Gedicht als einer der wenigen Dichter zur Mitte des 19. Jahrhunderts eine Szene vor Abfahrt des Dampfzuges, die auch explizit auf das Verhalten der Reisenden und ihrer räumlichen Umgebung eingeht.

»Und schon drängt sich das Volk im hohen, geräumigen Saale,

Wogend in Ungeduld mit laut ertosenden Stimmen;

Fordernd fliegen die Blicke zur Bahn. Sie aber, dort drüben

Vor den verschlossenen Pforten, stumm lieget sie noch und einsam,

Wie ein verzauberter Weg, der nimmer für menschliche Tritte;

Traun, fast möchte sie scheinen ein Weg für mächt'gere Geister! -

Jetzt, in der Nähe, horch! Erdröhnet so schrilles Cewieher,

Wie von riesigen Rossen, in jauchzendem Uebermüthen

Schlägt's wild gellend empor, erfüllend die weitesten Räume,

Und mit jähem Ceschrei aufhallet erschrocken das Echo.

Freudig vernimmt das Volk das Zeichen baldigen Aufbruchs,

Drängt sich hin zu den Pforten, zu schau'n das erwachende Dampfross. (...) « ${ }^{119}$

Mühls lebendige Szene zielt zwar in erster Linie darauf ab, die in den 1850er Jahren noch immer neue und aufregende Dampfkraft zu mystifizieren. Sie gibt aber zugleich Hinweise auf eine zu jener Zeit praktizierte Abfahrtsorganisation und die Orte des Wartens. Mit dem geräumigen Saal, in dem sich das Volk zusammendrängt, kann hier natürlich nur der Wartesaal gemeint sein. Interessant ist hierbei aber vor allem der Umstand, dass dieser Wartesaal offenbar bis kurz vor Abfahrt verschlossen bleibt und der Bahnsteig dadurch nicht frei zugänglich ist. Diese Unzugänglichkeit verstärkt hierbei offenbar noch die Erhabenheit der neuen Technologie. Die zum Bahnsteig ausgerichteten Fenster und Türen des Wartesaals ermöglichen die einzigen Beobachtungsmöglichkeiten des Erwartungsobjekts, das sich in der Exklusivität des Gleisbettes und der angeschlossenen Bahnsteige befindet. Der Wartesaal wird hier also abermals als Ort aufgeregter Erwartung und keineswegs als ein Ort der Monotonie oder Langeweile inszeniert. Wie bereits bei Hans-Christian Andersens Schilderung seines Erstkontakts mit der Eisenbahn (1840), dürfte das stationäre Warten im Saal also auch mehr als ein Jahrzehnt später noch immer als Katalysator einer aufgeregten Erwartungshaltung fungiert haben. Entsprechend dieser aufgeregten Erwartung und den fordernden Blicken durch die Scheiben des Wartesaals, vernimmt das Volk freudig das (Glocken-)Zeichen des baldigen Aufbruchs und erfährt dieses als erlösendes Signal.

Zwar ist Mühls Gedicht ein fiktionales Werk, aber die Rezeption des Gedichtes konnte vermutlich deshalb so wirksam erscheinen, weil sie in etwa der Realität und der tatsächlichen Abfahrtsorganisation in den 1850er Jahren entsprach. Somit kann Mühls

119 Auszug aus Gustav Mühls Gedicht Schienenweg, erschienen im Cedichtband Aus dem Elsaß (Straßburg: Karl ]. Trübner, 1878) [Hervorhebung des Verfassers, R.K.]. 
Gedicht als ein wichtiges Indiz für die oben herausgearbeitete Etablierung und Verstetigung eines stationären Warteimperativs herangezogen werden, die den betrieblichen Standard jener Zeit ausmachte. Den Reisenden war es demnach auch im (südwest-) deutschen Eisenbahnkontext nicht möglich, sich frei auf dem Bahnsteig zu bewegen und sich - anders als in England - vor Abfahrt mit der Technologie vertraut zu machen. Wenngleich die Warteerfahrung grundlegend von aufgeregter Vorfreude geprägt war, so stellt sich die allgemeine Warteerfahrung - unter Annahme einer an realen Zuständen orientierten Gedichthandlung - zugleich als eine stark formalisierte und beengte Massenerfahrung dar.

\subsubsection{Prosa}

\section{Reisehandbücher}

$\mathrm{Zu}$ den wenigen für das Wartephänomen aufschlussreichen Werken im Feld der Reiseliteratur gehört zweifellos Georg Weerths humoristische Abhandlung der Skizzen aus dem sozialen und politischen Leben der Briten (1846). Der >Vormärzliterat< Weerth (1822-1856) war einer der ersten deutschen Schriftsteller, der sich zu den ökonomischen Verhältnissen seiner Zeit äußerte und insbesondere die Fehlentwicklungen der kapitalistischen Gesellschaft zu beschreiben versuchte. Er lebte Anfang der 1840er Jahre für einige Zeit im nordenglischen Bradford, wo als er Korrespondent eines Wollunternehmens tätig war und in dieser Zeit auch Marx und Engels kennenlernte. Weerths dortige Erfahrungen wurden als >Englandberichte in der Kölnischen Zeitung in Form unterhaltender und zugleich kritischer Reiseberichte veröffentlicht. Im Rahmen dieser (politischen) Reiseberichte spielt sich eine seiner vielfältigen Beobachtungen auf dem >Birminghamer Bahnhof ${ }^{120}$ in London ab. Sie soll hier deshalb herausgegriffen werden, weil in ihr nichts Geringeres als die vielleicht erste direkte Thematisierung der besonderen Situation des verkehrlichen Wartens innerhalb der deutschen Prosa ausgemacht werden kann.

»Bei einem Teller Schildkrötensuppe ${ }^{121}$ wartete ich in dem Stationssaale auf die Abfahrt des nächsten Eisenbahnzuges. Kalt wandelten die Menschen an mir vorüber und fragten nicht nach meinem Schmerz - ich auch nicht nach dem ihrigen. Übrigens wäre es sehr hübsch, wenn man auf den Eisenbahnstationen einen großen Folianten mit weißem Papier aufschlüge. Die Reisenden, welche auf die Abfahrt der Lokomotive warten, hätten dann Celegenheit, ihre Abschiedsempfindungen in Prosa und Versen niederzuschreiben. Welche Blicke in das menschliche Leben würde ein solcher Foliant eröffnen! Da würde man eine rührende Hymne auf ein Wirtshaus finden, wo man niederträchtig geprellt wurde. Da sähe man einen liebenden Nachruf an ein paar Dutzend unbefriedigte Gläubiger. Ein Dritter würde das schöne Fräulein zu schildern su-

120 Wahrscheinlich war hier die Londoner Euston Station gemeint.

121 Was aus heutiger Sicht exotisch anmuten mag, war seit dem 18. Jahrhundert eine beliebte wie weitverbreite Speise der englischen Küche. Hauptbestandteil war eine aus dem Fleisch der Suppenschildkröte zubereitete Brühe, die kräftig-pikant gewürzt wurde. Durch die verwandtschaftliche Nähe des englischen Königshauses zum Hannoveraner Königshaus wurde die Schildkrötensuppe auch in leicht veränderter Variante ein Teil der niedersächsischen Landesküche. 
chen, das gern sich seiner angenommen, als er in London fremd spazierenging; und so würde ein jeder etwas zu erzählen haben, was der Welt zu Nutz und Frommen gereichen könnte. $\ll^{122}$

Weerth nimmt sich selbst im besonderen Zustand des Wartens wahr und beobachtet aus dieser Position heraus das Verhalten der anderen Mitreisenden. Dieser Umstand mag zwar trivial erscheinen, sein 1846 erschienener Bericht aber er kann als einer der ersten literarischen Niederschläge des noch jungen Massenphänomens gelten. Darin greift er nicht nur eine für die Wartesituation offenbar prägsame Reflektion des Vergangenen (Abschiedsempfindungen) auf, sondern vermittelt aus seiner besonderen Situation heraus zudem das Bild einer sozial indifferenten und abgestumpften Umwelt. Seine Idee eines für alle Passagiere zugänglichen Gästebuches (Foliant) zum Verfassen und Lesen persönlicher Abschiedsgeschichten sieht Weerth folglich als eine scherzhafte wie sinnvolle Maßnahme an, um die kalte Anonymität der Wartesituation wieder mit Wärme und Leben zu füllen, denn so fährt er im Anschluss fort:

»Heutzutage ist das Leben auf einer Station gar zu trostlos; hier bekommt jemand durch die Kälte seiner Umgebung einen Schnupfen; dort verbrennt sich ein anderer in der Eile des Abschieds an den Fluten einer Teetasse den Mund, und jauchzt endlich die Lokomotive ihr Abfahrtslied, da wälzt sich die Lawine von Menschen, Koffern, Regenschirmen und Nachtsäcken mit einer solchen Hast in die Wagen, daß ein »Coddam! « und ein Rippenstoß das einzige ist, was man von seinen geliebten Nebenmenschen genossen hat. ${ }^{123}$

Weerths Reisebericht vom Londoner Bahnhof stellt erstmalig die Wartesituation als einen Indikator gesellschaftlicher Zustände dar. Sein Aufenthalt auf der Station führt ihn zur Reflektion der durch den Kapitalismus erzeugten Verhältnisse, insbesondere der sozialen Indifferenz und einer von Eile und Hast geprägten englischen Gesellschaft. Der Bahnhof wird hiermit zum Brennglas. Er zeichnet ein Bild einer von Unruhe und Zeitökonomie geprägten Zuggesellschaft. Der trostlose Anblick der Station, den Weerth schildert, kann neben der Wahrnehmung einer allgemein irritierenden Unruhe kontextuell wohl aber nicht zuletzt auch damit erklärt werden, dass englische Stationen anders als in Deutschland oder Frankreich - traditionell in den Wartesälen jeglichen Komfort vermissen ließen.

Neben Weerths externen Beobachtungen widmete sich aber auch die englische Reiseratgeberliteratur selbst punktuell dem Phänomen des Wartens, insbesondere in Form des Zwischenaufenthalts an Umsteigebahnhöfen. Denn diese gehörten in England aufgrund der hohen Netzdichte und der dadurch entstandenen Kreuzungspunkte offenbar zu einer Standarderfahrung der Reise. So erteilte etwa The Railway Traveller's Handy Book von 1862 für den Moment des langen Wartens an einer Provinzstation die folgenden wertvollen Ratschläge:

122 Georg Weerth, Sämtliche Werke, Bd. 3: Skizzen aus dem sozialen und politischen Leben der Briten (Berlin: Aufbau Verlag, 1957), 111 [Hervorhebung des Verfassers, R.K.]. 
»It sometimes happens that a person has to wait the arrival of the train at the station of some little country town. Under such circumstances, time hangs most heavily, and an hour appears as long as a day. The amusements within reach are of the most meagre description. The two or three persons who wander in and out of the station may have no marked peculiarities, and they are but two or three after all. There may be a few cocks and hens in the adjacent poultry-yard, but they are probably lazy or replete, and their movements are of the most commonplace and uninteresting description. As to the town itself, the chances are that it has little worth seeing, and a peregrination of its utmost limits can be accomplished in ten minutes. To while away the time under such unpromising aspects is somewhat of an art. If a person has a book with him, he need look no further for recreation. If not, let him procure three or four sheets of writing paper, a pen, and a bottle of ink, bring them back to the waitingroom, and sit down to write two or three letters to as many friends. It is astonishing how quickly time flies with those who are using the pen. If the thoughts come with difficulty, then much time is consumed in bringing them to bear; if thoughts come readily, then the noting them down consumes time also. Another end is accomplished, since time is economized and put to a good use, which would be otherwise frittered away. $\ll^{124}$

Diese Empfehlungen zur Verhandlung von Wartezeiten bilden einen der wenigen direkten Niederschläge der Verhandlung verkehrlicher Wartzeiten in der Konsolidierungsphase des Eisenbahnwesens. Dass er ausgerechnet im englischen Umfeld entsteht, wundert dabei angesichts der auf stärkere Zeitökonomie ausgerichteten englischen Gesellschaft des Industriekapitalismus kaum. Entsprechend liegt das Ziel der propagierten Maßnahmen zum Verbringen der Wartezeit darin, sie nicht einfach vergehen $\mathrm{zu}$ lassen, sondern es wird dezidiert vorgeschlagen, sie möglichst zu ökonomisieren und sie - ganz im Sinne der protestantischen Arbeitsethik - nützlich zu gestalten. Erst vor dem Hintergrund des zeitsensiblen englischen Wirtschafts- und Alltagsumfelds konnte demnach der Umstand eines Zwischenaufenthalts überhaupt als ein eigenes Unterkapitel thematisiert und - wie aus der Empfehlung hervorgeht problematisiert werden.

\section{Romane}

Im Gegensatz zur rückläufigen Tendenz der Verarbeitung des Eisenbahnmotivs in der Lyrik, wurde die Eisenbahn zur Mitte des 19. Jahrhunderts im Zuge des literarischen Realismus verstärkt im Genre der Romane verhandelt. Kistenmacher vermerkt, dass der Roman »den Stoff der Gegenwart ergreifen kann«, wohingegen die Lyrik erst »eine gesättigte, verdichtete Atmosphäre, aus der sie ihre Stimmung schöpft. « ${ }^{125}$ Die Romane des 19. Jahrhunderts gelten daher aus Sicht der Literatur- und Geschichtsforschung als die vielleicht stärkste Gattung einer Auseinandersetzung mit aktuellen gesellschaftlichen Entwicklungen, aus denen man, nach Ansicht von Osterhammel, »ebensoviel über

124 The Railway Traveller's Handy Book, 132 [Hervorhebungen des Verfassers, R.K.].

125 Kistenmacher, Maschine und Dichtung: ein Beitrag zur Geschichte der deutschen Literatur im 19. Jahrhundert, 30 . 
Normen, Verhaltensweisen, Statusunterschiede und materielle Lebensverhältnisse erfährt, wie aus den Werken der Sozialwissenschaftler. « ${ }^{126}$ Angesichts ihrer wachsenden gesellschaftlichen Bedeutung, ihrer Materialität, ihrer lebensweltlichen Präsenz wundert es kaum, dass innerhalb der Romanhandlungen auch die Eisenbahn eine zunehmende Rolle spielen musste.

Doch trotz der Sichtung zahlreicher Eisenbahnromane lassen sich für die hier angestrebte Rekonstruktion der Warteerfahrung zur Mitte des 19. Jahrhunderts wiederum nur sehr wenige, wenngleich zentrale Werke herausstellen. Hierzu zählt ohne Zweifel Anthony Trollopes 1866 erschienener Roman The Belton Estate. Trollope (1815-1882) zählte $\mathrm{zu}$ einem der produktivsten und meistgelesenen Autoren der viktorianischen Zeit. Innerhalb seines umfangreichen Gesamtwerkes zählte The Belton Estate zwar nicht zu den literaturgeschichtlichen Wegmarken des Autors, gleichwohl stellt er aus Sicht der Kulturgeschichte des (verkehrlichen) Wartens einen Meilenstein dar. Grund für diese Einordnung ist, dass Trollope in einer Buchpassage seine Hauptfigur (Clara Amedroz) zum Auftakt einer Zugreise an einem Bahnhof im südwestenglischen Taunton für eine Stunde warten lässt und diese aus Sicht der Figur erlebte Situation im Detail schildert.

»That hour at the Taunton station was terrible to her. I know of no hours more terrible than those so passed. The minutes will not go away, and utterly fail in making good their claim to be called winged. A man walks up and down the platform, and in that way obtains something of the advantage of exercise; but a woman finds herself bound to sit still within the dreary dulness of the waiting-room. There are, perhaps, people who under such circumstances can read, but they are few in number. The mind altogether declines to be active, whereas the body is seized by a spirit of restlessness to which delay and tranquillity are loathsome. The advertisements on the walls are examined, the map of some new Eden is studied - some Eden in which an irregular pond and a church are surrounded by a multiplicity of regular villas and shrubs - till the student feels that no consideration of health or economy would induce him to live there. Then the porters come in and out, till each porter has made himself odious to the sight. Everything is hideous, dirty, and disagreeable; and the mind wanders away, to consider why station-masters do not more frequently commit suicide. Clara Amedroz had already got beyond this stage, and was beginning to think of herself rather than of the station-master, when at last there sounded, close to her ears, the bell of promise, and she knew that the train was at hand. $\ll^{127}$

Diese für die Gesamthandlung unscheinbare Passage kann als eine der ersten direkten literarischen Verhandlungen des verkehrlichen Wartens auf Eisenbahnen im englischen Literaturkontext verstanden werden, die innerhalb einer Romanhandlung zutage tritt. Erstmals wird mit dieser kurzen Passage das Massenphänomen des mit dem >neuen Reisen verbundenen systemischen Aufenthalts im Detail kritisch und zudem vor allem geschlechtsspezifisch reflektiert. Die einstündige Wartezeit wird demnach aus Sicht

126 Osterhammel, Die Verwandlung der Welt, 48.

127 Anthony Trollope, Collection of British Authors. Vol. 812. The Belton Estate by Anthony Trollope (Leipzig: Bernhard Tauchnitz, 1866), $112 \mathrm{f}$. 
der weiblichen Hauptfigur wesentlich langwieriger erlebt als für einen Mann. Während Männer die Möglichkeit haben, den Bahnsteig - wie so oft im englischen Kontext - als Bewegungs- und Wartefläche zu nutzen und den im Warten suspendierten Zeitfluss durch das Abschreiten des Bahnsteigs mit einem räumlichen Bewegungsfluss kompensieren können, ist es für Frauen im viktorianischen England aufgrund gesellschaftlicher Konventionen nicht statthaft, die Wartezeit sin Bewegung zu verbringen. Die Hauptfigur Clara muss somit die Zeit stationär in einem (für England typischen) trostlosen Wartesaal verbringen und ist dort offenbar zum Stillsitzen verdammt. Der Wartesaal wird hiermit zum Symbolträger der geschlechtlichen Ungleichberechtigung und zur Kontrastfolie einer gegenüber der Freiheit des Bahnsteigs erklärten Immobilität. Während für Männer aufgrund ihrer Bewegungsmöglichkeit und der dortigen ablenkenden Eindrücke (Werbeplakate etc.) die Wartezeit kürzer wahrnahmen, bewirkte die erzwungene Immobilität des Aufenthalts in den Warteräumen aus Sicht der Frauen die Wahrnehmung einer weit längeren Wartezeit, bei der die Minuten nicht zu vergehen schienen. Zugleich wird das verkehrliche Warten hier erstmals deutlich in den Stand der Reflektionsarbeit gerückt, die die Figur im Wartesaal (erzwungenermaßen) über sich selbst nachdenken lässt. Die stationär verbrachte Wartezeit `muss` demnach aufgrund fehlender äußerer Einflüsse gedanklich und nach innen gerichtet verhandelt werden.

Zusammenfassend wird mit Trollopes realitätsnaher Schilderung das verkehrliche Warten als »a terrible gulf of time to be passed $\aleph^{128}$ beschrieben und somit in eine erstmals klar negative Konnotation gewendet. Die noch in den Jahrzehnten zuvor in den Quellen ssichtbare` Funktion des Wartens als katalytische Kraft der Vorfreude scheint sich hier im englischen Kontext der späten 1860er Jahre aufgrund der Gewöhnung an die Eisenbahnreise und nicht zuletzt auch aufgrund der geschlechtlich ungleichen Verhandlungsmöglichkeiten der Wartezeit vollends in Richtung einer Bürde aufgelöst zu haben. Die Wartezeit wird als derart negativ erlebt, dass das Glockengeläut der Bahnbeamten schließlich als Erlösung (bell of promise) aus dem Zwang zu Immobilität und der unweigerlichen Selbstreflektion inszeniert wird.

\section{Unterhaltungsliteratur}

Einer der meistgelesenen Autoren des deutschsprachigen Raums der 1850er und 1860er Jahre war Friedrich Hackländer (1816-1877). Er erlangte vor allem über seine vielfältigen Werke im Bereich der Reise- und Unterhaltungsliteratur (Trivialliteratur) beachtliche Bekanntheit. Sein Stil kann als realitätsnäher Technik-Realismus eingestuft werden, der zeitgemäße Aspekte (Industrialisierung, zeitgenössische Persönlichkeiten) in seine Geschichten einbezog und verarbeitete.

In seinem 1860 erschienenen Werk Tag und Nacht. Eine Geschichte in vierundzwanzig Stunden schildert Hackländer den Gang des Lebens während eines Tages in einer fiktiven Stadt, die vom strukturellen Wandel vom Postkutschen- zum Eisenbahnzeitalter ergriffen ist. Die Hauptfigur Kohler ist ein pensionierter Kaufmann, der tagtäglich das öffentliche Leben der Stadt inspiziert und dabei unter anderem auch täglich den Bahnhof besucht und dadurch Einblick in das beschleunigte Leben der Zeit gibt. 
»Ueberhaupt sind ja die Passagiere der Eisenbahn nicht mehr so geneigt, mit ihren Mitreisenden bekannt zu werden. Haben sie doch auch keine Zeit dazu, und nehmen sich öfters selbst alle Gelegenheit; die, welche eine lange Tour machen, denken begreiflicher Weise nur an ihre Bequemlichkeit, suchen sich womöglich ein leeres Coupé und reserviren die Plätze gegenüber, so lange das gehen will, durch Anhäufen von Nachtsäcken, Mänteln und dergleichen; müssen sie endlich diese Sitze den neu Angekommenen einräumen, so geschieht dies mißmuthig, man ist verdrießlich, man hält es für unnöthig, mit dem eingedrungenen vis-à-vis eine freundliche Unterhaltung an zuknüpfen. Leute dagegen, welche nur die Kleinigkeit von zehn oder zwanzig Meilen mit uns durch die Welt dahin sausen, existiren eigentlich gar nicht, man sieht sie ohne alles Interesse einsteigen und wieder verschwinden. ${ }^{129}$

In dieser Passage erinnert sich die Hauptfigur offenbar in nostalgischer Form an die alten Verhältnisse des Postkutschenwesens und bewertet die Eisenbahnreise als eine wesentlich unkommunikativere Reiseform. Die Flüchtigkeit des Kontaktes bzw. die Indifferenz der Eisenbahnpassagiere scheint sich vor allem bei Reisenden mit nur kurz entfernt liegenden Zielen zum typischen Reiseverhalten zu zählen. Zwar wird hierbei nicht direkt auf die Wartepraxis vor Abfahrt des Zuges Bezug genommen, aber wie aus den (fiktiven) Beobachtungen der Hauptfigur anzunehmen ist, benutzten jene Reisenden die Wartesäle vor Abfahrt gar nicht mehr. Die in Richtung einer Beschleunigung gewandelte Abfahrtsorganisation gegenüber dem Postkutschenwesen kommt noch deutlicher in einer weiteren Passage zum Ausdruck, in der die Beschleunigung des Lebens mit einer 14-maligen Erwähnung des Adjektivs seilig` nur allzu plakativ untermauert wird.

»Wie ganz anders war das früher! Da betrat man in aller Cemüthsruhe die alten, rauchigen Postpassagierstuben gewöhnlich eine gute Stunde vor Abfahrt des Eilwagens [Postkutsche, R.K.], man stürzte nicht nur so von der Kasse, wo man mit Mühe sein Billet errungen, an den Wartesaal, ohne rechts oder links zu schauen, an die gewisse Clasthüre, die der davor postirte Beamte verschlossen hält, bis die eilige, durstige Locomotive nach Wasser seufzt, bis die Glocke eiligertönt, bis die Conducteure eilig die Wagenthüren öffnen, und bis nun der ebenerwähnte Beamte eilig die Flügelthüren aufreißt, um den eiligen Passagier hinaus zu lassen, der keuchend vor Eile seinen Platz in einem Coupé erobert, eilig seine sieben Sachen irgendwo unterbringt, wo ihm dies eben möglich ist, und wenn er nicht daran verhindert wird von einem andern eiligen Passagier, der verdrießlich ist, weil er in der Eile ein Sechstreuzerstück verlor, als er am Buffet der Restauration eilig ein Butterbrod bezahlte, bis die unterdessen getränkte und gespeiste Locomotive eilig und ruckweise den Convoi hinter sich dreinzieht, eilig zum Bahnhofe hinaus, an Telegraphenstangen vorbei, eilig über Brücken hinweg, eilig hinaus in die weite, weite Welt. ॥ $^{130}$

129 Friedrich Hackländer, Tag und Nacht. Eine Geschichte in vierundzwanzig Stunden (Stuttgart: Eduard Hallberger, 1860), 157.

130 Ebd., 157f. [Hervorhebung des Verfassers, R.K.]. 
Aus dieser Passage erfahren wir für die kulturgeschichtliche Entwicklung des verkehrlichen Wartens, dass die übliche Wartezeit vor Abfahrt an einer Postpassagierstube ${ }^{131}$ mit seiner guten Stundeく wahrscheinlich nicht nur wesentlich länger war als im Eisenbahnkontext. Wir erhalten zudem wiederum einen indirekten Beweis des operativbetrieblichen Dogmas des stationären Warteimperativs im deutschen Eisenbahnkontext. So wurden die Passagiere vor Abfahrt auch im Rahmen von Hackländers (fiktiver) Narration zunächst im Wartesaal mit angeschlossener Versorgungsmöglichkeit (>Butterbrod $`$ ) eingeschlossen und festgehalten, bis das Glockensignal die Freigabe zum Betreten der Bahnsteige und Wagen gab. Darüber hinaus wird eine allgemeine Atmosphäre beschrieben, die von hastiger Eile und Ungeduld geprägt war. Das Eisenbahnwesen hatte damit das lange Warten auf die Postkutsche durch einen eilendes bzw. sstürzendes Warten transformiert, das zwar wesentlich kürzer war, aber dafür in weit unangenehmerer Weise praktiziert wurde. Der Ort des früheren Wartens in der heimeligen Vertrautheit der Postpassagierstube wird hier aus Sicht der Hauptfigur folglich als schmerzlich vermisstes Bild der salten Zeit< ins Feld geführt:

»]a, selige Erinnerung dagegen, die ernste, bescheidene Passagierstube mit ihrem matronenhaften Anstrich, grau mit grauen Verzierungen, mit dem alten, abgerutschten und fettig glänzenden Ledersopha, den ditto Stühlen, mit dem finsteren Beschwerdebuch und seinem Tintenfaß, in welchem die Feder gewöhnlich eingetrocknet war, wenn du sie brauchen wolltest, mit der großen Postkarte der ganzen Monarchie an der Wand, rechts von derselben das Portrait des Landesfürsten, links das des Ceneraloberpostmeisters - Clück selige, stille, vergängliche Zeit! Wie war es so ruhig in diesen Räumen! ${ }^{132}$

Der systemisch notwendige Aufenthalt am Bahnhof oder in der Postpassagierstube wird hier zusammenfassend als entscheidender Hebel zur Erklärung und Kritik eines sich zur Mitte des 19. Jahrhunderts gewandelten Zeitbewusstseins herangezogen. Hierbei ist herauszustellen, dass eine Kritik des Wegfalls des langen Wartens auf die Postkutsche (als Inbegriff der alten Zeitordnung) als die eigentliche Zumutung erfahren wird, nicht aber die eigentlich verkürzte Wartezeit im geräumigen Wartesaal. Mit anderen Worten: Das vergleichsweise längere Warten auf Abfahrt der Postkutsche wurde hier als erstrebenswerter Zustand gewertet, das neuartige (kurze) Warten auf Eisenbahn dagegen als entfremdete und isolierte Erfahrung deklariert.

»(...) Kaltes und herzloses Treiben in dem Wartesaal der Eisenbahn, wo Einer beim Anderen theilnahmslos vorüber treibt, kaum seinen Mitreisen flüchtig betrachtend, sich nur um sich selbst und sein Cepäck bekümmernd, in einer ewigen Unruhe vorwärts drängend, nur sein Ich im Auge, selbst einen genauen Freund nur flüchtig grüßend, ohne Rücksicht auf alle Andern, die mit ihm nach dem gleichen Ziele streben. ${ }^{133}$ 
Um den Kontrast einer sich einstellenden neuen Zeitordnung noch weiter auf die Spitze zu treiben, stellte Hackländer dieses neuartige Warten seiner Hauptfigur trotz der im Vergleich zur Postkutsche verkürzten Aufenthaltsdauer in den Räumlichkeiten schließlich als »Langeweile des Wartens ${ }^{134}$ dar. Hackländer war damit wohl einer der ersten deutschen Autoren, der die Charakteristik der Langeweile in den Kontext des verkehrlichen Wartens stellte. Erst der beschleunigte Verkehr sollte es hier jedoch sein, der paradoxerweise den Eindruck einer Monotonie und nur langsam verstreichenden Zeit erzeugen sollte.

In eine ähnlich kulturkritische Kerbe wie Hackländer schlägt auch Friedrich Gerstäckers 1867 erschienene Erzählung Aufder Eisenbahn. Hierin schildert er die Geschehnisse während einer Eisenbahnfahrt von Leipzig nach Coburg und geht dabei vor allem auf die sich durch die Einführung der Eisenbahn gewandelte Kommunikationskultur im Coupéwagen ein. Diesen konkreten Schilderungen gehen jedoch einige >philosophische Vorüberlegungen `voraus, die hier von besonderem Interesse sind. Grund dafür ist, dass sie eine Vorstellung einer sich wandelnden Zeiterfahrung zur Mitte des 19. Jahrhunderts am Ausgang der >Sattelzeit` geben, die auch die Wahrnehmung von Wartezeiten einschließt. In einer treffenden Reflektion der zeiträumlichen Zäsuren der Eisenbahnreise stellt Gerstäcker (1816-1872) fest:

»Wie ganz anders reisen wir jetzt, als früher; was für ein Drängen und Treiben das ist, in dieser vollkommen neuen Welt des Dampfes und der Elektrographen. Wie schnell fliegen wir, wie schnell fliegt die Zeit - und wie langsam gehen doch noch so viele Menschen in ihrem alten, ausgetretenen Gleis neben der Eisenbahn her, ja hielten uns wohl gern noch auf, um mit ihnen in Einem Tempo zu bleiben, den jeder rasche Fortschritt ist ihnen zuwider. « ${ }^{135}$

Gerstäckers Vorüberlegungen sind augenscheinlich stark von der Wahrnehmung einer epochalen Transformation geprägt, die durch die Dampftechnologie in Gang gesetzt wurde und die bestehenden Raum-Zeit-Verhältnisse aus den Fugen bringen sollte. Dabei erscheint die Zeitwahrnehmung in den 1860er Jahren im doppelten Sinne beschleunigt: Zum einen hinsichtlich des Zeitverlaufs während der Reise selbst, zum anderen aber auch hinsichtlich der gesamten Epoche. Interessant ist dabei zudem Gerstäckers Sozialanalyse der unterschiedlichen Geschwindigkeiten dieses Wandels. So würden keineswegs alle Bevölkerungsteile gleichsam von der Beschleunigung ergriffen werden, sondern neue Inkongruenzen zwischen einer >langsamen entstehen, zwischen Menschen, die >mit der neuen Zeit gehen alten Zeit noch verhaftet blieben. Um die Intensität und Qualität dieses Wandels noch plastischer zu machen, wird dazu von Gerstäcker im Weiteren (wie so oft) die Vergleichsfolie des Postkutschenwesens herangezogen.

»Die Fahrt mit dem Dampfwagen ist freilich nicht mehr so gemüthlich, wie die frühere alte Postfahrt. In unserer praktischen Zeit hat die Gemüthlichkeit überhaupt erstaunlich

134 Ebd., 163.

135 Friedrich Gerstäcker, »Auf der Eisenbahn. «, in Unter Palmen und Buchen gesammelte Erzählungen, Bd.3 (Leipzig: Arnold, 1867), 320 [Hervorhebung des Verfassers, R.K.]. 
abgenommen. Jetzt regiert der Eigennutz in der Welt, und wer einen Eckplatz im Coupé bekommen hat, lehnt sich behaglich hinein, streckt die Beine vor sich hin, und kümmert sich nicht um den Nachbar. ${ }^{136}$

Wie so häufig wird die neue Art des Reisens aus Sicht der Zeitgenossen als überhastet und zweckoptimiert empfunden. Die >Gemütlichkeit< des Postkutschenwesens ist passé und nicht mehr statthaft. Zudem realisiert Gerstäcker, dass sich durch die neue Verkehrsoption der Eisenbahn die Anlässe des Reisens vervielfacht hätten, die in einer modernen Mobilitätskultur der Möglichkeitserweiterung münden würden. So vermerkt Gerstäcker weiter:

»Das ganze Reisen ist auch ein anderes geworden. Früher gehörte ein Entschluss dazu, den alten Wohnsitz zu verlassen, um irgendeinen entfernten Ort zu erreichen. Vor allen Dingen musste man sich einen $\mathrm{Pa}$ mit genauer Personalbeschreibung verschaffen - Tagelang vorher eingeschrieben sein, um nicht in einem lästerlichen Beiwagen befördert zu werden - und dann die Abschiedsvisiten. - Jetzt dagegen trägt man die Paßkarte fix und fertig in der Tasche - oder braucht sie sie nicht einmal, und ist aus irgendeinem entfernten Teil Deutschlands zurückgekehrt, ehe nur irgendein Mensch eine Ahnung hatte, daß man überhaupt fortgewesen. Die Reisenden selber verband früher auch schon der gemeinsame Entschluß - die lange Fahrt miteinander. Wo zum ersten Mal Mittag gemacht wurde, saßen die »Passagiere« von den »Gästen« des Ortes getrennt, im »Passagierzimmer « allein und abgeschieden, oder im Gastzimmer an einem besonderen Theil des Tisches. (...) Wie hat sich das in unserer Zeit geändert. Jetzt werden wir mit einer Anzahl Personen zusammengeworfen, die uns nicht interessieren können, da sie vielleicht schon auf der nächsten Station aussteigen - selbst das wohin bleibt sich gleich, da sie uns wahrscheinlich nie im Leben mehr begegnen. »Reisegefährten «- das Wort existiert gar nicht mehr; man grüßt sich höchstens, wechselt vielleicht ein paar Worte mitsammen, und kennt sich nicht mehr, sobald man aussteigt, trotzdem man vielleicht eine Strecke gemeinschaftlich zurückgelegt hat, die unter frühern Verhältnissen eine feste und dauernde Freundschaft begründet hätte. « $^{137}$

Der hier diagnostizierte Wandel in Richtung der Entfesselung zuvor ungekannter Mobilitätspotentiale ging aus Gerstäckers Sicht zulasten der vormaligen Sozialität des Reisens. Die Schicksalsgemeinschaft einer Reisegruppe in der Postkutsche ist demnach genauso anachronistisch, wie die Notwendigkeit für eine Reise eine starke Entschlusskraft entwickeln zu müssen. Stattdessen würde das neue Reisen ganz im Zeichen von Anonymität und Entfremdung stehen. Wie in kaum einer anderen Quelle jener Zeit kommt hierbei die wahrgenommene Irritation der besonderen Situation im Wagen als auch im Wartesaal zum Ausdruck, in der viele sich fremde Personen >zusammengeworfen werden und im Moment des systemischen Wartens einen ungewollten Sozialraum bilden. Gerstäckers Befund kann damit als ein weiterer Beweis der Andersartigkeit des systemischen Wartens gegenüber in anderen Kontexten erfahrenen Wartesituationen

136 Ebd., 32of. [Hervorhebungen des Verfassers, R.K.].

137 Gerstäcker, »Auf der Eisenbahn«, $321 \mathrm{f}$. 
gelesen und verstanden werden, der im Rahmen dieser Arbeit im Theorem des systemischen Wartens herzuleiten versucht wurde.

Den Grund dieser sozialen und zeiträumlichen Transformation sieht Gerstäcker abermals in der paradigmatischen Technologieinnovation des 19. Jahrhunderts:

»Das macht der Dampf. Die Concentration der Zeit, wie man es nennen könnte, mit der wir in ein Coupé erst zusammengepreßt, und dann wieder gewaltsam auseinandergeschnellt werden. Wer kann sich dabei gemüthlich fühlen?« ${ }^{138}$

Entscheidend für einen Einblick in die zeitgenössische Wahrnehmung der Wartezeit ist nun aber, dass Gerstäcker die fehlende Gemütlichkeit dabei nicht nur der Fahrt selbst attestiert, sondern die Gemütlichkeit bereits im Wartesaal am Bahnhof unterminiert wird. Statt sich in aller Ruhe auf die Abfahrt mit der Postkutsche vorbereiten zu können erfordert die Abfahrtssituation am Bahnhof eine ungewollte Prozessbeschleunigung. So fährt Gerstäcker fort:

»]etzt dagegen ein rasches Läuten, ein Pfiff und fort geht der Zug, ein unglückseliges Menschenkind aber, das in diesem Augenblick noch vielleicht verzweifelnd aus dem Wartesaal stürzte, kann nur mit bestürztem Gesicht hinter dem Davonbrausenden drein sehen, wird noch dazu ausgelacht, und ist von seinen früheren Mitpassagieren im nächsten Augenblick vergessen. Und wie oft geschieht das. Deralte faule Schlendrian steckt da noch in einer Menge von Menschen, und kommen sie einmal hinaus in's Leben, treten sie aus ihrer Studierstube oder Werkstatt ins Freie, so hält es ungemein schwer ihnen begreiflich zu machen, daß die übrige Welt nicht auf sie wartet oder ihretwegen da ist - aber der Dampfwagen bringt's fertig. « $^{139}$

Mit dieser letzten Passage seiner philosophischen Vorüberlegungen bringt Gerstäcker schließlich zum Ausdruck, wie schwierig für weite Kreise die Anpassung an die Verhältnisse einer neuen auf Basis von Selbstkontrolle, Zeitdisziplin und Systemsynchronisation organisierten Gesellschaft war. Folglich würden durch die Anpassungsschwierigkeit (und der allgemeinen Unwissenheit der Abläufe am Bahnhof) regelmäßig Züge verpasst werden. Statt in solchen Situationen die Empathie der Mitreisenden zu erfahren, würde zudem das >Verpassen s sogar noch mit der sozialen Bestrafung des Auslachens quittiert werden. Sinnbildlich steht der verpasste Zug damit für die durch die Eisenbahn evozierten Verwerfungen zur Mitte des 19. Jahrhunderts. Der Wartesaal erscheint in diesem Spannungsgefüge aus alter und neuer Zeit dezidiert als der letzte Ort der traditionellen Ruhe bzw. - wie Gerstäcker es sagen würde - der Gemütlichkeit. Er bildet die Demarkationslinie zur beschleunigten Außenwelt, die einer großen Menge von Menschen beim Verlassen des Wartesaals das neue Gefühl vermittelt, dass die Welt nicht auf sie wartet.

\section{Essays}

Einer der international herausragenden Beobachter des Eisenbahnwesens jener Zeit war zweifellos der englische Kunsthistoriker John Ruskin (1819-1900). Er übte in seinen

138 Ebd., 322 [Hervorhebung des Verfassers, R.K.].

139 Ebd., 322f. [Hervorhebung des Verfassers, R.K.]. 
weithin rezipierten und einflussreichen Werken harsche Kritik an der Bahn (und den Bahnhöfen) und galt doch zugleich als >Vielfahrer und heimlicher Lokomotivenliebhaber. Ruskins ambivalente Haltung äußerte sich darin, dass er die Lokomotive, für sich betrachtet, zwar »als Werk des menschlichen Erfindungsgeistes« bewundern konnte, zugleich aber ständig Kritik »an der Einrichtung der Eisenbahn als ganze mitsamt ihren faktischen und psychologischen Begleiterscheinungen « $^{140}$ übte. Diese Kritik an den Einrichtungen kommt unter anderem in seinem 1849 erstmals veröffentlichten Essay The Seven Lamps of Architecture deutlich zum Ausdruck. Sie soll hier herausgegriffen werden, weil sich aus ihr indirekte Rückschlüsse auf die Rahmung, Atmosphäre und Wahrnehmung der verkehrlichen Wartezeit (im englischen Eisenbahnwesen) ableiten lassen können. Bezüglich der Anmutung der neuen Bahnhofsbauten bemerkt Ruskin:

»Another of the strange and evil tendencies of the present day is to the decoration of the railroad station. Now, if there be any place in the world in which people are deprived of that portion of temper and discretion which are necessary to the contemplation of beauty, it is there. It is the very temple of discomfort, and the only charity that the builder can extend to us is to show us, plainly as may be, how soonest to escape from it. ${ }^{141}$

Ruskin zeichnet hier ein Bild der Bahnstation, das durch Abwesenheit jeglichen ästhetischen Anspruchs und fehlender Aufenthalts- und Erlebnisqualität gekennzeichnet ist. Das schnelle Durchqueren bzw. die >Flucht aus diesen Gebäuden erscheint ihm als die eigentliche Hauptcharakteristik der neuen Bauaufgabe. Was Ruskin hier kritisiert, lag jedoch in der Tat in der planerischen Absicht dieses Bautyps. Er war die Schaffung eines zweckmäßig eingerichteten Übergangs auf das Bahnsystem. Dieses inhärent transitorische Element des Eisenbahnwesens erscheint Ruskin jedoch nicht tragbar, weil es die Menschen entmündigen und die Reisenden vom durchkreuzten Raum entfremden würde.

»The whole system of railroad travelling is addressed to people who, being in a hurry, are therefore, for the time being, miserable. No one would travel in that manner who could help it—who had time to go leisurely over hills and between hedges, instead of through tunnels and between banks: at least those who would, have no sense of beauty so acute as that we need consult it at the station. The railroad is in all its relations a matter of earnest business, to be got through as soon as possible. It transmutes a man from a traveller into a living parcel. $\ll^{142}$

Die Entfremdung der Eisenbahnreise gipfelt für Ruskin in der Einschätzung, dass die Reisenden nun mehr zum zweckrational beförderten Gut avanciert seien und ihres organischen Ursprungs beraubt würden. In der Tat wiesen die englischen Stationen, wie bereits an anderer Stelle erwähnt, oftmals den Charakter eines beschleunigten $\mathrm{Zu}$ - und Abgangs mit nur wenig Komfort auf. Wenn überhaupt Wartesäle vorhanden waren,

140 Heinimann, Technische Innovation und literarische Aneignung, 160.

141 Ruskin, The Seven Lamps of Architecture, 99 [Hervorhebung des Verfassers, R.K.].

142 Ebd. [Hervorhebung des Verfassers, R.K.]. 
wurden sie von den Reisenden nur allzu oft gemieden. Wenn möglich erreichten englische Reisende den Bahnhof gar erst in letzter Minute.

Auch in seinem 1853 veröffentlichten Werk The Stones of Venice lässt Ruskin an den neuen Verkehrsbauten kein gutes Haar.

»In the olden days of travelling, now to return no more, in which distance could not be vanquished without toil, but in which that toil was rewarded, partly by the power of deliberate survey of the countries through which the journey lay, and partly by the happiness of the evening hours, when, from the top of the last hill he had surmounted, the traveller beheld the quiet village where he was to rest, scattered among the meadows beside its valley stream; or, from the long hoped for turn in the dusty perspective of the causeway, saw, for the first time, the towers of some famed city, faint in the rays of sunset - hours of peaceful and thoughtful pleasure, for which the rush of the arrival in the railway station is perhaps not always, or to all men, an equivalent, - in those days, I say, when there was something more to be anticipated and remembered in the first aspect of each successive halting-place, than a new arrangement of glass roofing and iron girder, there were few moments of which the recollection was more fondly cherished by the traveller $[. ..] \ll^{143}$

Ruskin kritisiert die neue Bauaufgabe des Bahnhofsbaus als einen Hort der Monotonie des zu Erwartenden. Statt den 'genius loci< eines jeweiligen Ortes zu erfahren, würden die mehr oder weniger standardisierten Strukturen der Bahnhöfe keine Überraschungen bei Ankunft an einem Ort bereithalten. Zusammenfassend wird hier der Bahnhof als ein durchweg von Eile und Geschäftssinn geprägter, monotoner Raum ohne ansprechende bauliche Qualität dargestellt. ${ }^{144}$ Zwar bezieht sich Ruskin hierbei nicht direkt auf die Wartesituation am Bahnhof, aber es steht zu vermuten, dass er auch diese als von Unruhe, Aufregung und geringer Aufenthaltsqualität betrachtet haben mag. Die Vergleichsfolie dieses allgemeinen Rückschritts bildet bei Ruskin wie so oft in jener Zeit das Postkutschenwesen, das noch nicht die vorherrschende Eile und gewachsene Beschleunigung aufwies. Im vergleichenden Rückgriff auf die Postkutsche zeigte sich hierbei zugleich ein höherer Wert des alten Wartens (begriffen hier als Reisezeit in der Kutsche). Erst die Mühe und Anstrengung der langen Reise würden bei Ankunft am Ziel ein Gefühl der Belohnung erzeugen können, welches die Eisenbahn aufgrund ihrer Vereinfachung nicht mehr gewährleisten würde.

Das Motiv des Postkutschenvergleichs war eines der dominierenden Sprachbilder der Eisenbahnkritik und fand nicht nur im Bereich der akademischen Publikationen, sondern genauso im Bereich der Unterhaltungsliteratur Verwendung. Hier ist insbesondere eine von Friedrich Hackländer 1860 erschienene Geschichte zu erwähnen, die noch mehr als Ruskin den Wert des salten Wartens im Rahmen des Postkutschenwesens aufzeigt.

143 Ruskin, The Stones of Venice, 2: The Sea Stories:1f.

144 Unweigerlich drängt sich hierbei auch Marc Augés postmoderne Klassifizierung von >Nicht-Ortenく auf: Marc Augé, Orte und Nicht-Orte: Vorüberlegungen zu einer Ethnologie der Einsamkeit (Frankfurt a.M.: Fischer, 1994). 


\subsubsection{Lieder}

Auch Liedtexte können für eine Rekonstruktion der frühen Warteerfahrung von kulturhistorischem Wert sein. So ließ die Analyse einer Reihe von Liedanthologien ein Chanson des französischen Liedermachers Gustave Nadaud (1820-1893) zutage treten, das als einer der wenigen Beispiele der Verhandlung des Phänomens gelten darf. In Nadauds Chanson Zu Spät! (original Trop tarde), für das kein Entstehungsjahr bekannt ist (wahrscheinlich aber in 1860er Jahren entstanden sein dürfte), besingt er eine Figur, die aufgrund einer falsch gestellten Taschenuhr ihren Zug verpasst.
»(...) Ich hab' den Zug verpasst. Zu spät!
Im Bahnhof darf ich irrend harren.
Doch was irrend nun Ein Stunde thun?
Ich schlage Feuer, rauch' Cigarren.
Und was rauchend thun
In dem Bahnhof nun? (...) «
Betrübt der Dreizehn dort im Garten
Gedenken, die den Freund erwarten.
Schon der Tisch gedeckt,
Hand zum Gruss gestreckt!
Die Luft ist mild, der Himmel sonnig,
Wie ruht's im Grase sich so wonnig!
Zu Spät!
Ich hab' den Zug verpasst. Zu spät!
(...)
Beklage man mit lautem Munde
Die des Zufalls Ruf
Hier verspätet schuf,
Und wär' es nur um 'ne Sekunde.
Solch ein armer Wicht
Ist, der zu euch spricht.
Lacht ja nicht, denn ihr theilt mein Unheil,
Verdanket dem Minuten-Bruchteil,
Dass in meiner Hand
So dieses Lied entstand.
Hätt' ich den Bahnzug nicht verpasset,
Hätt' ich ein besseres verfasset. Zu spät!
Ich hab’ den Zug verpasst. Zu spät! « ${ }^{145}$

Das hier besungene Zuspätkommen wurde aufgrund der gewachsenen Anlässe und Anforderungen des pünktlichen Erscheinens (Arbeit, Abfahrten etc.) zu einer Kollektiverfahrung. Die geforderte Synchronisation des Menschen an das mechanisiert-lineare Zeitregime der Eisenbahnen war in diesem Fall offenbar nicht geglückt, der Zug wurde

145 Chansons de Gustave Nadaud (Paris: Henri Plon, 1870), 385ff. Die deutsche Übersetzung stamme von F.C. Petersen. 
verpasst. Die entstehende Wartezeit wurde zum irritierenden Moment und insbesondere mit Tabakkonsum zu kompensieren versucht. Die enge, historisch lang zurückreichende Verbindung zwischen Konsum von Genussmitteln und dem Verbringen von Wartezeiten wird durch Nadauds Chansons besonders augenscheinlich. Doch trotz der versäumten Ankunft bei den Freunden zeigt die erzwungene Wartezeit eine Ambivalenz auf. So hat sie zugleich etwas Gutes oder Versöhnliches, denn nur aufgrund dieser erzeugten Zwischenzeit konnte dieses Lied überhaupt erst entstehen. Die durch den modernen Verkehr geschaffenen temporalen Zwischenräume konnten demnach auch aufgrund ihrer darin erzeugten Reflektion durchaus als kreativ-produktive Kraft fungieren.

\subsubsection{Zeichnungen}

Im Bereich der bildenden Künste wurde das Wartephänomen in der Mitte des 19. Jahrhunderts trotz seiner wachsenden Präsenz und Bedeutung für immer mehr Menschen kaum stärker thematisiert als in den literarischen Gattungen. Die Quellenlage muss demnach auch hier als sehr unerheblich eingestuft werden. Eine herausragende Persönlichkeit, die sich diesem Motiv jedoch annahm, war der französische Maler Honoré Daumier (1808-1879). Daumier zählte zu einem »erbarmungslosen Moralisten und Sozialkritiker unter den Malern seiner Generation. ${ }^{146}$ Seine Mission bestand in der künstlerischen und zeitkritischen Darstellung realistischer Alltagsszenen der französischen Bevölkerung. Diese Suche nach Motiven führte ihn in den 1850er bis 1870er Jahren unter anderen auch in die Wartesäle der unteren Wagenklassen. Die in diesem Zusammenhang entstandenen Werke können aufgrund ihres Umfangs und ihrer Detailtiefe als die ersten und zugleich bedeutendsten bildkünstlerischen Verhandlungen wartender Reisender im 19. Jahrhundert gelten.

In seiner Serie Le wagon de ze classe (1862) hält Daumier (scheinbar) triviale Szenen der Reise in den Drittklasseabteilen fest. Wie der Titel verrät, hält Daumier hier vor allem die Szenerie während der Fahrt fest, dennoch begreift er offenbar auch den Aufenthalt in den Wartesälen als elementaren Bestandteil der Mobilitätserfahrung. Durch den Einbezug der Situation am Bahnhof gewährt Daumier einen beindruckenden wie einmaligen Einblick in das Innere der Wartesäle jener Zeit. Seine Zeichnungen zeigen »triste Szene einer armseligen Modernität am Rande des proletarischen Existenzminimums $\aleph^{147}$, die sich im Schatten der beschleunigten Moderne bewegen. Daumiers Werke zeigen vor allem Arbeiter und Bauern - die typische Nutzerschaft der dritten Wagenklasse - , die in ihren ermüdeten Anmutungen eine Antithese auf den weithin gefeierten Optimismus eines sozialen und wirtschaftlichen Freiheits- und Erlösungsversprechen der Eisenbahnen darstellen.

Johannes Mahr interpretiert Daumiers Personendarstellungen als eine »auf die eigene Körperlichkeit reduzierte Isolierung der vielen nebeneinander sitzenden Men-

146 Stanislaus von Moos, »Bahn, Zeit, Architektur. Notizen zu einer Typologie des Hybriden«, in Die Internationalität der Eisenbahn, 1850-1970, 51.

147 Ebd. 
Abbildung 26: Honoré Daumier, »Une salle d'attente de troisième classe« (1870er).

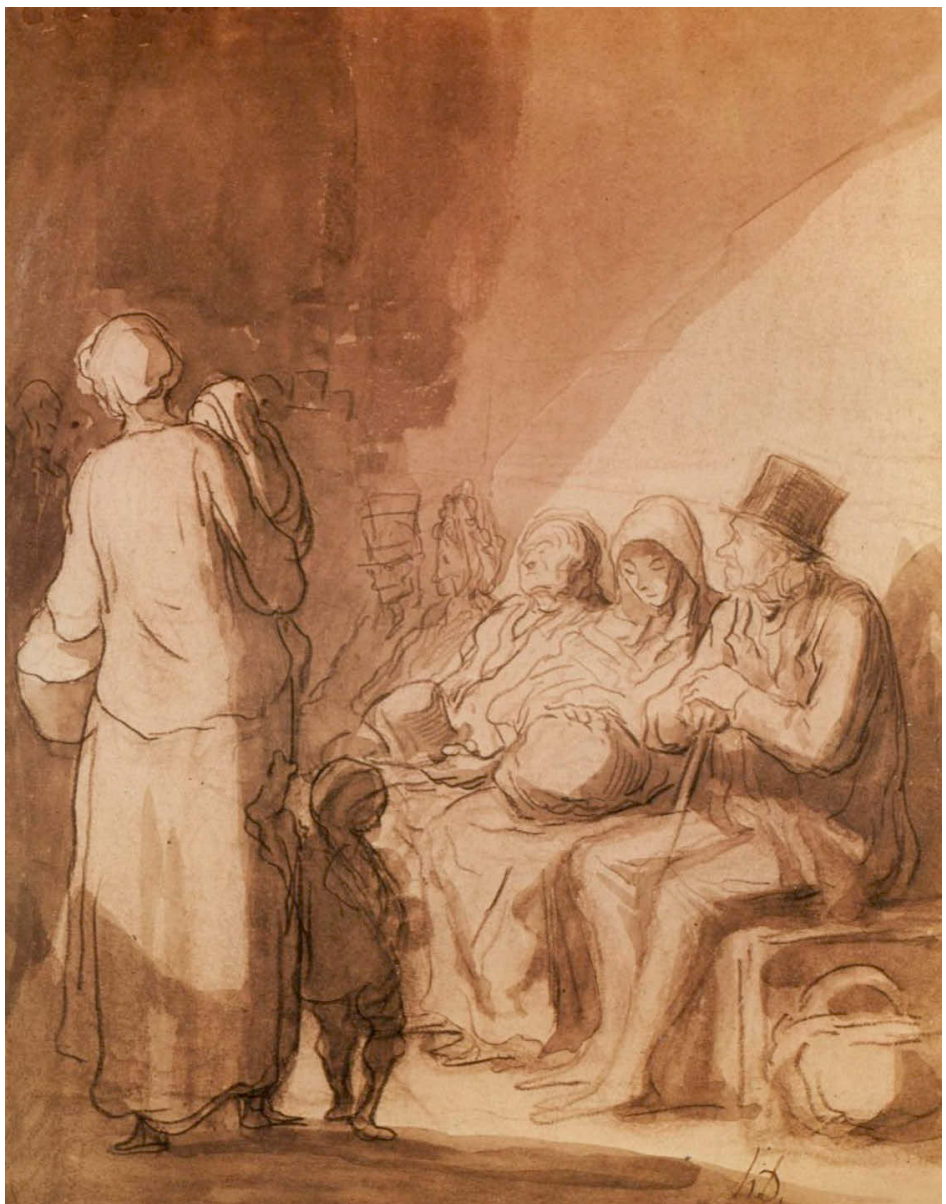

Quelle: Daumier Register, DR 10307, (Owww.daumier.org.

schen, die trotz der engen Berührung keinerlei Kontakt miteinander haben. ${ }^{148}$ Alte wie junge Menschen sind gleichsam als gedankenversunkene, schlafende, gelangweilte oder gar verärgerte Personen dargestellt. Sie wirken als wären sie zur Immobilität, Regungslosigkeit und unweigerlichen Reflektion gezwungen. Auffällig erscheint hierbei auch, dass entgegen der zur Mitte des 19. Jahrhunderts gewachsenen Bedeutung der Reiselektüre keine der dargestellten Personen liest, stattdessen gehen die Blicke der meisten Reisenden ins Leere. Zusammenfassend erfährt das Warten am Bahnhof auf Grundlage der dargestellten Personen eine deutlich negative Konnotation und lässt zumindest in der dritten Wagenklasse - kaum mehr etwas von der katalytischen Kraft 
Abbildung 27: Honoré Daumier, »L'attente à la gare« (1850er).

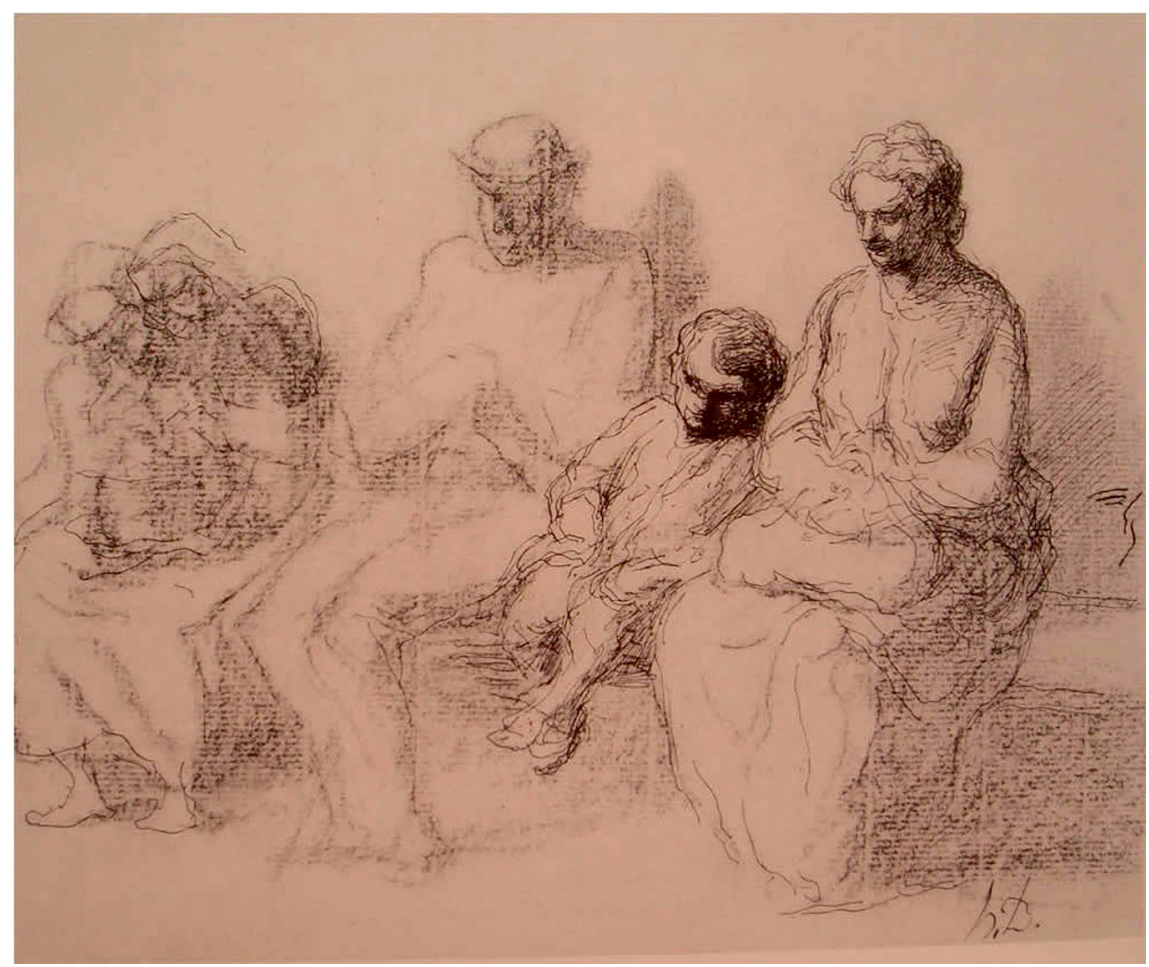

Quelle: Paris Musées/Musée Carnavalet.

einer freudigen Erwartung erkennen, die sich noch für die Pionierphase des Eisenbahnwesens nachweisen ließ. Statt die aufgeregte Grundstimmung zu verstärken, wird die irritierende Situation der kurzzeitigen Konzentration vieler sich fremder Reisender in einem Saal nunmehr von Daumier als die »Viertelstunde der unliebsamen Reflektion« (Abbildung 28) taxiert.

Hierzu könnte nicht zuletzt auch die kontextuelle Besonderheit der strengen Praktizierung des stationären Warteimperativs im französischen Bahnsystem geführt haben. Demnach war es den Reisenden in Frankreich nicht erlaubt, den Bahnsteig zu betreten und sich frei zu bewegen. Die unterschiedlichen Wagenklassen wurden zudem zeitlich gestaffelt abgefertigt, sodass die Reisenden dritter Klasse am längsten in den Wartesälen verharren mussten, bis sie die wenig komfortablen Wagen besteigen konnten.

Zusammenfassend ist mit Blick auf Daumiers exklusive Einblicke in die Warterealität zur Mitte des 19. Jahrhunderts festzuhalten, dass das Warten für die anklagende Repräsentation sozialer Ungleichheiten instrumentalisiert wird. So werden bewusst lediglich Szenen der unteren Wagenklassen dargestellt, weil Daumier die Situation jener Menschen offenbar als wirkungsvolles Bild der Inszenierung sozial bedingter, starker Abhängigkeiten, eines eingeschränkten Handlungsspielraums sowie eines modernen Imperativs zur persönlichen Mobilität diente. Der zeitliche Zwischenraum, so ließe 
Abbildung 28: Honoré Daumier, »La salle d'attente, ou le quart-d'heure de réflexions désagréables« (1855).

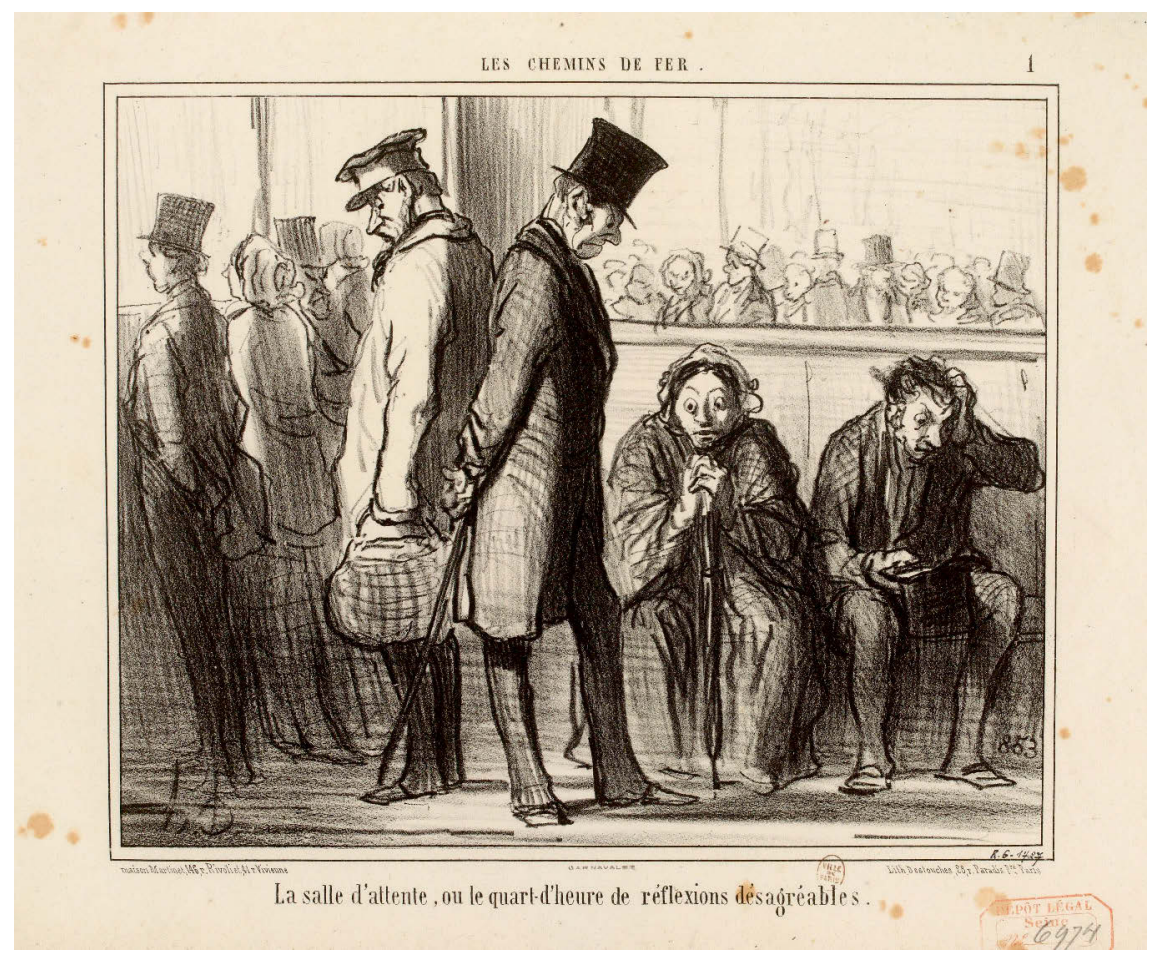

Quelle: Daumier Register, DR Nummer 2729, @www.daumier.org.

sich mit Daumiers dokumentarischen Darstellungen argumentieren, erfährt nicht nur erstmals den Charakter eines künstlerischen Motivs, sondern wird zudem in Form der Auswahl der Wartenden nicht zuletzt politisch aufgeladen, weil es sich als ein (weiteres) alltagsrelevantes Feld anbietet, um die ungleichen Lebensrealitäten der Gesellschaft abzubilden.

\subsection{Abschluss: Rahmung und Rezeption des Wartens in der Standardisierungs- und Konsolidierungsphase der Eisenbahnen (1845-1870)}

\section{Baulich-operative Rahmung des wartenden Passagiers (1845-1870)}

Die bauliche Rahmung des wartenden Passagiers zeigt gegenüber der Frühphase des Eisenbahnwesens zwei wesentliche Zäsuren. Zum einen ist die Phase der Standardisierung und Konsolidierung des Eisenbahnwesens zwischen 1845 und 1870 von einem Ende des Baus von Provisorien und interimistischen Lösungen gekennzeichnet. Waren die ersten Bahnhöfe noch Versuchsanordnungen zur Erprobung des Betriebes, zeigten 
die meisten Neu- und Umbauten eine Tendenz zur Antizipation zukünftig wachsender Verkehrs- und Raumnachfragen. Stellvertretend für diese sich abzeichnende Tendenz hält Eduard Schmitt im Rückblick auf die 1860er und frühen 1870er Jahre fest:

»Es ist bisher noch keine allgemein giltige Ansicht aufgestellt werden, ob es vorzuziehen sei, gleich bei der Neuerrichtung des Bahnhofes und der Inbetriebsetzung der Eisenbahnen die Stationen für einen grossen Betrieb vollständig auszustatten, oder ob man lieber provisorische Anlagen herstellen solle, durch welche man die Crösse des Verkehres erst genau kennen zu lernen im Stande ist. Viele Ingenieure haben das Letztere vorgezogen und haben die Bahn mit provisorischen Einrichtungen eröffnet, während andere (...) ihren Anlagen von Vornherein eine möglichst grosse Ausdehnung gaben. In den letzten Jahren scheint man sich, trotz mancher Erfahrung im entgegen gesetzten Sinne, der letztern Auffassung zuneigen zu wollen. Es ist nicht recht klar, ob dies das Resultat einer gesunden Calculation ist, oder ob man nicht vielmehr dem Verlangen nachgegeben hat, von Vornherein in möglichster Ausdehnung arbeiten zu lassen. ${ }^{149}$

Hieraus geht hervor, dass immer noch eine Fülle von Unsicherheiten bezüglich der Frage bestand, inwieweit sich das Eisenbahnwesen entwickeln und welche technischbaulichen Anpassungen dafür erforderlich würden. Die Erfahrung des Erfolgs der zurückliegenden Jahrzehnte gab jedoch dazu Anlass, trotz zurückliegender Rückschläge durch Wirtschafts- und Spekulationskrisen sowie durch Kriege die Neu- und Umbauten von vorn herein größer zu dimensionieren. Darüber hinaus wurden tiefere und zukunftsfestere Überlegungen zu Raumprogramm und Ausstattung der Empfangsgebäude angestellt. Entsprechend dieser programmatischen Wende wurde auch das wartebezogene Raumprogramm nicht mehr interimistisch und provisorisch gestaltet, sondern erstmals weiter qualifiziert. Innerhalb dieser Qualifizierung wurde der bereits zuvor etablierte stationäre Warteimperativ als operationelles Grundprinzip beibehalten und verfestigt. Dies bedeutete, dass Millionen von Passagieren dazu (außer im angelsächsisch-amerikanischem Kontext) zunächst vor Betreten der Wagen die Wartesäle passieren bzw. dort Platz nehmen und die Temporalerfahrung eines transitorischen ,Dazwischen-Seins` absolvieren mussten. Der präparatorische Aufenthalt vor Abfahrt und die damit verbundene Erfahrung einer zeitlichen Andersartigkeit in Form einer Anomalie vom sonst gewohnten linearen Zeitfluss, wurden damit in dieser Zeit zu einem festen Bestandteil der (modernen) Mobilitätserfahrung.

Die zweite Zäsur gegenüber der Frühphase, die direkte Auswirkung auf die individuelle Verhandlung des systemischen Wartens zeitigte, wurde durch die stärkere Kompensation des organisatorischen Zwangs zum Warten vor Abfahrt bedingt, die sich in Form der Befriedigung stark gestiegener Komfort- und Dienstleistungsanforderungen seitens Reisenden ausdrückte. Die Einrichtung von Versorgungsmöglichkeiten zur physiologischen (Speisen und Getränke in Bahnhofswirtschaften) sowie psychologischen Bedürfnisbefriedigung (Reiselektüre gegen die Monotonie des präparatorischen Wartens und der anschließenden Eisenbahnreise) ließen die Bahnhöfe über ihre formale 
Vermittlungsfunktion zwischen Stadt und Schiene zu komplexen Orten gesellschaftlichen Lebens werden: »Maschinenhaus, Passage, Forum, Basar, Kaffeehaus, Restaurant, Hotel, Fürstenpalast - alle diese Aufgaben hatte der Großstadtbahnhof zu übernehmen. ${ }^{150}$ Während damit die Pionierphase der Eisenbahn noch kritisch als technisch fortschrittlich, aber kaum kundenorientiert angesehen wurde, ${ }^{151}$ kam es beginnend mit der langen Phase von Bahnhofsneu und - umbauten ab Mitte der 1840er Jahre zum allmählichen Zusammenwirken technischer und serviceorientierter Verbesserungen.

\section{Zentrale Erkenntnisse der Rezeptionsgeschichte (1845-1870)}

Aus der Analyse der wenigen literarischen und künstlerischen Niederschläge, die sich innerhalb der Standardisierungs- und Konsolidierungsphase explizit mit der Verarbeitung oder Beobachtung des Wartephänomens beschäftigten, ließ sich der Eindruck gewinnen, dass die Erfahrung des Wartens an Bahnhöfen eine allmähliche Transformation vom aufgeregten Zustand zur Bürde erfuhr. Während der Aufenthalt am Bahnhof vor allem im deutschen Kontext noch für viele Reisende bis mindestens in die 1850er Jahre als eine katalytische Kraft einer positiv-aufgeregten Grundstimmung fungiert haben dürfte (Mühl), kam diese unterbewusst positive Konnotation (ausgehend von England) spätestens zur Mitte des Jahrhunderts bereits zum Erliegen und wurde zunehmend als irritierende oder entfremdende Situation problematisiert (Weerth, Trollope, Ruskin).

Zwar war die Eisenbahn für die weitesten Teile der Gesellschaft noch immer spannend und mysteriös, ${ }^{152}$ war die Eisenbahnreise »noch ein Erlebnis für das man sich Zeit ließ. $\varkappa^{153}$ Zugleich aber überlagerte sich die lang anhaltende Phase der positiven Aufregung durch eine allmähliche Gewöhnung an die neue >Industrialisierung des Reisens`, die auch eine Gewöhnung an das Erlernen und Verinnerlichen des linearen Uhrzeitregimes einschloss. In der Folge dieser Gewöhnung setzte sich zunehmend ein sensitivnervöses Reiseparadigma durch, das Schivelbusch wie folgt beschreibt:

»Im Alltagsleben setzt sich die Industrialisierung der Verkehrsmittel im Bewußtsein der Verkehrsteilnehmer schnell durch. Sie entwickeln eine neue Wahrnehmung. Bald erscheint ihnen nicht mehr die gleichförmig-schnelle Bewegung der Dampflokomotive gegenüber der durch Zugtiere hergestellten als das Unnatürliche, sondern umgekehrt: die mechanische Gleichförmigkeit wird ihnen die neue Natur, der gegenüber der Natur der Zugtiere als gefährliches Chaos erscheint. «" ${ }^{154}$

150 Krings, »Bahnhofsarchitektur: deutsche Großstadtbahnhöfe des Historismus«, 483.

151 Stellvertretend für diese Sicht auf die Frühphase sei dazu nochmal auf den schon zuvor erwähnten Reisebericht Lichthammers verwiesen: Lichthammer, »Ueber einige Bahnhöfe des westlichen Deutschlands und Belgiens«.

152 Meeks vermerkt für die Phase der zweiten Hälfte des 19. Jahrhunderts in dieser Hinsicht: »Trains themselves still seemed partly miraculous and wholly delightful, like new toys; our great-grandparents enjoyed the novel experiences associated with trains, including the varied noises toward which our eternal urban roar has made us so blasé. « Meeks, The Railroad Station: An Architectural History, 93.

153 Radlbeck, »Bahnhof und Empfangsgebäude«, 96.

154 Schivelbusch, Geschichte der Eisenbahnreise, 19. 
Die »mechanische Gleichförmigkeit « umfasste dabei aber nicht allein die Bewegung, sondern schloss auch den Lauf der Uhr ein. Damit wurde eine Grundbedingung zur (problematischen) Erfahrung von Wartezeiten erfüllt, denn erst das Vorhandensein zweier Zeiterfahrungsebenen, bewirkte, dass im Falle des Wartens die Einzelereignisse nicht mehr im Schema der Folge eines Vorher und Nachher ausgemacht werden konnten. Erst die Gewöhnung an die lineare Uhrzeit konnte überhaupt den Eindruck vermitteln, dass im Falle des Wartens das sonstige Ordnungsversprechen des Zeitflusses eine abrupte Unterbrechung erfährt.

Innerhalb dieses allgemeinen Gewöhnungszusammenhangs liegt ein weiterer Rezeptionsbefund der Phase 1845-1870 in der kulturkritischen Reflektion des Wartens und einer reziprok rückwärtigen Romantisierung des langen Wartens auf die Postkutsche. Die vielfach von Hast und Eile wahrgenommene Abfahrtssituation der industrialisierten Eisenbahnfahrt wird in jenem Zeitraum rezeptionsgeschichtlich nicht selten als Kontrastfolie einer verlorengegangen Reisekultur herangezogen, die sich durch einen hohen Grad an Kommunikation und Reizeinflüssen auszeichnete. Um die ungewollte, von Beschleunigung gekennzeichnete Transformation deutlich zu machen, wurde die Wartesituation am Bahnhof - trotz einer gegenüber der Postkutsche weit kürzeren Aufenthaltsdauer - als nervöser und unästhetischer Entwicklungsrückschritt problematisiert (Hackländer, Ruskin). Im Gesamteindruck dieser kulturkritischen Instrumentalisierung des Wartens lässt sich resümieren, dass für eisenbahnkonservative Akteursgruppen nicht das eigentliche Warten auf den Zug als problematisch erfahren wurde, sondern, dass vielmehr das neue System nicht mehr auf den Menschen wartete (Gerstäcker). Die Mechanisierung und Industrialisierung des Eisenbahnverkehrs begründete eine stärkere Verlagerung der Verantwortlichkeiten auf die Passagiere, die sich nunmehr dem organisatorischen Regime unterordnen bzw. sich mit der Eisenbahnzeit synchronisieren mussten (Nadaud). Diese sich auch im neuen >rastlosen $<$ Warten niederschlagende Komplexitätszunahme begründete somit die symbolhafte Romantisierung des langen und zeittoleranten Wartens auf die Postkutsche, das noch ein organisch-raumzeitliches Gleichgewicht aus Passagier und tierischer Antriebskraft repräsentierte. Die Werke von Hackländer, Ruskin oder Gerstäcker können somit zweifelsohne als empirische Belege für Kosellecks These eines gleichzeitigen Nebeneinanders von Beharrungs- und Modernisierungsimpulsen am Ende der `Sattelzeit herangezogen werden.

Zusammenfassend wird das verkehrsinduzierte Warten in der Phase der Standardisierung und Konsolidierung des Bahnhofsbaus zu einem zentralen operationalen- und Erfahrungsaspekt der Eisenbahnreise und damit zu einem von Millionen von Reisenden verinnerlichten Teilphänomen der neuen Mobilitätspraxis. Anhand der wenigen, aber eindrücklichen literarisch-künstlerischen Niederschläge wird die rezeptionsgeschichtliche Zäsur gegenüber der Pionierphase deutlich: das Warten tritt aus dem Stadium einer unterbewussten Verhandlung heraus, wird explizit und endgültig sentdeckt<. Diese Entdeckung erfolgt entlang folgender drei Felder: Moment eines katalytischen Hochgefühls (Mühl), Kulturkritik (Hackländer, Gerstäcker) des beschleunigten Lebens, belastende Routine und Ungerechtigkeit (Trollope, Daumier). Es wird übergeordnet zum 
Massenphänomen und kann über die Vielfalt nationaler und individueller Verschiedenheiten hinweg idealtypisch in etwa wie folgt rekonstruiert werden.

Reisende fanden sich zur Mitte des 19. Jahrhunderts tendenziell frühzeitig am Bahnhof ein, warteten weit deutlicher als zuvor (und oftmals dicht gedrängt) in klassenspezifischen Umgebungen und sahen sich (außer in England, Belgien und den USA) einer stärkeren Formalisierung als in der Frühphase gegenüber. Diese vor allem in Deutschland und Frankreich praktizierte Formalisierung in Form der Etablierung des betrieblichen Prinzips eines stationären Warteimperativs fand dabei seinen (ambivalenten) Niederschlag in den literarisch-künstlerischen Quellen jener Zeit. Während das Festhalten der Reisenden in den Wartesälen einerseits noch den katalytischen Charakter der Vorfreude auf den Reiseantritt verstärkte (Mühl), wurden im Zustand dieses erzwungenen Zwischenaufenthalts zugleich die (neuen) Abhängigkeiten und Ungleichheiten der modernen Gesellschaft besonders sichtbar und als negativer Zustand erlebt (Daumier).

Je stärker das Phänomen einer zu verhandelnden Zeitspanne vor Abfahrt ins Bewusstsein der Reisenden rückte, desto wichtiger wurde die Bedeutung kompensatorischer Maßnahmen, die zusammengenommen eine Kulinarisierung, Mediatisierung und Kommerzialisierung des Wartens erzeugten. Der betriebliche Zwang zum Warten wurde dabei vor allem dort versucht zu kompensieren, wo er besonders stark ausgeprägt war. So wundert es kaum, dass die Wartesäle in Deutschland wie in keiner anderen Eisenbahnnation durch umfangreiche Restaurationsbetriebe erweitert wurden. Die Existenz eines durch den modernen Massenverkehr selbst geschaffenen Temporalphänomens erschloss somit eine ganze Reihe neuer Geschäftsfelder. Warten und dessen gleichzeitige wirtschaftliche Verwertung gehen damit spätestens seit Mitte des 19. Jahrhunderts Hand in Hand.

Die Warteerfahrung und Wartepraxis am Bahnhof bilden damit bereits ab Mitte des 19. Jahrhunderts das gesamte Spektrum der sozialen Realität ab: Warten ist hier bereits für die einen Konsum und Repräsentation, für die anderen aber Spiegel eigener sozioökonomischer Abhängigkeiten, ungleicher Machtverhältnisse und geschlechtsspezifischer Konventionen. Trotz der baulich-betrieblichen Zwänge und einer heterogenen Verhandlung der Warteerfahrung wird der Zwischenaufenthalt in dieser Phase jedoch noch nicht als kollektive Problemstelle innerhalb einer stärker zeitökonomisch ausgerichteten Gesellschaft problematisiert. Der Zustand des Wartens wird hier offenbar noch nicht zum allgemeinen Stiefkind einer sich wenngleich bereits beschleunigenden Moderne erklärt. 



\section{Blütephase des Eisenbahnwesens Warten im modernen Großstadtbahnhof zwischen Kultivierung und >Verflüssigung، (1870-1900)}

Die technischen Entwicklungen des Eisenbahnwesens im letzten Drittel des 19. Jahrhunderts waren durch weitreichende Verbesserungen geprägt, die sich übergeordnet in der Steigerung von Sicherheit, Geschwindigkeit, Komfort und Effizienz niederschlugen. Während in dieser Zeit in technischer Hinsicht aufwendigere Tunnel- und Brückenbauten realisiert und die Elektrifizierung des Antriebs erprobt wurden, konnten mit der Entwicklung des luxuriösen >Pullman-Schlafwagens`(1872), verbesserter Beleuchtungs- und Beheizungssysteme oder der Einführung des Durchgangswagen (1870) wesentliche Komfortverbesserungen auf der Strecke geschaffen werden. ${ }^{1}$ Zudem bewirkte eine Vielzahl von fatalen Eisenbahnunglücken die Entwicklung verbesserter Bremstechnik und eines lückenlosen Signalwesens, die zusammen die Sicherheit des Eisenbahnwesens immens erhöhten. Diese Entwicklungen standen dabei stets im wechselseitigen Verhältnis einer stark wachsenden Verkehrsnachfrage. Während die Zunahme des Eisenbahnverkehrs einerseits als Treiber technischer Entwicklungen fungierte, induzierten die erreichten Sicherheits- und Komfortverbesserungen ihrerseits wiederum eine gesteigerte Verkehrsnachfrage. Im deutschen Kontext ist hinsichtlich des rapiden Verkehrszuwachses innerhalb des Zeitraums zwischen 1870 und 1900 insbesondere die Reichsgründung im Januar 1871 als entscheidender Impuls zu nennen, der selbst für das wachstumsverwöhnte Eisenbahnwesen eine neue Dimension der Verkehrssteigerung einzunehmen schien. So bilanzierte etwa der Vorsitzende des einflussreichen Vereins für Eisenbahnkunde Berlin, Theodor Weishaupt, im Herbst 1871 angesichts der durch die Reichsgründung bewirkten Verkehrsentwicklungen:

»(...) der Verkehr von Norden nach Süden - aus den deutschen Seestädten nach dem Innern des Landes - [hat] eine so ungewöhnliche Stärke angenommen, dass die Betriebsmittel der hierdurch betroffenen Bahnen auch nicht entfernt mehr genügen. Ueberhaupt sind die vorhandenen Betriebsmittel der Bahnverwaltungen zur Bewältigung der gesteigerten Verkehrsanforderungen unzureichend und kann leider durch 
die stattgehabten umfangreichen Bestellungen an Wagen und Maschinen für den Augenblick dem Bedürfniss noch nicht genügt werden. «²

Solche Kapazitätsengpässe, die auch zusätzlich durch Tarifsenkungen und die verbreitere Einführung der preisgünstigen vierten Wagenklasse stimuliert wurden, waren nur allzu typisch für das letzte Drittel des 19. Jahrhunderts. Die Phase kann damit angesichts der vielen sicherheits- und kundenorientierten Entwicklungen als Beginn der Blütephase des Eisenbahnwesens bezeichnet werden, in der die Eisenbahn den unangefochtener Hauptverkehrsträger bildete und deren Triumphzug sich noch bis zum 1. Weltkrieg erstrecken sollte. Zugleich war diese Entwicklungsphase wie auch in den Jahrzehnten zuvor nicht von einer linearen Wachstumsentwicklung, sondern von zwischenzeitlichen Stagnations- und Regressionsphasen geprägt. So führte im deutschen und österreichisch-ungarischen Kontext besonders die nach 1873 durch Spekulationen und überhitzte Konjunktur ausgelöste >Gründerkrise ${ }^{3}$ dazu, dass Ende der 1870er Jahre massive Kosteneinsparungen zu einem zwischenzeitlich rückläufigen Verkehrsangebot führten und vermehrte Versuche unternommen wurden, Elemente des kostengünstigeren US-amerikanischen Eisenbahnwesens in Deutschland zu adaptieren. Im Resultat dieser wirtschaftlichen Krisenzeiten entstand mancherorts vereinzelt gar der Einsatz von kleineren und effizienteren Dampfomnibussen, wie sie bspw. Ende der 1870er Jahre auf der Berlin-Görlitzer-Bahn zwischen dem Görlitzer Bahnhof und dem südöstlichen Vorort Grünau verkehrten. ${ }^{4}$

Der primär von technischen Innovationen und Komfortverbesserungen geprägte Ausgang des 19. Jahrhunderts beeinflusste vorwiegend den Streckenbau oder den Wagenpark, aber weniger den Bau von Empfangsgebäuden. Carol Meeks vermerkt hinsichtlich der Innovationsverlagerung in dieser Phase:

»While these mechanical and physical ameliorations were being adopted, no completely new type of station was developed; instead, a parallel process of modification and improvement of old types occurred. $\aleph^{5}$

Während die Verbesserungen vor allem in einer nochmals gewachsenen Komfort- und Dienstleistungsausstattung im Inneren der Empfangsgebäude mündeten, umfassten die Innovationen im Bereich der Gebäudetypologien im Wesentlichen zwei Aspekte, die massive Implikationen für Erfahrung und Wahrnehmung des systemischen Wartens haben sollten. Zum einen der Bau von Durchgangsbahnhöfen und damit verbundener Weiterentwicklung des Empfangsgebäudes mit einseitiger Erschließung um eine

Theodor Weishaupt, »Verein für Eisenbahnkunde zu Berlin. Sitzung am 12. September 1871.«, Deutsche Bauzeitung 5, Nr. 40 (1871): 319.

3 Rosenberg spricht von einer ab 1873 einsetzenden und bis in die frühen $1890 e r$ anhaltenden >Croßen Depression< der Bismarckzeit. Hans Rosenberg, Grosse Depression und Bismarckzeit: Wirtschaftsablauf, Gesellschaft und Politik in Mitteleuropa (Berlin: de Gruyter, 1967). kunde zu Berlin. Protocoll der Versammlung vom 11. März 1879«, Zeitschrift für Bauwesen XXIX. (1879): 469-76. 
Anordnung in sSeitentieflage . Zum anderen bestand die entscheidende Innovation jener Phase im zunehmenden Aufbau von Zirkulationsflächen in Form von Quer- und Kopfbahnsteigen innerhalb von Kopfbahnhöfen. Verbindendes Prinzip dieser Innovationen war die baulich-organisatorische Zielstellung einer sicheren und zentralisierten Führung großer Passagierströme, die sich aus dem Druck eines zum Massenverkehr entwickelten Eisenbahnwesens ergab. In der Folge entstanden in jener Phase Verkehrslösungen, deren Prinzipien zum Teil noch heute als vorbildlich und zweckmäßig betrachtet werden können. ${ }^{6}$ Sie sollen im Folgenden skizziert und hinsichtlich ihrer Auswirkungen auf die Praxis und Erfahrung des verkehrlichen Wartens beleuchtet werden.

\subsection{Bauliche und betriebliche Rahmenentwicklungen}

\subsubsection{Empfangsgebäude in Seitentieflage: Der sTyp Hannover`}

Nach Etablierung einer >Normalform` großstädtischer Empfangsgebäude in Gestalt eines Kopfbahnhofes mit seitlichen Erschließungstrakten für die getrennte An- und Abfahrt sowie einem repräsentativen Kopfgebäude für die Bahnverwaltung besteht die größte typologische Weiterentwicklung im letzten Drittel des 19. Jahrhunderts im Bau von Durchgangsbahnhöfen. Das deutsche Eisenbahnwesen zeigte hier mit der daran geknüpften Entwicklung des Empfangsgebäudes in Seitentieflage die größte Innovationskraft hinsichtlich des Bahnhofsbaus. Der vor allem in Deutschland seit der Reichsgründung immens gewachsene Zugverkehr und der Drang zur Reisezeitverkürzung auf den durch Netzzusammenschlüsse immer längeren Verbindungen erzeugten örtlich eine Abkehr vom Prinzip des stumpf endenden Kopfbahnhofes. Zwar hatten Metropolen wie Berlin, Paris oder London, die den Typen des Kopfbahnhofes bereits frühzeitig etabliert hatten, inzwischen innerstädtische Verbindungsbahnen für die Zirkulation zwischen der vielen Kopfbahnhöfen geschaffen (Berlin - Ringbahn, Paris - Gürtelbahn), doch Neubauten sollten zukünftig den Bahnverkehr ohne Stillstand am Prellbock durch sich hindurch fließen lassen.

Erster Bahnhofsbau dieser Art auf deutschem Boden war der Hannoveraner Hauptbahnhof. Der zwischen 1871 und 1879 realisierte und 1881 eröffnete Bahnhof löste einen bestehenden Vorgängerbau ab und schuf ein Empfangsgebäude in Seitenlage, dessen Gleiskörper in einer Höhenlage von 4,5 m über dem Straßenniveau lag. Die entscheidende Innovation des >Typs Hannover bestand dabei im Zugang zu den Gleisen, die nicht mehr wie noch zuvor zu Fuß überschritten werden mussten, sondern durch ein umfangreiches Tunnelsystem erschlossen wurden. Die Erschließung über nach Abfahrt, Ankunft und Gepäck getrennte Tunnelwege erschien den Architekten und Ingenieuren jener Zeit angesichts des zunehmenden Verkehrs als bedeutender Innovationsschritt zur Erhöhung der Betriebssicherheit und schloß an die zuvor bereits im englischen Kontext durch Errichtung von Freitreppen etablierte Form der erhöhten Betriebssicherheit an. Tatsächlich kamen die Reisenden in diesem Tunnel-Bautypus nicht 
Abbildung 29: Grundriss des Hannoveraner Hauptbahnhofs mit seinen dominanten Tunnelwegen (1881). Dieser neue Bautypus in Seitentieflage verhinderte die sonst üblichen Gleisüberschreitungen, jedoch zum Preis von verlängerten Wegen. Zudem lagen die Wartesäle weit von den Gleisen entfernt im stadtseitigen Empfangsgebäude und verfügten über keinerlei Sichtbezüge zu den Zügen.

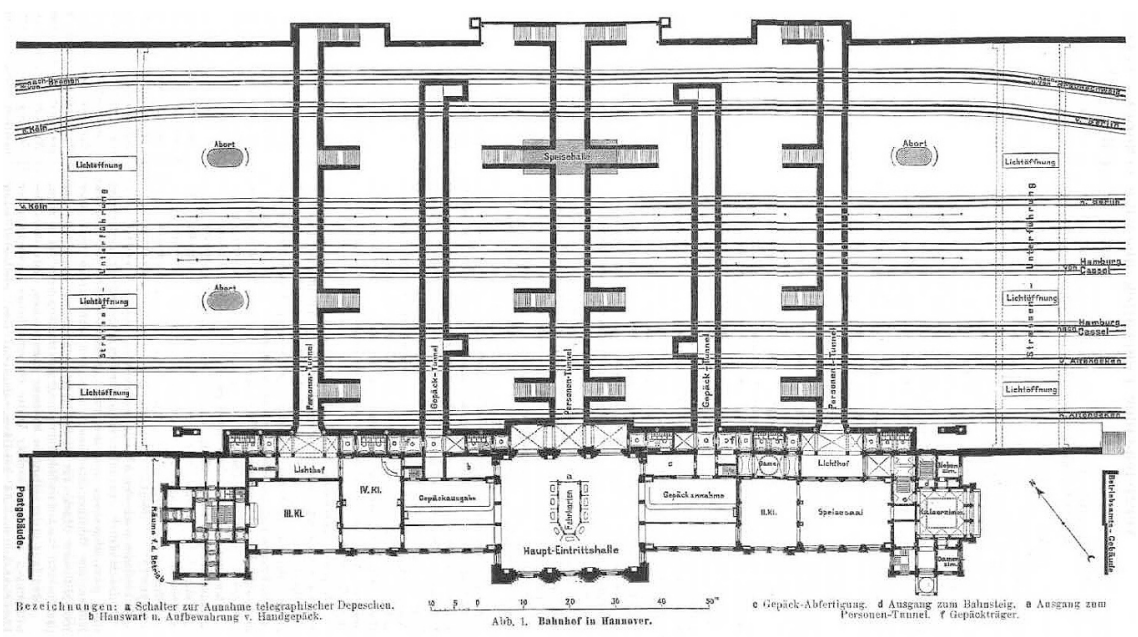

Quelle: Centralblatt der Bauverwaltung 1888, Nr. 32a, S. 350.

mehr in Kontakt mit dem Gleiskörper, weil nunmehr vom Personentunnel Treppenaufgänge zu den jeweiligen Bahnsteigen führten. Da das Empfangsgebäude auf Niveau der Straße lag, konnten die Bahnsteige mit nur einer Treppe und dadurch unter »thunlicher Verminderung der verlorenen Steigungen ${ }^{7}$ erreicht werden. Entsprechend wurde diese Anlage auch den englischen Bahnhöfen als überlegen eingestuft, da in diesen meist zwei Freitreppen auf dem Weg zum Bahnsteig absolviert werden mussten, um schlussendlich auf demselben Niveau anzugelangen.

Der >Typ Hannover wurde fortan zum Muster, das sich schnell verbreitete und die konzeptionelle Grundlage für viele weitere Bahnhofsbauten bildete, die sich bis zum heutigen Tag bewährt haben. ${ }^{8}$ Die Errichtung des ursprünglich konzipierten Tunnelsystems verursachte jedoch hohe Kosten und wurde in dieser konkreten Form mit fünf Tunneln nur noch in Straßburg (1883) realisiert. Überhaupt wurde die gefeierte Innovation der dadurch erhöhten Betriebssicherheit bereits von Beginn an wieder zur Disposition gestellt. So war in Architektenkreisen nach Errichtung des Hannoveraner Hauptbahnhofs nicht vollends klar, ob bzw. in welcher Form genau der Tunnelerschließung die Zukunft gehören sollte: 
»Die Thatsache, dass sich die Eisenbahn-Ingenieure zum Theil nur schwer mit diesem Construetionsmittel abgefunden und in der Anordnung der Tunnelanlagen, freilich auch nicht minder in den der Freitreppen eine sehr erhebliche Erschwernis für die Reisenden erblickt haben, von welcher, selbst auf Kosten gröserer Betriebssicherheit, wenn irgend möglich abzusehen sei. Diese Ansicht musste jedoch gegenüber der immer dringender werdenden Frage der Entlastung der Stationsbeamten von der Verantwortlichkeit für die Sicherheit der Reisenden mehr und mehr in den Hintergrund treten, und so finden wir bei allen neueren Entwürfen für grössere preussische Bahnhöfe den Grundsatz durchgeführt, dass die Ueberschreitung von Celeisen, soweit thunlich, überhaupt auszuschließen, unvermeidlichenfalls aber auf die Ueberschreitung höchstens eines Celeises zu beschränken sei. «?

Die Motive der Erhöhung der Betriebssicherheit und der Personalentlastung von Aufsichtspflichten in der Bahnhalle bewirkten die Errichtung eines Bautyps, der für die Betrachtung der historischen Entwicklung des verkehrsinduzierten Wartens von essentieller Bedeutung ist. Weil bei Durchgangsbahnhöfen jenes Typs die Wartesäle von den Bahnsteigen weit entfernt lagen bzw. keine direkte Sichtverbindung aufwiesen, verursachte die Errichtung des >Typs Hannover auf Seiten der Reisenden eine überaus negative psychologische Reaktion. Sie war dadurch begründet, dass - wie aus dem Grundriss in Abbildung 29 ersichtlich wird - die Wartesäle durch den Höhenunterschied zwischen Empfangsgebäude und Gleiskörper nicht mehr direkt an die Bahnsteige angrenzten und zunächst erst die Personentunnel passiert werden mussten. Zwar waren die Tunnel in Hannover mit gelb glasierten Mettlacher Fliesen ausgestattet, die besonders freundlich wirken sollten ${ }^{10}$ und es führte zudem auch ein Tunnel eigens direkt von den Wartesälen zu den Bahnsteigen, um damit den langen Weg zurück zur Haupthalle und dessen Tunnel zu sparen, doch es fehlte hier die bereits lang etablierte und psychologisch elementare Sichtbeziehung zum Gleis. Die neue Anordnung schien damit zwar die Sicherheit zu erhöhen, doch sie schien gleichzeitig quer zu den Ansprüchen der Reisenden und ihrer an Sichtbeziehungen geknüpften temporalen Selbstkontrolle zu liegen. Dieses Dilemma erzeugte in den Fachblättern heftige Diskussionen. In vollem Bewusstsein der Einschränkungen für Reisende versuchte der Leiter der technischen Ausführung und (Mit-)Begründer des neuen Bautypus des Empfangsgebäudes in Seitentieflage, Ernst Grüttefien, wenige Jahre nach Eröffnung dennoch den von ihm geschaffenen Typus im Namen der Sicherheit zu verteidigen und konstatierte:

»Im allgemeinen darf angenommen werden, das das heutige Publicum in jener Forderung keine Unbilligkeit mehr erblickt und der Rücksicht auf Betriebs Sicherheit seinerseits, durch Uebernahme einiger Unbequemlichkeiten gern Rechnung trägt. «"1

Tatsächlich schien sich im Anschluss die Errichtung dieses Typs weiter durchzusetzen. So wurden die Umbauten von Köln (1894), Bremen (1898), Nürnberg (1896), Essen 
(1902), Göttingen, Halle (1888) und Berlin (Umbau Ostbahnhof zum Durchgangsbahnhof für die Stadtbahn, 1881) allesamt in Seitentieflage errichtet, wenngleich mit weniger Tunneln als in Hannover. Doch der Stachel der veränderten Wahrnehmung des Wartens ohne den gewohnten Blick auf die Gleise und in einiger Entfernung von ihnen saß offenbar tief. Denn die spezifische Konstellation des Zusammenwirkens baulicher Organisation und der psychischen Situation der Reisenden bewirkte in Hannover und anderen Städten dieses Bahnhofstyps »einen ständig abnehmenden Besuch der Warteräume, die schließlich überwiegend als Bahnhofsgaststätte für das Stadtpublikum geführt wurden $\ll^{12}$ und in denen der Anteil der Reisenden gerade einmal noch 20 Prozent ausmachte. Der zuvor etablierte stationäre Warteimperativ erlebte mit dem Typus Hannover somit seine erste Wahrnehmungskrise. Zwar wurde, wie bereits dargelegt, auch schon stellenweise zuvor das Einschließen der Reisenden in die Wartesäle kritisiert, jedoch schien hierbei die jeweils bestehende Sichtverbindung zum Zug die Einbußen an Bewegungsfreiheit noch kompensieren zu können.

Abbildung 30: Grundriss des Hildesheimer Hauptbahnhofs mit Wartesaalgebäude in Insellage auf Bahnsteig (1884).
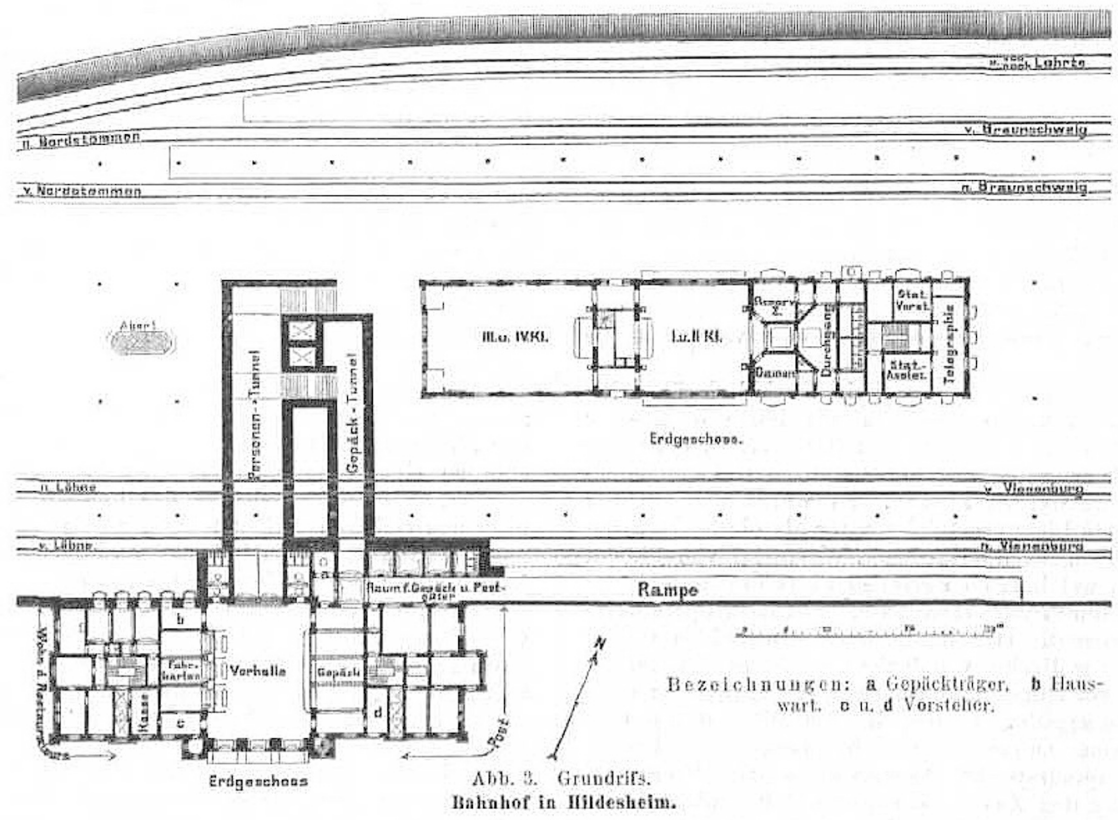

Quelle: Centralblatt der Bauverwaltung 1888, Nr. 32a, S. 352.

Infolge der fachlichen und öffentlichen Kritik an der Anordnung des neuen Hannoveraner Hauptbahnhofs samt seiner Irritationen für das Reisepublikum versuchte daher Ernst Grüttefien mit der Errichtung von Wartesälen auf den Bahnsteigen eine 
Kompromisslösung zu erreichen, um den Bahnverkehr wieder stärker ins Sichtfeld der Reisenden zu rücken. Mit dem Neubau des Bahnhofes von Hildesheim (1888) wurde dieser Kompromiss erstmals realisiert. Hier bestand zwar ein Personentunnel für die erschließenden Zuwegungen zum Bahnsteig, jedoch grenzte der Wartesaaltrakt nicht der Vorhalle an, sondern lag auf einem besonders breiten Bahnsteig und damit direkt neben den Zügen. Diese Anordnung erhielt von der Akademie für Bauwesen 1888 ein durchaus positives Gutachten und führte zu einer "großen Beliebtheit beim Publicum « ${ }^{13}$. So fasst Grüttefien das Gutachten in Bezug auf die Lösung eines Wartesaaltrakts in Insellage auf dem Bahnsteig wie folgt zusammen:

»Die Anordnung einen zur Seite der Celeise liegenden Empfangsgebäudes mit tief liegenden Abfertigung- und Warteräumen führe nicht nur zu einer architektonisch unvollkommenen, sondern auch zu einer für den Reisenden unerwünschten und unbequemen Lösung. In ersterer Beziehung aus dem Crunde, weil das Cebäude von der Bahnsteigseite aus um ein Ceschoß gekürzt, also in seiner Höhenentwicklung verstümmelt erscheine; in Rücksicht auf die Bequemlichkeit der Reisenden deshalb, weil dieselben von den Wartesälen nach den Bahnsteigen verhältnismäßig weite Wege zurückzulegen haben.«

Grüttefien fährt daraufhin fort und geht auf den spannenden Aspekt einer psychologischen Argumentation der Akademie ein:

»Ueberdies liege es in der Gewohnheit der Reisenden und sei ein berechtigtes Verlangen derselben, von den Fenstern der Wartesäle aus die Stellung und den Lauf der Züge überschauen und sich persönlich die Ueberzeugung davon verschaffen zu können, wann der geeignete Zeitpunkt zum Besteigen der Züge gekommen sei.«

Schließlich fällt das Plädoyer der Akademie für Bauwesen wie folgt aus:

»Es empfehle sich deshalb, das Empfangsgebäude mit allem Zubehör inselförmig zwischen den Geleisen anzuordnen, oder, sofern hierzu der nöthige Raum mangeln sollte, mindestens die Wartesäle an der angegebenen Stelle anzulegen und die Abfertigungs- und Betriebsräume nöthigenfalls in einem am Bahnhofsvorplätze tiefliegenden Vorgebäude unterzubringen. $\ll^{14}$

Dieser positiven Einschätzung der Akademie widerspricht jedoch wiederum die Eisenbahnverwaltung vehement und argumentiert dagegen aus sicherheitspolitischer Sicht:

»Es wurde vielmehr hervorgehoben, daß der Reisende unmöglich imstande sei, die Bedeutung der Zugbewegungen auf einem größeren Bahnhofe selbständig zu beurtheilen und deshalb unzweifelhaft sicherer gehe, wenn er das Abrufen zum Ein- 
steigen in den Wartesälen abwarte, welches stets so zeitig erfolge, daß der Zug ohne Uebereilung erreicht werden könne. $\aleph^{15}$

In der Folge wird das Experiment eines inselförmigen Empfangsgebäudes nur noch selten und nur in Fällen eines lokal überschaubaren Verkehrs installiert, so etwa in Erfurt oder Düsseldorf. Für komplexere Bahnhofskonstellationen blieb diese Insellösung vom eisenbahntechnischen Standpunkt betrachtet immer mit einem Restrisiko behaftet, weil die Betriebssicherheit bei dieser Anlage durch einige wenige unvermeidbare Gleisüberschreitungen nicht vollständig gewahrt werden konnte.

Zusammenfassend zeigte sich mit Etablierung dieser neuen Anordnung, dass der nutzerseitigen Beliebtheit gleisnaher Wartesäle von Seiten der Ingenieure mit Argumenten der Sicherheit und Bequemlichkeit (Treppensteigen) widersprochen wurde, aber zudem auch ein latentes Misstrauen gegenüber dem korrekten Verhalten der Reisenden herrschte, das schon Perdonnet viele Jahre zuvor anprangert hatte. Die zentrale Orientierung an Sicherheit statt an Kundenwünschen blieb jedoch auch für die kommenden Jahrzehnte der Common Sense unter den (deutschen) Planern und Architekten. So führte Cauer 1926 an:

»Der Vorteil des unmittelbaren Bahnsteigzugangs von den Wartesälen aus kann nur so lange mit Grund angeführt werden, als es sich um verhältnismäßig kleine Bahnhöfe handelt, bei denen nur zwei durchgehende Hauptgleise vorhanden sind «. ${ }^{16}$

\subsubsection{Neue Zirkulations- und Wartezonen: Mittel-, Kopf- und Querbahnsteige und das Paradigma eines reibungslosen Betriebs}

Neben der Anlage von Personen- und Gepäcktunneln in Empfangsgebäuden in Seitentieflage markierte die Einrichtung erweiterter Zirkulationszonen in der Gleishalle einen weiteren zentralen Aspekt der baulich-betrieblichen Rahmenentwicklung des späten 19. Jahrhunderts. Diese erweiterten Zirkulationszonen bewirkten eine für die Warteerfahrung entscheidende Weiterentwicklung in Richtung der Herauslösung des vorbereitenden Aufenthalts aus seinem vormals stationären Charakter und bedingten eine (moderne) Tendenz der >Verflüssigung ‘ des Wartens. Grund für die Erweiterung solcher Zirkulationszonen war wiederum die Verkehrszunahme im letzten Drittel des 19. Jahrhunderts, die zwei Problemlagen auf den Plan rief: Erstens eine erhöhte Sicherheitsproblematik durch Gleisüberschreitungen, zweitens die Problematik vermehrter Kreuzungen von Passagier- und Gepäckströmen.

\section{a) Lösung der Sicherheitsproblematik}

Um die gesteigerte Verkehrsnachfrage bedienen zu können, mussten die städtischen Großbahnhöfe mehr Gleise als zuvor aufnehmen und sich dadurch verbreitern. Bei Lage 
der Empfangsgebäude parallel zu den Gleisen waren Reisende deshalb immer öfter dazu gezwungen, die direkt am Empfangsgebäude anschließenden Gleise zu überschreiten, was mit einer Vielzahl von Gefahren, Hindernissen und Störungen des (pünktlichen) Betriebsablaufs verbunden war. Zur Lösung dieses Problems legte man Mittelbahnsteige an, die zwischen den Gleisen errichtet wurden und einen sicheren Zugang zu den Zügen im Zentrum der Gleishalle ermöglichten. Um diese Mittelbahnsteige vom Empfangsgebäude aus zu erreichen, wurden Quer- oder Kopfbahnsteige angelegt, die damit neben den bestehenden Zirkulationsräumen (Vestibüle, Korridore) einen neuen Hauptverkehrsweg erzeugen und eine wesentliche Weiterentwicklung hinsichtlich der im Bahnhof realisierten Passagier- und Gepäckströme begründen sollten. ${ }^{17}$

\section{2) Vermeidung von Kreuzungsbewegungen}

Neben der Lösung von Sicherheitsfragen markierte das übergeordnete Bestreben nach einem reibungslosen Betrieb ohne Kreuzungsbewegungen ein weiteres Motiv für die Errichtung von Kopf- und Querbahnsteigen. Wie sich in den vorgegangenen Kapiteln zeigte, war die Intention der Gewährleistung von kreuzungs- und kollisionsfreien Verkehrsströmen von Reisenden und Gepäck innerhalb der Gebäude bereits seit Jahrzehnten etablierter Bestandteil des Baudiskurses. ${ }^{18}$ Jedoch erzwang das immens ansteigende Produktions- und Verkehrswachstum der Gründerzeit und die dafür notwendigen Bauten ungleich stärkere Anstrengungen nach möglichst funktionalen Gestaltungen anzustellen. Die veränderte Grundproblematik bestand zum Ende des 19. Jahrhunderts vor allem darin, in zuvor ungekanntem Ausmaße Menschen ohne Stockungen nicht nur durch Bahnhöfe, sondern zugleich auch durch Schwimmbäder, Ämter, Krankenhäuser oder andere öffentliche Einrichtungen zu leiten. Erklärtes Ziel der architektonischen Praxis des späten 19. Jahrhunderts wurde daher zunehmend, mittels eines auf absolute Zweckmäßigkeit ausgerichteten Raumprogramms Stauungen und Kreuzungen zu vermeiden und somit drei wesentliche Ressourcen einzusparen, die im späten 19. Jahrhundert zu Domänen avancierten: Arbeit, Zeit und Kosten.

In Folge dieses (erzwungenen) Bestrebens etablierte sich der Bau eines Gebäudetypus, der nicht mehr allein in seiner baulichen Materialität, sondern vielmehr durch die in ihm verhandelten Ströme charakterisiert wurde. Solche von Susanne Jany treffend als »Prozessarchitekturen « $" 19$ bezeichneten Gebäude zielten darauf ab, jegliche Objektflüsse (Materialien als auch Menschen) in reibungslose Vorgänge zu verwandeln und öffentliche Gebäude »als gerichtete, störungsfreie und beschleunigte Prozesse (...) in Ana-

17 Radlbeck, »Bahnhof und Empfangsgebäude«, 49. Kopfbahnsteige wurden zwar auch in Bahnhöfen mit parallel zu den Gleisen liegenden Gebäuden errichtet, jedoch in weit kleinerem Maßstab als in Kopfbahnhöfen.

18 Hierzu sei etwa insbesondere nochmals auf die in der Allgemeinen Bauzeitung von 1838 veröffentlichten funktionalen Cesichtspunkte zum Bahnhofsbau verwiesen, die bereits dezidiert darauf abzielten, eine »Zirkulazion der Reisenden und Güter ohne Hemmnisse und Störungen« zu gewährleisten. Üeber Depots und Sammelplätze für Waaren und Reisende (Stazionsplätze) bei Eisenbahnen«, 163.

19 Susanne Jany, »Operative Räume. Prozessarchitekturen im späten 19. Jahrhundert«, Zeitschrift für Medienwissenschaft 7, Nr. 1 (2015): 33-43. 
logie $\mathrm{zu}$ industriellen Verfahren ${ }^{20} \mathrm{zu}$ entwerfen. Vorbild dieser Prozessarchitekturen wurde dabei das Paradigma wirtschaftlicher Produktion und damit die auf Zweckmäßigkeit, Zeit- und Kosteneffizienz ausgerichtete Fabrik der Hochindustrialisierung. Die Effizienz der Fabrik resultierte hinsichtlich ihrer inneren Disposition vor allem daraus, dass Materialströme nach dem »Gleichstromprinzip « ${ }^{21}$ in nur einer gerichteten Bewegung absolut kreuzungsfrei durch unterschiedliche Produktionsabteilungen sprozessiert « wurden. Das Erfolgsrezept des prozessarchitektonischen Prinzips bestand somit im Aufbau einer Raumordnung, die sich aus der linearen Abfolge einzelner Operationen ergab. Da es dabei gleichgültig war, ob Materialien oder Passagiere sprozessiert< werden sollten, konnte das Prinzip auf unterschiedlichste Anwendungskontexte übertragen werden, so auch auf den Grundrissentwurf von Bahnhöfen. In der Folge wurde der Bahnhof

»(...) als >metabolisierendes«, sprich verarbeitendes System vergegenwärtigt, das die Menge der Reisenden nicht nur im Stationsgebäude aufnimmt, sondern über Eingangshallen, Fahrkarten- und Cepäckschalter, über Warteräume, Gänge und Kontrollen durch den Bau hindurch prozessiert. ${ }^{22}$

Merkmal solcher Prozessarchitekturen war demnach, dass aufgrund der linearen Abfolge kein Punkt im Bahnhof zweimal betreten werden musste und keine Gegenströmungen entstanden. Das Paradigma kreuzungsfreier Ströme konnte jedoch vor allem in Stationen mit kopfseitiger Erschließung nur allzu leicht durch das Zusammentreffen abfahrender und ankommender Reisender in der Gleishalle torpediert werden. Jene Begegnungszone wurde daher zum neuralgischen Punkt und bedurfte besonderer Aufmerksamkeit. Eingebettet in das übergeordnete Konzept eines »baulichen Organismus« empfiehlt Eberhard Wulff deshalb im Jahr 1882 für die Verhinderung solcher Kreuzungsbewegungen auf Endstationen:

»(...) die Circulation der Abreisenden und Ankommenden sowohl innerhalb der Empfangsgebäude wie auf den Perrons in möglichst wenige und klar vorgezeichnete Hauptrichtungen zu concentriren und die Zahl der möglichen Kreuzungen auf ein Minimum zu reduciren. Die Schwierigkeit, dieses zu erreichen, steigt natürlich mit der Zahl der einmündenden und abzweigenden Linien und hilft man sich in den Fällen, wo Kreuzungen nicht zu vermeiden sind, dadurch, dass man den nach verschiedenen Richtungen hin zu passirenden Räumen entsprechende Breite gibt. « ${ }^{23}$

Entsprechend zeigte auch hier ein breit angelegter Kopfbahnsteig entscheidende Vorteile zur Vermeidung (oder zumindest Verringerung) von durch Kreuzungsbewegungen verursachten Stauungen. Die jahrzehntelange Suche nach architektonischen Lösungen für die Problematik der strikten Trennung abfahrender und ankommender Reisender

20 Ebd., 43.

21 Wilhelm Franz, Fabrikbauten, Handbuch der Architektur (4. Teil, 2. Halband, 5. Heft) (Leipzig: Gebhardt, 1923), 126.

22 Jany, »Operative Räume. Prozessarchitekturen im späten 19. Jahrhundert«, 33.

23 Wulff, Das Eisenbahn-Empfangs-Cebäude nach seinen praktischen Anforderungen und seiner künstlerischen Bedeutung, 17 [Herv. i. O.]. 
konnte (endlich) gelöst werden, indem beide Gruppen in den Bahnhöfen des späten 19. Jahrhunderts nunmehr denselben Zirkulationsraum nutzten und durch separate Eingänge an den Enden des Querbahnsteigs unmittelbar in die Stadt austreten konnten, ohne die Eingangshalle nutzen zu müssen und dort Gegenströmungen zu verursachen. Der Querbahnsteig - im Englischen als concourse bezeichnet - nahm schließlich zuvor getrennte Funktionen in ein und derselben Fläche auf und wurde zur »vast mixing chamber« bzw. zum »self-adjusting traffic center. ${ }^{24}$

Aufgrund der zahlreichen Sicherheits- und Prozessvorteile markierte die Errichtung solcher neuen Bahnsteigflächen daher zusammengenommen eine der bedeutendsten Erweiterungen des Baus von Empfangsgebäuden bis zur Jahrhundertwende. Die Vorteile einer sich selbst organisierenden Verkehrszone bewirkten, dass in Großstadtbahnhöfen das seitlich der Gleise gelegene Empfangsgebäude allmählich aufgegeben wurde und man zur rein kopfseitigen Gebäudeerschließung überging. Wie aus der schematischen Entwicklung der Kopfbahnhöfe hervorgeht (Abbildung 31) wurden die Passagierräume im Seitenflügel - ausgelöst durch die Zweckmäßigkeit des Kopfbahnsteigs - mit den Diensträumen der Verwaltung getauscht. Oder einfacher ausgedrückt: Der Kopfbau selbst wurde nun zum Empfangsgebäude.

Abbildung 31: Schematisch-tendenzielle Entwicklung des Kopfbahnhofes.
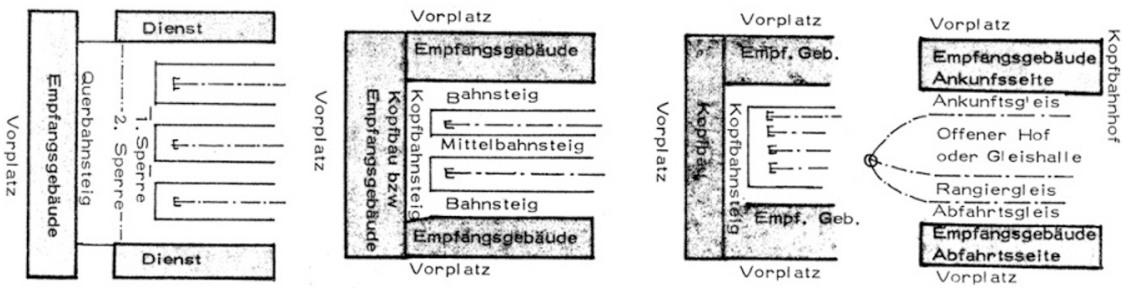

Quelle: Radlbeck 1981, S. 49.

Für diese Entwicklung zeigten sich die Pariser Kopfbahnhöfe als zentrale Referenz. So verfügte bereits weit vor vielen anderen Bahnhöfen jener Zeit der erste Bau des Gare du Nord (1847 fertiggestellt) über ein Zirkulationskonzept, das nunmehr im letzten Drittel des 19. Jahrhunderts zum internationalen Standard reifen sollte. Léonce Reynaud hatte den Pariser Nordbahnhof mit einem 40m breiten Kopfbahnsteig ausgestattet, der es Reisenden ermöglichte, sich frei am Kopfende der Gleise zu bewegen und diese ohne ein gefährliches Übersteigen der Gleise oder eine Beeinträchtigung des Zugverkehrs zu erreichen (Abbildung 32). ${ }^{25}$ Zudem wurde dem Kopfbahnsteig auf der Stadtseite eine ebenso breite Wandelhalle vorgeschaltet, die aufgrund ihrer immensen Ausmaße als salle des pas perdus, als `Saal der verlorenen Schritte <ezeichnet wurde. Solche

24 Meeks, The Railroad Station: An Architectural History, 79.

25 Vgl. Meeks, 61. Zugleich soll diese große Zirkulationsfläche nicht darüber hinwegtäuschen, dass, wie bereits erwähnt, die Reisenden im französischen Bahnkontext zuvor in der Regel in den Wartesälen für eine gewisse Zeit eingeschlossen wurden. 
vergleichsweise riesigen Zirkulations- und Verteilflächen existierten bereits im Rahmen großer französischer Gerichtsgebäude ${ }^{26}$ und reiften schließlich im Übertrag auf die Entwicklung von Bahnhofsgebäuden auch zu einer architektonisch wie kulturell aufgeladenen Baulegende des Eisenbahnwesens.

Diese sich demnach zum Ende des 19. Jahrhunderts immer stärker formierenden Bestrebungen in Richtung reibungsloser Zirkulation und Harmonisierung von Bewegungsflüssen lässt sich dabei wohl trefflich in den Kontext einer zeitgenössisch übergreifenden Kulturbestrebung stellen, die Georg Simmel im »ästhetischen Reiz« der Aufhebung individueller Zufälligkeiten und der symmetrisch-systematischen Organisation sah. So könnte das Verständnis der sich wandelnden Leitbilder des Bahnhofsbaus jener Zeit wohl kaum besser kontextualisiert werden, als über Simmels Beobachtung der modernen Lebenswelt und ihrer elementaren Orientierung an der Funktionsweise von Maschinen und Fabriken:

»Die absolute Zweckmäßigkeit und Zuverlässigkeit der Bewegungen, die äußerste Verminderung der Widerstände und Reibungen, das harmonische Ineinandergreifen der kleinsten und der größten Bestandteile: das verleiht der Maschine selbst bei oberflächlicher Betrachtung die die Organisation der Fabrik in erweitertem Maße wiederholt (...).. (7 $^{27}$

Auch der Bahnhof sollte in diesem Zuge seine Referenz in der Logik der Fabrik finden. In ihm wurden Stillstände rechtfertigungspflichtig, das Warten zunehmend aus seiner stationären Charakteristik gelöst und „verflüssigt«. Dies galt insbesondere für den großstädtischen Bahnhof, in dem das Warten bzw. das Spannungsverhältnis zwischen Bewegung und Verlangsamung aufgrund der herausgehobenen Temporalstruktur der Großstadt - im Ausdruck einer stärkeren Notwendigkeit und Abhängigkeit von zeitlicher Synchronisierung des wirtschaftlich, kulturell und sozial weit ausdifferenzierten urbanen Lebens - deutlicher hervortrat als im kleinstädtischen und ländlichen Bahnhofskontext.

\section{Tendenz zur ,Verflüssigungr des Wartens}

Die Errichtung solcher großdimensionierten Zirkulationszonen ist nun deshalb als elementar für die Veränderung der Wartepraxis in der Blütephase des Eisenbahnwesens einzustufen, weil sich in Folge ihres Baus das Warten auf Abfahrt in einer Reihe von (Groß)bahnhöfen bis zur Jahrhundertwende weit mehr als vorher in die Gleishalle und damit näher an die Züge verlagern sollte. Die Wartesäle erschienen somit mancherorts nicht mehr die letzte zwischen Zug und Stadt vorgeschaltete Ebene, sondern Kopfund Querbahnsteige schoben sich nun nochmals zwischen das stationäre Warten im

26 Der >salle des pas perdus` war der Ort, an dem Anwälte und Klienten ein letztes Mal miteinander interagieren und sich besprechen konnten bevor sie den Gerichtssaal betraten. Es war zudem der Ort, an dem nach Ende der Gerichtsverhandlung die Presse die Beteiligten der Verhandlung unmittelbar befragen konnte. Dieses Prinzip wird im gerichtlichen Kontext bis in die Gegenwart hinein verfolgt. Es hat zudem mit der heutigen Einrichtung von >Mixed Zones < in den Stadienkatakomben (Zone, in der Reporter und Sportler für Interviews zusammentreffen können) auch einen Übertrag in das Sportwesen erfahren. 
Saal und den Zügen in der Mitte der Wagenhalle. $\mathrm{Zu}$ dieser zonalen und damit einhergehend qualitativen Veränderung des Wartens vermerkt Meeks:

»The cross-platform, or »midway, « widened to thirty or more feet, was used as a waiting area adjacent to the train gates. $\aleph^{28}$

Auf dieser von freier Bewegung geprägten Fläche wurden die Reisenden allmählich von einer vormalig fremdgesteuerter Lenkung durch das Bahnpersonal entlassen und suchten sich ihre jeweiligen Wege zu den Gleisen zunehmend eigenständig. Diese durch den Querbahnsteig geschaffene neue Selbstverantwortlichkeit hatte nach Meeks neben der Verlagerung des Warteschauplatzes auf die Querbahnsteige auch noch eine andere direkte Auswirkung auf das Phänomen, denn:

»Once the function of the concourse was comprehended, it became possible (...) to provide separate quiet waiting areas while all moving traffic was handled in the concourse. ${ }^{29}$

Infolge der stärkeren Verlagerung der Zirkulation in die Gleishalle verloren die Warteräume mancherorts den Status eines obligatorisch zu durchschreitenden (und zu nutzenden) Raumes. Der für die Standardisierungs- und Konsolidierungsphase (1845-1870) noch so prägende stationäre Warteimperativ, die strenge Führung und Lenkung der Reisenden vom Stadtraum zum Bahnhof, begann damit erstmals zu bröckeln. Indem der Querbahnsteig mancherorts auch direkt aus der Eingangshalle heraus erreicht werden konnte, wurden damit die Wartesäle stärker von ihrem vormaligen Durchgangscharakter befreit. Weil sich die Reisenden aufgrund stärkerer Routinisierung der Bahnreise zunehmend selbst zurechtfanden und zudem die Sicherheit durch Wegfall von Gleisüberschreitungen gegeben war, konnte die vormalige Funktion der Wartesäle als einer Art `Zwangs-Schleuse $<$ aufgehoben, das systemische Warten allmählich in den Stand einer fakultativen Passagierentscheidung gehoben werden. Zusammenfassend trat somit das verkehrliche Warten auf Eisenbahnen zum Ende des 19. Jahrhunderts ortsspezifisch in eine Phase eines in die Fläche verteilten Wartens und damit in die Phase einer >Verflüssigung des Wartens ein. Diese Tendenz löste jedoch nicht das bestehende Prinzip des stationären Wartens ab, sondern vielmehr erhielt das Raumprogramm des Bahnhofs durch Einrichtung von Quer- und Kopfbahnsteigen eine stärkere Differenzierung zwischen Zonen der Zirkulation und Zonen der Retardierung von Strömen, die beide nebeneinander existierten.

Wenngleich das baulich-operative Novum des Quer- und Kopfbahnsteiges aufgrund des Verkehrszuwachses in immer mehr Großstadtbahnhöfen etabliert wurde, ist zudem $\mathrm{zu}$ vermerken, dass diese Entwicklung wiederum weder linear noch flächendeckend verlief. Wie sich mit dem noch folgenden Kapitel 8.4.1 zu zeigen sein wird, entsprachen etwa die neuen Kopfbahnhöfe Berlins, die um 1870 fertiggestellt wurden, noch gänzlich dem stationären Warteimperativ, in dem zunächst in den Wartesälen verpflichtend verweilt werden sollte, wohingegen die späteren Neubauten - darunter in Deutschland 
allen voran der Neubau von Frankfurt a.M. (eröffnet 1888) - vollends vom neuen Geist des Zirkulationskonzepts auf einem Querbahnsteig erfasst wurden.

Abbildung 32: Grundriss des Pariser Gare du Nord im Ursprungsstadium (1847) mit Kopfbahnsteig und vorgeschalteter Zirkulationszone des ssalle des pas perdus‘ (2). Die Wartesäle (5) schieben sich hier (noch) deutlich als Schleusenraum zwischen die stadt- und bahnseitiger Zirkulationszonen.

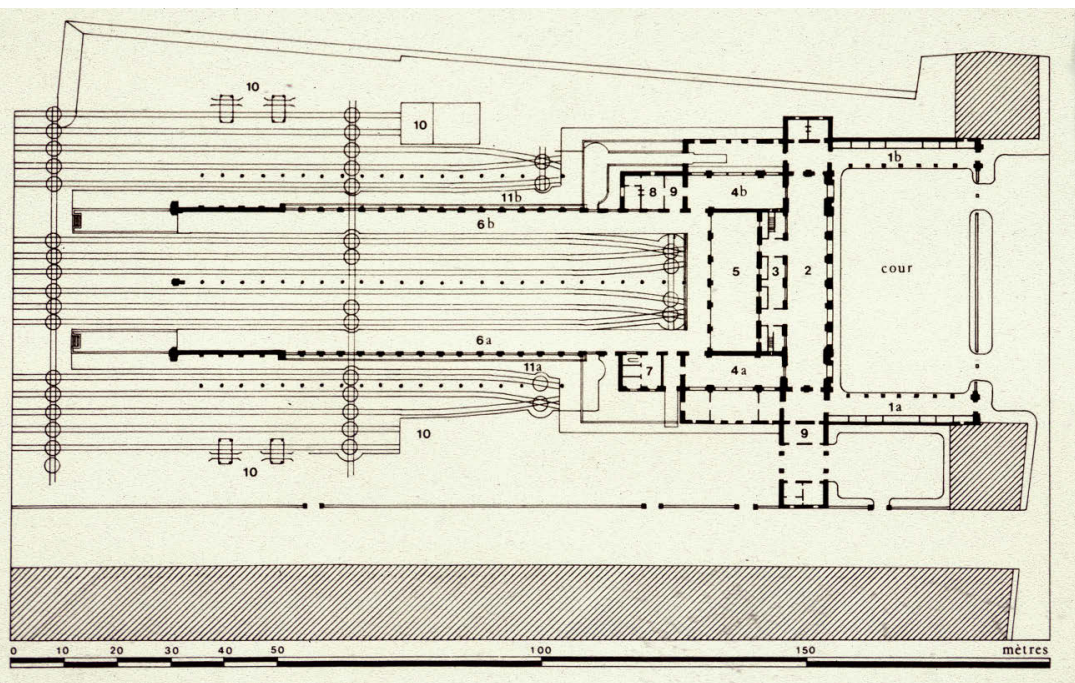

Quelle: Brown University Digital Repository, https://repository.library.brown.edu/studio/item/ bdr:80919/.

\subsubsection{Bahnsteigsperre}

Neben der Etablierung eines neuen Bautyps (Empfangsgebäude in Seitentieflage) und der Errichtung neuer Zirkulationszonen wurden im Zuge der Blütephase des Eisenbahnwesens auch operative Neuerungen verbreitet, die Einfluss auf eine veränderte Wahrnehmung des systemischen Wartens hatten. Zu ihnen gehörte die Einführung einer Bahnsteigsperre, die schrittweise seit den 1880er Jahren und ab 1893 flächendeckend in Preußen eingesetzt wurde. Diese physische Barriere hatte zum Ziel, nicht-reisendes Publikum davon abzuhalten mit in die Wartesäle oder auf den Bahnsteig zu gelangen, um dort bis zur Abfahrt in der Nähe der Angehörigen zu bleiben. Seit dem 1. Oktober 1893 war auf preußischen Staatsbahnen das Betreten der Bahnsteige sowie der Warteund Erfrischungsräume "nur nach Vorweis einer Fahr- oder einer besonderen Bahnsteigkarte ${ }^{30}$ möglich. Während es in Österreich, Frankreich und England bereits wesentlich früher verboten war, diese Räumlichkeiten als Gast zu betreten, war Deutschland - mit Ausnahme einiger norddeutscher Linien und Bayern - in dieser Hinsicht 
überwiegend liberal geblieben. So blieben, wie bereits an anderer Stelle erwähnt, die Wartesäle der neugebauten Berliner Kopfbahnhöfe auch weiterhin für nicht-reisendes Publikum geöffnet. Lediglich der Zugang zu den Bahnsteigen wurde an eine Fahrtberechtigung geknüpft, der restliche Bereich des Bahnhofes blieb hingegen ein im Grunde öffentlicher Raum.

Im Zuge des in den 1880er und 1890er Jahren abermals gestiegenen Verkehrswachstums gerieten jedoch durch die große Zahl von Begleitpersonen die verfügbaren Raumangebote in den Wartesälen und Restaurationen an ihre Kapazitätsgrenzen. Die überfüllten Räumlichkeiten behinderten dabei aus Sicht der Eisenbahnverwaltungen nicht nur die Betriebssicherheit, sie verhinderten zudem auch die Pünktlichkeit des Abfertigungsprozesses. ${ }^{31}$ Auch wenn sich die komplette Bahnsteigsperrung erst langsam durchzusetzen vermochte und besonders an Sonn- und Festtagen die Bahnsteige und Wartesäle nach wie vor von Begleitpersonen bevölkert werden konnten, wurde spätestens ab 1893 ein zuvor fahrgastorientiertes Prinzip zugunsten der Sicherheit zurückgefahren. Diese Entwicklung konterkarierte damit auch den hohen Attraktivitätswert, den ein offener Zugang zuvor für Schaulustige ausübte. So sind zahlreiche Berichte überliefert, in denen Bewohner kleinerer Ortschaften den Bahnhof zum Ziel ihres täglichen Spaziergangs und zu einem Teil ihrer sozialen Routine machten. Auch Eduard Schmitt prognostizierte 1873 - und damit in noch zeitlicher Entfernung zur Einführung der Bahnsteigsperre - , dass das Publikum kleiner Ortschaften »sehr unzufrieden sein [würde, R.K.], wenn es nicht auf dem Perron auf- und abgehen dürfte, um bei dem etwaigen Eintreffen eines Zuges die ankommenden oder durchpassirenden

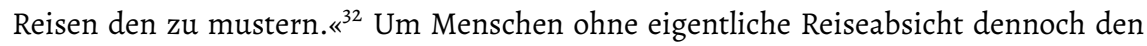
Zugang zum Bahnsteig zu gewähren, wurden spezielle Bahnsteigkarten verkauft, die es zum Teil bis heute in Deutschland gibt, so z.B. im Nahverkehrssystem der Münchner Verkehrsbetriebe. ${ }^{33}$

Neben diesen Auswirkungen für die Reisepraxis waren die entscheidenderen Konsequenzen dieser Abriegelung aber vor allem baulicher Natur. So wurde etwa kritisiert,

»(...) daß viele der bestehenden Bahnhöfe durch diese Veränderungen an ihrer organischen Anordnung nicht unbedeutend verloren haben; denn die Grundrisse der betreffenden Empfangsgebäude waren auf diese Art der Fahrkartenprüfung nicht eingerichtet. Zahlreiche vorhandene Türen mußten beseitigt oder dauernd geschlossen, neue Türen angelegt und vor allem Absperrgitter oder Schranken aufgestellt, sog. »Pferche« geschaffen werden. $\ll^{34}$

31
Ebd.

Schmitt, Vorträge Bahnhöfe und Hochbauten auf Locomotiv-Eisenbahnen, 90.

Trotz dieses aus Sicht der Fahrgäste erlebten Einschnittes in der Bewegungsfreiheit zeugt etwa Erich Kästners Bahnhofsvierzeiler aus dem frühen 20. Jahrhundert davon, dass die Bahnsteigsperre auch weiterhin Anlaufpunkt für Schaulustige gewesen sein dürfte: »]eden Abend stand er an der Sperre, ein armer, alter, gebeugter Mann, Er hoffte, daß einmal Cott ankäme! Es kamen immer nur Menschen an «, zitiert in Mario Leis, Bahnhöfe: Ceschichten von Ankunft und Abschied (Frankfurt a.M.: Insel, 2003), 148.

Schmitt, Anlage und Einrichtung der Cebäude, 26. 
Zudem musste der Entwurf neuer Bahnhofsanlagen das Verfahren der Fahrkartenprüfung berücksichtigen, was dauerhafte Schwierigkeiten in der Frage verursachte, ob man dabei die Warte- und Erfrischungsräume in die Bahnsteigsperre einbeziehen würde oder nicht. Die psychologische Konsequenz der Einführung einer Bahnsteigsperre dürfte jedoch darin bestanden haben, dass das Warten im Wartesaal und auf den Bahnsteigen weit weniger in Begleitung vertrauter Personen erlebt wurde und dass - vor allem in den unteren Klassen, in denen sich Begleitpersonen keine Bahnsteigkarte leisten konnten - das Warten seit 1893 zunehmend allein bzw. ohne begleitende Angehörige praktiziert worden sein dürfte.

\subsubsection{Vereinheitlichung des Zeitbezugssystems: Eisenbahnzeit}

Eine weitere operative Veränderung, die ganz allgemein Auswirkungen auf das Verständnis und die Wahrnehmung von Zeit hatte, war die Standardisierung des eisenbahnbezogenen Zeitwesens mittels der Einführung einer >Eisenbahnzeit. Sie wurde mit dem Ziel eingeführt, die bis dahin bestehenden unterschiedlichen Zeitregimes zu vereinheitlichen. Wie bereits in Kapitel 4.1.8 angeführt wurde, existierte bis in die $1890 e r$ Jahre hinein nicht nur ein Zeitbezugssystem, sondern es standen sich zwei Systeme am selben Ort gegenüber. Jede Ortschaft besaß zum einen eine ihr eigene >Lokalzeit<, die sich aufgrund ihrer relativen Lage zur Sonne ergab und innerhalb einer Region zeitliche Differenzen im Bereich von Stunden verursachen konnte. Weil die Eisenbahnen aber wie kein anderes Verkehrssystem zuvor für die Synchronisation von Technik in Raum und Zeit auf eine Standardisierung des Zeitwesens angewiesen waren, bestand seit Mitte des 19. Jahrhunderts zudem eine nur für das Eisenbahnwesen wirksame >Eisenbahnzeit‘, die fortan parallel zur >Lokalzeit ‘ bestand. Bahnhöfe mussten daher über zwei Zeitanzeiger verfügen, was für alle Akteure einen über Jahrzehnte wirksamen, sich immer weiter zuspitzenden Zeitkonflikt und eine erschwerte Fahrplanerstellung verursachte. Nach langen Überlegungen und Debatten innerhalb des VDEV und der Reichsregierung wurde 1893 schließlich die flächendeckende Einführung der 'Zonenzeit als Hauptreferenzsystem beschlossen. Diese Einführung bedeutete, dass das Zeitregime der Eisenbahnen über ihren eigentlichen Bestimmungsrahmen hinaus Wirksamkeit erhielt und auch die Zeitpolitik des gesamten gesellschaftlichen Lebens transformierte. Die Eingriffstiefe einer solchen Maßnahme für die bürgerliche Welt wurde in den $1850 e r$ Jahren noch als zu schwerwiegend eingeschätzt. ${ }^{35}$ Erst vier Jahrzehnte später wurden die Auswirkungen einer solchen Zeitumstellung für zumutbar gehalten.

Die wartezeitbezogene Konsequenz der vereinheitlichten Einführung einer Zonenzeit mag für die Reisenden ab 1893 darin bestanden haben, dass sich potentielle Wartezeiten reduzierten, die sich vormals aus der Differenz zwischen Eisenbahnzeit und Lokalzeit ergaben. Mit Einführung eines übergeordneten Zeitbezugsrahmens konnte daher die Planbarkeit der Abreise verbessert werden, was sich auch in einer Reduktion 
der absoluten Wartedauer am Bahnhof niedergeschlagen haben dürfte. Mit Übernahme des etablierten Zeitregimes der Eisenbahnen in das zivile Leben prägte sie wie kein anderes Medium der Industrialisierung die Zeitpolitik der Epoche. Die Einführung des neuen Zeitregimes vermochte dabei seitens der Reisenden vor allem einen Effekt bewirkt haben: die Steigerung der Zeiteffizienz. Damit erfolgte an dieser Stelle der strukturelle Abbau potenzieller Inkongruenzen zwischen vorherrschenden Temporalsystemen, die weiter oben als eine der zentralen Entstehungsbedingung von Wartezeiten herausgearbeitet wurden. ${ }^{36}$

Im Umkehrschluss dürften aber durch die Vereinheitlichung des Zeitbezugssystems potentiell auftretende Abweichungen vom Fahrplan, die zuvor möglicherweise aufgrund eines Unwissens hinsichtlich der Differenz zwischen Lokal- und Eisenbahnzeit übersehen worden waren, zugleich viel stärker explizit geworden sein. Mit anderen Worten: Je mehr sich mit Einführung der Zonenzeit eine exakte temporale Erwartungshaltung formierte, desto stärker traten auch mögliche Abweichungen zu Tage.

\subsection{Soziale Differenzierung der Warteraumstrukturen: Von Damenzimmern, Auswanderer- und Saisonarbeitersälen}

Neben den baulichen und betrieblichen Veränderungen, die jeweils positiven (Einführung Eisenbahnzeit) oder negativen Einfluss (>Typ Hannover`) auf die Wahrnehmung und Verhandlung des systemischen Wartens hatten, war das Innere der Empfangsgebäude von weiteren Veränderungen geprägt, die die Praxis des Wartens im letzten Drittel des 19. Jahrhunderts räumlich und sozial mitunter stark differenzierten. Wie die Beispiele der Pionierbahnhöfe von Liverpool oder Nürnberg zeigten, fungierte zu Beginn des Eisenbahnwesens oftmals nur ein einziger Raum als Hauptwartefläche und ähnelte darin den Vorgängerbauten des Postkutschenwesens. Dennoch zeigten sich mit Blick auf die Beispiele von Manchester und Berlin zugleich ortsabhängig auch bereits in der ersten Planung konzipierte, klassenspezifische Differenzierungen innerhalb der Gebäude. So wurden in Manchesters erstem Bahnhof Reisende noch vor Eintritt in das Empfangsgebäude nach Wagenklassen separiert. Ähnlich warteten die Passagiere in Berlins erstem Bahnhof in getrennten Wartebereichen, die sich zudem auch noch auf dem Bahnsteig fortsetzten. Diese bereits seit der Frühphase etablierte Klassentrennung wird mit der gesamtgesellschaftlichen Durchdringung des Eisenbahnwesens ab den späten 1840er Jahren jedoch zunächst um eine geschlechtsspezifische und zum Ende des 19. Jahrhunderts nochmalig eine sozioökonomische Dimension erweitert. Spezielle Damenzimmer, Auswanderersäle und Warteräume für Saisonarbeiter bilden darin die signifikantesten (sozialen) Differenzierungen des wartebezogenen Raumprogramms, auf die hier nun im Folgenden genauer eingegangen werden soll. 


\subsubsection{Damenzimmer}

Die geschlechtsspezifische Differenzierung des verkehrsinduzierten Wartens nimmt wie das Eisenbahnwesen selbst - seinen Ursprung im angloamerikanischen Kontext der 1830er Jahre. Während die ersten Bahnhofsgebäude von Liverpool und Manchester noch keine Geschlechtertrennung aufwiesen, verfügten so gut wie alle späteren Stationsbauten über »besondere Wartezimmer für Damen «" bzw. spezielle >ladies rooms`, so etwa nachweislich die Bahnhöfe von Birmingham (1838) ${ }^{38}$ oder der ikonische Londoner Bahnhof Euston Square (1838) ${ }^{39}$. Trotz der bereits beschriebenen >Abfahrtsmentalität « englischer Reisender, die unter anderem darin bestand, die Wartesäle oftmals gar nicht erst aufzusuchen, war in England »Auch auf den kleinsten Bahnhöfen (...) mindestens je ein Warteraum für Frauen und Männer vorhanden. $\aleph^{40}$ Aus dem 1862 erschienen Reisehandbuch The Railway Traveller's Handy Book wird die wahrgenommene Notwendigkeit solcher Räumlichkeiten - wohlgemerkt aus dezidiert männlicher Perspektive wie folgt verdeutlicht:

"Should you be accompanied by ladies, by children, or by both, it is essential that you should remove them out of the noise, bustle, and confusion in separably attendant on the arrival of a train. ${ }^{41}$

Angesichts der im Gesamten eher spartanischen und raumsparenden Grundausrichtung englischer Bahnhofsbauten musste interessanterweise dennoch jede Wagenklasse »womöglich nach Damen und Herren getrennt einen besonderen Warte- und Erfrischungsraum haben, wenn er auch nur klein ist. $\aleph^{42}$ Die daraus entstehende Diskrepanz zwischen Ökonomie und Raumprogramm verdeutlicht, wie unumgänglich den Zeitgenossen die Geschlechtertrennung im viktorianischen England erschienen sein muss. Zusammenfassend zeigte sich damit ein bedeutendes Charakteristikum des englischen Eisenbahnwesens nicht zuletzt darin, dass neben einer auch anderswo etablierten Klassentrennung eine wesentlich deutlichere Geschlechtertrennung verfolgt wurde.

Von ähnlich zentraler Bedeutung schienen für Frauen abgesonderte Wartebereiche auch in den USA zu sein. Hier stach die Relevanz der Geschlechtertrennung sogar noch stärker als im englischen Kontext heraus, denn es gab in der gesamten Frühund Wachstumsphase der US-Eisenbahn im Grunde keinerlei Trennung in Wagenklassen. Vielmehr warteten (und reisten) die Passagiere im sich über eine ungleich große Landfläche verteilenden Bahnnetz der USA im Grunde >klassenlos ${ }^{43}$. Umso paradoxer erscheint es aus heutiger Sicht, dass trotz dieser bewusst egalitären Auffassung der

37 Malberg, »Ueber einige Bahnhöfe und Stations-Hallen der englischen Eisenbahnen.«, Zeitschrift für Bauwesen IX. (1859): 298.

38 Üeber Depots und Sammelplätze für Waaren und Reisende (Stazionsplätze) bei Eisenbahnen«, 176.

39 Ebd., 164.

40 Johann Frahm, Das englische Eisenbahnwesen (Berlin: Springer, 1911), 91.

41 The Railway Traveller's Handy Book, 128.

42 Frahm, Das englische Eisenbahnwesen, 94.

43 Die >Klassenlosigkeit ‘ galt dabei jedoch wohlgemerkt nicht für >Farbige`, die in einigen Regionen bereits in der Frühphase des Eisenbahnwesens in abgesonderten Bereichen warten und auch in eigenen Wagons reisen mussten (A. Bendel, »Aufsätze, zusammengestellt aus den von dem ver- 
Abbildung 33: Damensalon im Hauptbahnhof Wiesbaden.

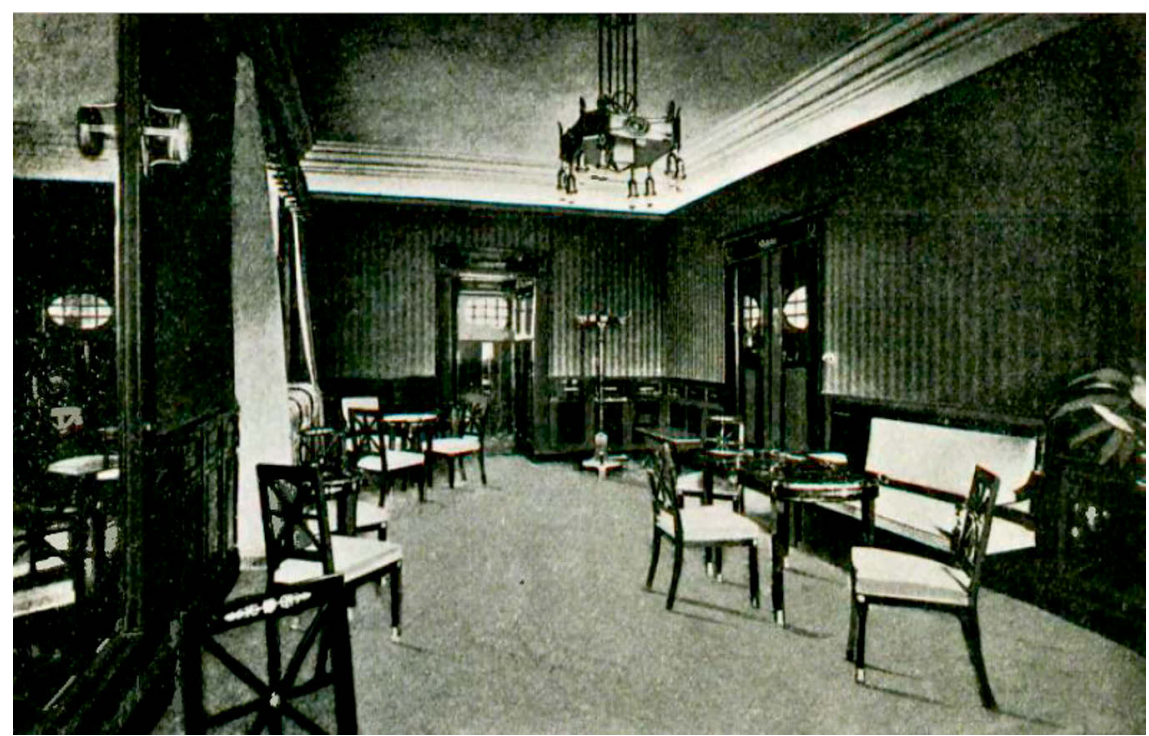

Quelle: Schmitt 1911, S. 55.

Eisenbahnnutzung vielerorts eine strikte Trennung von männlichen und weiblichen Fahrgästen vorherrschte, von der Perdonnet zu berichten weiß. ${ }^{44}$ Das im US-Kontext gern zur Schau gestellte "Gefühl der Gleichberechtigung Aller « ${ }^{45}$ schloss im Angesicht der vielen Damenzimmer an US-Bahnhöfen offenbar nicht die geschlechtliche Gleichberechtigung mit ein. Die bereits am Bahnhof etablierte Geschlechtertrennung setzte sich zum Teil vielmehr auch in der Bahn selbst fort, wie aus einem Reisebericht des Charles Dickens von einer Fahrt zwischen Boston und Lowell in den frühen 1840er Jahren hervorgeht:

»Es giebt keine Wagen erster und zweiter Klasse wie bei uns [in England, R.K.], aber es sind Wagen für Herren und solche für Damen vorhanden. Der hauptsächlichste Unterschied zwischen ihnen ist, dass in dem ersteren Jedermann raucht, während im zweiten es Niemand thut. ${ }^{46}$

In der weiteren Schilderung führt Dickens aber relativierend hinzu, dass im Damenabteil recht viele männliche Begleiter angetroffen werden konnten, was dahingehend

storbenen Geh. Regierungsrath Henz während seiner Reise in Nord-Amerika im Jahre 1859 gesammelten Notizen.«, Zeitschrift für Bauwesen XI. (1861): 461).

45 Bendel, »Aufsätze, zusammengestellt aus den von dem verstorbenen Geh. Regierungsrath Henz während seiner Reise in Nord-Amerika im Jahre 1859 gesammelten Notizen.«, 461. 
interpretiert werden kann, dass die Geschlechtertrennung nicht allzu streng wie in England ausgelegt wurde. Dickens beschreibt diese lockere Geschlechtertrennung wie folgt:

»Wenn eine Dame den Sitz eines männlichen Reisenden zu haben wünscht; so giebt der Herr, welche die Dame begleitet ihm Kenntnis davon, und dieser räumt den Sitz mit grosser Höflichkeit. « ${ }^{47}$

Selbst kleine US-amerikanische Stationen, die »kaum mehr (...), als eine verdeckte Halle oder einen Hausflur mit Holzbänken für das Publikum« aufwiesen, besaßen laut Reiseberichten das »unvermeidliche Damenzimmer. ${ }^{48}$ Dass das verkehrsinduzierte Warten auf Abfahrt in den USA mancherorts dabei eine eklatante Ungleichheit offenbarte, soll hier nur eine Beschreibung des Bahnhofs in New Haven von 1849/50 verdeutlichen, in der es heißt:

»(...) On either side of the main hall or platform, are extensive Parlors, that on the left side being for the accomodation of ladies and is furnished with a profusion of rich and costly sofas, divans, chairs, ottomans, mirrors etc., with convenient dressing rooms attached. Obliging servants are always in attendance. The Parlor on the right is for gentlemen's use, and is to be furbished as a Reading Room (...). « ${ }^{49}$

Während die Funktionsbeschreibung des Warteraums für Herren demnach dezidiert auf die Nutzung eines Lesesaals bzw. eines Bildungsortes rekurriert, bleibt die $\mathrm{Zu}$ schreibung des entsprechenden Raums für Damen dagegen auf das Ambiente einer reichdekorierten Schmuck- und Umkleidekammer beschränkt. Hinsichtlich des geschlechtsspezifischen Raumangebotes zeigten damit die jungen Vereinigten Staaten nicht nur deutliche Absonderungen im eigentlich egalitär angelegten Staatssystem, sondern zugleich auch genderspezifische Zuschreibungen bezüglich der gesellschaftlich erwarteten Wartepraxis. Die Wartesäle der Bahnhöfe spiegelten damit nicht nur vorherrschende Geschlechterrollen, sie reproduzierten sie nicht zuletzt damit auch. Angesichts der Vielzahl solcher geschlechts- und rassenspezifischen Aufladungen des Verkehrswesens resümieren auch Richards und MacKenzie schließlich trefflich:

»American stations in fact illustrated better than anywhere the great dichotomy between social theory and practice in the United States. $\aleph^{50}$

Wenngleich nicht zum übereinstimmenden Zeitpunkt, so zeigt sich doch auch wenige Jahre in Deutschland die Herausbildung distinguierter Warteräume für Damen. So verfügte der zweite Neubau des Stuttgarter Bahnhofes in den 1860er Jahren neben drei Wartesälen über einen »besonderen Raum für Damen $\aleph^{51}$, der dem Wartesaal

47 Ebd., 211.

48 Blanck, »Ueber den Bau der Eisenbahnen in den Vereinigten Staaten von Nord-Amerika«, Zeitschrift für Bauwesen XXVII. (1877): 552.

49 Benham's City Directory and Annual Advertiser, 1849-50, Nr. 10, New Haven 1849, zitiert in Meeks, The Railroad Station: An Architectural History, 53.

50 Jeffrey Richards und John M. MacKenzie, The Railway Station: a social history (Oxford: University Press Oxford, 1986), 146.

51 »Verein für Eisenbahnkunde zu Berlin. Protocoll der Versammlung vom 24. October 1868«, Zeitschrift für Bauwesen XIX. (1869): 430. 
erster Klasse angeschlossen war. Auch der Neubau des Schlesischen Bahnhofs in Berlin verfügte zusätzlich zu den typischen Wartesälen über ein Damenzimmer, in dem die Bedienung durch ein Glockensignal gerufen werden konnte. ${ }^{52}$ Dutzende weitere Grundrisse und Berichte schildern im deutschen Kontext das Vorhandensein solcher Strukturen ab Mitte der 1850er Jahre, so auch im Bahnhof der Königlichen Ostbahn Berlins, im ostpreußischen Dirschau genauso wie in Eydtkuhnen an der russisch-preußischen Grenze, in Halle oder Hildesheim. Solche Räumlichkeiten fanden sich dabei aber keinesfalls nur exklusiv im Eisenbahnwesen, sondern waren vielmehr auch in anderen öffentlichen Kontexten verbreitet, so lassen sich spezielle Damenzimmer in jener Zeit etwa auch in Kaffeehäusern oder Bibliotheken nachweisen.

Die Ausstattung solcher Damenzimmer in Bahnhöfen war oftmals von der ohnehin reichdekorierten und komfortablen Ausstattung der Wartesäle erster und zweiter Klasse nochmals unterschieden. So verfügte etwa das Damenzimmer im Bahnhof der Königlichen Ostbahn Berlins um 1870 nicht nur über eine separate (Wasch-)Toilette, sondern zudem über die Besonderheit von Spülvorrichtungen..$^{53} \mathrm{Da}$ im (deutschen) Bahnhofswesen die Exkremente üblicherweise in Fässern unterhalb der Toiletten gesammelt wurden und dies eine allmähliche Geruchsentwicklung nach sich zog, blieben die Damenzimmer durch die nur hier eingebauten Spülvorrichtungen von diesen Effekten verschont. Im weiteren Streckenverlauf der Ostbahn war etwa das Damenzimmer im Bahnhof Dirschau mit einer violett-rötlichen Winword Tapete verkleidet, vor der ein »Meublement « aus Mahagoniholz Sitzgelegenheiten bot. ${ }^{54}$ In Eydtkuhnen an der Grenze zu Russland waren die Zimmer für hohe Personen und das Damenzimmer unter einem Stichkappengesims mit einer silbergrauen, seidenen, mit Goldleisten eingefassten Tapete ausgestattet. ${ }^{55}$

Die Errichtung solcher Damenzimmer war dabei keineswegs eine freiwillige Bauleistung der Bahnverwaltungen, sondern stellte einen festen Teil der Baudirektiven dar. So formulierten Eduard Schmitt als auch Julius Rasch Anfang der 1870er Jahre hinsichtlich der Grunderfordernisse der Errichtung von Bahnhöfen die klare Notwendigkeit zur Installation von Damenzimmern. ${ }^{56}$ Auch zur absoluten Blütezeit des Eisenbahnwesens im frühen 20. Jahrhundert wurde für das Bauprogramm sgrößerer und ganz großer Stationen noch die Errichtung eines "Damensalons mit separatem Waschraum und Abort $~^{57}$ verlangt. Dabei sollten interessanterweise die Türen zu den Damenzimmern möglichst verglast sein, um »so den Einblick zu gestatten«, denn »Erfahrungsgemäß halten sich die Reisenden nicht gern in Räumen auf, die vom übrigen Verkehr zu sehr abgeschlossen sind. $\aleph^{58}$ Das Manko der mit Einrichtung der separierten Raumstruktur

52 »Berliner Neubauten. II. Der neue Bahnhof der Niederschlesisch-Märkischen Eisenbahn.«, Deutsche Bauzeitung III., Nr. 36 (1869): 430.

53 »Das Empfangsgebäude der Königlichen Ostbahn zu Berlin.«, 5.

54 W. Schultze, »Das Empfangs-Gebäude des Bahnhofes zu Dirschau.«, Zeitschrift für Bauwesen XIX. (1859): 287.

55 Cuno, »Das Empfangsgebäude des Bahnhofes Eydtkuhnen.«, Zeitschrift für Bauwesen XV. (1865): 103.

56 Schmitt, Vorträge Bahnhöfe und Hochbauten auf Locomotiv-Eisenbahnen, 587.

57 Schmitt, Anlage und Einrichtung der Gebäude, 55.

58 Ebd., 69. 
für Damen einhergehenden Abtrennung sollte demnach zumindest durch bestehende Sichtverbindungen zum Hauptwartesaal kompensiert werden. Die wechselseitige Sichtbarkeit der Geschehnisse sollte aber wohl nicht nur die Gefahr der Entstehung von Angsträumen vorbeugen, sondern sie ermöglichte den männlichen Begleitern im Hauptwartesaal zugleich gewiss auch eine soziale Kontrolle über die Aktivitäten im Damenzimmer.

Während solche Damenzimmer unter anderem verstärkt auch in Russland installiert wurden, ${ }^{59}$ waren Damenzimmer in Österreich nur äußerst selten vorhanden. Letzteres erschien aus Sicht des deutschen Eisenbahnwesens besonders bemerkenswert, denn die Abwesenheit von Damenzimmern verwunderte angesichts des Umstands, dass »in allen Wartesälen geraucht werden darf.. ${ }^{60}$ In deutlichem Kontrast zum österreichischen System wurden dagegen in Deutschland, England oder den USA die Damenzimmer immer als rauchfreie Wartezimmer konzipiert. Dieser Umstand eines ausgewiesenen Nichtraucherbereiches bewirkte mancherorts, dass die geschlechtsspezifische Trennung nicht vollends durchgeführt wurde. So konnten (bzw. mussten) offenbar zum Teil auch männliche Nichtraucher aus Ermangelung eines speziellen Nichtraucher-Herrenzimmers die Damensäle benutzen. ${ }^{61}$

Obwohl die Baudirektiven des späten 19. und frühen 20 . Jahrhunderts deutlich die Einrichtung geschlechtsspezifischer Warteräume einforderten, geht aus ihnen keinerlei Begründung hervor, warum eine solche Separierung überhaupt erforderlich erschien. Aus der kurzen Rekonstruktion von Lage und Ausstattung solcher Damenzimmer lässt sich aber schlussfolgern, dass die Funktion dieser Räumlichkeiten darin bestand, weiblichen Fahrgästen einen Ort der Ruhe und des (rauchfreien) Rückzugs zu schaffen. Die im Vergleich nochmals großzügigere Ausstattung der Damenzimmer lässt dabei vermuten, dass die Wartesituation vor Abfahrt für Frauen anders als für Männer wahrgenommen wurde und daher mit größerem Komfort kompensiert werden sollte. Zudem verweist das Vorhandensein jeweils separater Sanitär- und Waschanlagen in den Damenzimmern auf eine vergleichsweise stärkere Zentralität der weiblichen Reisehygiene. Es muss an dieser Stelle offenbleiben, ob die Einrichtung solcher speziell eingerichteten Damenzimmer von den weiblichen Reisenden selbst eingefordert oder aus männlicher, vorauseilender Sicht installiert worden waren. Angesichts eines klar männlich bestimmten Planungs- und Baudiskurses von Empfangsgebäuden kann jedoch vermutet werden, dass all jene Funktionsbestimmungen sich nicht zuletzt aus generellen gesellschaftlichen Auffassungen über die Frau und den weiblichen Körper im 19. Jahrhundert gespeist haben, die Andersartigkeit der Wartewahrnehmung und die entsprechende Komforterweiterung somit Gegenstand sozialer Konstruktionen gewesen sein dürften. Dazu zählten etwa auch zeitgenössisch verbreiteten Auffassungen, dass Frauen gegenüber Männern eine schnellere Reizbarkeit, einen Hang zur Nervosität sowie den Hang

59 von Röll, Enzyklopädie des Eisenbahnwesens, 4:332.

60 »Ueber österreichische Eisenbahnwagen.«, Deutsche Bauzeitung 8, Nr. 1 (1874): 4.

61 Das Damenzimmer des Bahnhofsneubaus von Wiesbaden kann hier als ein solches Beispiel angeführt werden. C. Cornelius, »Das neue Empfangsgebäude auf dem Hauptbahnhof in Wiesbaden.«, Zeitschrift für Bauwesen LVII. (1908): 35. 
zur Hysterie aufweisen würden. ${ }^{62}$ Entsprechend könnte die eingeschriebene Intention der Damenzimmer unter anderem entsprochen haben, weiblichen Reisenden einen möglichst reizarmen, von wenig Durchgangsverkehr geprägten Raum bereitzustellen.

Die verbindliche Installation solcher Warteräume, ihre dezidiert geschlechtsbezogene Bezeichnung als Damenzimmer sowie ihre fest umgrenzte Einrichtung als eigenständiger Raum können damit wohl zweifelsohne als Elemente jenes Prozesses aufgefasst werden, die an Michel Foucaults Konzept der "Biopolitik « ${ }^{63}$ anschließen und den Judith Butler als »Prozeß der Materialisierung« des biologischen Geschlechts bezeichnet. Dieser Prozeß werde zwar vor allem über die wiederholte Sprachnutzung realisiert, die im Laufe der Zeit eine stabile Begrenzung, Festigkeit und Oberfläche und damit eine »Materie« entwickeln würde. Im Falle der physischen Separierung des Damenzimmers erscheint es jedoch zudem plausibel, dass nicht allein die Sprache, sondern auch intentional geschaffene Räume und ihre wiederholte Nutzung eine feste diskursive Formation bzw. biopolitische Konzeption der >Dame< entwickelten. Daher kann vermutet werden, dass die Einrichtung und Benennung ${ }^{64}$ jener Damenzimmer im Laufe des 19. Jahrhunderts einen gewichtigen Beitrag dazu leisteten, das biologische Geschlecht mittels einer sedimentierten, andauernd wiederholenden oder rituellen Praxis überhaupt erst $\mathrm{zu} »$ naturalisieren. $^{65}$

Neben der konstruktivistischen Wirkung der Einrichtung geschlechtsspezifischer Wartezonen zeigt sich in diesem Zusammenhang zudem, wie stark das Phänomen des systemischen Wartens offenbar als Irritation sozialer Verhältnisse aufgefasst wurde und entsprechende bauliche Lösungen erforderte. Die gewählte Abtrennung eines Damensalons lässt vermuten, dass die Situation des Erwartens eines Zuges in einem Raum mit einer Vielzahl von Fremden offenbar keine akzeptable Situation darstellte. Relativierend muss hier jedoch bemerkt werden, dass Damenzimmer und -salons im deutschsprachigen Raum wohlgemerkt nur innerhalb der Wartesäle erster und zweiter Klasse vorhanden waren. Die Situation eines geschlechterübergreifenden Wartens erschien daher nur für Reisende der bürgerlichen Oberschicht inakzeptabel. Dagegen spielte die Geschlechtertrennung für die unteren Wagenklassen offenbar keine übergeordnet relevante Rolle. Wie bereits weiter oben angeführt, reiste ungefähr nur jeder fünfte Passagier in der ersten oder zweiten Klasse. Das geschlechtsspezifische Raumprogramm des verkehrlichen Wartens traf daher nur für eine Minderheit der Reisenden zu und muss im deutschensprachigen Raum - anders als in England oder den USA - als insgesamt randständige Erfahrung deklariert werden. Die Existenz solcher

62 Zur geschlechtsspezifischen Ausprägung des >Nervendiskurses`seit Ende des 19. Jahrhunderts: Janet Oppenheim, »Shattered Nerves«: Doctors, patients, and depression in Victorian England (Oxford: Oxford University Press, 1991); Regina Schaps, Hysterie und Weiblichkeit: Wissenschaftsmythen über die Frau (Frankfurt a.M.: Campus, 1992); Karen Nolte, Celebte Hysterie: Erfahrung, Eigensinn und psychiatrische Diskurse im Anstaltsalltag um 1900 (Frankfurt a.M.: Campus, 2003). Michel Foucault, Der Wille zum Wissen: Sexualität und Wahrheit (Frankfurt a.M.: Suhrkamp, 1997), 161-73.

64 Butler betont hinsichtlich der normierenden Relevanz sprachlicher Bezeichnungen: »Das Benennen setzt zugleich eine Grenze und wiederholt einschärfend die Norm.« Judith Butler, Körper von Cewicht. Die diskursiven Grenzen des Geschlechts (Berlin: Berlin Verlag, 1995), 29. 
geschlechtsspezifischen Warteräume ist im deutschen Kontext nach dem Zweiten Weltkrieg indes nicht mehr nachweisbar.

\subsubsection{Auswanderersäle}

Die zweite zentrale Differenzierung des wartebezogenen Raumprogramms während der Blütephase des Eisenbahnwesens erfolgte durch Einrichtung spezieller Auswanderersäle. In ihnen sollten Passagiere untergebracht werden, die auf dem Weg zu einer Hafenstadt waren, von der aus sie per Dampferfahrt Reiseziele in Übersee - insbesondere Amerika und Lateinamerika - ansteuerten. Solche Auswanderersäle fanden sich etwa prominent in Bremen und Hamburg. Wie sich etwa mit Blick auf die klassenspezifische Innenraumgestaltung des Bremer Hauptbahnhofes zeigt, lagen diese Säle in der Hierarchie der Wagenklassen nochmal deutlich unterhalb jener der ohnehin schon mager ausgestatteten vierten Wagenklasse. Krings berichtet, dass durch den Einsatz von gusseisernen Säulen, die Eisenbalken trugen und von gemauerten Kappen umspannt waren, der Auswanderer-Wartesaal von einem »kellerartigen Aussehen « ${ }^{66}$ geprägt war. Die Wände waren bis in $2 \mathrm{~m}$ Höhe mit einfach glasierten Platten verkleidet und darüber mit einfacher Ölfarbe bestrichen. Die Wahl solcher glasierten Wände wird durch den Architekten des Bremer Bahnhofes und Mitherausgeber der Deutschen Bauzeitung Karl Emil Otto Fritsch abfällig damit begründet, dass in Auswanderersaal »zeitweise ein aus den sarmatischen Hinterländern stammendes Publikum von zweifelhafter Reinlichkeit zusammen strömt. ${ }^{67}$

Weiterhin wurde die klassenspezifische Unterscheidung durch den Einsatz unterschiedlicher Holzarten zum Ausdruck gebracht. Waren die Möbel im Auswanderersaal aus Tannenholz, so wurden sie in der III. und IV. Klasse aus Buchenholz und für die I. und II. aus Eichenholz gefertigt. Zudem wurden die Wände im Bereich der unteren Klassen als einfach gegliederte, in Wachsfarbe gemalte Flächen gestaltet. Die Wände in der höheren Klasse waren dagegen »reicher in Form und Farbe ausgebildet und durch freistehende, mit rothem Stuckmarmor und bronzirten Zink-Kapitellen und Basen besonders geschmückt. Von der eleganten Deckenwölbung hingen hier große Kronleuchter von blankem, wie >Altmessing ' gebeiztem Messing. ${ }^{68}$

Der kellerartige Bremer Auswanderersaal lag in einem Seitenflügel und war eigenständig mit dem Bahnsteig verbunden, sodass die restlichen Reisenden auf dem Weg zum Zug jederzeit von den Emigranten separiert blieben. Mehr noch wurden diese Räume, so etwa in Hamburg, derartig ausgestattet, um den Auswanderern »bis zur Abreise nach Uebersee ein billiges und gutes Unterkommen zu geben, ohne dass die Leute genöthigt sind, die Stadt Hamburg selbst zu berühren.«"99

66 Krings, »Bahnhofsarchitektur: deutsche Großstadtbahnhöfe des Historismus «, 290.

67 Karl Emil Otto Fritsch, »Der neue Haupt-Personen-Bahnhof in Bremen.«, Deutsche Bauzeitung 24, Nr. 64 (1890): 383. Gemeint sind mit jenen ssarmantischen Hinterländern< Auswanderer aus Regionen, die zwischen den Flüssen Weichsel im Westen und der Wolga im Osten lagen und bereits eine lange Reise auf dem Weg zu den Hochseehäfen hinter sich hatten. 
Doch nicht nur in Küstennähe wurden solche Säle errichtet, auch tief im Hinterland wurden Bahnhöfe um solche Migrationszonen ergänzt. So verfügte der Hannoveraner Hauptbahnhof nach dem 1909-1910 vollzogenen Umbau über einen gemeinsamen Wartesaal für die IV. Klasse und für Auswanderer. ${ }^{70}$ Im Rahmen des Neubaus des Leipziger Hauptbahnhofes bildete die Errichtung einer >Auswanderer-Registratur/ gar einen Teil der Wettbewerbsbedingungen. ${ }^{71}$ Weitere solche speziellen Hallen und Säle bestanden etwa noch in Kassel oder Basel, in denen neben eigenen Wasch- und Toilettenanlagen auch oftmals ärztliche Untersuchungszimmer und Isolierzimmer eingerichtet wurden. ${ }^{72}$ Zudem wurde durch Einrichtung von Einwanderungszentren und speziellen Einwandererzügen die Trennung von Migranten und anderen Reisenden auch bei Ankunft in der >Neuen Welt $<$ weitergeführt, so etwa in den USA. ${ }^{73}$

\subsubsection{Saisonarbeitersäle}

Eine dritte Ebene der wartebezogenen Nutzerdifferenzierung erfolgte seit dem späten 19. Jahrhundert in der Einrichtung von speziellen Warteräumen für Saisonarbeiter, so etwa am prominentesten im Hauptbahnhof von Halle (Saale). Hier verfügte der Wartesaal IV. Klasse über einen nochmals abgetrennten Saal für die sogenannten >Sachsengänger ${ }^{74}$ Mit ihnen wurden im Volksmund Saison- und Landarbeiter aus Schlesien und Posen bezeichnet, die alljährlich im Frühjahr aus den ostelbischen Regionen nach Sachsen strömten, um - insbesondere als Erntehelfer in der sächsischen Zuckerindustrie - besser bezahlte Arbeit als in ihren Heimatregionen zu finden. Auch im Rahmen des Umbaus des Kasseler Hauptbahnhofs um 1910 wird ein zusätzlicher Wartesaal für die >Sachsengänger errichtet. ${ }^{75}$ Auch hier besteht das Prinzip darin, eine Personengruppe durch Einrichtung autarker Serviceinfrastrukturen von den restlichen Reisenden zu separieren.

Zusammenfassend zeigt sich mit Blick auf die seit dem späten 19. Jahrhundert einsetzende Differenzierung des wartebezogenen Raumprogramms, wie stark sich die Klassenstruktur des Kaiserreiches und die gewachsenen Migrationsströme im Spektrum vom Fürstenzimmer bis zum Auswanderersaal im Inneren der Gebäude spiegelten und jeweils baulich und bezüglich der Ausstattungen und relativen Größen unterschieden werden musste. ${ }^{76}$ Je stärker sich die Gesellschaftsstruktur des Kaiserreichs in der

70 Schmitt, Anlage und Einrichtung der Cebäude, 66.

71 »Der Wettbewerb zur Erlangung von Entwürfen für das Empfangsgebäude des neuen Hauptbahnhofes Leipzig.«, Deutsche Bauzeitung XLI., Nr. 49 (1907): 342.

72 »Der neue Zentral-Bahnhof der Schweizerischen Bundesbahnen in Basel«, Deutsche Bauzeitung XLI., Nr. 53 (1907): 375.

73 Vgl. Richards und MacKenzie, The Railway Station: a social history, 147.

74 »Der Umbau des Bahnbofes in Halle a. d. Saale in den Jahren 1880 bis 1892. «, Zeitschrift für Bauwesen XLIII. (1893): 355.

75 Masur, »Der Umbau des Hauptpersonenbahnhofs Cassel.«, Zeitschrift für Bauwesen 63 (1913): 460.

76 Vgl. Radlbeck, »Bahnhof und Empfangsgebäude«, 480; Claudia Wucherpfennig, Bahnhof: (stadt)gesellschaftlicher Mikrokosmos im Wandel; eine »neue kulturgeographische «Analyse (Oldenburg: BIS-Verl. der Carl-von-Ossietzky-Universität, 2006), 119. 
Hochindustrialisierung diversifizierte, desto mehr musste auch der Bahnhof die gesellschaftliche Stratifikation abbilden und `beherbergen`, um die bürgerliche Ordnung zu wahren. Als symptomatischer Ausdruck dieses Anpassungsdrucks wurden dazu bereits bestehende Bahnhofsbauten ständig an ihren Flügeln erweitert, um einerseits wachsende Ströme von Saisonarbeitern oder Auswanderern (aber auch Touristenströme) möglichst separiert unterzubringen. Im späten 19. Jahrhundert wird der Bahnhof damit zu einem gesamtgesellschaftlichen und internationalen Sozialraum in dessen Wartesälen sich die sozioökonomischen Verhältnisse der Hochindustrialisierung im Spektrum von opulenter Pracht bis hin zur erzwungenen Migration großer Bevölkerungsteile widerspiegelten. Die konzeptionelle Antwort auf die gewachsene gesellschaftliche Komplexität lag demnach dezidiert in der Trennung von Strömen, Räumen und Menschen. ${ }^{77}$ Während es diese Trennungen aus rein technisch-bahnbetrieblicher Perspektive im Grunde zu verhindern galt, weil sie die Abfahrtsorganisation erschwerten, die Kontrollintensität und den Raumbedarf erhöhten, wurden sie zugleich aus gesellschaftlicher Perspektive für unumgänglich gehalten.

\subsection{Bahnhofsarchitektur: Die Beruhigung der Massen}

Der Bau von Bahnhöfen zählte wie bereits an anderer Stelle erwähnt zu den wichtigsten neuen Bauaufgaben des 19. Jahrhunderts. Neben Fragen der funktionalen Anforderungen (Einrichtungen, Raumordnungen, Dimensionen etc.) war der Bahnhofsbau nicht zuletzt von Fragen der künstlerischen Gestaltung des Baukörpers begleitet. Nicht nur Architekten und Ingenieure trieben diese Suche nach der adäquaten künstlerischen Form voran, insbesondere die Eisenbahngesellschaften selbst maßen der Bahnhofsarchitektur über das gesamte 19. Jahrhundert hinweg große Bedeutung bei, weil die Empfangsgebäude neben den Lokomotiven die mit Abstand stärkste Repräsentationsebene boten. ${ }^{78}$

Wie auch hinsichtlich der funktionalen Anforderungen entwickelte sich das Wissen für die architektonischen und baukünstlerischen Kriterien jedoch nur äußerst langsam. Im Resultat war die Frühphase der Bahnhofsarchitektur auch in baukünstlerischer Form von der Exploration und dem Experimentieren gekennzeichnet. Für den Bau der vielen neuen Stationen seit 1830 bestand dabei für Architekten und Ingenieure meist noch keine feste Maßgabe zum absoluten Rationalismus, sodass oftmals freie Hand für die künstlerische Gestaltung blieb. In der Folge zeigten sich in gestalterischer Hinsicht bereits sehr früh unterschiedliche Auffassungen zum architektonischen Konzept des Bahnhofsbaus. Vor allem englische Architekten verfolgten für die Lösung der baukünstlerischen Aufgabe die Adaption traditioneller und pittoresker Motive, die einen >English

77 Das Prinzip der Trennung von Strömen und Gruppen im modernen Großstadtbahnhof kann hierbei als symptomatisches Prinzip für die Moderne selbst stehen, die fortan in vielen Lebensbereichen versuchte, eine Distinktion von Sphären anzustreben, die - wie Bruno Latour anmerkte - ihre wohl größte Ausprägung in der dichotomen Unterscheidung der Kultur- und Natursphäre bzw. der Sphären von Subjekten und Objekten erlebte. Bruno Latour, Wir sind nie modern gewesen: Versuch einer symmetrischen Anthropologie (Frankfurt a.M.: Suhrkamp, 2008). 
Railroad Style begründeten, der angesichts seiner Adaptionen in den USA (New Haven 1849) oder in Deutschland (Leipzig 1844) durchaus als >International Railroad Style bezeichnet werden durfte. ${ }^{79}$ Die dominierende Formensprache bildeten hierin gotische, romanische Stile und vor allem ein an die italienische Renaissance angelehnter Villenstil mit Uhrentürmen und Arkadengängen, die es ermöglichten, einerseits eindrucksvoll, aber auch schnell und kostengünstig zu bauen. Dieser in England praktizierte Baustil, den Meeks treffend als "picturesque eclectiscism « ${ }^{80}$ bezeichnet, wurde zudem mancherorts mit dem populären Symbolismus eines monumentalen Stadttors gekoppelt, so bspw. unübertroffen in der von Philip Hardwick gebauten Anlage eines riesigen dorischen Triumphbogens vor dem 1837 eröffneten Bahnhof London Euston Square Station, der eine doppelte Symbolik als >Tor zu Welt « und als Triumph des Menschen über die Naturgewalten erhielt. Ob als Stadttor, Villa oder burgartig ausgeführt, die baustilistischen Bezüge der ersten 25 Jahre des Bahnhofsbaus waren derart vielfältig, dass sie nach Ansicht Christian Barmans in der Architekturgeschichte nie wieder in einer solchen kurzen Zeitspanne erreicht werden sollten. ${ }^{81}$

Bereits in dieser eklektizistischen Anfangsphase formierte sich jedoch zugleich auch eine starke Gegenposition mit dem Plädoyer eines funktionalistischeren Ansatzes. Vertreten durch die französischen Eisenbahningenieure Auguste Perdonnet und César Daly sowie einigen englischen Eisenbahn- und Architekturkritikern wurde darin gefordert, dass die Bahnhofsarchitektur nicht lediglich im Zeichen der Adaption etablierter Formensprachen auf eine neue Bauaufgabe stehen, sondern vielmehr eine eigenständige Architektur erhalten sollte, die sich insbesondere an den betrieblichen Gegebenheiten des Eisenbahnverkehrs orientieren sollte, ohne dabei auf Monumentalität zu verzichten. ${ }^{82}$ Als stellvertretend für diese Gegenposition zum eklektizistischen >Railroad Style< kann der Pariser Bahnhof Gare de l'Est genannt werden.

Neben dem Oppositionspaar der eklektizistischen und einer eher funktionalistischen Auffassung der Bahnhofsarchitektur erwuchs im Rahmen der vielfältigen Bauaufgaben mit der zunehmenden Trennung von Architekt und Ingenieur ein zweites Gegensatzpaar. Während der Architekt für die Proportionen und die Dekoration des Empfangsgebäudes zuständig war (bzw. sich zuständig fühlte), kam den Ingenieuren zunehmend die Rolle der Gestaltung der überdachten Wagenhalle und der Funktionalität des Baus zu. Dieses nicht selten konfliktreiche Zusammenwirken sollte sich Laufe des 19. Jahrhunderts zu einem regelechten Kampf aufschwingen. ${ }^{83}$ Dieser entwickelte sich deshalb, weil die ursprünglich als Einheit verstandene Aufgabe Bahnhofsbaus aufgrund des Flächenwachstums und der stärkeren Differenzierung der einzelnen Bauelemente und Gebäudeteile nur noch schwerlich aufrechterhalten werden konnte. l'architecture sera appellee à déploycr toutes ses ressources, où leur construction devra être mon-
umentale.«César Daly, »Des Cares de Chemin de Fer«, Revue Ceneral d'Architecture et des travaux publics, Nr. 6 (1846): 517. Daly ruft dazu 1846 die Vision einer eigenständigen Bahnhofsarchitektur aus: „Un jour viendra
sans doute où les gares de chemins de fer compteront parmi les edifices les plus importants, où

Vgl. Meeks, The Railroad Station: An Architectural History, $27 \mathrm{f}$. 
Meeks fasst die Frühphase der gestalterischen Lösungen der neuen Bauaufgabe zusammenfassend als eine Art darwinistischen Ausleseprozess zusammen: "During two decades of rocket-like development, the new architectural problem had evoked scores of experimental solutions. Like those of nature, many were not destined for survival. Others were to prove fruitful by establishing patterns which endure for the rest of the century. ${ }^{84}$ Die Suchbewegung nach der perfekten Balance aus innerer Funktionalität und ekletischen Stilelementen uferte aber auch in der Folgezeit in einer Phalanx von vorgeschlagenen Gestaltungsidealen des Bahnhofsbaus, von denen exemplarisch jenes von Karl Emil Otto Fritsch auf dem Schinkelfest 1869 vorgetragene aufgeführt werden kann:

»(...) möglichste Klarheit und Grossartigkeit der Disposition, möglichste Grösse, wirksame Raumverhältnisse und monumentale Konstruktion, daneben schliesslich sparsame Kunstformen. ${ }^{85}$

Die Interpretation der hier geforderten sparsamen Kunstformen fiel dabei im Gegensatz zur propagierten Klarheit im deutschen Kontext nur allzu oft in Form des Rückgriffs auf mittelalterliche Bautraditionen aus, die den Bahnhofsbau zu einem wichtigen Element des Historismus werden ließen. ${ }^{86}$ Julius Rasch unternimmt für diesen stilistischen Rückgriff Anfang der 1870er Jahre einen äußerst interessanten Legitimationsversuch:

»Das Auftreten mittelalterlicher Stylformen, insbesondere des romanischen Styles, wie wir ihn bei den Bayrischen, Badischen, Hannoverschen und Braunschweigischen Eisenbahnbauten in ausgedehntem Maasse angewandt finden, erklärt sich damit als gesundes Bestreben nach Solidität und wahrer rationeller Construction. ${ }^{87}$

Der schwere romanische Stil sollte demnach offenbar Stabilität und Festigkeit der Konstruktion symbolisieren, vielleicht aber auch als eine gewisse Erdung und Wertestabilität in Zeiten des rapiden technischen und gesellschaftlichen Wandels herhalten. ${ }^{88}$ Die Lösung des Gegenwartsproblems der Errichtung von Bahnhofsgebäuden wurde daher nur allzu oft in Rückgriffen auf vergangene Bauepochen gesucht, was angesichts der hinter den Fassenden liegenden technischen Moderne in Form der Eisenbahn aus heutiger Sicht nur allzu paradox anmuten mag. Auf der Suche nach einem möglichen Erklärungsversuch für die Vermeidung der Ausarbeitung eines gänzlich neuartigen Architekturstils und dem resultierenden architektonischen >Rückschritt der pittoresken

84 Ebd., 48.

85 »Zur Schinkelfest-Konkurrenz des Architekten-Vereins zu Berlin.«, Deutsche Bauzeitung III. (1869): 39.

86 Krings definiert diese bis heute noch weithin sichtbare Bauepoche des Historismus allgemein als »eine Bezugnahme des zeitgenössischen Denkens und Handelns aufWerte, Motive u.ä. aus der zunehmend »wissenschaftlich«aufgearbeiteten europäischen Vergangenheit. «Krings, »Bahnhofsarchitektur: deutsche Großstadtbahnhöfe des Historismus«, II.

87 Rasch, »Die Eisenbahn-Hochbauten auf den Bahnhöfen und ausserhalb derselben.«, $561 f$.

88 Vgl. Thomsen, »Kathedralen der Moderne? Bahnhofsarchitektur - gestern, heute und morgen«, 17. 
Verkleidung einer disruptiven Verkehrstechnologie vermutet Meeks, dass die Architekten des 19. Jahrhunderts allein mit den praktischen Anforderungen alle Hände voll zu tun hatten und deshalb zunächst keinen eigenen Stil entwickeln konnten. ${ }^{89}$

Der Befund dieses allerorten praktizierten eklektischen Historismus lässt sich jedoch vielleicht auch aus der Frage heraus erklären, welche psychologische Funktion der Bau neuer Bahnhofsgebäude beinhaltete. So vermutet Schivelbusch im Zusammenhang mit der historistischen Gestaltung, dass diese nur »mit dem für das 19. Jahrhundert so charakteristischen Bestreben, das industrielle Gesicht der Dinge durch Ornamentierung zu verdecken ${ }^{90}$ heraus zu verstehen ist. Dieses >Verdecken verfolgte dabei aus seiner Sicht nicht nur den Zweck der Repräsentation, sondern verfolgte nicht zuletzt auch eine »Reizschutz-Funktion, [um] die so grundverschiedenen Bereiche von StadtRaum und Eisenbahn-Raum miteinander zu vermitteln. $\ll^{91}$ Die steinernen Fronten sollten damit also nicht nur einen Schleusenraum, einen transitorischen Übergang vom belebten System der Stadt auf die technische Sphäre der Eisenbahn schaffen, sondern

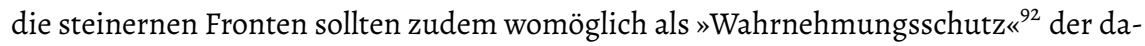
hinter befindlichen, als bedrohlich oder zumindest irritierend wahrgenommenen, beschleunigten Welt fungieren. Die großstädtischen Bahnhofsgebäude des mittleren und späten 19. Jahrhunderts, die verglichen zu ihrer bescheidenen Anfangszeit zu Prunkbauten wurden, sollten damit eine Doppelfunktion aus baukünstlerischer Würdigung des Eisenbahnwesens auf der einen und einer Beruhigung der Massen auf der anderen Seite erreichen. Auch Richards und MacKenzie vermuten in der historisierenden Gestaltung eine Beruhigungsfunktion der Reisenden mit dem Ziel »to comfort and reassure those concerned about the newness of it all. «"

Folgt man dieser These musste die Beruhigungsfunktion nicht nur in der äußeren Gestaltung (im Anblick des Bahnhofes aus der Ferne) zu Tage treten, sondern sie musste sich auch im Inneren der Empfangsgebäude fortsetzen, da der Bahnhof als »unmittelbar industrieller Bau « ${ }^{94}$ erlebt wurde, in dem die Transportindustrie der Eisenbahnen in mitunter irritierender Weise sichtbar, hörbar und fühlbar wurde. Die Beruhigungsfunktion wurde für die Reisenden dabei wohl nirgends deutlicher benötigt als in den Wartesälen, in denen die Reisenden kurz vor Abfahrt von Nervosität und angespannter Unsicherheit erfüllt sein konnten. Entsprechend wurden auch die Wartesäle aufwendig gestaltet, um Stabilität und Würde zu vermitteln und nicht zuletzt auch eine beruhigende Wirkung durch Elemente des Vertrauten zu erzielen.

Die These der architektonischen Beruhigungsfunktion und des Wahrnehmungsschutzes durch den Rückgriff auf historisierende Gestaltungselemente findet jedoch zugleich nicht einhellige Unterstützung. So argumentiert etwa Steven Parissien, daß der Historismus der Bahnbauten keineswegs altmodisch gewesen sei oder das moderne Design behindert hätte, sondern, dass der Historismus das moderne Design erst befreit hätte. Das Hauptziel der Bahnhofsarchitekten des 19. Jahrhunderts lag nach Parissien

89 Vgl. Meeks, The Railroad Station: An Architectural History, 44.

90 Schivelbusch, Geschichte der Eisenbahnreise, 155.

91 Ebd.

92 Claudia Wucherpfennig, Bahnhof: (stadt)gesellschaftlicher Mikrokosmos im Wandel, $98 \mathrm{f}$.

93 Richards und MacKenzie, The Railway Station: a social history, 3.

94 Schivelbusch, Geschichte der Eisenbahnreise, 153. 
somit nicht exklusiv darin, die Passagiere zu beruhigen, sondern die Wiederbelebung alter Stilformen »erwies sich vielmehr als hilfreich, wenn Kunden und Fahrgäste etwas zu sehen bekamen, mit dem sie sich identifizieren konnten. ${ }^{95}$

Übergreifend erscheint hier jedoch durchaus plausibel, dass die Aufgabe der baukünstlerischen Gestaltung der Bahnhofsbauten des 19. Jahrhunderts dezidiert auch in der Funktion eines Wahrnehmungsschutzes gelegen haben dürfte. Seit ihrer Entstehung sah sich die Eisenbahn einer großen Gegnerschaft gegenüber, die im beschleunigten Eisenbahntransport nicht zuletzt körperliche und psychische Gefahren sah. Die Architekten und Ingenieure jener Zeit waren sich dieser Problematik bewusst und dürften die historisierenden Stilformen auch nicht zuletzt mit dem Ziel eingesetzt haben, um mit der Anmutung des Schönen, Zierlichen und Filigranen eine Vertrautheit in der Neuheit und damit schließlich eine höhere Nutzerakzeptanz zu schaffen.

Abbildung 34: Hamburger Bahnhof in Berlin (um 1850). Die beruhigende Funktion der Architektur wird hier zum einen über die stadttorartigen Öffnungen als auch über die italianisierte Formensprache eines Palazzos zum Ausdruck gebracht, welche die Neuheit der Eisenbahn zu betonen und zugleich zu rerden versuchen.

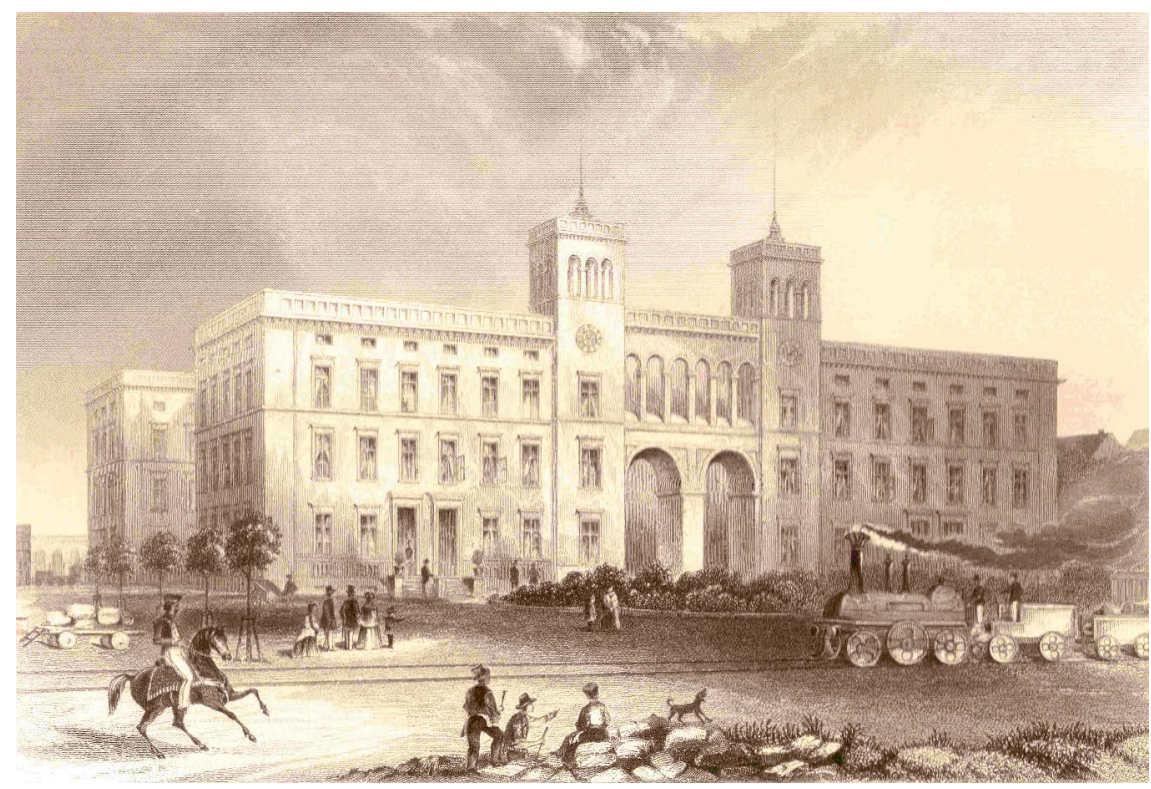

Quelle: Berlin und seine Kunstschätze. Payne, Leipzig, o.J., um 1850. 


\subsection{Exemplarische Bahnhofsbauten der Blütephase}

Einige der zu Beginn dieses Kapitels als für die Erfahrung und Verhandlung von verkehrlichen Wartezeiten herausgearbeiteten Hauptentwicklungslinien des Eisenbahnwesens im letzten Drittel des 19. Jahrhunderts - neue Zirkulationsflächen, Verlagerung und Aufweichung des stationären Warteimperativs, soziale Differenzierung des wartebezogenen Raumprogramms - sollen nun anhand zweier exemplarischer Bahnhofsbeispiele nochmals näher aufgezeigt und hinsichtlich ihrer Implikationen für die Wartepraxis diskutiert werden.

Dazu fällt die Wahl der Beispiele zum einen auf den Neubau des Potsdamer Bahnhofs in Berlin (eröffnet 1872), der als Beispiel des Übergangs von der zweiten zur dritten Bahnhofsgeneration verstanden werden kann und in dem Elemente des stationären Wartens bereits punktuell durch das später Verbreitung findende Zirkulationsprinzip (Querbahnsteig) abgelöst werden. Zum anderen fällt die Wahl auf den 1888 eröffneten Neubau des Frankfurter Hauptbahnhofes, in dem die herausgearbeiteten Tendenzen in Richtung eines Zirkulationsprinzips und der partiellen Verlagerung des Wartens in die Fläche die volle Wirkung entfalten und der nicht zuletzt deshalb als >klassischer Großstadtbahnhof schlechthin gilt.

\subsubsection{Berlin - Potsdamer Bahnhof (1872)}

Wie im Zuge der Schilderungen der ersten Bahnhofsgeneration aufgezeigt wurde, gelangte bereits der erste Potsdamer Bahnhof von 1838 nach nur wenigen Jahren an seine Kapazitätsgrenze, was insbesondere den zahlreichen Tagestouristen nach Potsdam geschuldet war. Als in den Folgejahren mit Verlängerung der Strecke von Potsdam nach Magdeburg (1846) auch die bereits bestehenden Verbindungen in Richtung Hannover angeschlossen wurden, stieg der Kapazitätsbedarf nochmal um ein Vielfaches. Daraufhin erfolgte 1846-48 eine erste große Umbauphase des zu diesem Zeitpunkt »völlig unzureichenden Empfangsgebäudes ${ }^{96}$ bei der unter anderem die Bahnsteige und Arkaden in ihrer Länge verdreifacht wurden, um Raum für die Passagieraufnahme zu schaffen und bei der nördlich ein Anschluss an die Berliner Verbindungsbahn gelegt wurde. Nachdem 1862 nochmals ein neues Empfangsgebäude errichtet wurde, erfolgte 1863 der Beschluss zum Bau eines umfassenden Neubaukomplexes an einem gänzlich anderen Standort, um zukünftig "mit Sicherheit und Präcision arbeiten und den Wünschen des Publicums genügen zu können. ${ }^{97}$ Allein zwischen 1843 und bis zur Halbzeit der Baufertigstellung 1870 erreichte das Personenverkehrsvolumen an der Berliner Station fast zwei Millionen Fahrgäste. Der Bauherr, die >Berlin-Potsdamer-Magdeburger Eisenbahngesellschaft<, beauftragte daher unter Leitung des damaligen Bauraths und

97 Julius Ludwig Quassowski, »Die Um- und Neubauten der Berlin-Potsdam-Magdeburger Eisenbahn.«, Zeitschrift für Bauwesen XXI., Nr. 4-7 (1871): 165. 
späteren Präsidenten der Eisenbahn-Direktion Ludwig von Quassowski die Baumeister Weise, Sillich und Doebner mit der Erstellung einer Planung für einen geräumigen Neubau in der Nähe des Landwehrkanals. ${ }^{98}$ Nach vierjähriger Bauzeit wurde der Bahnhof 1872 eröffnet und wurde zum wichtigsten Ausfalltor der deutschen Hauptstadt in Richtung Westeuropa. ${ }^{99}$

Abbildung 35: Empfangsgebäude des Potsdamer Bahnhofs in Berlin (1872).

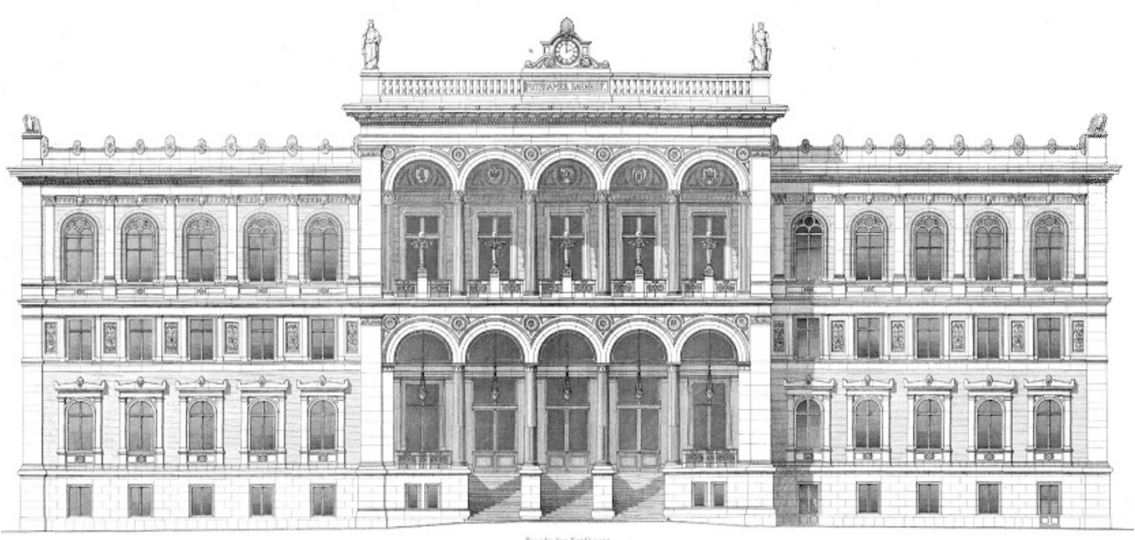

Quelle: Zeitschrift für Bauwesen 1877, Atlas Blatt 9.

Ähnlich wie der kurz zuvor fertiggestellte Görlitzer Bahnhof wurde die überdachte Gleishalle von einem L-förmigen Gebäude umgeben, das auf seiner Nordseite ein dreistöckiges Kopfgebäude aufwies. Dieses Kopfgebäude fungierte jedoch nicht als zentraler Aus- und Eingangsbereich, sondern die Hauptzirkulation der Reisenden - und damit der geschilderten Normalform der späten 1860er Jahre entsprechend - erfolgte über parallel zu den Gleisen errichtete Seitenflügel. Entsprechend wurde der Neubau des Potsdamer Bahnhofes auf seiner westlichen Abfahrtsseite von einem dreistöckigen Empfangsgebäude flankiert, das angesichts der Größe der sich darin befindlichen War-

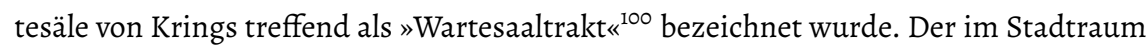
weithin sichtbare Kopfbau im Stile der Neo-Renaissance beherbergte dagegen bis auf punktuelle Sonderzugfahrten keine für den Normalbetrieb genutzten Passagierfunktionen, sondern repräsentierte vielmehr die selbstbewusste Bahnverwaltung, die sich wie schon beim Bau des ersten Bahnhofes 1838 - überaus privilegiert fühlte, als verkehrliches Bindeglied zwischen der politischen Hauptstadt Berlin und dem Residenzsitz der Hohenzollern in Potsdam zu fungieren. ${ }^{101}$

Königlich Preussisches Ministerium für Öffentliche Arbeiten, Berlin und seine Eisenbahnen 18461896, 157. 
Abbildung 36: Verkehrsentwicklung Potsdamer Bahn 1843-79 basierend aufGeschäftsberichten des Direktoriums der ehemaligen Berlin-Potsdam-Magdeburger Eisenbahngesellschaft und den seit Verstaatlichung geführten Verkehrs-Übersichten.

\begin{tabular}{|c|c|c|c|c|}
\hline \multirow[t]{2}{*}{1} & 2 & 3 & 4 & 5 \\
\hline & $\begin{array}{l}\text { Zabl der im } \\
\text { Vororts - und } \\
\text { Fernverkehr } \\
\text { beförderten } \\
\text { Personen }\end{array}$ & $\begin{array}{l}\text { Einnahn } \\
\text { Personen- } \\
\text { dt }\end{array}$ & $\begin{array}{l}\text { s dem } \\
\text { Güter- } \\
\text { A6 }\end{array}$ & $\begin{array}{c}\text { Gezablte } \\
\text { Dividende } \\
\text { in } \\
\%\end{array}$ \\
\hline $\begin{array}{l}1843 \\
1844 \\
1845 \\
\left.1847^{1}\right) \\
1850 \\
1855 \\
1860 \\
1865 \\
1870 \\
\left.1871^{2}\right) \\
1872^{2} \\
1873 \\
1874 \\
1875 \\
1876^{2} \\
1877^{2} \\
1878^{\circ} \\
\left.1879^{\circ}\right)\end{array}$ & $\begin{array}{c}\text { Die Zahle } \\
\text { sind in (run } \\
450 \\
431 \\
405 \\
407 \\
709 \\
687 \\
920 \\
1384 \\
1847 \\
2136 \\
2366 \\
3424 \\
3925 \\
4385 \\
4.454 \\
4.564 \\
4786 \\
4637\end{array}$ & $\begin{array}{c}\text { in den } \mathrm{Sp} \\
\text { n) Tausen } \\
467 \\
489 \\
467 \\
1233 \\
1609 \\
1689 \\
2.229 \\
2818 \\
3.19 \\
4.216 \\
3332 \\
4.409 \\
4.351 \\
4455 \\
4.383 \\
4428 \\
4.627 \\
4.598\end{array}$ & $\begin{array}{c}2 \text { bis } 4 \\
\text { ngegeben. } \\
53 \\
53 \\
61 \\
548 \\
1009 \\
1938 \\
2382 \\
3759 \\
5628 \\
6419 \\
4906 \\
6458 \\
7065 \\
7153 \\
7203 \\
7121 \\
6787 \\
6798\end{array}$ & $\begin{array}{l}? \\
? \\
? \\
4 \\
3 \\
5^{1 / 2} \\
9 \\
16 \\
20 \\
14 \\
8 \\
4 \\
1^{2} / 2 \\
3 \\
3^{1 / 2} \\
3^{1 / 2} \\
3^{1 / 2}\end{array}$ \\
\hline
\end{tabular}

1) Am 7. August 1846 wurde die Fortsetzung der Potsdamer Bahn bis Magdeburg oröffnet.

2) Im Laufe des Jahres 1871 wurden die einzelnen Strecken der in Mitbewerb tretenden Linien Berlin-Lehrte eröffnet.

3) Am 1. Januar 1880 fand die Verstaatlichung statt. Eine Dividende für das Jahr 1879 wurde nicht mehr gezahlt.

Quelle: Zeitschrift für Bauwesen 1893, S. 425.

Im Empfangsgebäude der Abfahrtsseite waren Flure, Fahrkarten- und Gepäckabfertigung auf Niveau der Zufahrtsstraße untergebracht. Bahnsteige und Wartesäle lagen jedoch 3,6m oberhalb des Eingangsniveaus, weil der Gleiskörper soweit erhöht werden musste, dass der angrenzende Landwehrkanal und dessen Uferstraßen ausreichend überquert werden konnten. Vom Eingangsvestibül aus waren Wartesäle und Gleishalle 
daher nur über eine große Freitreppe erreichbar, die zum Hauptgeschoss führte. Bezüglich seiner Grundrissdisposition zeigt der Potsdamer Bahnhof, dass wie bereits zwei Jahrzehnte zuvor im Bahnhof Elberfeld (1850) illustriert, die Symmetrie nach wie vor als zentrales Gestaltungselement innerhalb einer zeitgenössisch neo-klassizistischen Stilauffassung diente. In der Folge teilte das Eingangsvestibül mit seiner großen Freitreppe das passagierbezogene Raumprogramm in zwei Hälften. Das Symmetriestreben fungierte hierbei wie bereits in Elberfeld als willkommenes Mittel, um eine starke räumliche Trennung der Wagenklassen zu erreichen, denn wie in Elberfeld wurden die Reisenden 3. und 4. Klasse nach Fahrkartenerwerb und Gepäckaufgabe unmittelbar von jenen der 1. und 2. Klasse geschieden. In der Zeitschrift für Bauwesen bemerkt der Baudirektor des Bahnhofes, Julius Ludwig Quassowski, im Jahr 1877 rückblickend bezüglich dieser gewählten Form:

»Die Trennung des Publikums III. und IV. Klasse von demjenigen I. und II. Klasse, schon auf halber Treppenhöhe, erscheint vortheilhaft, da ein Begegnen in den engeren Corridoren dadurch vermieden wird. ${ }^{102}$

Diese frühzeitige Trennung der Reisenden, die analog etwa auch im Lehrter Bahnhof von Berlin oder dem Wiener Franz-Josephs-Bahnhof Anwendung fand, wurde hier also offenbar durch die Enge der Korridore legitimiert. Es steht zu vermuten, dass diese Erfahrung der beengten klassenübergreifenden Begegnung nur wenige Kilometer entfernt am zwei Jahre zuvor eröffneten Görlitzer Bahnhof nur allzu oft genug gemacht worden war, denn dort fungierte - wie in Kapitel 7.3.2 geschildert - nur ein einziger, für alle Reisenden gemeinsam zu nutzender Korridor als Zubringer zu den Wartesälen. Zudem wurde die Form der frühzeitigen Trennung der Reisenden immer wieder damit legitimiert, dass der Weg zu den jeweiligen Wartesälen durch eine getrennte Anordnung links und rechts der Eingangshalle deutlich kürzer ausfallen würde als bei hintereinander aufgereihten Wartesälen. Es steht jedoch zu vermuten, dass die soziale Implikation der symmetrischen Grundrissausrichtung in Form der Vermeidung von Begegnungen sehr unterschiedlicher sozialer Schichten ohnehin durchaus willkommen war, um die vorherrschenden gesellschaftlichen Verhältnisse adäquat im Bahnhof widerzuspiegeln. Nicht zufällig fiel die weiterführende räumliche Differenzierung in Berlin und vielen anderen Städten derart aus, dass die Wartesäle der gehobeneren Wagenklassen dem Wartesaal des Königlichen Hofes (in der Grundrissdarstellung des Potsdamer Bahnhofes unten rechts dargestellt) jeweils am nächsten lagen bzw. der Wartesäle 3. und 4. Klasse entsprechend am weitesten vom königlichen Wartesaal entfernt lagen. ${ }^{103}$ Diese Disposition mag kaum überraschen, repräsentiert sie doch somit die hierarchische Gesellschaftsorganisation des Kaiserreichs, in der das aufstrebende Bürgertum dem

102 Julius Ludwig Quassowski, »Der Personenbahnhof der Berlin-Potsdam-Magdeburger EisenbahnCesellschaft zu Berlin«, Zeitschrift für Bauwesen XXVII., Nr. 1-3 (1877): 25.

103 Anders als in den Vorgängerbauten wurde der Bahnhof nunmehr fast täglich von Angehörigen des Königlichen Hofes benutzt, die zwischen Berlin und der Residenz Potsdam reisten. Entsprechend wurde auch die Abfahrtsstation des Königlichen Hofes vergrößert. Die königlichen Warteräume wurden dazu derart angelegt, dass der Salonwagen des Königs direkt vor den Warteräumen platziert werden konnte, um somit einen direkten Zugang »ohne irgendeine Längsbewegung auf dem Perron« zu ermöglichen (Ebd., 26.). 
Hochadel in allen Belangen nachzueifern versuchte. Nicht zuletzt in der Wartesituation am Bahnhof oder vielleicht gar ganz besonders hier konnte sich das aufstrebende Bürgertum der wachsenden Nähe zum Hochadel in puncto Komfort, Reiseprivilegien und dem dafür notwendigen Kapital snahe fühlen und sich in Anbetracht dieser Nähe seiner Selbst vergewissern. ${ }^{104}$ Ästhetischer Gestaltungsanspruch (Symmetrie) und soziale Vorstellungen (Klassengesellschaft) griffen hierbei also durchaus ineinander und trugen zu einer gegenüber der Frühphase insgesamt stärkeren sozialen Differenzierung des wartebezogenen Raumprogramms bei, die eines der zentralen Charakteristika des letzten Drittels des 19. Jahrhunderts bildete. Dieser sozialen Differenzierung des Wartens noch weiter entsprechend verfügte der Neubau des Potsdamer Bahnhofs über ein $26 \mathrm{~m}^{2}$ großes Damenzimmer, das zwischen dem Wartesaal erster und zweiter Klasse eingerichtet wurde (Abbildung 37, Nr. 24) und eigens »mit einem Closet und einer Waschtoilette versehen ${ }^{105}$ war. Zumindest die höheren Wagenklassen erfuhren hierdurch erstmals eine deutlich geschlechtsspezifische Aufladung des systemischen Wartens.

Jenseits des Befunds einer Instrumentalisierung sozialer Unterschiede in der das Warten offensichtlich deutlich stärker in den Stand einer sozialen Dimension gerückt wurde, zeigte der Neubau des Potsdamer Bahnhofs übergeordnet die ungebrochene Zentralität des situativen Aufenthalts innerhalb der Betriebs- und Wegeführung, die bereits als Kultivierung des stationären Warteimperativs zu charakterisieren versucht wurde. Das wartebezogene Raumprogramm in Bahnhofsbauten der dritten Generation ist demnach abermals nicht von der Verkleinerung oder gar der Abschaffung von Wartesälen geprägt, sondern vielmehr von deren Verstetigung und Ausbau. Hiermit steht zu vermuten, dass der stationär-raumgebundene Warteimperativ, der organisatorische Zwang zum Kurzaufenthalt in den Wartesälen vor Abfahrt, weiterhin praktiziert und damit innerhalb der Reiseerfahrung nochmals spürbarer geworden sein musste. So waren die Wartesäle und angegliederten Infrastrukturen der Toiletten- und Restaurationsräume des Potsdamer Bahnhofs gegenüber dem Ursprungsbau von ca. $180 \mathrm{~m}^{2}$ auf mehr als $600 \mathrm{~m}^{2}$ angewachsen. ${ }^{106}$

Entgegen der operativen Persistenz des zwischenzeitlichen Sammelns der Reisenden in den Wartesälen zeigten sich mit dem Neubau des Potsdamer Bahnhofes jedoch zugleich zwei baulich-betriebliche Aspekte, die allesamt auf eine größere Rationalität und beschleunigte Zirkulation abzielten. Hierzu zählen die Funktionen der Korridore auf Höhe des oberen Hauptgeschosses sowie die Einrichtung eines Mittel- und Kopfbahnsteiges im Zusammenspiel mit einer temporären Nutzung des Kopfgebäudes für den Lokal- und Ausflugsverkehr. Diese baulichen Einrichtungen, die im Folgenden kurz beleuchtet werden, hatten direkte Auswirkungen auf den stationären Warteimperativ, der sich hier erstmals zu modifizieren schien. Sie ließen den Bahnhof der Berlin-

104 Otto Brunner, »Stadt und Bürgertum in der europäischen Ceschichte«, in Neue Wege der Verfassungsund Sozialgeschichte, hg. von Otto Brunner (Göttingen: Vandenhoeck und Ruprecht, 1980), 213224 sowie Werner Conze und Jürgen Kocka, Bildungsbürgertum im 19. Jahrhundert (Stuttgart: KlettCotta, 1985).

105 Quassowski, »Der Personenbahnhof der Berlin-Potsdam-Magdeburger Eisenbahn-Cesellschaft zu Berlin«, 25.

106 Ebd., 26. 
Potsdamer-Eisenbahngesellschaft damit zu einem Repräsentanten des Übergangs hin zum klassischen Großstadtbahnhof der `Ersten Moderne< werden.

\section{Stellung und Funktion der Korridore im Hauptgeschoss}

Wie aus dem Grundriss ersichtlich wird, erreichten die Reisenden nach Durchschreiten der Eingangshalle am oberen Ende der Freitreppe zunächst zu beiden Seiten einen Korridor, der sie zu ihren jeweiligen Wartesälen führte. Die Besonderheit dieser zunächst trivialen Einrichtung liegt jedoch darin, dass die Korridore nicht wie üblich auf der Stadtseite, sondern auf Seite der Gleishalle angeordnet wurden, wodurch sich die Korridore zwischen Wartesäle und Gleishalle schoben. Diese Anordnung wurde laut Aussage des leitenden Baudirektors Quassowski aus folgendem Grund gewählt:

»Die Anlage der Corridore an der Perronseite gewährt die Vortheile, daß das Publikum von denselben direct auf den Perron gelangen kann, ohne die Wartesäle zu betreten, daß der so lästige Zug in den Wartesälen vollständig vermieden wird und daß die Wartesäle directes Licht erhalten. $\ll^{107}$

Vor allem raumklimatische Gesichtspunkte sowie Fragen der bestmöglichen Beleuchtung bewirkten demnach eine leichte Verlagerung der Wartesäle, die dadurch nicht länger den direkten Zugang zu den Bahnsteigen ermöglichten. Zudem wollten aber offenbar auch einige Reisende entgegen der sonstigen Praxis die Wartesäle überhaupt gar nicht mehr aufsuchen. Quassowski führt zu diesem letzten Punkt der veränderten Gewohnheiten der Reisenden an:

»Da es besonders im Local- und Extrazug-Verkehr hier üblich ist, daß das Publikum gleich bei der Ankunft auf dem Bahnhofe in die Wagen steigt, so ist solches durch getroffene Einrichtung wesentlich erleichtert, und werden diejenigen Reisenden, welche es vorziehen, bis kurz vor dem Abgange der Züge in Wartesälen resp. in der Restauration sich aufzuhalten, weniger genirt. $\ll^{108}$

Offenkundig wurde mit der Anordnung des Korridors an der Perronseite also erstmals nicht nur nachweislich eine Trennung der Wartenden nach Reisedauer und Reiseentfernung vorgenommen, was für sich genommen bereits einer bedeutenden Differenzierung des systemischen Wartens gleichkommt. Vielmehr wurde mit dieser baulichen Einrichtung auch einer veränderten bzw. beschleunigten Abfahrtspraxis Rechnung getragen bzw. die Praxis der Umgehung der Wartesäle durch die getroffene Einrichtung stimuliert. Diese nunmehr beschleunigte Abfahrtspraxis, die dem systemischen Warten in dafür eingerichteten Räumlichkeiten weniger Bedeutung zumaß, wurde demnach vor allem von der Gruppe der Pendler und Ausflügler getragen, die wahrscheinlich später als andere Reisende am Bahnhof eintrafen und die Wartezeit am Bahnhof der nur kurzen Fahrtdauer verhältnismäßig anpassen wollten. Der Abschluss der Wartesäle gegen Zugluft und durchströmende Reisende ließ diese Raumgruppe damit hier erstmals weniger als Schleuse denn als optionales Raumangebot erscheinen.

107 Ebd., $25 f$.

108 Quassowski, »Der Personenbahnhof der Berlin-Potsdam-Magdeburger Eisenbahn-Cesellschaft zu Berlin«, 26. 
Abbildung 37: Grundriss Potsdamer Bahnhof in Berlin mit Wartesaal IV. Klasse (16), Büffet (17), Wartesaal III. Klasse (18), Korridor (19), Toiletten (20, 30), Eingangshalle (23), Wartesaal II. Klasse (27), Wartesaal I. Klasse (22), Damenzimmer (24), Toilette für Damen (25), Speisesaal (28), Büffet (29).

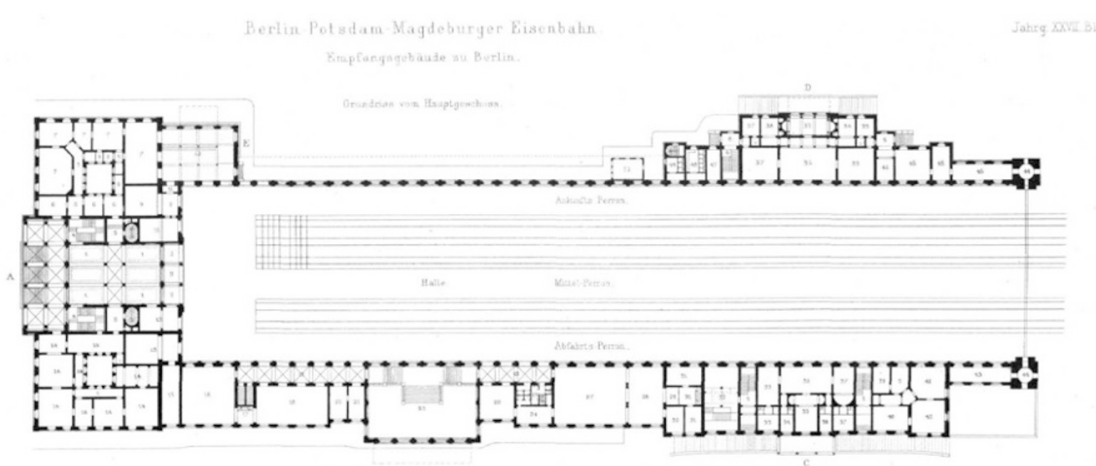

Quelle: Zeitschrift für Bauwesen 1877, Atlas, Blatt 8.

Der mit der Platzierung des bahnseitigen Korridors entsprochenen (oder stimulierten) Beschleunigung des Verkehrsablaufs geschah jedoch wohlgemerkt auf Kosten der psychologisch so zentralen Sichtverbindung vom Wartesaal zum Erwartungsobjekt (dem Zug). Der vormals fast überall etablierte Direktzugang wurde im Potsdamer Bahnhof durch das Zirkulationsmedium des Korridors getrennt, was Quassowski noch weit vor Fertigstellung Baus im Jahr 1869 folgendermaßen zu kompensieren suchte:

»Die Wartesäle selbst, die komfortabel eingerichtet und durch direktes Seitenlicht erleuchtet werden, konnten nach dieser Anordnung mit der Perronhalle theilweise nicht in direkter Verbindung stehen, sondern sind durch einen Korridor von ihr geschieden worden. (...) den Nachtheil, dass ein Theil des wartenden Publikums die Züge nicht beobachten kann, hofft man durch durchgängige Anordnung von Clasthüren zu beseitigen. $\ll^{109}$

Auch nach Fertigstellung des Bahnhofes versuchte Quassowski der inzwischen entgegengebrachten Kritik dieser Anordnung mit dem gleichen Transparenz-Argument zu begegnen:

»Da die Wartesäle außerdem in jedem Felde eine Clasthür nach dem Corridor erhalten haben, welcher nur durch offene Bogenöffnungen von dem Perron getrennt ist, und somit der Zug und der Verkehr an demselben vom Wartesaal aus genügend übersehen werden kann, so ist auch dem Vorwurf gegen eine derartige Anordnung

109 Julius Ludwig Quassowski, »Der neue Bahnhof der Berlin-Potsdam-Magdeburger Eisenbahn zu Berlin.«, Deutsche Bauzeitung III., Nr. 19 (1869): 219. 
begegnet daß das Publikum beim Herannahen der Abfahrtszeit ängstlich und unruhig wird, weil die Säle nicht direct am Perron liegen. $\ll^{110}$

Typisch für die Entstehungszeit dieser Zitate waren Architekten und Ingenieure der 1860er und 1870er offenbar in vollem Bewusstsein der psychologischen Herausforderungen des systemischen Wartens und versuchten möglichst die moderne Urangst des Verpassens mittels Sichtbeziehungen zum Gleis aufzufangen. Tatsächlich kamen die geschaffenen Sichtbeziehungen zum Zug durch die Glastüren aber nicht allen wartenden Reisenden zugute. In besonderem Maße dürfte dieser Umstand für weibliche Reisende zugetroffen haben, die - wie auch in vielen anderen Bahnhöfen - über gar keine Sichtbeziehung zu den Zügen in der Gleishalle verfügten, da das Damenzimmer straßenseitig angeordnet und damit die Sichtbeziehung zur Gleishalle von dazwischenliegenden Toiletten und Waschzimmern blockiert wurde.

Ausgehend vom Arrangement und der Funktionen der Korridore lassen sich mit dem Potsdamer Bahnhof somit zusammenfassend erste leichte Veränderungen des bis dahin etablierten, stationären Warteimperativs nachweisen. So mussten in den frühen 1870er Jahren offenbar nicht mehr alle Reisende gleichsam die Wartesäle aufsuchen, sondern favorisierte eine Teilgruppe - wie in England - die Züge direkt und ohne Umwege zu besteigen. Die Wartesäle wurden demnach aufgrund der lokalen Verkehrsspezifik eines Großstadtbahnhofes mit einer Vielzahl von Vorort- und Sonderfahrten nur mehr "von einen Theil des Publikums benutzt «" ${ }^{111}$, wodurch das verkehrliche Warten eine erste Form der Differenzierung in Form seiner Verkürzung und seiner räumlichen Verlagerung bzw. Abschottung erfuhr.

\section{Mittel- und Kopfbahnsteig und temporäre Nutzung des Kopfgebäudes}

Eine weitere Differenzierung des verkehrlichen Wartens wurde durch die Einrichtung eines Mittel- und Kopfbahnsteiges erzielt. Aus Gründen der Betriebssicherheit sollten die fünf verfügbaren Gleise nicht mehr überschritten werden, sodass ein >Mittel-Perron im Zentrum der Gleishalle installiert wurde, der einen schienenfreien Einstieg in jene Züge gewährleistete, die in der Mitte der Gleishalle abgestellt wurden. Dem Mittelperron vorgeschaltet lag ein Kopfbahnsteig, der auch eine Verbindung zum Wartesaaltrakt ermöglichte. Dieser Mittelbahnsteig wurde jedoch nicht für fahrplanmäßige Fahrten des Fernverkehrs genutzt, sondern war lediglich »für einzelne Local- und Extrazüge und für den Verbindungsbahn- Verkehr « ${ }^{112}$ bestimmt. Wenngleich die Mehrheit des Reisepublikums in etablierter Art und Weise den Zugang über den Seitenflügel nahm, bestand die Neuheit im Neubau des Potsdamer Bahnhofs somit darin, dass für spezielle Züge eine kopfseitige Erschließung vorgenommen wurde. Mit anderen Worten: Einer kleinen, aber wachsenden Gruppe von Reisenden war es für den Stadt- und Ausflugsverkehr nunmehr gestattet, einen gänzlich anderen Zugang zum Zug zu wählen.

110 Quassowski, »Der Personenbahnhof der Berlin-Potsdam-Magdeburger Eisenbahn-Gesellschaft zu Berlin«, 26.

111 Ebd.

112 Quassowski, »Der Personenbahnhof der Berlin-Potsdam-Magdeburger Eisenbahn-Cesellschaft zu Berlin«, 21. 
Vor allem Reisende, die über Abonnetmentkarten und Retourtickets verfügten, ${ }^{113} \mathrm{ka}$ men dadurch mit dem eigentlichen Wartesaaltrakt im Seitenflügel überhaupt gar nicht mehr in Berührung und umgingen die sonst übliche Praxis des Zwischenaufenthalts in den Wartesälen. Stattdessen nutzten sie das Kopfgebäude als (beschleunigten) Hauptzugang und den Kopf- bzw. Mittelperron als Zirkulations- und Aufenthaltsort, wenn sie nicht ohnehin gleich die Züge bestiegen und darin die Abfahrt erwarteten.

Wenngleich die Mehrheit der Reisenden nach wie vor über den Seitenflügel in die Züge einstieg und die Erfahrung einer gewissen stationären Schleusung durchlebte, zeigte der Potsdamer Bahnhof eine stärkere, für diese Zeit symptomatische Differenzierung des Reisepublikums hinsichtlich gewandelter Ansprüche, was sich auch in der unterschiedlichen Verhandlung des temporären Kurzaufenthalts vor Abfahrt ausdrückte. Alte und neue Abfahrtsmodi - jene des Warteimperativs und jene des direkten und umweglosen Zugangs - lagen in diesem Bahnhof dicht beieinander, weshalb er eine Hybridstellung innerhalb der Entwicklung in Richtung der noch stärker auf beschleunigte Zirkulation ausgerichteten Großstadtbahnhöfe einnimmt.

\section{Lokalbahn-Erweiterungen des Potsdamer Bahnhofs (1891): Verlagerung des Wartens vom Saal auf den Bahnsteig}

Abbildung 38: Grundriss des Potsdamer Bahnhofs Berlin. Rechts und links der Hallenausfahrt wurden 1891 zwei Anschlussbahnhöfe für den Lokalverkehr errichtet, die - im Gegensatz zum Fernbahnhof-über keinerlei Wartesäle mehr verfügten.

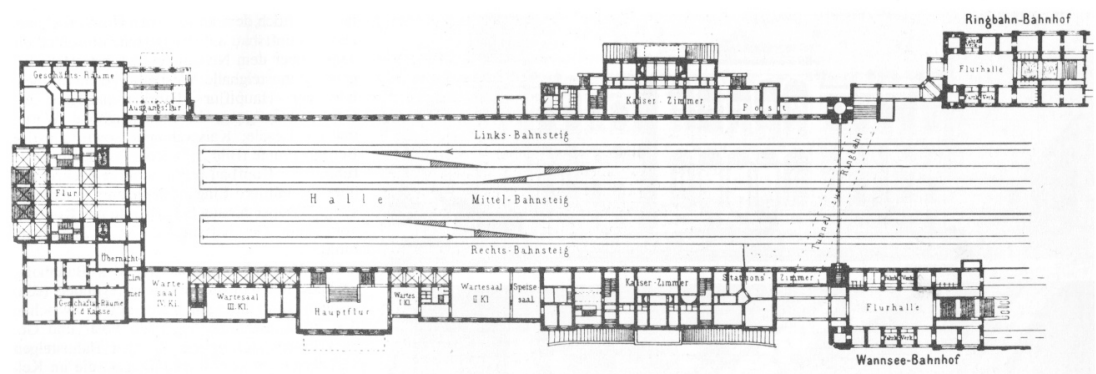

Quelle: Berger 1987.

Das immense Stadtwachstum Berlins und der wachsende Lokalverkehr bedingten zum Ende des 19. Jahrhunderts nochmals die Erweiterung des Potsdamer Bahnhofes um den Bau zweier neuer Flügelbahnhöfe für die Ringbahn und die Wannseebahn. Mit diesen 1891 eröffneten, nahezu identischen Anbauten wurden der Fern- und Lokalverkehr des Potsdamer Bahnhofes voneinander getrennt. Ein auf der Ostseite gelegenes Gebäude vermittelte den Übergang zur Ringbahn, ein auf einer Westseite gelegenes Gebäude jenen zur Wannseebahn, die den Vorortverkehr in Richtung der aufblühenden Stadtgemeinden Schöneberg, Steglitz und Zehlendorf erschloss. Die Gebäude wur- 
den durch einen sechs Meter breiten Tunnel mit dem Hauptgebäude des Potsdamer Bahnhofes verbunden an deren Enden Treppenaufgänge zu den im Niveau gegenüber dem alten Bahnhof nochmals höherliegenden Abfahrtsgleisen führten. Die hier herauszustellende Besonderheit lag nun darin, dass sich in diesen Gebäuden erstmals im deutschen Kontext keine eigens eingerichteten Wartesäle oder gar Warteräume mehr befanden (siehe Abbildung 39), denn:

»Bei Vorortbahnhöfen pflegt die Mehrzahl der Reisenden die Warteräume nicht aufzusuchen, sondern sich unmittelbar nach den Bahnsteigen zu begeben, um dort die Ankunft der Züge zu erwarten. $\ll^{114}$

Abbildung 39: Grundriss des Anschlussbahnhofs der Wannseebahn an den Potsdamer Bahnhof.

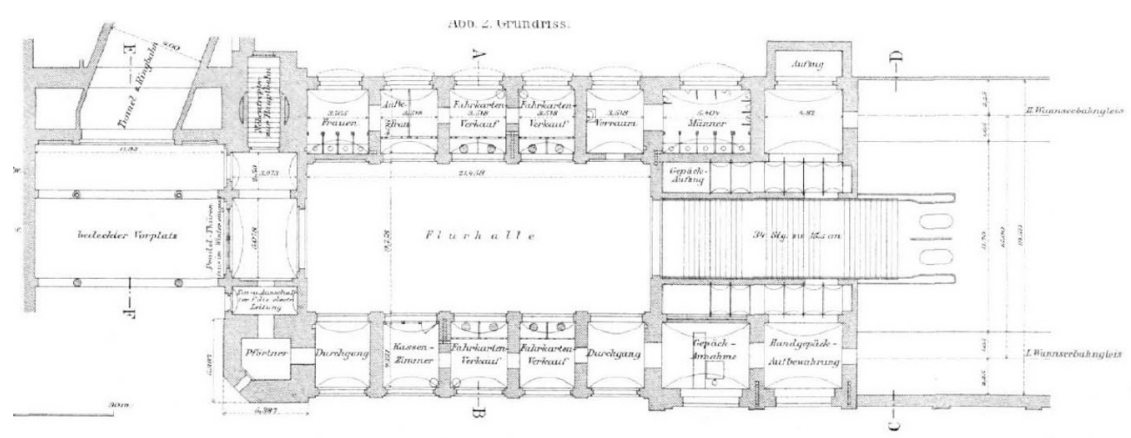

Quelle: Zeitschrift für Bauwesen 1893, Atlas Blatt.47.

Auf den überdachten Bahnsteigen angekommen standen den Reisenden eine Reihe neuer, wenngleich weit weniger komfortabler Warteinfrastrukturen in Form von doppelsitzigen Bänken und kleinen Wartehäuschen zur Verfügung. Während die Sitzbänke durch »mit hohen Rück- und Seitenwänden Schutz gegen Wind und Wetter« ermöglichen sollten, wurden zudem auf den Stationen der Wannseebahn »allseits geschlossene heizbare Wartehäuschen aufgestellt. «115

Zusammenfassend repräsentierten diese beiden Anbauten, dass der präparatorische Aufenthalt vor Abfahrt mit Etablierung des Vorortverkehrs eine neue effiziente Form erhielt, die zunehmend in Opposition zur würdevollen Kultivierung des (längeren) Wartens im Fernbahnhof zu stehen begann. Zum einen ließen die Routine, Regelmäßigkeit und Zeiteffizienz der Reisenden, aber auch der dichte Takt der Züge ${ }^{116}$ ein Verweilen in Wartesälen nicht mehr notwendig erscheinen, zum anderen verhinderte die schiere Masse an Personen die Aufnahme von Reisenden in dafür geeigneten

114 Paul Michaelis, »Die Beseitigung des Schienenüberganges des Breitenweges in Magdeburg- Neustadt. «, Zeitschrift für Bauwesen LII., Nr. 7-9 (1902): 375.

115 »Der Bau der Wannseebahn und die Umgestaltung des Potsdamer Bahnhofes in Berlin. «, Zeitschrift für Bauwesen XLIII. (1893): 432.

116 Züge zwischen dem Potsdamer Bahnhof und Zehlendorf verkehrten in den 1890er Jahren bereits im Fünfminutentakt. 
Räumen. Diese Verlagerung des Wartens vom Gebäude auf den Bahnsteig ging auch mit einem deutlichen semantischen Wandel einher, denn die Gebäude der beiden Flügelbahnhöfe wurden - dem Charakter ihres transitorischen Massenverkehrscharakters entsprechend - fortan nicht mehr Empfangsgebäude, sondern nur noch treffend als »Abfertigungsgebäude ${ }^{117}$ bezeichnet.

\subsubsection{Frankfurt a.M. (1888)}

Mit einer Fläche von ca. $40.000 \mathrm{~m}^{2}$, seinen 18 Gleisen und einem 220 Meter breiten stadtseitigen Kopfgebäude gilt der Neubau des >Frankfurter Centralbahnhofes`zweifellos als Prototyp eines großstädtischen Kopfbahnhofs. Der im August 1888 eröffnete, maßgeblich von Hermann Eggert und Johann Wilhelm Schwedler verantwortete Bahnhofsbau vereinigte drei einzelne zuvor nebeneinander liegende Bahnhofsgebäude und wurde in einem internationalen Wettbewerbsverfahren als Denkmal- und Repräsentationsbau intendiert, der von überzeitlicher Qualität sein und bis ins kommende Jahrhundert hinein Geltung haben sollte.

Eingebettet in eine klassizistische Stil- und Formensprache und einer nahezu vollständig durchgeführten Symmetrie wurden in der damals größten europäischen Bahnhofsanlage moderne Neuerungen der optimierten Verkehrsführung etabliert. So verfügte der Frankfurter Hauptbahnhof durch ein den Funktionsabläufen entsprechendes System der Raumfolgen und übersichtliche Verbindungswege über eine für damalige Vorstellungen optimale Zirkulation der Reisenden. Gesetztes Ziel sollte es laut dem verantwortlichen Bauleiter Eggert sein, den Reisenden eine »erforderliche Uebersicht zu geben, um sich leicht zurechtzufinden, und dieselben so in die Wartesäle zu vertheilen, daß sie die von den verschiedenen Bahnsteigen abfahrenden Züge auf kürzestem Wege und ohne störende Gegenströmungen erreichen könnten. «118 Um die Personenströme zu optimieren, wurden dazu die Raumgruppen ab Eintritt in den Bahnhof entlang der drei zentralen Passagierfunktionen des Fahrkartenkaufs, dem Warten und dem Betreten der Gleise in eine "naturgemäße Folge ${ }^{119}$ gebracht. Diese Konzeption ließ die Frankfurter Grundrissdisposition zum Paradebeispiel einer >Prozessarchitektur werden, in dem das »Phantasma universeller Prozessierung und reibungslosen Betriebs « ${ }^{120}$ durch Vermeidung von Kreuzungen und Gegenströmungen realisiert wurde. Der Frankfurter Centralbahnhof bildete damit nicht weniger als »die »Summe« aller voraufgegangenen Lösungen. ${ }^{121}$

Wesentliches Element des optimierten Verkehrsflusses und reibungslosen Betriebs markierte ein $17 \mathrm{~m}$ tiefer Kopfbahnsteig, der nach Durchschreiten der zentralen Eingangshalle erreicht wurde und die gesamte Breite der Gleishalle (198m) ausfüllte. Flankiert wurde dieser Kopfbahnsteig vom Novum seitlicher Ausgänge an den beiden Enden des Kopfbahnsteiges hinter denen außerhalb des Bahnhofes gelegene, überdachte

117 »Der Bau der Wannseebahn und die Umgestaltung des Potsdamer Bahnhofes in Berlin.«, 436.

118 Hermann Eggert, »Das Empfängsgebäude des Hauptbahnhofes in Frankfurt a.M.«, Zeitschrift für Bauwesen 41, Nr. 10 (1891): 402.

119 Ebd., 404.

120 Jany, »Operative Räume. Prozessarchitekturen im späten 19. Jahrhundert«, 35.

121 Krings, »Bahnhofsarchitektur: deutsche Großstadtbahnhöfe des Historismus«, 229. 
Abbildung 40: Grundriss des neuen Centralbahnhofes Frankfurt a.M.

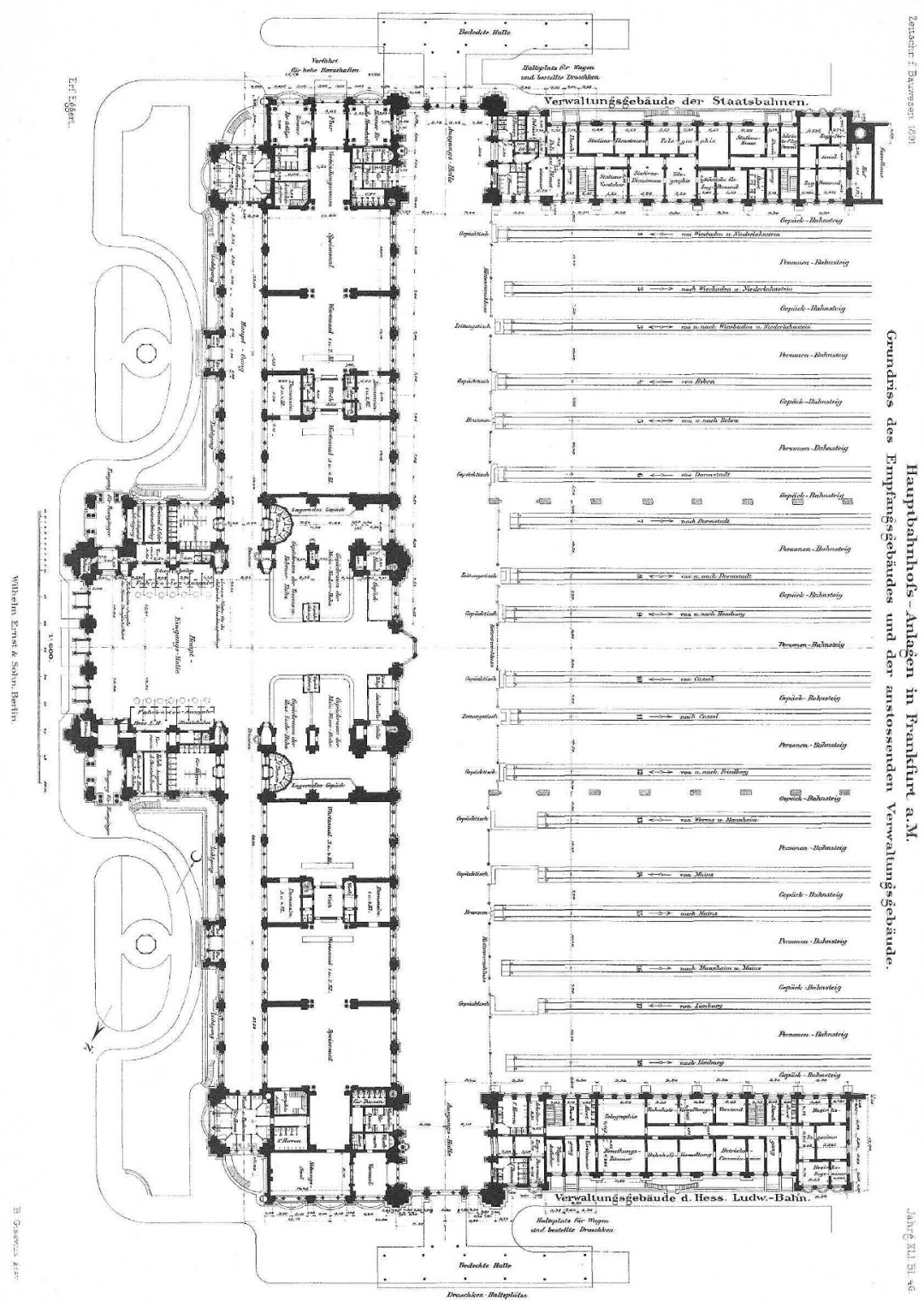

Quelle: Zeitschrift für Bauwesen 1891, Atlas Blatt.46. 
Droschkenhallen den weiterführenden Verkehr in die Stadt vermittelten. Durch den breiten Kopfbahnsteig und die seitlichen Ausgänge konnten die Personenströme ankommender Reisender optimal aus dem Bahnhof geleitet und dabei Kreuzungsverkehre mit abreisenden Passagieren aufgrund der großen Ausweichfläche minimiert werden. Die im vorangegangenen Beispiel des Potsdamer Bahnhofs bereits partiell und temporär praktizierte kopfseitige Erschließung (für den Extrazug- und Vorortverkehr) wird damit in Frankfurt nunmehr vollends als Standardlösung etabliert. In der Folge werden mit dem Kopfbahnhof Frankfurter Typs fast alle Funktionen, die vormalig durch seitlich gelegene Empfangsgebäude erfüllt wurden, durch die kopfseitige Erschließung getauscht. ${ }^{122}$ Demnach fungiert hier nicht mehr das seitliche Empfangsgebäude als zentrale Verkehrs- und Zirkulationsfläche, sondern ein verbreiteter Kopf- oder Querbahnsteig nahm die Zirkulationsfunktionen $\mathrm{ab}$ - und anreisender Personenströme in sich auf. Während die riesige Zirkulationsfläche abreisende Passagiere nach Fahrkartenkauf und Gepäckannahme auf gleichrangige Zungenbahnsteige vermittelte, die einen sicheren Einstieg in die Züge ohne jegliche Gleisüberschreitungen ermöglichten, konnten ankommende Reisende den Bahnhof über die seitlichen Ausgänge des Kopfbahnsteigs unmittelbar verlassen.

Zäsural für die bau- und kulturhistorische Betrachtung des verkehrlichen Wartens ist dabei nun aber, dass der breite Kopfbahnsteig nicht exklusiv der reibungslosen Zirkulation diente, sondern er angesichts der immens gewachsenen Passagierzahlen unter anderem auch »(...) zum Aufenthalt des Publicums bestimmt« war. Mit ihm sollte »eine Ueberfüllung der auch für den Gepäckverkehr bestimmten hinreichend breiten Zungensteige vermieden werden. ${ }^{123}$ Neben dieser Entlastungsfunktion wurde der Kopfbahnsteig jedoch zugleich auch mit Bänken zum Aufenthalt sowie mit Trinkbrunnen und Zeitungstischen, Schreibpulten, Telegrafenstelle sowie mit Tafeln für öffentliche Anzeigen ausgestattet. Diese Funktions- und Servicevielfalt lässt vermuten, dass die staatlichen Bahnbehörden das systemisch notwendige Warten weit mehr als zuvor vom stationären Aufenthalt in den Wartesälen auch zusätzlich in die Fläche zu verlagern versuchten. Diese These wird nicht zuletzt dadurch gestützt, dass anders als zuvor nunmehr die Gleishalle »dem Verkehr des Publicums völlig freigegeben ${ }^{124}$ wurde. Wie aus dem Grundriss (Abbildung 40) ersichtlich wird, war es den Reisenden nach Fahrkartenkauf und Gepäckaufgabe somit entweder möglich, den (althergebrachten) >Umwegく über die Wartesäle (und dortigen Aufenthalt) zu nehmen und erst von dort aus den Kopfbahnsteig sowie anschließend die Zungenbahnsteige zu betreten. Oder Reisende konnten alternativ den Kopfbahnsteig direkt von der Eintrittshalle und ohne Nutzung der Wartesäle betreten. Interessanterweise bestanden die ursprünglichen Frankfurter Planungen sogar darin, den Kopfbahnsteig als Hauptverkehrszone zu entwickeln und Reisende erst von dort aus in die Wartesäle zu verteilen. Die Akademie für Bauwesen, die das dem Wettbewerb zugrunde gelegte Bauprogramm nochmals überprüfte, äußerte jedoch Bedenken, »daß es dabei schwerlich zu ermöglichen gewesen sein würde, für

122 Vgl. Radlbeck, »Bahnhof und Empfangsgebäude«, 49.

123 H. Wegele, »Die Hauptbahnhofs-Anlagen in Frankfurt a.M.«, Zeitschrift für Bauwesen XLI., Nr. 1-3 (1891): 101.

124 Eggert, »Das Empfängsgebäude des Hauptbahnhofes in Frankfurt a.M.«, 412. 
die Reisenden ein so leichtes Zurechtfinden zu schaffen, wie bei der anderen Lösung. ${ }^{125}$ Diese andere Lösung bestand darin, die Wartesäle von der Mitte der Eingangshalle aus »durch stattlich gewölbte Gänge von 7,5m Breite « ${ }^{126}$ erreichbar zu machen, an denen sich auch die Mehrheit der Verkaufsläden für Zigarren und Zeitungen befanden. Dem Kopfbahnsteig wurde daher noch eine weitere Zirkulationsebene im Inneren des Empfangsgebäudes vorgeschaltet, die zunächst den Weg zu den Wartesälen vermittelte.

Wenngleich die Wartesäle in diesem Prototyp des modernen Großstadtbahnhofs auch gänzlich umgangen werden konnten, hatten sie im überzeitlich intendierten Baukonzept dennoch weiterhin ihren Platz gefunden und ergänzten damit das auf dem Querbahnsteig >verflüssigteく Warten um die traditionell `stationären Einrichtungen. Trotz des in Fläche und Bedeutung gewachsenen Querbahnsteigs zeigte sich entsprechend eine nach wie vor deutliche Zentralität der Wartesäle in der Grundrissdisposition. Wenn die Intention dieses Baus darin bestand, noch über viele Jahrzehnte als Standard für den Bahnhofsbau zu fungieren, so wurde das etablierte Konzept des stationären Wartens aus Sicht der Planer demnach offenbar als nicht weniger überzeitlich und zukunftssicher betrachtet als das neue Konzept des optimierten Verkehrsflusses durch die Einrichtung selbstorganisierter Zirkulationsflächen. Das stationäre Warten bildete somit trotz der im Gesamten auf den reibungslosen Fluss abzielenden Konzeption von >Prozessarchitekturen « weiterhin einen festen Bestandteil. In Analogie zur bereits angeführten, effizienzsteigernden Vorschaltung von Sekretariaten im organisationalen Kontext vermerkt Jany hinsichtlich der Bedeutung von Wartezonen im modernen Bauwesen:

»Für die Sicherung möglichst kontinuierlicher Übertragungsprozesse erscheint das Einrichten von Diskontinuitäten wesentlich. Elemente, die sich als prozessarchitektonische `Zwischenspeicher kennzeichnen lassen, wie Warteräume, Speicherrutschen oder Verteilregale, ermöglichen gerade dadurch effiziente Übertragungen, dass sie Aufstauungen und Verzögerungen provozieren und dadurch Anschlüsse produzieren. ${ }^{127}$

Entsprechend dieser Prozesslogik stellte sich der Frankfurter Centralbahnhof als ein Nebeneinander funktionaler Zonen der Zirkulation und der zwischenzeitlichen Retardierung von Strömen dar. Ferner als Mischform eines >stationären und eines in der Fläche `verflüssigten`, weniger konkret raumgebunden Wartens auf der selbstorganisierten Zirkulationsfläche des Kopfbahnsteiges.

Für das stationäre Warten wurde ein der Gleishalle vorgelagerter, flacher Kopfbau errichtet, in dem sich vier riesige Säle identischer Fläche für Reisende erster und zweiter sowie dritter und vierter Klasse sowie ein jeweils angeschlossener Speisesaal befanden. Darüber hinaus erfolgte die für jene Zeit typische Differenzierung des wartebezogenen Raumprogramms in Form der Einrichtung eines speziellen Fürstenzimmers in "gediegener und behaglicher Pracht " $^{128}$ und einem Raum für >Höchste und Allerhöchste

125 Ebd., 403.

126 Ebd.

127 Jany, »Operative Räume. Prozessarchitekturen im späten 19. Jahrhundert«, 38.

128 Eggert, »Das Empfängsgebäude des Hauptbahnhofes in Frankfurt a.M.«, 414. 
Herrschaften . Zudem durfte natürlich die inzwischen obligatorisch gewordene Errichtung zweier zwischen den Wartesälen platzierter Damenzimmer mit eigenen Toilettenräumen nicht fehlen. Die Besonderheit der Damenzimmer bestand jedoch darin, dass nunmehr nicht nur die oberen Wagenklassen über ein Damenzimmer verfügten, sondern auch erstmals die dritte und vierte Wagenklasse eine geschlechtsspezifische Differenzierung des Raumprogramms erfuhr. Die Wartesaalgruppen befanden sich jeweils links und rechts der Mittelachse ${ }^{129}$ und lagen damit - wenngleich in Sichtbeziehung in einiger Entfernung zu den Zungenbahnsteigen.

Abbildung 41: Erweiterung des Wartens in die Fläche: Bahnsteighalle des neuen Centralbahnhofes von Frankfurt a.M. mit breitem Kopfbahnsteig und zu den Zügen führenden Zungenbahnsteigen (Radierung um 1888).

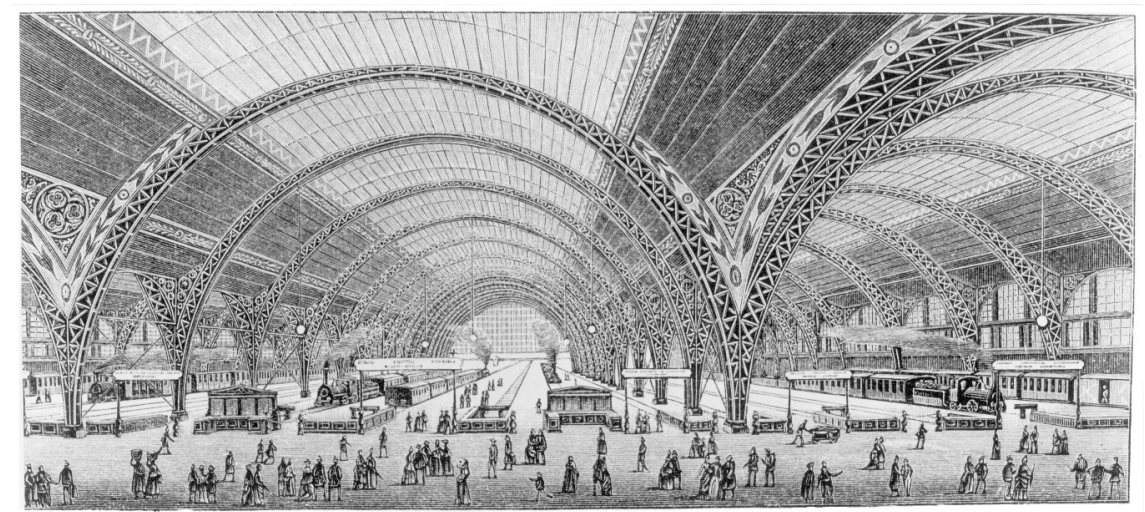

Quelle: DB Museum.

Die Innenraumgestaltungen der Wartesäle fielen dem selbstgewählten Status eines ikonischen Repräsentationsbaus entsprechend besonders würdevoll aus und dies offenbar klassenübergreifend. Horizontale Decken aus Ziegelgewölben wurden zwischen sichtbar gelassene Eisenträger installiert, die abwechslungsreiche Kassettierungen erzeugten. Die Beleuchtung der feuersicher konstruierten Wartesäle erfolgte durch riesige, »in reicher Schmiedetechnik durchgeführte Kronleuchter « ${ }^{130}$ und zahlreiche Wandleuchter sowie durch leicht getönte Oberlichter, die den Räumen eine »behagliche Stimmung ${ }{ }^{131}$ geben sollten. Die Fenster wurden mit Kathedralglasfüllungen versehen, die Decken mit Stuckgesimsen und die Bogenöffnungen zwischen den Wartesälen erster und zweiter Klasse mit Marmorsäulen eingefasst. An holzvertäfelten Wänden wurden

129 Der Bahnhof war links und rechts seiner Mittelachse in zwei quasi identische Teile aufgegliedert, die von jeweils eigenständigen Bahnverwaltungen (der Hess. Ludwigsbahn und den Preußischen Staatsbahnen) betrieben wurden und jeweils über eigenständige Warte- und Restaurationsbereiche verfügten.

130 Eggert, »Das Empfängsgebäude des Hauptbahnhofes in Frankfurt a.M.«, 413.

131 Ebd., 414. 
gußeisern umkleidete Wasserheizkörper, große Buffetschränke platziert und Sitzbänke eingelassen, die mit der Vertäfelung eine organische Verbindung eingehen sollten. Die Färbung der Saalwände wurde in »Steintönen, unter spärlicher Anwendung farbenreichen Schmuckes « ${ }^{132}$ ausgeführt, die ebenfalls eine behagliche und beruhigende Wirkung erzielen sollten. Den Speisesälen wurden Toiletten und Waschräume angeschlossen, die in Frankfurt derart aufwendig ausgestaltet wurden, dass in ihnen ganze Bäder eingerichtet wurden, die wahrscheinlich von Passagieren mit besonders langen Umsteigezeiten genutzt werden sollten.

Abbildung 42: Frankfurt a.M.: Wartesaal erster und zweiter Klasse mit dahinterliegendem Speisesaal.

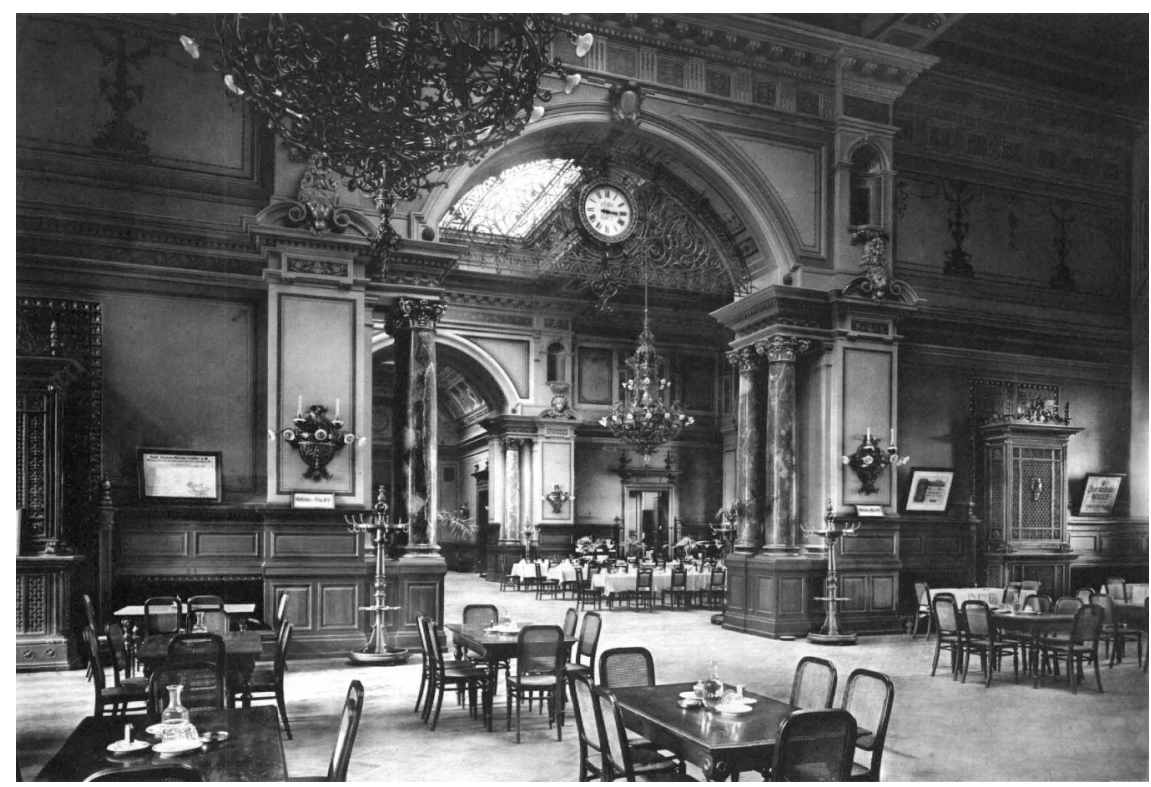

Quelle: Zeitschrift für Bauwesen 1891, Jahrgang XLI., Atlas Blatt 50.

Wie aus Abbildung 42 hervorgeht, waren die Wartesäle der ersten und zweiten Klasse durchgängig mit Tischgruppen ausgestattet, an denen jeweils sechs mit Rohrgeflecht bespannte Stühle angeordnet waren. Die Stellung der Tische zueinander ist als aufgelockert zu bezeichnen, die Abstände sind eher groß und schaffen keinesfalls den Eindruck beengter Verhältnisse. Ferner suggeriert die allein durch Tische und Stühle organisierte Möblierung, dass die Praxis des Wartens in Frankfurt - wie so oft im deutschen Kontext - offenbar unmittelbar mit dem Konsum von Speisen und Getränken in Verbindung stand. Auf jedem Tisch stehen bereits Wasserflaschen und Gläser bereit, der angrenzende Schanktisch dürfte jedoch eine Reihe weiterer Getränke und Speisen auf die Tische befördert haben. Aufwendigere Mahlzeiten wurden dagegen im angrenzenden Speisesaal eingenommen. Zudem war es angesichts bereitgestellter Aschenbecher 
auf den Tischen in den Wartesälen erlaubt zu rauchen. Weiterhin ist zu bemerken, dass die Sitzkonstellationen an den Tischen die soziale Interaktion befördert haben dürfte. Es sind weder Einzeltische noch Zwei-Personen-Tische zu erkennen, sodass Alleinreisende oder Paare meist mit anderen Reisenden am selben Tisch saßen, aßen und tranken. Die Wartepraxis dürfte demnach in den meisten Fällen von einer relativ starken Nähe zu unbekannten Mitreisenden geprägt gewesen sein.

Wie ebenfalls aus der genannten Abbildung ersichtlich wird, nahm im Spektrum all dieser luxuriösen Gestaltungselemente eine in schmiedeeisernem Gitter aufgehängte Uhr den zentralen und gut einzusehenden Platz im Übergang zwischen den Sälen ein. Diese Uhr vermochte dabei das lineare Zeitregime des modernen Lebens im Allgemeinen und das Zeitregime der Eisenbahnen im Besonderen zu symbolisieren. Die übergreifende Zentralität des Zeitbezugssystems, derer sich die Passagiere im Wartesaal stets vergewissern mussten, materialisierte sich damit folgerichtig auch in der Anwesenheit von Zeitmessgeräten. Diese Uhr ist es zugleich, die jenen Räume überhaupt erst die entscheidende Charakteristik des Transitorischen verleiht und die Säle in den besonderen Kontext einer neuen Mobilitäts- und Temporalkultur stellt. Mit anderen Worten: Während die Ausstattungsmerkmale dieser Wartesäle im Grund genommen auch anderen Versammlungssälen öffentlicher Gebäude jener Zeit ähnelten, war es insbesondere die zentrale Stellung der Uhr, die diese Räume (plakativ) zu Räumen werden ließen, die im Zeichen einer nur ihr eigenen Temporalität standen.

Bezüglich der Warteerfahrung in Frankfurt kann zusammenfassend festgehalten werden, dass die baulich-räumliche Rahmung des situativen Aufenthalts in einem der größten europäischen Bahnhöfe des späten 19. Jahrhunderts als überaus würdevoll und kultiviert bezeichnet werden konnte. Der Passagier in diesem modernen Großstadtbahnhof des späten 19. Jahrhunderts verbrachte seinen Aufenthalt im opulenten Umfeld eines ikonischen Verkehrsbaus, dessen prachtvolle Säle das gewachsene Selbstgefühl und die Stellung des industrialisierten Reisens repräsentierten. Dieser Gesamteindruck war angesichts der auch schon zuvor reich ausgestatteten Wartesäle älterer Stationen jedoch kein unbedingt neuer Anblick. Die wartebezogene Neuheit bestand vielmehr darin, die Wahl des Wartemodus nunmehr erweitern und nach Belieben modifizieren zu können. So konnten Passagiere sich entweder stationär im Wartesaal oder in der Restauration oder aber fluid auf der Zirkulationsfläche des Querbahnsteiges aufhalten. Der zuvor etablierte stationäre Warteimperativ konnte umgangen, die Bewegungsfreiheit wesentlich erhöht werden. Dieser für die Wahrnehmung des Wartens psychologisch wichtige Zugewinn an Bewegungs- und Handlungsfreiheit wurde jedoch von einer größeren Entfernung zum Erwartungsobjekt konterkariert. Obgleich der Aufenthalt in den Wartesälen eine Sichtbeziehung zu den einfahrenden Zügen ermöglichte, war die Distanz zwischen Wartesaal und Bahnsteig durch den dazwischengeschalteten Querbahnsteig im modernen Großstadtbahnhof ungleich größer. Da die Situation auf dem stark frequentierten Kopfbahnsteig nur schwerlich zu überblicken war, dürften die meisten Reisenden aufgrund wachsender Nervosität vor Abfahrt den stationären Aufenthalt nicht bis zur letzten Minute in den Wartesälen verbracht, sondern das Warten einige Minuten vor Abfahrt auf den Kopfbahnsteig verlagert haben. Zudem steht auf Grundlage der Auswertung des knappen Bildmaterials zu vermuten, dass angesichts der gewählten Möblierungen - zumindest jene der ersten und zweiten Klasse - der sta- 
tionäre Aufenthalt keine Abschottung, sondern eine tendenziell hohe Soziabilität und kommunikative Charakteristik gegenüber unbekannten Mitreisenden aufwies.

\subsection{Rezeptionsgeschichte des verkehrlichen Wartens (1870-1900)}

Im Sinne einer Rekonstruktion der Innenperspektive des Wartens sollen nun wiederum die rezeptionsgeschichtlichen Niederschläge des verkehrlichen Wartens im letzten Drittel des 19. Jahrhunderts beleuchtet werden. Trotz des Durchbruchs der Eisenbahnen zum unangefochtenen Massenverkehrsmittel und einer immensen weltweiten Bedeutungssteigerung der Eisenbahnen können Aussagen zur Verhandlung, Praxis und Erfahrung des Wartens hier wiederum nur anhand sehr weniger Quellen getroffen werden, die direkt und explizit auf das Phänomen rekurrieren. Die folgende Selektion repräsentiert dazu die aussagekräftigsten Ergebnisse einer breiten Suchbewegung in der Vielfalt literarischer Gattungen und kann gleichwohl aufgrund des riesigen Korpus keinen Anspruch auf Vollständigkeit gewähren.

\subsubsection{Lyrik}

Wie innerhalb der beiden zurückliegenden Entwicklungsphasen des Eisenbahnwesens zeigte auch die Lyrik des späten 19. Jahrhunderts kein signifikantes Interesse an der vertieften Beschäftigung mit dem Motiv der neuerlichen Mensch-Maschine-Interaktion, sondern bearbeitete primär abstraktere und symbolisierendere Motive. Eine entscheidende Ausnahme bildete hier jedoch die in den 1880er Jahren einsetzende Strömung des Naturalismus, die sich ausgehend von der deutschen Lyrik auch in Epik und Dramatik auszubreiten begann. Diese Stilrichtung verfolgte das Ziel, die Wirklichkeit ohne jegliche Ausschmückungen oder subjektive Ansichten exakt abzubilden. Anspruch des Naturalismus war die Genauigkeit der Milieubezeichnung sowie die strikte Abhängigkeit der geschilderten Figuren von ihrer Umwelt aufzuzeigen. Diese stilistische und perspektivische Entwicklung markierte damit die Ankunft der Lyrik in der Moderne.

Einer der wichtigsten Vertreter des lyrischen Naturalismus war der Dichter Detlev Freiherr von Liliencron (1844-1909), der erstmals moderne Alltagsphänomene und lebensweltliche Umstände in den Vordergrund seiner Werke stellte. Er gab den sonst klassischen Ich-Bezug des Dichters auf, quittierte das sonst übliche Schwelgen in romantisch-verklärten Erinnerungen und gab die symbolisierende Überhöhung zugunsten einer realistischeren Schilderung und eines Reizes der Gegenstände auf. Diese Form der Lyrik sah schließlich im technischen Gegenstand der Eisenbahn ein faszinierendes Phänomen und keine mythische Erscheinung. ${ }^{133}$ Von Liliencron widmete sich in mehreren Gedichten der Eisenbahnthematik, wobei im Folgenden besonders ein Gedicht herausgegriffen wird, das explizite Bezüge zum verkehrsbezogenen Warten aufzeigt. In seinem in den 1890er Jahren entstandenen Liebesgedicht Ich war so Glücklich wird das lyrische Ich ganz im Sinne des naturalistischen Interesses an neuen Wahrnehmungsfeldern zum Beobachter einer Bahnhofsszenerie. Im Rahmen eines sommerlichen Aus- 
flugs zu einem Jahrmarkt in einer anderen Stadt erwartet das lyrische Ich frisch verliebt seine Begleitung im Wartesaal eines Bahnhofs und schildert die Situation in einer Passage wie folgt:

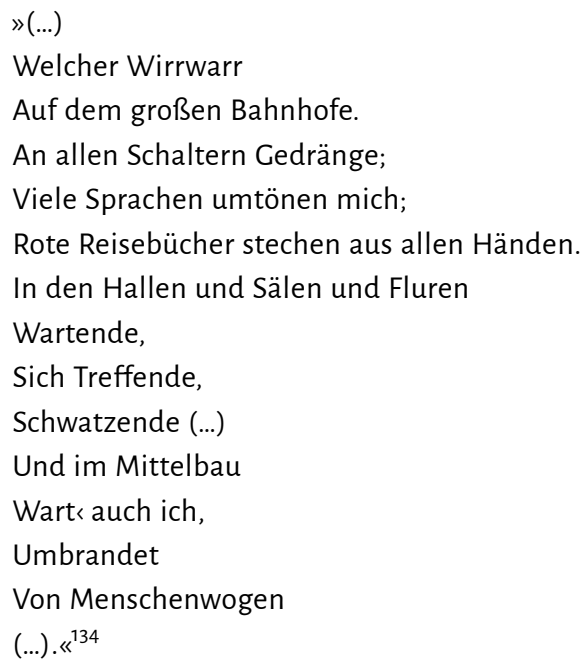

Entgegen der sonst üblichen lyrischen Beschäftigung mit den vertrauten Schauplätzen von Wald, Heide, Garten oder Stube sieht sich der Naturalist von Liliencron hier als Beobachter einer städtischen Alltagsszene, die auch das Alltagsphänomen des Wartens einschließt. Das Gedicht kann damit als erstes Gedicht überhaupt gelten, das innerhalb der deutschsprachigen Lyrik das verkehrliche Warten explizit thematisierte und das lyrische Ich bewusst in das Stadium des selbsterlebten Wartens einbezieht (Wart< auch ich). Zwar geht aus diesen wenigen Zeilen für die Rekonstruktion der verkehrlichen Warterfahrung im späten 19. Jahrhundert bis auf die offenbar hohe Personenfrequenz und ein gesteigertes Kommunikationsniveau in den Wartesälen kaum mehr hervor. Dennoch ist mit dieser Passage als erstaunlicher Befund festzuhalten, dass es trotz der bereits von Millionen Passagieren seit Jahrzehnten praktizierten Eisenbahnreise erst bis die in 1890er Jahre hinein dauerte, bis sich eine lyrische Figur erstmals mit dem Massenphänomen des systemischen Wartens auf Eisenbahnen befasste und sich selbst explizit als wartender Passagier verstand.

Die realitätsnahen Erfahrungen und die Begeisterung für die Mensch-MaschineInteraktion des Naturalismus sollten jedoch bereits um 1900 jäh wieder verflachen. So resümiert Johannes Mahr zum lyrischen Ende der deutschen Kaiserzeit:

»Nur während einer kurzen Zeit, als in den achtziger Jahren die ersten Versuche naturalistischer Lyrik entstanden, (...) begann man, das Wechselverhältnis zwischen Mensch und Technik näher zu untersuchen, die gegenseitige Störung ebenso zu registrieren wie die von der Maschine ausgebende Möglichkeit neuen Lebens. Doch diese 
Ansätze wurden nicht weitergeführt. Aufs Ganze gesehen blieben die beiden Sphären strikt getrennt. ${ }^{135}$

In der Folge wurde das >Lob der Maschine $<$ rein auf die Bewegung reduziert, ohne dabei den Zweck der Maschinisierung oder die Wechselwirkungen mit dem menschlichen Leben in den Fokus zu rücken. Liliencrons Gedicht ist somit ein zentraler - wenngleich später - Meilenstein der kulturgeschichtlichen Verhandlung des hier im Mittelpunkt der Arbeit stehenden Alltagsphänomens. Trotz der späten Thematisierung erscheint das Phänomen hier als selbstverständlicher Reisebestandteil anerkannt und verinnerlicht worden zu sein.

\subsubsection{Prosa}

Für weitere Anhaltspunkte zur Rekonstruktion von Erfahrung und Rezeption des Wartens soll nun im Folgenden aus der deutschsprachigen Prosa eine Reihe von Novellen, Romane und Reiseberichte mit Eisenbahnbezug herausgegriffen werden, die eine zeitgenössische Rezeption des schwer greifbaren Temporalphänomens im späten 19. Jahrhundert erhellen sollen.

Den Auftakt bietet dazu Peter Roseggers (1843-1918) Ende der 1870er Jahre entstandene Novelle Als ich das erstemal aufdem Dampfsagen saß (1877), die als »wohl die bekannteste Eisenbahngeschichte des 19. Jahrhunderts ${ }^{136}$ bzw. als ein »Lesebuch-Klassiker ${ }^{137}$ des späten 19. Jahrhunderts gilt. Die Novelle des Österreichers wird hier deshalb herausgegriffen, weil sie angesichts ihrer literaturgeschichtlichen Zentralfunktion der Widmung gegenüber dem Eisenbahnmotiv möglicherweise einen besonders erleuchtenden Zugang zum zeitgenössischen Verständnis der Rolle des Wartens innerhalb der Eisenbahnreise bereithält. Leider muss jedoch konstatiert werden, dass sich die prominente Eisenbahnerzählung als wenig ergiebig für die vorliegende Fragestellung erweist. So zeigt Roseggers von allgemeiner Technikskepsis geprägte Erzählung bis auf eine Bahnhofsszene kurz vor Einstieg keinerlei Hinweise auf eine Thematisierung oder Problematisierung des Wartens. Stattdessen wird hier die Neuheit der Eisenbahn - wie oftmals auch im lyrischen Kontext - sprachlich als mystisches Fabelwesen inszeniert.

»(...) Mittlerweile kroch aus dem nächsten, unteren Tunnel der Zug hervor, schnaufte heran, und ich glaubte schon, das gewaltige Ding wolle nicht anhalten. Es zischte und spie und ächzte - da stand es still. ${ }^{138}$

Diese kurze Passage ist die einzig relevante Stelle der gesamten Erzählung, die die Hauptfigur in Erwartung einer Abfahrt zeigt. Sie zeigt zugleich keinen Hinweis auf etwaige Irritationen oder einer spezifischen Verhandlung des Aufenthalts in den Wartesälen. Dieser Fehlbefund ist jedoch deshalb wichtig, weil er deutlich anzeigt, dass die

135 Ebd., 211.

136 Mahr, Eisenbahnen in der deutschen Dichtung, 49.

137 Heinimann, Technische Innovation und literarische Aneignung, 225.

138 Peter Rosegger, »Als ich das erstemal auf dem Dampfwagen saß«, in Waldheimat. Erinnerungen aus der Jugendzeit. Bd.1. Kinderjahre. (Leipzig: Hartleben, 1882), 227-35. 
späten 1870er Jahre offenbar noch immer stellenweise im Bann einer eisenbahntechnischen Neuerfahrung standen bzw. das Narrativ vom Reiz des neuen Reisens noch immer salonfähig war. Entsprechend erfolgte die literarische Widmung des Eisenbahnmotivs wie hier noch punktuell in Form salter Geschichten « eines verstörenden Erstkontakts mit der als gefahrvoll wahrgenommenen Dampftechnologie.

Ganz anders als Roseggers anachronistische Erzählung widmete sich Wilhelm Heinrich von Riehl (1823-1897) in seiner 1880 entstandenen Novelle Am Quell der Genesung dem Umstand des Wartens am Bahnhof. Hier scheint das Verkehrsmittel vollends zur gewohnten Selbstverständlichkeit geworden zu sein, wodurch auch andere Aspekte der Eisenbahnreise in den Vordergrund treten. Von Riehl thematisierte im Rahmen der Eisenbahnreise seiner wohlhabenden Hauptfigur Eugen Milett von Hannover nach Wien wie kein anderer deutscher Schriftsteller zuvor die Zentralität des Wartens als Bestandteil der Eisenbahnreise und die dafür notwendige Tugend der Geduld. Am fiktiven Kreuzungsbahnhof Huppenberg angekommen, hatte von Riehls Figur eine zweistündige Wartezeit zu verbringen, bis ihn ein Zug in Richtung Böhmen befördern sollte. Diese Wartezeit beschreibt Riehl in sarkastischer Manier wie folgt:

»Es ist vielleicht noch keinem Bildhauer eingefallen, die Geduld plastisch, monumental darzustellen. Und doch wäre ein Denkmal der Ceduld eine lohnende Aufgabe. Man könnte das Standbild in Zinkguß billig vervielfältigen zum ortsgemäßen Schmuck einer großen Zahl deutscher »Warte-Bahnhöfe«. Huppenberg verdiente ein solches Standbild vor allen. Man kann Huppenberg nicht mit der Wartestation Hagen vergleichen, wo man im Cetümmel sich selbst verliert; nicht mit der Geduldstation Oberhausen, wo sich uns die schönste Gelegenheit bietet, nach stundenlangen Warten in den falschen Zug zu geraten; nicht mit der Kreuzungs- und Kreuzstation Löhne, wo der Reisende, welcher von Osnabrück nach Bielefeld fährt, Zeit genug hat, dem erwarteten Zuge auf eine Station gemüthlich entgegenzuspazieren; nicht in Bebra, wo uns der prächtige Heldentenor, womit der weltbekannte Pförtner die Züge ausruft, das Warten musikalisch verkürzt; nicht in Lehrte, Heudeber, Wunstorf, Scherfede, Kreiensen, in deren mehr oder minder schönen Hallen viele hunderttausend Menschen schon eine unendliche Größe von Langeweile zusammengewartet habe. Huppenberg ist nur mit sich selbst vergleichbar. ${ }^{139}$

Im Kontrast zur prosaischen Tradition früherer Literaten des 19. Jahrhunderts erfährt das verkehrliche Warten mit Riehls Passage von 1880 eine (erstmals) explizite und vergleichsweise detaillierte Thematisierung. Die Bahnhöfe - in der vorherigen Rezeption überwiegend Stätten des Durchgangs oder wenig realistischer Beschreibung - werden hier plötzlich zu >Warte-Bahnhöfen<, einzelne Haltestellen zu mehr oder weniger großen >Geduldstationen<. Nicht mehr die antizipierte Beförderung wird hier also thematisiert, sondern das Antizipieren selbst gerät in den Stand einer wahrgenommenen und zu verhandelnden Praxis. Zudem erklärt der Vermerk einer von hunderttausenden

139 Wilhelm Heinrich von Riehl, »Am Quell der Cenesung«, in Lebensrätsel: Fünf Novellen, hg. von KarlMaria Guth, Neuausgabe des Erstdrucks von 1888 (Berlin: Hofenberg, 2018), 145f. Abgedruckt zudem in Guido Fuchs, Hg., In der Bahnhofsgaststätte: ein literarisches Menü in zwölf Cängen (Hildesheim: Monika Fuchs, 2018), 168-71. 
Menschen durchlebten Praxis das systemische Warten am Bahnhof zu einer Kollektiverfahrung des modernen Lebens. Dass diese Praxis als schmerzlich, langweilig und unwürdig erlebt wird - speziell für einen Reisenden aus gehobener Schicht - verrät die direkt anschließende Passage, die schildert, was Milett nach Ankunft am Bahnhof zu unternehmen versucht.

»Herr Milett trat zunächst ins Wartezimmer, wo er wenigstens Schatten zu finden hoffte. Allein in dem engen Raum kochte eine Bruthitze, welche durch eine großgedruckte Empfehlung des Apolinariswassers, den einzigen Schmuck der Wände, nicht gemildert wurde. In der Ecke saß eine einsame Dame und bewachte ihr Handgepäck mit einer Ausdauer, die einer besseren Sache würdig war. Unser Reisender prallte zurück und ging in das Restaurationslokal. Dort aber prallte er noch stärker zurück: es war vollgepropft mit biertrinkenden, rauchenden Bauern. $\aleph^{140}$

Wenngleich die Station Huppenberg einen fiktiven Bahnhof darstellt, erfahren wir aus dieser Darstellung, dass die Wartesäle bereits im letzten Drittel des 19. Jahrhunderts als Reklameflächen gedient haben. Der erzwungene Aufenthalt steht demnach bereits frühzeitig im werbegeschichtlichen Zusammenhang einer kommerziellen Verwertung. Zudem steht trotz des fiktiven Ortes zu vermuten, dass der Anblick eines mit Einheimischen gefüllten Provinzbahnhofes tatsächlich zur Tagesordnung gehört haben dürfte. So existieren - wie bereits an anderer Stelle erwähnt - unzählige Schilderungen, die den Bahnhof als Versammlungsort der lokalen Bevölkerung (ohne Fahrtwunsch) belegen. Da Riehls Figur diesen Wartesaal nicht benutzen möchte, suchte er nach einem alternativen Aufenthaltsort und findet im weiteren Verlauf der Handlung eine typische alternative Warteinfrastruktur der Bahnhöfe des späten 19. Jahrhunderts.

»(...) Nebenan war allerdings eine öffentliche Anlage, der schüchterne Versuch eines Gartens zur Erholung für das Wartepublikum. Sandige Wege schlängelten sich zwischen verdorrtem und zertretenem Rasen, der hie und da durch kleine, verkümmernde Birken- und Tannenbäumchen belebt wurde. Eine Alle von dünnen, größtenteils abgestorbenen Ebereschen verband den »Park« mit dem Hause. $\aleph^{141}$

Solche Außenanlagen und öffentlichen Gärten existierten an vielen Bahnhöfen und kompensierten (zumindest in der Sommerzeit) die Bewegungseinschränkung des stationären Warteimperativs, das die Reisenden oftmals mehr oder minder in die Wartesäle einschloss. In diesem >Warte-Garten angelagt trifft die Hauptfigur Milett darauf einen anderen wartenden Reisenden, der der Hauptfigur eine überraschende Erkenntnis offeriert:

»[Milett, R.K.] begann das Gespräch, indem er über das unangenehme Warten an so öder Stätte klagte. Der andere aber entgegnete, er habe sich vielmehr auf die zwei Raststunden in Huppenberg gefreut; er komme jedes Jahr einmal hier her, und da 
habe er sein Vergnügen an den Birken- und Tannenbäumchen, die er nun schon seit acht Jahren beobachte. $\ll^{142}$

Die Zentralität des Wartens abermals betonend, will Riehls Hauptfigur das Gespräch über das gemeinsame Schicksal des Wartens eröffnen, wird aber vollends von der Begegnung eines Fremden überrascht, der sich nicht wie er selbst über die lange Wartezeit ärgert, sondern »der sich auf die Wartestunden in dieser Einöde gefreut hatte (...). « ${ }^{143}$ Riehl offeriert hier einen Einblick in die subjektiv sehr unterschiedlich gelagerte Zeiterfahrung des Menschen, die zweifellos auch den Zustand des Wartens einschließt. Die Negativwahrnehmung des Zwischenaufenthalts scheint hier demnach nicht übergesellschaftlich zu greifen, sondern stellt sind als personen- und situationsabhängige Größe dar.

Im Zusammenspiel der direkten Thematisierung und seiner in die Handlung eingeschriebenen Differenzierung der Zeitwahrnehmung des Wartens muss Riehls Novelle als eine der frühesten Rezeptionen des verkehrlichen Wartens und als kulturgeschichtlicher Meilenstein der deutschen Literatur zu jenem Zeitphänomen betrachtet werden. Sie zeigt, dass in den 1880er Jahren die Eisenbahn derart selbstverständlich geworden war, dass die Beschäftigung mit den Sub-Phänomenen der Eisenbahnreise überhaupt erst möglich, das triviale Warten als Bestandteil deutlicher wahrgenommen, problematisiert und differenziert wurde.

Diese mit den 1880er Jahren selbstverständliche gewordenen gesellschaftlichen Durchdringung der Eisenbahn wird auch in weiteren Werken jener Zeit deutlich, so etwa Max Kretzers (1854-1941) Sozialroman Meister Timpe aus dem Jahr 1888. Er handelt von einem Berliner Drechslermeister, der den verzweifelten Kampf des Kleinhandwerks gegen die kapitalistische Fabrikkonkurrenz verkörpert. Das zentrale Symbol einer den Handwerksmeister überrollenden modernen Industriewelt stellt dabei die neu zu errichtende Berliner Stadtbahn dar. Der geplante Stadtbahnbau bildet den Handlungsrahmen für einen Konflikt zwischen dem Handwerksmeister dessen reichem Kaufmannsnachbar Urban, der das Haus des Handwerksmeisters zur Immobilienspekulation im Rahmen des Stadtbahnbaus kaufen möchte.

Ohne auf den Verlauf der tragischen Handlung eingehen zu wollen, ist hierbei entscheidend, dass die Stadtbahn in der literarischen Verhandlung der 1880er Jahre ein Verkehrsmittel wie jedes andere darstellt. "Die Eisenbahn«, so resümiert Mahr über deren Rolle in Max Kretzers Roman, »ist damit für die Menschen selbstverständlich geworden, ohne daß der Eingriff, den sie für die Natur und für das Leben der Menschen bedeutet, in der Literatur besonders reflektiert worden wäre. ${ }^{144}$ Diese überdeutliche Gewöhnung an das Eisenbahnsystem, die mit diesem Roman zum Ausdruck kommt, kann als ein wichtiges Indiz für die Beziehung der Menschen gegenüber dem Verkehrssystem im späten 19. Jahrhundert herangezogen werden. Wenn (besonders im großstädtischen Kontext) hiermit die Eisenbahn also vollends angekommen zu sein schien, so dürfte möglicherweise auch die Erfahrung und Verhandlung des Wartens auf diese Verkehrstechnologie bereits ähnlich vertraut und routiniert gewesen sein. Hierbei ist

142 Ebd., 147.

143 Ebd., 148.

144 Mahr, Eisenbahnen in der deutschen Dichtung, 50. 
besonders auffällig, dass der häufig selbst genutzte und eng getaktete städtische Nahverkehr die Routinisierung der gesellschaftlichen Wahrnehmung der Eisenbahn weit stärker erzeugte als der Fernverkehr. Im Zusammenhang der allgemeinen Gewöhnung ist somit auch zu erklären, warum die Berliner Bahnhöfe des Nahverkehrs die ersten Einrichtungen waren, die nicht mehr über Wartesäle verfügten (Kap. 8.4.1).

\section{Reiseberichte}

Innerhalb der Gattung der Reiseberichte soll an dieser Stelle Carl Spittelers 1896 erschienenes Werk Der Gotthardtunnel herausgegriffen werden, weil in der Schilderung der Alpendurchquerung eine andersgeartete Zeitwahrnehmung zum Ausdruck kommt, die Analogien zur Empfindung von Wartezeiten bereithält. Die Tunnelfahrt gehörte neben der allgemeinen Geschwindigkeitserfahrung zu der wohl stärksten Wahrnehmungsveränderung im Zusammenhang mit der Eisenbahnreise. Die Kombination aus beschleunigter Bewegung und beengter, dampferfüllter Dunkelheit im Tunnel zählte zu den zeitgenössisch größten Herausforderungen und Akzeptanzhürden. Während die ersten Tunnelbauten Englands anfangs nur maximal wenige hundert Meter lang waren, galt die Eröffnung des knapp 15km langen Gotthardtunnels im Jahr 1882 nicht nur als ingenieurstechnische Meisterleistung, sondern zugleich als eine psychische Herausforderung für die Passagiere. Spitteler prognostiziert für seine Leserschaft die Besonderheit einer während der Durchquerung gänzlich veränderten Zeitwahrnehmung wie folgt:

»Ohne Prophet zu sein, maße ich mir doch eine Voraussage an. Das erste Mal, daß einer durch den Tunnel fährt, wird er ihn unfehlbar weit kürzer finden, als er erwartet hatte, das zweite Mal länger, das dritte Mal wieder kürzer, und so weiter in regelmäßiger Abwechslung wie gerade und ungerade. Vorausgesetzt, daß die Pausen zwischen den Reisen nicht zu lange sind; denn nach längeren Pausen fängt das Vexierspiel von vorne an. Die Sache erklärt sich leicht. Nämlich das erste Mal macht sich der Reisende unter dem Einfluß des Ruhms, den der Cotthardtunnel wegen seiner Länge (fünfzehn Kilometer) genießt, aufeine erstaunliche Langzeitigkeit, aufeine Art Ewigkeit in Miniatur gefaßt. Allein zwanzig Minuten, wenn man bequem sitzt, mit einem guten Mittagessen im Leib, und vielleicht noch unvermerkt ein paar Minütchen einnickt, das geht glatt vorüber. Das zweite Mal werden wir umgekehrt durch die Erinnerung beeinflusst, wie kurz uns der Tunnel vorgekommen war; folglich unterschätzen wir ihn diesmal und finden ihn natürlich unerwartet lang. Und so fort. Immer fälscht ein vorausgehendes Cedankenbild die Erwartung; was Wunder, daß die Erwartung getäuscht wird? Und die Moral dieses Trugspieles? Daß die Phantasie überhaupt kein Maß hat, um räumliche und zeitliche Entfernungen zu messen, noch weniger die Fähigkeit, sie im Gedächtnis zu behalten. So philosophisch das klingt, so ist es doch wahr. $\ll^{145}$

Was hier zum Ausdruck kommt, ist eine gänzlich neuartige Zeiterfahrung, die bei der dunklen Tunneldurchfahrt von allen bisherigen Referenz- und Orientierungsgrößen abgetrennt zu sein scheint, da die vorbeiziehende Landschaft keinen Anhaltspunkt zum Zeitverlauf mehr bietet. Auch wenn die absolute Zeitdauer jeweils die gleiche ist, betont

145 Carl Spitteler, »Der Gotthardtunnel «, in Gesammelte Werke, Bd.8, hg. von Gottfried Bohnenblust, Wilhelm Altegg, und Robert Faesi (Zürich: Artemis, 1947) [Hervorhebungen des Verfassers, R.K.]. 
Spitteler (1845-1924) den so richtigen wie zentralen Befund, dass die gefühlte Dauer jeweils abhängig von Erfahrung, Frequenz und Erwartungshaltung jeweils kürzer oder länger erscheint. Diese bei der Tunnelfahrt explizierte Zeitirritation ist jedoch nicht allein auf die Durchquerung von Tunneln zu verzeichnen, sondern dürfte in ähnlicher Weise auf die Wahrnehmung von Wartezeiten übertragbar gewesen sein. Gleich einer Tunnelfahrt ist auch der Aufenthalt in den Wartesälen, Korridoren und Bahnsteigen für die Wartenden aufgrund unterschiedlicher Erfahrungen, Regelmäßigkeiten, Rahmenbedingungen (Ablenkungen) und Erwartungshaltung gänzlich verschieden gelagert. Auch wenn Spitteler hier also nicht das auf das Warten vor Abfahrt rekurriert, dürfte die serstaunliche Langezeitigkeit und >die Verfälschung eines vorausgehenden Gedankenbildes` mit Sicherheit auch für den Fall der Wartezeiterfahrung denkbar gewesen sein.

Ein zweiter Reisebericht, der das konkrete Warteverhalten beleuchten soll, kann durch Frederick Williams (1829-1886) berühmte Abhandlung zur Eisenbahngeschichte erfolgen. Sein Buch Our Iron Roads, Their History, Construction and Social Influences bearbeitet in mehreren Neuauflagen die Geschichte des englischen Eisenbahnwesens und geht dabei vor allem auch auf die sozialen Implikationen der neuen Verkehrstechnologie ein. Aus der 1883 erschienenen Neuauflage ist die Passage eines Reiseberichts der Fahrt von London nach Schottland besonders herauszuheben, weil sie einen phänomenologischen Einblick in die Praxis wartender Passagiere gibt, die auf dem Bahnsteig bei einem 30-minütigen Zwischenhalt in York ausharren. Williams bemerkt zum Verhalten der Reisenden:

"Some travellers are dropping in at this intermediate station, for a train is nearly due. They beguile the interval by strolling up and down the platform, perhaps pausing now and then to study an advertisement on the wall, possibly the map, as Anthony Trollope says, »of some new Eden - some Eden in which an irregular pond and a church are surrounded by a multiplicity of regular villas and shrubs - till the student feels that no considerations, even of health or economy, could induce him to live there. (...) But the train is in sight. ${ }^{146}$

Auf durchaus humoristische Weise betont Williams die englische Praxis, die Wartezeit durch Bewegung auf dem Bahnsteig zu kompensieren. Diese Praxis war - wie bereits an mehreren Stellen rekonstruiert - nur aufgrund der liberaleren Abfahrtsorganisation des englischen Eisenbahnwesens möglich. Die freiere Bewegungsmöglichkeit während der Wartezeit gestattete nicht nur eine Inspektion der Eisenbahntechnik, sondern ermöglichte zudem eine bessere Selbstkontrolle der Zeitwahrnehmung. Der eigene Bewegungsstrom würde es demnach ermöglichen, wie Williams zeitpsychologisch vermutet, das Zeitintervall >täuschen zu können und die Wartezeit dadurch weniger langwierig erscheinen zu lassen. Williams Referenz an Trollope knüpft dabei nicht nur exakt an die in The Belton Estate beschriebene Warteszene am Bahnhof Taunton an, sondern bestätigt

146 Williams, Our Iron Roads: Their History, Construction, and Administration, 262 [Hervorhebungen des Verfassers, R.K.]. 
genauso die Praxis des >strolling up and down` und der erlösenden Zugeinfahrt. Entgegen Trollopes aufschlussreicher Schilderung einer geschlechtsspezifisch unterschiedlich gelagerten Wartezeiterfahrung nimmt Williams hier jedoch leider keine differenzierte Betrachtung vor. Übergeordnet erscheint das Warten hier aber bereits deutlich als Bürde konnotiert und als Zeitintervall zu werden, das in irgendeiner Weise gefüllt werden muss.

\subsection{Abschluss: Rahmung und Verhandlung des Wartens im modernen Großstadtbahnhof (1870-1900)}

Die Eisenbahn erlebte im letzten Drittel des Jahrhunderts den Aufstieg in ihre Blütezeit. Diese war nicht nur durch ein quantitatives Verkehrs- und Streckenwachstum gekennzeichnet, sondern auch durch qualitative Weiterentwicklungen, die sich in der Steigerung von Komfort, Sicherheit, Geschwindigkeit und Effizienz niederschlugen. Dabei bewirkten insbesondere die baulich-operativen Tendenzen zur Steigerung der Sicherheit und Effizienz die wohl größten Veränderungen der bis zu diesem Zeitpunkt etablierten Warteerfahrung und -praxis. Diese Veränderungen wirkten jedoch - wie bereits in den Bauphasen zuvor - nicht zeitgleich und flächendeckend, sondern immer nur ortsspezifisch. Eine pauschalisierte Rekonstruktion der baulich-operativen Rahmung und deren Implikation für Wahrnehmung, Dauer und Erfahrung des Wartens kann somit nur schwerlich gelingen. Vielmehr wäre eine detaillierte Rekonstruktion jeweils nur unter Berücksichtigung der lokal stark variierenden Bau- und Betriebsverhältnisse zu leisten. Im Sinne des Interesses an einer konjunkturellen Entwicklung des Wartephänomens soll daher im Folgenden versucht werden, die wartezeitrelevanten Entwicklungen der dritten Bahnhofsgeneration entlang von sechs übergeordneten Tendenzen $z u$ fassen.

\section{Tendenz 1: Erste Wahrnehmungskrise}

Die Einführung des neuen Bautypus des Durchgangsbahnhofs mit Empfangsgebäude in Seitentieflage (Typ Hannover) bewirkte in einer Reihe von Großbahnhöfen den Abbruch der bereits lang etablierten und psychologisch elementaren Sichtbeziehung zum Gleis. Im Sinne der erhöhten Sicherheit sollten die Passagiere in vielen modernen Großstadtbahnhöfen die Bahnsteige nurmehr über Tunnel erreichen können. Die Wartesäle grenzten damit nicht mehr direkt an den Bahnsteigen an, sondern lagen weit entfernt von ihnen im Inneren des Empfangsgebäudes. In Folge der aufgehobenen Sichtbeziehung zu einfahrenden oder bereitstehenden Zügen mussten Passagiere in solchen Bahnhöfen nunmehr eine stärkere zeitbezogene Selbstkontrolle entwickeln, da das stets an Bewegungskategorien gebundene Zeiterleben hier deutlich eingeschränkt wurde. Das bauliche Setting weit entfernter Wartesäle verstärkte damit die Ur-Angst einer verpassten Abfahrt. Was aus Betriebssicht als zweckmäßige Maßnahme erschien, wurde von Seiten der Reisenden als ungeliebter Zustand erlebt. Verursacht durch die erhöhte Sicherheitsproblematik, die wiederum der allgemeinen Verkehrssteigerung geschuldet war, erlebte das systemische Warten auf Abfahrt mit Bau dieses Bahnhofstypen eine erste Wahrnehmungskrise und bewirkte eine erstmals rückläufige 
Wartesaalnutzung. Reisende an solchen Bahnhöfen begannen von nun an, die Bahnsteige ohne Umwege über die Wartesäle direkt zu erreichen, um die Angst vor dem Verpassen der Abfahrt und die damit verbundene Nervosität zu minimieren.

\section{Tendenz 2: Verlagerung und /Verflüssigung، des Wartens}

Eine weitere ortsspezifische Veränderung mit Implikationen für das Warten griff an den großstädtischen Kopfbahnhöfen. Hier wurden - wiederum auf Druck der (sicheren) Gewährleistung noch größerer Verkehrsströme - durch den Bau von Mittel-, Querund Kopfbahnsteigen neue Zirkulationsflächen geschaffen. Getrieben vom zeitgenössischen Anspruch der Gewährleistung reibungsloser und kreuzungsfreier Passagierströme avancierte der Querbahnsteig zur zunehmend selbstorganisierten Verkehrsfläche, die dem bis dahin dominierenden Prinzip des stationären Aufenthalts in den Wartesälen entgegentrat. Wo solche Zirkulationsflächen gebaut wurden, bewirkten sie in der Folge die partielle >Verflüssigung des Phänomens und die punktuelle Aufhebung des strikten Warteimperativs. Mit anderen Worten: Das ausgehende 19. Jahrhundert war von einer Verlagerung des stationären Aufenthalts in den Wartesälen auf die Fläche der Quer- und Kopfbahnsteige geprägt. Während der Neubau des Potsdamer Bahnhofs von Berlin (1872) bereits erste Anzeichen der Zunahme solcher Zirkulationsflächen zeigte, stand der ikonische Neubau des Frankfurter Hauptbahnhofes (1888) bereits ganz deutlich im Zeichen einer modernen, auf Effizienz und Massendurchsatz abzielenden Verkehrsorganisation, die den Querbahnsteig als ihren zentralen Erfüllungsgehilfen einsetzte. Unterstützt durch zahlreiche Serviceeinrichtungen und Sitzgelegenheiten auf dem Querbahnsteig geriet der präparatorische Aufenthalt damit zunehmend in Bewegung<. Vielleicht stellvertretend für die Phase der Modernisierung in der Hochindustrialisierung verlagerte sich dabei der sgemütliche Aufenthalt in eine sfluide` Praxis, wobei die Praktiken nicht nahtlos substituiert wurden, sondern, wie etwa in Frankfurt, vielmehr alte und neue Wartepraktiken nebeneinander bestanden. Geknüpft an diese baulichen Entwicklungen in Richtung stärkerer Zirkulation wurden die großstädtischen Bahnhöfe der dritten Generation für die bürgerlichen Kreise zu Verlängerungen der städtischen Flaniermeilen, Passagen und Kaufhäuser. ${ }^{147}$ Inspiriert von den Vorbildern der Pariser Kopfbahnhöfe und ihren ssalles des pas perdus` wurde die Praxis des fluiden Wartens semantisch in aller Deutlichkeit durch den Begriff der >Wandelhalle verdeutlicht. In dieser Bezeichnung kommen die übergeordneten Tendenzen einer geringeren Formalisierung bzw. einer Liberalisierung vom Dogma des stationären Wartens zum Ausdruck, die charakteristisch für das Ende des 19. Jahrhunderts werden sollten.

\section{Tendenz 3: Neue Barrieren}

Weiteren Einfluss auf die veränderte Warteerfahrung nahm die in Deutschland seit 1893 flächendeckend eingeführte Bahnsteigsperre. Diese neue Barriere diente der besseren Kontrolle von Fahrtberechtigungen vor Abreise und wurde entweder am Zugang zum Personentunnel (Durchgangsbahnhof) oder vor Betreten der Mittel- und Zungenbahnsteige (Kopfbahnhof) platziert. Während also die Errichtung von neuen Zirkulations- 
flächen die innere Disposition der Bahnhöfe weiter verflüssigte und von den beengten Räumlichkeiten der Wartesäle befreite, bewirkte die Einführung der Bahnsteigsperre eine neue Quelle generierter Wartezeiten, weil Reisende an der Sperre einzeln kontrolliert werden mussten. Mit Einführung der Sperre zeigt sich zugleich die Dialektik von Retardierung und Zirkulation, die so prägend für die gesamte Theoretisierung der Bahnhofsentwicklung ist. Während die Errichtung der Sperre zunächst aus Sicht der Reisenden eine Verzögerung des Zugangs zum Zug bedeutete, erzeugte die planvolle Einrichtung aus Betriebssicht wiederum eine bessere Kontrollierbarkeit von Strömen damit eine insgesamt effizientere und störungsfreiere Abfertigung. Neben Einführung der Sperre sorgte zudem auch die ortsspezifische Einführung von Bahnsteigkarten für eine effizientere und pünktlichere Abfertigung. Während es in vielen deutschen Bahngebieten (vor allem in Preußen) möglich war, dass Angehörige mit in die Wartesäle gelangen, wurde diese liberale Praxis im letzten Drittel des Jahrhunderts aufgegeben. Das Warten auf Abfahrt wurde damit - vor allem in den unteren Wagenklassen - zunehmend zu einem unbegleiteten Warten.

\section{Tendenz 4: Entwicklung einer temporalen Erwartungshaltung}

Als vierter Einflussfaktor auf eine veränderte Wartezeiterfahrung des späten 19. Jahrhunderts dürfte die Einführung der Eisenbahnzeit gegolten haben. Mit der Vereinheitlichung des Zeitbezugssystems konnte die Betriebsführung wesentlich vereinfacht werden, da die Differenzen zwischen bereits lang genutzter Eisenbahnzeit und Lokalzeit aufgehoben wurden. In der Folge der Vereinheitlichung konnten aus Sicht der Reisenden potentielle Wartezeiten reduziert werden, die sich vormals aus der Differenz zwischen Eisenbahnzeit und Lokalzeit ergeben hatten. Die Einführung der Eisenbahnzeit als Zeitbezugssystem des gesamten Lebens (auch außerhalb der Eisenbahnen) verursachte zwar eine Umstellung vom Bezugssystem der jeweiligen Lokalzeit, wirkte jedoch im Falle der Eisenbahnreise komplexitätsreduzierend, da nurmehr ein Bezugssystem genutzt werden konnte. Doch auch wenn die Einführung der Eisenbahnzeit eine Vereinfachung darstellte, dürfte damit ungewollt auch der Effekt erzeugt worden sein, dass Abweichungen vom Fahrplan (Verspätungen) wesentlich mehr als zuvor explizit wurden. Konnte eine Verspätung aus Sicht der Reisenden zuvor möglicherweise noch in der fehlenden Differenz aus Lokal- und Eisenbahnzeit untergegangen sein, konnte sich jetzt mehr denn je eine temporale Erwartungshaltung der pünktlichen Abfahrt formieren, die reziprok eine verringerte Wartetoleranz verursachen konnte.

\section{Tendenz 5: Stärkere soziale Differenzierungen des Wartens}

Eine fünfte Tendenz mit wartebezogener Implikation liegt im Befund der stärkeren sozialen Ausdifferenzierung des Raumprogramms in den Bahnhöfen. Die zum Teil verpflichtende Erweiterung der klassischen Wartesäle und Restaurationen um zusätzliche Damen- und Nichtraucherzimmer, Auswanderer- und Saisonarbeitersäle zeigt den Versuch, die gewachsene Differenzierung der Industriegesellschaft entsprechend auch im Raumprogramm der dritten Baugeneration abzubilden. Der Aufenthalt vor Abfahrt vermochte damit stärker als zuvor den sozioökonomischen Status der wartenden Person sichtbar werden zu lassen. Entsprechend zeigten auch die Ausstattungsdetails der 
unterschiedlichen Warteräume gegenüber der zweiten Generation ein noch größeres Spektrum, das von verfliesten Wänden (Auswanderersäle) auf der einen Seite bis hin zu marmorverkleideten Sälen auf der anderen Seite reichte. Die soziale Segregation wurde zudem auch durch den Umstand verschärft, dass die reisende Oberschicht kaum mehr in Kontakt mit anderen Wagenklassen kam, weil die vorbereitenden Aufgaben des Fahrkartenkaufs und der Gepäckaufgabe oftmals von Bediensteten übernommen wurden. Der zentrale Ort des Wartens war für die Oberschicht daher wahrscheinlich ganz überwiegend der Saal. Die Auslagerung von Gepäckaufgabe und Fahrkartenkauf bewirkte zudem, dass Reisende mit höherem Status den Bahnhof mit wesentlich weniger Zeitverlauf erreichen und die Züge direkt besteigen konnten. ${ }^{148}$ Während die Wartesäle der unteren Fahrklassen die Anmutung gediegener, aber überfüllter Säle hatten, dürften die opulenten Wartesäle der oberen Wagenklassen mit ihrem hohen Ausstattungsgrad und einer würdevollen Aufenthaltsqualität paradoxerweise die am wenigsten frequentierten Räume dargestellt haben. Die luxuriösen Säle dürften oftmals gar eher durchschritten als genutzt worden sein. Zwar kann hinsichtlich der durchschnittlichen Wartedauer der Reisenden aufgrund fehlender Statistiken nur spekuliert werden, doch es ist anzunehmen, dass Fernreisende der dritten und vierten Wagenklasse aufgrund einer Vielzahl von Unsicherheiten, Abhängigkeiten (und Unwissenheiten) bereits frühzeitig am Bahnhof eintrafen und eine weit längere Wartezeit verbrachten als Reisende der oberen Wagenklassen.

\section{Tendenz 6: Von Sälen zu Bänken (verändernde Rolle des Nahverkehrs)}

Die vielleicht umfangreichste Implikation für die verkehrliche Wartepraxis erzeugte die wachsende Bedeutung des städtischen Vorort- und Nahverkehrs. Wie am Beispiel der Erweiterungen des Potsdamer Bahnhofs in den 1890er Jahren aufgezeigt wurde, erhielten die Vorortbahnhöfe erstmals keine eigens eingerichteten Wartesäle mehr. Stattdessen wurden die Warteinfrastrukturen gänzlich auf den Bahnsteig und mit einfachen Bänken oder Wartebuden verlegt. Aufgrund seiner Profanität, der engen Zugtaktung, aber auch aufgrund der Nutzungsroutine bewirkte der Nahverkehr - ähnlich wie die Zirkulationszone des Kopfbahnhofes - letztlich eine Aufweichung der stationären, auf einen langen Voraufenthalt abzielende Wartepraxis. Das würdevolle Warten im Saal erschien den Verantwortlichen als auch den Reisenden angesichts des Verkehrsdruck weder notwendig noch zweckmäßig. Der Ort des Wartens war hier fortan nicht mehr der würdevolle Saal, sondern die zweckoptimierte Fläche des Bahnsteiges.

Zusammenfassend stand das letzte Drittel des 19. Jahrhunderts in eisenbahntechnischer Hinsicht ganz im Zeichen einer allgemeinen Gewöhnung und Erfahrungssättigung. Während sich die Phase zwischen 1845 und 1870 noch als ein Hin- und Hergerissensein zwischen alter und neuer Zeitordnung präsentierte, zeugten die baulichen und künstlerischen Niederschläge im letzten Drittel des Jahrhunderts davon, dass sich die Menschen an das neue linear-mechanisierte Zeitregime, die permanente temporale Selbstkontrolle und den Synchronisationszwangs einer komplexer werdenden Industriegesellschaft zunehmend gewöhnt zu haben schienen. Wie aus dem naturalistischen 
Gedicht von Liliencron hervorgeht, wird darin das Warten als ein unhinterfragter Reisebestandteil explizit miteingeschlossen. Entgegen der Standardisierungs- und Konsolidierungsphase des Eisenbahnwesens finden sich zum Ende des Jahrhunderts keinerlei Hinweise mehr, die auf ein Vermissen der Postkutsche oder der alten Zeit schließen lassen. Die Gewöhnung an die zeiträumlichen und psychologischen Veränderungen der Eisenbahn scheint dagegen bereits so weit fortgeschritten zu sein, dass einzig allein die Fahrt durch einen 15km langen Tunnel den Zeitgenossen noch als Wahrnehmungsherausforderung erschien (Spitteler).

Angesichts dieser offensichtlichen Gewöhnung an die Eisenbahnreise (Kretzer, von Riehl) muss als erstaunlicher Befund festgehalten werden, dass das verkehrliche Warten trotz eines kollektiven Massenerlebnisses nur äußerst wenige explizite Niederschläge in Literatur und Kunst erfuhr. Zwar konnte die rezeptionsgeschichtliche Rekonstruktion natürlich nicht den Anspruch entwickeln, die Gesamtheit der Literatur jener Zeit zum Wartephänomen hin befragt zu haben, dennoch zeigte die Auswertung eines großen Korpus, dass das Warten zu jener Zeit weniger als Problem, sondern - wenn überhaupt - vielmehr als überwiegend unhinterfragte Notwendigkeit behandelt wurde. Wenngleich sich unzählige Werke der Prosa und Lyrik jener Zeit mit dem Motiv der Eisenbahn befassten, wurde die Verkehrstechnologie entweder meist nur metaphorisch genutzt oder sie bildete lediglich den Handlungsrahmen. Kaum aber gingen diese Arbeiten auf die tatsächliche Verkehrspraxis ein, obwohl die Anomalie der Wartezeit angesichts des sich gesellschaftlich etablierenden Zeitbezugsrahmens (Uhrzeit) tendenziell deutlicher hervortrat. Weder lässt sich damit also behaupten, dass sich die in der vorherigen Phase punktuell herausarbeitete Problematisierung des Zustands in der dritten Phase verstärken würde, noch dass es eine andersgelagerte Verhandlung des Phänomens gäbe. Kurzum: Das Warten blieb - zumindest aus Sicht seiner literarischkünstlerischen Beschäftigung - auch zum Ende des 19. Jahrhunderts ein weitgehend unreflektiertes Alltagsphänomen. Einzig die Novelle von Wilhelm Heinrich von Riehl aus dem Jahr 1880 bildete hier eine überdeutliche Ausnahme, die sich dem Phänomen in einem Seitenstrang der Handlung explizit annahm. 


\section{Marginalisierung des stationären Wartens im modernen Zweckbau (1900-1935)}

Das frühe 20. Jahrhundert war bis zum Ausbruch des Ersten Weltkrieges noch einmal von einer Welle der Verkehrssteigerungen geprägt. Gemessen an den Passagierzahlen und existierenden weltweiten Streckenkilometern steuerte die Bedeutung des Eisenbahnwesens auf seinen (bisherigen) Höhepunkt zu. In der Fläche verdichteten sich die zahlreichen Hauptstrecken und weckten damit, wie ein Zeitgenosse resümierte, »die Produktionskraft und den Gewerbfleiss des zwischenliegenden Hinterlandes. « ${ }^{1}$ Entsprechend war die Phase nach 1900 durch den Bau kleinerer Lokalbahnen geprägt, die Anschluss an die Hauptstrecken ermöglichten und das Netz insgesamt noch engmaschiger werden ließen. Die Eisenbahn war das zentrale Verkehrsmittel und war (mit Ausnahme Englands) nach zahlreichen Verstaatlichungen überwiegend zu einer staatlichen Kernaufgabe und einer zentralen Einnahmequelle avanciert. Im städtischen Kontext wurden die Nah- und Vorortverkehre immer bedeutender, um innerhalb der Agglomerationen die wachsenden Distanzen zwischen Zentrum und Peripherie zu kompensieren, Wohn- und Arbeitsquartiere zu erschließen oder auch, um die verstreut liegenden Kopfbahnhöfe miteinander zu verbinden. ${ }^{2}$ Der Nahverkehr musste an den Bahnhöfen getrennt vom Fernverkehr eingebunden werden und bedurfte aufgrund einer unterschiedlichen Betriebscharakteristik (schnellere Passagierabfertigung, meist keine Gepäckabfertigung, Fahrtkartenschalter mit stoßartigem Andrang) zunehmend eigener baulicher Strukturen. ${ }^{3}$

Aufgrund der allgemeinen Verkehrszunahme mussten auch im frühen 20. Jahrhundert Empfangsgebäude neugebaut oder bestehende erweitert werden. In ihnen, den Gebäuden der 4. Generation, kam wiederum ein gewandeltes Verständnis der baulichen Rahmung des verkehrlichen Wartens zum Tragen, das im Mittelpunkt dieses letz-

A. Goering, „Ueber die verschiedenen Formen und Zwecke des Eisenbahnwesens, Rede zum Ceburtsfeste Seiner Majestät des Kaisers und Königs Wilhelm II., in der Aula der Königlichen Technischen Hochschule zu Berlin« (Technische Hochschule Berlin, 26. Januar 1899), 6. 
ten Hauptkapitels stehen soll. Im Folgenden wird dazu nochmals die Entwicklung des baulichen und betrieblichen Rahmens rekonstruiert, in der das bis dahin etablierte stationäre Warten eine bedeutende Zäsur erhalten sollte. Dazu werden die richtungsweisenden und handlungsleitenden Werke dreier prominenter Architekten und Bauingenieure des frühen 20. Jahrhunderts beleuchtet, die einen nunmehr noch stärker auf Effizienz und Ökonomie zielenden Baudiskurs mitprägten. Um diese sich darin kristallisierenden Entwicklungen besser illustrieren zu können, werden die Entwicklungen sodann an einer Reihe exemplarischer deutscher Bahnhofsneubauten nachgezeichnet. Die gesammelten Erkenntnisse zur baulich-operativen Rahmung des Wartens werden anschließend um rezeptionsgeschichtliche Niederschläge des Wartens ergänzt, die in Lyrik, Prosa und Zeichnungen des frühen 20. Jahrhunderts zum Ausdruck kamen.

\subsection{Bauliche und betriebliche Rahmenentwicklung: Zweifel an etablier- ten Formen und Triumph der modernen Zweckmäßigkeit}

Die Fachdiskurse zum deutschen Bahnhofsbau wurden seit der Jahrhundertwende immer stärker von den leitenden Prinzipien der Ökonomie und Zweckmäßigkeit geprägt. Zwar standen die unzähligen in Fachblättern und Handbüchern veröffentlichten Baudirektiven, Handlungsempfehlungen und Maximen der vorangegangenen Dekaden bereits ebenfalls im Zeichen einer Effizienzkultur, doch erst im neuen Jahrhundert reifte eine auf Zweckmäßigkeit, kreuzungsfreie Zirkulation und Beschleunigung abzielende Baukonzeption zur stabilen diskursiven Formation. Wenn die innovativen Pionierbahnhöfe von Hannover (Durchgangsbahnhof mit Tunnelerschließung) und Frankfurt (Querbahnsteig mit seitlichen Ausgängen) vor der Jahrhundertwende noch als punktuelle Leuchttürme einer neuen, auf Zirkulation und Massenverkehr ausgelegten Bauphilosophie erschienen, ${ }^{4}$ wurden deren Prinzipien der inneren Verkehrsorganisation für die Mehrzahl der Neu- und Umbauten im frühen 20. Jahrhundert endgültig zur Leitreferenz. Grund dafür war nicht nur der Druck weiterer Verkehrssteigerungen und die Herausforderung noch mehr Menschen als zuvor durch die Bahnhöfe >prozessieren $\mathrm{zu}$ müssen, sondern auch ein wachsender Kostendruck seitens der Bahnverwaltungen. In den konfliktreichen Auseinandersetzungen zwischen den beiden am Bahnhofsbau beteiligten Berufsgruppen, den Architekten auf der einen und den Ingenieuren auf der anderen Seite, bevorzugten die »auf äußerste Effizienz, Rationalität und Sparsamkeit erpichten Bahnverwaltungen ${ }^{5}$ seit dem letzten Drittel des 19. Jahrhunderts immer häufiger das in seiner Grundausrichtung zweckrational orientierte Ingenieurswesen. Nicht selten hatten die Verwaltungen, diesem Ethos entsprechend, >ihre Ingenieure selbst über Jahrzehnte hinweg herangebildet. In der Folge der Bevorzugung ingenieurstechnischer Herangehensweisen gegenüber den ästhetischen-künstlerischen Ansätzen determinierten die von Ingenieuren zugrunde gelegten Daten oftmals das Schaffen der Architekten. So mussten sich die mitwirkenden Architekten spätestens seit Beginn des 
neuen Jahrhunderts »diesem häufig als Einschränkung ihrer künstlerischen Freiheiten empfundenen Forderungen in einem oft mühsamen Gewöhnungsprozeß anpassen. ${ }^{6}$

Die tendenzielle Bevorzugung des Ingenieurwesens seitens der inzwischen mehrheitlich staatlichen Eisenbahnverwaltungen wirkte sich wiederum förderlich auf eine Begründung der Verkehrswissenschaften sowie einer damit verbundenen SubProfessionalisierung des Eisenbahningenieurswesens aus. Der Bauingenieur und Rektor der Königlich Preußischen Technischen Hochschule zu Berlin, Adolf Goering, hatte den Bau von Bahnhofsanlagen inzwischen gar zu einer eigenen Wissenschaft erhoben. Im Rahmen seiner fast drei Jahrzehnte währenden Lehrtätigkeit (1877-1906) erwirkte Goering, den Eisenbahnbau als Lehrfach und wissenschaftliche Disziplin mit eigenständigen Methoden und Systematiken $\mathrm{zu}$ begründen. Wie viele andere Ingenieurswissenschaften konnte sich damit auch das Eisenbahningenieurswesen um die Jahrhundertwende professionell etablieren und folglich »eine eigenständige, gruppenspezifische Sicht der gesellschaftlichen Entwicklung " ${ }^{7}$ entfalten. Während Goering unter anderem zentrale Lehrbücher zum Streckenbau verfasste, bestand seine wohl wichtigste Leistung in der Entwicklung wissenschaftlicher Grundlagen zum Bahnhofsbau, die nicht mehr nur auf Erfahrungen früherer Bautätigkeiten beruhten, sondern auf planmäßigen Grundsätzen. Diese Grundsätze sollten nach der Jahrhundertwende zum technischen Standard avancieren. Goering war eine der zentralen Figuren des deutschen Eisenbahnwesens um 1900, der durch seine lange Lehr- und Forschungsarbeit starken Einfluss auf eine ganze Generation von Eisenbahningenieuren ausübte. ${ }^{8}$ Um die baulich-betrieblichen Rahmenentwicklungen des deutschen Bahnhofsbaus im frühen 20. Jahrhundert, die wiederum Einfluss auf die Rahmung und Verhandlung des verkehrlichen Wartens nahm, zu verstehen, erscheint es daher sinnvoll Goerings wissenschaftliche Überlegungen näher zu beleuchten.

\section{Adolf Goering (1907) - Handbuch der Ingenieurwissenschaften}

Kurz nach dem Tod Goerings (1906) erschien das gerade noch vollendete Kapitel zur >Anordnung von Bahnhöfen<, das unter Mitwirkung des Eisenbahningenieurs Moritz Oder entstanden war und als eigener Teilband des Handbuchs der Ingenieurwissenschaften herausgebracht wurde. Mit dem 1907 erschienenen Beitrag gaben Goering und Oder eine Marschrichtung vor, die fast schon als eine leitende Programmatik der gesamten baulichen Moderne bezeichnet werden kann:

»Die Anlagen sollen den jeweiligen Verkehrs- und Betriebsbedürfnissen in sicherer, aber zugleich in möglichst einfacher Weise entsprechen. Sie sollen Unnützes vermei-

6 Ebd.

7 Hans-Liudger Dienel, Hg., Der Optimismus der Ingenieure: Triumph der Technik in der Krise der Moderne um 1900 (Stuttgart: F. Steiner, 1998), 13.

8 Die nachhallende Wirkung der Goering'schen Schule wird in einem von Fritz Eiselen verfassten Nachruf deutlich: »(...) durch seine Vorträge und Hebungen [hat er, R.K.] einer ganzen Generation junger Ingenieure das wissenschaftliche Rüstzeug für ihr späteres Leben mitgegeben, sie befähigt (...), sich in die praktischen Aufgaben ihres Berufes hineinzudenken, diese einerseits nach einheitlichen großen Cesichtspunkten zu beurteilen, aber anderseits ihrer Eigenart auch durch besondere Anordnungen gerecht zu werden. « Fritz Eiselen, »Adolf Göring †«, Deutsche Bauzeitung 40, Nr. 122 (1906): 717. 
den, das Nützliche in geeignetster Form darbieten. Als nützlich hat hierbei das zu gelten, was - gleichviel ob zunächst dem Publikum oder den Beamten - dauernd Zeit erspart. Eine nur der schönen Erscheinung gewidmete Ausgabe ist zwar ein zinsloses Kapital, kann aber, solange sie den Grundsatz der Zweckmäßigkeit nicht schädigt, wie bemerkt, wohl begründet sein. Dagegen muß alles, was dauernd unnütze Bewegungen von Menschen oder Fahrzeugen veranlaßt (...) nicht nur als zinsloses, sondern als schädliches (»fressendes«) Kapital bezeichnet werden. «"

Auch der Ingenieur und Baurat Eduard Schmitt, der bereits in den zurückliegenden Jahrzehnten zentrale Standardwerke zum Eisenbahnhochbau verfasst hatte, vermerkte im 1911 erschienenen Handbuch für Architektur als ersten von insgesamt fünfleitenden Baugrundsätzen, dass jegliche Eisenbahnhochbauten ökonomisch und zweckmäßig gestaltet, bzw. in "thunlichst vollkommener, einfacher, und bequemer Weise ${ }^{10}$ errichtet werden müsste. Während Schmitt 1882 in seinen Vorträgen über Bahnhöfe und Hochbauten noch drei Hauptbedingungen postulierte, die unter anderem prominent forderten, dass Empfangsgebäude »das Gepräge des Würdevollen und Vornehmen zur Schau tragen «" sollten, war bei ihm knapp drei Jahrzehnte später keine solche Forderung mehr zu finden. Statt den gestalterischen Anspruch als einen der Kernaspekte aufzugreifen, sollten Bahnhofsgebäude nunmehr durch einfache und leicht ausführbare Konstruktionen mit großer Widerstandsfähigkeit und geringen Unterhaltungskosten bestechen. ${ }^{12}$

Das sich im Begriff der Zweckmäßigkeit verbergende Ziel von Zeit- und Kostenersparnissen reifte im Zusammenhang mit dem Bau von Bahnhofsgebäuden folglich zu oberstem Gebot. Getragen vom Geist eines ökonomisierten Weltbildes effizienter Zirkulation und Zweckmäßigkeit waren dabei die Fachdebatten des frühen 20. Jahrhunderts oftmals vom Ausgangsbefund begleitet, dass die Bahnhofsgebäude in Deutschland inzwischen zu riesigen Anlagen gewachsenen waren, die als völlig überdimensioniert und verschwenderisch kritisiert wurden.

\section{Zentralkritik: Monumentalität, statt Zweckmäßigkeit}

Die Kritik entzündete sich letztlich am bis dahin vorherrschenden Anspruch der Monumentalität großstädtischer Anlagen, die - wie ganz offenkundig im Beispiel des Frankfurter Centralbahnhofs (1888) - noch das Ziel verfolgten, einen Bau von überzeitlicher Qualität und Gültigkeit zu schaffen. Entgegen einer im Grunde auf >Entzeitlichung، zielenden Monumentalität propagierte eine sich nach 1900 immer stärker formierende Denkrichtung das Prinzip der Flexibilisierung. Wahrscheinlich in entschiedener Kritik an den jüngst fertiggestellten Monumentalbauten von Frankfurt, aber auch an denen von Köln (1894) und Hamburg (1906) vermerkte Adolf Goering, dass es aufgrund »unberechenbar[er] Beweglichkeit und Veränderlichkeit der Verkehrsverhältnisse « ${ }^{13}$ schlicht-

9 Goering und Oder, Der Eisenbahnbau, Anordnung der Bahnhöfe, 4 [Hervorhebungen des Verfassers, R.K.].

10 Schmitt, Anlage und Einrichtung der Cebäude, 2.

11 Schmitt, Vorträge Bahnhöfe und Hochbauten auf Locomotiv-Eisenbahnen: Zweiter Theil. Hochbauten für die Zugförderung und Bahnbewachung, 4.

12 Schmitt, Anlage und Einrichtung der Cebäude, 2.

13 Goering und Oder, Der Eisenbahnbau: Anordnung der Bahnhöfe, 3. 
weg nicht möglich sei, Bahnhofsanlagen für die Ewigkeit zu bauen. Statt den Anspruch einer überzeitlichen Gültigkeit anzustreben, forderte er vielmehr einen Paradigmenwechsel von der Monumentalität zur Flexibilität und erklärte programmatisch, dass die Anlagen »stets auf den Zuwachs des Verkehrs eingerichtet, also dehnbar, je nach den wechselnden Verkehrsbedürfnissen schmiegsam entworfen werden [müssten, R.K.]. « ${ }^{14}$

Analog zu Goering und Oder postulierte auch Eduard Schmitt die Losung der Flexibilität und forderte, dass jedes Gebäude entwicklungsfähig sein sollte, »ohne bedeutete Änderungen nach sich zu ziehen. ${ }^{15}$ Tatsächlich waren viele Bahnhöfe in den Jahrzehnten zuvor trotz kühnster Antizipation von der jeweiligen Verkehrsentwicklung überholt worden, welche teure Um- oder Neubauten erforderlich machten. Auf Grundlage solcher Erfahrungen - aber auch auf Grundlage einer weiterhin ungebrochenen Wachstumsprognose ${ }^{16}$ des Eisenbahnverkehrs - lag aus Sicht eines nunmehr wissenschaftlich fundierten Bahnhofsbaus offenbar der einzige Weg in der expliziten Flexibilisierung der Planung. Die Veränderungsdynamiken der Industrialisierung konnten demnach nur noch über Anpassung an dieselben kompensiert werden. Entgegen der teleologischen Idee des Plans, der auf einen stabilen und determinierten Endpunkt zusteuert, sollten demnach die Veränderung selbst zu einem übergeordneten Charakteristikum und damit zum Strukturelement modernen Bauens reifen.

Das Element einer auf Überzeitlichkeit ausgerichteten Monumentalität war jedoch nicht der einzige Kritikpunkt eines nun wissenschaftlich betriebenen Bahnhofsbaus. Vielmehr torpedierten die jüngst errichteten Großanlagen auch das Prinzip der geforderten Zweckmäßigkeit. So stellte Goering nochmals klar:

»Alle Eisenbahnbauten und ihre Bahnhofsanlagen mit Einschluß der Hochbauten das sollte nie vergessen werden - sind in erster Linie Nützlichkeitsbauten, die den gegenwärtigen und in absehbarer Zukunft zu erwartenden Verhältnissen angepaßt, nicht aber als Monumentalbauten für Jahrhunderte zu betrachten sind. $\ll^{17}$

Zwar ließ Goering auch Zugeständnisse an eine ansprechende Gestaltung durch Architekten erkennen, aber niemals "sollte der äußeren Erscheinung die Hauptsache, die zweckmäßigste Ermöglichung der Betriebsabwicklung, geopfert werden. $\ll^{18}$ Das Vorbild für die zweckmäßige Grundausrichtung lieferte (wieder einmal) das englische Bahnwesen, das dem Ingenieur Goering als progressive Referenz erschien:

14 Ebd., 4.

15 Schmitt, Anlage und Einrichtung der Cebäude, 2.

16 Goering prognostizierte 1899 bei einer Festrede zum Geburtstag Kaiser Wilhelms II. in der Aula der Technischen Hochschule Berlin zur Zukunft des Eisenbahnhochbaus: »Es ist (...) durchaus irrig, solche Bauthätigkeit als etwas Vorübergehendes (»künftig Wegfallendes«) zu betrachten. Sie ist vielmehr ebenso fortlaufend, wie der Betrieb der Bahnen, hat niemals geschlummert und wird immer mit ihm Hand in Hand gehen müssen. Coering, »Ueber die verschiedenen Formen und Zwecke des Eisenbahnwesens, Rede zum Geburtsfeste Seiner Majestät des Kaisers und Königs Wilhelm II., in der Aula der Königlichen Technischen Hochschule zu Berlin«, 8.

17 Goering und Oder, Der Eisenbahnbau, Anordnung der Bahnhöfe, 3 [Hervorhebungen des Verfassers, R.K.].

18 Ebd. 
»Im Cegensatz zu jener weiträumigen und oft überreichen Ausbildung zeigen die meisten Personenbahnhöfe Englands bei einer bis in die neueste Zeit ziemlich mageren Ausstattung, andererseits, wie durch zweckmäßige Einrichtungen ein noch weit größerer Verkehr auf viel kleinerem Raume gut bewältigt werden kann und wie man z.B. dort für den bequemen und Abstrom der mit Fernzügen Ankommenden in einer Weise sorgt, die in Deutschland leider noch immer keine Nachfolge gefunden hat. « ${ }^{19}$

Tatsächlich wurde vielfach begeistert vom kollisionslosen Passagierstrom im Vestibül englischer Bahnhöfe berichtet, in ihnen die Reisenden auf direktem Weg zum Zug geführt wurden, anstatt sie (wie oftmals auf deutschen Bahnhöfen) in kleine seitliche Flure zu schicken, aus denen sie sich wieder gegen den Strom herauskämpfen mussten. ${ }^{20}$ Dank solcher baulichen Maßnahmen, die nicht zuletzt den besseren klimatischen Bedingungen in England geschuldet waren, aber auch dank der attestierten kulturellen Eigenart englischer Reisender, die Eisenbahnen mit "größerer Umsicht, Ruhe und Gewandtheit ${ }^{21} \mathrm{zu}$ nutzen, wäre es in England möglich, auf verhältnismäßig engem Raum eine außerordentliche Personenverkehrsleistung zu realisieren. In diesem reformierten und stark durch das englische Bahnwesen stimulierten Verständnis war es folglich

»(...) zweifelhaft, ob es berechtigt ist, die Empfangsgebäude der Bahnhöfe in großen Orten unbedingt als Monumentalbauten ersten Ranges zu behandeln und ihnen, bisweilen auf Kosten der Zweckmäßigkeit, eine Weiträumigkeit oder Anordnung zu geben, die durch unnötig weite Wege für Beamte und Reisende zeitraubend werden kann, und eine Ausstattung der Innenräume, zu deren beschaulicher Betrachtung der meist eilige Reisende nicht Muße findet, wohingegen die äußere Erscheinung des Cebäudes von manchen Vorübergehenden auch mit der Ruhe betrachtet werden kann, daher schon eher zu eindrucksvoller Gestaltung Anlaß bietet. « $^{22}$

Goerings Plädoyer für eine allgemeine Verkleinerung der Räume und Gänge sowie die Verringerung ihrer aufwendigen Innenausstattungen erwächst zweifelsohne aus seiner auf Zweckmäßigkeit und Kostenreduktion abzielenden Grundüberzeugung. Diese Forderung wurde durch die gewandelten Nutzungspraxis legitimiert, wonach die reiligen Reisenden die Empfangsgebäude meist nur noch ohne Aufenthalt durchqueren würden. So begründete Goering seine veränderte Planungsphilosophie auch indirekt mit einer (vermuteten) nutzerseitigen Nachfrage zweckmäßigerer Innenraumgestaltungen, die nicht zuletzt auch das stationäre Warten betrafen.

Nicht nur die großen Eingangshallen und Korridore gerieten im Kontext einer allgemeinen Effizienzorientierung in den Verdacht eine Quelle sunnützer Bewegungen von Menschen zu sein, insbesondere die Raumgruppen der Warte- und Speisesäle standen hierbei in der Kritik, eine »unverhältnismäßig große Grundfläche in Anspruch « ${ }^{23}$

20

Ebd.

Taeger, »Ueber englisches Eisenbahnwesen.«, Zeitschrift für Bauwesen XXVII., Nr. 4-7 (1877): 283.

Donath, »Neuere Bahnhofs-Anlagen in England«, Zeitschrift für Bauwesen XXXI. (1881): 57.

Goering und Oder, Der Eisenbahnbau, Anordnung der Bahnhöfe, 3 [Hervorhebung des Verfassers, R.K.].

Schmitt, Anlage und Einrichtung der Gebäude, 78. 
zu nehmen. Folglich wurde die Forderung nach einem Umdenken bezüglich der Flächenbedarfe von Warte- und Speisesälen laut, die insbesondere in Deutschland in der Folge erhöhter Baukosten, sinkender Übersichtlichkeit und langer, ermüdender Wege "geradezu gewaltige Abmessungen angenommen haben. $\aleph^{24}$

\section{Ablehnung symmetrischer Grundrisse}

An den Kritikpunkt des zu großen Flächenbedarfs von Räumen, die ohnehin nur noch schnell durchquert würden, schloss sich unmittelbar die übergeordnete Kritik am Festhalten an symmetrischer Grundrissdispositionen an. Der symmetrische Aufbau der Empfangsgebäude wurde von den zunehmend einflussreicheren Eisenbahningenieuren als Hauptgrund für die ausufernden Gebäudeflächen identifiziert. Die Anlage von Passagierräumen links und rechts der Eingangshalle - wie etwa im Berliner Potsdamer Bahnhof (1872) - würde zu viel Platz verschwenden und doppelte Einrichtungen (z.B. für die Restauration) benötigen. Bereits Eberhard Wulffs Konzept des >baulichen Organismus s sprach sich 1882, und damit weit vor Goering/Oder und Schmitt, in aller Deutlichkeit gegen das vorherrschende Prinzip symmetrischer Grundrissanordnungen aus und vermerkte, dass der symmetrische Aufbau

»(...) alle Zweckmässigkeitsrücksichten in den Hintergrund gedrängt und (...) sich die Symmetrie (...), wie in tausend anderen Fällen, als eine wahre Tyrannin der heutigen Architektur gekennzeichnet [hat, R.K.]. « ${ }^{25}$

Diese >Tyrannei der Symmetrie w würde für viele Kollisionen von Passagier- und Gepäckströmen verantwortlich sein und damit massiv das Gebot des Zirkulationsprinzips stören, nach dem die Passagiere durch die Verkehrsbauwerke ohne Gegenströmungen, Rückwege oder Kreuzungsbewegungen sprozessiert « werden sollten. Auch Rüdell betonte 1903 die Notwendigkeit der Abkehr von den (ästhetischen) Bauidealen des vorigen Jahrhunderts, die den veränderten Ansprüchen an Zirkulation, Zeit- und Kosteneffizienz nicht mehr gerecht wurden und vermerkte:

»(...) wenn es etwas gibt, das naturgemäß auf eine unsymmetrische Ausbildung hindrängt, dann ist es ein Eisenbahn-Empfangsgebäude. Denn es ist stets die Verbindung von zwei grundverschiedenen Arten von Räumen; von großen, hohen Hallen und Sälen für die Scharender Reisenden und von kleinen, niedrigen Zimmern für die geringe Zahl der Beamten. ${ }^{26}$

\section{Neue Lösungsansätze des zweckmäßigen Bahnhofsbaus}

Um zukünftig die Prinzipien der Zweckmäßigkeit, Zirkulation und Beschleunigung realisieren zu können wurde also zuallererst die strikte Aufgabe der Symmetrie und damit verbunden eine Komprimierung der Wartesäle vorgeschlagen. Ziel des wartebezogenen Raumprogramms sollte es sein, die Wartesäle nicht mehr voneinander zu

24 Ebd., 79.

25 Wulff, Das Eisenbahn-Empfangs-Gebäude nach seinen praktischen Anforderungen und seiner künstlerischen Bedeutung, 19.

26 A. Rüdell, »Neuere Eisenbahnhochbauten«, Zentralblatt der Bauverwaltung XXIII., Nr. 47 (1903): 292. 
trennen, sondern die Raumgruppe der Wartesäle - wohlgemerkt bei Aufrechterhaltung der Klasseneinteilungen - als funktionale Einheit zusammenzubinden. Nur so konnten aus Sicht Wulffs und vieler anderer prominenter Eisenbahn- und Bauingenieure die Wege optimiert und zudem Kosten gespart werden. Die vorangehend skizzierten Beispiele des Elberfelder und des Potsdamer Bahnhofs in Berlin, in denen die Wartesäle im Sinne einer symmetrischen Durchbildung links und rechts des Eingangsvestibüls voneinander getrennt angeordnet wurden, bildeten nunmehr das Feindbild eines modernisierten und wissenschaftlich betriebenen Bahnhofsbaus. Um nur noch eine gastronomische Einrichtung zu benötigen und Kollisionen zu mindern, lag somit ein zentraler Lösungsansatz in der Zusammenlegung der Wartesäle. Das Eisenbahn-VerordnungsBlatt empfiehlt 1901 hierzu, dass »alle Warteräume an einer Seite des Einganges zu vereinigen ${ }^{27}$ seien. Die Modernisierung der Bahnhöfe zu größerer Zweckmäßigkeit und effizienterer Zirkulation zielte damit also im Besonderen auch auf die Modernisierung der Verkehrs- und Kulturpraxis des Wartens.

\section{Eduard Schmitt (1911): Fünf Maßnahmen zur Verkleinerung der Warteflächen}

Eduard Schmitt schlug zur Einschränkung der in Deutschland vergleichsweise überdimensionierten Wartesaal-Grundflächen fünf Maßnahmen vor, die für die kommenden Jahrzehnte und im Grunde bis in die Gegenwart hinein von entscheidender Bedeutung für Verortung und Erfahrung verkehrlicher Wartezeiten werden sollten. Als erste Option schlug Schmitt vor, eine direkte Verbindung von der Eingangshalle zum Bahnsteig einzurichten, denn damit würde

»(...) eine sehr große Anzahl von Reisenden veranlaßt, die Wartesäle überhaupt nicht zu benutzen, sondern unmittelbar den Bahnsteig zu betreten. ${ }^{28}$

Die Praxis des unmittelbaren Zugangs zum Bahnsteig und die damit verbundene Umgehung des stationären Wartens wurde, wie bereits geschildert, in England vom Anbeginn des Eisenbahnwesens verfolgt. Englische Bahnhöfe wiesen daher vergleichsweise kleine und weit weniger opulent ausgestaltete Wartemöglichkeiten auf. Das präparatorische Warten auf die Abfahrt wurde entweder direkt auf dem Bahnsteig oder - falls bereitstehend - bereits in den Wagen verbracht. Die überall überdachten Bahnsteige bildeten die Hauptverkehrs- und Hauptwartezonen des englischen Bahnwesens, flächenintensive Wartesäle oder Gastronomien waren daher nicht notwendig. Zwar war die englische Praxis über Jahrzehnte hinweg diskutiert und vor allem angesichts des im Vergleich zu Deutschland geringen Luxus nicht selten verhöhnt worden, doch die im frühen 20. Jahrhundert von größerer Effizienz geprägten Bauprinzipien ließen den englischen Ansatz im frühen 20. Jahrhundert (plötzlich) überaus attraktiv erscheinen. Mit ihm verbunden war nichts Geringeres als die Aufhebung des über Jahrzehnte hinweg bestehenden Betriebsstandards eines stationären Warteimperativs, der verpflichtenden Schleusung der Reisenden durch die Wartesäle und (zum Teil) deren Einschluss in dieselben. 
Eine zweite Maßnahme zur Verkleinerung der Wartesäle, die direkte Auswirkungen auf die Erfahrung systemischer Wartezeiten haben sollte, lag in der Einrichtung nur eines einzigen Wartesaals. Statt wie bisher drei bis vier separate Säle einzurichten, schlug Schmitt vor, die klassenspezifischen Abtrennungen innerhalb eines großen Raumes nur durch ca. $2 \mathrm{~m}$ hohe Bretterwände, Scheidewände oder Schwerwände herzustellen. Für diese Maßnahme der Raumersparnis nahm sich Schmitt das französische Bahnwesen zum Vorbild, in dem seit Langem solche Raum-in-Raum-Konstruktionen vorherrschten.

Drittens schlug Schmitt vor, die Bahnhofswirtschaften nach italienischem Vorbild strikt von den Wartesälen zu trennen, um diese (nicht jedoch den Bahnhof selbst) von der bis dahin prägenden Kulinarisierung des Wartens abzusondern. Zusätzliche Gasträume, Küchenräume, Räume für den Wirt oder Lager könnten somit aus dem Verkehrsablauf extrahiert werden, der Zugang zum Bahnsystem zweckmäßiger und gerichteter gestaltet werden.

Viertens schlug Schmitt nach französischem und US-amerikanischem Vorbild vor, mittels Installation einer Warte- oder Wandelhalle mit nur sehr kleinen angeschlossenen Warteräumen eine Reduktion der bezüglich Größe und Luxus >mutierten ` deutschen Wartesäle zu erreichen. Ein solcher ssalle des pas perdus fand sich in etwa in den Pariser Kopfbahnhöfen (Gare du Nord), in den USA wurde er als >Concourse < bezeichnet. Solche Wandelhallen würden als selbstjustierende Verkehrsflächen fungieren, auf denen zugleich gewartet werden könnte. Die großen Wartesäle würden somit obsolet, das stationäre Warten - wie partiell im Falle des neuen Frankfurter Centralbahnhofes mehr und mehr >verflüssigt < und in die Fläche verlagert werden können.

Ebenfalls nach US-amerikanischen Vorbildern schlug Schmitt schließlich als fünfte Maßnahme vor, die Eingangs- und Schalterhalle selbst zu einer Wartehalle werden $\mathrm{zu}$ lassen. Diese Anordnung wurde insbesondere in den monumentalen Großbahnhöfen der USA (etwa Washington Union Station, New York Central Station) oder auch im dänischen Bahnwesen praktiziert. Die Vereinigung von Warte- und Schalterhalle würde zwar den Vorteil einer vereinfachten Grundrissbildung bieten, wäre aber »für die Reisenden, die längere Zeit warten müssen, höchst unbequem, da sie unter der fortwährenden Unruhe der kommenden und gehenden Personen zu leiden« hätten. »Ein ruhiges Plätzchen«, so Schmitt weiter, »finden nur die Frauen, für die immer ein besonderer Warteraum vorgesehen ist, während die Männer auf die - übrigens nicht immer vorhandenen - Wirtschaftsräume oder auf das Raucherzimmer angewiesen sind. ${ }^{29}$

Auch wenn all diese Optionen ortsspezifischen Anpassungen unterliegen müssten, stellte Schmitt hinsichtlich dieser fünf vorgeschlagenen Maßnahmen übergreifend fest:

»Solche Anlagen sind vollkommen im Geiste der neuen Verkehrsverhältnisse gelegen. Denn die in kurzen Zwischenräumen einander folgenden Züge bedingen längeres Verweilen der Reisenden auf dem Bahnhofe nur selten. ${ }^{30}$

Wie wenige Jahre zuvor Adolf Goering registrierte auch Eduard Schmitt eine offenbar veränderte Nutzungspraxis der Reisenden, die den stationären Aufenthalt nicht mehr 
zwingend benötigten und das verkehrliche Warten in eine moderne Phase des Vermeidens und Umgehens transferierten. Die »neuen Verkehrsverhältnisse « umfassten somit nicht nur die Erhöhung des Verkehrstaktes, sondern auch eine Veränderung des Modus des Wartens in Richtung einer Marginalisierung des stationären Wartens vor der Abfahrt.

\section{Wilhelm Cauer (1926) - Zur Gestaltung von Personenbahnhöfen}

Der Erste Weltkrieg, die »Urkatastrophe $\aleph^{31}$ des 20 . Jahrhunderts, bewirkte durch die massenhafte Erfahrung des maschinellen Tötens nicht nur eine unversöhnliche Krise des kulturell-ethischen Fortschrittstelos und der westlichen Zivilisationsmission der Moderne. ${ }^{32}$ Mit ihm kam auch das jähe Ende der fast einhundertjährigen Geschichte des Bahnhofsbaus in Deutschland. Der Druck der im Versailler Vertrag verankerten Reparationszahlungen erforderte zunächst die Einstellung jeglicher Bautätigkeiten. Erst zu Mitte der 1920er Jahre setzten wieder eine akademische Auseinandersetzung mit dem Bahnhofsbau ein, die deutlich an die seit 1900 entstandenen, auf Ökonomie und Zweckmäßigkeit abzielenden Konzeptionen eines wissenschaftlich betriebenen Bahnhofsbaus Goerisch'scher Schule anknüpfte.

Zu ihren Vertretern zählte auch Wilhelm Cauer, dessen 1926 erschienene Abhandlung über Personenbahnhöfe hier herausgegriffen werden soll, weil sie für die Bauund Kulturgeschichte des verkehrlichen Wartens von besonderer Bedeutung ist. Cauers theoretisches Standardwerk zur Gestaltung von Personenbahnhöfen wurde bereits 1913 veröffentlicht, erhielt aber 1926, angesichts der sich veränderten Rahmenbedingungen und Erfahrungen der 1920er Jahre, eine umfassende Überarbeitung, die auch eine Anpassung älterer Grundsätze zur Behandlung von Wartezonen beinhaltete. Wie zuvor Goering und Schmitt folgte auch Cauer hierbei der grundsätzlichen Zielstellung, Bahnhofsanlagen in absoluter Zweckmäßigkeit, Bequemlichkeit und Übersichtlichkeit sowie mit möglichst kurzen und direkten Bahnsteigzugängen auszuführen. ${ }^{33}$

Das Mittel zum Erreichen dieser Zielstellungen sah Cauer dezidiert in einer Abkehr vom symmetrischen Grundriss, der für ihn als >unzweckmäßig` galt, weil er unter anderem den Reisenden beim Betreten des Bahnhofs eine schlechte Übersicht und Orientierung gewährte und die Bewirtschaftung der Räume erschwerte. Um das Dogma der Zweckmäßigkeit zu verwirklichen, sollte man sich daher zunächst vom »Vorurteil der Symmetrie « ${ }^{34}$ freimachen und die Wartesäle nicht weiter getrennt links und rechts der Eingangshalle anordnen. Dieser Bruch mit der Bau- und Planungstradition des 19. Jahrhunderts, die sich mit Cauers neuaufgelegtem Theoriewerk auch nach dem Ersten Weltkrieg weiter verstetigte, wird zusammenfassend in folgender Aussage deutlich:

George F. Kennan, The decline of Bismarck's European order: Franco-Russian relations 1875-1890 (Princeton: Princeton University Press, 1981).

Vgl. Michael Adas, »Contested hegemony: The Great War and the Afro-Asian assault on the civilizing mission ideology«, Journal of World History 15, Nr. 1 (2004): 31-63.

33 Diese Anknüpfung an die Vorkriegsprogrammatik mochte bei Cauer auch deshalb bestehen, weil er wie viele andere bedeutende Eisenbahningenieure jener Zeit der Coering'schen Schule entstammte. 
»Das Streben nach Symmetrie, das man in älteren Empfangsgebäude in der Kopfwie der Durchgangsform häufig verkörpert sieht, führt abgesehen von der Zersplitterung der Wartesäle in der Regel auch sonst zu einer gezwungenen Raumanordnung, die die einzelnen Teile nicht so auszubilden gestattet, wie es der Zweck eines jeden erfordert. Von der symmetrischen Anordnung großer und kleiner Empfangsgebäude sollte man grundsätzlich absehen, die Wartesäle aber stets in einer zusammenhängenden Cruppe anordnen. $\ll^{35}$

Um mehr Übersichtlichkeit und Klarheit für Reisende, eine klarere Trennung von Dienst- und Reiseverkehr, bessere und schnellere Überwachung des Verkehrs mit weniger Beamten und überhaupt Raum- und Dienstersparnisse erreichen zu können, führte für Cauer also kein Weg an einer asymmetrischen Grundrissanordnung vorbei. Jene Programmatik, die bereits bei Wulff (1882), Goering (1907) und Schmitt (1911) einen zentralen Gesichtspunkt des (wissenschaftlichen) Bahnhofsbaus bildete, soll hier nochmals in seiner Bedeutsamkeit betont werden, weil sie direkte Auswirkungen auf die bauliche Rahmung und Lokalität des Wartens hatte. Denn innerhalb einer solchen asymmetrischen Grundrissausrichtung gliederte sich die Wartesaalgruppe nunmehr »Zweckmäßig seitwärts an den Weg an, den die Reisenden vom Eintritt in das Empfangsgebäude an zur Fahrkartenausgabe, Gepäckabfertigung und zu Bahnsteigen zurückzulegen haben, so daß die Reisenden beliebig die Wartesäle aufsuchen können oder nicht. ${ }^{36}$

Das Resultat dieser Neugruppierung der Wartesäle, die in Deutschland meist links vom Eingang und »gern der Tiefe des Raumes nach hintereinander ${ }^{37}$ platziert wurden, fasst Cauer wie folgt zusammen:

»Zwischen Wartesälen und Abfertigungsräumen hindurch kann dann der Reisende folglich ohne Berührung der Wartesäle, je nach Lage des Falles unmittelbar oder mittels Tunnel oder Brücke und anschließenden Treppen zu den Bahnsteigen gelangen. $\aleph^{38}$

Die von Cauer und anderen einflussreichen Protagonisten eingeforderte Verlagerung der Wartesäle an eine Seite des Empfangsgebäudes führte damit zur Betonung des direkten Durchgangs zum Zug ohne Umwege über die Wartesäle. War es in den Jahrzehnten zuvor noch das baulich-operative Ziel, die Reisenden vor der Abfahrt zu sammeln, lag das Ideal nunmehr in der Vermeidung großer Aufenthaltsräume und einer direkten Wegeführung zu den Zügen. Wenngleich diese Verschiebung zunächst auf den ersten Blick unerheblich erscheinen mag, spiegelt sie doch physisch wie symbolisch unmissverständlich das Credo einer gänzlich neuen, modernen, auf beschleunigte Zirkulation und einer Reduktion des (stationären) Wartens abzielende Verkehrswegeorganisation, die im deutschen Raum spätestens in der Zwischenkriegszeit zum dominierenden Aspekt des Bahnhofsbaus reifte. Hinsichtlich dieser allmählichen Entwicklung einer seitlichen Verlagerung der Wartesäle vermerkte Cauer:

35 Ebd., 19 [Hervorhebungen des Verfassers, R.K.].

36 Ebd., 20 [Hervorhebung durch den Verfasser, R.K.].

37 Ebd., 42.

38 Ebd., 19. 
»Um für die Reisenden den Weg zum Bahnsteig möglichst kurz, einfach und übersichtlich zu gestalten, ist man in Deutschland etwa seit den achtziger Jahren des vorigen Jahrhunderts allgemein dazu übergegangen, die Reisenden nicht mehr, wie in früheren Zeiten üblich, zum Durchschreiten der Wartesäle zu zwingen. Diese sind vielmehr seitlich des direkten Bahnsteigzugangs so anzuordnen, daß die Reisenden nach Belieben einen Abstecher in die Wartesäle machen oder auf kürzestem Wege die Bahnsteige aufsuchen können. «39

Auch wenn die operative Wendung zum allmählich freieren und direkteren Zugang im späten 19. Jahrhundert ihren Anfang nahm, wurde sie erst in den Bahnhofsneubauten des frühen 20. Jahrhunderts vollends wirksam. Diese Entwicklung kann jedoch nicht allein aus der baulichen Umsetzung des >Phantasmas eines reibungslosen Betriebs $<$ heraus erklärt werden. Vielmehr waren es auch die Reisenden selbst, die, vor dem Hintergrund sich gewandelter technischer, wirtschaftlicher und kultureller Rahmenbedingungen und daraus resultierender Nutzungspraxen, solche baulichen Veränderungen bewirkten. So führte auf technischer Seite die Verbreitung von Speisewagen ab 1900 dazu, dass der Aufenthalt in den Bahnhofswirtschaften nicht mehr unbedingt nötig wurde, da man sich dank der rollenden Gaststätte auch während der Fahrt mit Speisen und Getränken versorgen konnte. Im Resultat konnte die absolute Wartezeit vor der Abfahrt dadurch wesentlich verkürzt werden und das Eintreffen am Bahnhof rückte wesentlich näher an die Abfahrtszeit. Auch die schwierige wirtschaftliche Situation der 1920er Jahre mit zum Teil erheblichen Verteuerungen der Grundnahrungsmittel, zwang die Reisenden der unteren Wagenklassen zunehmend, sich selbst mit Speisen und Getränken zu versorgen, die sie weder am Bahnhof noch im Zug kauften. ${ }^{40}$ Die Selbstverpflegung bewirkte damit ebenfalls eine allgemeine Verkürzung des vorbereitenden Aufenthalts. Nicht allein die betrieblichen und baulichen Rahmungen hatten demnach Einfluss auf die Warteerfahrung, sondern auch die wirtschaftliche Situation wirkte auf die Erfahrung des Temporalphänomens >Warten< ein.

Darüber hinaus stand in zeitkultureller Hinsicht die (städtische) Alltagserfahrung des frühen 20. Jahrhunderts entschieden im Zeichen einer weithin attestierten (und gewünschten) Beschleunigung des Lebenstempos, in der Wartezeiten zunehmend weniger tolerierbar erschienen. Georg Simmel sah in dieser Beschleunigung des Lebenstempos »das Produkt aus der Summe und der Tiefe seiner Veränderungen ${ }^{41}$ und leitete sie zuvorderst aus den Effekten der Etablierung der Geldwirtschaft ab. Das Geld würde hierbei wie kein anderes Symbol den »absoluten Bewegungscharakter der Welt « ${ }^{42}$ darstellen und damit den Inhalten des Lebens bestimmte psychologische Ordnungen und Formen geben. Diese im Zusammenhang mit der Geldwirtschaft dominierende Ordnung und Form sei schließlich jene der beschleunigten Zirkulation, welcher sich der moderne Mensch anpassen müsse.

39 Ebd., 18f. [Hervorhebungen des Verfassers, R.K.].

40 Ebd., 20.

41 Simmel, Philosophie des Geldes, 809.

42 Ebd., 830. 
»Endlich muß die Ceschwindigkeit, die der Zirkulation des Geldes gegenüber der aller anderen Objekte eigen ist, das allgemeine Lebenstempo unmittelbar und in demselben Maße steigern, in dem das Geld das allgemeine Interessenzentrum wird. ${ }^{43}$

Ferner betonte Simmel an anderer Stelle, dass das metropolitane Leben nach einer "minutenhaften Präzision« verlangt und die Großstadtbewohner in den Zwang versetzt, die mechanisierte Zeit - bewirkt durch die allgemeine Verbreitung von Taschenuhren als zentrales Organisations- und Orientierungsprinzip schlechthin zu verinnerlichen. ${ }^{44}$ Die alltägliche Abhängigkeit von verlässlichen, exakten Zeitangaben und damit verbundener Synchronisation war für Simmel im Jahr 1903 bereits derart fortgeschritten, dass jegliche Abweichung vom präzisen Zeitregime weitreichende Folgen hätte:

»Wenn alle Uhren in Berlin plötzlich in verschiedener Richtung falschgehen würden, auch nur um den Spielraum einer Stunde, so wäre sein ganzes wirtschaftliches und sonstiges Verkehrsleben auf lange hinaus zerrüttet. Dazu kommt, scheinbar noch äußerlicher, die Größe der Entfernungen, die alles Warten und Vergebenskommen zu einem gar nicht aufzubringenden Zeitaufwand machen. So ist die Technik des großstädtischen Lebens überhaupt nicht denkbar, ohne dass alle Tätigkeiten und Wechselbeziehungen aufs pünktlichste in ein festes, übersubjektives Zeitschema eingeordnet würden. $\ll^{45}$

Die moderne Großstadt der Jahrhundertwende kann demnach als der Schauplatz gelten, an dem die Ökonomisierung der Zeit als Wert und Ressource in Konvergenz mit der täglichen Anwendung und Verinnerlichung dieses Prinzips stärksten Ausdruck gefunden hat und reziprok (unproduktive) Wartezeiten tendenziell als problematisch erlebt wurden. Auch der Großstadtbahnhof der Jahrhundertwende war somit ein Ort, an dem die Bewegung gegenüber der Beständigkeit endgültig die Oberhand zu gewinnen begann. ${ }^{46}$ Bezeichnend für die Zeit ist Simmels Beobachtung, dass die runde, rollende Geldmünze im Laufe der Neuzeit die widerständige, eckige Münze verdrängt hatte: Stillstände avancierten demnach offensichtlich zunehmend zu einem unzulässigen Daseins-Modus, zudem nicht zuletzt auch das verkehrliche Warten zählte. Je mehr Tempo und Schnelligkeit zu positiv besetzten Begriffen wurden, ${ }^{47}$ desto mehr mussten Wartezeiten in den Status eines Problems rücken.

Es sind somit nicht zuletzt die kulturellen und gesellschaftlichen Rahmenentwicklungen der Jahrhundertwende, die den langen stationären Aufenthalt in den Wartesälen immer stärker in Opposition zu dem rastlosen Leben außerhalb des Bahnhofs treten

Ebd., 823.

44 Georg Simmel, Georg Simmel. Cesamtausgabe. Bd. 7: Aufsätze und Abhandlungen 1901-1908, hg. von Rüdiger Kramme, Otthein Rammstedt, und Angela Rammstedt (Frankfurt a.M.: Suhrkamp, 1995), 119.

45 Ebd., 120.

46 So begreift Simmel den Modernisierungsprozess als den Wandel von einem ausbalancierten Verhältnis zwischen Bewegung und Verharrung in Richtung des Primats der Bewegung und damit in Richtung einer Welt, die »das Schauspiel eines Perpetuum mobile« bieten würde. Simmel, Philosophie des Geldes, 827.

Vgl. Borscheid, Das Tempo-Virus, 10. 
ließ und das Warten spätestens in der Zwischenkriegszeit wenig tolerierbar machte. Auch vor dem Hintergrund dieser nutzerseitigen Veränderung in Richtung stärkerer Zeiteffizienz wurden die Wartesäle immer häufiger umgangen und - zumindest im Nah- und Berufsverkehr - der direkte Weg zum Einstieg gesucht. Architekten, Ingenieure und Planer beobachteten allerorten eine gegenüber dem 19. Jahrhundert gesteigerte `Eile der Reisenden. Auch diese Beobachtungen wirkten mit Sicherheit auf die operativ-bauliche Wende und die Überlegungen zur Aufgabe langer Korridore und raumgreifender Wartezonen ein.

Cauer stellt 1926 als Folge der inzwischen nutzerseitig stattfindenden Veränderungen den Befund:

»Die Wartesäle werden infolge der Ausrüstung der Züge mit Speisewagen und der Aufstellung von Erfrischungsbuden oder Erfrischungstischen auf den Bahnsteigen in geringerem Umfange als früher von Durchreisenden aufgesucht, um Speisen und Getränke einzunehmen. « $^{48}$

Als Folge dieser Veränderungen waren eine Reihe von Wartesälen bereits wesentlich verkleinert worden. So wurden etwa aufgrund der Einführung von Speisewagen die sonst für die Mittagsmahlzeiten genutzten Wartesäle auf den Bahnsteigen von Hannover oder Straßburg »durch Erfrischungsbuden ersetzt, die weniger Raum in Anspruch nehmen. $\aleph^{49}$ Die Ersetzung großer Säle durch die Trivialarchitektur der Erfrischungsbude kann hierbei sinnbildlich für den allgemein einsetzenden Rückbau des >würdevollen Wartens in opulenter Sälen gesehen werden, die der Beschleunigungslogik der kapitalistischen Moderne immer mehr zu widersprechen schienen.

Symptomatisch schlägt Cauer 1926 vor, die durch Verkleinerung der Wartesäle eingesparten Flächen zur allgemeinen Ökonomisierung des Bahnhofs einzusetzen. So forderte er, dass die Bahnbetreiber »mehr als früher bestrebt [sein sollten, R.K.], auf den Bahnhöfen Nebenbetriebe vorzusehen $^{50}$, um damit neue Einnahmequellen zu generieren. Statt die großen Warteflächen zum, wie Goering sie bezeichnete, »zinnlosen« oder gar »schädlichen Kapital« werden zu lassen, sprach sich Cauer für eine Umwandlung in Verkaufsflächen aus, denn, so Cauer: »die auf den Bahnhöfen errichteten Verkaufsstellen pflegen bei der günstigen Lage der Stände große Umsätze zu erzielen, so daß hohe Mieten gezahlt werden, die die Anlagekosten mehr als verzinsen. ${ }^{51}$

Lange bevor Schnellrestaurantketten und >Fast-Fashion` in die Bahnhöfe einzogen, nimmt Cauer damit hier bereits das sich seit den 1990er Jahren etablierende Konzept der Einkaufsbahnhöfe vorweg.

\section{Implikationen des wissenschaftlich betriebenen Bahnhofsbaus für die Warteerfahrung}

Die Auswirkung immer häufigeren Abkehr von symmetrischen Grundrissen, basierend auf dem übergeordneten Streben nach Effizienz und Zirkulation, lässt sich für das Temporalphänomen des Wartens in einem Kernbefund verdichten: Das Warten auf die Ei-

48 Cauer, Personenbahnhöfe, 6.

49 Ebd., 20.

50 Ebd., 7.

51 Ebd. 
senbahn wurde im ersten Drittel des 20. Jahrhunderts endgültig fakultativ. Der vormalige stationäre Warteimperativ, die erzwungene Schleusung der Reisenden durch die Wartesäle, wurde zunehmend aufgehoben bzw. wuchs in den Stand einer optionalen Mobilitätspraxis. Der im 19. Jahrhundert zum zentralen Bestandteil der Reiseerfahrung gereifte Aufenthalt in den Wartesälen verlor mit den baulich-betrieblichen Rahmenentwicklung des frühen 20. Jahrhunderts zunehmend an Bedeutung, wenngleich das stationäre, würdevoll-opulent gerahmte Warten nicht schlagartig endete. Der Prozess in Richtung allgemein größerer Zweckmäßigkeit vollzog sich dabei nicht exklusiv als Resultat veränderter Raumdispositionen, sondern das veränderte Raumprogramm wurde zugleich durch die von Ingenieuren und Architekten gemachten Beobachtungen veränderter Nutzungspraxen der Reisenden legitimiert. So hielt etwa Cauer die Einrichtung möglichst kurzer Wege für die Abreisenden überhaupt nur deshalb für eine entscheidende Einrichtung, "weil diese stets bis zu den Abfahrtszeitpunkten der Züge nur über begrenzte Zeit verfügen und sich oft in Eile befinden. $\aleph^{52}$ Waren andererseits die Wartesäle erst einmal an die Seite verlegt und bedurften keiner verpflichtenden Nutzung mehr, bewirkte diese Raumsituation wiederum eine nochmalige Verstärkung der Nicht-Nutzung der Wartesäle. Vor allem der Nah- und Lokalverkehr bot hierfür das entscheidende Übungsfeld zur Internalisierung und Routinisierung eines direkteren, zeiteffizienteren und damit zweckmäßigeren Übergangs von der Stadt zum Bahnsystem. Kurzum: Die Ökonomisierung von räumlichen Settings und des individuellen Passagierverhaltens wirkten mit Beginn des 20. Jahrhunderts koevolutionär zusammen. Das baulich-betriebliche Effizienzdenken auf der einen und die gewachsene Zeitökonomie seitens der Reisenden auf der anderen Seite griffen wechselseitig ineinander und bewirkten dabei den gleichen Effekt: den Beginn einer allmählichen Marginalisierung des stationären Wartens inklusive einer Reduktion des präparatorischen Aufenthalts vor Abfahrt.

Die stark von Flexibilisierung und Ökonomisierung geprägten Überlegungen ließen den Bau von Bahnhofsgebäuden sicherlich nur zu einem von vielen Spielfeldern der baulichen Moderne werden, die im Sinne der Prozessbeschleunigung vom Ideal der reibungslosen Effizienz und ökonomischer Zweckmäßigkeit ergriffen wurden. Im Spiegel ihrer Grundrissentwicklungen repräsentierten sie den auf Effizienz abzielenden Paradigmenwechsel jedoch besonders deutlich. Um die von Zweckmäßigkeit, Effizienz und gewandeltem Nutzerverhalten getriebenen Veränderungen gegenüber der vorherigen Bahnhofsgeneration zu illustrieren, sollen im Folgenden noch einmal einige Beispiele von nach 1900 in Deutschland entstandenen Bahnhofsneubauten aufgeführt werden. Ziel dieser exemplarischen Betrachtungen soll es sein, die direktere und verkürzte Wegeführung zum Gleis und die allmähliche Verkleinerung bzw. Marginalisierung des wartebezogenen Raumprogramms nachvollziehbar zu machen. Diese Entwicklung nimmt mit dem Bau des Hauptbahnhofs von Wiesbaden (1906) einen prominenten Anfang, wird im ikonischen Bau des Stuttgarter Hauptbahnhofes (1922) weitergeführt und findet im Neubau des Hauptbahnhofes von Oberhausen (1935) seinen wohl deutlichsten Ausdruck. 


\subsection{Exemplarische Bahnhofsbauten der Marginalisierung des stationären Wartens}

\subsubsection{Wiesbaden (1906)}

Die hessische Kur- und Bäderstadt Wiesbaden verfügte, ähnlich wie das benachbarte Frankfurt a.M., lange Zeit über drei eigenständige Bahnhöfe, die zwar in unmittelbarer Nähe zueinander lagen, aber für Reisende im Übergangsverkehr erhebliche Schwierigkeiten erzeugten. Vor diesem Hintergrund sollte ein Bahnhofsneubau die Zusammenlegung der Einrichtungen in einem Hauptbahnhof ermöglichen. Diese Zusammenlegung wurde nicht zuletzt auch durch die Verstaatlichung der hessischen Ludwigsbahn ermöglicht, die ab 1897 in die Verwaltung der Preußisch-Hessischen Eisenbahngemeinschaft übergegangen war. Durch die Verstaatlichung der Linie konnte der Bahnbetrieb nunmehr ohne Rücksicht auf Absprachen mit einem privatwirtschaftlichen Unternehmen zentral an einem Ort realisiert werden. Die seit dem letzten Drittel des 19. Jahrhunderts massiv vorangetriebene Verstaatlichungswelle und die damit ermöglichte Konsolidierung baulicher Ressourcen kann somit als eine weitere Rahmenbedingung für die Realisierung eines auf Effizienz, Ökonomie und Zweckmäßigkeit ausgerichteten Bahnhofsbaus angesehen werden.

Der Entwurf des 1906 eröffneten Hauptbahnhofes Wiesbaden entstammte dem Architekten Fritz Klingholz, der durch sein zeitweiliges Studium an der Preußischen Königlich Technischen Hochschule Berlin auch die Prägung des Eisenbahningenieurs Adolf Goering und dessen wissenschaftlichen Grundsätzen zum Bahnhofsbau erhalten haben dürfte. Entsprechend der Goering'schen Schule zeigte die Grundrissgestaltung von Wiesbaden zumindest in auffälliger Weise die Abkehr von der Symmetrie und kontrastierte damit deutlich die (symmetrische) Anlage des Frankfurter Hauptbahnhofs. Die leitenden Gesichtspunkte für die asymmetrische Grundrissplanung lagen aus Sicht des Bauleiters und späteren Reichsbahndirektors Cornelius, der zusammen mit Klingholz den Bau verantwortete, im Wunsch, möglichst alle Räume mit Tageslicht zu versorgen und die Bewegungsströme ankommender und abfahrender Passagiere nach Möglichkeit zu trennen, "um Verkehrskreuzungen und -stockungen zu vermeiden. ${ }^{53}$ In dieser Aussage spiegelt sich bereits das für die vierte Phase des deutschen Eisenbahnhochbaus so prägende Dogma der kreuzungsfreien Zirkulation. Komplementär dazu zeigte sich aber im Anspruch, »für die Reisenden vom Eingang bis zum Zuge möglichst kurze Wege ${ }^{54}$ einzurichten, zugleich ein weiteres so grundlegendes Element der zweckmäßigen Bauprogrammatik. Nicht mehr lange Korridore und Zwischenzonen sollten die Reisenden in diesem Kopfbahnhof zu den Zügen führen, sondern möglichst kurze und direkte Wege. Diese Forderung wurde in Wiesbaden dadurch erfüllt, dass die Reisenden nach Eintritt in die Vorhalle mit den Fahrkarten- und Gepäckschaltern unmittelbar und ohne Umwege über die Wartesäle in eine große Querbahnsteighalle geleitet wurden. Diese zeitgenössisch als >Wandelhalle bezeichnete Zirkulationszone 
(Abbildung 44) bildete dem Bauleiter Cornelius zufolge »das Verbindungsglied (...) zwischen den Bahnsteigen und den dem Publikum zugänglichen Räumen des eigentlichen Empfangsgebäudes. « ${ }^{55}$

Abbildung 43: Grundriss des Wiesbadener Hauptbahnhofes von 1906. Am unteren linken Bildrand ist die Schalterhalle zu sehen, die den Passagierstrom neuartig direkt und ohne Umwege über die Wartesäle auf die Hauptzirkulationszone des Querbahnsteigs vermittelte.

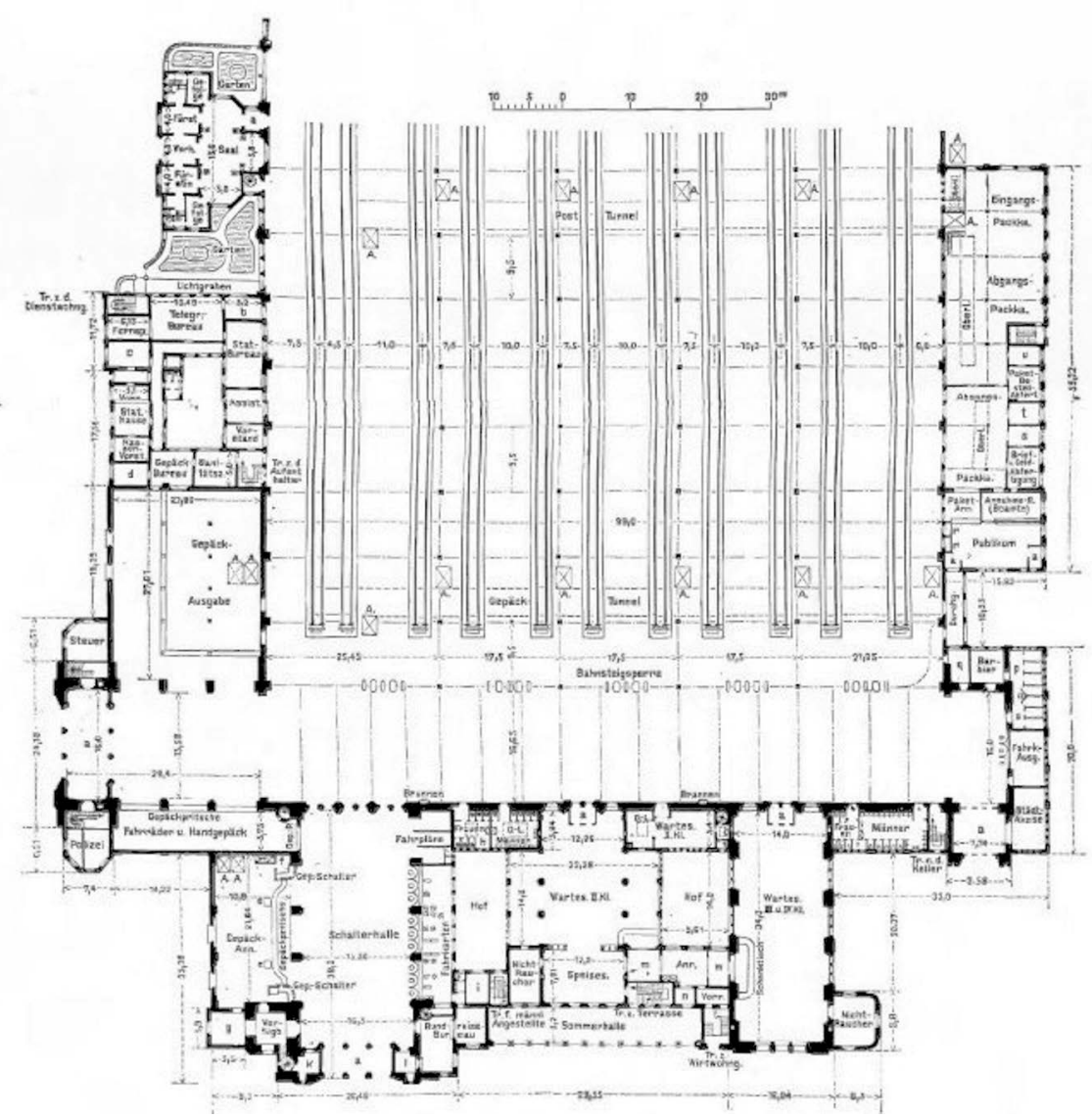

Quelle: Zeitschrift für Bauwesen 1908, S. 27-28.

Wie aus dem Grundriss (Abbildung 43) ersichtlich wird, erreichten die Reisenden zunächst die Zirkulationszone und erst dann die daran angeschlossen die Wartesäle, was einer Umkehrung der zuvor etablierten betrieblichen Logik des stationären Warteimperativs gleichkommt. Auf der riesigen Zirkulationsfläche angelangt, konnten die Reisenden nun frei entscheiden, ob sie sich swandelnd ‘ auf dem Querbahnsteig aufhalten, sich in den Wartesälen niederlassen oder sich nach dem Passieren der Bahnsteigsperre (Fahrkartenkontrolle) direkt zu den Bahnsteigen begeben wollten. Wie im 
Abschnitt zum Bau des Frankfurter Centralbahnhofes beschrieben, war die >Erstverteilung der am Bahnhof eintreffenden Passagiere auf den Querbahnsteig bereits auch in der Konzeption von Frankfurt angedacht worden. Sie wurde jedoch aufgrund der (auch der Symmetrie geschuldeten) schlechteren Übersichtlichkeit für die Reisenden nur partiell realisiert. Stattdessen erfuhr die Mehrzahl der Reisenden in Frankfurt noch den Gag durch Korridore und die Schleusung durch vorgeschaltete Wartesäle. Knapp zwei Jahrzehnte später zeigte sich mit Wiesbaden dagegen, dass sich die Wegeführung immer stärker in Richtung eines Direktzugangs samt einer damit verbundenen Marginalisierung des stationären Wartens wandelte. Die selbstständige Orientierung der Reisenden auf dem Querbahnsteig erschien nach 1900 nicht zuletzt aufgrund der gewachsenen Routinisierung der Eisenbahnreise als gegeben.

Abbildung 44: Postkarte des Neuen Bahnhofs Wiesbaden mit Querbahnsteig bzw. Wandelhalle und Zugang zum Wartesaal II. Klasse. Neben dem Eingang zum Wartesaal ist eine Körperwaage auszumachen, die den Passagieren als Angebot des Zeitvertreibs eingerichtet wurde (um 1906).

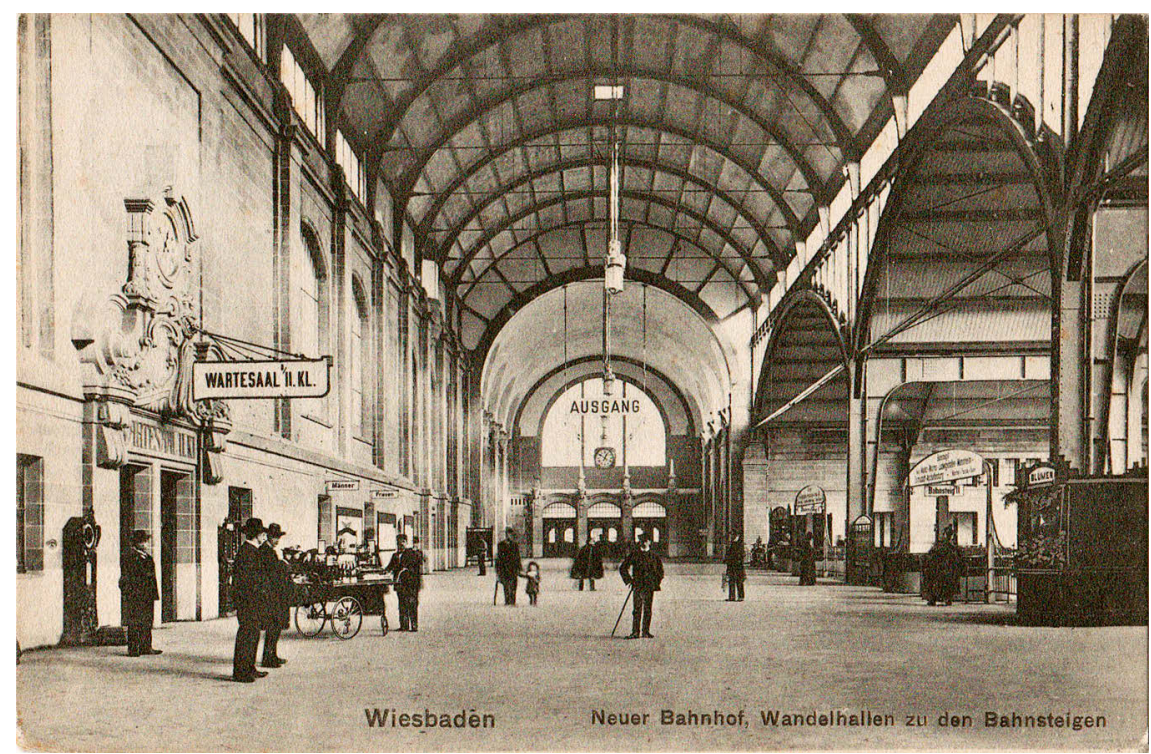

Quelle: Stadtarchiv Wiesbaden, Sammlung Ursula Killmann.

Wenngleich die Bahnsteige direkt erreicht werden konnten und die Wartesäle dadurch nicht mehr obligatorisch betreten bzw. genutzt werden mussten, waren sie innerhalb des Grundrisses nach wie vor deutlich präsent. Das wartebezogene Raumprogramm umfasste nach wie vor drei nach Klassen unterteilte Wartesäle, einen separaten Speisesaal, zwei Schanktische sowie zwei Damen- bzw. Nichtraucherzimmer und ähnelte damit in puncto Flächenbedarf den Vorgängerbauten des späten 19. Jahrhunderts. Der Stellenwert des systemischen Wartens in Form großer Säle war aus Sicht der Planung offenbar ungebrochen persistent. Zudem war die Ausstattung weiterhin sehr 
dekorativ und zum Teil gar opulent ausgestattet. ${ }^{56}$ Die beiden großen Wartesäle und der Speisesaal erhielten Wandervertäfelungen aus Eiche, der Speisesaal zudem reich vergoldete Stuckverzierungen, marmorverkleidete Wände sowie Spiegel an den Stirnseiten. ${ }^{57}$ Reisende der ersten Klasse nahmen auf roten Ledersitzen Platz, die »zu behaglichem Ruhen ${ }^{58}$ einluden, jene der zweiten Klasse mussten mit lederartigem grünem Pegamoid vorlieb nehmen. Der Wartesaal dritter und vierter Klasse war standesgemäß mit Holzstühlen sowie Tischen mit einem Bezug aus grünem Linoleum ausgestattet. Zentral in jenen Räumen war wiederum die Installation einer großen Uhr, die jeweils reich geschmückt an der Stirnseite der Wartesäle angebracht war und die Räume als Orte einer spezifischen Temporalität auszeichnete. Die großen Uhren sollten während des Aufenthalts in den Sälen die individuelle Synchronisation der Reisenden mit dem Bahnsystem gewährleisten. Der Abgleich zwischen aktueller Zeit und Abfahrtzeit war hier besonders notwendig, weil aufgrund der kleinen Türen und Fenster zum Querbahnsteig kaum eine Sichtbeziehung zum abfahrenden Zug möglich war. Dieser Umstand bewirkte für den Aufenthalt in den Wartesälen die starke Notwendigkeit einer zeitbezogenen Selbstkontrolle, die den Bahnhof, wie bereits seit Jahrzehnten, zum Schauplatz der Verinnerlichung des mechanisierten Uhrzeitregimes werden ließen.

Doch trotz der nach wie vor großflächig konzipierten und zum Teil luxuriös eingerichteten Wartesälen, trat die vorgeschaltete >Wandelhalle von Wiesbaden in eine funktionelle Konkurrenz zu den klassischen Wartesälen. Diese Konkurrenz wurde nicht allein durch den direkten Zugang von der Eingangshalle unterstrichen, sondern auch durch die Einrichtung einer Serviceinfrastruktur in der Querbahnsteighalle (Trinkbrunnen, Uhren, Körpergewichtswagen, Sitzbänke, Friseursalon), welche die gewachsene Bedeutung der Zirkulationsfläche gegenüber den Flächen des stationären Aufenthalts betonte. Sie wurde aber nicht zuletzt auch durch die sprachliche Repräsentation einer >Wandelhalle betont, die vermuten lässt, dass sich die Wartepraxis stärker in die Fläche und in den Modus der Bewegung verlagerte. Trotz des ungebrochen zentralen Stellenwerts des stationären Wartens kann der Wiesbadener Hauptbahnhof von 1906 deshalb als ein paradigmatischer Bahnhofsbau auf dem Weg in die verkehrliche Moderne identifiziert werden, ${ }^{59}$ in dem der stationäre Warteimperativ nur noch in den Stand einer fakultativen Reisepraxis rückte. Zum Ziel einer optimierten Zirkulation wurde die bis dahin baulich-betriebliche Praxis einer Zwangs-Schleusung der Reisenden vollends aufgegeben. Wie bereits in Frankfurt (1888) wurde aber zunächst keiner der Warte-Modi dominant, vielmehr koexistierte die Wartepraxis des stationären Aufenthalts und des fluiden, 'wandelnden Wartens in der Fläche (Querbahnsteig), wobei der Wiesbadener Bahnhof durch den nunmehr direkten Bahnsteigzugang bereits die deutliche Entwicklung in Richtung der später gänzlichen Umgehung der Wartesäle aufzeigte.

Dies war sicherlich auch dem speziellen Umstand eines höhergestellten Reisepublikums geschuldet, das Wiesbaden für den Kuraufenthalt aufsuchte.

57 Cornelius, »Das neue Empfangsgebäude auf dem Hauptbahnhof in Wiesbaden.«, 38.

58 Ebd., 39.

59 Weitere von direkten Gleiszugängen geprägte Neubauten von Klingholz umfassten die Bahnhöfe von Essen (1902), Koblenz (1902), Worms (1904) oder Lübeck (1908). 
Die in diesem exemplarischen Beispiel zum Ausdruck kommende Tendenz zur gewachsenen Bedeutung der von Bewegung geprägten >Wandelhalle` gegenüber den stationären Wartesälen wurde dabei auch von der gewachsenen Zirkulation im umliegenden Stadtraum vorangetrieben. Die am Beispiel Wiesbaden verkürzte und direkte Wegeführung von der Stadt zu den Gleisen zeigt, dass die Flusslogik des städtischen Straßensystems nun auch im Inneren des Bahnhofs weitergeführt wurde, das Bahnhofsgebäude demnach möglichst keine Barriere bzw. Zirkulationshemmung darstellen sollte. Nicht nur wurde der Standort des neuen Hauptbahnhofes bewusst am Schnittpunkt dreier städtischer Verkehrsachsen gewählt und die Achse der Eingangshalle in direkter Verlängerung einer zum Marktplatz führenden Hauptstraße verlegt, sondern auch der östliche Seitenausgang vermittelte die ankommenden Fernreisenden (vorwiegend Kurgäste) direkt und intentional auf eine Hauptverkehrsachse in Richtung der Kurbäder. Die städtische Zirkulation und die Zirkulation der Reisenden innerhalb des Bahnhofsgebäudes standen somit in den Verkehrsneubauten des frühen 20. Jahrhunderts noch stärker als zuvor in einem unmittelbaren Zusammenhang. Der Bahnhof wurde noch deutlicher zum Transitbau, die sich darin befindlichen Wartesäle reziprok zu Orten einer von der linearen Bewegung abgesonderten Zone.

Doch auch wenn aus baulich-operativer Betrachtung die Zirkulation gegenüber dem stationären Warten an Bedeutung gewann, wäre die Schlussfolgerung eines sofortigen Bruchs der Wartepraxis nach Eröffnung des Bahnhofes Wiesbaden zweifelsohne ein Trugschluss. Der Bau neuer Empfangsgebäude mit direktem Gleiszugang bewirkte keine unmittelbare Veränderung der Nutzungspraxis, sondern vielmehr läutete er eine inkrementelle Veränderung ein. Das etablierte, klassengetrennte Warten im Saal mit frühzeitigem Erscheinen am Bahnhof existierte weiterhin und wurde erst in der Zwischenkriegszeit allmählich von einer zunehmend modernen Praxis des zeiteffizienten Direktzugangs ohne vorherigen Aufenthalt in den Sälen abgelöst.

Aus soziologischer Sicht betrachtet führte die Einführung des `klassenlosen ২ Querbahnsteiges jedoch bereits seit seiner Installation wieder unmittelbar zu einer stärkeren Durchmischung bzw. potentiellen Begegnung der Reisenden. Die Reisenden betraten den Bahnhof nicht - wie mancherorts im 19. Jahrhundert üblich - durch unterschiedliche, nach Wagenklassen getrennte Eingänge, sondern betraten ihn gemeinsam bzw. 'wandelten` gemeinsam über den Querbahnsteig. Nur die Wartesäle vermochten das einzig nach Klassen getrennte Raumprogramm darzustellen. Sobald aber die Passagiere aus den Wartesälen auf den Querbahnsteig traten, waren die räumlichen Klassentrennungen der Säle aufgehoben. Der Querbahnsteig, der sich im Typus des großstädtischen Kopfbahnhofs zur Standardlösung entwickelte, kann somit sogar als eine Art der Redemokratisierung der Eisenbahnreise aufgefasst werden. Wohl nirgends sonst war die soziokulturelle Heterogenität der Eisenbahnreise stärker sichtbar, Begegnungen leichter realisierbar, als in diesen `Sälen der verlorenen Schritteく.

\subsubsection{Stuttgart (1922)}

Als ein zweites Beispiel der sich im frühen 20. Jahrhundert veränderten inneren Wegeführung mit direkter Auswirkung auf das Phänomen des systemischen Wartens wird der Neubau des Stuttgarter Hauptbahnhofes von Friedrich Schoeler und Paul Bonatz 
Abbildung 45: Grundriss des Stuttgarter Hauptbahnhofs im Jahr 1943.

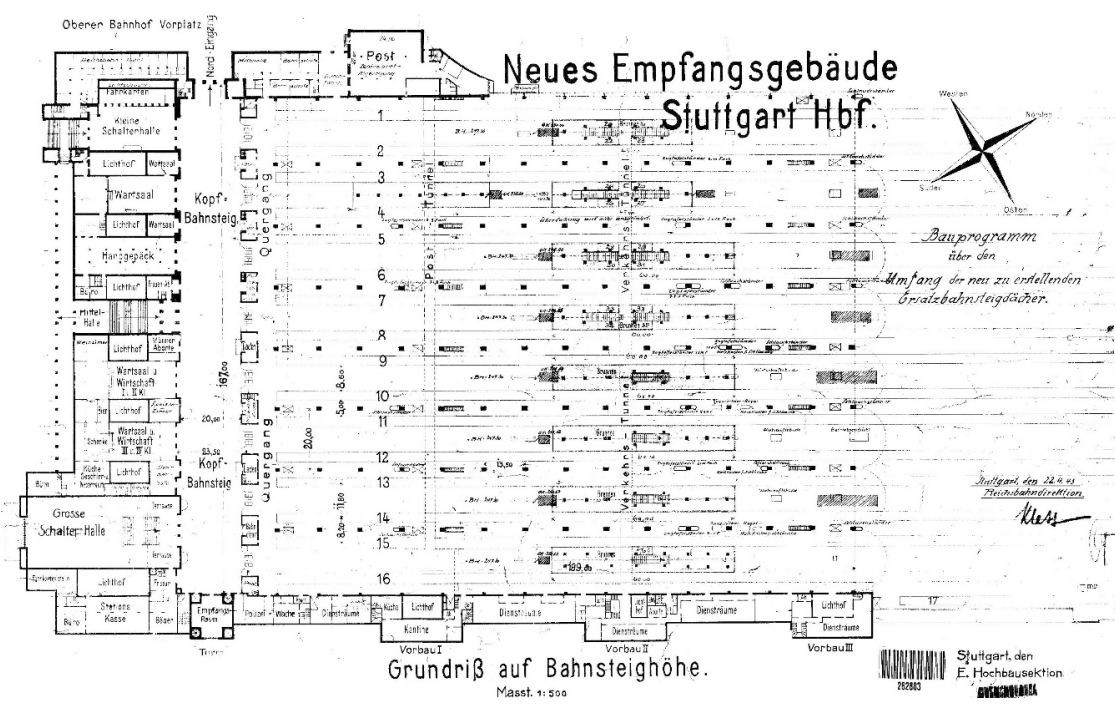

Quelle: Landesarchiv Baden-Württemberg, Abt. Staatsarchiv Ludwigsburg Karlsruhe, K 412 IV DO 10888.

genauer betrachtet. Er soll deshalb herausgegriffen werden, weil er aus Sicht der Architekturgeschichte als derjenige Bau unter den Bahnhofsbauen der Zwischenkriegszeit gilt, der »nicht nur der anerkannteste Bau gewesen sein dürfte ${ }^{60}$, sondern auch als wichtiges Vorbild für eine Reihe weiterer Neu- und Umbauten diente. Somit kann das wartebezogene Raumprogramm des Stuttgarter Bahnhofs durchaus als richtungsweisend charakterisiert werden.

Der Entwurfswettbewerb fand noch vor dem Ersten Weltkrieg statt. Die Wettbewerbsgewinner Friedrich Eugen Schoeler und Paul Bonatz konnten den Bau jedoch erst 1922 (Bauteil 1 mit 9 Gleisen) bzw. 1928 (Fertigstellung des zweiten Bauteils) unter dem deutlichen Einfluss der Architekturbewegung des >Neuen Bauens $<$ vollenden. Wichtiges Charakteristikum der nationalen und internationalen Strahlkraft des Stuttgarter Bahnhofs, der zu einem ikonischen Verkehrsbau der Moderne werden sollte, war neben der funktionalistischen Grundrissgestaltung und der reduziert-wuchtigen Fassadengestaltung samt großem Uhrenturm wiederum die Einrichtung eines Querbahnsteiges, der "als architektonisch ansprechender Raum im Kern des Gebäudes ${ }^{61}$ lag. Dieser sollte im Sinne eines zweckmäßigen Verkehrsbaus direkt und ohne ein Durchschreiten der Wartesäle über drei stadtseitige Zugänge erreicht werden. Hier angekommen, konnten die Reisenden die Züge über Zungenbahnsteige unmittelbar besteigen oder sich in die angrenzenden Warteräume begeben. Die Einrichtung der 167m langen Zirkulationszone allein war jedoch nicht die entscheidende Neuheit, die hier im Zentrum des Interesses

60 Kubinszky, Bahnhöfe Europas, 141.

61 Ebd., 143. 
steht. So wurden im Grunde jeglicher neuangelegten Kopfbahnhöfe der Zeit mit Querbahnsteigen und direkter Wegeführung von der Stadt zu den Bahnsteigen ausgeführt, wobei der Monumentalbau des Leipziger Hauptbahnhofes (1915 fertiggestellt) in dieser Beziehung zweifelsohne den Gipfel der Entwicklung markierte. Zudem entsprach auch die Einrichtung von Wartesälen am Querbahnsteig dem gängigen Muster jener Zeit. Wie am Wiesbadener Beispiel gezeigt, wurden in den deutschen Neubauten nach 1900, trotz der gewachsenen Rolle des Querbahnsteiges, weiterhin auch Wartesäle eingerichtet. Diese mussten jedoch nicht mehr obligatorisch passiert werden, sondern stellten optionale Aufenthaltszonen dar. Der Stuttgarter Hauptbahnhof entspricht also grundsätzlich diesem Schema. Er sticht jedoch in einem Punkt heraus, denn statt wie zuvor in Leipzig noch riesige, vom Querbahnsteig abzweigende Wartesäle einzurichten, haben sie im Neubau von Schoeler und Bonatz erstmals "nicht mehr die wichtige Rolle«. ${ }^{62}$ Sie konnten (oder sollten) nicht mehr alle Reisende aufnehmen.

Der neue Stuttgarter Hauptbahnhof verfügte nach wie vor über drei Wartesäle (jeweils einen für die I. und II. Klasse, die III. und IV. Klasse sowie einen separaten Wartesaal für den Nahverkehr), doch ihre Fläche war im Verhältnis zum Raumprogramm des Querbahnsteigs, der Schalterhallen und der restlichen Einrichtungen erstaunlich gering. Wenngleich aus Sicht der, in der Grundrissgestaltung eingeschriebenen Nutzungsvorstellungen an der Tradition eines würdevollen Wartens in Sälen mit angeschlossener Gastronomie festgehalten wurde, war der Modus des Wartens in diesem Bahnhof der Klassischen Moderne also gleichwohl durch eine deutliche Flächenreduktion gegenüber jüngeren Bauten vor dem Ersten Weltkrieg gekennzeichnet. Zudem wurde die bereits in Wiesbaden erkennbare funktionelle Konkurrenz des Querbahnsteiges gegenüber den Wartesälen in Stuttgart nochmals verstärkt. So zeigte der Stuttgarter Bahnhof nicht nur eine deutliche quantitative Vergrößerung der Zirkulationsfläche gegenüber den Wartezonen, sondern mit Ladengeschäften auf dem Querbahnsteig auch eine qualitative Veränderung, welche die Reisende zusätzlich auf die Fläche des Querbahnsteigs `zog‘. Die Rolle des stationären Wartens hat sich mit Blick auf die Grundrissgestaltung weiter in Richtung der Marginalisierung, der Umgehung bzw. in Richtung einer Verlagerung auf die Zirkulationsflächen verändert. Das stationäre Warten mit dem langen präparatorischen Aufenthalts vor Abfahrt eines Zuges hat deutlich an Bedeutung verloren.

Die Tendenz der Verkleinerung der Wartezonen verstetigte sich auch mit Blick auf das Raumprogramm bei den großstädtischen Bahnhofsneubauten der darauffolgenden Jahre. Die Bahnhöfe von Düsseldorf (1934), Duisburg (1934) und Oberhausen (1935), die ihre Inspiration und Referenz offenkundig im Stuttgarter Hauptbahnhof fanden, zeigten, dass die Bedeutung der vormals riesigen Wartesäle auch innerhalb des Raumprogramms von Durchgangsbahnhöfen zurück ging. Diese drei Bahnhöfe zählen zu den wichtigsten der insgesamt vergleichsweise wenigen neuen Großstadtbahnhöfe, die bis zum Ausbruch des Zweiten Weltkrieges vollendet wurden. Zum einen waren die allermeisten Orte bereits mit Anlagen ausgestattet, zum anderen zeigte die gewachsene Konkurrenz der neuen Verkehrsträgers Automobil und Omnibus seine Wirkung. Zwar 
blieb die Bahn in der Zwischenkriegszeit trotz der Zunahme des motorisierten Verkehrs mit der zehnfachen Menge transportierter Personen auf der Schiene gegenüber der Straße noch immer das dominierende Verkehrsmittel, ${ }^{63}$ doch spätestens seit den 1930er Jahren wurde der Bahnhofsbau vom Autobahnbau abgelöst, an dem sich auch deutsche Eisenbahnbeamte beteiligten. ${ }^{64}$

Zum Ende der einhundertjährigen Längsschnittbetrachtung dieser Arbeit soll nun noch auf die Entwicklung des Bahnhofsbaus der frühen 1930er Jahre eingegangen werden. Dazu wird der Oberhausener Hauptbahnhof als exemplarischer Großstadtbahnhof jener Zeit herausgegriffen, im dem das Argument einer Marginalisierung des stationären Wartens seinen Abschluss findet.

\subsubsection{Oberhausen (1935)}

Die Industriestadt Oberhausen war im späten 19. Jahrhundert zum wichtigsten Eisenbahnknotenpunkt im Ruhrgebiet gewachsen. Als Ende 1929 eine Eingemeindung zweier umliegender Kommunen die Einwohnerzahl auf fast 200.000 Einwohner verdoppelte, wünschte die Stadt einen repräsentativen Neubau, der dem nun großstädtischen Anspruch genügen sollte. ${ }^{65}$ Der Architekt, Reichsbahnoberrat Karl Hermann, entwarf für Oberhausen einen sachlich-funktionalen Backsteinbau, der sich gestalterisch und in Bezug auf die Massengliederung am Stuttgarter Hauptbahnhof orientierte und mit seinem prägnanten Uhrenturm als repräsentativer Verkehrsbau der Klassischen Moderne gilt. Für die Grundrissbildung verfolgte Hermann im typischen Duktus des prozessorientierten Dogmas das Ziel, »daß sich glatte Verkehrseinrichtungen, leichtes und schnelles Zurechtfinden und möglichst kurze Wege ergaben. ${ }^{66}$ Zudem orientierte sich Hermann offenbar an Wulffs 1882 veröffentlichen Maximen eines >baulichen Organismus<. So war für Hermann bezüglich Gliederung und Aufbau des Baukörpers der Grundsatz maßgebend, "von innen nach außen, d.h. aus dem Grundriß und der Zweckbestimmung der einzelnen Bauteile organisch das Äußere zu gestalten. « ${ }^{67}$

Wichtiger aber als die historische Referenz zu Vorgängerkonzeptionen des späten 19. Jahrhunderts ist hierbei, dass innerhalb der Umsetzung dieser Zielstellung der Bedeutungsverlust des stationären Aufenthalts überdeutlich wird. So diagnostizierte der Architekturhistoriker Mihály Kubinszky mit Blick auf diesen Bahnhof ganz und gar ein »Verschwinden der Warteräume«, die in ihrer Grundfläche »nicht einmal mehr ein Viertel der Vorhalle ${ }^{68}$ einnahmen. Zwar ist dem Befund des völligen Verschwindens entgegenzutreten - es wurden immerhin noch zwei nach Klassen getrennte Wartesäle

Vgl. Christoph Maria Merki, Der holprige Siegeszug des Automobils 1895-1930: Zur Motorisierung des Strassenverkehrs in Frankreich, Deutschland und der Schweiz (Wien: Böhlau, 2002), 106.

64 Vgl. Geisthövel, Knoch, und Cottwaldt, »Der Bahnhof«, 22.

65 Vgl. Heinz Reif, »Die verspätete Stadt Oberhausen: Stadtplanung, Stadtentwicklung und Bodennutzungsinteressen 1846-1929«, Geschichte im Westen, Nr. 2 (1986): 20. Hermann, »Das Neue Bahnhof-Empfangsgebäude in Oberhausen (Rheinl.)«, Zentralblatt der Bauverwaltung vereinigt mit Zeitschrift für Bauwesen 54, Nr. 52 (1934): 811.

67 Ebd., 815.

68 Kubinszky, Bahnhöfe Europas, 145 [Hervorhebungen des Verfassers, R.K.]. 
Abbildung 46: Grundriss des Hauptbahnhofes Oberhausen.

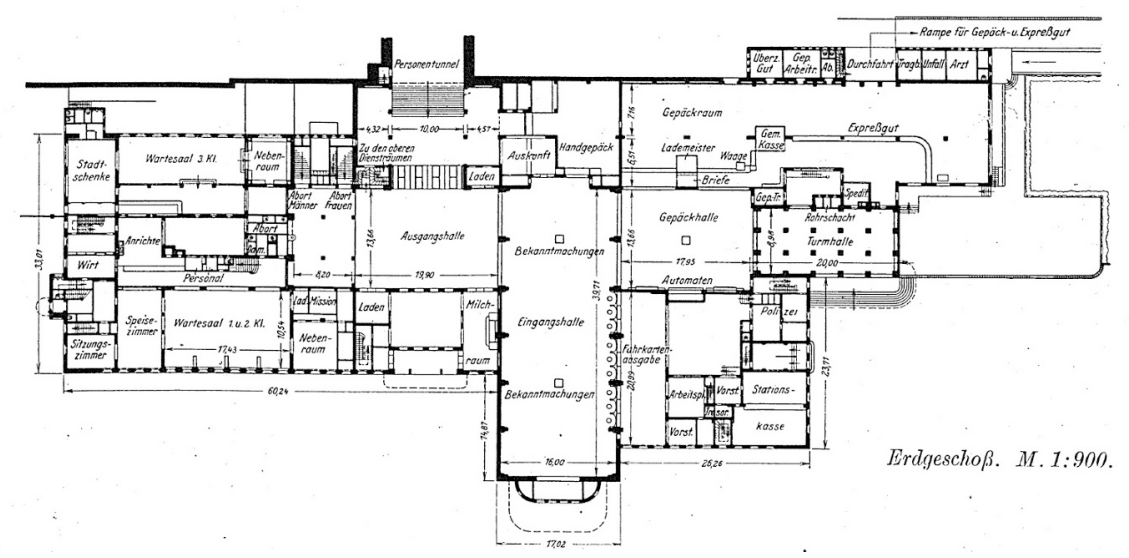

Quelle: Röttcher 1933, S. 106.

eingerichtet -, doch sie wurden an die äußerste Flanke des Empfangsgebäudes verlegt, sodass sie eher abseits vom eigentlichen Bewegungsstrom von der Stadt zum Zug lagen. In aller Deutlichkeit lässt sich die veränderte Stellung des wartebezogenen Raumprogramms (und damit der stationären Wartepraxis selbst) in einem Lageplan des Bahnhofs Oberhausen aus dem Jahr 1933 von Röttcher ablesen, in dem die kreuzungsfreien Bewegungsströme ankommender und abreisender Passagiere mit Pfeilen und Linien nachgezeichnet sind (Abbildung 47). Die Reisenden sollten nach Betreten der Schalterhalle, dem Fahrkartenerwerb und der Gepäckaufgabe im Sinne einer perfektionierten >Prozessarchitektur den direkten Weg durch die Bahnsteigsperre (Fahrkartenkontrolle) in Richtung Personentunnel und den hochgelegenen Bahnsteigen nehmen. Der Weg über die am linken Gebäuderand angelegten Wartesäle, der für die längste Zeit des 19. Jahrhunderts die übliche Verkehrspraxis darstellte, war hier gar nicht mehr vorgesehen. Zwar verfügten die Wartesäle über einfache, aber schmückende Ausstattungselemente (eichene Holzvertäfelungen, Pfeiler-, Tür- und Fensterumrahmungen aus poliertem Muschelkalk), ${ }^{69}$ doch ihre Nutzung dürfte im spezifischen Fall dieses Empfangsgebäudes in Seitentieflage aufgrund der weiten Wege zum Zug und fehlender Sichtbeziehungen zum Gleis ohnehin bereits stark abgenommen haben. ${ }^{70}$

Die Reisepraxis eines verlängerten Aufenthalts in den Wartesälen scheint aus Sicht der Planung spätestens in den frühen 1930er Jahren zum randständigen Phänomen geworden zu sein. Die vorhandenen Warteräume hätten keinesfalls mehr alle Reisenden

69 Zwar stammten die Entwurfspläne noch aus der Zeit der späten Weimarer Republik, die Ausführung Anfang der 1930er Jahre stand jedoch schon deutlich im Zeichen des aufstrebenden Nationalsozialismus, so legte Hermann etwa darauf Wert, »nur einheimische deutsche Baustoffe zu verwenden. « Hermann, »Das Neue Bahnhof-Empfangsgebäude in Oberhausen (Rheinl.)«, 815. Zur Rekapitulation der von Seiten der Reisenden stark kritisierten, fehlenden Sichtbeziehungen in diesem Typus sei in diesem Zusammenhang nochmals auf die Reaktionen nach dem Bau des Hannoveraner Hauptbahnhofes verwiesen (Kap. 8.1.1). 
Abbildung 47: Lageplan des Hauptbahnhofes Oberhausen.

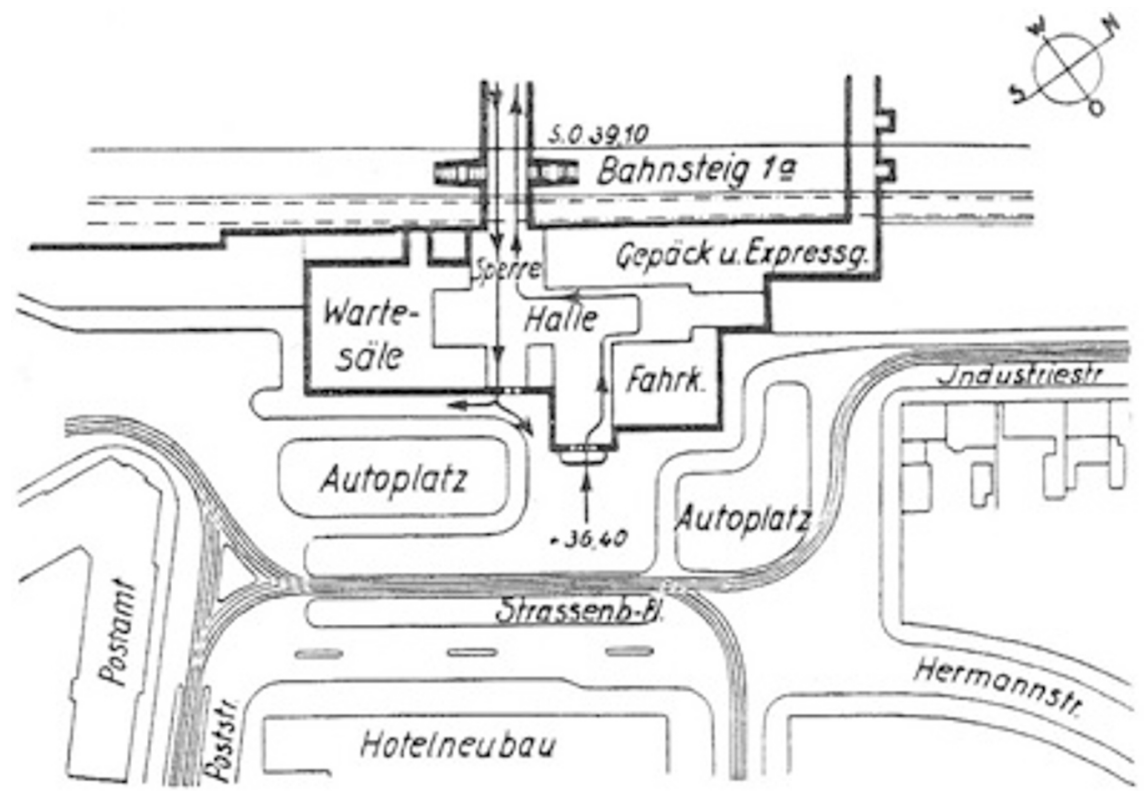

Quelle: Röttcher 1933, S. 106.

der Züge aufnehmen können. Es ist anzunehmen, dass überwiegend nur noch Reisende im Fernverkehr einen Abstecher in die Wartesäle machten, wohingegen das Gros der Reisenden die Praxis eines längeren Aufenthalts vor Abfahrt umging. Exemplarisch für diese Entwicklung ist, dass in Oberhausen dem Wartesaal für die dritte Klasse bereits in der Ursprungsplanung eine `Stadtschenke angeschlossen war, die sich offenbar eher dem Stadtpublikum als dem Reisepublikum widmete.

\subsection{Rezeptionsgeschichte (1900-1935)}

Abschließend sollen auch für die vierte Phase der Entwicklung von Bahnhofsbauten die baulich-operativen Befunde durch eine Auswahl literarischer Niederschläge zum (verkehrlichen) Warten ergänzt werden. Die folgende Auswahl stellt die relevantesten Niederschläge vor, die sich aus der Sichtung eines umfangreichen (deutschsprachigen) Literaturkorpus rekrutierten. Angesichts der Fülle von literarischen Niederschlägen, die sich im Rahmen der Strömungen des Naturalismus, Realismus oder Expressionismus zwischen 1900 und 1930 dem Eisenbahnmotiv stärker als je zuvor widmeten, kann hier wiederum kein Anspruch auf Vollständigkeit bestehen. Das Kriterium der Auswahl bestand dabei vielmehr darin, Aussagen zu einer übergeordneten Rekonstruktion der Warteerfahrung zwischen 1900-1930 treffen zu können. 


\subsubsection{Lyrik}

Nachdem die in Deutschland gut zwei Jahrzehnte währende Phase des poetischen Naturalismus um $1900 \mathrm{zu}$ erliegen kam, formierte sich kurz vor Ausbruch des Ersten Weltkrieges mit dem >Nyland-Kreis eine neue Strömung der lyrischen Technikeuphorie. Wenngleich diese Phase aus Sicht der an den Wechselwirkungen zwischen Mensch und Technik interessierten Literaturwissenschaft als unreflektiert, kritiklos und bisweilen naiv angesehen wurde,$^{71}$ findet sich gleichwohl in einem Gedicht des $>$ Nyland-Kreises eine explizite Erwähnung des verkehrlichen Wartens. Das 1912 erschienene Gedicht Frühe im Bahnhofe von Wilhelm Vershofen (1878-1960) schwelgt heroisierend in der weltlichen Überlegenheit menschengeschaffener Dampfkraft gegenüber der Natur.

»Schlaft, Götter! Schlaft eure ewige Lüge!

Wir wachen! Wir Menschen! - Krafterfüllt

Atmen die Weltenstürmer, die Züge,

Warte ich selber, dampfumhüllt.

$(\ldots) \ll^{72}$

Wie bereits bei Liliencron (1890er Jahre) - wenngleich weniger realitätsnah - erfährt sich auch hier das lyrische Ich im Zustand eines Zwischenstadiums. Zwar steht der zur kraftvollen Schönheit verklärte Technikoptimismus im weiteren Verlauf des Gedichtes klar im Zentrum der Beobachtung, doch Vershofen erhebt das Warten in die Funktion einer katalytischen Qualität und Vorfreude, um endlich (am Ende des Gedichts) >funkelnd mit goldenen Maschinen davon zu rauschen.

Noch wesentlich deutlicher wird der Einbezug des Wartens in die lyrische Technikeuphorie in einem kurze Zeit später veröffentlichten Gedicht von Joseph Winkler (18811966). Er galt als Führungsfigur und stärkste poetische Kraft des `Nyland-Kreises`, der seine Bezeichnung nach Winklers Anwesen >Nyland in Westfalen erhielt. In seiner 1912 erschienenen Eisernen Sonette findet das verkehrliche Warten eine kurze Erwähnung. In futuristischer Manier feiert das Sonett den Rausch der Geschwindigkeit und imaginiert dazu die Fahrt mit einem Zug und den anschließenden Flug mit einem Zeppelin. Kurz vor dem fast unbemerkten inhaltlichen Umstieg von der Bahn auf das Luftschiff endet das zweite Sonett mit folgender Passage:

$»(\ldots)$

Wie Schemen sind wir, die im Wind vergehn,

Abglanz des Lebens, Samen, Flug und Ferne,

Schon andere wartend an den Steigen stehn,

Und wie so tief herauf wir rückwärts sehn,

Wild strudelnd hinten steigen tausend Sterne ...

Wer will des Daseins Göttlichkeit verstehn?

(...) $\ll^{73}$

71 Mahr, Eisenbahnen in der deutschen Dichtung, 240.

72 Wilhelm Vershofen, »Frühe im Bahnhof«, Quadriga, Nr. 2 (1912): 67 [Hervorhebung des Verfassers, R.K.].

Josef Winckler, »Eiserne Sonette«, Quadriga, Nr. 3 (1912): 107f. [Hervorhebung des Verfassers, R.K.]. 
Im Rahmen der vom lyrischen Ich wahrgenommenen Raumdurchquerung werden aus dem Zugfenster wartende Passagiere beobachtet, die bereits an den Bahnsteigen stehen. Ihr gespanntes Warten repräsentiert dabei die kollektive Kraft, die der Geschwindigkeit der modernen Verkehrsmittel innewohnt und offenbar immer größere Menschenmengen in ihren Bann zieht. Das Warten wurde durch Winkler nicht als negative Alltagspraxis, sondern als freudige, aufgeregte Erwartung der Mitfahrt und Teilhabe an Geschwindigkeit und Raumüberwindung inszeniert. Es wird hier innerhalb der Technikbegeisterung, ähnlich der eines Vershofen und Winkler, nicht nur explizit als Mobilitätspraxis erwähnt, sondern es steht zudem wieder in der Tradition einer noch unterbewusst positiven Warteerfahrung, die bereits für die Pionierzeit der Eisenbahn prägend war (siehe Hans-Christian Andersen, Kap. 6.3.3). Mit anderen Worten: Warten verstärkt hier die Vorfreude auf die Geschwindigkeitserfahrung.

Einen weiteren Einblick in die Rezeption des Wartens jener Zeit gewährt Franz Werfel (1890-1945). 1890 in Prag geboren, gilt der Schriftsteller jüdisch-deutschböhmischer Herkunft als wichtiger Autor von Erzählwerken und Theaterstücken und als einer der bedeutendsten Vertreter des lyrischen Expressionismus. In seinem wahrscheinlich aus den 1920er Jahren stammenden Gedicht Im Wartesaal erfährt das (verkehrliche) Warten eine bis zu diesem Zeitpunkt unbekannt explizite Bearbeitung.

»Wir warten alle allzumal

In einem kalten Wartesaal

Auf den Personenzug des Todes.

Seht ihr draußen die bunten Lampen lohn?

Die Engel schweben mit Sternen

Die Schaffner mit Laternen

Im Nieselregen auf der Station.

Bald hören wir im Wartesaal

Auf schrillen plötzlich das Signal.

Im Eisenofen kohlt kein Brand.

Das Licht starrt dumpf und feucht die Wand.

Ein Wartesaal ist keine Wohnung.

Auf harten Bänken hockend ringsherum

Mit Lippen zugepreßten

Und haßgeschärften Gesten

Bewachen alle ihr Gepäck. Warum?

Im Regen vor dem Wartesaal

Vermehrt sich der Laternen Zahl.

Der Ein' sein Bündel arm umkrallt.

Des Andern Schnappsack ist uralt.

Suitcase und Pelz und Plaid gehört dem Dritten.

Doch alle bitter hüten ihren Schatz,

Bereit, schon vorzupfeilen

Mit Stößen, Püffen, Keilen, 
Als fand' nicht jedermann im Zuge Platz.

Im Regen vor dem Wartesaal

Erwacht ein Läuten, fern und fahl.

So hebt die Augen doch und schaut,

Reicht, Leute einen Blick euch traut,

Geholt aus der Gemeinschaft Tiefen.

Denn mehr als das, was trennend an euch zehrt,

Seid ihr durch Warte-Stunden

Geheim in Gott verbunden.

Und ist dies nicht ein Liebeslächeln wert?

Die Türe knarrt im Wartesaal,

Einströmt die Nacht und das Signal $-\ll^{74}$

Entgegen der bis zu diesem Zeitpunkt eher diffusen, randständigen oder impliziten Thematisierung, erfährt das Warten hier eine klare und explizite Bearbeitung, ja das Phänomen bildet überhaupt den Kerngegenstand des Gedichts. Deutlich wird hierbei, dass das verkehrliche Warten auf das Signal des eintreffenden Personenzuges als Metapher für die Erwartung des Todes ausgerichtet ist. Trotz dieser existentialistischen Metaphorik liefert Werfel die im Rahmen der deutschsprachigen Lyrik vielleicht detaillierteste Beschreibung einer Abfahrtssituation im frühen 20. Jahrhunderts. Er beschreibt die Atmosphäre im Wartesaal als von großem Misstrauen (»Bewachen alle ihr Gepäck«), einem geringem Kommunikationsgrad (»Mit Lippen zugpressten [...] Gesten«) und notdürftigem Komfort (starres Licht, feuchte Wände, harte Bänke, keine Heizung) geprägt. Über die sozialen Schichten hinweg, scheinen sich die Reisenden im Wartesaal voller Unbehagen und angespannter Erwartung auf das Ergattern eines Sitzplatzes vorzubereiten. Trotz der geteilten Praxis des Wartens, die im Grunde eine Gemeinschaft der Wartenden bildet, scheint die Atmosphäre hier einzig und allein vom Selbstbezug geprägt zu sein. Erst der im Personenzug symbolisierte Tod würde die sozial voneinander isolierte Warte-Gemeinschaft wieder vereinen.

Werfels Metapher vom Warten als ein Warten auf den Tod erinnert damit an die fundamentalontologische Philosophie Heideggers (1927) ${ }^{75}$ sowie Samuel Becketts ikonischer Verarbeitung in 'Warten auf Godot< (1952). Wenngleich Werfels Gedicht auf die existentialistische Ebene abhebt, wird das Sprachbild des Wartens für die Leser nur

74 »edichte aus dem Nachlass - Franz Werfel«, https://www.literatisch.de/gedichte-aus-demnachlass-franz-werfel.html, zugegriffen am 12. Februar 2020.

75 Mit Freude hätte Heidegger vermutlich auch Werfels ähnlich gelagerte Cedanken zur Wartezeit rezipiert, die in seinem 1929 erschienenen Roman Barbara oder die Frömmigkeit zutage treten und auf die >Uneigentlichkeit<des Daseins abheben: »(...) in all diesem jagenden Gehabe tritt das menschliche Provisorium als faßliches Zeichen zutage, die Sinnlosigkeit, das unselige Verstoßensein und der zwangsläufig bittere Egoismus dieses Lebens. Ein Wartesaal dritter Klasse zum Beispiel im Spätherbst, wenn es draußen nieselt und in der Dämmerung hocken die Menschen auf den Bänken, ihre verbrauchten Handtaschen und die verschnürten Pakete hütend - gibt es ein treffenderes Sinnbild der Todeserwartung?« Zitiert in Guido Fuchs, In der Bahnhofsgaststätte, 174. 
sinnhaft, wenn das verkehrliche Warten tatsächlich für die Analogie einer skalten Erfahrung، herhalten konnte. Reziprok kann daher geschlossen werden, dass Werfel die Kollektiverfahrung des Wartens auf Eisenbahnen in den 1920er Jahren als eine dezidiert unangenehme, würdelose und von sozialer Isolation geprägten Grenzerfahrung ansah. Im Kontrast zu den lyrischen und literarischen Verhandlungen der vorherigen Jahrzehnte manifestiert sich mit Rückgriff auf das Gedicht Werfels der Eindruck, dass sich das verkehrliche Warten im frühen 20. Jahrhundert zu einer unbequemen, krisenhaften und möglichst zu vermeidenden Alltagserfahrung transformiert hatte.

Fred Endrikats Gedicht Briefaus dem Wartesaal ergänzt das Bild der Warteerfahrung und ihrer räumlichen Umgebung im frühen 20. Jahrhundert. Endrikat (1890-1942) liefert darin eine humoristisch-kabarettistische Rückschau auf einen Moment des gemeinsamen Wartens mit einer eng verbundenen Person und gewährt dabei einen Einblick in die >Kulinarik« der Bahnhofsgastronomie.

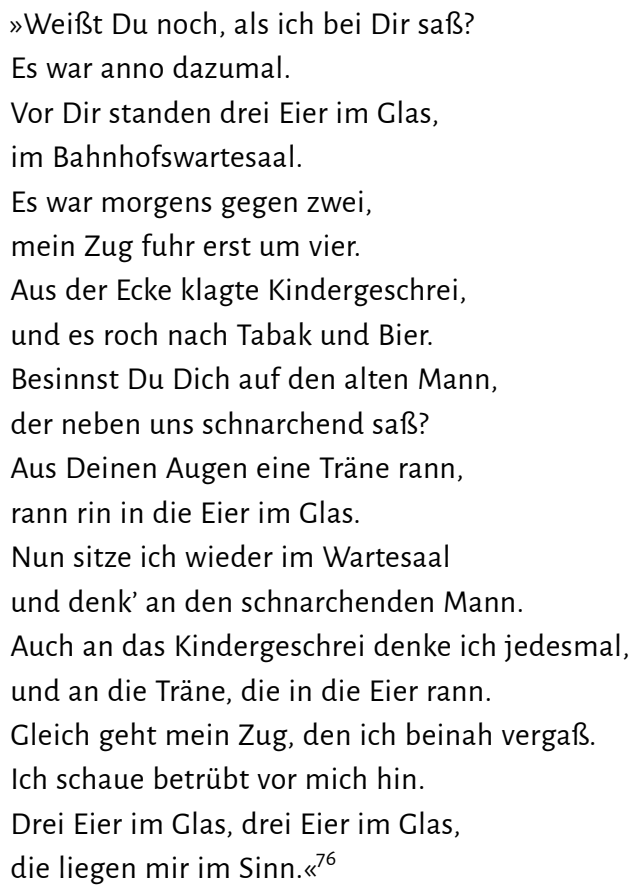

Endikats Gedicht offeriert uns nicht nur einen Blick auf eine anscheinend typische Speise im Bahnhofsrestaurant (Soleier), sondern darüber hinaus in die olfaktorische und akustische Situation während eines zweistündigen Aufenthalts im nächtlichen Bahnhof. Während einige Menschen schlafen, schnarchen und Kinder schreien ist offenbar die Gaststätte im Wartesaal auch noch um zwei Uhr morgens geöffnet. Der Wartesaal ist demnach auch bei Nacht ein lebhafter Ort, an dem geraucht und nicht zuletzt getrunken wird. Die historische Persistenz der Verbindung des Wartens mit dem Konsum von Genussmitteln zur Beruhigung, Zerstreuung oder Betäubung wird mit Endikats Gedicht abermals überdeutlich. 
Nachdem die lyrischen Niederschläge des frühen 20. Jahrhunderts eine Tendenz zur expliziteren Verhandlung des Phänomens zeigten, sollen nun eine Auswahl zeitgenössischer Werke der Prosa hinsichtlich möglicher Einblicke in das Warten zum Zeitpunkt der klassischen Moderne liefern.

\subsubsection{Prosa}

Der Schriftsteller Hans Fallada (1893-1947) zählte zu den zentralen Figuren der neusachlichen Literatur in Deutschland. Sie ist von oft einer detailliert-nüchternen Darstellung der gesellschaftlichen Realität geprägt und erhebt keinen Anspruch auf Objektivität. In seinem 1941 erstmals erschienenen Roman Damals bei uns daheim. Erfundenes, Erlebtes, Erfahrenes schildert Fallada seine Kindheits- und Jugenderfahrungen im Berlin des späten 19. Jahrhunderts. Eine Erinnerungen handelt vom Anfang einer Familienreise in die Sommerferien, die ihren Beginn am Stettiner Bahnhof in Berlin um 1900 nahm. In dieser Schilderung lassen sich für die Rekonstruktion der Warteerfahrung und Wartepraxis der Jahrhundertwende einige Elemente finden.

Fallada erinnert sich an den Stettiner Bahnhof - dem Berliner Ausfalltor in Richtung Ostseeküste - als einen "wallenden und wogenden Strudel ${ }^{77}$, in dem er und seine Familie "nur Teilchen einer wirbelnden, laufenden, scheltenden, lachenden Menge ${ }^{78}$ waren. Er vermittelt das Bild einer aufgeregten und bisweilen chaotischen Atmosphäre vor der Abfahrt, die sich aus der großen Menschenmenge und den vielen Gepäckstücken ergab. Mitten im Gewühl ist Falladas Familie, die bei Ankunft am Bahnhof verzweifelt versucht einen Gepäckträger zu finden und dabei Probleme mit einem Schutzmann bekommt, der sie im Zustand des Wartens als Hindernis für den Verkehrsfluss am Bahnhof betrachtet. Jenseits der Schilderungen vielfacher organisatorischer Schwierigkeiten wird hier offensichtlich, dass nachdem die Familie um den jungen Fallada die Empfangshalle erreichte und der Familienvater ihre Gepäckstücke endlich aufgegeben hatte, alle Figuren direkt auf den Kopfbahnsteig zusteuern, ohne einen Umweg über die vorhandenen Wartesäle zu nehmen.

»Der Marsch zum Bahnsteig, zum Zuge beginnt. »Bahnsteig sieben!« ruft Vater noch der Mutter zu. (...) Es ist aber unmöglich, in geschlossener Formation zu marschieren. Immerzu drängen sich Leute dazwischen. Wir sammeln uns erst wieder am Häuschen des Billettknipsers. « ${ }^{79}$

Die Wegeführung der lässt sich Familie lückenlos rekonstruieren: Nach Eintritt in die Empfangshalle gingen die Reisenden in Falladas Geschichte geradewegs in die Gleishalle des Stettiner Bahnhofs und vor dort aus zum Zug. Der Bahnhof ist als Kopfbahnhof mit kopfseitiger Erschließung konzipiert, an dessen Seitenflügeln große Wartesäle mit Gaststätten und Büffets eingerichtet waren. Theoretisch wäre es der Familie also durchaus möglich gewesen, sich zunächst in den Sälen niederzulassen, doch von den 
Wartesälen des Bahnhofs ist in Falladas Schilderungen an keiner Stelle die Rede. Stattdessen ging ihr Weg in direkter Linie von der Eingangshalle in Richtung der vor den Zungenbahnsteigen liegenden Bahnsteigsperre. Die einzige stationäre Wartezeit, die sie auf dem direkten Weg zum Zug absolvierten, erfolgte nicht wie sonst üblich der Aufenthalt in den Wartesälen, sondern die Familie wartete für einen Moment auf den Stufen zur leicht erhöht liegend Gleishalle:

»Wir drängen uns unter Mutters Kommando an die Treppe, die zu den Bahnsteigen hinaufführt. Jeder von uns - außer Ede, der seinen Kopf durchgesetzt hat - trägt mindestens zwei Handgepäckstücke, Christa und Mutter sogar drei oder vier. Am Fuß der Treppe angekommen, wird alles abgesetzt, eine Bastion gebildet und sofort wieder eingerissen, denn schon wieder werden wir als Verkehrshindernis beschimpft. Ich klettere zwei oder drei Stufen hoch und halte mich an dem Geländer fest. So erhöht sehe ich auf die brausende Halle hinab, auf dieses endlose, immerfort wechselnde Cewühl von Köpfen. (...). $\ll^{80}$

Falladas Schilderung, die in der Sprache einer Militärexpedition verfasst ist, gibt zweifellos eine punktuelle und subjektive Erfahrung der Eisenbahnreise wieder. Dennoch lässt die direkte Wegführung darauf schließen, dass der lange, stationäre Aufenthalt in den Wartesälen um 1900 nicht mehr den Normalfall bildete. Falladas Erinnerungen reihen sich damit ganz in die Tendenz zur Marginalisierung des stationären Wartens ein, ermöglicht durch die bauliche Disposition eines direkten Gleiszuganges aus der Eingangshalle. Diese schien demnach auch - zumindest im Bautyps des Kopfbahnhofes die Nutzungspraxis in Richtung einer möglichst großen Unmittelbarkeit und damit einer möglichst verkürzten Wartezeit zu verschieben. Wo es möglich war, warteten die Reisenden - wie auch die Familie Fallada - vorzugsweise nicht mehr in angrenzenden Wartesälen, sondern - wie in England - im Verkehrsmittel selbst.

Das seit der Jahrhundertwende zunehmend thematisierte Motiv der Eisenbahnen als Schlüssel zum Verständnis der sozialen, emotionalen und existentiellen Bedingungen des Menschen beschäftigte auch den österreichischen Schriftsteller Alfred Polgar (1873-1914). In seiner Erzählung Abschied aufdem Bahnsteig (o.J.) verweist er auf die paradoxe Besonderheit der letzten Minuten des Abschieds, die trotz ihrer eigentlich absolut betrachtet kurzen Zeitdauer eine bizarre Zeit- und Selbstwahrnehmung bedingen würde. Polgar skizziert die paradoxen Mechanismen, die während des Abschieds zweier sich nahestehender Menschen greifen:

»(...) Diese letzten Minuten, bevor der Zug sich in Bewegung setzt, haben ein Gift in sich, das auch die lebendigsten Interessen- und Gefühlsbeziehungen zwischen zwei Menschen (zwischen dem, der wegreist und dem anderen, der dableibt) in einer Art von Krampf erstarren läßt. Erst treten Lähmungserscheinungen des Gehirns und der Zunge ein. Alle Quellen des Cesprächs scheinen wie festgefroren. (...) In solchen endlosen Abschiedsminuten benimmt sich auch der Unbefangene gezwungen, hat selbst die Wahrheit etwas Unechtes, nämlich einen Beigeschmack von leerer Formalität. (...) 
Endlich setzt sich der Zug doch in Bewegung (...) und im selben Augenblick ist die fatale Starre gelockert, treten tausend Dinge, an die noch hätte erinnert werden müssen, ins Cedächtnis, drängen tausend Worte, die noch zu sagen gewesen wären, auf die Lippen. Und das Gefühl der Erleichterung, daß der Abschied überstanden ist, wird sofort zugedeckt von dem Gefühl der Bangigkeit, die jeder Abschied von einem geliebten Menschen mit sich bringt. Warum sind die letzten Minuten auf dem Bahnsteig so quälend und gequält? Weils wir uns ihres besonderen Anspruchs auf Gefühl und Gefühlsdauer bewußt werden (...) und beide glaubhaft doch nur aus dem Unterbewußten zu produzieren vermögen. $«^{81}$

Polgars Versuch, die Besonderheit dieser Form des Wartens zu beleuchten, ufern in der Erkenntnis einer sich einstellenden Verkrampfung, einer Sprachlosigkeit und Inhaltsleere. Das Warten kurz vor Abfahrt erscheint hier als quälender und bisweilen an Peinlichkeit grenzender Zustand, der durch die endliche Abfahrt erlöst wird. Diese Erlösung erscheint jedoch zugleich nur kurzfristig zu sein, denn bald darauf würde bei den Betroffenen eine andersartige Leere eintreten. Polgars Interpretation des Wartens als einer `leeren Formalität verstärkt den übergeordneten Eindruck einer sich im frühen 20. Jahrhundert formierenden Sichtweise auf das Warten als einem psychisch fordernden und irritierenden Alltagsphänomen. Wartesituationen, besonders solche im Zusammenhang mit einem Abschied, würden wie kaum eine andere Situation des menschlichen Lebens die sonstige Souveränität und Kontrolle außer Kraft setzen und stattdessen irritierende Fragen über die eigene Rolle und Sinnhaftigkeit evozieren.

Einen raren Hinweis auf die konkrete Tätigkeit wartender Reisender in Deutschland liefert ferner eine humoristische Reflektion über das Reiseverhalten, die 1938 im nationalsozialistischen Satireblatt $>$ Brennessel ${ }^{82}$ erschien. Der unbekannt gebliebene Autor bekennt darin einleitend: »Ich liebe Wartesäle«. Zwar seien sie »scheußlich, unmodern, muffig, unerfreulich, laut. Aber sie haben etwas von dem Zauber, der um das Reisen ist. $\ll^{83}$ In Ermangelung der Möglichkeit selbst zu Reisen nutzt der Autor zumindest das transitorische Flair des Wartesaals für eine kostengünstige Art der Reiseerfahrung und wird in der Folge zum Beobachter der ihn umgebenden Tätigkeiten.

»Die meisten Leute schreiben Ansichtskarten. Das ist eine der wichtigsten Tätigkeiten der Menschen im Wartesaal. Man kann das verstehen. Die Leute sind in einer frem-

81 Alfred Polgar, »Abschied auf dem Bahnsteig«, in Kleine Schriften, hg. von Marcel Reich-Ranicki, Bd. 3: Irrlicht (Hamburg: Rowohlt, 1984), 163 [Hervorhebung des Verfassers, R.K.].

82 Die >Brennessek < wurde ab 1931 als Gegenstück zum wesentlich erfolgreicheren, linksgerichteten sSimplicissimus a aufgelegt und war in die nationalsozialistische Propagandapolitik eingebunden. Ursula E. Koch, »Die Brennessel (1931-1938) «, in Handbuch des Antisemitismus: Judenfeindschaft in Geschichte und Gegenwart, hg. von Wolfgang Benz, Bd. 6-Publikationen (Berlin: DeGruyter, 2013), 8182. Trotz dieser propagandistischen Ausrichtung lässt in der hier zitierten Reflektion über einen Wartesaal nur schwerlich eine politische Aussage erkennen, vielmehr erscheint sie als phänomenologische Beobachtung. Wenn hierin eine politische Haltung zum Ausdruck kommen mochte, dann womöglich in Cestalt des sich im Wartesaal versammelnden Volkskörpers, der in diesen Räumen auf seiner Durchreise von allen Winkeln des Reiches zusammenströmte.

83 »Wartesäle«, Die Brennessel 8, Nr. 43 (25. Oktober 1938): 506. Zudem auch abgedruckt in Fuchs, In der Bahnhofsgaststätte, $18 \mathrm{ff}$. 
den Stadt, oft genug nur für die kurze Spanne zwischen der Ankunft des einen und der Abfahrt des nächsten Zuges. Das muß festgenagelt werden, und der Poststempel ist gewissermaßen ein amtlicher Nagel. Wenn man seine Postkarten ausgeschrieben hat, löst man Kreuzworträtsel. Das ist eine schöne und beruhigende Tätigkeit, eine Tätigkeit, bei der man sich angenehm überlegen fühlt, weil man bald merkt, daß den Kreuzworträtsel-Verfassern selten etwas Neues einfällt. « ${ }^{84}$

$\mathrm{Zu}$ der bereits seit Jahrzehnten etablierten Lesepraxis gesellte sich mit dem Lösen von Kreuzworträtseln offenbar eine weitere, in den 1930er Jahren weit verbreitete Praxis des Zeitvertreibs. Während das Lösen von Rätseln dabei den Bedarf nach innerer Beruhigung der Reisenden befriedigte, erklärt sich die Beobachtung des Schreibens von Ansichtskarten aus dem Umstand, dass sich in den Wartesälen vorwiegend Durchreisende aufhalten würden.

»Die meisten Menschen kennen von den meisten Städten nur den Bahnhofswartesaal. Sie haben ein Reiseziel und müssen unterwegs umsteigen. Einige Städte sind geradezu berühmt geworden dadurch, daß man in ihnen umsteigt, Hof zum Beispiel, Korbetha oder Bebra, wer hätte noch nie in Bebra eine Tasse Kaffee oder in Hof ein paar Würstchen genossen? Aber wer kennt Korbetha und Bebra selbst? Man hat nichts von diesen Städten gesehen als ein paar Hausgiebel, die zum Wartesaalfenster hineinblickten. An solche Giebel klammert sich oft das Auge des Fremden. ${ }^{85}$

Der Wartesaal wird hier dezidiert als Transitort und oftmals als der einzige Berührungspunkt zum lokalen Umfeld beschrieben. Das Speisen im transitorischen Umfeld der Wartesäle konnte somit eine ganz eigene Erinnerungsgeografie erschaffen, die mitunter zur Kollektiverfahrung reifte. Diese transitorische Charakteristik samt nur punktueller Sichtbeziehung zum umgebenden Ort setzt sich bis in die Gegenwart hinein mittlerweile an den Großflughäfen der Welt - fort. So bieten etwa die großen Drehkreuze des globalen Luftverkehrs den Durchreisenden nur in sehr begrenztem Maße die Möglichkeit zu lokalen Bezugnahmen. An solchen >Nicht-Orten kommt der Architektur eine wichtige Rolle zu. Sie versucht - etwa bei der an regionale Bautraditionen anknüpfenden Innenraumgestaltungen der Flughäfen von Abu Dhabi oder Dubai - den Reisenden auf der Durchreise zumindest eine Anmutung ortspezifischer Informationen zu vermitteln.

Jenseits dieser seltenen positiven Konnotation des Wartens aus den 1930er Jahren, die mitunter überhaupt nur aus Sicht eines nichtreisenden Zuschauers erwachsen konnte, war die Realität des temporären Aufenthalts im ersten Drittel des 20. Jahrhunderts aber oftmals von existentiellen Bedürfnissen geprägt, für die der Wartesaal vielerorts zweckentfremdet wurde. Von ihnen weiß Joseph Roth zu berichten. Der österreichische Journalist und Schriftsteller (1894-1939) stellte während seiner Berliner Zeit Beobachtungen an, die auf die Verhältnisse und Atmosphären in den Wartesälen der Berliner Großbahnhöfe der 1920er Jahre schließen lassen, einer Zeit der politischen, wirtschaftlichen und identitären Krise Deutschlands nach dem Ersten Weltkrieg. In seinem im 
November 1920 im 12-Uhr-Blatt der Neuen Berliner Zeitung veröffentlichten Artikel Wartesaal IV. Klasse. Die Passagiere, die nicht reisen beleuchtet Roth eindrücklich, wie ein Wartesaal der vierten Klasse sich zu einem Refugium und Zufluchtsort für eine Gesellschaft entwickelt hatte, die von schwerlastenden Reparationsverpflichtungen und ökonomischen Verwerfungen gezeichnet war.

»Einmal war der Wartesaal ein Gefäß mit ewig wechselndem Inhalt. Er sog einen Strom Passagiere ein und spie ihn wieder auf die Bahnsteige aus. Er roch süßlich nach Steinkohle und Lederkoffer, nach Abenteuern. Er roch nach Welt. Heute ist er Asyl für Obdachlose. Er riecht nur mehr nach Straße, er ist nicht mehr Ouvertüre der Welt, sondern Intermezzo der Stadt. Um Mitternacht füllt er sich mit Menschen, die von Beruf heimatlos sind: Zigarrenrestesucher und Straßenmädchen und so. ${ }^{86}$

In kraftvoller und zugleich dystopischer Manier schildert Roth die sich mit den neuen Nutzern gewandelte Atmosphäre und anarchistische Szenerie dieses Wartesaals.
»(...) Der Wartesaal IV. Klasse pustet feuchte Wärme aus, wenn die Tür aufgeht. Er macht sich Luft wie jemand, der in Cefahr war zu ersticken. Im rötlichen Düster schwanken formlos verschwommen Mensch und Gegenstand. Der Rauch beißt dem Büfettschrank, den Bänken, den Koffern die Kanten ab. Er amputiert dem Kellner die Rockschöße, verschluckt die Nasen der Passagiere. Mischt einen Brei aus Klei- dung, Holz, Körper, Lichtschimmer. Die Frau am Büfett ist eingeschlafen. Unbewacht blinken Flaschen und Cläser, wölben Zigarren ihre Bäuche in rotgoldenen Livreewes- ten, verkümmern Heringe auf klebrigem Porzellan, verschrumpeln Würste sichtlich im Dunst. Man sieht das Vorwärtskriechen einer großen Verwesung. ${ }^{87}$

Roth zeichnete mit diesem dokumentarischen Zeitungsbericht ein Bild, dass keinerlei >Würde des Wartens` mehr erkennen lässt. Zwar wurde auch in den Jahrzehnten zuvor in den Sälen der unteren Wagenklassen geraucht, getrunken und die Speisen waren qualitativ kaum hochwertig, doch der Zustand der Berliner Wartesäle nach dem Ersten Weltkrieg relativiert offenbar selbst die spartanische Anmutung früherer Tage. Die Würde des Wartens scheint hier an ihrem historischen Tiefpunkt angelangt zu sein. Roth beschreibt eine Wartesaalnutzung, die in den Novembertagen des Jahres 1920 offenbar weit stärker von Nicht-Reisenden geprägt war, als von Menschen mit einem tatsächlichen Fahrtwunsch. Erklärungswürdig erscheint dabei der Umstand, dass die Wartesäle zu jener Zeit eigentlich nicht ohne ein gültiges Ticket zugänglich waren. Roth informiert in diesem Zusammenhang folglich zur subversiven Strategie der Zuflucht suchenden:

»Manchmal kommt ein Bahnpolizist mit einer weißen Armbinde und fragt, ob die Herrschaften »wirklich reisen«. Man reist nicht wirklich: Man löst nur eine Fahrkarte vierter Klasse bis zur nächsten Station, um im Wartesaal sitzen zu können. Liebespärchen kommen, Grauschädel entrüsten sich sittlich, der Wartesaal sei kein Tiergarten;

Joseph Roth, »Wartesaal IV. Klasse. Die Passagiere, die nicht reisen«, in Joseph Roth Werke, Bd. 1: Das journalistische Werk, 1915-1923 (Kiepenheuer \& Witsch, 1989), 450. 
er ist aber doch einer, Tiergartenfortsetzung im Winter. In den Winkeln, sorgsam verhüllt von einem Oberbett aus Dämmerflaum, flüstern sie Zwiesprache der Liebe. Kutscher trotten herein, blaugekittelt. Sie haben etwas Pferdehaftes, sie können, glaube ich, wenn sie wollen, jeden Augenblick wiehern. Sie schneuzen sich, es klingt wie Pferdeniesen, und sie wecken den Kellner: Einen Kümmel! Sie werfen trinkend Kopf mit Zylinder rasch hintenüber, schütteln sich, zahlen, wollen noch ein wenig in der Wärme bleiben, sie hamstern Wärme und gehen hinaus, wenn sie genug haben. ${ }^{88}$

Um auf legalem Wege in das (wärmende) Bahnsystem zu gelangen und den Bahnhof defacto als eine Art Notunterkunft nutzen zu können, behelfen sich die obdachlosen und mittellosen Personen demnach der Strategie eines Pseudo-Fahrkartenkaufs. Die Situationsbeschreibung des Berliner Wartesaals vermittelt damit auf der einen Seite, dass die Öffentlichkeit des Bahnhofes ausgenutzt und zweckentfremdet wurde, zugleich zeigt sich mit diesen Einrichtungen, die essentielle Funktion einer sozialen >Ausgleichsfläche in gesamtgesellschaftlichen Notlagen, die bis in die heutige Zeit hinein Relevanz hat. So bilden die Eingangs- und Gastronomiebereiche öffentlicher Gebäude sowie die Stationen des ÖPNV weiterhin wichtige Aufenthalts-, Kontakt- und Möglichkeitszonen für marginalisierte Gesellschaftsgruppen, die anderweitig nur erschwerte Möglichkeiten für Obdach und vor allem Teilhabe erhalten.

Der Warteraum wurde nicht nur in der Literatur und der Presse als Ort des sozialen Elends rezipiert, er wurde in diesem Sinne auch immer wieder zum Motiv der Bildenden Kunst, besonders im Bereich der Grafik.

\subsubsection{Lithografien und Zeichnungen}

Einer der schärfsten Beobachter der Zwischenkriegsgesellschaft war der Maler, Zeichner und Illustrator Hans Baluschek (1870-1935). Als Mitglied der Berliner Secession, glühender Unterstützer der Weimarer Republik und Vertreter des kritischen Realismus, verfolgte Baluschek das Ziel, mit seinen Arbeiten die großstädtischen Lebens- und Alltagsbedingungen möglichst realistisch abzubilden. Schwerpunkt seiner Arbeiten bildete dabei das Arbeitermilieu, dessen Situation er in anklagender und sozialkritischer Absicht veranschaulichte. Zusammen mit Heinrich Zille und Käthe Kollwitz wurde Baluschek zum »künstlerischen Anwalt der Sprachlosen und Ohnmächtigen « ${ }^{89}$ der Weimarer Zeit. Motivisch pflegte Baluschek dabei eine besondere Affinität zur städtischen Technosphäre und interessierte sich insbesondere für das Eisenbahnwesen. In diesem Zusammenhang entstand 1926 sein Zyklus >Volk II mit der Lithografie mit dem Titel Wartesaal IV. Klasse. Diese Lithografie bildet eines der wenigen eindrücklich künstlerischen Zeugnisse einer Wartsituation im frühen 20. Jahrhundert.

Baluschek zeigt die Situation eines dicht gefüllten Wartesaals der vierten Klasse an einem der Berliner Großbahnhöfe zur Mitte er 1920er Jahre, in dem Reisende auf die Abfahrt eines Zuges warten. Sie sitzen auf Bänken, improvisierten Sitzgelegenheiten (eigene Koffer) oder stehen im Saal mit Blickrichtung zur unmittelbar angrenzenden

88 Ebd.

89 Margrit Bröhan, Hans Baluschek: 1870-1935; Maler, Zeichner, Illustrator (Berlin: Bröhan-Museum, 2002), 86. 
Abbildung 48: Hans Baluschek: Wartesaal IV. Klasse, Zyklus »Volk«II, Nr.12 (1926).

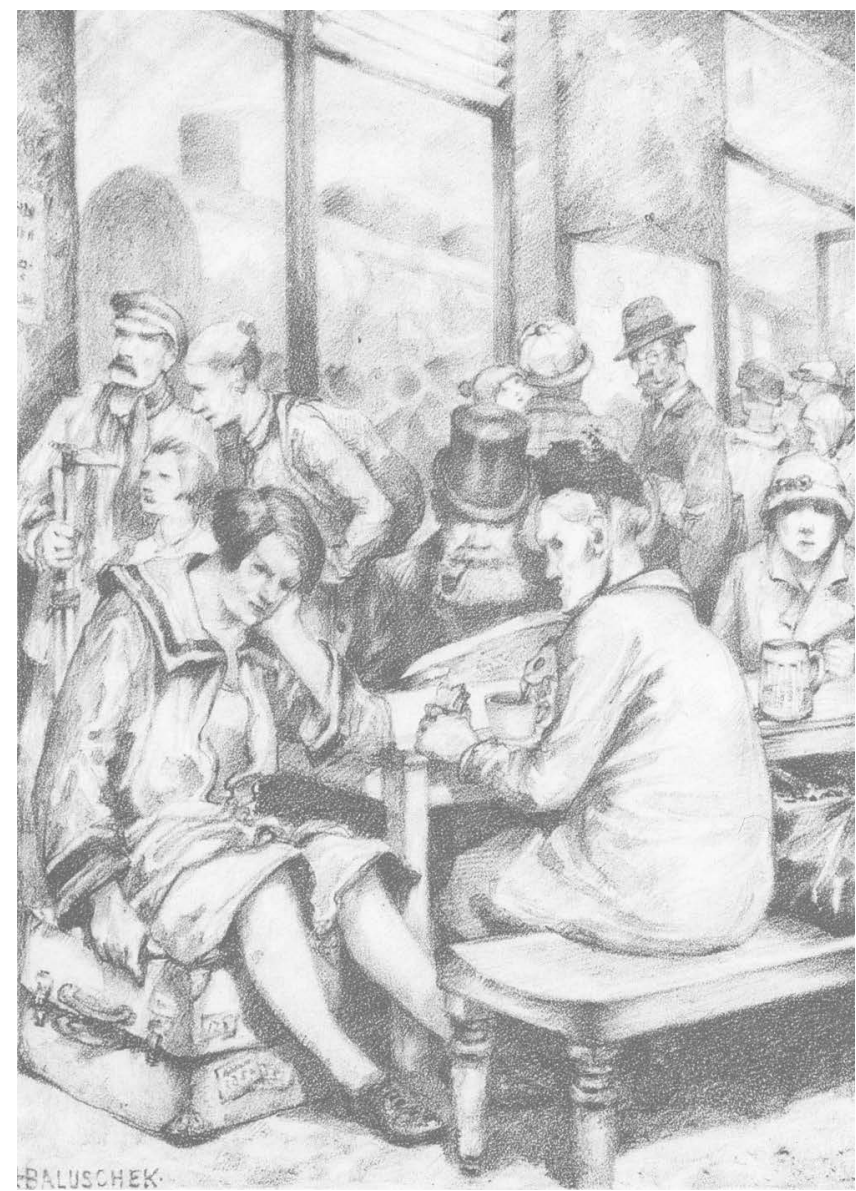

Quelle: Sammlung Bröhan-Museum Berlin.

Gleishalle und der schon bereitstehenden Lokomotive. $\mathrm{Zu}$ sehen sind Reisende unterschiedlichen Alters, Familien mit Kindern, aber auch ältere und jüngere Alleinreisende. Während die Reisegruppen im Hintergrund miteinander zu kommunizieren scheinen, sind die Personen im Vordergrund als gedankenversunken ohne Kommunikation untereinander (wahrscheinlich Alleinreisende) dargestellt. Eine junge Frau erscheint im Zustand einer träumerisch-gelangweilten Pose und stützt ihren Kopf mit der eigenen Hand. Eine andere Reisende isst mit grimmiger Miene ein Brot zu Tee, Kaffee oder Suppe. Ein abgestellter Bierkrug verrät, dass auch in diesem Saal das Warten auf Abfahrt in engem Zusammenhang mit dem Genuss alkoholischer Getränke stand und das Warten von Kritikern nicht unberechtigt als >Trinkzwang aufgefasst wurde. Der Aufenthalt an diesem Berliner Bahnhof wurde somit - typisch für den deutschen Bahnkontext - von 
einem gastronomischen Angebot flankiert, der in diesem Fall jedoch keine vollwertige Gaststätte darstellte, sondern in einem Wartesaal der vierten Klasse die Form eines Büffets oder Schanktisches eingenommen haben dürfte. Baluscheks Darstellung zeigt zudem einen älteren Mann mit Zylinder, der offenbar eine Zeitung liest und dazu eine Pfeife raucht. Baluscheks Lithografie bekräftigt mit diesem Detail die Erkenntnis, dass in deutschen (und vor allem den österreichischen) Wartesälen das Rauchen allerorten gestattet war.

Die Türen des Wartesaals zum Bahnsteig sind in Baluscheks Darstellung bereits geöffnet und es scheint sich bereits eine größere Menge Reisender auf dem Bahnsteig zu befinden. Der strenge stationäre Warteimperativ der zweiten und dritten Bahnhofsgeneration war offensichtlich aufgehoben, die Reisenden waren nicht (mehr) in den Wartesälen eingesperrt. Der Bahnsteig kann demnach ebenfalls als Aufenthaltszone genutzt werden, welcher die Sichtbeziehung zum Erwartungsobjekt gewährleistet.

Die Anmutung einer dicht gedrängten Menschenmenge wundert, angesichts der zum Zeitpunkt der Entstehung bestehenden Klassennutzung, kaum. Um 1928 nutzten bereits 83,5 Prozent aller Reisender die vierte Klasse, wohingegen nur 15,3 Prozent die 3. und lediglich 1,2 Prozent die 1. oder zweite Klasse nutzten. ${ }^{\circ}{ }^{\circ}$ Zugleich stellt die Darstellung eines der letzten Zeugnisse der vierten Wagenklasse dar, die im Oktober 1928 aufgelöst wurde (die dritte Klasse erst 1956).

Wie erwähnt, fertigte Baluschek diese Lithografie im Rahmen des Zyklus >Volkı an, dessen Ziel es war, ein >Bilderbuch des sozialen Lebens $<$ zu verfassen. Die Zeichnungen des Zyklus sind jeweils "selbstständige in sich abgeschlossene Zeichnungen, die untereinander in keinem anderen Zusammenhang stehen, als dass sie Stationen des gegenwärtigen Volkslebens beschreiben sollten. ${ }^{91} \mathrm{Zu}$ seinen sozialkritischen Darstellungen der proletarischen Alltagswelt, die von der industriellen Arbeitswelt über Obdachlosigkeit bis hin zu den Momenten des spärlichen Vergnügens auf dem Rummelplatz reichten, gehörte für Baluschek offenbar auch das Warten am Bahnhof zum markanten Element. Auch hier, im Moment des Wartens, will er - wie in den anderen Grafiken aus dem Zyklus - die Leiden der Menschen zeigen und deren Situationen und lebenswirkliche Wahrheiten offenlegen. In dieser Intention knüpft Baluschek direkt an Honoré Daumiers Arbeiten aus dem französischen Bahnwesen der 1850er und 1870er Jahren an, der das verkehrlichen Wartens der unteren Wagenklasse bereits viele Jahre zuvor als einen Indikator gesellschaftlicher Missstände darstellte.

Baluscheks Lithografie wird hier daher in Verschränkung mit Daumiers Arbeiten zusammenfassend als zentral für eine Kulturgeschichte des Wartens erachtet, weil mit ihr schließlich die triviale Notwendigkeit des stationären Aufenthalts am Bahnhof expliziert und das Phänomen mit künstlerischen Mitteln als ein zentraler Bestandteil der Lebenswelt anerkannt wird. Trotz der Prominenz seiner Wartesaalzeichnung war Baluschek jedoch nicht der einzige Protagonist der 1920er Jahre, der das Warten als zentrale Alltagserfahrung einfing.

Eberhard Kolb, »Die Reichsbahn vom Dawes-Plan bis zum Ende der Weimarer Republik«, in Die Eisenbahn in Deutschland: von den Anfängen bis zur Gegenwart, hg. von Lothar Gall und Manfred Pohl (Beck: München, 1999), 146. 
Neben Hans Baluschek zählte auch Eduard Braun (1902-1972) zum Kreis von Expressionisten und Vertretern der Neuen Sachlichkeit, die sich punktuell dem Wartemotiv widmeten. Wenngleich er weniger Bekanntheit erlangte, schuf Braun ab Ende der 1920er Jahre eine Werkreihe über den großstädtischen Kosmos Berlins. Zu diesen entstandenen Werken zählt auch ein als Im Wartesaal III. und IV. Klasse betitelter Holzschnitt aus dem Jahr 1927.

Abbildung 49: Eduard Braun, Im Wartesaal III. und IV. Klasse (1927).

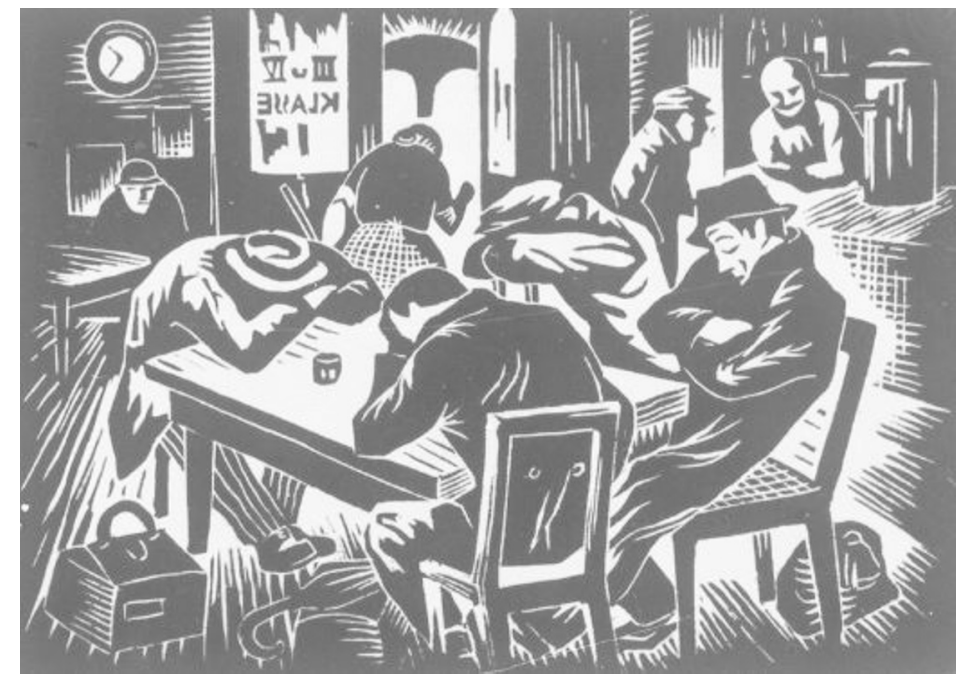

Quelle: Sammlung Galerie Nierendorf Berlin.

Brauns Darstellung eines (Berliner) Wartesaals lässt in vielleicht noch eindrücklicherer Weise als bei Baluschek die Grenzerfahrung des Wartens auf Abfahrt deutlich werden. Zwar erscheint der Wartesaal hier weniger überfüllt als in Baluscheks Grafik, doch zeigt die dargestellte Szene vier schlafender Männer zugleich eindrucksvoller den Transitcharakter des Aufenthalts. Die Reisenden befinden sich weder in einem Zuhause noch befinden sie sich gänzlich in der städtischen Öffentlichkeit. Die sich daraus ergebende Liminalität des Wartesaals wird ihnen zur unbequemen und wenig würdevollen Schlafstätte. Die Einfachheit der Ausstattung (Holztische und Holzstühle) wird bzw. muss als Schlafmöglichkeit genutzt und zweckentfremdet werden. Brauns Holzschnitt zeigt damit, wie stark die Raum- und Sachzwänge der Eisenbahnreise die Passagiere in ein Dilemma versetzen, das beim Warten in aller Deutlichkeit hervortritt. Sie können sich einerseits nicht von diesem Ort der Abfahrt entfernen und haben zugleich Grundbedürfnisse, die an Ort und Stelle - vom Bahnhofswirt gänzlich toleriert - befriedigt werden müssen.

Brauns Holzstich skizziert damit eindrücklich die `Geworfenheit der Passagiere im Zwischenraum des Wartesaals, wobei nicht klar ist, ob die Szenerie nachts oder tagsüber spielt. Zudem bleibt fraglich, ob die schlafenden Männer tatsächlich Reisende sind oder sie - wie in Roths Schilderungen - den Wartesaal als Schlafstätte zweckentfrem- 
den. Da jedoch Handgepäckstücke zu erkennen sind, erscheint es schlüssig, dass sie Passagiere sind. Auch in dieser Darstellung stellt sich das verkehrliche Warten als sozialkritischer Alltagsbefund des Proletariats dar, der die Reisenden in den unteren Wagenklassen in den Stand der Würdelosigkeit hebt und die Erfahrung des Wartens als oktroyiertes, fremdgesteuertes und negativ erfahrenes Temporalphänomen erscheinen lässt.

Abbildung 50: Walter Ophey, Nachts im Wartesaal (um 1923).

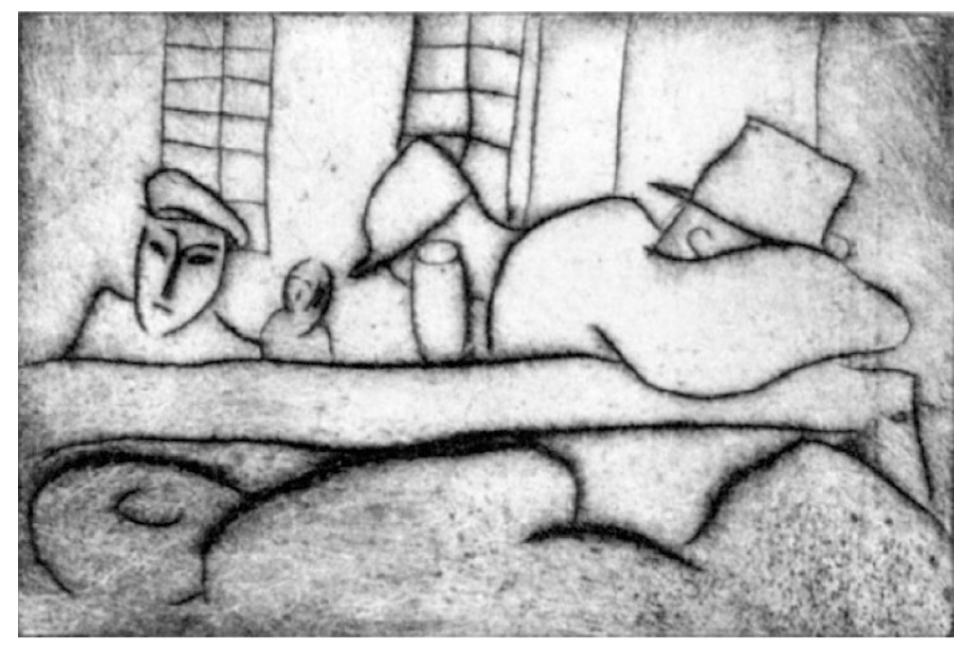

Quelle: Kunstmuseum Düsseldorf.

Neben Baluschek und Braun kann mit dem deutschen Grafiker und Maler Walter Ophey (1882-1930) abschließend noch ein weiterer expressionistischer und neusachlicher Vertreter der 1920er Jahre aufgeführt werden, der sich dem Motiv des Wartens widmete. Seine 1925 entstandene Kaltnadelradierung Nachts im Wartesaal illustriert einmal mehr den Wartesaal als Zwischenraum und Schleuse, der weder privat noch gänzlich öffentlich ist.

Auch in dieser Darstellung sehen wir Passagiere, die den Wartesaal für ihr Nachtlager zweckentfremden und sich im wohl vertrautesten Wartemodus befinden: dem Schlaf. Symbolisiert durch das Glas in der Bildmitte hier ist auch zugleich wiederum die enge Verbindung zur gastronomischen Versorgung, genauer zum Alkoholausschank sichtbar, der wahrscheinlich als Mittel gegen die Langeweile oder zur Betäubung der unwürdigen Situation benötigt wurde. Während Ophey im Vergleich zu Baluschek und Braun nicht explizit angibt, welche Wagenklassen hier dargestellt wird, last sich angesichts des Kleidungsstils und der improvisierten Schlafpositionen (zum Teil unter einem Tisch oder vor einer Theke) wiederum ableiten, dass es sich um einen Wartesaal IV. oder III. Klasse gehandelt haben wird.

Das Motiv des (nächtlichen) Wartesaals kann somit zusammenfassend als eine übergeordnete Tendenz der expressionistisch-sozialkritischen Verhandlung des Eisenbahnwesens deklariert werden. Ob für Baluschek, Braun oder Ophey, der Wartesaal der 
unteren Wagenklasse bildet einen exemplarischen Schauplatz der sozialen Disparität, die in Form eines alltagsrelevanten und wenig würdevollen Zwischenstadiums zu einer krisenhaften Kollektiverfahrung gereift war. Der Eisenbahnkosmos - über die längste Zeit das Symbol für Fortschritt, Bewegung und Geschwindigkeit - wurde nach dem 1. Weltkrieg zu einer Metapher wirtschaftlichen Stillstands und gesellschaftlicher Resignation.

\subsection{Abschluss: Rahmung und Verhandlung des verkehrlichen Wartens am Ende der 'Ersten Moderne،}

Das frühe 20. Jahrhundert war hinsichtlich des systemischen Wartens auf Eisenbahnen gegenüber den zurückliegenden Phasen von drei ineinandergreifenden Zäsuren geprägt: Erstens verlagerten sich durch zweckmäßigere Bauprinzipien die bisherigen Orte des Wartens, zweitens veränderten sich die Nutzungspraktiken der Reisenden und drittens stand das verkehrliche Warten im Zeichen eines sprunghaften Rezeptionszuwachses samt einer konnotativen Transformation in Richtung eines ungeliebten und krisenhaften Zustands.

\section{a) Bauliche Zäsuren: Direktzugänge, Querbahnsteige und Raumverkleinerungen}

Die baulich-operative Rahmung des systemischen Wartens ist in der vierten Phase des Bahnhofsbaus von einer allmählichen Marginalisierung und Aufhebung des stationären Schleusencharakters geprägt. Im Zuge einer sich geänderten Verkehrsorganisation im Inneren der Bahnhöfe wurde in den großstädtischen Bahnhofsneubauten der Moderne vom vormaligen Prinzip des stationären Warteimperativs abgerückt, der Fokus auf einen möglichst unmittelbaren Zugang zum Bahnsteig gelegt (Wiesbaden, Stuttgart, Leipzig). In der Folge wurde die erzwungene Schleusung durch den Wartesaal aufgehoben, die Wartesäle innerhalb der nunmehr asymmetrischen Grundrissgestaltung an die Peripherie der Empfangsgebäude verlegt (Oberhausen). Wichtiger als der Wartesaal wurde im Falle eines Kopfbahnhofes der direkt aus der Eingangshalle erreichbare Querbahnsteig, der zur sich selbstorganisierenden Hauptverkehrsfläche avancierte und in funktionale Konkurrenz zu den raumgreifenden Wartesälen trat. Der Querbahnsteig (oder Concourse) nahm hierbei zum Teil die Wartefunktion in sich auf und ließ die großen Säle zunehmend obsolet erscheinen. Er symbolisierte dabei wie kein anderes Grundrisselement des modernen Großstadtbahnhofs das über Jahrzehnte gereifte ingenieurswissenschaftliche Dogma der reibungslosen Zirkulation, das schließlich in einem zur Schwelle des 20. Jahrhunderts wissenschaftlich betriebenen Bahnhofsbau mündete. Im Falle einer seitlichen Erschließung (Durchgangsbahnhöfe) erfüllte wiederum ein von der Eingangshalle erreichbarer Personentunnel die Funktion eines Direktzugangs zu den Bahnsteigen, ohne einen Umweg über Wartesäle nehmen zu müssen.

Die Gründe für diese baulichen Zäsuren, die in einer allmählichen Marginalisierung der Wartesäle resultierten, lagen in einem sich zur Jahrhundertwende verschärften Verkehrs- und Kostendruck. Die industrielle Gesellschaft am Ende der >Ersten Mo- 
derne ${ }^{92}$ erforderte ein weitaus höheres Mobilitätsniveau als in den zurückliegenden Jahrzehnten. Bis 1914 erfolgte somit in Deutschland nochmals eine deutliche Zunahme des Personenverkehrs; die >Wahlverwandtschaft zwischen Moderne und Mobilität ${ }^{93}$ kam nun vollends zur Geltung. Um die immens gewachsenen Passagierströme sicher und effektiv auf das Bahnsystem zu überführen sowie Bahnhöfe kosteneffizienter zu gestalten, wurde ein wissenschaftlich betriebener Bahnhofsbau etabliert, der die innere Gestaltung der Empfangsgebäude in Richtung kreuzungsfreier Passagierströme und einer Verkleinerung der Räume novellierte. Während also die Lösung des wachsenden Verkehrsdrucks durch eine optimierte Verkehrsführung auf neuen Zirkulationszonen gesucht wurde, konnte gleichzeitig dem Kostendruck durch eine Verkleinerung des Raumprogramms begegnet werden. Beide Effekte bewirkten zusammen, dass die großen Wartesäle des 19. Jahrhunderts aus Kreisen des Bau- und Eisenbahningenieurswesens zunehmend harsch in die Kritik gerieten, für die sneuen Ansprüche unzweckmäßig, überdimensioniert und unzeitgemäß zu sein. Die resultierende Verkleinerung und Marginalisierung der raumgreifenden Warteinfrastruktur wurde zudem parallel durch Einführung der Speise- und Kurswagen begünstigt. Während der Speisewagen die Notwendigkeit für gleisnahe Versorgungseinrichtungen am Bahnhof reduzierte, erübrigte die Einführung von Kurswagen im Fernverkehr (umsteigefreies Erreichen des Ziels) die Notwendigkeit für Umsteigezeiten und entsprechender Warteinfrastrukturen auf Zwischenhalten.

Noch stärker zeigte sich die raumbezogene Veränderung des Wartens mit Blick auf den Lokal- und Vorortverkehr. So fanden sich etwa in den Passagiergebäuden der Berliner Vorortbahnen überhaupt gar keine Wartesäle mehr. Stattdessen war der systemische Aufenthalt vollends auf den Bahnsteig und dortige Wartebuden verlagert. Die stärkere Differenzierung von Nah- und Fernverkehr bewirkte somit eine Zweiteilung der Wartepraxis. Das Warten auf Nahverkehrszüge spielte sich nur noch auf dem Bahnsteig ab, der (würdevolle) Aufenthalt in den Wartesälen traf überwiegend nur noch auf Reisende an den Fernbahnhöfen zu. Während sich die Orte des Wartens also tendenziell vom Saal in die Fläche oder direkt auf die Bahnsteige verlagerten, wurde die allgemeine Marginalisierung der Wartesaalnutzung aber zudem auch durch passagierseitige Veränderungen selbst getragen.

\section{b) Zäsuren der Nutzungspraxis: Meidung der Wartesäle}

Die Wahrnehmung der Eisenbahn stand spätestens um die Jahrhundertwende im Zeichen einer vollständigen Gewöhnung. Das `neue Verkehrssystem war inzwischen bereits fast zwei Generationen alt und konnte im deutschen Kontext kaum mehr als aufregendes Novum bezeichnet werden. Angesichts der reduzierten Unsicherheiten in der Eisenbahnnutzung war eine übermäßig frühe Ankunft am Bahnhof nicht mehr unbedingt nötig. Insbesondere die Zunahme des routinisierten Berufs- und Nahverkehrs

Hiermit wird - wie bereits in Kap. 3.1 diskutiert - auf die von Christof Dipper vorgeschlagene Periodisierung der Moderne zurückgegriffen, der die `Erste Moderneく im Zeitraum von 1880-1930 verortet. 
förderte hierbei einen Wandel hin zu einer Mobilitätskultur, die Wert auf den direkten und zeiteffizienten Übergang zum Bahnsystem legte und aufgrund eingeübter Wege, organisatorischer Kenntnisse und der Umgehung von Fahrkartenkäufen (durch Abonnements) keinen präparatorischen Aufenthalt in den Wartesälen mehr benötigte. Diese gewachsene Gewöhnung bildete wiederum die Grundlage für die Einrichtung neuer Zirkulationsflächen innerhalb der Empfangsgebäude. Mit Blick auf die aufeinander aufbauenden Entwicklungen des Frankfurter und Wiesbadener Hauptbahnhofes wurde beispielhaft deutlich, dass erst als die Reisenden die Betriebsabläufe und Wegeführungen verinnerlicht hatten, der Querbahnsteig überhaupt die Aufgabe einer sich selbst organisierenden Verkehrsfläche erfüllen konnte.

Die wesentliche nutzerseitige Zäsur der vierten Bahnhofsgeneration besteht somit in der sich vom Nahverkehr her ausbreitenden Praxis eines beschleunigten Zugangs zum Zug. Diese Praxis wurde zum einen durch die neuen Zirkulationsflächen und direkten Zugangsverbindungen (Querbahnsteig, Personentunnel) baulich ermöglicht und zugleich nutzerseitig aufgrund des gesellschaftlichen Elements des gewachsenen Zeitdrucks eingefordert. Resümierend vermerkte der Architekturhistoriker Mihály Kubinszky zu diesem Prozess der modernen Verkehrszugangspraxis:

»Die Warteräume verloren allmählich von ihrer Bedeutung. Der moderne Mensch hat es stets eilig, und die Romantik der Eisenbahnfahrt ist längst überwunden. Statt sich im Wartesaal auszuruhen, kommt der Reisende meist erst in den letzten Minuten am Bahnhof an, durchschreitet rasch die Schalterhalle und begibt sich gleich zum Bahnsteig. Auch für die Trennung nach Klassen ist kaum noch eine Notwendigkeit, oft wird nur ein einheitlicher Wartesaal angelegt. «" ${ }^{94}$

Zusammengenommen war damit der Zenit der Wartesaalnutzung und des langen, würdevollen Wartens nach 1900 bereits überschritten, die absolute Wartezeit der Reisenden gegenüber früheren Phasen deutlich reduziert. Hierzu dürfte auch der Umstand beigetragen haben, dass die bauliche Organisation einer Vielzahl der Neu- und Umbauten von Empfangsgebäuden auf Durchgangsbahnhöfen dem Typ Hannover folgte. Hierbei wurden die Gebäude in Seitentieflage angelegt und der Zugang zu den Bahnsteigen einzig und allein durch einen vorgeschalteten Personentunnel ermöglicht. Die Wartesäle wurden links oder rechts der Eingangshalle angelegt und standen durch ihre von den Bahnsteigen weit entfernten Lage dem psychologischen Wunsch der Reisenden entgegen, eine Sichtverbindung zu den Zügen herzustellen oder sich unmittelbar am Abfahrtsort zu befinden. Vielmehr verstärkte die vorgelagerte Position der Warteräume die Angst des Zurückbleibens am Bahnhof, die Walter Benjamin treffend als »Urbild aller Versäumnis «" ${ }^{95}$ bezeichnete. Angesichts dieser psychologisch ungünstigen Raumdisposition nahm die Wartesaalnutzung an solchen Bahnhöfen tendenziell ab und die Reisenden (insbesondere jene des Nah- und Regionalverkehrs) orientierten sich nach dem Eintreffen am Bahnhof lieber direkt zu den Bahnsteigen. Der (lange) Aufenthalt in den Sälen wurde zwar fakultativ und zur optionalen Mobilitätspraxis, doch (deshalb) 
nicht mehr von allen Reisenden in Anspruch genommen. Trotz des sich nach 1900 etablierenden Nutzungswandels blieben die Wartesaalstrukturen samt Gastronomie und Bahnhofswirtschaften vielerorts erhalten, die Grundrisse der modernen Neubauten lassen keinen harten Bruch zur vorherigen Tradition raumgreifender Wartesäle vermuten. Dennoch waren es vorwiegend nur noch die Reisenden des Fernverkehrs, die aufgrund entstehender Zwischenaufenthalte bei Umsteigesituationen oder aufgrund weit entfernter Ziele und damit verbundener Unsicherheiten (Informationsbeschaffung, Verpflegung etc.) die Wartesäle nutzten. Eine 1914 veröffentlichte Beobachtung im Handbuch der Ingenieurwissenschaften stützt dabei die Einschätzung einer nunmehr vor allem auf den Fernverkehr reduzierten Wartepraxis:

»In Deutschland kommen die Reisenden des Fernverkehrs im allgemeinen frühzeitig zum Bahnhof, um den Zug nicht zu versäumen oder um sich rechtzeitig einen guten Platz zu sichern. Vielfach suchen sie vor Betreten des Bahnsteiges die Warteräume auf und nehmen dort Erfrischungen ein, besonders in Norddeutschland, wo Wartesäle und Bahnhofswirtschaft fast immer vereinigt sind. Die Wartesäle der deutschen Bahnen, insbesondere auf mittleren und großen Stationen, sind daher im allgemeinen recht geräumig. Ähnlich liegen die Verhältnisse in Osterreich und Rußland. Auch in Frankreich finden sich die Reisenden meist längere Zeit vor Abfahrt des Zuges ein, doch dient hier, ebenso wie in Italien, vielfach die Eingangshalle als Hauptaufenthaltsraum, während die Wartesäle nur klein sind. ${ }^{96}$

\section{c) Wahrnehmungsbezogene Zäsuren: Warten wird >Problem<}

Die dritte Zäsur der vierten Phase von Bahnhofsgenerationen besteht im sprunghaften Anstieg der Thematisierung des Phänomens innerhalb von sprach- und bildkünstlerischen Kreisen. Im Rahmen von stärker als zuvor am realistischen Abbild der Welt interessierten Kunstströmungen (Neue Sachlichkeit, Expressionismus, Naturalismus) fand das verkehrliche Warten weit größere Beachtung als im 19. Jahrhundert. Figuren in der technikeuphorischen Lyrik (>Nyland-Kreis`) oder der neusachlichen Prosa nahmen sich selbst oder andere Personen nun weit häufiger und direkter im Stadium des Wartens wahr. Das verkehrliche Warten wurde dabei insbesondere in der expressionistischen Literatur zum existentialistischen Symbolträger der menschlichen Sinnsuche (Werfel) oder zum Ausdrucksfeld der Adressierung sozialer Missstände (Roth). Aber auch im Rahmen der bildkünstlerischen Darstellungen des Expressionismus wurde das Motiv wartender Reisender nunmehr explizit aufgenommen. Hier diente die Thematisierung des Alltags- und Massenphänomens - wie auch in der sozialkritischen Prosa der Adressierung sozialer Missstände und einer realistischen Abbildung der Lebenswirklichkeit der unteren Bevölkerungsschichten.

Wenngleich nicht über die hier analysierte Literatur erschlossen, bestand zudem eine bedeutende Wahrnehmungszäsur des Wartens zweifelsohne in der Erfahrung des

96 M. Oder, Der Eisenbahnbau, hg. von Ferdinand Loewe und Hermann Zimmermann, Bd. 4: Anordnung der Bahnhöfe, Handbuch der Ingenieurwissenschaften, 5.Teil (Leipzig und Berlin: Engelmann, 1914), 1. 
Ersten Weltkriegs. Die Verwerfungen des Krieges riefen eine nie gekannte Dimension des Wartens hervor, die zur quälenden Kollektiverfahrung reifte. Ob Soldaten oder Zivilisten, der Krieg bewirkte, dass weite Teile der Bevölkerung, ja ganze Nationen, in ein Zwischenstadium des nervösen Er- und Abwartens verfielen. So berichteten etwa Soldaten, dass der Frontalltag für die überwiegende Zeit aus Warten bestand. Die aktiven Kampfhandlungen der modernen, industrialisierten Kriegsführung begrenzten sich oftmals auf nur kurze Momente. Die Zwischenzeit war vom Abwarten geprägt: auf Kampfbereitschaft der Truppenteile, den Tagesanbruch, den Beginn der Nacht, auf günstige Wetterbedingungen etc. »Die Hälfe seines Lebens, wartet der Soldat vergebens«, lautete entsprechend ein weitverbreitetes deutsches Sprichwort des Ersten (und Zweiten) Weltkriegs (siehe Abbildung 51). Äquivalent wurde die moderne Kriegsführung von US-amerikanischer Seite als »months of boredom punctuated by moments of extreme terror ${ }^{97}$ bezeichnet. Aber auch die in der Heimat verbliebenen Angehörigen verfielen in den Zustand eines Dauerwartens: auf Meldungen, Briefe, Lebenszeichen und schließlich auf die Rückkehr. Das Warten auf die Abfahrt mit der Eisenbahn mochte angesichts dieser übergeordneten, existentiellen Kollektiverfahrungen des Wartens weit weniger explizit wahrgenommen oder problematisiert worden sein. Somit ist anzunehmen, dass die Erfahrung verkehrsinduzierter Wartezeiten zwischen 1914-1918 im Rahmen eines gesellschaftlichen Wartemodus subsummiert worden sein dürfte.

Mit Blick auf die gesamte Zeitspanne der vierten Phase lässt sich als rezeptionsgeschichtlicher Befund zusammenfassend festhalten, dass rein quantitativ das Phänomen in der Kunst der Moderne eine deutliche Aufmerksamkeitssteigerung erfuhr. Die Häufigkeit und Direktheit mit der das Phänomen in der Zwischenkriegszeit in Literatur und Kunst thematisiert und problematisiert wurde, zeugt dabei von einer alltagspraktischen Erfahrungssättigung, wie sie in keiner der vorangegangenen Phasen zu beobachten war. Diese stärkere Thematisierung fällt hierbei zugleich qualitativ mit einer übergreifenden Problematisierung des Phänomens zusammen. Das (verkehrliche) Warten erfährt somit aus Sicht seiner künstlerischen Verhandlungen im Laufe der 1920er Jahre eine deutliche Transformation in Richtung der Kennzeichnung einer krisenhaften Alltagswahrnehmung. Die Konnotation des Wartens dreht sich hierbei nicht zuletzt auch deshalb ins Negative, weil der krisenhafte Zustand des langen und unwürdigen Wartens ganz besonders von den gesellschaftlich benachteiligten Gruppen erfahren wird. Kurzum: Das Warten findet im Laufe der 1920er Jahre erstmals seine Begründung als ein gesellschaftliches Massenphänomen bzw. existentielles und gesellschaftliches Problem. Diese Entdeckung eines krisenhaften und ungeliebten Zustands findet wohl kaum einen paradigmatischeren Ausdruck als in einem Ausspruch Fred Endikats:

»Liebe färbt das Warten rosa, doch im Leben gilt die Prosa. ${ }^{98}$

Die Prosa des Lebens kann hier stellvertretend für die drastische Beschleunigung des Lebenstempos und der daran gekoppelten Ökonomisierung des Zeitwerts stehen, die alle Bevölkerungsteile der modernen Industriegesellschaft erfasst hatte. Diese Prosa

97 The New York Times Current History: The European War, Bd. 1: From the Beginning to March, 1915 (New York: C-H Publishing Corporation, 1915), 979. 
Abbildung 51: »Die Hälfte seines Lebens wartet der Soldat vergebens", Bildpostkarte aus der Zeit des Nationalsozialismus(o.J.).

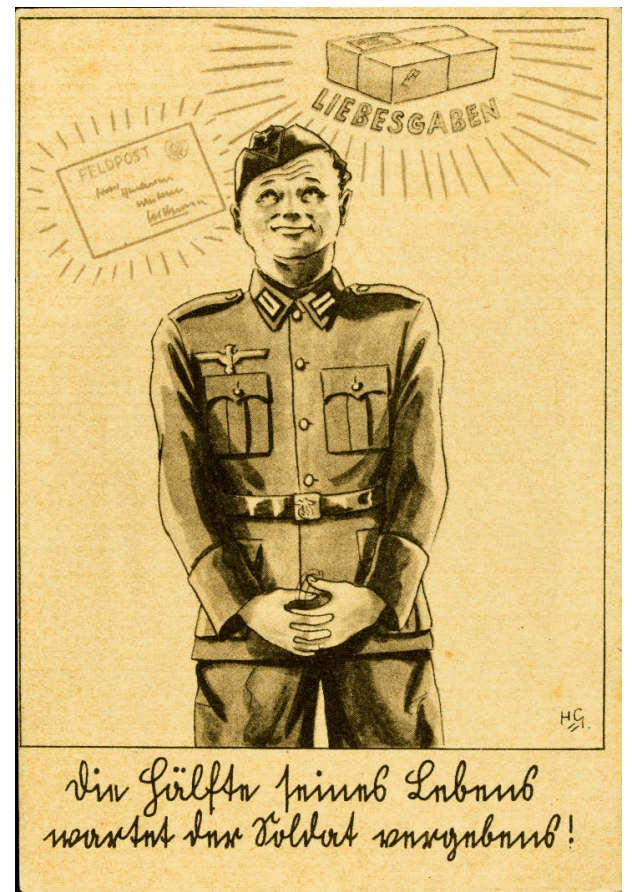

Quelle: Historische Bildpostkarten - Universität Osnabrück Sammlung Prof. Dr. Sabine Giesbrecht, http://nbn-resolving.org/urn:nbn:degbv:700-2-00158 74-0

des modernen Lebens zeigte dabei weit weniger Toleranz gegenüber Wartezeiten oder anderen Dysfunktionalitäten als in den Jahrzehnten zuvor, sondern war vielmehr von stetiger Nervosität geprägt, die teils leidvoll erfahren (Neurasthenie), teils zum inszenierten Lebensstil der Kaiserzeit gehörte. ${ }^{99}$

Jegliche baulichen, technischen und operativen Entwicklungen im Bau von Empfangsgebäuden zeugen von diesem ökonomisierten Zeitwert, der das Warten, den >zinslosen stationären Aufenthalt, zunehmend zu vermeiden versuchte. Ob Querbahnsteige, Personentunnel oder Speisewagen, jede dieser Neuerungen hatte den Anspruch, verbesserter Zirkulation und gewachsener Zeiteffizienz zu entsprechen, die Georg Simmel - einer der schärfsten Beobachter seiner Zeit - als Charakteristika des modernen, großstädtischen Lebens ausmachte. Um zudem mit Weber zu sprechen, spiegeln damit 
die Bahnhofsentwicklungen der vierten Generation zusammengenommen den Übergang von einem "gewachsenen « Zustand aller Lebensformen in den Zustand »rationaler Organisiertheit «, ${ }^{100}$ der sich im 19.Jahrhundert auszubilden begann und im frühen 20. Jahrhundert vollends etabliert war. Die romantische Konnotation des Wartens (auf gemütliche Postkutschen oder eine geliebte Person) hatte sich damit im Alltag des frühen 20. Jahrhunderts endgültig in Richtung eines zumindest rechtfertigungspflichtigen und teils bereits krisenhaften Zustands verschoben. Das Warten wurde im frühen 20. Jahrhundert zu einem Konfliktfall der Moderne, die es folglich mit noch drastischeren Mitteln zu mindern oder vermeiden suchte.

Diese zunehmend kritische Wahrnehmung des Wartens wurde dabei zugleich stellenweise auch in umgekehrter Weise für eine allgemeine Kulturkritik an der beschleunigten Moderne instrumentalisiert. So wurde etwa der allgemeine Verlust der Wartetoleranz als kultureller Rückschritt interpretiert. Wie aus dem Buch »Der gute Ton. Ein Ratgeber für richtiges Benehmen in allen Lebenslagen « aus den frühen 1930er Jahre hervorgeht, wurde dabei insbesondere der jungen Generation attestiert, dass ihr jegliche Fähigkeit und Tugend des Wartens abhandengekommen sei.

»Nicht warten und nichts erwarten können, nicht warten wollen, irgend ein Wartenmüssen als persönliche Beleidigung aufzufassen, ist ein charakteristisches Merkmal der neuesten Zeit. Uns scheint, das einstige endlose Warten auf die Post, z.B., müsse unerträglich gewesen sein. Wir können uns ein Leben ohne Radio, Telephon, Auto und alle modernen Verkehrsmittel gar nicht mehr vorstellen. Das Neueste gleich zu erreichen, zu ergreifen, freilich auch wieder fallen zu lassen, liegt im Sinn der Zeit. « ${ }^{101}$

Analog der Diskurse um die Romantisierung der Postkutsche im Rahmen des aufstrebenden Eisenbahnwesens zur Mitte des 19. Jahrhunderts wurde damit das lange Warten (-können) von konservativen Kreisen auch fast 100 Jahre später als erstrebenswerte Tugend deklariert bzw. für einen kulturkritischen Situationsbefund instrumentalisiert. Überhaupt wären die technischen Errungenschaften von einer Illusion der Zeitersparnis getragen, die sich aber nicht einstellen, sondern die fehlende Wartetoleranz paradoxerweise noch verschärfen würde. So stellte die besagte Ratgeberliteratur zur Paradoxie der verkehrlichen Moderne weiter fest:

»Wir glaubten mit der wahnsinnigen Beschleunigung aller Verkehrsmittel das Warten abgeschafft zu haben, aber es ist nur schlimmer, intensiver geworden, sein Wesen spielt sich ab wie immer, nur als Quintessenz empfunden, und es ist schwerer geworden, in die Wartezeit einen guten Ton klingen zu lassen. Die Ungeduld von einer Post zur anderen, einst auf größere Zeitspanne verteilt, ballt sich zusammen in Stunden, in halbe Stunden. In einer Minute vor der Telephonentscheidung kann man eine Ewigkeit des Harrens durchleben, die schwere Anforderungen an die Nerven stellt. « $^{102}$

\footnotetext{
100 Alfred Weber, Haben wir Deutschen nach 1945 versagt?: politische Schriften: ein Lesebuch (Frankfurt a.M.: Fischer Taschenbuch Verlag, 1982), 32.

101 Alexander von Gleichen-Russwurm, »Im Wartesaal des Lebens«, in Der gute Ton. Ein Ratgeber für richtiges Benehmen in allen Lebenslagen (Leipzig: Hachmeister und Thal, 1932), 22.

102 Gleichen-Russwurm, »Im Wartesaal des Lebens«, 23.
} 
Die technisch ermöglichte Beschleunigung des Lebens wurde damit interessanterweise bereits zeitgenössisch nicht als Lösung der Zeitproblematik interpretiert, sondern als deren eigentlicher Ursprung. Erst die technisch evozierte Kompression der Zeiträume von Tagen auf Minuten (und Sekunden) hätte das Warten überhaupt als expliziten Zeitzwischenraum erzeugt und erfahrbar gemacht. Ähnlich argumentierte auch das schwedische Schriftstellerpaar Carl Olof und Elly Petersen in ihrer 1933 erschienenen Erzählung Die Moosschwaige, in der sie das Paradox der modernen Zeitersparnis eindrücklich thematisierten:

»Alle Erfindungen, die Zeit zu bezwingen, um noch mehr Zeit zu gewinnen, haben genau das Cegenteil bewirkt. Sie haben uns die Zeit genommen! Das Paradoxe ist wie immer zur Wahrheit geworden. Je schneller und eiliger alles auf der Welt vor sich geht, desto weniger Zeit bleibt dem Menschen übrig, zu sich zu kommen, desto seltener findet er Gelegenheit, einfach Mensch zu sein. ${ }^{103}$

\section{Rekonstruktion der verkehrlichen Warterfahrung im frühen 20. Jahrhundert}

Der Versuch einer idealtypischen Rekonstruktion der Warteerfahrung im Bahnhof der Moderne ließe sich auf Grundlage der gesammelten Quellenaussagen zusammenfassend wie folgt beschreiben. Gegenüber der Eisenbahnreise zu Mitte und Ende des vorigen Jahrhunderts wurden die Passagiere allmählich vom Regime einer strengen Formalität befreit. Die Passagiere hatten sich an die Eisenbahnreise gewöhnt, bewegten sich selbstständig und benötigten zunehmend weniger Aufsicht und Lenkung. Durch Aufgabe des stationären Warteimperativs konnten Reisende die Wartesäle nunmehr freiwillig und optional nutzen, ohne sie zwangsläufig passieren zu müssen oder der betrieblichen Erwartung eines langen Aufenthalts zu entsprechen. Zudem wurde der Bewegungsradius während der Wartezeit erhöht, denn nach dem Passieren der Bahnsteigsperre konnten die Passagiere nunmehr die Bahnsteige als erweiterte Aufenthaltsfläche mit Sicht auf den einfahrenden Zug nutzen.

In sozialräumlicher Hinsicht zeigte sich auch in der Moderne eine Kontinuität der Klassentrennung. Die Reisenden der unteren und oberen Wagenklassen wurden nach wie vor voneinander separiert. Während die Nutzung der vierten und dritten Klasse noch weiter zunahm, verringerte sich die Nutzung der ersten und zweiten Klasse nochmals, wodurch die Ausstattung der Räumlichkeiten für die gehobenen Wagenklassen eine immer größere Diskrepanz zu ihrer tatsächlichen Nutzung aufwiesen. Zugleich erzeugten die neuen Zirkulationszonen der Querbahnsteige und Personentunnel neue ’klassenlose Begegnungsflächen, da sie von allen Passagieren gleichsam genutzt wurden. Bezüglich der objektiven Wartedauer ist, wie bereits angedeutet, davon auszugehen, dass sich die Wartezeiten vor Abfahrt aufgrund der routinisierten Praxis und der direkteren baulichen Zugangsmöglichkeiten gegenüber den früheren Phasen deutlich verringert haben dürften. Während dies insbesondere für den Nah- und Lokalverkehr zugetroffen haben mochte, erschienen lediglich die Reisenden des Fernverkehrs nach wie vor frühzeitig am Bahnhof und verfügten über größere Zeitpolster. Die tatsächliche Wartepraxis war dabei nach wie vor stark vom Verzehr kleinerer Speisen und einer 
Vielzahl von Getränken geprägt. Während in den unteren Wagenklassen vorwiegend Würste und Suppen gereicht wurden, war der Getränkekonsum offenbar vor allem alkoholischen Getränken dominiert. Nicht selten wurde hierbei kritisiert, dass die enge Verschränkung von Wartesälen und der Bahnhofsgastronomie als >Trinkzwangく interpretiert werden konnte. Tatsächlich erwähnt fast jede bildliche oder sprachliche Darstellung des Wartesaals im frühen 20. Jahrhundert den Konsum alkoholischer Getränke. Wartesäle waren zudem von permanentem Tabakrauch geprägt. Die Hauptaktivität der Reisenden bildete die Lektüre eines breiten Spektrums von Reiseliteratur. Seit den 1930er Jahren offenbar auch verstärkt das Lösen von Kreuzworträtseln hinzu. ${ }^{104}$ Die Passagiere genossen dabei ein zunehmend verbessertes Serviceumfeld. Die Wartesäle der Neu- und Umbauten waren zwar weniger üppig ausgestattet, aber es zogen mit Lautsprecheranlagen und anderen informatorischen Einrichtungen zugleich neue technische Hilfsmittel in die Wartesäle ein, die den Reisenden den Aufenthalt erleichtern sollten. Hierzu zählte auch die Einrichtung von Zugabfahrtsanzeigern, Zugmeldetafeln sowie Einrichtungen, die selbstständig die Zeit bis zur Abfahrt anzeigen konnten. ${ }^{105}$ Das Warten auf die Abfahrt erfolgte damit zwar zweifellos nicht mehr in der erhöhenden und opulenten Rahmung des späten 19. Jahrhunderts, ermöglichte aber nach wie vor ein ansprechendes und stärker individualisiertes Warten. ${ }^{106}$ Trotz dieser tendenziellen Verbesserungen (Entformalisierung, Freiwilligkeit, Servicezuwachs) lässt sich konstatieren, dass der stationäre Aufenthalt im Bahnhof der Moderne nicht zuletzt aufgrund der gewachsenen Zeitökonomie seiner Nutzerschaft im Rückzug begriffen war, sich die Charakteristik des verkehrlichen Wartens in den kollektiven Anspruch seiner Vermeidung und Umgehung wandelte.

Der Faktor Zeit war damit im frühen 20. Jahrhundert offenkundig zum Problem geworden. Die Luhmann'sche These einer Temporalisierung der Welt im Übergang vom 19. zum 20. Jahrhundert, nach der die Zeit als qualitative Erklärungsgröße und Indikator für gesellschaftliche Komplexitätssteigerungen fungiert, findet damit nicht zuletzt in der Zunahme der Problematisierung von Wartezeit einen historischen Beleg. Die neuerliche Problematisierung des Wartens - so ließe sich die These weiterführen fungierte als ein Niederschlagsfeld am Ende der `Ersten Moderneく, um die übergreifend gewachsene Komplexität - insbesondere hinsichtlich sozialer Verwerfungen und Ungleichheiten - zu adressieren.

104 Kreuzworträtsel erschienen in einer deutschen Zeitung erstmals 1925 in der Berliner Illustrierten.

105 Schmitt, Anlage und Einrichtung der Gebäude, 71.

106 Ausnahmen eines würdevollen Wartens bildeten hierfür zweifelsohne die nächtlichen Aufenthalte in den Wartesälen dritter und vierter Klasse, die in den Zeichnungen von Baluschek, Braun und Ophey thematisiert wurden. 


\section{Exploration: Bau- und Wahrnehmungskonjunkturen im weiteren Verlauf des 20 . und frühen 21. Jahrhunderts}

Das nun abschließende Kapitel zielt auf eine explorativ-thesenhafte Erschließung der Wahrnehmungskonjunkturen des verkehrlichen Wartens nach 1935 (verstanden als eine 5. Phase des Bahnhofsbaus). Hierbei wird eine verdichtete chronologische Betrachtung der warterelevanten baulichen Entwicklungen und den damit verbundenen Wahrnehmungs- bzw. Nutzungsveränderungen angestrebt. Im Unterschied $\mathrm{zu}$ den vorangegangenen Kapiteln besteht dabei nicht der Anspruch auf detaillierte empirische Rückbindungen, sondern Ziel des Explorationskapitels ist die Ableitung übergeordneter konjunktureller Entwicklungen, die sich aus einer Reihe aufzuzeigender Kultur- und Technikzusammenhänge der zweiten Hälfte des 20. und des frühen 21. Jahrhunderts ergaben. Wenngleich das Kapitel dabei weniger historiografische Substanz entwickelt und die Betrachtung der Bau- und Wahrnehmungsgeschichte des Wartens nach 1935 zweifellos eine eigene Arbeit rechtfertigt, komplementiert die hier angestrebte explorativ-thesenhafte Betrachtung gleichwohl die diachrone Analyse der Bau- und Kulturgeschichte des Wartens von den 1830er Jahren bis hinein in die Gegenwart.

\section{a) Bauliche Entwicklungskonjunkturen nach 1935}

Die Blütezeit der Eisenbahnen im Allgemeinen und des Bahnhofsbaus im Besonderen trat mit den 1930er Jahren an ihr Ende. Der Fokus des NS-Regimes lag primär auf dem Autobahnbau, ${ }^{1}$ neue Massenverkehrsmittel - allen voran der Omnibus, der motorisierte Individualverkehr und in Ansätzen bereits der Flugverkehr - traten als neue Transportalternativen in Konkurrenz zum Eisenbahnwesen. Im Zweiten Weltkrieg wurden die Bahnhöfe in strategischer Hinsicht zu Orten von Truppen- und Materialtransport und in emotionaler Hinsicht $\mathrm{zu} » O r t e n$ des bangen Abschiednehmens und tränenvollen

1 Anders als Hitler in Deutschland unterstützte Mussolini in Italien neben dem Autobahnbau auch weit stärker den Bau moderner Bahnhöfe (allen voran Santa Maria Novella in Florenz, 1934). 
Wiedersehens für kurze Fronturlaube. «2 Aufgrund ihrer kriegsstrategischen Bedeutung wurden sie zunächst allerorten zu Hauptzielen von Bombenangriffen, kurz darauf zu Schauplätzen großer Flüchtlingsströme.

Nach dem Krieg stand die Eisenbahn vor allem im deutschen Kontext aufgrund immenser Zerstörungen an einem Nullpunkt und musste sich gänzlich neu begründen. Um ihre Stellung als zentrales Massenverkehrsmedium zu behaupten, musste sich die Eisenbahn in der Nachkriegsmoderne »der neuesten technischen Errungenschaften bedienen «. ${ }^{3}$ Zentralstellwerke, Elektrolokomotiven oder auch der Bau von Bahnübergängen und Unterführungen sollten Sicherheit, Pünktlichkeit und Reisegeschwindigkeiten erhöhen, neue Züge mit verbesserter Beleuchtung, Heizung und Klimatisierung den Reisekomfort steigern. Mit anderen Worten: Die Eisenbahn passte sich mehr und mehr dem modernen Leben an.

Im Rahmen dieser weltweiten Modernisierungsbestrebungen war jedoch das Empfangsgebäude von einem massiven Bedeutungsverlust betroffen. Statt dem Bahnhof wie zuvor eine Sonderstellung zukommen zu lassen, wurde er nun unter den Ansprüchen einer modernen Stadt- und Verkehrsplanung stärker formal in bestehende $\mathrm{Zu}$ sammenhänge eingegliedert. In der Folge waren die Bahnhöfe der Nachkriegsmoderne durch eine Verkleinerung der Grundflächen und den Verlust ihrer vormaligen Repräsentationsarchitektur gekennzeichnet. ${ }^{4}$ Der Bedeutungsverlust wurde in architektonischer Hinsicht vor allem durch Wegfall des feierlich betonten Empfangsbereichs deutlich. Für eine architektonisch-gestalterische Unterstreichung des Empfangs wurde keine Notwendigkeit mehr gesehen, stattdessen wurde die mit der Eisenbahn realisierte Mobilität stärker funktionalisiert und schließlich >entzaubert`. Empfangsgebäude neuer oder wiederaufgebauter deutscher Bahnhöfe ähnelten in der Uniformität ihrer Rasterfassade nicht selten Kaufhäusern, Bürogebäuden oder Parkhäusern. So stellte Krings mit Blick auf den Neubau des Münchner Hauptbahnhofes in den späten 1950er Jahren scherzhaft fest, dass, um nach außen hin die gewohnte Signifikanz eines Bahnhofs zu verdeutlichen, »die Beschriftung »Hauptbahnhof « zu Hilfe gerufen werden [musste, R.K.]«. ${ }^{5}$ Mit ähnlicher Ansicht attestiert Radlbeck dem einst ikonischen Verkehrsbau für die Phase der Nachkriegsmoderne: »Der Bahnhof ist nur noch Zwischenstation ohne symbolische Bedeutung. $\ll^{6}$

Die Entzauberung der Eisenbahnreise blieb dabei auch für die Rahmung und Erfahrung des systemischen Wartens nicht folgenlos. Ähnlich wie die baulich-bedeutungsvolle Unterstreichung des Empfangs in der Eingangshalle standen im Bahnhof der Nachkriegsmoderne auch die dahinterliegenden Wartesäle zur Disposition, auch sie waren durch einen weiteren Bedeutungsverlust gekennzeichnet. Die sich bereits vor dem Zweiten Weltkrieg abzeichnenden Tendenzen der Verkleinerung und Marginalisierung der Warteräume (Stuttgart, Oberhausen) setzten sich somit nach dem Krieg weiter 
fort. So zeigten jegliche Bahnhofsneubauten der Bundesrepublik (z.B. Bochum, Heidelberg, Münster, Köln, Würzburg, Saarbrücken oder Braunschweig) eine Verkleinerung oder gar den Wegfall vormals raumgreifender Wartestrukturen. Wo sie noch bestanden, wurden, die Entwicklung sprachlich untermauernd, aus Wartesälen nunmehr Warteräume. Überhaupt wurde die Mehrheit der neu- oder wiederaufgebauten Bahnhöfe westdeutscher Groß- und Mittelstädte in Richtung von Einkaufs- und Dienstleistungscentern erweitert, in denen nunmehr »der Einbau von Kiosks, Pavillons, Kinos und ähnlichem sowie die Errichtung von Gaststätten (...) die Funktion der Wartesäle übernahmen. ${ }^{7}$ Der Bahnhofskosmos entsprach damit zunehmend dem Paradigma der westlichen Konsumorientierung. So etwa auch beim Umbau des kriegszerstörten Frankfurter Hauptbahnhofes, in dem nach 1945 eine massive Umgestaltung der Warteräume in Restaurants und Geschäfte erfolgte. Krings vermerkt zu dessen Entwicklung:

»Im Außenbau fast unverändert belassen, wurde es im Innern nach 1945 besonders im Bereich der Warteräume vollständig neu organisiert; verschiedene Restaurants, Ladengeschäfte und Räume für andere Dienstleistungen wurden hier ohne Rücksicht auf den alten Bestand eingerichtet. $\ll^{8}$

Ob als Folge einer veränderten Wartekonnotation oder aus ökonomischem Zwang der Bahn heraus, ihre Räumlichkeiten kommerziell verwertbar zu machen: Die einstmals riesigen Wartesäle des Frankfurter Hauptbahnhofes und mit ihnen die Praxis des langen, stationären Aufenthalts wurden von neuen Räumen und Praktiken abgelöst. Die neuen Orte des (stationären) Wartens bildeten hier das Bahnhofsrestaurant sowie in den Gängen und auf den Querbahnsteig aufgestellte Bänke und Sitzschalen.

Wohl noch plakativer kann die funktionale Transformation von Warteflächen zu Konsum- und Vergnügungsflächen anhand des Stuttgarter Hauptbahnhofs illustriert werden, in dem der nach einem Bombenangriff zerstörte Wartesaaltrakt des Nahverkehrs (in Abbildung 45 oben rechts) nach 1945 nicht wiedereröffnet und stattdessen 1949 in ein Kino umgewandelt wurde. Statt den funktionalen Vorkriegszustand einer Wartemöglichkeit wiederherzustellen, bewirkte und beförderte die Zäsur des Krieges auch hier eine Neuausrichtung der Raum- und Zeitnutzung im Bahnhof. Statt wie vor dem Krieg üblich die Wartezeit lesend auf Bänken oder im Restaurant zu verbringen, bot der Kinobesuch den Passagieren ein neues Aktivitätsangebot. Als bereits etabliertes Zerstreuungsmedium der 1920er Jahre eroberte damit das Kino nunmehr auch den Bahnhofskontext. Das in Stuttgart entstandene Kino - genannt Bahnhofslichtspiele (kurz Bali) - war das erste seiner Art. Ihm sollten viele weitere folgen und den Bahnhof im Laufe des 20. Jahrhunderts zum ikonischen Inbegriff des nur aus dem transitorischen Bahnhofskontext heraus entstandenen Sub-Genres des Aktualitätenkinos werden lassen. Hierbei wurde meist in rotierenden Blöcken ein Mix aus Nachrichtensendungen, Kulturfilmen und Zeichentrickfilmen gezeigt, die es insbesondere Reisenden mit einer 
längeren Umsteigezeit ermöglichten, ihre Wartezeit zu verkürzen und sie unterhaltsam zu füllen. ${ }^{9}$

Zusammengenommen war damit die Praxis des stationären Aufenthalts im Saal die dominierende Praxis des 19. und in Teilen noch des frühen 20. Jahrhunderts - nach dem Zweiten Weltkrieg an ihr Ende gelangt. Der Aufenthalt vor Abfahrt belief sich zunehmend auf das transitorische Durchschreiten von Geschäften, dem Aufenthalt in Kinos, der Bahnhofsgaststätte oder er verlagerte sich vollends auf den Bahnsteig. Zwar bewirkte die flächendeckende Einführung von Lautsprecherdurchsagen und überdachten Bahnsteigen psychologische und physiologische Verbesserungen für die Wartenden, doch die würdevolle und bisweilen repräsentative Wartekultur in Sälen mit angeschlossener Restauration wich einer funktionalistischeren, beschleunigteren oder unterhaltenderen Wartekultur. Wucherpfennig vermerkt zu diesem baulich unterstützten reisekulturellen Wandel in der Nachkriegsmoderne:

»Der Passagier ist hier zum Passanten geworden, der en passant den Bahnhof durchschreitet. Das Empfangsgebäude wurde zunehmend (wenn auch nicht für alle) zum Transitraum. ${ }^{10}$

Diese Entwicklung des Empfangsgebäudes zum Transitraum war jedoch keine harte Zäsur, sondern sie bildet vielmehr den vorläufigen Endpunkt eines historischen Prozesses, der seinen Anfang in den auf Effizienz und Zweckmäßigkeit zielenden Maximen Eberhard Wulffs zum Ende des 19. Jahrhunderts nimmt, durch den wissenschaftlichen Bahnhofsbau Adolf Goerings nach 1900 etabliert, in den Neubauten der klassischen Moderne erstmals angewendet wird und schließlich in den Neubauten der Nachkriegsmoderne seine Vollendung findet. Wartesäle und Warteräume verlieren damit spätestens in den 1950er und 1960er Jahren ihre ehemals prominente Rolle und werden durch Geschäfts- und Unterhaltungszonen ersetzt. Die fünfte Bahnhofsgeneration seit 1830 lässt sich somit als diejenige Phase einstufen, die nach einer langen Phase des Aufstiegs und der Etablierung den Fall der klassischen Warteinfrastruktur (und -kultur) besiegelt.

Mit dem Verschwinden der Warteräume fielen jedoch zugleich auch die vormaligen Klassentrennungen. Zwar bestanden auch nach dem Krieg noch Wagenklassen - das weltweit dominierende Dreiklassensystem wurde 1956 auf Beschluss der International Union of Railways (UIC) auf allen Mitgliedsbahnen in ein Zweiklassensystem umgewandelt - doch die nach Klassen getrennten Wartesäle und die mit ihr manifestierte Abbildung sozioökonomischer Unterschiede gehörten (zumindest im Empfangsgebäude) der Vergangenheit an. Die mit Aufgabe der Warteräume evozierte Entwicklung zum Transitraum ist somit nicht allein Ausdruck einer im 20. Jahrhundert fortschreitenden Beschleunigung des Lebenstempos, sondern die Abschaffung des klassenspezifischen Wartesaals zeigte zudem eine deutliche Artikulation »egalitäre[r] Grundideen des fordistischen Gesellschaftsmodells «. ${ }^{11}$ Statt getrennter Bahnhofszugänge und klassen- 
gestaffelter Einstiegsprozeduren wurden die sozioökonomischen Unterschiede vor der Fahrt nunmehr über die Art der Speisen und Getränke und die dafür gebotenen Einrichtungen (im Spektrum vom Restaurant, über das Büffet, die Milchbar, bis hin zur Schänke) repräsentiert.

Die bauliche Entwicklung einer durch Wegfall oder Umwandlung ehemaliger Warteflächen gewandelten Wartepraxis blieb dabei keineswegs nur auf Deutschland beschränkt. Vielmehr waren international ähnliche Entwicklungen des Verschwindens der Warteräume zu verzeichnen. So war etwa im italienischen Kontext ebenfalls eine Verkleinerung der Wartesäle zu beobachten, die - im Beispiel des Neubaus von Reggio Emilia - »kaum noch größer sind als ein Zimmer. ${ }^{12}$ Aber auch der Neubau des Wiener Westbahnhofes (1952-1954) zeigte die Reduzierung bzw. Eliminierung seiner zuvor noch raumgreifenden Wartesäle. Die Reduktion von Warteflächen wurde dabei in den darauffolgenden Dekaden auch immer wieder von systemischen Verbesserungen im Bahnsystem selbst motiviert. So erzeugte eine bessere Vertaktung der Verbindungen eine Verringerung von Umsteigezeiten und insgesamt eine Abnahme der Reise- und Wartezeiten im System. ${ }^{13}$

\section{Rehabilitation des Wartesaals: Renaissance der Bahnhöfe}

Seit Mitte des 20. Jahrhunderts galt der Bahnhofsbau als eine randständige und wenig beachtete Bauaufgabe. In den entstehenden Neubauten sollte sich dabei die Entwicklung zum reinen Transitraum durch Reduktion raumgreifender Warteflächen weiter fortsetzen. Erst die 1990er Jahre markierten hier einen Wendepunkt, der sich zu einer sechsten Phase des Bahnhofsbaus unter dem Slogan einer Renaissance der Bahnhöfe formieren lässt. ${ }^{14}$ Nachdem der Bahnverkehr in einer gesellschaftlich und verkehrspolitisch zunehmend auf das Automobil ausgerichteten Mobilitätspraxis über Jahrzehnte hinweg sinkende Fahrgastzahlen verzeichnet hatte und der Anteil der Eisenbahn an der Gesamtverkehrsleistung des Personenverkehrs zwischen 1950 und 1990 von fast 40 Prozent auf nur noch sechs Prozent gesunken war, ${ }^{15}$ sollte mit der Bahnreform von 1994 eine Trendwende eingeleitet werden. Ziel der Reform war die Umwandlung der Bundesbahn in ein privatwirtschaftliches Unternehmen des Bundes, die Fusion mit der Reichsbahn der DDR sowie die allgemeine Wiederbelebung des Eisenbahnverkehrs. Die frühen 1990er Jahre markierten damit schließlich »eine Phase des Überdenkens, des optimistischen Neuplanens, des Versuchs der Eisenbahn, sich mit tragfähigen Konzepten für Bahnhofsbau und Verkehrsgestaltung am eigenen Schopf aus dem Sumpf des

12 Kubinszky, Bahnhöfe Europas, 212.

13 Diese Entwicklung wird mit der geplanten Einführung eines Deutschlandtaktes gegenwärtig weiter fortgeführt. Hierzu auch der Rückverweis auf die systemische Verringerung von Wartezeiten mittels mathematisch-planerischer Interventionen (Kap. 3.2.1).

14 Genaugenommen setzte die Deutsche Bahn AG diesen programmatischen Titel sogar selbst auf und initiierte 1994 die Ausstellung »Renaissance der Bahnhöfe. Die Stadt im 21. Jahrhundert«, die auch 1996 auf der Architekturbiennale von Venedig zu sehen war.

15 Hierzu überblickshaft auch: Ueli Haefeli, »Entwicklungslinien deutscher Verkehrspolitik im 19. und 20. Jahrhundert«, in Handbuch Verkehrspolitik, hg. von Oliver Schwedes, Weert Canzler, und Andreas Knie (Wiesbaden: Springer, 2016), 97-115. 
Niedergangs der Eisenbahnkultur zu ziehen. ${ }^{16}$ Im Zuge dieser Selbstrettung wurde das operative Geschäft von einem massiven Investitionsprogramm begleitet, das neben dem Streckenausbau und neuen Fahrzeuganschaffungen auch Investitionen in die Bahnhofsanlagen umfasste. Die Investitionen mündeten in der Sanierung und im Neubau einer Reihe von Bahnhöfen in Groß- und Mittelstädten, allen voran in der Umgestaltung des Leipziger Hauptbahnhofes (eröffnet 1997) und dem Neubau des Berliner Hauptbahnhofes (eröffnet 2006). In diesen und anderen Baumaßnahmen hielt erstmals seit Jahrzehnten wieder ein wartebezogenes Raumprogramm Einzug, das sich jedoch in Form eines exklusiven Lounge-Konzepts materialisierte. Die modernisierten Bahnhofsbauten verfügten nun zwar (wieder) über dezidierte Warteräume, doch diese standen (und stehen bis heute) nur Reisenden erster Klasse oder Teilnehmenden des DB-Vielfahrerprogramms BahnComfort zur Verfügung. Somit ist im Rahmen der Renaissance der Bahnhöfe seit den 1990er Jahren zwar eine zarte Tendenz zur Rehabilitierung des würdevollen Wartens zu beobachten, die neugeschaffenen Strukturen der $D B$ Lounges reichen aber - und dies trotz insgesamt starker architektonischer und sprachlicher Rückgriffe auf die symbolische Bedeutsamkeit des Eisenbahnwesens in seiner Blütezeit ${ }^{17}$ - kaum an vormalige Raumangebote und -anmutungen heran. Aktuell bestehen 15 solcher Lounges in deutschen Bahnhöfen, die zwar jährlich von mehr als fünf Millionen Passagieren besucht werden, ${ }^{18}$ doch angesichts der Gesamtverkehrsleistung von 4,7 Milliarden Reisender im Betriebsjahr $2018^{19}$ nehmen die in den DB Lounges wartenden Reisenden einen nur verschwindenden Anteil ein. Die Mehrheit der Reisenden erwartet die Abfahrt dagegen auf den aufgestellten Sitzbänken, stehend direkt am Gleis oder vor allem in den zahlreichen Geschäften der zum Einkaufsbahnhof restrukturierten Verkehrsbauten. Das systemische Warten auf Eisenbahnen ist in den Bahnhöfen der sechsten Generation somit überwiegend von der Praxis des möglichst späten Erscheinens am Bahnhof oder des Konsums geprägt. Hinsichtlich dieser historischen Kontinuität, die nun jedoch gänzlich zum strukturbildenden Element geworden ist, vermerken Herzog und Leis:

»Die Bahnhofsarchitektur erweist sich als durchaus kompatibel mit der modernen Erlebniswelt des Konsums, die einen überbordenden Markenmix und Dienstleistungs-

16 Wucherpfennig, Bahnhof: (stadt)gesellschaftlicher Mikrokosmos im Wandel, 50. Tatsächlich verlief die Entwicklung der Fahrgastzahlen zunächst positiv, brach jedoch von 2000-2004 wieder ein und sank sogar unter das Niveau vor der Bahnreform. Seit 2004 steigen jedoch die Fahrgastzahlen jährlich wieder an, zuletzt (2017 zu 2018) um $4 \%$.

17 So zielte die Konzeption des für den Neubau des Berliner Hauptbahnhofes verantwortlichen Architekturbüros GMP ganz in alter Tradition auf den Bau einer `Kathedrale des Verkehrs « samt sprachlicher und materieller Anleihen an ein >Tor zur Welts.

18 Deutsche Bahn AG, »Für eine starke Schiene: Leipziger DB Lounge und DB Reisezentrum im neuen Design und mit neuem Konzept«, 14. August 2019, https://www.deutschebahn.com/prleipzig-de/aktuell/presseinformationen/Fuer-eine-starke-Schiene-Leipziger-DB-Lounge-und-DBReisezentrum-im-neuen-Design-und-mit-neuem-Konzept-4389980, zugegriffen am 14.12.2019.

19 Deutsche Bahn AG, »Kennzahlen 2018«, 2019, https://www.deutschebahn.com/resource/blob/4045082/74a5d3db2bc75888121897cefada8823/20190328_pbk_2019_kennzahlen-data.pdf, zugegriffen am 14.12.2019. 
angebote in Fülle bietet. (...) Bahnhöfe entwickeln sich (...) zu Schleusen für Shopping, mithin zu eigenen Wirtschaftsräumen. ${ }^{20}$

Auch mit Blick auf weitere ikonische Neubauten der sechsten Phase - Waterloo International Station für den Eurostar (1994) oder Calatravas TGV-Bahnhof Satolas am Lyoner Flughafen (1994) - wird keine »eindeutige stilbildende wie funktionale Identität der Bahnhofsarchitektur des 21. Jahrhunderts $\aleph^{21}$ ersichtlich. Mit diesem Befund scheint sich angesichts der in allen Epochen eklektischen und heterogenen Bahnhofsarchitektur jedoch eher eine Kontinuität als eine Ausnahme abzuzeichnen. Verbindendes Element in der sechsten Phase ist vielmehr, dass sich die Neubauten deutlich an der Flughafenästhetik zu orientieren scheinen. Zudem bildet die Verwertungsmöglichkeit einer eingebauten Ladenpassage ein weiteres inhaltlich leitendes Strukturelement der internationalen Bahnhofsmodernisierungen. Wenngleich also die Bauaufgabe Bahnhof nach einer langen Phase der Vernachlässigung wieder ihre architektonisch und stadtraumrelevante Rolle wiederzuentdecken scheint, werden die wenigen Neubauten nicht selten als Leuchttürme kritisiert, die trotz des milliardenschweren Investitionsprogramms in der Fläche kaum Wirkung und Sichtbarkeit entwickeln würden. So resümiert ein Beitrag in der Deutschen Bauzeitung 15 Jahre nach Beginn der Bahnreform und dem Aufbruch in eine Renaissance der Bahnhöfe, dass die Situation des Gesamtsystems nach wie vor problematisch sei und diese Renaissance bislang nur wenige Groß- und Mittelstädte erreicht habe. Für die meisten Bahnhöfe gelte stattdessen noch immer, dass »die einst im Bahnhof angebotenen Dienstleistungen vom Reisenden schmerzlich vermisst [wer-

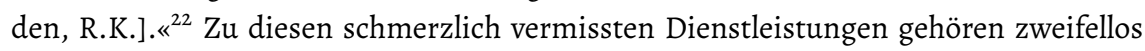
auch komfortable und würdevolle Wartemöglichkeiten jenseits der wenigen exklusiven DB Lounges und einiger neu errichteter Wartezonen auf Bahnsteigen und in Verbindungshallen. Aus der diachron kulturgeschichtlichen Perspektive des verkehrlichen Wartens bleibt somit an dieser Stelle festzuhalten, dass die aktuelle sechste Phase des Bahnhofsbaus zwar eine Wiederentdeckung und Rehabilitation des Warte-Phänomens beinhaltet, die baulichen Maßnahmen in der Breite bislang aber kaum eine bedeutende Aufwertung der Aufenthaltsqualität erzeugt haben. Angesichts der schwerpunkthaft dienstleistungsorientierten Umgestaltung zu Einkaufsbahnhöfen liegt die äußere Zuschreibung der Wartepraxis dagegen offensichtlich im fluiden Warten, dem Wandeln und Flanieren in der Angebotswelt der Ladenpassage, nicht jedoch im stationären Aufenthalt.

\section{b) Wahrnehmungskonjunkturen des (verkehrlichen) Wartens}

Nachdem die bauliche Rahmung des Wartens auf Eisenbahnen im weiteren Verlauf des 20. und frühen 21. Jahrhunderts umrissen wurde, bleibt nun die spannende wie kom-

20 Herzog und Leis, »Der Bahnhof: Kathedrale, Erlebniswelt, Sozialstation und Konsumparadies«, 13.

21 Wucherpfennig, Bahnhof: (stadt)gesellschaftlicher Mikrokosmos im Wandel, 60.

22 Lars Quadejacob, »»Renaissance der Bahnhöfes? - 15 Jahre Deutsche Bahn AG «, db deutsche bauzeitung, 02 2009, https://www.db-bauzeitung.de/aktuell/diskurs/renaissance-der-bahnhoefe-15jahre-deutsche-bahn-ag/, zugegriffen am 18.12.2019. 
plexe Frage zu explorieren, welche Konjunkturen in dieser Zeitspanne die öffentliche Wahrnehmung des verkehrlichen Wartens durchlaufen hat.

Dabei steht diese Exploration vor der Problematik, dass die Bewertung und Wahrnehmung von Wartezeiten - begriffen als ein Spezialfall der Zeitwahrnehmung - nur in Abhängigkeit von Kontextbedingungen eines übergeordneten Zeitbewusstseins erfolgen kann. Mit Rückgriff auf die zeittheoretischen Kapitel (vor allem 2.4 und 3.1.1) soll daher noch einmal in Erinnerung gerufen werden, dass sich die Wahrnehmung von Zeitphänomenen aus kultursoziologischer Perspektive heraus stets an vorfindbaren Zeitstrukturen orientiert. Die idealtypisch leitende Zeitstruktur funktional differenzierter Gesellschaften der Hochmoderne bildet dabei das lineare Zeitbewusstsein mit offener Zukunft. ${ }^{23}$ Danach läuft die historische Entwicklung nicht (mehr) teleologisch auf ein Ziel zu, sondern wird als offen (und gestaltbar) angenommen. Ein Erstbefund auf dem Weg zur Beantwortung der Frage nach Wahrnehmungskonjunkturen lautet somit, dass sich das verkehrliche Warten im 20. und frühen 21. Jahrhundert wie bereits im 19. Jahrhundert im übergeordneten Rahmen derselben normativ leitenden Zeitstruktur abspielt. Innerhalb dieser Zeitstruktur prägt sich jede Form der Zeitwahrnehmung (im westlichen Kulturkreis) wechselseitig im Verhältnis zwischen subjektiver Erfahrung von Rhythmen und Abfolgen aus, die gegen eine objektive Referenzgröße der mechanisierten Uhr- oder Kalenderzeit gehalten werden. Der spezifische Moment des Wartens bedingt hierbei nun, dass die Ableitungszusammenhänge zwischen subjektivem Zeitempfinden und objektiven Bezugsgrößen erheblich gestört werden. ${ }^{24}$ Diese gegenüber dem 19. Jahrhundert unveränderte Ausgangslage bewirkt somit, dass Wartezeiten auch im weiteren Verlauf der Moderne tendenziell als irritierende Unterbrechung des Zeitempfindens (in Form eines linearen Zeitflusses) wahrgenommen werden.

Jenseits des stabilen zeitstrukturellen Rahmens liegt jedoch der entscheidende kontextuelle Wandel des 20. Jahrhunderts in einer veränderten Qualität des modernen Zeitbewusstseins. Für Hartmut Rosa liegt diese veränderte Qualität in der permanenten Beschleunigung und einer daraus resultierenden Zeitkrise. Zwar erzeugen hochmoderne Gesellschaften immer größere Zeitersparnisse, zugleich aber sind sie vom kollektiven Gefühl ergriffen, permanent keine Zeit zu haben, was sich pathologisch gar in einer Chronophobie - der Angst vor dem unaufhaltsamen Vergehen der Zeit - äußern kann. Das Leitmotiv der Beschleunigung konnte im Laufe des 20. Jahrhunderts also deshalb greifen, weil die dadurch erzielten Zeitersparnisse eine zentrale gesellschaftliche Zielstellung bilden. Rosa betrachtet diese allgemeine Aspiration nach zeitsparender Geschwindigkeitszunahme daher sogar als »das eigentlich treibende Moment der (modernen) Geschichte. $\ll^{25}$ Angesichts der Ausgangslage eines gegenüber dem 19. Jahrhundert verstärkten Akzelerationsprozesses, der Zeit noch stärker als knappe Ressource und Produktionsfaktor begreift, erfahren die ohnehin als Irritation wahrgenommenen Verlangsamungen oder Stillstände im 20. Jahrhundert eine nochmals stärkere Problematisierung. In welcher Form auch immer die Phänomene von Verharrung und Stillstand erscheinen, sie stehen im Laufe des 20. Jahrhunderts unter zunehmendem Verdacht, 
das Telos der Moderne zu gefährden. Wenn ein konstitutives Leitprinzip der Moderne also in der Erwartung und Realisierung von Beschleunigung auszumachen ist, so ist anzunehmen, dass auch das (lange) Warten auf Beförderung in den Stand eines problembehafteten Ereignisses trat.

\section{Die Rolle neuer Verkehrstechnologien}

Jenseits einer grundsätzlichen Rechtfertigungspflicht von Stillständen gegenüber der Bewegung steht hierbei zu vermuten, dass sich eine negative Wahrnehmung des situativen Wartens auf Eisenbahnen (und öffentlichen Verkehr allgemein) im weiteren Verlauf des 20. Jahrhunderts insbesondere auch aufgrund des kontrastierenden Paradigmas konkurrierender Verkehrsmittel auszubreiten begann. Diese Parallelentwicklung erscheint deshalb signifikant für die Wahrnehmung systemischer Wartesituationen, weil der sich seit dem frühen 20 . Jahrhundert rapide ausbreitende Individualverkehr (sowohl motorisiert als auch nicht-motorisiert) gänzlich neue Möglichkeiten zur unmittelbaren Verkehrsmittelnutzung schuf. Die einsetzende Differenzierung der Verkehrslandschaft erzeugte durch die Zugewinne an Geschwindigkeit und individueller Nutzung gänzlich neue temporale Erwartungshaltungen und ermöglichte zugleich erstmals neue Vergleichsebenen zur Beurteilung der situativen Wartezeit vor der Abfahrt. Mit anderen Worten: Während das Warten auf Beförderung im Laufe des 19. Jahrhunderts aufgrund der für die Mehrheit der Menschen primär öffentlich erfahrenen Verkehrsbewegungen (auf Eisenbahnen, Schiffen etc.) im Grunde als alternativ- und referenzlos erscheinen musste, ermöglichte der Individualverkehr des frühen 20 . Jahrhunderts erstmals eine kontrastierende Wahrnehmung. Hierbei dürfte zunächst insbesondere das Fahrrad eine zentrale Rolle gespielt haben, zu dessen revolutionärer Bedeutung für die Verkehrspraxis Colin und Marilyn Pooley festhalten:

»From the late-nineteenth century the bicycle could provide quick and convenient travel over relatively short distances, and it could be used as a substitute for walking (where it had the advantage of speed) or public transport (where its main advantages were privacy and flexibility). Before the 1920 s bicycles were too expensive for most families on low incomes, and cycling was mainly undertaken by the middle classes (and above) for leisure purposes. $\aleph^{26}$

Mit Aufkommen des Fahrrads erschien das Warten auf öffentlichen Verkehr nicht mehr alternativlos. Die Unmittelbarkeit des Fahrtantritts mit dem Fahrrad benötigte schlichtweg keinen präparatorischen Aufenthalt mehr. Die referenzielle Erfahrung der Unmittelbarkeit, der Flexibilität sowie der Entdeckung der Möglichkeit zur individuellen Mobilitätsbefriedigung samt seiner intrinsischen Qualitäten dürfte somit seit der rapiden Verbreitung des Fahrrads in den 1920er Jahren auch die Warteerfahrung verändert, sie aus der unhinterfragten Wahrnehmung einer Alternativlosigkeit befreit und sie (zu-

26 Colin C. Pooley und Marilyn E. Pooley, » We're going to move . . . I can't rush backwards and forwards, I'll go mad - I am sure of it. «, in Architectures of Hurry: Mobilities, Cities and Modernity, hg. von Phillip Gordon Mackintosh, Richard Dennis, und Deryck Holdsworth (New York: Routledge, 2018), 199. 
mindest im Nahverkehrsbereich) als (zeitraubenden) Unterschied spürbar gemacht haben.

Parallel zum Fahrrad stellten das Motorrad ${ }^{27}$ und das Automobil die entscheidenden Vehikel zur Entdeckung individueller (wartefreier) Mobilität dar. Zwar steuerten zunächst aufgrund der teuren Anschaffung und Haltung nur verhältnismäßig wenige Menschen ein Auto, doch die sich durch den motorisierten Verkehr einstellende temporale Erwartungshaltung einer unmittelbaren Abfahrt wirkte hier in Verbindung mit dem hohen Geschwindigkeitsniveau umso stärker. Die individuelle Auto- und Motorradnutzung stand (und steht) somit verkehrsgeschichtlich in der wohl denkbar größten Opposition zur Verkehrspraxis eines präparatorischen Aufenthalts im Wartesaal. Der Aufstieg der Individualmobilität im frühen 20. Jahrhundert kann somit nicht zuletzt als ein Erklärungsangebot der erstmals stärkeren Thematisierung (und Problematisierung) des Wartens auf Eisenbahnen angeführt werden, die ein Ergebnis der rezeptionsgeschichtlichen Analyse der vierten Entwicklungsphase (Kap. 9.3) darstellte. Zwar konnten hier keine Belegstellen gefunden werden, die eine negative Wendung des Wartens direkt in Zusammenhang mit einer Alternativerfahrung des wartefreien Individualverkehrs brachten, dennoch dürfte die weitverbreitete Erfahrung des Radfahrens und der Auto- bzw. Motorradnutzung unterbewusst wirksam geworden sein.

Mit dem Aufkommen der zivilen Luftfahrt erlebte das Verkehrswesen in den 1920er Jahren nochmals eine Verbreiterung der Verkehrslandschaft. Aufgrund der direkten Verkehrsbewegung in der Luft und der hohen Geschwindigkeitspotentiale versprach der Flugverkehr entsprechend große Zeitersparnisse zu erzielen. Doch trotz der großen Geschwindigkeitspotentiale bot der Flugverkehr zumindest nicht den Vorteil eines unmittelbaren Zugangs. Auch am Flughafen war - wie im Bahnhof - ein präparatorischer Zwischenaufenthalt zu absolvieren. Das Flugzeug konnte nicht unmittelbar bestiegen werden und auch die operative Praxis vor Abflug erforderte analog zu den Eisenbahnen eine intendierte Retardierung von Passagierströmen zum Zweck der Gewährleistung von Kontrolle und Sicherheit. Zwar zählte die Flugreise in den 1920er und 1930er Jahren zweifellos zur exklusiven und repräsentativen Verkehrspraxis der Oberschicht, doch zumindest hinsichtlich des verkehrlichen Wartens stand der Flugverkehr in keiner anderen Beziehung als andere öffentliche Verkehrsangebote, die jeweils die strukturelle Besonderheit der Synchronisation vieler Reisender in ein und demselben Verkehrsmittel sicherstellen mussten. Ausgehend von Rosas Auffassung, nach der in der beschleunigten Moderne ein subjektiver Eindruck von Verlangsamung besonders dort groß erscheint, wo unterschiedliche Prozessgeschwindigkeiten aufeinander treffen, ${ }^{28}$ kann die systemische Wartezeit vor dem Abflug aber möglicherweise als signifikantestes Feld der kritischen Wartezeitwahrnehmung verstanden werden. Mit Blick auf den Flugverkehr wird zudem frappierend deutlich, wie sehr das systemische Warten auf

27 Das Motorrad ist hier im Besonderen zu erwähnen, da es in den 1920er Jahren im Gegensatz zum Automobil von weiten größeren Kreisen der Gesellschaft erworben werden konnte. Vgl. zur technik- und verkehrsgeschichtlichen Bedeutung des Motorrads in der Weimarer Republik: Sasha Disko, »Men, Motorcycles and Modernity: Motorization During the Weimar Republic« (Unveröffentlichte Dissertation, New York University, 2008). 
Beförderung im öffentlichen Verkehr vom jeweiligen Geschwindigkeitsniveau des Verkehrsmittels abhängt. So ist die Wartezeit vor Abfahrt mit einem Bus oder einer S-Bahn in der Regel wesentlich kürzer als jene vor Abflug eines Verkehrsflugzeuges. Obwohl beide Verkehrsmittel objektiv betrachtet unmittelbar bestiegen werden könnten, korreliert die höhere Transportgeschwindigkeit des Flugzeugs mit erhöhten Sicherheitsund Synchronisationsbedarfen, die in längeren Wartezeiten resultieren. Weil die Organisation von beschleunigtem Massenverkehr ein organisatorisches Problem darstellt, zeigt sich somit die seit dem frühen 20 . Jahrhundert absolute Wartezeit auch als eine Funktion der Beförderungsgeschwindigkeit. ${ }^{29}$

Zusammenfassend ergibt sich damit für das frühe 20. Jahrhundert der wahrnehmungskonjunkturelle Befund, dass das verkehrliche Warten im Zuge des Aufschwungs des Individualverkehrs in den 1920er und 1930er Jahren einen konnotativen Knick erfährt. Diese Entwicklung sollte sich nach 1945 angesichts der Massenmotorisierung in den westlichen Industrienationen noch weiter verstärken. So kann vermutet werden, dass sich die bereits in Teilen der Gesellschaft ausgebildete temporale Erwartungshaltung einer unmittelbaren und flexiblen Abfahrt im Zuge der Etablierung automobiler Gesellschaften noch weiter verschärft haben dürfte. In gleichem Maße wie die individuelle Mobilität zum gesellschaftspolitischen Dogma erklärt wurde und der Besitz des eigenen Autos zur kollektiven und persönlichen Zielstellung avancierte, dürfte die Toleranz gegenüber den im öffentlichen Verkehr erzwungenen systemischen Wartezeiten abgenommen haben. Zudem wurde die sinkende Toleranz gegenüber Wartezeiten bei öffentlicher Beförderung auch dadurch verstärkt, weil in den 1950er bis 1970er Jahren das Warten auf Abfahrt an schlecht ausgestatteten Bahnhöfen und Haltestellen zu einem Symbol der sozialen Desynchronisation vom gesellschaftlichen Dogma der Individualmobilität reifen konnte. Mit anderen Worten: Während das Warten auf Abfahrt aus zeittheoretischer Perspektive ohnehin bereits eine temporale Desynchronisation zum sonst erwartbaren Zeitfluss darstellt, bewirkte das übergeordnete Leitbild einer automobilen Gesellschaft in der zweiten Hälfte des 20. Jahrhunderts aller Wahrscheinlichkeit nach die zusätzliche Verschärfung um die Dimension einer sozialen Desynchronisation. Das Warten an Stationen des öffentlichen Verkehrs konnte nicht selten - vor allem im Falle des vorbeifahrenden Individualverkehrs (Bushaltestelle) - als materieller Ausdruck sozioökonomischer Unterschiede interpretiert werden. Infolgedessen soll an dieser Stelle als explorative These festgehalten werden, dass sich die Konnotation des Temporalphänomens in den westlichen Industrienationen spätestens seit den 1960er Jahren kontinuierlich weiter ins Negative wendete.

Der mit der Massenmotorisierung manifestierte Anspruch einer flexiblen und unmittelbaren Verkehrsmittelnutzung zeitigte dabei aber zugleich einen der signifikantesten Paradoxaleffekte der beschleunigungsaffinen Moderne. So entstand mit dem Ver-

Vgl. zur Thematik des Zusammenhangs unterschiedlicher Ceschwindigkeitsniveaus und absolvierter Wartezeiten im öffentlichen Verkehr: Robin Kellermann, »Bus Stop, Platform, Departure Gate: A Comparative Assessment of Transport Environments Concerning the Interrelations of Speed and Waiting. " (12th Annual Conference of the International Association for the History of Transport, Traffic and Mobility ( $\left.T^{2} M\right)$, Philadelphia, USA, 2014). 
Abbildung 52: Lufthansa-Wartebereich am Zentralflughafen Berlin-Tempelhof (1930).

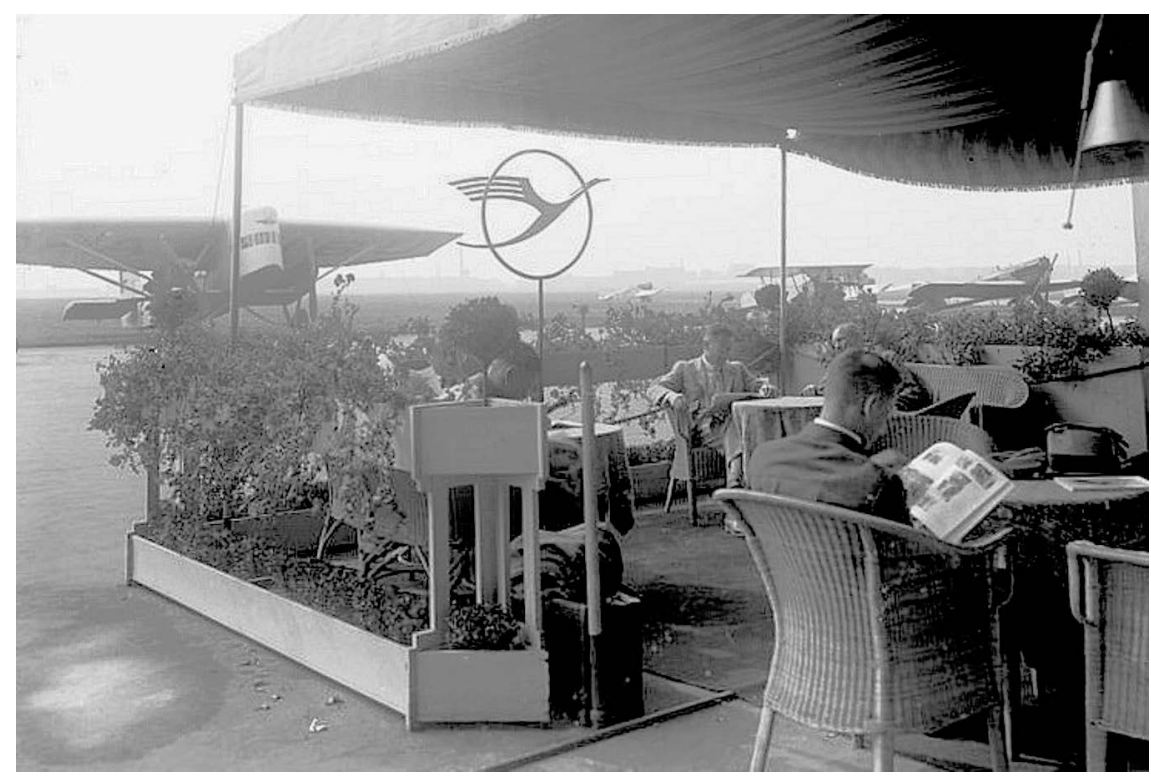

Quelle: Bundesarchiv, Bildinventar 102-09525.

kehrsstau ausgerechnet die wohl prominenteste verkehrliche Warteausprägung überhaupt. ${ }^{30}$ Der Stau zeigt sich hier als dysfunktionale Nebenfolge der allgemeinen Aspiration beschleunigter Mobilität und verdeutlicht die Anfälligkeit des Akzelerationsprozesses für "potentielle Reibungsprobleme an den Synchronisationsstellen $« .{ }^{31}$ Der Stau offeriert damit eindrücklich die bis in die Gegenwart hinein ungebrochene Wechselwirkung von Prozessen der Beschleunigung und Bremsung. So treten Phänomene der Retardierung zum Teil selbst erst als dysfunktionale Nebenfolgen der Beschleunigungsprozesse auf.

Zusammenfassend kann trotz der Zunahme von Dysfunktionalitäten im Verkehrswesen für die zweite Hälfte des 20. Jahrhunderts vermutet werden, dass der situative Aufenthalt an Bahnhöfen und Haltstellen des öffentlichen Verkehrs im Kontext des übergeordneten Leitbilds von beschleunigter Individualmobilität zu einer kollektiven Erfahrung wurde, die es möglichst zu vermeiden gilt. Der Aufenthalt in den zunehmend unattraktiven Bahnhöfen, die kaum mehr über Warteinfrastrukturen verfügen, wird dabei zu einem Teilaspekt der übergreifend sinkenden Attraktivität des öffentlichen Verkehrs. Getrieben durch die temporale Erwartungshaltung einer unmittelbaren und zeitsparenden Verkehrsmittelnutzung ist die Toleranz und Bereitschaft für den

Dazu für den bundesdeutschen Kontext Dietmar Klenke, »Freier Stau für freie Bürger«: die Ceschichte der bundesdeutschen Verkehrspolitik; 1949-1994 (Darmstadt: Wissenschaftliche Buchgesellschaft, 1995).

Rosa, Beschleunigung: die Veränderung der Zeitstrukturen in der Moderne, 145. 
situativen Aufenthalt tendenziell als niedrig einzustufen. Denn wie in kaum einer anderen Alltagssituation wird dem modernen Subjekt hierbei in Erinnerung gerufen, dass der Stillstand (insbesondere im Falle der Verspätung) gegenüber der Bewegung die Charakteristik eines krisenhaften Zustands samt negativer sozioökonomischer Symbolik erhalten hat.

\section{Warten im digitalen Zeitalter}

Die explorative Erschließung von Entwicklungskonjunkturen der verkehrlichen Wartezeitwahrnehmung muss aber nicht nur im Zusammenhang mit der Etablierung neuer Verkehrstechnologien betrachtet werden, sondern sie wird zudem auch durch andere Technologieangebote beeinflusst, die nicht unmittelbar mit dem Verkehrswesen zusammenhängen. Die stärkste technologische Zäsur, die neben dem Aufkommen neuer Verkehrstechnologien aktuell Einfluss auf Wahrnehmung und Praxis des situativen Wartens genommen haben dürfte, ist fraglos die Durchdringung der Gesellschaft mit Informations- und Kommunikationstechnologien (IKT) seit den 1990er Jahren. In dieser digitalen Revolution sieht Rosa den massivsten Beschleunigungsschub der Moderne überhaupt, weil mit ihr eine gänzlich neue Art der Prozessverstärkung und der globalen Vernetzung in Verbindung steht..$^{32}$ Sie bildet eine anhaltende Triebkraft wirtschaftlicher, informationeller und kultureller Transformation und eines generationellen Anpassungsprozesses, der auf allen gesellschaftlichen Ebenen wirksam wird. Informationen, die zuvor nur in spezifischen physischen Formen vorkamen (Bücher, Archive, $\mathrm{Mu}$ seen, Bibliotheken etc.) oder in Personen verkörpert waren (Wissenschaftler, Politiker, Archivare etc.) werden mobilisiert, ihr Austausch in ungekannter Art beschleunigt.

Im Spektrum der unzähligen Niederschlagsfelder, in denen der Einsatz und die Nutzung digitaler Technologien und mobilisierter Informationen eine raumzeitliche Veränderungswirkung entwickeln, ist auch das situative Warten von einer tiefgreifenden Veränderungsdynamik geprägt. IKT verändern die Praxis und damit verbunden die Wahrnehmung des situativen Aufenthalts an Bahnhöfen und Haltestellen immens, denn die individuelle Nutzung von IKT mittels internetfähiger Smartphones ermöglicht eine Reihe neuer Handlungsspielräume für die produktive und informatorisch aufgewertete Reisezeitnutzung, die in der Verkehrsgeschichte beispiellos sind.

Die Nutzung von Smartphones im Verkehrskontext bedient hierbei vor allem die für die Verkehrspraxis immanente Problematik eines vergleichsweise hohen Informationsbedarfs. Aufgrund der vielfältigen Raum- und Sachzwänge erfordert die Reise im Allgemeinen und jene mit öffentlichen Verkehrsmitteln im Besonderen traditionell ein permanentes Geflecht an Informationen (Orte, Zeiten, Wege etc.). Die unablässige Notwendigkeit zur raumzeitlichen Orientierung und dem Treffen von Entscheidungen schafft Abhängigkeiten und kreiert Ungewissheiten, die sich auf die psychologische Verfassung der Reisenden auswirkt und erheblichen Einfluss auf die Nutzungsbereitschaft ausüben kann. Entsprechend ist die Geschichte der Eisenbahnreise auch stets eine Geschichte der technisch und zeichenhaft bestrebten Kompensation der Unsicherheiten gewesen, die sich in Gestalt von Fahrplänen und Zuganzeigern bis hin zur Etablierung von Lautsprecherdurchsagen niederschlägt. Reziprok ist auch der Aufstieg 
des Individualverkehrs aus einer informationellen Perspektive nicht zuletzt dadurch zu erklären, dass Reisende im Individualverkehr die Wahrnehmung einer größeren Kontrollfähigkeit erlangen und (gefühlt) die Abhängigkeit von externen Einflüssen verringern können.

In dieser Gemengelange entfalten IKT die für das Temporalphänomen des Wartens wohl stärkste Wirkung. Sie veranlassen eine verkehrsgeschichtlich beispiellose Reduktion von Unsicherheit erzeugenden Informationsdefiziten. Internetfähige Smartphones und IKT-basierte Einrichtungen in Empfangsgebäuden, an Bahn- und Flugsteigen oder Haltestellen reduzieren die aus Sicht der Reisenden gefühlte Kontingenz der Ereignisse, schaffen eine stärkere Planbarkeit und erhöhen die Wahrnehmung situativer Kontrolle. Zudem wird durch die Mitführung von Smartphones, Tablets oder Laptops der Aktionsspielraum der Reisezeitnutzung grundlegend in Richtung neuer Möglichkeiten der Kommunikation, Unterhaltung und Zerstreuung erweitert. Kurzum: Das ohnehin bereits reichhaltig gefüllte Reservoir der Möglichkeiten eines »equipped waiting «33 wird gegenwärtig deutlich vergrößert. Die historisch gewachsene und habitualisierte Reisezeitnutzung (Lesen, Kommunikation im Abteil etc.) wird durch die IKT-Nutzung in Richtung eines vielfältigen Medienkonsums und neuer Arbeitsmöglichkeiten weiterentwickelt. Lyons und Urry bemerken hinsichtlich dieser revolutionären Wirkung:

»We have already highlighted that it is not the ICTs themselves are important in relation to this question. Rather, it is the change that they might bring about to the types of activity that can be undertaken on the move and more particularly still to the underlying attributes of these activities. In this context there is a need to understand to what extent ICTs provide more than only substitutes to their straditionak counterparts and indeed to what extent ICTs used on the move will influence the pool of social practices. Yet again the call for empirical evidence is made - not only do we need to develop the productivity distributions but we need to see how they are changing, or not, over time and determine to what such change is attributable. ${ }^{34}$

\section{Erneute Subsumierung der Warteerfahrung?}

Die Praxis des (verkehrlichen) Wartens ist durch den Einsatz von IKT also gegenwärtig wahrlich in Bewegung geraten. Sie hat dabei das Phänomen selbst verändert. Das Zusammenspiel der Reduktion von Unsicherheiten bei gleichzeitiger Erweiterung der (wahrgenommenen) Kontrollfähigkeit und faktischer Handlungsmöglichkeiten muss aus einer mobilitätsgeschichtlichen Längsschnittperspektive als historisch absolut einschneidend und bedeutsam eingeordnet werden. Die Einführung von IKT im öffentlichen Verkehrswesen kann dabei, so soll hier argumentiert werden, gar als ähnlich einschneidender Moment aufgefasst werden, wie jener des Aufkommens des Phänomens in den 1830er Jahren selbst.

33 Gasparini, »On Waiting «. In diesem Zusammenhang ist zu bemerken, dass auch das Medium der Musik bereits seit den frühen 1980er Jahren mittels tragbarer Abspielgeräte (Walkman etc.) das Spektrum der Reisezeitnutzung erweiterte.

34 Glenn Lyons und John Urry, »Travel time use in the information age«, Transportation Research Part A: Policy and Practice 39, Nr. 2-3 (2005): 25. 
Die theoretisch denkbare und angestrebte vollumfängliche Informationsbereitstellung (Echtzeitpositionen auf Karten, Push-Mitteilungen über Verspätungen, Umleitungen etc.) lässt erstmals in der Geschichte der Reise die modalen Grenzen zwischen dem situativen Warten auf Beförderung und der Beförderung selbst verschwimmen. Beide Modalitäten, der situative Aufenthalt und der Transport nähern sich an. Reisende werden durch die ungekannte Mediatisierung des Smartphones und seiner ermöglichten virtuellen Mobilität nicht erst mit Bewegung des Zuges zum Passagier, sondern sind es bereits vor Eintreffen bzw. Abfahrt des Zuges. So ließe sich die These formulieren, dass das Warten im digitalen Zeitalter bereits vollends die Qualität des Mobilen erlangt hat. Das Phänomen des vormals primär statischen Aufenthalts wird zunehmend verflüssigt $<$ und verliert an Trennschärfe gegenüber dem Modus eines >Nicht-Wartens $<$. Es verliert sich ferner in einer neuen, von Aktivität geprägten Gemengelage. Diese Verflüssigungsthese ruft gleichsam die Situation der Pionierphase des Eisenbahnwesens in Erinnerung, in der das Warten unter eine aufgeregte Gesamterfahrung subsumiert wurde, die prominent im Reisebericht von Hans-Christian Andersen und dessen Erstkontakt mit der Eisenbahn in den 1830er Jahren zum Ausdruck kam. Es bleibt also zu diskutieren und zu beobachten, ob sich hier nach fast 200 Jahren ein Kreis schließt, indem das verkehrliche Warten wiederum unter eine Gesamterfahrung subsumiert wird.

\section{Neue Ambivalenzen und Abhängigkeiten}

Während die IKT-Nutzung durchaus zu einer allgemeinen Entspannung der negativen Konnotation des Wartens und zu dessen Rehabilitation - vielleicht sogar zur kollektiv wahrgenommenen Transformation in einen mögenswerten Zwischenzustand beitragen kann, sind zugleich Zweifel an dieser These anzumelden. Sie bestehen darin, dass der allgemeine Informationszugewinn zugleich paradoxale Effekte der Wartezeitwahrnehmung generieren könnte. ${ }^{35}$ So wird zwar etwa mit Blick auf die Installation von Echtzeitinformationssystemen an Haltestellen einerseits nachweislich die wahrgenommene Wartezeit deutlich reduziert, ${ }^{36}$ zugleich wird durch die Anzeige der noch verbleibenden Zeit bis zur Abfahrt die Wartezeit wiederum erst herausgestellt, ihre Andersartigkeit nochmalig betont. Das ohnehin vorhandene Bewusstsein eines steuren Zeitwerts wird durch die Countdown-Anzeige auf Bildschirmen nochmals sausgestelltr. Diese rausgestellte Zeit - so könnte eine kulturkritische Ableitung lauten - stellt aber im Grunde jene Zeit aus, die verloren wird. Die angezeigten Minuten bis zur Abfahrt explizieren damit die Andersartigkeit der Wartezeit im Verkehr und bewirken die Festigung einer dichotomen Wahrnehmung von linearem Zeitfluss und dessen (negativer)

35 Vgl. Robin Kellermann, »The Final Countdown. Ambiguities of real time information systems >directing s the waiting experience in public transportation«, in Experiencing Networked Urban Mobilities, hg. von Malene Freudendal-Pedersen, Katrine Hartmann-Petersen, und Emmy Laura Perez Fjalland (London: Routledge, 2017), 19-26.

36 Vgl. Katrin Dziekan und Karl Kottenhoff, »Dynamic At-Stop Real-Time Information Displays for Public Transport: Effects on Customers«, Transportation Research Part A: Policy and Practice 41, Nr. 6 (Juli 2007): 489-501; William Chow, David Block-Schachter, und Samuel Hickey, »Impacts of RealTime Passenger Information Signs in Rail Stations at the Massachusetts Bay Transportation Authority«, Transportation Research Record: Journal of the Transportation Research Board 2419, Nr. 1 (Januar 2014): 1-10. 
Unterbrechung in Form der Wartezeit. In diesem Sinne könnte eine zeitkulturkritische Position in der Installation von IKT-basierten Echtzeitinformationssystemen darin bestehen, dass das ohnehin konfliktreiche und fragwürdige Verhältnis gegenüber Wartezeiten in einer auf Effizienz, Geschwindigkeit und Linearität ausgerichteten Zeitkultur der westlichen Welt abermals bestätigt wird. Anstatt die in unseren Gesellschaften entstehenden Zeitnischen zu rehabilitieren, bedienen Echtzeitinformationssysteme (oder Apps) eher ein produktivistisches Verständnis vom Warten, das David Bissell als Logik eines "quiescing time, in effect to silence it ${ }^{37}$ beschreibt. Der paradoxale Effekt von IKT könnte somit darin bestehen, dass die Wartezeit zwar sgezähmt<, zugleich aber eine relevante Diskussion über das Anerkennen von Wartezeiten als »meaningful experience ${ }^{38}$ oder gar 'geschenkter Zeit ${ }^{39}$ verdrängt und so eine Chance des novellierten Zeitumgangs vertan wird.

\section{Abbildung 53: Moderiertes Warten:}

Echtzeitinformationssystem im Berliner Nahverkehr (eigene Aufnahme).

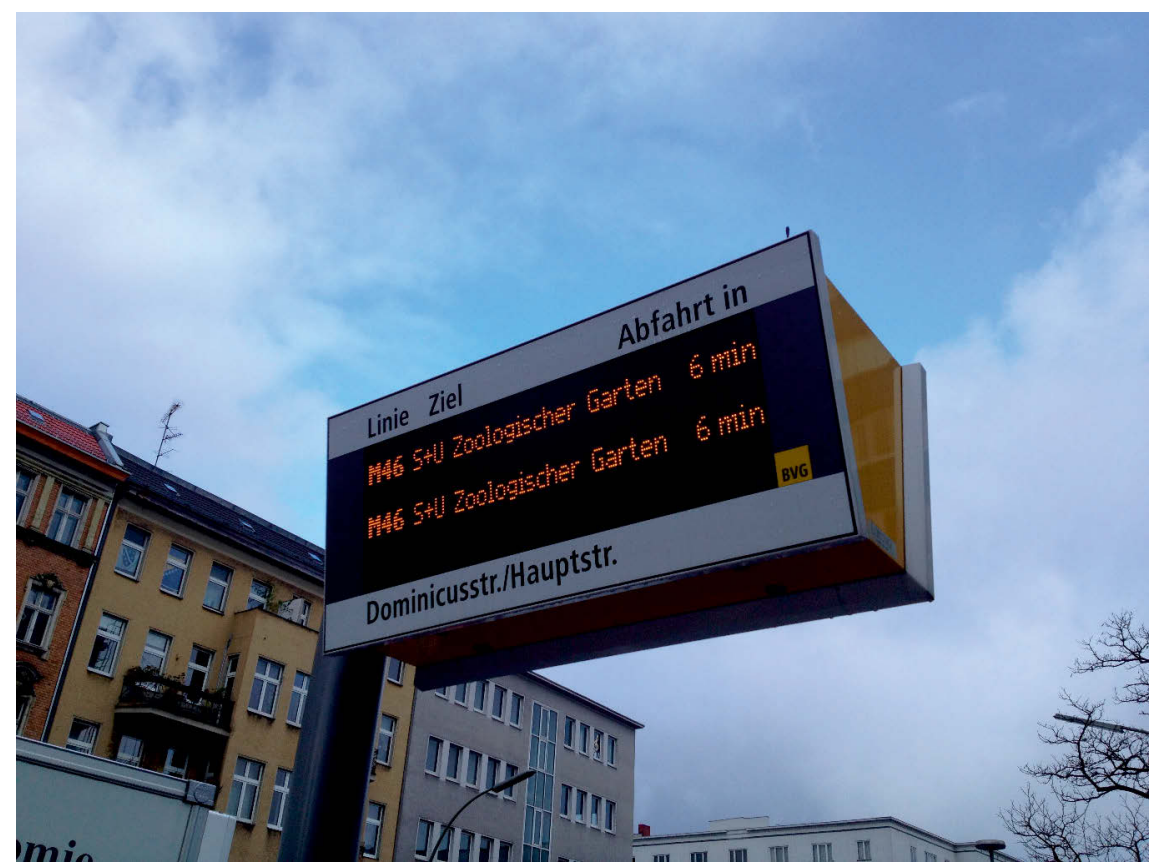

Eine zweite Paradoxie könnte darin liegen, dass durch die Exaktheit der noch verbleibenden Wartedauer eine noch stärkere Sensibilisierung für Zeitzwischenräume erfolgt, die nicht mehr nur Minuten umfasst, sondern sich nunmehr bis auf das Niveau von Sekunden verkleinert. Daher steht zu vermuten, dass Passagiere im öffentli-

37 Bissell, »Animating Suspension«, 278.

38 Gasparini, »On Waiting«, 37.

39 Juliet Jain und Glenn Lyons, »The gift of travel time«, Journal of transport geography 16, Nr. 2 (2008): 81-89. 
chen Verkehr mittelfristig eine gesteigerte temporale Erwartungshaltung entwickeln, die sich im Falle von tatsächlichen Verspätungen und fehlender Verlässlichkeit des Systems als neue Quelle der Unzufriedenheit entpuppen kann. Mit anderen Worten: Wird die suggerierte Kontrolle der Situation einmal durch Verspätungen oder Datenprobleme nicht eingehalten und springt die Anzeige nach dem Verstreichen der Wartezeit wieder auf einen neuen Zeitwert, schlägt der suggerierte Informationszugewinn möglicherweise gegenteilig in verstärkte Unzufriedenheit um. So bemerken etwa Dziekan und Kottenhoff, dass die vonseiten der Passagiere entwickelte Erwartungshaltung vonseiten der Verkehrsunternehmen auf Dauer wohl nur schwerlich eingehalten werden kann. Der Versuch, durch IKT den öffentlichen Nahverkehr mit sekundengenauen Abfahrtsinformationen zu attraktivieren, berge somit auch das Risiko, zu einem »losing battle for the public transport industry ${ }^{40} \mathrm{zu}$ werden. 



\section{Fazit: Zur Bau- und Kulturgeschichte des (verkehrlichen) Wartens}

Diese Arbeit trat im Bestreben an, sich einem omnipräsenten, aber weitgehend unbeachteten Temporalphänomen zu widmen, das sich seit dem frühen 19. Jahrhundert auf der Rückseite der Modernisierungsprozesse und gleichsam mit ihnen auszubreiten begann: dem systemischen Warten. Weder von überaus langer Dauer noch von existentieller Bedrohlichkeit, beschreibt es den situativen Aufenthalt vor Empfang oder Nutzung von Leistungen innerhalb moderner Systemzusammenhänge, der analog zur Novität der Warteanlässe selbst einen relativ neuartigen Erfahrungsmodus des Transitorischen begründete und dessen Verhandlung das Erlernen neuer Bau- und Kulturpraktiken erforderte.

Das wohl prominenteste und älteste Niederschlagsfeld solch situativer Transiterfahrungen bildet die (öffentliche) Verkehrswelt, die im doppelten Sinne als transitorisch erfahren wird: einerseits in Form der physischen Raumüberwindung während der Fahrt, zum anderen in Form der noch physisch unbewegten Situation vor Abfahrt im Umfeld von Bahnhöfen, Haltestellen oder Flugsteigen. Ausgehend vom Befund, dass die Geschichte der Moderne bereits zurecht gebührende Charakterisierung als Epoche der beschleunigten Raumüberwindung erfuhr, jedoch ungleich weniger als eine Epoche der parallelen Entstehung rückwärtiger Retardierungsmomente konzeptualisiert wurde, legte die vorliegende Arbeit ihr Erkenntnisinteresse dezidiert auf letzteren Aspekt des Transitorischen und fokussierte sich auf eine historische Betrachtung von Wartesituationen vor Abfahrt. Zur Eingrenzung des Untersuchungsgegenstands wurde das Erwarten der Eisenbahn gewählt, die das dominierende Verkehrsmittel des Industriezeitalters darstellte und in Gestalt der dampfgetriebenen Lokomotive zum ikonischen Medium der modernen Verkehrsrevolution des 19. Jahrhunderts reifte. Diese Fokussierung erfolgte insbesondere deshalb, weil der Eisenbahnverkehr gleichsam Schauplatz und Verursacher der Erstverhandlung einer andersgearteten, modernen Warteerfahrung wurde.

Wenngleich das Temporalphänomen Warten in der sozial- und kulturwissenschaftlichen Forschung seit dem ausgehenden 20. Jahrhundert zunehmende Aufmerksamkeit erfuhr, ist es bislang nicht hinsichtlich seiner eigentlichen Historizität betrachtet wor- 
den. Weder die Kulturgeschichte noch die Verkehrs- oder Baugeschichte widmeten sich in planvoll-systematischer Form dem Passagier im Modus des situativen Zwischenaufenthalts und dessen Entwicklung im historischen Verlauf. Obwohl sich das verkehrliche Warten wahrlich zu einer Kollektiverfahrung herausbildete und Bahnhöfen attestiert wurde, dass sie im Verlauf der Moderne die Kirchen »als Kultstätten für den Gott des Wartens abgelöst « ${ }^{1}$ hätten, blieb die sozial- und geisteswissenschaftliche Beschäftigung des verkehrsbezogenen Modernisierungsprozesses meist an den bewegten Phänomen von Geschwindigkeit, Tempo und Beschleunigung orientiert oder reduzierte die raumzeitlichen Veränderungen der Eisenbahnen verallgemeinert auf eine »Transitdiagnose ${ }^{2}$. Diese Leerstelle suchte die vorliegende Arbeit zu füllen und verfolgte dazu entlang zweier leitender Fragestellungen das Ziel, einen historiografischen Beitrag zur Aufdeckung der Konjunkturen und Veränderungslinien des verkehrsinduzierten Wartens zu leisten.

Ausgehend von einer umfangreichen zeittheoretischen Einordnung des Wartephänomens in Form der Aufarbeitung von Grundbedingungen, Besonderheiten und Strukturmerkmalen des Wartens sowie dessen Qualifizierung und Abgrenzung innerhalb der Modernisierungsprozesse (systemisches Warten) erfolgte ein empirisch-historiografischer Zugriff auf das flüchtige Phänomen mittels der verschränkenden Betrachtung einer Außen- und Innenperspektive auf das Warten. Während eine baugeschichtliche Leitfragestellung rekonstruierte, wie sich die materielle und betriebliche Rahmung des wartenden Passagiers am Bahnhof veränderte und die Räume des Wartens untersuchte (Außenperspektive), widmete sich die zweite Leitfragestellung einer Rekonstruktion der passagierseitigen erfahrungs- und rezeptionsgeschichtlichen Niederschläge in Literatur und Kunst (Innenperspektive). Um den historischen Wandel der baulichen Rahmung und die konnotativen Zuschreibungen aufzuzeigen, wurde eine diachrone Längsschnittbetrachtung realisiert, die im Kern einen Untersuchungszeitraum von 1830 bis 1935 umfasste und mittels eines explorativ-thesenhaften Anschlusses den Bogen bis in das frühe 21. Jahrhundert hinein schlug. Der Kern des Untersuchungszeitraums wurde in vier Phasen periodisiert, die sich an übergreifenden Generationen des Bahnhofsbaus orientierten und eine jeweils alternierende Verhandlung der Innen- und Außenperspektive des Wartens aufzeigten. Der geografische Fokus lag dabei auf dem deutschen Eisenbahnwesen, zeigte sich aber durch vergleichende Perspektiven gegenüber internationalen Entwicklungen informiert.

\section{Zur Baugeschichte des Wartens}

Im Ergebnis des baugeschichtlichen Untersuchungsstrangs zeigte sich, dass Warteräume bereits in der experimentellen Pionierphase des Eisenbahnwesens (1830-1845, Phase 1) einen nachweisbaren, wenn auch geringen Bestandteil des Raumprogramms ausmachten, im Zuge der Konsolidierung des Eisenbahnwesens (1845-1870, Phase 2) und 
dessen Aufstiegs zur Blütezeit (1870-1900, Phase 3) im Rahmen standardisierter Grundrissdispositionen als reich ausgestatte Säle zur größten Raumgruppe anwuchsen, zum Ende der Blütezeit den Beginn ihrer planvollen Verkleinerung und schließlich im Bauprogramm des modernen Großstadtbahnhofs einen deutlichen Bedeutungsverlust erfuhren (1900-1935, Phase 4).

Lage und Stellung des wartebezogenen Raumprogramms spiegelten dabei sich jeweils wandelnde operative Betriebskonzepte des Verkehrszugangs, die den wartenden Passagier mehr oder weniger stark formalisierten und disziplinierten. Während die Pionierphase der Eisenbahnen neben der verpflichtenden Nutzung von Warteräumen für die Reisenden zum Teil noch recht große informelle Spielräume und deutliche Bewegungsfreiheiten bot, bildete sich zur Mitte des 19. Jahrhunderts ein formalisiertes Regime der Zwangsschleusung durch die Wartesäle heraus, das ungefähr bis zur Schwelle des 20. Jahrhunderts dominierte und dem Abfertigungsprinzip heutiger Flughäfen ähnelte. Im Rahmen dieses stationären Warteimperativs war es den Reisenden in vielen europäischen Ländern vor Abfahrt nicht gestattet, den Bahnsteig oder bereitstehende Züge zu betreten, vielmehr waren sie dazu angehalten, sich solange in nach Wagenklassen separierten Wartesälen aufzuhalten, bis ein Einstiegssignal ertönte. Dieser organisatorische Zwang zum Warten in teils verschlossenen Sälen wurde dabei intentional als eine Art Zeitstrategie implementiert, um die betrieblichen Abläufe zur Gewährleistung von Pünktlichkeit und Sicherheit in der Gleishalle nicht zu gefährden. Jenes Abfertigungsprinzip - materialisiert in der Errichtung großer Säle, die sich als Schleusenraum zwischen Empfangshalle und Gleishalle schoben - bewirkte, dass der anthropologische Ur-Modus des Wartens eine Modernisierung erfuhr und der transitorische Zustand des systemischen Wartens in Form des temporären Sammelns und Bremsens von Passagierströmen zum festen Bestandteil der modernen Mobilitätserfahrung avancierte. Weil die wartenden Reisenden im Vergleich zu anderen Wartezusammenhängen hier jedoch nicht als Bittsteller, sondern als zahlende Kunden auftraten, wurde versucht, diesen organisatorischen Zwang durch eine Ausweitung von Komfortund Serviceeinrichtungen (insbesondere gastronomische Einrichtungen) zu kompensieren. Infolgedessen konvergierte die Wartesituation vor allem im deutschsprachigen Raum seit Mitte des 19. Jahrhunderts fast untrennbar mit dem Konsum von Speisen und Getränken.

Der im Laufe des 19. Jahrhunderts wachsende Formalisierungsgrad der Abfahrtsorganisation folgte jedoch international keinem homogenen Muster, sondern variierte von Nation zu Nation mitunter sehr deutlich. Während insbesondere im deutschen und französischen Kontext Reisende förmlich in die Wartesäle eingesperrt wurden und diese die Wartezeit dadurch wesentlich angespannter und nervöser erlebten, war es den Reisenden im englischen Bahnsystem von Anbeginn möglich, sich frei auf den Bahnsteigen zu bewegen. Infolgedessen war der stationäre Aufenthalt im Wartesaal der englischen Bahnreisekultur überwiegend fremd und wurden entsprechende bauliche Strukturen teils gar nicht erst errichtet. Wartebezogenes Bauprogramm und Abfahrtsorganisation repräsentierten somit nicht zuletzt auch die Kultur- und Technikzusammenhänge bzw. die Gesellschaftsauffassungen der jeweiligen Nationen, die von einer patriarchalisch-ordnenden Auffassung (Deutschland, Österreich, Frankreich) mit tendenziell starker Reglementierung der Bewegungsfreiheit bis hin zu einer liberal- 
individualistischen Auffassung (England, Belgien) reichten, in der das Warten auf Abfahrt wesentlich selbstbestimmter und unmittelbarer an den Zügen verbracht werden konnte.

Erst vor dem Hintergrund des wachsenden Verkehrsdrucks und der kategorischen Zielstellung der Gewährleistung kreuzungsfreier und reibungsloser Passagierströme wurde nach 1900 - angefangen mit den großen Kopfbahnhöfen der Metropolen - das stationäre Festhalten der Reisenden zugunsten einer moderneren, fluiden Zugangslösung aufgegeben. Den baulichen Rahmen bildete hierfür die Einrichtung eines Direktzugangs aus der Eingangshalle auf einen Quer- oder Kopfbahnsteig, der mit seiner Charakteristik einer selbstorganisierten Zirkulationszone zunehmend in funktionale Konkurrenz zum geschlossenen Wartesaal und dessen stationärer Nutzungspraxis trat. So geartet stand das frühe 20. Jahrhundert im Zeichen einer allmählichen Befreiung vom zuvor dominierenden stationären Warteimperativ. Repräsentiert durch stark verkleinerte und an die Ränder der Empfangsgebäude verlegte Wartesäle in den Bahnhofsneubauten der 1920er und 1930er Jahre wurde der lange stationäre Aufenthalt als Sekundäreffekt einer auf Effizienz und reibungslose Passagierströme ausgerichteten Wegeführung zunehmend zur randständigen und damit optionalen Mobilitätspraxis, der mehrheitlich nur noch von Reisenden im Fernverkehr nachgegangen wurde. Motor dieser Entwicklungen war im deutschen Kontext insbesondere ein um 1900 wissenschaftlich betriebener Bahnhofsbau, der die Prozessabläufe der modernen Fabrik auf die Passagierströme im Bahnhof zu übertragen und dabei die großen Wartesäle zugunsten einer Flusslogik aufzugeben suchte. Die Vertreter des Bau- und Eisenbahningenieurswesen stiegen damit zur zentralen Akteursgruppe der Schaffung moderner, prozessoptimierter Bahnhofsgebäude auf, in denen das lange, stationäre Warten zunehmend als ineffizienter und unökonomischer Störfaktor der Betriebsabläufe, die raumgreifenden Wartesäle als zinsloses Kapital identifiziert wurden. In den Bahnhöfen der Nachkriegsmoderne setzte sich der Bedeutungsverlust des wartebezogenen Raumprogramms noch weiter fort. Durch Verkleinerung und Umwidmung von Flächen im Bahnhofsinneren wurde der situative Aufenthalt in Wartesälen meist durch Gewerbeflächen substituiert, sodass sich die Aktivitäten vor Abfahrt noch stärker als zuvor in Richtung der Konsumption von Waren und Dienstleistungen verschoben. Ehemalige Wartesäle wurden zunächst in Kinos und Gaststätten, dann in ganze Ladenstraßen verwandelt. Erst im Zuge einer seit Mitte der 1990er Jahre programmatischen >Renaissance der Bahnhöfe findet die Abfahrtssituation in Form der Errichtung exklusiver WarteLounges punktuell wieder eine bauliche Berücksichtigung.

Zusammenfassend lässt sich die bau- und betriebsgeschichtliche Rekonstruktion des verkehrlichen Wartens im deutschen Eisenbahnkontext somit als Aufstieg und Fall des Wartesaals umreißen, der im 19. Jahrhundert seine Etablierung als konstitutives Element des Bauprogramms, seit dem frühen 20. Jahrhundert eine Marginalisierung und zur Mitte des 20. Jahrhunderts seine Auflösung erfuhr, dem jedoch im Kontext der aktuellen Reattraktivierung des Eisenbahnverkehrs eine gewisse Rehabilitierung widerfährt. 


\section{Zur Erfahrungs- und Rezeptionsgeschichte des Wartens}

Im Ergebnis des erfahrungs- und rezeptionsgeschichtlichen Untersuchungsstranges zeigte sich, dass die literarisch-künstlerische Verhandlung des Phänomens parallel zur baulich-operativen Verhandlung im Verlauf des Betrachtungszeitraums von einer hohen Veränderungsdynamik gekennzeichnet war, die sich quantitativ in einer zunehmenden Thematisierung und qualitativ im Wandel von einem subtil wirkenden Hochgefühl (1830-1845) zum existentiell-krisenhaften Zustand (1920er) ausdrückte.

Für die Pionierphase des Eisenbahnzeitalters (1830-1845) ließ sich zunächst bis auf punktuelle Beschwerden im Kontext unzulänglicher Betriebsverhältnisse (Nürnberg nach 1835) zunächst keine explizite Thematisierung ausmachen. Vielmehr konnte herausgearbeitet werden, dass die meist lange Wartezeit vor Abfahrt zunächst unterbewusst unter eine Gesamterfahrung des Neuen subsumiert worden sein dürfte. Die am Bahnhof verbrachte Wartezeit erhielt darin mitunter die Qualität einer katalytischen Kraft, welche die positiv aufgeregte Grundstimmung des >Eisenbahnfiebers noch weiter steigerte. In deutlicher Relativierung der heutigen Zuschreibung eines meist unliebsamen Alltagsübels, stellte sich demnach der Beginn des systemischen Wartens auf öffentlichen Verkehr als ein tendenziell positiv konnotiertes, mitunter repräsentatives Ereignis dar. Die Reisenden fanden sich dabei aufgrund präparatorischer Ungewissheiten vor Reiseantritt, aber auch aus Neugierde in der Regel bereits weit vor Abfahrt am Bahnhof ein und warteten teils nach Klassen getrennt (Manchester 1830, Berlin 1838), teils noch klassenlos und informell (Liverpool 1839, Nürnberg 1835) in spärlich ausgestatteten Räumlichkeiten, die zu Beginn meist keine gastronomische Versorgung aufwiesen. Die Abfahrtssituation mutete dabei räumlich insgesamt noch stark der Vorerfahrung des systemischen Wartens in Posthöfen an, stellte in sozial(psychologischer) Hinsicht aber angesichts zum Teil hunderter gleichzeitig abreisender Passagiere, die sich in engen Räumen zusammengedrängten, ein Erfahrungsnovum dar.

Im Zuge der anschließenden Konsolidierung des Eisenbahnwesens (1845-1870, Phase 2) und einer einsetzenden Gewöhnung an die neue Verkehrstechnologie zeigten sich erste explizite literarisch-künstlerische Thematisierungen des verkehrlichen Wartens. Wiederum entgegen der Vermutung einer per se negativen Bewertung des Aufenthalts in Wartesälen äußerte sich die literarische Verhandlung dabei interessanterweise häufig als kulturkritische Reflektion des neuen, eilenden Wartens und reziprok in der Romantisierung des langen und gemütlicheren Wartens auf die Postkutsche. So verdichtete sich aus der Analyse der Prosa von Friedrich Hackländer oder Friedrich Gerstäcker der zeitgeschichtliche Befund, dass zur Mitte des 19. Jahrhunderts nicht das eigentliche Warten aufden Zug als problematisch erfahren wurde, sondern vielmehr der Umstand, dass das rationalisierte Verkehrssystem der Eisenbahn nicht mehr aufden Menschen wartete. Der gegenüber der Postkutschenreise ungewohnt kurze Aufenthalt am Bahnhof wurde damit zum stellvertretenden Ausdruck einer zeitgenössisch irritierenden Beschleunigungserfahrung. Das neue, wesentlich kürzere Warten wurde (paradoxerweise) für eine allgemeine Kulturkritik instrumentalisiert, das lange Warten als Kontrastfolie 
der vermissten alten Zeit herangezogen. In aller Deutlichkeit zeigte sich in diesem Befund das gleichzeitige Nebeneinander von Beharrungs- und Modernisierungsimpulsen, das nach Ansicht von Reinhart Koselleck charakteristisch für das Ende der >Sattelzeit< erscheint.

Zur Mitte des 19. Jahrhunderts trat somit folglich das verkehrliche Warten stärker aus dem Stadium einer unterbewussten Verhandlung heraus, wurde explizit und endgültig als Teilaspekt der Reise entdeckt. Jene Entdeckung des Wartens als Sujet erfolgte neben der erwähnten kulturkritischen Instrumentalisierung zudem in der Lyrik noch punktuell als Moment des katalytischen Hochgefühls, aber - verdeutlicht in den Zeichnungen eines Honoré Daumier und der zentralen Romanfigur in Anthony Trollopes The Belton Estate - auch erstmals in Form der Thematisierung einer belastenden Routine und eines sozial wie geschlechtsspezifisch ungleich erlebten Temporalzustands. Die Praxis des Wartens (und der anschließenden Fahrt) transformierte sich dabei spätestens zur Mitte des 19. Jahrhunderts in Richtung der Nutzung kompensatorischer $>$ Ersatzlandschaften $<$ die in Form von Literaturmedien oder der Nutzung gastronomischer Angebote nicht nur die Wartezeit füllten, sondern die aufkommende Monotonie einer zunehmend auf das Verstreichen der Zeit gerichteten Wahrnehmung ausgleichen konnten. Das Lesen und das Speisen wurden damit folglich zu den paradigmatischen Warteaktivitäten des sich etablierenden Eisenbahnwesens. Parallel zur betrieblichen Praxis des stationären Warteimperativs etablierte sich zudem endgültig die klassenspezifische Separierung der Reisenden, wodurch die für die Pionierphase noch stellenweise bestehende Möglichkeit zum Austausch in einem gesellschaftsübergreifenden Ausmaß stark reduziert wurde.

Zur Phase des Aufstiegs der Eisenbahn in ihre Blütezeit (1870-1900, Phase 3) zeugten die identifizierten literarisch-künstlerischen Niederschläge davon, dass sich die Menschen an das durch die Eisenbahnen etablierte linear-mechanisierte Zeitregime, die permanente temporale Selbstkontrolle und den Synchronisationszwang einer komplexer werdenden Industriegesellschaft zunehmend gewöhnt hatten. So fanden sich zum einen keinerlei Hinweise mehr, die auf ein Vermissen der Postkutsche bzw. der alten Zeit schließen lassen. Zum anderen bildete das Eisenbahnmotiv häufig den selbstverständlichen Hintergrund oder den Rahmen literarischer Handlungen, in denen das Warten in den opulenten Sälen der Bahnhöfe trotz seiner Ausreifung zu einer Kollektiverfahrung für Millionen von Reisenden gleichwohl nur äußerst spärliche Beachtung fand. Dies legte den Schluss nahe, dass der Zustand des Wartens im letzten Drittel des 19. Jahrhunderts (noch) nicht übergreifend konsensual als problembehafteter Reisebestandteil wahrgenommen wurde.

Wenngleich aus der Literatur keine breitenwirksame Problematisierung des verkehrlichen Wartens zu beobachten war, löste in dieser Phase gleichwohl die Etablierung eines neuen Bahnhofstypus (Empfangsgebäude in Seitentieflage, Typ Hannover) eine erste real erlebte Wahrnehmungskrise des Wartens aus, da es Reisenden hier nicht mehr möglich war, in unmittelbarer Nähe und Sichtverbindung zum abfahrenden Zug $\mathrm{zu}$ warten. Der neue Bahnhofstypus verschlechterte die psychologisch notwendigen Voraussetzungen einer positiven Warteerfahrung und erfuhr entsprechende Beanstandung seitens der Reisenden. Diese bauliche Neuerung führte mithin dazu, dass die 
Nutzung von Wartesälen in solchen Bahnhöfen abzunehmen begann, sich Reisende unmittelbarer am Bahnhof einfanden und sich ohne Umwege über die Wartesäle direkt zu den Bahnsteigen begaben. Zudem verursachte die wachsende Nutzung und Bedeutung des Nah- und Vorortverkehrs im Rahmen des Urbanisierungsprozesses die Entstehung eines stärker utilitaristischen und zielorientierten Nutzerkreises, was eine deutliche Differenzierung der Wartepraxis in ein langes Warten im Saal (Fernverkehr) und ein vergleichsweise kurzes Warten am Bahnsteig (Nahverkehr) beförderte.

Jenseits dieser orts- und betriebsspezifisch bedingten Verkürzungen des Aufenthalts erreichte die Warteerfahrung im letzten Drittel des 19. Jahrhunderts angesichts reich ausgestatteter Säle in zu Service- und Dienstleistungszentren transformierten Bahnhöfen den Höhepunkt des Würdevollen. Ein solches würdevolles Warten wurde dabei nicht allein durch die bauliche Rahmung ermöglicht, sondern auch durch betriebliche Neuerungen. So wurden Reisende durch Einrichtung neuer Zirkulationszonen in großstädtischen Kopfbahnhöfen (Frankfurt 1888) vom Zwang des Aufenthalts im Wartesaal befreit und erhielten einen neuen Grad an Bewegungsfreiheit und Selbstbestimmung. Die Vielfalt kompensatorischer Maßnahmen, die neben einer opulent, komfortorientierten und zugleich das Gemüt beruhigenden Architektur auch die Einrichtung eines breiten Dienstleistungsangebotes vor Abfahrt umfassten, resultierten zusammengenommen in einer Kommerzialisierung, Mediatisierung und nicht zuletzt einer Kulinarisierung des Wartens vor Abfahrt. Diese zunehmend kompensatorischen und distrahierenden Entwicklungen des situativen Aufenthalts können möglicherweise als eine Begründung herangezogen werden, warum das verkehrliche Warten auf Eisenbahnen in Literatur und Kunst jener Phase kein gesellschaftliches Problembewusstsein erfuhr.

Der Höhepunkt des würdevollen Wartens konvergierte dabei zugleich mit dem Höhepunkt des sozial differenzierten Wartens. So zeigte das wartebezogene Raumprogramm der Großbahnhöfe der Kaiserzeit, dass in Ergänzung klassenspezifischer Säle der mittlerweile weiter stratifizierten Industriegesellschaft in Form der Einrichtung zusätzlicher Raumgruppen im Spektrum von Damenzimmern bis hin zu Auswanderersälen entsprochen werden musste. Die Bandbreite der Wartesäle im Bahnhof erfüllte damit neben der rein betrieblich-technischen Funktion der Gewährleistung eines Übergangs von Reisenden auf das Verkehrssystem nicht zuletzt immer auch eine soziale Funktion der Trennung sozioökonomischer Positionen bzw. der Aufrechterhaltung und Spiegelung gesellschaftlicher (Macht-)Verhältnisse.

Mit einer sprunghaften Thematisierung und inhaltlichen Problematisierung markierte das frühe 20. Jahrhundert (1900-1935, Phase 4) die literarisch-künstlerisch fruchtbarste Phase der Verhandlung des verkehrlichen Wartens. Der Aufenthalt im Wartesaal wurde im Kontext des Expressionismus und der Neuen Sachlichkeit besonders in den 1920er Jahren als Modus des existenziellen Daseins verhandelt und zur politisierten Explikation sozialer Missstände des großstädtischen Proletariats der Zwischenkriegsgesellschaft herangezogen. Die Zeichnungen und Lithografien eines Hans Baluschek, Eduard Braun oder Walter Ophey entdeckten im Rahmen eines gewachsenen Interesses an realen Lebenswelten das Motiv des Wartesaals der unteren Wagenklassen und illustrierten die dortige Atmosphäre als exemplarischen Schauplatz der sozialen Disparität, 
in dem das Warten für die Reisenden im Spektrum von Routine und Würdelosigkeit zu einer tendenziell krisenhaften Kollektiverfahrung gereift war. Der Bahnhofswartesaal diente hierbei nicht nur dem Aufenthalt der Reisenden, sondern wurde insbesondere in der Zwischenkriegszeit auch zum sinnbildlichen Notlager der großstädtischen Unterschicht, die sich im sozioökonomischen Transitzustand befand.

Jenseits dieser künstlerischen Niederschläge, die das Schlafen auf Bänken, Stühlen und Tischen zur symbolhaften Wartepraxis der 1920er Jahre stilisierten, war der situative Aufenthalt im modernen Großstadtbahnhof auch nach wie vor von den Tätigkeiten des Lesens, Speisens und der Kommunikation geprägt. Zugleich war das frühe 20. Jahrhundert aber durch eine allgemeine Verkürzung der Wartedauer im Bahnhof sowie Vermeidungs- und Umgehungsstrategien des situativen Aufenthalts charakterisiert. Sie ergaben sich erstens aus der erlernten Praxis der zugangsbeschleunigten Nahverkehrsnutzung, zweitens aus den baulich-betrieblichen Neuerungen eines Direktzugangs sowie der Einführung von Speisewagen und drittens aus einer gewachsenen Zeitsensibilität der modernen Industriegesellschaft, die eine sinkende Toleranz gegenüber zeitlichen Stillstandsmomenten zeigte. Baulich-technische Entwicklungen und veränderte Nutzungspräferenzen wirkten somit nach 1900 wechselseitig zusammen und resultierten in einer Abnahme der Wartesaalnutzung, die mehrheitlich nur noch bei Fernverkehrsreisenden beobachtet werden konnte. In Entsprechung der flussorientierten Logik des Bauprogramms moderner Großstadtbahnhöfe (Wiesbaden, Stuttgart, Oberhausen) verlagerte sich das Warten aus dem Saal zunehmend in die Fläche bzw. direkt an den Bahnsteig, sodass nun auch die Wartepraxis oftmals in Bewegung stattfand.

Die deutlich gewachsene literarisch-künstlerische Beschäftigung mit dem Wartephänomen und dessen tendenzielle Vermeidung seitens der Reisenden können als Anzeichen für eine gesellschaftliche Beschleunigungswelle gelesen werden, die das erste Drittel des 20. Jahrhundert erfasste und auf deren Rückseite (bzw. in deren Rückräumen) das Warten stärker denn je als Störfaktor hervortrat. Dies wird nicht zuletzt darin deutlich, dass in Analogie zur Beschleunigungswelle der Konsolidierungsphase des Eisenbahnwesens (Phase 2) auch hier von konservativ-moderneskeptischen Akteuren die Rhetorik eines überhasteten >Nicht-Mehr-Warten-Könnens`als Verfall der Tugendhaftigkeit und damit als Kulturkritik an einer beschleunigten Gegenwart ins Feld geführt wurde. Ausgelöst durch die massenhafte Häufung und lebensweltliche Durchdringung von temporären Zwangspausen oder Verlangsamungen, die nicht allein durch das Verkehrswesen, sondern auch durch wirtschaftliche Krisen und Bürokratie bedingt waren, kann damit geschlussfolgert werden, dass die Etablierung des Wartens als eine modernetypische Grunderfahrung erst in jenem Zeitraum eine Breitenwirksamkeit erfuhr.

Wenn an dieser Stelle Ulrich Becks These gefolgt wird, nach der Phänomene erst dann ins gesellschaftliche Visier geraten, sobald mit ihnen ein konkretes Problembewusstsein verbunden ist, ${ }^{3}$ bildet somit das frühe 20 . Jahrhundert die entscheidende Zäsur der Wahrnehmung des systemischen Wartens, das aus dem Stand eines bis dahin weitgehend unhinterfragten Phänomens in den Stand eines modernen Kollateralschadens und einer temporalen wie sozialen Dysfunktionalität gehoben wird. Das Zusam- 
menspiel sinkender Wartetoleranz, baulich-betrieblicher Maßnahmen zur Privilegierung von Zirkulationszonen gegenüber dem Wartesaal sowie die sozialkritische Problematisierung des schier endlosen Wartens der Arbeiterklasse lassen damit im Rahmen der diachronen Beleuchtung des Temporalphänomens abschließend die Erkenntnis reifen, dass die gesellschaftliche Konnotation systemischer Wartesituationen im ersten Drittel des 20. Jahrhunderts einen historischen Umschlagpunkt erreichte und die Kollektivzuschreibung eines unliebsamen bis krisenhaften Zustands erhielt, der bis in die Gegenwart hinein wirksam bleibt.

Die rezeptions- und erfahrungsgeschichtliche Analyse stellt sich somit zusammenfassend als Aufstieg und Fall des würdevollen Wartens dar, das bis zum späten 19. Jahrhundert eine bauliche und operationelle Etablierung sowie eine repräsentative Aufladung erfährt, im frühen 20. Jahrhundert im Zuge des Zusammenspiels nutzerseitiger Verhaltensänderungen, baulicher Neuorientierung auf Zweckmäßigkeit und forciert durch ökonomische Krisen nach dem Ersten Weltkrieg für einen Großteil der Reisenden den Status eines erhabenen, achtungsvollen Zustands verliert.

\section{Forschungsbeiträge und Anschlussfähigkeit}

Die vorliegende Arbeit entwarf das historiografische Panorama eines Alltagsphänomens. Dabei wurden Erkenntnisse gewonnen, die an übergeordnete Forschungsfragen eines breiten Feldes geistes- und sozialwissenschaftlicher Disziplinen mit Schwerpunkt auf Mobilitäts- und Zeitphänomene anknüpfen.

\section{Historische Mobilitätsforschung}

Die gesammelten Erkenntnisse sind zunächst für die historische Mobilitätsforschung von Relevanz, die ohne den Einbezug von Situationen des temporären Zwischenaufenthalts bzw. Situationen temporärer Immobilität in ihre zuletzt stärker auf nutzerseitige Erfahrungen und Mobilitätskulturen ausgerichteten Programmatik ${ }^{4}$ kein ganzheitliches Verständnis der historischen Genese des (öffentlichen) Verkehrswesens wird leisten können. Eine rein an Bewegungs- und Beschleunigungsprozessen verhaftete Mobilitätsforschung würde weder die Entwicklung von Mobilitätskulturen noch die Entstehung der Verkehrsmittelwahl vollumfänglich erfassen. So kann mit dieser Arbeit etwa gezeigt werden, dass sich Wartephänomene nicht zuletzt als konstitutive Teilerklärung des Triumphzugs der Individualmobilität im frühen 20. Jahrhundert begreifen lassen, weil Fahrräder, Motorräder oder Autos neben einer flexibleren Routenwahl auch eine neue Unmittelbarkeit der Zugangspraxis ermöglichten, welche die bis dahin prävalente Notwendigkeit des situativen Wartens schlichtweg nicht mehr erforderten. Die Geschichte der Individualmobilität kann also mit Einbezug eines historischen Verständnisses verkehrsinduzierter Wartesituationen auch als eine Geschichte der Abwendung und Umgehung jener Situationen gelesen werden. Darüber hinaus bietet diese Perspektive in verkehrshistorischen Arbeiten auch das Potential einer disziplinären Erneuerung. So würde eine Vertiefung des historischen Verständnisses vom wartenden 
Passagier die bislang oft noch immer auf technische und infrastrukturelle Aspekte beschränkte Verkehrsgeschichte (endlich) zu einer Mobilitätsgeschichte werden lassen, die den cultural turn verinnerlicht und die in Anbetracht des flüchtigen und schwer fassbaren Gegenstands zu interdisziplinären und transnationalen Herangehensweisen 'gezwungen wäre. ${ }^{5}$ Die kulturgeschichtliche Thematisierung des verkehrsinduzierten Wartens bedeutet in seiner Programmatik nicht nur eine mobilitätstheoretische Perspektivenerweiterung des Modernisierungsprozesses um eine verhältnismäßig unbekannte temporale Dimension bzw. eine dialektische >Gegengröße $z$ zu leisten, sondern auch die unbequemen, aber dennoch omnipräsenten Brüche moderner Mobilitäts- und Geschwindigkeitsutopien offenzulegen und sie als verkehrsimmanent anzuerkennen. Zusammengenommen könnten durch eine stärker kulturwissenschaftlich inspirierte Mobilitätsgeschichte ${ }^{6}$ damit die rückseitigen, jedoch komplementären Effekte der Modernisierungsprozesse zu einem qualifizierten wie innovativen Arbeitsfeld aufsteigen.

\section{Mobility Studies}

Weiterhin liefert die vorliegende Arbeit eine Vielzahl empirisch gesättigter Einblicke in die evidente Relationalität von Bewegung und Verlangsamung und adressiert damit einen Forschungsschwerpunkt der an der Theoretisierung von Mobilitätsphänomenen interessierten Mobility Studies. So kann die Arbeit in dieser Hinsicht zeigen, dass die sich zunächst im Prinzip des stationären Warteimperativs ausdrückende Domestizierung des Passagiers als eine Form der »institutionellen Stilllegung " $^{7}$ fungierte, die aus Betreibersicht den Beschleunigungserfolg der verkehrlichen Moderne überhaupt erst ermöglichte. Im Wartesaal und in dessen verpflichtender Nutzung manifestierten sich damit eindrücklich die paradoxalen Wechselwirkungen von Beschleunigung und Retardierung. Letztere ist entgegen des üblichen Beschleunigungsimpetus einer Vielzahl von Modernisierungsprozessen immanent. Ausgehend vom Eisenbahnwesen des 19. Jahrhunderts stellte die intentionale Stauung und Verlangsamung von Strömen eine Vorbedingung für die Gewährleistung eines beschleunigten öffentlichen Massenverkehrs dar. Mit anderen Worten: Ohne die operative Praxis eines zwischenzeitlichen Sammelns von Reisenden - resultierend in systemischen Wartezeiten - wäre der Aufbau eines effizienten und pünktlichen Massenverkehrsmittels nur schwerlich geglückt.

In Form der hier geleisteten Historisierung eines zentralen Mobilitätsphänomens kann also nicht nur einer Kernforderung der Mobility Studies entsprochen werden, ${ }^{8}$ son-

Vgl. Robin Kellermann, »Reconnecting Mobility History: Towards `Histories of Waiting « «13th Annual Conference of the International Association for the History of Transport, Traffic and Mobility $\left(\mathrm{T}^{2} \mathrm{M}\right)$, Caserta (ITA), Sept. 2015.

6 Hier sei insbesondere auf die Bestandsaufnahme des Mobilitätshistorikers Gijs Mom verwiesen, der die zu zaghaften Anstrengungen der Verkehrsgeschichte bezüglich der Verinnerlichung des cultural turn samt dem Fehlen thematischer Betrachtungen von Phänomenen der Immobilität kritisierte. Vgl. Gijs Mom, »The crisis of transport history: a critique, and a vista«, Mobility in History 6, Nr. 1 (2015): 7-19. Ein ähnlicher Tenor zur programmatischen Erneuerung der Verkehrs- und Mobilitätsgeschichte findet sich zudem in Massimo Moraglio, »Seeking a (New) Ontology for Transport History«.

7 Rosa, Beschleunigung: die Veränderung der Zeitstrukturen in der Moderne, 155.

8 Mimi Sheller, »The New Mobilities Paradigm for a Live Sociology«, Current Sociology 62, Nr. 6 (2014): 789-811. 
dern die Historiografie der rückseitigen Effekte des beschleunigten Eisenbahnverkehrs beleuchtet auch die funktionale Rolle der Verlangsamung für die Gewährleistung der Beschleunigung und damit eine Reihe der Entstehungs- und Produktionsbedingungen moderner Stillstandsphänomene. ${ }^{9}$ Wenngleich das Prinzip der temporären Stauung von Passagieren aufgrund neuer Zirkulationsflächen, gewachsenem Verkehrsdruck und der Routinisierung der Reisenden im Eisenbahnkontext des 20. Jahrhunderts nicht mehr für zwingend notwendig erachtet wurde, zeigt sich mit Blick auf die gegenwärtige Abfertigungspraxis an Flughäfen eine Kontinuität des systemischen Wartens. Während demnach der heutige Flugverkehr der Abfahrtsorganisation vieler Bahnhöfe des 19. Jahrhunderts gleichkommt, kann mit Blick auf die baulich-operative Verhandlung des wartenden Passagiers im Eisenbahnwesen konstatiert werden, dass die Bauman'sche Charakterisierung der Moderne als einer liquid modernity ${ }^{10}$ bereits im frühen 20 . Jahrhundert ihre bauliche Entsprechung gefunden hat.

Die Entdeckung beschleunigter Mobilität fällt aber keineswegs erst in der Gegenwart mit der Entdeckung von Stillstandsmomenten zusammen. So konnte für den relationalen Charakter von Bewegung und Retardierung wohl kein frappierenderes Beispiel aufgezeigt werden als jenes des verspäteten Eintreffens des Eröffnungszuges zwischen Liverpool und Manchester am 15. September 1830, durch das sich die Geschichte der Verspätung im modernen Verkehrswesen sogar um zweieinhalb Stunden älter darstellt als die der planmäßigen Ankunft. Wartephänomene treten demnach in modernen Systemzusammenhängen stets in unmittelbarer Nähe zu Beschleunigungsphänomenen auf. Jene Phänomene theoretisch herzuleiten und im Begriffsangebot des systemischen Wartens auch sprachlich zu fassen, war ein wichtiges Anliegen dieser Arbeit, um nicht zuletzt der zeitsoziologischen und kulturtheoretischen Forschung zu einer besseren Differenzierung von Wartephänomenen und zu einer Abgrenzung von anderen Formen des erlebten Aufschubs zu verhelfen.

\section{Bau- und Architekturgeschichte}

Ferner liefern die im Rahmen dieser Arbeit gewonnenen Erkenntnisse zur Entwicklung des Wartesaals wichtige Beiträge für die Bau- und Architekturgeschichte des Bahnhofs, indem bestehende Arbeiten um die fokussierte Archäologie eines wesentlichen Raumelements ergänzt werden. Dieses baulich-architektonisch in der Tradition eines Versammlungssaals behandelte Raumelement wuchs nicht nur zur größten Raumgruppe innerhalb der Empfangsgebäude heran, sondern wurde aufgrund seiner funktionalen Bedeutung im Betriebsablauf zum konstitutiven Element sich wandelnder Grundrissdispositionen. Die hier aufzeigte Geschichte von Aufstieg und Marginalisierung des Bahnhofswartesaals repräsentiert zudem nicht nur die seit der Wende vom 19. zum 20. Jahrhundert verstärkte Ausrichtung am Dogma des Funktionalismus und der Zweckmäßigkeit, sondern sie spiegelt auch eine akteursgeschichtliche Umorientierung wider, must stop in order to prepare for later movement. «Adey, »If mobility is everything then it is nothing: towards a relational politics of (im) mobilities«, 20. 
die den Bau moderner Verkehrsbauwerke um 1900 zunehmend vom Verantwortungsbereich der Architektur in den Verantwortungsbereich des Ingenieurswesens rückte.

Wirtschafts- und Mediengeschichte

Darüber hinaus entwickeln die gesammelten Erkenntnisse Relevanz für die Wirtschaftsund Mediengeschichte. So zeigt die Arbeit, dass verkehrsbezogene Wartephänomene vor und während der Fahrt gänzlich neue Ökonomien und Medienformen entstehen ließen, die ihren Daseinszweck überhaupt erst aus der Existenz jenes temporalen Zwischenstadiums zogen. Je stärker das Phänomen einer zu verhandelnden Zeitspanne vor Abfahrt und während der anschließenden Fahrt ins Bewusstsein der Reisenden rückte, desto wichtiger wurde die Bedeutung kompensatorischer Maßnahmen, was insgesamt $\mathrm{zu}$ einer Kulinarisierung, Mediatisierung und Kommerzialisierung des Wartens führte. Das transitorische Welterleben des modernen öffentlichen Verkehrs bewirkte damit nicht nur die Entwicklung gänzlich neuer Literaturgattungen, sondern auch die Entwicklung einer neuen Gastronomiekultur. Das von Millionen von Reisenden erlebte Warten auf Abfahrt und die Eisenbahnfahrt selbst zeigt sich damit aus Perspektive der Wirtschafts- und Mediengeschichte alles andere als trivial, sondern muss als konstitutives Element einer modernen Produktion und Konsumption von Medien, Waren und Dienstleistungen verstanden werden. Während der Aufenthalt im Wartesaal neue Bedarfe schuf und die Entstehung neuer Angebotslagen bewirkte, fungierten die Wartesäle zugleich auch als Werbeflächen und Produktionsorte einer modernen Konsumorientierung. Zusammenfassend ließe sich sogar die These formulieren, dass die von der modernen (öffentlichen) Verkehrswelt geschaffenen Anlässe zum Verweilen, die Zeitnischen im Zwischenraum, einen nicht unzureichenden Beitrag zum Aufstieg der Genussmittelindustrie und der Unterhaltungselektronik geleistet haben mögen. So zeigt die Arbeit etwa, wie sehr der Aufenthalt im Wartesaal mit dem Konsum von Tabakwaren und alkoholischen Getränken korrelierte.

\section{Sozialgeschichte}

Schließlich können die Erkenntnisse dieser Arbeit einen Beitrag zur Sozialgeschichte des 19. und 20. Jahrhunderts leisten. So wird etwa anhand der Entwicklung des wartebezogenen Raumprogramms an Bahnhöfen des 19. Jahrhunderts aufgezeigt, wie die durch universelle Abfahrts- und Ankunftszeit für alle Passagiere egalisierende und demokratisierende Wirkung der Eisenbahnreise innerhalb einer klassenbewussten Gesellschaftsstruktur als problematisch empfunden wurde und man schon frühzeitig versuchte, diese durch Implementierung künstlicher Klassenunterschiede und räumlicher Separierung wieder zu relativieren. Durch die Perspektive der Abfahrtsorganisation an Bahnhöfen wurde damit exemplarisch verdeutlicht, dass Wartephänomene stets untrennbar mit Machtverhältnissen und sozioökonomischen Dispositionen in Verbindung stehen. Obwohl die Reisenden im Vergleich zu anderen Wartekontexten prinzipiell als zahlende Kunden auftreten, zeugt die historische Gewachsenheit unterschiedlicher Ausstattungen und Zustiegsregelungen vor Abfahrt vom Versuch einer permanenten sozialen und räumlichen Distinktion der Verkehrsnutzerschaft, die zwar im Laufe des 20. Jahrhunderts durch die Reduktion von Wagenklassen stetig zurückgefahren 
wurde, aber in Form des priority boardings oder exklusiver Warte-Lounges im Flugwesen bis in die Gegenwart hinein seine historische Persistenz aufzeigt. Zudem konnte die Arbeit zu einer Historisierung geschlechtsspezifischer Unterschiede der Mobilitätserfahrung beitragen. So zeigte sich, dass sich das Verbringen der Wartezeit für Frauen oftmals wesentlich formalisierter bzw. weniger selbstbestimmt darstellte sowie die verpflichtende Installation von (rauchfreien) Damenzimmern in deutschen, englischen und US-amerikanischen Bahnhöfen die geschlechtsspezifischen Auffassungen und Erwartungshaltungen der jeweiligen Zeit zu manifestieren und reproduzieren vermochte.

\section{Reflektionen und Ausblicke}

Wie jede Untersuchung sah sich auch die vorliegende einer Reihe von Herausforderungen gegenüber, die im Folgenden kurz reflektiert werden und darin Anschlüsse für weiterführende Forschungsarbeiten offerieren.

1) Der Gegenstand des verkehrsbezogenen Wartens stellte sich nicht selten als ein schwer zu fassendes, flüchtiges und nur unterbewusst wirksames Phänomen dar, das trotz seiner Omnipräsenz nur verhältnismäßig wenig explizite Widmung erfuhr. Während sich der Zugriff über die baulich-betriebliche Verhandlung wartender Passagiere mittels der Rekonstruktion von Baudirektiven und Grundrissentwicklungen als fruchtbares Erkenntnisfeld präsentierte, konnte der rezeptions- und erfahrungsgeschichtliche Zugriff die Entwicklungskonjunkturen als auch die konkreten Wartepraktiken und -aktivitäten weniger scharf nachzeichnen. Wenngleich diese Unschärfe der Natur des Quellenmaterials geschuldet ist, hätte eine Erweiterung des Quellenkorpus um bspw. Tageszeitungen, Polizeiakten oder Tagebucheinträge die subjektbezogenen Konjunkturen eventuell noch stärker abgebildet. Insgesamt wurde aufgrund des Eindrucks einer sich abzeichnenden Unschärfe und aus forschungspragmatischen Überlegungen der rezeptions- und erfahrungsgeschichtliche Untersuchungsstrang nicht in gleichwertiger Tiefe verfolgt wie der baugeschichtliche. Aus diesem Grund bietet sich für zukünftige Arbeiten an, die subjektbezogene Perspektive von Wartephänomenen noch stärker ins Zentrum zu stellen und die historischen Veränderungslinien konkreter Aktivitäten der Wartezeitverbringung in Form einer Mikrosoziologie oder gar einer Praxeologie des Wartens zu beschreiben. Zudem wurden die Quellenfunde nur punktuell im Kontext ihrer politisch-gesellschaftlichen, sondern vielmehr im Kontext verkehrshistorischer und zeitkultureller Rahmenbedingungen interpretiert, sodass für zukünftige Arbeiten in Erwägung zu ziehen wäre, eine stärkere historische Kontextualisierung zu leisten, um damit eventuell weiterführende Aussagen zur Rezeption des verkehrsbezogenen Wartens im 19. und 20. Jahrhundert treffen zu können.

2) Wie fast jede Periodisierung läuft auch die hier gewählte Gefahr, allzu leichtfertig als Entwicklungstrajektorie mit definitiven Bruchkanten und Zäsuren missverstanden zu werden. Die gewählte Unterteilung des Kernbetrachtungszeitraums in vier und die anschließende Exploration entlang von zwei Phasen der Bahnhofsentwicklung sind vielmehr als in idealtypische Phasen verdichtete Konjunkturzusam- 
menhänge des Wartens anzusehen. Tatsächlich fanden in jeder der gewählten sechs Phasen der Bahnhofsentwicklung zwischen 1830 und der Gegenwart Überlagerungen und Parallelentwicklungen statt, ebenso variierten die baulichen Verhältnisse und die daran geknüpften subjektiven Verhandlungen des Wartens ortsspezifisch stark. Trotz oberflächlicher Übereinstimmungen zeigen weder die Architektur des Bahnhofsbaus noch dessen innere Organisation bei näherer Betrachtung ein absolut identisches Muster, was die Abstraktion übergeordneter Entwicklungslinien mitunter erschwerte, die Zielstellung einer konjunkturellen Komplexitätsreduktion aber umso erforderlicher erscheinen ließ.

3) Um eine Komplexitätsreduktion der ohnehin schwierigen Bearbeitung von Temporalphänomen zu erreichen, fokussierte sich die Arbeit dezidiert auf die reguläre Wartesituation vor Abfahrt, behandelte damit nicht das ebenfalls als Warten interpretierbare Fahren im Zug. Diese analytische Trennung erfolgte, um in der Rede vom systemischen Warten die stark unterschiedlichen psychologischen Dispositionen vor und während der Fahrt nicht leichtfertig zu vermengen. Die Erwartung der Abfahrt ist jedoch zwangsläufig mit dem Antizipieren der Fahrt selbst und der Ankunft am Zielort verknüpft. Das systemische Warten auf Abfahrt ist somit also in einen größeren Erwartungszusammenhang eingebettet, der hier jedoch im Sinne der Zielstellung generalisierter Aussagen zu Konjunkturen der Warteerfahrung im Bahnhof meist außen vor gelassen wurde. Trotz der hier notwendigen Komplexitätsreduktion kann in diesem Zusammenhang als ein für Folgearbeiten zentraler Hinweis gelten, dass die unterschiedlichen Zeitmodi des verkehrsinduzierten Wartens stets differenziert zwischen einem Warten vor, während und nach der Fahrt betrachtet werden müssen.

4) Der modale Fokus richtete sich - ebenfalls forschungspragmatisch motiviert - fast vollends auf den Eisenbahnverkehr, weil hierdurch der gesamte Betrachtungszeitraum mithilfe ein und desselben Verkehrsträgers erfasst werden konnte und nur dadurch evidente Entwicklungsaussagen zwischen den jeweiligen Zeitschichten getroffen werden konnten. Zwar flossen auch Wartesituationen auf vormoderne Postkutschen sowie auf den modernen Flugverkehr punktuell in die Betrachtung ein, doch standen die potentiell denkbaren intermodalen Vergleichsperspektiven auf die sich parallel zur Eisenbahn entwickelnden Verkehrsträger (Pferdeomnibus, Straßenbahn, Bus etc.) hier nicht im Zentrum des Interesses. Angesichts ihrer Bedeutung für die Produktion und Erfahrung verkehrsbezogener Wartezeiten bietet sich daher für zukünftige Arbeiten eine modale Erweiterung auf andere Verkehrsträger und zudem auch eine zeitliche Erweiterung der Analyse auf deren Wirkung in der ‘Zweiten Moderne an.

5) Der geografische Fokus der Arbeit lag in erster Linie auf dem deutschen Kontext. Verkehrliche Wartesituationen sind aber selbstredend ein internationales Phänomen. Zwar wurde an zahlreichen Stellen die deutsche Entwicklung in einen internationalen Kontext gestellt, doch sollte der Anspruch weiterführender Arbeiten angesichts der Notwendigkeit einer stark transnational und weniger eurozentristisch 
ausgerichteten Forschung darin bestehen, von einer Kulturgeschichte zur Weltgeschichte des Wartens zu gelangen. So wäre zu fragen, ob und wie der Export des stationären Warteimperativs in die Kolonialstaaten des 19. Jahrhunderts im Rahmen genuiner Zeitkulturen verhandelt, wie sich die Kolonialisierung des linear-mechanisierten Zeitregimes in Bezug auf die Wartepraxis (bspw. in Indien oder Sumatra) darstellte. Ausgehend von den hier erzielten Erkenntnissen bietet es sich an, zukünftig Vergleichsstudien zu erarbeiten, die kulturelle Unterschiede der Warterfahrungen in den Mittelpunkt stellen. Allein die wenigen hier angeschnittenen nationalen Vergleiche lassen dabei vermuten, dass diese interkulturelle Entdeckung des Wartens ein reichhaltiges Arbeitsfeld darstellt.

6) Der originäre Kernbetrachtungszeitraum sollte das erste Jahrhundert des Eisenbahnwesens umfassen. Er wurde nicht allein aus forschungsprogrammatischen Gesichtspunkten in dieser Zeitspanne gewählt, sondern auch deswegen, weil sich die Geschichte des Eisenbahnwesens innerhalb dieser Spanne als Aufstieg, Blüte und Fall darstellt und sich die nach 1900 auftretenden Prozesse (Marginalisierung des Wartesaals, Reduktion der Wartezeit, Verlagerung vom Saal in die Fläche) fast ungebrochen bis in die Gegenwart weiterziehen. Um die Brücke zur Gegenwart zu schlagen, komplementierte ein thesenhaft ausgerichtetes Explorationskapitel den diachronen Längsschnitt vom Beginn des Eisenbahnwesens bis zur Gegenwart. Darin wurde bereits in Ansätzen deutlich, inwieweit das digitale Zeitalter durch Informations- und Aktionsgewinne eine historische Neubewertung des verkehrsbezogenen Wartens zwischen Rehabilitierung und möglichen ReboundEffekten neuer Abhängigkeiten und erhöhter Zeitsensibilität erfordert. Für eine weiterführende Erforschung verkehrsbezogener Wartesituationen erscheint es daher unumgänglich, die Wirkung digitaler Technologieangebote auf gegenwärtige Raum-Zeit-Wahrnehmungen als Schwerpunkt der an Zeitphänomenen interessierten Kultur-, Technik- und Mobilitätsforschung zu etablieren.

7) Das entwickelte Theorem des systemischen Wartens blieb im Rahmen dieser Arbeit allein auf die Verkehrswelt beschränkt, sollte aber auch in der Vielzahl anderer Auftrittsfelder des modernen Lebens (Schwimmbäder, Opernhäuser, Ämter) eine historische Aufarbeitung finden. Zudem könnte ein ergänzender Beitrag zur Theoretisierung des Wartens in der Differenzierung von Objekt, Subjekt und Kontext der Erwartung liegen. Im Übertrag eines Theorieangebotes aus der Technikakzeptanzforschung ${ }^{11}$ könnte hier ein gewinnbringender Weg liegen, der Komplexität der (historischen) Erforschung von Temporalphänomenen besser zu begegnen.

Die Kulturgeschichte nimmt für sich in Anspruch, an vermeintlich oberflächlichen und banalen Phänomenen Fundamentales einer bestimmten Kulturepoche zu erkennen. ${ }^{12}$

Doris Lucke, Akzeptanz: Legitimität in der »Abstimmungsgesellschaft« (Opladen: Leske \& Budrich, 1995); Martina Schäfer und Dorothee Keppler, »Modelle der technikorientierten Akzeptanzforschung (Zentrum Technik und Gesellschaft, TU Berlin, 2013), $16 \mathrm{ff}$. 
Passagiere im Modus des Wartens gehören zu genau solchen Symptomen einer Kultur der Moderne, die es im Schatten ihrer Meisternarrative aufzuarbeiten gilt. In diesem Zusammenhang lag die Motivation dieser Arbeit in der Offenlegung der dem Warten immanenten Komplexität, die in Opposition zur gängigen Zuschreibung eines monotonen Zustands tritt. So entpuppte sich das Temporalphänomen bei näherer Betrachtung als ein reiches Analyse- und Niederschlagsfeld fernab der scheinbaren Trivialität eines langweilenden Zustands. Die herausgehobene Temporalität wird zum einen real erlebt, dient zum anderen aber nur allzu oft als Projektionsfläche und Anlass für die Thematisierung sozialer, politischer Missstände oder einer kulturkritischen Instrumentalisierung für das Vermissen alter Verhältnisse und überfordernder Gegenwartserfahrungen. Wartephänomene treten damit in den Stand einer wichtigen Indikatorenfunktion. In diesem Verständnis spiegelt die Geschichte des (verkehrlichen) Wartens nicht nur die sich wandelnde Stellung der Eisenbahn innerhalb des Verkehrswesens, sondern ihre Entwicklungskonjunkturen veranschaulichen zugleich auch die sich wandelnden gesellschaftlichen und temporalkulturellen Selbstverständnisse der jeweiligen Modernisierungsperioden. Während der Wartesaal im 19. Jahrhundert in sozialer Hinsicht ein Abbild vorherrschender Klassenstrukturen und deren noch relativ geringer Zeitsensibilität darstellte, wurde er im Laufe des 20. Jahrhundert zur symbolhaften Antithese moderner Affirmationen, zum Schauplatz eines Anachronismus, der nicht mehr im Zentrum lag, sondern in den »Hinterhof der Moderne $«^{13}$ rückte, in dem das Warten (im Verkehrskontext) den Status eines gesellschaftsübergreifend negativ konnotierten Zustands erlangte.

Der zentrale kulturgeschichtliche Beitrag dieser Arbeit besteht damit zum einen in der historischen Einordung (und Relativierung) eines heute ungeliebten Zustands, zum anderen aber vor allem in dessen grundsätzlicher Thematisierung, denn die Geschichte der Moderne wird sich ohne die in ihr geschaffenen Retardierungsprozesse, ohne ihre Rückräume und »Hinterhöfe« weder systemisch noch alltagspraktisch rekonstruieren lassen. 


\section{Abbildungsverzeichnis}

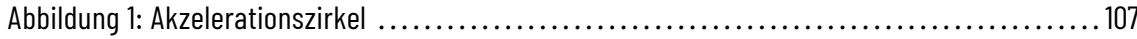

Abbildung 2: Erweiterung des Akzelerationszirkels ................................. 111

Abbildung 3: Idealisiertes Schema zur zeitgeschichtlichen Verortung des Wartens ......... 118

Abbildung 4: Dresden Postplatz (1946): Straßenbahnhaltestellen mit Wartehalle .............. 151

Abbildung 5: Schema des Reiseverlaufs . ........................................ 154

Abbildung 6: Umkehrung des Kräftespiels und der Mechanisierung der Triebkräfte ............ 166

Abbildung 7: Entwicklungen des Personenverkehrs in Deutschland ..................... 170

Abbildung 8: Bahnkarte Deutschlands und angrenzender Länder (1899)................. 171

Abbildung 9: Postpassagierstube in Schottland .................................. 198

Abbildung 10: Typologie der Bahnhofsbauten in der Frühphase des Eisenbahnwesens..........203

Abbildung 11: Bahnhof in Liverpool mit Empfangsgebäude und überdachter Wagenhalle ........ 208

Abbildung 12: Situationsplan und (vermuteter) Grundriss der Crown Street Station Liverpool ... 210

Abbildung 13: Ansicht der Manchester Liverpool Road Station aus dem Jahr 1905

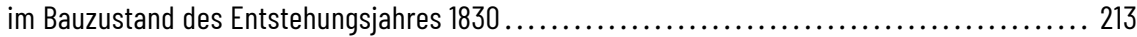

Abbildung 14: Grundriss des Empfangsgebäudes mit einer innerhalb des Raumprogramms erstmals deutlich sichtbar verfolgten Klassentrennung .............................. 216

Abbildung 15: Ludwigsbahnhof in Nürnberg (um 1836) ......................................... 219

Abbildung 16: Situationsplan des Bahnhofs Nürnberg (um 1835) .........................220

Abbildung 17: Erster Potsdamer Bahnhof in Berlin (1843) mit Empfangsgebäude und

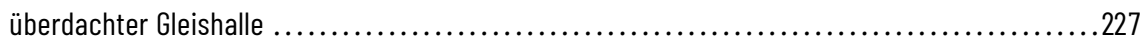

Abbildung 18: Grundriss des Potsdamer Bahnhofs in Berlin, 1838 .......................229

Abbildung 19: Grundriss des Empfangsgebäudes des Potsdamer Bahnhofs 1838 ............... 230

Abbildung 20: Idealtypischer Grundrissentwurf für Kopfstationen mit seitlich der Gleise

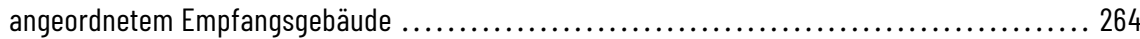

Abbildung 21: Empfangsgebäude des Bahnhofs Elberfeld (um 1850) ........................... 292

Abbildung 22: Grundriss Bahnhof Elberfeld (um 1850) .............................. 293

Abbildung 23: Innenansicht des Wartesaals 3. Klasse im Hauptbahnhof Wuppertal

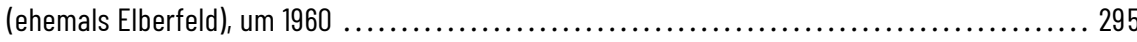

Abbildung 24: Görlitzer Bahnhof zur Zeit seiner Eröffnung (um 1868) .................... 296

Abbildung 25: Grundriss des Görlitzer Bahnhofs in Berlin .......................... 297

Abbildung 26: »Une salle d'attente de troisième classe« (Honoré Daumier, 1870er) ............. 317

Abbildung 27: »L'attente à la gare« (Honoré Daumier, 1850er). ......................... 318 
Abbildung 28: »La salle d'attente, ou le quart-d'heure de réflexions désagréables «

(Honoré Daumier, 1855). ................................................ 319

Abbildung 29: Grundriss des Hannoveraner Hauptbahnhofs mit seinen dominanten Tunnelwegen (1881) .328

Abbildung 30: Grundriss des Hildesheimer Hauptbahnhofs mit Wartesaalgebäude in Insellage

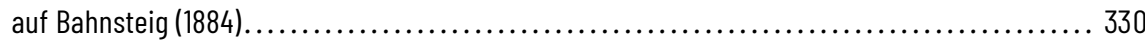

Abbildung 31: Schematisch-tendenzielle Entwicklung des Kopfbahnhofes .................. 335

Abbildung 32: Grundriss des Pariser Gare du Nord im Ursprungsstadium (1847)

mit Kopfbahnsteig und vorgeschalteter Zirkulationszone des 'salle des pas perdus ‘........ 338

Abbildung 33: Damensalon im Hauptbahnhof Wiesbaden ........................... 343

Abbildung 34: Hamburger Bahnhof in Berlin (um 1850) ............................... 354

Abbildung 35: Empfangsgebäude des Potsdamer Bahnhofs in Berlin (1872) ................ 356

Abbildung 36: Verkehrsentwicklung Potsdamer Bahn 1843-79 ......................... 357

Abbildung 37: Grundriss Potsdamer Bahnhof in Berlin mit Wartesaal IV. Klasse ............ 361

Abbildung 38: Grundriss des Potsdamer Bahnhofs Berlin ........................... 363

Abbildung 39: Grundriss des Anschlussbahnhofs der Wannseebahn (Potsdamer Bahnhof) ..... 364

Abbildung 40: Grundriss des neuen Centralbahnhofes Frankfurt a.M ................... 366

Abbildung 41: Bahnsteighalle des neuen Centralbahnhofes von Frankfurt a.M. mit breitem Kopfbahnsteig (um 1888) ............................................. 369

Abbildung 42: Wartesaal erster und zweiter Klasse mit dahinterliegendem Speisesaal

in Frankfurt a.M. ...................................................... 370

Abbildung 43: Grundriss des Wiesbadener Hauptbahnhofes von 1906 ..................... 401

Abbildung 44: Postkarte des Neuen Bahnhofs Wiesbaden mit Querbahnsteig ............... 402

Abbildung 45: Grundriss des Stuttgarter Hauptbahnhofs im Jahr $1943 \ldots \ldots \ldots \ldots \ldots \ldots \ldots . \ldots 05$

Abbildung 46: Grundriss des Hauptbahnhofes Oberhausen ............................ 408

Abbildung 47: Lageplan des Hauptbahnhofes Oberhausen ............................ 409

Abbildung 48: Wartesaal IV. Klasse, Zyklus »Volk« II, Nr.12 (Hans Baluschek, 1926). ........... 420

Abbildung 49: Eduard Braun, Im Wartesaal III. und IV. Klasse (1927) .........................422

Abbildung 50: Walter Ophey, Nachts im Wartesaal (um 1923) ........................... 423

Abbildung 51: »Die Hälfte seines Lebens wartet der Soldat vergebens«, Bildpostkarte aus der Zeit des Nationalsozialismus ...................................... 429

Abbildung 52: Lufthansa-Wartebereich am Zentralflughafen Berlin-Tempelhof (1930). ........ 444

Abbildung 53: Echtzeitinformationssystem im Berliner Nahverkehr ...................... 448 


\section{Quellen und Literatur}

\section{Quellen}

Aristoteles. Physikvorlesung. Herausgegeben von Hellmut Flashar. Übersetzt von Hans Wagner. 5. Aufl. Werke, in deutscher Übersetzung/Aristoteles. Berlin: Akademie Verlag, 1995.

Augustinus. Des heiligen Kirchenvaters Aurelius Augustinus Bekenntnisse. Übersetzt von Alfred Hofmann. Bibliothek der Kirchenväter, 1. Reihe, Bd. 18; Augustinus VII. München: Kösel, 1914.

Baader, Joseph von. Ueber die Vortheile einer verbesserten Bauart von Eisenbahnen und Wagen. München: E.A. Fleischmann, 1826.

Bendel, A. »Aufsätze, zusammengestellt aus den von dem verstorbenen Geh. Regierungsrath Henz während seiner Reise in Nord-Amerika im Jahre 1859 gesammelten Notizen. "Zeitschrift für Bauwesen XI. (1861): 461-84.

Benjamin, Walter. »Kriminalromane, auf Reisen«. In Gesammelte Schriften, herausgegeben von Rolf Tiedemann und Hermann Schweppenhäuse, IV: Kleine Prosa:88-89. Frankfurt a.M.: Suhrkamp, 1972.

Berliner Senatsverwaltung für Stadtentwicklung. "Verordnung über den Betrieb von baulichen Anlagen«, 2007. www.versammlungsstaettenverordnung.de/bundeslaen der/downloads/BERLIN/BetrVO_07.pdf.

Blanck. "Ueber den Bau der Eisenbahnen in den Vereinigten Staaten von NordAmerika«. Zeitschrift für Bauwesen XXVII. (1877): 547-60.

Booth, Henry. An account of the Liverpool and Manchester Railway. Liverpool: Wales and Baines, 1830.

Bury, T.T. Coloured views on the Liverpool and Manchester Railway. London: Ackermann \& Co., 1833.

Busse, Conrad. »Englische Bahnhöfe«. Deutsche Bauzeitung 2, Nr. 34 (1868): 359.

Cauer, Wilhelm. Personenbahnhöfe. 2. Aufl. Berlin: Springer, 1926.

Cornelius, G. »Das neue Empfangsgebäude auf dem Hauptbahnhof in Wiesbaden.«Zeitschrift für Bauwesen LVII. (1908): 29-48.

Crelle, August L. »Einige techn. Nachrichten v. d. Eisenbahn zwischen Berlin u. Potsdam. "Journal für die Baukunst: in zwanglosen Heften 15 (1841). 
—_. »Zum uberschläg. Entwurf e. Eisenbahn zwischen Frankfurt a. d. O. und Breslau. Journal für die Baukunst: in zwanglosen Heften 13 (1839).

Cuno. »Das Empfangsgebäude des Bahnhofes Eydtkuhnen.«Zeitschrift für Bauwesen XV. (1865): 101-6.

Daly, César. »Des Gares de Chemin de Fer«. Revue General d'Architecture et des travaux publics, Nr. 6 (1846): 509-18.

- "Gare du Chemin de Fer du Nord.« Revue General d'Architecture et des travaux publics, Nr. 6 (1846): 529-40.

Deutsche Bahn AG. »Für eine starke Schiene: Leipziger DB Lounge und DB Reisezentrum im neuen Design und mit neuem Konzept«, 14. August 2019. https://www. deutschebahn.com/pr-leipzig-de/aktuell/presseinformationen/Fuer-eine-starkeSchiene-Leipziger-DB-Lounge-und-DB-Reisezentrum-im-neuen-Design-undmit-neuem-Konzept-4389980.

Deutscher Bundestag. »Pünktlichkeit und Zugausfälle bei der Deutschen Bahn bis 2018«. Drucksache 19/8483, 2019. https://dipbt.bundestag.de/doc/btd/19/084/19084 83.pdf.

Dollfus, Charles M. Histoire de la Locomotion Terrestre. Paris: L'Illustration, 1935.

Donath. »Neuere Bahnhofs-Anlagen in England«. Zeitschrift für Bauwesen XXXI. (1881): 51-58.

Eggert, Hermann. »Das Empfangsgebäude des Hauptbahnhofes in Frankfurt a.M.« Zeitschrift für Bauwesen 41, Nr. 10 (1891): 401-18.

Eiselen, Fritz. »Adolf Göring †'«. Deutsche Bauzeitung 40, Nr. 122 (1906): 716-717.

Endrikat, Fred. Fred Endrikat Lesebuch. Herausgegeben von Walter Gödden. 2., durchges. Aufl. Nylands kleine westfälische Bibliothek, Bd. 21. Bielefeld: Aisthesis-Verlag, 2011.

Fallada, Hans. Damals bei uns daheim. Erfundenes, Erlebtes, Erfahrenes. Hamburg: Blüchert, 1941.

Flattich, Wilhelm. »Ueber Gesammt-Anordnung der Bahnhöfe und Stationen, insbesondere der Hochbauten. «Allgemeine Bauzeitung 35 (1870): 244-59.

Frahm, Johann. Das englische Eisenbahnwesen. Berlin: Springer, 1911.

Frank, J. Der praktische Eisenbahnbeamte. Magdeburg: Emil Baensch, 1851.

Fritsch, Karl Emil Otto. »Der neue Haupt-Personen-Bahnhof in Bremen. « Deutsche Bauzeitung 24, Nr. 64 (1890): 381-83.

Gerstäcker, Friedrich. »Auf der Eisenbahn.«In Unter Palmen und Buchen gesammelte Erzählungen, Bd.3, 320-41. Leipzig: Arnold, 1867.

Goering, A. »Ueber die verschiedenen Formen und Zwecke des Eisenbahnwesens, Rede zum Geburtsfeste Seiner Majestät des Kaisers und Königs Wilhelm II., in der Aula der Königlichen Technischen Hochschule zu Berlin«. Technische Hochschule Berlin, 26. Januar 1899.

Goering, A., und M. Oder. Der Eisenbahnbau. Herausgegeben von Ferdinand Loewe und Hermann Zimmermann. Bd. 4: Anordnung der Bahnhöfe. Handbuch der Ingenieurwissenschaften, 5.Teil. Leipzig: Engelmann, 1907.

Gropius, George. Die Berlin-Potsdamer Eisenbahn: Mit einer Abbildung und einer Charte. Berlin: Weidle, 1838. 
Grüttefien, Ernst. »Vergleichender Ueberblick über die neueren Umgestaltungen der größeren preußischen Bahnhöfe.« Centralblatt der Bauverwaltung, 349-356, VIII., Nr. $32 a$ (1888).

Gustave, Nadaud. Chansons de Gustave Nadaud. 8. Aufl. Paris: Henri Plon, 1870.

Hackländer, Friedrich. Tag und Nacht. Eine Geschichte in vierundzwanzig Stunden. Stuttgart: Eduard Hallberger, 1860.

Hans-Christian, Andersen. Eines Dichters Bazar. Bd. 1. Leipzig: Eduard Kummer, 1843.

Harkort, Friedrich. »Eisenbahnen (Railroads)«. Hermann. Zeitschrift von und für Westphalen, die Lande zwischen Weser und Maas, Nr. 26 (März 1825).

Hartmann, Karl. Praktisches Handbuch über die Anlage von Eisenbahnen, ihre Kosten, Unterhaltung und ihren Ertrag, über die Anfertigung und Prüfung guß-und stabeiserner Schienen, und die Einrichtung der Dampf-und anderen Eisenbahnwagen: nebst anhangsweisen Betrachtungen über die Anwendung der Dampfwagen aufgewöhnlichen Kunst-Straßen. Augsburg: Jenisch und Stage, 1837.

Heine, Heinrich. Werke und Briefe in zehn Bänden. Herausgegeben von Hans Kaufmann. 2. Aufl. Berlin und Weimar: Aufbau, 1972.

Hermann. "Das Neue Bahnhof-Empfangsgebäude in Oberhausen (Rheinl.)«. Zentralblatt der Bauverwaltung vereinigt mit Zeitschrift für Bauwesen 54, Nr. 52 (1934): 811-17.

Heusinger von Waldegg, Edmund, Hg. Die Eisenbahn-Hochbauten auf den Bahnhöfen und ausserhalb derselben. Leipzig: Wilhelm Engelmann, 1873.

—. Handbuch für Specielle Eisenbahn-Technik. Dritte, Verbesserte Auflage. Erster Band: Der Eisenbahnhochbau. Leipzig: Wilhelm Engelmann, 1873.

—. »Technische Vereinbarungen des Vereins Deutscher Eisenbahnverwaltungen über den Bau und die Betriebseinrichtungen der Eisenbahnen«. Organ für die Fortschritte des Eisenbahnwesens Erster Supplementband (1866): 1-18.

Housselle, W. »Die Pariser Gürtelbahn.« Zeitschrift für Bauwesen XIX. (1870): 243-54.

—. »Ueber Kopfstationen«. Deutsche Bauzeitung VI., Nr. 1 (1872): 2-4; 9-12.

Hugo, Victor. "À mes amis L. B. et S.-B. - Les Feuilles d'automne«. In Cuvres complètes: Les feuilles d'automne; Les chants du crépuscule; Les voix intérieures; Les rayons et les ombres, 2:76-79. Paris: Ollendorf, 1909.

Ivatt, Edmund B. Railway Management at Stations. 3. Aufl. London: McCorquodale, 1898.

Kant, Immanuel. Kritik der reinen Vernunft. 1. Aufl. Riga: Johann Friedrich Hartknoch, 1781.

Kästner, Erich. Gesammelte Schriften, Bd. 1-7. Berlin: Dressler, 1959.

Kirwan, Joseph. A Descriptive and Historical Account of the Liverpool and Manchester Railway, From Its First Projection to Present Time. Glasgow and London: M'Phun, Simpkin and Marshall, 1831.

Kletke, G.M. Die Preußischen Eisenbahnen. Dritter Abschnitt: Über Spezielle Vorschriften zur Benutzung der Eisenbahnbeförderung. Berlin: Mhlius'sche Buchhandlung, 1844.

Königlich Preussisches Ministerium für Öffentliche Arbeiten. Berlin und seine Eisenbahnen 1846-1896. Bd. 1. Berlin: Julius Springer, 1896.

Königliche Eisenbahndirektion zu Berlin. Festschrift über die Thätigkeit des Vereins Deutscher Eisenbahn-Verwaltungen in den ersten 50 Jahren seines Bestehens, 1846-1896. Berlin: Nauck, 1896. 
Lichthammer. »Ueber einige Bahnhöfe des westlichen Deutschlands und Belgiens«. Allgemeine Bauzeitung 7 (1842): 354-63.

Lips, Alexander. Die Nürnberg-Fürther Eisenbahn in ihren nächsten Wirkungen und Resultaten. Nürnberg: Riegel und Wießner, 1836.

List, Friedrich. Das deutsche National-Transport-System in volks-und staatswirthschaftlicher Beziehung. Altona und Leipzig: Johann Friedrich Hammerich, 1838.

- Ueber ein sächsisches Eisenbahn-System als Grundlage eines allgemeinen deutschen Eisenbahn-Systems und insbesondere über die Anlegung einer Eisenbahn von Leipzig nach Dresden. Leipzig: Liebeskind, 1833.

Löper, Carl. Stammbuch der neueren Verkehrsmittel, Eisenbahnen, Dampfschiffe, Telegraphen und Luftschiffe. Heidelberg: Decker, 1984.

Malberg. »Ueber einige Bahnhöfe und Stations-Hallen der englischen Eisenbahnen.« Zeitschrift für Bauwesen IX. (1859): 295-312.

Masur. »Der Umbau des Hauptpersonenbahnhofs Cassel.« Zeitschrift für Bauwesen 63 (1913): 447-64.

Meyers Großes Konversations-Lexikon. 6. Aufl. Bd. 5. Leipzig und Wien: Bibliographisches Institut, 1903.

Michaelis, Paul. "Die Beseitigung des Schienenüberganges des Breitenweges in Magdeburg- Neustadt.« Zeitschrift für Bauwesen LII., Nr. 7-9 (1902): 371-79.

Mühl, Gustav. Aus dem Elsaß. Straßburg: Karl J. Trübner, 1878.

Negrelli, Luigi. Ausflug nach Frankreich, England und Belgien zur Beobachtung der dortigen Eisenbahnen, mit einem Anhange über Anwendung von Eisenbahnen in Gebirgsländern. Frauenfeld: Beyel, 1838.

o.A. »Berliner Neubauten. II. Der neue Bahnhof der Niederschlesisch-Märkischen Eisenbahn.« Deutsche Bauzeitung III., Nr. 36 (1869): 429-31.

—_. »Das Empfangsgebäude der Königlichen Ostbahn zu Berlin.«Zeitschrift für Bauwesen XIX. (1870): 3-16.

—. Das grösste Wunderwerk unserer Zeit, oder, Die Eisenbahn für Dampfwägen zwischen Liverpool und Manchester in England. Nürnberg: Friedrich Campe, 1832.

—. "Der Bahnhof der Berlin - Görlitzer Eisenbahn in Berlin«. Wochenblatt des Architekten-Vereins zu Berlin 1, Nr. 45 (1867): 433-35.

—. "Der Bahnhof der Lyoner Eisenbahn in Paris.«Allgemeine Bauzeitung 24 (1859): 74-76.

—. "Der Bau der Wannseebahn und die Umgestaltung des Potsdamer Bahnhofes in Berlin.« Zeitschrift für Bauwesen XLIII. (1893): 421-40.

—. .Der neue Zentral-Bahnhof der Schweizerischen Bundesbahnen in Basel«. Deutsche Bauzeitung XLI., Nr. 53 (1907): 375.

—. "Der Umbau des Bahnhofes in Halle a. d. Saale in den Jahren 1880 bis 1892." Zeitschrift für Bauwesen XLIII. (1893): 345-72.

—_. »Der Wettbewerb zur Erlangung von Entwürfen für das Empfangsgebäude des neuen Hauptbahnhofes Leipzig.« Deutsche Bauzeitung XLI., Nr. 49 (1907): 342.

—. Deutschland und seine Eisenbahnen. Leipzig: Wigand, 1838.

—. »Die Eisenbahnen im Königreich Hannover«. Allgemeine Bauzeitung, Nr. 16 (1851): 213-89. 
— . „Eisenbahn von Paris nach St. Germain.«Allgemeine Bauzeitung 3, Nr. 27 (1838): 240-49.

—. »Englische Eisenbahn-Einrichtungen«. Zeitschrift für Bauwesen XIII. (1863): 60720.

- "Mitteilungen des Arch.- u. Ing.-Vereins zu Hamburg.« Deutsche Bauzeitung 36, Nr. 23 (1902): 154-56.

—. "Königlich privilegirte Berlinische Zeitung von Staats- und gelehrten Sachen«, 25. September 1839.

- The New York Times Current History: The European War. Bd. 1: From the Beginning to March, 1915. New York: C-H Publishing Corporation, 1915.

- The Railway Traveller's Handy Book. London: Lockwood and Co., 1862.

- „Ueber Depots und Sammelplätze für Waaren und Reisende (Stazionsplätze) bei Eisenbahnen«. Allgemeine Bauzeitung 3, Nr. 19, 20, 21 (1838): 163-65, 175-84, 19496.

—. "Ueber österreichische Eisenbahnwagen.« Deutsche Bauzeitung 8, Nr. 1 (1874): 4-5.

—_. »Wartesäle«. Die Brennessel 8, Nr. 43 (25. Oktober 1938): 506.

-Wheeler's Manchester Chronicle, 19. Juni 1830.

—. "Zur Schinkelfest-Konkurrenz des Architekten-Vereins zu Berlin. « Deutsche Bauzeitung III. (1869): 37-40.

Oder, M. Der Eisenbahnbau. Herausgegeben von Ferdinand Loewe und Hermann Zimmermann. Bd. 4: Anordnung der Bahnhöfe. Handbuch der Ingenieurwissenschaften, 5.Teil. Leipzig und Berlin: Engelmann, 1914.

Orth, August. »Der Bahnhof der Berlin-Görlitzer Eisenbahn zu Berlin«. Zeitschrift für Bauwesen XXII., Nr. 1-3 (1872): 547-52.

Paulus, Rudolf. Bau und Ausrüstung der Eisenbahnen. Stuttgart: Julius Maier, 1872.

Perdonnet, Auguste. Traité Élémentaire des Chemins de Fer. Bd. 2. Paris: Langlois et Leclercq, 1856.

—. »Ueber den Raum, den die verschiedenen Theile der Eisenbahnen einnehmen müssen.«Allgemeine Bauzeitung 23 (1858): 262-93.

—. »Von dem Nutzen der Eisenbahnen.«Allgemeine Bauzeitung 1, Nr. 48 (1836): 397402, 404-8.

Petersen, Carl Olof, und Elly Petersen. Die Moosschwaige. München: Knorr und Hirth, 1933.

Platon. Sämtliche Dialoge. Timaios und Kritias. Sophistes [u.a.]. Übersetzt von Otto Apelt. Unveränd. Nachdr. Bd. 6. Philosophische Bibliothek. Hamburg: Felix Meiner, 1998.

Polgar, Alfred. »Abschied auf dem Bahnsteig«. In Kleine Schriften, herausgegeben von Marcel Reich-Ranicki, 3: Irrlicht:162-64. Hamburg: Rowohlt, 1984.

Quassowski, Julius Ludwig. »Der neue Bahnhof der Berlin-Potsdam-Magdeburger Eisenbahn zu Berlin.« Deutsche Bauzeitung III., Nr. 19 (1869): 217-19.

—. »Der Personenbahnhof der Berlin-Potsdam-Magdeburger EisenbahnGesellschaft zu Berlin«. Zeitschrift für Bauwesen XXVII., Nr. 1-3 (1877): 18-30.

—. »Die Um- und Neubauten der Berlin-Potsdam-Magdeburger Eisenbahn.«Zeitschrift für Bauwesen XXI., Nr. 4-7 (1871): 163-84. 
Rasch, Julius. »Die Eisenbahn-Hochbauten auf den Bahnhöfen und ausserhalb derselben.« In Handbuch für Specielle Eisenbahn-Technik, herausgegeben von Edmund Heusinger von Waldegg, Dritte, Verbesserte Auflage., 1: Der Eisenbahnhochbau: 561-669. Leipzig: Wilhelm Engelmann, 1873.

Reder. »Verein für Eisenbahnkunde zu Berlin. Protocoll der Versammlung vom 11. März 1879«. Zeitschrift für Bauwesen XXIX. (1879): 469-76.

Reichsbahndirektion Berlin. Festschrift Zur Jahrhundertfeier Der Berlin-Potsdamer Eisenbahn. Leipzig: Konkordia-Verlag, 1938.

Riehl, Wilhelm Heinrich von. „Am Quell der Genesung«. In Lebensrätsel: Fünf Novellen, herausgegeben von Karl-Maria Guth, Neuausgabe des Erstdrucks von 1888., 138-74. Berlin: Hofenberg, 2018.

Röll, Viktor von. Enzyklopädie des Eisenbahnwesens. 2. Aufl. Bd. 4. Wien: Urban \& Schwarzenberg, 1913.

Rosegger, Peter. »Als ich das erstemal auf dem Dampfwagen saß«. In Waldheimat. Erinnerungen aus der Jugendzeit. Bd. 1. Kinderjahre., 227-35. Leipzig: Hartleben, 1882.

Roth, Joseph. »Wartesaal IV. Klasse. Die Passagiere, die nicht reisen«. In Joseph Roth Werke, 1: Das journalistische Werk, 1915-1923:450. Kiepenheuer \& Witsch, 1989.

Rüdell, A. »Neuere Eisenbahnhochbauten«. Zentralblatt der Bauverwaltung XXIII., Nr. 47 (1903): 289-93.

Ruskin, John. The Seven Lamps of Architecture. New York: John Wiley \& Son, 1866. . The Stones of Venice. Bd. 2: The Sea Stories. London: Smith, Elder, and Co., 1853.

Scharrer, Johannes. Deutschlands erste Eisenbahn mit Dampfkraft oder Verhandlungen der Ludwigs-Eisenbahn-Gesellschaft. Nürnberg: Riegel und Wießner, 1836.

- Deutschlands erste Eisenbahn mit Dampfkraft oder Verhandlungen der LudwigsEisenbahn-Gesellschaft in Nürnberg. Nürnberg: Riegel und Wießner, 1837.

Schmitt, Eduard. Anlage und Einrichtung der Gebäude. 2.Halbband, 4.Heft (Empfangsgebäude der Bahnhöfe und Bahnsteigüberdachungen (Bahnsteighallen und dächer). Handbuch der Architektur, Vierter Teil. Entwerfen. Leipzig: Gebhardt, 1911.

- Vorträge Bahnhöfe und Hochbauten aufLocomotiv-Eisenbahnen: Erster Theil. Die Anlage der Bahnhöfe. Leipzig: Arthur Felix, 1873.

- Vorträge Bahnhöfe und Hochbauten auf Locomotiv-Eisenbahnen: Zweiter Theil. Hochbauten für die Zugförderung und Bahnbewachung. Leipzig: Arthur Felix, 1882.

Schultze, W. »Das Empfangs-Gebäude des Bahnhofes zu Dirschau. Z Zeitschrift für Bauwesen XIX. (1859): 285-88.

Schwabe, H. »Über Englische Bahnhofs-Anlagen«. Allgemeine Bauzeitung 41 (1876): 69-74. Schwabe, Hermann. »Architekten-Verein zu Berlin. Versammlung am 26. April 1873«. Deutsche Bauzeitung 7, Nr. 36 (1873): 143.

- Ueber das englische Eisenbahnwesen. Berlin: Ernst \& Korn, 1871.

Spitteler, Carl. »Der Gotthardtunnel«. In Gesammelte Werke, Bd.8, herausgegeben von Gottfried Bohnenblust, Wilhelm Altegg, und Robert Faesi. Zürich: Artemis, 1947.

Taeger. »Ueber englisches Eisenbahnwesen.« Zeitschrift für Bauwesen XXVII., Nr. 4-7 (1877): 265-96.

Trollope, Anthony. Collection of British Authors. Vol. 812. The Belton Estate by Anthony Trollope. Leipzig: Bernhard Tauchnitz, 1866. 
Verein Deutscher Eisenbahn-Verwaltungen. Deutsche Eisenbahn-Statistik für das BetriebsJahr 1875. Bd. XXVI. Jahrgang. Berlin: Rauck'sche Buchdruckerei, 1877.

—. Festschrift über die Thätigkeit des Vereins Deutscher Eisenbahn-Verwaltungen in den ersten 50 Jahren seines Bestehens, 1846-1896. Berlin: Nauck, 1896.

Verein für Eisenbahnkunde zu Berlin. »Mittheilung des Vereins für Eisenbahnkunde zu Berlin. Versammlung am 9. März 1875«. Deutsche Bauzeitung 9, Nr. 33 (1875): 167-68.

— . „Verein für Eisenbahnkunde zu Berlin. Protocoll der Versammlung vom 10. November 1866«. Zeitschrift für Bauwesen XVII. (1867): 289ff.

—. —Verein für Eisenbahnkunde zu Berlin. Protocoll der Versammlung vom 10. November 1874«. Zeitschrift für Bauwesen XXV. (1875): 282f.

—. »Verein für Eisenbahnkunde zu Berlin. Protocoll der Versammlung vom 11. Februar 1879«. Zeitschrift für Bauwesen XXIX. (1879): 461-69.

—. "Verein für Eisenbahnkunde zu Berlin. Protocoll der Versammlung vom 24. October 1868«. Zeitschrift für Bauwesen XIX. (1869): 429-36.

—. „Verein für Eisenbahnkunde zu Berlin. Protocoll der Versammlungen am 11. März 1873.«Zeitschrift für Bauwesen XXIII. (1873): 529-37.

—. „Verein für Eisenbahnkunde zu Berlin. Protocoll der Versammlungen am 13. October und 10. November 1874.«Zeitschrift für Bauwesen XXV. (1875): 279-85.

—. „Verein für Eisenbahnkunde zu Berlin. Protocoll vom 8. Januar und vom 12. Februar 1861«. Zeitschrift für Bauwesen XI. (1861).

—. »Verein für Eisenbahnkunde zu Berlin. Vortrag zum Stiftungsfest am 8.October 1867«. Zeitschrift für Bauwesen 18, Nr. Heft IV-VII (1868).

Vershofen, Wilhelm. »Frühe im Bahnhof«. Quadriga, Nr. 2 (1912): 67.

Walker, James Scott. An Accurate Description of the Liverpool and Manchester Railway. Third edition. Liverpool: JF Canneli, 1832.

Weber, Max. Die protestantische Ethik und der »Geist« des Kapitalismus. Herausgegeben von Klaus Lichtblau und Johannes Weiß. Neuausgabe der ersten Fassung von 1904-05 mit einem Verzeichnis der wichtigsten Zusätze und Veränderungen aus der zweiten Fassung von 1920. Klassiker der Sozialwissenschaften. Wiesbaden: Springer VS, 2016.

Weber, Max Maria von. Schule des Eisenbahnwesens: Geschichte, Technik, Administration und Statistik der Eisenbahnen. Dritte, Vermehrte Auflage, neu Bearbeitet von Eduard Schmitt. Leipzig: Verlagsbuchhandlung von J. J. Weber, $1873 a$.

—. „Einleitung«. In Handbuch für Specielle Eisenbahn-Technik, herausgegeben von Edmund Heusinger von Waldegg, Dritte, Verbesserte Auflage., Erster Band: Der Eisenbahhochbau:1-12. Leipzig: Wilhelm Engelmann, 1873b.

Wedekind, Frank. Gedichte aus dem »Simplicissimus«. Göttingen: Wallstein Verlag, 2019.

Weerth, Georg. Sämtliche Werke. Bd. 3: Skizzen aus dem sozialen und politischen Leben der Briten. Berlin: Aufbau Verlag, 1957.

Wegele, H. »Die Hauptbahnhofs-Anlagen in Frankfurt a.M.« Zeitschrift für Bauwesen XLI., Nr. 1-3 (1891): 83-104.

Weishaupt, Theodor. »Verein für Eisenbahnkunde zu Berlin. Sitzung am 12. September 1871.« Deutsche Bauzeitung 5, Nr. 40 (1871): 319-20.

Werfel, Franz. »Gedichte aus dem Nachlass - Franz Werfel«, 12. Februar 2020. https:// www.literatisch.de/gedichte-aus-dem-nachlass-franz-werfel.html. 
Whishaw, Francis. The Railways of Great Britain and Ireland. 2. Aufl. London: John Weale, 1842.

Williams, Frederick S. Our Iron Roads: Their History, Construction, and Administration. London: Bemrose \& Sons, 1883.

Winckler, Josef. »Eiserne Sonette«. Quadriga, Nr. 3 (1912): $107 \mathrm{f}$.

Wulff, Eberhard. Das Eisenbahn-Empfangs-Gebäude nach seinen praktischen Anforderungen und seiner künstlerischen Bedeutung: an den Bauausführungen der Rheinischen Eisenbahn erläutert. Leipzig: Scholtze, 1882.

\section{Literatur}

Adam, Barbara. Time and Social Theory. Cambridge: Polity Press, 1990.

Adas, Michael. »Contested hegemony: The Great War and the Afro-Asian assault on the civilizing mission ideology«. Journal of World History 15, Nr. 1 (2004): 31-63.

Adey, Peter. "If mobility is everything then it is nothing: towards a relational politics of (im) mobilities«. Mobilities 1, Nr. 1 (2006): 75-94.

Adey, Peter, David Bissell, Kevin Hannam, Peter Merriman, und Mimi Sheller. »Introduction«. In The Routledge Handbook of Mobilities, herausgegeben von Peter Adey, David Bissell, Kevin Hannam, Peter Merriman, und Mimi Sheller, 1-20. London and New York: Routledge, 2014.

Arschavir, A.A. "The Inception of the English Railway Station«. Architectural History 4 (1961): 63-76.

Augé, Marc. Orte und Nicht-Orte: Vorüberlegungen zu einer Ethnologie der Einsamkeit. Frankfurt a.M.: Fischer, 1994.

Bagwell, Philip. The railway clearing house in the British economy 1842-1922. London: Allen \& Unwin, 1968.

. The transport revolution 1770-1985. London: Routledge, 2002.

Baker, J., und M. Cameron. »The Effects of the Service Environment on Affect and Consumer Perception of Waiting Time: An Integrative Review and Research Propositions«. Journal of the Academy of Marketing Science 24, Nr. 4 (1. September 1996): 338-49.

Barman, Christian Augustus. An introduction to railway architecture. London: Art and Technics, 1950.

Bauman, Zygmunt. Liquid Modernity. Cambridge: Polity, 2000.

Beck, Ulrich. »World Risk Society as Cosmopolitan Society?: Ecological Questions in a Framework of Manufactured Uncertainties«. Theory, Culture \& Society 13, Nr. 4 (November 1996): 1-32.

Beck, Ulrich, und Martin Mulsow. »Einleitung«. In Vergangenheit und Zukunft der Moderne, herausgegeben von Ulrich Beck und Martin Mulsow, Erste Auflage, Originalausgabe., 7-43. Berlin: Suhrkamp, 2014.

-, Hg. Vergangenheit und Zukunft der Moderne. Erste Auflage, Originalausgabe. Edition Suhrkamp 2685. Berlin: Suhrkamp, 2014.

Beckett, Samuel. Waiting for Godot: A Tragicomedy in Two Acts. Grove Press, 2011. 
Behringer, Wolfgang. Im Zeichen des Merkur: Reichspost und Kommunikationsrevolution in der Frühen Neuzeit. Göttingen: Vandenhoeck \& Ruprecht, 2003.

Bekasova, Alexandra. »The Making of Passengers in the Russian Empire: CoachTransport Companies, Guidebooks, and National Identity in Russia, 1820-1860s«. In Russia in Motion: Cultures of Human Mobility since 1850, herausgegeben von John Randolph und Eugene M. Avrutin, 199-217. Chicago: University of Illinois Press, 2012.

Bellebaum, Alfred. »Warten. Über Umgang mit Zeit«. In Unser Alltag ist voll von Gesellschaft: sozialwissenschaftliche Beiträge, herausgegeben von Robert Hettlage und Alfred Bellebaum, 231-58. Wiesbaden: Springer VS, 2014.

Ben-Akiva, Moshe E., und Steven R. Lerman. Discrete choice analysis: theory and application to travel demand. Bd. 9. MIT press, 1985.

Benjamin, Walter. Das Passagen-Werk. Herausgegeben von Rolf Tiedemann. 1. Aufl. Bd. 2. Frankfurt a.M.: Suhrkamp, 1982.

Benz, Nadine. (Erzählte) Zeit des Wartens: Semantiken und Narrative eines temporalen Phänomens. Zäsuren, Bd. 4. Göttingen: V\&R Unipress, 2013.

Berger, Louis. Der alte Harkort: ein westfälisches Lebens- und Zeitbild. Leipzig: Julius Baedeker, 1891.

Berger, Manfred. Historische Bahnhofsbauten. Bd. 1: Sachsen, Preussen, Mecklenburg und Thüringen. Berlin: transpress, 1980.

- Historische Bahnhofsbauten. Bd. 2: Braunschweig, Hannover, Preussen, Bremen, Hamburg, Oldenburg und Schleswig-Holstein. Berlin: transpress, 1987.

Bergmann, Werner. »Das Problem der Zeit in der Soziologie. Ein Literaturüberblick zum Stand der >zeitsoziologischen Theorie und Forschung." Kölner Zeitschrift für Soziologie und Sozialpsychologie 35, Nr. 3 (1983): 462-504.

- "The problem of time in sociology: An overview of the literature on the state of theory and research on the >Sociology of Time<, 1900-82«. Time \& Society 1, Nr. 1 (1992): 81-134.

Bergson, Henri. Denken und schöpferisches Werden: Aufsätze und Vorträge. Unveränd. Nachdr. [der Ausg.] Paris, 1946. Eva-Taschenbuch 50. Hamburg: EVA, Europ. Verl.-Anst, 2008.

—. Schöpferische Entwicklung. Übersetzt von Gertrud Kantorowicz. 1. Aufl. Jena: E. Diederichs, 1921.

Berry, Leonard L., Kathleen Seiders, und Dhruv Grewal. »Understanding service convenience«. Journal of Marketing 66, Nr. 3 (2002): 1-17.

Biddle, Gordon. Victorian Stations: Railway Stations in England and Wales, 1830-1923. Newton Abbot: David and Charles, 1973.

Bielen, Frédéric, und Nathalie Demoulin. »Waiting time influence on the satisfactionloyalty relationship in services«. Managing Service Quality: An International Journal 17, Nr. 2 (2007): 174-93.

Bissell, David. »Animating Suspension: Waiting for Mobilities«. Mobilities 2, Nr. 2 (Juli 2007): 277-98.

- »The Poetics of Waiting Without Value: Harold Schweizer, On Waiting. London: Routledge, 2008. ISBN 0415775078«. Time $\&$ Society 18, Nr. 2-3 (1. September 2009): 410-13. 
Bissell, David, und Gillian Fuller, Hg. Stillness in a mobile world. London; New York: Routledge, 2011.

—. »Stillness unbound «. In Stillness in a mobile world, herausgegeben von David Bissell und Gillian Fuller, 1-17. London; New York: Routledge, 2011.

Bley, Peter. 150 Jahre Eisenbahn Berlin-Potsdam: aus d. Geschichte d. ältesten Eisenbahn in Berlin u. Preussen. Düsseldorf: Alba, 1988.

Bock, Philip K. »Social structure and language structure«. Journal of Anthropological Research 42, Nr. 3 (1986): 427-37.

Bohannan, Paul. »Concepts of time among the Tiv of Nigeria«. Southwestern Journal of Anthropology 9, Nr. 3 (1953): 251-62.

Borscheid, Peter. Das Tempo-Virus: eine Kulturgeschichte der Beschleunigung. Frankfurt a.M.; New York: Campus, 2004.

—. "Zeit und Raum. Von der Beschleunigung des Lebens«. In Geschichte der deutschen Wirtschaft im 20. Jahrhundert, herausgegeben von Reinhard Spree, Originalausgabe., 23-49. München: Beck, 2001.

Brantz, Dorothee. "Introduction«. In Beastly natures: Animals, humans, and the study of history, herausgegeben von Dorothee Brantz, 1-13. Charlottesville: University of Virginia Press, 2010.

Brezina, Tadej, und Hermann Knoflacher. »Railway trip speeds and areal coverage. The emperor's new clothes of effectivity? « Journal of Transport Geography 39 (2014): 121-30.

Bröhan, Margrit. Hans Baluschek: 1870-1935; Maler, Zeichner, Illustrator. 2., erw. Aufl. Berlin: Bröhan-Museum, 2002.

Brunner, Otto. »Stadt und Bürgertum in der europäischen Geschichte«. In Neue Wege der Verfassungs- und Sozialgeschichte, herausgegeben von Otto Brunner, 213-224. Göttingen: Vandenhoeck und Ruprecht, 1980.

Bulle, Heinrich. »Geleisestraßen des Altertums«. Sitzungsberichte der bayerischen Akademie der Wissenschaften, Nr. Heft 2 (1947).

Butler, Judith. Körper von Gewicht. Die diskursiven Grenzen des Geschlechts. Berlin: Berlin Verlag, 1995.

Canzler, Weert, Vincent Kaufmann, und Sven Kesselring, Hg. Tracing mobilities: towards a cosmopolitan perspective. Transport and society. Aldershot, England; Burlington, VT: Ashgate, 2008.

Canzler, Weert, und Andreas Knie. Möglichkeitsräume: Grundrisse einer modernen Mobilitäts-und Verkehrspolitik. Wien: Böhlau, 1998.

Carey, James W. Communication as culture: essays on media and society. Media and popular culture. Boston: Unwin Hyman, 1989.

Carlyle, Thomas. The Works. Herausgegeben von H.D. Traill. Centenary Edition. Bd. 2730. New York: AMS Press, 1974.

Carmon, Ziv, J. George Shanthikumar, und Tali F. Carmon. »A psychological perspective on service segmentation models: The significance of accounting for consumers' perceptions of waiting and service«. Management Science 41, Nr. 11 (1995): 1806-15.

Chintschin, Alexander. »Mathematical theory of a stationary queue«. Matematicheskii Sbornik 39, Nr. 4 (1932): 73-84.

Chow, William, David Block-Schachter, und Samuel Hickey. »Impacts of Real-Time Passenger Information Signs in Rail Stations at the Massachusetts Bay Transportation 
Authority«. Transportation Research Record: Journal of the Transportation Research Board 2419, Nr. 1 (Januar 2014): 1-10.

Conrad, Peter. Modern Times, Modern Places: Life and Art in the 2oth Century. London: Thames \& Hudson, 1999.

Conze, Werner, und Jürgen Kocka. Bildungsbürgertum im 19. Jahrhundert. Bd. 38. Stuttgart: Klett-Cotta, 1985.

Cresswell, Tim. »Friction«. In The Routledge Handbook of Mobilities, herausgegeben von Peter Adey, David Bissell, Kevin Hannam, Peter Merriman, und Mimi Sheller, 10515. London and New York: Routledge, 2014.

—. »Towards a Politics of Mobility«. Environment and Planning D: Society and Space 28, Nr. 1 (2010): 17-31.

Daniel, Ute. Kompendium Kulturgeschichte: Theorien, Praxis, Schlüsselwörter. 1. Aufl. Frankfurt a.M.: Suhrkamp, 2001.

Davenport, Andrew, Christophe Gefflot, und Chris Beck. »Slack-based techniques for robust schedules«. In Proceedings of the Sixth European Conference on Planning. Toledo (Spain): AAAI Press, 2001.

Dawes, Jillian, und Jennifer Rowley. »The Waiting Experience: Towards Service Quality in the Leisure Industry«. International Journal of Contemporary Hospitality Management 8, Nr. 1 (Februar 1996): 16-21.

Décultot, Elisabeth, und Daniel Fulda, Hg. Sattelzeit: historiographiegeschichtliche Revisionen. Hallesche Beiträge zur Europäischen Aufklärung 52. Berlin; Boston: De Gruyter, 2016.

Deleuze, Gilles. Das Bewegungs-Bild. 1. Aufl. Kino, Gilles Deleuze ; Bd.1. Frankfurt a.M.: Suhrkamp, 1997.

Dellaert, Benedict GC, und Barbara E. Kahn. »How tolerable is delay? Consumers' evaluations of internet web sites after waiting«. Journal of interactive marketing 13, Nr. 1 (1999): 41-54.

Deutsche Bahn AG. »Kennzahlen 2018«, 2019. https:/www.deutschebahn.com/ resource/blob/4045082/74a5d3db2bc75888121897cefada8823/20190328_pbk_2019_ kennzahlen-data.pdf.

Dienel, Hans-Liudger, Hg. Der Optimismus der Ingenieure: Triumph der Technik in der Krise der Moderne um 1900. Stuttgart: F. Steiner, 1998.

Dienel, Hans-Liudger, und Helmuth Trischler. »Geschichte der Zukunft des Verkehrs: Eine Einführung. «In Geschichte der Zukunft des Verkehrs: Verkehrskonzepte von der frühen Neuzeit bis zum 21. Jahrhundert, herausgegeben von Hans-Liudger Dienel und Helmuth Trischler, 11-39. Frankfurt a.M.; New York: Campus Verlag, 1997.

Dipper, Christof. »Die Epoche der Moderne: Konzeption und Kerngehalt«. In Vergangenheit und Zukunft der Moderne, herausgegeben von Ulrich Beck und Martin Mulsow, Erste Aufl., Originalausgabe., 103-80. Berlin: Suhrkamp, 2014.

-. "Moderne«. Docupedia-Zeitgeschichte, 2010.

Disko, Sasha. »Men, Motorcycles and Modernity: Motorization During the Weimar Republic«. Unveröffentlichte Dissertation, New York University, 2008.

Divall, Colin, und George Revill. »Cultures of Transport: Representation, Practice and Technology«. The Journal of Transport History 26, Nr. 1 (2005): 99-111. 
Dohr-van Rossum, Gerhard. »Schlaguhr und Zeitorganisation«. In Im Netz der Zeit: menschliches Zeiterleben interdisplinär, herausgegeben von Rudolf Wendorff, 49-60. Edition Universitas. Stuttgart: S. Hirzel, 1989.

Donaghy, Thomas J. Liverpool \& Manchester Railway Operations, 1831-1845. Newton Abbot: David \& Charles Publishers, 1972.

Doob, Leonard W. Patterning of Time. New York: Yale University Press, 1972.

Dubé, Laurette, Bernd H. Schmitt, und France Leclerc. "Consumers' Affective Response to Delays at Different Phases of a Service Delivery«. Journal of Applied Social Psychology 21, Nr. 10 (Mai 1991): 810-20.

Dube-Rioux, Laurette, Bernd H. Schmitt, und France Leclerc. »Consumers' reactions to waiting: when delays affect the perception of service quality«. NA-Advances in Consumer Research 16 (1989): 59-63.

Duchrow, Ulrich. »Der sogenannte psychologische Zeitbegriff Augustins im Verhältnis zur physikalischen und geschichtlichen Zeit«. Zeitschrift für Theologie und Kirche 63, Nr. 3 (1966): 267-88.

Durrande-Moreau, Agnes. »Waiting for service: ten years of empirical research«. International Journal of Service Industry Management 10, Nr. 2 (1999): 171-94.

Dziekan, Katrin, und Karl Kottenhoff. »Dynamic At-Stop Real-Time Information Displays for Public Transport: Effects on Customers«. Transportation Research Part A: Policy and Practice 41, Nr. 6 (Juli 2007): 489-501.

Dziekan, Katrin, und Meinhard Zistel. "Öffentlicher Verkehr«. In Verkehrspolitik, herausgegeben von Oliver Schwedes, 347-72. Wiesbaden: Springer, 2018.

Ebbighausen, Rodion. Das Warten: ein phänomenologisches Essay. Würzburg: Königshausen \& Neumann, 2010.

Ehn, Billy, und Orvar Löfgren. Nichtstun: eine Kulturanalyse des Ereignislosen und Flüchtigen. Übersetzt von Michael Adrian. 1. Aufl. Hamburg: Hamburger Edition, 2012.

Eichholtz, Dietrich. Junker und Bourgeoisie vor 1848 in der preußischen Eisenbahngeschichte. Berlin, 1962.

Elias, Norbert. Über die Zeit. Herausgegeben von Michael Schröter. Übersetzt von Holger Fliessbach und Michael Schröter. Gesammelte Schriften 9. Frankfurt a.M.: Suhrkamp, 2004.

Erlang, Agner Krarup. »The theory of probabilities and telephone conversations«. Nyt Tidsskrift for Matematik B 20, Nr. 6 (1909): 87-98.

Evans-Pritchard, E. E. The Nuer. Oxford: Oxford University Press, 1940.

Fan, Yingling, Andrew Guthrie, und David Levinson. "Waiting Time Perceptions at Transit Stops and Stations: Effects of Basic Amenities, Gender, and Security«. Transportation Research Part A: Policy and Practice 88 (Juni 2016): 251-64.

Fitzgerald, R. S. Liverpool Road Station, Manchester: an historical and architectural survey. Manchester: Manchester University Press, 1980.

Fogel, Robert. Railroads and American Economic Growth: Essays in Econometric History. Baltimore: Johns Hopkins Press, 1964.

Foucault, Michel. Der Wille zum Wissen: Sexualität und Wahrheit. Frankfurt a.M.: Suhrkamp, 1997.

Franz, Leonhard. »Alte Geleisestraßen in Tirol«. Veröffentlichungen des Tiroler Landesmuseums Ferdinandeum, Nr. 31 (1951): 133-46. 
Franz, Wilhelm. Fabrikbauten. Handbuch der Architektur (4. Teil, 2. Halband, 5.Heft). Leipzig: Gebhardt, 1923.

Fremdling, Rainer. Eisenbahnen und deutsches Wirtschaftswachstum, 1840-1879: ein Beitrag zur Entwicklungstheorie und zur Theorie der Infrastruktur. Bd. 2. Dortmund: Gesellschaft für Westfälische Wirtschaftsgeschichte, 1975.

—. "Railroads and German Economic Growth: A Leading Sector Analysis with a Comparison to the United States and Great Britain«. The Journal of Economic History 37, Nr. 3 (1977): 583-604.

Friman, Margareta. "Affective dimensions of the waiting experience«. Transportation research part F: traffic psychology and behaviour 13, Nr. 3 (2010): 197-205.

Fuchs, Guido, Hg. In der Bahnhofsgaststätte: ein literarisches Menü in zwölf Gängen. Hildesheim: Monika Fuchs, 2018.

Fulda, Daniel. „Sattelzeit. Karriere und Problematik eines kulturwissenschaftlichen Zentralbegriffs«. In Sattelzeit: historiographiegeschichtliche Revisionen, herausgegeben von Elisabeth Décultot und Daniel Fulda, 1-16. Hallesche Beiträge zur Europäischen Aufklärung 52. Berlin; Boston: De Gruyter, 2016.

Fuller, Gillian. »The queue project«. The Semiotic Review of Books 16, Nr. 3 (2007): 1-5.

Garfield, Simon. The last journey of William Huskisson: how a day of triumph became a day of despair at the turn of the wheel. London: Faber, 2002.

Gasparini, Giovanni. »On Waiting«. Time \& Society 4, Nr. 1 (1995): 29-45.

Geertz, Clifford. The Interpretation of Cultures. Selected Essays by Clifford Geertz. New York: Basic Books, Inc., 1973.

Geißler, Karlheinz. »Last und Lust des Wartens«. Zeitpolitisches Magazin 9, Nr. 20 (Juli 2012): 4-5.

Geisthövel, Alexa, und Habbo Knoch. Orte der Moderne: Erfahrungswelten des 19. und 20. Jahrhunderts. Frankfurt a.M.; New York: Campus Verlag, 2005.

Geisthövel, Alexa, Habbo Knoch, und Christian W. Gottwaldt, Hg. »Der Bahnhof«. In Orte der Moderne: Erfahrungswelten des 19. und 20. Jahrhunderts, 17-26. Frankfurt a.M.; New York: Campus Verlag, 2005.

Giddens, Anthony. Konsequenzen der Moderne. 1. Aufl., [Nachdr.]. Frankfurt a.M.: Suhrkamp, 1996.

- . Time and social organization«. In Social theory and modern sociology, herausgegeben von Anthony Giddens, 140-65. Stanford: Stanford University Press, 1987.

Gimmler, Antje, Mike Sandbothe, und Walther Ch. Zimmerli. Die Wiederentdeckung der Zeit: Reflexionen - Analysen - Konzepte. Darmstadt: Wissenschaftliche Buchgesellschaft, 1997.

Glasbrenner, Adolf. »Herr Buffey auf der Berliner-Leipziger-Eisenbahn«. Berlin wie es isst - und trinkt, Nr. Heft XXI. (1844).

Glaser, Hermann. »Topos Bahnhof«. In Renaissance der Bahnhöfe, herausgegeben von Bund Deutscher Architekten BDA, Deutsche Bahn AG, und Förderverein Deutsches Architekturzentrum DAZ in Zusammenarbeit mit Meinhard von Gerkan, 280-85. Wiesbaden: Vieweg+Teubner Verlag, 1996.

Gleichen-Russwurm, Alexander von. "Im Wartesaal des Lebens«. In Der gute Ton. Ein Ratgeber für richtiges Benehmen in allen Lebenslagen, 22-27. Leipzig: Hachmeister und Thal, 1932. 
Gloy, Karen. Philosophiegeschichte der Zeit. München: Wilhelm Fink, 2008.

Göttlich, Andreas. »Einleitung. Warten - Gesellschaftliche Dimensionen Und Kulturelle Formen«. Sociologia Internationalis 54, Nr. 1-2 (Januar 2016): 1-25.

Gottwaldt, Christian W. »Kathedralen der Moderne? Bahnhofsarchitektur - gestern, heute und morgen«. In Der Bahnhof: Basilika der Mobilität - Erlebniswelt der Moderne, herausgegeben von Markwart Herzog und Mario Leis, 17-60. Irseer Dialoge, Bd. 14. Stuttgart: W. Kohlhammer, 2010.

Gräff, Friederike. Warten: Erkundungen eines ungeliebten Zustands. Ch. Links Verlag, 2014. Green, Harvey. »Cultural History and the Material(s) Turn«. Cultural History 1, Nr. 1 (2012): 61-82.

Hadfield, Charles, und Gordon Biddle. The Canals of North West England. Bd. 1. Newton Abbot: David \& Charles, 1970.

Haefeli, Ueli. »Beobachter einer mobilen Welt. Gedanken zum mobilitätshistorischen Wert belletristischer Quellen am Beispiel Friedrich Dürrenmatt «. Wege und Geschichte 2017, Nr. 1 (2017): 35-39.

- . „Entwicklungslinien deutscher Verkehrspolitik im 19. und 20. Jahrhundert«. In Handbuch Verkehrspolitik, herausgegeben von Oliver Schwedes, Weert Canzler, und Andreas Knie, 97-115. Wiesbaden: Springer Fachmedien Wiesbaden, 2016.

Hage, Ghassan. Waiting. MUP Academic Monographs. Carlton: Melbourne University Publishing, 2009.

Hall, Edward Twitchell. The Dance of Life: The Other Dimension of Time. New York, NY: Anchor Books, Doubleday, 1989.

Hallowell, A. Irving. »Temporal Orientation In Western Civilization And In A Pre-Literate Society«. American Anthropologist 39, Nr. 4 (1937): 647-70.

Hannam, Kevin, Mimi Sheller, und John Urry. »Mobilities, immobilities and moorings«. Mobilities 1, Nr. 1 (2006): 1-22.

Harrison, Paul. »How shall I say it...? « Relating the nonrelational«. Environment and Planning A 39, Nr. 3 (2007): 590-608.

Hartung, Gerald, Hg. Mensch und Zeit. Studien zur interdisziplinären Anthropologie. Wiesbaden: Springer VS, 2015.

Harvey, David. »Time-space compression and the postmodern condition«. Modernity: Critical Concepts 4 (1999): 98-118.

Hasselbusch, Inken. Norbert Elias und Pierre Bourdieu im Vergleich. Eine Untersuchung zu Theorieentwicklung, Begrifflichkeit und Rezeption. Karlsruhe: PH Karlsruhe, 2014.

Haug, Christine. »Das halbe Geschäft beruht auf Eisenbahnstationen...«. Zur Entstehungsgeschichte der Eisenbahnbibliotheken im 19. Jahrhundert«. Internationales Archiv für Sozialgeschichte der deutschen Literatur (IASL) 23, Nr. 2 (1998): 70-117.

—. «Ein Buchladen auf Stationen, wo sich zwei Linien kreuzen, müsste gute Geschäfte machen...«: Der deutsche Bahnhofs- und Verkehrsbuchhandel von 1850 bis zum Ende der Weimarer Republik im internationalen Vergleich«. In Die Internationalität der Eisenbahn, 1850-1970, herausgegeben von Monika Burri, Kilian T. Elsasser, und David Gugerli, 71-89. Zürich: Chronos, 2003.

- Reisen und Lesen im Zeitalter der Industrialisierung: die Geschichte des Bahnhofs- und Verkehrsbuchhandels in Deutschland von seinen Anfängen um 1850 bis zum Ende der Wei- 
marer Republik. Veröffentlichungen des Leipziger Arbeitskreises zur Geschichte des Buchwesens, Bd. 17. Wiesbaden: Harrassowitz, 2007.

Hegel, Georg Wilhelm Friedrich. Grundlinien der Philosophie des Rechts. Bd. 7. Hegel: Werke. Frankfurt a.M.: Suhrkamp, 1979.

Heidegger, Martin. Sein und Zeit. 17. unveränderte Aufl. Tübingen: Niemeyer, 1993.

Heidegger, Martin. Der Begriff der Zeit. Herausgegeben von Friedrich-Wilhelm von Herrmann. Gesamtausgabe. III. Abteilung, Unveröffentliche Abhandlungen, Vorträge, Gedachtes/Martin Heidegger, Bd. 64. Frankfurt a.M.: Vittorio Klostermann, 2004.

Heinimann, Alfred Christoph. Technische Innovation und literarische Aneignung: die Eisenbahn in der deutschen und englischen Literatur des 19. Jahrhunderts. Basler Studien zur deutschen Sprache und Literatur 63. Bern: Francke, 1992.

Herr-Laporte, Catherine. »Rien ne sert de courir; il faut partir à point: temps et mobilité dans un long xviiie siècle«. In Les Débuts du Conservatoire des Arts et Métiers, herausgegeben von Liliane Hilarie-Pérez, Stéphane Lembré, und Delphine Spicq, 119-42. Toulouse: Presses Universitaires du Midi, 2019.

Herzog, Markwart, und Mario Leis. »Der Bahnhof: Kathedrale, Erlebniswelt, Sozialstation und Konsumparadies«. In Der Bahnhof: Basilika der Mobilität-Erlebniswelt der Moderne, herausgegeben von Markwart Herzog und Mario Leis, 7-16. Irseer Dialoge, Bd. 14. Stuttgart: W. Kohlhammer, 2010.

Herzog, Markwart, Mario Leis, und Roland Girtler, Hg. Der Bahnhof: Basilika der Mobilität - Erlebniswelt der Moderne. Irseer Dialoge, Bd. 14. Stuttgart: W. Kohlhammer, 2010.

Hirsh, I. J., R. C. Bilger, und B. H. Deatherage. »The effect of auditory and visual background on apparent duration«. The American Journal of Psychology 69, Nr. 4 (1956): 561-74.

Hoffman, K. Douglas, Scott W. Kelley, und Beth C. Chung. »A CIT investigation of servicescape failures and associated recovery strategies«. Journal of Services Marketing 17, Nr. 4 (2003): 322-40.

Honnef, Klaus, und Dieter Leistner. Waiting: Menschen an Haltestellen. Stuttgart: avedition, 2019.

Hornik, Jacob. »Subjective vs. objective time measures: A note on the perception of time in consumer behavior". Journal of Consumer Research 11, Nr. I (1984): 615-18.

Houston, Mark B., Lance A. Bettencourt, und Sutha Wenger. »The relationship between waiting in a service queue and evaluations of service quality: A field theory perspective«. Psychology \& Marketing 15, Nr. 8 (1998): 735-53.

Hubregtse, Menno. Wayfinding, consumption, and air terminal design. New York: Routledge, 2020.

Hui, Michael K., Laurette Dube, und Jean-Charles Chebat. »The impact of music on consumers' reactions to waiting for services«. Journal of Retailing 73, Nr. 1 (1997): 87104.

Hui, Michael K., und David K. Tse. »What to tell consumers in waits of different lengths: An integrative model of service evaluation«. The Journal of Marketing 60, Nr. 2 (1996): 81-90.

Husserl, Edmund. Zur Phänomenologie des inneren Zeitbewusstseins: mit den Texten aus der Erstausgabe und dem Nachlass. Herausgegeben von Rudolf Bernet. Hamburg: Felix Meiner, 2013. 
Husserl, Edmund. Erfahrung und Urteil, Untersuchungen zur Genealogie der Logik. Herausgegeben von Ludwig Landgrebe. 2. Aufl. Hamburg: Claassen Verlag, 1954.

Jackson, James R. »Jobshop-like queueing systems«. Management science 10, Nr. 1 (1963): 131-42.

Jain, Juliet, und Glenn Lyons. »The gift of travel time«. Journal of transport geography 16, Nr. 2 (2008): 81-89.

Jany, Susanne. »Operative Räume. Prozessarchitekturen im späten 19. Jahrhundert«. Zeitschrift für Medienwissenschaft 7, Nr. I (2015): 33-43.

Kaschuba, Wolfgang. Die Überwindung der Distanz: Zeit und Raum in der europäischen Moderne. 1. Aufl. Frankfurt a.M.: Fischer, 2004.

Katz, Karen L., Blaire M. Larson, und Richard C. Larson. »Prescription for the waitingin-line blues: Entertain, enlighten, and engage«. MIT Sloan Management Review 32, Nr. 2 (1991): 44-53.

Kaufmann, Vincent. »Mobility as a Tool for Sociology«. Sociologica, Nr. 1 (2014).

Kellermann, Norman. Searching for a Path out of Distance Fares: A Review of Historical Passenger Railway Pricing and an Agent-Based Simulation Study on Possible Fare Amendments. Köln: Kölner Wiss.-Verlag, 2014.

Kellermann, Robin. »Bus Stop, Platform, Departure Gate: A Comparative Assessment of Transport Environments Concerning the Interrelations of Speed and Waiting.« Philadelphia, USA, 2014.

—. »Reconnecting Mobility History: Towards `Histories of Waiting ‘.« Caserta (ITA), 2015.

- »The Final Countdown. Ambiguities of real time information systems >directing the waiting experience in public transportation «. In Experiencing Networked Urban Mobilities, herausgegeben von Malene Freudendal-Pedersen, Katrine HartmannPetersen, und Emmy Laura Perez Fjalland, 19-26. London: Routledge, 2017.

—. »Waiting for Railways (1830-1914)«. In Timescapes of Waiting: Spaces of Stasis, Delay and Deferral, herausgegeben von Christoph Singer, Robert Wirth, und Olaf Berwald, 35-57. 31. Leiden \& Boston: Brill, 2019.

- . »Waiting (for Departure)«. In Routledge Handbook of Urban Mobilities, herausgegeben von Ole B. Jensen, Claus Lassen, Vincent Kaufmann, Malene FreudendalPetersen, und Ida Sofie Gøtzsche Lange, 144-153. London: Routledge, 2020.

Kendall, David G. "Stochastic processes occurring in the theory of queues and their analysis by the method of the imbedded Markov chain«. The Annals of Mathematical Statistics 24, Nr. 3 (1953): 338-54.

Kennan, George F. The decline of Bismarck's European order: Franco-Russian relations 18751890. Princeton: Princeton University Press, 1981.

Kern, Stephen. The culture of time and space, 1880-1918. Cambridge: Harvard University Press, 2003.

Kesselring, Sven, und Wolfgang Bonß. »Mobilität und Moderne. Zur gesellschaftstheoretischen Verortung des Mobilitätsbegriffs«. In Erziehung zur Mobilität. Jugendliche in der automobilen Gesellschaft., herausgegeben von Claus Tully, 39-66. Frankfurt a.M.: Campus, 1999.

Kistenmacher, Hans Werner. Maschine und Dichtung: ein Beitrag zur Geschichte der deutschen Literatur im 19. Jahrhundert. Greifswald: Hartmann, 1914. 
Klenke, Dietmar. »Freier Stau für freie Bürger«: die Geschichte der bundesdeutschen Verkehrspolitik; 1949-1994. Darmstadt: Wissenschaftliche Buchgesellschaft, 1995.

Koch, Ursula E. »Die Brennessel (1931-1938)«. In Handbuch des Antisemitismus: Judenfeindschaft in Geschichte und Gegenwart, herausgegeben von Wolfgang Benz, 6Publikationen:81-82. Berlin: DeGruyter, 2013.

Kocka, Jürgen. Das lange 19. Jahrhundert. 10. Aufl. Bd. 13. Stuttgart: Klett-Cotta, 2001.

Köhler, Andrea. Lange Weile: Über das Warten. 1. Aufl. Bibliothek der Lebenskunst. Frankfurt a.M.: Insel Verlag, 2007.

Kolb, Eberhard. »Die Reichsbahn vom Dawes-Plan bis zum Ende der Weimarer Republik«. In Die Eisenbahn in Deutschland: von den Anfängen bis zur Gegenwart, herausgegeben von Lothar Gall und Manfred Pohl, 109-64. Beck: München, 1999.

Kölle, Brigitte, und Claudia Peppel. Die Kunst des Wartens. Berlin: Verlag Klaus Wagenbach, 2019.

Koselleck, Reinhart. »Einleitung«. In Geschichtliche Grundbegriffe, herausgegeben von Otto Brunner, Werner Conze, und Reinhart Koselleck, 1:xiii-xxvii. Stuttgart: KlettCotta, 1972.

- Vergangene Zukunft: zur Semantik geschichtlicher Zeiten. 4. Aufl. Frankfurt a.M.: Suhrkamp, 2000.

- Zeitschichten: Studien zur Historik. 3. Aufl. Frankfurt a.M.: Suhrkamp, 2013.

Kossak, Andreas. »Quo vadis, elektronisches Ticketing.« Der Nahverkehr, 2005, 7-8.

Kostoff, Ronald N., Robert Boylan, und Gene R. Simons. »Disruptive Technology Roadmaps«. Technological Forecasting and Social Change 71, Nr. 1-2 (Januar 2004): 141-59.

Kottje, Friedrich. "Zur Einführung«. In Denken und schöpferisches Werden: Aufsätze und Vorträge, herausgegeben von Henri Bergson, Unveränd. Nachdr. [der Ausg.] Paris, 1946., 7-19. Eva-Taschenbuch 50. Hamburg: EVA, Europ. Verl.-Anst, 2008.

Kracauer, Siegfried. »Die Wartenden«. In Schriften Band 5.1: Aufsätze 1915-1926, 160-70. Frankfurt a.M.: Suhrkamp, 1990.

Krings, Ulrich. »Bahnhofsarchitektur: deutsche Großstadtbahnhöfe des Historismus«. Dissertation, TU München, 1981.

Kroon, Leo G., Rommert Dekker, und Michiel J. C. M. Vromans. „Cyclic Railway Timetabling: A Stochastic Optimization Approach«. In Algorithmic Methods for Railway Optimization, herausgegeben von Frank Geraets, Leo Kroon, Anita Schoebel, Dorothea Wagner, und Christos D. Zaroliagis, 41-66. Springer Berlin Heidelberg, 2007.

Krotz, Friedrich. Mediatisierung: Fallstudien zum Wandel von Kommunikation. 1. Aufl. Wiesbaden: VS Verlag für Sozialwissenschaften, 2007.

Kubinszky, Mihály. Bahnhöfe Europas: Ihre Geschichte, Kunst und Technik. Für Eisenbahnfreunde, Architekten und kulturgeschichtlich Interessierte. Stuttgart: Franck'sche Verlagshandlung, 1969.

Landwehr, Achim. Kulturgeschichte. Stuttgart: Ulmer, 2009.

Langheinrich, Marc. »RFID and privacy«. In Security, Privacy, and Trust in Modern Data Management, 433-50. Springer, 2007.

Larson, Richard C. »Perspectives on Queues: Social Justice and the Psychology of Queuing.« Operations Research 35, Nr. 6 (1987): 895-905.

Lash, Scott, und John Urry. Economies of signs and space. Bd. 26. Sage, 1993. 
Latour, Bruno. Wir sind nie modern gewesen: Versuch einer symmetrischen Anthropologie. Übersetzt von Gustav Roßler. Frankfurt a.M.: Suhrkamp, 2008.

Lauer, Robert H. Temporal man: The meaning and uses of social time. New York: Praeger, 1981.

Leach, E. R. Rethinking anthropology. London: Athlone P., 1966.

Leis, Mario. Bahnhöfe: Geschichten von Ankunft und Abschied. 1. Aufl. Frankfurt a.M.: Insel, 2003.

Levine, Robert. Eine Landkarte der Zeit: wie Kulturen mit Zeit umgehen. München: Piper, 1998.

Lewin, Kurt. »Defining the'field at a given time.«. Psychological review 50, Nr. 3 (1943): 292-310.

Little, John DC. »A proof for the queuing formula: $L=\lambda W$ «. Operations research 9, Nr. 3 (1961): 383-87.

Loehlin, John C. »The influence of different activities on the apparent length of time.« Psychological Monographs: General and Applied 73, Nr. 4 (1959): 1.

Lucke, Doris. Akzeptanz: Legitimität in der »Abstimmungsgesellschaft«. Opladen: Leske \& Budrich, 1995.

Luhmann, Niklas. Die Gesellschaft der Gesellschaft, Teilbd.2. 2. Aufl. Frankfurt a.M.: Suhrkamp, 1999.

—_. »Die Zukunft kann nicht beginnen. Temporalstrukturen der modernen Gesellschaft«. In Vor der Jahrtausendwende: Bericht zur Lage der Zukunft, herausgegeben von Peter Sloterdijk, Bd. 1:119-50. Frankfurt a.M.: Suhrkamp, 1990.

—_. »Temporalisierung von Komplexität. Zur Semantik neuzeitlicher Zeitbegriffe«. In Gesellschaftsstruktur und Semantik. Studien zur Wissenssoziologie der modernen Gesellschaft, herausgegeben von Niklas Luhmann, 1:235-300. Frankfurt a.M.: Suhrkamp, 1980.

Lyons, Glenn, und John Urry. »Travel time use in the information age«. Transportation Research Part A: Policy and Practice 39, Nr. 2-3 (2005): 257-76.

Mahr, Johannes. Eisenbahnen in der deutschen Dichtung. München: W. Fink, 1982.

Maister, David H. »The Psychology of Waiting Lines«. In The Service Encounter: Managing Employee/Customer Interaction in Service Businesses, herausgegeben von Michael R. Solomon, Carol F. Suprenant, und John A. Czepiel, 113-23. Lexington: Lexington Books, 1985.

Mann, Leon. "Queue culture: The waiting line as a social system«. American Journal of Sociology 75, Nr. 3 (1969): 340-54.

Marklund, Andreas, und Mogens Rüdiger, Hg. Historicizing infrastructure. 1. Aufl. Aalborg: Aalborg University Press, 2017.

Marotzki, Winfried, und Horst Niesyto, Hg. Bildinterpretation und Bildverstehen: methodische Ansätze aus sozialwissenschaftlicher, kunst- und medienpädagogischer Perspektive. 1. Aufl. Medienbildung und Gesellschaft, Bd. 2. Wiesbaden: VS Verlag für Sozialwissenschaften, 2006.

Marx, Karl, und Friedrich Engels. Das Kapital - Kritik der politischen Ökonomie (Erstes Buch: Der Produktionsprozeß des Kapitals). Nach der vierten, von Friedrich Engels durchgesehenen und Herausgegebenen Auflage, Hamburg 1890. Karl Marx und Friedrich Engels, Werke 23. Berlin: Dietz Verlag, 1962. 
- "Manifest der Kommunistischen Partei«. In Karl Marx und Friedrich Engels, Werke, 6., 4:459-93. Berlin: Dietz Verlag, 1972.

Maslow, Abraham Harold. »A theory of human motivation. «Psychological review 50, Nr. 4 (1943): 370-96.

Mata-Codesal, Diana. »Ways of Staying Put in Ecuador: Social and Embodied Experiences of Mobility-Immobility Interactions «. Journal of Ethnic and Migration Studies 41, Nr. 14 (2015): 2274-90.

Maurer, Andrea. »Stand und Perspektiven der zeitsoziologischen Forschung«. In Soziologie in Deutschland und die Transformation großer gesellschaftlicher Systeme, herausgegeben von Hansgünter Meyer, 590-607. Berlin: Akademie Verlag, 1992.

McDonnell, John. »Music, scent and time preferences for waiting lines«. International Journal of Bank Marketing 25, Nr. 4 (2007): 223-37.

McTaggart, John M.E. »The Unreality of Time«. Mind 17, Nr. 68 (1908): 457-74.

Mead, George Herbert. »The nature of the past «. In Essays in Honour of John Dewey, herausgegeben von John Cross, 235-42. New York: Henry Hall, 1929.

Meeks, C. L. V. »Some Early Depot Drawings«. Journal of the Society of Architectural Historians 8 , Nr. 1/2 (1949): 33-42.

Meeks, Carol L.V. The Railroad Station: An Architectural History. New Haven: Yale University Press, 1956.

Merki, Christoph Maria. Der holprige Siegeszug des Automobils 1895-1930: Zur Motorisierung des Strassenverkehrs in Frankreich, Deutschland und der Schweiz. Wien: Böhlau, 2002.

Metz, David. »The myth of travel time saving «. Transport reviews 28, Nr. 3 (2008): 321-36.

Meyer, Thierry. "Subjective importance of goal and reactions to waiting in line«. The Journal of Social Psychology 134, Nr. 6 (1994): 819-27.

Minaty, Wolfgang, Hg. Die Eisenbahn: Gedichte, Prosa, Bilder. 1. Aufl. Insel Taschenbuch 676. Frankfurt a.M.: Insel: Vertrieb durch den Suhrkamp Taschenbuch Verlag, 1984.

Mom, Gijs. »The crisis of transport history: a critique, and a vista«. Mobility in History 6, Nr. 1 (2015): 7-19.

Moos, Stanislaus von. "Bahn, Zeit, Architektur. Notizen zu einer Typologie des Hybriden«. In Die Internationalität der Eisenbahn, 1850-1970, herausgegeben von Monika Burri, Kilian T. Elsasser, und David Gugerli, 47-69. Zürich: Chronos, 2003.

Moraglio, Massimo. »Seeking a (New) Ontology for Transport History«. The Journal of Transport History 38, Nr. 1 (Juni 2017): 3-10.

Moraglio, Massimo, Hans-Liudger Dienel, und Robin Kellermann. »Didactical Functions of Dark and Bright Scenarios: Examples from the European Transport Industry«. In Envisioning Uncertain Futures, herausgegeben von Roman Peperhove, Karlheinz Steinmüller, und Hans-Liudger Dienel, 83-103. Wiesbaden: Springer, 2018.

Moran, Joe. »November in Berlin: the End of the Everyday«. History Workshop Journal 57, Nr. 1 (2004): 216-34.

Naef, Rahel, und Debra A. Bournes. »The lived experience of waiting: a parse method study«. Nursing Science Quarterly 22, Nr. 2 (2009): 141-53.

Nie, Winter. »Waiting: integrating social and psychological perspectives in operations management«. Omega 28, Nr. 6 (2000): 611-29.

Nolte, Karen. Gelebte Hysterie: Erfahrung, Eigensinn und psychiatrische Diskurse im Anstaltsalltag um 1900. Frankfurt a.M.: Campus, 2003. 
Nowotny, Helga. Eigenzeit: Entstehung und Strukturierung eines Zeitgefühls. 1. Aufl. Frankfurt a.M.: Suhrkamp, 1989.

Oberschmidt, Norbert. Das Rad: eine bewegte Geschichte. Heidelberg: Verlag Regionalkultur, 2015.

Oppenheim, Janet. »Shattered Nerves«: Doctors, patients, and depression in Victorian England. Oxford: Oxford University Press, 1991.

Osterhammel, Jürgen. Die Verwandlung der Welt: eine Geschichte des 19. Jahrhunderts. 2. Aufl. der Sonderausgabe, 2016. Historische Bibliothek der Gerda-Henkel-Stiftung. München: Verlag C. H. Beck oHG, 2016.

—. »Übergange ins 19.Jahrhundert - Anmerkungen eines Historikers«. In Von Bach zu Mendelssohn und Schumann: Aufführungspraxis und Musiklandschaft zwischen Kontinuität und Wandel, herausgegeben von Anselm Hartinger, Christoph Wolff, und Peter Wollny, 21-40. Beiträge zur Geschichte der Bach-Rezeption, Bd. 4. Wiesbaden: Breitkopf \& Härtel, 2012.

Osuna, Edgar Elias. »The psychological cost of waiting«. Journal of Mathematical Psychology 29, Nr. 1 (1985): 82-105.

Palm, Conny. »Methods of judging the annoyance caused by congestion«. Tele 4 (1953): 189-208.

Paris, Rainer. »Warten auf Amtsfluren«. KZfSS Kölner Zeitschrift für Soziologie und Sozialpsychologie 53, Nr. 4 (2001): 705-33.

Parissien, Steven. Bahnhöfe der Welt: eine Architektur- und Kulturgeschichte. Übersetzt von Martin Rometsch. Deutsche Erstausgabe. München: Knesebeck, 1997.

Payk, Theo Rudolf. »Zeit - Lebensbedingung, Anschauungsweise oder Täuschung?« In Im Netz der Zeit: menschliches Zeiterleben interdisplinär, herausgegeben von Rudolf Wendorff, 69-77. Edition Universitas. Stuttgart: S. Hirzel, 1989.

Pikulik, Lothar. Warten, Erwartung: eine Lebensform in End-und Übergangszeiten: in Beispielen aus der Geistesgeschichte, Literatur und Kunst. Sammlung Vandenhoeck. Göttingen: Vandenhoeck \& Ruprecht, 1997.

Plessner, Helmuth. Die Stufen des Organischen und der Mensch: Einleitung in die philosophische Anthropologie. Bd. 2200. Walter de Gruyter, 1975.

Pollaczek, Felix. »Über eine Aufgabe der Wahrscheinlichkeitstheorie. I«. Mathematische Zeitschrift 32, Nr. 1 (1930): 64-100.

Pooley, Colin G. »Travelling through the City: Using Life Writing to Explore Individual Experiences of Urban Travel C1840-1940«. Mobilities 12, Nr. 4 (2017): 598-609.

Pooley, Colin G., und Marilyn E. Pooley. »We're going to move ... I can't rush backwards and forwards, I'll go mad - I am sure of it.«. In Architectures of Hurry: Mobilities, Cities and Modernity, herausgegeben von Phillip Gordon Mackintosh, Richard Dennis, und Deryck Holdsworth, 194-208. New York: Routledge, 2018.

Prigogine, Ilya. »Time, Irreversibility and Structure«. In The Physicist's Conception of Nature, herausgegeben von Jagdish Mehra, 561-93. Dordrecht: Springer, 1973.

Pruyn, Ad, und Ale Smidts. "Effects of waiting on the satisfaction with the service: Beyond objective time measures «. International journal of research in marketing $15, \mathrm{Nr}$. 4 (1998): 321-34. 
Puff, Helmut. »Waiting in the Antechamber«. In Timescapes of Waiting: Spaces of Stasis, Delay and Deferral, herausgegeben von Christoph Singer, Robert Wirth, und Olaf Berwald, 17-34. 31. Leiden \& Boston: Brill, 2019.

Radkau, Joachim. Das Zeitalter der Nervosität: Deutschland zwischen Bismarck und Hitler. München: Hanser, 1998.

- Technik in Deutschland: vom 18. Jahrhundert bis heute. Frankfurt; New York: Campus Verlag, 2008.

Radlbeck, Karl. »Bahnhof und Empfangsgebäude: die Entwicklung vom Haus zum Verkehrswegekreuz«. Dissertation, TU München, 1981.

Rammler, Stephan. Mobilität in der Moderne: Geschichte und Theorie der Verkehrssoziologie. Berlin: Ed. Sigma, 2001.

- "The Wahlverwandtschaft of modernity and mobility«. In Tracing Mobilities. Towards a Cosmopolitan Perspective, herausgegeben von Weert Canzler, Vincent Kaufmann, und Sven Kesselring, 57-76. London; New York: Routledge, 2008.

Rammstedt, Otthein. »Alltagsbewußtsein von Zeit«. Kölner Zeitschrift für Soziologie und Sozialpsychologie 27, Nr. 1 (1975): 47-63.

Rank, Emil. Das Eisenbahntarifwesen in seiner Beziehung zu Volkswirtschaft und Verwaltung. Wien: A. Hölder, 1895.

Reif, Heinz. "Die verspätete Stadt Oberhausen: Stadtplanung, Stadtentwicklung und Bodennutzungsinteressen 1846-1929«. Geschichte im Westen, Nr. 2 (1986): 7-29.

Reulecke, Jürgen. Geschichte der Urbanisierung in Deutschland. 1. Aufl. Frankfurt a.M.: Suhrkamp, 1985.

Reuter, Timo. Warten: Eine verlernte Kunst. Frankfurt a.M.: Westend, 2020.

Revill, George. Railway. London: Reaktion Books, 2012.

Richards, Jeffrey, und John M. MacKenzie. The Railway Station: a social history. Oxford: University Press Oxford, 1986.

Ricœur, Paul. Die erzählte Zeit. Übersetzt von Andreas Knop. 1. Aufl. Zeit und Erzählung, Paul Ricœur ; Bd. 3. München: Wilhelm Fink, 1991.

Rifkin, Jeremy. Uhrwerk Universum. München: Knaur, 1990.

Rinderspacher, Jürgen P. »Mit der Zeit arbeiten: Über einige grundlegende Zusammenhänge von Zeit und Ökonomie«. In Im Netz der Zeit: menschliches Zeiterleben interdisziplinär, herausgegeben von Rudolf Wendorff, 91-104. Edition Universitas. Stuttgart: S. Hirzel, 1989.

Römer, Inga. Das Zeitdenken bei Husserl, Heidegger und Ricœur. Phaenomenologica 196. Dordrecht: Springer, 2010.

Rosa, Hartmut. Beschleunigung: die Veränderung der Zeitstrukturen in der Moderne. Suhrkamp Verlag, 2005.

Rosenberg, Hans. Grosse Depression und Bismarckzeit: Wirtschaftsablauf, Gesellschaft und Politik in Mitteleuropa. Bd. 24. Berlin: de Gruyter, 1967.

Rostow, Walt W. The Process of Economic Growth. 2. Aufl. New York: Norton Library, 1962. Roth, Ralf. Das Jahrhundert der Eisenbahn: die Herrschaft über Raum und Zeit 1800-1914. Thorbecke, 2005.

Röttcher, Hugo. Hochbauten der deutschen Reichsbahn. Berlin: Verlag der Verkehrswissenschaftlichen Lehrmittelgesellschaft m.b.H. bei der Deutschen Reichsbahn, 1933. 
Safranski, Rüdiger. Zeit: was sie mit uns macht und was wir aus ihr machen. München: Carl Hanser, 2015.

Salander, Corinna. Das Europäische Bahnsystem: Akteure, Prozesse, Regelwerke. Wiesbaden: Springer, 2018.

Salazar, Noel B. "Keywords of mobility«. In Keywords of mobility: Critical engagements, herausgegeben von Noel B. Salazar und Kiran Jayaram, 1:1-12. New York: Berghahn Books, 2016.

Sandbothe, Mike. Die Verzeitlichung der Zeit: Grundtendenzen der modernen Zeitdebatte in Philosophie und Wissenschaft. Darmstadt: Wissenschaftliche Buchgesellschaft, 1998.

—_. »Die Verzeitlichung der Zeit in der modernen Philosophie«. In Die Wiederentdeckung der Zeit: Reflexionen - Analysen - Konzepte, herausgegeben von Antje Gimmler, Walther Ch. Zimmerli, und Mike Sandbothe, 1. Aufl., 41-62. Darmstadt: PrimusVerl, 1997.

Sauter-Servaes, Thomas, und Stephan Rammler. "Delaytainment an Flughäfen: Die Notwendigkeit eines Verspätungsservices und erste Gestaltungsideen«. WZB Discussion Paper. Berlin: Wissenschaftszentrum Berlin für Sozialforschung (WZB), 2002.

Schaps, Regina. Hysterie und Weiblichkeit: Wissenschaftsmythen über die Frau. Frankfurt a.M.: Campus, 1992.

Schenk, Frithjof Benjamin. »Reisen in die Vergangenheit: Eisenbahn und Erinnerung im späten Zarenreich«. In Europäische Erinnerungsräume, herausgegeben von Kirstin Buchinger, Claire Gantet, und Jakob Vogel, 58-71. Frankfurt; New York: Campus Verlag, 2009.

Scherl, August. Ein neues Schnellbahn-System: Vorschläge zur Verbesserung des PersonenVerkehrs. Berlin: Scherl, 1909.

Schiemann, Gregor. »Lebensweltliche und physikalische Zeit«. In Mensch und Zeit, herausgegeben von Gerald Hartung, 207-25. Studien zur interdisziplinären Anthropologie. Wiesbaden: Springer VS, 2015.

Schilling, Heinz. »Zeitlose Ziele: Versuch über das lange Warten«. In Welche Farbe hat die Zeit, herausgegeben von Heinz Schilling, 245-310. Frankfurt a.M.: Universität Frankfurt, Institut für Kulturanthropologie, 2002.

Schipporeit, Reiner. Berlin-Potsdamer Eisenbahn: Bau, Technik, Betrieb. Berlin: Museumspädagogischer Dienst, 1988.

Schivelbusch, Wolfgang. Geschichte der Eisenbahnreise: zur Industrialisierung von Raum und Zeit im 19. Jahrhundert. 6. Aufl. Frankfurt a.M.: Fischer-Taschenbuch-Verlag, 2000.

Schlette, Heinz Robert. Weltseele: Geschichte und Hermeneutik. 1. Aufl. Frankfurt a.M.: J. Knecht, 1993.

Schmidt, Ina. Vom Leben zum Sein: der frühe Martin Heidegger und die Lebensphilosophie. Epistemata. Reihe Philosophie, Bd. 395. Würzburg: Königshausen \& Neumann, 2005.

Schmidt-Lauff, Sabine. Zeit und Bildung. Annäherungen an eine zeittheoretische Grundlegung. Münster: Waxmann Verlag, 2012.

Schmucki, Barbara. Der Traum vom Verkehrsfluss: städtische Verkehrsplanung seit 1945 im deutsch-deutschen Vergleich. Bd. 4. Frankfurt a.M.: Campus Verlag, 2001. 
Schräder-Naef, Regula D. »Zeit als Belastung?«In Im Netz der Zeit: menschliches Zeiterleben interdisziplinär, herausgegeben von Rudolf Wendorff, 17-25. Edition Universitas. Stuttgart: S. Hirzel, 1989.

Schütz, Alfred, und Thomas Luckmann. Strukturen der Lebenswelt. 1. Aufl. Frankfurt a.M.: Suhrkamp, 1979.

Schwartz, Barry. »Queues, priorities, and social process«. Social Psychology 41, Nr. 1 (1978a): 3-12.

- Queuing and Waiting: Studies in the Social Organization of Access and Delay. Chicago: University of Chicago Press, 1975.

—. »Time, Patience, and Black People: A Study of Temporal Access to Medical Care«. Sociological Focus 11, Nr. I (1978b): 11-20.

—. "Waiting, exchange, and power: The distribution of time in social systems«. American Journal of Sociology 79, Nr. 4 (1974): 841-70.

Schweizer, Harold. On Waiting. Thinking in action. London; New York: Routledge, 2008.

Schwemmer, Oswald. Ernst Cassirer: Ein Philosoph der europäischen Moderne. Berlin: Akademie Verlag, 1997.

Seiffert, Helmut. Einführung in die Wissenschaftstheorie 2: Phänomenologie - Hermeneutik und historische Methode - Dialektik. 10., durchges. Aufl. Einführung in die Wissenschaftstheorie Bd. 2. München: Beck'sche schwarze Reihe, 1996.

Sewell, William H. Refiguring the social'in social science: An interpretivist manifesto. University of Chicago Press Chicago, 2005.

Sheller, Mimi. Mobility justice: the politics of movement in the age of extremes. London: Verso, 2018.

- »The New Mobilities Paradigm for a Live Sociology«. Current Sociology 62, Nr. 6 (2014): 789-811.

Sheller, Mimi, und John Urry. »The new mobilities paradigm«. Environment and planning A 38, Nr. 2 (2006): 207-26.

Sieferle, Rolf Peter. Fortschrittsfeinde? Opposition gegen Technik und Industrie von der Romantik bis zur Gegenwart. München: Beck, 1984.

Simmel, Georg. Die Großstädte und das Geistesleben. 1. Aufl. Frankfurt a.M.: Suhrkamp, 2006.

- Georg Simmel. Gesamtausgabe. Bd. 7: Aufsätze und Abhandlungen 1901-1908. Herausgegeben von Rüdiger Kramme, Otthein Rammstedt, und Angela Rammstedt. 1. Aufl. Frankfurt a.M.: Suhrkamp, 1995.

- Philosophie des Geldes. Nachdruck der 2.Ausgabe von 1907. Köln: Anaconda, 2009.

Singer, Christoph, Singer Christoph, Robert Wirth, und Berwald Olaf. Timescapes of waiting: spaces of stasis, delay and deferral. Spatial practices. Leiden; Boston: Brill Rodopi, 2019.

Slater, Keith. Human Comfort. Springfield: CC Thomas, 1985.

Sombart, Werner. Der moderne Kapitalismus. Bd. 3: Das Wirtschaftsleben im Zeitalter des Hochkapitalismus. München und Leipzig: Duncker \& Humblot, 1927.

Sorokin, Pitirim A., und Robert K. Merton. »Social time: A methodological and functional analysis«. American Journal of Sociology 42, Nr. 5 (1937): 615-29.

Speich, Daniel. »Rechts und Links der Eisenbahn: Zur visuellen Standardisierung der touristischen Eisenbahnfahrt«. In Die Internationalität der Eisenbahn, 1850-1970, her- 
ausgegeben von Monika Burri, Kilian T. Elsasser, und David Gugerli, 91-109. Zürich: Chronos, 2003.

Steinmüller, Karlheinz. »Zukunftsforschung in Deutschland«. Zeitschrift für Zukunftsforschung 1, Nr. 1 (2012): 6-19.

Tabboni, Simonetta. »The Idea of Social Time in Norbert Elias«. Time $\&$ Society 10, Nr. 1 (März 2001): 5-27.

Taylor, Shirley. »Waiting for service: the relationship between delays and evaluations of service«. The Journal of Marketing 58, Nr. 2 (1994): 56-69.

Tedlock, Barbara. Time and the highland Maya. Albuquerque: University of New Mexico Press, 1992.

Thomsen, Christian W. »Kathedralen der Moderne? Bahnhofsarchitektur - gestern, heute und morgen«. In Der Bahnhof: Basilika der Mobilität - Erlebniswelt der Moder$n e$, herausgegeben von Markwart Herzog und Mario Leis, 17-60. Irseer Dialoge, Bd. 14. Stuttgart: W. Kohlhammer, 2010.

Torres, E., J. S. Domínguez, L. Valdes, und R. Aza. »Passenger waiting time in an airport and expenditure carried out in the commercial area«. Journal of Air Transport Management 11, Nr. 6 (2005): 363-67.

Toulmin, Stephen. Cosmopolis: the hidden agenda of modernity. University of Chicago Press ed. Chicago: University of Chicago Press, 1992.

Tünnemann, Christian. »Bahnhofskino: Programm und Publikum an einem Durchgangsort«. Unveröffentlichte Magisterarbeit, 2003.

Urry, John. Global Complexity. Malden, MA: Polity, 2003.

- Mobilities. London: Polity, 2007.

Utz, Peter. »Aus dem Warten heraus. An die Bahnhöfe der Schweizer Literatur grenzt das Meer.« Herausgegeben von Heinz Ludwig Arnold. Text und Kritik, Sonderheft: Literatur in der Schweiz, 1998, 111-20.

Vannini, Phillip. »Mind the gap: The tempo rubato of dwelling in lineups«. Mobilities 6, Nr. 2 (2011): 273-99.

Vidal, Laurent, und Alain Musset, Hg. Waiting territories in the Americas: life in the intervals of migration and urban transit. Newcastle upon Tyne: Cambridge Scholars Publishing, 2016.

Virilio, Paul. Der eigentliche Unfall. Passagen Forum. Wien: Passagen, 2009.

—. Der große Beschleuniger. Herausgegeben von Peter Engelmann. Übersetzt von Paul Maercker. Dt. Erstausg. Passagen Forum. Wien: Passagen-Verl, 2012.

- Geschwindigkeit und Politik: Ein Essay zur Dromologie. Merve-Verlag, 1980.

- Rasender Stillstand: Essay. Edition Akzente. München: Hanser, 1992.

- Vitesse et politique: essai de dromologie. Bd. 6. Paris: Editions Galilée, 1977.

Vozyanov, Andrey. »Approaches to Waiting in Mobility Studies: Utilization, Conceptualization, Historicizing «. Mobility in History 5, Nr. 1 (1. Januar 2014): 64-73.

Wardman, Mark. »Public Transport Values of Time«. Transport Policy 11, Nr. 4 (Oktober 2004): 363-77.

- . Valuing Convenience in Public Transport: Roundtable Summary and Conclusions«. International Transport Forum Discussion Papers. Paris: OECD/ITF, 2014. https://www.oecd-ilibrary.org/transport/valuing-convenience-in-public-tran sport_5jz4ork8h2fo-en. 
Weber, Alfred. Haben wir Deutschen nach 1945 versagt?: politische Schriften: ein Lesebuch. Frankfurt a.M.: Fischer Taschenbuch Verlag, 1982.

Weigert, Andrew J. Sociology of everyday life. New York: Longman, 1981.

Weinberg, Bruce D. »Don't keep your internet customers waiting too long at the (virtual) front door«. Journal of Interactive Marketing 14, Nr. I (2000): 30-39.

Wendorff, Rudolf, Hg. Im Netz der Zeit: menschliches Zeiterleben interdisplinär. Edition Universitas. Stuttgart: S. Hirzel, 1989.

- Zeit und Kultur: Geschichte des Zeitbewußtseins in Europa. 3. Opladen: Westdeutscher Verlag, 1985.

Wilhelmer, Lars. Transit-Orte in der Literatur: Eisenbahn-Hotel-Hafen-Flughafen. Bielefeld: transcript Verlag, 2015.

Wright, Paul. »Disused Stations: Liverpool Crown Street Station«, 2014. www.disusedstations.org.uk/l/liverpool_crown_street/.

Wucherpfennig, Claudia. Bahnhof: (stadt)gesellschaftlicher Mikrokosmos im Wandel; eine "neue kulturgeographische" Analyse. Wahrnehmungsgeographische Studien 22. Oldenburg: BIS-Verl. der Carl-von-Ossietzky-Universität, 2006.

Yates, John. Why are We Waiting?: An Analysis of Hospital Waiting-lists. Oxford: Oxford University Press, 1987.

Zapf, Wolfgang. »Entwicklung und Sozialstruktur moderner Gesellschaften«. In Einführung in Hauptbegriffe der Soziologie, herausgegeben von Hermann Korte und Bernhard Schäfers, 303-20. Wiesbaden: Springer Fachmedien Wiesbaden, 2016.

Zeiher, Helga. »Thema: Warten müssen Einführung in den Themenschwerpunkt«. Zeitpolitisches Magazin 9, Nr. 20 (Juli 2012): 1-3.

Zeithaml, V.A., M. J. Bitner, und D. D Gremler. Services Marketing: Integrating Customer Focus across the Firm. 6. Aufl. New York; London: McGraw-Hill Higher Education, 2012.

Zerubavel, Eviatar. Hidden Rhythms: Schedules and Calendars in Social Life. Berkeley: Univ. of California Press, 1985.

- »The language of time: Toward a semiotics of temporality«. The Sociological Quarterly 28, Nr. 3 (1987): 343-56.

. The seven day circle: the history and meaning of the week. Chicago: University of Chicago Press, 1989.

—. »The standardization of time: A sociohistorical perspective«. American Journal of Sociology 88, Nr. 1 (1982): 1-23.

—. »Timetables and Scheduling: On the Social Organization of Time«. Sociological Inquiry 46, Nr. 2 (April 1976): 87-94.

Zhang, Luian, Martin G. Helander, und Colin G. Drury. »Identifying Factors of Comfort and Discomfort in Sitting «. Human Factors: The Journal of the Human Factors and Ergonomics Society 38, Nr. 3 (1996): 377-89.

Zhou, Rongrong, und Dilip Soman. "Consumers' waiting in queues: The role of firstorder and second-order justice«. Psychology \& Marketing 25, Nr. 3 (2008): 262-79. 


\section{Kulturwissenschaft}

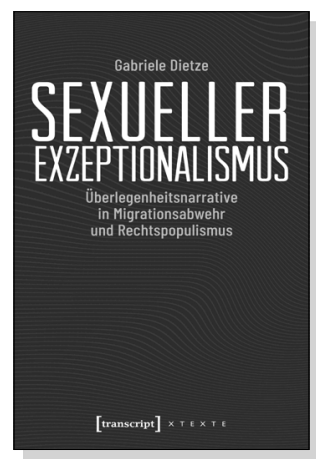

Gabriele Dietze

Sexueller Exzeptionalismus

Überlegenheitsnarrative in Migrationsabwehr und

Rechtspopulismus

2019, 222 S., kart., Dispersionsbindung, 32 SW-Abbildungen $19,99 €(D E), 978-3-8376-4708-2$

E-Book: 17,99 € (DE), ISBN 978-3-8394-4708-6

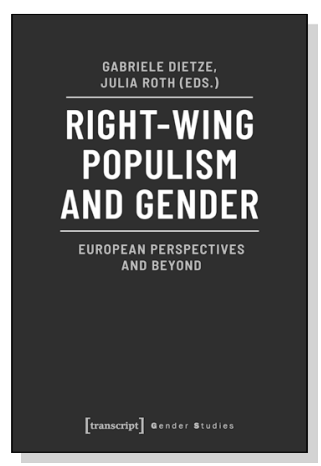

Gabriele Dietze, Julia Roth (eds.)

Right-Wing Populism and Gender

European Perspectives and Beyond

April 2020, 286 p., pb., ill.

$35,00 €(D E), 978-3-8376-4980-2$

E-Book: 34,99€ (DE), ISBN 978-3-8394-4980-6

\section{Raum}

Stephan Günzel

Eine kulturwissenschaftliche Einführung

Raum

Eine kulturwissenschaftliche

Einführung

März 2020, 192 S., kart.

3. Auflage

20,00€ (DE), 978-3-8376-5217-8

E-Book: 17,99 € (DE), ISBN 978-3-8394-5217-2

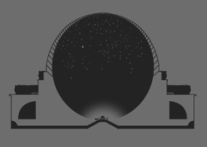




\section{Kulturwissenschaft}

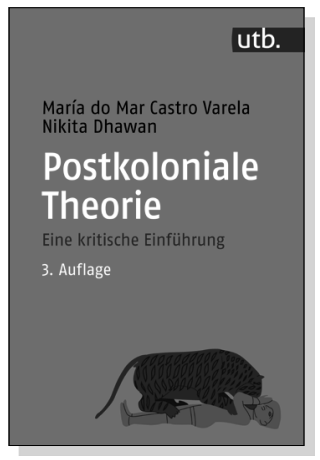

María do Mar Castro Varela, Nikita Dhawan

Postkoloniale Theorie

Eine kritische Einführung

Februar 2020, 384 S., kart.

25,00€ (DE), 978-3-8376-5218-5

E-Book: 22,99€ (DE), ISBN 978-3-8394-5218-9

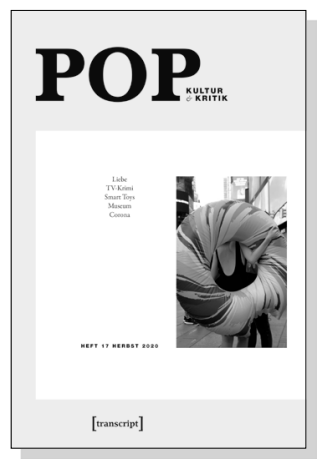

Thomas Hecken, Moritz Baßler, Elena Beregow,

Robin Curtis, Heinz Drügh, Mascha Jacobs,

Annekathrin Kohout, Nicolas Pethes, Miriam Zeh (Hg.)

POP

Kultur \& Kritik (Jg. 9, 2/2020)

Oktober 2020, 178 S., kart.

$16,80 €(D E), 978-3-8376-4937-6$

E-Book:

PDF: 16,80€ (DE), ISBN 978-3-8394-4937-0

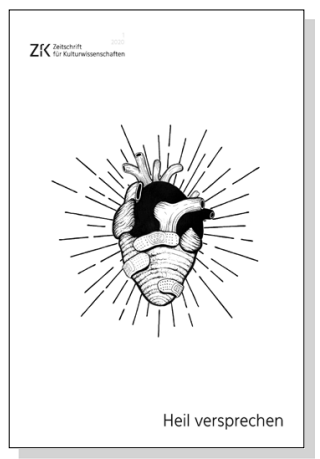

Karin Harrasser, Insa Härtel,

Karl-Josef Pazzini, Sonja Witte (Hg.)

\section{Heil versprechen}

Zeitschrift für Kulturwissenschaften, Heft 1/2020

Juli 2020, 184 S., kart.

$14,99 €(D E), 978-3-8376-4953-6$

E-Book:

PDF: 14,99€ (DE), ISBN 978-3-8394-4953-0 
